ORNL/ CDIAC --37

DE92 004582

Environmental Sciences Division

\title{
AN UP'DATED GLOBAL GRID POINT SURFACE AIR TEMPERATURE ANOMALY DATA SET: 1851-1990
}

Contributed by

P. D. Jones, S. C. B. Raper, B. S. G. Cherry

C. M. Goodess, T. M. L. Wigley, B. Santer, P. M. Kelly

Climatic Research Unit

University of East Anglia

Norwich, United Kingdom

R. S. Bradley

University of Massachusetts

Amherst, Massachusetts

H. F. Diaz

National Oceanic and Atmospheric Administration

Environmental Research Laboratories

Boulder, Colorado

Prepared by R. J. Sepanski, T. A. Boden, and R. C. Daniels

Environmental Sciences Division

Publication No. 3520

Date Published: October 1991

Prepared for the

Carbon Dioxide Research Program

Environmental Sciences Division

U.S. Department of Energy

Office of Health and Environmental Research

(Budget Activity Number KP 050000 0)

Prepared by the

OAK RIDGE NATIONAL LABORATORY

Oak Ridge, Tennessee 37831-6335 managed by

MARTIN MARIETTA ENERGY SYSTEMS,INC.

for the

U.S. DEPARTMENT OF ENERGY

under contract DE-AC05-84OR21400

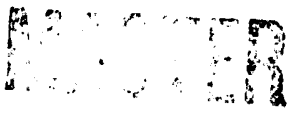


TABLE OF CONTENTS

$\underline{\text { Page }}$

LIST OF FIGURES $\ldots \ldots \ldots \ldots \ldots \ldots \ldots \ldots \ldots \ldots \ldots \ldots \ldots \ldots, \mathrm{v}$

LIST OF TABLES $\ldots \ldots \ldots \ldots \ldots \ldots \ldots \ldots \ldots \ldots \ldots \ldots \ldots \ldots \ldots \ldots \ldots \ldots \ldots$

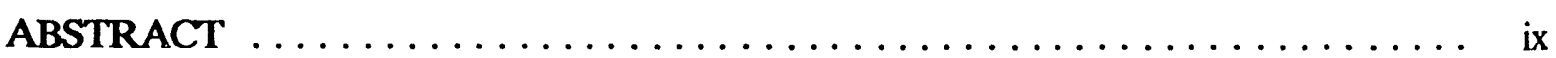

PART 1: INFORMATION ABOUT THE NUMERIC DATA PACKAGE $\ldots \ldots \ldots 1$

1. NAME OF THE NUMERIC DATA PACKAGE $\ldots \ldots \ldots \ldots \ldots \ldots \ldots$

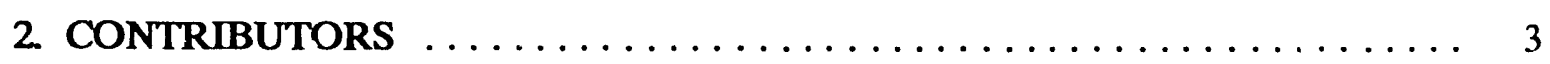

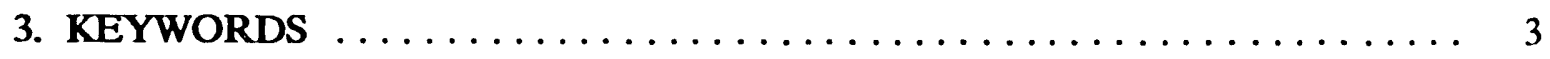

4. BACKGROUND INFORMATION $\ldots \ldots \ldots \ldots \ldots \ldots \ldots \ldots \ldots \ldots \ldots$

5. SOURCE AND SCOPE OF THE DATA $\ldots \ldots \ldots \ldots \ldots \ldots \ldots \ldots$

6. APPLICATIONS OF THE DATA $\ldots \ldots \ldots \ldots \ldots \ldots \ldots \ldots \ldots \ldots \ldots$

7. LIMITATIONS AND RESTRICTIONS $\ldots \ldots \ldots \ldots \ldots \ldots \ldots \ldots \ldots$

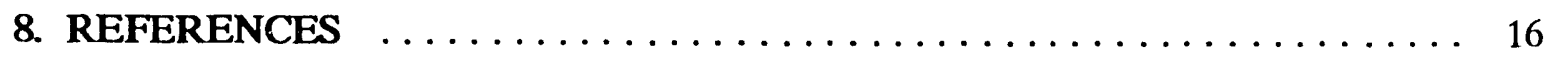

9. DATA CHECKS PERFORMED BY CDIAC $\ldots \ldots \ldots \ldots \ldots \ldots \ldots \ldots$

10. HOW TO OBTAIN THE PACKAGE $\ldots \ldots \ldots \ldots \ldots \ldots \ldots \ldots \ldots, 20$

PART 2: INFORMATION ABOUT THE MAGNETIC TAPE $\ldots \ldots \ldots \ldots \ldots 21$

11. CONTENTS OF THE MAGNETIC TAPE $\ldots \ldots \ldots \ldots \ldots \ldots \ldots \ldots$

12. DESCRIPTTVE FILE ON THE TAPE $\ldots \ldots \ldots \ldots \ldots \ldots \ldots \ldots \ldots$

13. LISTINGS OF THE FORTRAN IV DATA RETRIEVAL PROGRAMS $\ldots \ldots 33$

14. LISTING OF THE SAS INPUT/OUTPUT RETRIEVAL PROGRAM $\ldots \ldots \quad 40$

15. VERIFICATION OF DATA TRANSPORT $\ldots \ldots \ldots \ldots \ldots \ldots \ldots \ldots, 59$ 
TABLE OF CONTENTS (continued)

APPENDIX A REPRINTS OF PERTINENT LITERATURE

A grid point surface air temperature data set for the Northern Hemisphere, by P. D. Jones, S. C. B. Raper, B. Santer, B. S. G. Cherry, C. M. Goodess, P. M. Kelly, T. M. L. Wigley, R. S. Bradley, and H. F. Diaz. 1985. . . . . .

Global-scale temperature changes to August 1987 and a comparison of satellite and conventional data, by P. D. Jones, T. M. L. Wigley,

G. Ohring, and A. Thomasell. 1988.

A grid point surface air temperature data set for the Southern Hemisphere, by P. D. Jones, S. C. B. Raper, C. M. Goodess, B. S. G. Cherry, and

T. M. L. Wigley. 1986.

ANOMALIES, 1851 -1990 - MICROFICHE . . . . . . . . . . Back cover 


\section{LIST OF FIGURES}

Figure

Page

1 Grid point locations for which any monthly surface air temperature anomaly data are available from the period 1851 to $1990 \ldots \ldots \ldots \ldots \ldots \ldots \ldots$

2 Grid point locations for which continuous monthly surface air temperature anomaly data are available over the entire period of record, 1851 to $1990 \ldots \ldots 8$

3 Grid point locations for which continuous monthly surface air temperature anomaly data are available over the period 1900 to $1990 \ldots \ldots \ldots \ldots \ldots$

4 Grid point locations for which surface air temperature anomaly data are available for at least $90 \%$ of all months over the period 1900 to $1990 \ldots \ldots$. . 10

5 Average number of stations contributing monthly temperature data from

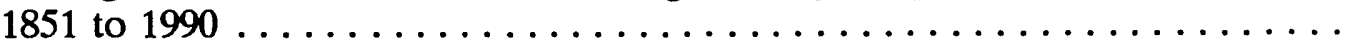

6 Year 1851: Average number of stations contributing monthly temperature

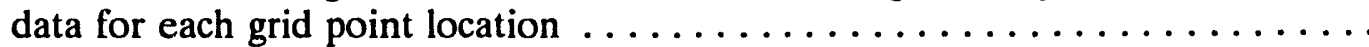

7 Year 1900: Average number of stations contributing monthly temperature

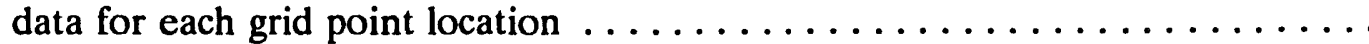

8 Year 1960: Average number of stations contributing monthly temperature

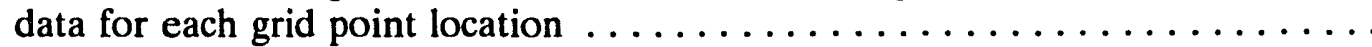

9 Year 1990: Average number of stations contributing monthly temperature

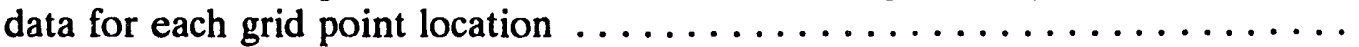

10 Number of months per grid point location for which changes were made in the updated data set for the period 1979 to 1984

11 Variability in monthly temperature anomaly data for each grid point location over the period 1851 to 1990 


\section{LIST OF TABLES}

\section{Table}

$\underline{\text { Page }}$

1 Partial listing of the gridded surface air temperature anomalies for the

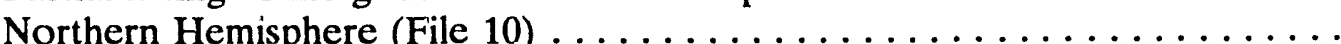

2 Partial listing of the gridded surface air temperature anomalies for the

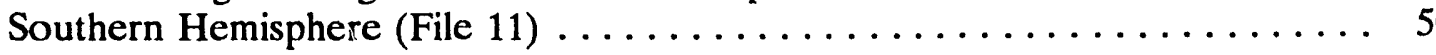

3 Partial listing of the gridded surface air temperature anomalies for the Antarctic (File 12) $\ldots \ldots \ldots \ldots \ldots \ldots \ldots \ldots \ldots \ldots \ldots \ldots$

4 Partial listing of the monthly mean temperature records for individual stations in the Northern Hemisphere (File 13) ..................

5 Partial listing of the monthly mean temperature records for individual stations

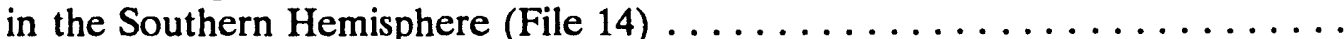

6 Characteristics of numeric variables for the gridded surface air temperature anomaly file for the Northern Hemisphere

7 Characteristics of numeric variables for the gridded surface air temperature anomaly file for the Southern Hemisphere

8 Characteristics of numeric variables for the gridded surface air temperature anomaly file for the Antarctic

9 Characteristics of numeric variables for the monthly mean temperature records for individual stations in the Northern Hemisphere

10 Characteristics of numeric variables for the monthly mean temperature records for individual stations in the Southern Hemisphere 


\begin{abstract}
JONES, P. D., S. C. B. RAPER, B. S. G. CHERRY, C. M. GOODESS, T. M. L. WIGLEY, B. SANTER, P. M. KELLY, R. S. BRADLEY, and H. F. DIAZ. 1991. An updated global grid point surface air temperature anomaly data set: 1851-1990. ORNL/CDIAC-37, NDP-020/R1. Carbon Dioxide Information Analysis Center, Oak Ridge National Laboratory, Oak Ridge, Tennessee. 422 pp.
\end{abstract}

This document presents land-based monthly surface air temperature anomalies (departures from a 1951-1970 reference period mean) on a $5^{\circ}$ latitude by $10^{\circ}$ longitude global grid. Monthly surface air temperature anomalies (departures from a 1957-1975 reference period mean) for the Antarctic (grid points from $65^{\circ} \mathrm{S}$ to $85^{\circ} \mathrm{S}$ ) are presented in a similar way as a separate data set. The data were derived primarily from the World Weather Records and the archives of the United Kingdom Meteorological Office. This long-term record of temperature anomalies may be used in studies addressing possible greenhouse-gasinduced climate changes. To date, the data have been employed in generating regional, hemispheric, and global time series for determining whether recent (i.e., post-1900) warming trends have taken place.

This document also presents the monthly mean temperature records for the individual stations that were used to generate the set of gridded anomalies. The periods of record vary by station. Northern Hemisphere station data have been corrected for inhomogeneities, while Southern Hemisphere data are presented in uncorrected form.

All data have been assessed for quality (gross accuracy and consistency, temporal variability, and spatial and temporal completeness of record) and for long-term homogeneity. Although the period of record extends from 1851 to 1990, few grid point locations have contributed data for the entire period of record.

These data are available free of charge as a numeric data package (NDP) from the Carbon Dioxide Information Analysis Center. The NDP consists of this document and a rnagnetic tape containing machine-readable files (not available on floppy diskettes, due to size constraints). This document provides sample listings of temperature anomalies, station numbers, and mean inverse distance data, as well as a complete listing of the gridded surface air temperature anomalies on microfiche (Appendix B). This document also offers retrieval program listings (in FORTRAN and SAS ${ }^{*}$ languages), furnishes graphical summaries and information on sampling methods and data selection, defines limitations and restrictions of the data, and provides reprints of pertinent literature.

"SAS is the registered trademark of SAS Institute, Inc., Cary, North Carolina 27511-8000. 
PART 1

INFORMATION ABOUT THE NUMERIC DATA PACKAGE 


\title{
1. NAME OF THE NUMERIC DATA PACKAGE
}

An Updated Global Grid Point Surface Air Temperature Anomaly Data Set: 1851-1990

\section{CONTRIBUTORS}

\author{
P. D. Jones \\ B. S. G. Cherry \\ S. C. B. Raper \\ T. M. L. Wigley \\ C. M. Goodess \\ P. M. Kelly \\ Climatic Research Unit \\ University of East Anglia \\ Norwich, United Kingdom \\ B. Santer \\ R. S. Bradley \\ University of Massachusetts \\ Amherst, Massachusetts \\ H. F. Diaz \\ National Oceanic and Atmospheric Administration \\ Environmental Research Laboratories \\ Boulder, Colorado
}

\section{KEYWORDS}

Surface air temperatures, temperature anomalies, gridded temperature data, climatic trends, time series, data homogeneity

\section{BACKGROUND INFORMATION}

Because reliable thermometers were not developed until the mid-18th century, almost all long-term temperature records are shorter than 200 years. For the most part, the development of a large-scale temperature recording network did not begin until the early- to mid-19th century (Bradley et al. 1985). As additional stations began operating, global coverage improved. However, differences in instrumentation and calculation methods among stations and among countries have made it difficult to compile an accurate data set for global surface air temperatures. Furthermore, changes in location, in instrumentation, and in calculation methods at individual stations, as well as other factors, such as urbanization, have resulted in an inhomogeneous data set (i.e., showing jumps, discontinuities, or trends attributable to nonclimatic sources) (see, for example, Jones et al. 1986a). The data set contained and described in this package extends back to 1851 and is, to the extent possible, homogeneous. This package is an updated and expanded version of that contained in Jones et al. 1986b. These data sets are identical for the period 1851-1978; however, the updated version corrects erroneous data and adds new station data for the period 1979-1984. The updated package also extends the data set by adding data for the Northern (grid points from 
$85^{\circ} \mathrm{N}$ to $0^{\circ}$ ) and Southern (grid points from $5^{\circ} \mathrm{S}$ to $60^{\circ} \mathrm{S}$ ) Hemispheres for the period $1985-1990$, and, for the first time, presents Antarctic (grid points from $65^{\circ} \mathrm{S}$ to $85^{\circ} \mathrm{S}$ ) data for the period 1957-1990. In addition, this package includes the monthly mean temperature records for the individual stations that were used to generate the gridded anomalies.

The gridded anomaly data were evaluated for homogeneity, by comparison with neighboring stations, and were classified as immediately usable, corrected, or uncorrectable. The results of this assessment (for data from grid points $85^{\circ} \mathrm{N}$ to $60^{\circ} \mathrm{S}$ and through 1984), including any corrections applied to the data, are presented in Jones et al. $(1985,1986 \mathrm{c})$. The gridded data set was generated from the station anomalies by an interpolation procedure averaging station data that were weighted according to the inverse of the distance of the station to the nearest grid point. The gridded data are departures (anomalies) from the station means for each month over the 1951-1970 reference period, or, for the Antarctic data, the 1957-1975 reference period. It was necessary to reduce all the station data to anomalies because of different station elevations and, to a lesser extent, different observation times.

\section{SOURCE AND SCOPE OF THE DATA}

The basis of the data set is derived from the World Weather Records (WWR), published by the Smithsonian Institution (1927, 1935, and 1947) and the U.S. Weather Bureau (1959-1982). Additional data were added from material available in published and manuscript form in meteorological archives. For the Northern Hemisphere, much of the additional information came from the archives of the United Kingdom Meteorological Office. Areas where data coverage was considerably expanded include the Soviet Union, northern Europe, northern Africa, and the People's Republic of China. For the Southern Hemisphere, data were added for Argentina, Chile, Indonesia, Australia, Pacific Islands (particularly Tahiti), New Zealand, Peru, and (for 1957 onwards) some parts of Antarctica. Details of these additional sources can be found in Bradley et al. (1985) and Jones et al. $(1985,1986 a)$ for the Northern Hemisphere and in Jones et al. (1986c, 1986d) for the Southern Hemisphere. Data for the Antarctic were assembled primarily from the World Weather Records and the Monthly Climatic Data for the World.

The present updated version of this data set is identical to the earlier version for all records from 1851 through 1978, except for the addition of a separate data set containing Antarctic (grid points from $65^{\circ} \mathrm{S}$ to $85^{\circ} \mathrm{S}$ ) surface air temperature anomalies beginning in 1957. Beginning with 1979 data, this document differs from the earlier version (Jones et al. $1986 \mathrm{~b}$ ) in several ways. Erroneous data for some sites have been corrected after a review of the actual station temperature data, and inconsistencies in the representation of missing values have been removed. For some grid locations, dat.. have been added from stations that had not contributed to the original set. Data from satellites have also been used to correct station records in cases in which large discrepancies were evident (Jones et al. 1988). The present package also extends the record by adding monthly surface air temperature anomalies for the Northern (grid points from $85^{\circ} \mathrm{N}$ to $0^{\circ}$ ) and Southern (grid points from $5^{\circ} \mathrm{S}$ to $60^{\circ} \mathrm{S}$ ) Hemispheres for the period 1985-1990.

This document also includes the monthly mean temperature records for the individual stations that were used to generate the set of gridded anomalies. The periods of record vary by station, with data for 1988 being the most recent presented (although data for 1989 and 1990 were also used to generate the updated gridded anomalies). Northern Hemisphere 
(stations from $87.5^{\circ} \mathrm{N}$ to $2.5^{\circ} \mathrm{S}$ ) station data have been corrected for inhomogeneities, while Southern Hemisphere (stations from $2.5^{\circ} \mathrm{S}$ to $62.5^{\circ} \mathrm{S}$ ) data are presented in uncorrected form and missing 5 stations (Masterton, New Zealand; Lincoln College, New Zeaiand; Cape Leeuwin, Australia; Cape Naturaliste, Australia; and Angururu, Australia). Further details concerning these station records, including station histories, are given in Jones et al. (1985; 1986c), copies of which are included in Appendix A. Individual station data for the Antarctic (stations south of $62.5^{\circ} \mathrm{S}$ ) are not presented in this package but are given in Jones and Limbert (1989) and may be obtained free of charge from the Carbon Dioxide Information Analysis Center.

Analysis of these gridded surface air temperature anomaly data over the period 1881-1984 shows a linear warming trend of $0.52^{\circ} \mathrm{C}$ for the Northern Hemisphere (Jones et al. 1986a), and $0.51^{\circ} \mathrm{C}$ for the Southern Hemisphere, excluding the Antarctic (Jones et al. 1986d). A similar trends analysis incorporating the entire data set through 1990 has not yet been published.

\section{APPLICATIONS OF THE DATA}

A representative global data set of surface air temperatures is crucial for understanding past climatic trends and for comparing future measurements. For example, this baseline data set will be important in detecting any climate shift that may have been induced by increased concentrations of atmospheric greenhouse gases. The gridded data have been used in establishing hemispheric time series of surface air temperatures (e.g., Fig. 6, Jones et al. 1986c; Fig. 5, Jones et al. 1986a). The methods used to calculate spatial mean surface air temperatures differ among researchers, particularly in regard to averaging procedures and the extrapolation of extant data to data-poor areas (e.g., Wigley et al. 1985). When used in estimating global mean temperatures, these data are often combined with data for sea surface temperatures (SST) and, preferably, corrected for the effects of El Nino/Southern Oscillation (ENSO) events (see, for example, Jones 1988).

\section{LIMITATIONS AND RESTRICTIONS}

Although the data are calculated, stored, and presented in this data set to an accuracy of $0.01^{\circ} \mathrm{C}\left(0.1^{\circ} \mathrm{C}\right.$ for Antarctic data), the individual monthly grid point anomalies are probably only accurate to at best $\pm 0.2^{\circ} \mathrm{C}$, given the accuracy of the original data (see Jones et al. 1985). The size of this error decreases, however, as averages for larger and larger regions are calculated.

Homogeneity of the data was checked by comparison with data from adjacent stations; not all station histories were examined. Thus, it is possible that some inhomogeneities could have escaped detection if a group of stations were affected similarly by a non-climatic factor.

Interstation comparisons were based on annual means, rather than on monthly means. It is possible, then, that an inhomogeneity due to urbanization could have remained undetected if a season-specific effect was not identified in the annual data. More detail on the measures taken to improve the homogeneity of the data set can be found in Appendix $\mathrm{A}$. An assessment of the effect of urban warming on hemispheric average temperature anomalies derived from this data set is given in Jones et al. (1989). 
The data set suffers from large discontinuities in both temporal and spatial coverage (Figs. 1-9). During the period $1900-1988$, for example, nearly $60 \%$ of all contributing grid locations lack 10 or more years of data. Spatially, coverage is particularly poor before 1900 . In 1851 , for example, temperature anomaly data are available for only 48 grid loci, virtually all north of the equator; the entire Southern Hemisphere is represented by a single grid point, using data from a single station (Fig. 6). Jones et al. (1986d) considers the Southern Hemisphere data to be reliable only back to about 1890 for making annual hemispheric estimates and back to about 1860 for estimating overall trends. Even in 1990, however, large spatial gaps exist in the data set (Fig. 9). In the Southern Hemisphere, there is a complete lack of data from a number of grid locations in South America and central Africa. In the Northern Hemisphere, data for high-latitude locations are sparse, and there are a number of gaps in temperate regions, including two grid locations in the continental United States (resulting from the rejection of some station data during the 1980s due to urbanization effects). Considering the overall sparsity of polar data and the low weighting factor usually assigned to high-latitude data in generating area average temperature series (e.g., Jones et al. 1985), the result is likely to be an effective omission of high latitude data from such area average series. However, on the basis of the consistency of findings derived from satellite data and from surface data, Jones and Wigley (1990) have argued that incomplete coverage does not seriously affect the quality of surface temperature data.

Although each grid point temperature anomaly serves as an average value for all stations nearest to that grid point, many of the gridded anomalies use data from a single station. In 1990 , for example, over half of all grid point temperature anomalies were based (as a monthly average) on data from one station. Even in 1960, the year in which the number of contributing stations was at a maximum, over $40 \%$ of all grid point anomalies were based on single station data.

In cases for the period 1979-84 in which the updated data contained in this document involve a change in the number of stations contributing to a grid point temperature anomaly, no corresponding changc were made to the associated mean inverse distance values. In these instances, therefore, the mean inverse distance data presented in this document must be assumed to be incorrect. 


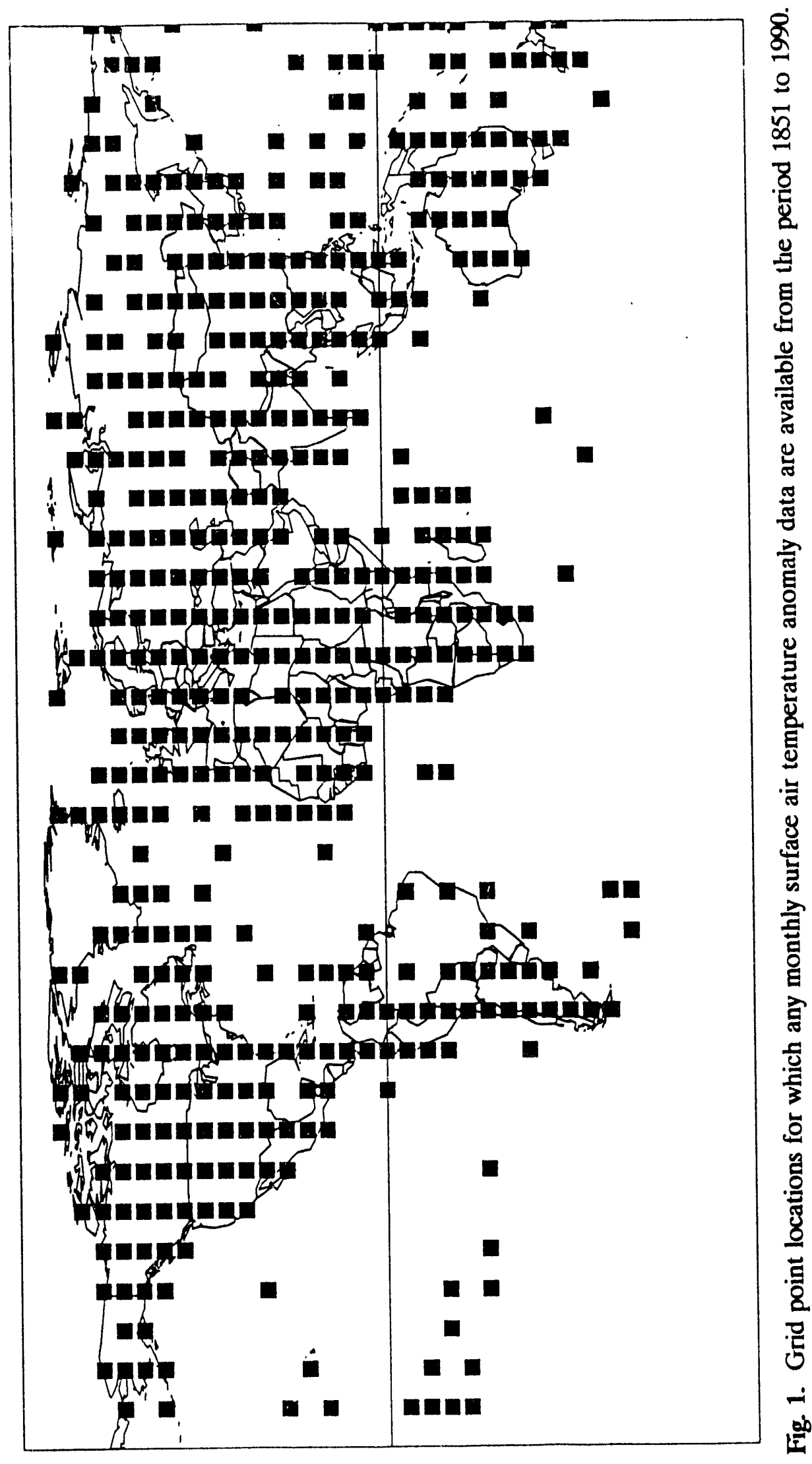




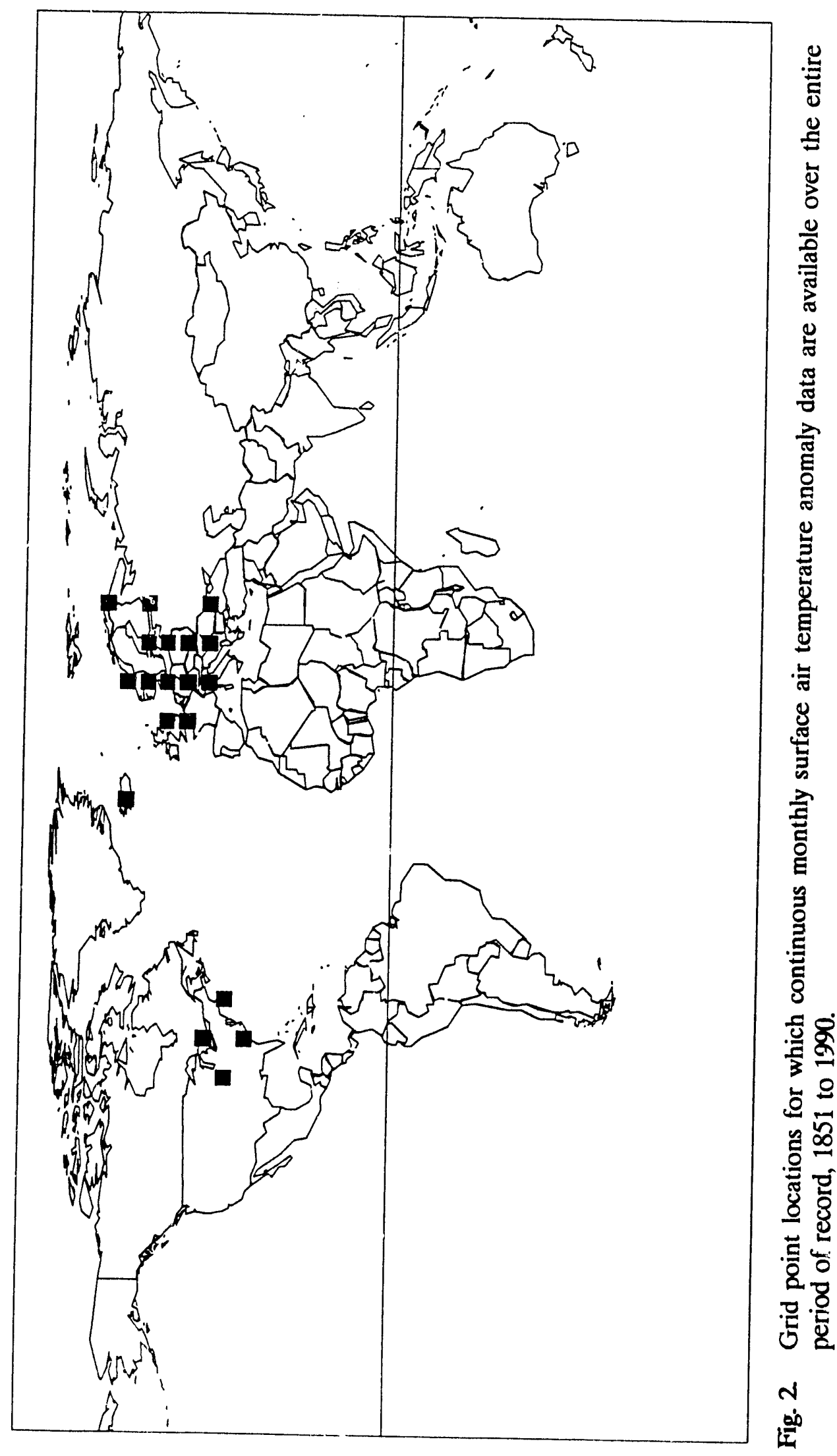




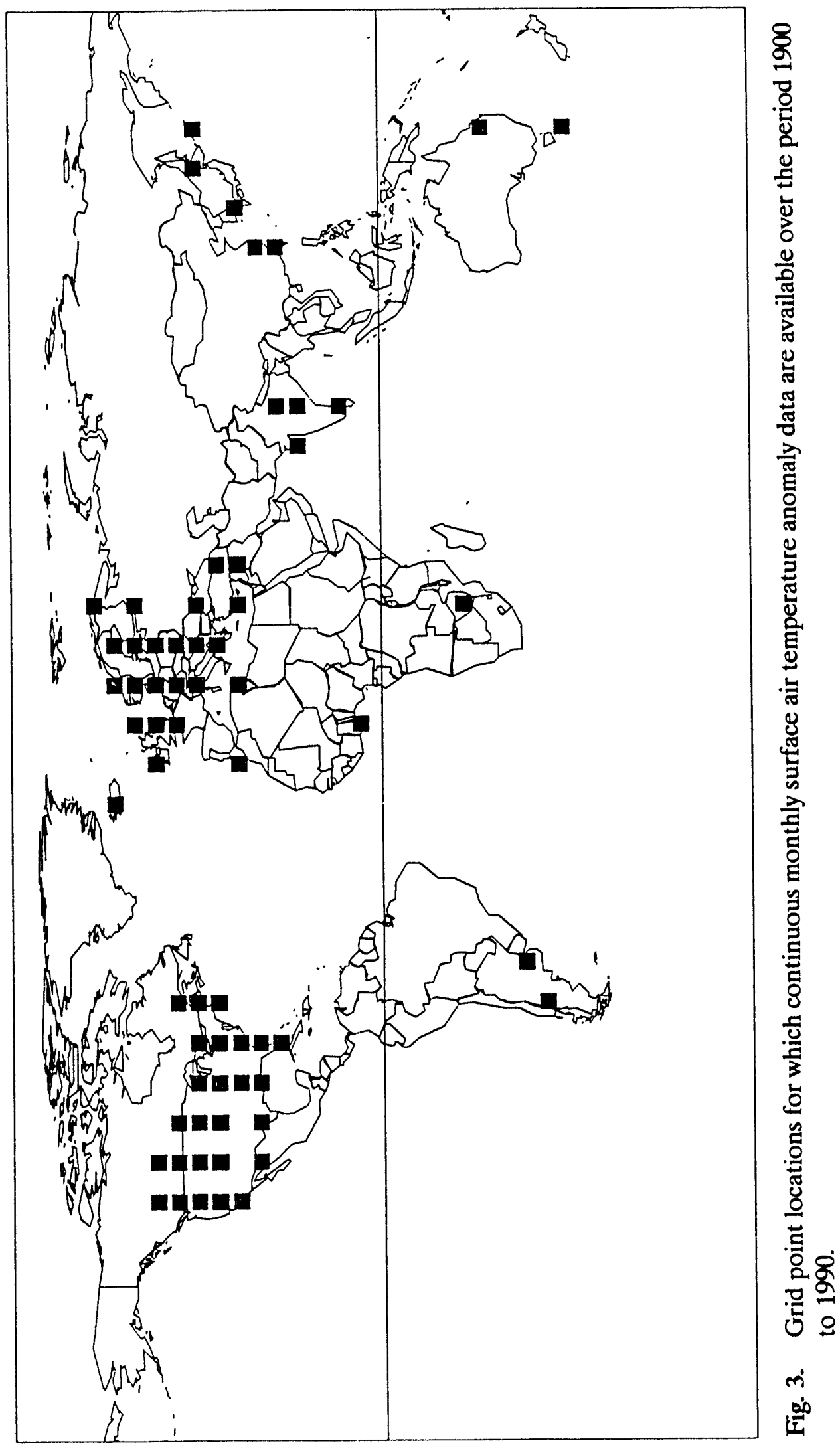




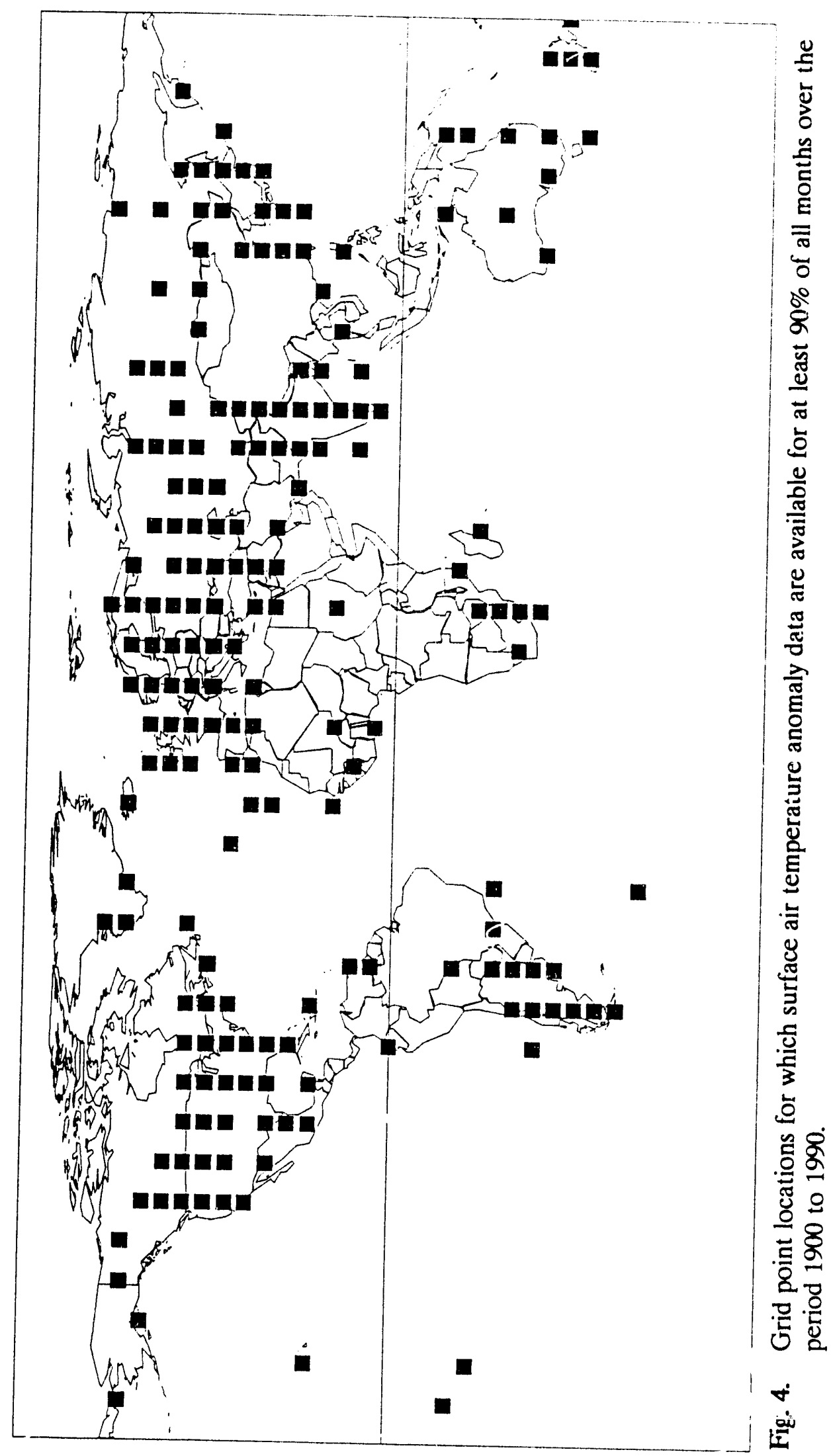




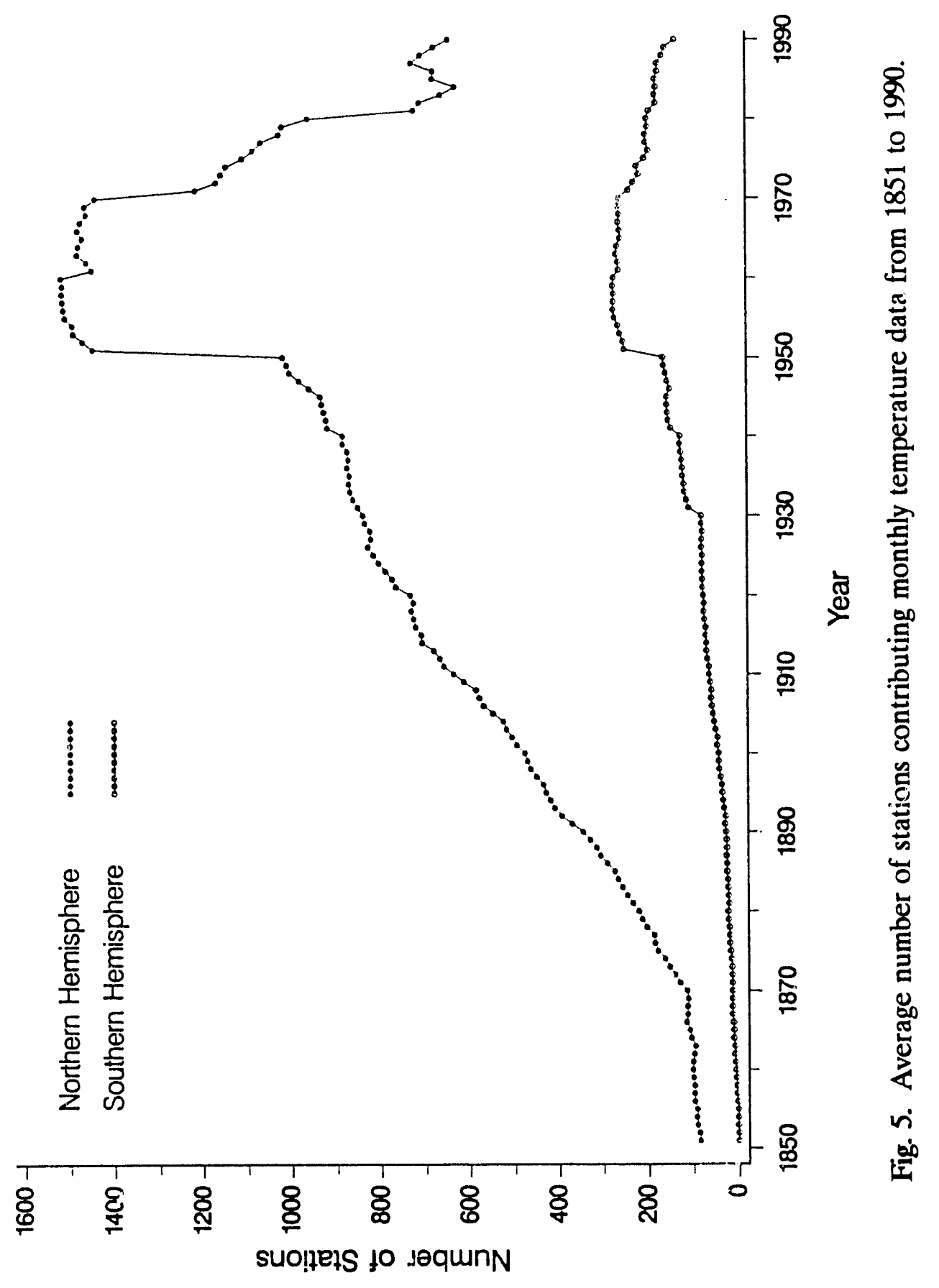




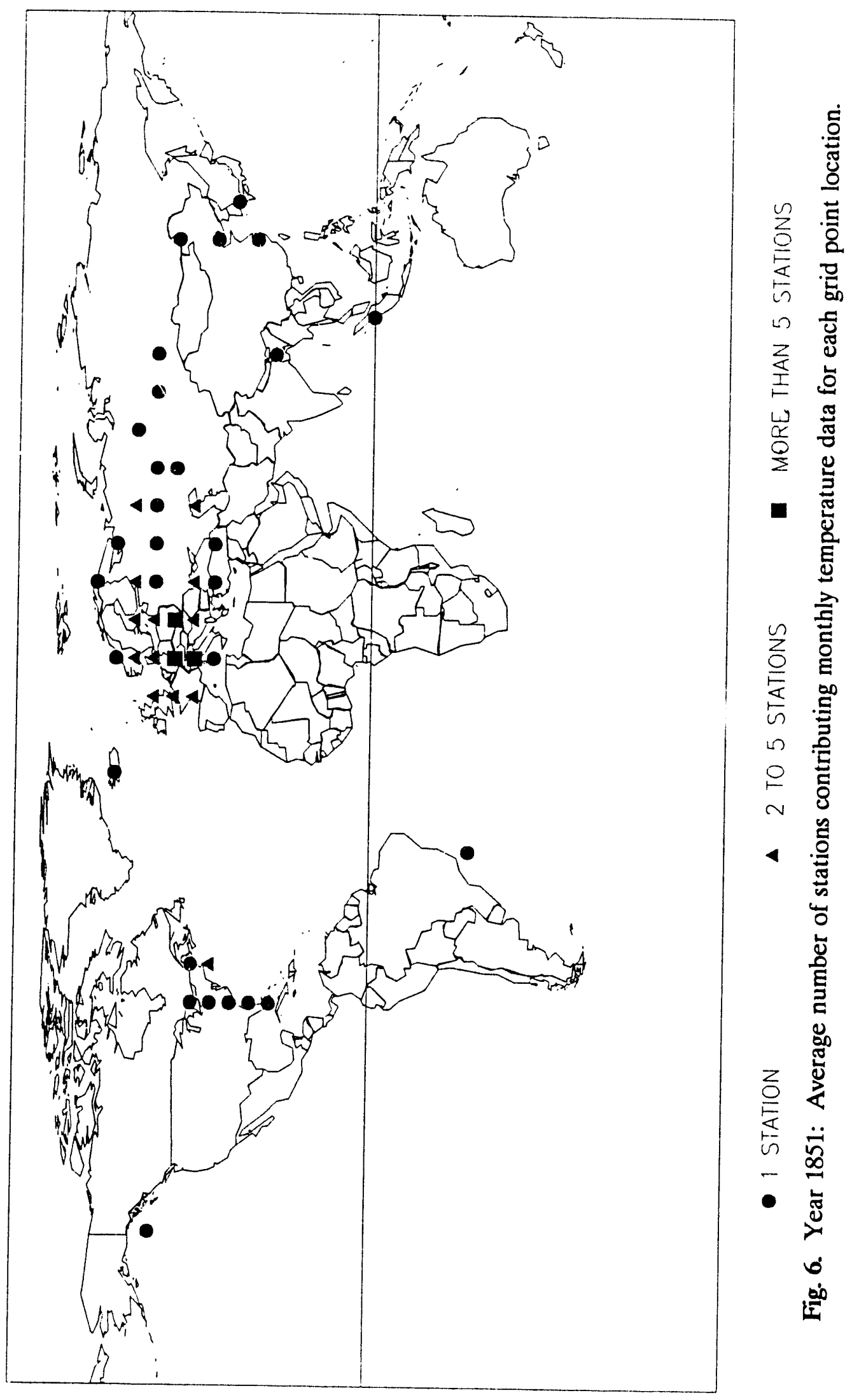




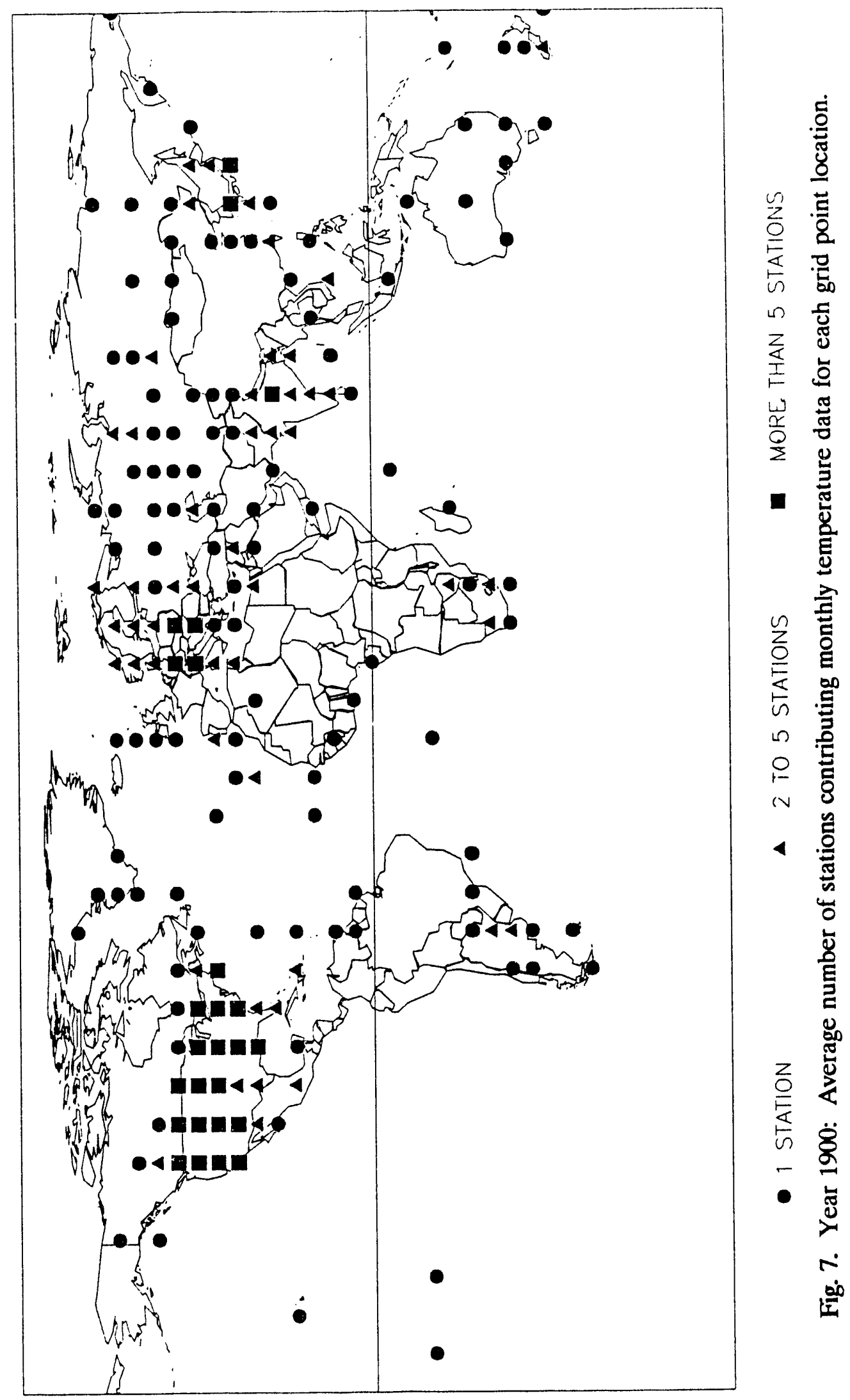




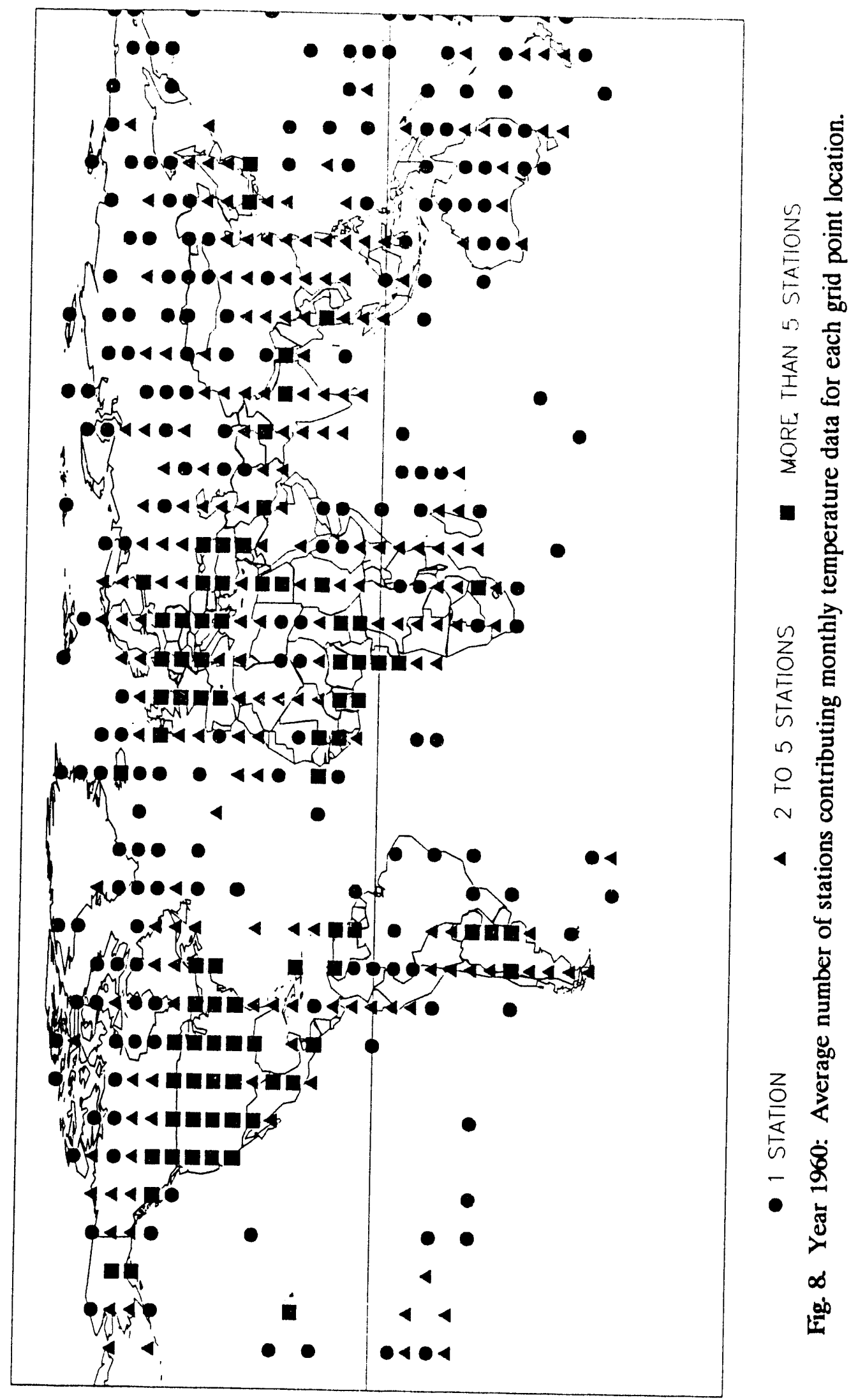




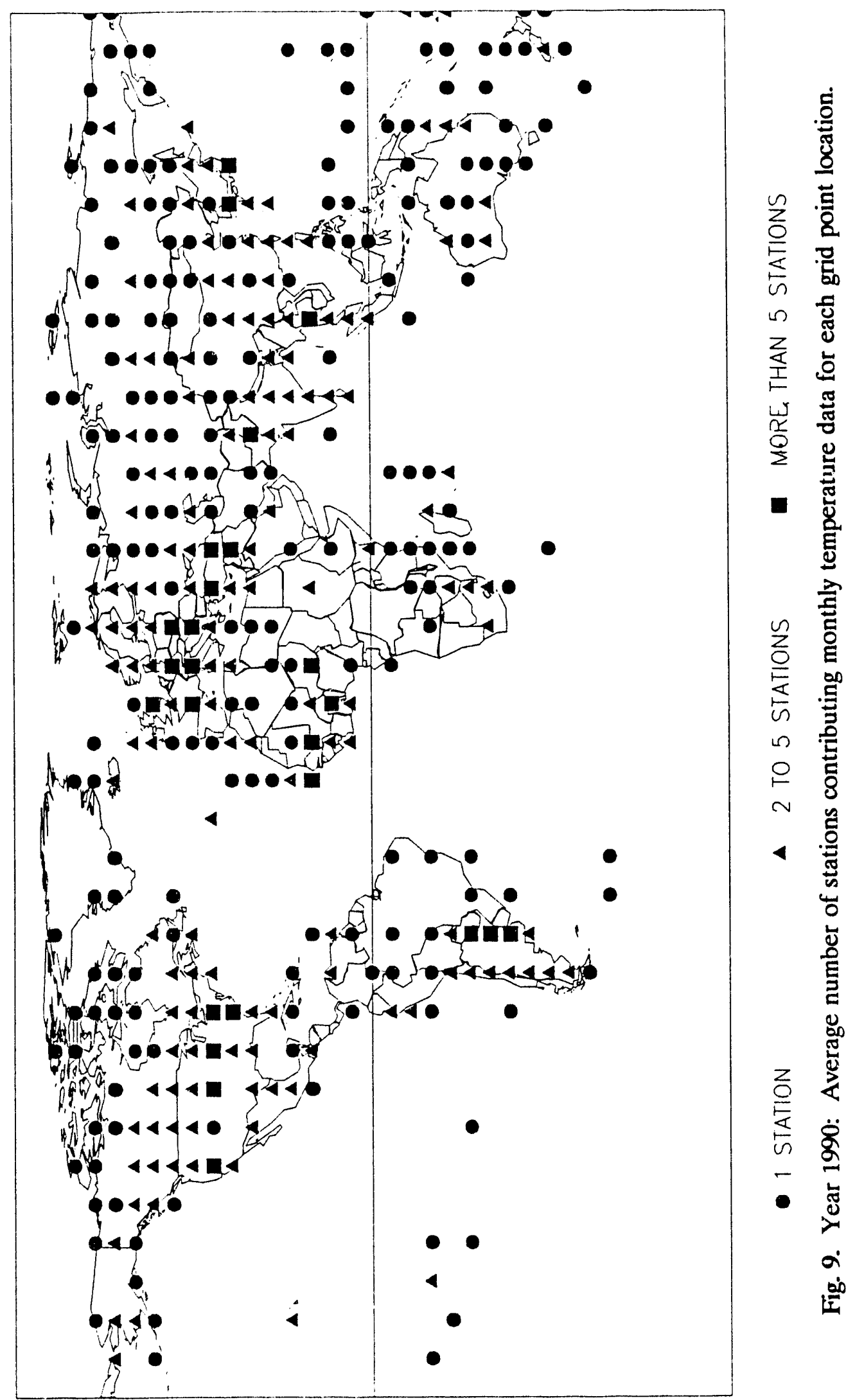




\section{REFERENCES}

Bradley, R. S., P. M. Kelly, P. D. Jones, C. M. Goodess, and H. F. Diaz. 1985. A climatic data bank for Northern Hemisphere land areas, 1851-1980. DOE Technical Report No. TR017. U.S. Department of Energy, Carbon Dioxide Research Division, Washington, D.C.

Jones, P. D. 1988. The influence of ENSO on global temperatures. Climate Monitor 17:80-89.

Jones, P. D., and D. W. S. Limbert. 1989. Antarctic surface temperature and pressure data. ORNL/CDIAC-27, NDP-032. Oak Ridge National Laboratory, Oak Ridge, Tennessee.

Jones, P. D., and T. M. L. Wigley. 1990. Satellite data under scrutiny. Nature 344:711.

Jones, P. D., S. C. B. Raper, B. Santer, B. S. G. Cherry, C. M. Goodess, P. M. Kelly, T. M. L. Wigley, R. S. Bradley, and H. F. Diaz. 19.85. A grid point surface air temperature data set for the Northern Heinisphere. DOE Technical Report No. TR022. U.S. Department of Energy, Carbon Dioxide Research Division, Washington, D.C.

Jones, P. D., S. C. B. Raper, R. S. Bradley, H. F. Diaz, P. M. Kelly, and T. M. L. Wigley. 1986a. Northern Hemisphere surface air temperature variations: 1851-1984. Journal of Climate and Applied Meteorology 25:161-79.

Jones, P. D., S. C. B. Raper, B. S. G. Cherry, C. M. Goodess, T. M. L. Wigley, B. Santer, P. M. Kelly, R. S. Bradley, and H. F. Diaz. 1986b. A global grid point surface air temperature data set: 1851-1984. NDP-020. Carbon Dioxide Information Analysis Center, Oak Ridge National Laboratory, Oak Ridge, Tennessee.

Jones, P. D., S. C. B. Raper, C. M. Goodess, B. S. G. Cherry, and T. M. L. Wigley. 1986 c. $A$ grid point surface air temperature data set for the Southern Hemisphere. DOE Technical Report No. TR027. U.S. Department of Energy, Carbon Dioxide Research Division, Washington, D.C.

Jones, P. D., S. C. B. Raper, and T. M. L. Wigley. 1986d. Southern Hemisphere surface air temperature variations: 1851-1984. Journal of Climate and Applied Meteorology 25:1213-1230.

Jones, P. D., T. M. L. Wigley, G. Ohring, and A. Thomasell. 1988. Global-scale temperature changes to August 1987 and a comparison of satellite and conventional data. pp. 326-334. in Proceedings of the Twelfth Annual Climate Diagnostics Workshop, Department of Microbiology, University of Utah, Salt Lake City, October 12-16, 1987. U.S. Department of Commerce, National Oceanic and Atmospheric Administration.

Jones, P. D., P. M. Kelly, C. M. Goodess, and T. Karl. 1989. The effect of urban warming on the Northern Hemisphere temperature average. Journal of Climate 2:285-90. 
Smithsonian Institution. 1927, 1935, 1947. World Weather Records. Miscellaneous Collections, Vols. 79, 90, 104. Washington, D.C.

U.S. Weather Burcau. 1959-1982. World Weather Records. 1941-1950 (1361 pp.), 1951-1960 (Vols. 1-6), 1961-1970 (Vols. 1-6). U.S. Department of Commerce, Washington, D.C.

Wigley, T. M. L., J. K. Angeli, and P. D. Jones. 1985. Analysis of the temperature record. pp. 55-90. in M. C. MacCracken and F. M. Luther (eds.), Detecting the Climatic Effects of Increasing Carbon Dioxide. DOE/ER-0235. U.S. Department of Energy, Washington, D.C.

This data package includes reprints of Jones et al. 1985, Jones et al. 1986c, and Jones et al. 1988 (see Appendix A).

\section{DATA CHECKS PERFORMED BY CDIAC}

The Carbon Dioxide Information Analysis Center (CDIAC) endeavors to provide quality assurance (QA) of all data before their distribution. To ensure the highest possible quality in the data, CDIAC conducts extensive reviews for reasonableness, accuracy, completeness, and consistency of form. While having common objectives, the specific form of these reviews must be tailored to each data set; the process may involve considerable programming efforts. The entire QA process is an important part of CDIAC's effort to ensure that accurate, usable $\mathrm{CO}_{2}$-related data are available to researchers.

The following summarizes the QA checks performed on the gridded surface air temperature data by CDIAC.

1. The format of all information, including header items, was checked to ensure consistency throughout each data file. Inconsistencies discovered either within the data set or between the original version and the present updated version include: (1) the presence of an extraneous line length record, not present in the earlier version of the data set, at the beginning of each line; and (2) inconsistencies in the form in which the year of record was presented within the data set.

2. All records were compared with the corresponding records (where available) in the original version to cite changes made to the updated version. These changes are summarized in Fig. 10.

3. The spatial and temporal continuity of the gridded temperature data set was reviewed, along with the corresponding data on the number of contributing stations. These results are summarized in Figs. 1-9.

4. Range and variability checks were performed on the temperature anomaly data to ensure reasonableness. The variability of the temperature data for years $1851-1990$, is shown in Fig. 11. 


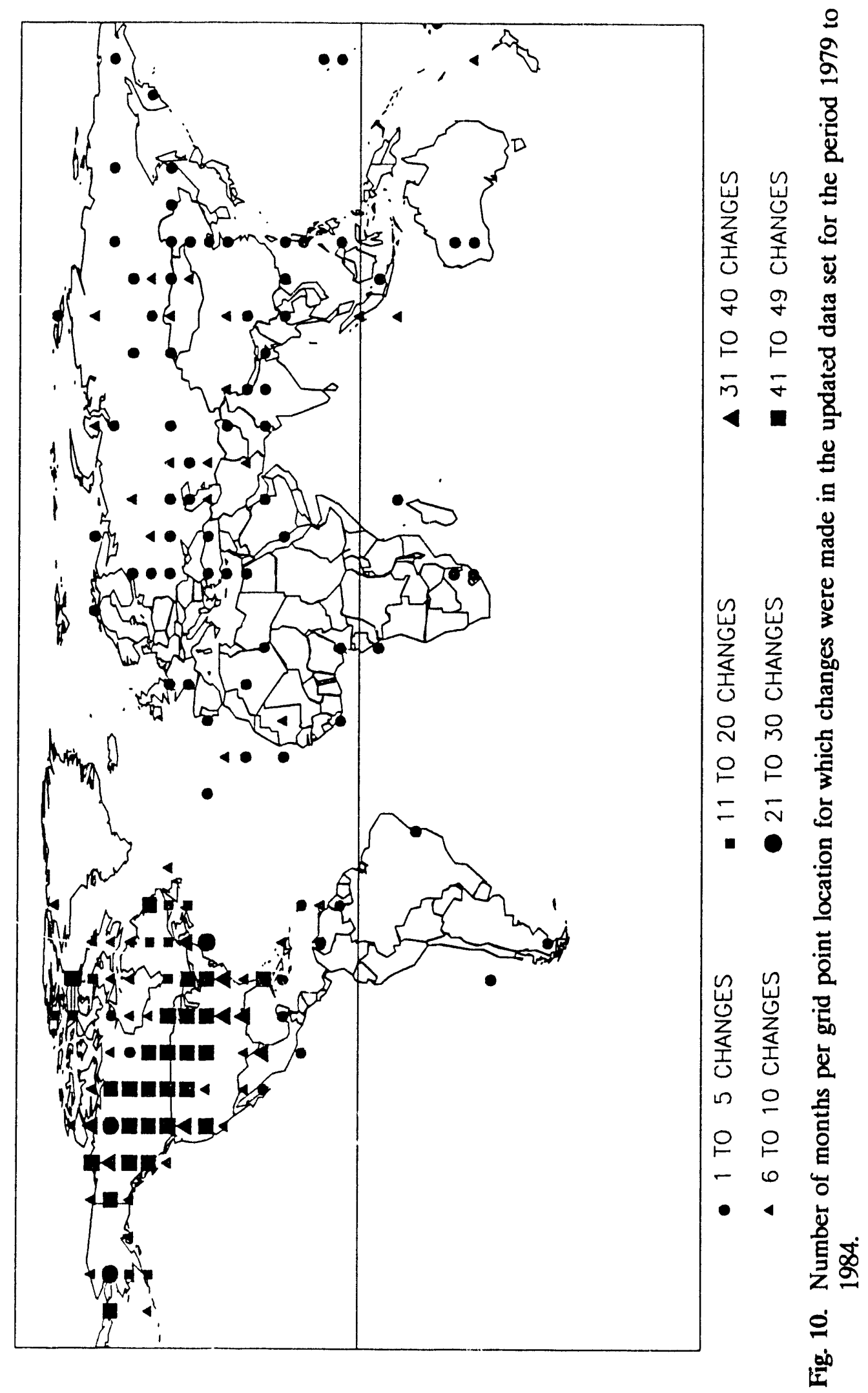




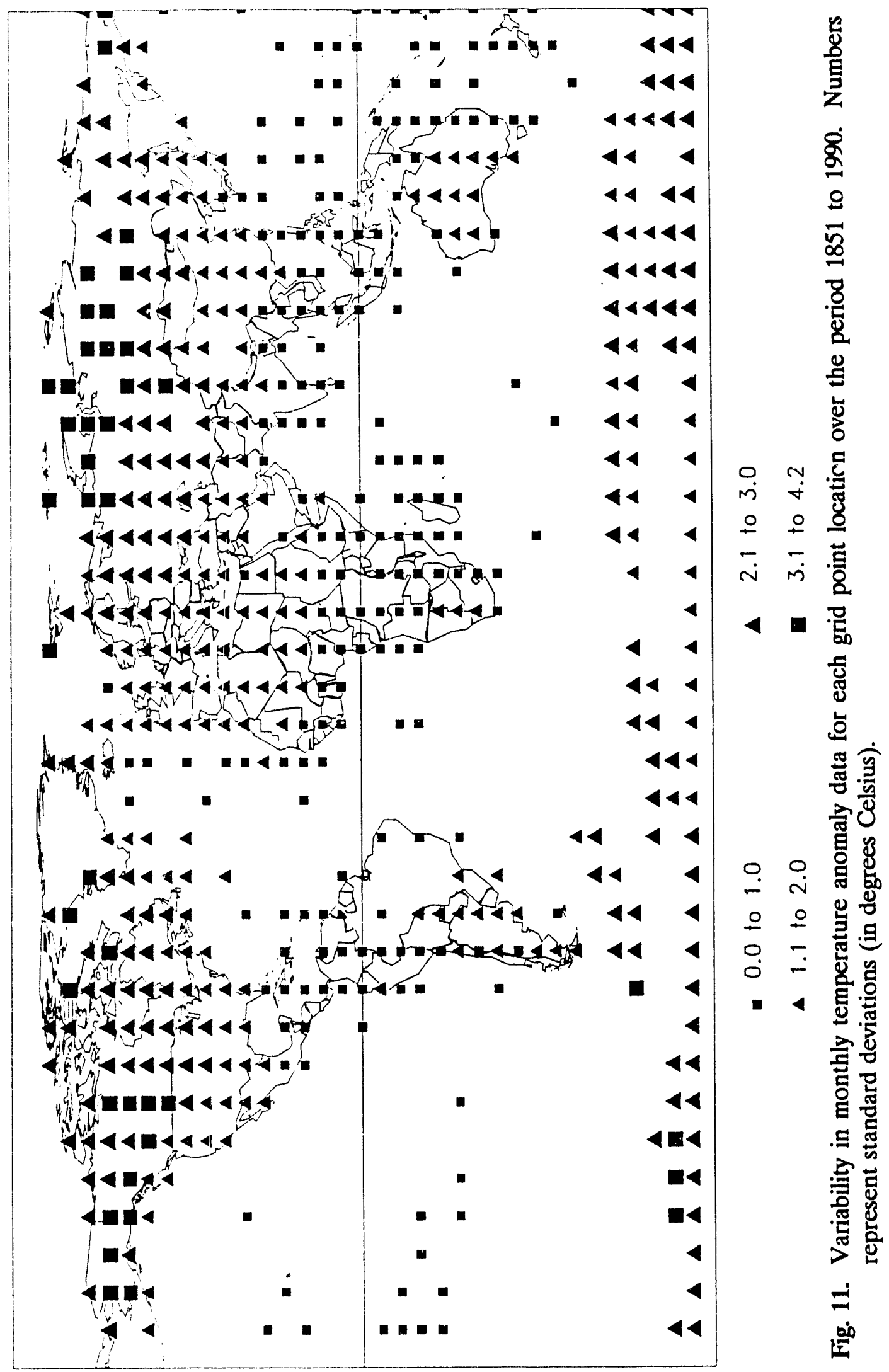


It is not the task of CDIAC to make alterations or deletions to the values of data it receives. Therefore, aside from the elimination of inconsistencies and redundancies in header items described in item 1 above, the surface air temperature anomaly files distributed by CDIAC in this package are identical to the original files sent to CDIAC.

Packaging of the monthly mean temperature records for individual stations required the merging of a number of separate files and the correction of incomplete or inconsistent header information. In addition, each data record, containing the 12 monthly mean temperatures for a given year, was appended with a summary value representing the mean of the 12 monthly values. No alterations have otherwise been made to any of the monthly data values contained in these files. Therefore, any limitations present in these data (e.g., the lack of corrections for inhomogeneities and the absence of data for 5 stations in the Southern Hemisphere) reflect those present in the original files obtained by CDIAC.

\section{HOW TO OBTAIN THE PACKAGE}

This document describes a data set consisting of the departures of 1851-1990 surface air temperatures from the mean of the 1951-1970 reference period, expressed on a global $10^{\circ}$ longitude grid by $5^{\circ}$ latitude grid, covering latitudes from $85^{\circ} \mathrm{N}$ to $60^{\circ} \mathrm{S}$. Antarctic $\left(65^{\circ} \mathrm{S}\right.$ to $\left.85^{\circ} \mathrm{S}\right)$ data are similarly presented as a separate data set consisting of the departures of 1957-1990 surface air temperatures from the mean of the 1957-1975 reference period. These data are provided on microfiche (inside back cover) in the package and are available upon request on nine-track magnetic tapes from CDIAC. Also described is a data set consisting of the actual monthly mean temperature records for individual stations from which the set of gridded departures (anomalies) were derived. Requests for magnetic tapes should include any specific instructions for transmitting the data required by the user to access the data. Requests not accompanied by specific instructions will be filled on nine-track, $6250 \mathrm{BPI}$, standard-labeled tapes with characters written in EBCDIC (Extended Binary Codes Decimal Interchange Code) and files formatted as noted in Section 11. Because of the size of the data files (12-20 MB), it is not feasible to distribute these data on floppy diskettes, even as compressed files. Requests should be addressed to the following:

Carbon Dioxide Information Analysis Center

Oak Ridge National Laboratory

Post Office Box 2008

Oak Ridge, Tennessee 37831-6335

U.S.A.

The tapes and documentation can be ordered by telephone, fax machine, or electronic mail.

$\begin{array}{lrr}\text { Telephone: } & (615) & 574-0390 \\ \text { FTS } & 624-0390 \\ \text { Fax: } & (615) & 574-2232 \\ & \text { FTS } & 624-2232\end{array}$

Electronic Mail: $\quad$ BITNET: CDP@ORNLSTC INTERNET: CDP@STC10.CTD.ORNL.GOV OMNET: CDIAC 
PART 2

INFORMATION ABOUT THE MAGNETIC TAPE 


\section{CONTENTS OF THE MAGNETIC TAPE}

The following is a list of files distributed on magnetic tape by CDIAC along with this documentation.

\begin{tabular}{|c|c|c|c|c|c|}
\hline & $\begin{array}{c}\text { File number } \\
\text { and description }\end{array}$ & $\begin{array}{l}\text { Number of } \\
\text { logical } \\
\text { records }\end{array}$ & $\begin{array}{l}\text { Record } \\
\text { format }^{\mathrm{a}}\end{array}$ & $\begin{array}{l}\text { Block } \\
\text { size }\end{array}$ & $\begin{array}{l}\text { Record } \\
\text { length }\end{array}$ \\
\hline 1. & $\begin{array}{l}\text { General descripti e } \\
\text { information file }\end{array}$ & 361 & FB & 8000 & 80 \\
\hline 2. & $\begin{array}{l}\text { FORTRAN IV data } \\
\text { retrieval ccde to } \\
\text { read and print the } \\
\text { gridded surface air } \\
\text { temperature anomaly } \\
\text { data file for the } \\
\text { Northern Hemisphere } \\
\text { (File 10) }\end{array}$ & 56 & FB & 8000 & 80 \\
\hline 3. & $\begin{array}{l}\text { FORTRAN IV data } \\
\text { retrieval code to } \\
\text { read and print the } \\
\text { gridded surface air } \\
\text { temperature anomaly } \\
\text { data file for the } \\
\text { Southern Herinisphere } \\
\text { (File 11) }\end{array}$ & 56 & FB & 8000 & 80 \\
\hline 4. & $\begin{array}{l}\text { FORTRAN IV data } \\
\text { retrieval code to } \\
\text { read and print the } \\
\text { gridded surface air } \\
\text { temperature anomaly } \\
\text { data file for the } \\
\text { Antarctic (File 12) }\end{array}$ & 42 & FB & 8000 & 80 \\
\hline 5. & $\begin{array}{l}\text { FORTRAN IV data } \\
\text { retrieval cods to } \\
\text { read and print } \\
\text { the monthly mean } \\
\text { temperature records } \\
\text { for individual } \\
\text { stations (Files } 13 \\
\text { and } 14 \text { ) }\end{array}$ & 27 & FB & 8000 & 80 \\
\hline
\end{tabular}


File number and description

\section{Number of}

logical

records
Record

format ${ }^{a}$
Block

size

Record

length

6. $\mathrm{SAS}^{\mathrm{b}}$ input/output

102

FB

8000

80

routine to read and

print the gridded

surface air temperature

anomaly data file

for the Northern

Hemisphere (File 10)

7. $S A S^{b}$ input/output routine to read and print the gridded surface air temperature anomaly data file for the Southern Hemisphere (File 11)

8. $S A S^{b}$ input/output routine to read and print the gridded surface air temperature anomaly data file for the Antarctic (File 12)

9. SAS $^{\mathrm{b}}$ input/output

print the monthly mean temperature records for individual stations (Files 13 and 14)

10. Gridded surface air temperature anomalies for the Northern Hemisphere, 1851-1990

11. Gridded surface air temperature anomalies for the Southern Hemisphere, 1851-1990

12. Gridded surface air temperature anomalies for the Antarctic, 1957-1990 


\begin{tabular}{|c|c|c|c|c|c|}
\hline & $\begin{array}{l}\text { File number } \\
\text { and description }\end{array}$ & $\begin{array}{l}\text { Number of } \\
\text { logical } \\
\text { records }\end{array}$ & $\begin{array}{l}\text { Record } \\
\text { format }^{\mathrm{a}}\end{array}$ & $\begin{array}{l}\text { Block } \\
\text { size }\end{array}$ & $\begin{array}{l}\text { Record } \\
\text { length }\end{array}$ \\
\hline 13. & $\begin{array}{l}\text { Monthly mean temperature } \\
\text { records for individual } \\
\text { stations in the } \\
\text { Northern Hemisphere } \\
\text { (corrected) }\end{array}$ & 116,931 & FB & 8000 & 80 \\
\hline \multirow[t]{2}{*}{14.} & $\begin{array}{l}\text { Monthly mean temperature } \\
\text { records for individual } \\
\text { stations in the } \\
\text { Southern Hemisphere } \\
\text { (uncorrected and } 5 \\
\text { stations }^{c} \text { missing) }\end{array}$ & 16,738 & FB & 8000 & 80 \\
\hline & Total records & $\overline{522,510}$ & & & \\
\hline
\end{tabular}

${ }^{\mathrm{a}} \mathrm{FB}=$ fixed block.

'SAS is the registered trademark of SAS Institute, Inc., Cary, North Carolina 27511-8000.

${ }^{\mathrm{c}}$ Masterton, New Zealand

Lincoln College, New Zealand

Cape Leeuwin, Australia

Cape Naturaliste, Australia

Angururu, Australia 


\title{
12. DESCRIPTIVE FILE ON THE TAPE
}

The following is a listing of File 1 on the magnetic tape distributed by CDIAC. This file is intended to complement the documentation and provide details (i.e., variable descriptions, formats, and units) about each data file on the magnetic tape.

\section{TITLE OF THE DATA SET}

An Updated Global Grid Point Surface Air Temperature Anomaly Data Set: 1851-1990

\section{DATA CONTRIBUTORS}

\author{
P. D. Jones \\ B. S. G. Cherry \\ T. M. L. Wigley \\ S. C. B. Raper \\ C. M. Goodess \\ P. M. Kelly \\ Climatic Research Unit \\ University of East Anglia \\ Norwich, United Kingdom \\ R. S. Bradley \\ University of Massachusetts \\ Amherst, Massachusetts \\ H. F. Diaz \\ National Oceanic and Atmospheric Administration \\ Environmental Research Laboratories \\ Boulder, Colorado
}

\section{SOURCE AND SCOPE OF THE DATA}

The data files included on this magnetic tape provide gridded surface air temperature anomaly data for a total of 486 grid cells in the Northern and Southern Hemispheres (latitudes from $85^{\circ} \mathrm{N}$ to $60^{\circ} \mathrm{S}$ ), and an additional 100 grid cells in the Antarctic (latitudes from $65^{\circ} \mathrm{S}$ to $85^{\circ} \mathrm{S}$ ). Each grid cell represents an area of $5^{\circ}$ latitude by $10^{\circ}$ longitude. These data are derived from temperature records of land-based stations for the period 1851-1990, except for the Antarctic data, where the period is 1957-1990. The gridded data are departures (anomalies) from the station means for each month over the 1951-1970 reference period, or, for the Antarctic data, the 1957-1975 reference period. It was necessary to reduce all the station data to anomalies because of different station elevations and, to a lesser extent, different observation times.

The primary sources of these data are the World Weather Records (WWR), published by the Smithsonian Institution and the U.S. Weather Bureau, the archives of the United Kingdom Meteorological Office, and the Monthly Climatic Data for the World, published by the National Climatic Data Center (Asheville, North Carolina). Additional sources are 
described in Bradley et al. (1985) and in Jones et al. (1985, 1986a, 1986x, 1986d). The present updated version of this data set is identical to the earlier version (Jones et al. 1986b) for all records from 1851 through 1978. For the period 1979-1984, the present data set corrects erroneous data using satellite data for some sites and appends data for other sites by adding previously unavailable station data (Jones et al. 1988). The present package also adds monthly surface air temperature anomalies for the period 1985-1990, Antarctic monthly surface air temperature anomalies for the period 1957-1990, as well as the monthly mean temperature records for individual stations (Antarctic stations excluded) that were used to generate the set of gridded anomalies. Individual station data for the Antarctic (stations south of $62.5^{\circ} \mathrm{S}$ ) are not presented in this package but are given in Jones and Limbert (1989) and may be obtained free of charge from the Carbon Dioxide Information Analysis Center.

\section{DATA FORMAT}

Fourteen files are provided on this magnetic tape, including this descriptive file, four FORTRAN IV and four SAS data retrieval programs, three data files containing gridded surface air temperature anomaly data, and two files containing the monthly mean temperature records for individual stations.

\section{Gridded Anomaly Data, Northern Hemisphere}

The data file containing the gridded surface air temperature anomaly data for the Northern Hemisphere (File 10) is formatted in the following way:

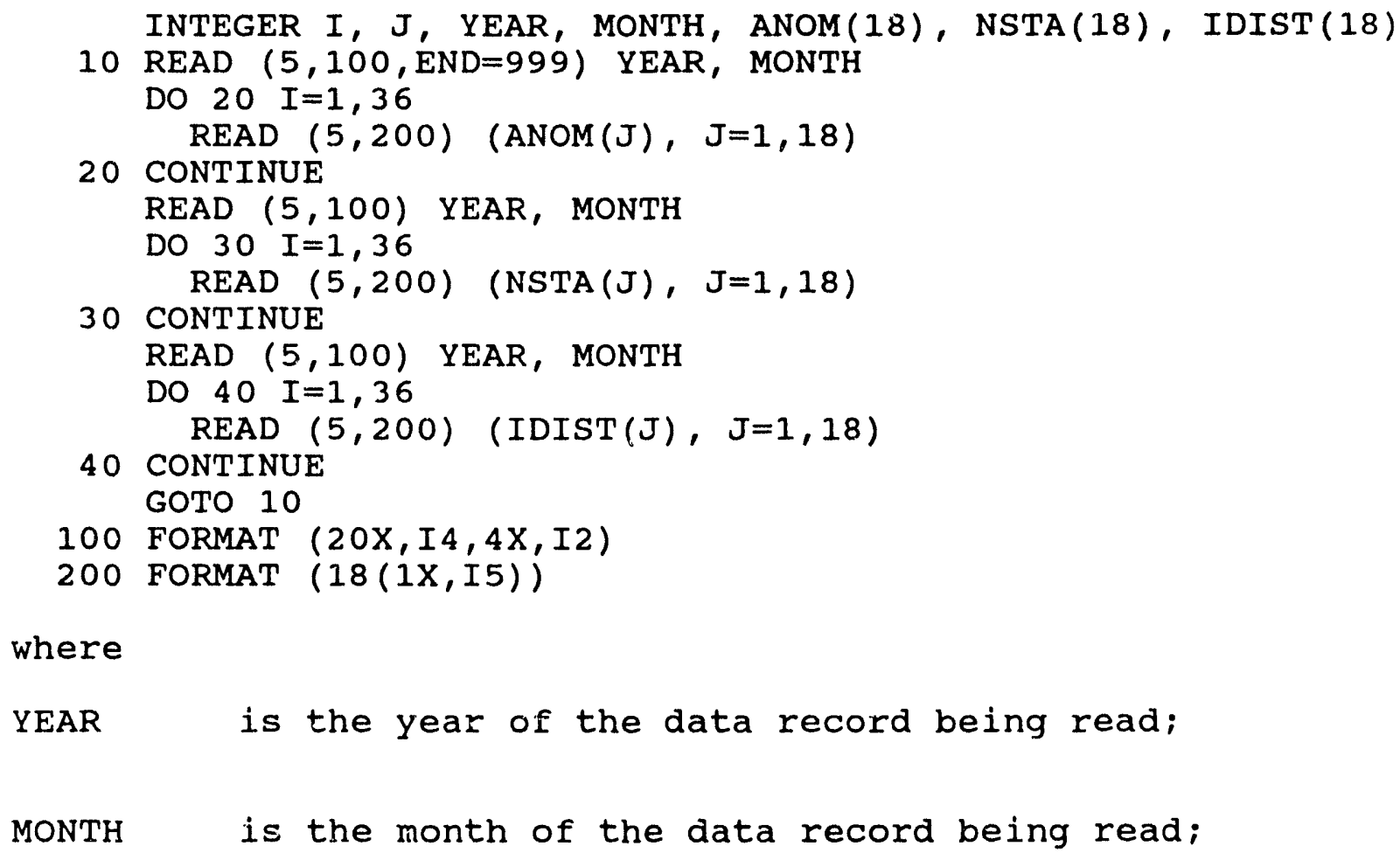

where

YEAR is the year of the data record being read;

MONTH is the month of the data record being read; 


\begin{tabular}{|c|c|}
\hline ANOM & $\begin{array}{l}\text { is the gridded surface air temperature anomaly i } \\
\text { degrees Celsius, multiplied by } 100 ;\end{array}$ \\
\hline NSTA & $\begin{array}{l}\text { is the number of stations used to calculate the } \\
\text { gridded anomaly; }\end{array}$ \\
\hline IDIST & $\begin{array}{l}\text { is } 10,000 \text { times the mean value (for all } \\
\text { contributing stations) of the inverse of the } \\
\text { great circle distance between the station and the } \\
\text { grid point; }\end{array}$ \\
\hline$I$ & $\begin{array}{l}\text { represents the data line being read (each of the } \\
36 \text { lines of data represents a } 10^{\circ} \text { longitude band, } \\
\text { centered on } 0^{\circ}, 10^{\circ} \mathrm{E}, 20^{\circ} \mathrm{E}, \ldots, 170^{\circ} \mathrm{E}, 180^{\circ}, \\
170^{\circ} \mathrm{W}, \ldots, 10^{\circ} \mathrm{W} \text { ) : }\end{array}$ \\
\hline $\mathbf{J}$ & $\begin{array}{l}\text { represents the data column being read (each of } \\
\text { the } 18 \text { columns of data represents a } 5^{\circ} \text { latitude } \\
\text { band, centered on } 85^{\circ} \mathrm{N}, 80^{\circ} \mathrm{N}, \ldots, 5^{\circ} \mathrm{N}, 0^{\circ} \text { ); }\end{array}$ \\
\hline
\end{tabular}

Missing values for the temperature anomalies are represented by -9999 . Missing values for the number of stations and mean inverse distances are represented by 0 .

\section{Gridded Anomaly Data, Southern Hemisphere}

The data file containing the gridded surface air temperature anomaly data for the Southern Hemisphere (File 11) is formatted in the following way:

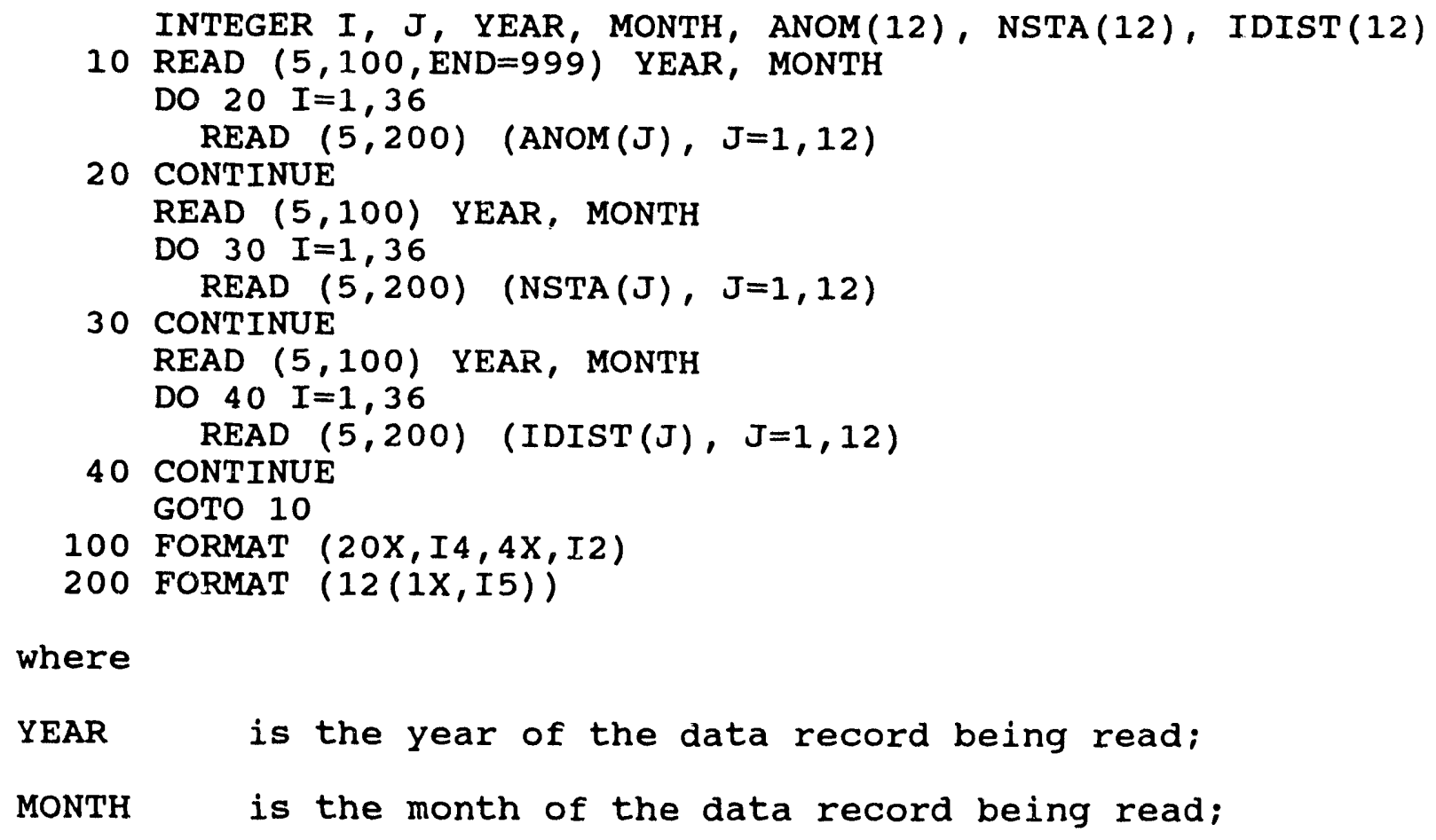

YEAR is the year of the data record being read;

MONTH is the month of the data record being read;

where 


\begin{tabular}{|c|c|}
\hline ANOM & $\begin{array}{l}\text { is the gridded surface air temperature anomaly in } \\
\text { degrees Celsius, multiplied by } 100 ;\end{array}$ \\
\hline NSTA & $\begin{array}{l}\text { is the number of stations used to calculate the } \\
\text { gridded anomaly; }\end{array}$ \\
\hline IDIST & $\begin{array}{l}\text { is } 10,000 \text { times the mean value (for all } \\
\text { contributing stations) of the inverse of the } \\
\text { great circle distance between the station and the } \\
\text { grid poirt: }\end{array}$ \\
\hline$I$ & $\begin{array}{l}\text { represents the data line being read (each of the } \\
36^{2} \text { lines of data represents a } 10^{\circ} \text { longitude band, } \\
\text { centered on } 0^{\circ}, 10^{\circ} \mathrm{E}, 20^{\circ} \mathrm{E}, \ldots, 170^{\circ} \mathrm{E}, 180^{\circ} \text {, } \\
\left.170^{\circ} \mathrm{W}, \ldots, 10^{\circ} \mathrm{W}\right) \text {; }\end{array}$ \\
\hline $\mathrm{J}$ & $\begin{array}{l}\text { represents the data column being read (each of } \\
\text { the } 12 \text { columns of data represents a } 5^{\circ} \text { latitude } \\
\text { band, centered on } 5^{\circ} \mathrm{S}, 10^{\circ} \mathrm{S}, \ldots .60^{\circ} \mathrm{S} \text { ); }\end{array}$ \\
\hline
\end{tabular}

Missing values for the temperature anomalies are represented by -9999 . Missing values for the number of stations and mean inverse distances are represented by 0 .

\section{Gridded Anomaly Data, Antarctic}

The data file containing the gridded surface air temperature anomaly data (anomalies only - no information concerning the number of stations and the mean inverse distances) for the Antarctic (File 12) is formatted in the following way:

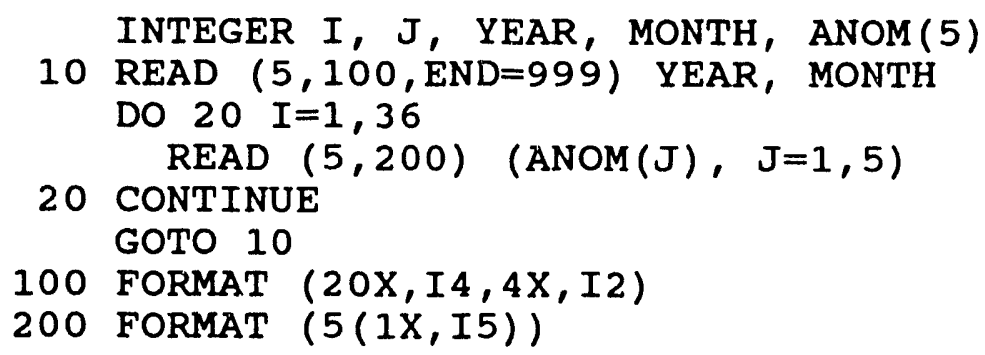

where

YEAR is the year of the data record being read;

MONTH is the month of the data record being read;

ANOM is the gridded surface air temperature anomaly in degrees Celsius, multiplied by 100; 

36 lines of data represents a $10^{\circ}$ longitude band, centered on $0^{\circ}, 10^{\circ} \mathrm{E}, 20^{\circ} \mathrm{E}, \ldots, 170^{\circ} \mathrm{E}, 180^{\circ}$, $170^{\circ} \mathrm{W}, \ldots, 10^{\circ} \mathrm{W}$ ):

Missing values for the temperature anomalies are represented by -9999 .

\section{Monthly Mean Temperature Data for Individual Stations}

The data files containing the monthly mean temperature records for individual stations (Files 13 and 14) are each formatted as

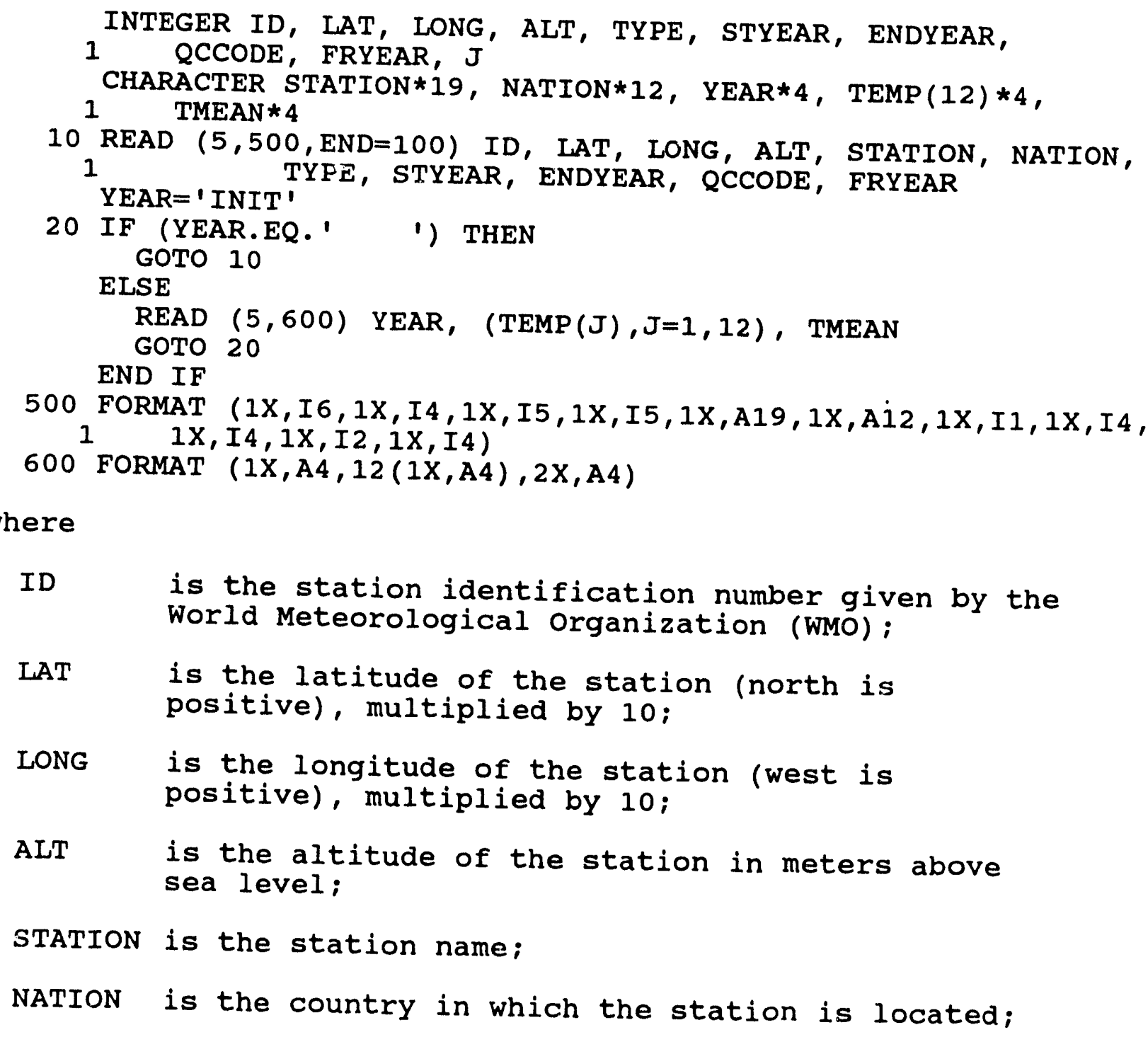

ID is the station identification number given by the World Meteorological Organization (WMO);

LAT is the latitude of the station (north is positive), multiplied by 10 ;

LONG is the longitude of the station (west is positive), multiplied by 10 ;

ALT is the altitude of the station in meters above sea level;

STATION is the station name;

NATION is the country in which the station is located; 
TYPE is an integer code whose value indicates whether data entries are temperature ('1') or precipitation ('2');

STYEAR is the first year for which temperature records are given;

ENDYEAR is the most recent year for which temperature records are given:

QCCODE is the quality control code (see Jones et al. 1985):

FRYEAR is the first year for which reliable data is available (see Jones et al. 1985);

YEAR is the year of the data record being read;

TEMP is the monthly temperature value in degrees Celsius, multiplied by 10 . Temperature values for Northern Hemisphere stations (File 13) have been corrected for inhomogeneities, while those for Southern Hemisphere stations (File 14) are uncorrected;

$\mathrm{J}$ represents the data column being read. Each of the 12 columns of data represents the average temperature ior one month (January - December);

TMEAN is the mean of the 12 monthly temperatures in degrees Celsius, multiplind by 10;

Missing values for the monthly temperatures are represented by -999 . In cases where one or more monthly temperatures are missing, values for the mean of the 12 monthly temperatures are given as $\mathbf{- 9 9 9}$. Missing values for latitude and altitude are represented by -999. Missing values for longitude are represented by -1999 .

File 13 contains the monthly temperature data (corrected for inhomogeneities) for stations in the Northern Hemisphere $\left(87.5^{\circ} \mathrm{N}\right.$ to $\left.2.5^{\circ} \mathrm{S}\right)$. File 14 contains the monthly temperature data (uncorrected) for stations in the Southern Hemisphere $\left(2.5^{\circ} \mathrm{S}\right.$ to $\left.62.5^{\circ} \mathrm{S}\right)$, with the following 5 stations missing: Masterton, New Zealend; Lincoln College, New Zealand; Cape Leeuwin, Australia; Cape Naturaliste, Australia; and Angururu, Australia.

\section{REFERENCES}

Bradley, R. S., P. M. Kelly, P. D. Jones, C. M. Goodess, and H. F. Diaz. 1985. A climatic data bank for Northern Hemisphere land areas, 1851-1980. DOE Technical Report No. TR017. U.S. Department of Energy, Carbon Dioxide Research Division, Washington, D.C. 
Jones, P. D., and D. W. S. Limbert. 1989. Antarctic surface temperature and pressure data. ORNL/CDIAC-27, NDP-032. Oak Ridge National Laboratory, Oak Ridge, Tennessee.

Jones, P. D., S. C. B. Raper, B. Santer, B. S. G. Cherry, C. M. Goodess, P. M. Kelly, T. M. L. Wigley, R. S. Bradley, and H. F. Diaz. 1985. A grid point surface air temperature data set for the Northern Hemisphere. DOE Technical Report No. TR022. U.S. Department of Energy, Carbon Dioxide Research Division, Washington, D.C.

Jones, P. D., S. C. B. Raper, R. S. Bradley, H. F. Diaz, P. M. Kclly, and T. M. L. Wigley. 1986a. Northern Hemisphere surface air temperature variations: 1851-1984. Journal of Climate and Applied Meteorology 25:161-79.

Jones, P. D., S. C. B. Raper, B. S. G. Cherry, C. M. Goodess, T. M. L. Wigley, B. Santer, P. M. Kelly, R. S. Bradley, and H. F. Diaz. 1986b. A global grid point surface air temperature data set: 1851-1984. NDP-020. Carbon Dioxide Information Analysis Center, Oak Ridge National Laboratory, Oak Ridge, Tennessee.

Jones, P. D., S. C. B. Raper, C. M. Goodess, B. S. G. Cherry, and T. M. L. Wigley. 1986c. A grid point surface air temperature data set for the Southern Hemisphere. DOE Technical Report No. TR027. U.S. Department of Energy, Carbon Dioxide Research Division, Washington, D.C.

Jones, P. D., S. C. B. Raper, and T. M. L. Wigley. 1986d. Southern Hemisphere surface air temperature variations: 1851-1984. Journal of Climate and Applied Meteorology 25:1213-1230.

Jones, P. D., T. M. L. Wigley, G. Ohring, and A. Thomasell. 1988. Global-scale temperature changes to August 1987 and a comparison of satellite and conventional data, pp. 326-334 in Proceedings of the Twelfth Annual Climate Diagnostics Workshop, Department of Microbiology, University of Utah, Salt Lake City, October 12-16, 1987. U.S. Department of Commerce, National Oceanic and Atmospheric Administration.

Smithsonian Institution. 1927, 1935, 1947. World Weather Records. Miscellaneous Collections, Vols. 79, 90, 104. Washington, D.C.

U.S. Weather Bureau. 1959-1982. World Weather Records. 1941-1950 (1361 pp.), 1951-1960 (Vols. 1-6), 1961-1970 (Vols. 1-6). U.S. Department of Commerce, Washington, D.C. 


\section{LISTINGS OF THE FORTRAN IV DATA RETRIEVAL PROGRAMS}

The following is a listing of the FORTRAN IV data retrieval program provided on magnetic tape (File 2) by CDIAC to read and print the gridded surface air temperature anomaly file for the Northern Hemisphere (File 10-see Table 1 for a partial listing of this file). The job control language (JCL) statements shown below are not provided in the file on the magnetic tape. The JCL statements required will vary for each individual requesting these data. The JCL statements shown below are provided to illustrate the statements that would be required by an individual at ORNL who has requested these data on a nine-track, $6250 \mathrm{BPI}$, standard-labeled tape with characters written in EBCDIC and is attempting to read the tape on an IBM mainframe (e.g., IBM 3090).

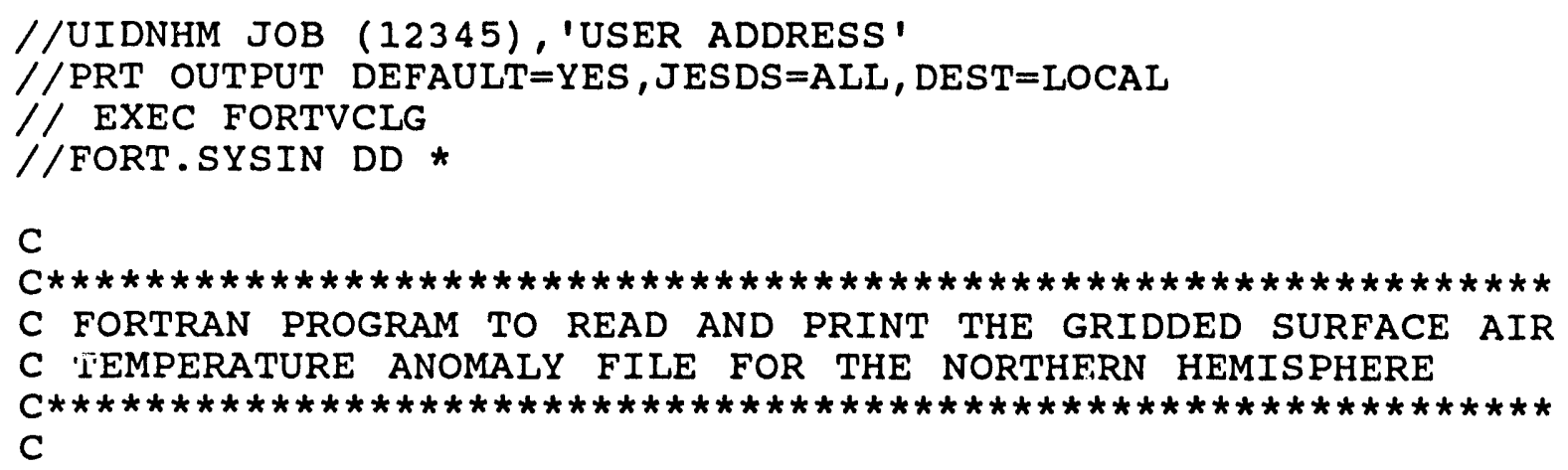


WRITE $(6,600)$ LONG (J), (DATA $(F), K=1,18)$ CONTINUE

$$
\begin{aligned}
& \text { DO } 60 \mathrm{~J}=20,36 \\
& \operatorname{READ}(5,550) \quad(\operatorname{DATA}(K), \quad K=1,18)
\end{aligned}
$$

60 CONTINUE

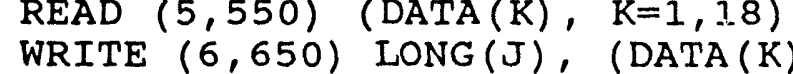

70 CONTINUE

WRITE $(6,700)$

$$
\text { GOTO } 45
$$

400 FORMAT (20X,I4, 4X, I2)

450 FORMAT ( $1 \mathrm{X}$, 'TEMPERATURE ANOMALY DATA', $4 \mathrm{X}$, 'YEAR $=$ ', I4, $12 \mathrm{X},{ }^{\prime} \mathrm{MONTH}=1, \mathrm{I} 2 /$ )

460 FORMAT ( $1 \mathrm{X}$, 'NUMBER OF CONTRIBUTING STATIONS', $4 \mathrm{X}$,

$$
\left.1 \text { 'YEAR }=1, I 4,2 X,{ }^{\prime} \text { MONTH }=1, I 2 / 1\right)
$$

470 FCRMAT ( $1 \mathrm{X}$, 'MEAN INVERSE DISTANCE OF STATIONS', $4 \mathrm{X}$,

$1 \quad$ 'YEAR $=1, I 4,2 \mathrm{X},{ }^{\prime}$ MONTH $\left.=1, I 2 /\right)$

500 FORMAT $\left(9 \mathrm{X}, 18\left(3 \mathrm{X}, \mathrm{I} 2, \mathrm{IN}^{\prime}\right) /\right)$

550 FORMAT $(18(1 X, I 5))$

600 FORMAT $(1 X, I 3, ' E ', 4 X, 18(1 X, I 5))$

650 FORMAT $(1 X, I 3, ' W ', 4 X, 18(1 X, I 5))$

700 FORMAT $(2(/))$

800 STOP

END

$/ /$ GO.FTO5FO01 DD UNIT=TAPE62, VOL $=S E R=T A P E V O L, D I S P=(, P A S S)$,

// DSN=TAB . NDPO2OR1 . NHEM90. ANOM, LABEL $=(10, S L)$,

// $\mathrm{DCB}=(\mathrm{RECFM}=\mathrm{FB}, \mathrm{LRECL}=108, \mathrm{BLKSIZE}=5400)$

//GO.FTO6FO01 DD * 
The following is a listing of the FORTRAN IV data retrieval program provided on magnetic tape (File 3) by CDIAC to read and print the gridded surface air temperature anomaly file for the Southern Hemisphere (File 11-see Table 2 for a partial listing of this file.). The JCL statements shown below are not provifed in the file on the magnetic tape. The JCL statements required will vary for each individual requesting these data. The JCL statements shown below are provided to illustrate the statements that would be required by an individual at ORNL who has requested these data on a nine-track, $6250 \mathrm{BPI}$, standardlabeled tape with characters written in EBCDIC and is attempting to read the tape on an IBM mainframe (e.g., IBM 3090).

//UIDSHM JOB (12345), 'USER ADDRESS'

//PRT OUTPUT DEFAULT=YES, JESDS=ALL, DEST=LOCAL

// EXEC FORTVCLG

//FORT.SYSIN DD *

C

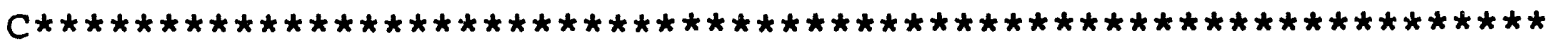

C FORTRAN PROGRAM TO READ AND PRINT THE GRIDDED SURFACE AIR

C TEMPERATURE ANOMALY FILE FOR THE SOUTHERN HEMISPHERE

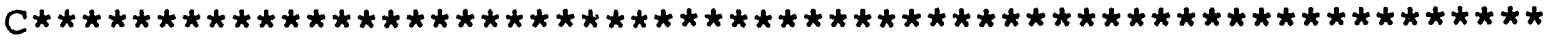

C

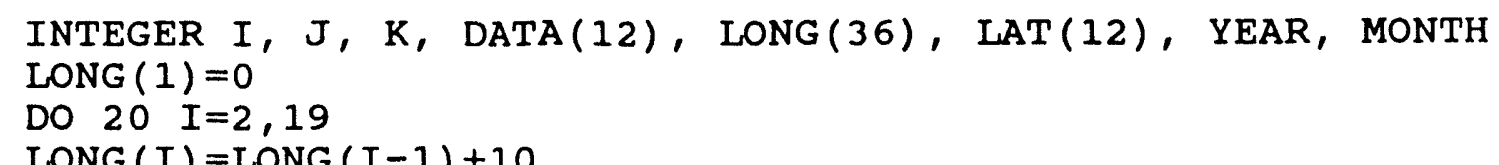

20

LONG $(I)=$ LONG $(I-1)+10$

LONG $(20)=170$

DO $30 \quad I=21,36$

30 CONTINUE

LONG $(I)=$ LONG $(I-1)-10$

$\operatorname{LAT}(1)=5$

DO $40 \quad I=2,12$

40 CONTINUE

$\operatorname{LAT}(I)=\operatorname{LAT}(I-1)+5$

45 DO $70 \quad I=1,3$

$\operatorname{READ}(5,400, \mathrm{END}=800)$ YEAR, MONTH

IF (I.EQ.1) THEN

WRITE $(6,450)$ YEAR, MONTH

END IF

IF (I.EQ.2) THEN

END IF WRITE $(6,460)$ YEAR, MONTH

IF (I.EQ.3) THEN

END IF

WRITE $(6,470)$ YEAR, MONTH

WRITE $(6,500) \quad(\operatorname{LAT}(K), K=1,12)$

DO $50 \mathrm{~J}=1,19$

$\operatorname{READ}(5,550) \quad(\operatorname{DATA}(K), \quad K=1,12)$

50 CONTINUE

DO $60 \mathrm{~J}=20,36$ 


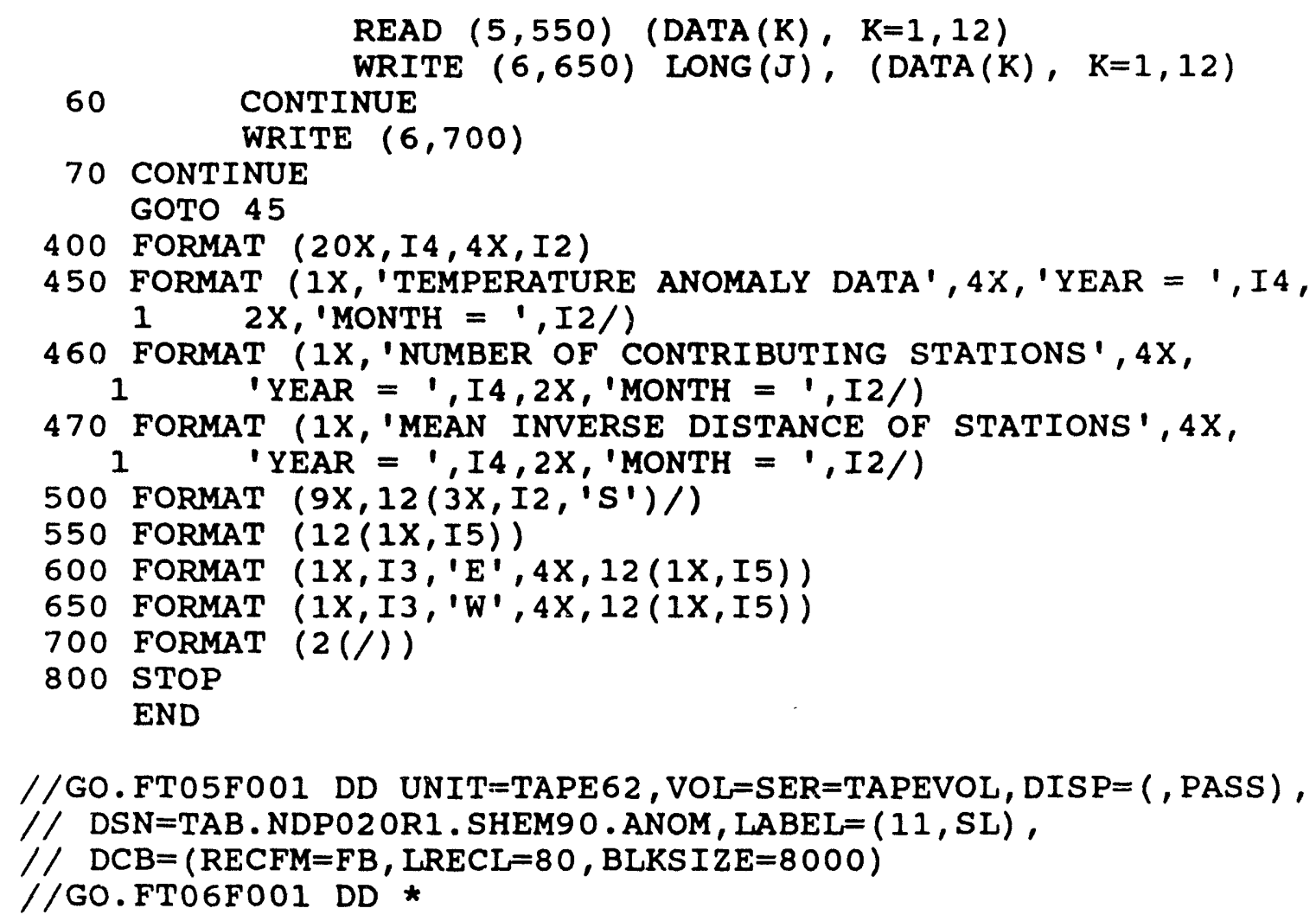


The following is a listing of the FORTRAN IV data retrieval program provided on magnetic tape (File 4) by CDIAC to read and print the gridded surface air temperature anomaly file for the Antarctic (File 12-see Table 3 for a partial listing of this file.). The JCL statements shown below are not provided in the file on the magnetic tape. The JCL statements required will vary for each individual requesting these data. The ICL statements shown belc $y$ are provided to illustrate the statements that would be required by an individual at ORNL who has requested these data on a nine-track, $6250 \mathrm{BPI}$, standard-labeled tape with characters vritten in EBCDIC and is attempting to read the tape on an IBM rnainframe (e.g., IBM 3090).

//UIDSHM JOB (12345), 'USER ADDRESS'

$/ /$ PRT OUTPUT DEFAULT=YES , JESDS $=$ ALL , DEST $=$ LOCAL

// EXEC FORTVCLG

//FORT.SYSIN DD *

C

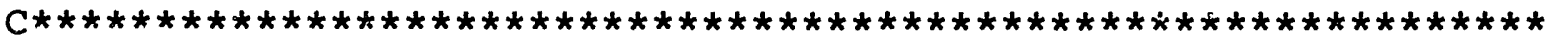

C FORTRAN PROGRAM 'TO READ AND PRINT THE GRIDDED SURFACE

C TEMPERATURE ANOMALY FILE FOR THE ANTARCTIC

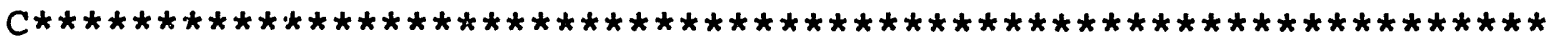
C

INTEGER I, J, K, DATA(5), INNG(36), LAT(5)，YEAR, MONTH LONG (1) $=0$

DO $20 \quad I=2,19$

LONG $(I)=$ LONG $(I-1)+10$

20 CONTINUE

LONG $(20)=170$

DO $30 \quad I=21,36$

LONG $(I)=$ LONG $(I-1)-10$

30 CONTINUE

$\operatorname{LAT}(1)=65$

DO $40 \quad I=2,5$

$\operatorname{LAT}(I)=\operatorname{LAT}(I-1)+5$

40 CONTINUE

$45 \operatorname{READ}(5,400, \mathrm{END}=800)$ YEAR, MONTH

WRITE $(6,450)$ YEAR, MONTH

WRITE $(6,500) \quad(\operatorname{LAT}(K), K=1,5)$

DO $50 \quad J=1,19$

$\operatorname{READ}(5,550) \quad(\operatorname{DATA}(K), K=1,5)$

WRITE $(6,600)$ LONG (J), (DATA $(K), \quad K=1,5)$

50 CONTINUE

DO $60 \mathrm{~J}=20,36$

READ $(5,550) \quad(\operatorname{DATA}(K), K=1,5)$

WRITE $(6,650)$ LONG (J), (DATA $(K), K=1,5)$

60 CONTINUE

WRITE $(6,700)$

GOTO 45

400 FORMAT (20X, I $4,4 \mathrm{X}, \mathrm{I} 2)$

450 FORMAT ( $1 \mathrm{X}$, 'TEMPERATURE ANOMALY DATA', $4 \mathrm{X}$, 'YEÄR = ', I4, $\left.12 \mathrm{X},{ }^{\prime} \mathrm{MONTH}=1, \mathrm{I} 2 /\right)$

500 FORMAT $\left(9 X, 5\left(3 X, I 2, S^{\prime}\right) /\right)$ 


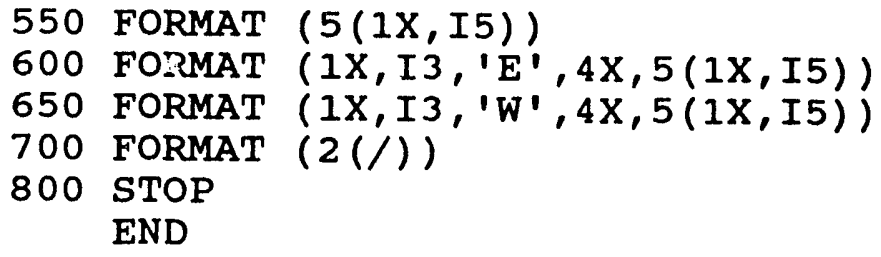

//GO.FT05F001 DD UNIT=TAPE62, VOL=SER=TAPEVOL, DISP=(, PASS ), // DSN=TAB . NDP02 OR1. ANTARC. ANOM, LABEL $=(12, \mathrm{SL})$,

// $\mathrm{DCB}=(\mathrm{RECFM}=\mathrm{FB}, \mathrm{LRECL}=80, \mathrm{BLKSIZE}=8000)$

//GO.FTO6FO01 DD * 
The following is a listing of the FORTRAN IV data retrieval program provided on magnetic tape (File 5) by CDIAC to read and print either of the monthly mean temperature records for individual stations (Files 13 and 14-see Tables 4 and 5 for partial listings of these files). The JCL statements shown below are not provided in the file on the magnetic tape. The JCL statements required will vary for each individual requesting these data. The JCL statements shown below are provided to illustrate the statements that would be required by an individual at ORNL who has requested these data on a nine-track, $6250 \mathrm{BPI}$, standardlabeled tape with characters written in EBCDIC and is attempting to read the tape on an IBM mainframe (e.g., IBM 3090).

//UIDSHM JOB (12345), 'USER ADDRESS'

$/ /$ PRT OUTPUT DEFAULT=YES , JESDS=ALL , DEST=LOCAL

$/ /$ EXEC FORTVCLG

//FORT.SYSIN DD *

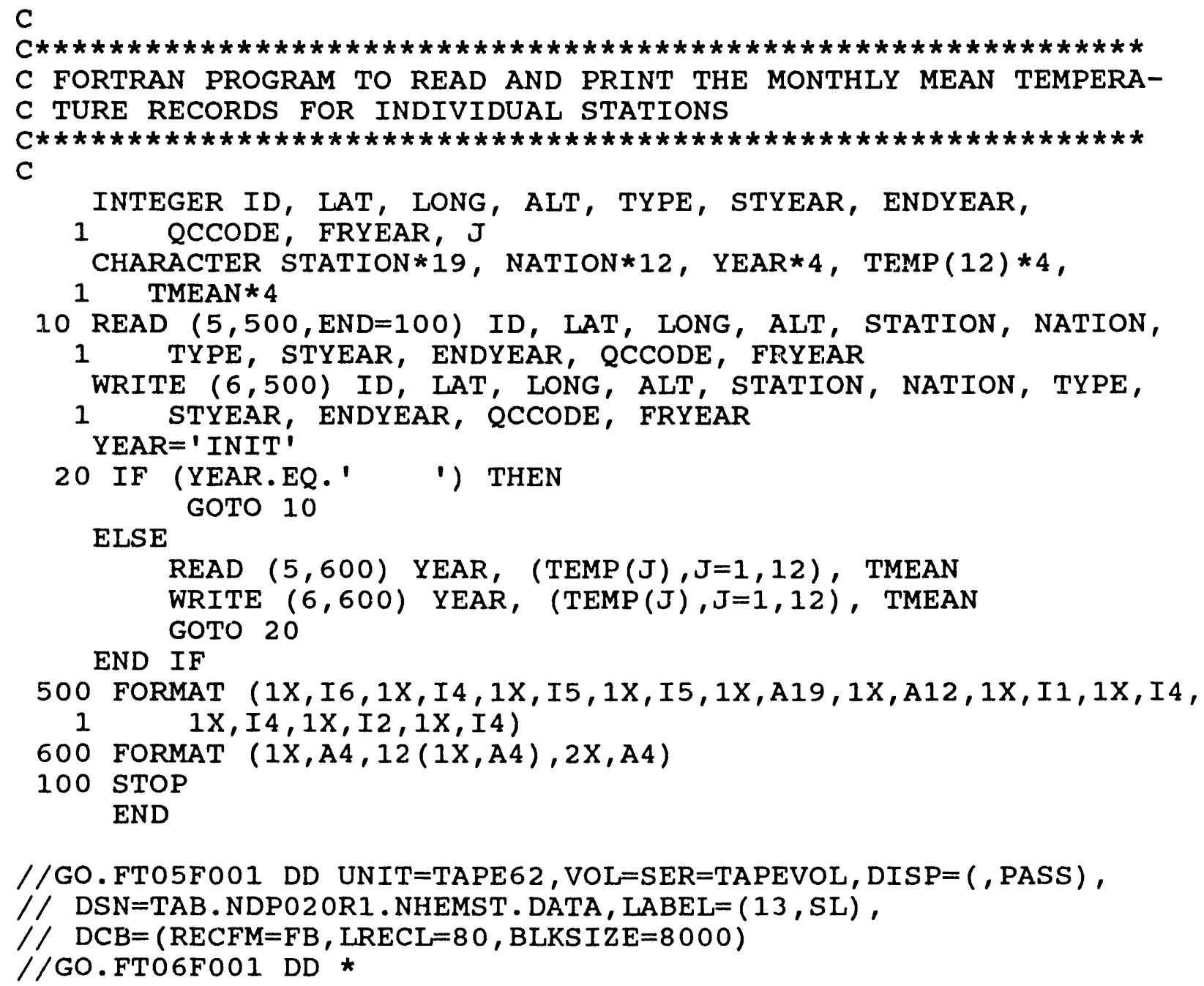




\section{LISTING OF THE SAS INPUT/OUTPUT RETRIEVAL PROGRAM}

The following is a listing of the SAS data retrieval program provided on magnetic tape (File 6) by CDIAC to read and print the gridded surface air temperature anomaly file for the Northern Hemisphere (File 10). The JCL statements shown below are not provided in the file on the magnetic tape. The JCL statements required will vary for each individual requesting these data. The JCL statements shown below are provided to illustrate the statements that would be required by an individual at ORNL who has requested these data on a nine-track, $6250 \mathrm{BPI}$, standard-labeled tape with characters written in EBCDIC and is attempting to read the tape on an IBM mainframe (e.g., IBM 3090).

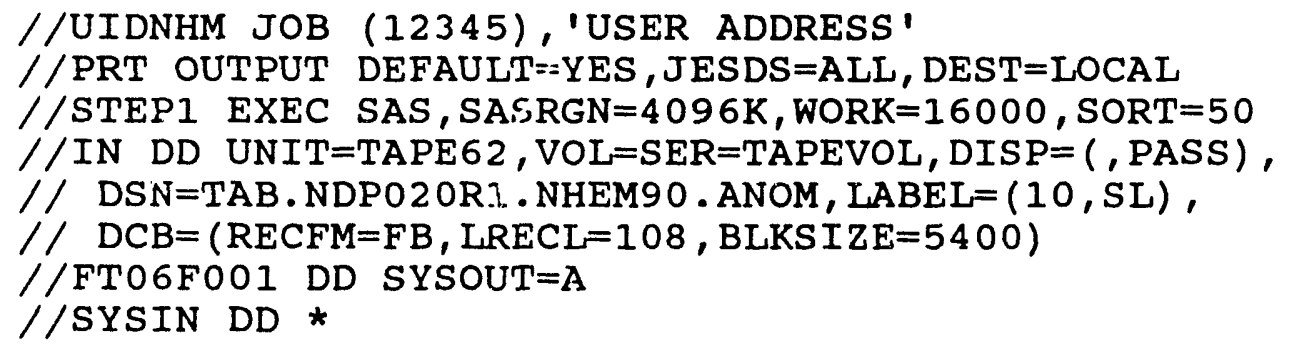




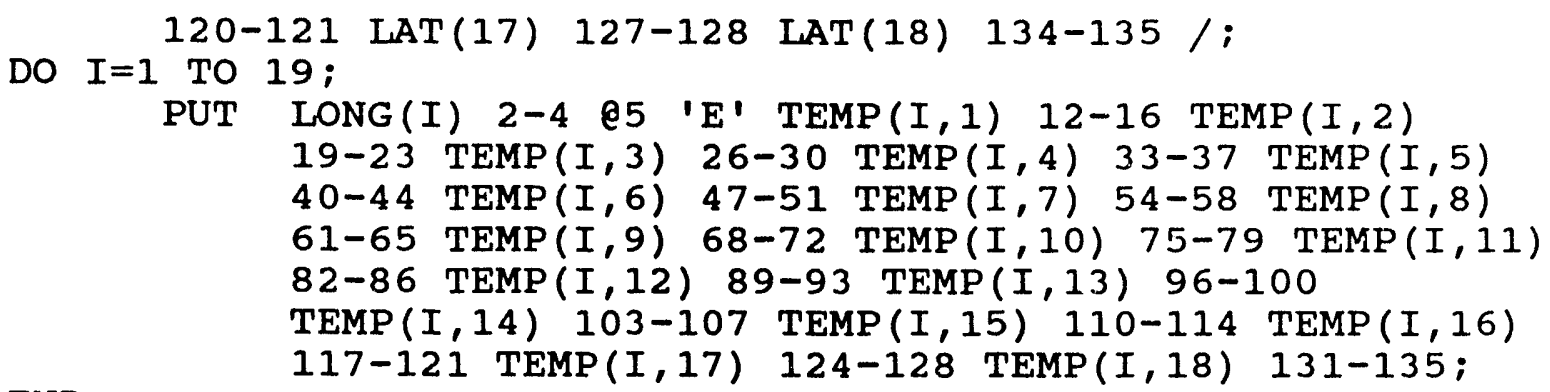

END;

PUT $/ /$ ' NUMBER OF CONTRIBUTING STATIONS' @40 YEAR= Q55 MONTH $=/$;

PUT LAT(1) 15-16 LAT(2) 22-23 LAT(3) 29-30 LAT(4) 36-37

ILAT (5) 43-44 LAT(6) 50-51 LAT(7) 57-58 LAAT(8) 64-65

LAT (9) 71-72 LAT(10) 78-79 LAT(11) 85-86 LAT(12) 92-93

LAT (13) 99-100 LAT(14) 106-107 LAT(15) 113-114 LAT(16) 120-121 LAT(17) 127-128 LAT(18) 134-135/;

DO $I=1$ TO 19;

PUT LONG(I) 2-4 @5 'E' STA(I, 1) 15-16 STA $(I, 2) \quad 22-23$

$\operatorname{STA}(I, 3)$ 29-30 STA $(I, 4)$ 36-37 STA $(I, 5)$ 43-44

$\operatorname{STA}(I, 6)$ 50-51 STA $(I, 7)$ 57-58 STA $(I, 8)$ 64-65

$\operatorname{STA}(I, 9)$ 71-72 STA(I, 10) 78-79 STA $(I, 11)$ 85-86

STA $(I, 12)$ 92-93 STA $(I, 13)$ 99-100 STA $(I, 14)$

106-107 STA(I, 15) 113-114 STA(I, 16) 120-121

END;

STA $(I, 17)$ 127-128 STA $(I, 18)$ 134-135;

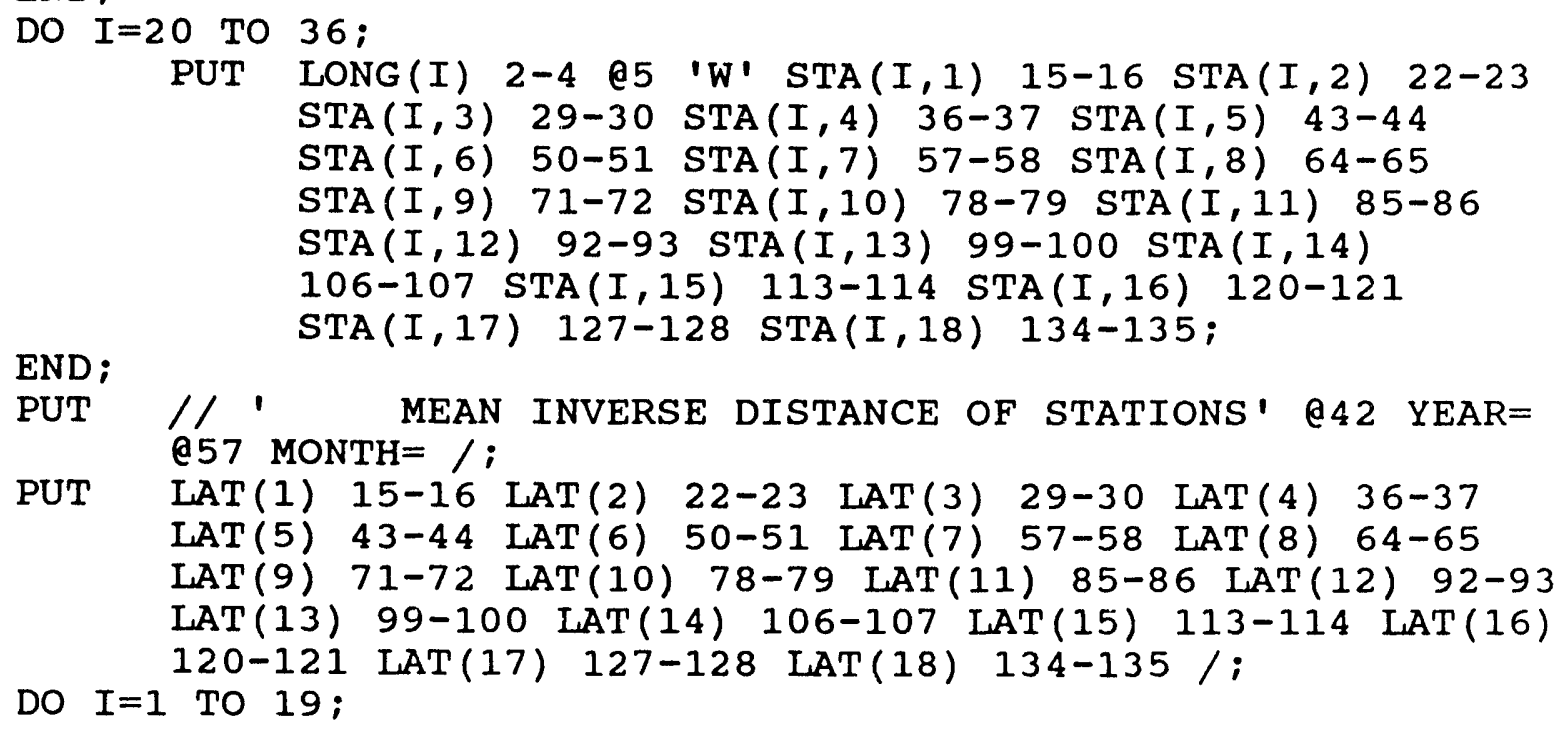

END;

PUT // ' MEAN INVERSE DISTANCE OF STATIONS' 242 YEAR= Q57 MONTH $=/$;

PUT LAT(1) 15-16 LAT(2) 22-23 LAT(3) 29-30 LAT(4) 36-37

LAT (5) 43-44 LAT(6) 50-51 LAT(7) 57-58 LAT(8) 64-65

LAT (9) 71-72 LAT(10) 78-79 LAT(11) 85-86 LAT(12) 92-93

LAT (13) 99-100 LAT(14) 106-107 LAT(15) 113-114 LAT(16)

DO $I=1$ TO 19;

120-121 LAT(17) 127-128 LAT(18) 134-135/; 


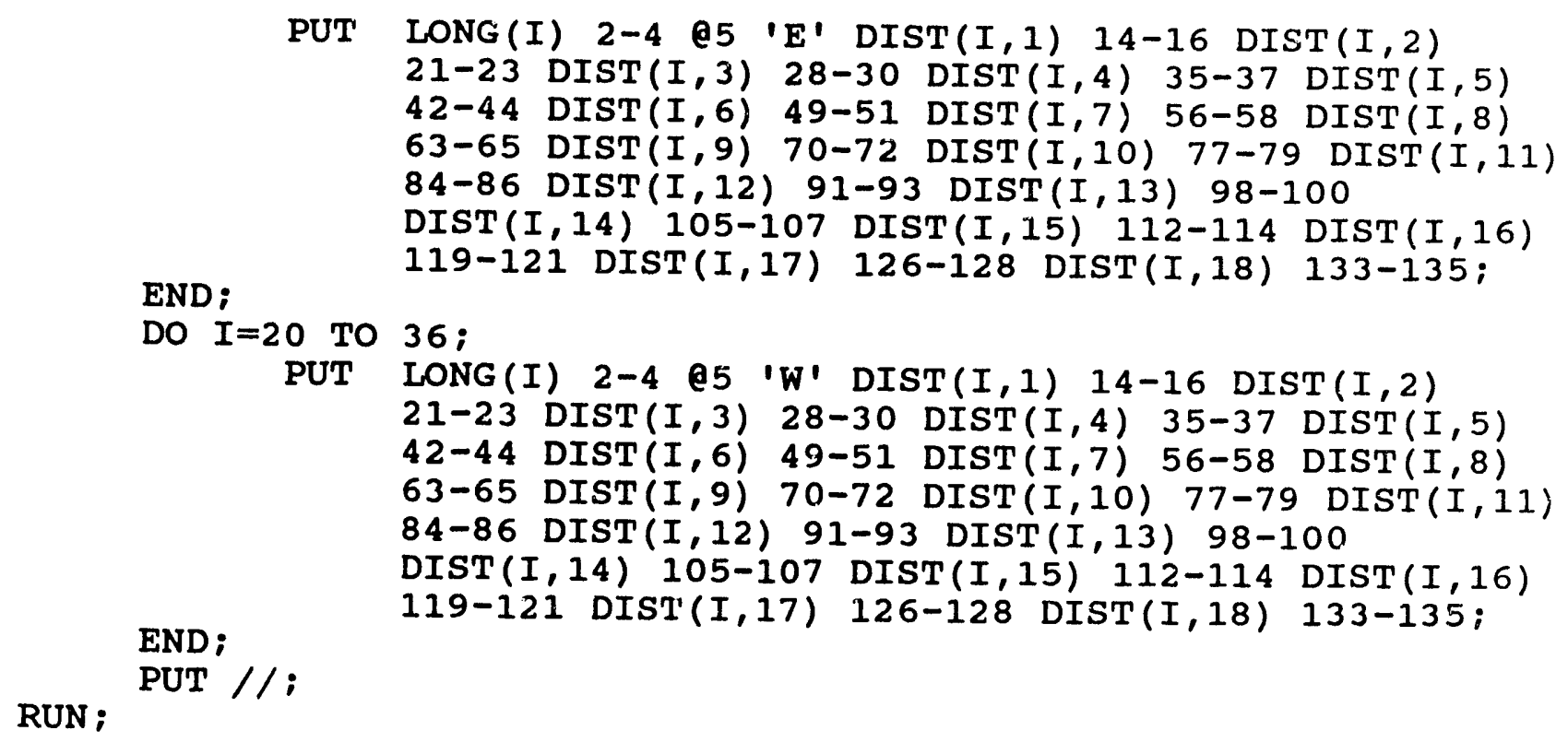


The following is a listing of the SAS data retrieval program provided on magnetic tape (File 7) by CDIAC to read and print the gridded surface air temperature anomaly file for the Southern Hemisphere (File 11). The JCL statements shown below are not provided in the file on the magnetic tape. The JCL statements required will vary for each individual requesting these data. The JCL statements shown below are provided to illustrate the statements that would be required by an individual at ORNL who has requested these data on a nine-track, $6250 \mathrm{BPI}$, standard-labeled tape with characters written in EBCDIC and is attempting to read the tape on an IBM mainframe (e.g., IBM 3090).

//UIDSHM JOB (12345), 'USER ADDRESS'

$/ /$ PRT OUTPUT DEFAULT=YES, JESDS=ALL, DEST $=$ LOCAL

//STEP1 EXEC SAS, SASRGN=4096K, WORK=16000, SORT=50

//IN DD UNIT=TAPE62, VOL=SER=TAPEVOL, DISP= (, PASS ),

// DSN=TAB. NDP02 ORI. SHEM9 0. ANOM, LABEL $=(11, \mathrm{SL})$,

$/ / \mathrm{DCB}=(\mathrm{RECFM}=\mathrm{FB}, \mathrm{LRECL}=80, \mathrm{BLKSIZE}=8000)$

//FT06F001 DD SYSOUT=A

$/ /$ SYSIN DD *

OPTIONS LINESIZE=95;

DATA ANOMALY;

INFILE IN;

INPUT YEAR 21-24 MONTH 29-30 \#2 \&2 (T1-T432) (:5.) \#39 Q2

DATA. PRINT; $(\mathrm{S} 1-\mathrm{S} 432)(: 5) \#$.76 @2 (D1-D432) (:5.);

SET ANOMALY;

FILE PRINT;

ARRAY TEMP $(36,12)$ T1-T432;

ARRAY STA $(36,12)$ S1-S432;

ARRAY DIST $(36,12)$ D1-D432;

ARRAY LONG (36) X1-X36;

ARRAY LAT (12) Y1-Y12;

LONG $(1)=0$;

DO $I=2$ TO 19 ;

LONG $(I)=$ LONG $(I-1)+10$;

END;

LONG $(20)=170$;

DO $I=21$ TO 36 ;

LONG $(I)=$ LONG $(I-1)-10$;

END;

$\operatorname{LAT}(1)=5$;

DO $I=2$ TO 12 ;

$\operatorname{LAT}(I)=\operatorname{LAT}(I-1)+5$;

END;

PUT ' TEMPERATURE ANOMALY DATA' 935 YEAR= $950 \mathrm{MONTH}=1$;

PUT Q2 'LONG' Q5I 'LAT (S)';

PUT LAT(1) 15-16 LAT(2) 22-23 LAT(3) 29-30 LAT(4) 36-37

LAT (5) 43-44 LAT(6) 50-51 LAT(7) 57-58 LAT(8) 64-65

LAT (9) 71-72 LAT(10) 78-79 LAT(11) 85-86 LAT(12) 92-93 $1 ;$

DO $I=1$ TO 19 ;

PUT LONG(I) 2-4 @5 'E' $\operatorname{TEMP}(I, 1)$ 12-16 $\operatorname{TEMP}(I, 2)$

19-23 TEMP(I, 3) 26-30 $\operatorname{TEMP}(I, 4)$ 33-37 $\operatorname{TEMP}(I, 5)$ 


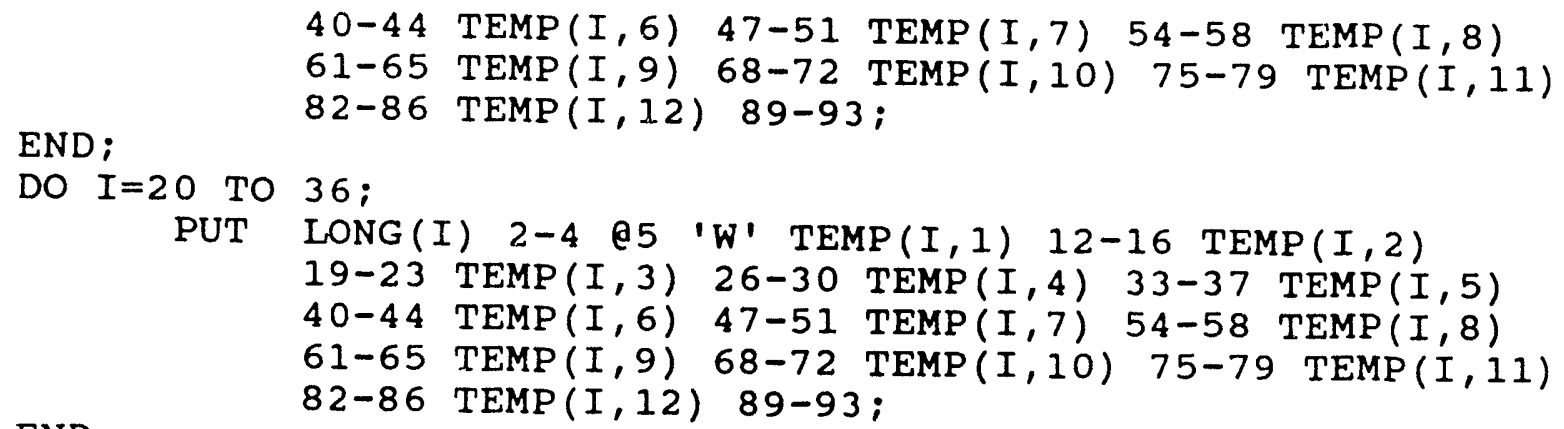

END;

END;

PUT // ' MEAN INVERSE DISTANCE OF STATIONS' 942 YEAR= Q57 MONTH $=/ ;$

PUT LAT(1) 15-16 LAT(2) 22-23 LAT(3) 29-30 LAT(4) 36-37

LAT (5) 43-44 LAT(6) 50-51 LAT(7) 57-58 LAT(8) 64-65

LAT (9) 71-72 LAT(10) 78-79 LAT(11) 85-86 LAT(12) 92-93

DO $I=1$ TO 19 ;

PUT LONG (I) 2-4 e5 'E' $\operatorname{DIST}(I, 1) \quad 14-16 \operatorname{DIST}(I, 2)$

21-23 DIST $(I, 3)$ 28-30 DIST $(I, 4)$ 35-37 DIST $(I, 5)$

42-44 DIST $(I, 6)$ 49-51 DIST $(I, 7)$ 56-58 DIST $(I, 8)$

63-65 DIST $(I, 9)$ 70-72 DIST(I, 10) 77-79 DIST $(I, 11)$

END;

84-86 DIST $(I, 12)$ 91-93;

DO $I=20$ TO 36 ;

PUT LONG(I) 2-4 e5 ' $W$ ' $\operatorname{DIST}(I, 1) \quad 14-16 \operatorname{DIST}(I, 2)$

21-23 DIST $(I, 3)$ 28-30 DIST $(I, k)$ 35-37 DIST $(I, 5)$

42-44 DIST $(I, 6)$ 49-51 DIST $(I, 7)$ 56-58 DIST $(I, 8)$

63-65 DIST $(I, 9) \quad 70-72$ DIST $(I, 10)$ 77-79 DIST $(I, 11)$

END;

84-86 DIST $(I, 22)$ 91-93;

RUN ;

PUT // ; 
The following is a listing of the SAS data retrieval program provided on magnetic tape (File 8 ) by CDIAC to read and print the gridded surface air temperature anomaly file for the Antarctic (File 12). The JCL statements shown below are not provided in the file on the magnetic tape. The JCL statements required will vary for each individual requesting these data. The JCL statements shown below are provided to illustrate the statements that would be required by an individual at ORNL who has requested these data on a nine-track, 6250 BPI, standard-labeled tape with characters written in EBCDIC and is attempting to read the tape on an IBM mainframe (e.g., IBM 3090).

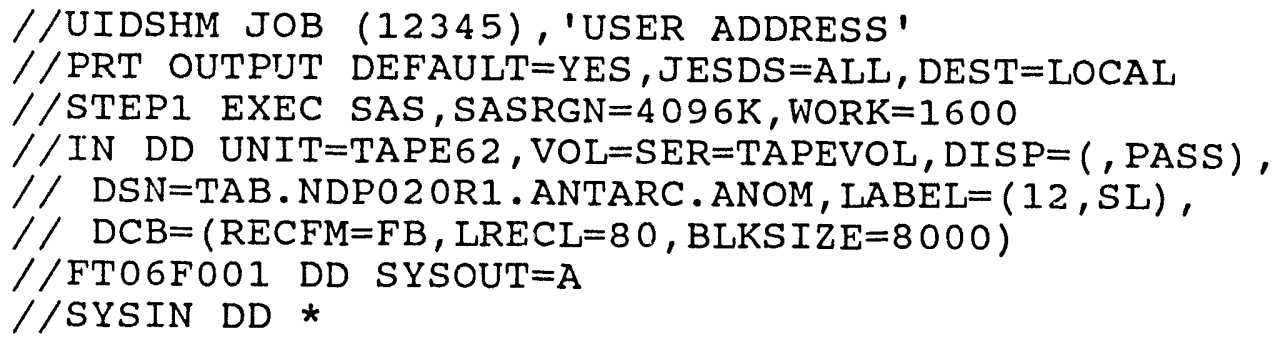

DATA ANOMALY;

INFILE IN;

INPUT YEAR 21-24 MONTH 29-30 \#2 a2 (T1-T180)(:5.);

DATA PRINT;

SET ANOMALY;

FILE PRINT;

ARRAY TEMP $(36,5)$ T1-T180;

ARRAY LONG (36) X1-X36;

ARRAY LAT(5) Y1-Y5;

LONG $(1)=0$;

DO $I=2$ TO 19;

END :

LONG $(I)=$ LONG $(I-1)+10$;

LONG $(20)=170$;

DO $I=21$ TO 36 ;

LONG $(I)=$ LONG $(I-I)-10$;

END;

$\operatorname{LAT}(1)=65$;

DO $I=2$ TO 5 ;

$\operatorname{LAT}(I)=\operatorname{LAT}(I-1)+5$;

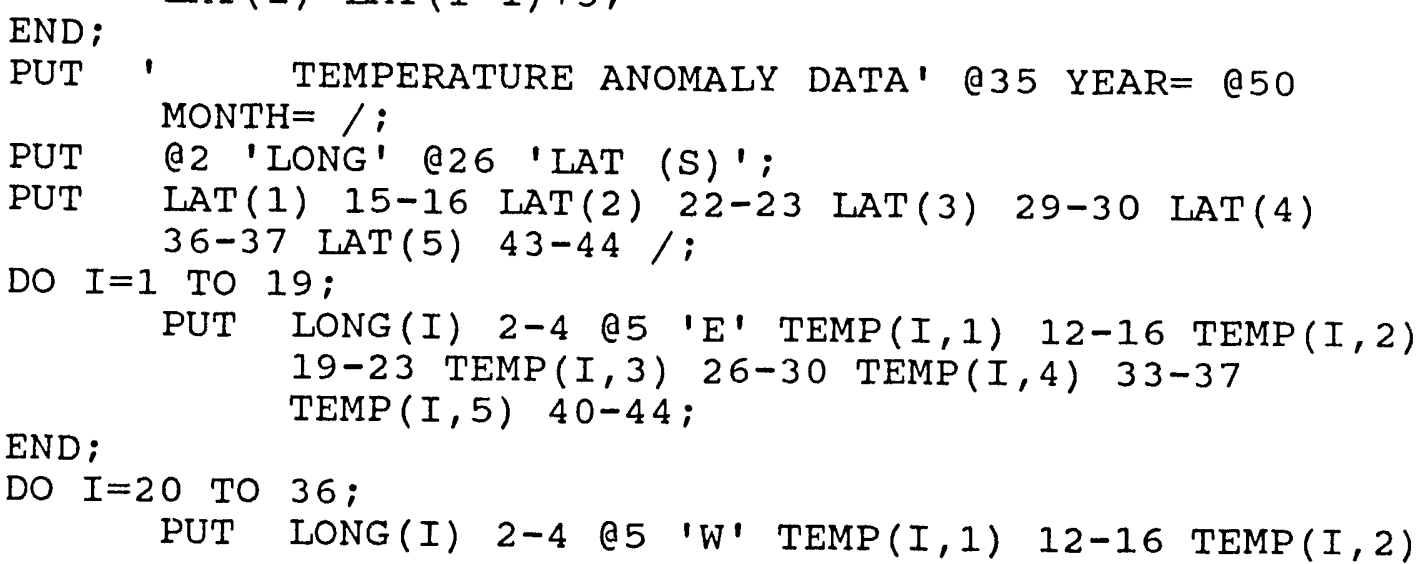


19-23 TEMP(I, 3) 26-30 TEMP(I, 4) 33-37

END;

$\operatorname{TEMP}(I, 5) \quad 40-44$;

RUN ;

PUT //; 
The following is a listing of the SAS data retrieval program provided on magnetic tape (File 9) by CDIAC to read and print either of the monthly mean temperature records for individual stations (Files 13 and 14). The JCL statements shown below are not provided in the file on the magnetic tape. The JCL statements required will vary for each individual requesting these data. The JCL statements shown below are provided to illustrate the statements that would be required by an individual at ORNL who has requested these data on a nine-track, $6250 \mathrm{BPI}$, standard-labeled tape with characters written in EBCDIC and is attempting to read the tape on an IBM mainframe (e.g., IBM 3090).

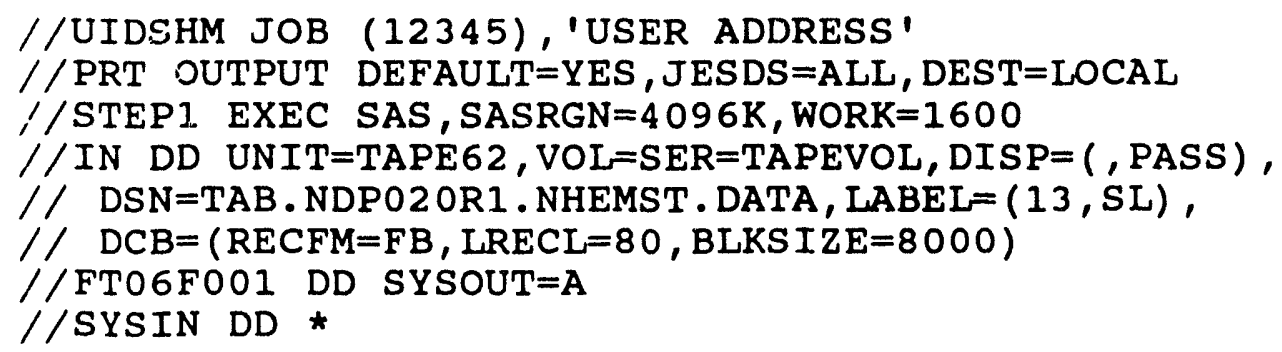


Table 1. Partial listing of the gridded surface air temperature anomalies for the Northern Hemisphere (File 10)

\begin{tabular}{|c|c|c|c|c|c|c|c|c|c|c|c|c|c|c|c|c|c|}
\hline 999 & .9999 & .9999 & 1851 & 1 & -9999 & .9999 & .9999 & .9909 & .9999 & .9999 & .9999 & $.99 \times 99$ & .9909 & .9999 & .9999 & -9999 & .9999 \\
\hline 9999 & .9999 & .9999 & .9999 & .9999 & .9999 & 190 & 161 & 167 & .9999 & .9999 & .90999 & $.9 \times \times y 9$ & .99099 & .9099 & .9999 & .9999 & .9999 \\
\hline 999 & .9999 & .9999 & 999 & 230 & 208 & 65 & 154 & 235 & 20 & .9999 & .9999 & .99999 & .9999 & .9999 & .9999 & 999. & .9999 \\
\hline 999 & .9999 & .9999 & -9999 & .9999 & 166 & 37 & -5 & 15 & .9999 & .9999 & .9999 & -9999 & .99999 & .9999 & .9299 & .9999 & .9909 \\
\hline .9999 & .9999 & .9999 & 90 & .9999 & 170 & -30 & .9999 & .233 & -100 & .9999 & .99499 & .9999 & .99999 & .9999 & .9999 & .99999 & .9999 \\
\hline 999 & .9999 & .9999 & .9999 & 360 & .9999 & -130 & .9999 & .9999 & .170 & .9499 & .9999 & .9999 & .9999 & .99999 & $.99 \times 99$ & -99999 & .9999 \\
\hline .9999 & .9999 & .9999 & .9999 & .9999 & 111 & -30 & .9999 & -.367 & .9999 & .9999 & .9999 & .9999 & .99999 & .9099 & .9999 & .9999 & .9999 \\
\hline .9999 & .9999 & .9999 & .9999 & .9999 & .9999 & -180 & -110 & .9999 & .9999 & .9999 & .9999 & .9999 & .9999 & .9999 & 9999 & .9999 & .9999 \\
\hline .9999 & .9999 & .9999 & .9999 & .9999 & 220 & .9999 & .9999 & .9999 & .9999 & .9999 & .9999 & .9999 & .9999 & .9999 & -99999 & -9999 & .9999 \\
\hline-9999 & .9999 & .9999 & -9999 & .9999 & .9999 & -340 & .9999 & .9999 & .9999 & .9999 & .9999 & .9999 & .9999 & .90999 & .9999 & .9999 & .9999 \\
\hline .9999 & .9999 & .9999 & .9999 & .9999 & .9999 & 120 & .9999 & .9999 & .9999 & .9999 & .9999 & 50 & -9999 & .9999 & .9999 & .9999 & .9999 \\
\hline-9999 & .9999 & .9999 & .9999 & .9999 & .9999 & .9999 & .9999 & .9999 & .9999 & -9909 & .9999 & .9999 & .9999 & .9999 & .9999 & -9999 & 50 \\
\hline .9999 & .9999 & .9999 & .9999 & .9999 & .9999 & -9999 & .9999 & .9999 & .9999 & .9999 & .9999 & -9999 & .9999 & .9999 & .9999 & .9999 & -9999 \\
\hline-9999 & .9999 & -9999 & .9999 & .9999 & .9999 & .9999 & -90 & -9999 & 130 & .9999 & 240 & -9999 & .9999 & .9999 & .9999 & .9999 & -9999 \\
\hline .9999 & .9999 & .9999 & .9999 & .9999 & .9999 & .9999 & .9999 & .9999 & .9999 & 100 & .9999 & .9999 & .9999 & .9999 & .9999 & .9999 & .9999 \\
\hline-9999 & .9999 & .9999 & .9999 & .9999. & .9999 & -9999 & .9999 & -9999 & .9999 & .9999 & .9999 & .9999 & .9999 & .9999 & .9999 & .9999 & .9999 \\
\hline-9999 & -9999 & .9999 & .9999 & .9999 . & .9999 & .9999 & .9999 & .9999 & .9999 & .9999 & -9999 & .9999 & .9999 & .9999 & .9999 & .9999 & .9999 \\
\hline .9999 & .9999 & .9999 & .9999 & .9999 & .9999 & .9999 & .9999 & .9999 & .9999 & .9999 & .9999 & .9999 & -9999 & .9999 & .9999 & .9999 & .9999 \\
\hline .9999 & .9999 & .9999 & .9999 & .9999 & .9999 & .9999 & .9999 & .9999 & -9999 & .9999 & .9999 & .9999 & .9999 & .9999 & .9999 & .9999 & -9999 \\
\hline-9999 & .9999 & .9999 & .9999 & .9999 & .9999 & -9999 & .9999 & .9999 & -9999 & .9999 & .9999 & .9999 & .9999 & .9999 & .9999 & .9999 & .9999 \\
\hline-9999 & -9999 & -9999 & .9999 & -9999. & .9999 & -9999 & .9999 & -9999 & -9999 & .9999 & .9999 & .9999 & .9999 & -9999 & -9999 & .9999 & -9999 \\
\hline-9999 & .9999 & -9999 & .9999 & .9999 & .9999 & -9999 & .9999 & -9999 & -9999 & -9999 & .9999 & .9999 & .9999 & .9999 & .9999 & -9999 & .9999 \\
\hline .9999 & .9999 & .9999 & .9999 & .9999 & .9999 & .9999 & .9999 & .9999 & -9999 & .9999 & -9999 & .9999 & .9999 & .9999 & .9999 & 99 . & -9999 \\
\hline-9999 & -9999 & -9999 & .9999 & -9999 & -9999 & -10 & .9999 & .9999 & -9999 & -9999 & -9999 & .9999 & 99 & .9999 & .9999 & .9999 & -9999 \\
\hline .9999 & -9999 & .9999 & -9999 & .9999. & .9999 & .9999 & .9999 & -9999 & -9999 & -9994 & -9999 & -9999 & .9999 & .9999 & .9999 & -9999 & .9999 \\
\hline-9999 & .9999 & .9999 & .9999 & .9999 & .9999 & .9999 & -9999 & -9999 & -9999 & -290 & -9999 & .9999 & .9999 & .9999 & .9999 & -9999 & .9999 \\
\hline-9999 & .9999 & -9999 & .9999 & -9999 & .9999 & .9999 & .9999 & .9999 & -9991 & 210 & .9999 & -9999 & 99 & .9999 & 99 & 99 & -9999 \\
\hline-9999 & -9999 & -9999 & -9999 & -9999 & .9999 & .9999 & .9999 & .9999 & -9999 & -9999 & .9999 & -9999 & .9999 & .9999 & .9999 & .9999 & -9999 \\
\hline-9999 & -9999 & -9999 & .9999 & .9999 & .9999 & .9999 & .9999 & .9999 & 260 & .9999 & .9999 & -9999 & .9999 & -9999 & .9999 & 99 & .9999 \\
\hline .9999 & .9999 & .9999 & .9999 & .9909 & .9999 & -9999 & .9999 & 210 & 220 & 190 & 100 & 230 & 29 & .9999 & & 99 & .9999 \\
\hline .9999 & .9999 & .9999 & .9999 & .9999 & -9999 & .9999 & .9999 & 70 & -15 & .9999 & .9999 & .9999 & 99 & .9999 & .9999 & .9999 & -9999 \\
\hline .9999 & -9999 & .9999 & -9999 & .9999 & .9999 & .9999 & .9999 & .9999 & .9999 & .9999 & .9999 & -9999 & .9999 & .9999 & .9999 & -9999 & .9999 \\
\hline .9999 & .9999 & .9999 & -9999 & .9999 & .9999 & .9999 & .9999 & -9999 & .9999 & .95 & -9 & 99 & 9 & .9999 & 99 & 99 & .9999 \\
\hline .9999 & & .9999 & -9999 & .9999 & .9999 & .9999 & .9999 & 99 & -9999 & & 99 & 99 & & 99 & 99 & .9999 & -9999 \\
\hline .9999 & -9999 & .9999 & .9999 & .9999 & .9999 & -9999 & -9999 & .9999 & -9999 & .9999 & -9999 & -9999 & .9999 & .9999 & .9999 & .9999 & .9999 \\
\hline-9999 & .9999 & .9999 & .9999 & 190 & .9999 & .9999 & .9999 & .9999 & -9999 & -99 & .9999 & .9999 & 99 & -9999 & 99 & .9999 & .9999 \\
\hline .9999 & .9999 & .9999 & -9999 & .9999 & .9999 & .9999 & .9999 & 99 & -9999 & & & & & & 99 & .9999 & -9999 \\
\hline .9999 & .9999 & .9999 & 1851 & 1 & .9999 & .9999 & .9999 & .9999 & -9999 & .9999 & .9999 & .9999 & .9999 & .9999 & .9999 & -9999 & .9999 \\
\hline 0 & 0 & 0 & 0 & 0 & 0 & 2 & 2 & 5 & 0 & 0 & 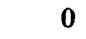 & 0 & 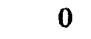 & 0 & 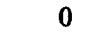 & 0 & 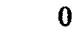 \\
\hline 0 & 0 & 0 & 0 & 1 & 2 & 2 & 10 & 7 & 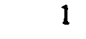 & & 0 & & & 0 & & & \\
\hline 0 & 0 & 0 & 0 & 0 & 2 & 3 & 6 & 2 & 0 & ( & 0 & 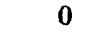 & 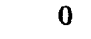 & 0 & 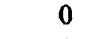 & & \\
\hline 0 & 0 & 0 & 1 & 0 & 2 & 1 & 0 & $J$ & 1 & 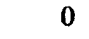 & U & 0 & 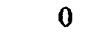 & 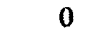 & . & & \\
\hline 0 & 0 & 0 & 0 & 1 & 0 & 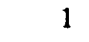 & 0 & 0 & 1 & 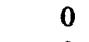 & 0 & & & 0 & & & \\
\hline 0 & 0 & 0 & 0 & 0 & 2 & 1 & 0 & 2 & 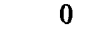 & 0 & 0 & & 0 & 0 & & & \\
\hline 0 & 0 & 0 & 0 & 0 & 0 & 1 & I & 0 & 0 & - & 0 & 0 & 0 & 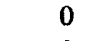 & & 0 & \\
\hline 0 & 0 & 0 & 0 & . & 1 & 0 & 0 & 0 & 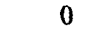 & & 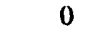 & & & 0 & & 0 & \\
\hline 0 & 0 & 0 & 0 & 0 & 0 & 1 & 0 & 0 & 0 & 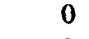 & $c$ & & & 0 & & & \\
\hline 0 & 0 & 0 & 0 & 0 & 0 & 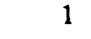 & 0 & 0 & 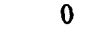 & 0 & & 1 & & 0 & 0 & 0 & \\
\hline 0 & 0 & 0 & 0 & 0 & - & 0 & 0 & 0 & 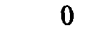 & 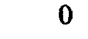 & & 0 & & 0 & 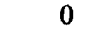 & 0 & \\
\hline 0 & 0 & 0 & 0 & U & 0 & U & 0 & 0 & 0 & 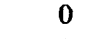 & 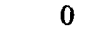 & 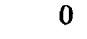 & & 0 & & & \\
\hline 0 & 0 & 0 & 0 & 0 & 0 & 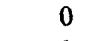 & 1 & 0 & 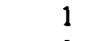 & 0 & & 0 & & 0 & 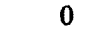 & 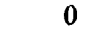 & \\
\hline 0 & 0 & 0 & 0 & 0 & ( & 0 & 0 & 0 & 0 & 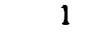 & & 0 & & 0 & U & 0 & \\
\hline 0 & 0 & 0 & 0 & 0 & 0 & 0 & 0 & 0 & 0 & 0 & & 0 & & 0 & 0 & & \\
\hline 0 & 0 & 0 & 0 & 0 & 0 & 0 & 0 & 0 & 0 & 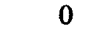 & 0 & 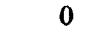 & , & 0 & 0 & 0 & \\
\hline 0 & 0 & 0 & 0 & 0 & 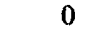 & 0 & . & 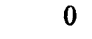 & & 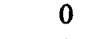 & & 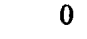 & , & 0 & 0 & 0 & \\
\hline 0 & 0 & 0 & 0 & 0 & 0 & 0 & 0 & 0 & 0 & 0 & & 0 & , & 0 & 0 & 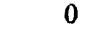 & \\
\hline 0 & 0 & 0 & 0 & 0 & 0 & 0 & 0 & 0 & 0 & 0 & 0 & 0 & 0 & 0 & 0 & 0 & \\
\hline
\end{tabular}


Table 1. (continued)

\begin{tabular}{|c|c|c|c|c|c|c|c|c|c|c|c|c|c|c|c|c|c|}
\hline 0 & 0 & 0 & 0 & 0 & 0 & 0 & 0 & 0 & 0 & 0 & 0 & 0 & 0 & 0 & 0 & 0 & 0 \\
\hline 0 & 0 & 0 & 0 & 0 & 0 & 0 & 0 & 0 & 0 & 0 & 0 & 0 & 0 & 0 & 0 & 0 & 0 \\
\hline 0 & 0 & 0 & 0 & 0 & 0 & 0 & 0 & 0 & 0 & 0 & 0 & 0 & 0 & 0 & 0 & 0 & 0 \\
\hline 0 & 0 & 0 & 0 & 0 & 0 & 1 & 0 & 0 & 0 & 0 & 0 & 0 & 0 & 0 & 0 & 0 & 0 \\
\hline 0 & 0 & 0 & 0 & 0 & 0 & 0 & 0 & 0 & 0 & 0 & 0 & 0 & () & 0 & 0 & 0 & 0 \\
\hline 0 & 0 & 0 & 0 & 0 & 0 & 0 & 0 & 0 & 0 & 1 & 0 & 0 & 0 & 0 & 0 & 0 & 0 \\
\hline 0 & 0 & 0 & 0 & 0 & 0 & 0 & 0 & 0 & 0 & 1 & 0 & 0 & 0 & 0 & 0 & 0 & 0 \\
\hline 0 & 0 & 0 & 0 & 0 & 0 & 0 & 0 & 0 & 0 & 0 & 0 & 0 & 0 & 0 & 0 & 0 & 0 \\
\hline 0 & 0 & 0 & 0 & 0 & 0 & 0 & 0 & 0 & 1 & 0 & 0 & 0 & 0 & 0 & 0 & 0 & 0 \\
\hline 0 & 0 & 0 & 0 & 0 & 0 & 0 & 0 & 1 & 1 & 1 & 1 & 1 & 0 & 0 & 0 & 0 & 0 \\
\hline 0 & 0 & 0 & 0 & 0 & 0 & 0 & 0 & 1 & 3 & 0 & 0 & 0 & 0 & 0 & o & 0 & 0 \\
\hline 0 & 0 & 0 & 0 & 0 & 0 & 0 & 0 & 0 & 0 & 0 & 0 & 0 & 0 & 0 & 0 & 0 & 0 \\
\hline 0 & 0 & 0 & 0 & 0 & 0 & 0 & 0 & 0 & 0 & 0 & 0 & 0 & 0 & 0 & 0 & 0 & 0 \\
\hline 0 & 0 & 0 & 0 & 0 & 0 & 0 & 0 & 0 & 0 & 0 & 0 & 0 & 0 & 0 & 0 & 0 & 0 \\
\hline 0 & 0 & 0 & 0 & 0 & 0 & 0 & 0 & 0 & 0 & 0 & 0 & 0 & 0 & 0 & 0 & 0 & 0 \\
\hline 0 & 0 & 0 & 0 & 1 & 0 & 0 & 0 & 0 & 0 & 0 & 0 & 0 & 0 & 0 & 0 & 0 & 0 \\
\hline 0 & 0 & 0 & 0 & 0 & 0 & 0 & 0 & 0 & 0 & 0 & 0 & 0 & 0 & 0 & 0 & 0 & 0 \\
\hline .9999 & -9999 & $.99(9)$ & 1851 & 1 & .9999 & .9999 & .9999 & .9999 & .9999 & .9999 & -9999 & -9999 & -9999 - & -9999 & -9999 & -9999 & -9999 \\
\hline 0 & 0 & 0 & 0 & 0 & 0 & 133 & 70 & 93 & 0 & 0 & 0 & 0 & 0 & 0 & 0 & 0 & 0 \\
\hline 0 & 0 & 0 & 0 & 103 & 135 & 78 & 87 & 102 & 66 & 0 & 0 & 0 & 0 & 0 & 0 & 0 & 0 \\
\hline 0 & 0 & 0 & 0 & 0 & 107 & 109 & 86 & 59 & 0 & 0 & 0 & 0 & 0 & 0 & 0 & 0 & 0 \\
\hline 0 & 0 & 0 & 200 & 0 & 133 & 61 & 0 & 81 & 138 & 0 & 0 & 0 & 0 & 0 & 0 & 0 & 0 \\
\hline 0 & 0 & 0 & 0 & 200 & 0 & 106 & 0 & 0 & 42 & 0 & 0 & 0 & 0 & 0 & 0 & 0 & 0 \\
\hline 0 & 0 & 0 & 0 & 0 & 111 & 175 & 0 & 142 & 0 & 0 & 0 & 0 & 0 & 0 & 0 & 0 & 0 \\
\hline 0 & 0 & 0 & 0 & 0 & 0 & 91 & 47 & 0 & 0 & 0 & 0 & 0 & 0 & 0 & 0 & 0 & 0 \\
\hline 0 & 0 & 0 & 0 & 0 & 82 & 0 & 0 & 0 & 0 & 0 & 0 & 0 & 0 & 0 & 0 & 0 & 0 \\
\hline 0 & 0 & 0 & 0 & 0 & 0 & 60 & 0 & 0 & 0 & 0 & 0 & 0 & 0 & 0 & 0 & 0 & 0 \\
\hline 0 & 0 & 0 & 0 & 0 & 0 & 52 & 0 & 0 & 0 & 0 & 0 & 64 & 0 & 0 & 0 & 0 & 0 \\
\hline 0 & 0 & 0 & 0 & 0 & 0 & 0 & 0 & 0 & 0 & 0 & 0 & 0 & 0 & 0 & 0 & 0 & 169 \\
\hline 0 & 0 & 0 & 0 & 0 & 0 & 0 & 0 & 0 & 0 & 0 & 0 & 0 & 0 & 0 & 0 & 0 & 0 \\
\hline 0 & 0 & 0 & 0 & 0 & 0 & 0 & 126 & 0 & 62 & 0 & 98 & 0 & 0 & 0 & 0 & 0 & 0 \\
\hline 0 & 0 & 0 & 0 & 0 & 0 & 0 & 0 & 0 & 0 & 72 & 0 & 0 & 0 & 0 & 0 & 0 & 0 \\
\hline 0 & 0 & 0 & 0 & 0 & 0 & 0 & 0 & 0 & 0 & 0 & 0 & 0 & 0 & 0 & 0 & 0 & 0 \\
\hline 0 & 0 & 0 & 0 & 0 & 0 & 0 & 0 & 0 & 0 & 0 & 0 & 0 & 0 & 0 & 0 & 0 & 0 \\
\hline 0 & 0 & 0 & 0 & 0 & 0 & 0 & 0 & 0 & 0 & 0 & 0 & 0 & 0 & 0 & 0 & 0 & 0 \\
\hline 0 & 0 & 0 & 0 & 0 & 0 & 0 & 0 & 0 & 0 & 0 & 0 & 0 & 0 & 0 & 0 & 0 & 0 \\
\hline 0 & 0 & 0 & 0 & 0 & 0 & 0 & 0 & 0 & 0 & 0 & 0 & 0 & 0 & 0 & 0 & 0 & 0 \\
\hline 0 & 0 & 0 & 0 & 0 & 0 & 0 & 0 & 0 & 0 & 0 & 0 & 0 & 0 & 0 & 0 & 0 & 0 \\
\hline 0 & 0 & 0 & 0 & 0 & 0 & 0 & 0 & 0 & 0 & 0 & 0 & 0 & 0 & 0 & 0 & 0 & 0 \\
\hline 0 & 0 & 0 & 0 & 0 & 0 & 0 & 0 & 0 & 0 & 0 & 0 & 0 & 0 & 0 & 0 & 0 & 0 \\
\hline 0 & 0 & 0 & 0 & 0 & 0 & 50 & 0 & 0 & 0 & 0 & 0 & 0 & 0 & 0 & 0 & 0 & 0 \\
\hline 0 & 0 & 0 & 0 & 0 & 0 & 0 & 0 & 0 & 0 & 0 & 0 & 0 & 0 & 0 & 0 & 0 & 0 \\
\hline 0 & 0 & 0 & 0 & 0 & 0 & 0 & 0 & 0 & 0 & 51 & 0 & 0 & 0 & 0 & 0 & 0 & 0 \\
\hline 0 & 0 & 0 & 0 & 0 & 0 & 0 & 0 & 0 & 0 & 49 & 0 & 0 & 0 & 0 & 0 & 0 & 0 \\
\hline 0 & 0 & 0 & 0 & 0 & 0 & 0 & 0 & 0 & 0 & 0 & 0 & 0 & 0 & 0 & 0 & 0 & 0 \\
\hline 0 & ) & 0 & 0 & 0 & 0 & 0 & 0 & 0 & 68 & 0 & 0 & 0 & 0 & 0 & 0 & 0 & 0 \\
\hline 0 & 0 & 0 & 0 & 0 & 0 & 0 & 0 & 66 & 45 & 76 & 56 & 99 & 0 & 0 & 0 & 0 & 0 \\
\hline 0 & 0 & 0 & 0 & 0 & 0 & 0 & 0 & 47 & 64 & 0 & 0 & 0 & 0 & 0 & 0 & 0 & 0 \\
\hline 0 & 0 & 0 & 0 & 0 & 0 & 0 & 0 & 0 & 0 & 0 & 0 & 0 & 0 & 0 & 0 & 0 & 0 \\
\hline 0 & 0 & 0 & 0 & 0 & 0 & 0 & 0 & 0 & 0 & 0 & 0 & 0 & 0 & 0 & 0 & 0 & 0 \\
\hline 0 & 0 & 0 & 0 & 0 & 0 & 0 & 0 & 0 & 0 & 0 & 0 & 0 & 0 & 0 & 0 & 0 & 0 \\
\hline 0 & 0 & 0 & 0 & 0 & 0 & 0 & 0 & 0 & 0 & 0 & 0 & 0 & 0 & 0 & 0 & 0 & 0 \\
\hline 0 & 0 & 0 & 0 & 141 & 0 & 0 & 0 & 0 & 0 & 0 & 0 & 0 & 0 & 0 & 0 & 0 & 0 \\
\hline 0 & 0 & 0 & 0 & 0 & 0 & 0 & 0 & 0 & 0 & 0 & 0 & 0 & 0 & 0 & 0 & 0 & ) \\
\hline-9999 & -9999 & .9999 & 1851 & 2 & .9999 & -90999 & .99099 & .9909 & .9999 & .9999 & .9999 & .9999 & (q)(y) &.$(x)(9)$ & 9909 & -9999 & 99999 \\
\hline .99999 & .9999 & .9999 & .0909 & -9999 & .9909 & 120 & -15 & -71 & $.99(4)$ & .9099 & .99999 &.$(x)$ & $g(y)$ & $.09(x)$ & .9999 & -9999 & -9949 \\
\hline-9999 & .9999 & .9909 & -9999 & 270 & 202 & 161 & -7 & 112 & -30 & -9999 & .00099 & $-\cos 99$ & $.990 \%$ & -9099 & .9999 & .9999 & -9999 \\
\hline .9909 & -9999 & .99099 & .9999 & $.99 \times 99$ & 124 & 230 & 94 & 28 & $.90(x)$ & .90999 & .9999 & -9099 & (xycy) & $0(099$ & .9999 & -9999 & .9999 \\
\hline
\end{tabular}


Table 2. Partial listing of the gridded surface air temperature anomalies for the Southern Hemisphere (File 11)

\begin{tabular}{|c|c|c|c|c|c|c|c|c|c|c|c|}
\hline-9999 & -9999 & -9999 & 1851 & 1 & -9999 & -9999 & -9999 & -9999 & .9999 & -9999 & -9999 \\
\hline-9999 & -9999 & 9999 & -9999 & -9999 & .9999 & -9999 & -9999 & .9999 & -9999 & .9999 & -9999 \\
\hline-9999 & -9999 & -9999 & -9999 & -9999 & -9999 & -9999 & -9999 & -9999 & -9999 & -9999 & -9999 \\
\hline-9999 & -9999 & -9999 & -9999 & -9999 & -9999 & -9999 & -9999 & -9999 & -9999 & -9999 & -9999 \\
\hline-9999 & -9999 & -9999 & -9999 & -9999 & -9999 & -9999 & -9999 & -9999 & -9999 & 9999 & -9999 \\
\hline-9999 & -9999 & 9999 & -9999 & -9999 & -9999 & -9999 & -9999 & .9999 & -9999 & -9999 & -9999 \\
\hline .9999 & -9999 & .9999 & .9999 & .9999 & -9999 & -9999 & -9999 & $-\Upsilon 999$ & -9999 & -9999 & -9999 \\
\hline -9999 & -9999 & .9999 & -9999 & -9999 & -9999 & -9999 & -9999 & -9999 & -9999 & -9999 & .9999 \\
\hline-9999 & -9999 & -9999 & .9999 & -9999 & -9999 & -9999 & -9999 & -9999 & -9999 & -9999 & -0999 \\
\hline-9999 & -9999 & -9999 & -9999 & -9999 & -9999 & .9999 & -9999 & -9999 & -9999 & -9999 & -9999 \\
\hline .9999 & -9999 & -9999 & -9999 & -9999 & .9999 & -9999 & -9999 & -9999 & .9999 & -9999 & -9999 \\
\hline-9999 & -9999 & -9999 & -9999 & -9999 & -9999 & .9999 & -9999 & -9999 & -9999 & $-99 \times 9$ & -9999 \\
\hline-9999 & -9999 & -9999 & -9949 & -9999 & .9999 & -9999 & -9999 & -9999 & -9994 & .9999 & -9999 \\
\hline-9999 & -9999 & -9999 & -9999 & -9999 & -9999 & -9999 & -9999 & -9999 & -9999 & -9999 & -9999 \\
\hline-9999 & -9999 & -9999 & -9999 & -9999 & .9999 & .9999 & .9999 & -9999 & -9999 & .9999 & .9999 \\
\hline-9999 & -9999 & -9999 & -9999 & -9999 & .9999 & -9999 & -9999 & -9999 & -9999 & .9999 & -9999 \\
\hline .9999 & -9999 & -9999 & -9999 & -9999 & -9999 & .9999 & -9999 & .9999 & -9999 & .9999 & -9999 \\
\hline-9999 & -9999 & -9999 & -9999 & -9999 & -9999 & -9999 & -9999 & -9999 & -9999 & -9999 & -9999 \\
\hline-9999 & -9999 & -9999 & -9999 & -9999 & -9999 & -9999 & -9999 & -9999 & -9999 & -9999 & -9999 \\
\hline-9999 & -9999 & -9999 & -9999 & -9999 & -9999 & -9999 & -9999 & .9999 & .9999 & -9999 & -9999 \\
\hline-9999 & -9999 & -9999 & -9999 & -9999 & -9999 & -9999 & -9999 & -9999 & -9999 & -9999 & -9999 \\
\hline .9999 & -9999 & -9999 & -9999 & -9999 & -9999 & -9999 & -9999 & -9999 & .9999 & -9999 & .9999 \\
\hline-9999 & -9999 & -9999 & -9999 & -9999 & -9999 & -9999 & -9999 & -9999 & -9999 & -9999 & -9999 \\
\hline -9999 & -9999 & -9999 & -9999 & -9999 & -9999 & .9999 & -9999 & -9999 & -9999 & -9999 & .9999 \\
\hline .9999 & -9999 & -9999 & .9999 & .9999 & .9999 & -9999 & -9999 & -9999 & -9999 & -9999 & .9999 \\
\hline-9999 & -9999 & -9999 & -9999 & -9999 & -9999 & -9999 & -9999 & -9999 & -9999 & -9999 & -9999 \\
\hline-9999 & -9999 & -9999 & -9999 & -9999 & -9999 & -9999 & .9999 & -9999 & -9999 & -9999 & -9999 \\
\hline -9999 & .9999 & -9999 & -9999 & -9999 & -9999 & -9999 & -9999 & -9999 & -9999 & -9999 & -9999 \\
\hline .9999 & 9999. & -9999 & .9999 & -9999 & -9999 & .9999 & -9999 & -9999 & .9999 & -9999 & .9999 \\
\hline-9999 & -9999 & -9999 & -9999 & -9999 & -9999 & -9099 & -9999 & -9999 & -9999 & -9999 & -9999 \\
\hline-9999 & -9999 & -9999 & -9999 & .9999 & -9999 & -9999 & -9999 & -9999 & -9999 & -9999 & -9999 \\
\hline .9999 & -9999 & -9999 & -9999 & -9999 & -9999 & -9999 & -9999 & -9999 & -9999 & .9999 & -9999 \\
\hline-9999 & -9999 & -9999 & -9999 & -9999 & -9999 & -9999 & -9999 & -9999 & -9999 & -9999 & -9999 \\
\hline-9999 & -9999 & -9999 & 7999 & 170 & -9999 & -9999 & -9999 & -9999 & .9999 & -9999 & -9999 \\
\hline .9999 & -9999 & .9999 & -9999 & -9999 & -9999 & -9999 & -9999 & -9999 & -9999 & -9999 & .9999 \\
\hline-9999 & .9999 & -9999 & -9999 & -9999 & -9999 & -9999 & .9999 & -9999 & -9999 & -9999 & -9999 \\
\hline-9999 & -9999 & -9999 & -9999 & .9999 & -9999 & -9999 & -9999 & -9999 & -9999 & -9999 & -9999 \\
\hline 0 & 0 & 0 & 1851 & 1 & 0 & 0 & 0 & 0 & 0 & 0 & 0 \\
\hline 0 & 0 & 0 & 0 & 0 & 0 & 0 & 0 & 0 & 0 & 0 & 0 \\
\hline 0 & 0 & 0 & 0 & 0 & 0 & 0 & 0 & 0 & 0 & 0 & 0 \\
\hline 0 & 0 & 0 & 0 & 0 & 0 & 0 & 0 & 0 & 0 & 0 & 0 \\
\hline 0 & 0 & 0 & 0 & 0 & 0 & 0 & 0 & 0 & 0 & 0 & 0 \\
\hline 0 & 0 & 0 & 0 & 0 & 0 & 0 & 0 & 0 & 0 & 0 & 0 \\
\hline 0 & 0 & 0 & 0 & 0 & 0 & 0 & 0 & 0 & 0 & 0 & 0 \\
\hline 0 & 0 & 0 & 0 & 0 & 0 & 0 & 0 & 0 & 0 & 0 & 0 \\
\hline 0 & 0 & 0 & 0 & 0 & 0 & 0 & 0 & 0 & 0 & 0 & 0 \\
\hline 0 & 0 & 0 & 0 & 0 & 0 & 0 & 0 & 0 & 0 & 0 & 0 \\
\hline 0 & 0 & 0 & 0 & 0 & 0 & 0 & 0 & 0 & 0 & 0 & 0 \\
\hline
\end{tabular}


Table 2. (continued)

\begin{tabular}{|c|c|c|c|c|c|c|c|c|c|c|c|}
\hline 0 & 0 & 0 & 0 & 0 & 0 & 0 & 0 & 0 & 0 & 0 & 0 \\
\hline 0 & 0 & 0 & 0 & 0 & 0 & 0 & 0 & 0 & 0 & 0 & 0 \\
\hline 0 & 0 & 0 & 0 & 0 & 0 & 0 & 0 & 0 & 0 & 0 & 0 \\
\hline 0 & 0 & 0 & 0 & 0 & 0 & 0 & 0 & 0 & 0 & 0 & 0 \\
\hline 0 & 0 & 0 & 0 & 0 & 0 & 0 & 0 & 0 & 0 & 0 & 0 \\
\hline 0 & 0 & 0 & 0 & 0 & 0 & 0 & 0 & 0 & 0 & 0 & 0 \\
\hline 0 & 0 & 0 & 0 & 0 & 0 & 0 & 0 & 0 & 0 & 0 & 0 \\
\hline 0 & 0 & 0 & 0 & 0 & 0 & 0 & 0 & 0 & 0 & 0 & 0 \\
\hline 0 & 0 & 0 & 0 & 0 & 0 & 0 & 0 & 0 & 0 & 0 & 0 \\
\hline 0 & 0 & 0 & 0 & 0 & 0 & 0 & 0 & 0 & 0 & 0 & 0 \\
\hline 0 & 0 & 0 & 0 & 0 & 0 & 0 & 0 & 0 & 0 & 0 & 0 \\
\hline 0 & 0 & 0 & 0 & 0 & 0 & 0 & 0 & 0 & 0 & 0 & 0 \\
\hline 0 & 0 & 0 & 0 & 0 & 0 & 0 & 0 & 0 & 0 & 0 & 0 \\
\hline 0 & 0 & 0 & 0 & 0 & 0 & 0 & 0 & 0 & 0 & 0 & 0 \\
\hline 0 & 0 & 0 & 0 & 0 & 0 & 0 & 0 & 0 & 0 & 0 & 0 \\
\hline 0 & 0 & 0 & 0 & 0 & 0 & 0 & 0 & 0 & 0 & 0 & 0 \\
\hline 0 & 0 & 0 & 0 & 0 & 0 & 0 & 0 & 0 & 0 & 0 & 0 \\
\hline 0 & 0 & 0 & 0 & 0 & 0 & 0 & 0 & 0 & 0 & 0 & 0 \\
\hline 0 & 0 & 0 & 0 & 0 & 0 & 0 & 0 & 0 & 0 & 0 & 0 \\
\hline 0 & 0 & 0 & 0 & 0 & 0 & 0 & 0 & 0 & 0 & 0 & 0 \\
\hline 0 & 0 & 0 & 0 & 0 & 0 & 0 & 0 & 0 & 0 & 0 & 0 \\
\hline 0 & 0 & 0 & 0 & 0 & 0 & 0 & 0 & 0 & 0 & 0 & 0 \\
\hline 0 & 0 & 0 & 0 & 1 & 0 & 0 & 0 & 0 & 0 & 0 & 0 \\
\hline 0 & 0 & 0 & 0 & 0 & 0 & 0 & 0 & 0 & 0 & 0 & 0 \\
\hline 0 & 0 & 0 & 0 & 0 & 0 & 0 & 0 & 0 & 0 & 0 & 0 \\
\hline 0 & 0 & 0 & 0 & 0 & 0 & 0 & 0 & 0 & 0 & 0 & 0 \\
\hline 0 & 0 & 0 & 1851 & 1 & 0 & 0 & 0 & 0 & 0 & 0 & 0 \\
\hline 0 & 0 & 0 & 0 & 0 & 0 & 0 & 0 & 0 & 0 & 0 & 0 \\
\hline 0 & 0 & 0 & 0 & 0 & 0 & 0 & 0 & 0 & 0 & 0 & 0 \\
\hline 0 & 0 & 0 & 0 & 0 & 0 & 0 & 0 & 0 & 0 & 0 & 0 \\
\hline 0 & 0 & 0 & 0 & 0 & 0 & 0 & 0 & 0 & 0 & 0 & 0 \\
\hline 0 & 0 & 0 & 0 & 0 & 0 & 0 & 0 & 0 & 0 & 0 & 0 \\
\hline 0 & 0 & 0 & 0 & 0 & 0 & 0 & 0 & 0 & 0 & 0 & 0 \\
\hline 0 & 0 & 0 & 0 & n & 0 & 0 & 0 & 0 & 0 & 0 & 0 \\
\hline 0 & 0 & 0 & 0 & 0 & 0 & 0 & 0 & 0 & 0 & 0 & 0 \\
\hline 0 & 0 & 0 & 0 & 0 & 0 & 0 & 0 & 0 & 0 & 0 & 0 \\
\hline 0 & 0 & 0 & 0 & 0 & 0 & 0 & 0 & 0 & 0 & 0 & 0 \\
\hline 0 & 0 & 0 & 0 & 0 & (1) & 0 & 0 & 0 & 0 & 0 & $\mathbf{0}$ \\
\hline 0 & 0 & 0 & 0 & 0 & (1) & 0 & 0 & 0 & 0 & 0 & 0 \\
\hline 0 & 0 & 0 & 0 & 0 & 0 & 0 & 0 & 0 & 0 & 0 & 0 \\
\hline 0 & 0 & 0 & 0 & 0 & 0 & 0 & 0 & 0 & 0 & 0 & 0 \\
\hline 0 & 0 & 0 & 0 & 0 & 0 & 0 & 0 & 0 & 0 & 0 & 0 \\
\hline 0 & 0 & 0 & 0 & 0 & 0 & 0 & 0 & 0 & 0 & 0 & 0 \\
\hline 0 & 0 & 0 & 0 & 0 & 0 & 0 & 0 & 0 & 0 & 0 & 0 \\
\hline 0 & 0 & 0 & 0 & 0 & 0 & 0 & 0 & 0 & 0 & 0 & 0 \\
\hline 0 & 0 & 0 & 0 & 0 & 0 & 0 & 0 & 0 & 0 & 0 & 0 \\
\hline 0 & 0 & 0 & 0 & 0 & 0 & 0 & 0 & 0 & 0 & 0 & 0 \\
\hline 0 & 0 & 0 & 0 & 0 & 0 & 0 & 0 & $i$ & 0 & 0 & 0 \\
\hline 0 & 0 & 0 & 0 & 0 & 0 & 0 & 0 & 0 & 0 & 0 & 0 \\
\hline
\end{tabular}


Table 2 (continued)

\begin{tabular}{rrrrrrrrrrrr}
\hline 0 & 0 & 0 & 0 & 0 & 0 & 0 & 0 & 0 & 0 & 0 & 0 \\
0 & 0 & 0 & 0 & 0 & 0 & 0 & 0 & 0 & 0 & 0 & 0 \\
0 & 0 & 0 & 0 & 0 & 0 & 0 & 0 & 0 & 0 & 0 & 0 \\
0 & 0 & 0 & 0 & 0 & 0 & 0 & 0 & 0 & 0 & 0 & 0 \\
0 & 0 & 0 & 0 & 0 & 0 & 0 & 0 & 0 & 0 & 0 & 0 \\
0 & 0 & 0 & 0 & 0 & 0 & 0 & 0 & 0 & 0 & 0 & 0 \\
0 & 0 & 0 & 0 & 0 & 0 & 0 & 0 & 0 & 0 & 0 & 0 \\
0 & 0 & 0 & 0 & 0 & 0 & 0 & 0 & 0 & 0 & 0 & 0 \\
0 & 0 & 0 & 0 & 0 & 0 & 0 & 0 & 0 & 0 & 0 & 0 \\
0 & 0 & 0 & 0 & 0 & 0 & 0 & 0 & 0 & 0 & 0 & 0 \\
0 & 0 & 0 & 0 & 46 & 0 & 0 & 0 & 0 & 0 & 0 & 0 \\
0 & 0 & 0 & 0 & 0 & 0 & 0 & 0 & 0 & 0 & 0 & 0 \\
0 & 0 & 0 & 0 & 0 & 0 & 0 & 0 & 0 & 0 & 0 & 0 \\
0 & 0 & 0 & 0 & 0 & 0 & 0 & 0 & 0 & 0 & 0 & 0 \\
0 & 0 & 0 & 1851 & 2 & 0 & 0 & 0 & 0 & 0 & 0 & 0 \\
-9999 & -9999 & -9999 & -9999 & -9999 & -9999 & -9999 & -9999 & -9999 & -9999 & -9999 & -9999 \\
-9999 & -9999 & -9999 & -9999 & -9999 & -9999 & -9999 & -9999 & -9999 & -9999 & -9999 & -9999 \\
-9999 & -9999 & -9999 & -9999 & -9999 & -9999 & -9999 & -9999 & -9999 & -9999 & -9999 & -9999 \\
-9999 & -9999 & -9999 & -9999 & -9999 & -9999 & -9999 & -9999 & -9999 & -9999 & -9999 & -9999 \\
\hline
\end{tabular}


Table 3. Partial listing of the gridded surface air temperature anomalies for the Antarctic (File 12)

\begin{tabular}{|c|c|c|c|c|}
\hline -9999 & -9999 & -9999 & 1957 & 1 \\
\hline-9999 & -9999 & -9999 & -9999 & -20 \\
\hline -9999 & -9999 & -9999 & -9999 & -20 \\
\hline -9999 & -9999 & -9999 & -9999 & -10 \\
\hline-9999 & -9999 & -9999 & -9999 & -10 \\
\hline -9999 & -9999 & -9999 & -9999 & -10 \\
\hline-9999 & -9999 & -9999 & -9999 & -10 \\
\hline 80 & 60 & -9999 & -9999 & -10 \\
\hline 90 & 60 & -9999 & -9999 & -10 \\
\hline-9999 & -9999 & -9999 & -9999 & -10 \\
\hline 110 & 70 & -9999 & -9999 & -10 \\
\hline 110 & 70 & -9999 & -9999 & -10 \\
\hline -9999 & -9999 & -9999 & -9999 & -10 \\
\hline-9999 & -9999 & -9999 & -9999 & -10 \\
\hline 100 & 60 & -9999 & -9999 & -10 \\
\hline 100 & 60 & -9999 & -9999 & -10 \\
\hline 100 & 50 & -10 & -50 & -10 \\
\hline-9999 & -9999 & -20 & .60 & -10 \\
\hline -9999 & -9999 & -30 & -60 & -10 \\
\hline -9999 & -9999 & -20 & -50 & -60 \\
\hline-9999 & -9999 & -9999 & -60 & -60 \\
\hline-9999 & -9999 & -9999 & -9999 & -60 \\
\hline -9999 & -9999 & -9999 & -9999 & -60 \\
\hline -9999 & -9999 & -9999 & -90 & -70 \\
\hline -9999 & -9999 & -9999 & -90 & -60 \\
\hline -9999 & -9999 & -50 & -90 & -60 \\
\hline-9999 & -9999 & -9999 & -80 & -60 \\
\hline-9999 & -9999 & -9999 & -70 & -60 \\
\hline-9999 & -9999 & -9999 & -9999 & -50 \\
\hline-9999 & 50 & -9999 & -9999 & -50 \\
\hline 80 & 90 & -9999 & -9999 & -40 \\
\hline 30 & 60 & -9999 & -9999 & -30 \\
\hline-10 & -9999 & -9999 & -9999 & -30 \\
\hline-9999 & -9999 & -50 & -9999 & -30 \\
\hline-9999 & -9999 & -60 & -50 & -30 \\
\hline-9999 & -9999 & -70 & -50 & -20 \\
\hline-9999 & -9999 & -60 & -9999 & -20 \\
\hline-9999 & -9999 & -9999 & 1957 & 2 \\
\hline -9999 & -9999 & -9999 & -9999 & 130 \\
\hline -9999 & -9999 & -9999 & -9999 & 130 \\
\hline -9999 & -9999 & -9999 & -9999 & 140 \\
\hline-9999 & -9999 & -9999 & -9999 & 140 \\
\hline -9999 & -9999 & -9999 & -9999 & 150 \\
\hline-9999 & -9999 & -9999 & -9999 & 150 \\
\hline-10 & 30 & -9999 & -9999 & 160 \\
\hline-10 & 30 & -9999 & -9999 & 160 \\
\hline 10 & 20 & -9999 & -9999 & 160 \\
\hline 50 & 50 & -9999 & -9999 & 160 \\
\hline
\end{tabular}


Table 3. (continued)

\begin{tabular}{rrrrr}
\hline 40 & 50 & -9999 & -9999 & 170 \\
-9999 & -9999 & -9999 & -9999 & 170 \\
-9999 & -9999 & -9999 & -9999 & 170 \\
-10 & 20 & -9999 & -9999 & 170 \\
-20 & 10 & -9999 & -9999 & 180 \\
-20 & 10 & 40 & 70 & 180 \\
-9999 & -9999 & 30 & 70 & 190 \\
-9999 & -9999 & 30 & 60 & 190 \\
-9999 & -9999 & -100 & -60 & -10 \\
-9999 & -9999 & -9999 & -50 & -10 \\
-9999 & -9999 & -9999 & -9999 & 10 \\
-9999 & -9999 & -9999 & -9999 & 0 \\
-9999 & -9999 & -9999 & -90 & 0 \\
-9999 & -9999 & -9999 & -90 & 0 \\
-9999 & -9999 & -60 & -90 & 10 \\
\hline
\end{tabular}


Table 4. Partial listing of the monthly mean temperature records for individual stations in the Northern Hemisphere (File 13)

\begin{tabular}{|c|c|c|c|c|c|c|c|c|c|c|c|c|c|}
\hline \multirow{2}{*}{$\begin{array}{l}10010 \\
1921\end{array}$} & 710 & \multicolumn{2}{|c|}{84} & \multicolumn{4}{|c|}{9 JAN MAYEN } & \multicolumn{3}{|c|}{ NORWAY } & \multirow{2}{*}{$\begin{array}{c}1 \\
-21\end{array}$} & \multicolumn{2}{|c|}{19211988101921} \\
\hline & -44 & -71 & -68 & -43 & -8 & 22 & 47 & 58 & 27 & -20 & & -40 & -13 \\
\hline 1922 & -10 & -18 & -62 & -38 & -16 & 28 & 47 & 62 & 27 & -1 & -38 & -27 & -4 \\
\hline 1923 & -60 & -30 & -9 & -16 & -16 & 10 & 48 & 41 & 22 & 9 & -24 & -38 & -5 \\
\hline 1924 & -8 & -49 & -51 & -38 & -2 & 27 & 68 & 72 & 38 & 13 & -26 & -26 & 2 \\
\hline 1925 & -34 & -32 & .42 & -9 & 9 & 38 & 50 & 61 & 42 & 1 & -30 & -46 & 1 \\
\hline 1926 & -19 & -24 & .59 & -5 & 1 & 32 & 61 & 57 & 23 & -26 & -10 & -48 & -1 \\
\hline 1927 & -45 & -23 & -39 & -54 & -17 & 20 & 60 & 60 & 32 & -13 & -12 & -36 & -6 \\
\hline 1928 & -35 & -33 & -36 & -20 & -7 & 19 & 41 & 47 & 37 & 13 & -11 & -22 & -1 \\
\hline 1929 & -30 & 0 & -19 & -32 & 0 & 26 & 40 & 49 & 28 & -18 & -6 & 1 & 3 \\
\hline 1930 & -32 & -28 & -50 & 8 & 14 & 53 & 60 & 73 & 43 & 1 & -30 & -12 & 8 \\
\hline 1931 & -36 & -42 & -61 & -3 & -5 & 22 & 61 & 52 & 35 & -20 & 20 & -37 & -1 \\
\hline 1932 & -45 & -16 & -35 & -40 & 6 & 28 & 66 & 61 & 21 & -4 & -31 & -20 & -1 \\
\hline 1933 & -8 & -49 & -32 & -46 & -1 & 43 & 61 & 73 & 55 & -4 & -2 & -6 & 7 \\
\hline 1934 & -43 & -71 & -35 & -46 & -5 & 33 & 68 & 77 & 80 & 19 & -14 & 3 & 6 \\
\hline 1935 & -30 & -60 & -31 & -32 & -15 & 22 & 54 & 55 & 28 & 2 & 9 & -31 & -2 \\
\hline 1936 & -70 & -46 & -58 & -34 & 17 & 30 & 57 & 69 & 36 & 7 & -18 & -70 & -7 \\
\hline 1937 & -9 & -61 & -69 & -10 & 9 & 29 & 54 & 60 & 40 & -3 & -20 & -6 & 1 \\
\hline 1938 & -51 & -34 & -59 & -39 & -11 & 37 & 58 & 59 & 41 & 42 & 11 & 17 & 6 \\
\hline 1939 & -26 & -32 & -14 & -29 & 12 & 31 & 59 & 74 & 45 & 21 & -37 & -58 & 4 \\
\hline 1940 & -31 & -72 & -49 & -42 & 6 & 36 & 48 & 45 & -999 & -999 & -999 & -999 & -999 \\
\hline 1941 & -999 & -103 & -999 & -999 & -13 & 18 & 56 & 49 & 44 & 4 & 8 & -43 & -999 \\
\hline 1942 & -31 & -145 & -86 & .73 & -29 & -999 & -999 & 45 & 30 & 4 & -31 & -57 & -999 \\
\hline 1943 & -76 & -52 & -55 & -45 & -26 & 12 & 41 & 22 & 29 & 12 & -25 & -31 & -16 \\
\hline 1944 & -68 & -36 & -52 & -46 & 1 & 24 & 49 & 49 & 36 & 2 & -30 & -30 & -8 \\
\hline 1945 & -54 & -63 & -36 & -21 & 5 & 31 & 56 & 58 & 47 & -6 & -4 & -53 & -3 \\
\hline 1946 & 2 & -52 & -48 & -39 & -9 & 29 & 56 & 65 & 48 & 30 & -17 & 6 & 6 \\
\hline 1947 & 12 & -20 & -74 & -31 & 14 & 32 & 64 & 69 & 41 & 9 & -33 & -68 & 1 \\
\hline 1948 & -79 & -21 & -38 & -29 & -18 & 9 & 48 & 42 & 20 & -2 & -33 & -44 & -12 \\
\hline 1949 & -46 & -39 & -47 & -41 & -9 & 33 & 47 & 41 & 32 & -9 & 3 & -37 & -6 \\
\hline 1950 & -2 & -999 & -43 & -27 & -5 & 22 & 53 & 72 & 45 & 21 & -5 & -41 & -999 \\
\hline 1951 & -43 & -24 & -70 & -52 & -7 & 3 & 39 & 62 & 41 & 7 & -39 & -38 & -10 \\
\hline 1952 & -43 & -59 & -51 & -13 & -4 & 25 & 45 & 35 & 21 & 37 & -16 & -34 & -5 \\
\hline 1953 & -50 & -56 & -60 & -59 & -6 & 46 & 55 & 74 & 47 & 19 & -4 & -5 & 0 \\
\hline 1954 & -42 & -33 & -87 & -41 & -1 & 15 & 45 & 43 & 26 & -2 & 23 & -16 & -6 \\
\hline 1955 & -71 & -78 & -66 & -31 & -20 & 17 & 49 & 53 & 43 & -12 & -21 & -41 & -15 \\
\hline 1956 & -49 & -39 & -27 & -45 & -6 & 6 & 49 & 37 & 20 & 0 & -4 & 1 & -5 \\
\hline 1957 & -11 & -33 & -32 & -12 & -9 & 13 & 42 & 51 & 34 & 6 & -5 & -41 & 0 \\
\hline 1958 & -26 & -48 & -32 & -12 & -3 & 27 & 42 & 57 & 41 & 24 & -7 & -41 & 2 \\
\hline 1959 & -66 & -54 & -28 & -59 & -16 & 9 & 36 & 47 & 33 & 34 & -10 & -11 & -7 \\
\hline 1960 & -25 & -51 & -16 & -14 & 4 & 25 & 53 & 57 & 59 & 7 & 4 & -22 & 7 \\
\hline 1961 & -21 & -36 & -69 & -56 & 2 & 24 & 42 & 64 & 46 & 41 & -14 & -58 & -3 \\
\hline 1962 & -29 & -37 & -72 & -30 & 5 & 11 & 41 & 55 & 36 & -18 & -26 & -31 & -8 \\
\hline 1963 & -67 & -116 & -30 & -39 & 4 & 30 & 33 & 46 & 40 & 20 & -28 & -37 & -12 \\
\hline 1964 & -52 & -60 & -17 & -22 & -10 & 15 & 37 & 44 & 8 & 5 & -59 & -64 & -15 \\
\hline 1965 & -55 & -43 & -110 & -31 & -20 & 12 & 36 & 58 & 30 & 19 & -33 & -76 & -18 \\
\hline 1966 & -111 & -89 & -87 & -12 & -12 & 33 & 49 & 40 & 13 & -7 & -37 & -42 & -22 \\
\hline 1967 & -79 & -38 & -92 & -43 & -10 & 11 & 35 & 34 & 30 & -28 & -59 & -55 & -25 \\
\hline
\end{tabular}


Table 4. (continued)

\begin{tabular}{|c|c|c|c|c|c|c|c|c|c|c|c|c|c|}
\hline 1968 & -999 & -123 & -134 & -51 & -31 & 10 & 22 & 25 & 24 & -35 & -18 & -83 & -999 \\
\hline 1969 & -97 & -999 & -97 & -52 & -12 & 26 & 51 & 67 & 22 & -22 & -61 & -71 & -999 \\
\hline 1970 & -999 & -999 & -999 & -44 & 1 & 28 & 37 & 44 & 27 & 0 & -19 & -55 & -999 \\
\hline 1971 & -100 & -49 & -74 & -47 & -1 & 25 & 36 & 44 & 25 & 13 & -89 & -60 & -23 \\
\hline 1972 & -11 & -62 & -51 & -36 & -1 & 29 & 53 & 44 & 32 & -6 & -19 & -18 & -4 \\
\hline 1973 & -20 & -126 & -66 & -74 & -9 & 19 & 41 & 51 & 41 & -11 & .74 & -66 & -25 \\
\hline 1974 & -14 & -38 & -13 & -14 & 9 & 31 & 37 & 45 & 29 & 13 & 6 & -56 & 3 \\
\hline 1975 & -68 & -36 & -59 & -50 & -16 & 6 & 41 & 52 & 14 & 9 & -16 & -84 & -17 \\
\hline 1976 & -66 & -26 & -15 & -44 & 4 & 30 & 51 & 53 & 28 & 33 & -27 & -31 & -1 \\
\hline 1977 & -59 & -52 & -82 & -56 & -15 & 15 & 40 & 42 & 28 & 11 & -28 & -23 & -15 \\
\hline 1978 & -69 & -95 & -55 & -27 & -7 & 21 & 45 & 56 & 31 & 3 & -58 & -45 & -17 \\
\hline 1979 & -98 & -68 & -50 & -34 & -27 & 18 & 39 & 54 & 22 & 13 & -24 & -13 & -14 \\
\hline 1980 & -33 & -49 & -28 & -27 & 9 & 27 & 50 & 52 & 32 & -22 & -41 & -68 & -8 \\
\hline 1981 & -77 & -52 & -69 & -40 & -7 & 6 & 37 & 46 & 21 & -10 & -28 & -60 & -19 \\
\hline 1982 & -90 & -35 & -46 & -58 & -19 & 7 & 36 & 47 & 14 & 9 & -30 & -42 & -17 \\
\hline 1983 & -41 & -49 & -53 & -33 & -1 & 16 & 44 & 43 & 20 & -14 & -18 & -45 & -11 \\
\hline 1984 & -30 & -13 & -33 & -4 & -5 & 27 & 46 & 51 & 34 & 10 & -1 & 4 & 7 \\
\hline 1985 & -34 & -50 & -46 & -58 & -3 & 21 & 50 & 48 & 21 & -3 & -34 & -73 & -13 \\
\hline 1986 & -59 & -60 & -44 & -36 & -7 & 27 & 36 & 52 & 26 & 11 & -20 & -20 & -8 \\
\hline 1987 & -26 & -93 & -42 & -16 & 2 & 25 & 53 & 48 & 36 & 8 & -21 & -110 & -11 \\
\hline 1988 & -109 & -33 & -77 & -71 & -10 & 15 & 44 & 58 & 31 & 4 & -46 & -87 & -23 \\
\hline 10050 & 780 & & 142 & 9 & ISFJO & $\mathrm{D} \mathrm{R}$ & DIO & & RWA & & 1 & 191219 & 979101912 \\
\hline 1912 & -245 & -264 & -219 & -197 & -60 & 19 & 41 & 26 & -28 & -87 & -130 & -125 & -106 \\
\hline 1913 & -158 & -208 & -178 & -97 & -52 & 2 & 46 & 52 & 7 & -86 & -78 & -132 & -74 \\
\hline 1914 & -218 & -240 & -199 & -105 & -52 & 18 & 49 & 48 & -9 & -46 & -133 & -179 & -89 \\
\hline 1915 & -143 & -196 & -216 & -110 & -88 & 16 & 39 & 36 & -5 & -49 & -208 & -226 & -96 \\
\hline
\end{tabular}


Table 5. Partial listing of the monthly mean temperature records for individual stations in the Southern Hemisphere (File 14)

\begin{tabular}{|c|c|c|c|c|c|c|c|c|c|c|c|c|c|}
\hline 61900 & -80 & 1 & 45 & & SCEN & SION & IS. & & ASCEN & SION IS & & 319 & 101923 \\
\hline 1923 & -999 & -999 & 271 & 268 & 268 & 262 & 251 & 252 & 277 & 254 & 263 & 271 & -999 \\
\hline 1924 & 272 & 278 & 281 & 277 & 273 & 266 & 254 & 248 & 243 & 247 & 248 & 252 & 262 \\
\hline 1925 & 257 & 267 & 277 & 275 & 271 & 265 & 256 & 252 & 254 & 252 & -999 & 258 & -999 \\
\hline 1926 & 263 & 276 & 279 & 281 & 268 & 263 & 253 & 251 & 246 & 249 & 248 & 254 & 261 \\
\hline 1927 & 262 & 269 & 274 & 271 & 271 & 261 & 253 & 249 & 245 & 247 & 251 & 255 & 259 \\
\hline 1928 & 261 & 271 & 276 & 276 & 267 & 259 & 251 & 246 & 243 & 242 & 244 & 251 & 257 \\
\hline 1929 & 262 & 271 & 279 & 281 & 273 & 263 & 252 & 247 & 239 & 243 & 244 & 251 & 259 \\
\hline 1930 & -999 & -999 & -999 & -999 & -999 & -999 & -999 & -999 & -999 & -999 & -999 & -999 & -999 \\
\hline 1931 & 259 & 274 & 278 & 277 & 273 & 261 & 251 & 243 & 243 & 241 & 243 & 251 & 258 \\
\hline 1932 & 261 & 266 & 268 & 277 & 269 & 261 & 248 & 246 & 239 & 237 & 246 & 248 & 256 \\
\hline 1933 & 260 & 268 & 277 & 279 & 272 & 264 & 255 & 252 & 246 & 248 & 245 & 252 & 260 \\
\hline 1934 & 259 & 270 & 274 & 277 & 268 & 262 & 261 & 258 & 259 & 258 & 258 & 262 & 264 \\
\hline 1935 & 266 & 277 & 281 & 279 & 276 & 270 & 253 & 253 & 247 & 250 & 252 & 256 & 263 \\
\hline 1936 & 263 & 268 & 271 & 275 & 271 & 264 & 259 & 248 & 245 & 246 & 250 & 256 & 260 \\
\hline 1937 & 263 & 269 & 276 & 278 & 273 & 263 & 258 & 249 & 255 & 256 & 253 & 258 & 263 \\
\hline 1938 & 262 & 269 & 268 & 272 & 272 & 269 & 266 & 253 & 254 & 254 & 259 & 262 & 263 \\
\hline 1939 & 264 & 266 & 269 & 272 & 269 & 266 & 256 & 254 & 253 & 254 & 254 & 257 & 261 \\
\hline 1940 & 259 & 263 & 265 & 268 & 267 & 267 & 256 & 255 & 256 & 259 & 258 & 263 & 261 \\
\hline 1941 & 267 & 271 & 271 & 267 & 267 & 264 & 255 & 255 & 243 & 244 & 249 & 253 & 259 \\
\hline 1942 & 256 & 266 & 272 & 268 & 264 & 257 & 248 & 245 & 246 & 247 & 251 & 252 & 256 \\
\hline 1943 & 254 & 255 & 256 & 256 & 255 & 257 & 255 & 247 & 247 & 249 & 247 & 250 & 252 \\
\hline 1944 & 257 & 258 & 262 & 266 & 263 & 265 & 258 & 253 & 250 & 253 & 252 & 257 & 258 \\
\hline 1945 & 258 & 258 & 264 & 262 & 259 & 253 & 257 & 252 & 251 & 254 & 257 & 256 & 257 \\
\hline 1946 & 257 & 266 & 267 & 269 & 267 & 262 & 256 & 255 & 244 & 243 & 248 & 251 & 257 \\
\hline 1947 & 264 & 273 & 282 & 277 & 272 & 261 & 252 & 251 & 247 & 251 & 256 & 258 & 262 \\
\hline 1948 & 263 & 274 & 285 & 280 & 276 & 263 & 254 & 248 & 243 & 243 & 247 & 252 & 261 \\
\hline 1949 & 263 & 274 & 281 & 284 & 278 & 265 & 259 & 252 & 252 & 252 & 254 & 257 & 264 \\
\hline 1950 & 265 & 274 & 281 & 279 & 276 & 262 & 253 & 248 & 246 & 248 & 249 & 252 & 261 \\
\hline 1951 & 258 & 266 & 275 & 276 & 271 & 259 & 253 & 247 & 245 & 243 & 249 & 260 & 259 \\
\hline 1952 & 265 & 272 & 282 & 279 & 273 & 259 & 249 & 244 & 244 & 243 & 254 & 258 & 260 \\
\hline 1953 & 263 & 268 & 279 & 279 & 271 & 262 & 251 & 245 & 246 & 247 & 251 & 256 & 260 \\
\hline 1954 & 261 & 269 & 274 & 274 & 271 & 260 & 252 & 246 & 238 & 244 & 249 & 253 & 258 \\
\hline 1955 & 258 & 271 & 277 & 278 & 273 & 264 & 255 & 246 & 244 & 245 & 253 & 253 & 260 \\
\hline 1956 & 258 & 268 & 272 & 274 & 272 & 262 & 254 & 250 & 248 & 246 & 253 & 255 & 259 \\
\hline 1957 & 262 & 274 & 277 & 281 & 275 & 267 & 258 & 251 & 248 & 245 & 252 & 257 & 262 \\
\hline 1958 & 261 & 271 & 278 & 278 & 275 & 272 & 253 & 245 & 237 & 240 & 247 & 249 & 259 \\
\hline 1959 & 262 & 263 & 271 & 273 & 268 & 259 & 254 & 248 & 243 & 245 & 246 & 251 & 257 \\
\hline 1960 & 259 & 267 & 279 & 277 & 269 & 258 & 256 & 246 & 247 & 242 & 251 & 253 & 259 \\
\hline 1961 & 267 & 275 & 281 & 277 & 273 & 261 & 253 & 247 & 242 & 243 & 252 & 256 & 261 \\
\hline 1962 & 261 & 271 & 275 & 277 & 271 & 260 & 253 & 249 & 245 & 249 & 251 & 257 & 260 \\
\hline 1963 & 264 & 275 & 280 & 284 & 273 & 262 & 253 & 245 & 253 & 253 & 261 & 268 & 264 \\
\hline 1964 & 276 & 281 & 286 & 283 & 274 & 263 & 256 & 250 & 245 & 249 & 248 & 251 & 264 \\
\hline 1965 & 261 & 269 & 279 & 279 & 275 & 254 & 253 & 250 & 239 & 244 & 246 & 253 & 259 \\
\hline 1966 & 259 & 271 & 277 & 278 & 273 & 266 & 259 & 251 & 251 & 247 & 252 & 261 & 262 \\
\hline 1967 & 267 & 278 & 280 & 280 & 272 & 254 & 250 & 241 & 241 & 239 & 245 & 255 & 259 \\
\hline 1968 & 267 & 275 & 2 & 15 & 71 & 261 & 57 & 251 & 248 & 249 & 251 & 251 & 261 \\
\hline
\end{tabular}


Table 5. (continued)

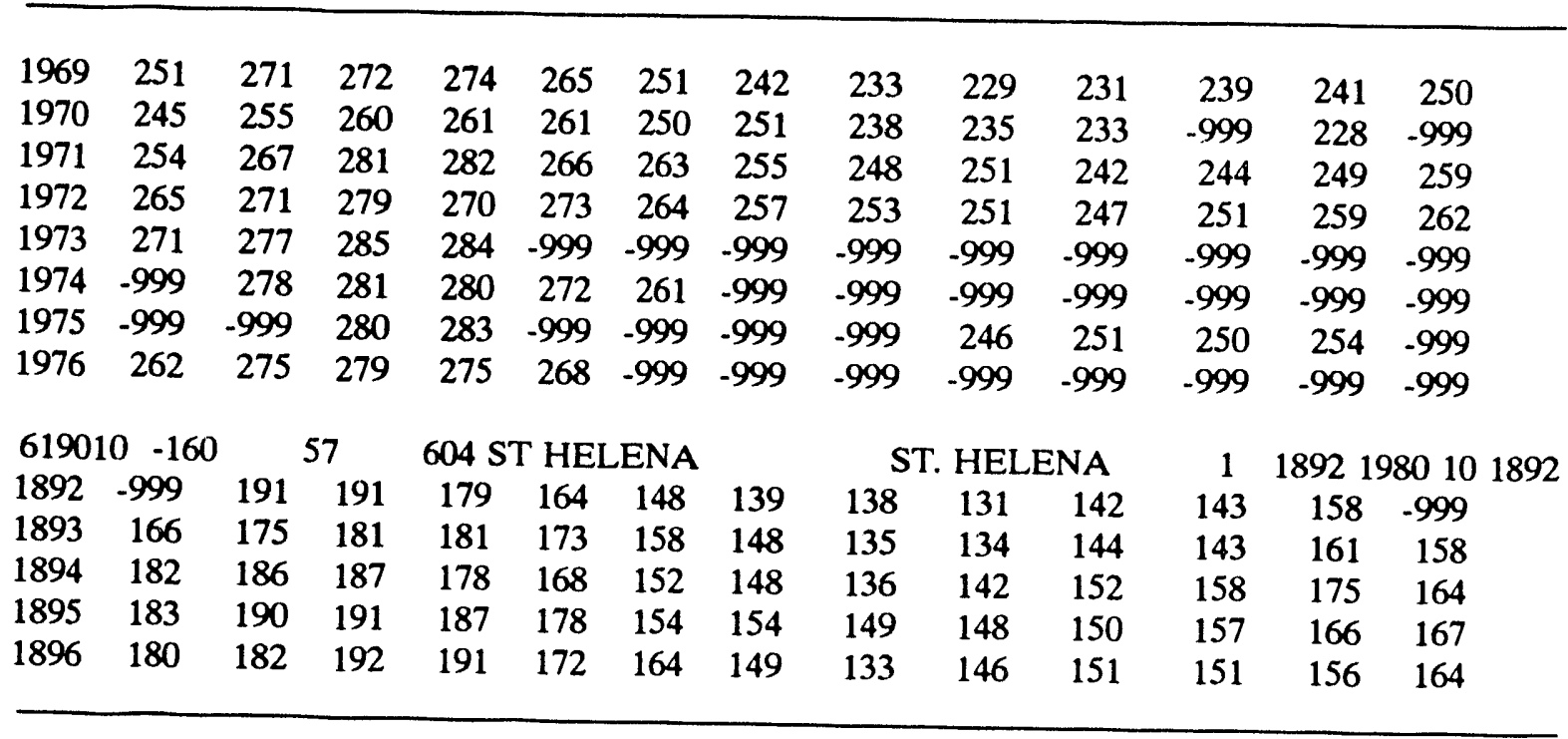




\section{VERIFICATION OF DATA TRANSPORT}

The data files containing the gridded surface air temperature anomalies and the mean monthly temperatures for individual stations can be read by using the FORTRAN or SAS input/output routines provided. Users should verify that the data have been correctly transported to their systems by generating some or all of the statistics presented in Tables 6 through 10. These statistics were generated in SAS (PROC MEANS) but can be duplicated in other statistical packages or languages. If the statistics generated by the user differ from those presented here, the data sets may have been corrupted in transport.

These statistics are presented only as a tool to ensure proper reading of the data sets. They are not to be construed as summarizing these data. 
Table 6. Characteristics of numeric variables for the gridded surface air temperature anomaly file for the Northern Hemisphere

\begin{tabular}{lcrrr}
\hline Variable & $\begin{array}{c}\text { Number of } \\
\text { observations }\end{array}$ & Mean & $\begin{array}{c}\text { Minimum } \\
\text { value }\end{array}$ & $\begin{array}{c}\text { Maximum } \\
\text { value }\end{array}$ \\
\hline YEAR & 1680 & 1920.500 & 1851.000 & 1990.000 \\
MONTH & 1680 & 6.500 & 1.000 & 12.000 \\
MTEMP & 1680 & -6884.168 & -9305.241 & -4497.821 \\
MSTA & 1680 & 1.073 & 0.130 & 2.350 \\
MDIST & 1680 & 37.603 & 6.370 & 405.093 \\
\hline
\end{tabular}

The following is a listing of the SAS program used to generate the statistics described in the table.

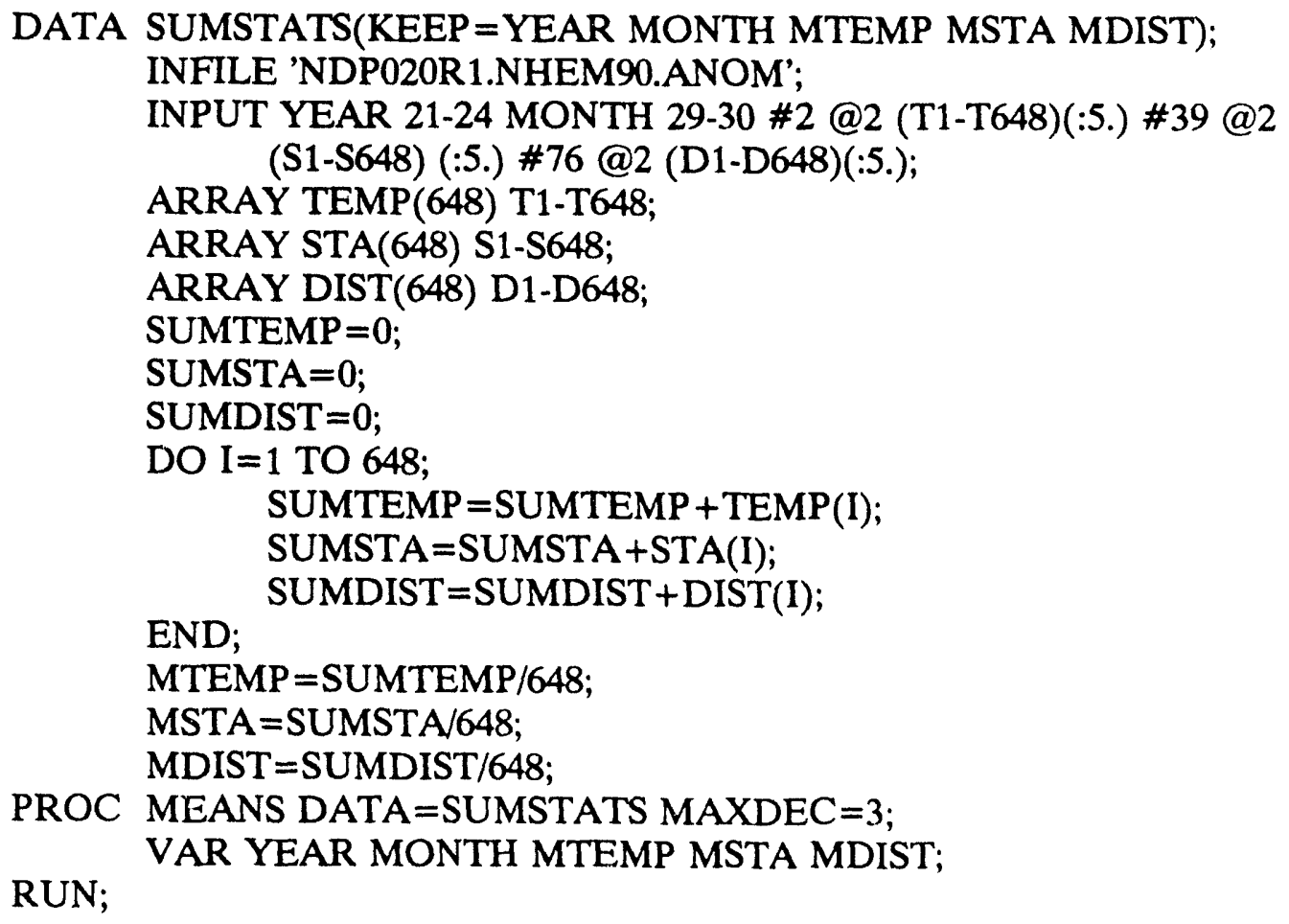


Table 7. Characteristics of numeric variables for the gridded surface air temperature anomaly file for the Southern Hemisphere

\begin{tabular}{lcrrr}
\hline Variable & $\begin{array}{c}\text { Number of } \\
\text { observations }\end{array}$ & Mean & $\begin{array}{c}\text { Minimum } \\
\text { value }\end{array}$ & \multicolumn{1}{c}{$\begin{array}{c}\text { Maximum } \\
\text { value }\end{array}$} \\
\hline & 1680 & 1920.500 & 1851.000 & 1990.000 \\
YEAR & 1680 & 6.500 & 1.000 & 12.000 \\
MONTH & 1680 & -8612.954 & -9975.947 & -7094.181 \\
MTEMP & 1680 & 0.243 & 0.002 & 0.639 \\
MSTA & 1680 & 10.671 & 0.106 & 22.512 \\
MDIST & & & & \\
\hline
\end{tabular}

The following is a listing of the SAS program used to generate the statistics described in the table.

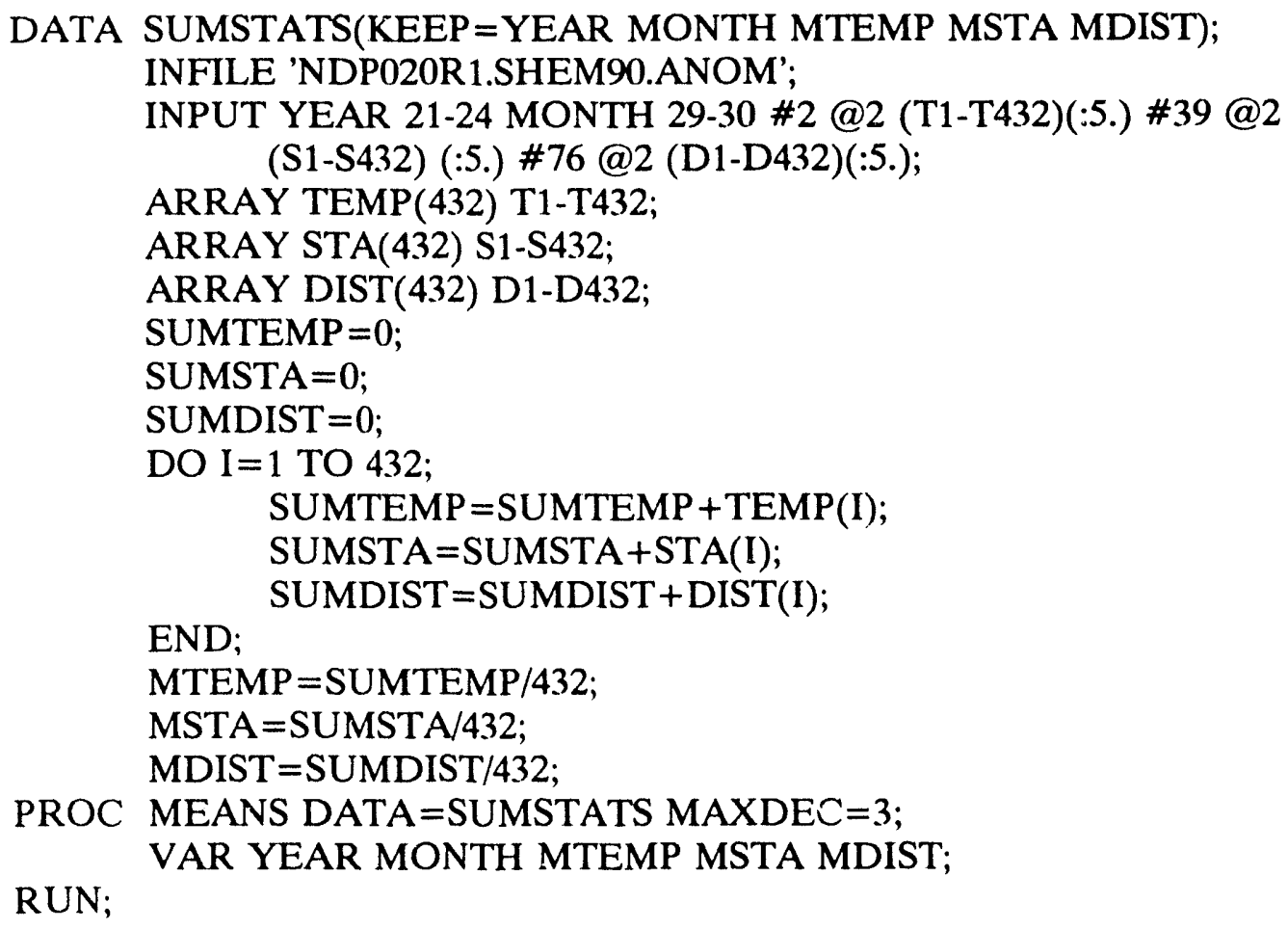


Table 8. Characteristics of numeric variables for the gridded surface air temperature anomaly file for the Antarctic

\begin{tabular}{lcrrr}
\hline Variable & $\begin{array}{c}\text { Number of } \\
\text { observations }\end{array}$ & Mean & $\begin{array}{c}\text { Minimum } \\
\text { value }\end{array}$ & $\begin{array}{c}\text { Maximum } \\
\text { value }\end{array}$ \\
\hline YEAR & 408 & 1973.500 & 1957.000 & 1990.000 \\
MONTH & 408 & 6.500 & 1.000 & 12.000 \\
MTEMP & 408 & -5183.105 & -9999.000 & -4330.278 \\
\hline
\end{tabular}

The following is a listing of the SAS program used to generate the statistics described in the tabie.

DATA SUMSTATS(KEEP =YEAR MONTH MTEMP);

INFILE 'NDP020R1.ANTARC.ANOM';

INPUT YEAR 21-24 MONTH 29-30 \#2 @2 (T1-T180)(:5.);

ARRAY TEMP(180) T1-T180;

SUMTEMP $=0$;

DO I=1 TO 180 ;

END;

SUMTEMP =SUMTEMP + TEMP(I);

MTEMP =SUMTEMP/180;

PROC MEANS DATA =SUMSTATS MAXDEC =3;

RUN;

VAR YEAR MONTH MTEMP; 
Table 9. Characteristics of numeric variables for the monthly mean temperature records for individual stations in the Northern Hemisphere

\begin{tabular}{lrrrr}
\hline Variable & $\begin{array}{c}\text { Number of } \\
\text { observations }\end{array}$ & Mean & $\begin{array}{c}\text { Minimum } \\
\text { value }\end{array}$ & $\begin{array}{c}\text { Maximum } \\
\text { value }\end{array}$ \\
\hline & 1584 & 538993.548 & 10010.000 & 999060.000 \\
ID & 1584 & 355.812 & -23.000 & 825.000 \\
LAT & 1584 & 157.770 & -1799.000 & 1795.000 \\
LONG & 113763 & 1934.064 & 1701.000 & 1988.000 \\
YEAR & 113763 & -136.370 & -999.000 & 318.000 \\
TMEAN & & & & \\
\hline
\end{tabular}

The following is a listing of the SAS program used to generate the statistics described in the table.

DATA SUMSTATS;

INFILE 'NDP020R1.NHEMST.DATA';

INPUTX\$5Y\$6@;

IF $X$ NE' ' AND Y NE', THEN

INPUT ID 2-7 LAT 9-12 LONG 14-18;

ELSE IF X NE' ' AND Y EQ ' ' THEN

INPUT YEAR 2-5 TMEAN 68-71;

ELSE INPUT;

PROC MEANS MAXDEC $=3$ DATA =SUMSTATS;

VAR ID LAT LONG YEAR TMEAN;

RUN; 
Table 10. Characteristics of numeric variables for the monthly mean temperature records for individual stations in the Southern Hemisphere

\begin{tabular}{lrrrr}
\hline Variable & $\begin{array}{c}\text { Number of } \\
\text { observations }\end{array}$ & Mean & \multicolumn{1}{c}{$\begin{array}{c}\text { Minimum } \\
\text { value }\end{array}$} & $\begin{array}{c}\text { Maximum } \\
\text { value }\end{array}$ \\
\hline ID & 288 & 827340.538 & 619000.000 & 999006.000 \\
LAT & 288 & -238.736 & -608.000 & -26.000 \\
LONG & 288 & -124.083 & -1791.000 & 1800.000 \\
YEAR & 16163 & 1947.656 & 1787.000 & 1988.000 \\
TMEAN & 16163 & -55.135 & -999.000 & 296.000 \\
\hline
\end{tabular}

The following is a listing of the SAS program used to generate the statistics described in the table.

\section{DATA SUMSTATS;}

INFILE 'NDP020R1.SHEMST.DATA';

INPUT X\$5Y\$6@;

IF $X$ NE' ' AND Y NE' 'THEN

INPUT ID 2-7 LAT 9-12 LONG 14-18;

ELSE IF X NE' ' AND Y EQ ', THEN

INPUT YEAR 2-5 TMEAN 68-71;

ELSE INPUT;

PROC MEANS MAXDEC $=3$ DATA =SUMSTATS;

VAR ID LAT LONG YEAR TMEAN;

RUN; 
APPENDIX A

REPRINTS OF PERTINENT LITERATURE 
Office of Energy Research

Office of Basic Energy Sciences

Carbon Dioxide Research Division

Washington, D.C. 20545

\section{A Grid Point Surface Air Temperature Data Set for the Northern Hemisphere}

Prepared by:

P.D. Jones, S.C.B. Raper, B. Santer

B.S.G. Cherry, C. Goodess, P.M. Kelly, T.M.L. Wigley University of East Anglia

Norwich, UK

R.S. Bradley

University of Massachusetts

Amherst, MA

and

H.F. Diaz

NOAA/ERL

Boulder, CO

Under Contract No. DE-AC02-79EV10098 


\section{ABSTRACT}

$\Delta$ compilation of 2666 station records of monthly surface air temperature has been assembled for the Northern Bemisphere. In order to use these data to fcrm a gridded data set for the Northern Bemisphere we have assessed, where possible, the homogeneity of each of these records. The results of this ascesenent are presented and stacions are clased as immediately usable, corrected or uncorrectable. Full details of how this has been achieved for each station are presented in tabular form.

of the 2666 station records, 1584 vere used to produce the gridded temperature data set. Temperature anomaliea were calculated with respect to the appropriate monthly mean for the reference period $1951-70$ using the homogenized data. Anomalies at each point of a $5^{\circ}$ latitude by $10^{\circ}$ longitude grid were interpolated from the station data for each month for the period 1851 to 1984. 
Fig. 1: Station temperature difference time series: Gordon Castle $\left(57.6^{\circ} \mathrm{N}, 3.1^{\circ} \mathrm{W}\right)$ minus Aberdeen $\left(57.2^{\circ} \mathrm{N}, 2.1^{\circ} \mathrm{W}\right)$, 1901-1974. The analysis identifies Aberdeen as the errant station as a similar jump at 1948 also occurs when the station is compared with Glasgow $\left(55.9^{\circ} \mathrm{N}\right.$, $\left.4.3^{\circ} \mathrm{W}\right)$ and Edinbuigh $\left(55.9^{\circ} \mathrm{N}, 3.4^{\circ} \mathrm{W}\right)$. The station history information reveals that the site was moved to Dyce airport in 1948. The straight lines are the mean station differences for the two periods, 1901-1947, 1948-1974. Correction details are given in Appendix A.

Fig. 2: Station temperature difference time series:

$\nabla$ ishakhapatnam $\left(17.7^{\circ} \mathrm{N}, 83.3^{\circ} \mathrm{E}\right)$ minus Begampet $\left(17.5^{\circ} \mathrm{N}\right.$, $\left.78.5^{\circ} \mathrm{E}\right), 1901-1980$. The analysis identifies Begampet as the errant station as a similar jump at 1951 also occurs when the station is compared with Akola $\left(20.7^{\circ} \mathrm{N}\right.$, $\left.77.0^{\circ} \mathrm{E}\right)$ and $\mathrm{Jagdal}$ pur $\left(19.1^{\circ} \mathrm{N}, 82.0^{\circ} \mathrm{E}\right)$. The station history information reveals that the station was moved to the airport in 1951. The straight lines are the mean station differences for the two periods, i9011950, 1951-1980. Correction details are given in Appendix A.

Fig. 3: Station temperature difference time series: Nemuro $\left(44.3^{\circ} \mathrm{N}, 145.6^{\circ} \mathrm{E}\right)$ minus Sapporo $\left(43.1^{\circ} \mathrm{N}, 141.4^{\circ} \mathrm{E}\right)$, 1901-1980. The analysis identifies Sapporo as the errant station as a similar jump during 1939 also occurs when the station is compared with Abashiri $\left(44.0^{\circ} \mathrm{N}, 144.3^{\circ} \mathrm{E}\right)$ and Akita $\left(39.7^{\circ} \mathrm{N}, 140.1^{\circ} \mathrm{E}\right)$. The station history information reveals that the station was moved to a new site approximately $2 \mathrm{~km}$ southeast of its earlier position. The straight 1 ines are the mean station differences for the two periods, 1901-1938, 1940-1980. Correction details are given in Appendix A.

Fig. 4: Station temperature difference time series: Rome $\left(41.7^{\circ} \mathrm{N} 12.5^{\circ} \mathrm{E}\right)$ minus Naples $\left(40.9^{\circ} \mathrm{N}, 14.3^{\circ} \mathrm{E}\right), 1871-$ 1980. The two parts of Naples record $1871-1925$ and 1961-1980 were records from different sites. The 8 traight 1 ines are the mean 8 tation differences for the two periods, 1901-1925, 1961-1980. Correction details are given in Appendix A.

Fig. 5: Locations of the 1584 stations used in the gridding technique. 
The work described in this Technical keport was funded by the U.S. Department of Energy under Contracts: DB-AC02-79 BV10098 and DB-ACO2$81 \mathrm{EV} 10739$. 
Fig. 1: Station temperature difference time series: Gordon Cast le $\left(57.6^{\circ} \mathrm{N}, 3.1^{\circ} \mathrm{W}\right)$ minus Aberdeen $\left(57.2^{\circ} \mathrm{N}, 2.1^{\circ} \mathrm{W}\right)$, 1901-1974. The analysis identifies Aberdeen as the errant station as a similar jump at 1948 also occurs when the station is compared with Glasgow $\left(55.9^{\circ} \mathrm{N}\right.$, $\left.4.3^{\circ} \mathrm{W}\right)$ and Edinburgh $\left(55.9^{\circ} \mathrm{N}, 3.4^{\circ} \mathrm{W}\right)$. The station history information reveals that the site was moved to Dyce airport in 1948. The straight 1 ines are the mean station differences for the two periods, 1901-1947, 1948-1974. Correction details are given in Appendix A.

8ig. 2: Station temperature difference time series:

$\nabla$ ishakhapataam $\left(17.7^{\circ} \mathrm{N}, 83.3^{\circ} \mathrm{E}\right)$ minus Begampet $\left(17.5^{\circ} \mathrm{N}\right.$, $\left.78.5^{\circ} \mathrm{E}\right), 1901-1980$. The analysis identifies Begampet as the errant station ac a similar jump at 1951 also occurs when the station is compared with Akola $\left(20.7^{\circ} \mathrm{N}\right.$, $\left.77.0^{\circ} \mathrm{E}\right)$ and Jagdal pur $\left(19.1^{\circ} \mathrm{N}, 82.0^{\circ} \mathrm{E}\right)$. The station history information reveals that the station was moved to the airport in 1951. The straight 1 ines are the mean tation differences for the two periods, 19011950, 1951-1980. Correction details are given in Appendix A.

Fig. 3: Station temperature difference time series: Nemuro $\left(44.3^{\circ} \mathrm{N}, 145.6^{\circ} \mathrm{E}\right)$ minus Sapporo $\left(43.1^{\circ} \mathrm{N}, 141.4^{\circ} \mathrm{E}\right)$, 1901-1980. The analysis identifies Sapporo as the errant station as a similar jump during 1939 also occurs when the station is compared with Abashiri $\left(44.0^{\circ} \mathrm{N}, 144.3^{\circ} \mathrm{E}\right)$ and Akita $\left(39.7^{\circ} \mathrm{N}, 140.1^{\circ} \mathrm{E}\right)$. The station history information reveals that the station was moved to a new site approximately 2lom southeast of its earlier position. The straight 1 ines are the mean -tation differences for the two periods, 1901-1938, 1940-1980. Correction details are given in Appendix A.

Fig. 4: Station temperature difference time series: Rome $\left(41.7^{\circ} \mathrm{N} 12.5^{\circ} \mathrm{E}\right)$ minus Naples $\left(40.9^{\circ} \mathrm{N}, 14.3^{\circ} \mathrm{E}\right), 1871-$ 1980. The two parts of Naples record 1871-1925 and 1961-1980 were records from different sites. The straight 1 ines are the mean station differences for the two periods, 1901-1925, 1961-1980. Correction details are given in Appendix A.

Fig. 5: Locations of the 1584 stations used in the gridding technique. 


\section{ABSTRACT}

A compilation of 2666 station records of monthly surface air temperature has been assembled fnr the Northern Bemisphere. In order to use these data to form a gridded data set for the Northern Hemisphere we have assessed, where possible, the homogeneity of each of these records. The results of this assessment are presented and stations are classed as immediately usable, corrected or uncorrectable. Full details of how this has been achieved for each station are presented in tabular form.

of the 2666 station records, 1584 were used to produce the gridded temperature data set. Temperature anomalies were calculated with respect to the appropriate monthly mean for the reference period 1951-70 using the homogenized data. Anomalies at each point of a $5^{\circ}$ latitude by $10^{\circ}$ longitude grid were interpolated from the station data for each month for the period 1851 to 1984 . 
Abstract

i

Table of Contente

ii

List of Figures

iii

Acknowledgements

iv

Introduction

Station Bomogeneity Assesoment

3

Gridding the Station Surface Air Temperature Data

Results

Conclusions

18

References

Appendix A: Station History Information and Bomogeneity Assessment Details

Appendix B: Stations used in the Gridding Algoritbm 


\section{INTRODOCTION}

Most studies of "global" or "hemispheric" temperature fluctuations have relied on the compilatione of station data in World Weather Becords (WWR), publisbed by the Smithsonian Institution (1927, 1934, 1947) and the Onited States Weather Bureau (1959-82). These data have formed the basis of many attempts to grid surface air temperature onto a regular spatial network and/or to form large area average surface air temperature series. Comprehensive reviews of these studies, from the early analyses of Willett (1950) and Mitchell (1961, 1963) to the recent work of Jones et al. (1982), are given by Chen (1982) and E1lsaesser et.al. (1985).

Bradley et al. (1985) have added considerably to the WWR data using material available in published and manucript form in meteorological archives, particularly those of the O.R. Meteorological office. The additions made to the air temperature data base for the Northern Bemisphere prior to 1900 al low much more representarive values of hemispheric mean air temperature to be calculated back to 1851. Full details of these improvements in station coverage are given in Bradley et al. (1985). The most important improvements in coverage occur over parts of the Soviet Union and northern Europe, particularly before 1881. The lack of readily available data for the Soviet Union has constrained all previous studies of hemispheric mean temperatures to start about 1880 or later. Further improvements in coverage have also been made for the twentieth century, particularly over nortiern Africa before 1940 and over the Peoples Republic of China (PRC). In the latter region, some 30 station records have been assembled with data back to the $1920 \mathrm{~s}$ with another 20 station records covering northern and western China for 1951-84. No other source of data for the 1951-60 decade is known outside the PRC.

In this technical note, we document the use of this extended data bank to construct a reliable gridded surface air temperature data set for the Northern Bemisphere for the years 1851-1984. In order to achieve this, it has been necessary to examine each individual station temperature series for possible inhomogeneities (errors of non-climatic origin). The full results of this examination are described here and the derivation of the gridded data set is presented. Details of each of the 2666 stations in the data bank are documented in Appendices using the formats described in Goodess et al. (1985) 
$-2-$

and Bradley et al. (1985). 
STATION BOMOGENEITY ASSESSMENT

\section{Bessons for Station Inhomogeneities}

The four main factors affecting station homogeneity are (Mitchel1, 1953;

see also the summary by Bradley and Jones, 1985):

(i) changes in instrumentation, exposure and measurement techniques;

(ii) changes in station location (altitude or position);

(iii) changes in observation times and the methods used to calculate monthly means; and

(iv) changes in the enviroment around the station, particularly with respect to urban growth.

The effects of these four major factors have been discused at length in Bradley et al. (1985), Bradley and Jones (1985) and Jones et al. (1985).

\section{Effects of Station Inhomogeneitieg}

Change in station location could be an important factor in determining station homogeneity. As will be show later in this report, at least 807 of al 1 inhomogeneities in station records can be traced back in the station biatory information to changes in station location. Hovever, merely searching through the station histories for indications of site changes, of which there may be a number, gives a pessimistic view of the potential bomogeneity of a particular station's data. Comparisons with neighbouring stations show that, in the majority of cases, documented site changes have an insignificant effect on the homogeneity of the data.

The station history information given by Bradley et al. (1985) shows that there have also been changes in observation times and/or the way monthly means are calculated at almost every station. Correction of all observations to a comon standard is, however, extremely difficult, mosty because sufficient hourly data are not available for the calculation of correction factors. Nevertheless, in many publications (including WWB) both documented and undocumented corrections have been applied to adjust values to a 'true' or 24 bour mean. Such procedures were widely used up until the $1940 \mathrm{~s}$. They are discussed in more detail with reference to the United States data in WWR by Bradley et al. ( 1985$)$.

Changes in the enviroment around the station, especially the growth of

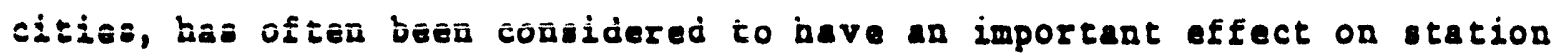


homogeneity (Mitchel1, 1953; Dronia, 1967; Cayan and Douglas, 1984; Ruk la et a 1., 1985). Many more references are cited by Landsbers (1981). From the mass of literature on the subject it would appear that the effect is widespread. However, al though effects have been demonstrated in both small and large cities in Europe and Nortb America in particular, relationships between city size and the magnitude of the urbanization effect are not straightforward, being highly dependent on local climate and the exact location of the station in the city. Relationships found in North America cannot be extrapolated to other parts of the Northern Hemisphere, particularly to cities on the Asian and African continents.

\section{Assessment of Homogeneity}

There are 2666 stations in the temperature station data set for the Northern Hemisphere. To check all these stations for homogeneity represents an awesome task. There are two possible approaches to this problem: all records could be exhaustively checked using the available station history information as a guide to potential errors; or, inconsistencies between neighbouring stations can be used as a guide to the major inhomogeneities in the data set. For the whole data set, the former approach could only be undertaken by an organization such as the World Meteorological Organization through correspondence with all the member countries of WMO, simply because station history information is seldom published. We have chosen to use the latter method. We are only concerned with errors that are large enough to affect studies of large scale climatic change. For such a purpose, the detailed checking of individual records is not considered necessary.

To test homogeneity, we have compared records from neighbouring stations, searching for discontinuities and trends in station differences. The metbod assumes that, within small areas (the size depends on data availability and latitude and varies from $10^{3}$ to $10^{5} \mathrm{~km}^{2}$ ), the effects of changes in climate will be similar. Records from four to five neighbouring sites were compared on climatological time scales of the oratr of 20 years using the following procedure:

(1) For each station, the entire record was 1 isted as anomalies from the appropriate monthly mean based on the entire station record length. Outliers were detected by inspection and either verified, corrected, or 
replaced with a missing observation code. The use of automatic statistical tests to identify outliers is not always effective as, in data sets of 1 ess than 30 years, the outliers can easily distort estimates of the monthly standard deviation. Outliers identified were commonly the result of the use of the wrong units, punching errors of exact $1 \mathrm{~g} 10^{\circ} \mathrm{C}$, or by the omission of a minus sign (this occurred in the Jenne (1975) version of WWR at almost every station in Greenland during the Novembers of the years 1951-60). Outlier inspections were carried out for every station, including those which were geographically isolated and could not subsequently be compared with neighbouring stations.

(2) Por all groups of neighbouring stations, the record of annual temperature anomalies, after removal of outliers, was compared with all other records in the group by plotting the differences between the annual values as a time series, a method proposed by Conrad and Pollak (1962). If no inhomogeneity exists, the series of differences should be a sationary time series. Abrupt changes in these difference time ceries point to an inhomogeneity in one of the series. By comparing all possible station pairs, the erroneous stations generally become apparent. In some instances, it was necessary to compare stations with additional stations that were not initially selected in the comparison 8roup. For stations with long records, data were compared with data from the nearest station with an appropriately long record. When inhomogeneities were identified, confirmation was sought in the station history information. For stations with recordo starting in the nineteenth century, the station history information given in Bradley et al. (1985) was used. For other stations, we used the compilation given in Appendix A.

(3) When a particular record showed a sudden jump or discontinuity, corrections were derived on a monthly basis and the errant data were adjusted. Station records which indicated numerous (generally more than two) discontinuities were not corrected, but were flagged as uncorrectable and unusable in subsequent anslyses. 
(4) The time series of station differences often showed trends or gradual changes. It was often possible to identify such warming or cooling trends with a particular stacion, but it was not possible to adequately correct such records. These were, therefore, also flagsed as uncorrectable and unusable. Stations with izhomogeneous warming trands which were likely to be caused by urbanization were claseed in a separate "affected by urbanization" category.

Some examples of the approach are shown in Figures 1 to 4 Bach is discussed in the appropriate figure caption. The examples are:

Pigure 1, Gordon Castle (WMO No. 030680) minus Aberdeen (030910) (Onited Ringdom)

Bigure 2, Vishakhapatnam (431280) minus Begampet (431280) (India)

Figure 3, Nemuro (474200) minus Sapporo ( 474120 ) (Japan)

Bigure 4, Bome (162420) minus Naples (162890) (Italy).

Purther examples are given in Jones et al. (1985).

For each of the 2666 stations, a few (general ig two) of the neighbouring starions used in the homogeneity comparisons are listed in Appendix $A$ together with the years over which comparisons were made. In general, more intercomparisons were made than are 1 isted. Only the relevant stations which supplied the necessary evidence of homogeneity or inhomogeneity have been included.

\section{Correcting Errant Station Records}

When an abrupt change in a station's record was identified and sufficient overlap with neighbouring correct stations available, correction factors were calculated on a monthly basin to produce a homogeneous series for that site. In the above examples, the records for Aberdeen, Begampet, Sapporo and Naples were adjusted or "homogenized". Correction factors were obtained by differencing the mean temperature before and after the discontinuity and comparing this with a similar difference at correct neighbouring station(s). Corrections were always made to adjust an earlier part of the errant station record to the most recent period. Correction factors were derived on a monthly basis despite the errant stations having 


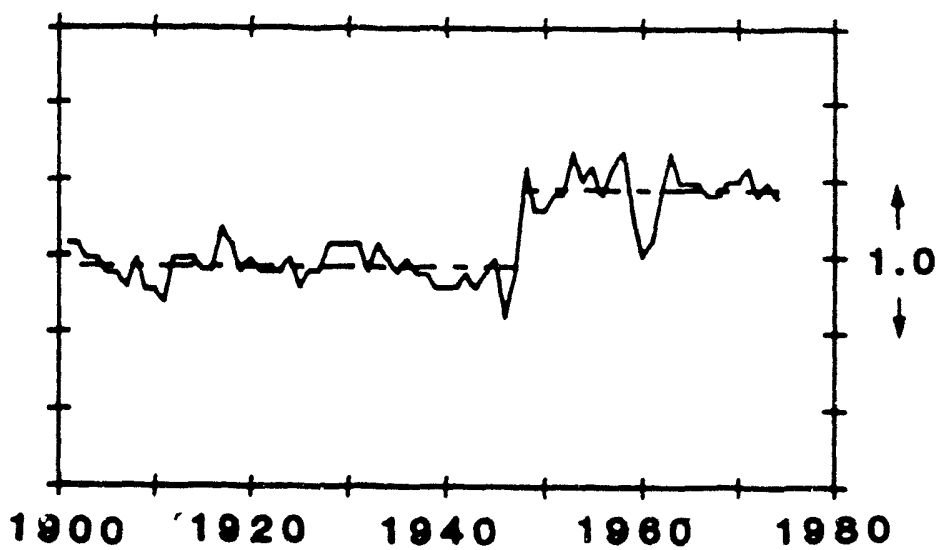

Fig. 1: Station temperature difference time series: Gordon Castle $\left(57.6^{\circ} \mathrm{N}\right.$, $\left.3.1^{\circ} \mathrm{W}\right)$ minus $A b e r d e e n\left(57.2^{\circ} \mathrm{N}, 2.1^{\circ} \mathrm{W}\right), 1901-1974$. The anslysis identifies Aberdeen as the errant station as a similar jump at 1948 also occurs when the station is compared with 61 asgow $\left(55.9^{\circ} \mathrm{k}\right.$, $4.3^{\circ} \mathrm{W}$ ) and Edinburgh $\left(55.9^{\circ} \mathrm{N}, 3.4^{\circ} \mathrm{W}\right)$. The station history information reveals that the site was moved to Dyce airport in 1948. The straight 1 ines are the mean station differences for the two periods, 1901-1947, 1948-1974. Correction details are given in Appendix A.

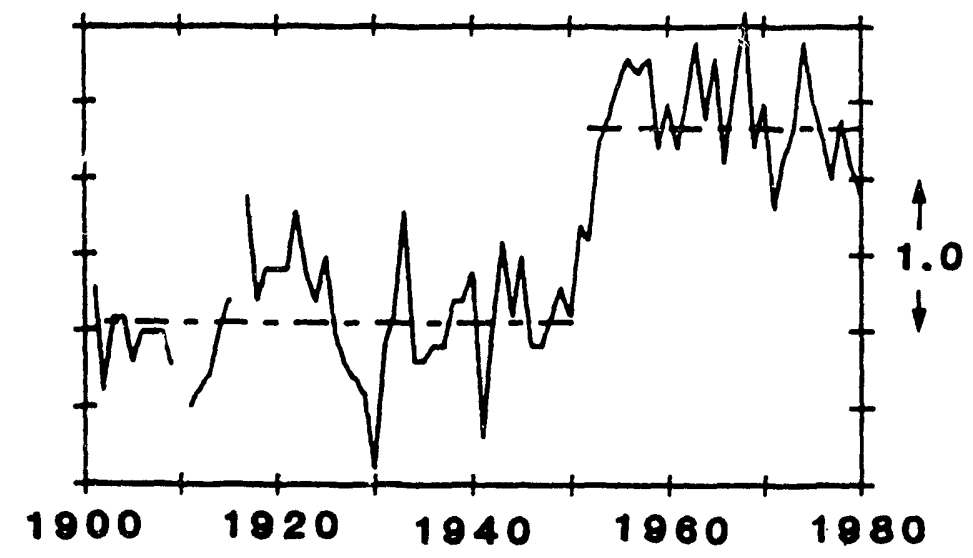

Fig. 2: Station temperature difference time series: $\nabla$ ishakhapatnam $\left(17.7^{\circ} \mathrm{N}\right.$, $83.3^{\circ} \mathrm{E}$ ) minus Begampet $\left(17.5^{\circ} \mathrm{N}, 78.5^{\circ} \mathrm{E}\right), 1901-1980$. The analysis identifies Begampet as the errant station as a similar jump at 1951 also occurs when the station is compared with Akola $\left(20.7^{\circ} \mathrm{N}\right.$, $77.0^{\circ} \mathrm{E}$ ) and Jagdal pur $\left(19.1^{\circ} \mathrm{N}, 82.0^{\circ} \mathrm{E}\right)$. The station history information raveals that the station wes moved to the airport in 1951. The straight 1 ines are the mean station differences for the

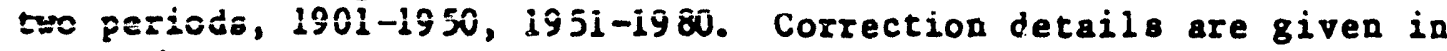
Appendix A. 


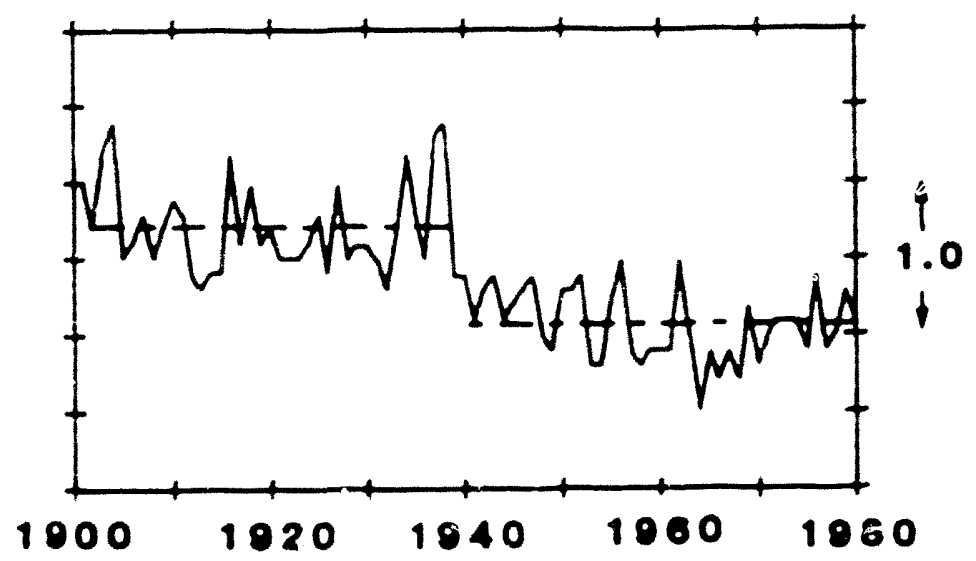

- 7ig. 3: Station temperature difference tine eeries: Henuro ( $44.39 \mathrm{M}$, $\left.145.6^{\circ} \mathrm{E}\right)$ minus Sapporo $\left(43.1^{\circ} \mathrm{K}, 141.4^{\circ} \mathrm{E}\right), 1901-1980$. The analysis identifies Sapporo as the errant station as a similar jump during 1939 also occurs when the tation is compared with Abashiri $\left(44.0^{\circ} \mathrm{M}, 1443^{\circ} \mathrm{E}\right)$ and Akita $\left(39.7^{\circ} \mathrm{N}, 140.1^{\circ} \mathrm{g}\right)$. The station hietory information reveal. that the station was moved to a new site approximately $2 \mathrm{com}$ soutbest of its earlier position. The straight lines are the mean station differences for the two periods, 19011938, 1940-1980. Correction details are given in Appendix A.

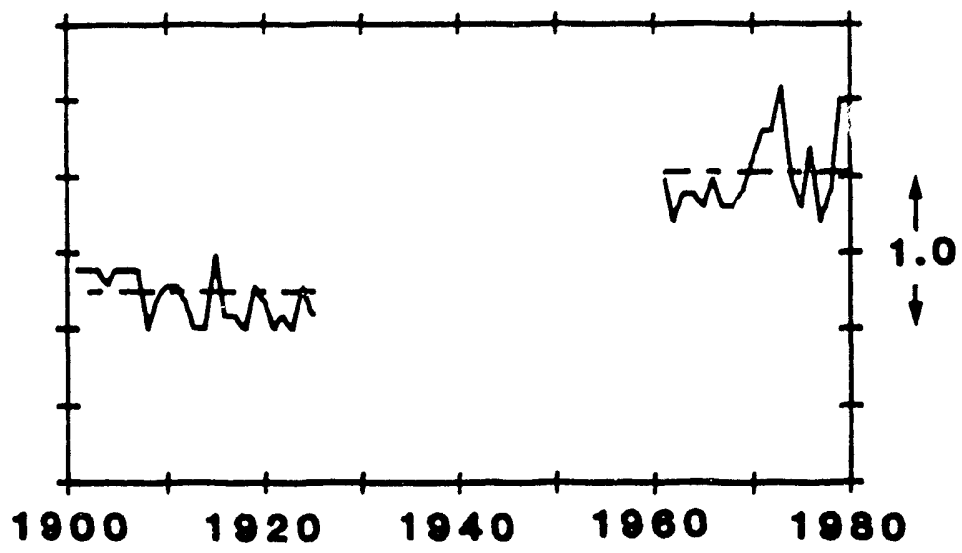

Bis. 4: Station temperature difference time series: Rome $\left(41.7^{\circ} \mathrm{N} 12.5^{\circ} \mathrm{E}\right)$ minus Naples $\left(40.9 \%, 14.3^{\circ} \mathrm{E}\right), 1871-1980$. The two parts of Naples record 1871-1925 and 1961-1980 were records from different sites. The straight 1 ines are the mean station differences for the two periods, 1901-1925, 1961-1980. Correction details are given in Appendix $\Delta$ 
been identified on an annal base. The correction factor in a particular montb is given by

$$
C=x_{j}-x_{1}-1 \sum_{1=1}^{N}\left(x_{i 0}-z_{i 1}\right)
$$

where subscripts 0 and 1 refer to the time periods before and after the discontisuity, $X$ is the monthly mean temperature at the errant site and $Y_{i}$ is the montbly mean temperature at the ith (of N) neighbouring sites with a homogeneous record.

In the Sapporo example in Figure 3, N=3, 0-1900-1938, 1-1940-1970. The monthly correction factors for Sapporo (and all other corrected stations) are given in Appendix A. The corrections vere applied to all months prior to July 1939 as it was know that the station moved to a new site at the beginaing of July 1939. If the exact month of the station move vere known, it was used. This detail was generally only known for the Onited Statee, Canada and Japan. In ether cases, such as the other three examplea il lustrated above, the corrections vere applied through to December of the year in which the discontinuity was identified.

Detail for each corrected etation are given in Appendix $\Delta$ in the relevant station history information. For each atation where corrections wer made, the twelve monthly correction factors are listed, together with the livmogeneous or part-bomogeneous stations used in their derivation and the periods over which they were calculated and applied.

\section{Results of the Eciation Bomogeneity Assessment}

Full details of the homogenization analyees are listed in Appendix A. From the many-station intercomparisons undertaken, each station has been assigned a quality control code. Details of the code are given at the beginning of Appendix A. For esch station, the stations used to define this code and the stations used to correct errant stations are listed in Appendix A. Approximately $24 \%$ of the 2666 stations could not be tested for homogeneity. Some station records were too short for comparison with neighbouring stations, whilst other stations were located in regions or operated in t__e periods for which neighbouring station data were not available. The lack of availability of comparison data is evident at many island stations, particularly in the Pacific. Such stations were, however, 
checked carefully for extreme out 1 iers.

In order to sumerise the information contained in Appendix A, the numbers of etations in each homogenization categorg have been totalled for seven regions of the Northern Bemisphere. The regions were selected on the basis of their World Meteorological Organization station numbers, and therefore correspond to large geographical areas. The station counts are listed in Table 1. $65.5 \%$ of all the stations in the data set were classed in either the correct or corrected category. Only $10.5 \%$ of stations were clased as uncorrectable and, of these, less than 27 were found to be affected by urban varming.

The mall number of stations identified as affected by urbanization may be due in part to the method of analyois. It is possible that the urbanization effect might be seasonalig specific and not easily identified by an analyais of annual data. If 80 , then errors could occur in our monthly data; but any errors in the annual data must, of course, be minimal. Orbanization effects could also escape detection by our methods if all the -tations in a large area vere aifected. In such cases, we would only fail to identify an urbanization effect if all otations were affected almost equally. This seeme unlikely. Meverthelese, some of the data which we have judged to be correct may still have opurious trende due to urbaniration, and more detailed analyses are certainly warranted in regions like eastern OSA and western Europe, especially if reginnel studies of the hemispheric data set are contemplated.

Further discussion of the results of the howogeneity assessment can be found in Jones et a1. (1985). 
TABLE 1. Numbers of stations in each homogenization category for different regions of the Northern Hemisphere.

\begin{tabular}{|c|c|c|c|c|c|c|}
\hline & $\mathbf{A}$ & B & c & D & $\mathbf{E}$ & $\mathbf{F}$ \\
\hline $\begin{array}{l}\text { Europe } \\
\text { (excl. OSSR) }\end{array}$ & 290 & 12 & 170 & 58 & 7 & 537 \\
\hline OSSR & 188 & 8 & 0 & 7 & 0 & 203 \\
\hline $\begin{array}{l}\text { Asis } \\
(\operatorname{excl} \text {. PRC) }\end{array}$ & 149 & 30 & 91 & 7 & 0 & 277 \\
\hline PRC & 42 & 0 & 70 & 10 & 0 & 122 \\
\hline $\begin{array}{l}\text { Africa } \\
\left(\mathrm{N} \text { of } 2.5^{\circ} \mathrm{S}\right)\end{array}$ & 160 & 39 & 8.44 & 16 & 0 & 359 \\
\hline $\begin{array}{l}\text { Americas } \\
\left(\mathrm{N} \text { of } 2.5^{\circ} \mathrm{S}\right)\end{array}$ & 588 & 160 & 136 & 131 & 31 & 1046 \\
\hline $\begin{array}{l}\text { Indonesia, } \\
\text { Philippines, } \\
\text { Pacific Is. }\end{array}$ & 78 & 0 & 34 & 10 & 0 & 122 \\
\hline All 7 regions & 1495 & 249 & 645 & 239 & 38 & 2666 \\
\hline \% of 2666 & 56 & 9.5 & 24 & 9 & 1.5 & \\
\hline
\end{tabular}

A: Stations correct after a specified year. (The specified year is not always the first year of record; in such cases, the earlier untested parts of the record were not used in any subsequent analyses. The length of the discarded section of records can be found by comparing the first year of record with the first reliable year of record, both of which are 1 isted in Appendix A.)

B: Stations homogenized.

C: Stations not examined (record too short or no adjacent stations for comparison).

D: Stations incorrect (e.g. numerous jumps and/or trends including nonclimatic cooling trends).

E: Stations with non-climatic waming trends.

F: Station totals. 
GRIDDING THE STATION SORPACE AIR TEMPERATORE DATA

Baving assessed, where possible, the homogeneity of each station record in our Northern Hemisphere dats bank, we have over 2000 potentially usable stations. The stations are irregularly distributed ovcr the land masses of the Northern Hemisphere with the majority of stations located ir Europe and over the United States. Station density is considerably less in the less densely populated areas, particularly over Saharan Africa and partz of Asia. In order to reduce the effects of this irregular distribution, it is necessary to interpolate the data onto a regular grid.

Because of differing station altitudes, differing methods of calculating monthly means and differing observation times, it is not appropriate to interpolate raw station data. Almost all previous analyses overcome this problem by using anomalies from a selected reference period. (Of course, reference period means and anomalies must be calculated using the homogenized data) A decision must be made concerning bow many years of data are necessary to calculate a suitable reference period mean. Fcr example, Yamamoto (1981) selected a near-bundred year refezence period but, because so few stations have such long records, he was forced to omit many stations. The best method is to calculate anomalies from a period of good data coverage; for example, Jones et al. (1982) used the period 1946-60.

The period of best data coverage in the data set described here is $1951-$ 70. For stations to be used in the gridding analysis we require at least 15 years of the data between 1951-70. Even using this reference period omits many valuable long records that ceased recording in 1950 or 1960 . In order to use some of these data, reference period means were estimated using data from nearby stations. The accuracy of these reference period means is probably better than $\pm 0.2^{\circ} \mathrm{C}$.

Inevitably, some station data cannot be used because reference period means cannot be calculated. This reduces the number of usable stations to 1584. These stations are 1 isted in Appendix $B$ and their locations are shown in Figure 5. Station counts for the seven regions (used in Table 1) are 1 isted in Table 2.

Most of the previous methods of data interpolation have been discussed in Jones et al. (1982, 1985). Further information may also be found in Ellsaesser et al. (1985) and Wigley et al. (1985). Previous analyses can be 
TABLE 2. Stations with sufficient data in the reference period mean, 1951-70.

\begin{tabular}{|c|c|c|c|c|}
\hline & $\mathbf{A}$ & B & c & D \\
\hline $\begin{array}{l}\text { Europe } \\
\text { (exc1. USSR) }\end{array}$ & 227 & 12 & 44 & 283 \\
\hline OSSR & 134 & 8 & 0 & 142 \\
\hline $\begin{array}{l}\text { Asia } \\
\text { (excl. PRC) }\end{array}$ & 118 & 26 & 19 & 163 \\
\hline PRC & 42 & 0 & 0 & 42 \\
\hline $\begin{array}{l}\text { Africa } \\
\left(\mathrm{N} . \text { of } 2.5^{\circ} \mathrm{S}\right)\end{array}$ & 141 & 37 & 8 & 186 \\
\hline $\begin{array}{l}\text { Americas } \\
\left(N \text { of } 2.5^{\circ} \mathrm{S}\right)\end{array}$ & 534 & 149 & 7 & 690 \\
\hline $\begin{array}{l}\text { Indonesia, } \\
\text { Philippines, } \\
\text { Pacific Is. }\end{array}$ & 78 & 0 & 0 & 78 \\
\hline Al1 7 regiona & 1274 & 232 & 78 & 1584 \\
\hline of 1584 & 80.4 & 14.7 & 4.9 & \\
\hline
\end{tabular}
A: Stations correct after a specified year.
B : Stations homogenized.
C: Stations not checked.
D: Totas. 


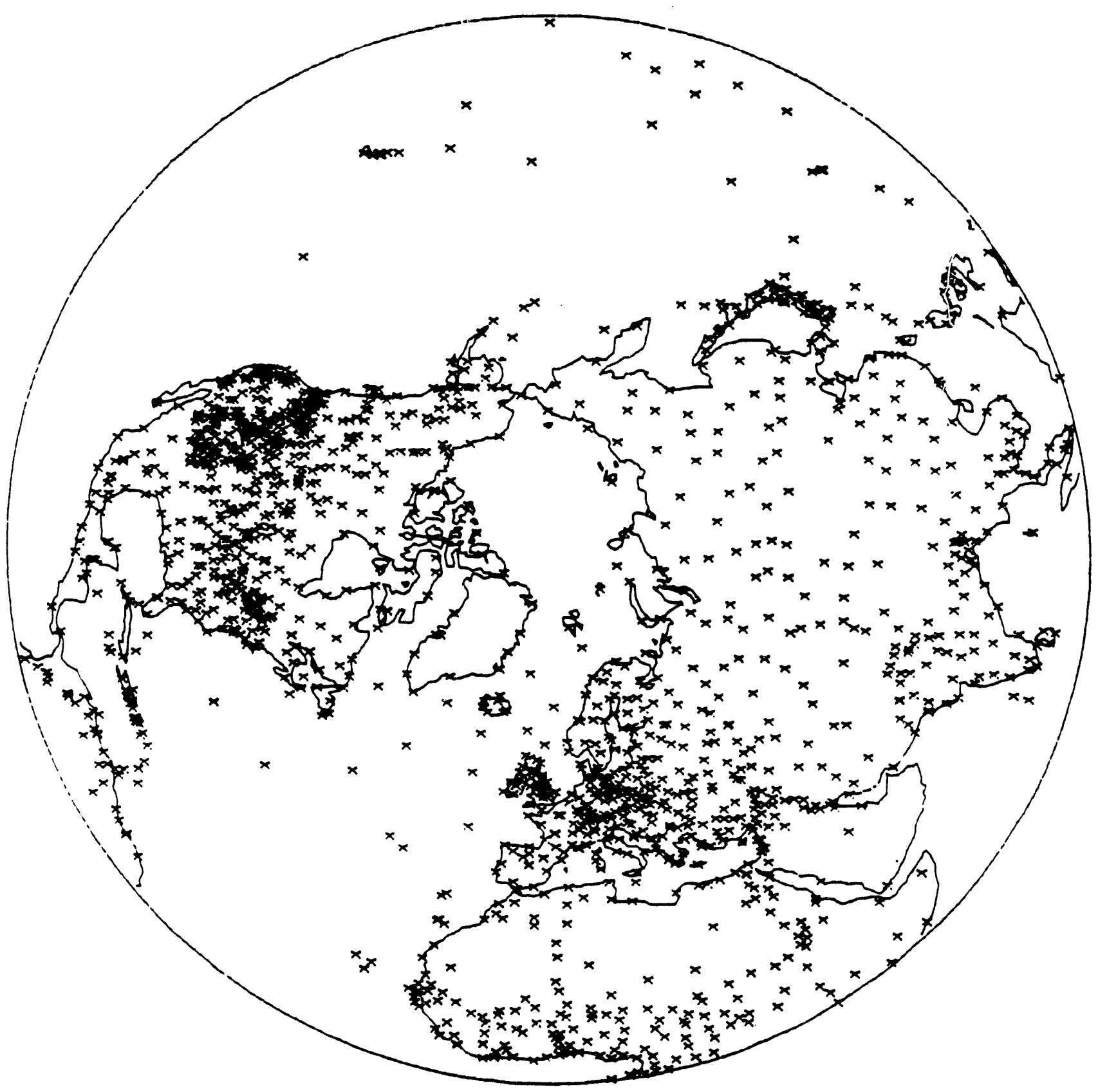

Fig. 5: Locations of the 1584 stations used in the gridding technique. 
classed into two main categories, subjective or objective techniques.

Subjective techniques have been used almost entirely by Soviet workers, in particular by Borzenkova et al. (1976) and vinnikov et al. (1980). In these studies, station temperature data were hand plotted onto hemispheric charts for each month over the period of analyses, in this case 1891-1978. The maps were contoured subjectively and grid point values extracted onto a $5^{\circ}$ latitude by $10^{\circ}$ longitude grid. Recent workers have essentially built on earlier analysis of a chart series available in the Soviet Union; see, for example, Sharov (1960-67), Budyko (1969) and Vinaikov (1977). Further details of the techniques are given by $\nabla$ innikov (1977), Jones et al. (1982) and Robock (1982).

Objective methods bave employed numerical techniques to extrapolate or interpolate grid point temperature from the irregular distribution of station data. Examples are the works of Yamamoto and co-workers (e.g. Yamamoto and Boshiai, 1980; Yamamoto 1981), Hansen et al. (1981), and Jones et al. (1982).

All of the published methods (both subjective and objective) have deficiencies. The wethod of Vinnikov et al. (1980), involving nearly 1200 maps, is both time-ccinsuming and subjective. The results could not practically be repeated even if the precise data sources were known. Yamamoto's (1981) results are not strictly comparable to the other analyses discussed here because a zero anomaly value was assumed for all grid points where interpolation could not be made. This assumption reduces the variance of their Northern Hemisphere average series by about one half compared to the other analyses (Kellogs and Bojkov, 1982). Hansen et al's (1981) method is difficult to assess as no complete description of the method has been published.

The method of Jones et al. (1982) is described in detail, but there are also problems with their method. They used the six siations nearest to a grid point in order to calculate the grid point value. However, because the station density increases through time, the six stations nearest to a grid point change. The stations used during the period of best data coverage in the 1950 s were, on average, nearer the grid point than at other times. In some regions, particularly Arctic regions, stations were used to interpolate grid point values at more than one grid point. This could raise the degree of spatial autocorrelation above the real value. In data-dense areas, particularly oyer the Uaited Statés and central Europe, much of the station 
data was not used at all.

In order to eliminate some of these problems, a new method of gridding has been employed. The grid spacing used in the present analysis is $5^{\circ}$ latitude by $10^{\circ}$ longitude involving 649 grid points over the Northern Hemisphere. At each grid point, anomaly values for all stations that have this as their nearest grid point are averaged using inverse distance weighting :

$$
T_{8}=\sum_{8=1}^{n} \alpha_{8} T_{8} / \sum_{8=1}^{n} \alpha_{8}
$$

where

$$
\begin{aligned}
& T_{g} \text { is the interpolated grid point temperature anomaly } \\
& T_{8}(8-1, n) \text { is the station temperature anomaly } \\
& \alpha_{8}(g=1, n) \text { is the inverse of the great circle distance between } \\
& \text { the station and grid point. (as was constrained to } 1 / \alpha s<0.02 \\
& \text { nautical miles, since some stations are located very close to } g r i d \\
& \text { points.) }
\end{aligned}
$$

This method has two advantages: data for a particular station are used for interpolation at only one grid point; and all the available atation data are used. For some grid points, when only one station record is available, the station anomaly value becomes the grid point value. In data dense areas of Nortb America and Europe, up to 40 stations may be averaged to calculate a single grid point value. The method has a slight disadvantage in that $\mathrm{T}_{8}$ values based on large $N$ may have lower inter-annual variance compared with those based or smaller $N$. However, spatial correlation effects and the inverse distance weighting factors tend to minimise this problem. 


\section{RESOLIS}

\section{The Gridded Date 8et}

The new gridding method has been used to interpo: : te from station anomalies, with respect to the 1951-70 reference period, to the regular grid, for each month from January 1851 to December 1984. Grid point anomalies have been calculated to an accuracy of $0.01^{\circ} \mathrm{C}$. Such an accuracy, however, does not necessarily reflect the accuracy of the original data and has only been used for computer torage purposes. Individual monthly grid point anomalies are probably accurate to $\pm 0.2^{\circ} \mathrm{C}$.

The number of stations $(a) a v a i l a b l e$ at each grid point varies through time and from grid point to grid point. In some cases, 2 is one, and the station anomaly value is used as the grid point value. In order to assess the reliability of the interpolated grid point temperature anomaly, two quantities other than the temperature anomaly itself have been stored in our gridded data file. These two quantities are the number of stations used ( $a$ ) and the quantity $B=1 / \mathrm{a} \sum_{-1}^{\mathrm{a} a}$, for every gridpoint for each month for esch year. $B$ is a measure of how close the atations are to the relevant grid point; $1 /$ b being a mean distance in nautical mijes.

The data set is availsble on a computer magnetic tape. 
CORCLUSIONS

\section{The Hemispheric Average Series}

The method of calculation of the area average surface air temperature series is relatively straight forward; esch grid point is averaged after being weighted by the area of the hemisphere it represents. Weighting is achieved using the cosine of the latitude of the grid point.

$$
\text { NHT }=\sum_{g=1}^{M} T_{g} \cos \left(\phi_{g}\right) / \sum_{g=1}^{M} \cos \left(\phi_{g}\right)
$$

where $M$ is the number of grid points with temperature snomalies $\left(T_{g}\right)$ in a particular month and $\phi_{g}$ is the latitude of the grid point.

The number of grid points for which a valu can be calculated increases between 1851 and 1950. The estimates of hemispheric mean temperature are, herefore, more reliable in recent decades (especially since 1930) than during the nineteenth century. The spatial representativeness of the series over the 1851 to 1930 period has been assessed by Jones et al. (1985). The hemispheric temperature series appears to be reliable on a year to year basis after about 1875 despite the marked changes in spatial coverage. Prior to 1875, yearly temperature estimates are less reliable. Al though the general trends of temperature over the 1851-1874 period are considered reliable by Jones et al. (1985), differences between land and marine data exist which stil require explanacion.

The nineteenth-century data shows a slight cooling between the $1870 \mathrm{~s}$ and the late 18808. The mean temperature prevailing between 1851 and the 1 ate 18708 was similar to that of the 1900 s and 19108. Around 1920, a rapid warming took place and the period $1921-1984$ was about $0.4^{\circ} \mathrm{C}$ warmer than the earlier period 1851-1920. Most of the warming between 1921 and 1984 took place over the periods 1921 to 1940 and 1965 to 1984. A cooling of about $0.28^{\circ} \mathrm{C}$ is evident between 1940 and 1965. The magnitude of this cooling in the present analysis is considerably smaller than in the earlier analyses of Vinnikov et a1. (1980), Hansen et al. (1981) and Jones et al. (1982), amounting to about $0.38^{\circ} \mathrm{O}$ in those studies.

There is no doubt that further errors could be eliminated from the data set, but not without considerable effort. For studies of hemispheric-scale temperature variations the consistency between various independent data sets (upper air data, marine data and gurface atation data) attesto to the 
reliability of the data set produced here (see Wigley et al., 1985). Further discussion of the data set is given in Jones et al. (1985). 
Borzenkova, I.I., R.Ya. Vinnikov, L.P. Spirina and D.J. Stekhnovokii, 1976: Change in air temperature of the Nortbern Hemisphere for the period 1681-1975. Meteorologiya i Gidrologiys, 1976. No. 7, 27-35 (in Russian).

Bradley, R.S., and P.D. Jones, 1985: Data bases for detecting $\mathrm{CO}_{2}$-induced climatic change. (In) D.S. Depertment of Energy State of the Art Report on the Detection of Climatic Changes D.S. Dept. of Energy Carbon Dioxide Research Division, Washington. D.C. (to be published).

Bradley, R.S., P.M. Relly, P.D. Jones, B.F. Diaz and C. Goodes 8, 1985: A climatic data bank for the Northern Bemisphere land areas, 1851-1980. DoE Technical Report No, TRO17, D.S. Dept. of Energy Carbon Dioxide Research Division, Washington. D.C., 335 Pp.

Cayan, D.R, and A.V. Doug 1 as, 1984: Orban influences on surface temperatures in the Snuthwestern Oaited States during recent decades. I. Climate and Applied Meteorology, 23, 1520-1530.

Conrad, V., and Pollak, L.D. 1962: Methods in Climatology. Harvard Oniversity Press, Cambridge, Kass., 459 Pp.

Droni3, H, 1967: Der Styddteeinfluss auf den weltweiten Temperaturtrend (On Orban influencen on worldwide temperature trends.) Meteor. $A b b$. Ber 1 in 74(4), 68 Pp. (In German.)

B1 lsaesser, Z.W., M.C. MacCracken and J.J. Walton, 1985: Global climatic trends as revealed by the recorded data. Reviews of Geophrsics and Space Physics (in press).

Goodess, C.M., M. Wigzel 1 and P.K. Kel1y, 1985: The design of a climate data bank and information retrival syatem. Proc. Tenth Northern Libraries Collogur. Centre for Cold Oceans Resources Engineering (c-Core) Special Report Memorial Oniversity of Newfoundland, St John's (in prese).

Bansen, J.E., D. Johnson, A. Lacis, S. Lebedeff, P. Lee, D. Find and G. Russe 11, 1981 : C 1 imatic impact of. increasing atmospheric carbon dioxide. Science, 213, $957-966$.

Jenne, R. 1975: Data sets for meteorological research. NCAR-TN/JA-111. National Center for Atwospheric Research, Boulder, 194 pp.

Jones, P.D., T.M.L. Wigley and P.M. Rel1y, 1982: Variations in surface air temperatures: Part 1. Northern Hemisphere, 1881-1980. Monthly Weather Review, $110,59-72$.

Jones, P.D., S.C.B. Raper, R.S. Bradley, H.F. Diaz, P.M. Rel1y and T.M.L. Wigley, 1985: Northern Hemisphere Surface Air Temperature Variations 1851-1984. Journal of Climate and Applied Meteorology (in prene). 
Re1 log8, W.W. and Bojkov, R.D. (Bds.), 1982: Report of JSC/CAS Meeting of Experts on Detection of Possible Climate Change, WCP-29, World Meteorological Organization, Geneva.

Ruk 1a, G.J., J. Gavin and T.R. Rar1, 1985: Impact of urban heating on recent temperature trends in eastern and central North America. Preprints. Third Conference on Climate Variations and Symposium on Contemporary Climate: 1850-2100, 23-24. American Meteorological Society, Boston, Mass.

Landsberg, H.E, 1981: The Orban C1imate. Academic Pres8, New York, 275 PP.

Mitche11, J.M. Jr, 1953: On the causes of instrumentally observed secular temperature trends. Journal of Meteorolosy, 10, 244-261.

Robock, A., 1982: The Russian surface temperature data set. Journal of Applied Meteoro logr, 21, 1781-1785.

Sharov, V.Ya. (Ed.), 1960-1967: Maps of Air Temperature Deyiations from Long= Term Means for the Northern Remisphere, No. 1-4, Main jeophysical Observatory, Leningrad. (In Russian.)

Smithsonian Institution, 1927, 1935, 1947: World Weather Record8, Smithsonian Inst. Miscel Laneous Collections, $7018.79,90$ and 104. Smithsonian Inst., Hashington, D.C.

D.S. Weather Bureau, 1959-1982: World Weather Records, 1941-50 (1361 pp.), 1951-60 (Vol 8. 1-6), 1961-70 (Vol8. 1-6). U.S. Department of Commerce, Washington, D.C.

Vinnikov, R.Ya., 1977: Procedures for acquisition and interp station of data on the variations of Northern Hemisphere surface air te perature during 1881-1975. Meteorologiys i Gidrologiya, 1977. No. 9, 110-114. (In Russian.)

Vinnikov, R.Ya., G.V. Gruza, V.F. Zakharov, A.A. Ririllov, N.P. Kovyneva and E.Ya. Rankova, 1980: Contemporary variations of the Northern Hemisphere climate. Meteorologiya i Gidrologiya, 1980, No, 6, 5-17 (in Russian).

Wigley, T.M.L., J.K. Angell and P.D. Jones, 1985: Analysis of the temperature record. ( In) U.S. Department of Energy State of the Art Report on the Detection of Climatic Change U.S. Dept. of Energy Carbon Dioxide Research Division, Washington, D.C. (to be published).

Yamamoto, Ro, 1981: Change of global climate during recent 100 years. Proc. of the Technical Conference on Climate - Asia and Western Pacific, 1520 Dec. 1980 , Guangzhou, China. WMO Report No. 578 , Geneva.

Yamamoto, R, and M. Hoshiai, 1980: Fluctuations of the Northern Hemisphere mean surface air temperature during recent 100 years estimated by optimum interpolation. J. Meteor. Soc. Japan, 58, 187-193. 


\section{APPENDIX A}

Station History Information and Homogeneity Assessment Details

Column Headings

Line 1:

Who Number (generally with additional 0 )

Station Name

Country

Latitude

Longitude

Beight

First year of data (In some cases this may. be the first year with precipitation data. Temperature-data.starts later.)

Last year of data

Quality code

First reliable year of data

Line 2:

Source: Codes used by Bradley et al. (1985)

Subsequent lines:

Notes and homogeneity details.

Additional Information

Missing Codes :

Latitude - 999

Longitude - 1999

Height - 999

Quality Code:

First Digit

1 - Reliable back to first reliable year

2 - Corrected back to first reliable year

4 - Affected by urban warming

5,8 - Non-homogeneous and uncorrectable

6 - Not compared with neighbouring stations

7 - Reliable back to first reliable year, uncorrectable for earlier years

Second Digit

0 - Record 907 complete

1 - Short record of less than 20 years

2 - Record less than $90 \%$ complete, generally containing mang years of missing data

3 - Antique record with data almost entirely from the nineteenth century or earlier 

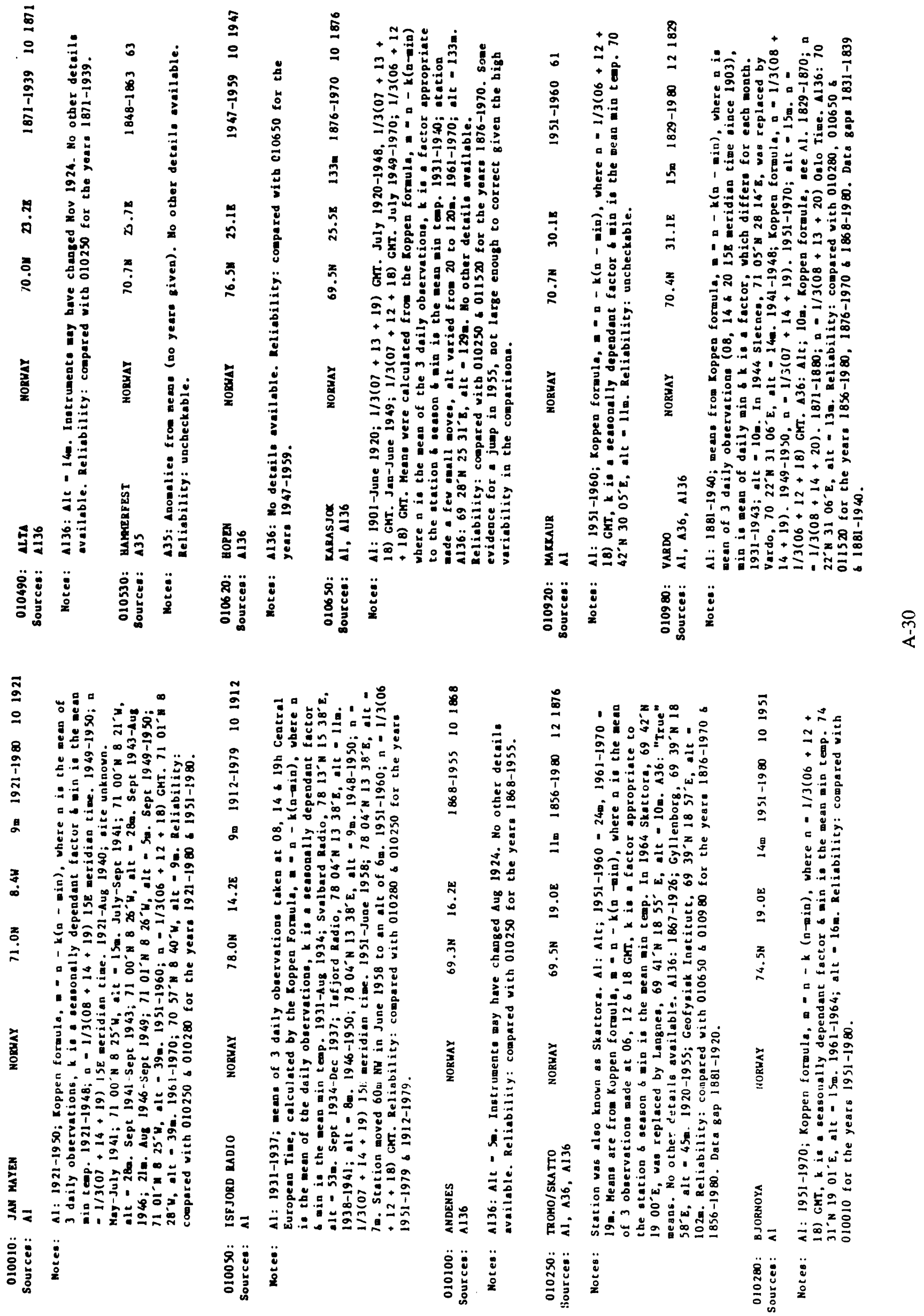

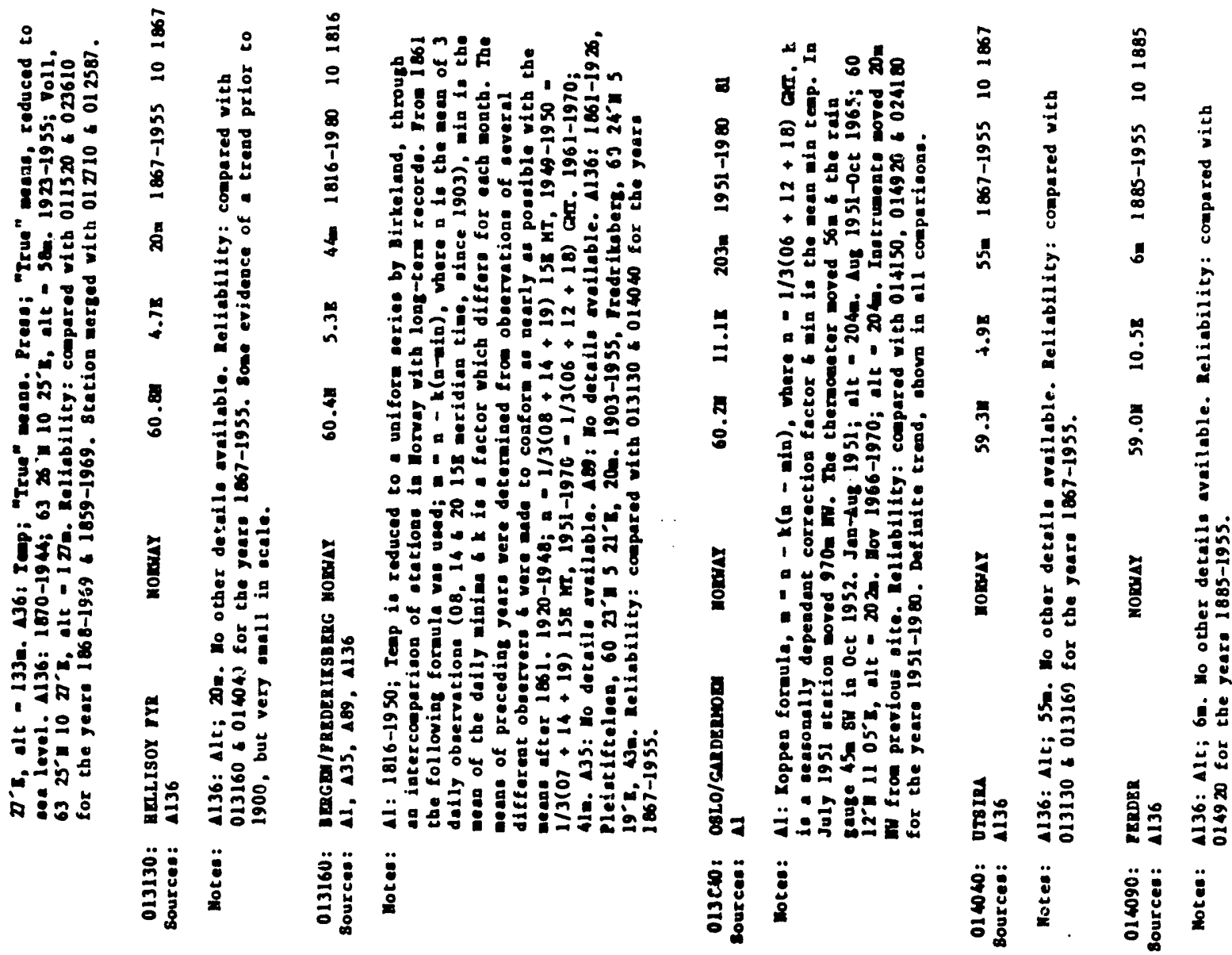

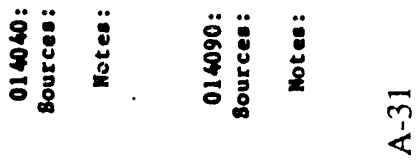

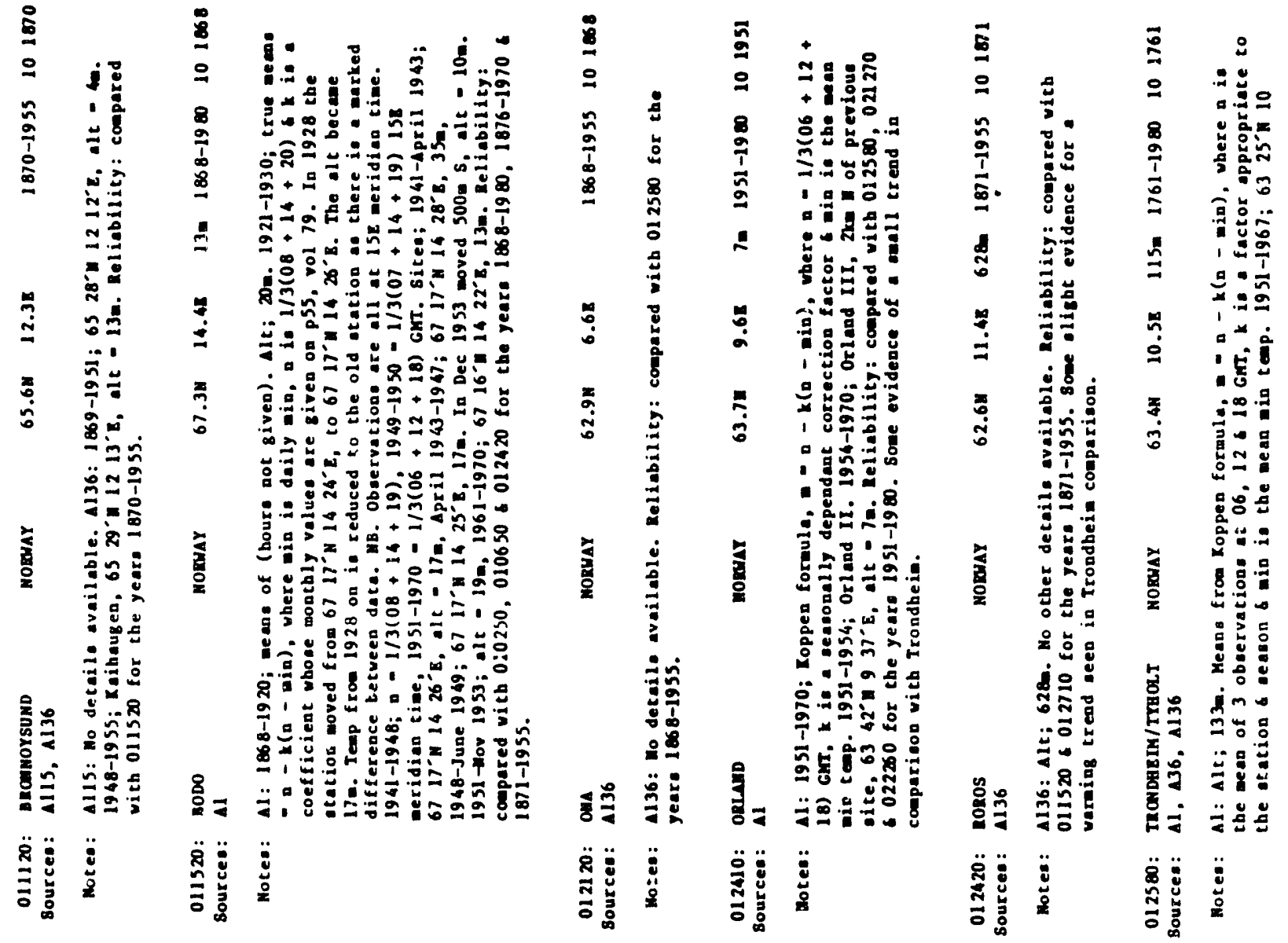



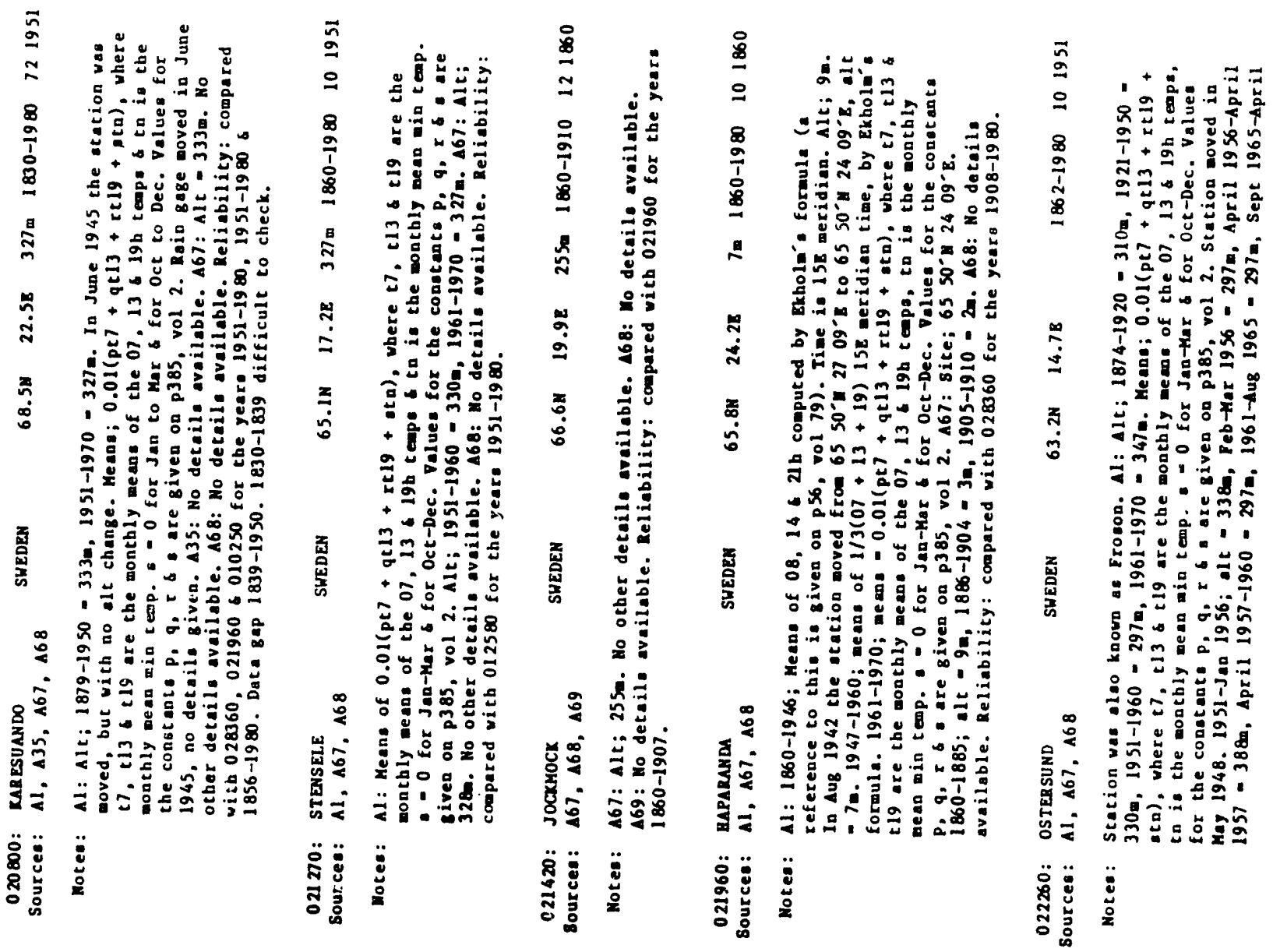

$\stackrel{2}{4}$
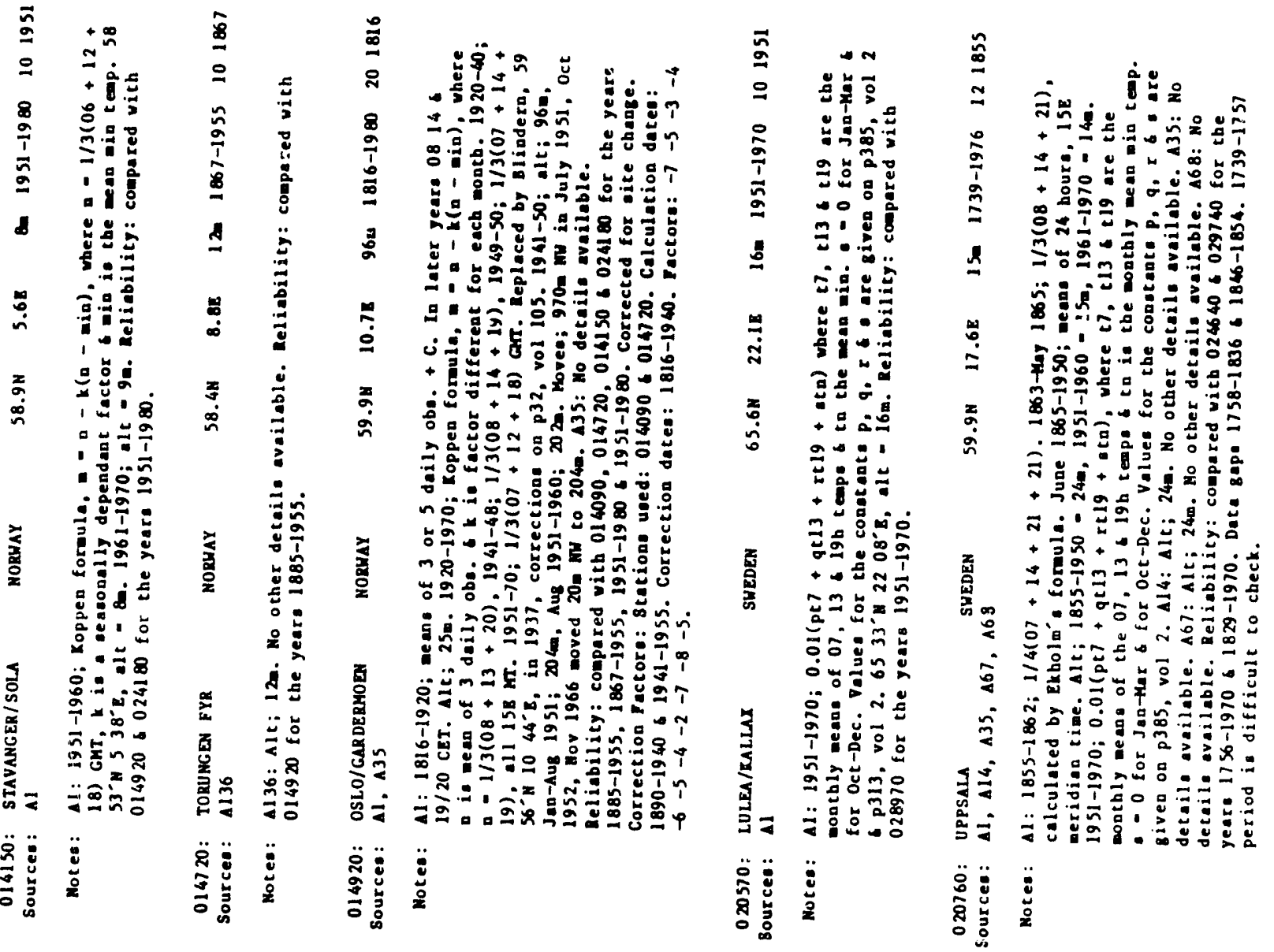
$$
\stackrel{8}{2}
$$$$
\text { 政 }
$$

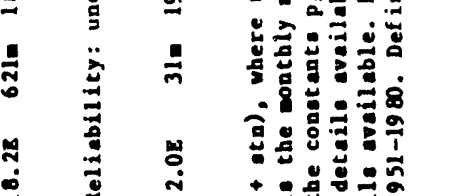

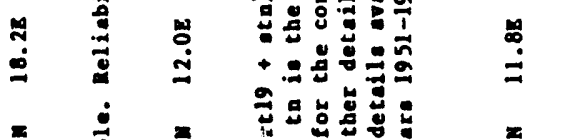$$
\text { 产 }
$$

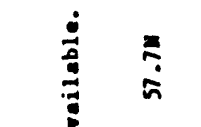

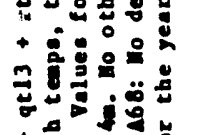

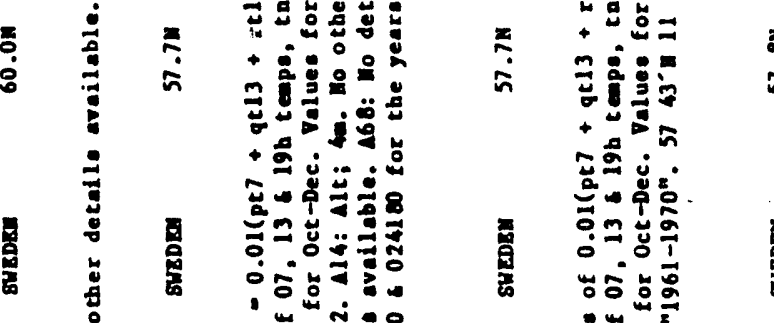

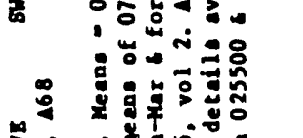

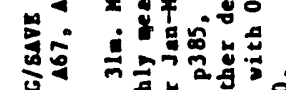

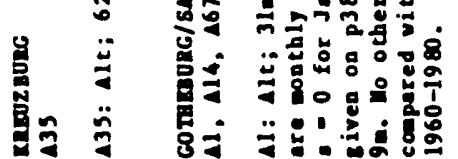

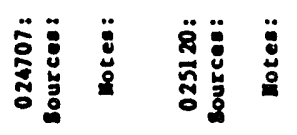

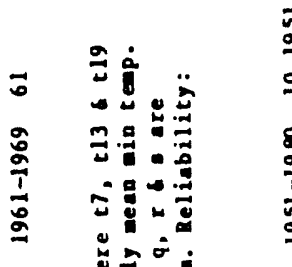

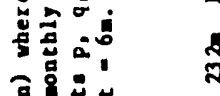

敦

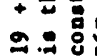

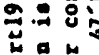

1.

:

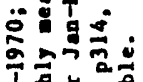

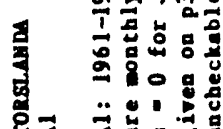

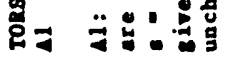

实苟

ลี $\stackrel{n}{ \pm}$

ì

III

1

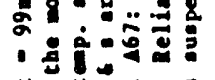

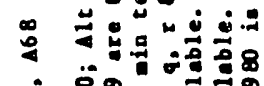

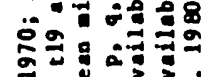

政

案

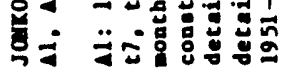

各苛高

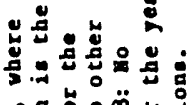

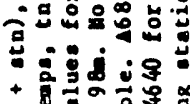

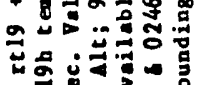

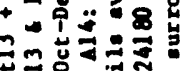
$+20$

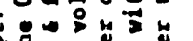

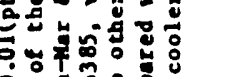

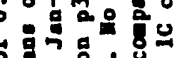

$\stackrel{\mathrm{a}}{-}$ $\stackrel{\infty}{\dot{n}}$<smiles>C1CCCC1</smiles>

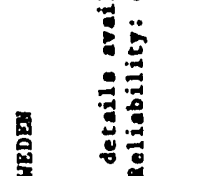<smiles>[Li]</smiles>

列

نำ

in

II $\stackrel{\overrightarrow{1}}{a} \quad \vdots$

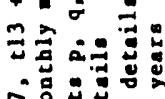

2

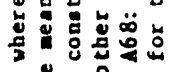

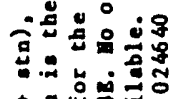

品

5

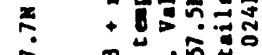

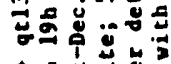

动范然

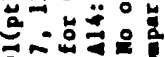

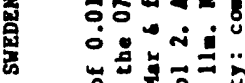

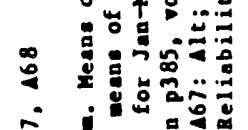

क

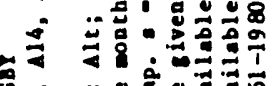

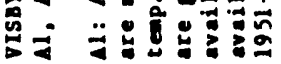

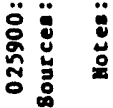

$\stackrel{m}{\dot{4}}$

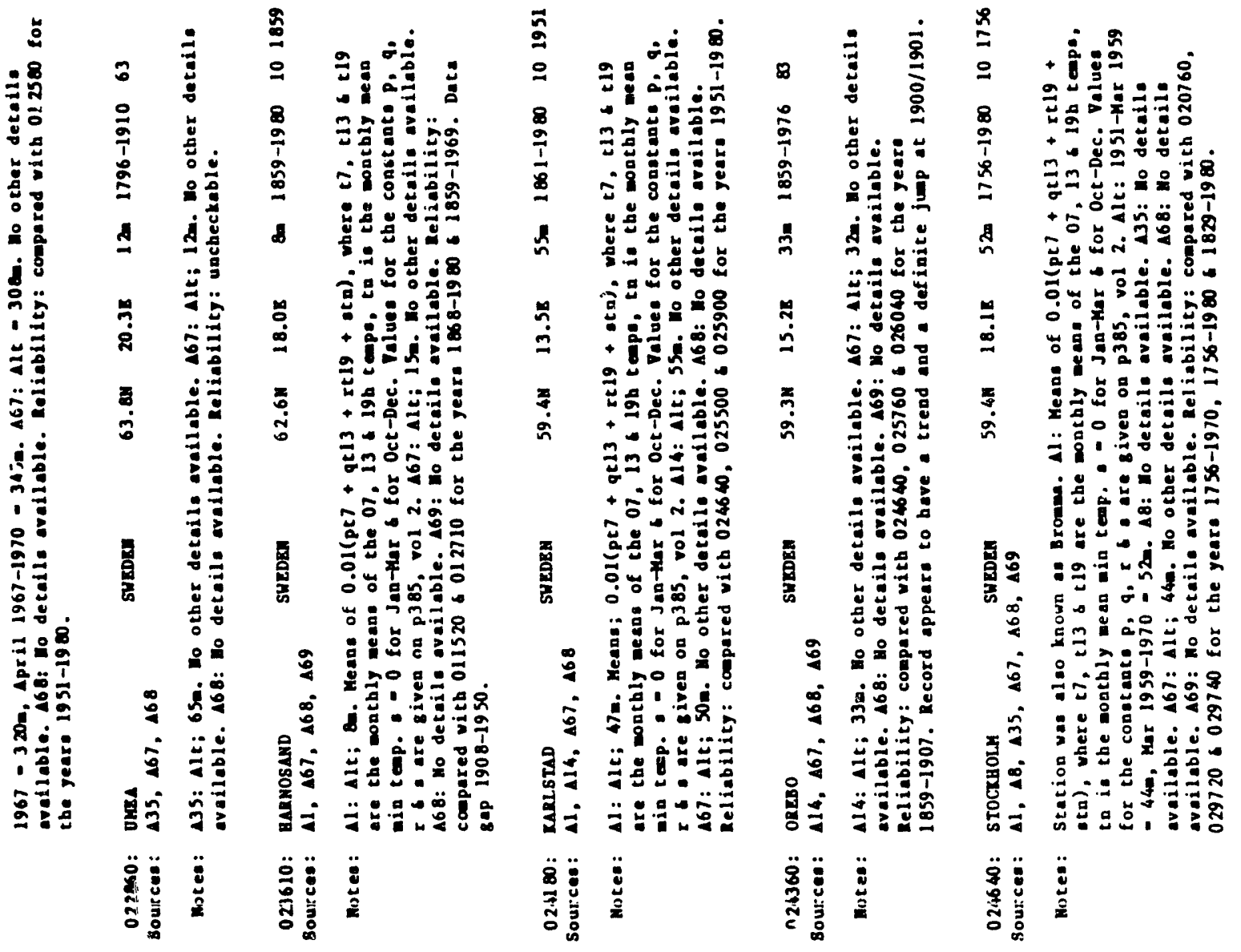




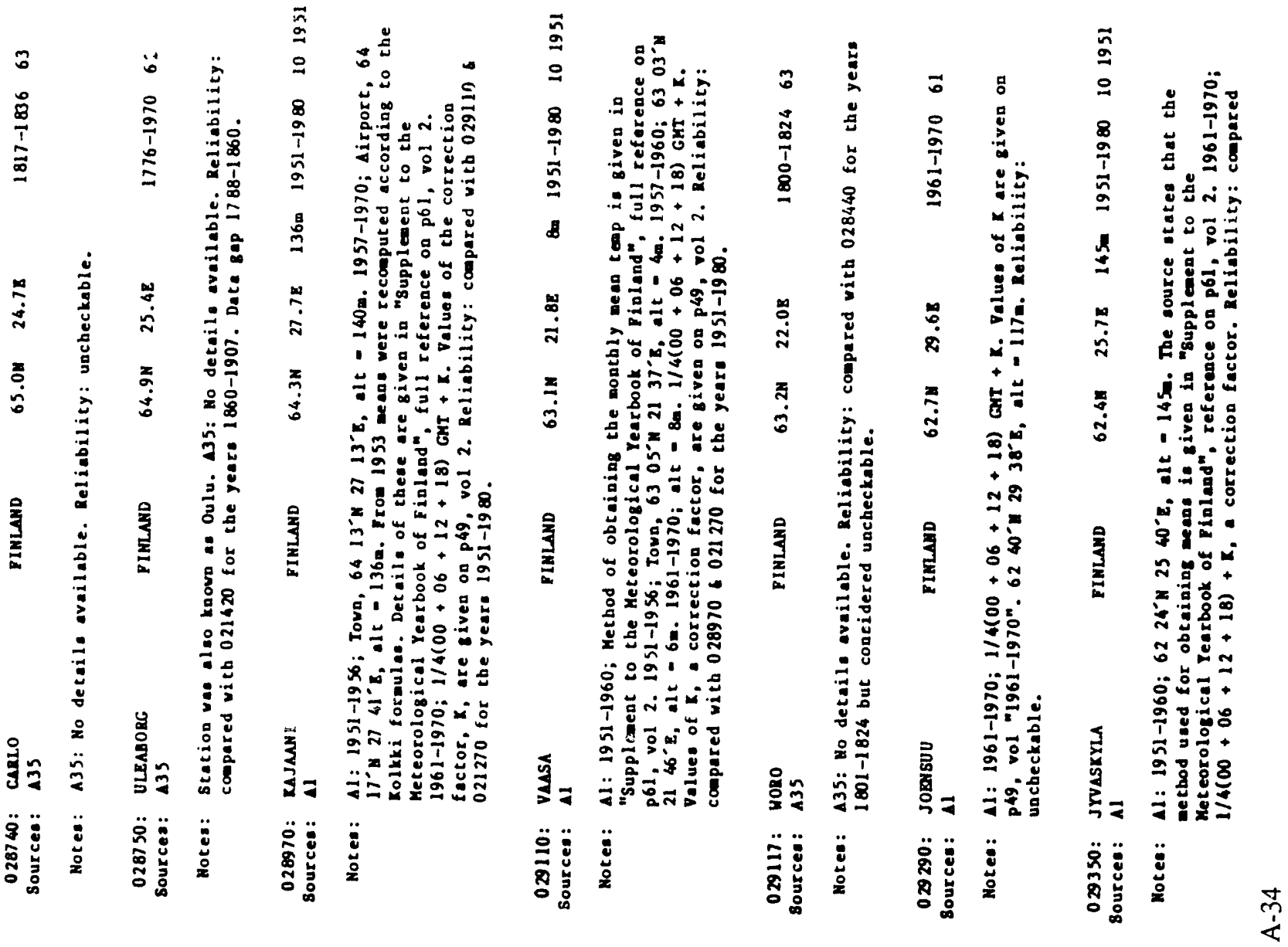

$-$

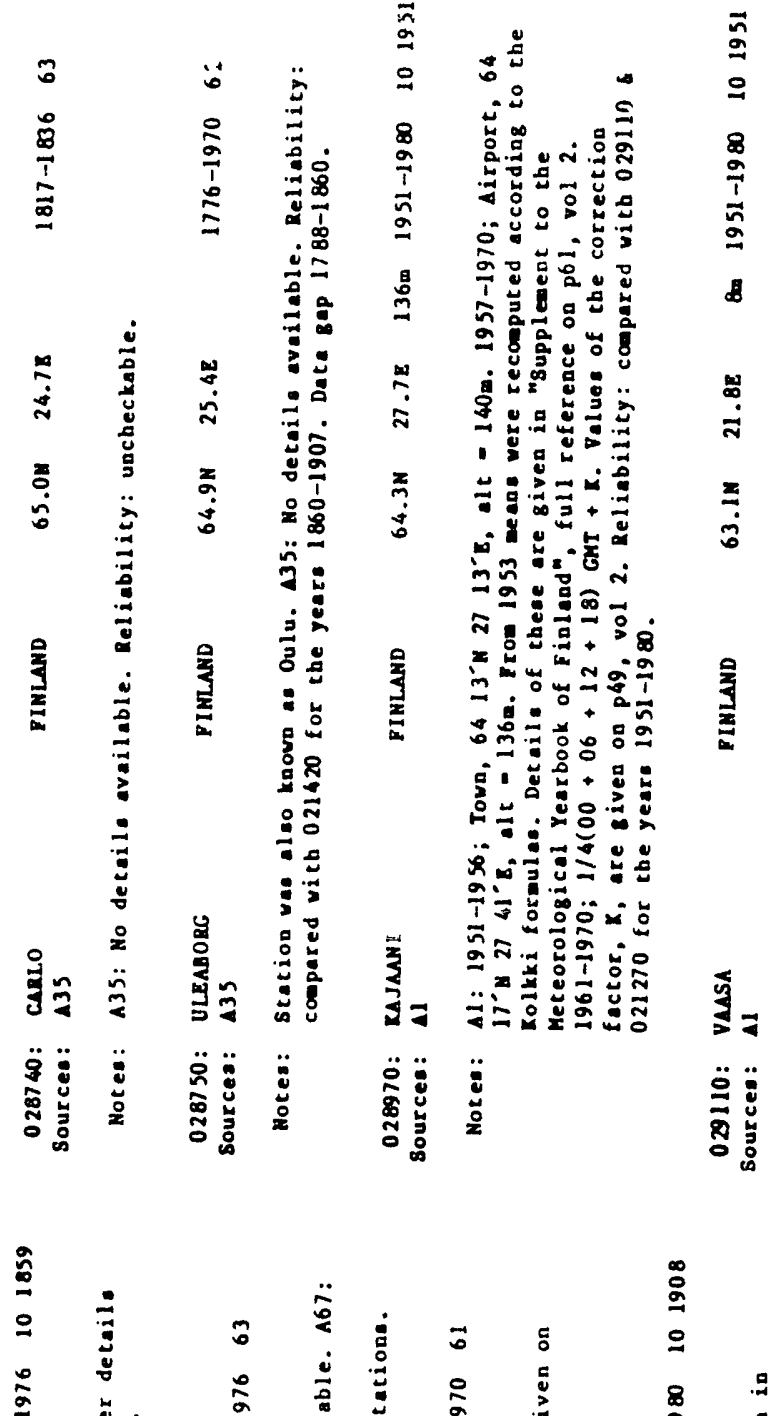

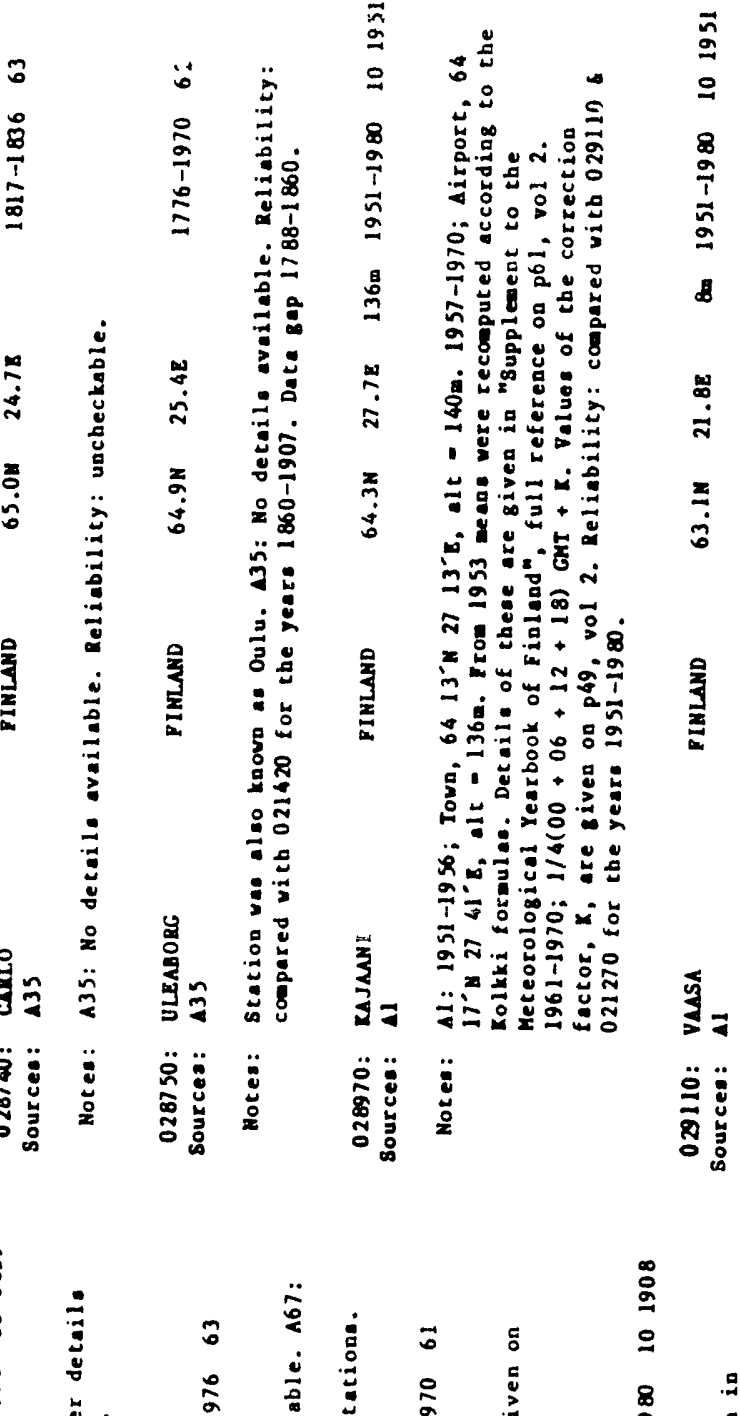

容

(

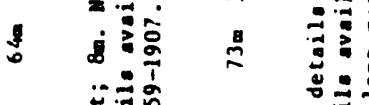

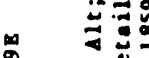

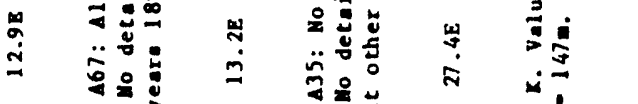

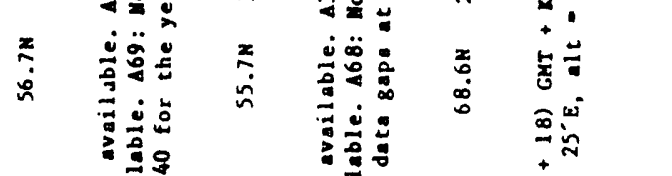

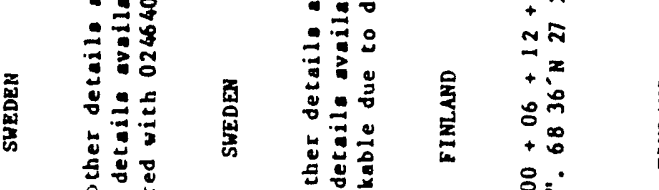

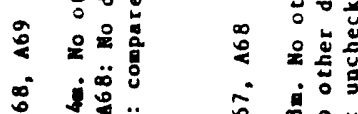

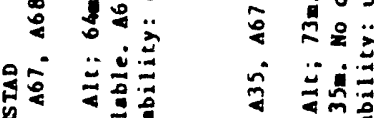

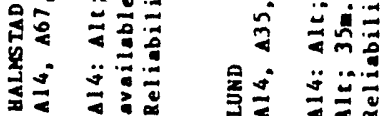

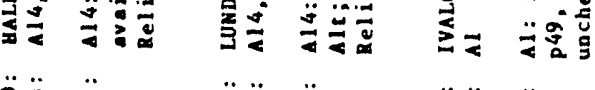

औौ

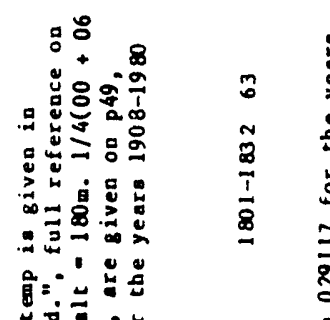

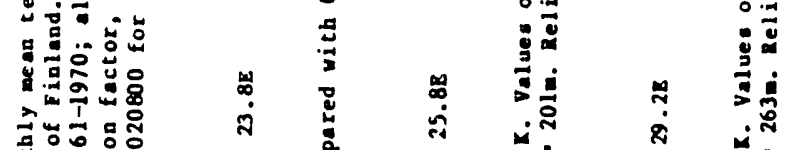

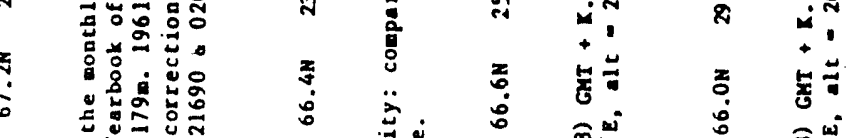

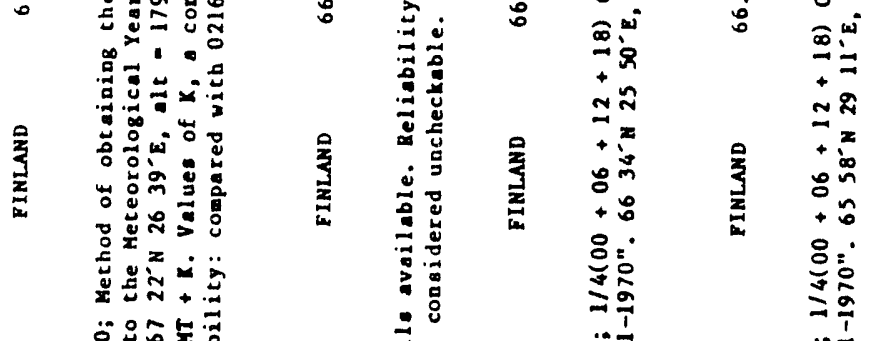

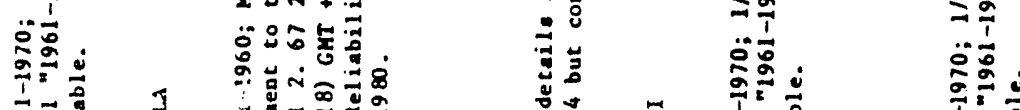

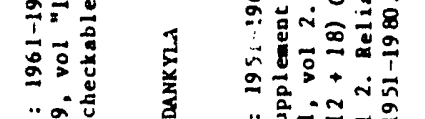

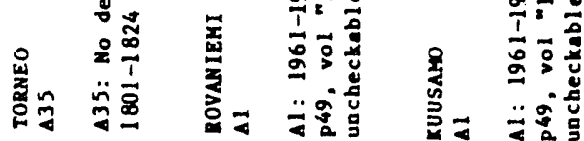

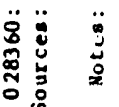

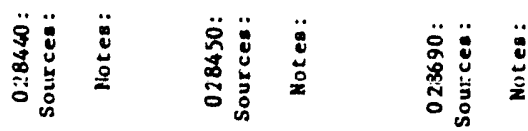



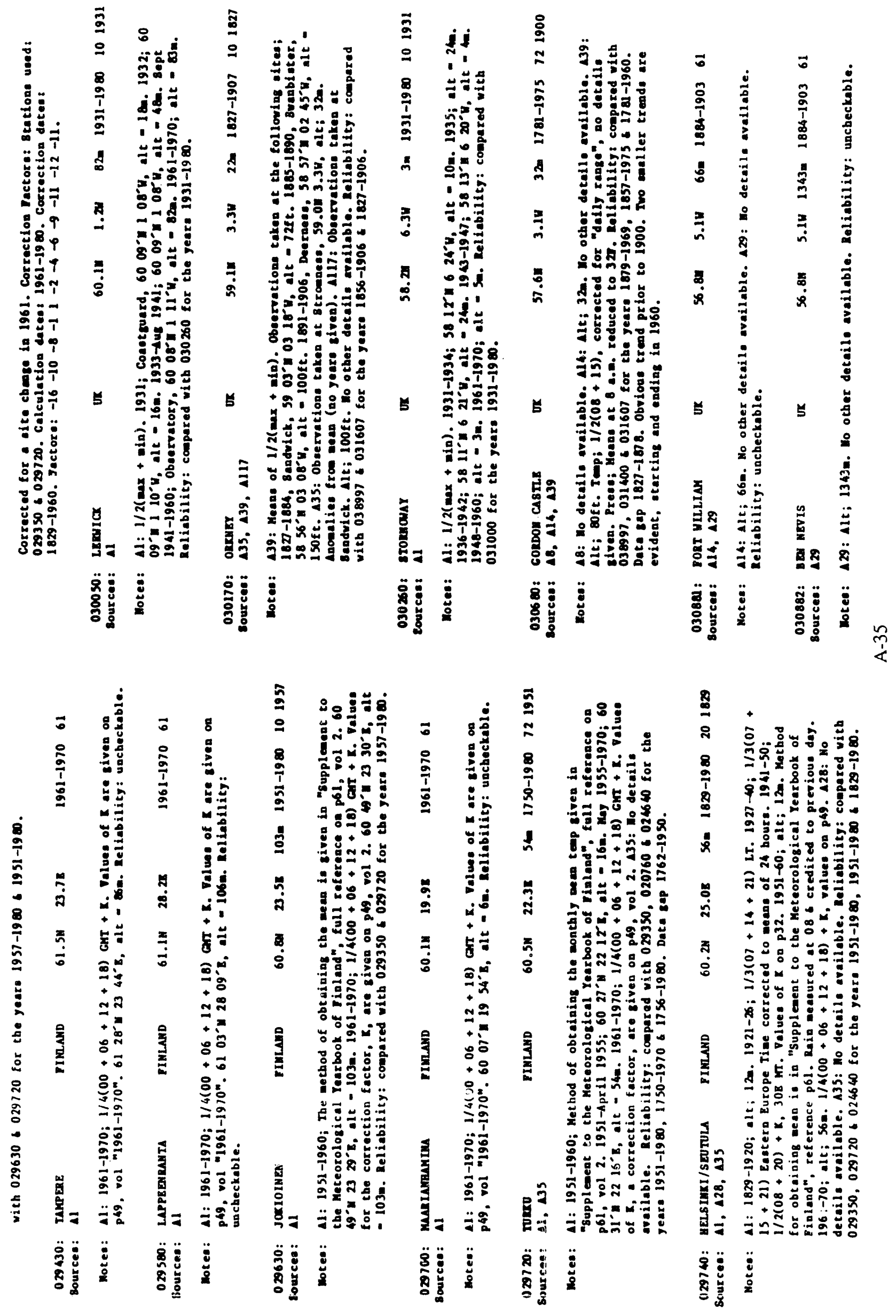


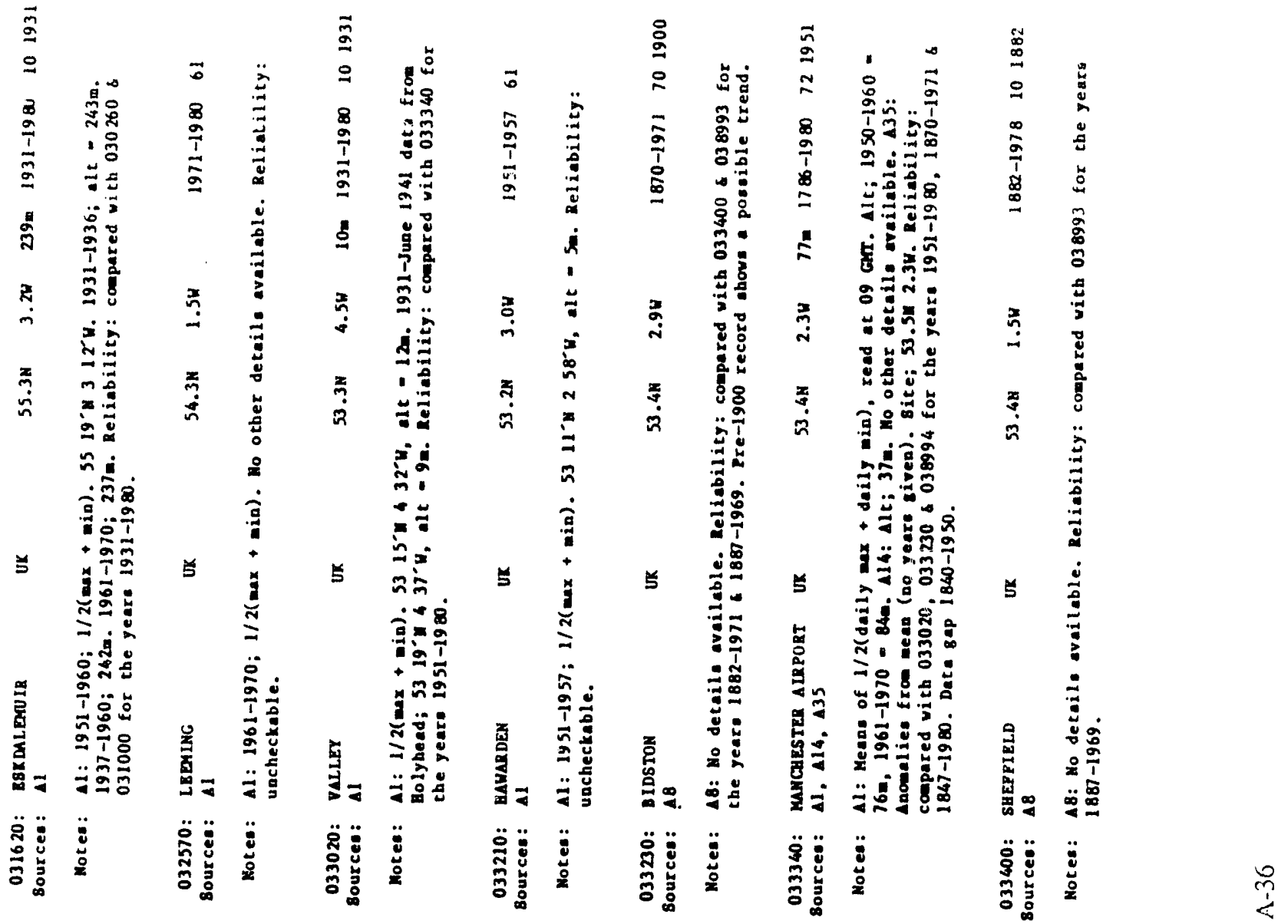

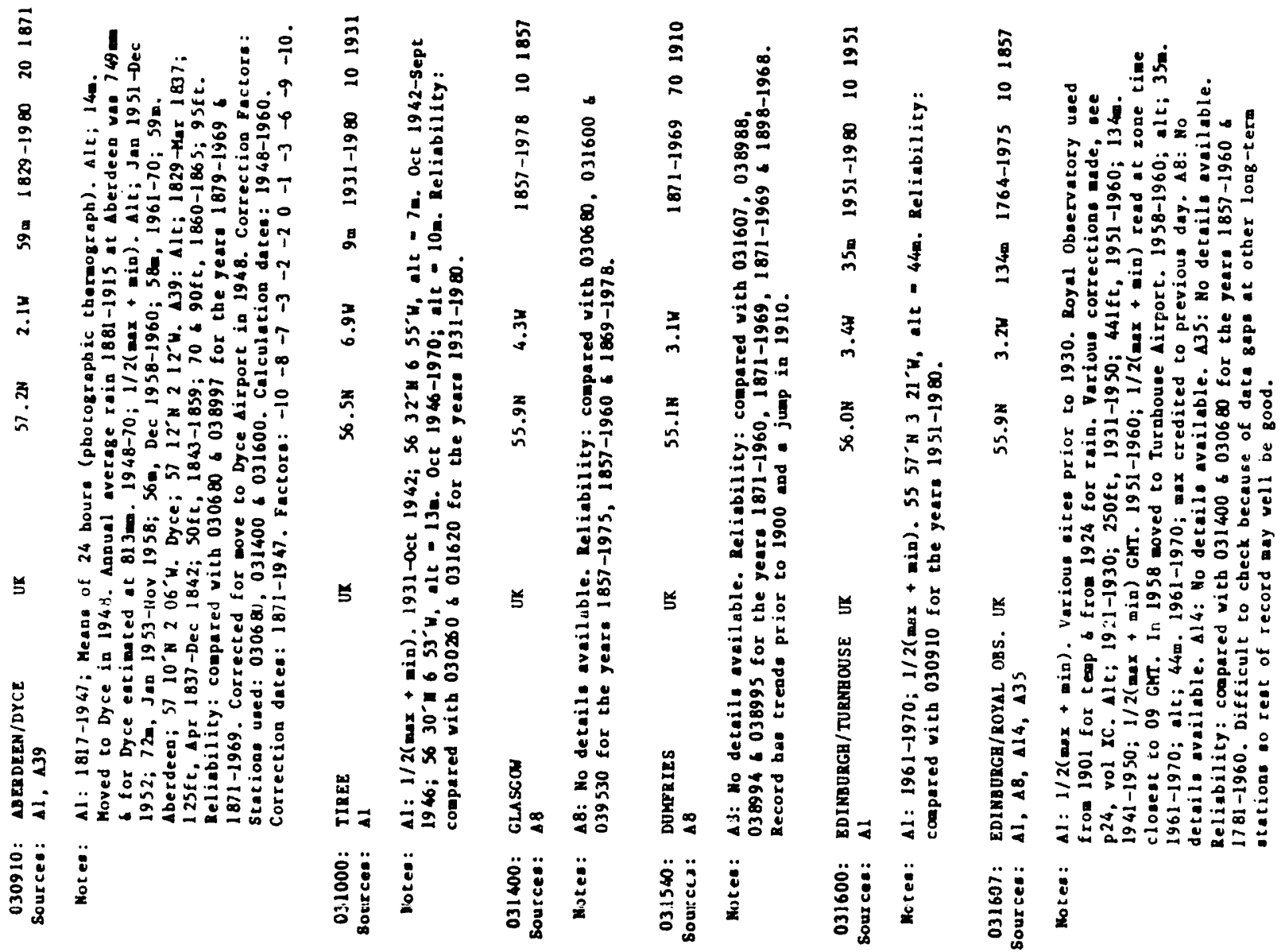




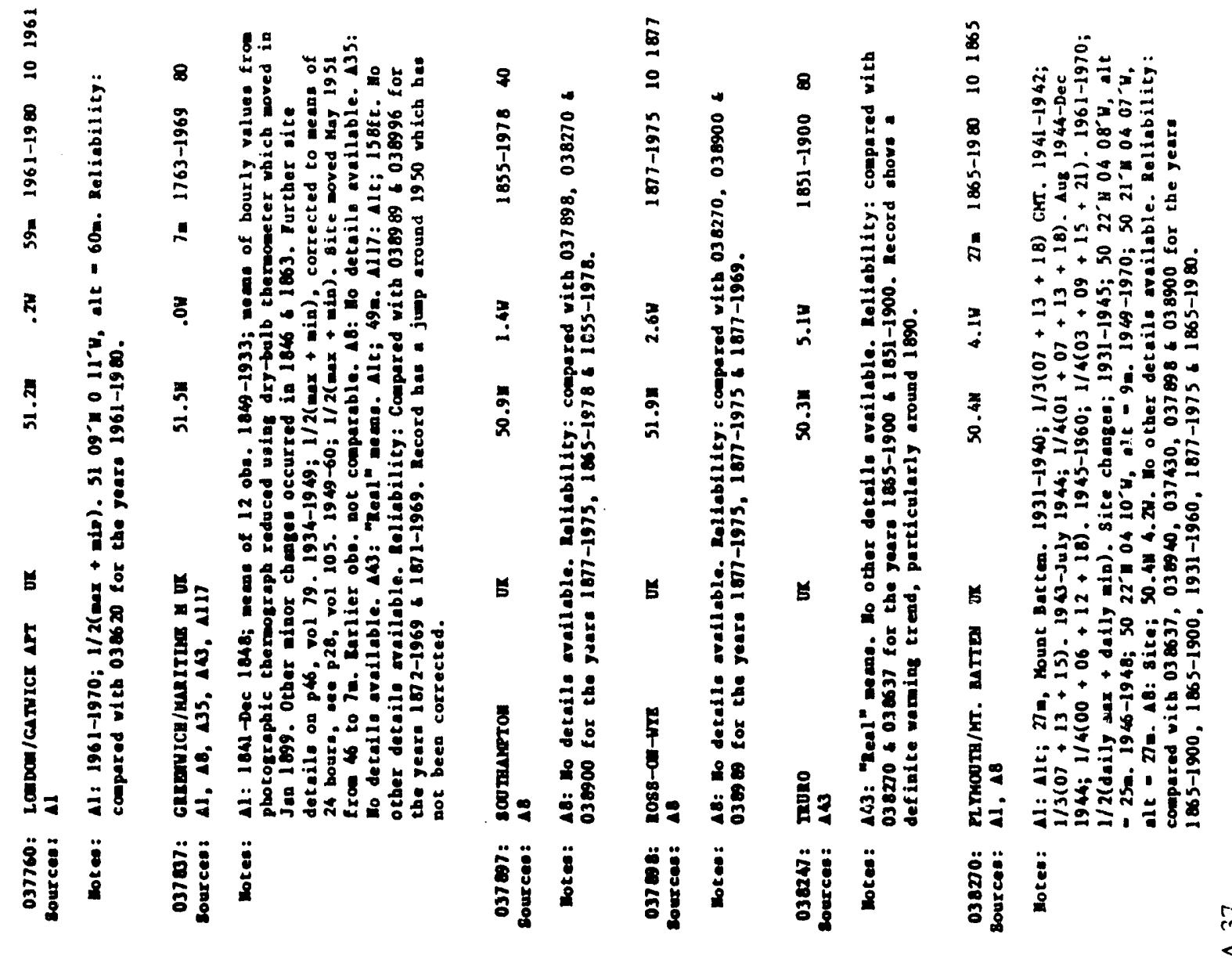

管

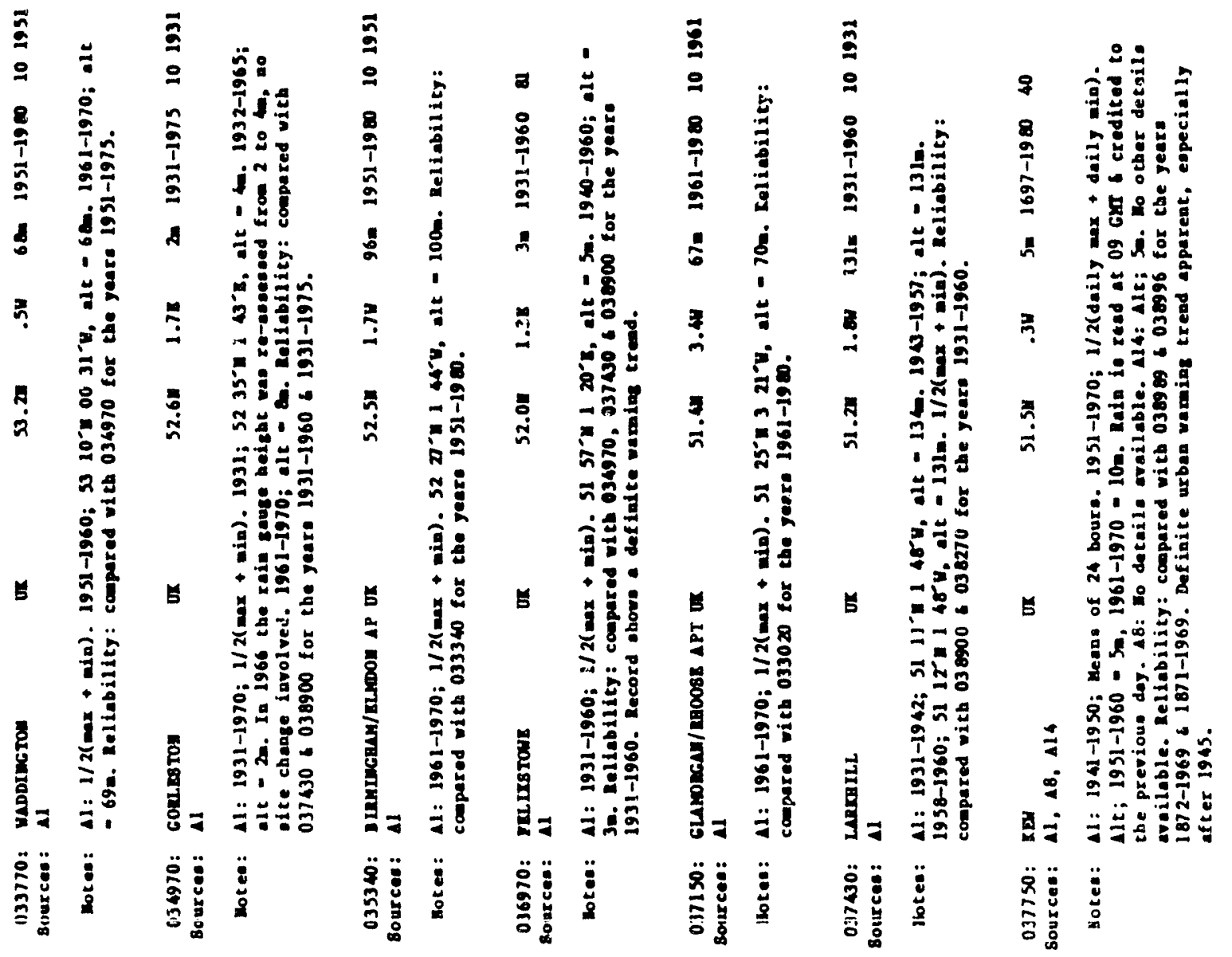




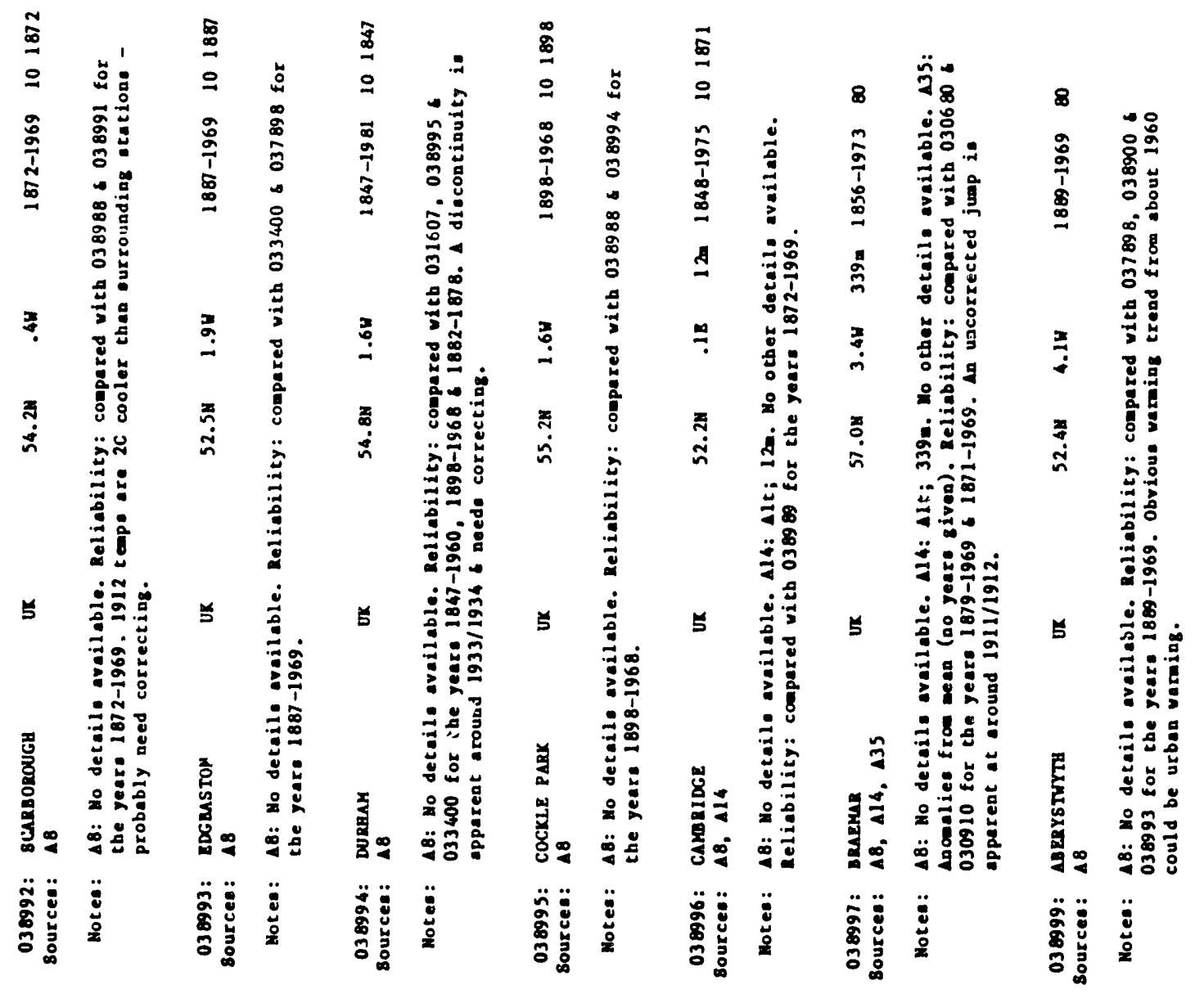

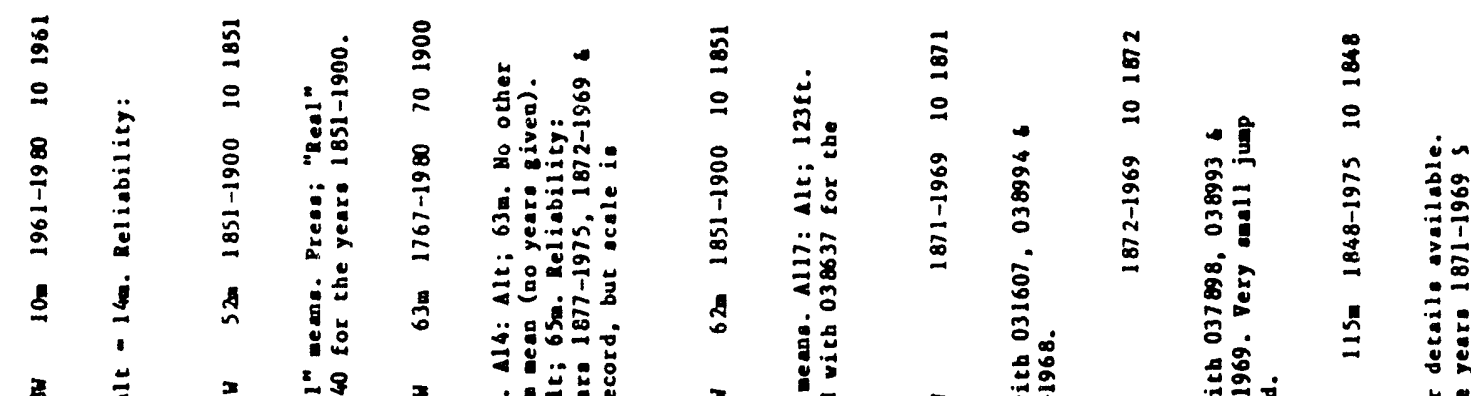

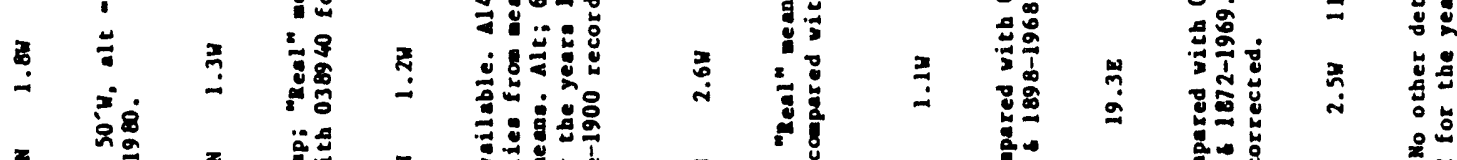

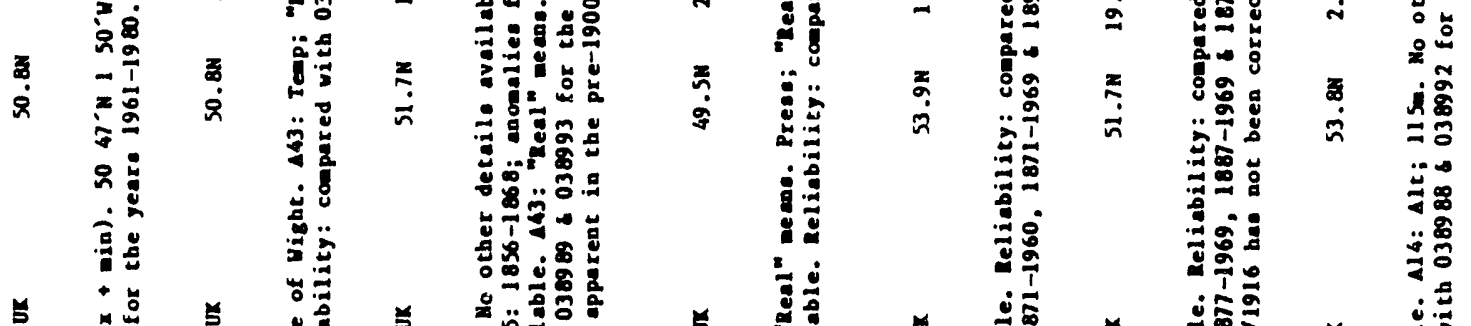

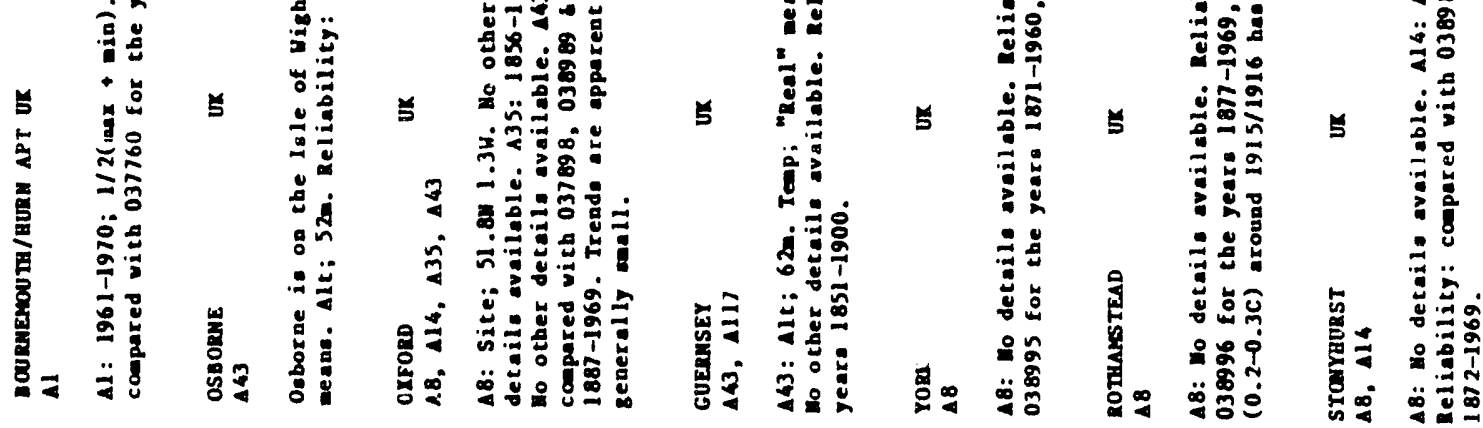

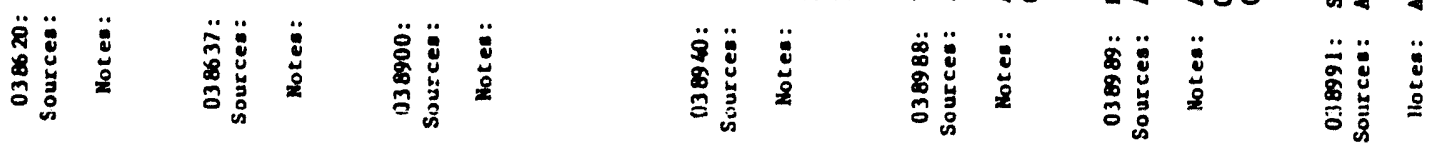



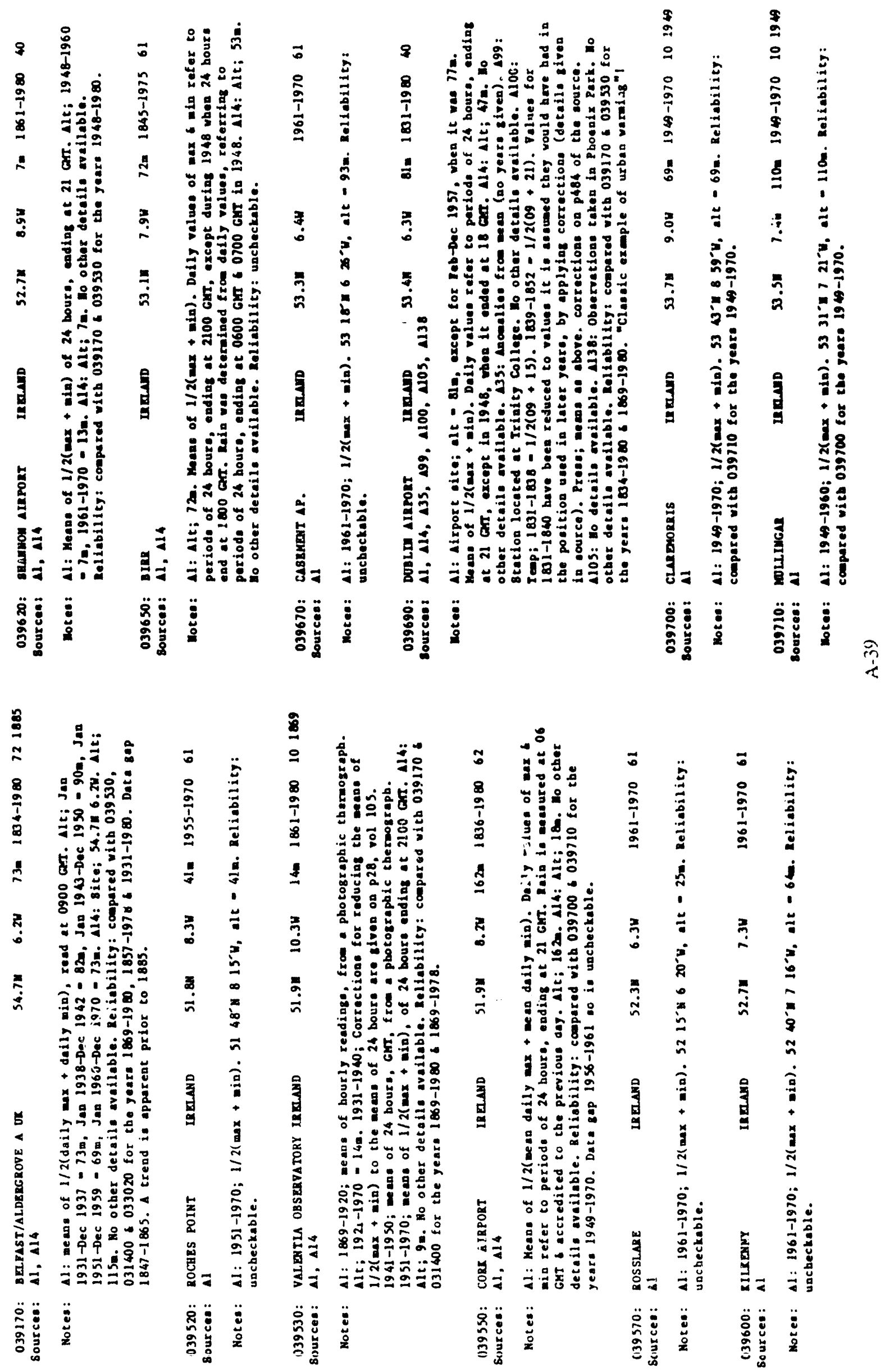

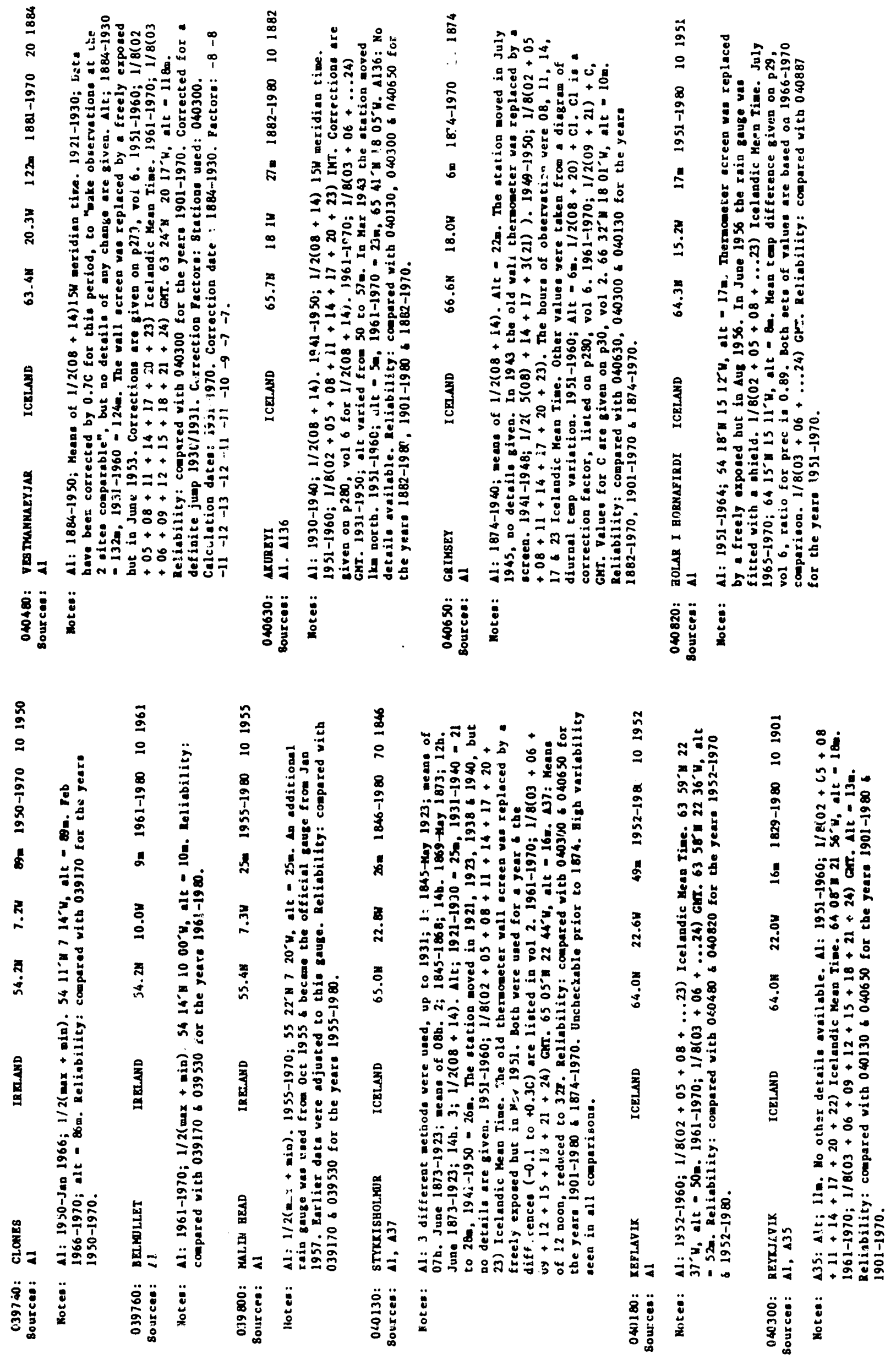


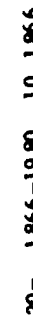

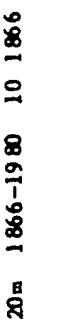

$=\quad 30$

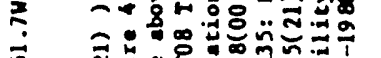

เ

$$
\text { + }
$$

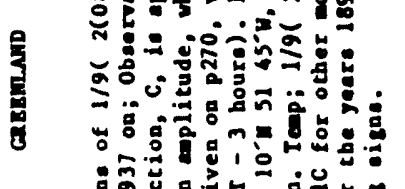

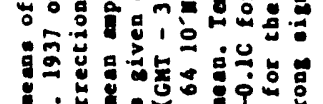

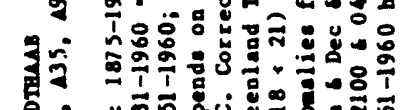

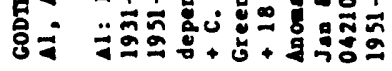

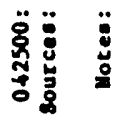

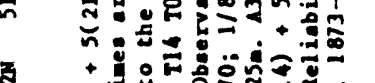

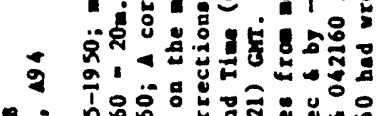

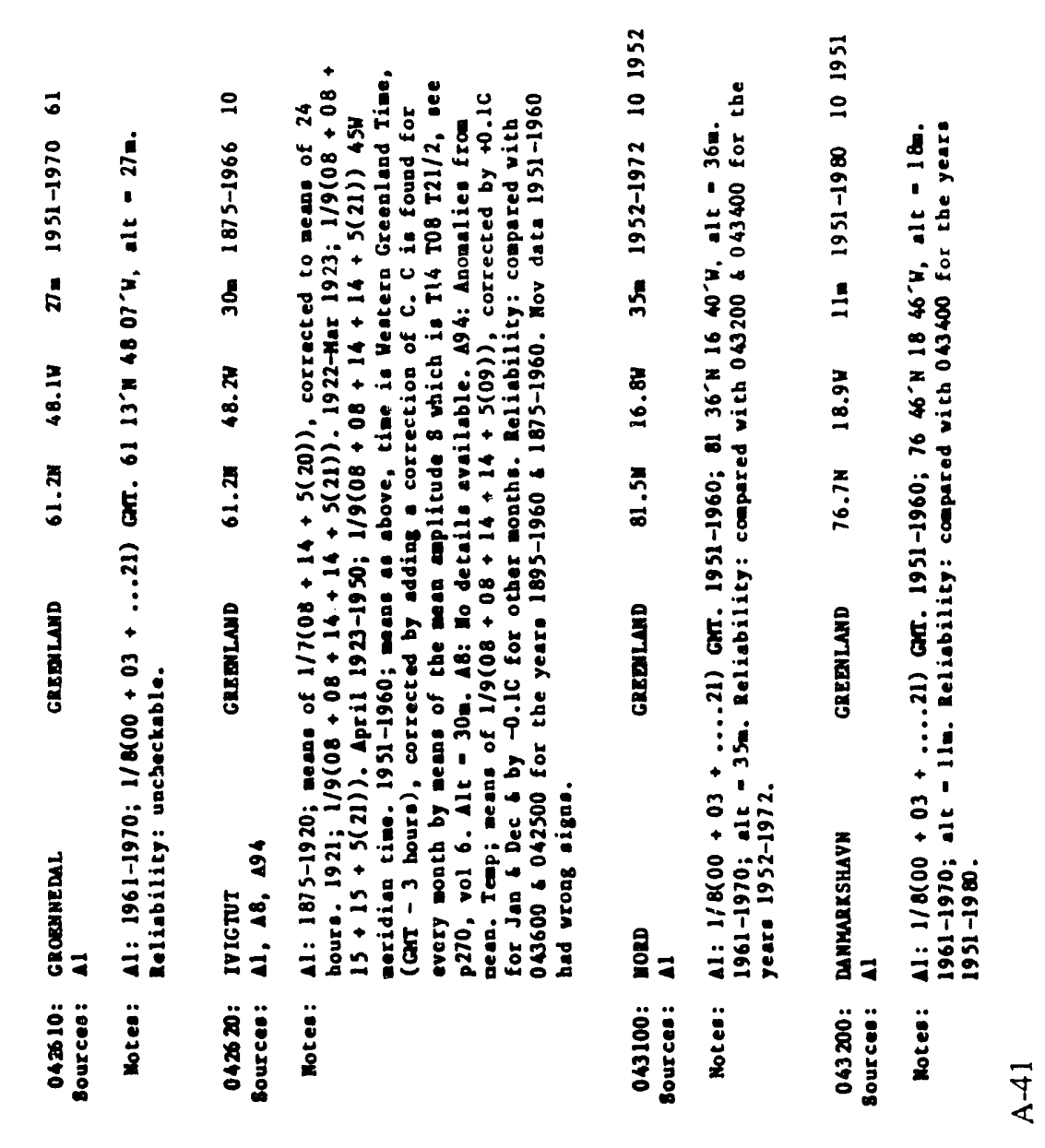

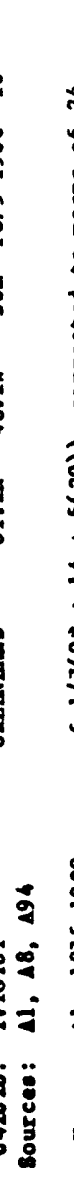

$1+$

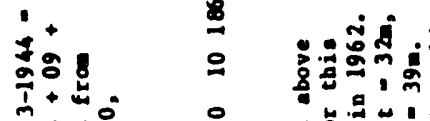

亩:

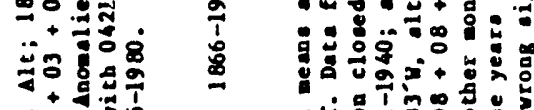

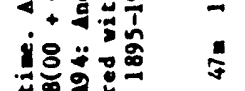

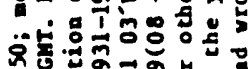

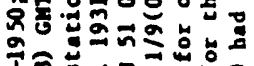

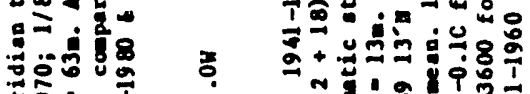

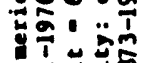

$\frac{1}{2}=$

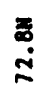

응

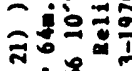

สำ:

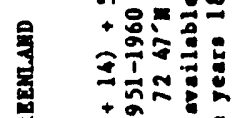

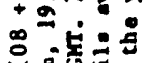

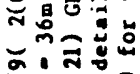

我泀

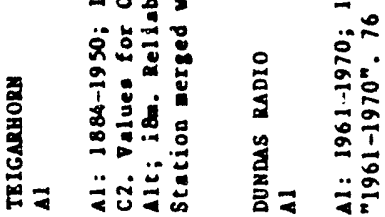

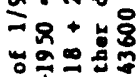

ลี

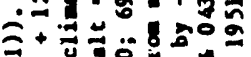

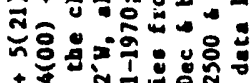

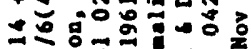

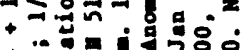

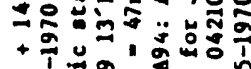

ะ

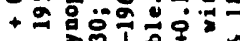

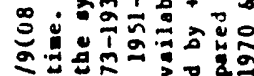

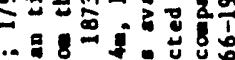

$\stackrel{0}{1}$

宸

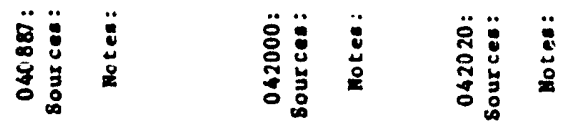

窇。

䖤的是

車总

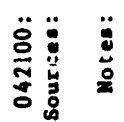

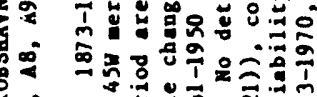

莙落
窟蜜

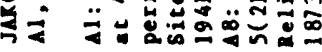

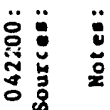




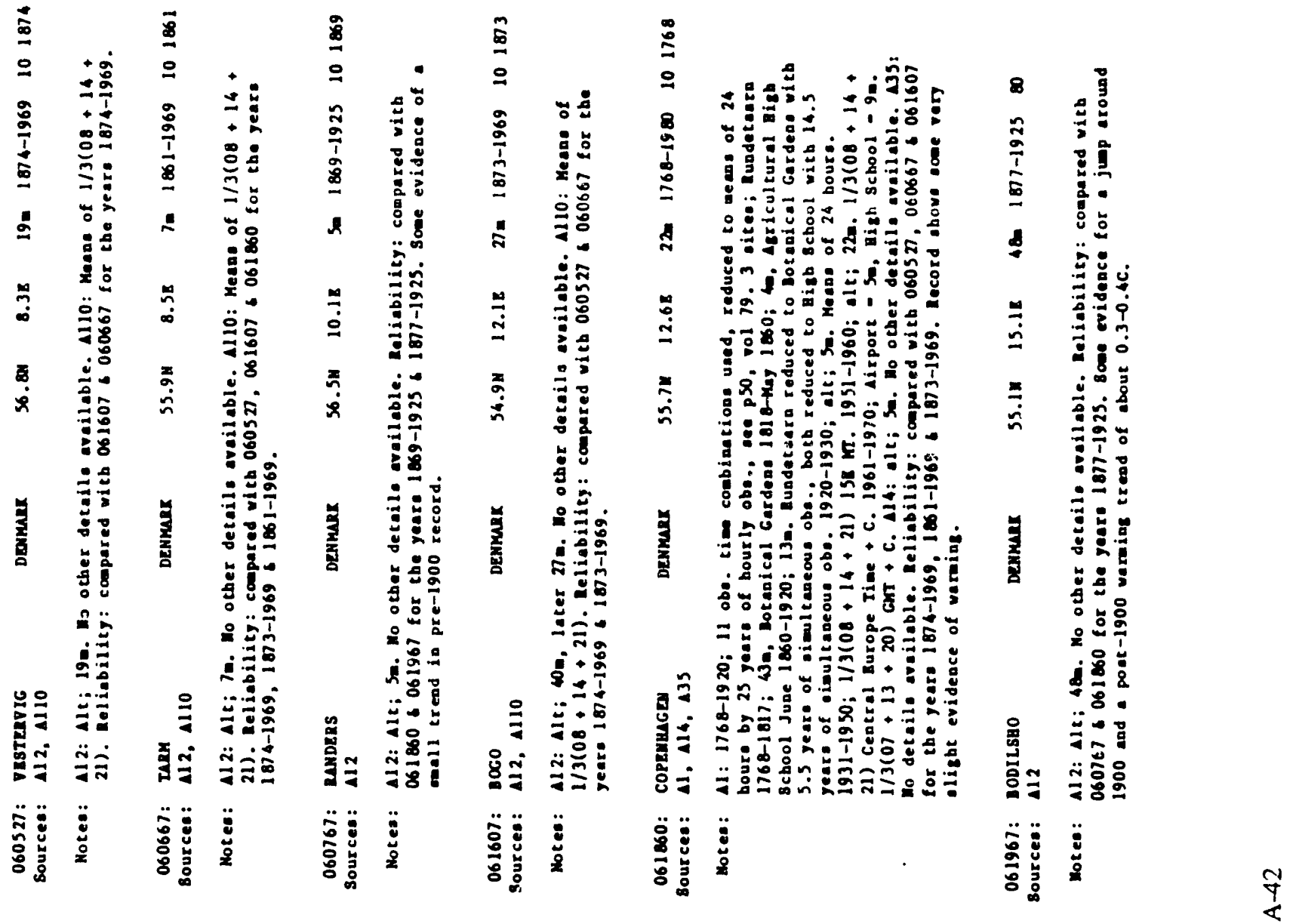

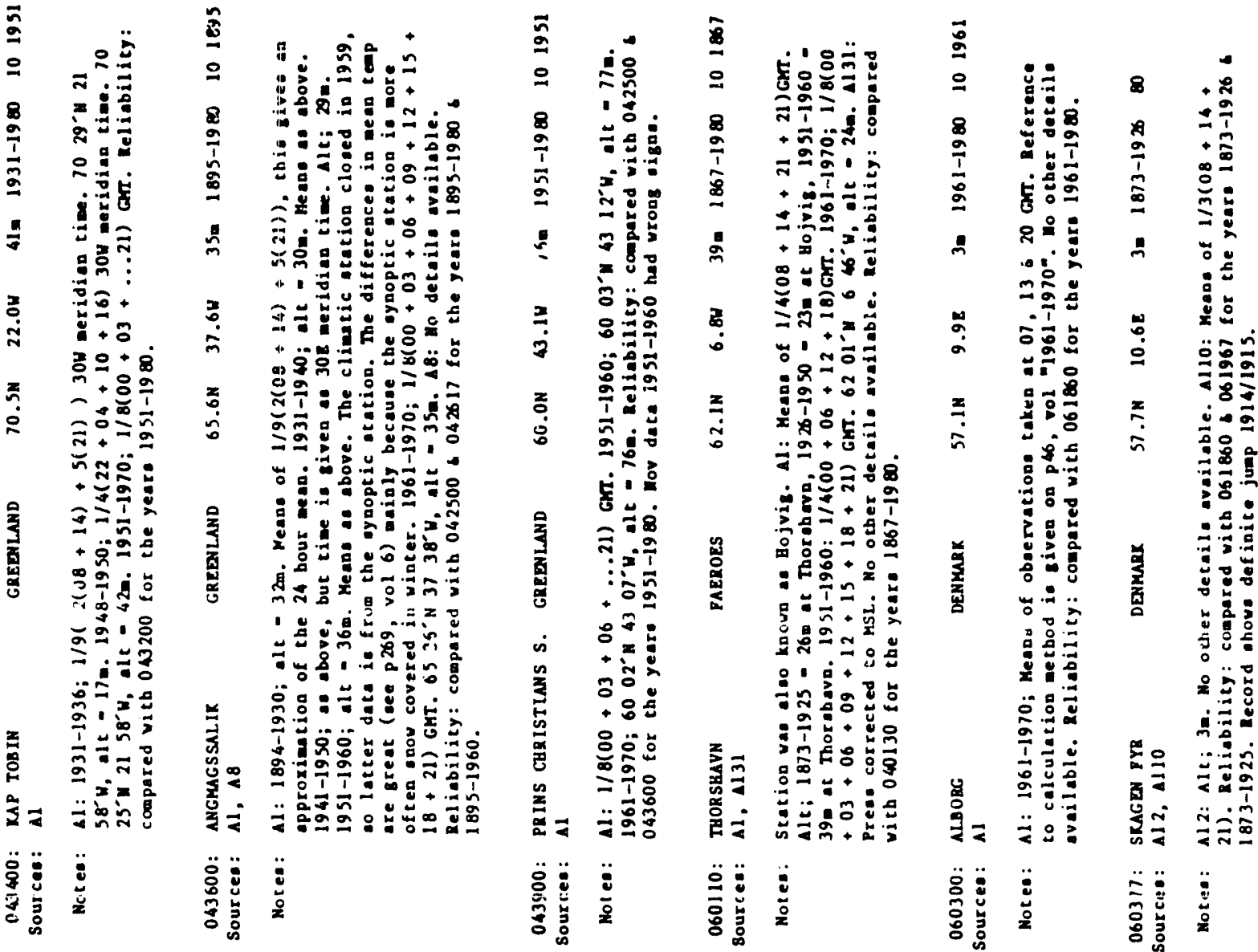



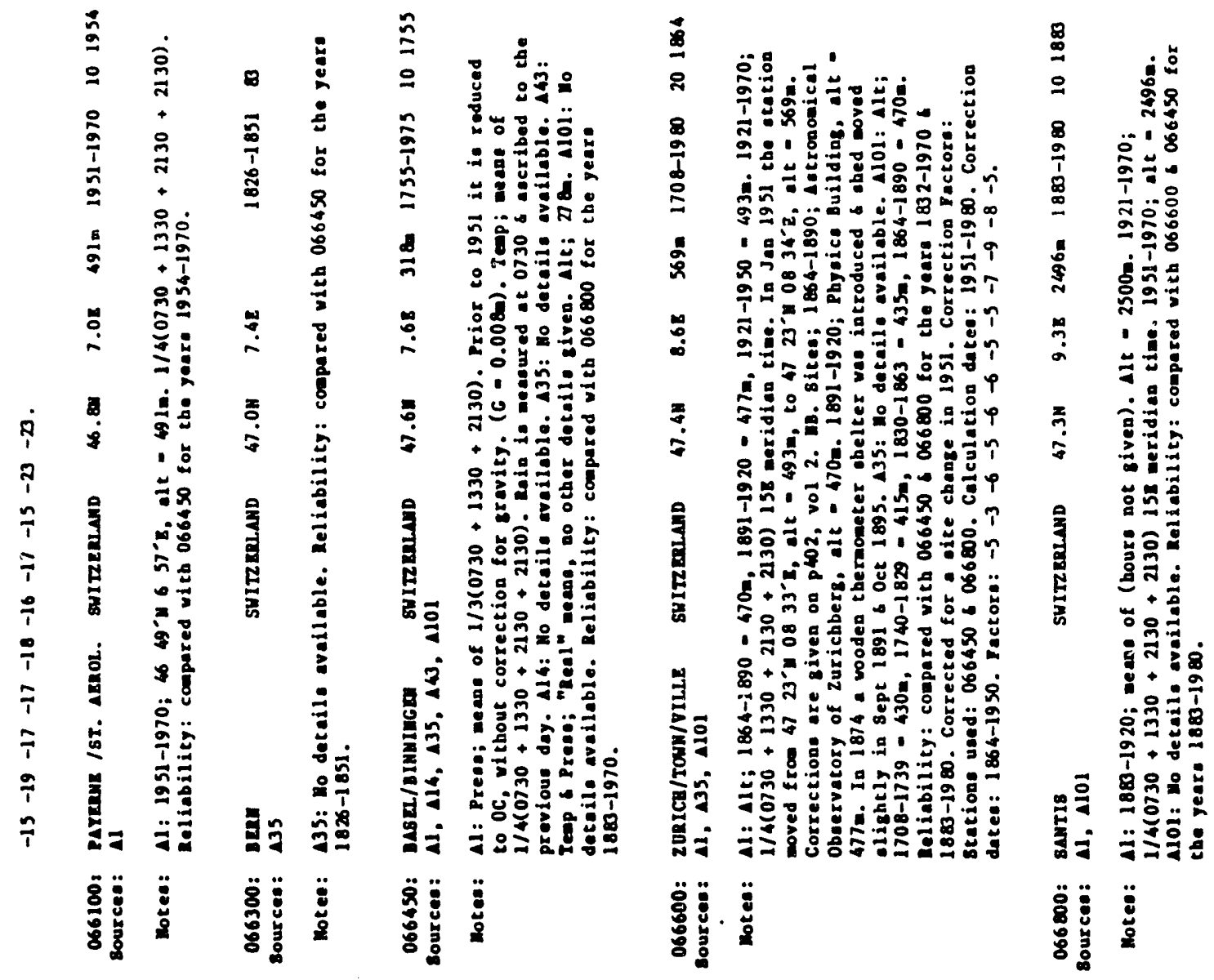

$\stackrel{m}{y}$

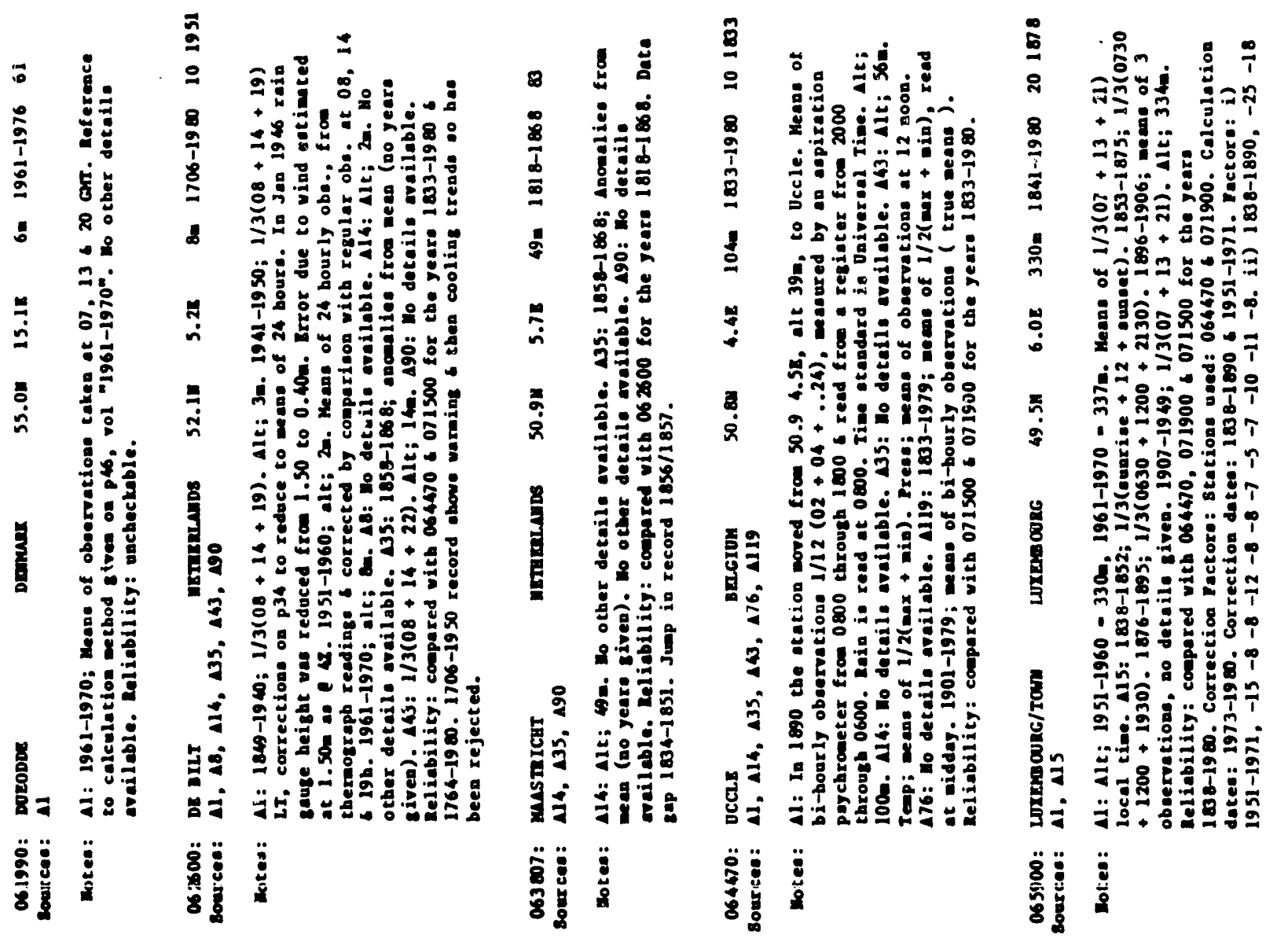



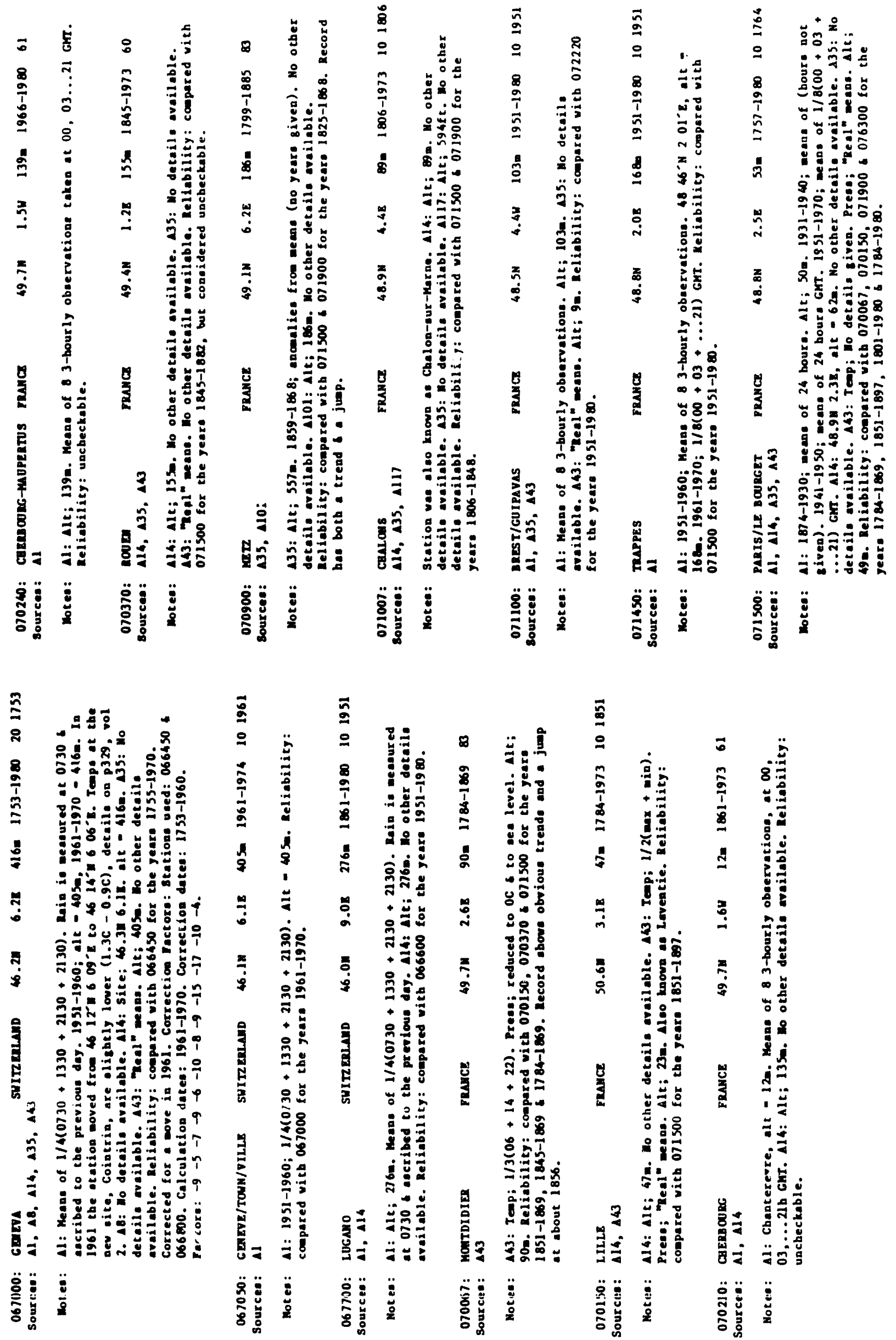


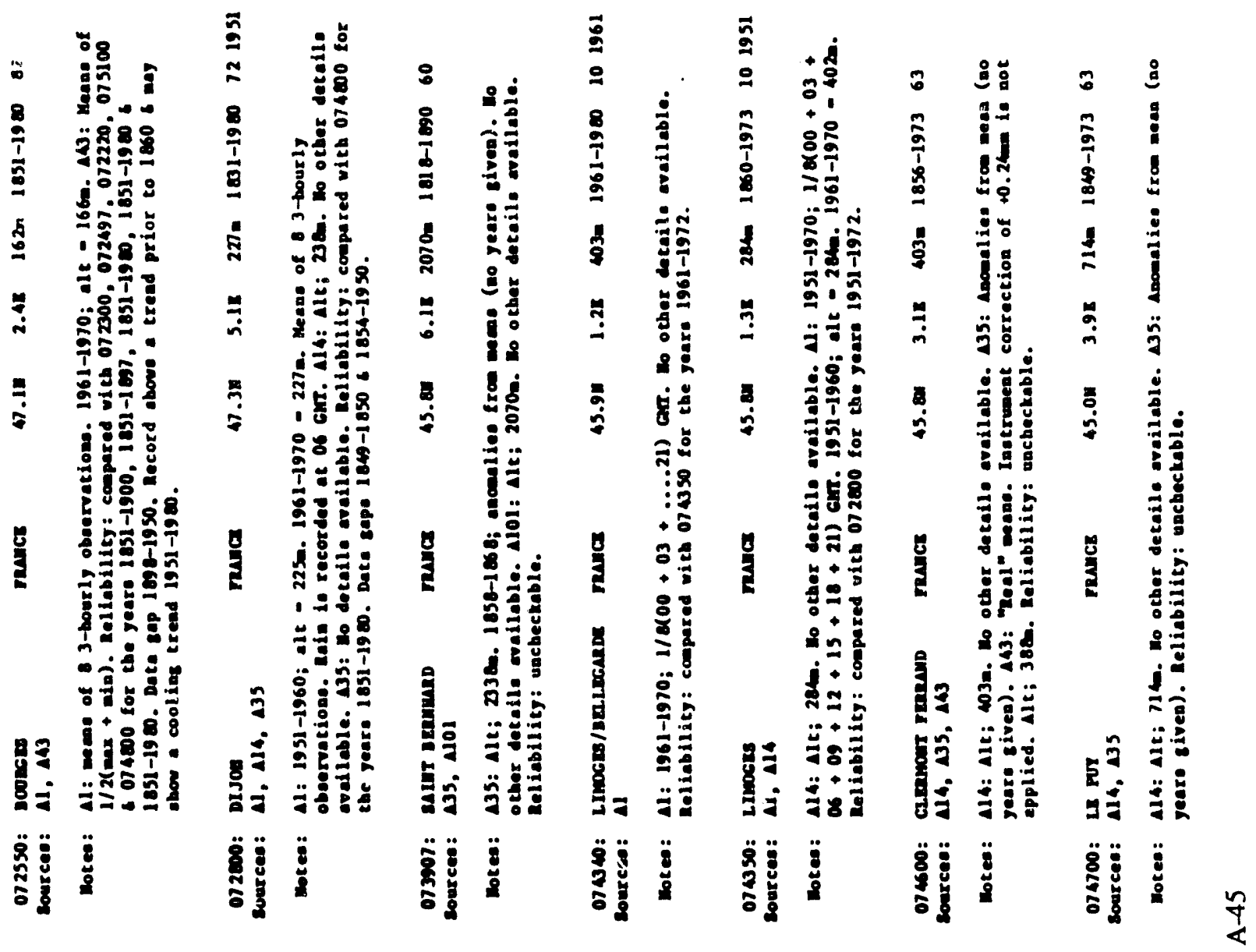

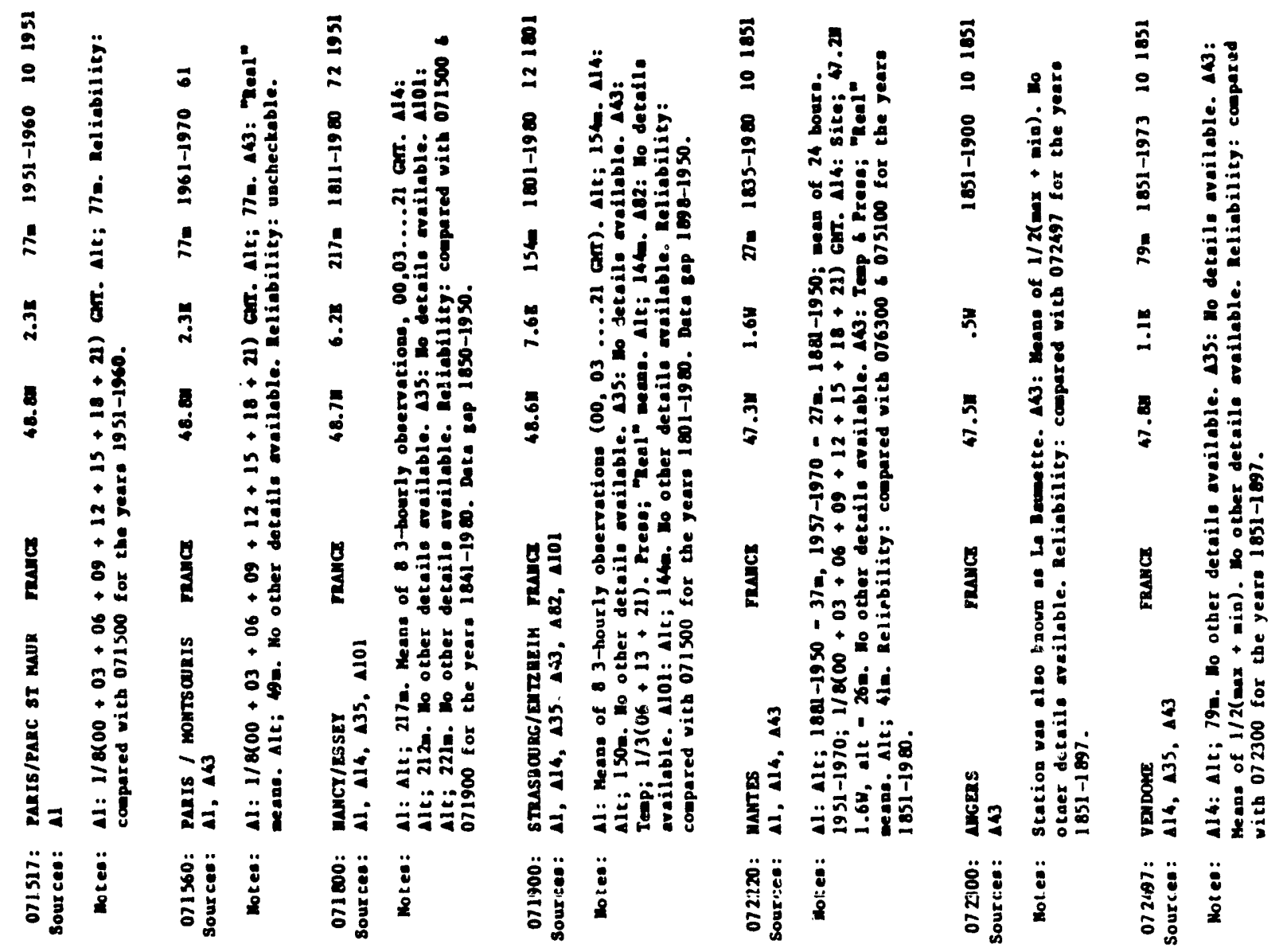




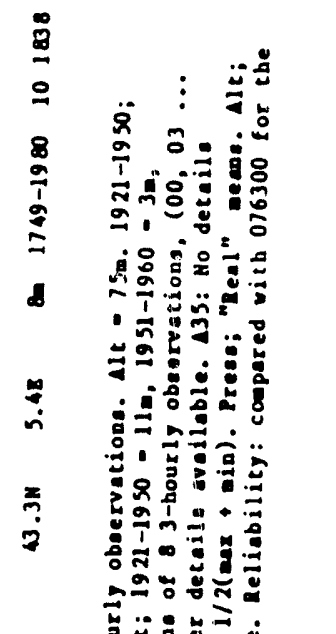

1)

o i i is

tyitio

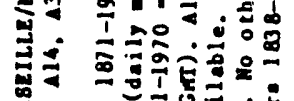

II

เท

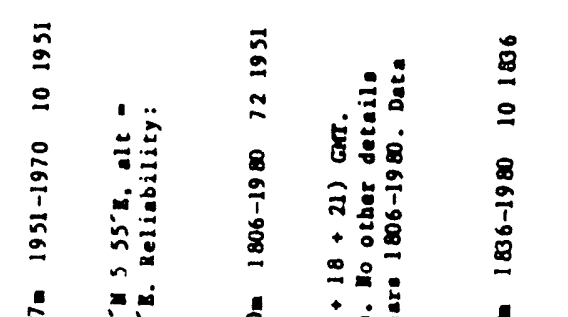

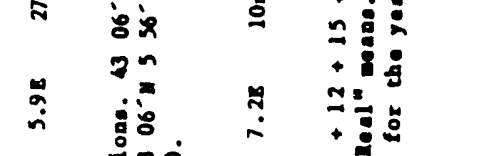

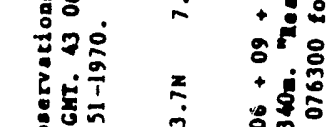

ว

ลี้ำ

我

ธ。

送

苗

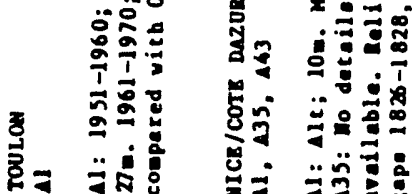

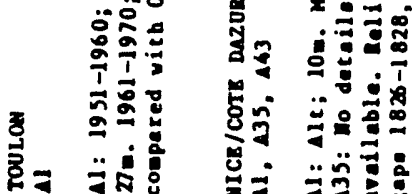

葛

\section{荾苛}

i.

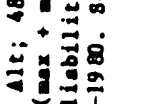

迢吉市

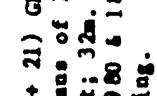

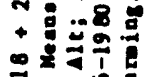

+

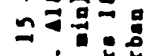

$\stackrel{5}{5}$

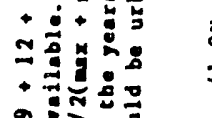

จ

:

范 ํํㅇำ

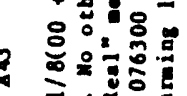

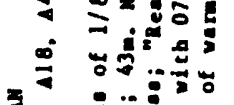

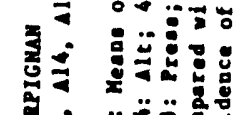

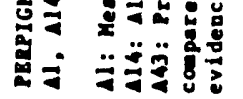

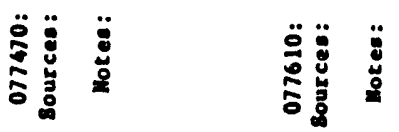

कू

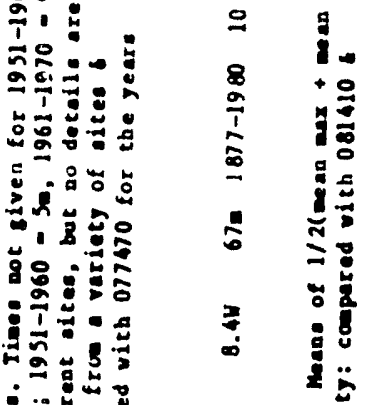

势

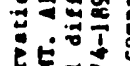

둥형.



苟

용

。苗

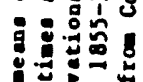

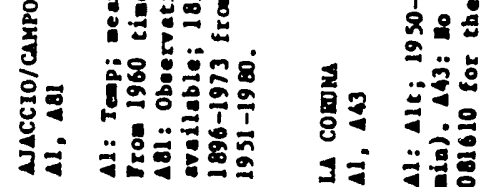

递苛范

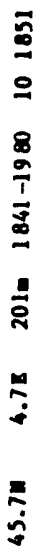

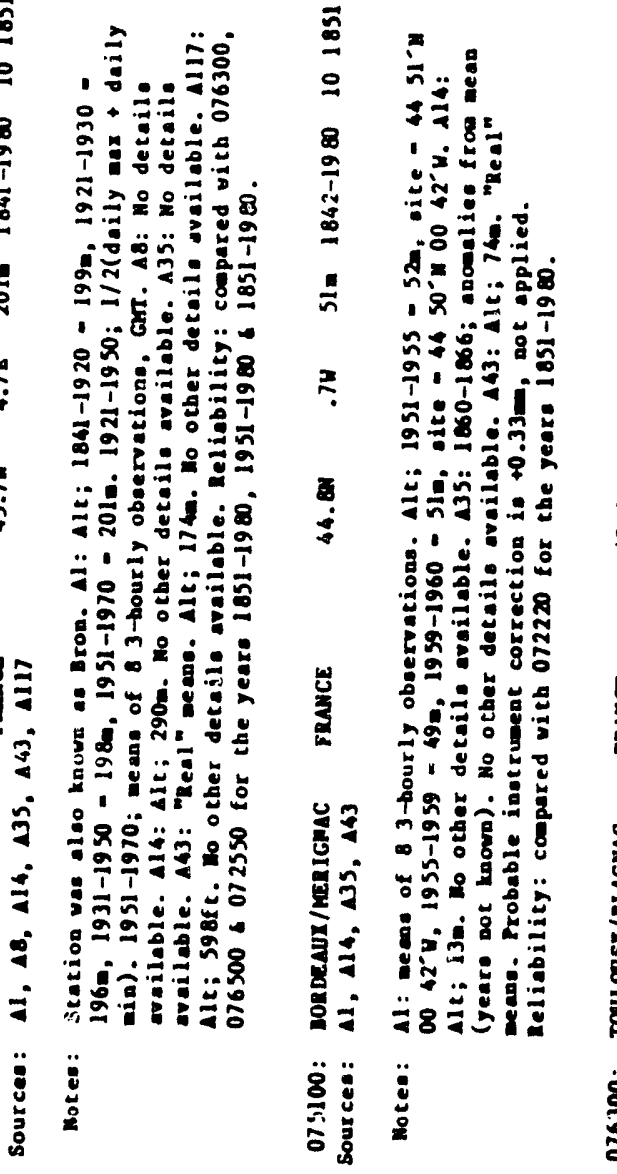

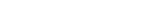

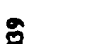



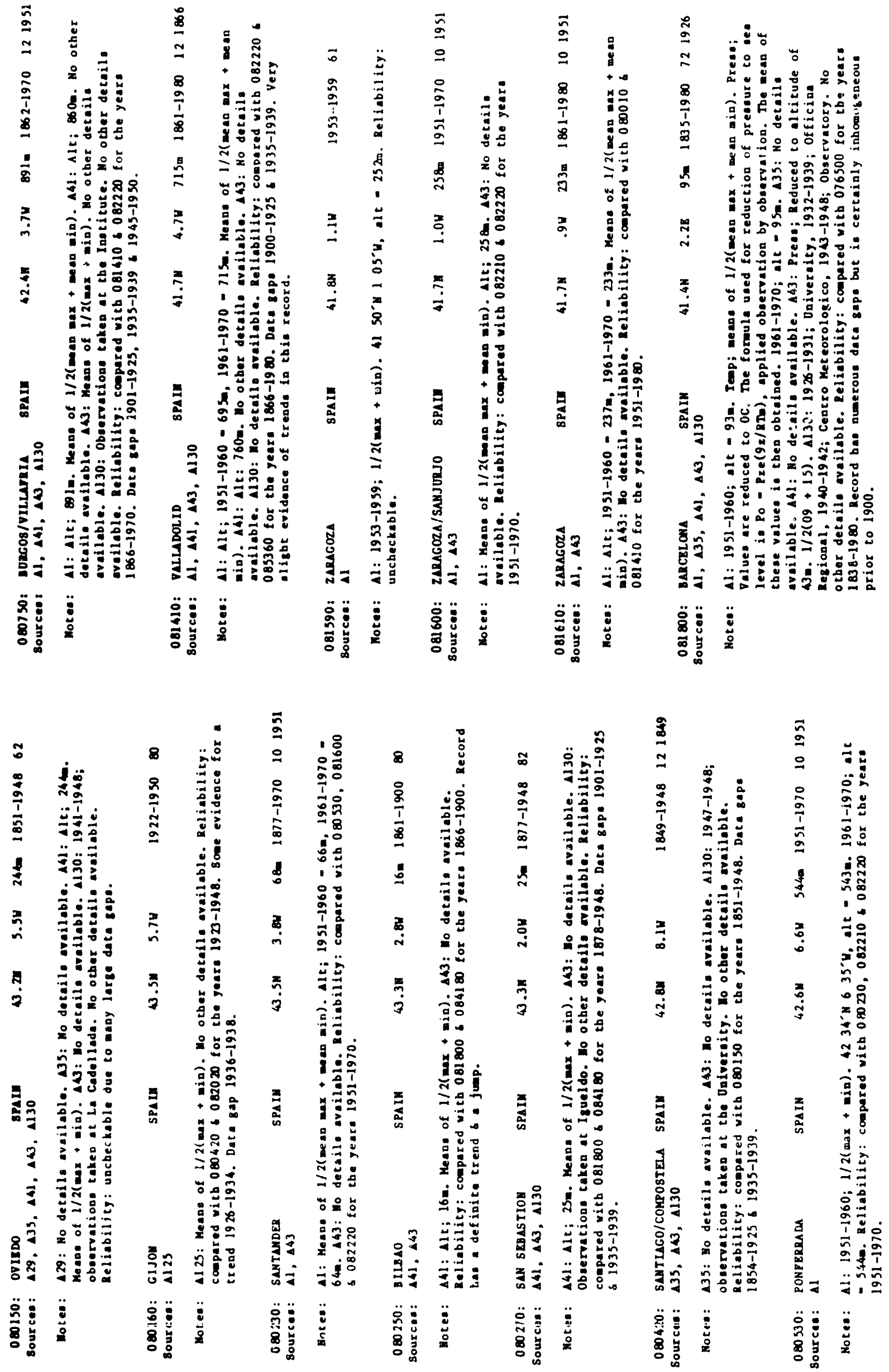


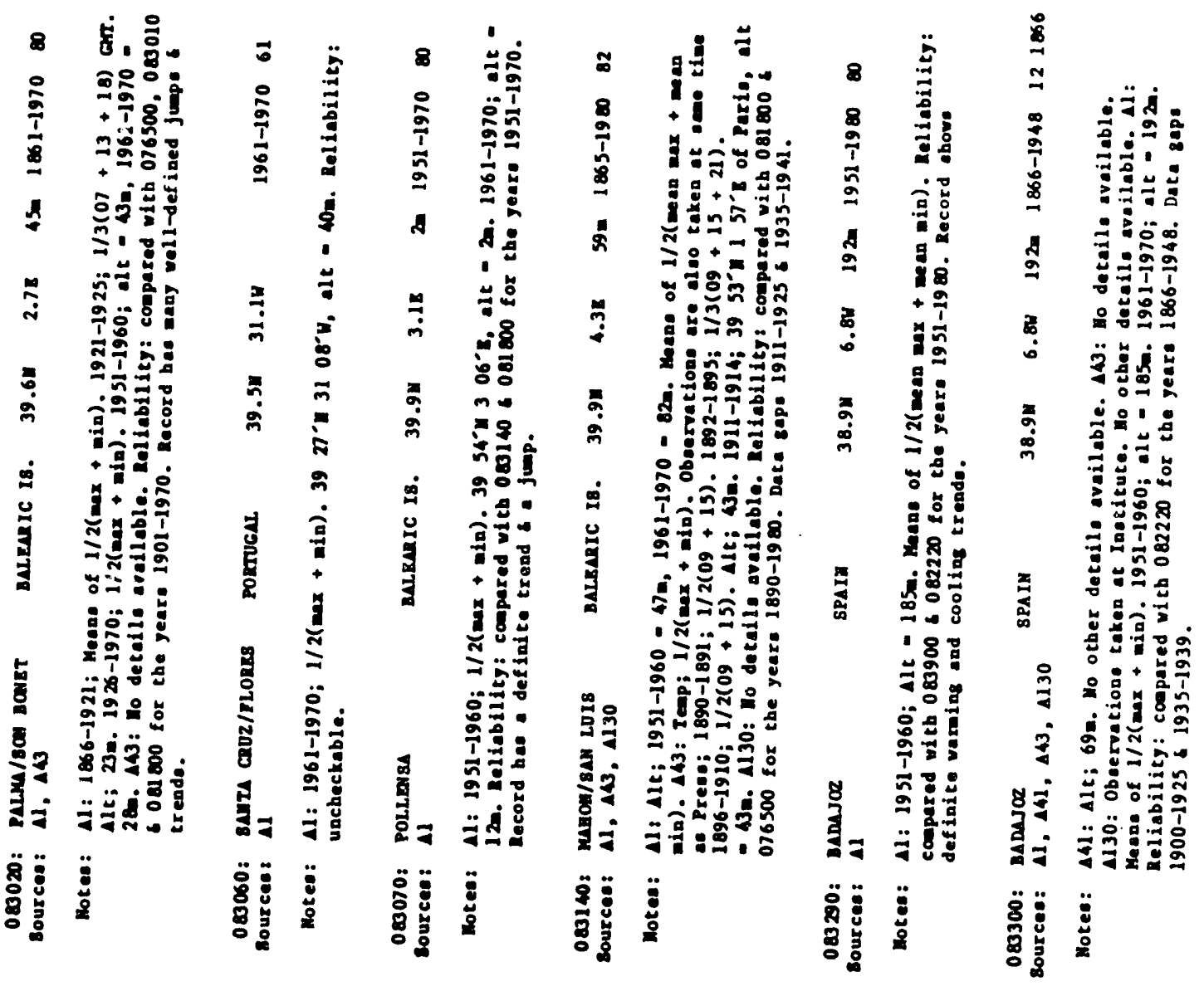

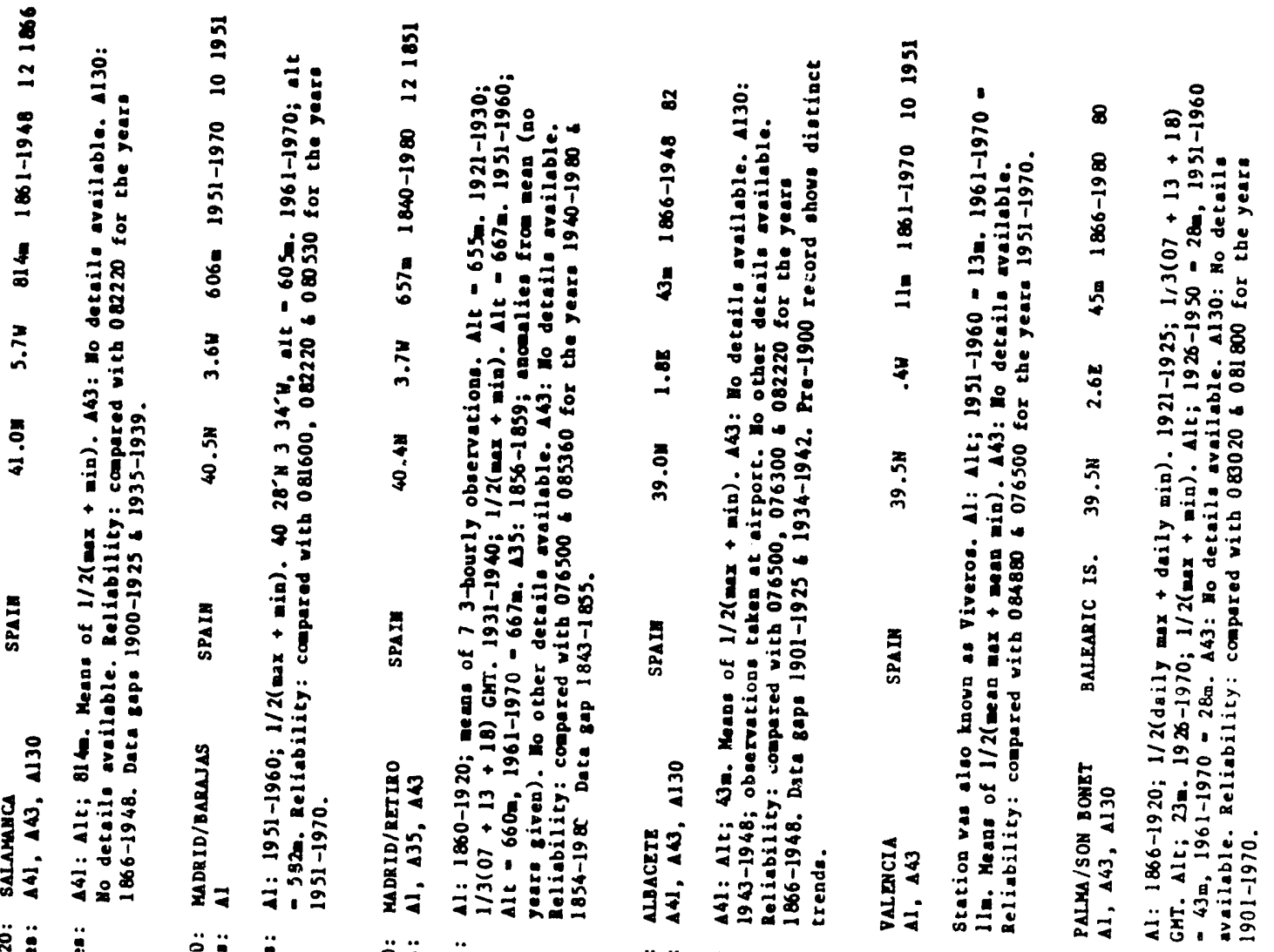

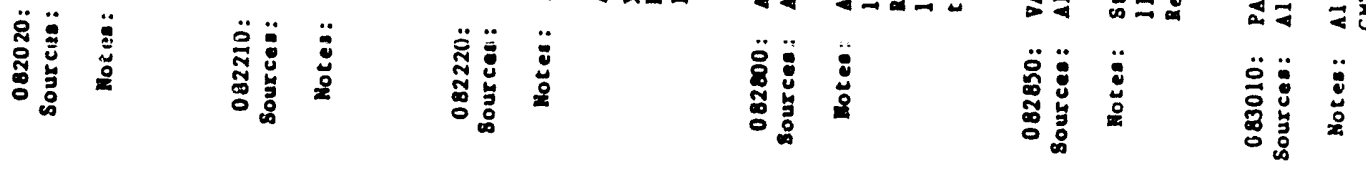



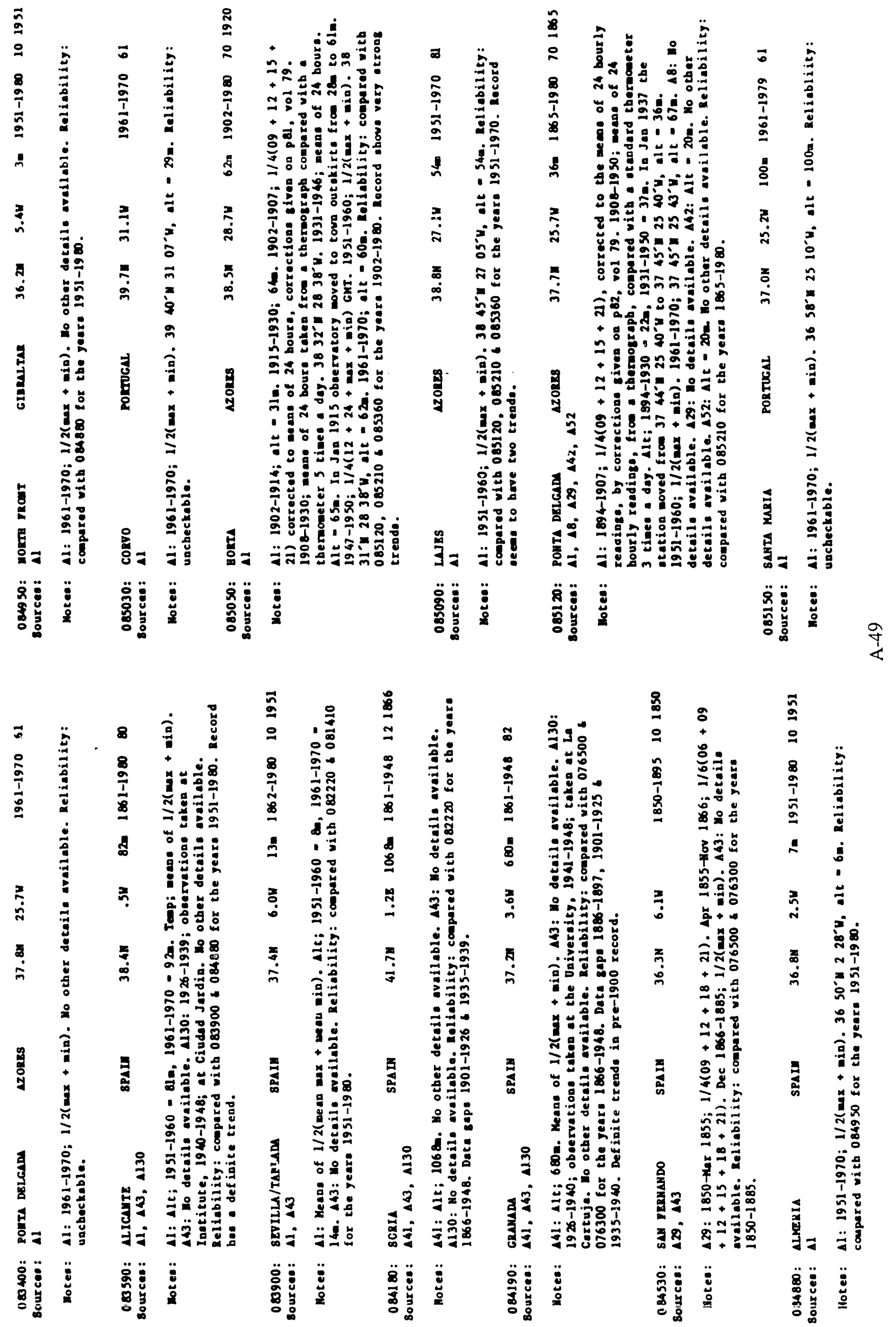


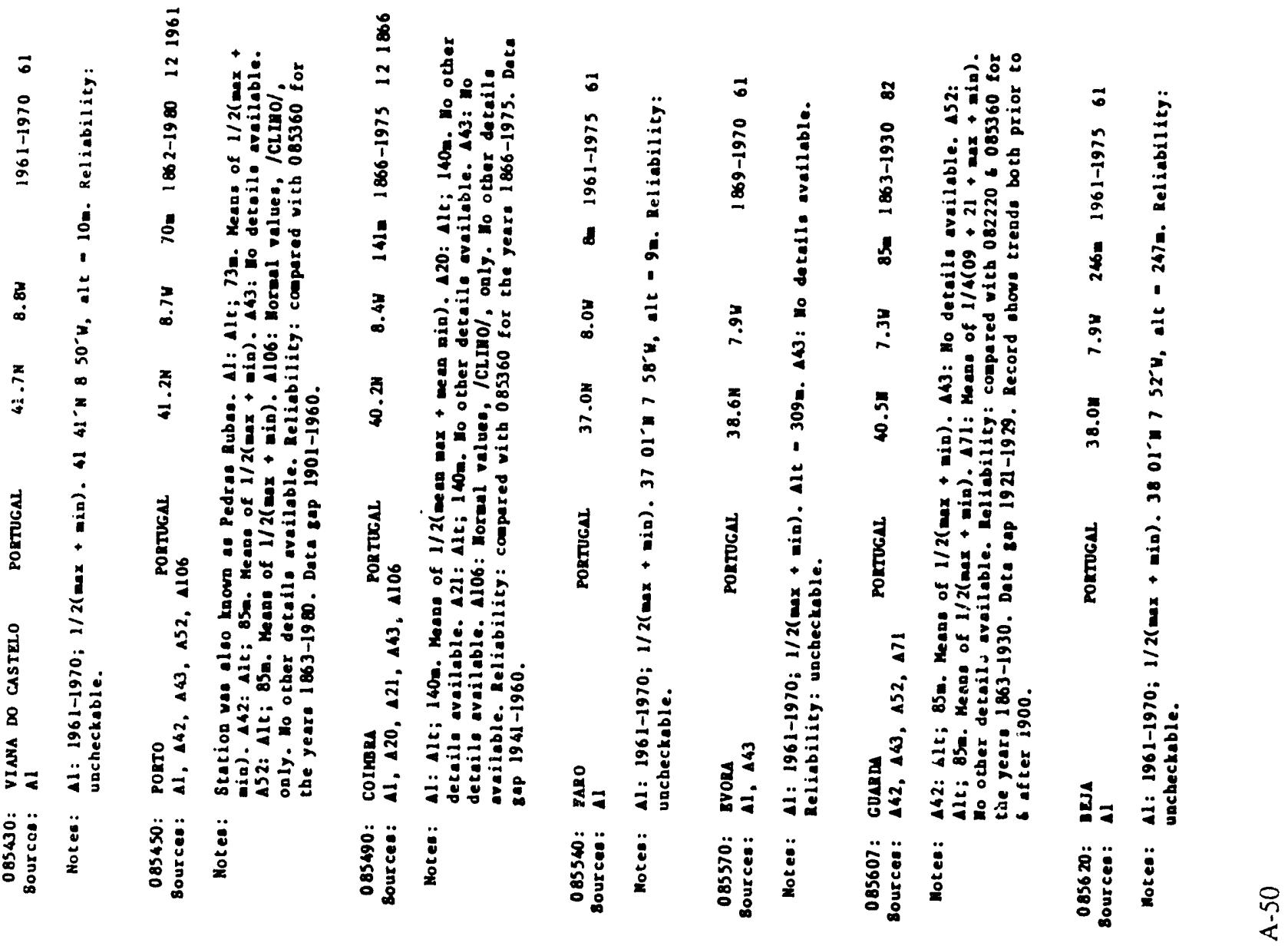

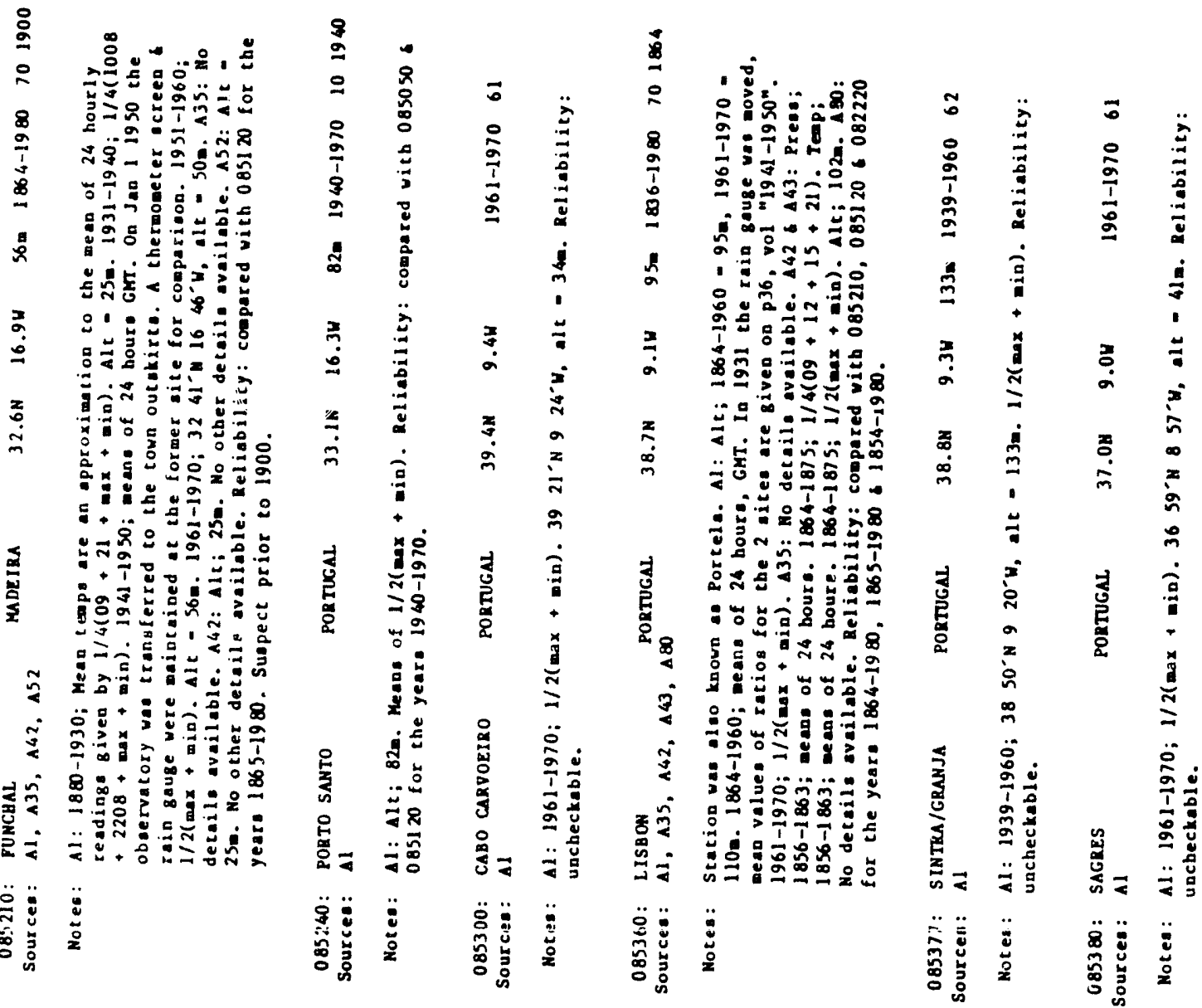



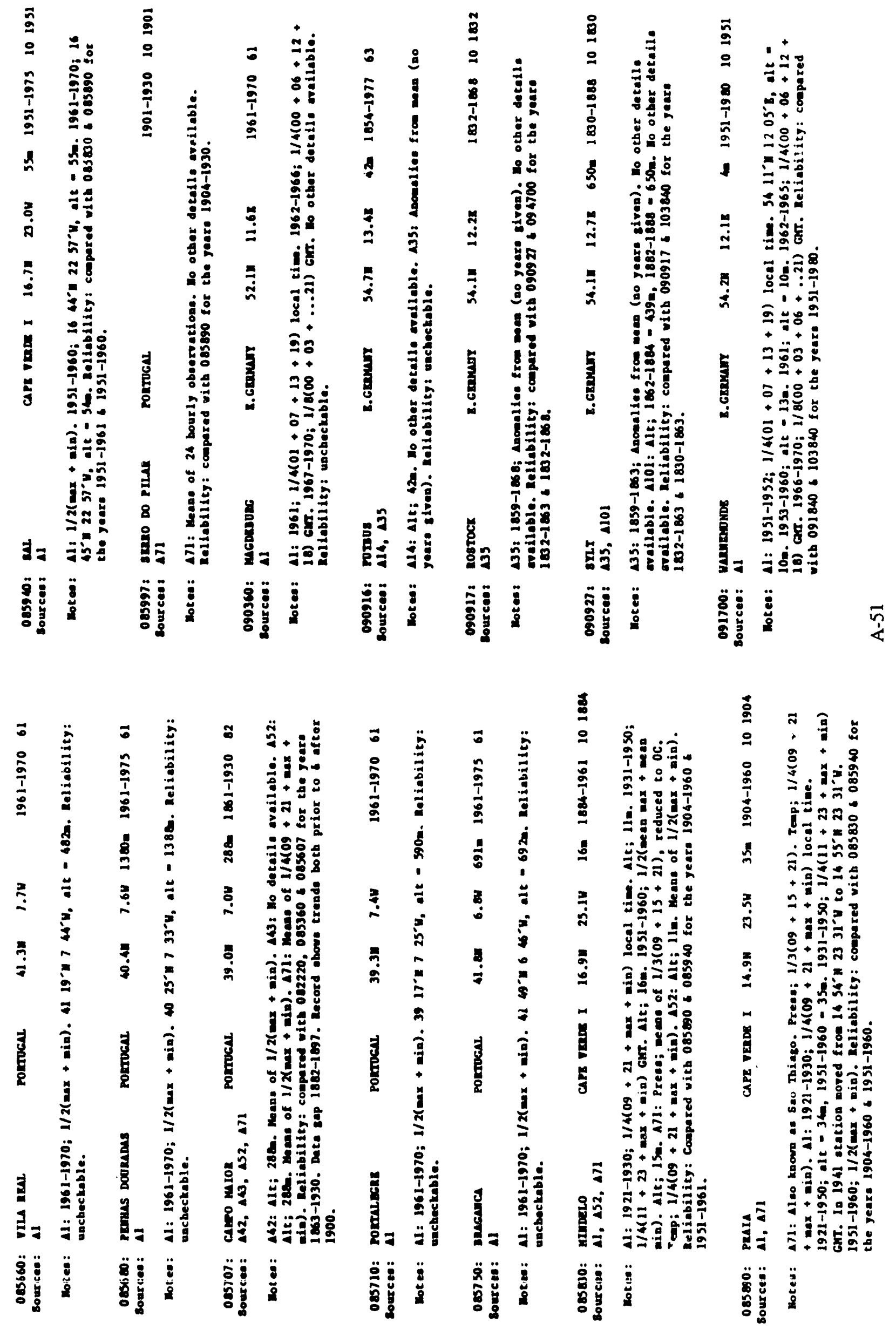


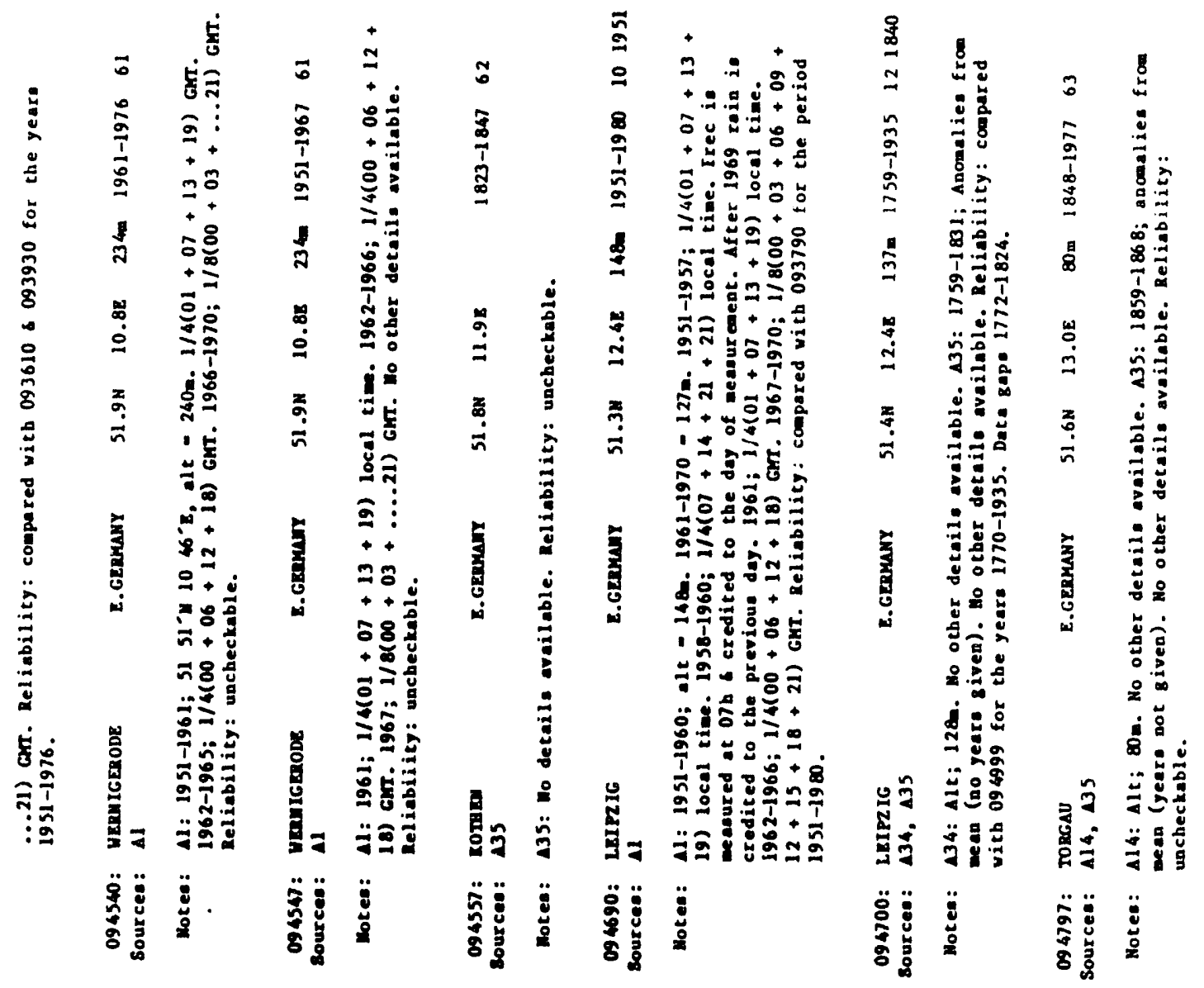

荌

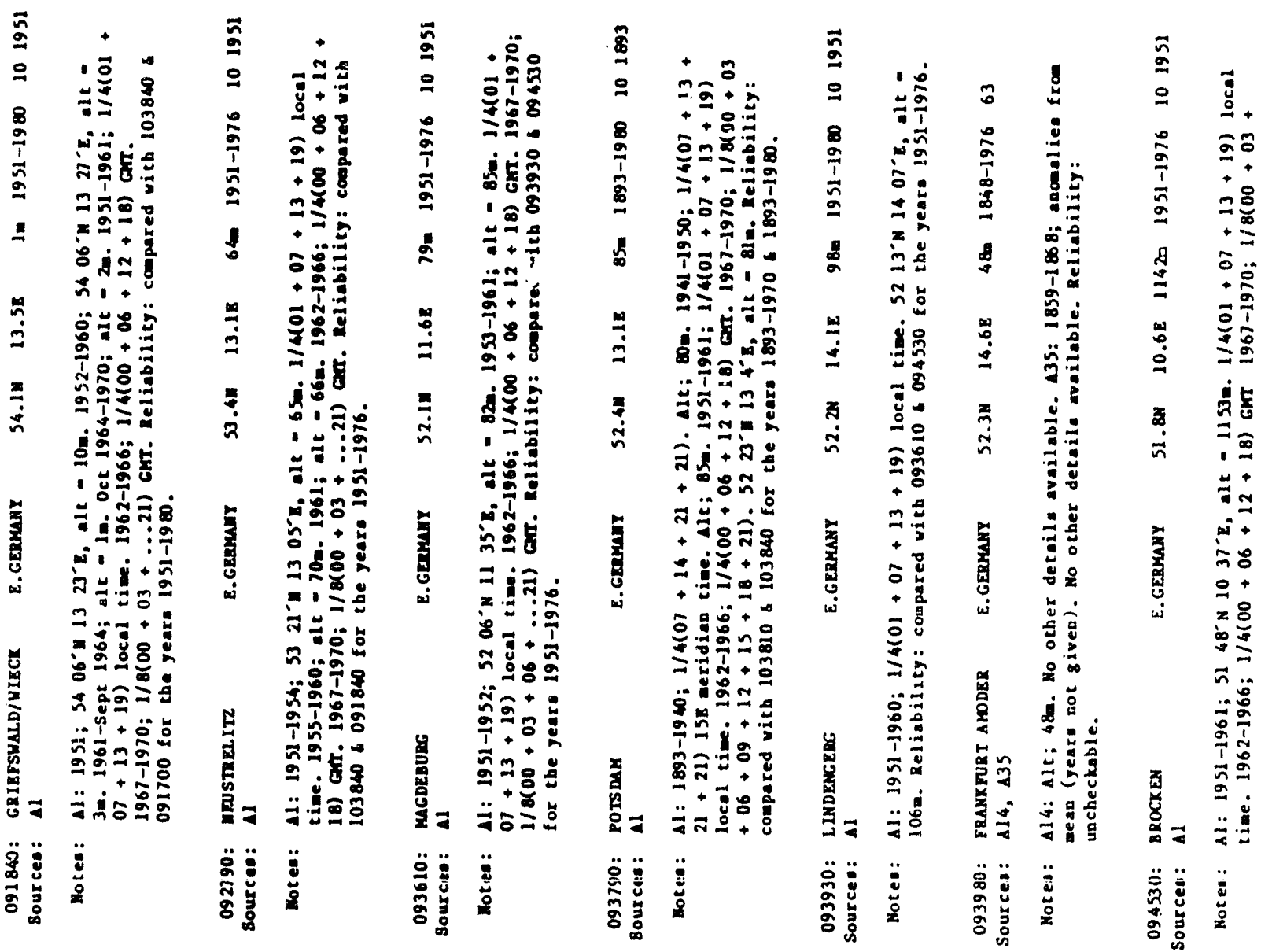



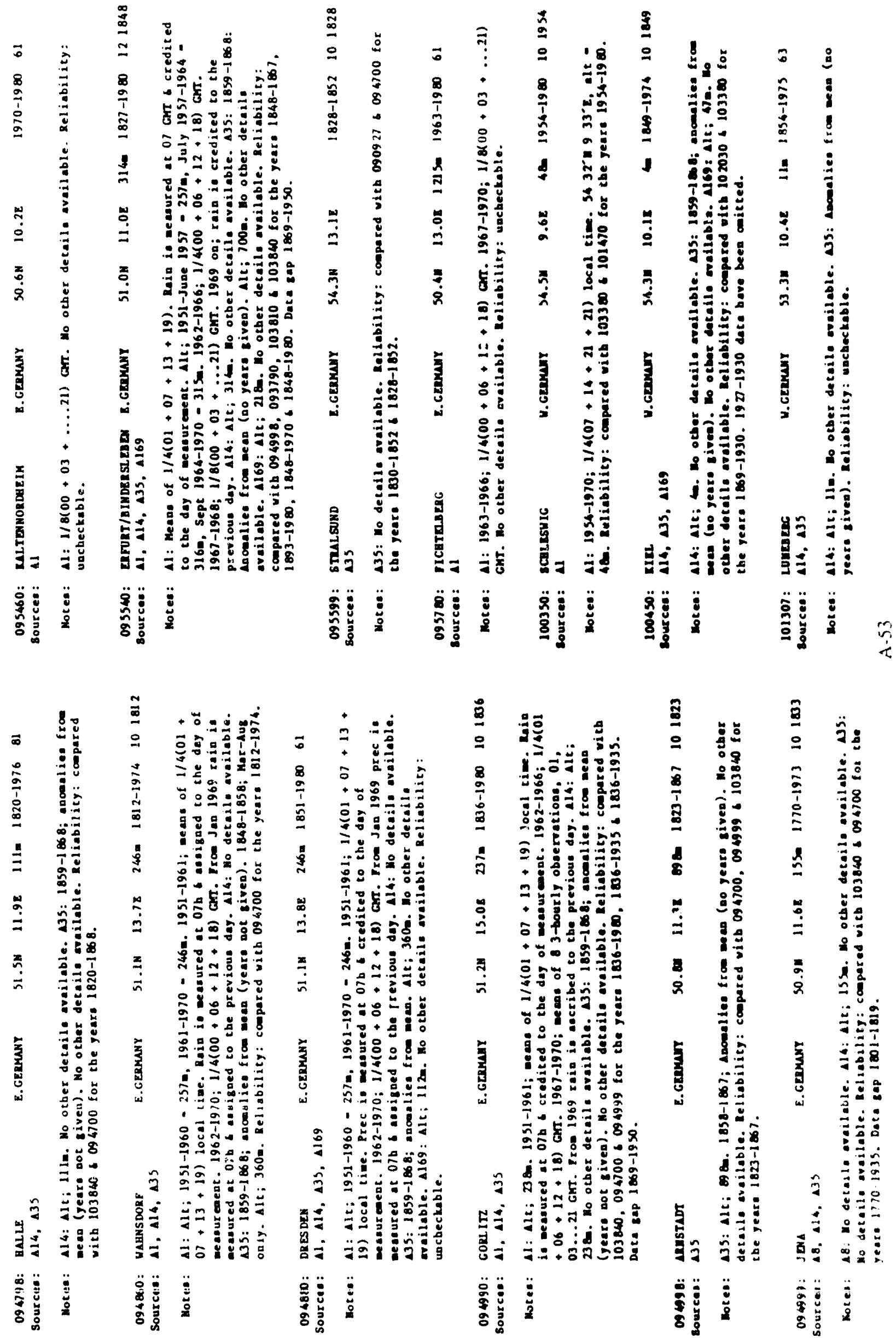

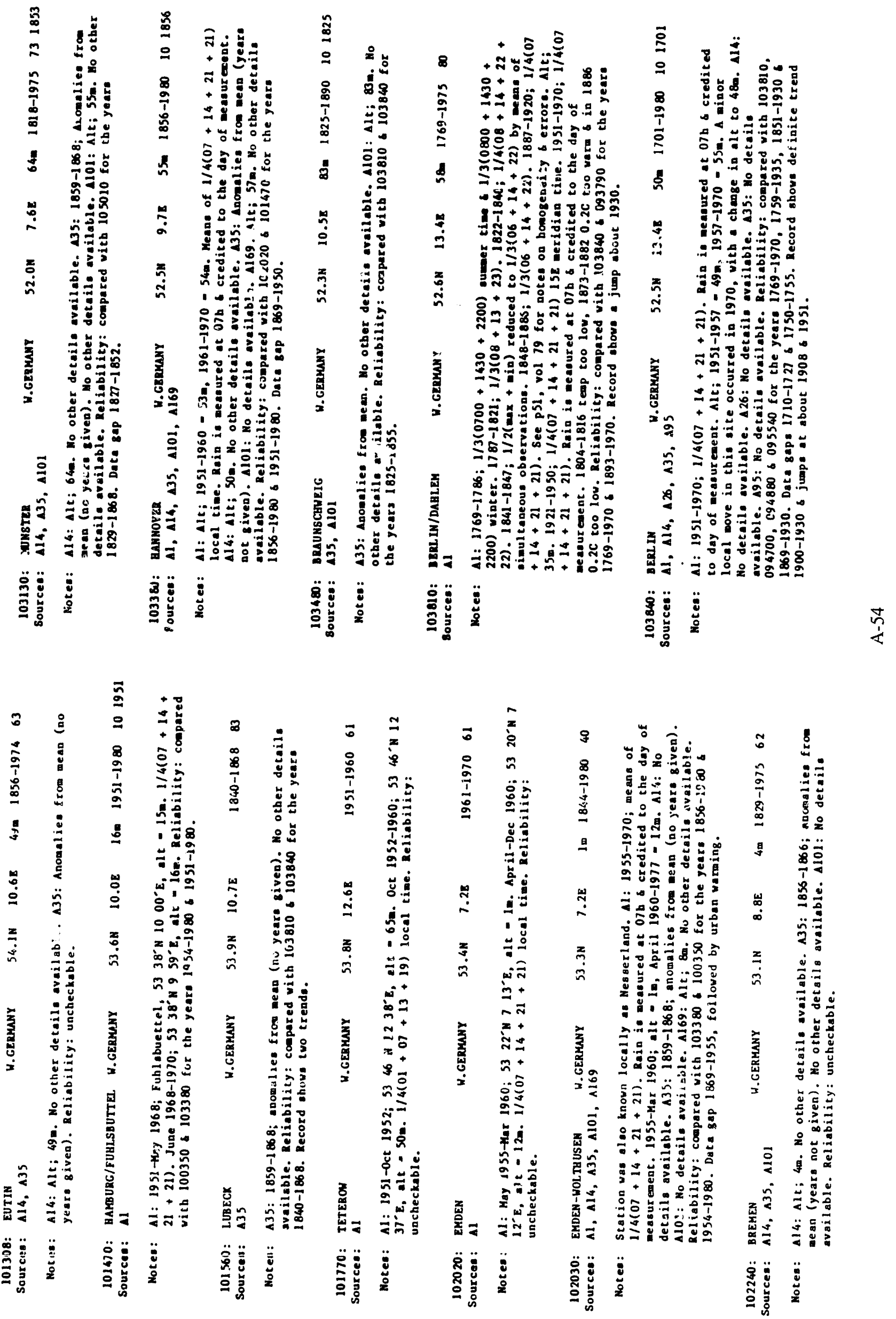

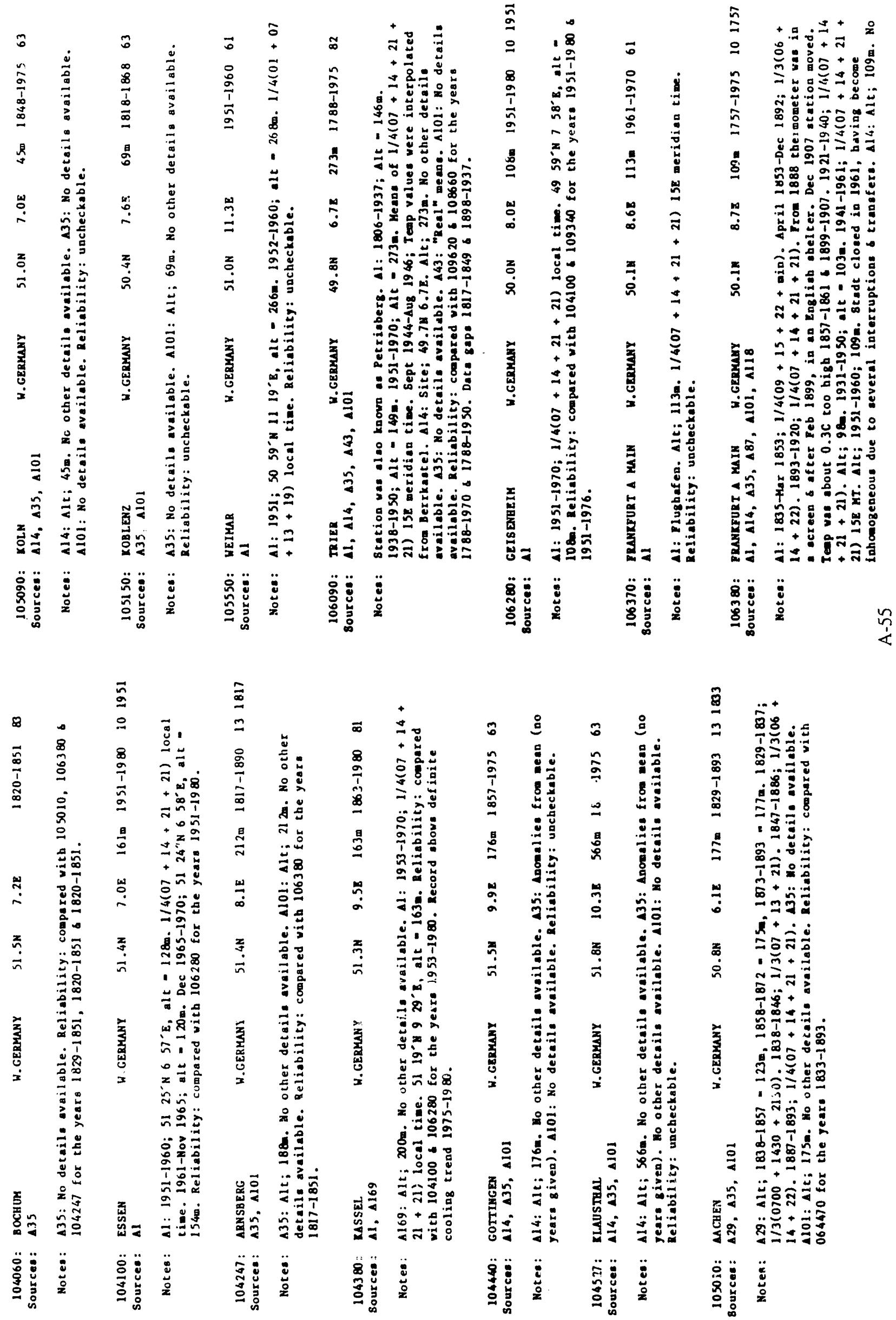


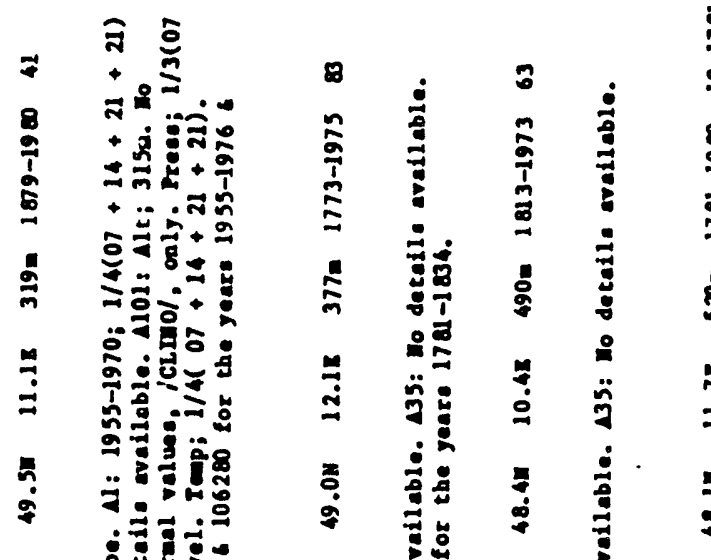

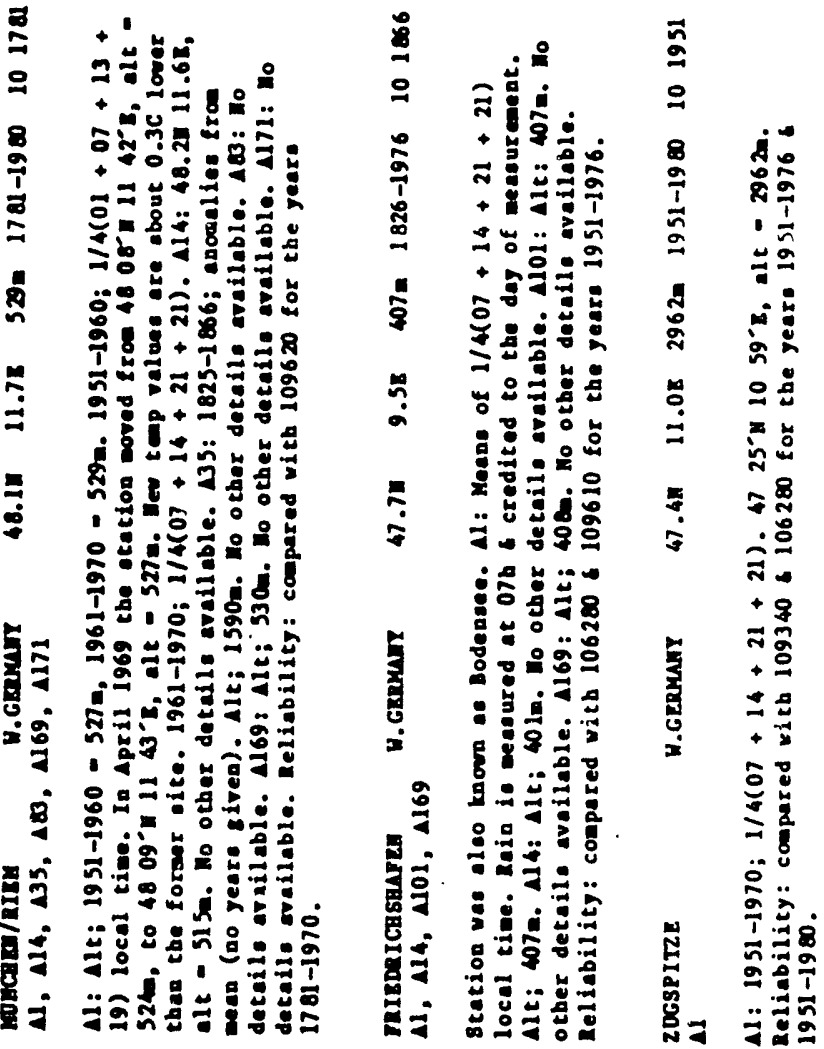

暳

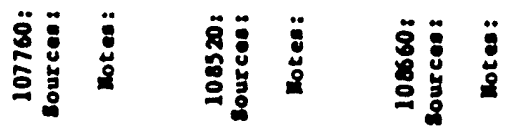

!I

递苛

号

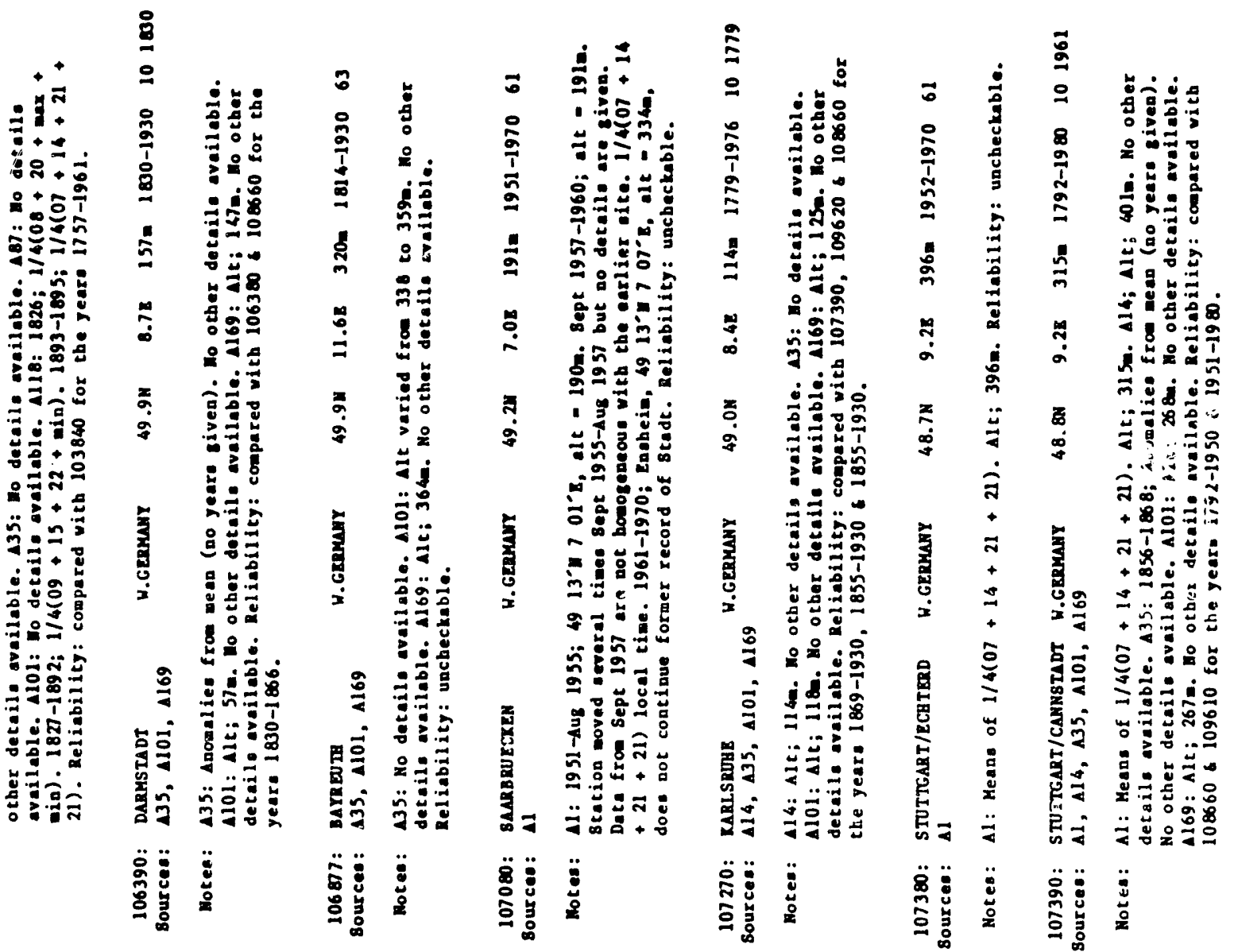




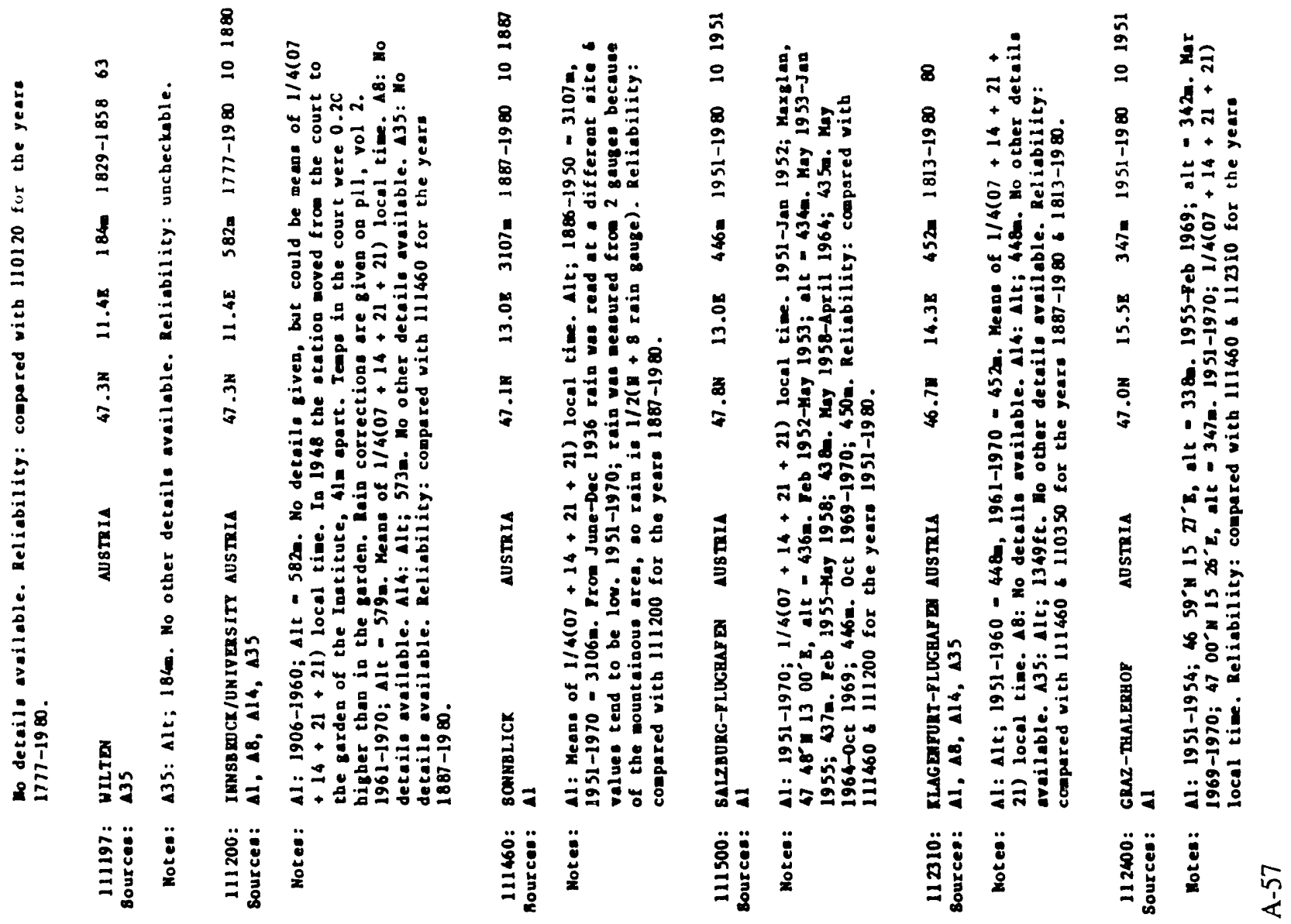

\section{照}$$
\text { 竞 }
$$

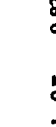

a

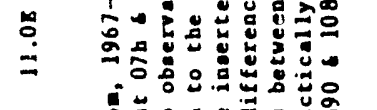

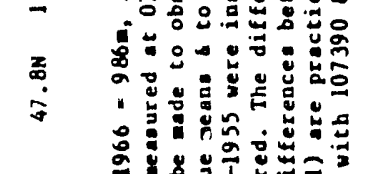

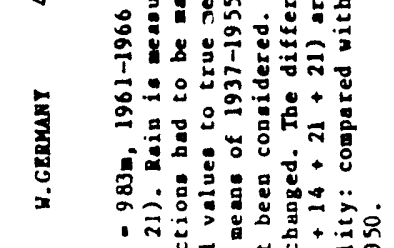

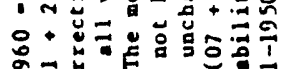

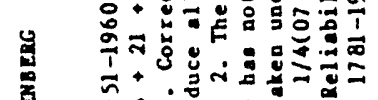

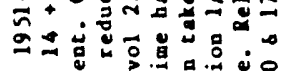

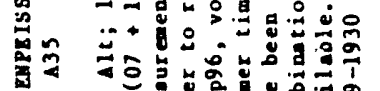

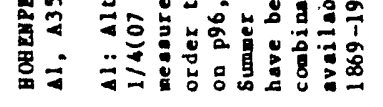

in

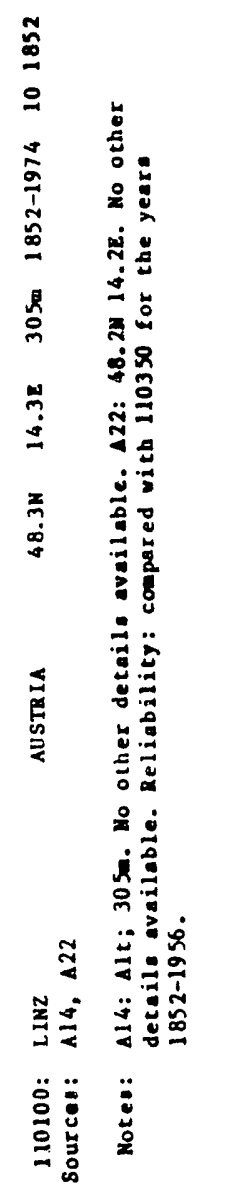

$\stackrel{8}{9}$

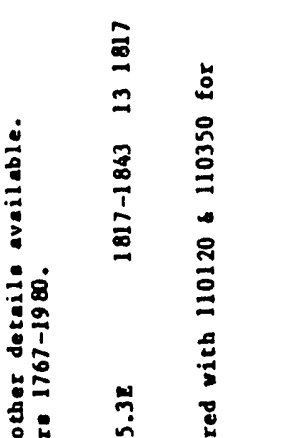

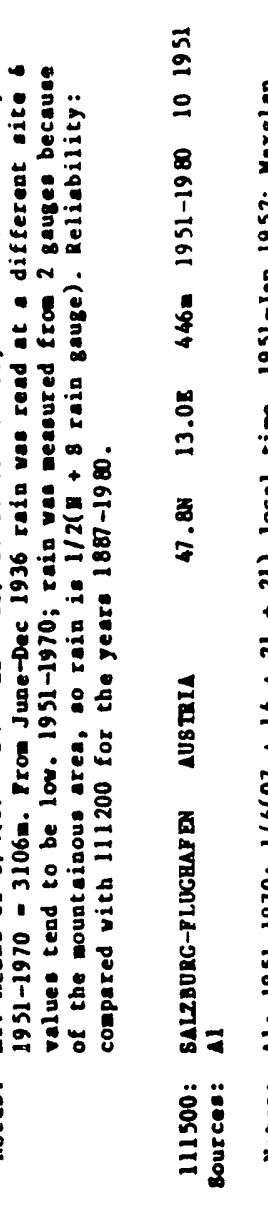

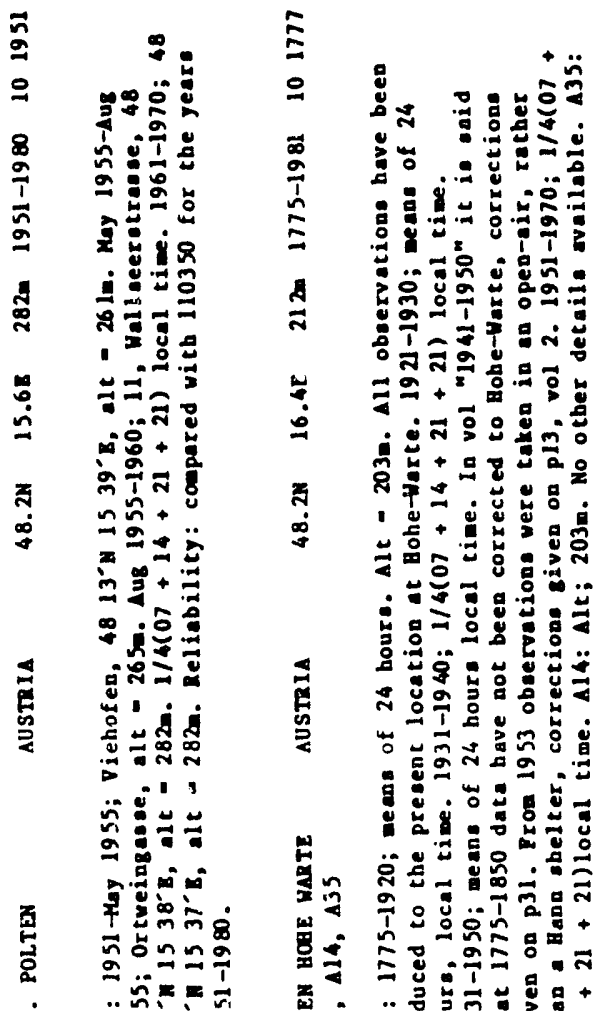

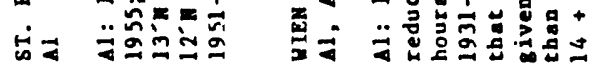
芯苛苛 


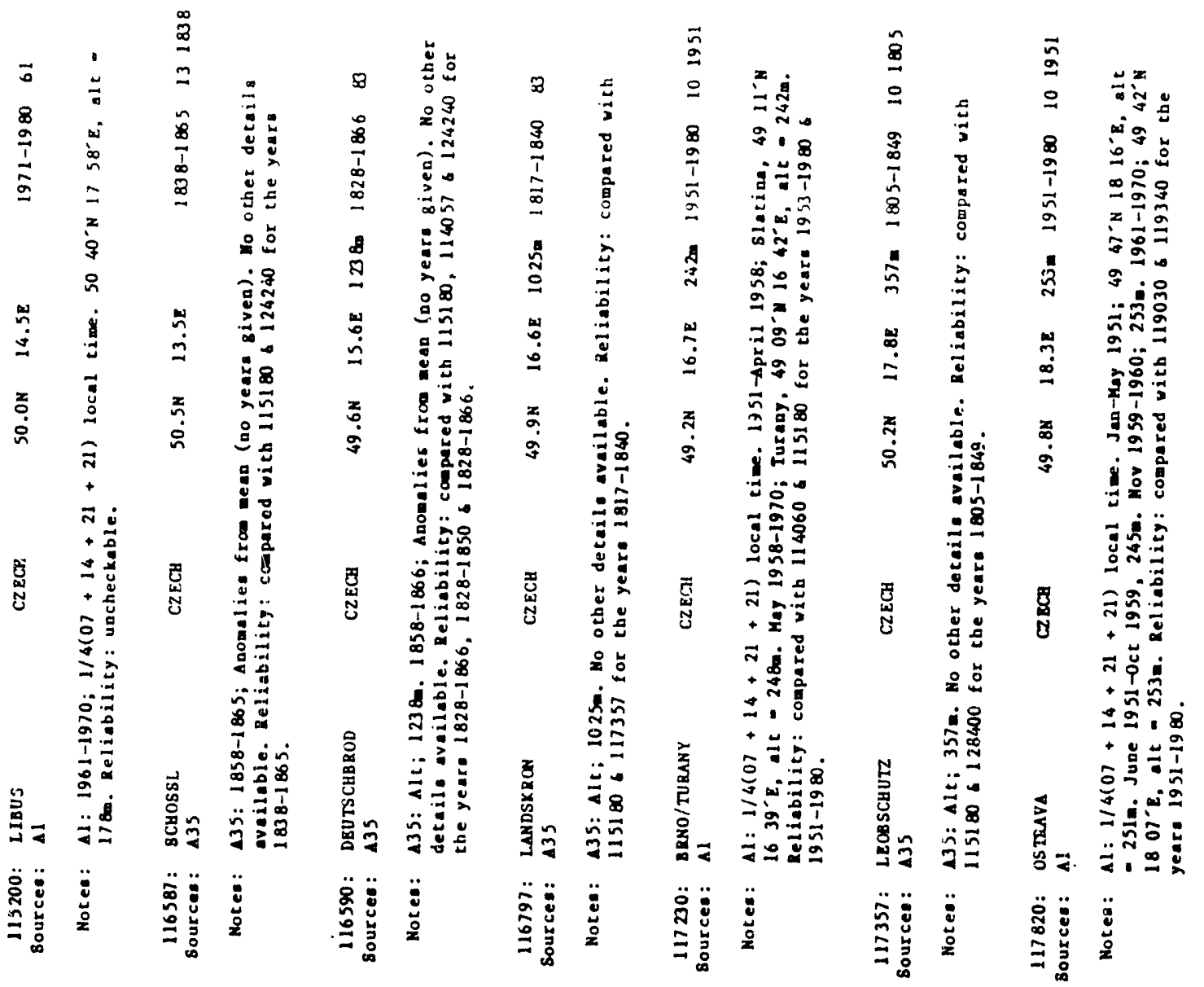

$\stackrel{\infty}{<}$

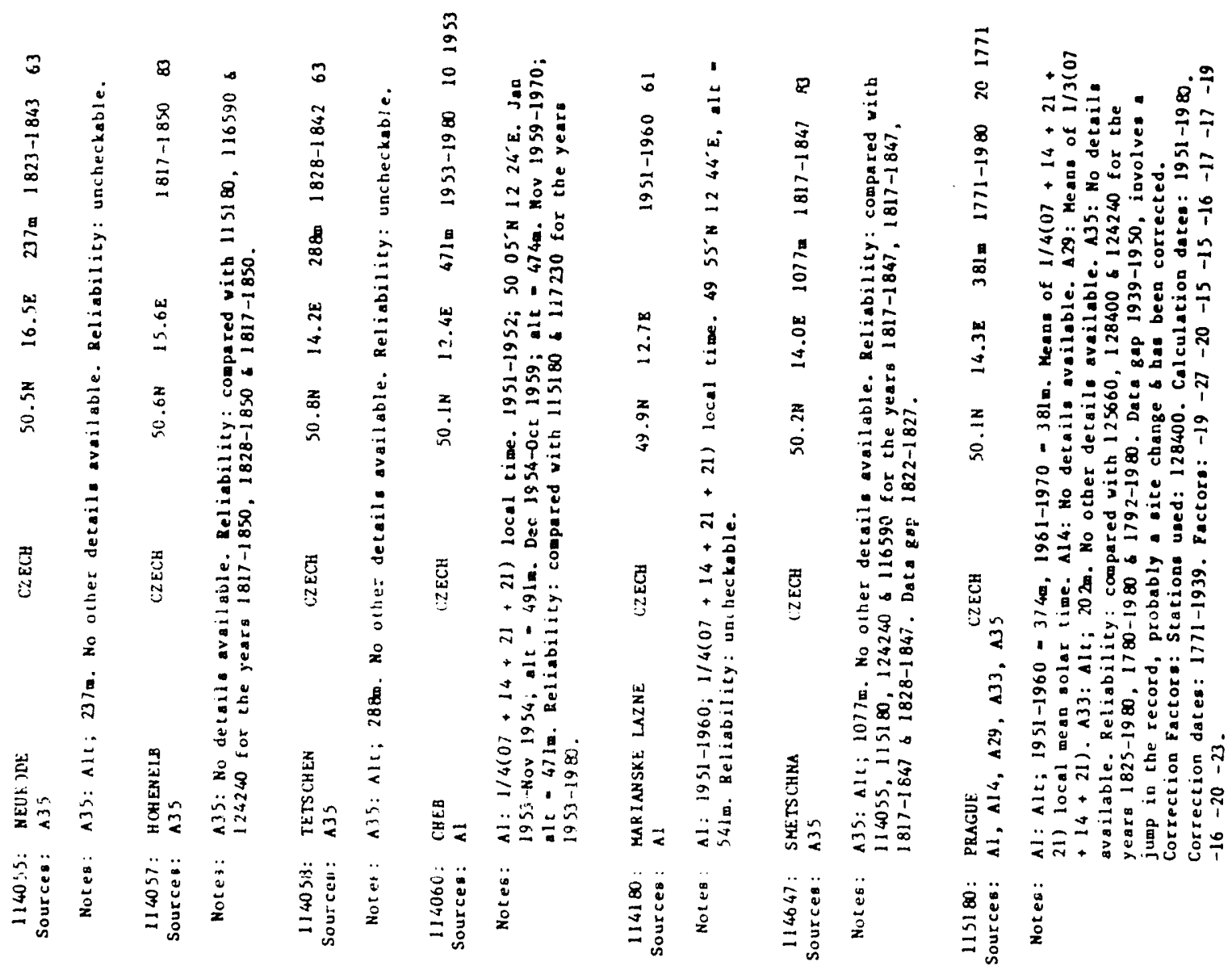



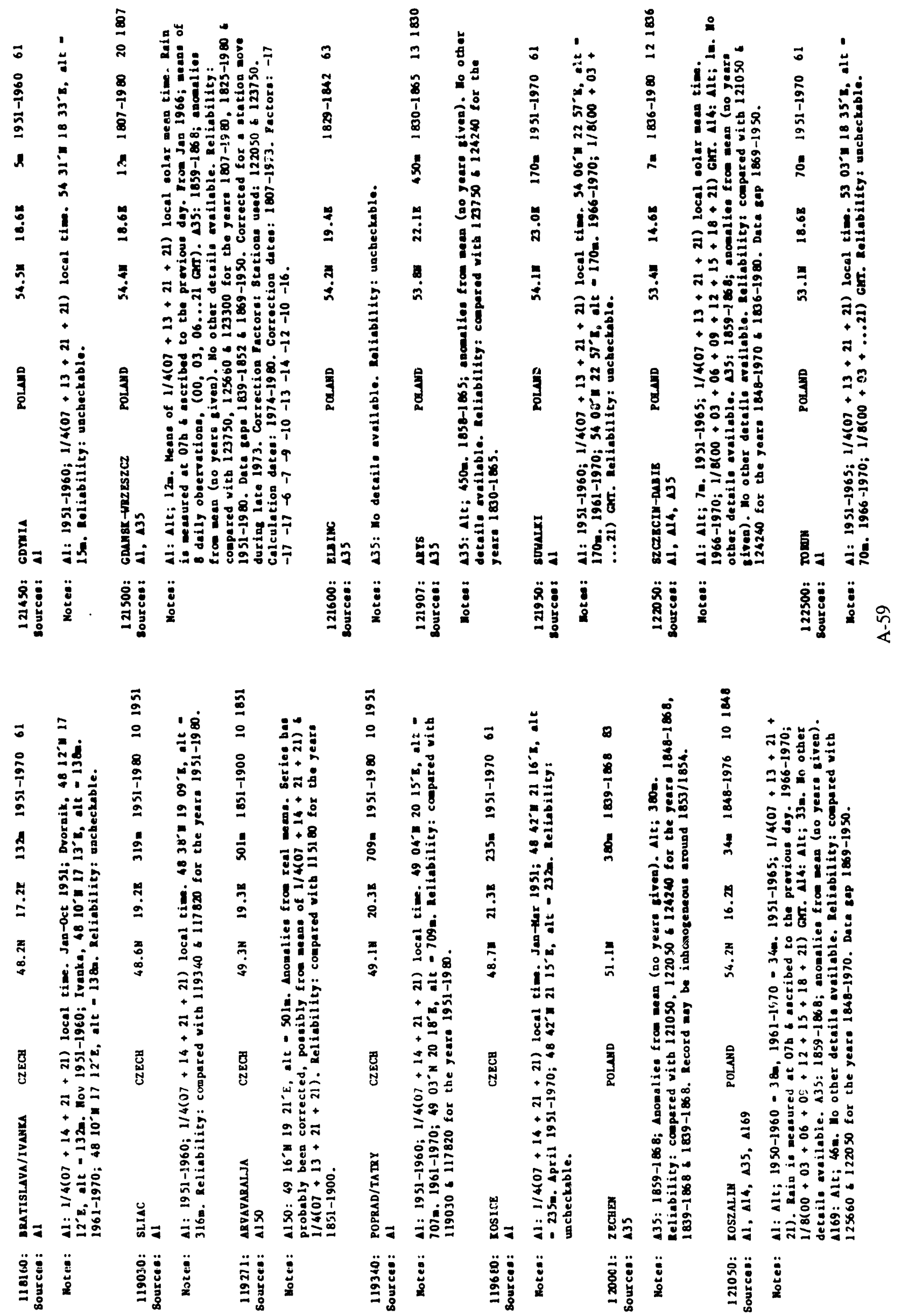

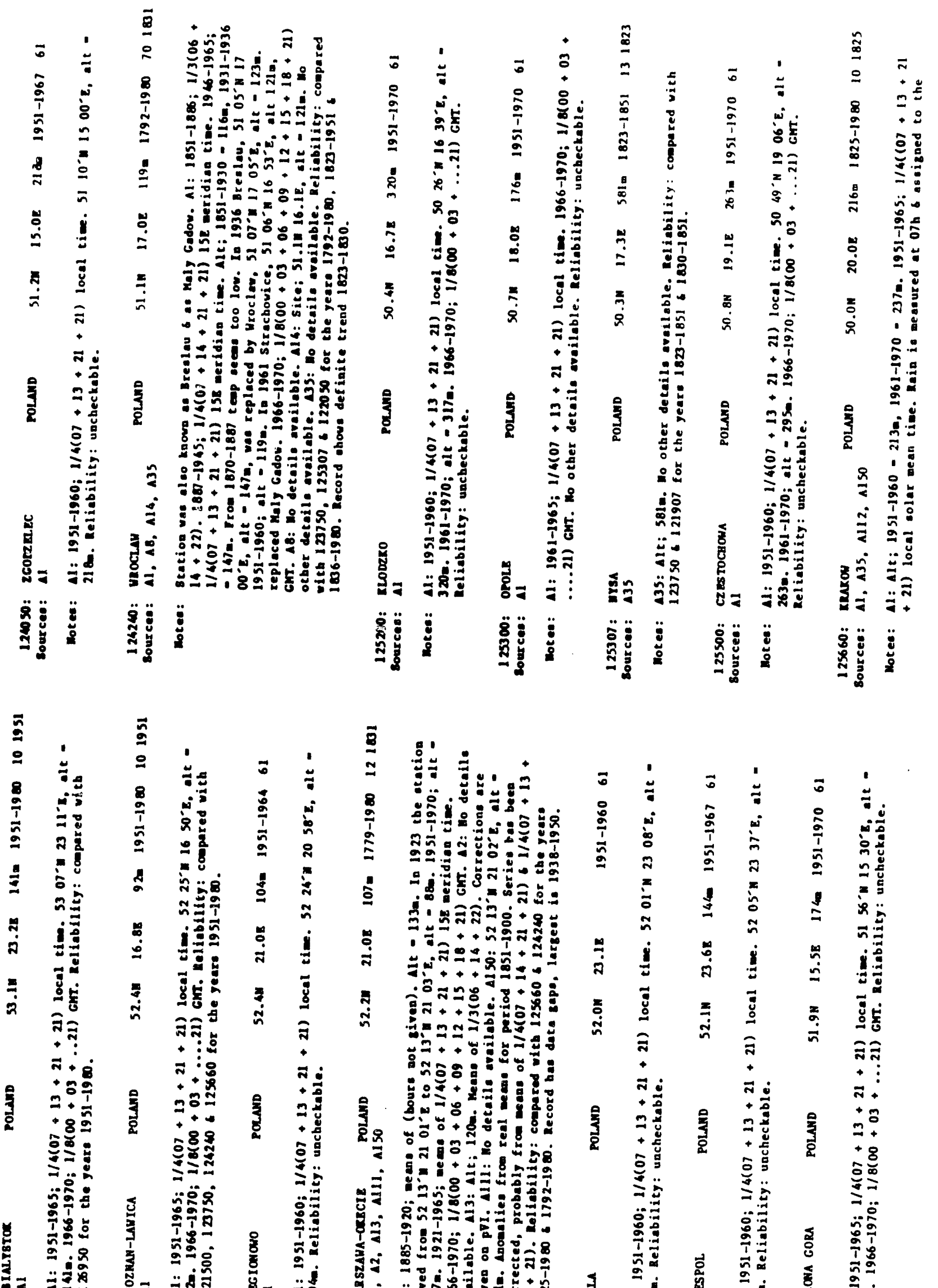

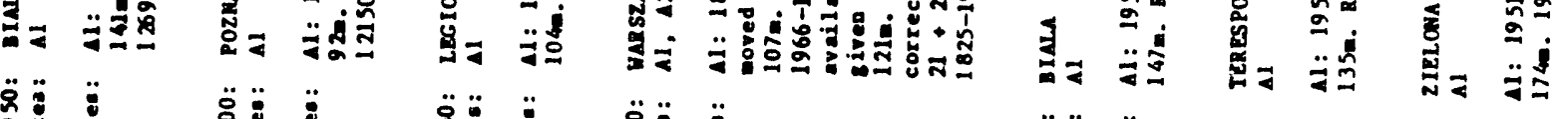

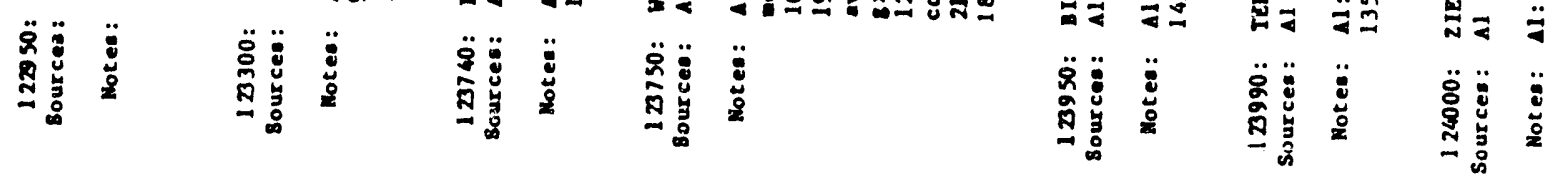




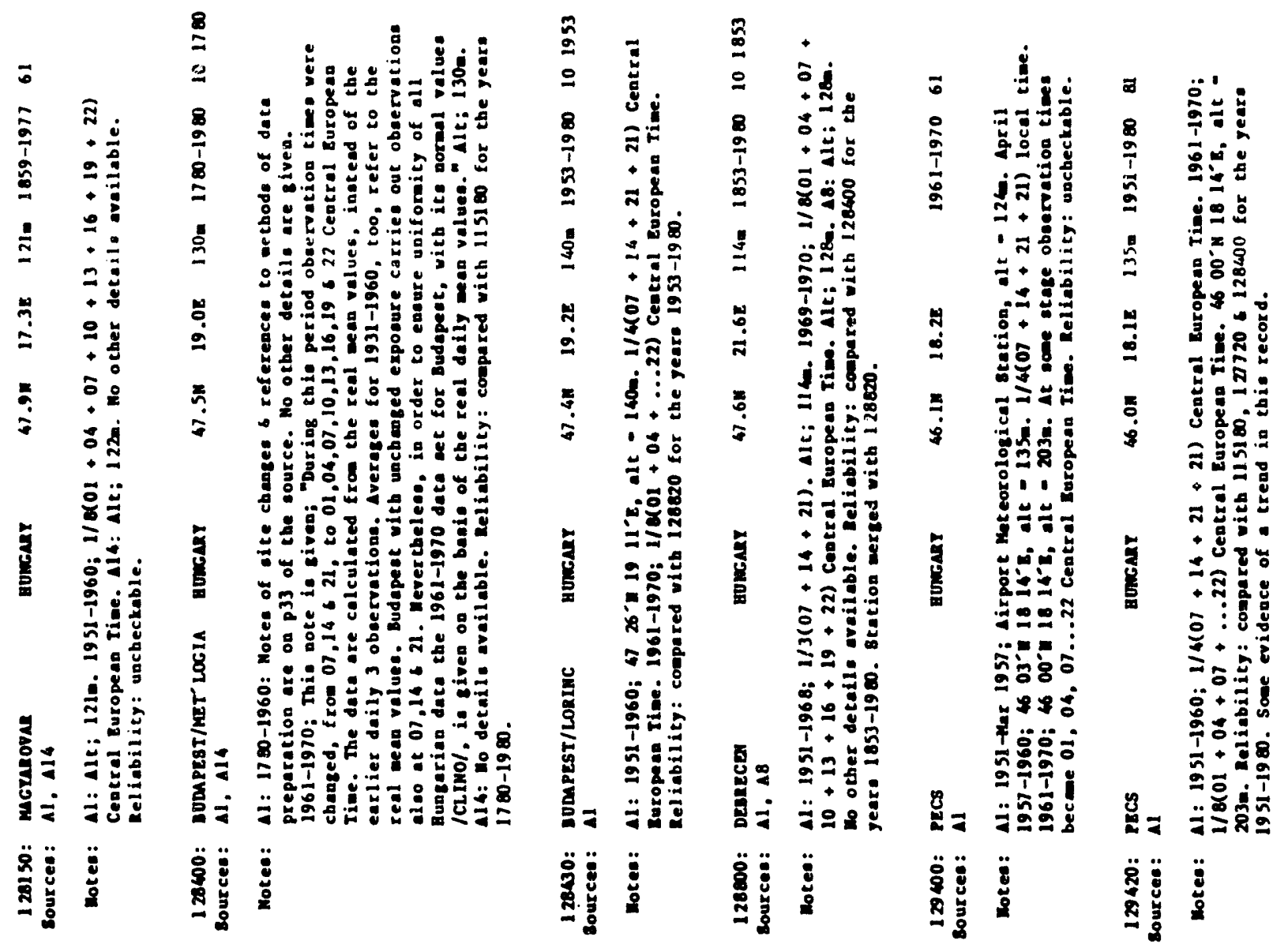

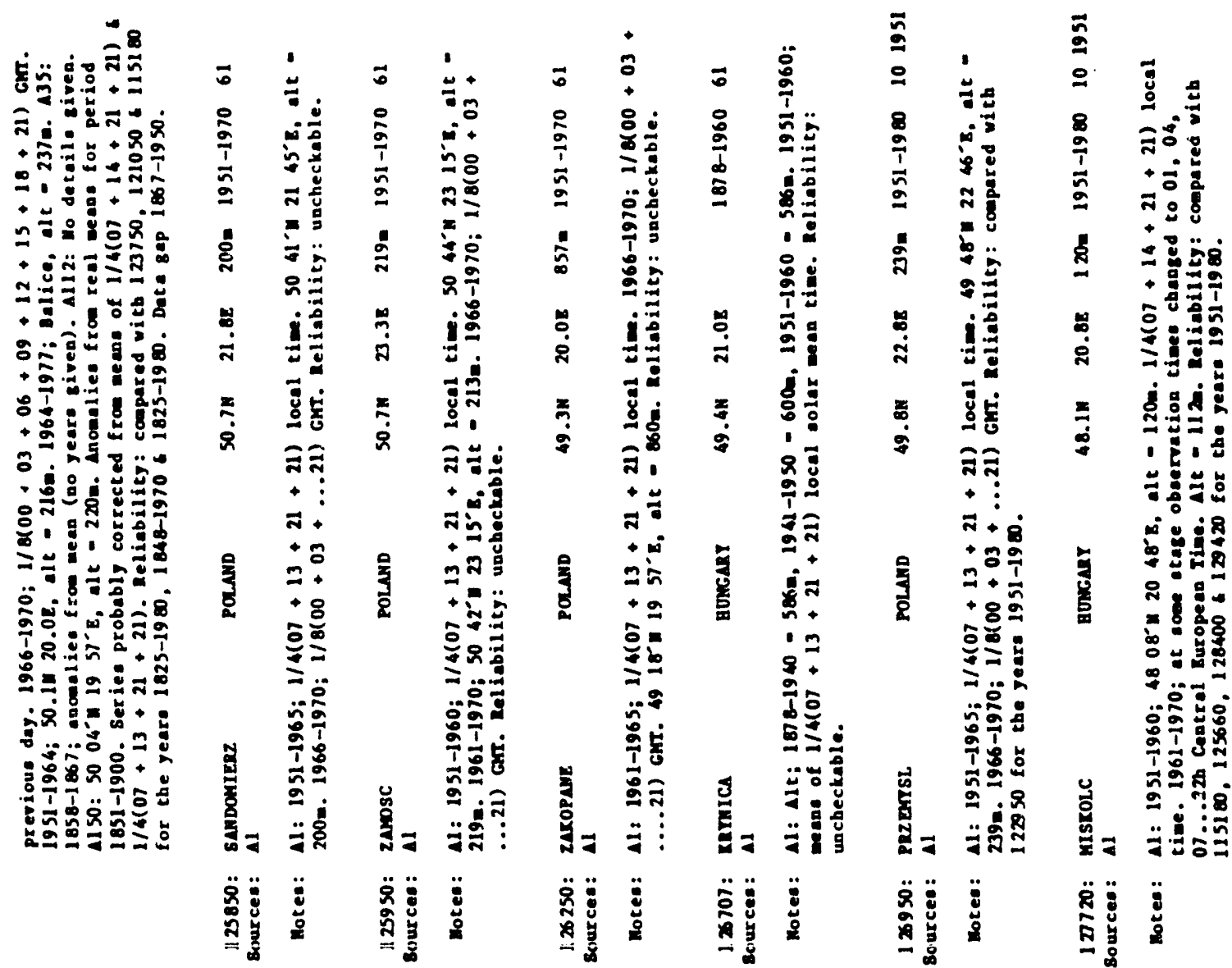




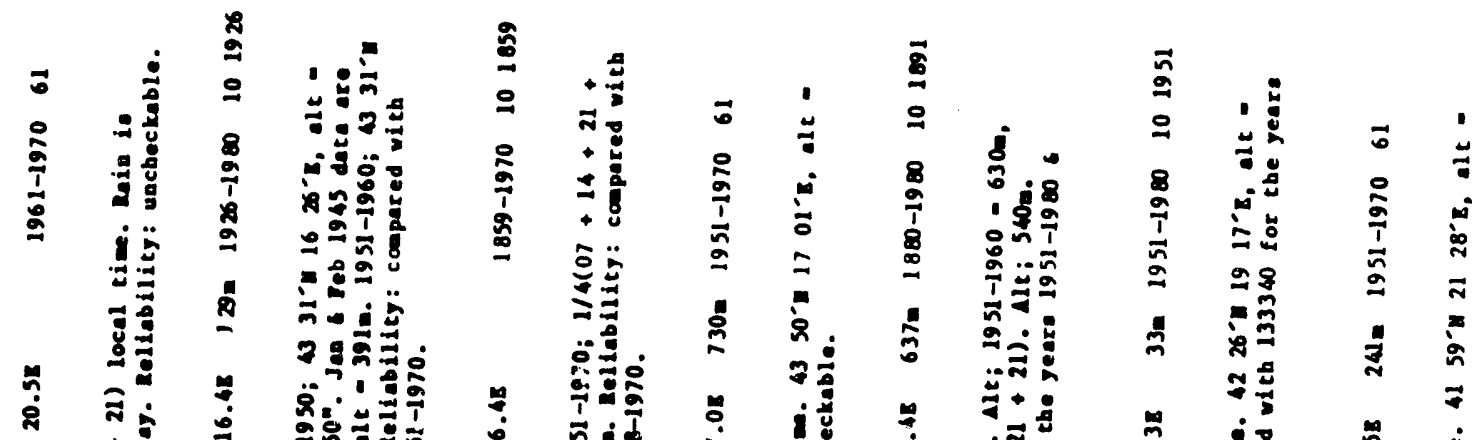

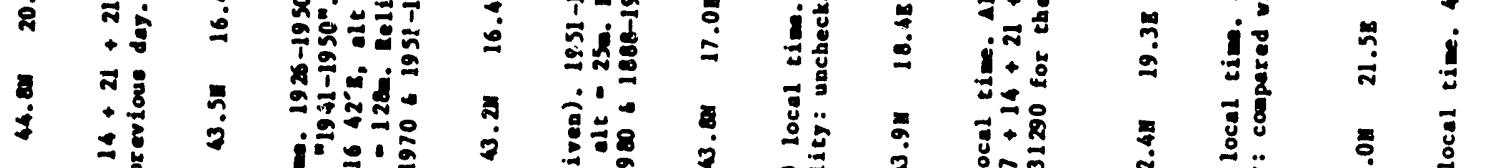

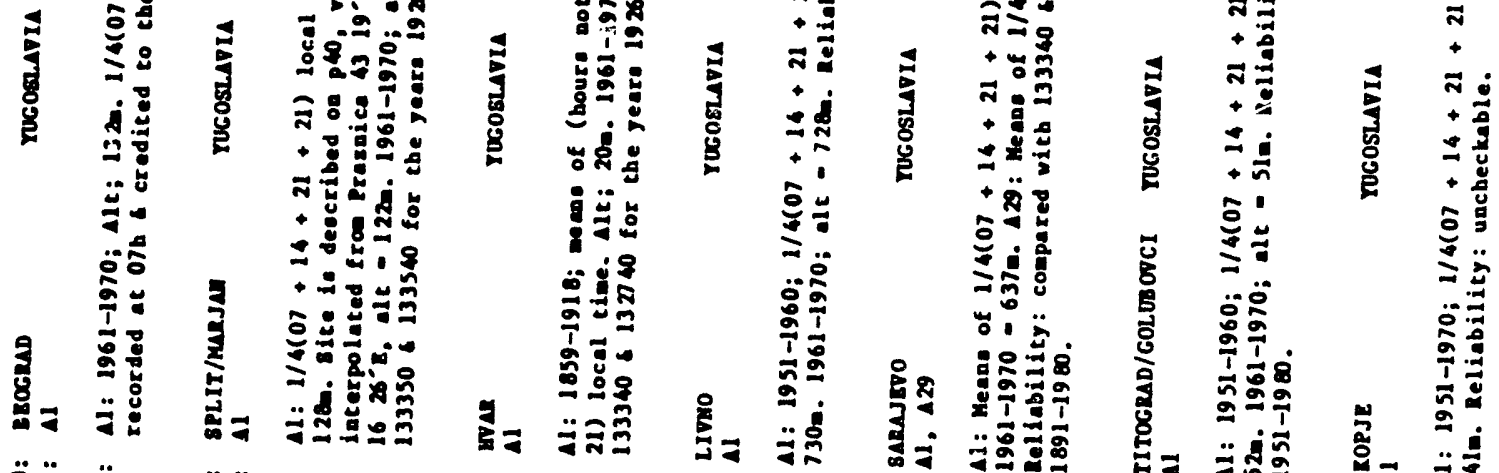

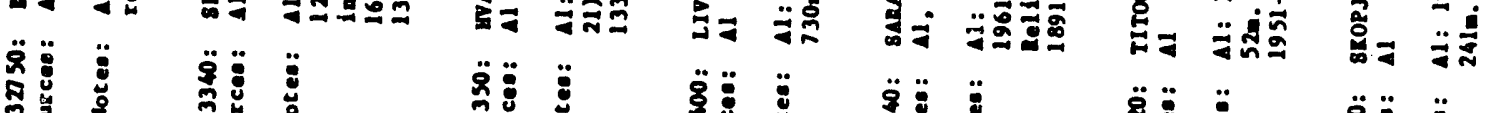

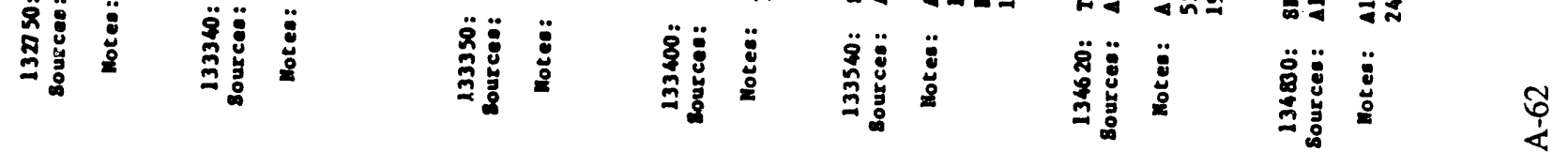

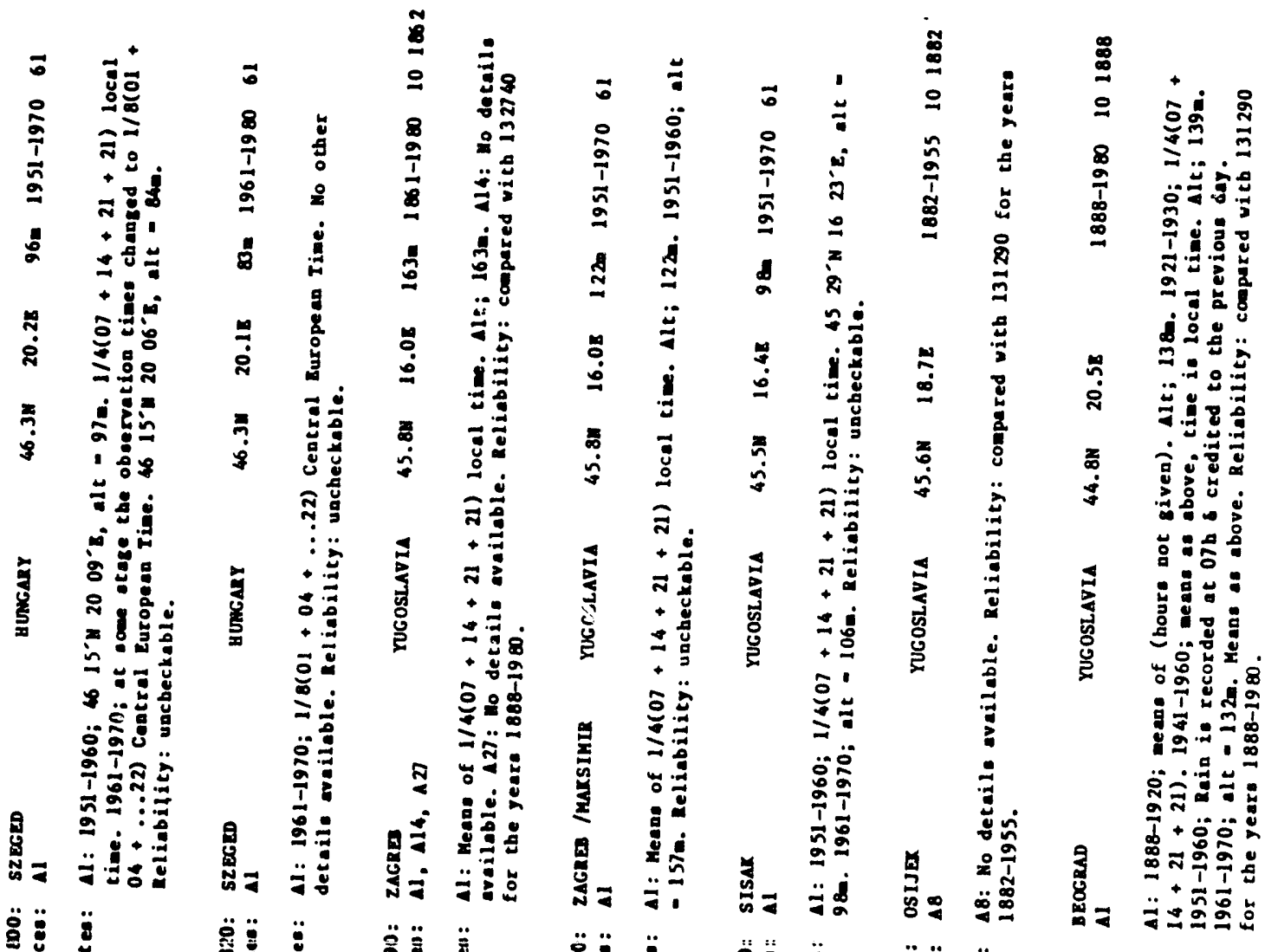

ปी 

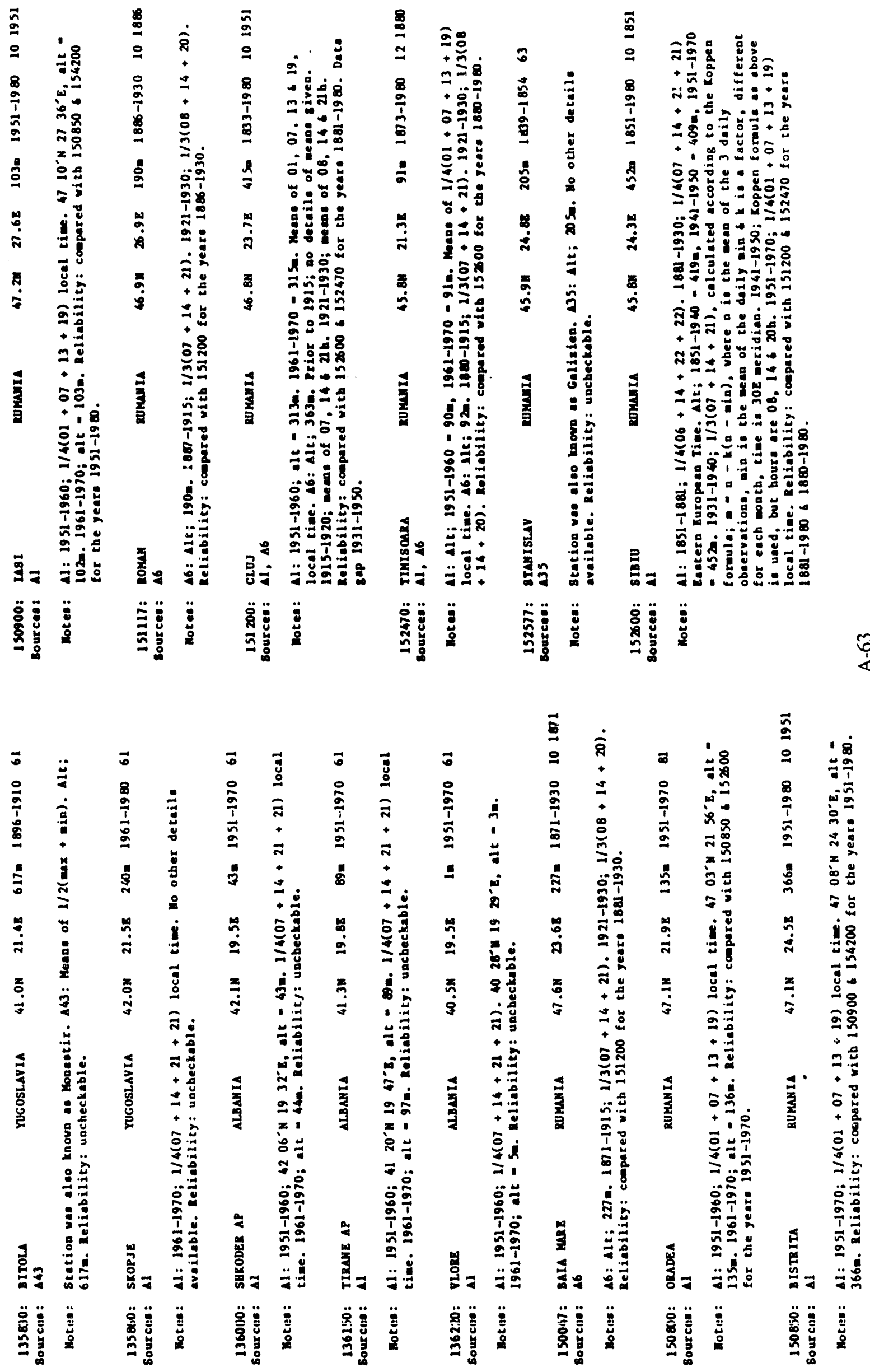


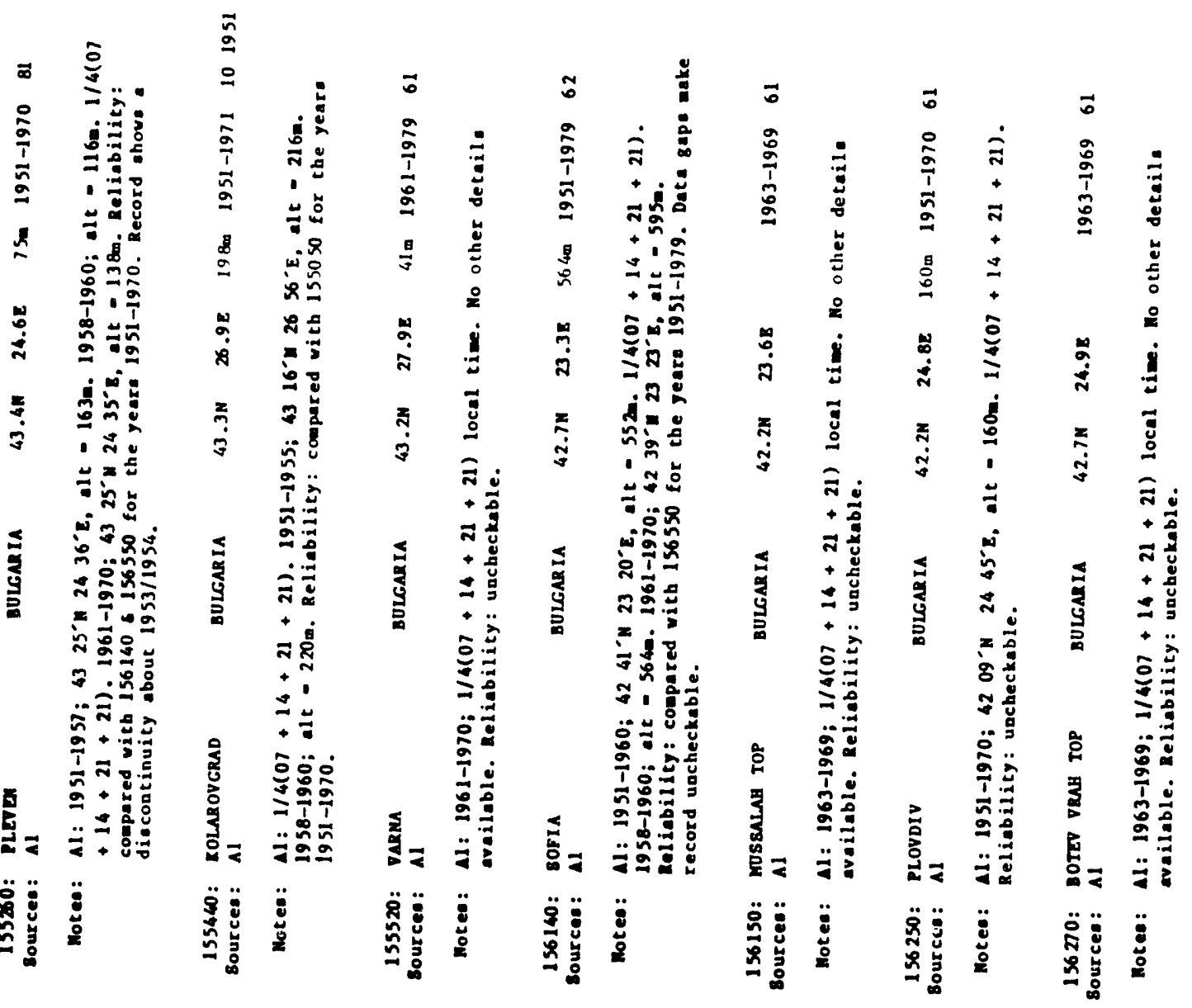

$\vdots$
$\vdots$
8
$\vdots$
$\vdots$
8
1

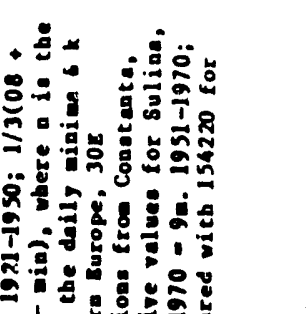

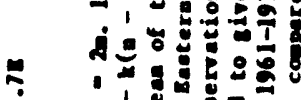

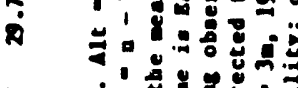

ค

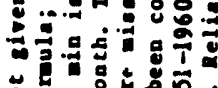

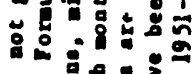

1116 sfy He In

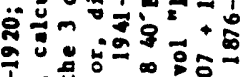
苟

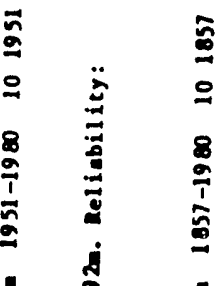

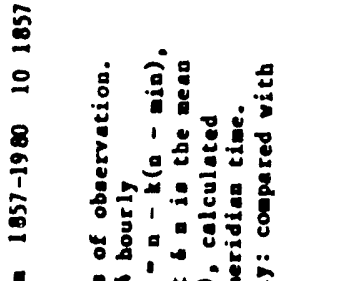

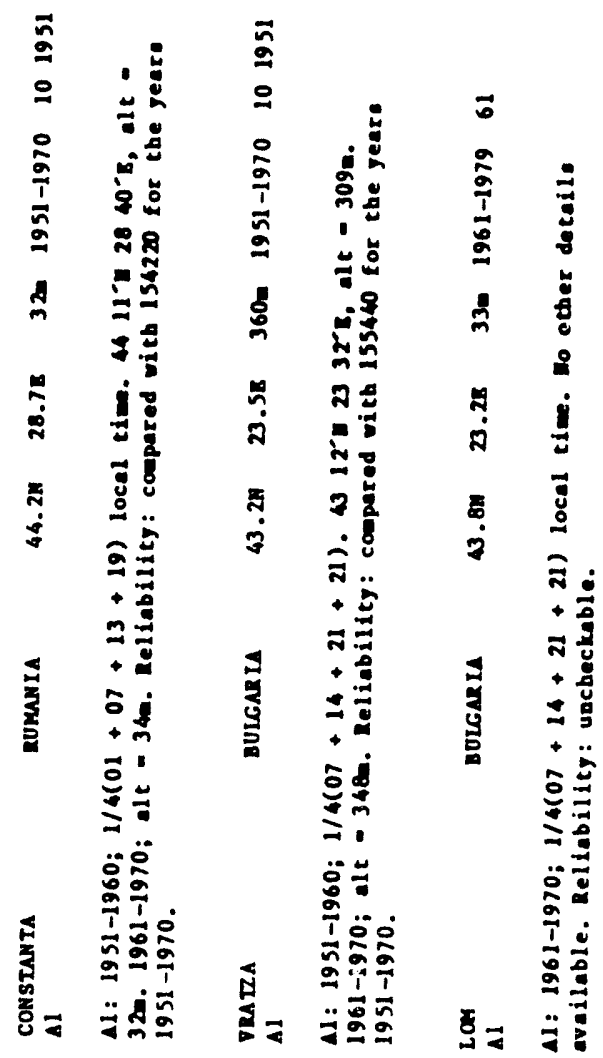
㩆 औौ U1 

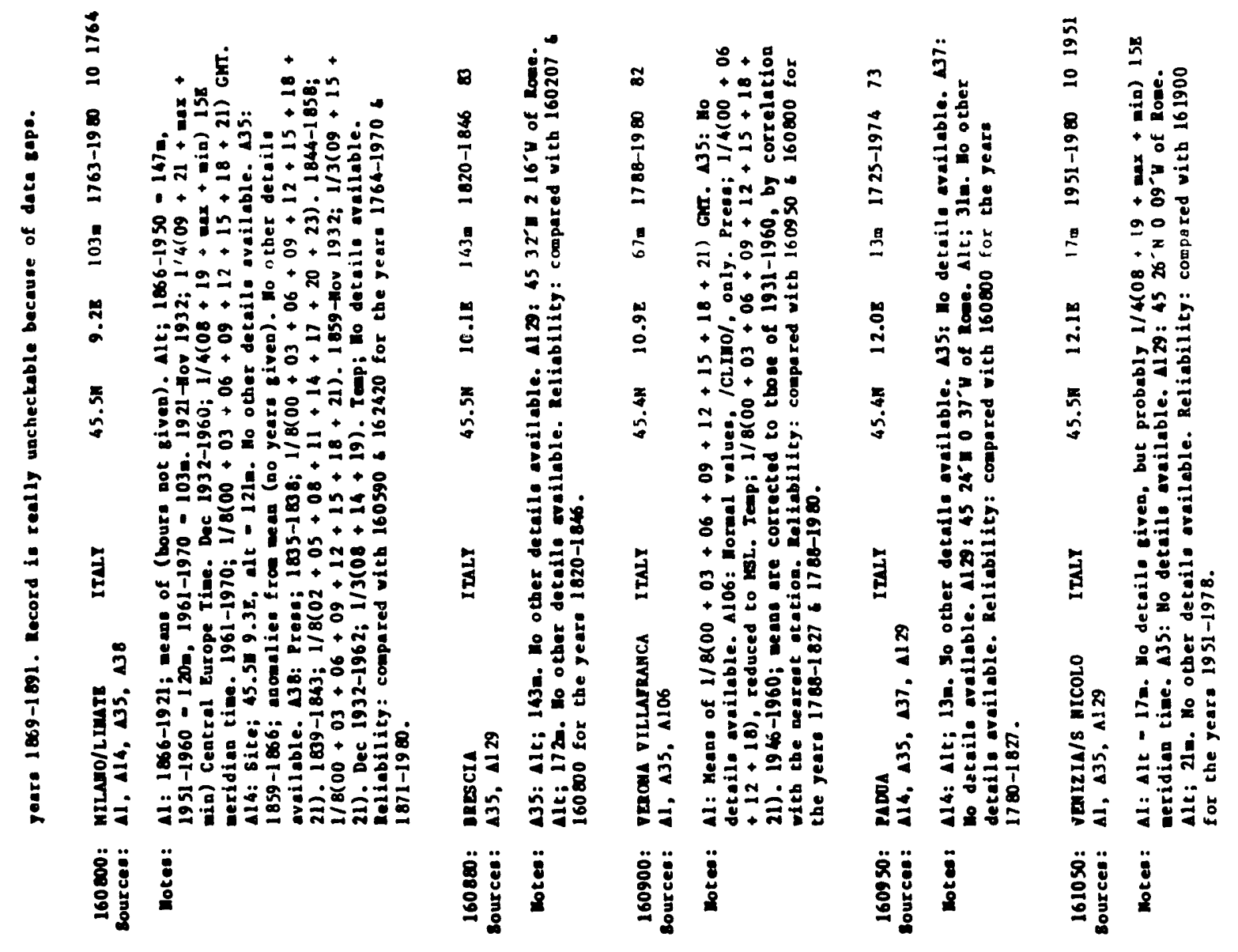

$n$
$\vdots$
4

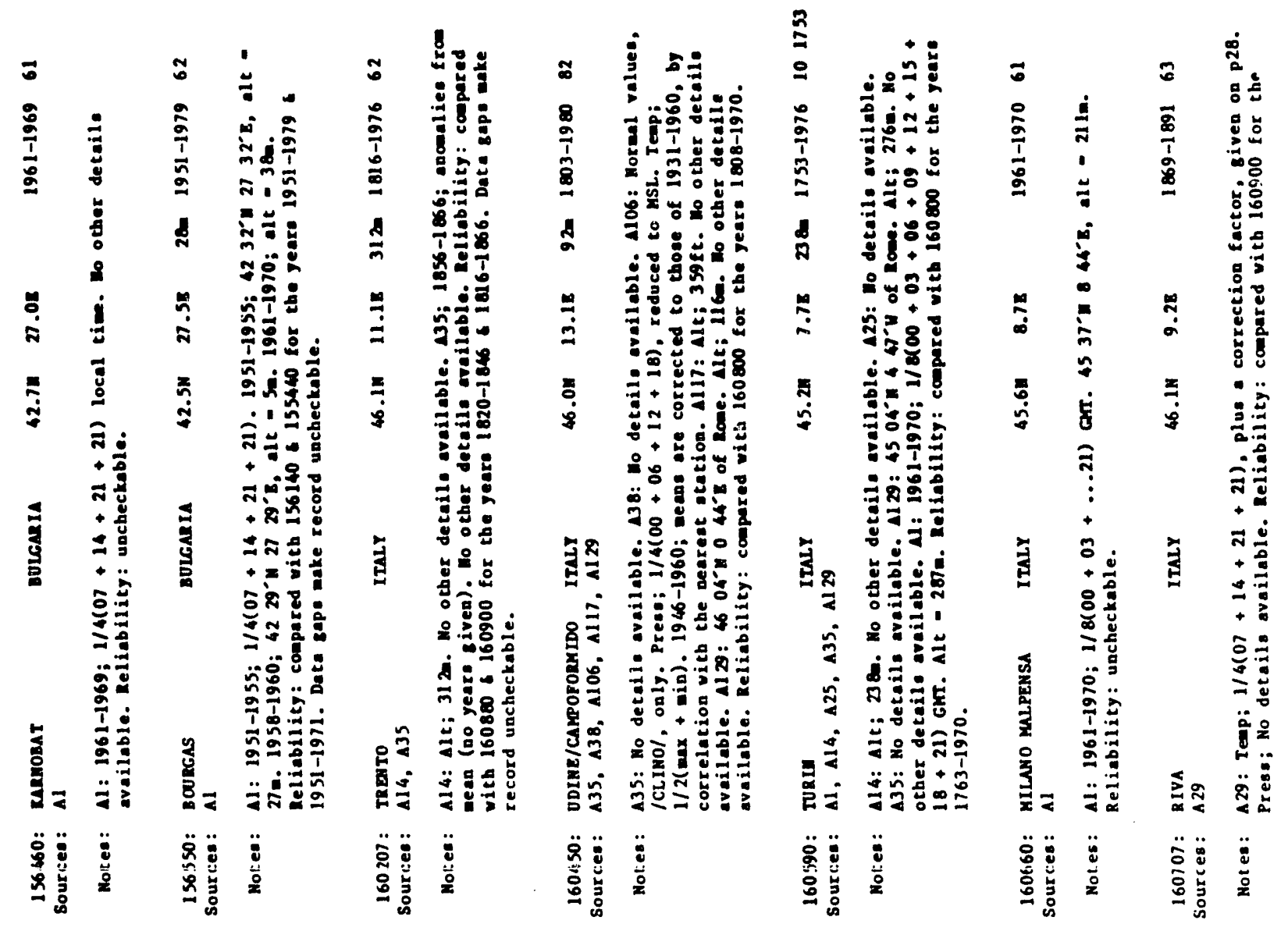



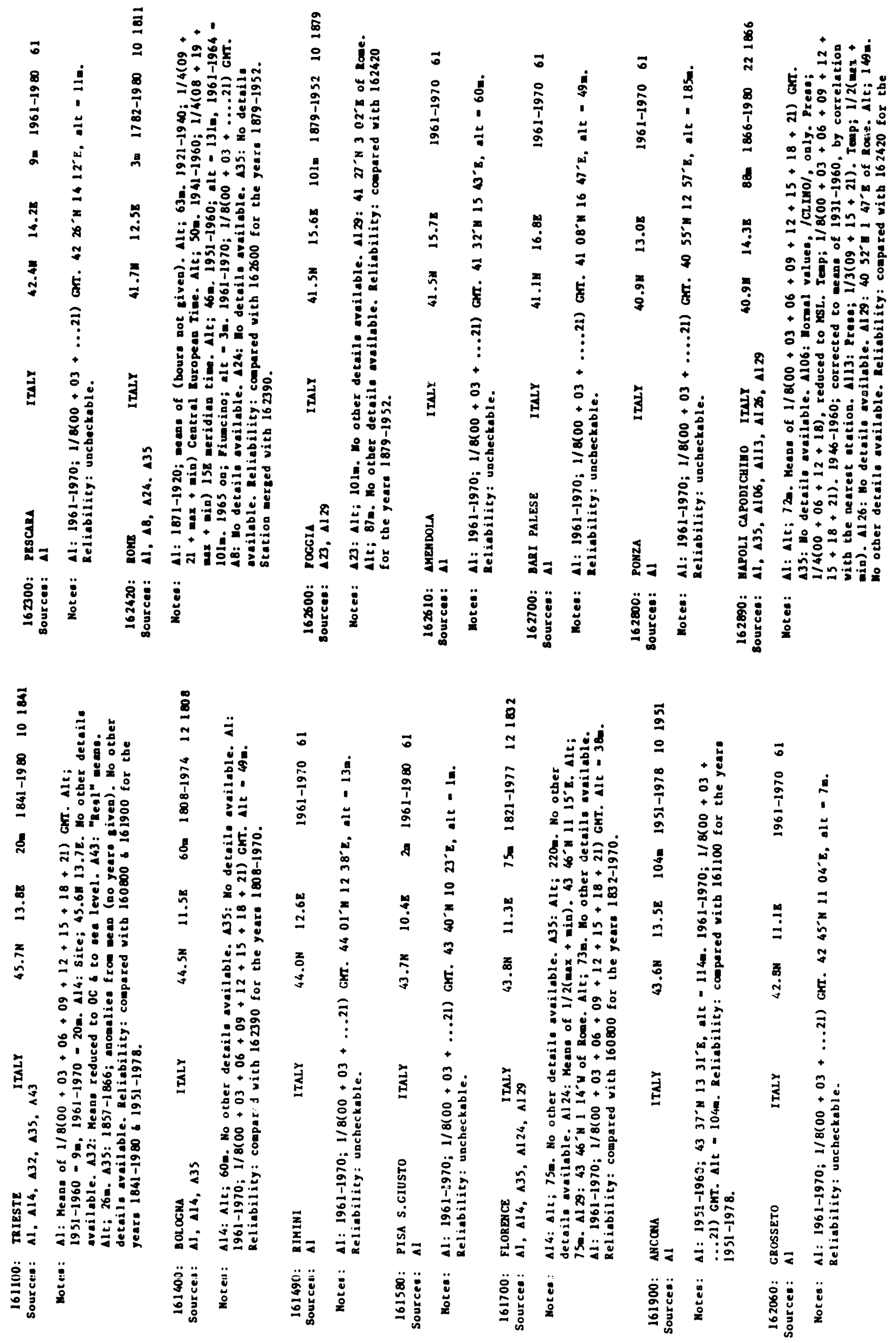


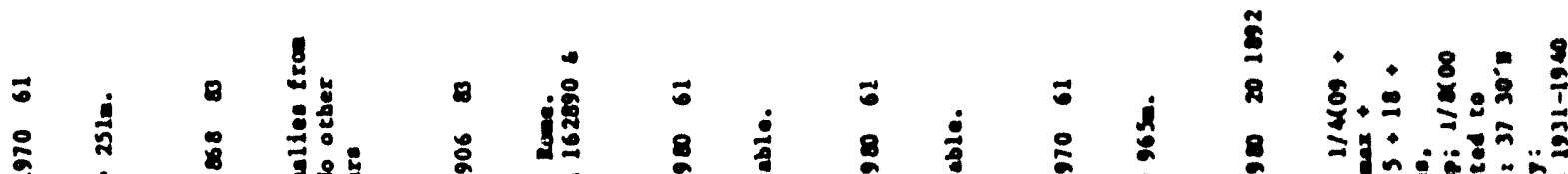

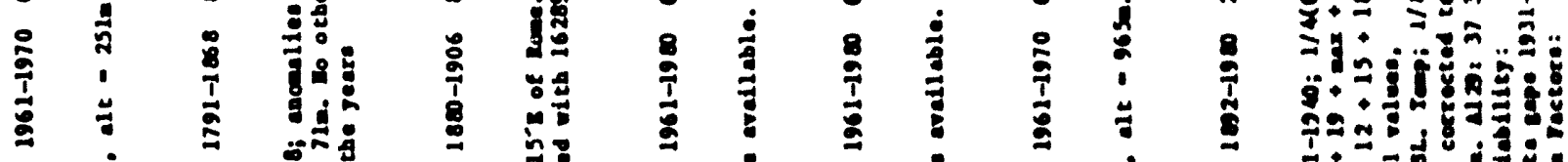
$\Xi$ \&

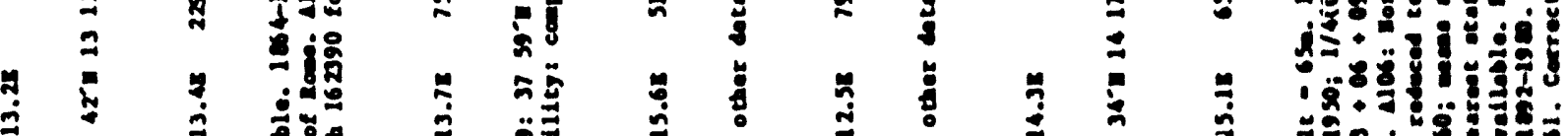

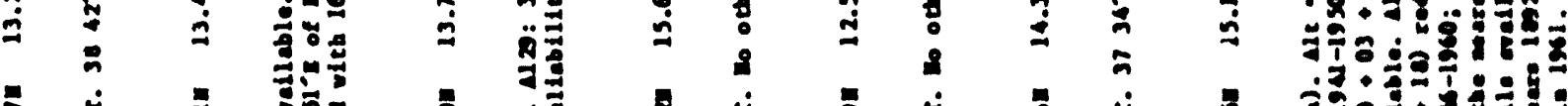

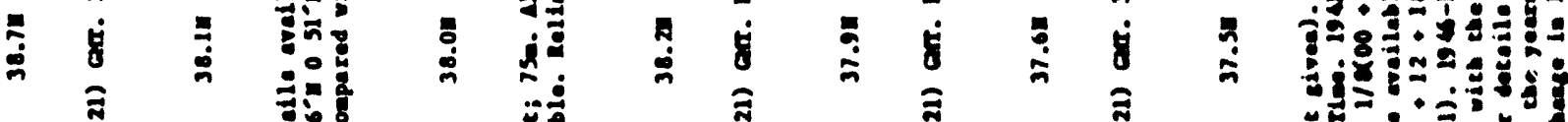
สิ

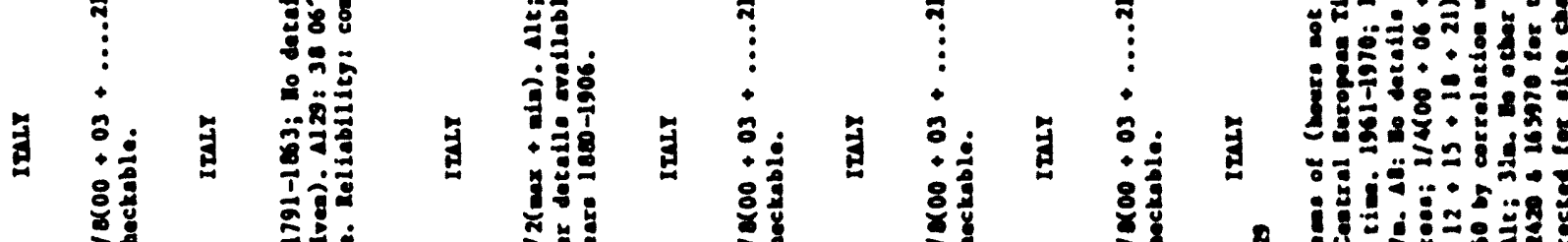

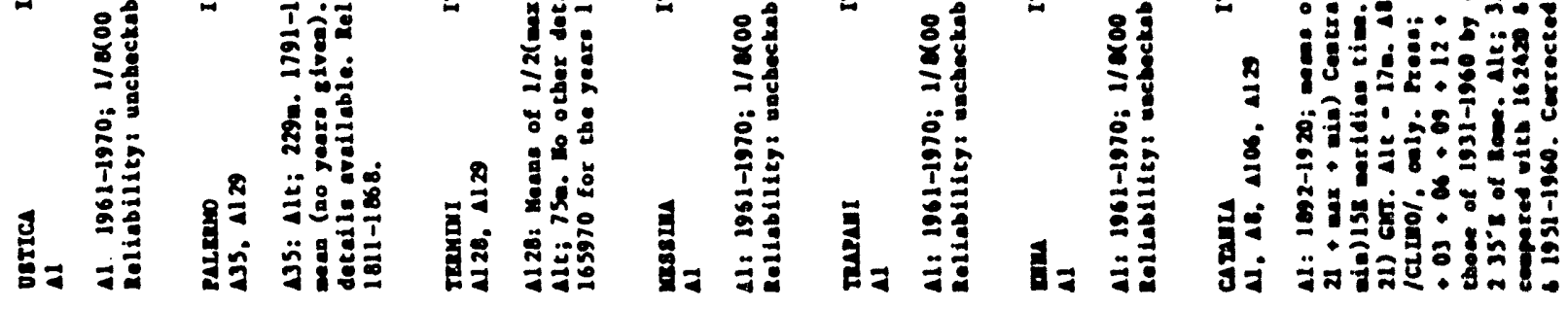

แI

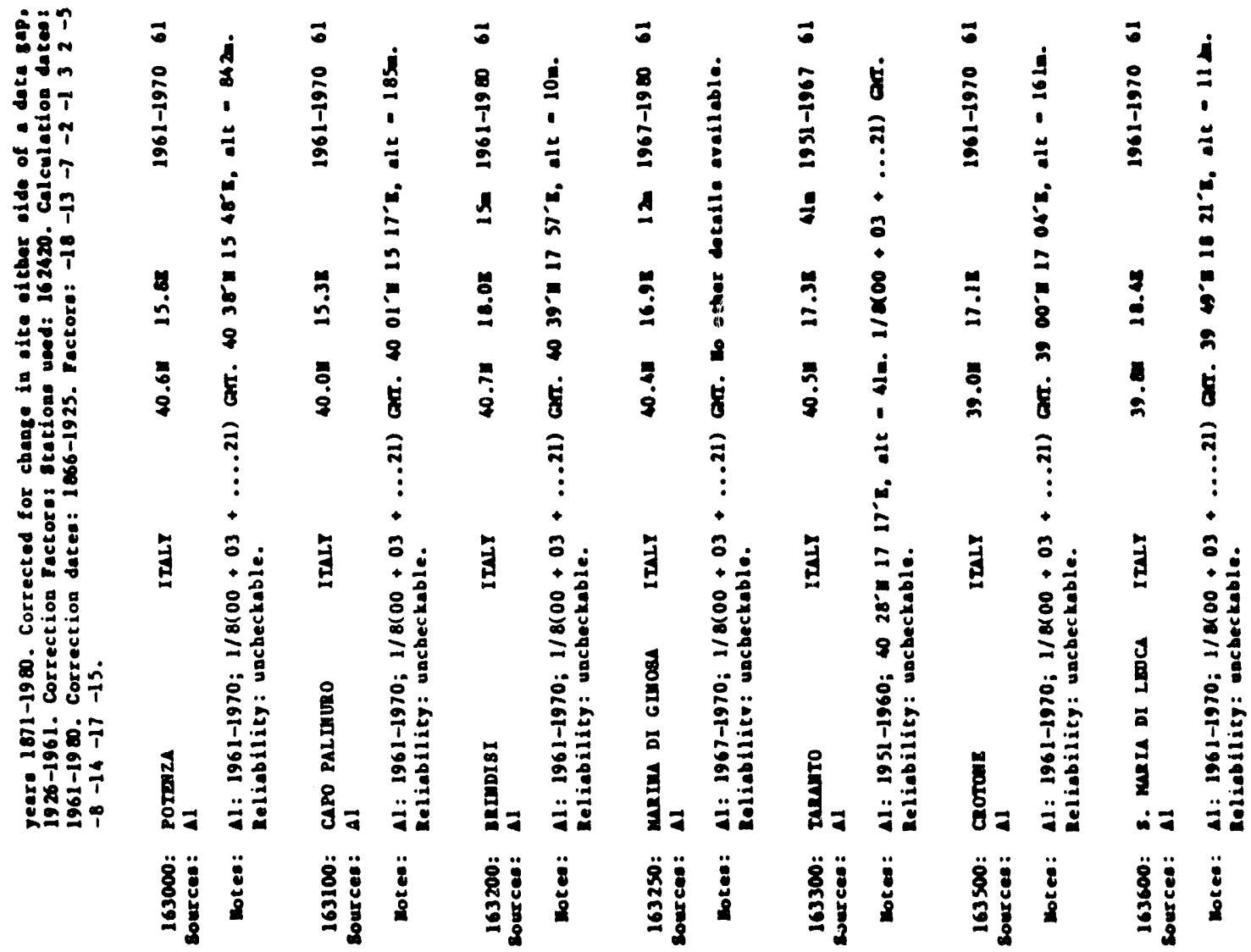




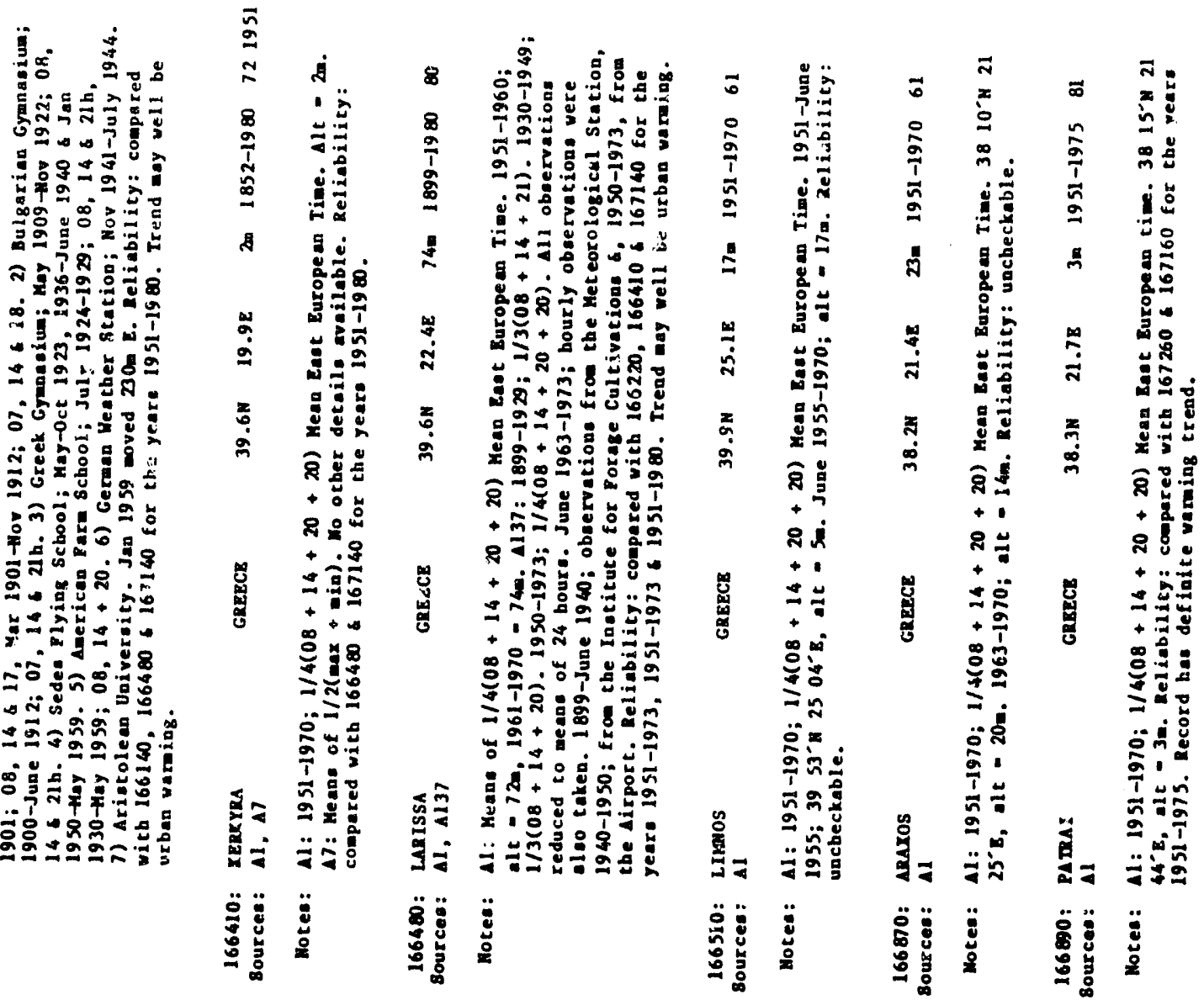

$\frac{0}{0}$

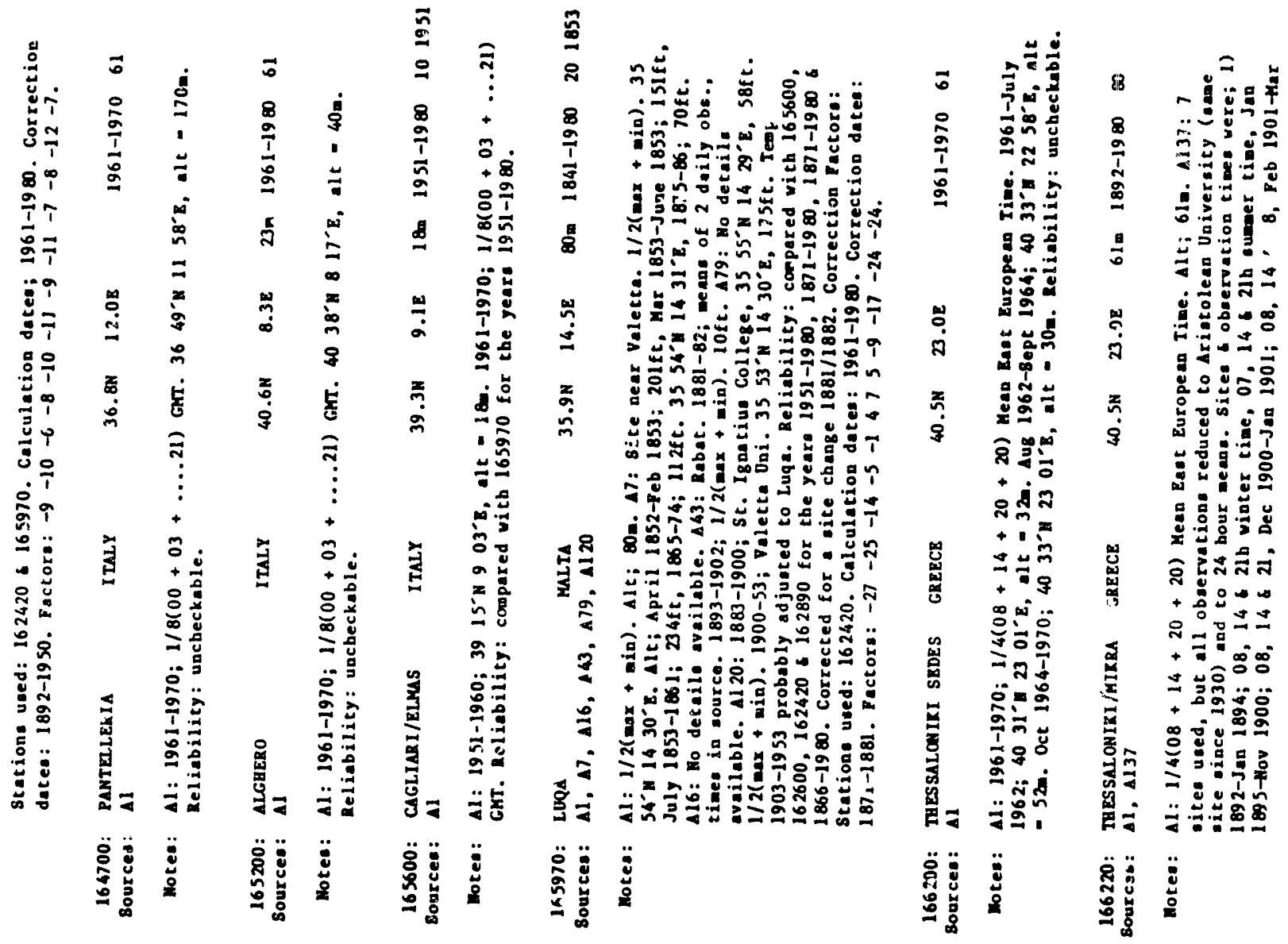


8

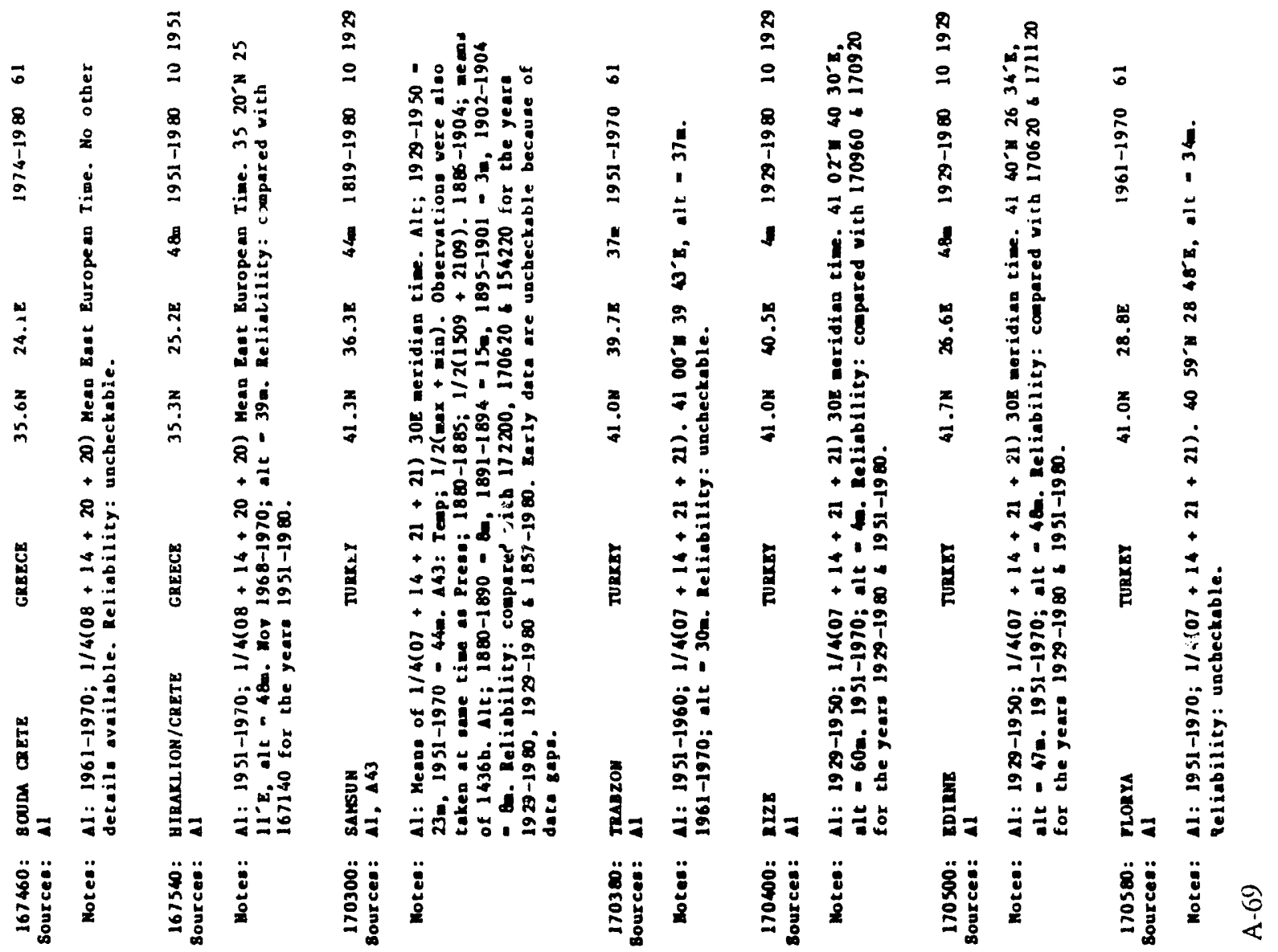

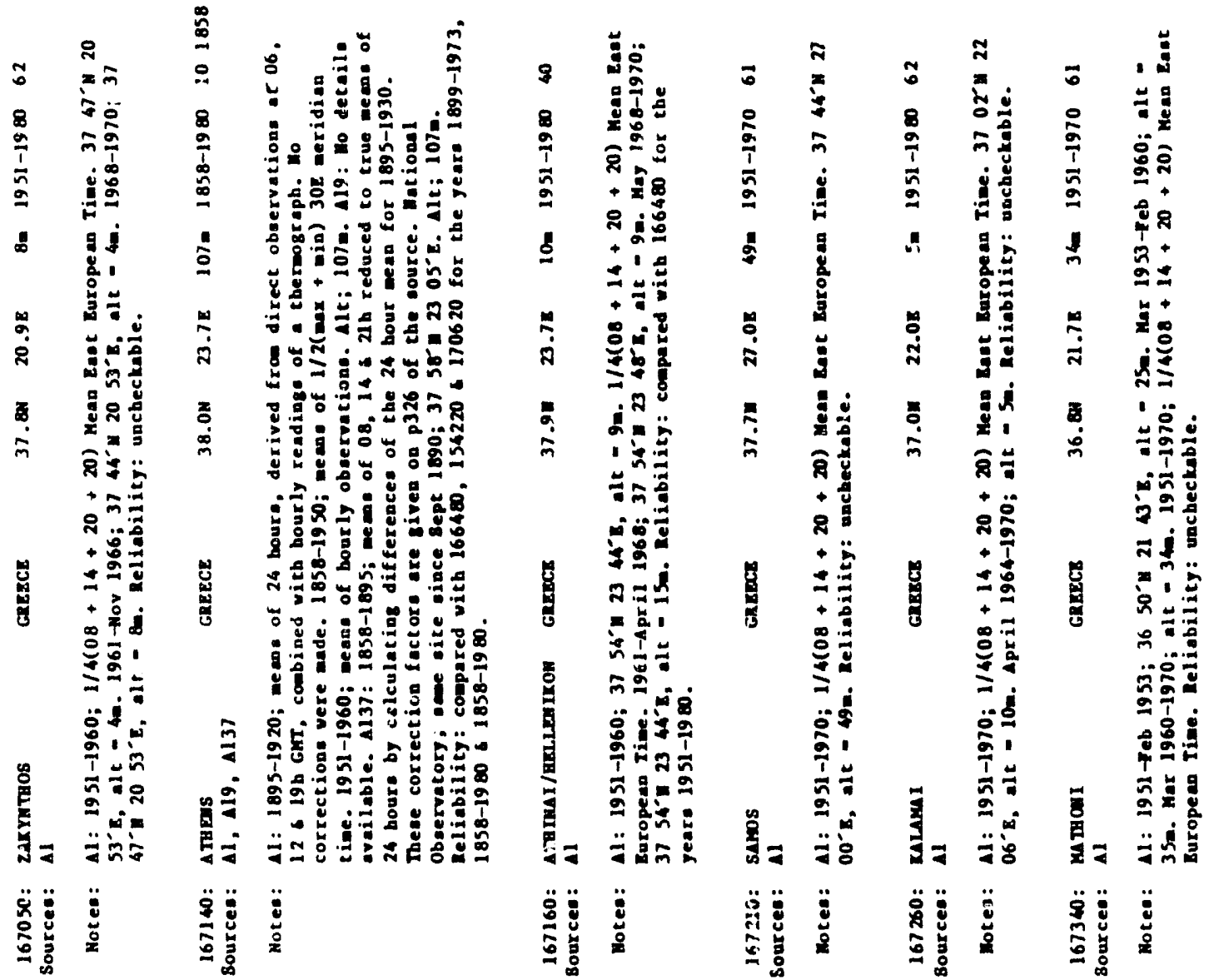




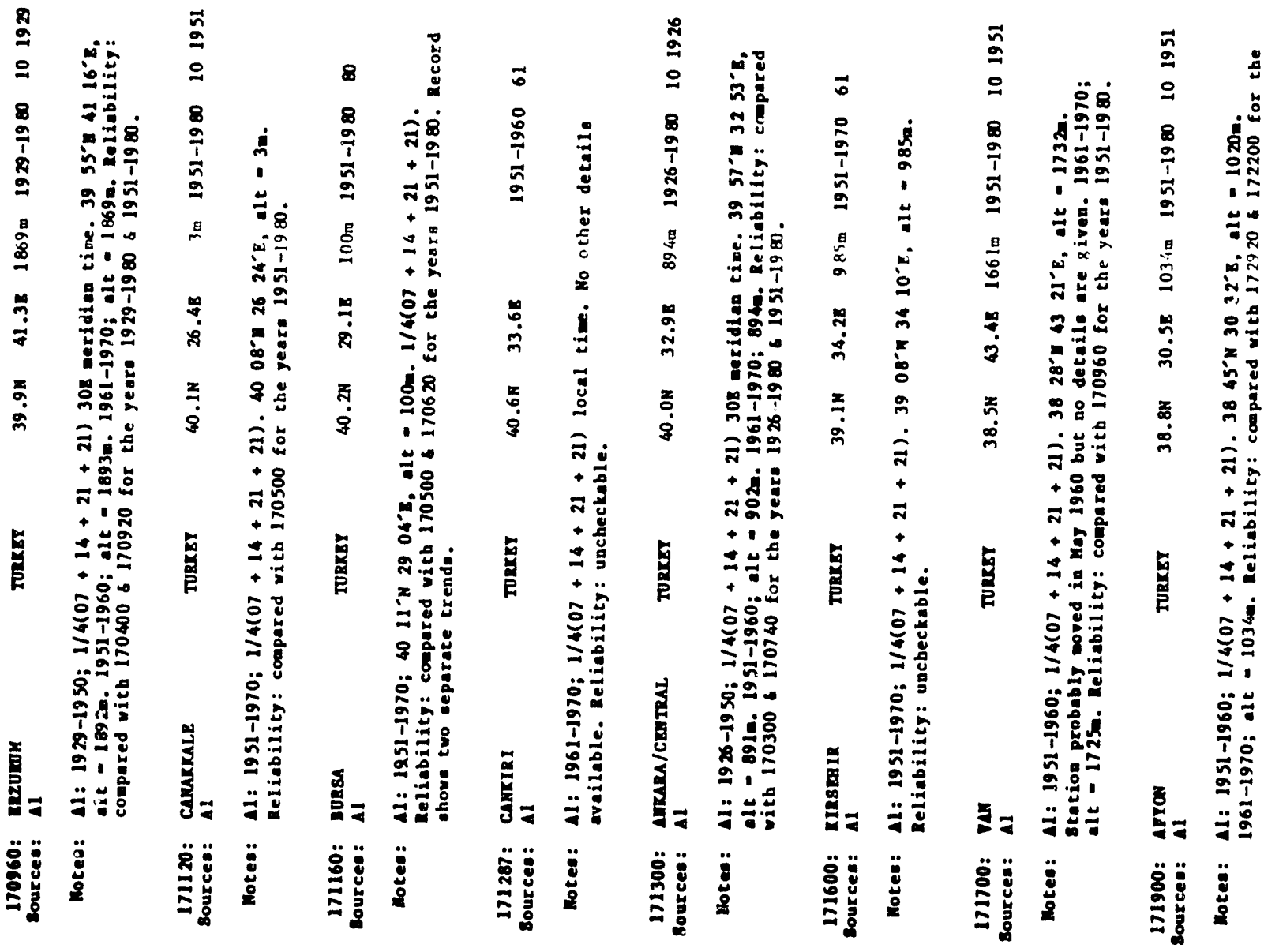

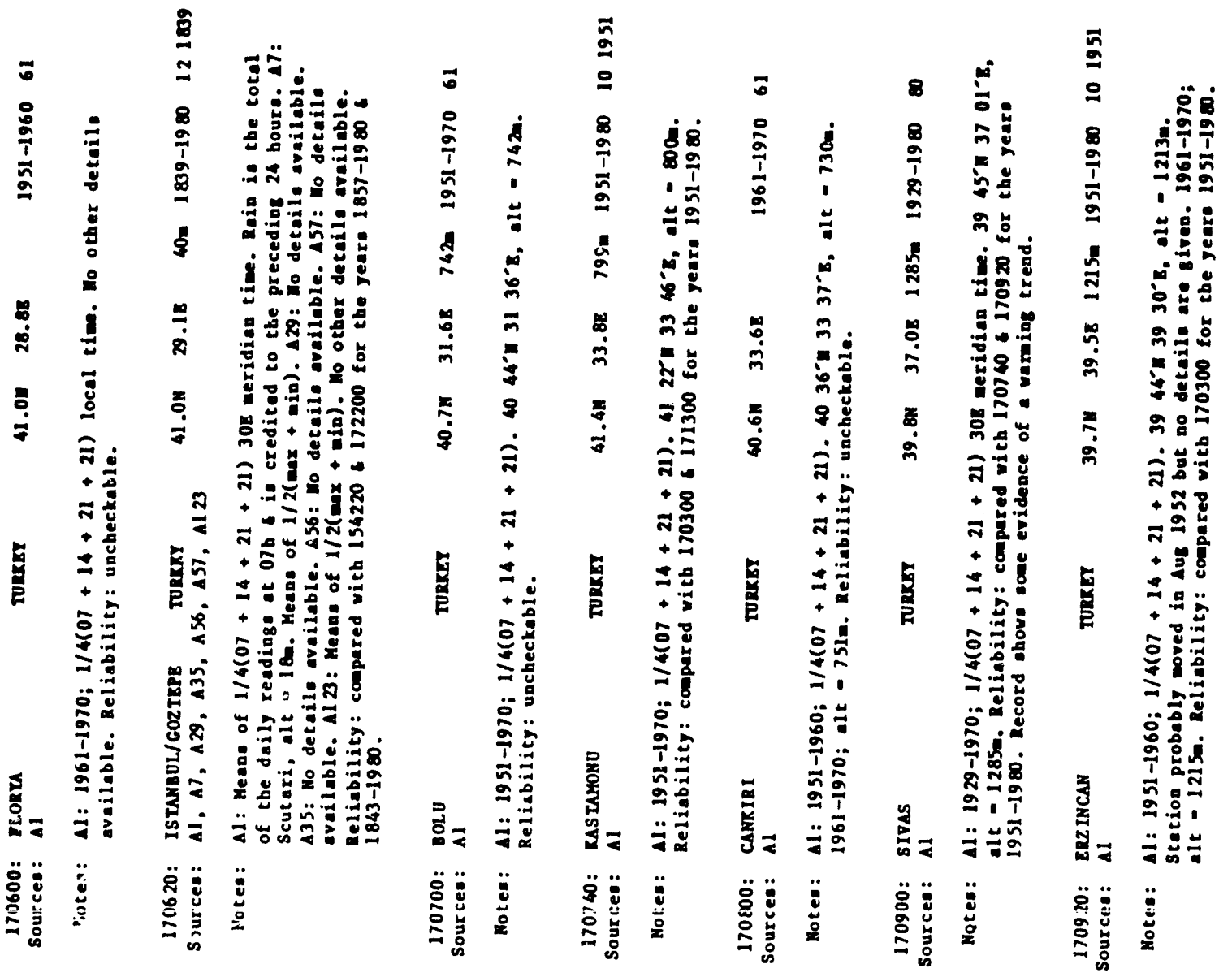




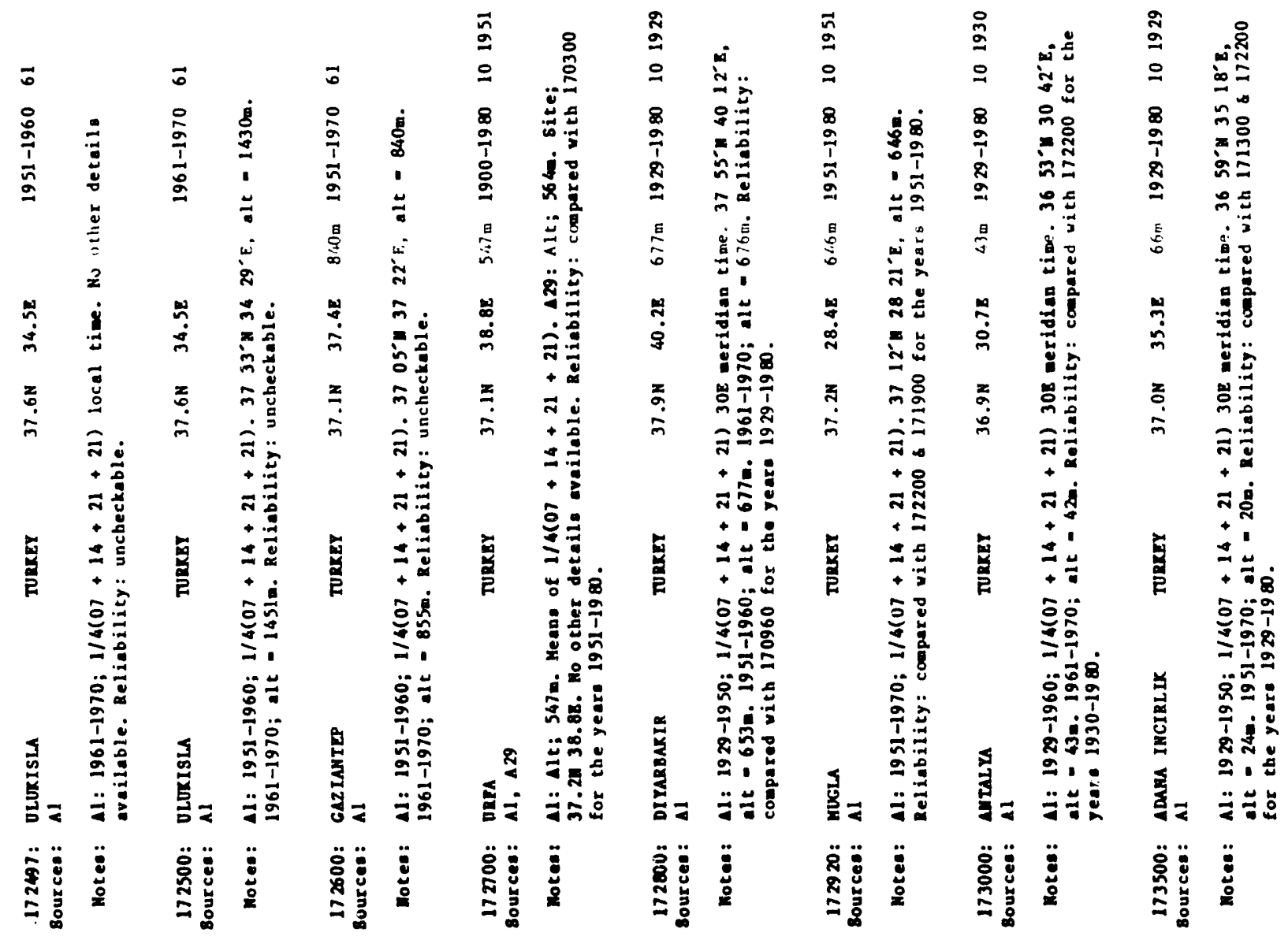

交

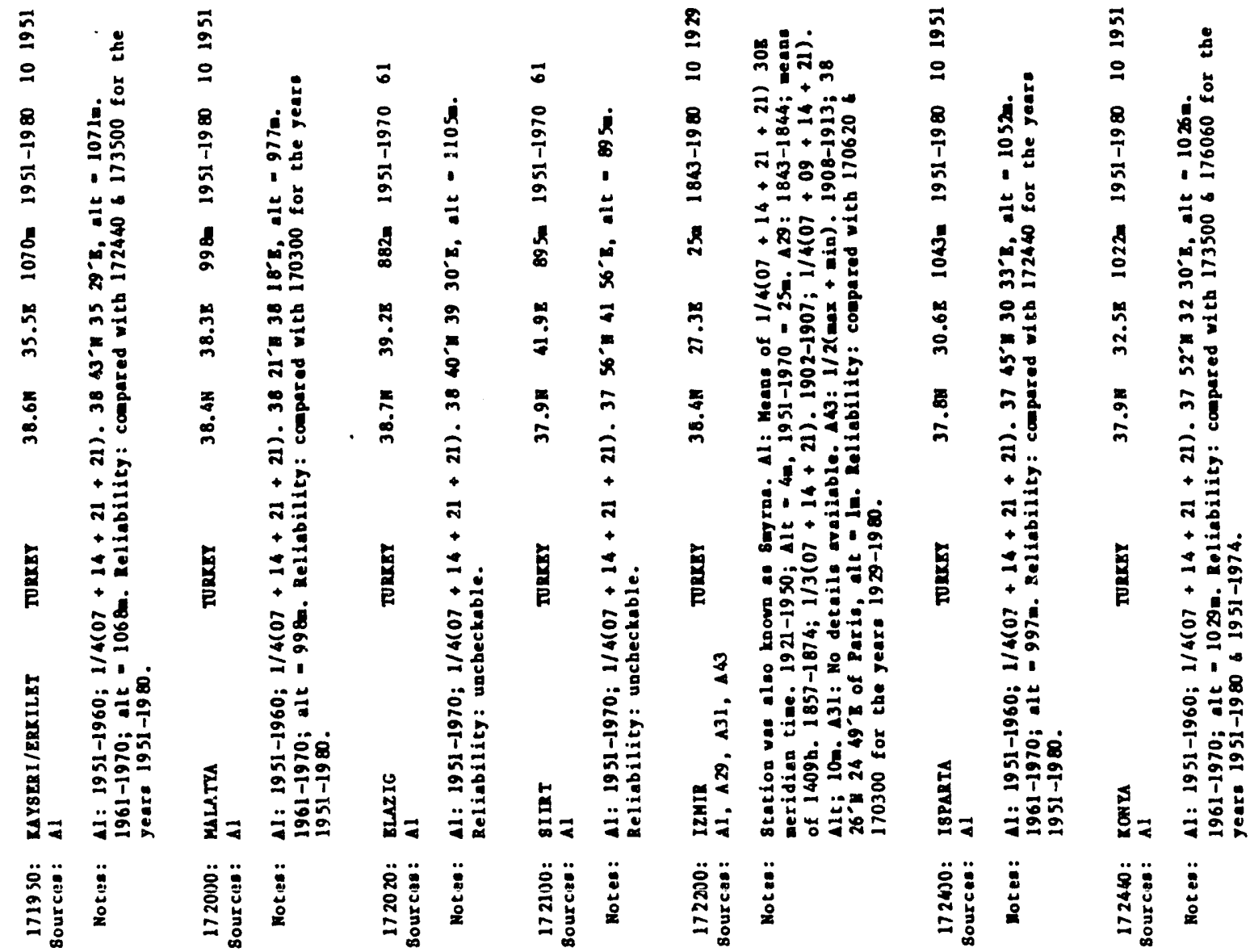




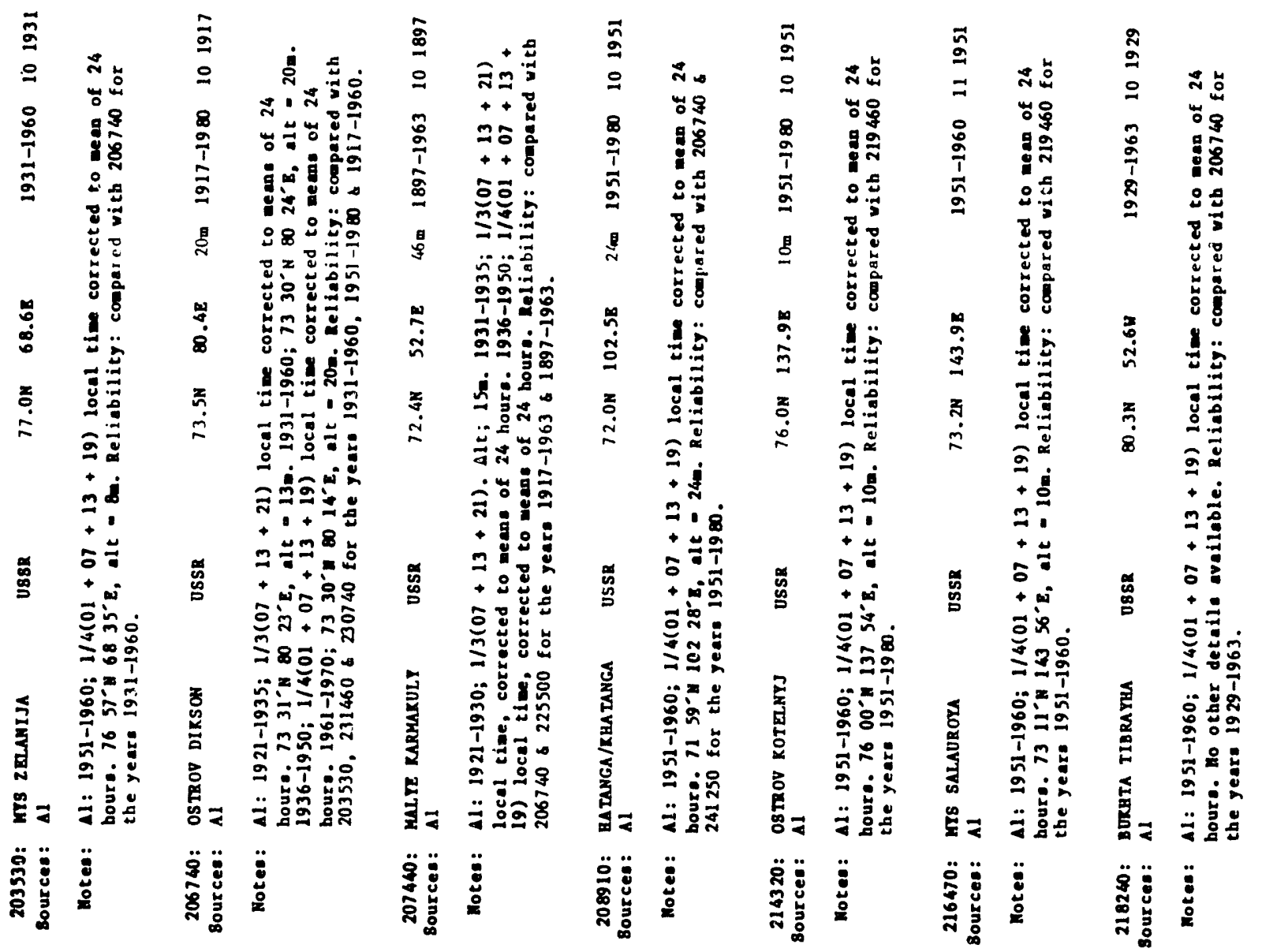

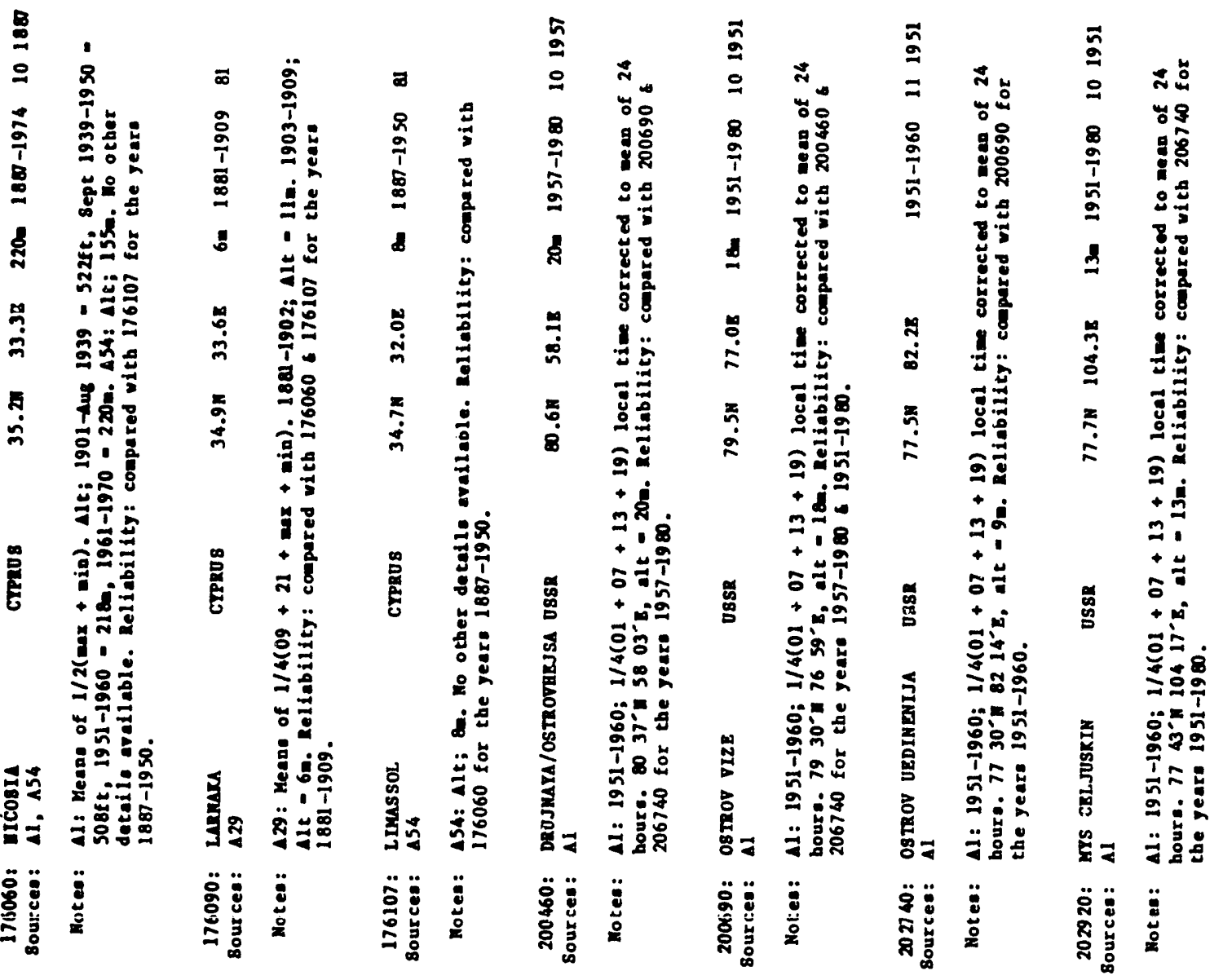



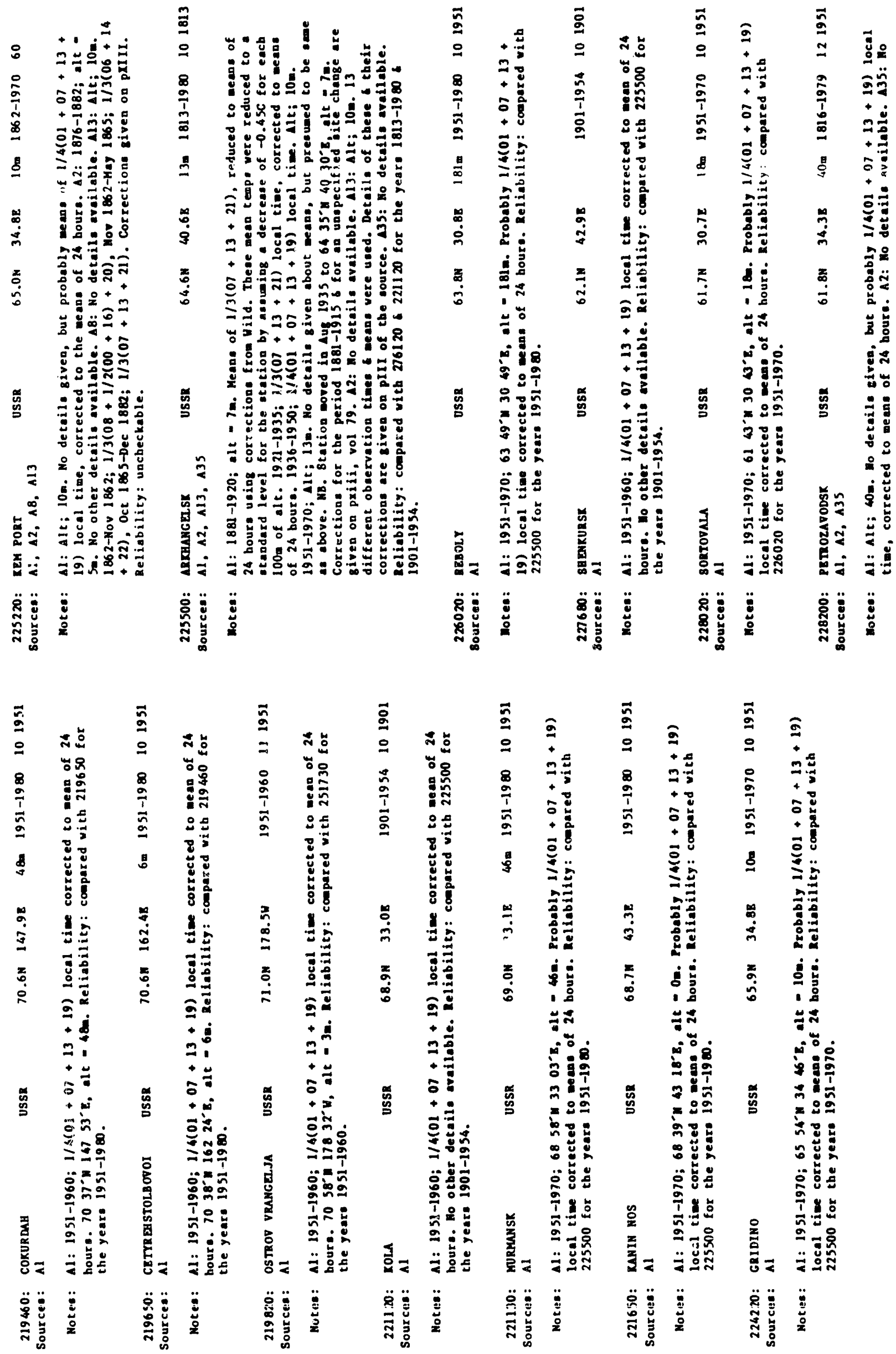

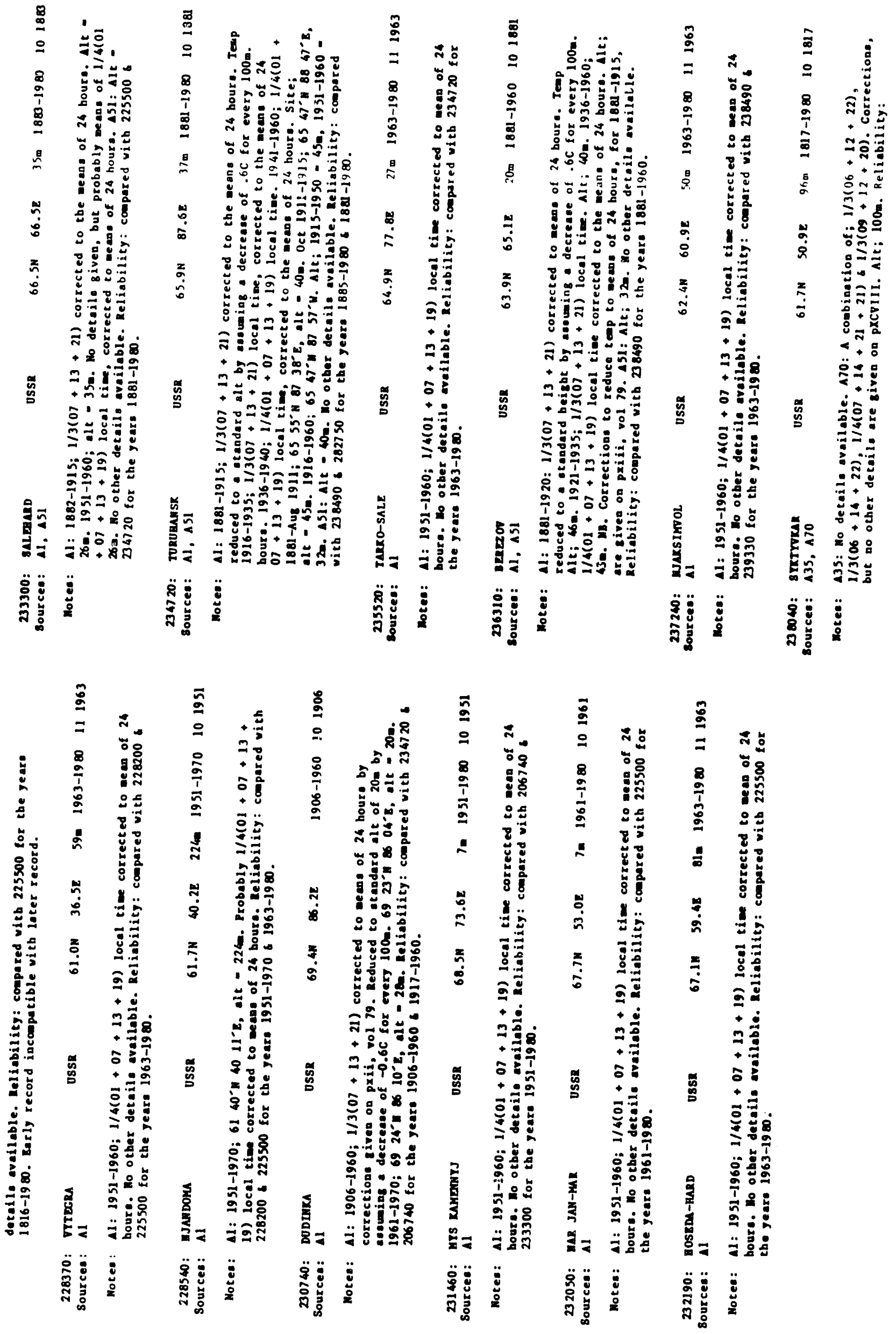


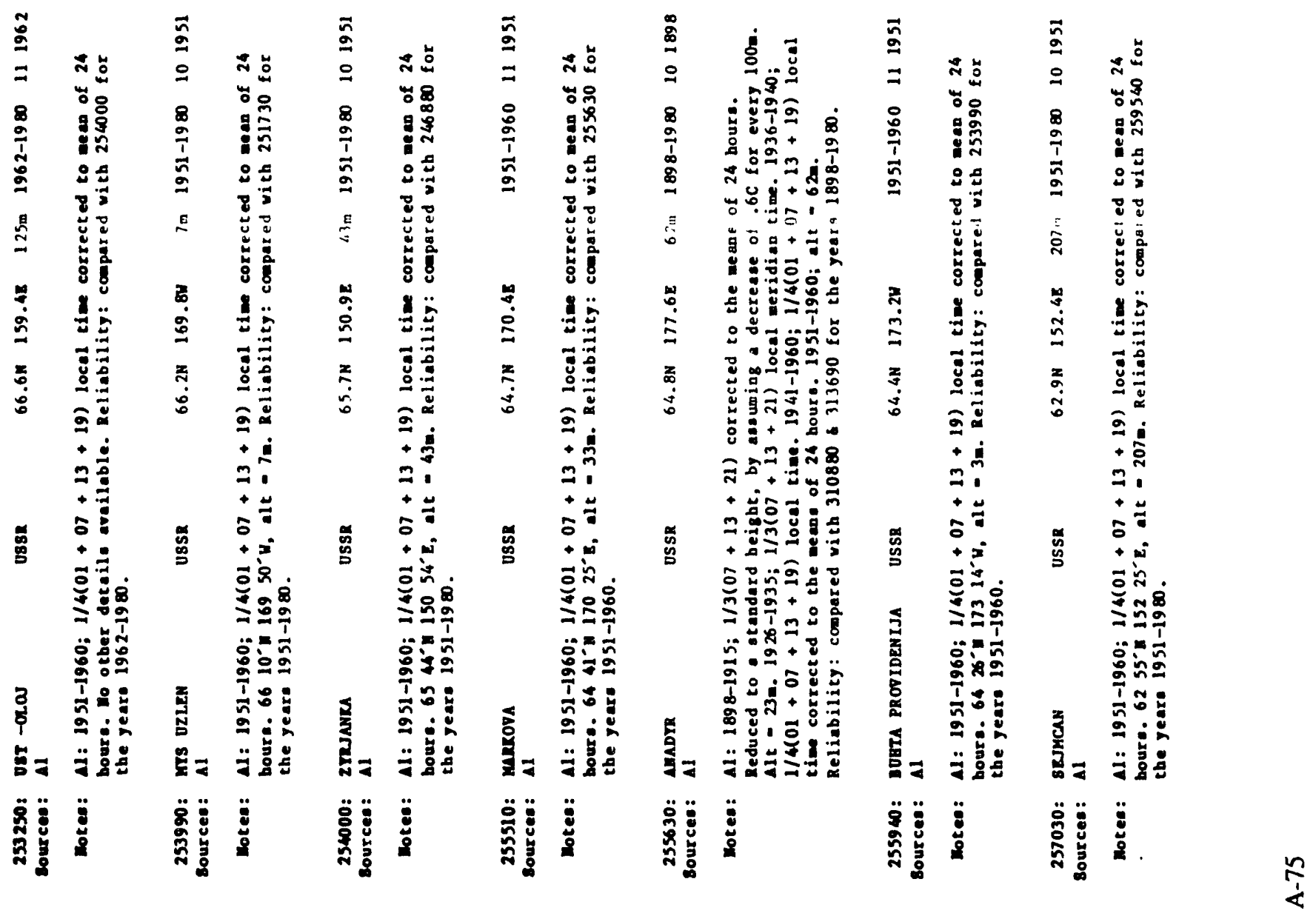

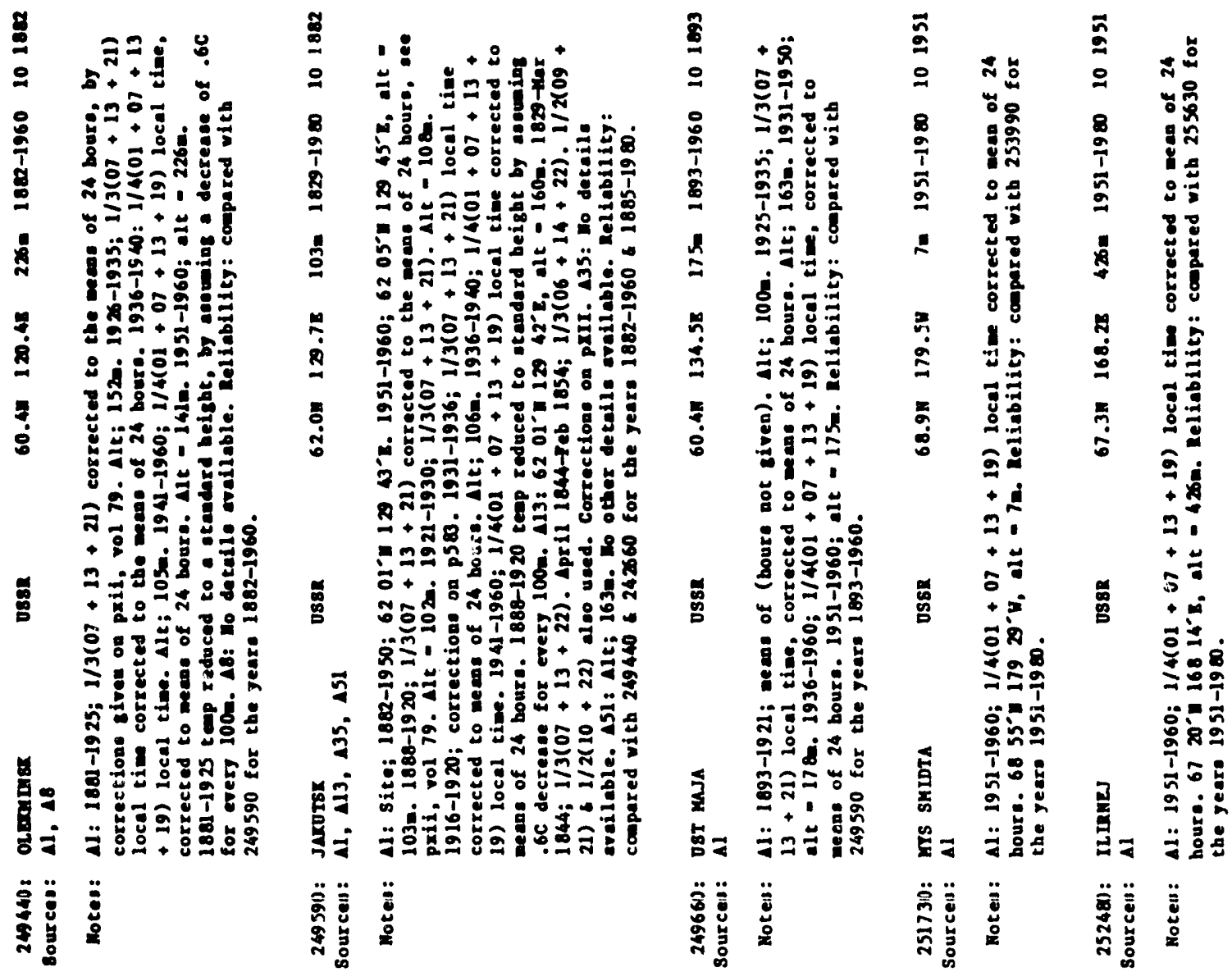




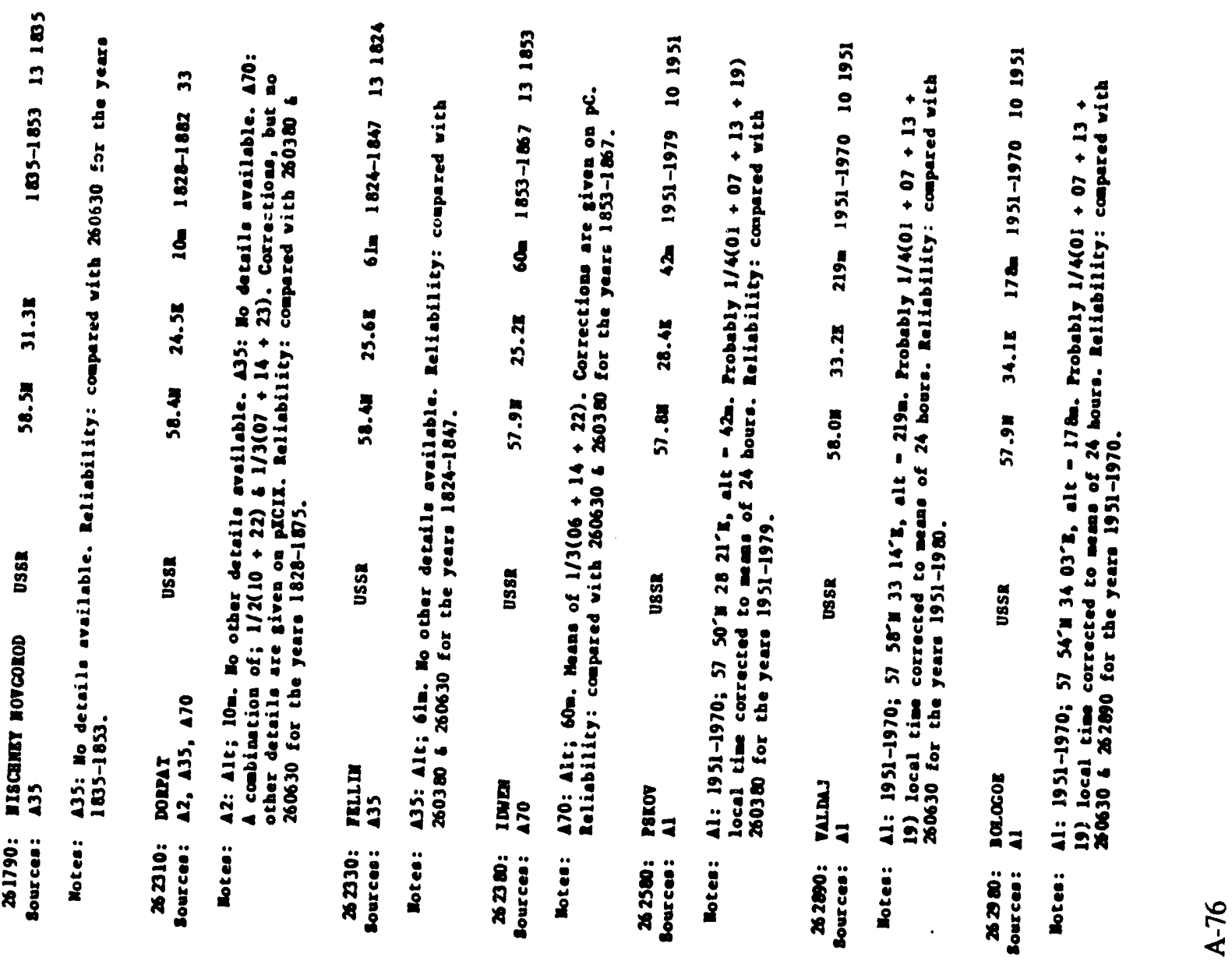

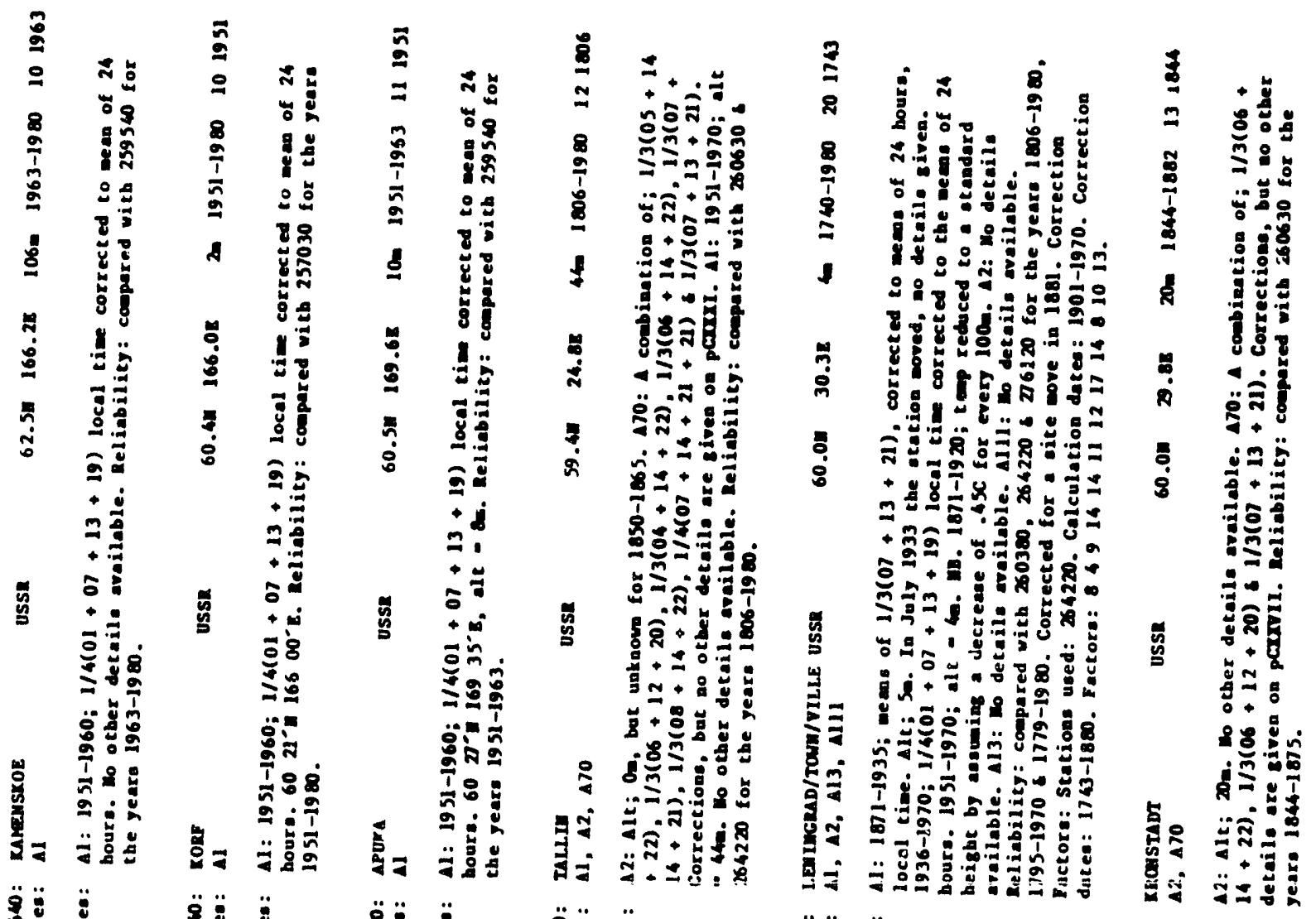

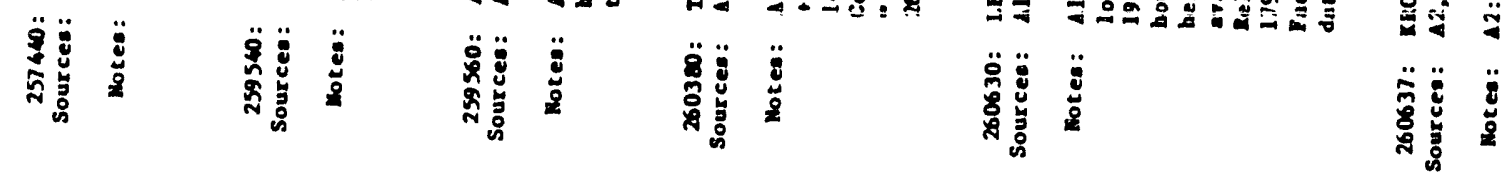



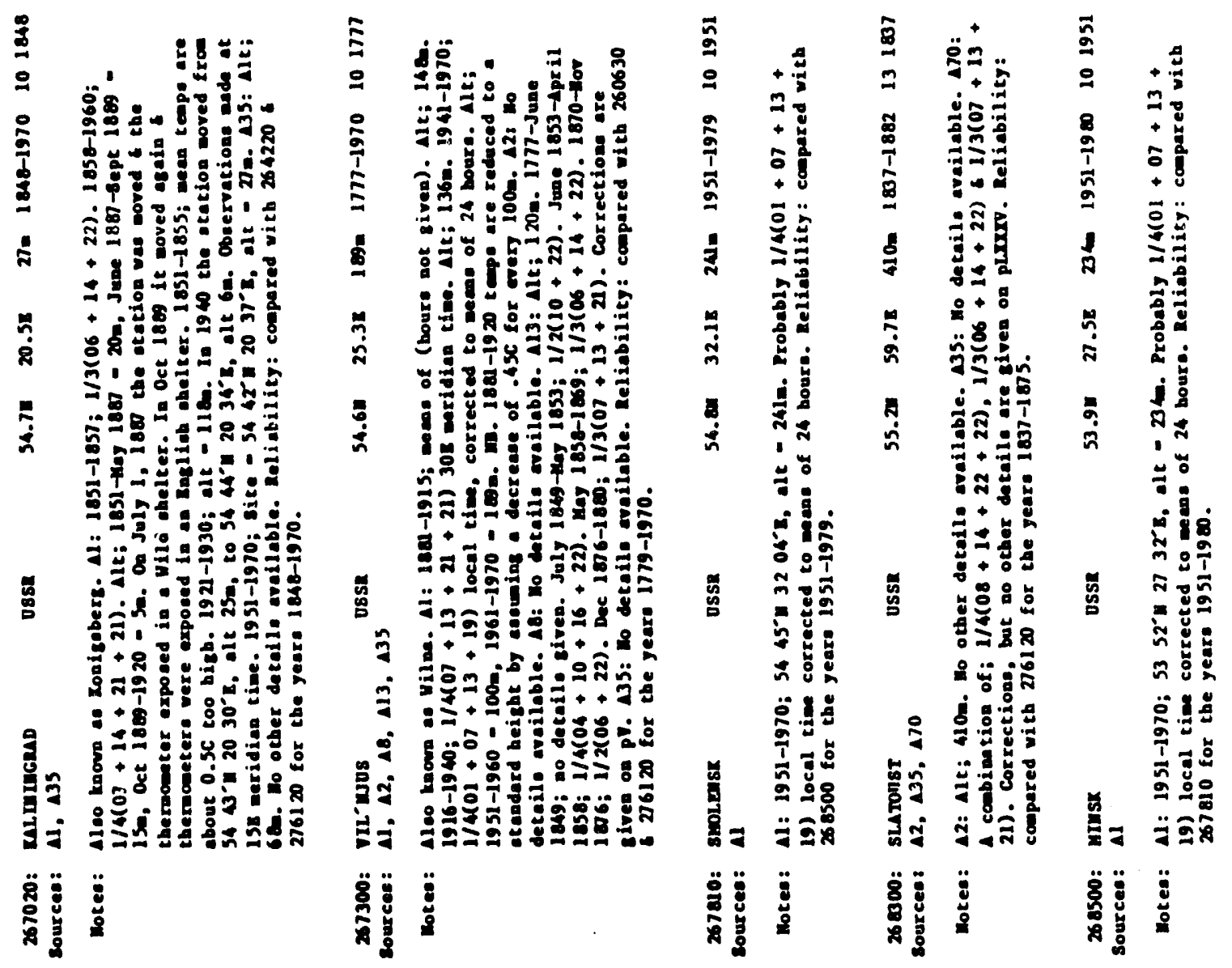

$\frac{7}{4}$

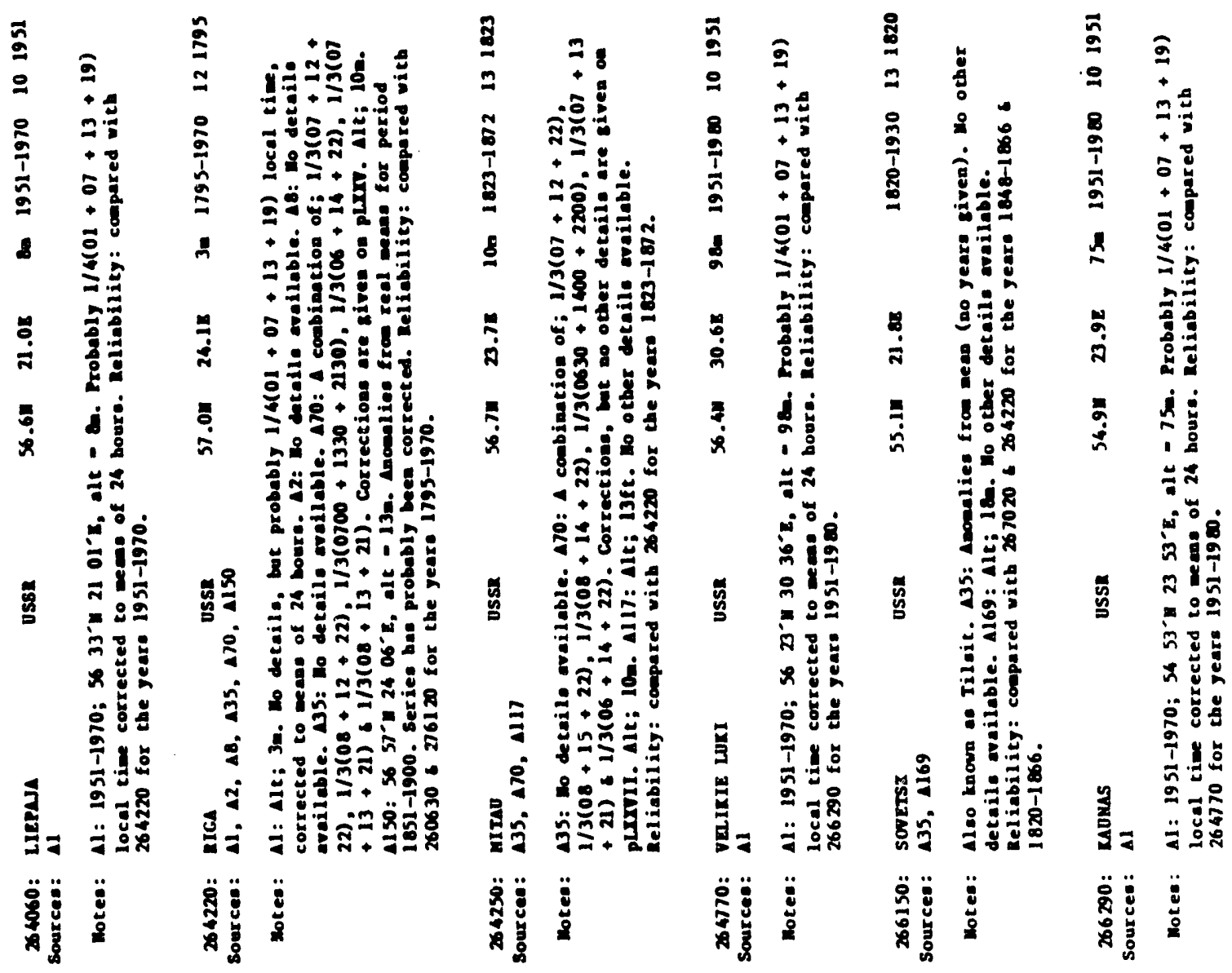



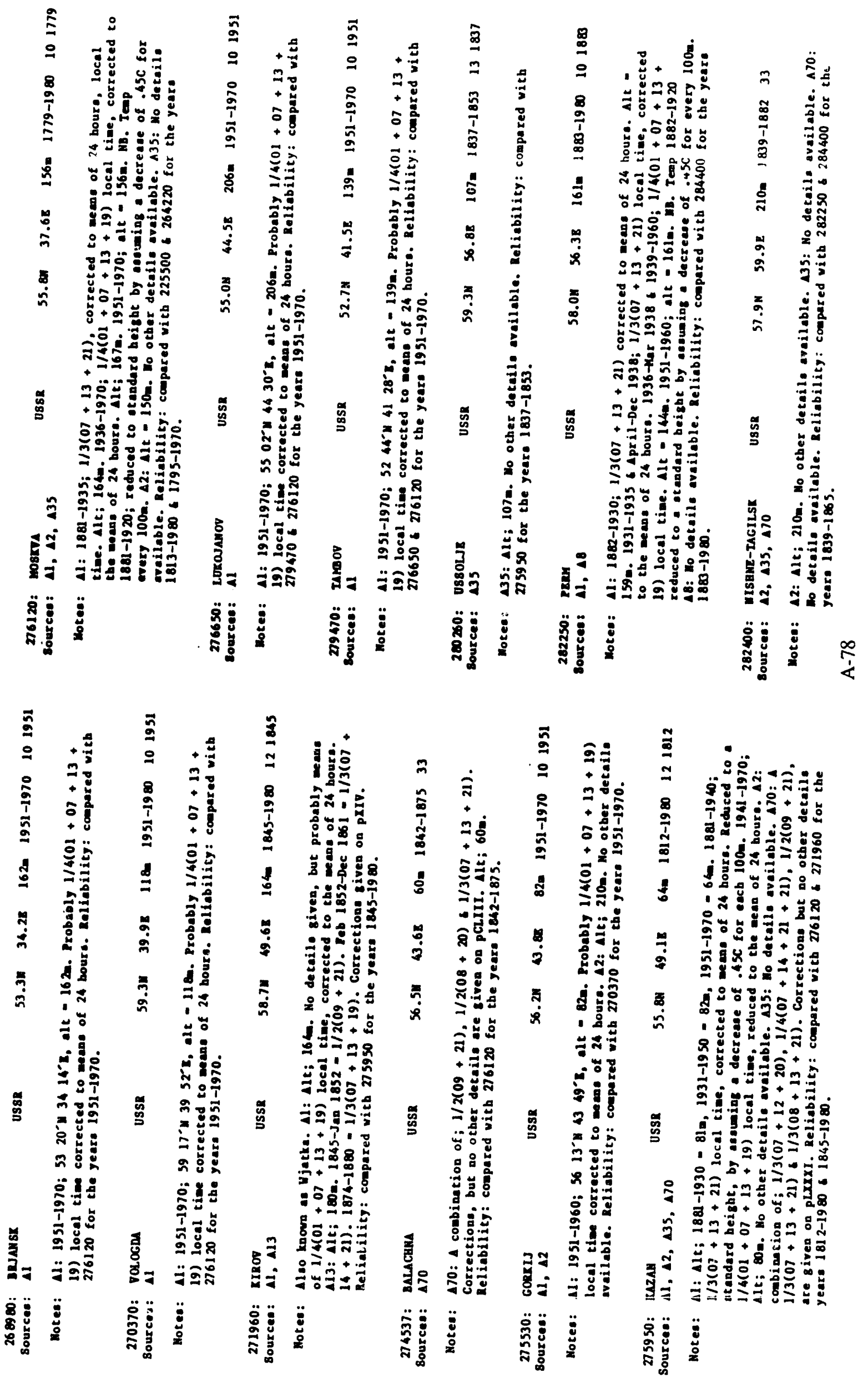

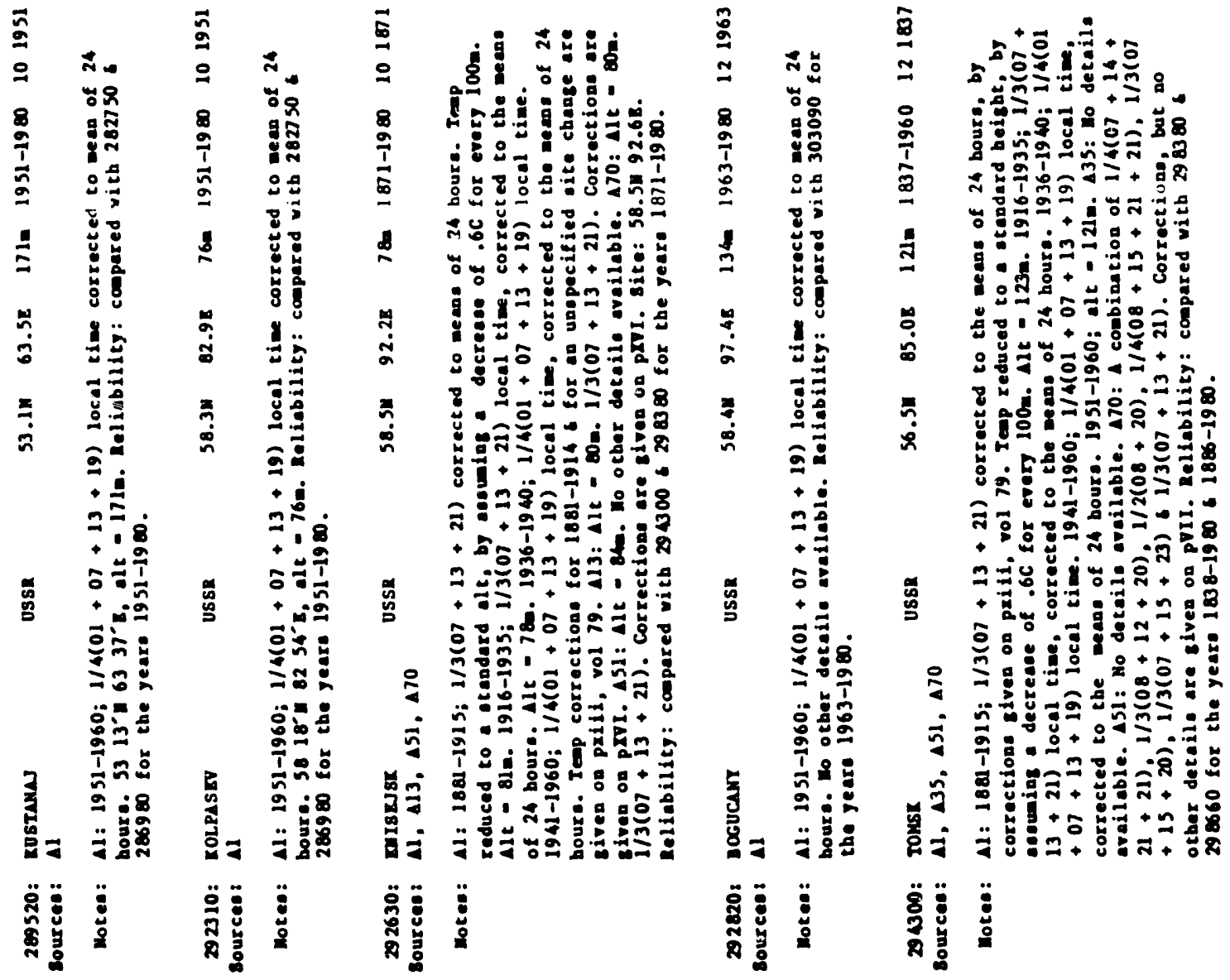

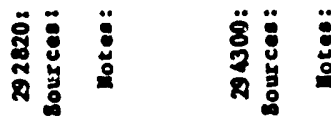

$\overrightarrow{0}$

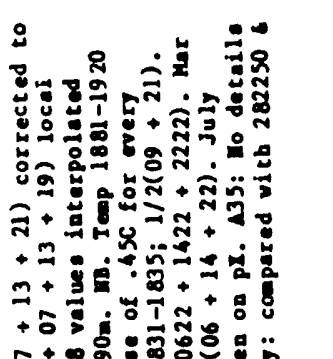

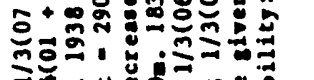

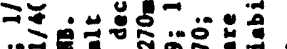
ڤึ

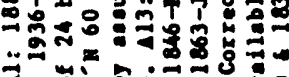

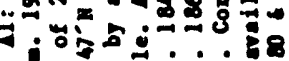

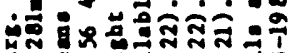

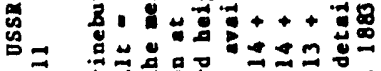

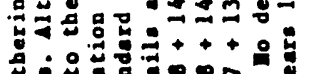

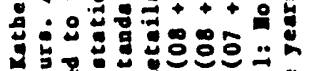

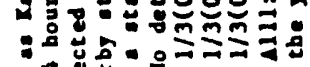

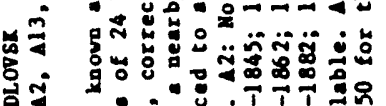

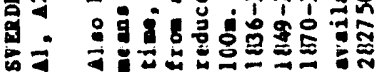
亳苛莒

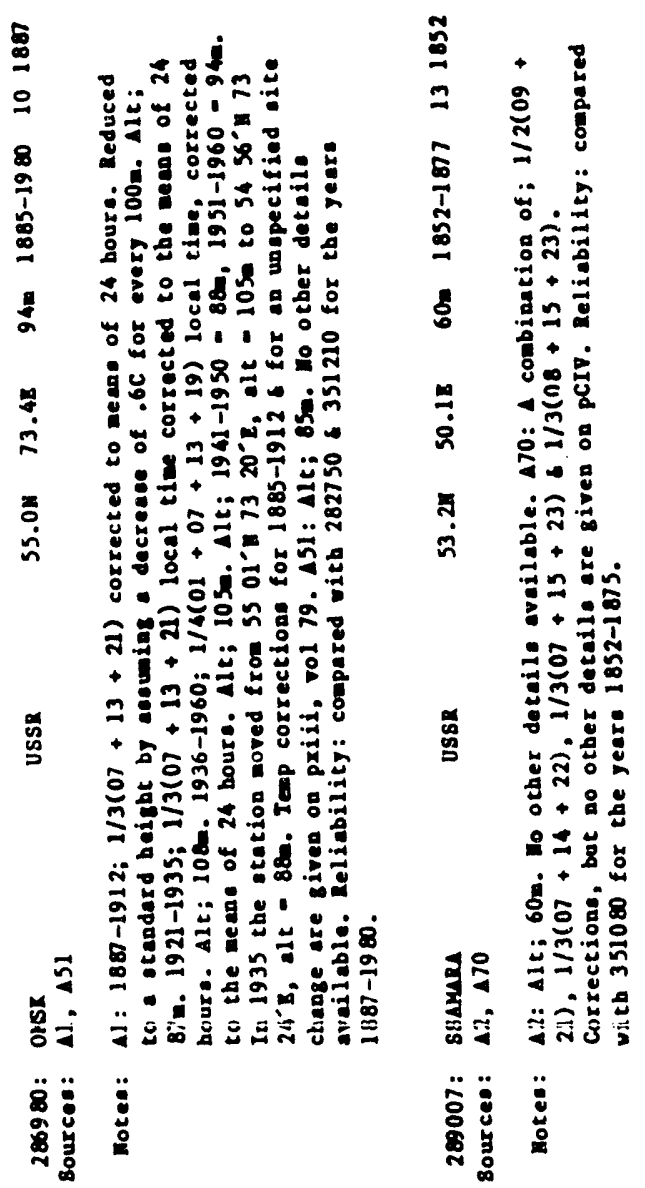



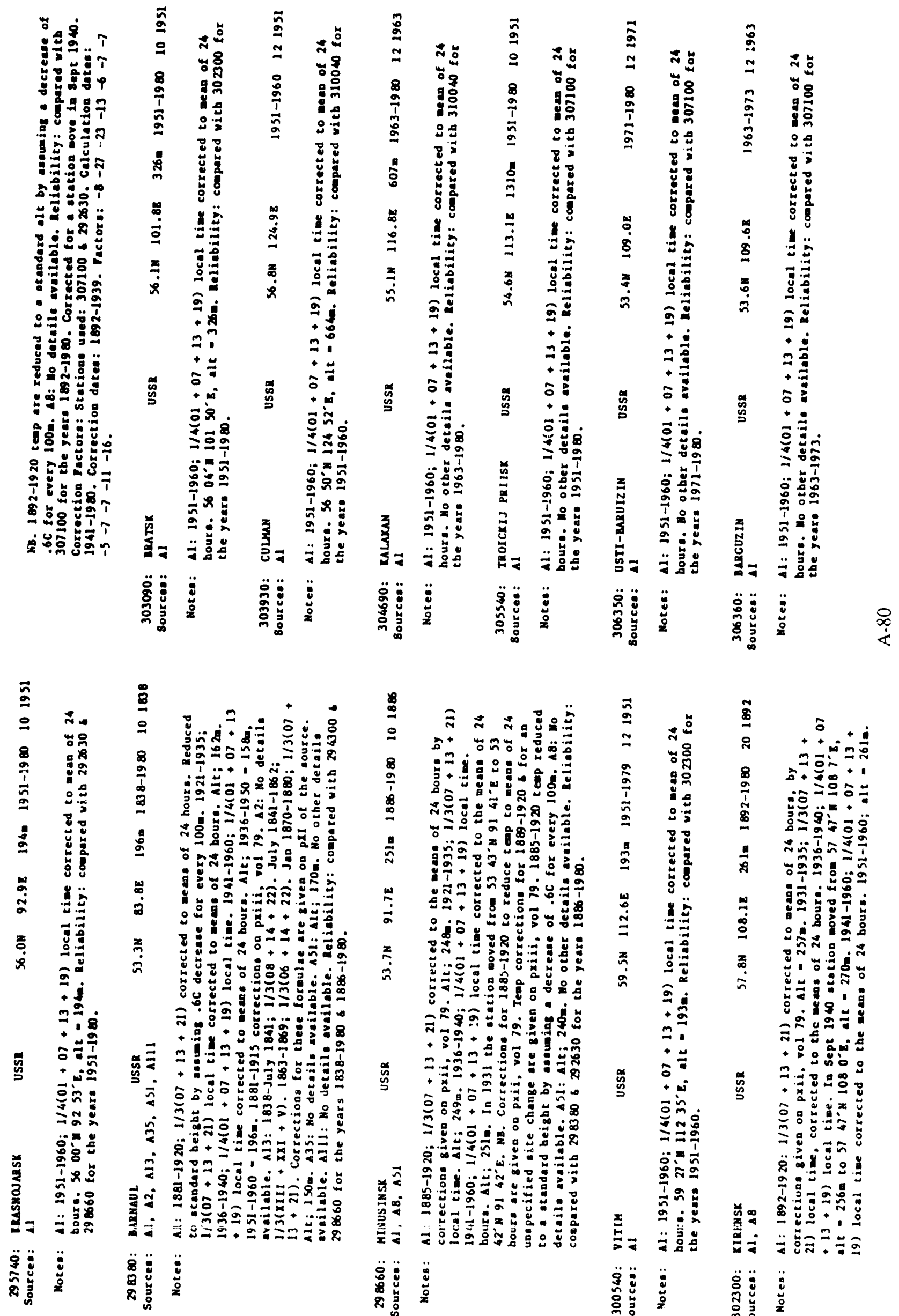

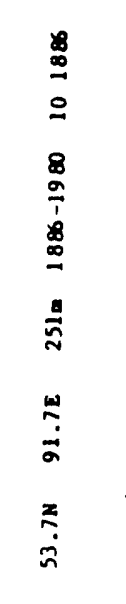




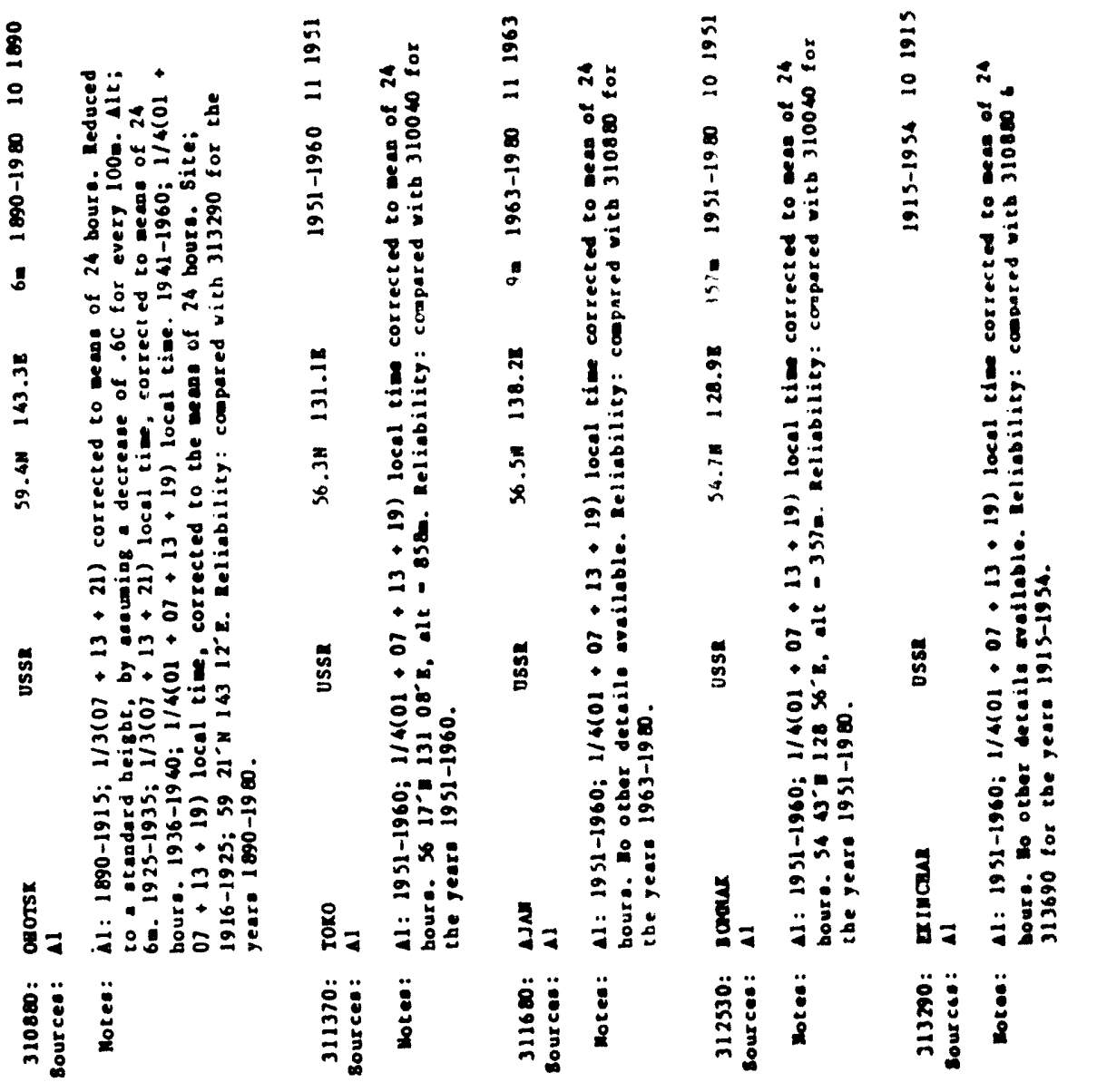

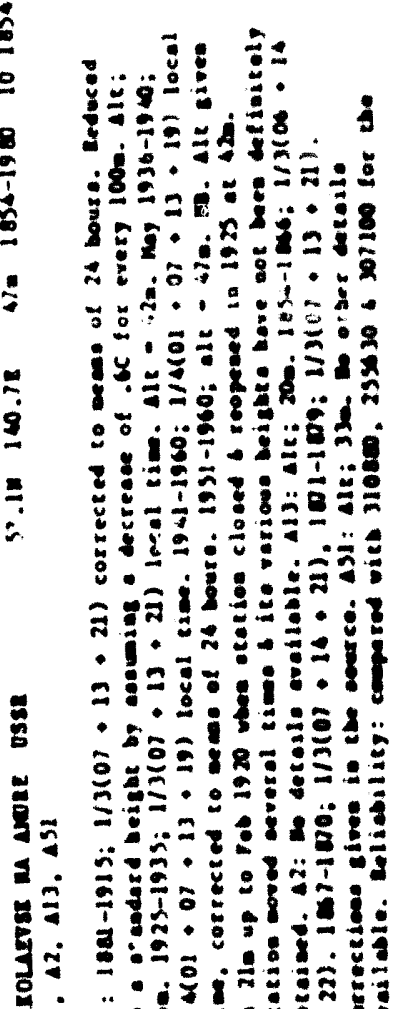




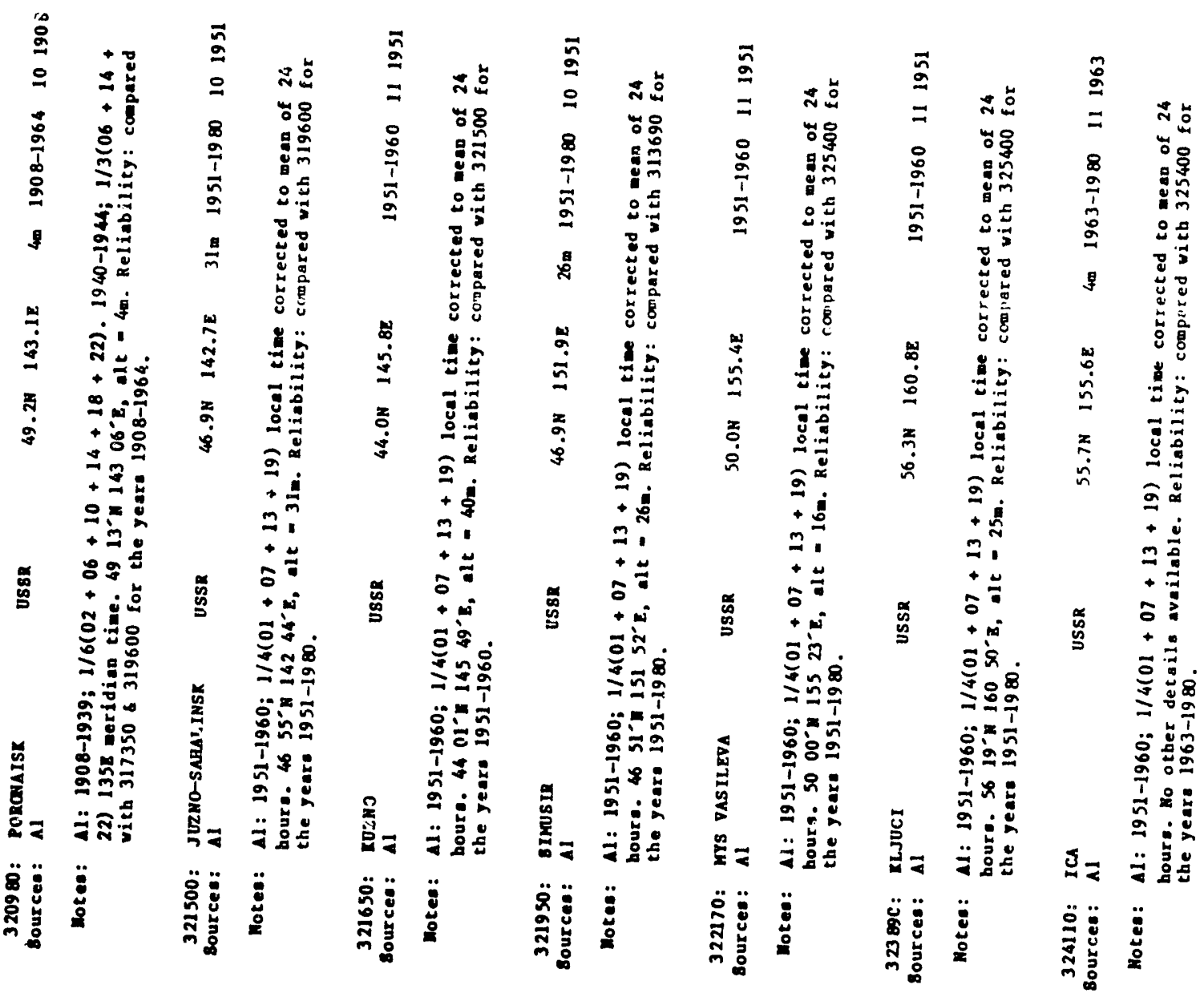

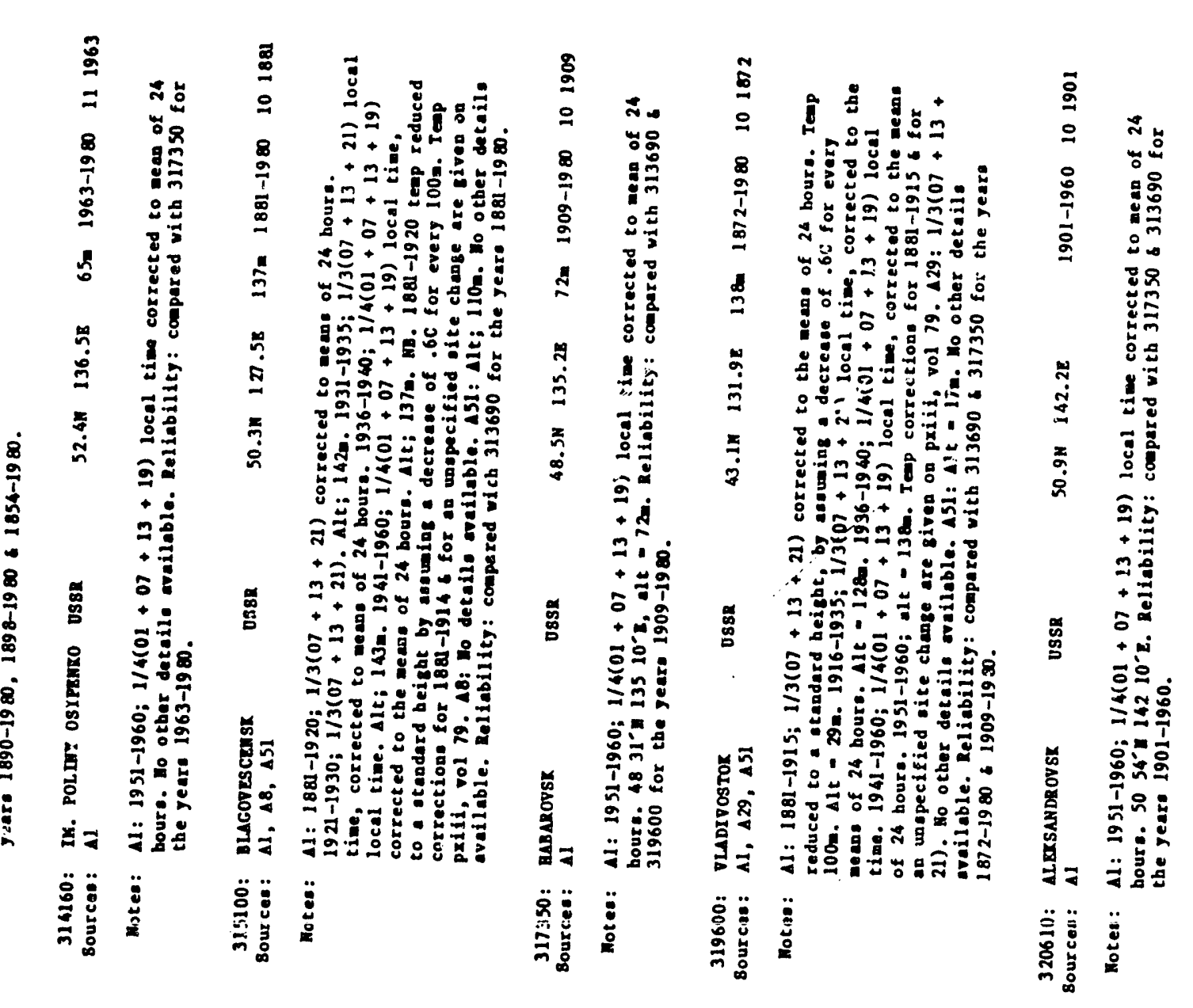




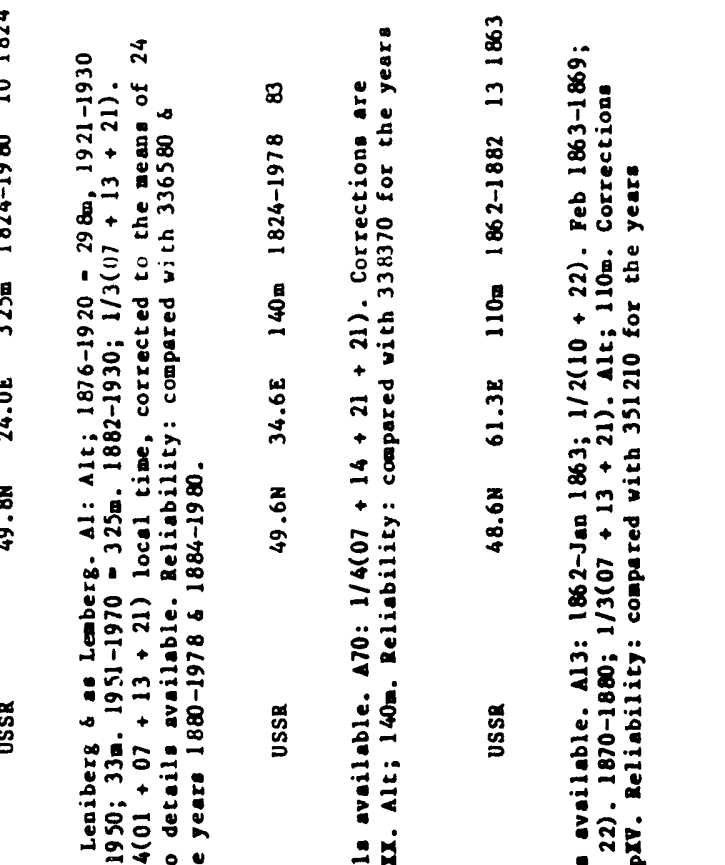

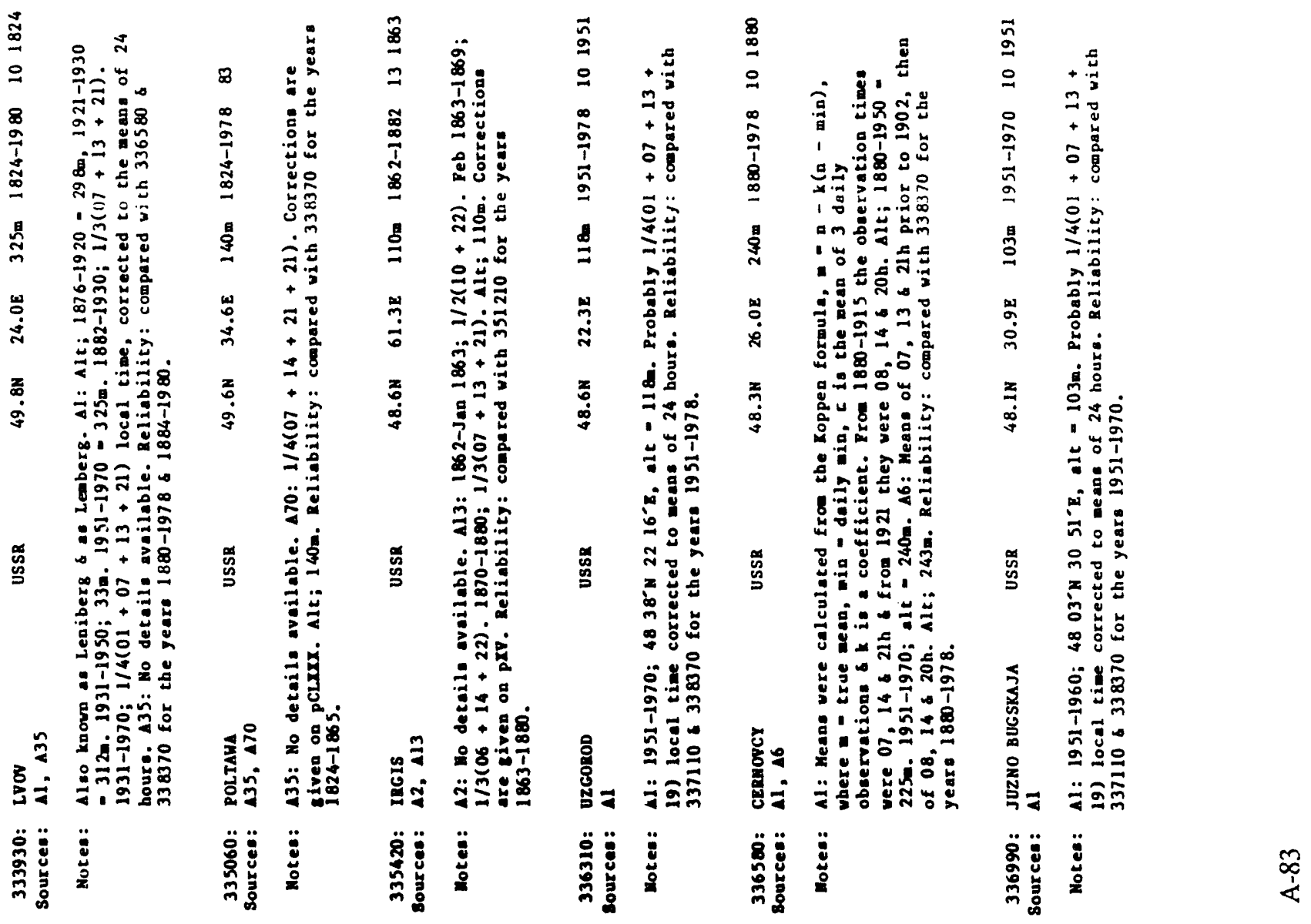

N

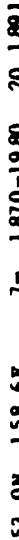

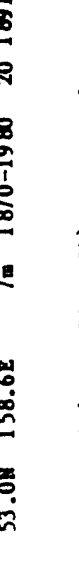

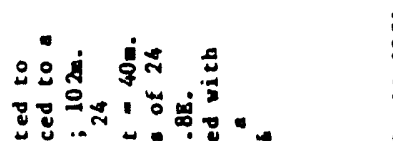

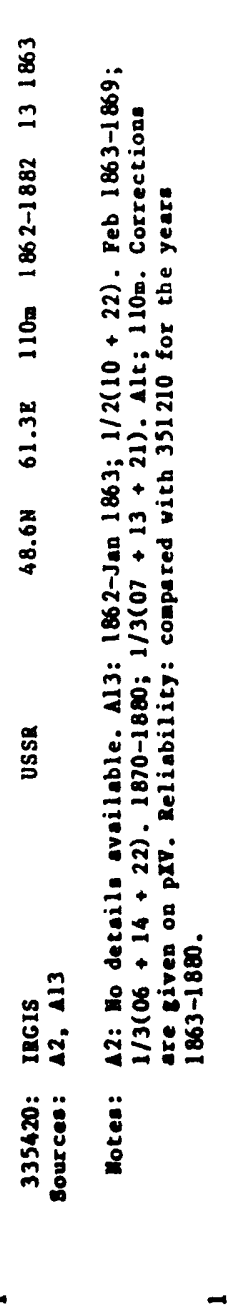

ลี

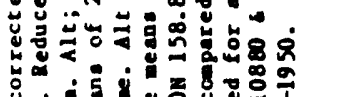

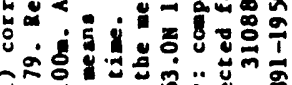

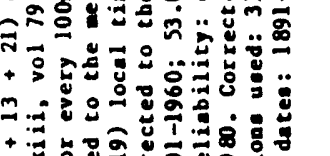

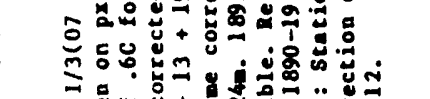

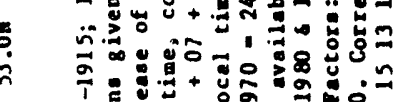

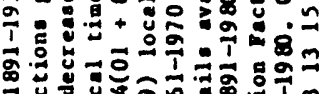

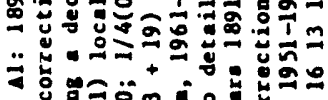

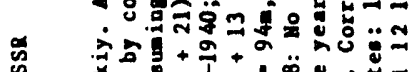

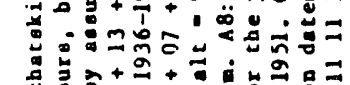

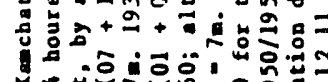

\% :

总

ธั่ำ

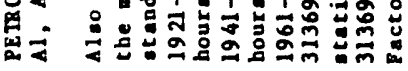

躍

I

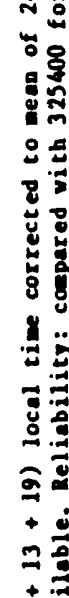

+
+8
28
+8
08
+8

$\bar{n}$
$\vdots$
$\frac{1}{1}$

蕰

a

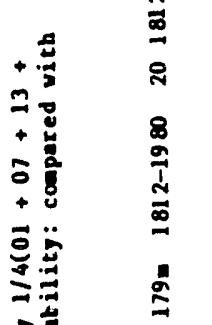

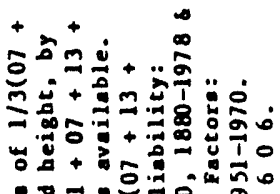

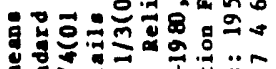

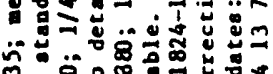

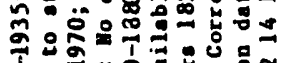

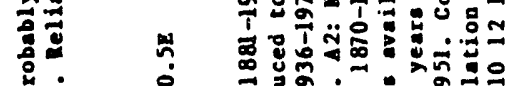

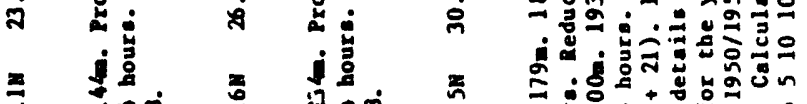

ñ

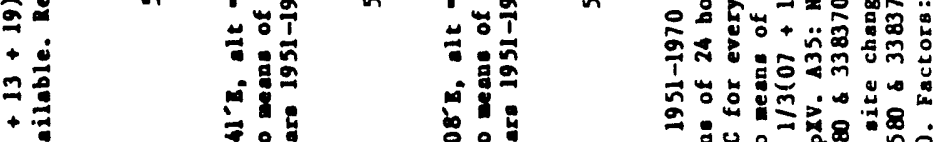

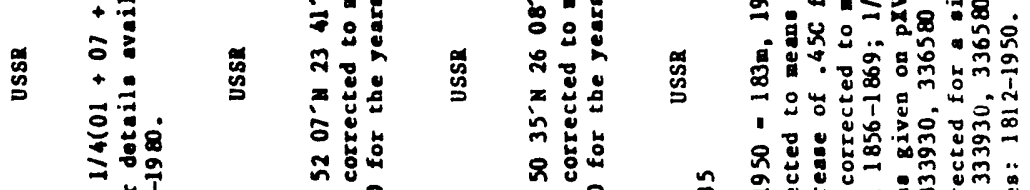

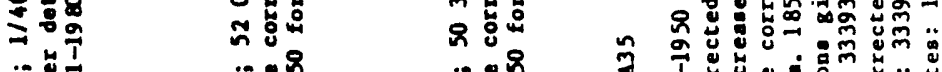

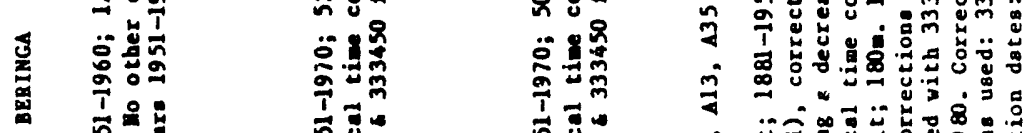

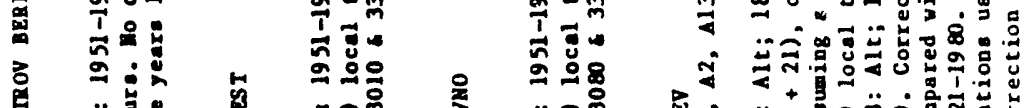

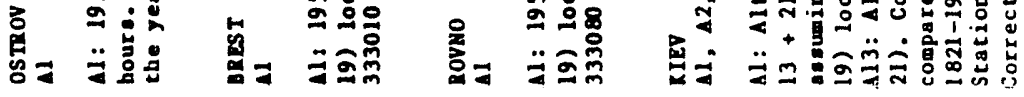

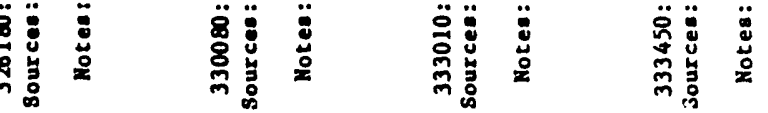




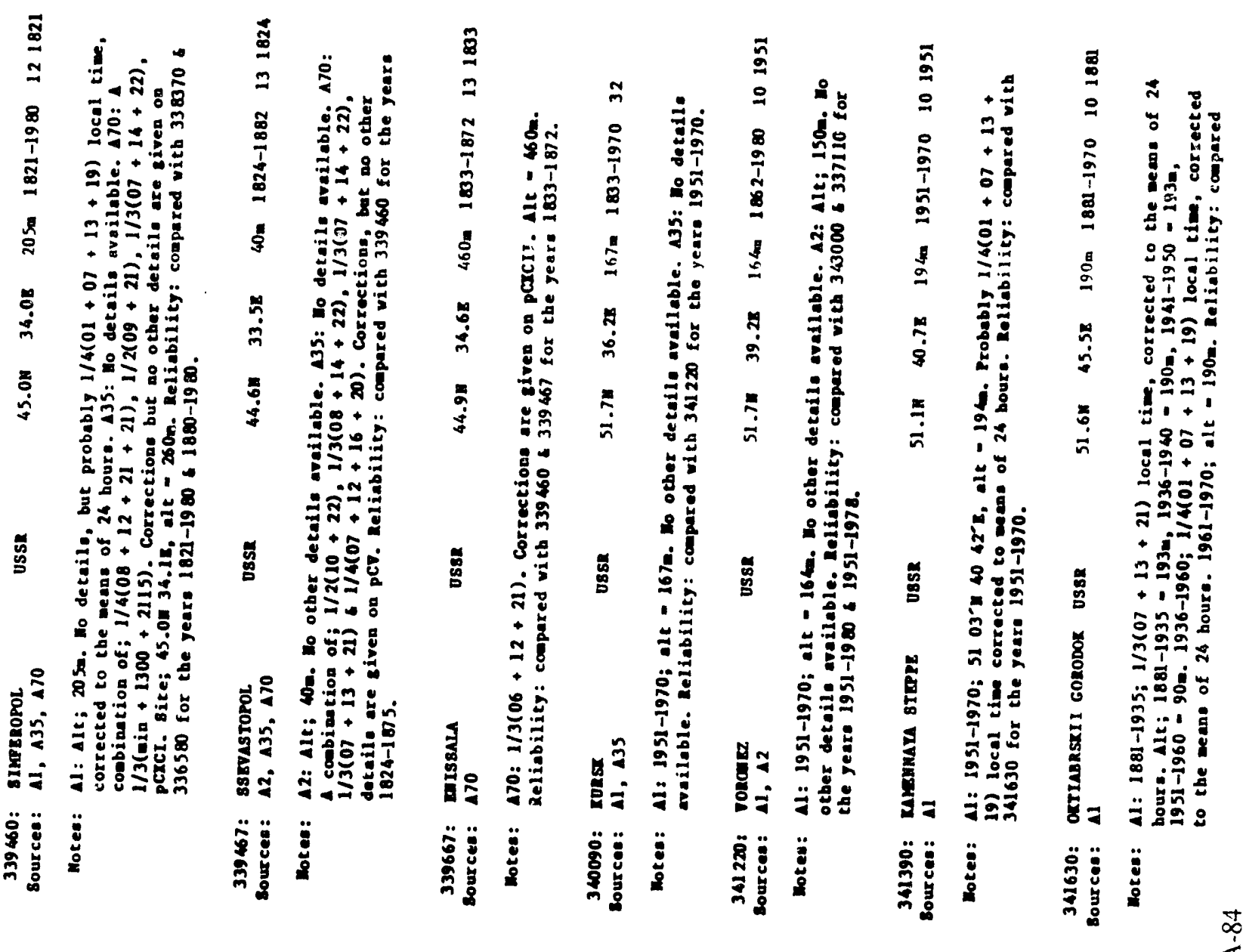

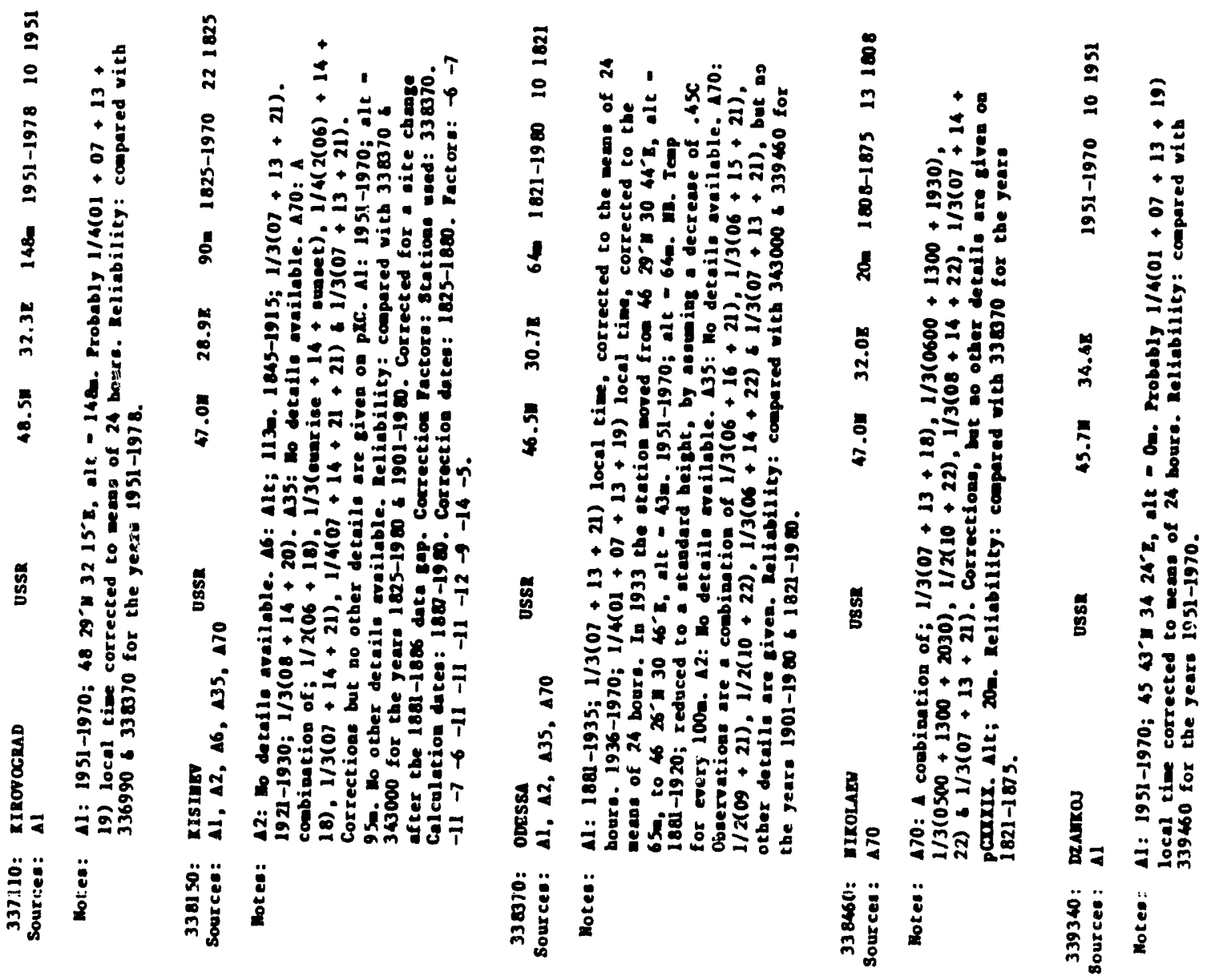




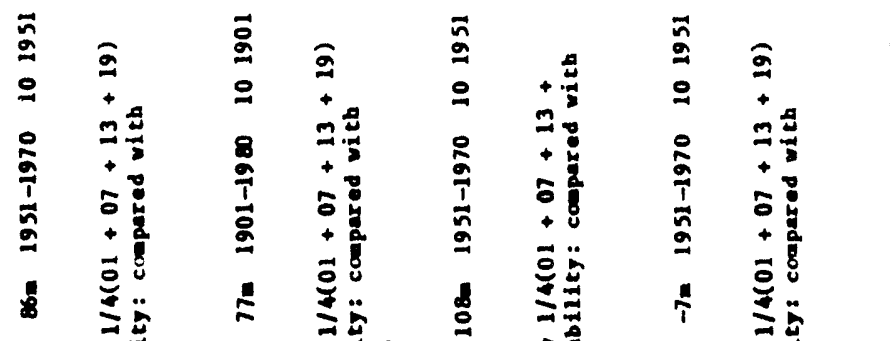

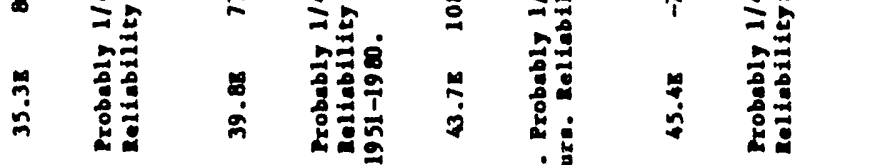

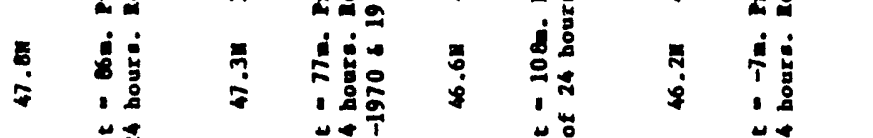

:

, i :

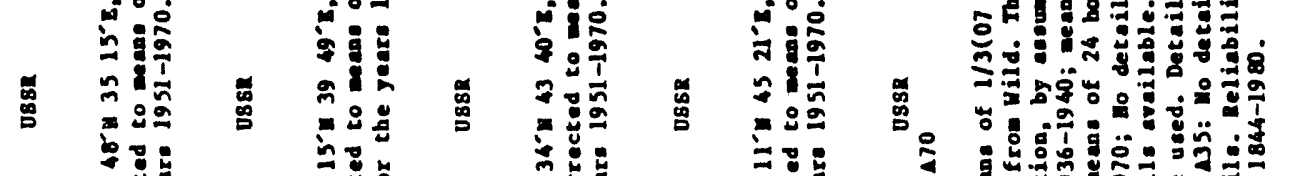

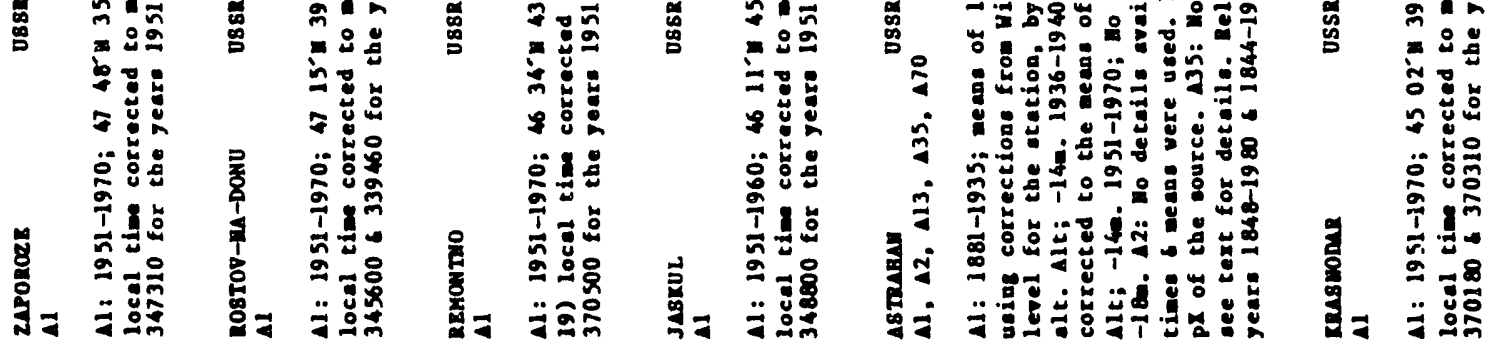

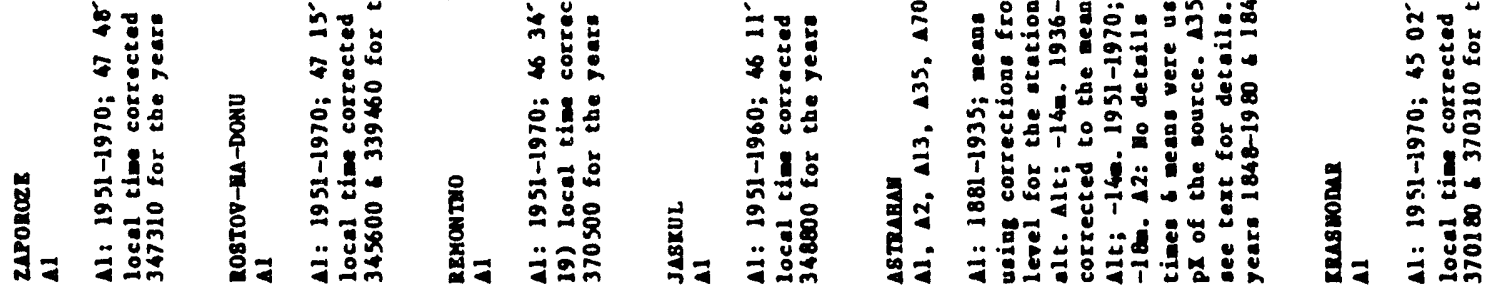

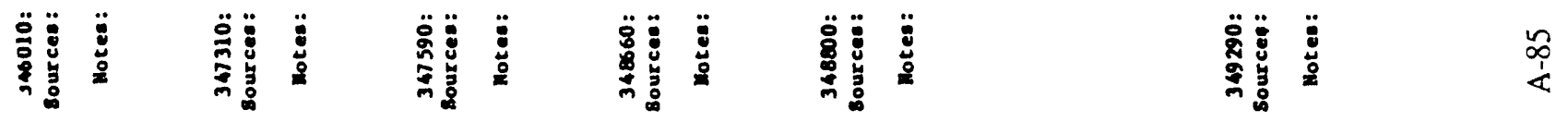

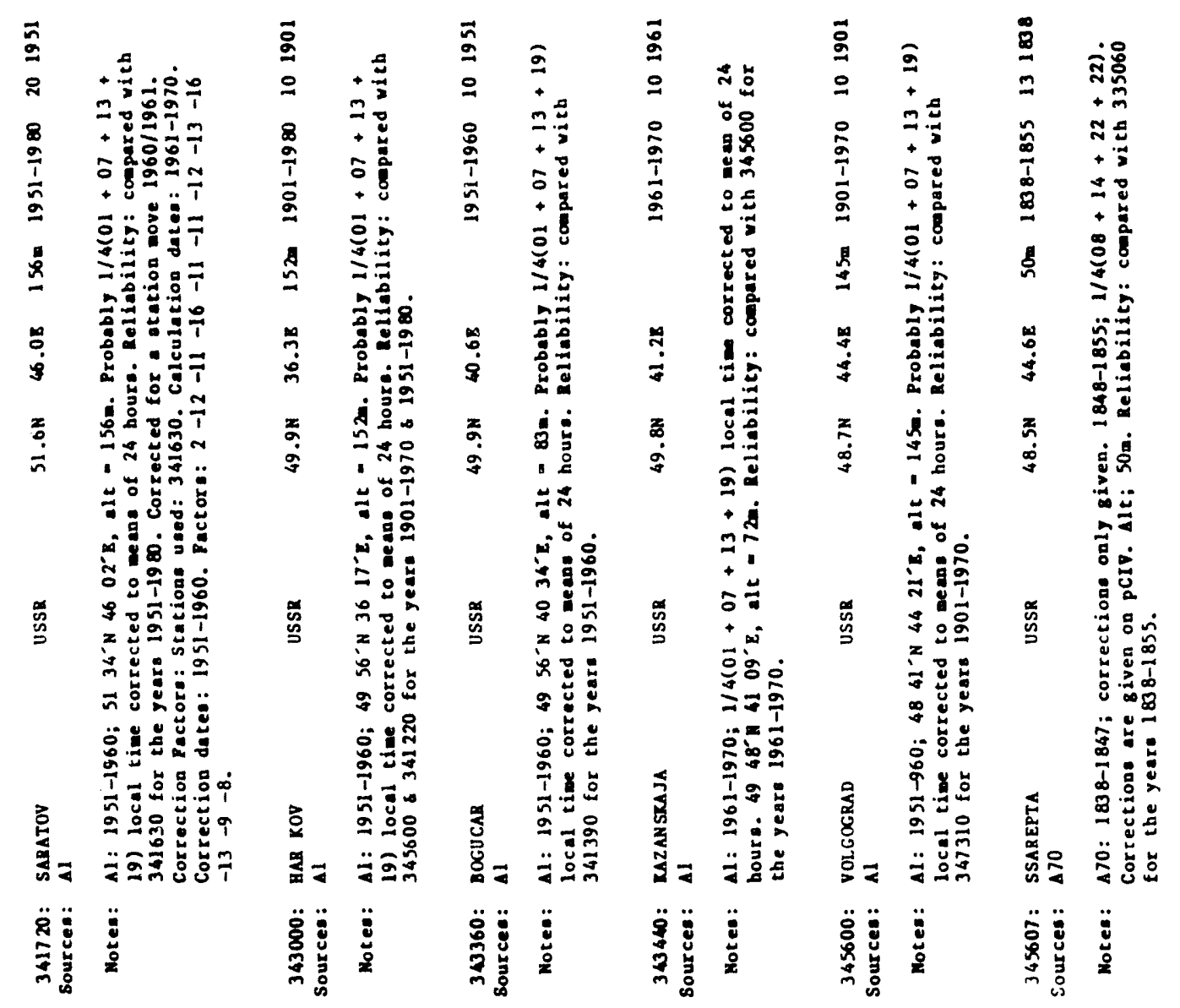



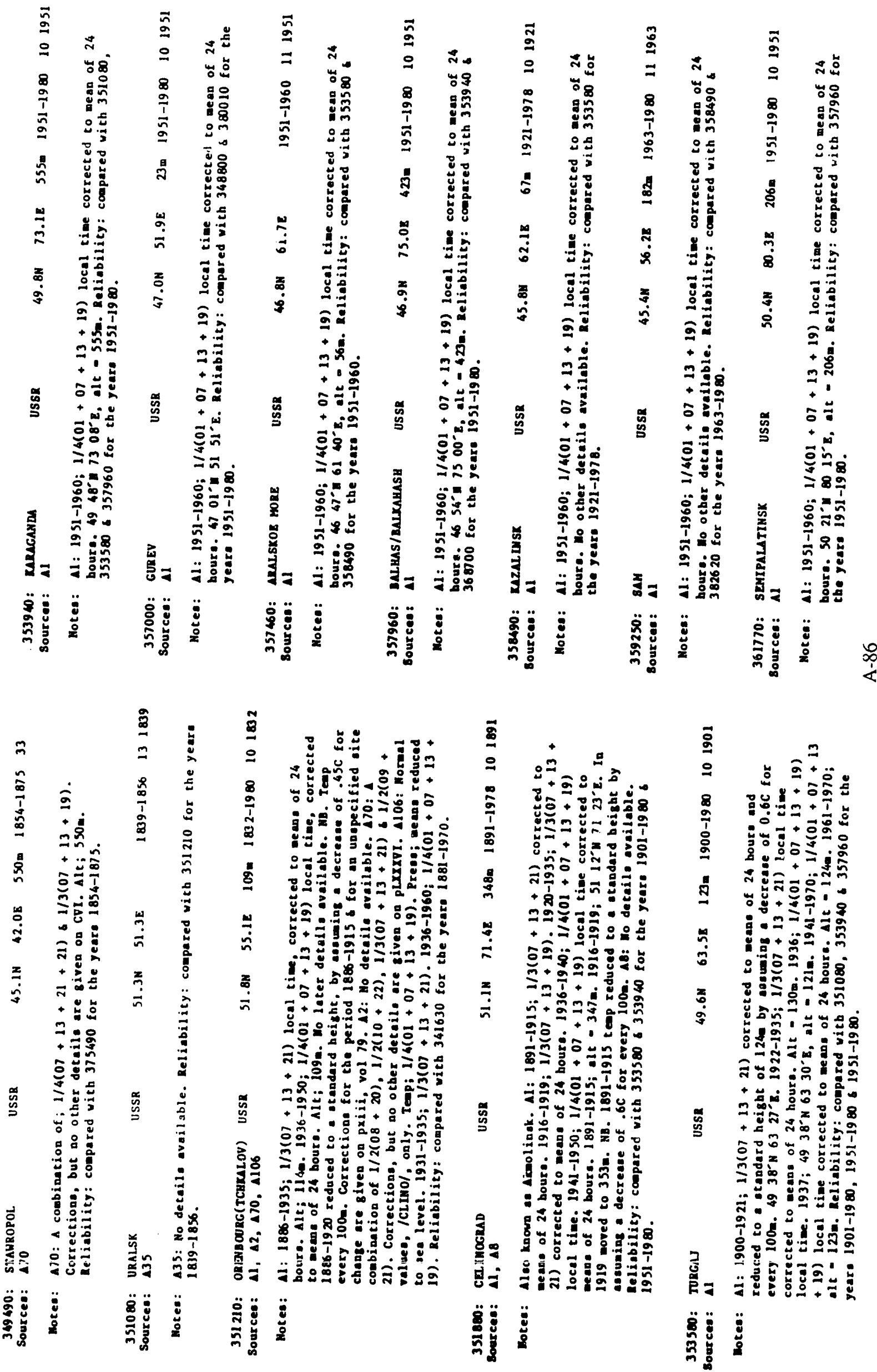


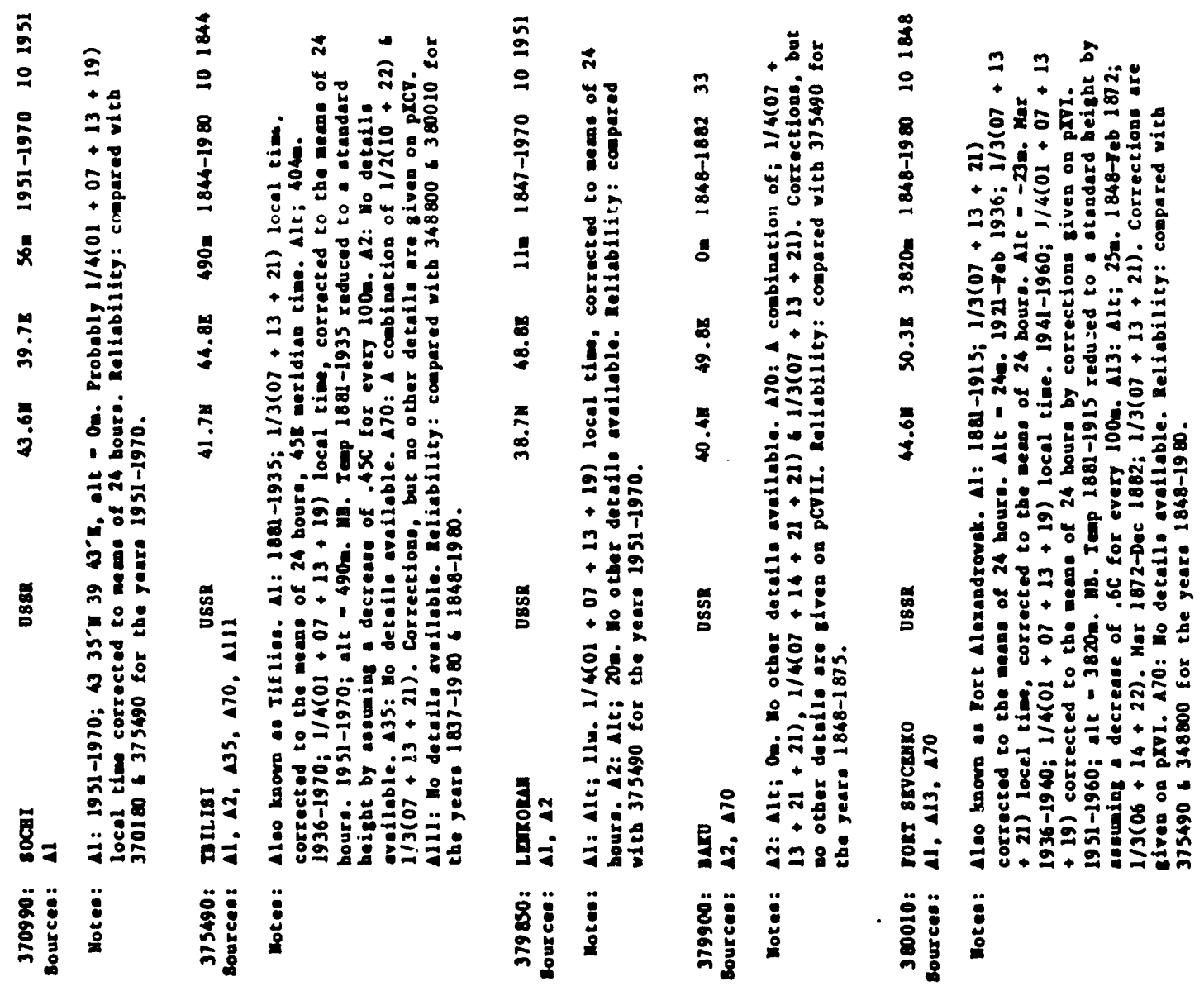

$\infty$
1
1

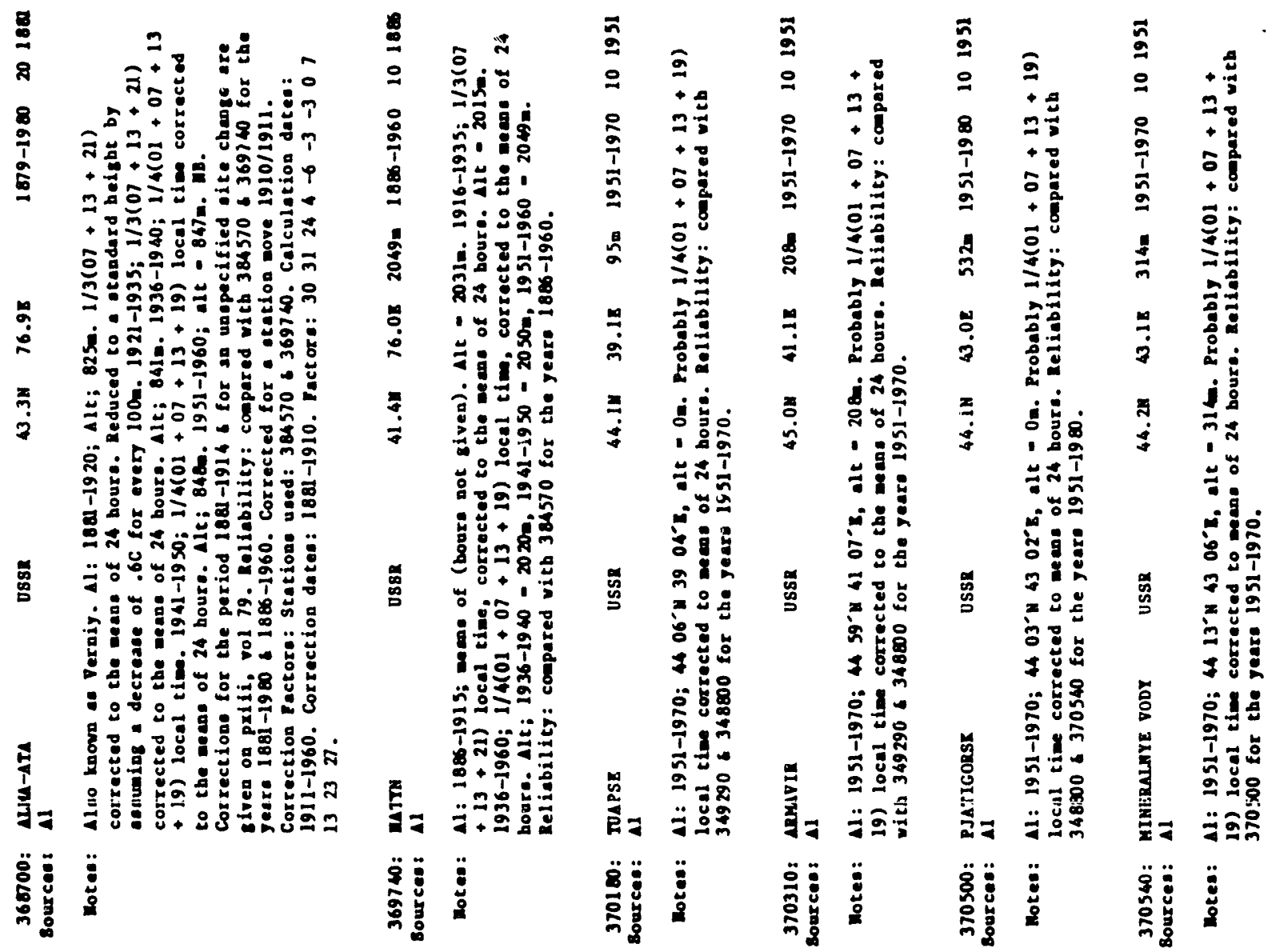


ఏ

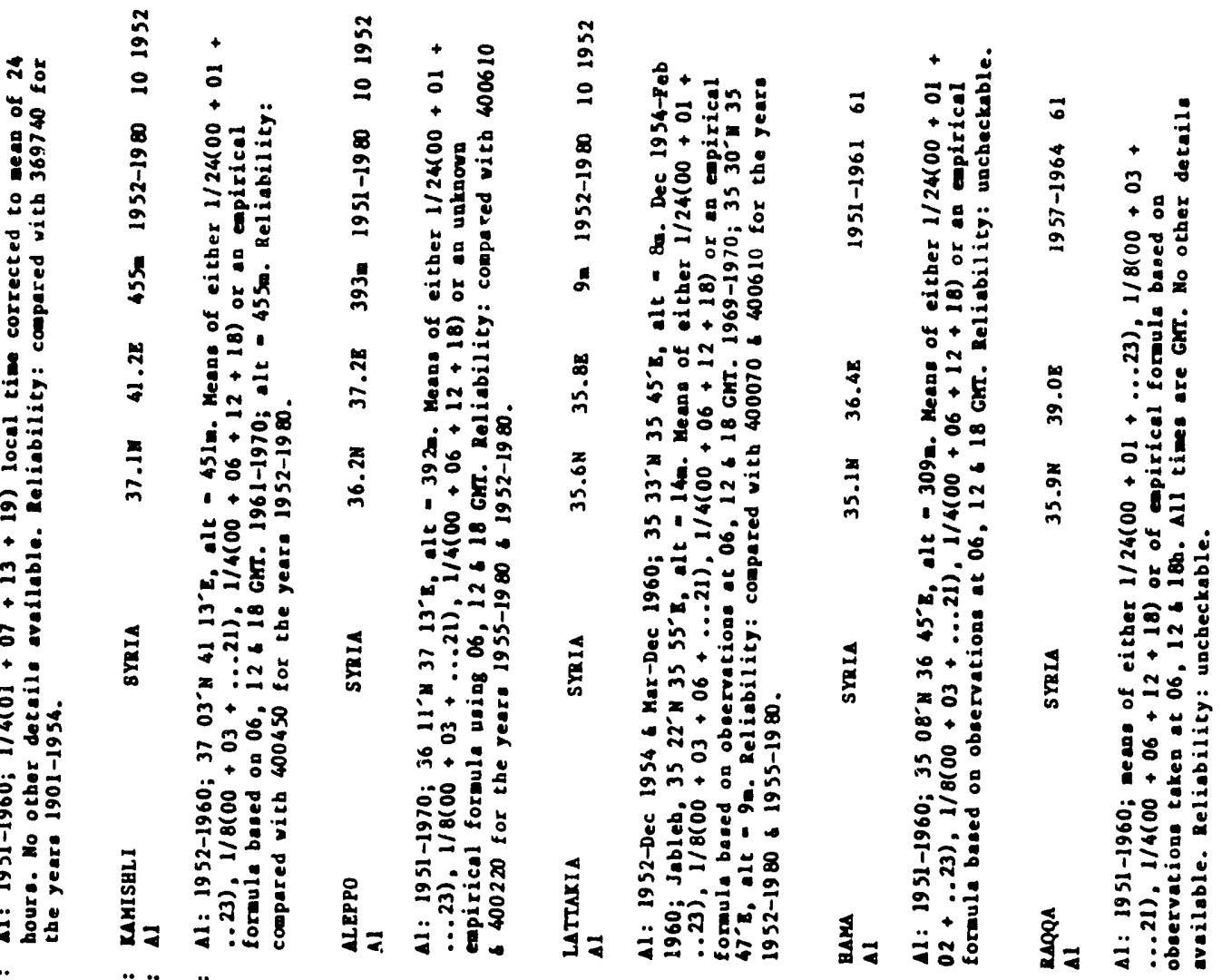

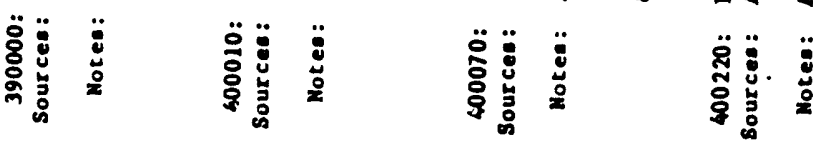

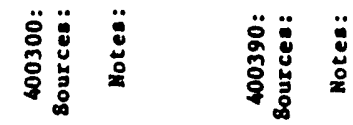

$\underset{\infty}{\infty}$

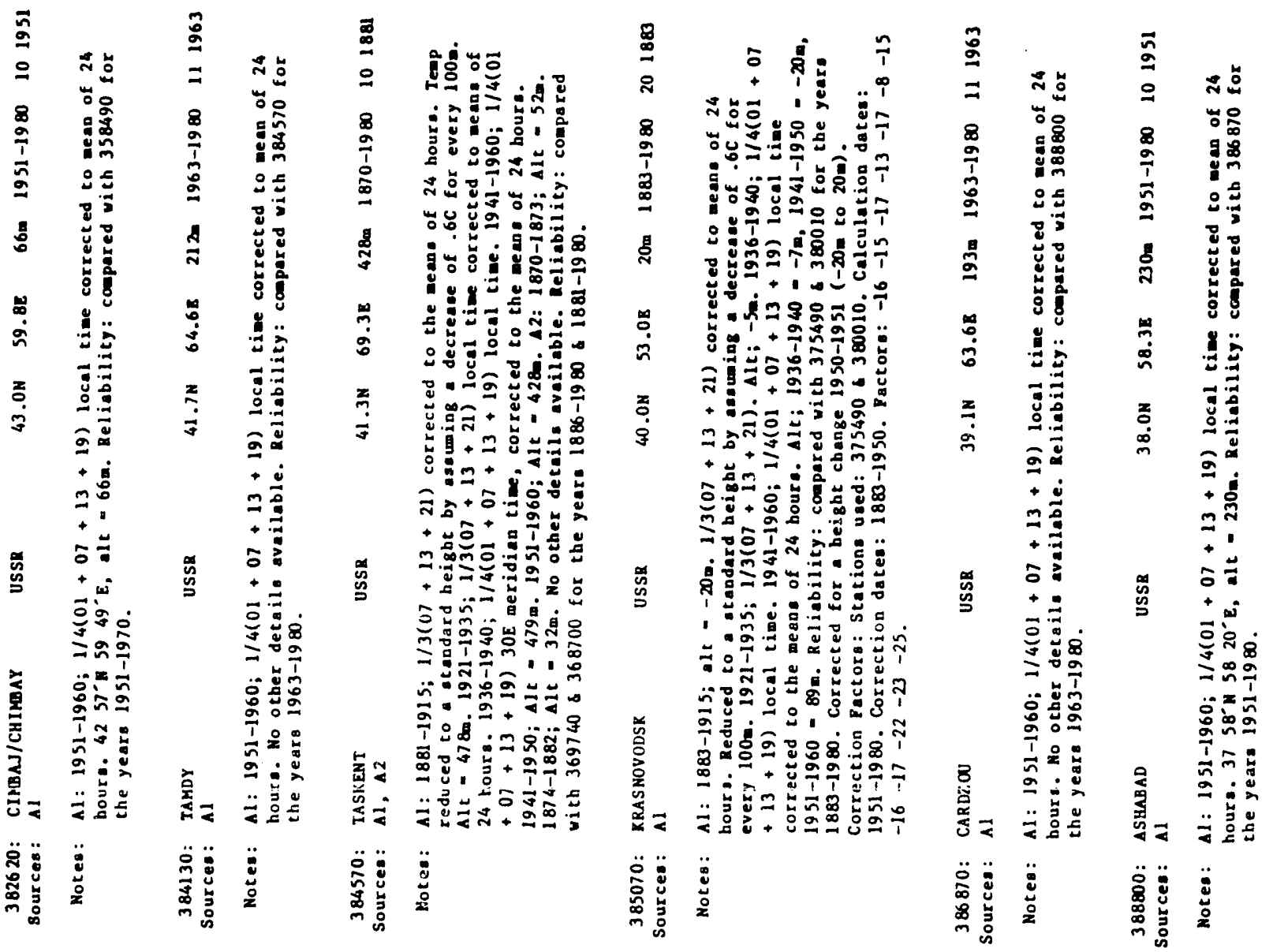




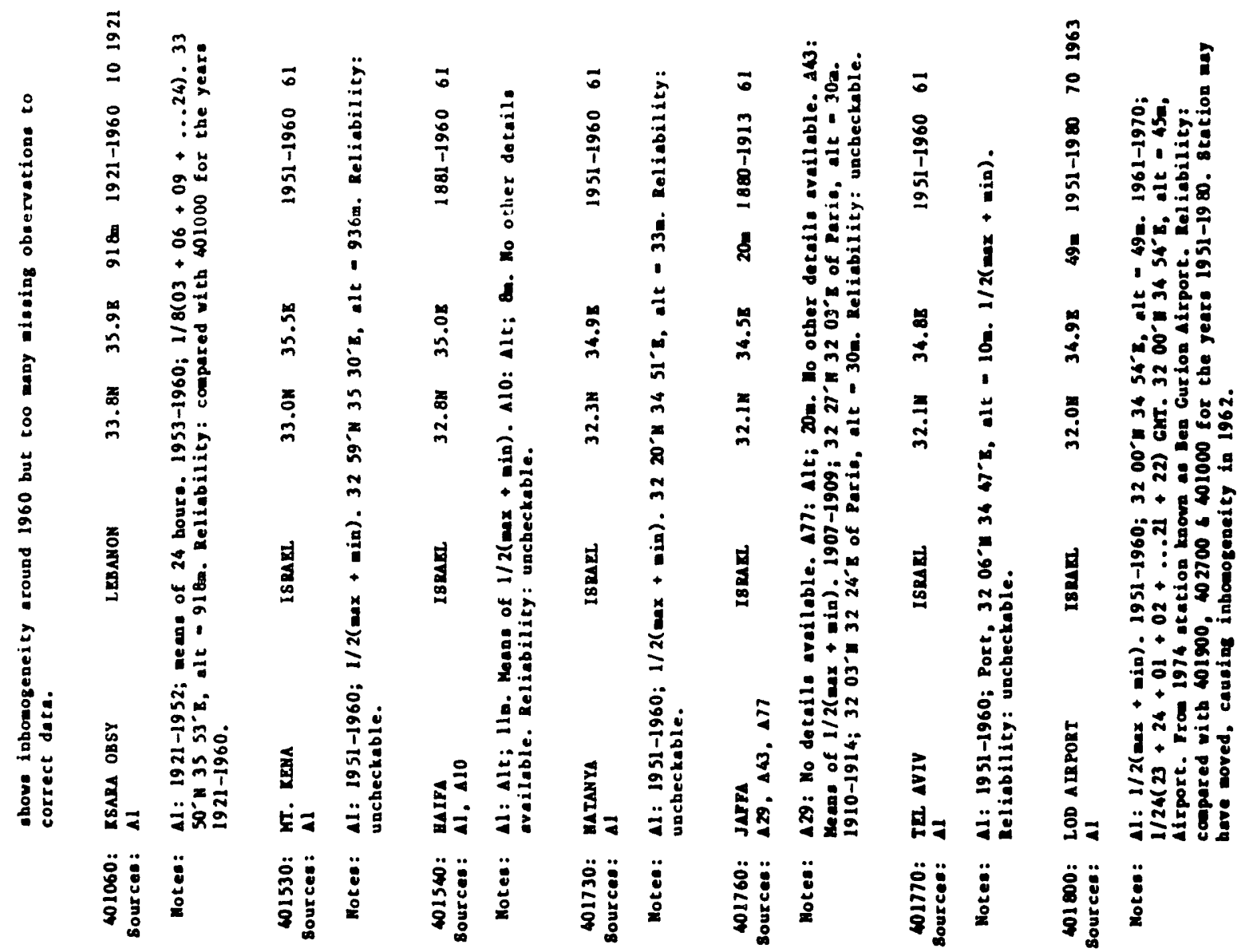

\&ุ

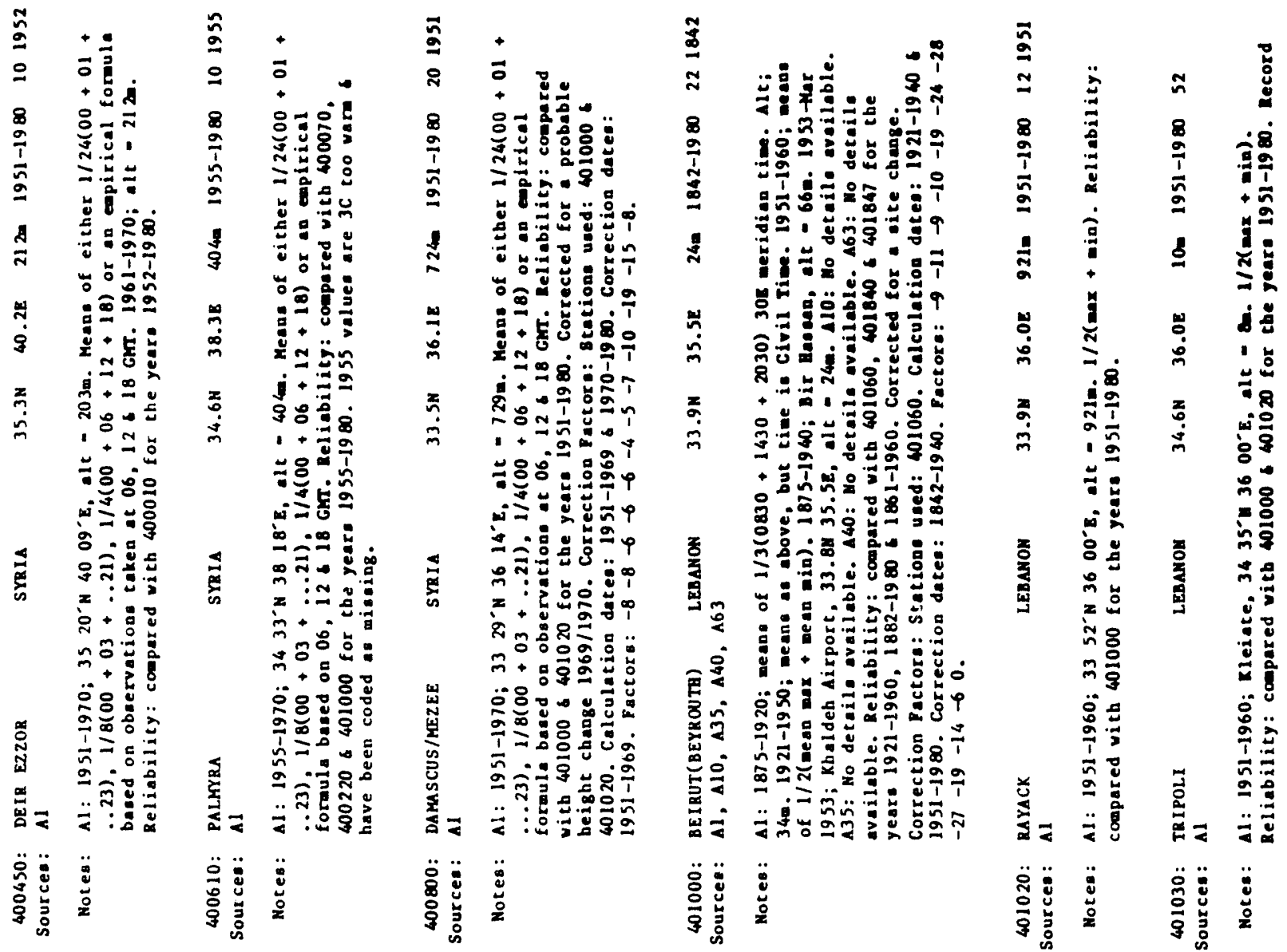




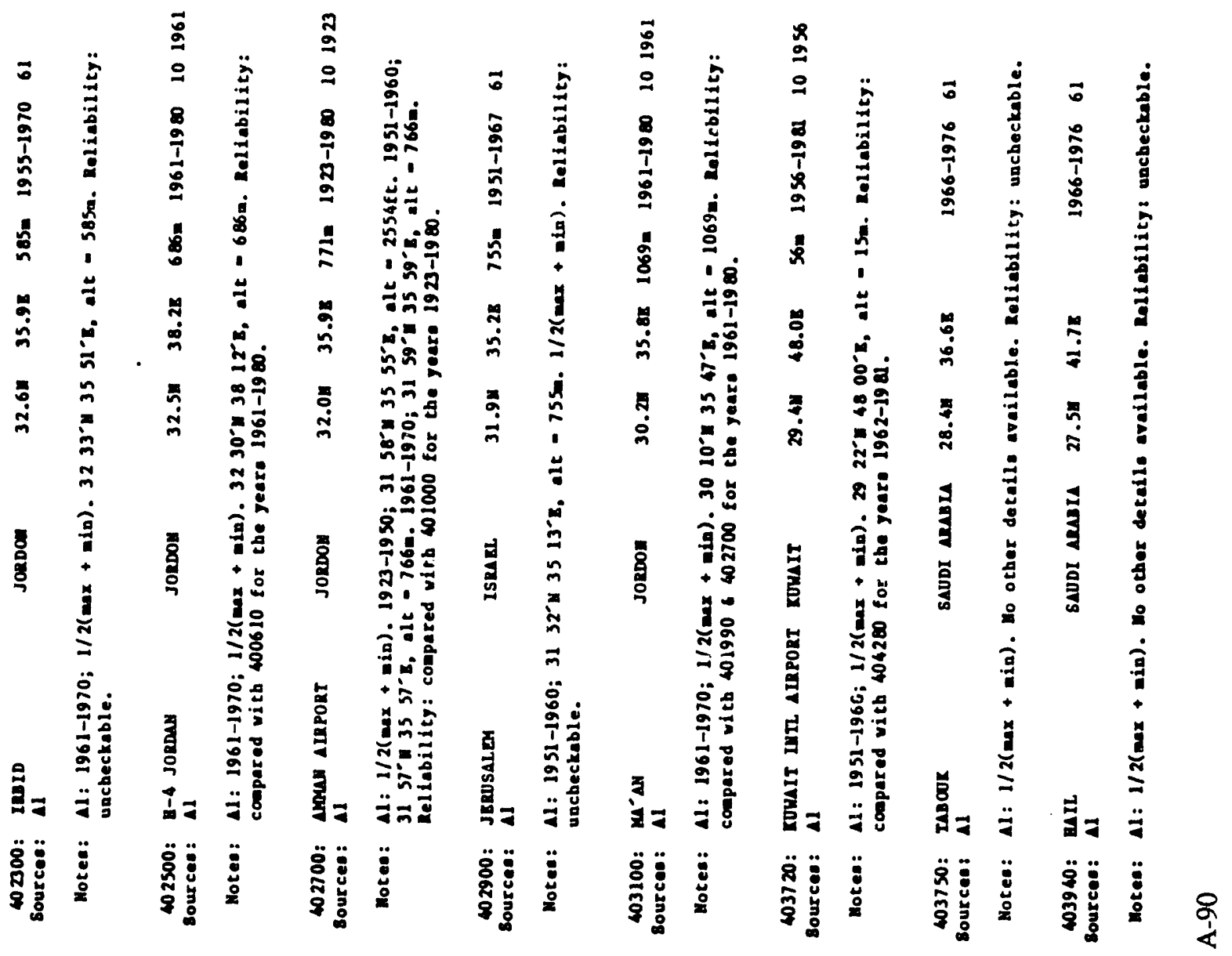

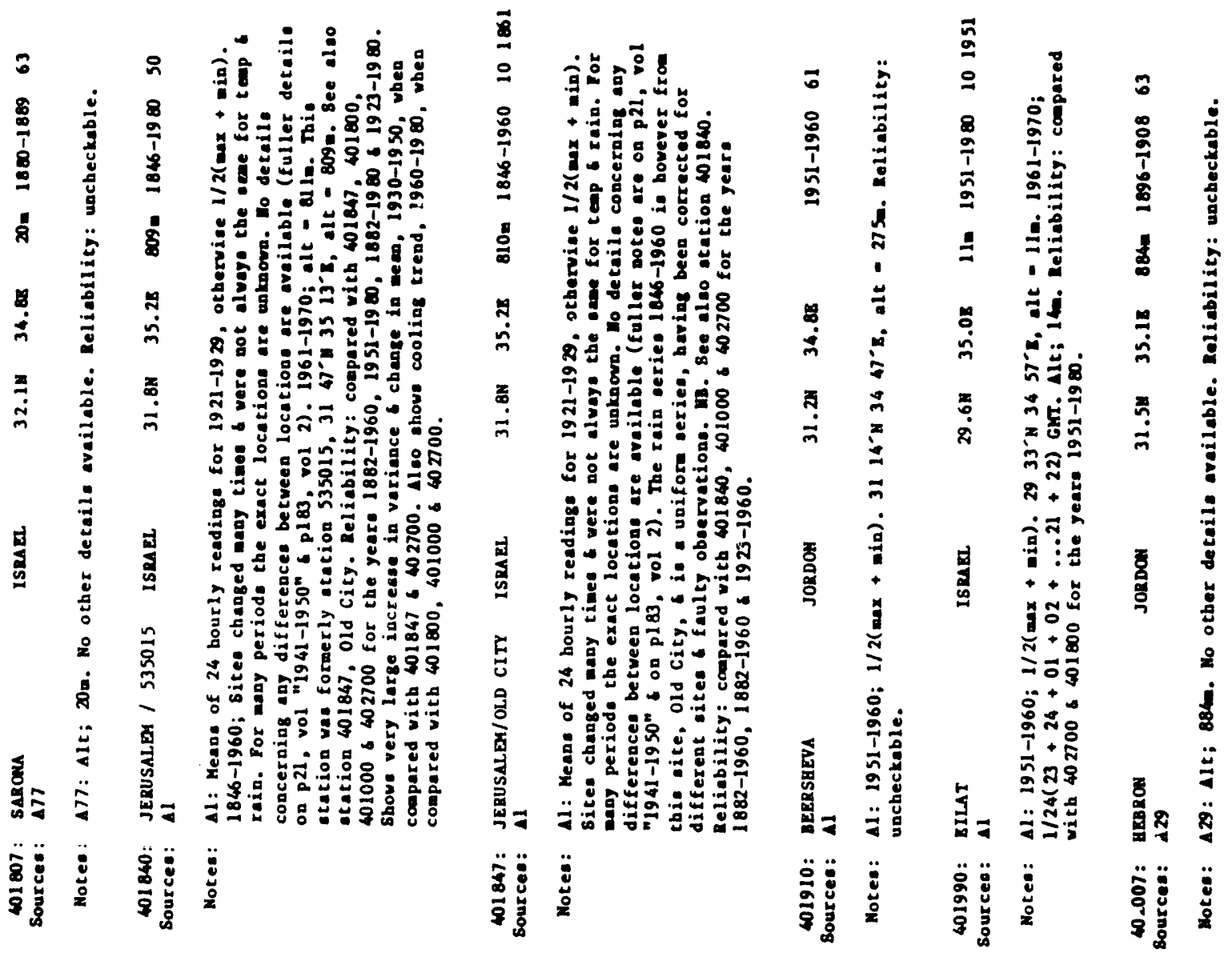


$\stackrel{m}{0}$

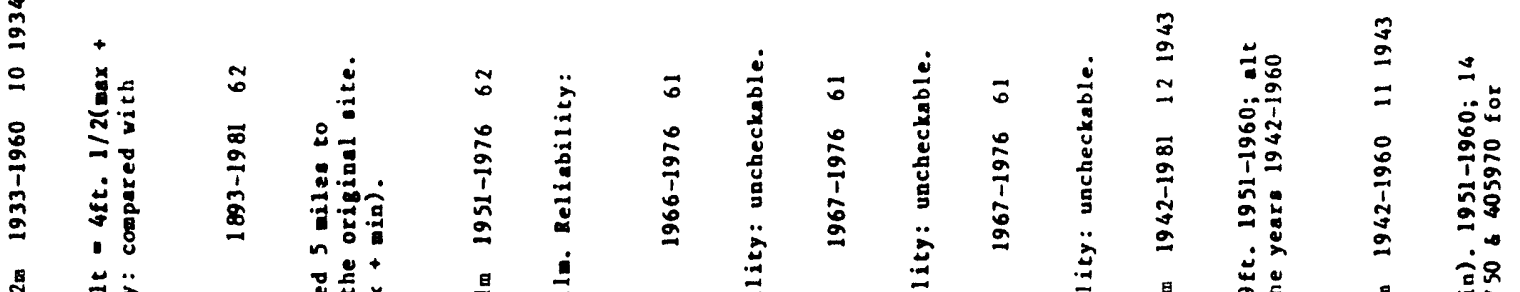

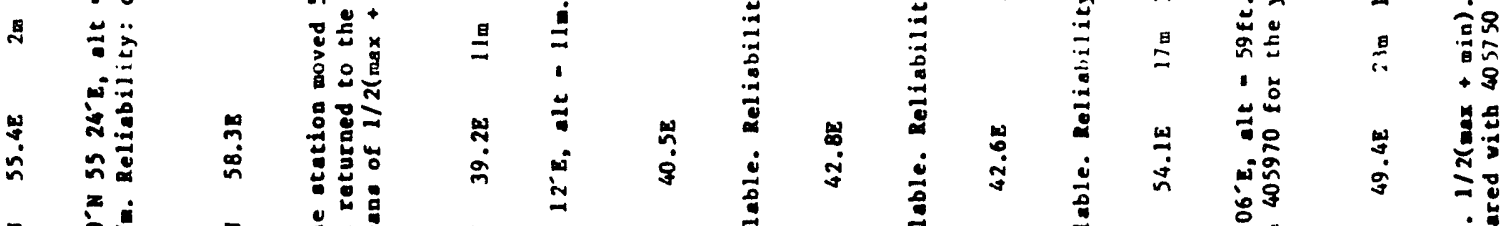

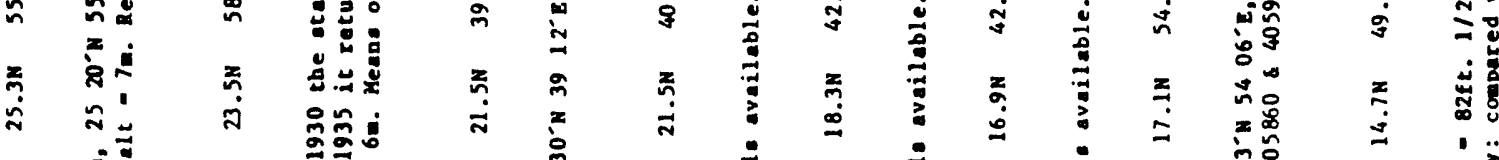

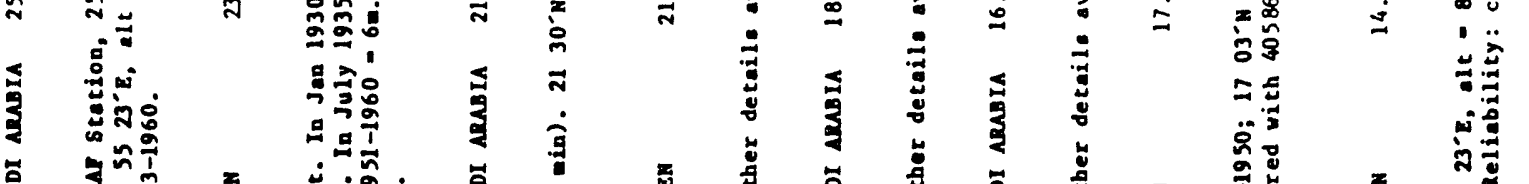

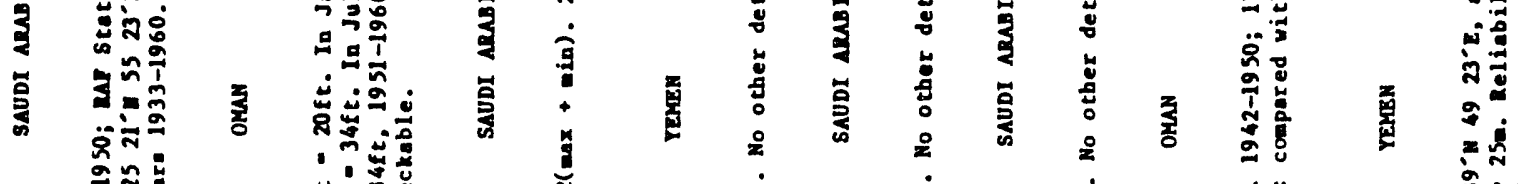

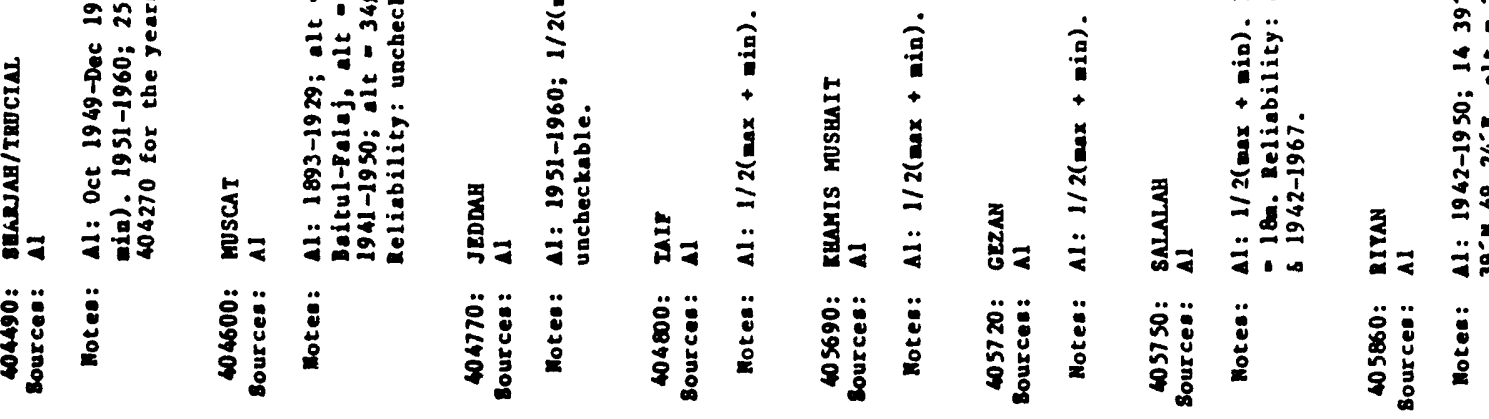

a

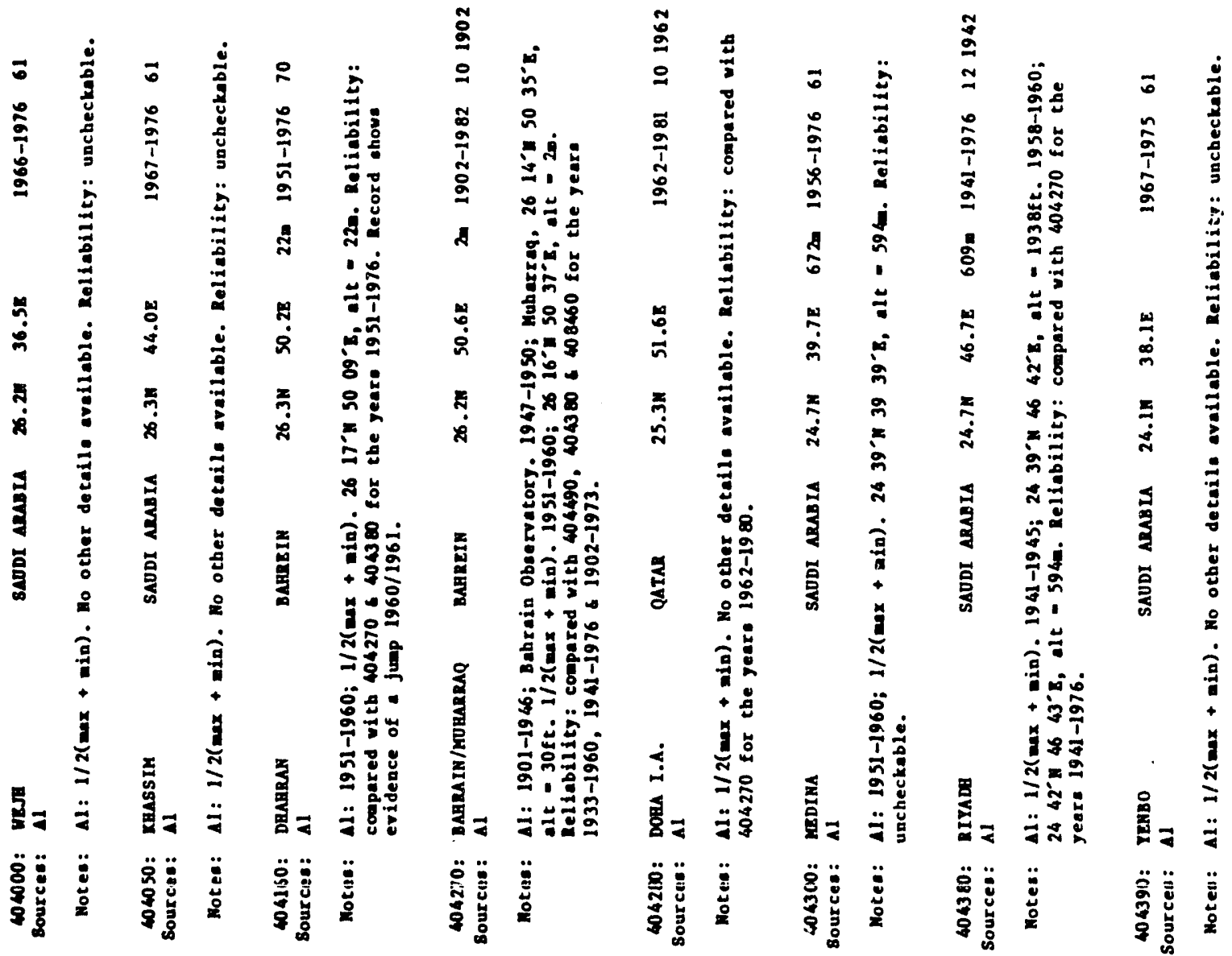




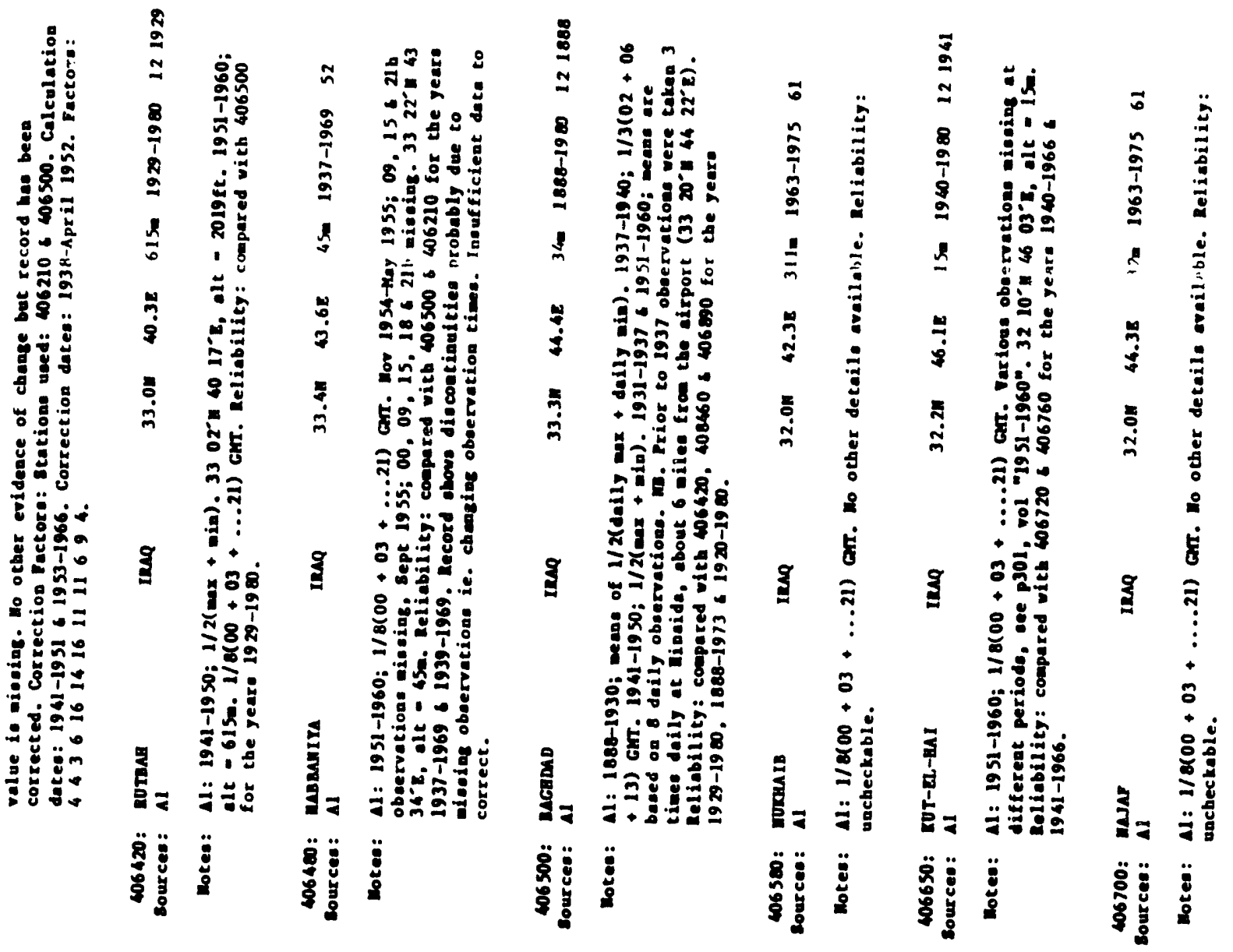

๙ু

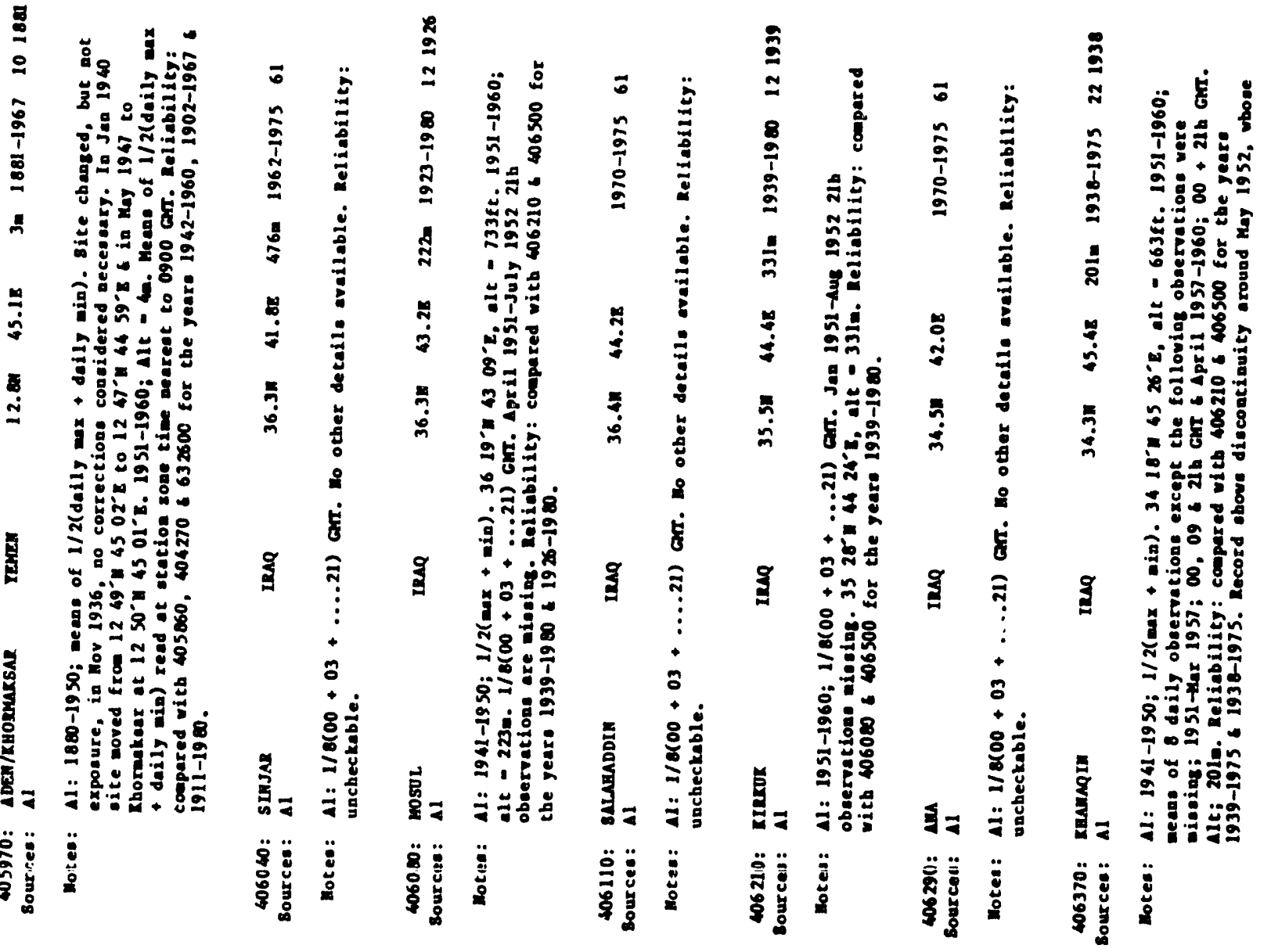




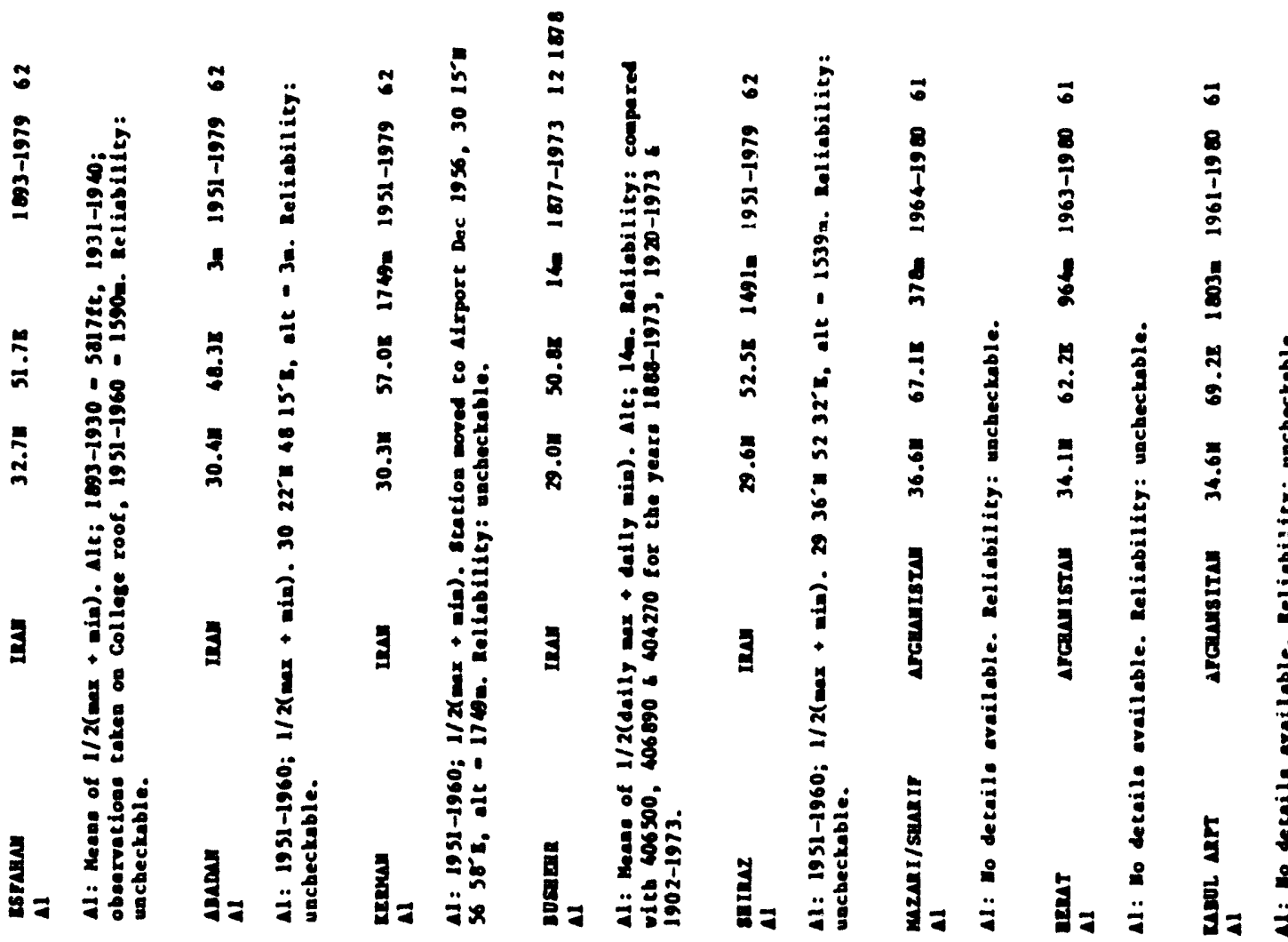

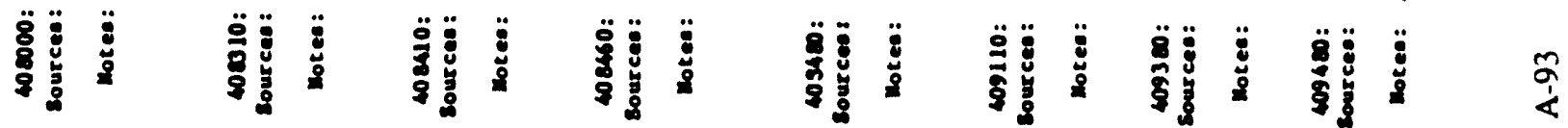

ส

$\therefore \quad \dot{0}$

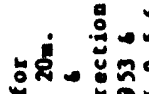

客

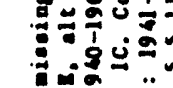

8

蕰

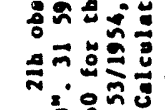

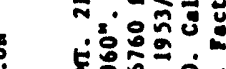

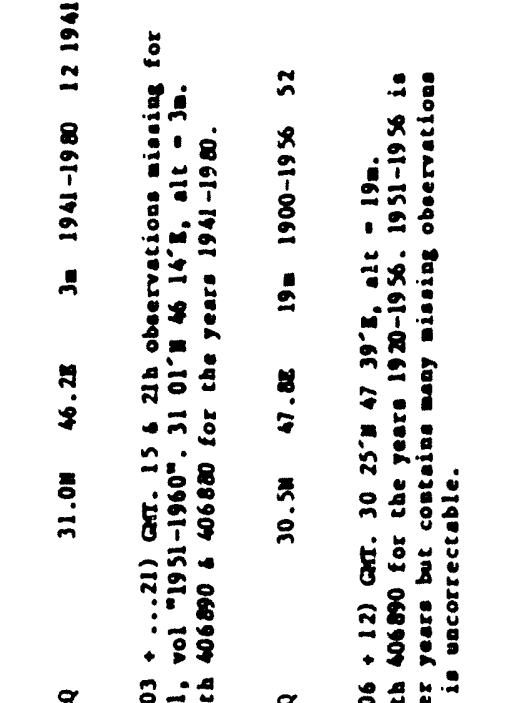

\&

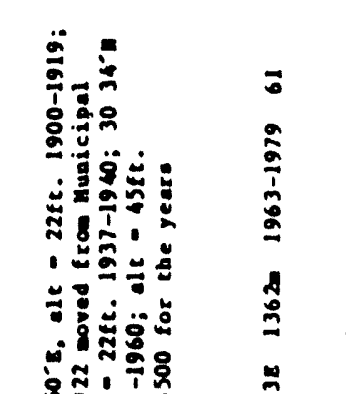

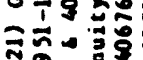

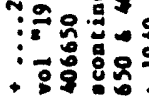

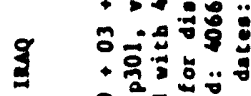

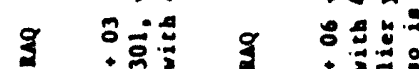

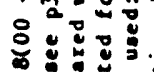

:

-

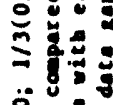

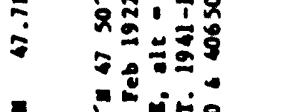

㝏

:

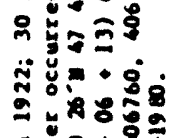

ํํำ

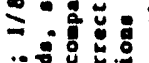

这

II

its

in

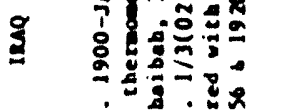

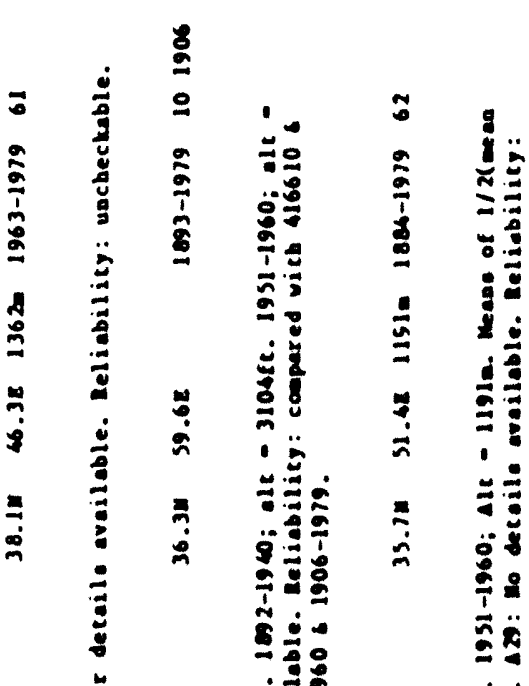

. .

$y=$

II

is

i

iो 11

ii

if

,

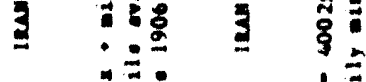

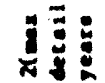

题 

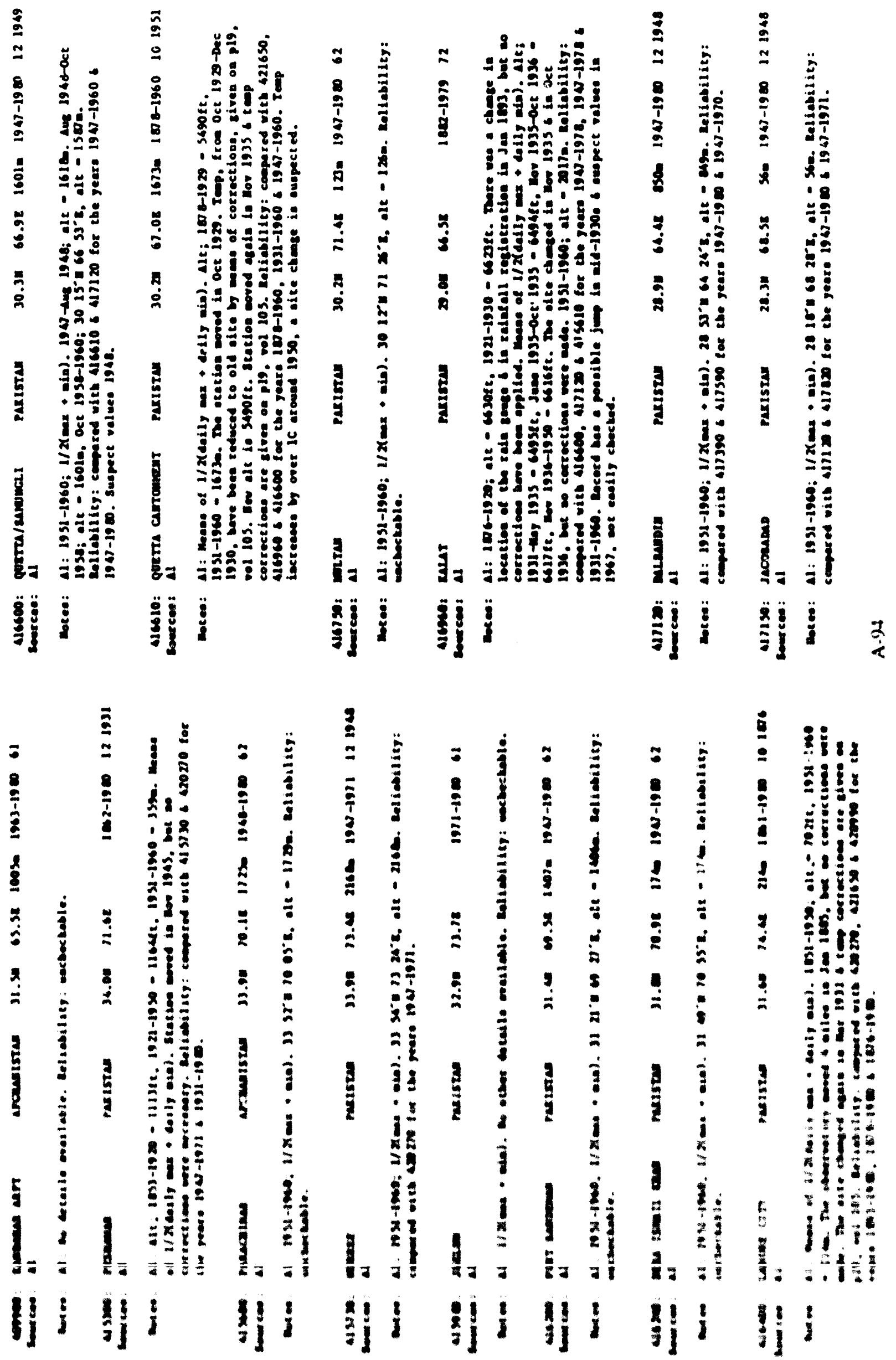


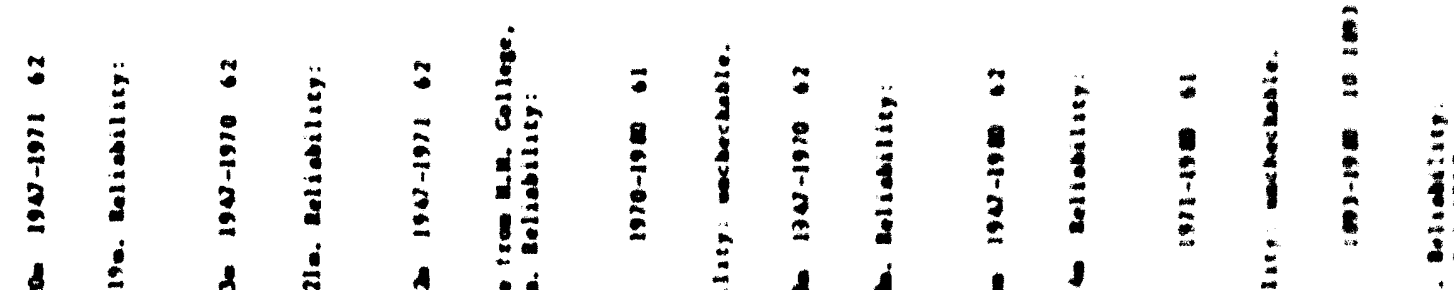

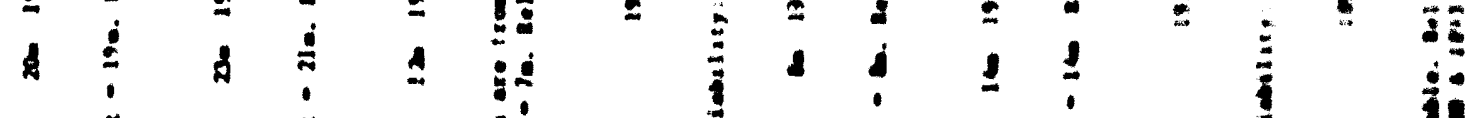

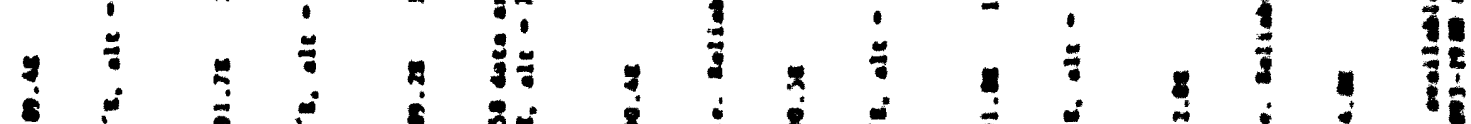

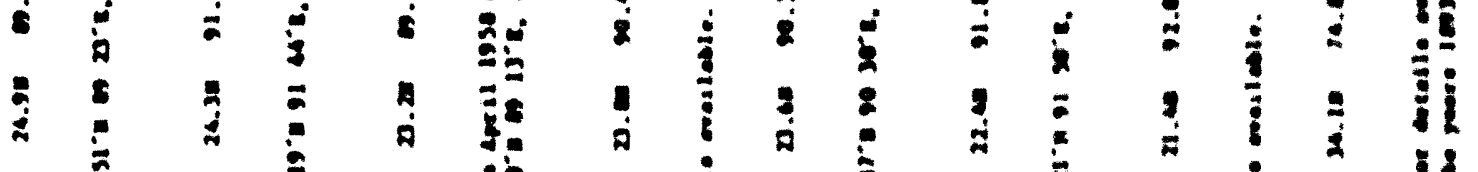

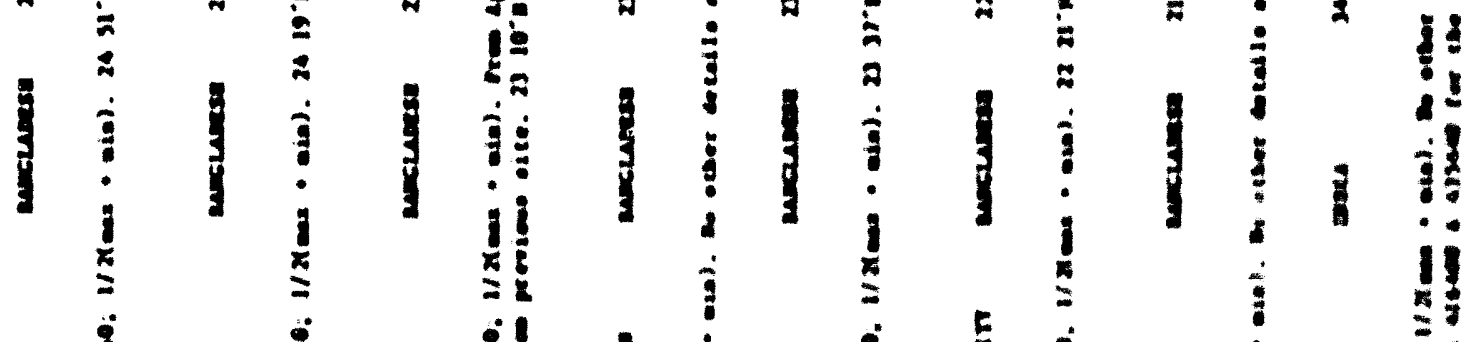

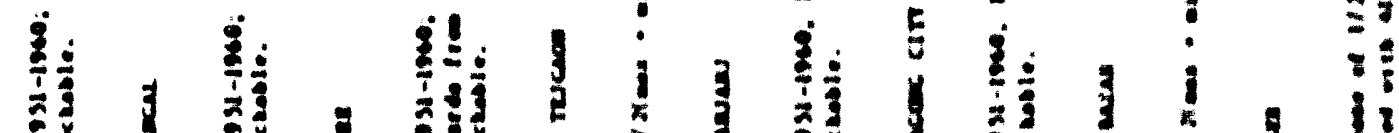

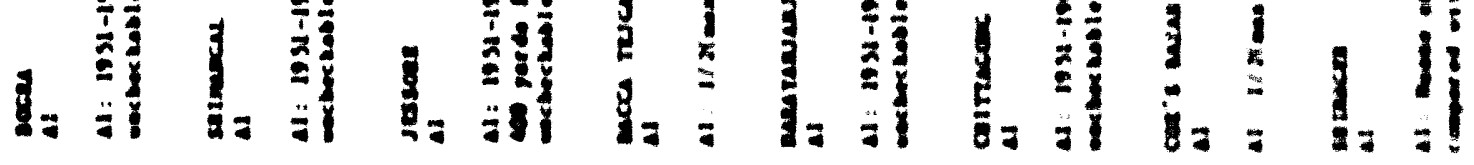

8

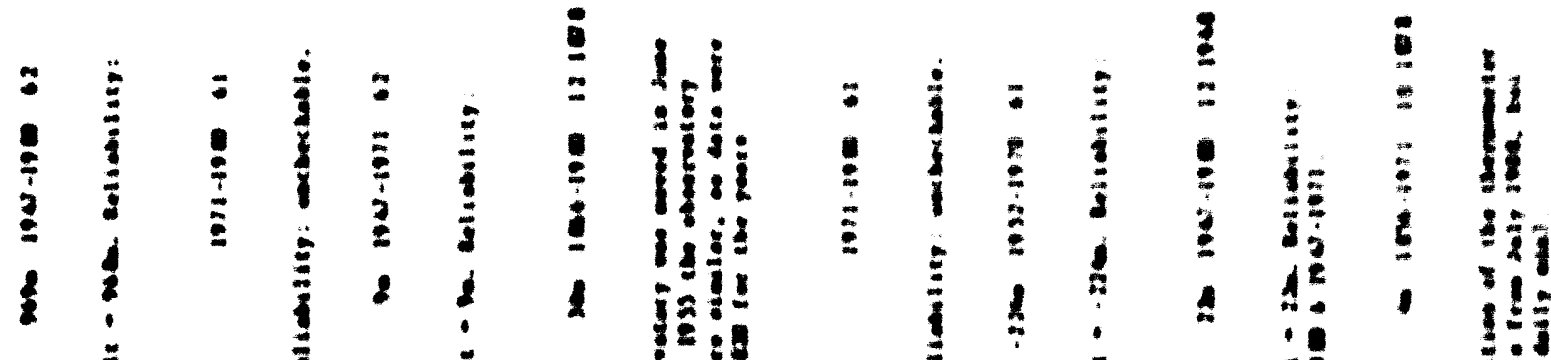

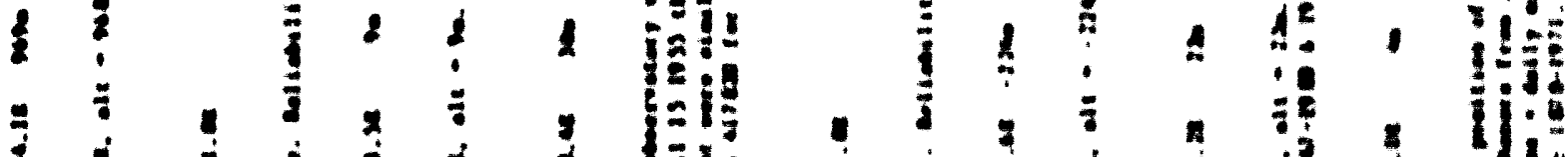

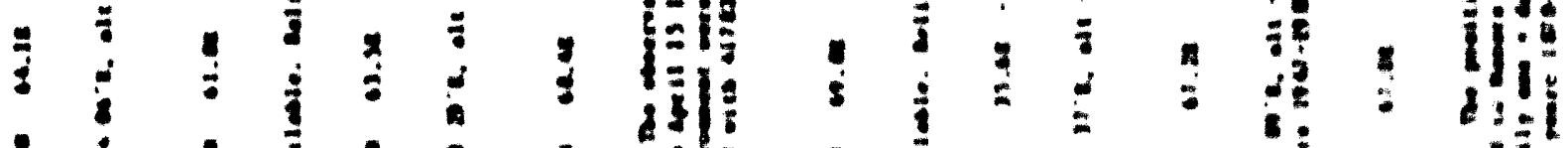

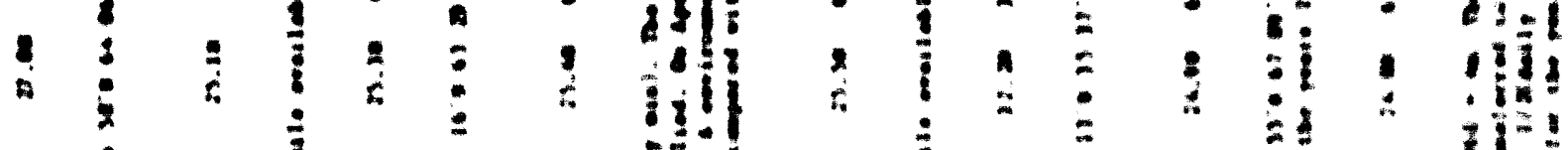

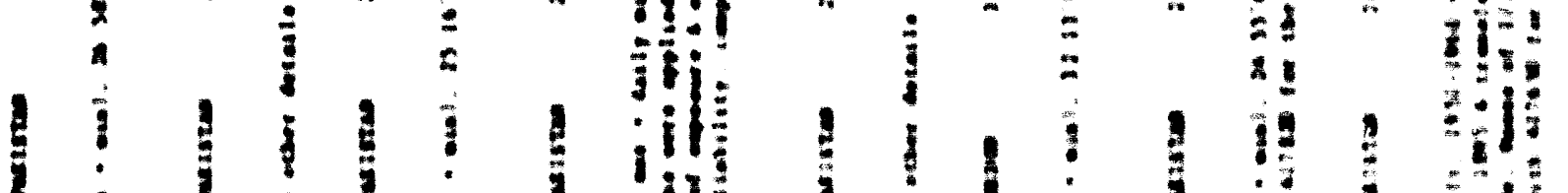

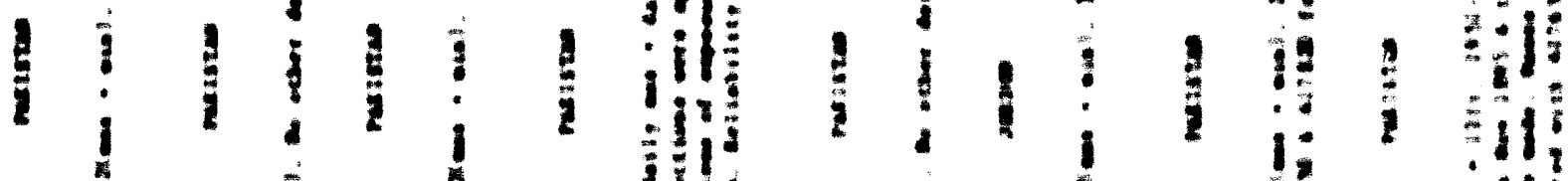

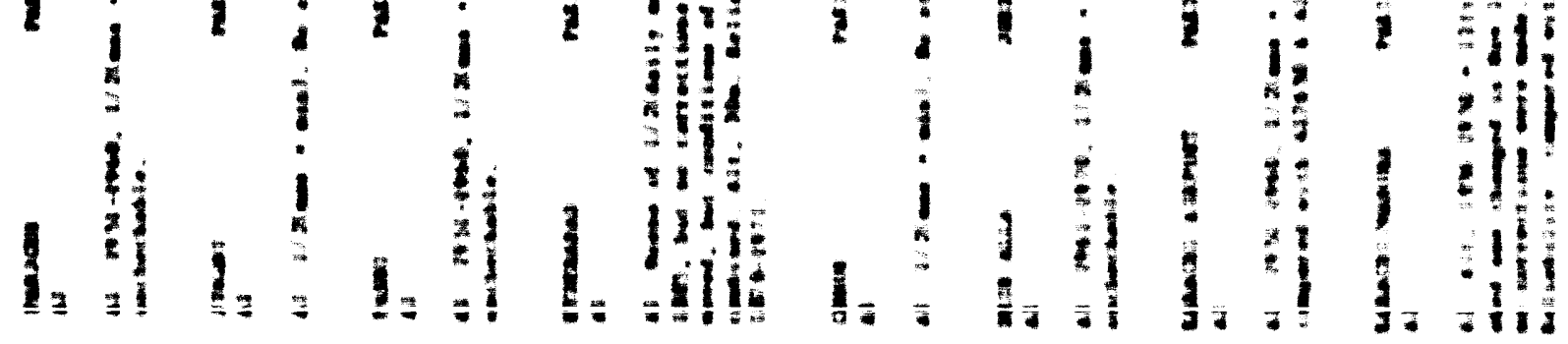

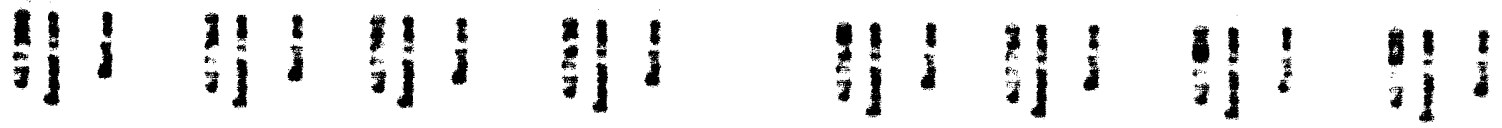



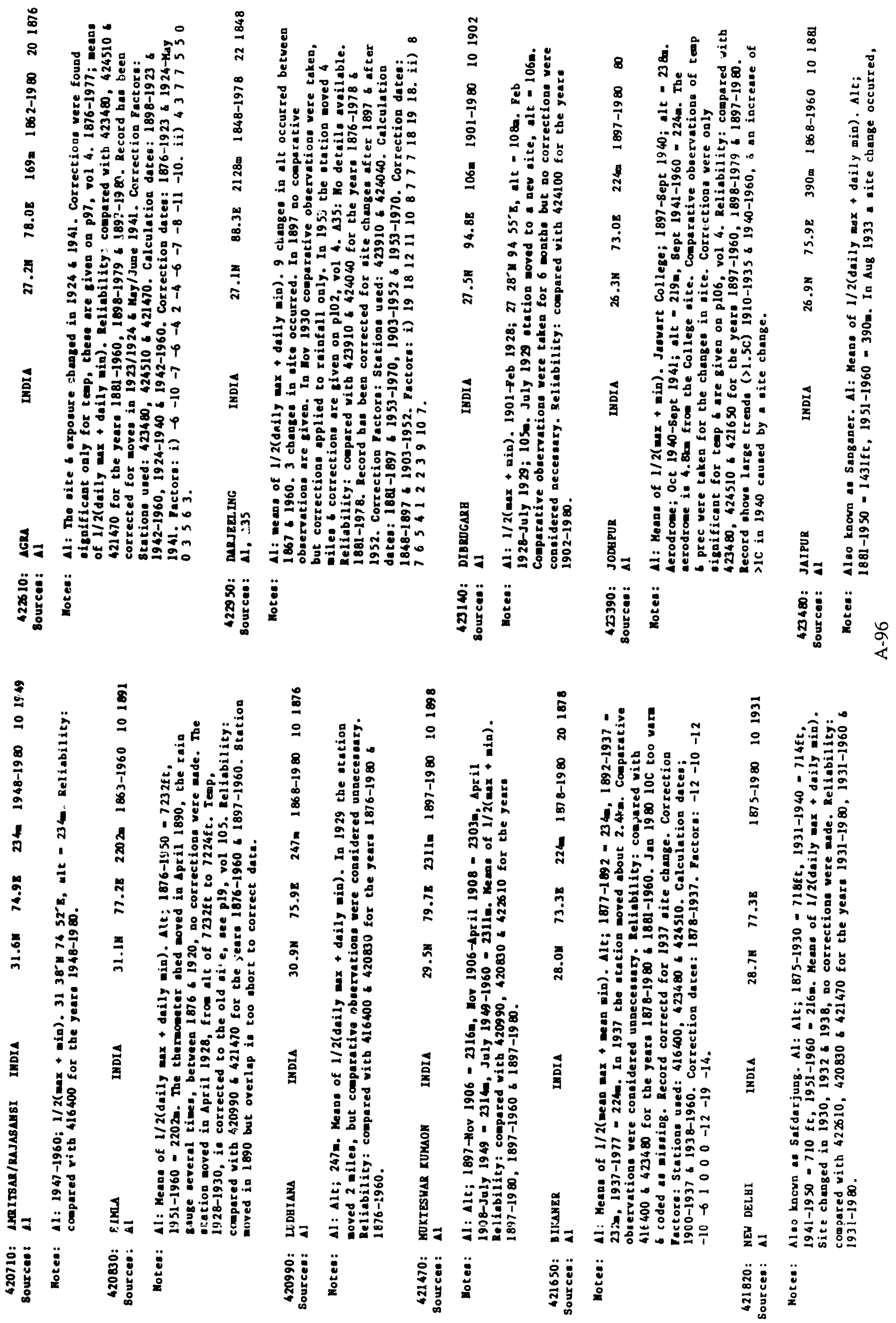


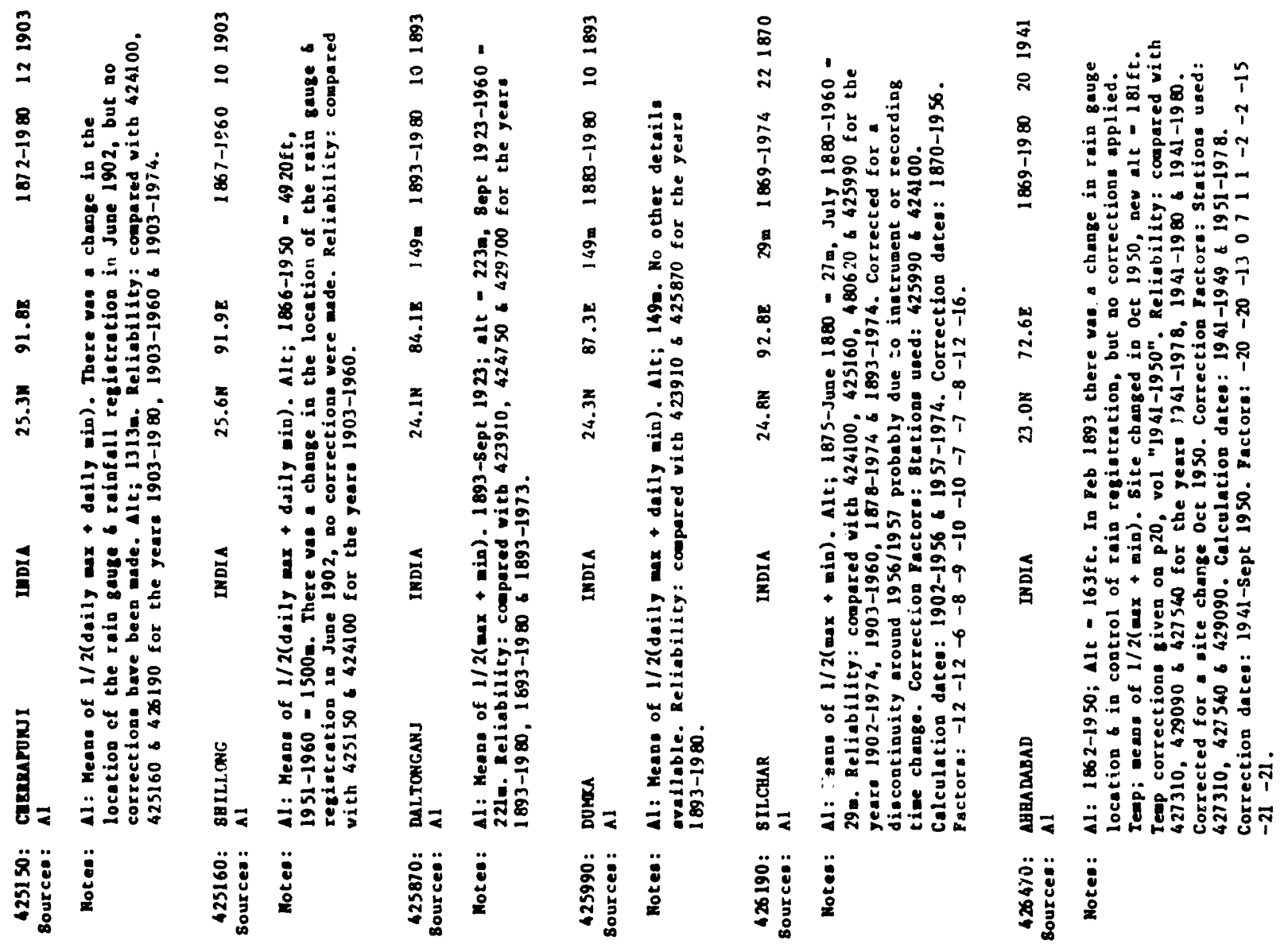

言

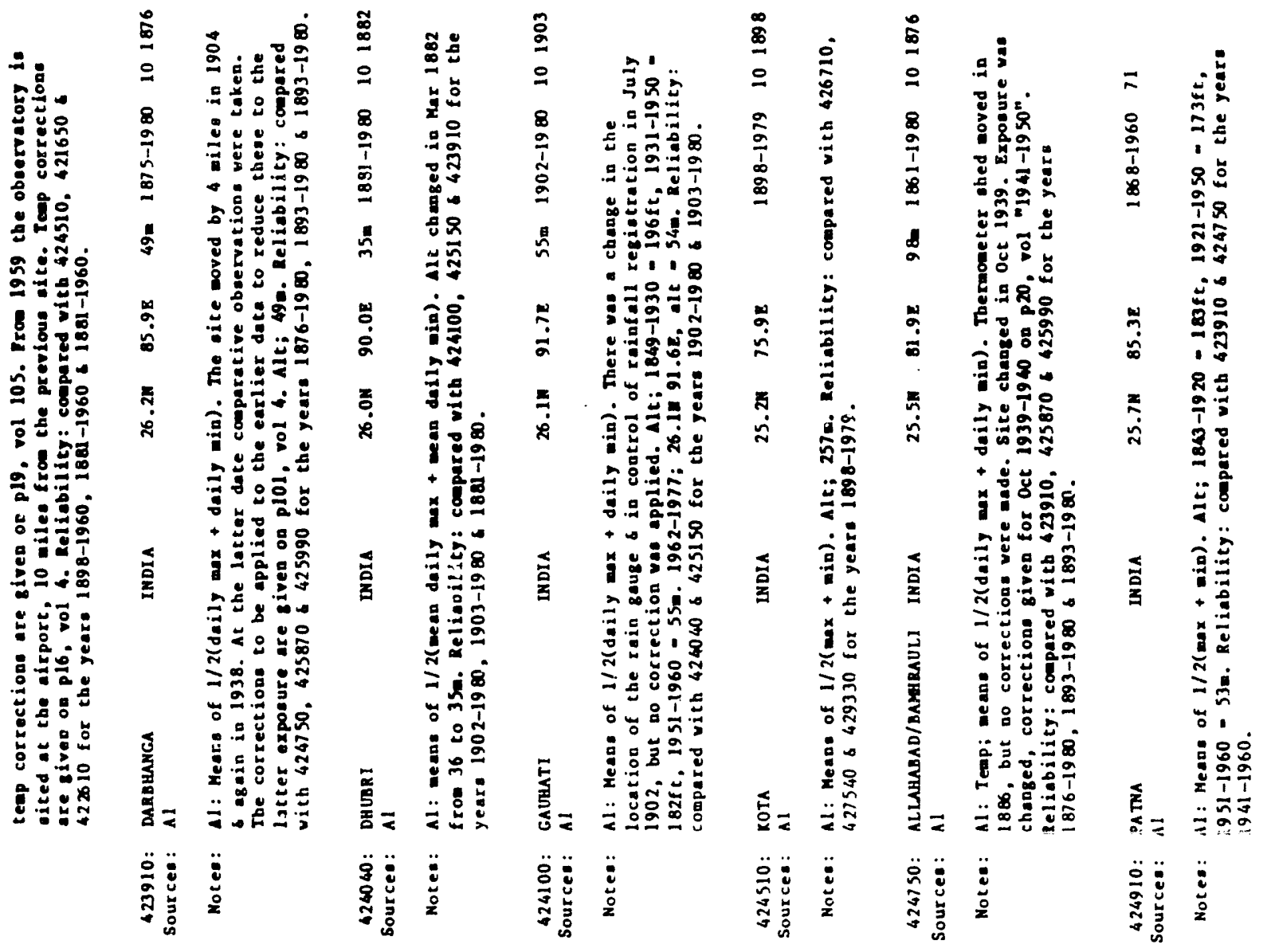




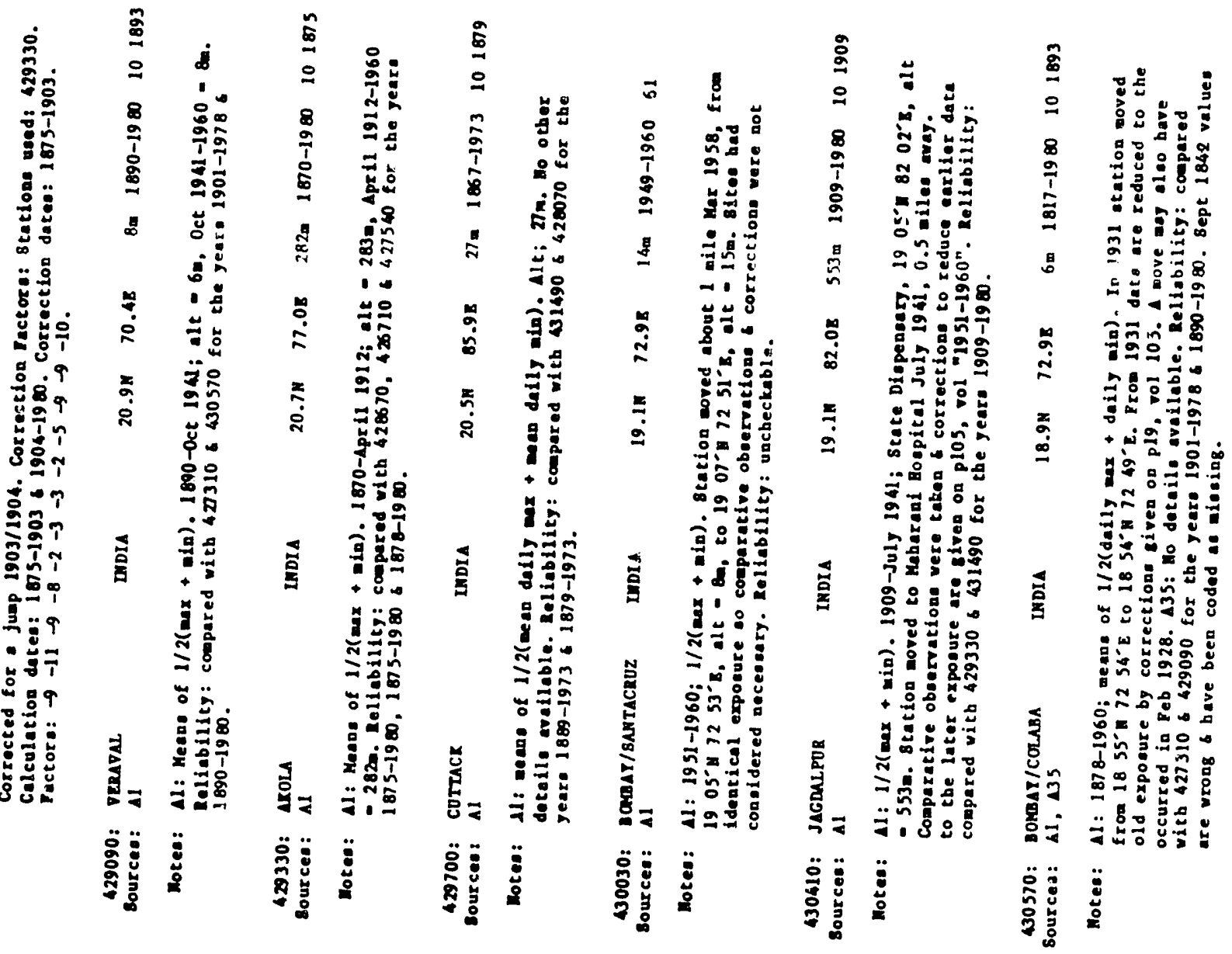

$\frac{\infty}{1}$

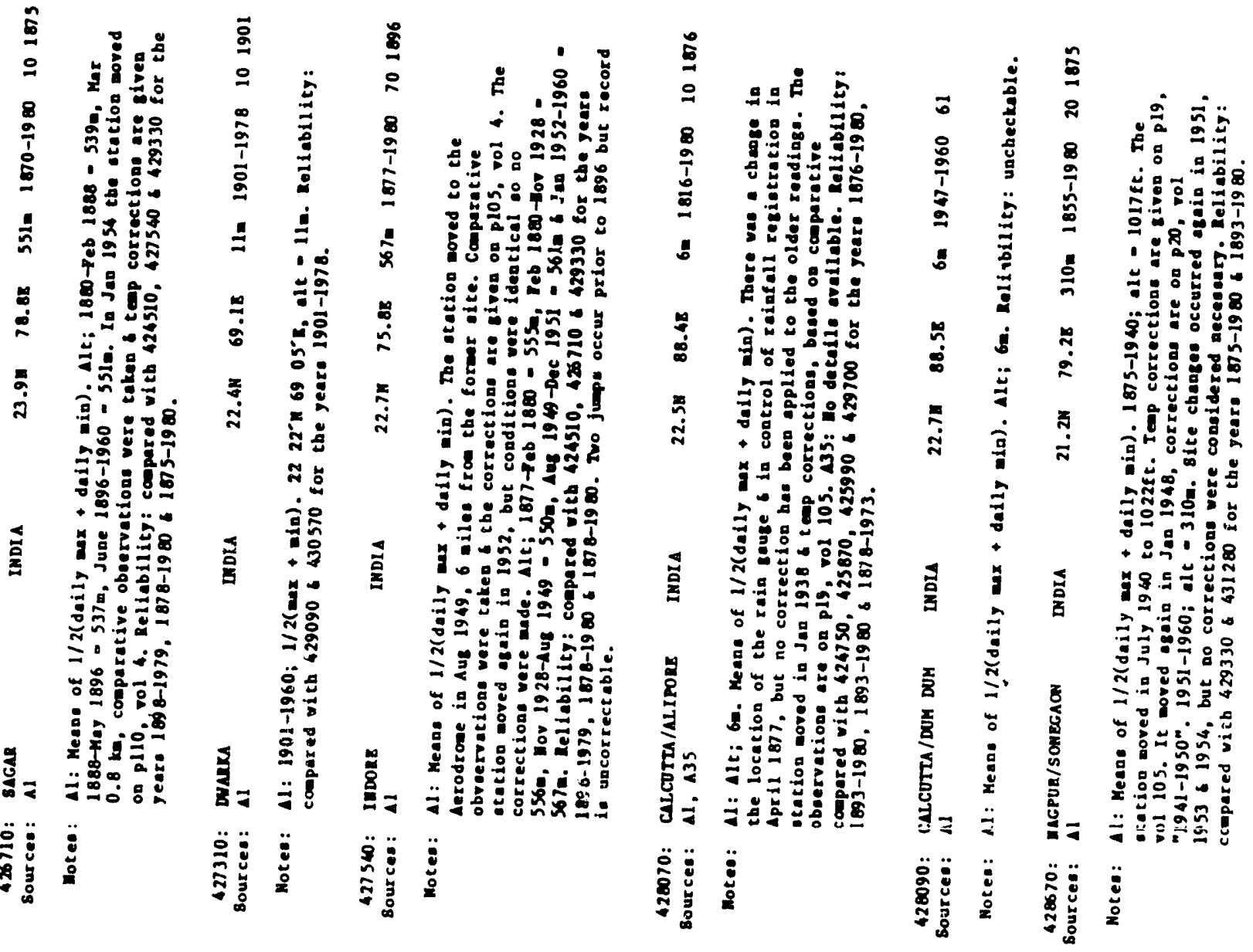



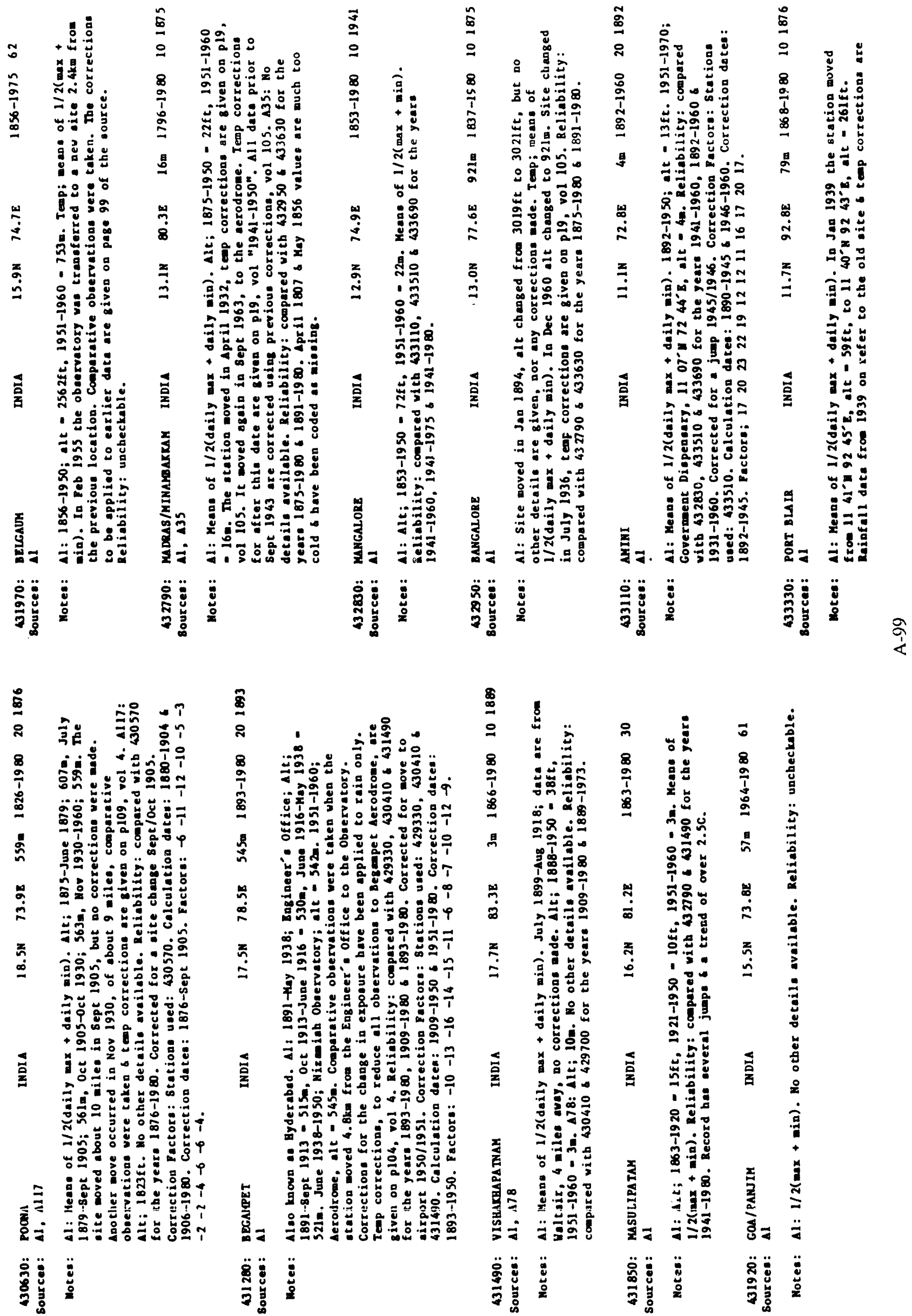

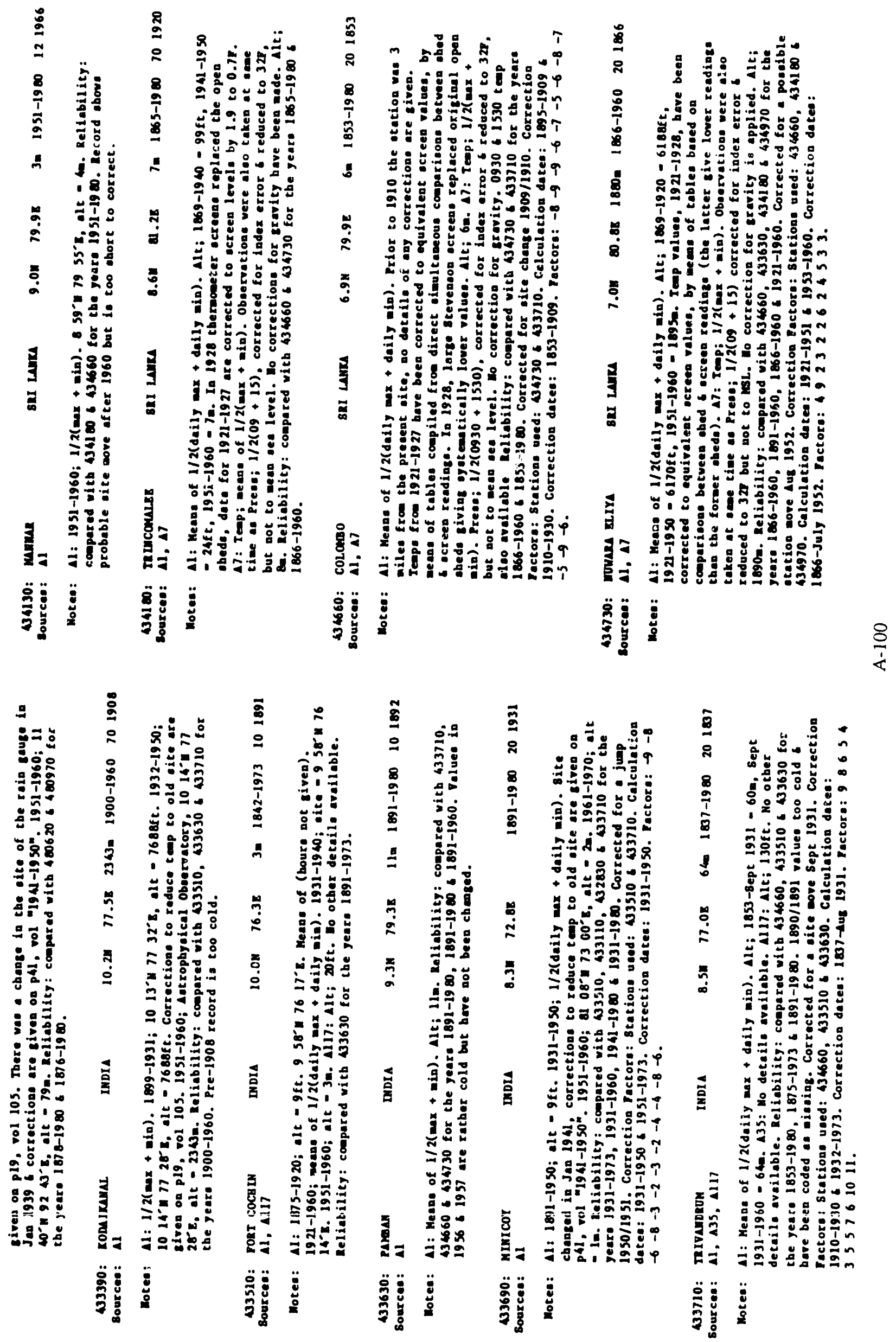


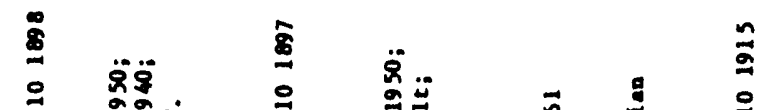

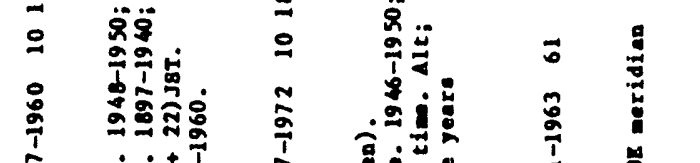

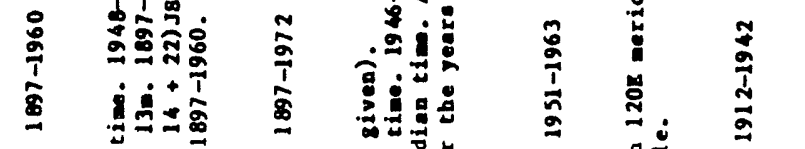

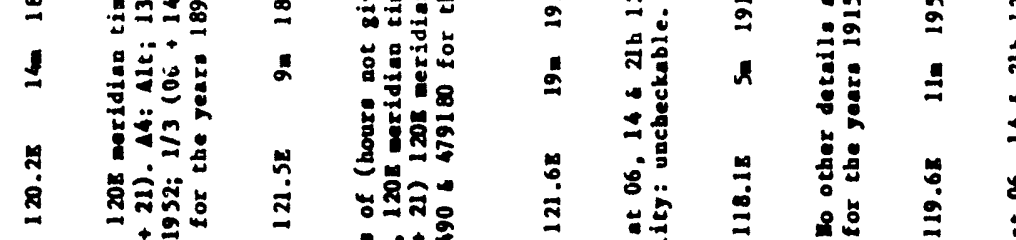

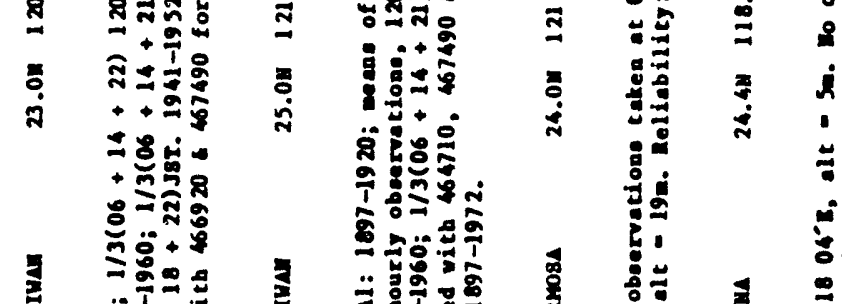

.

=

:

再:

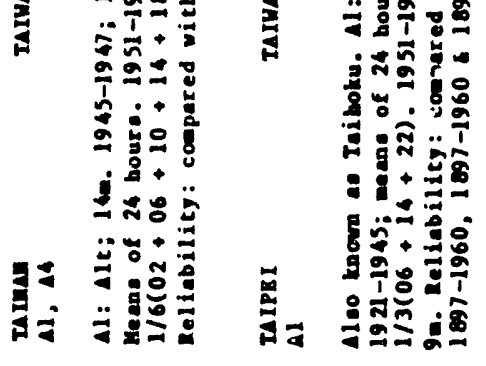

चा iा

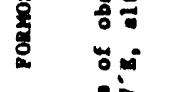

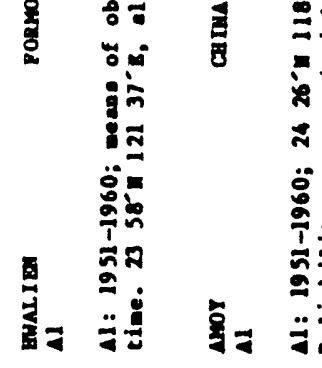

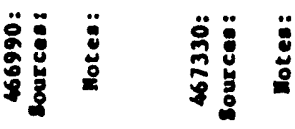

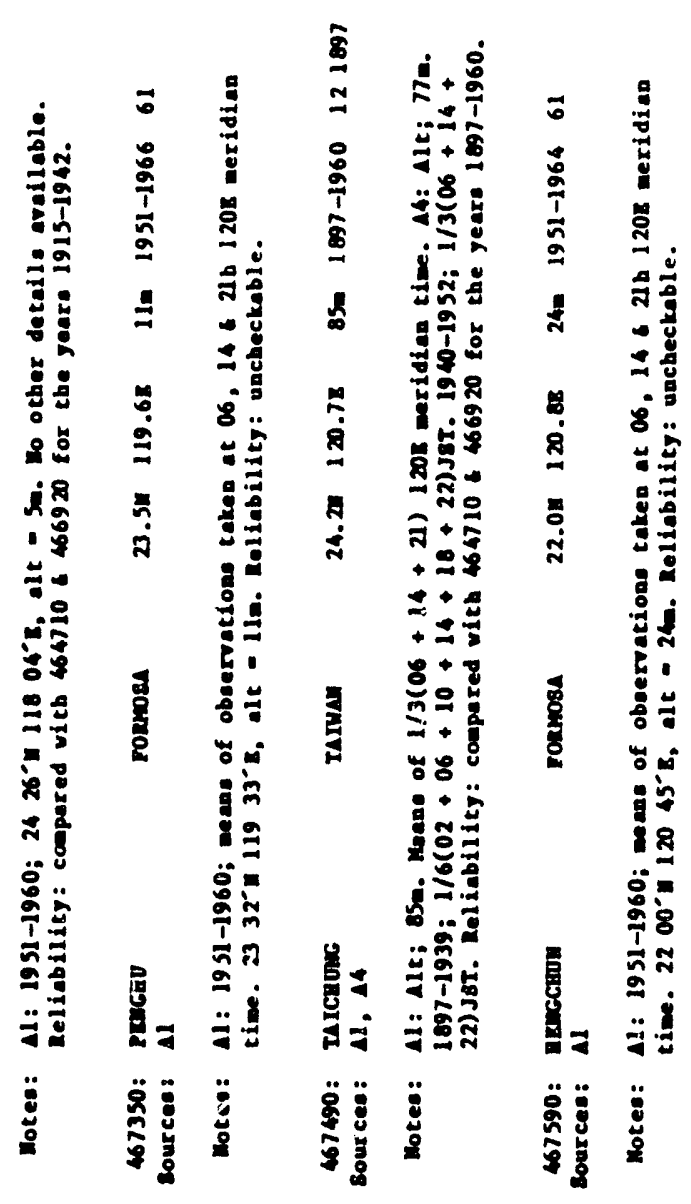

$\frac{0}{\dot{1}}$

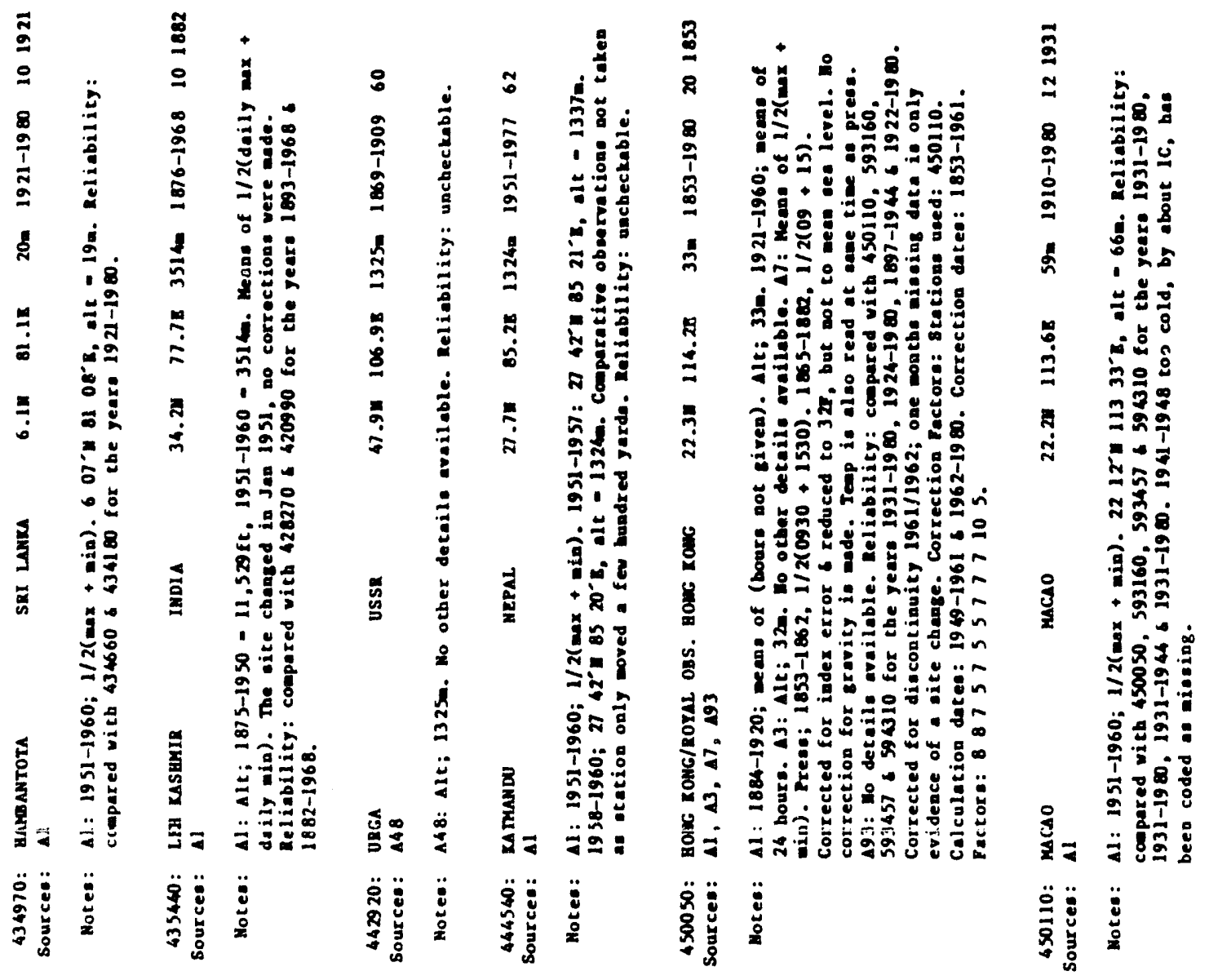



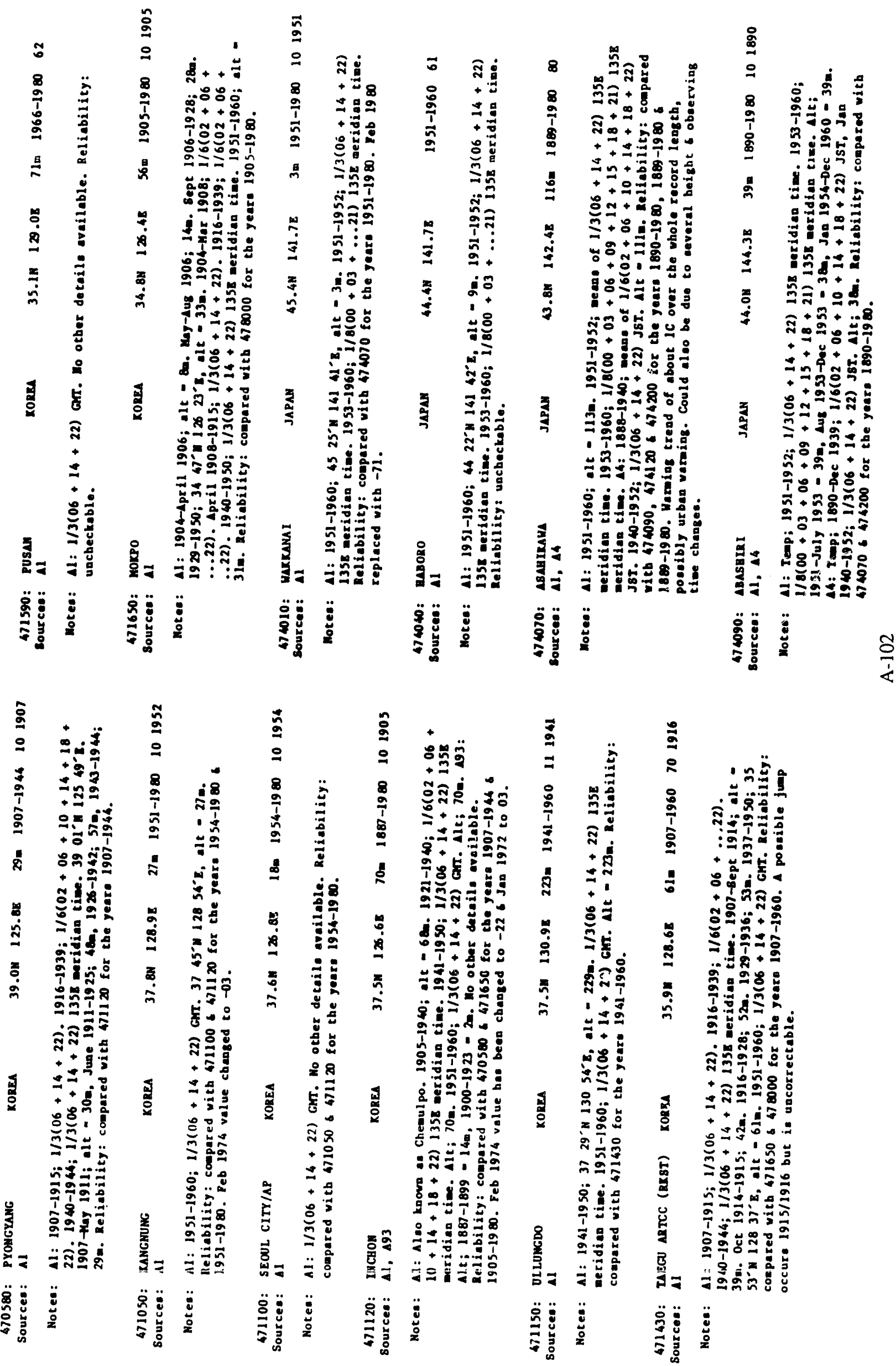


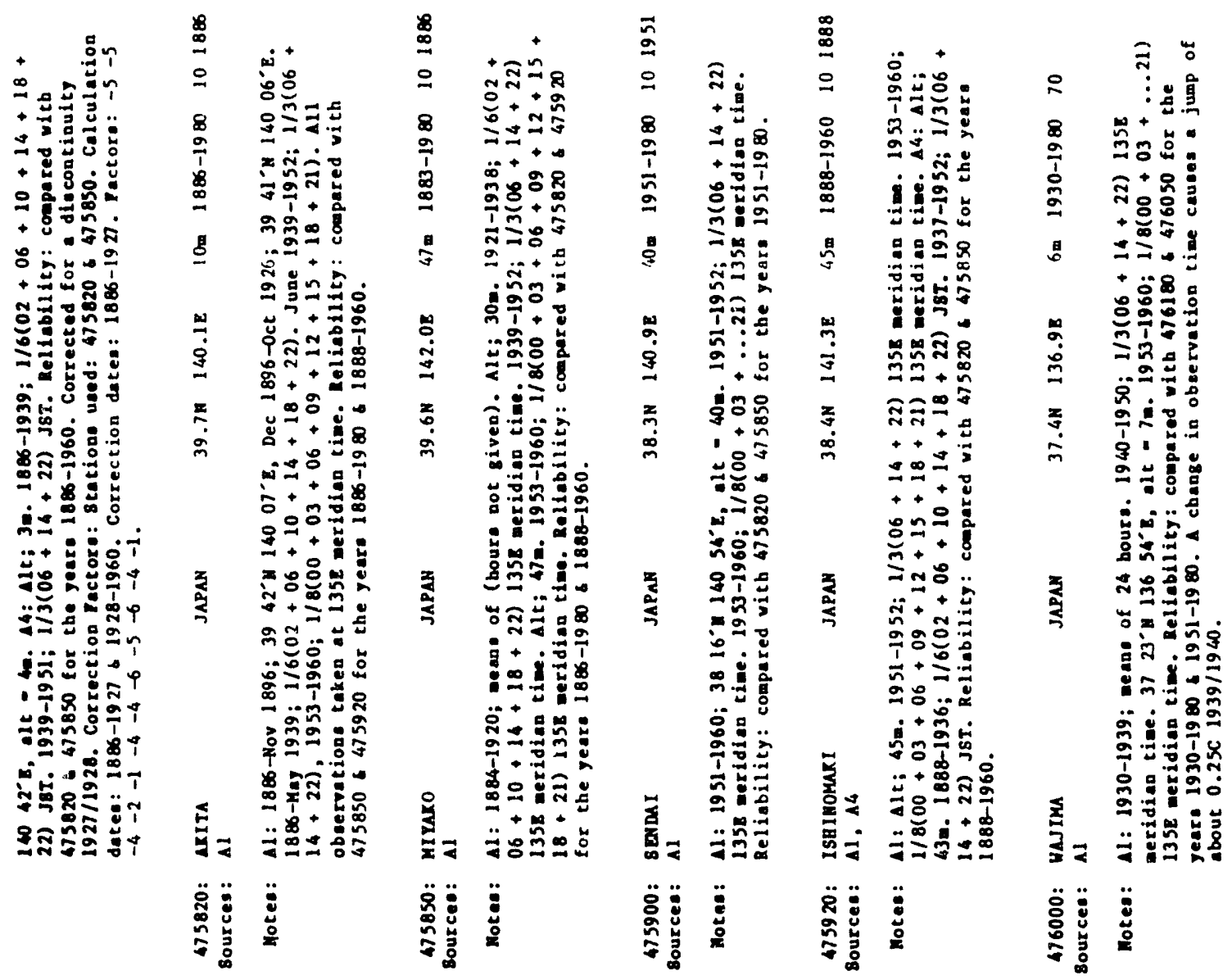

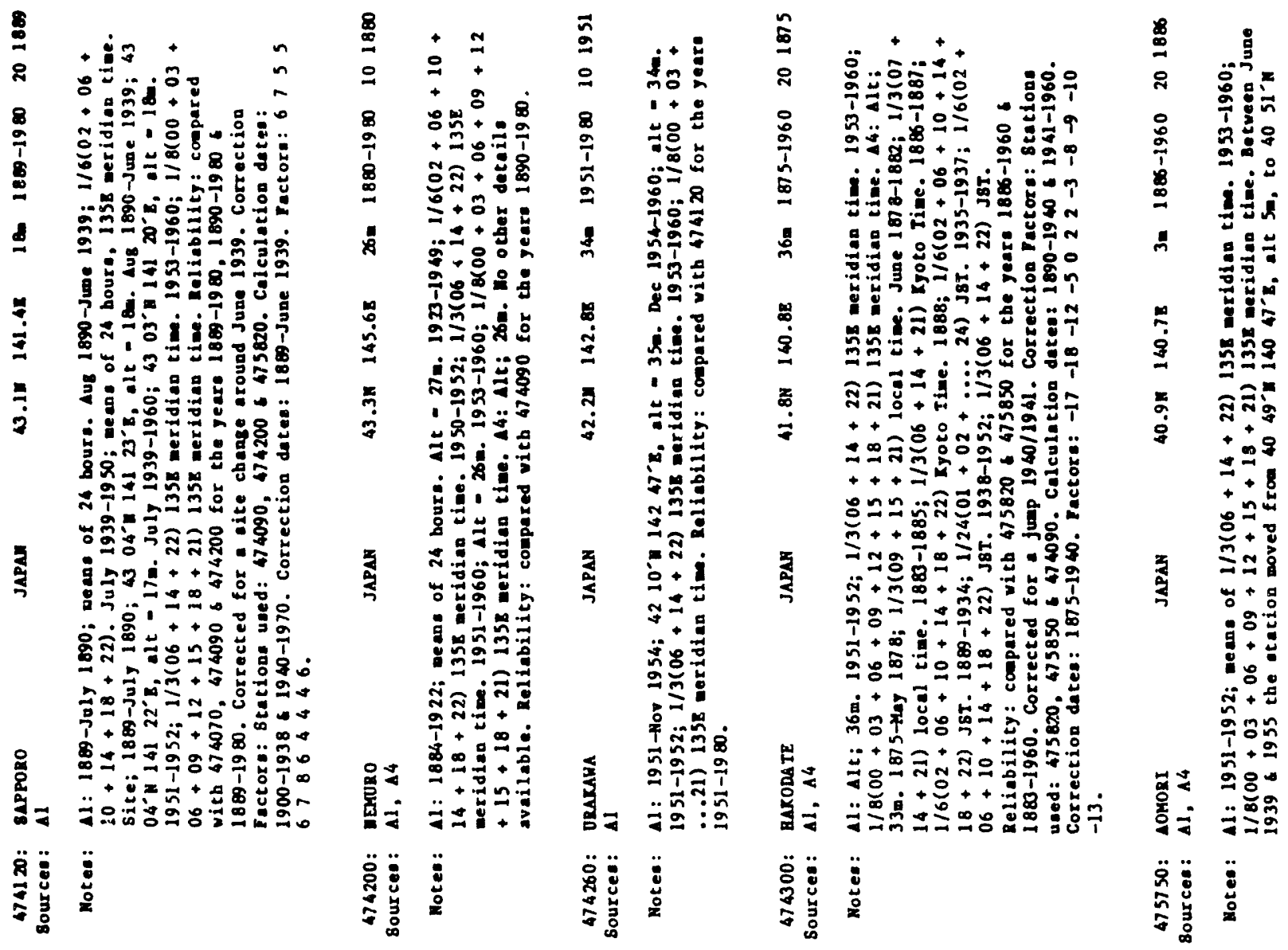




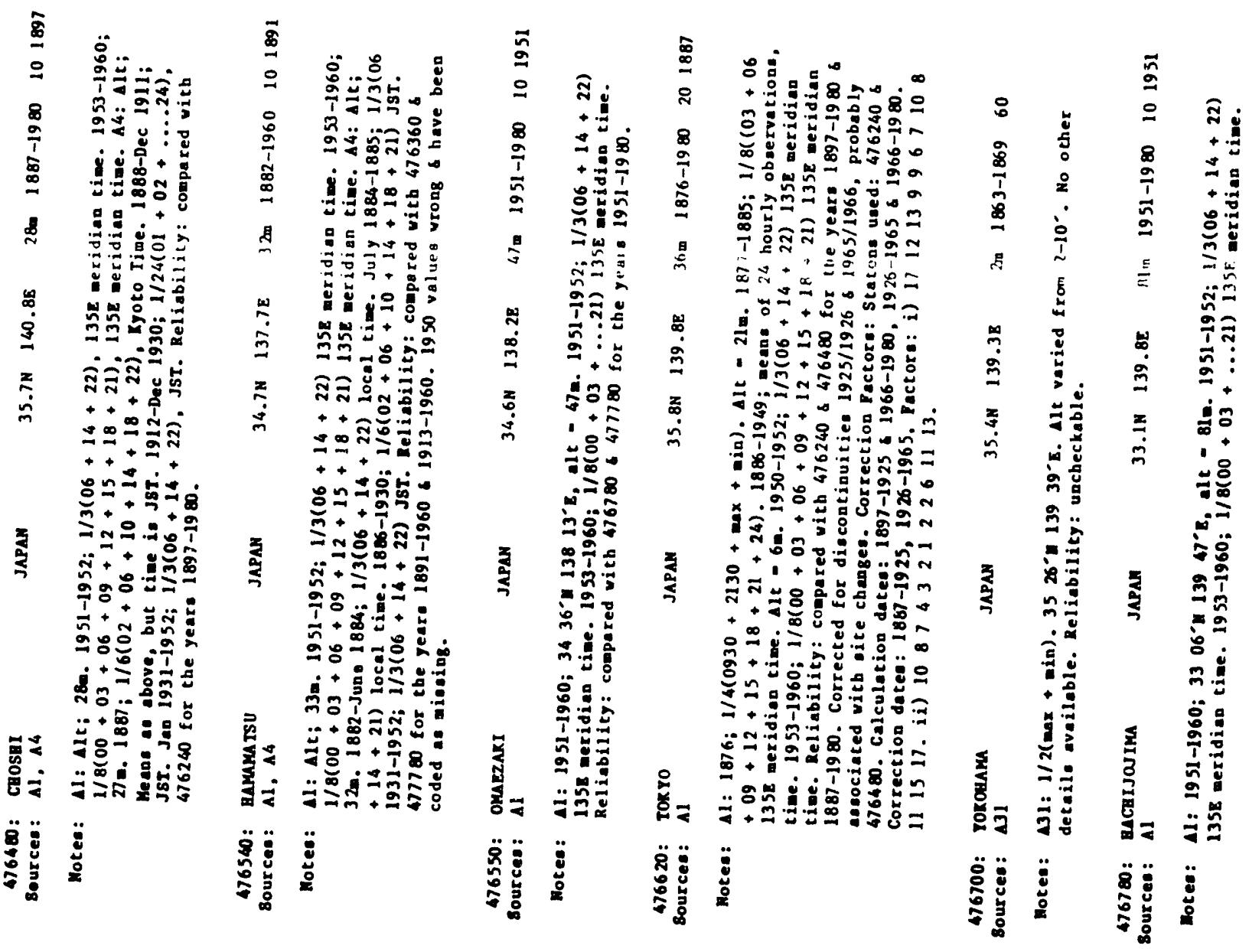

Q

苟

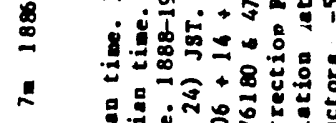

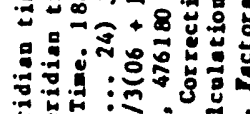

*

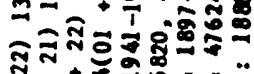

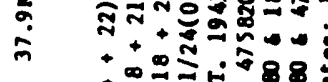

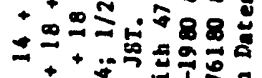

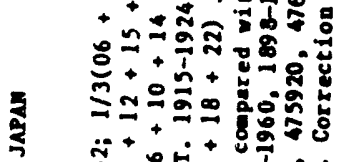

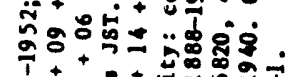

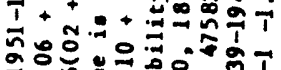

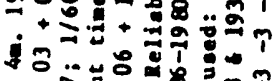

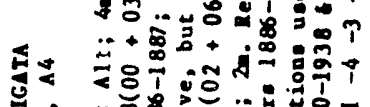

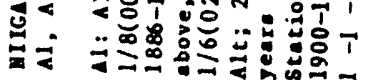

in

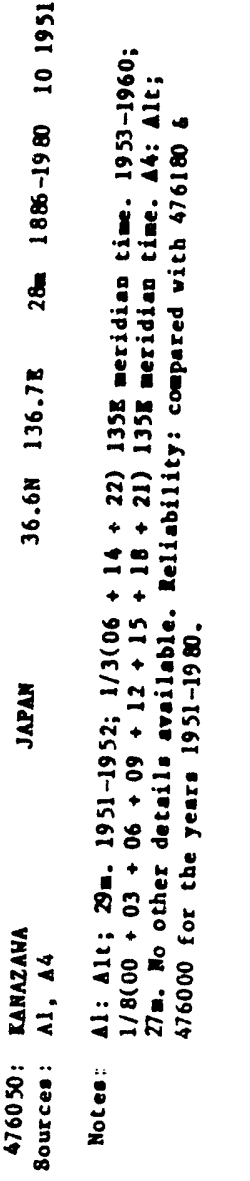

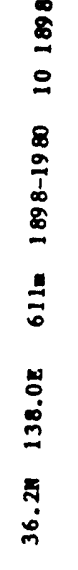

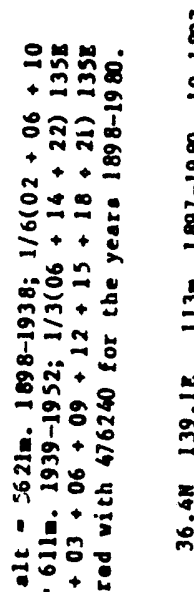

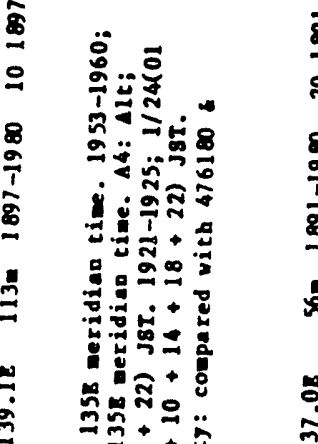

สิธี่:

$\div+\div \overline{0}$ ले

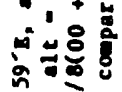

$+7+0$

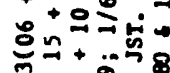

ㄴํำ

政

年

กิ้กอัด

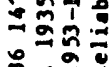

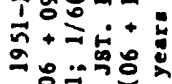

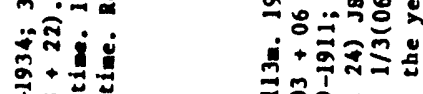

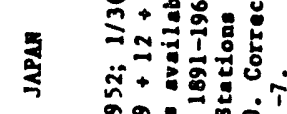

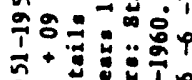

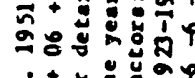

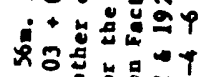

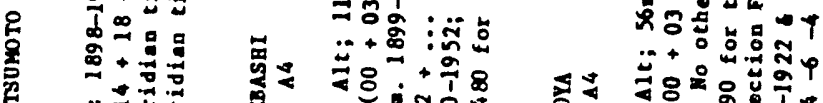

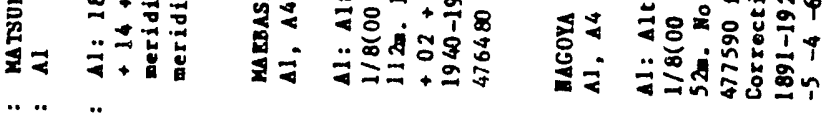

葛范

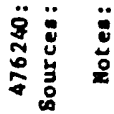

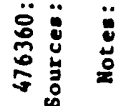



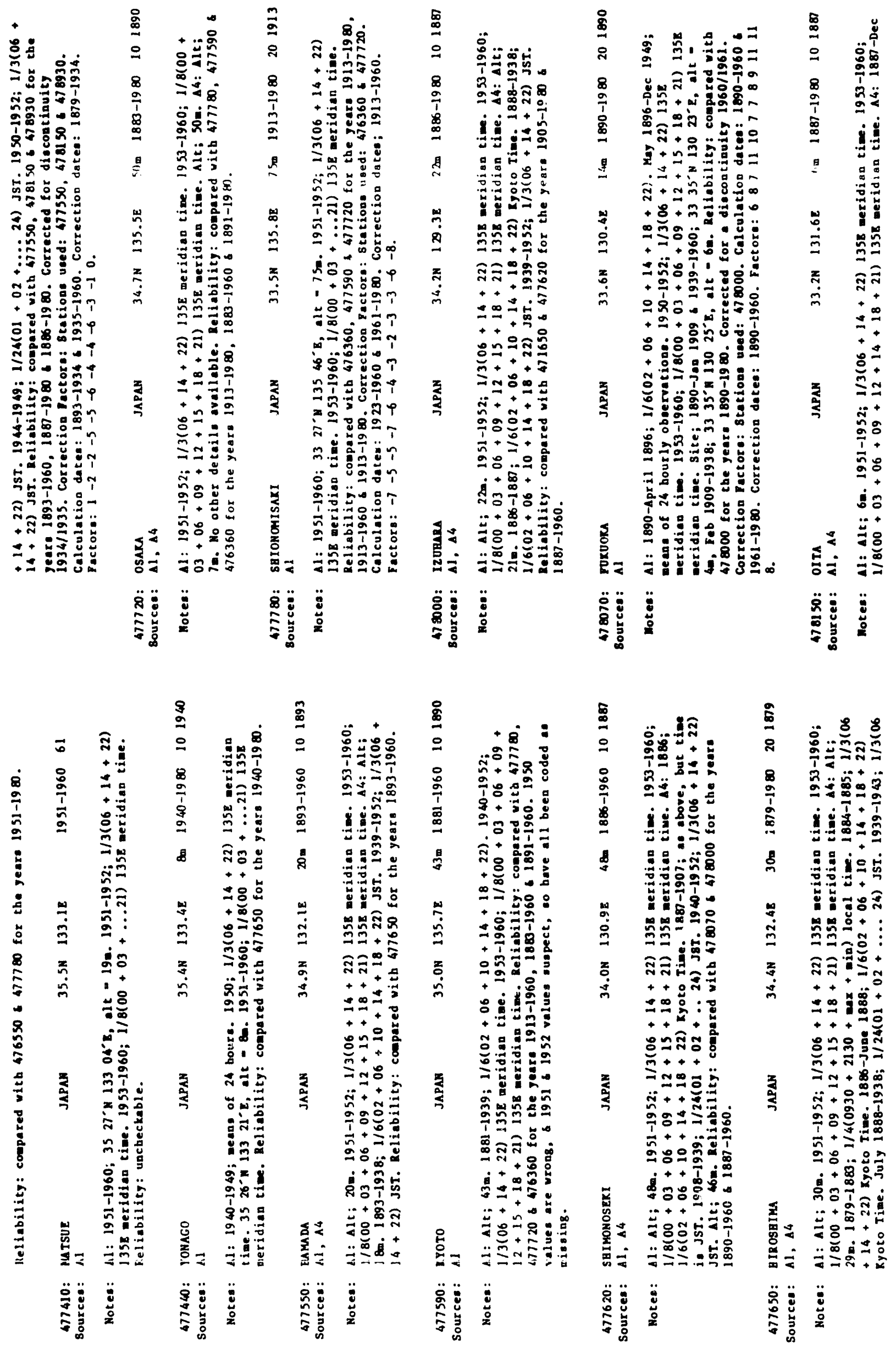

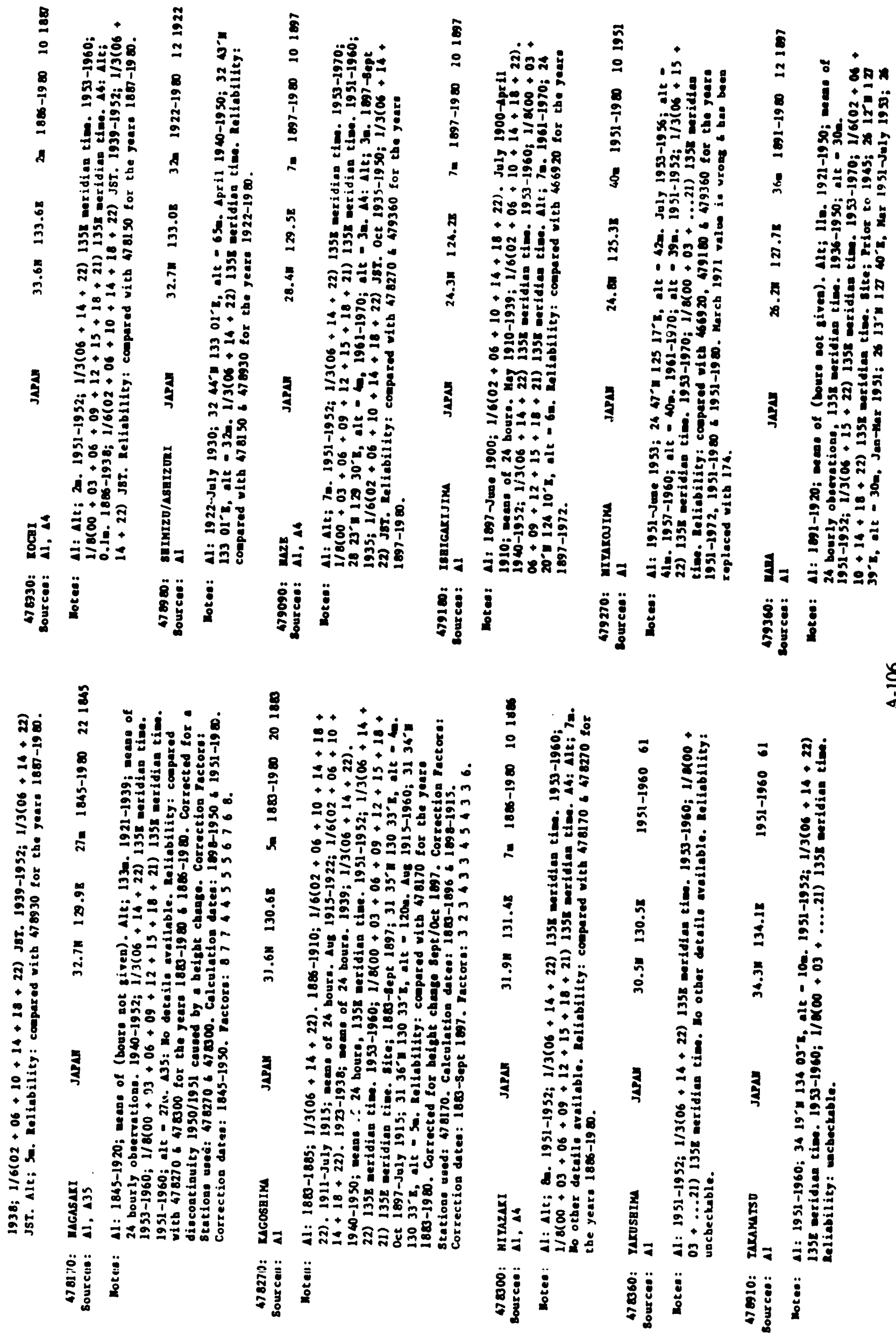


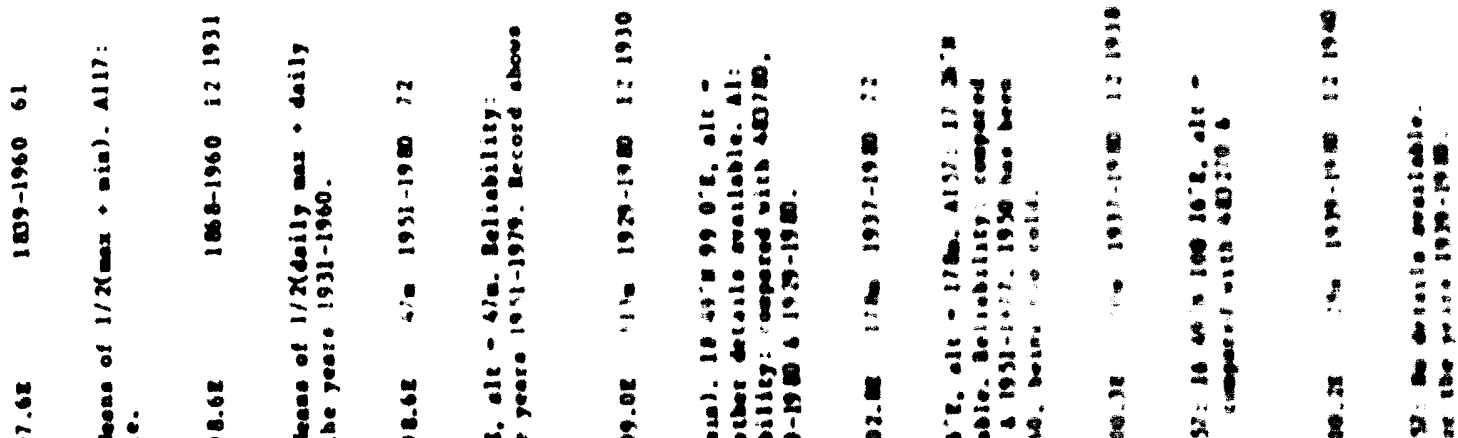

-

-

政

政

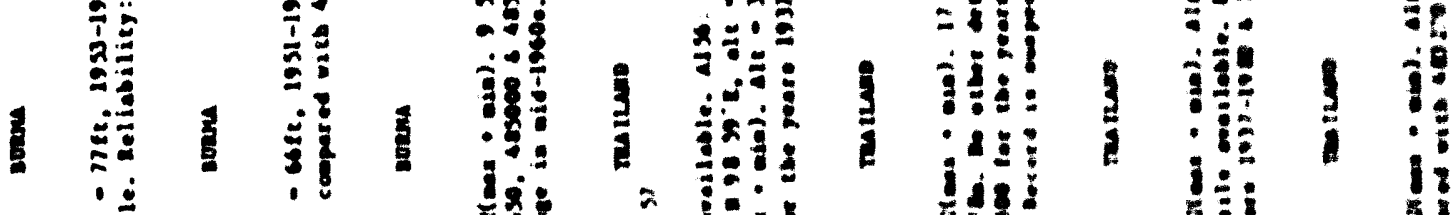

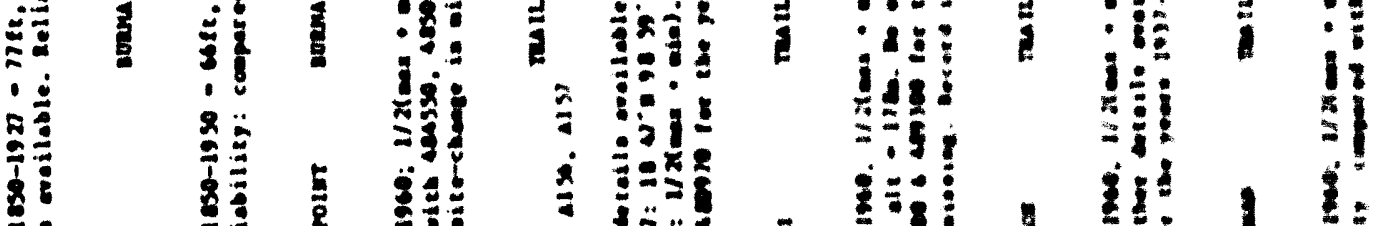

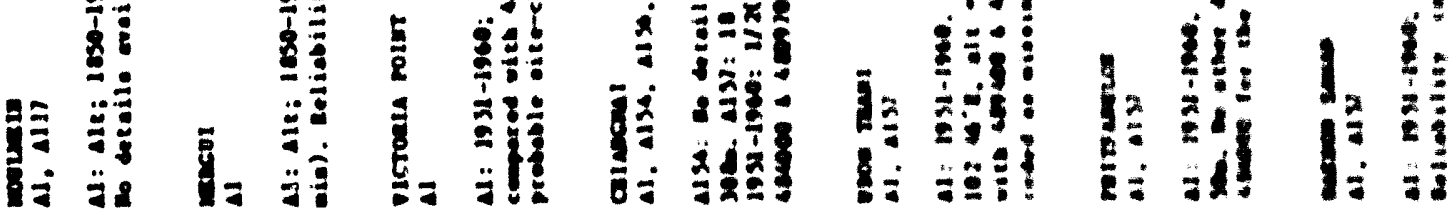

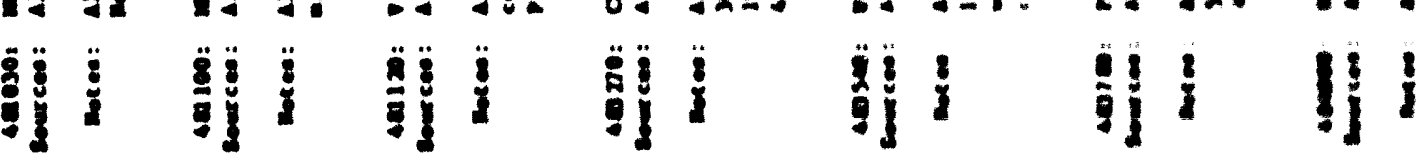

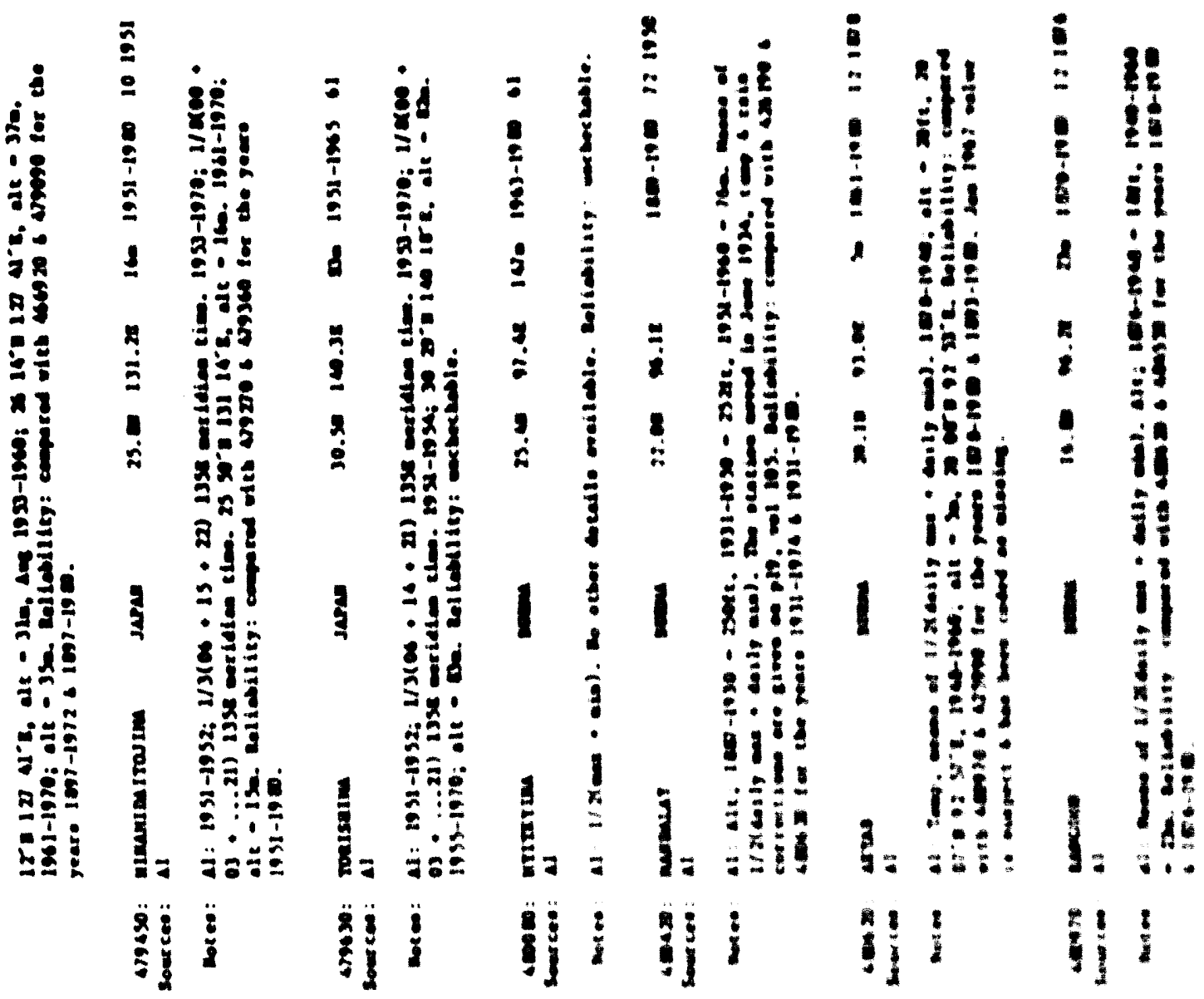




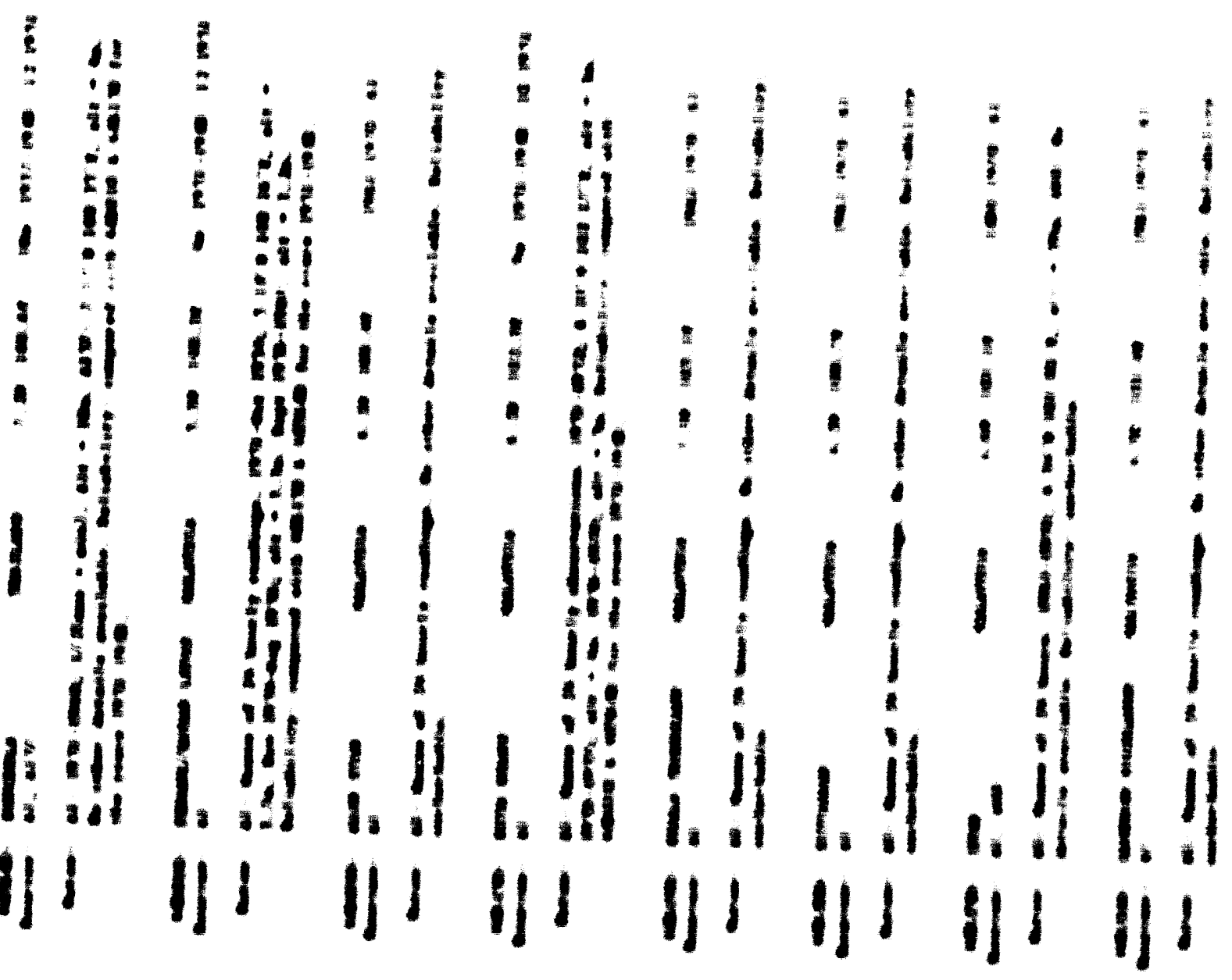

$11,1,1$ ! ill

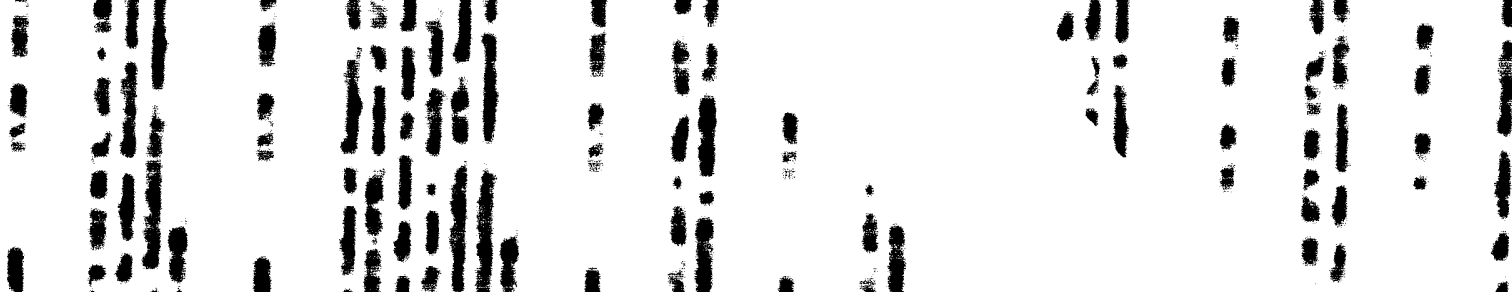

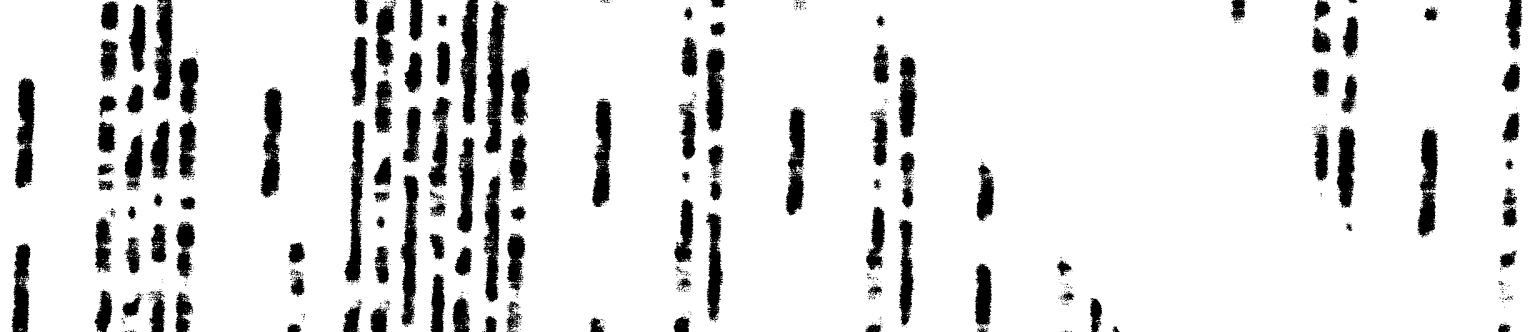
la if if ifl li: lil if. 
$!$

I

i)
!.

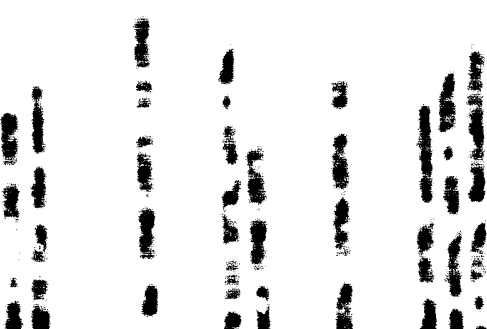

i ' i '

H

10

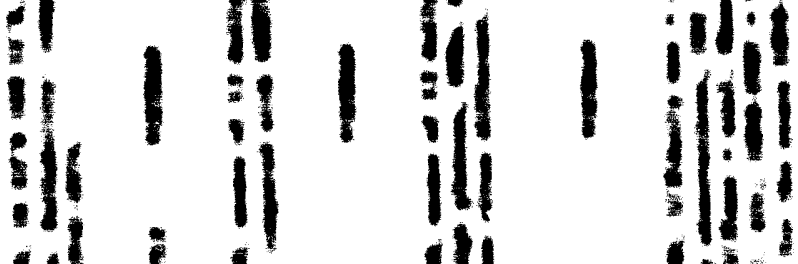

1 1. 11) (1):

i) ii)
4 :

$101: 118: 5$

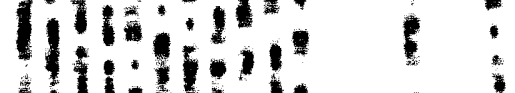

11:1:1:

10):1.1:

- 1)

$1.15118\}$

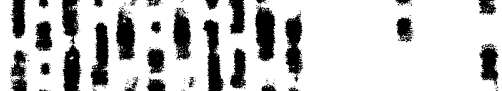

IIs)

\&

f

II!
II

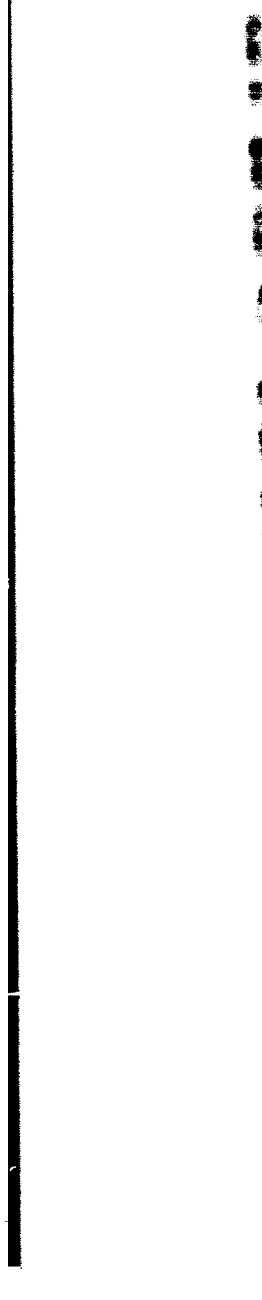

?hing 4?<smiles>[Al]</smiles>

in

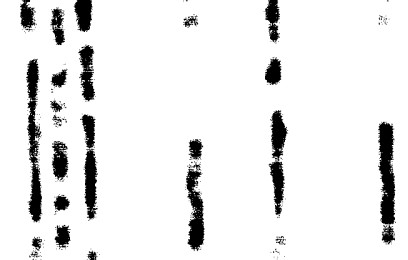

1

in 11

i. . i

if!

ii:

i)!

!ii

ifing 1

1,12

1011

14,11

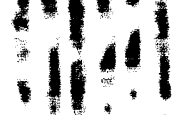

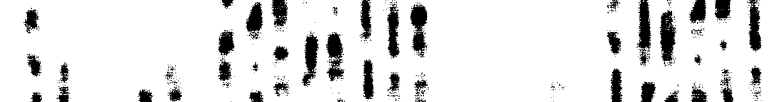

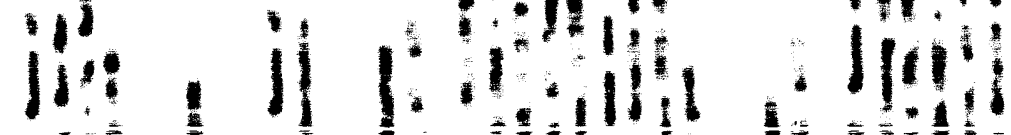

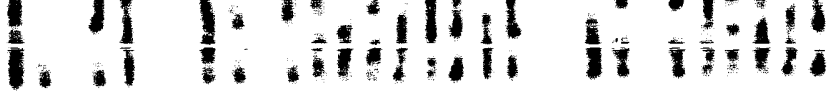

11111

11 


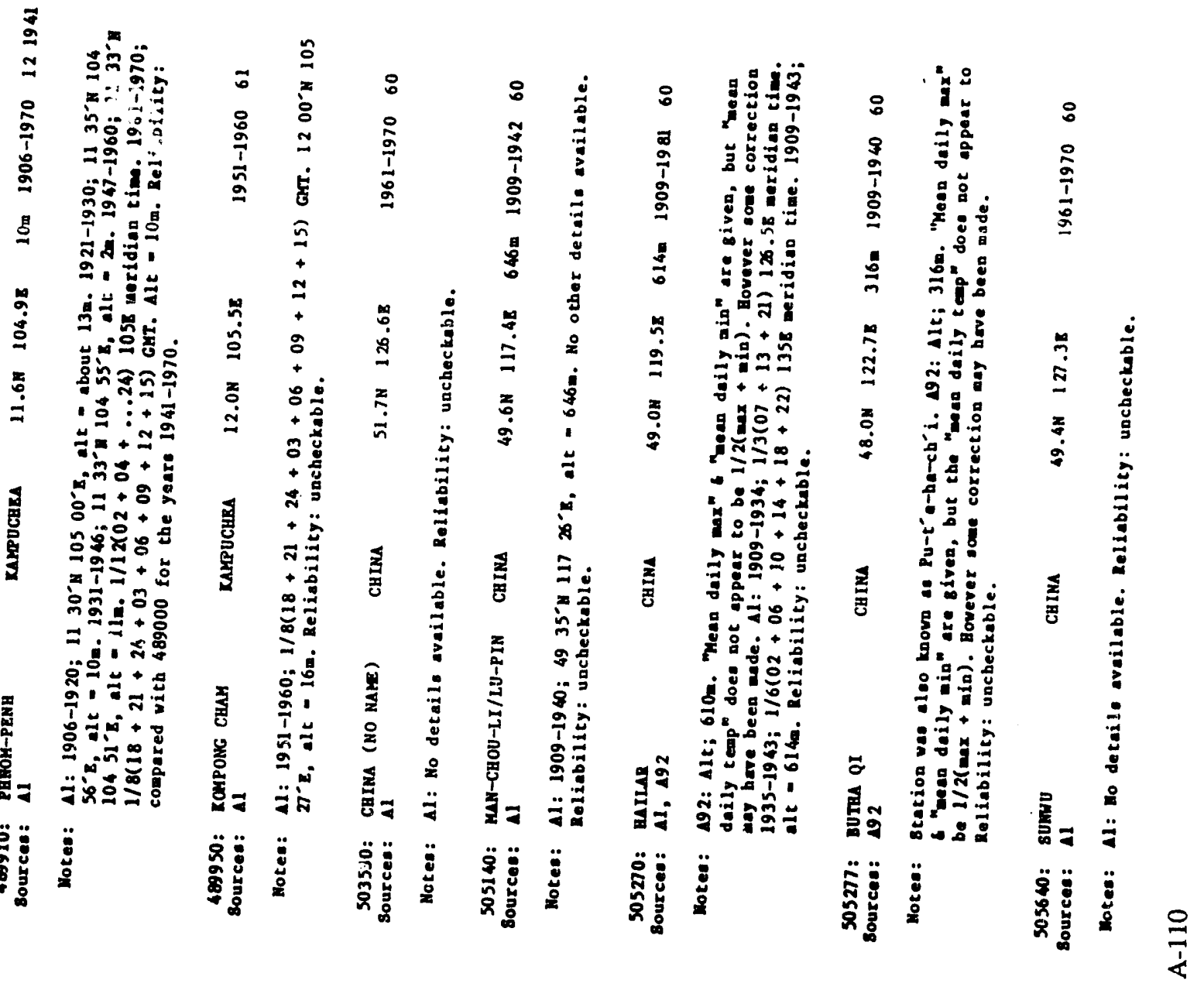

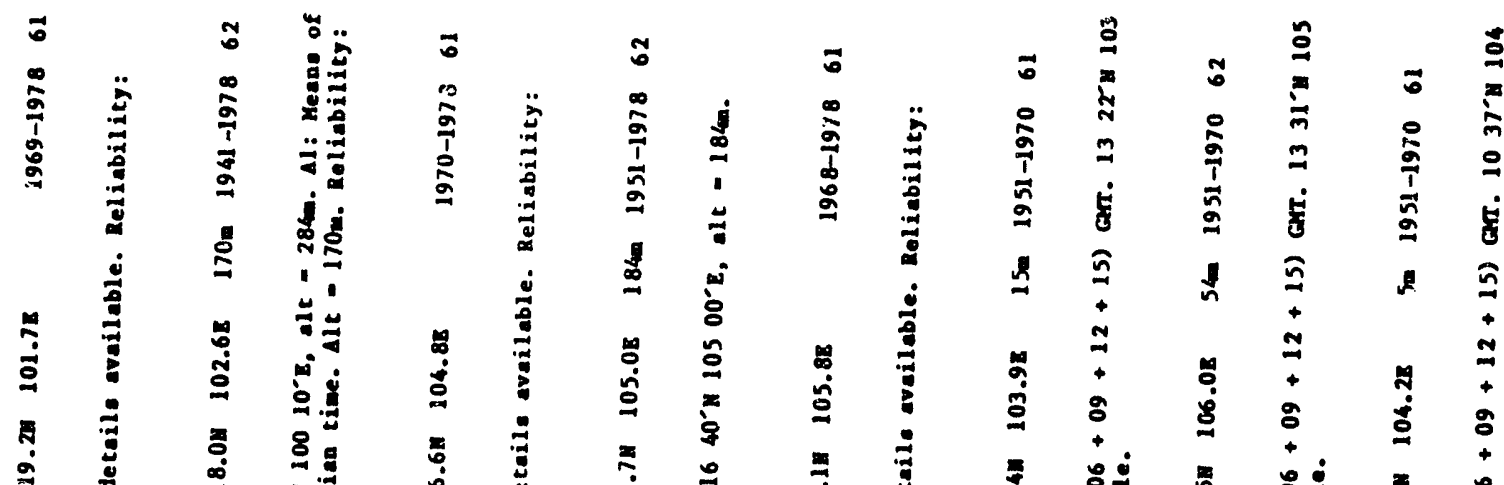

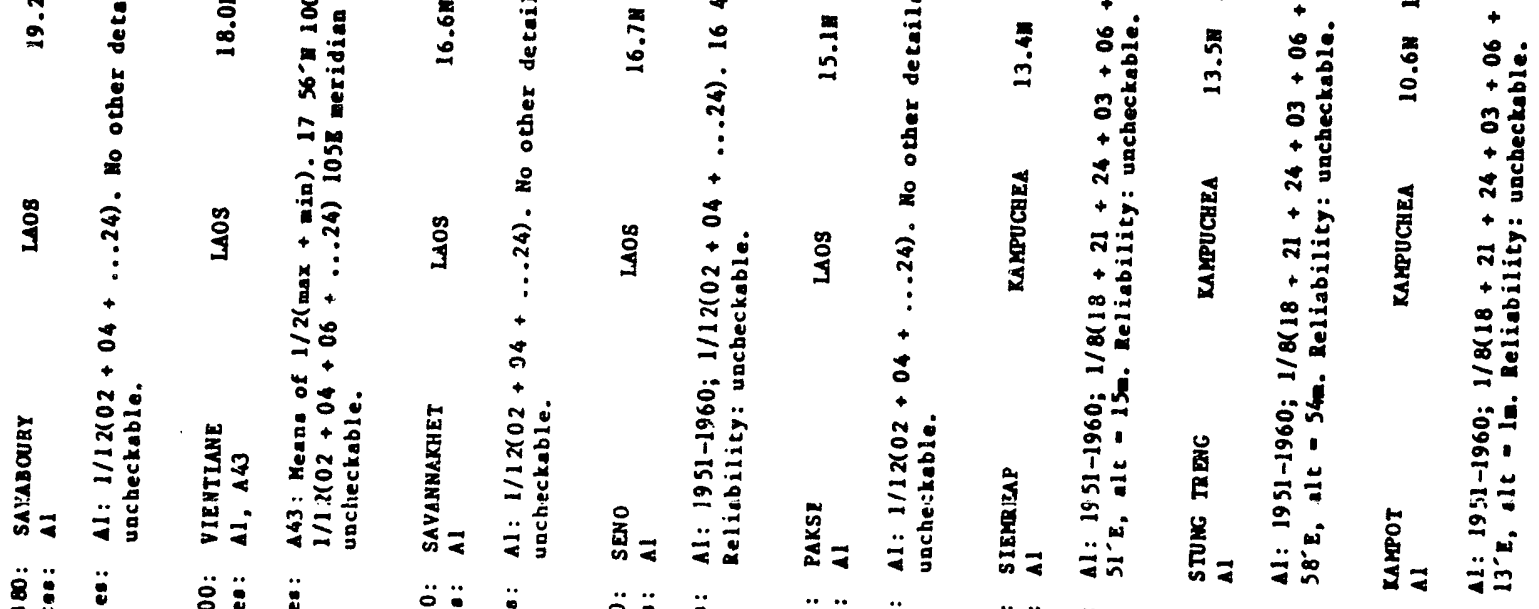
प1 


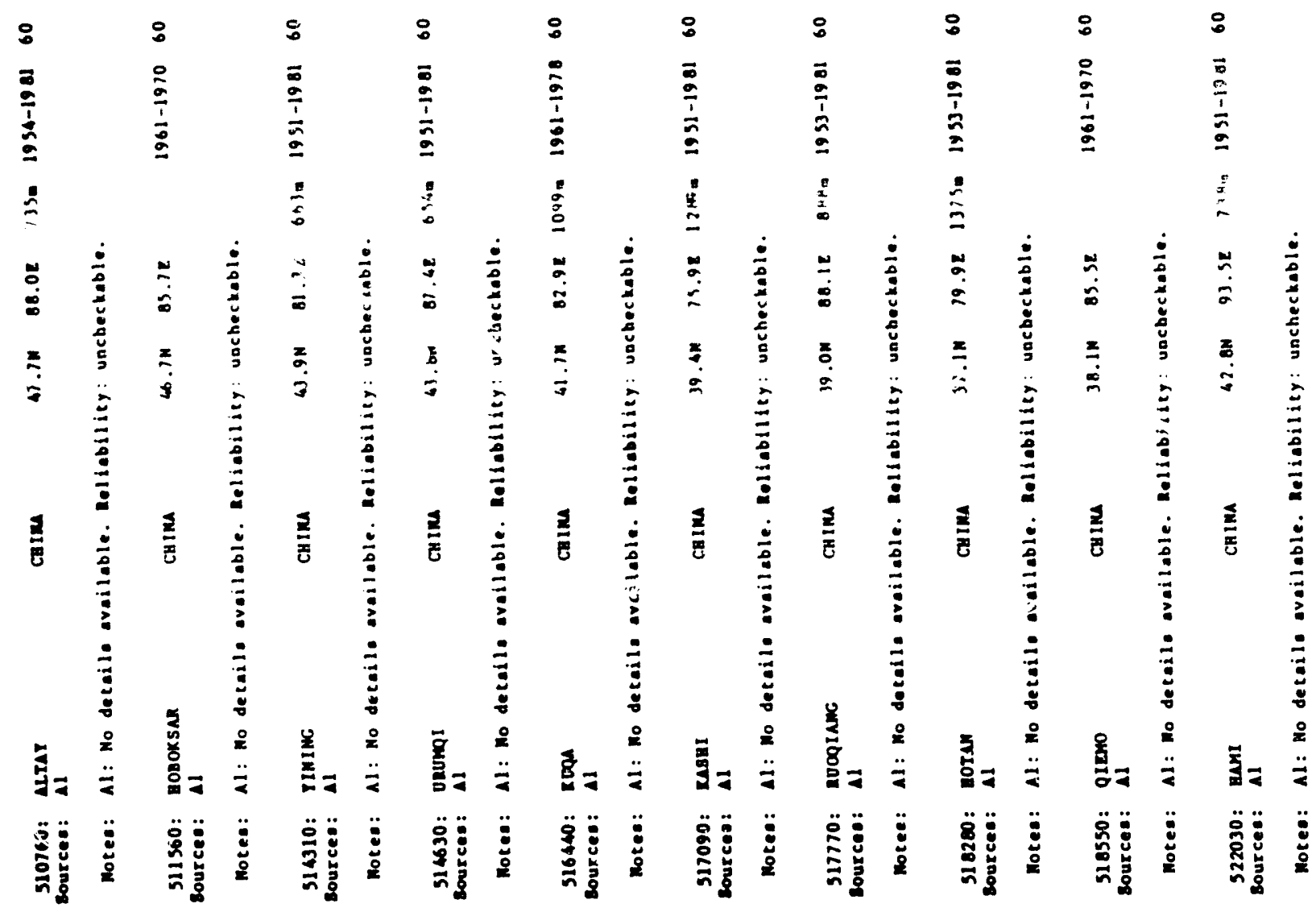

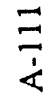

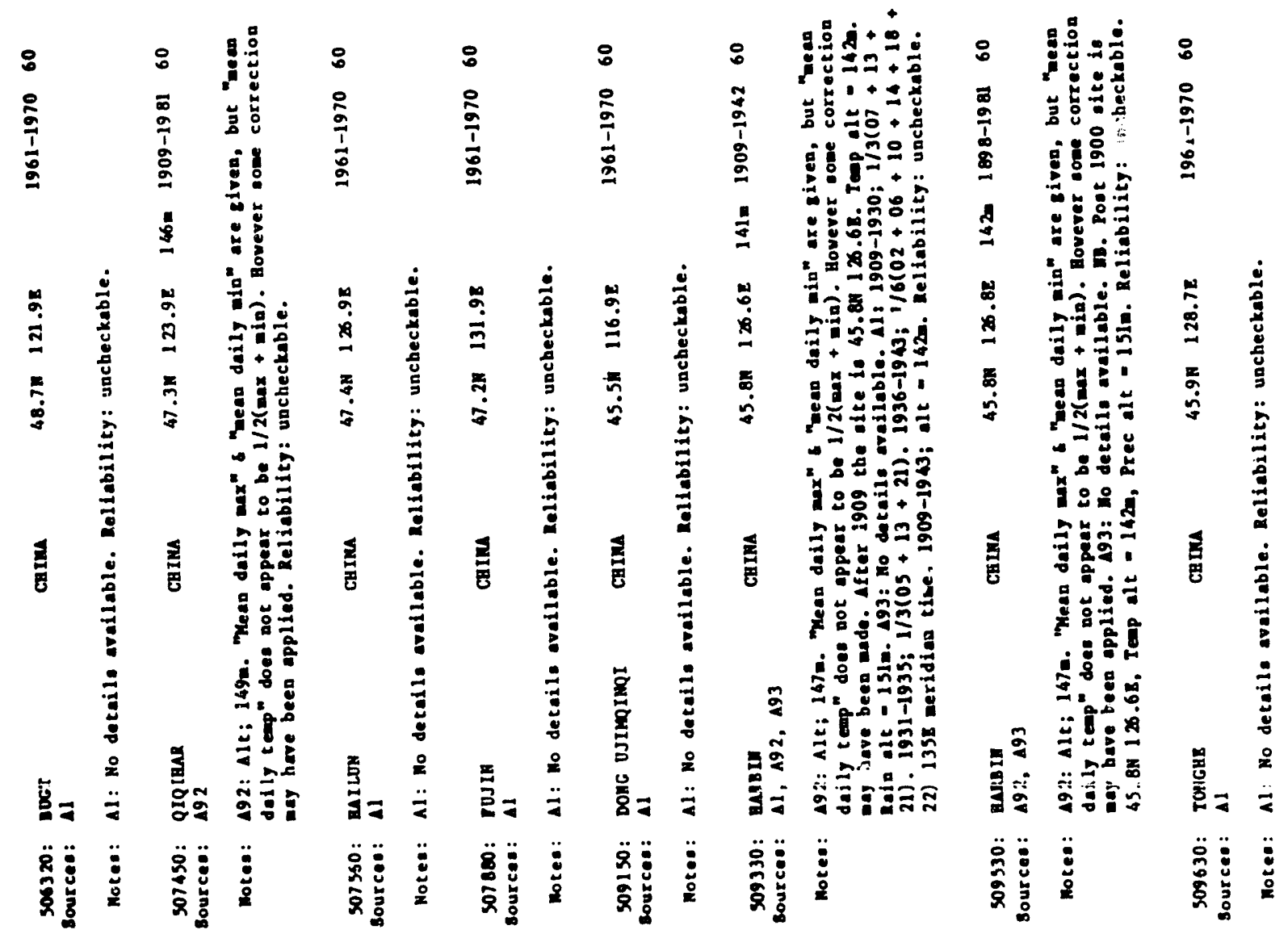



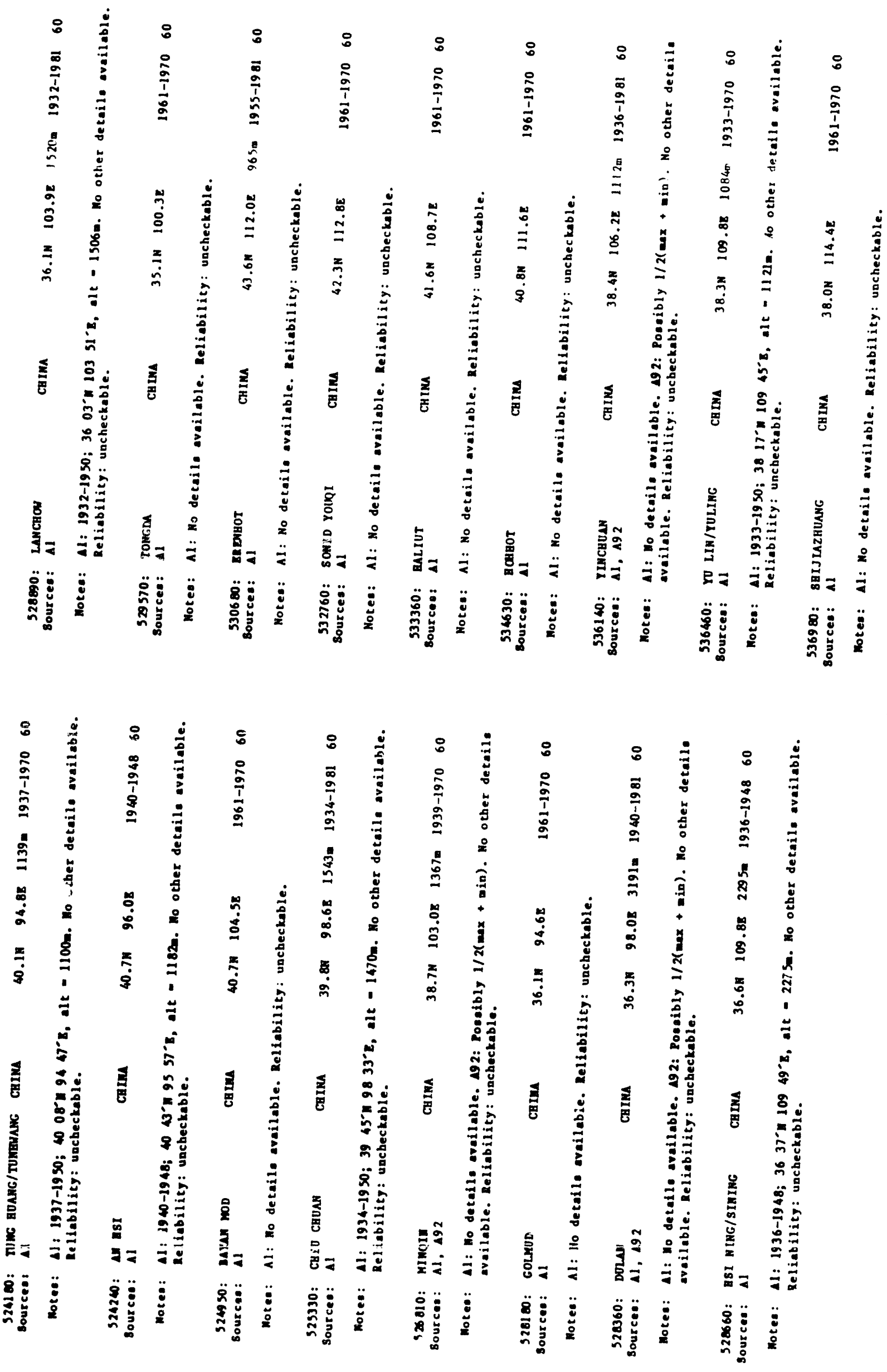

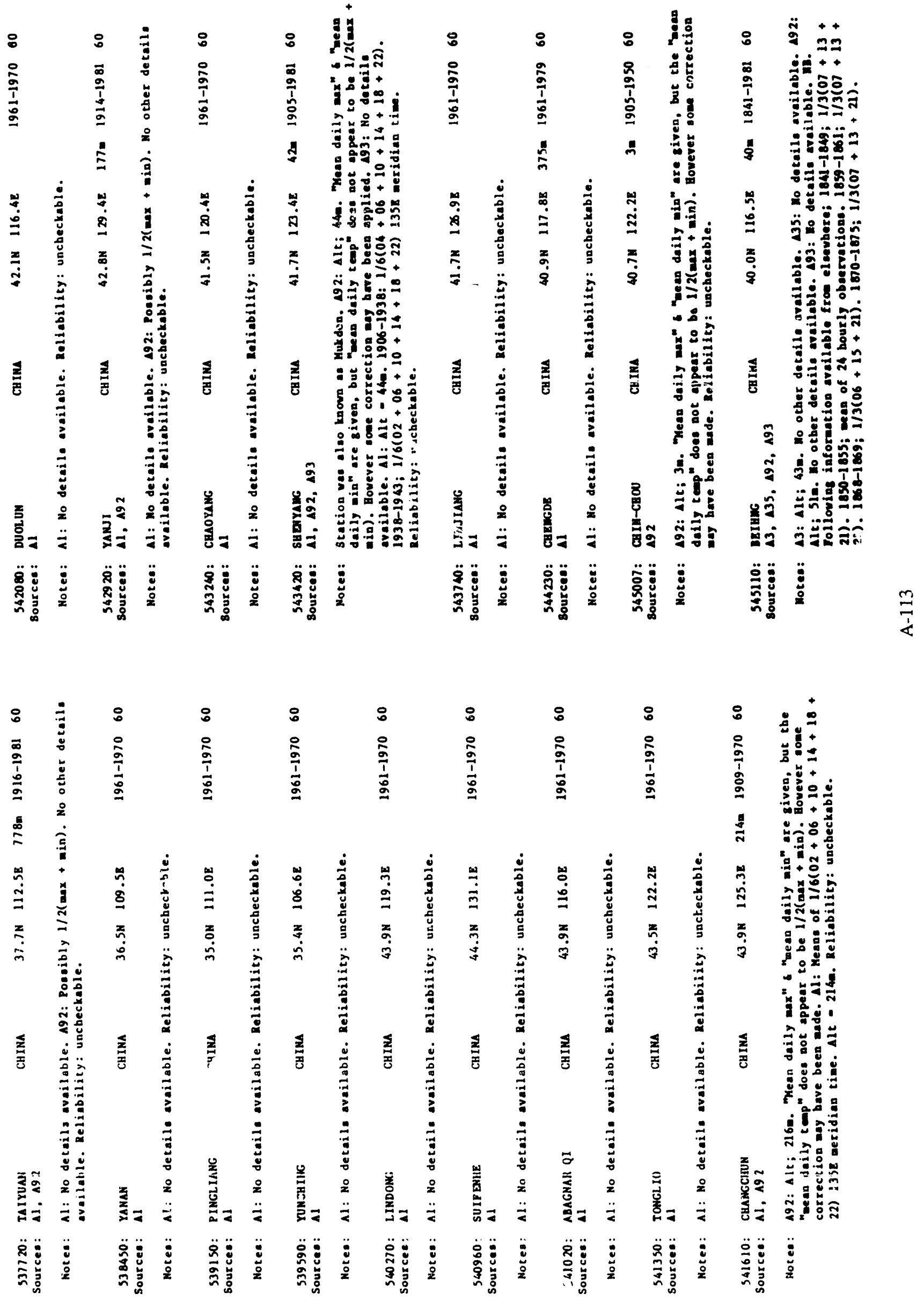


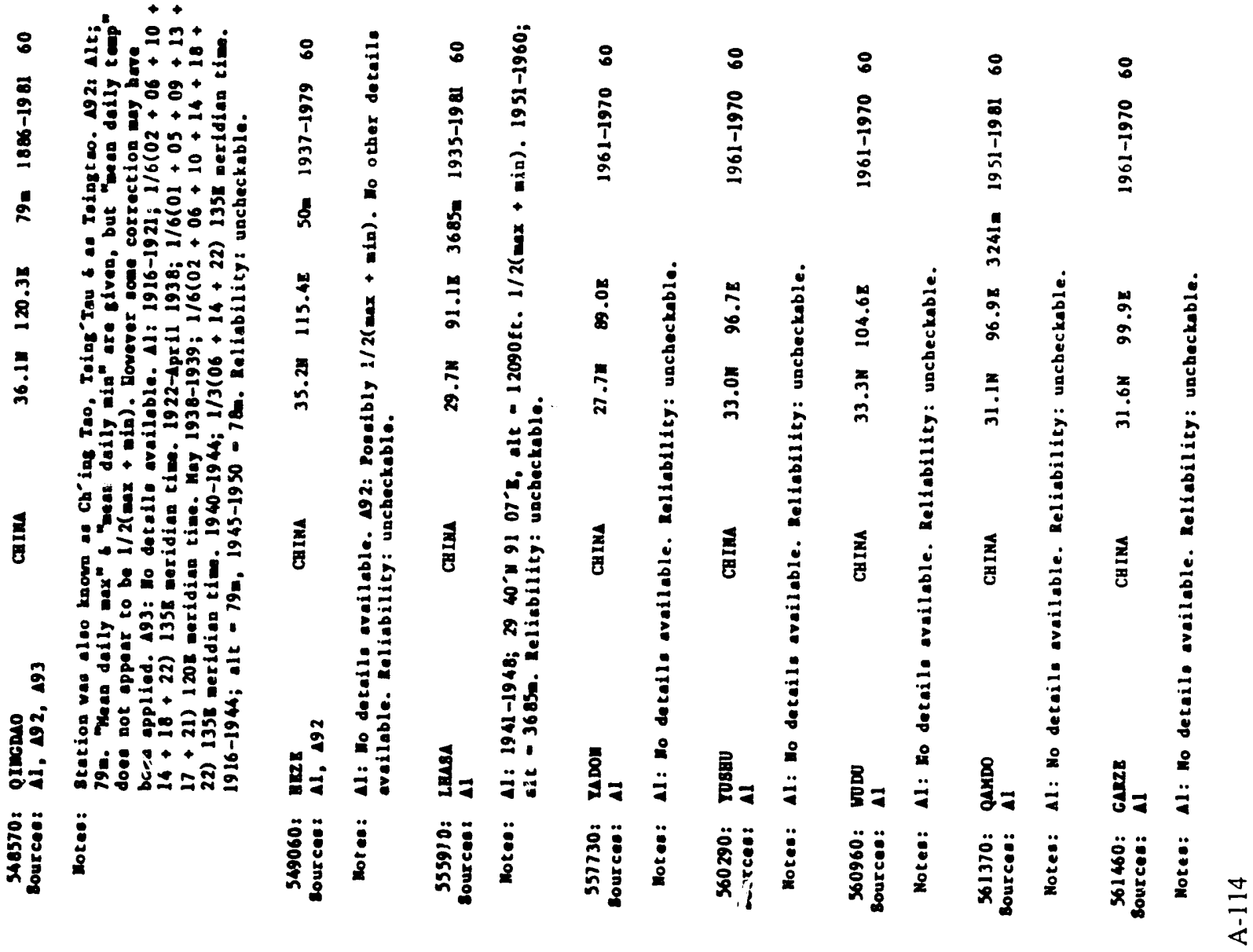

$=$

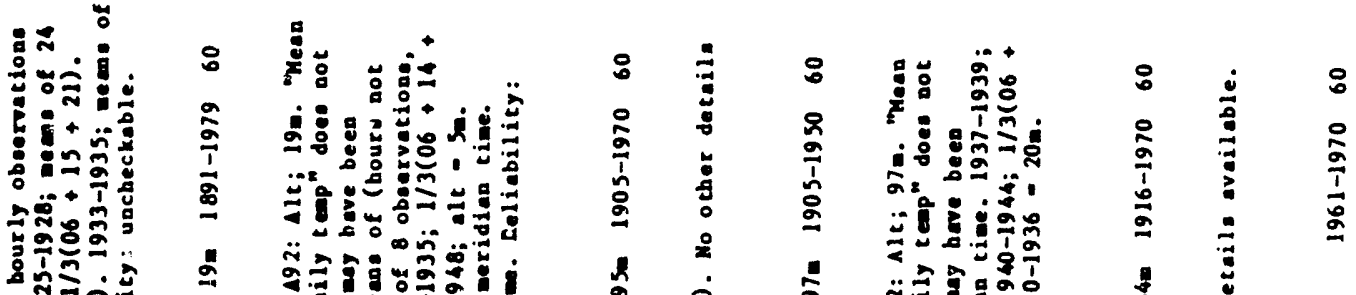

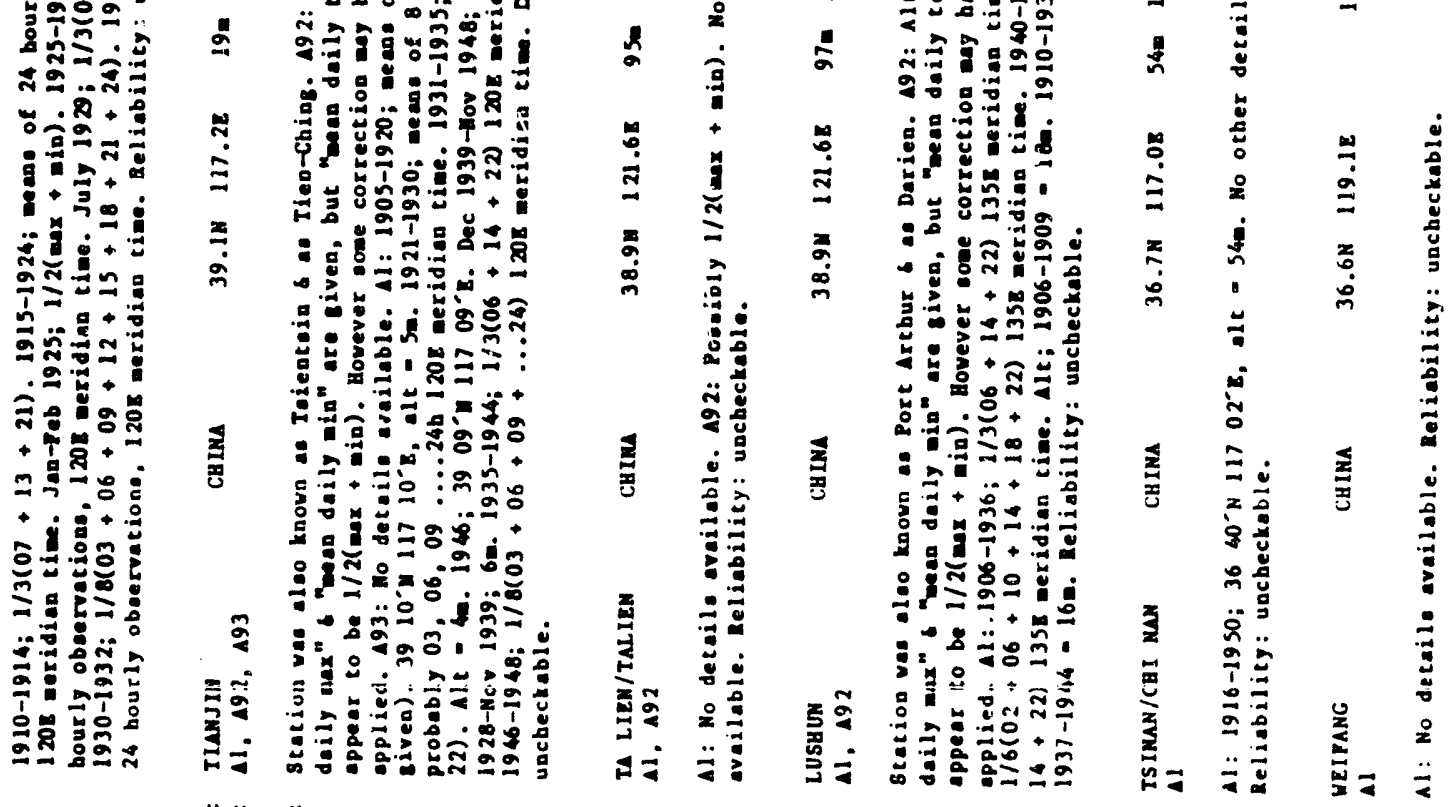

II

แ⿺

粊 


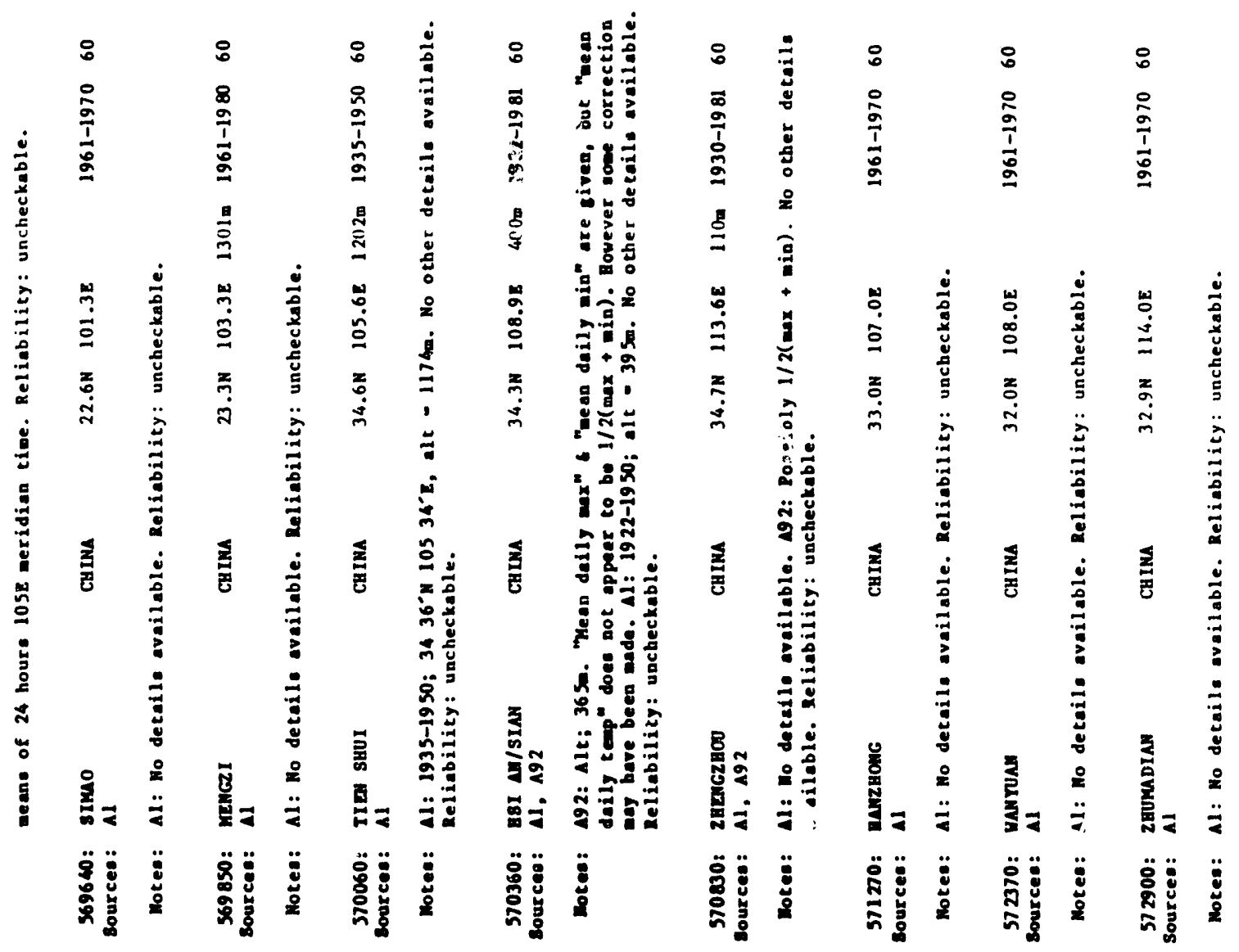

$\frac{1}{2}$

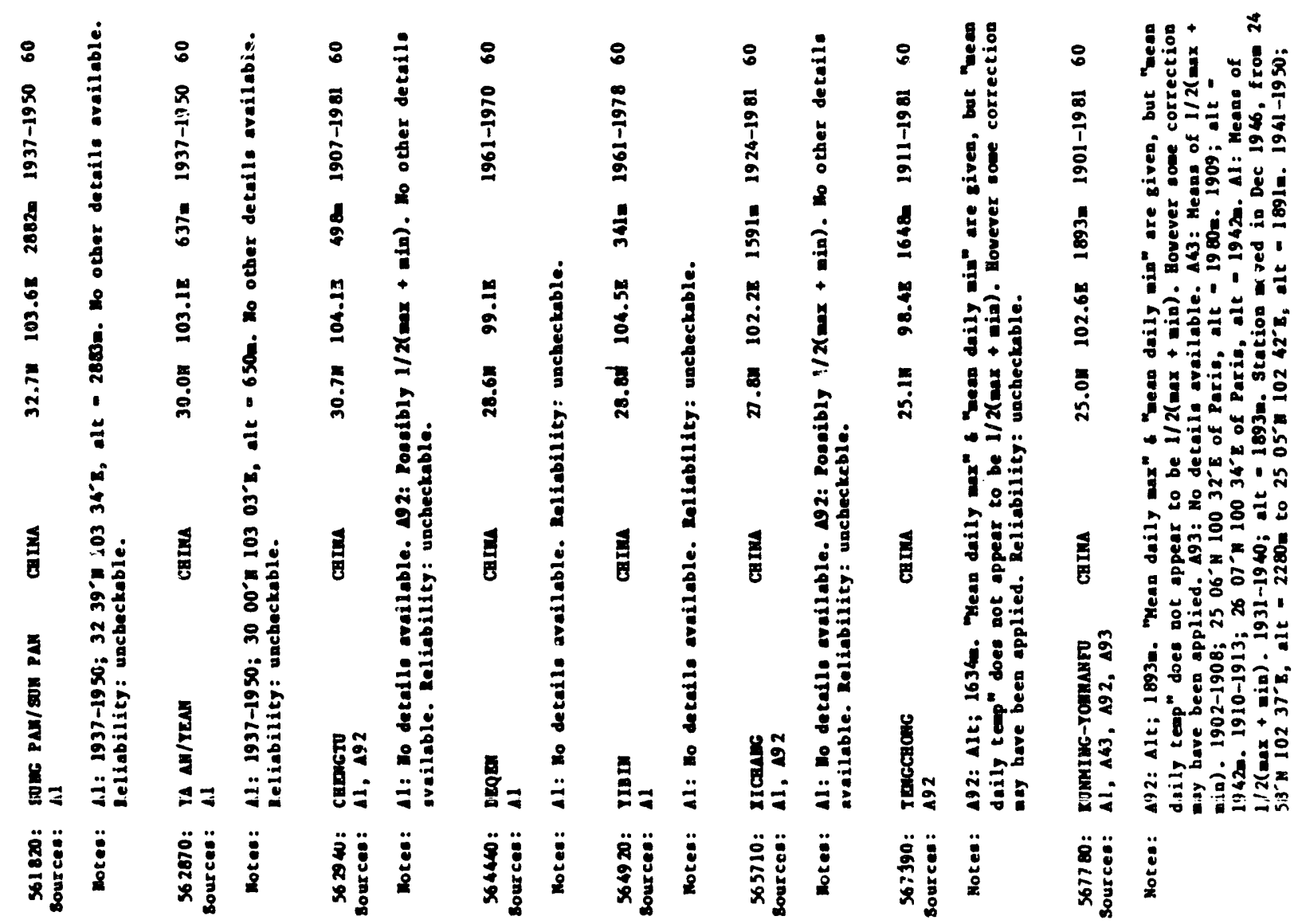




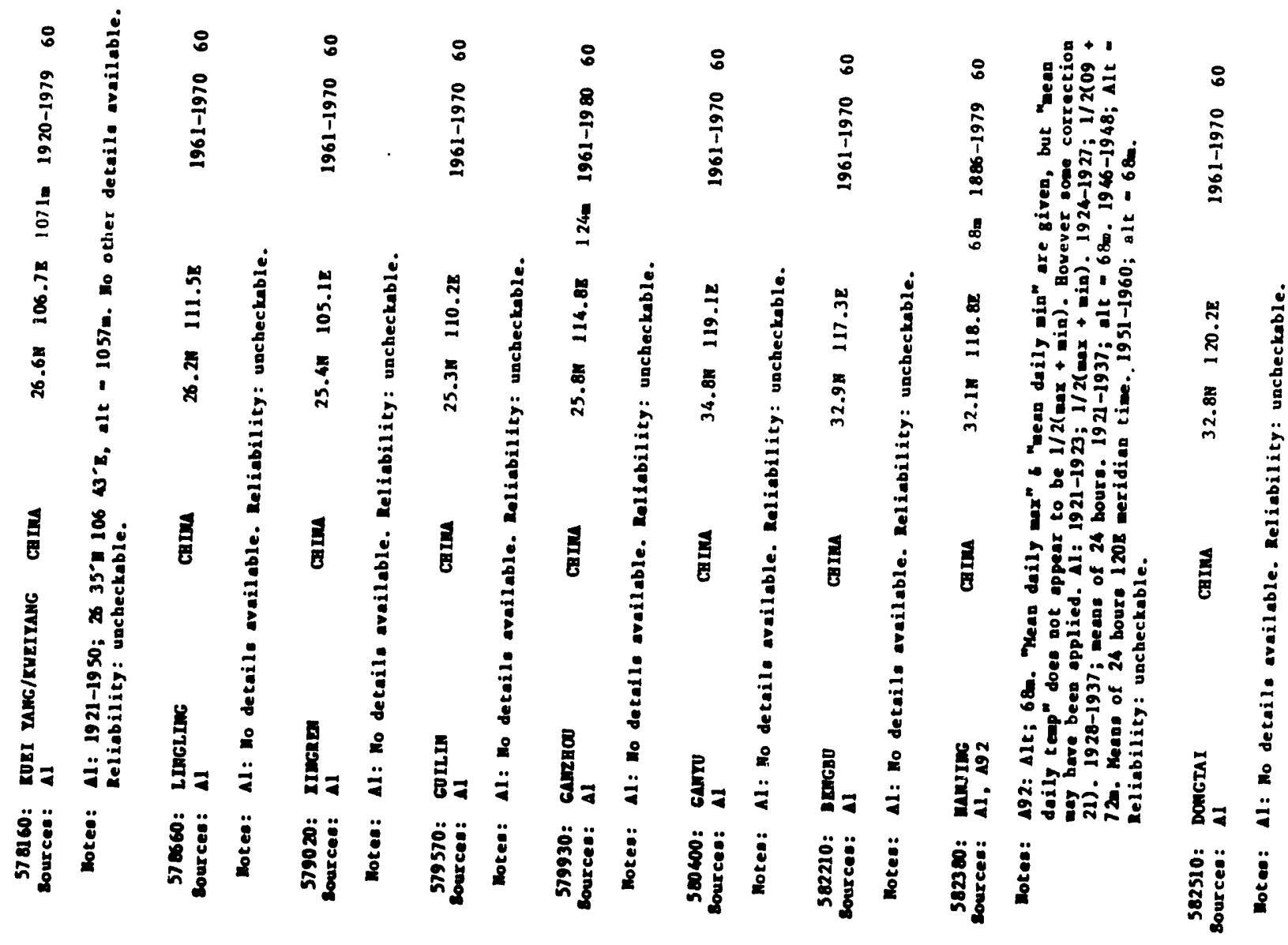

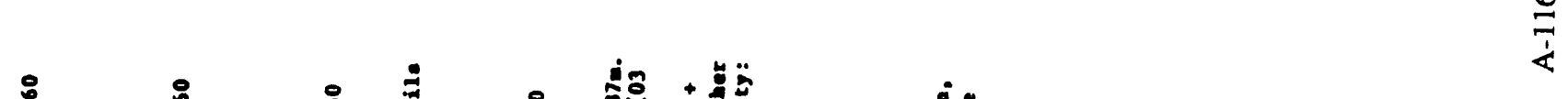

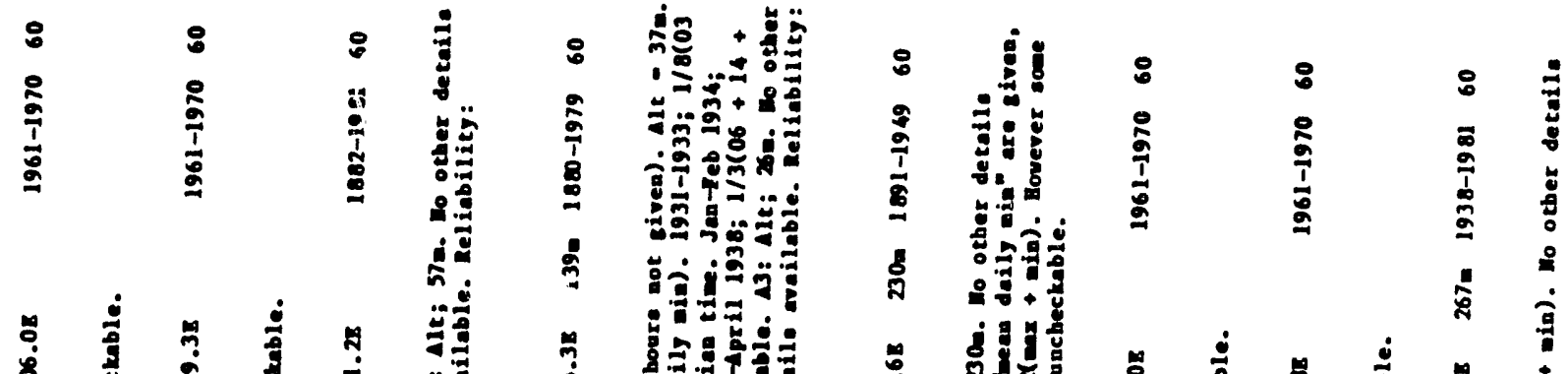

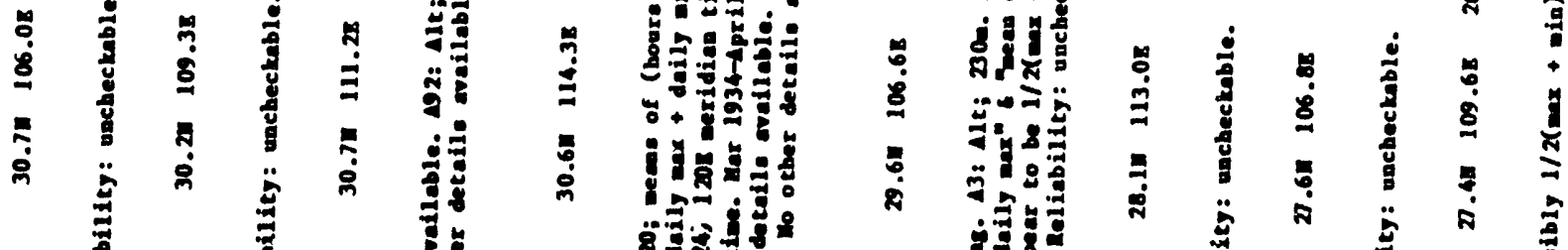

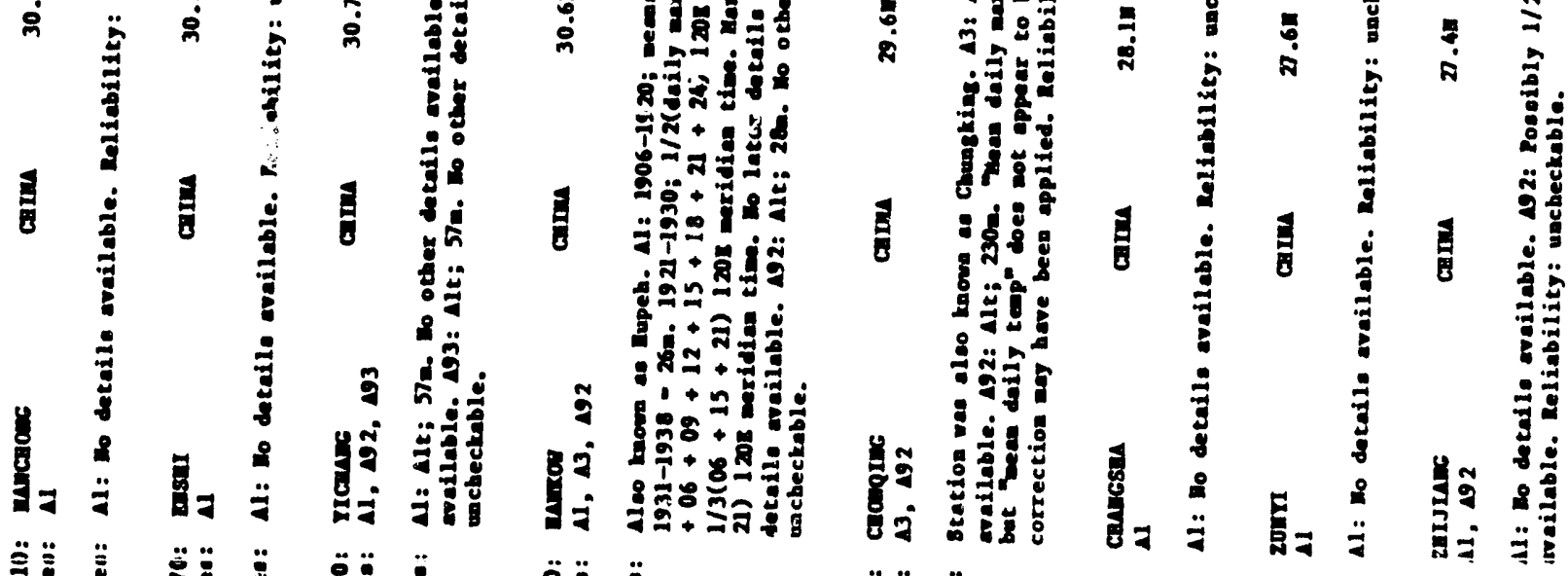
II 


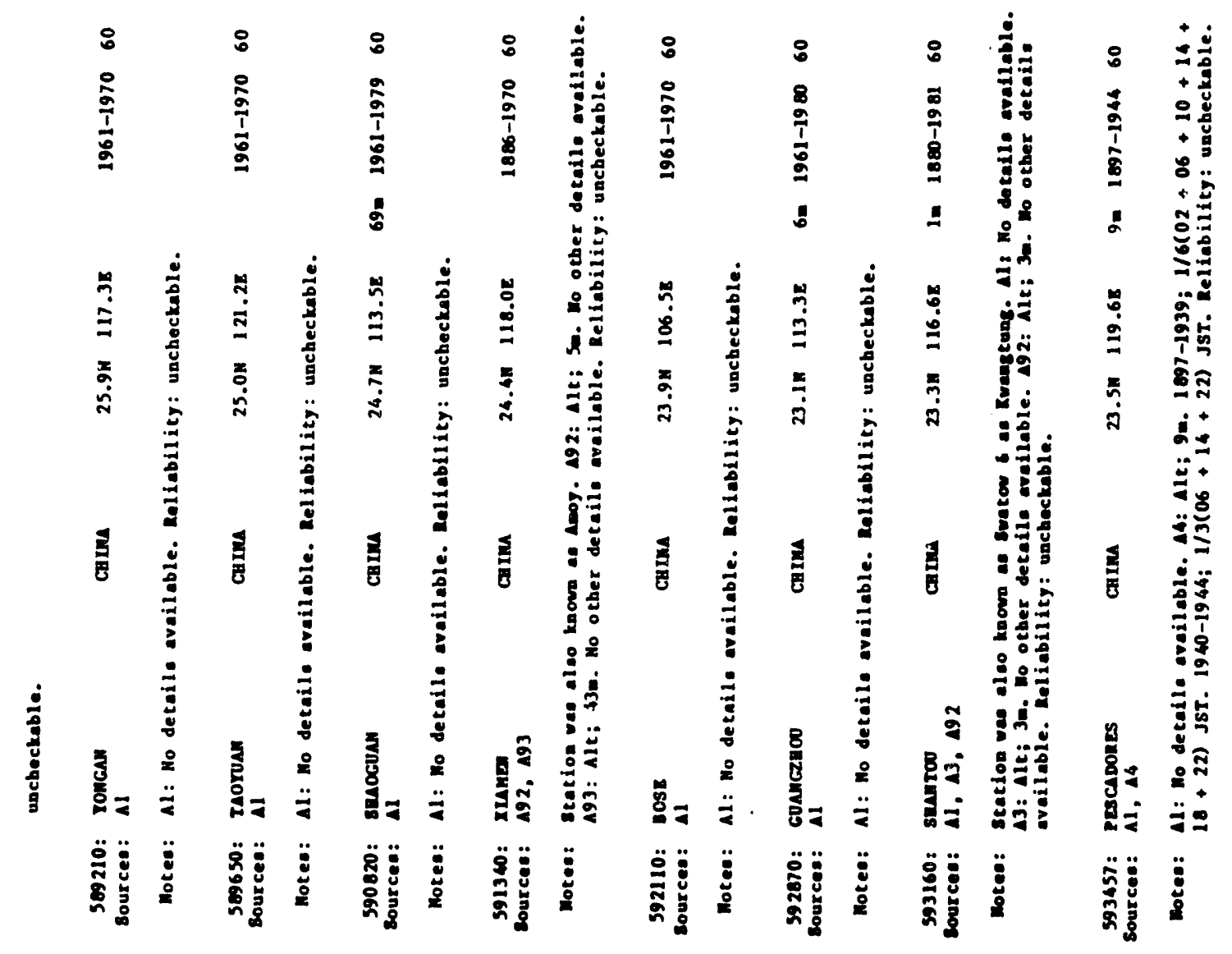

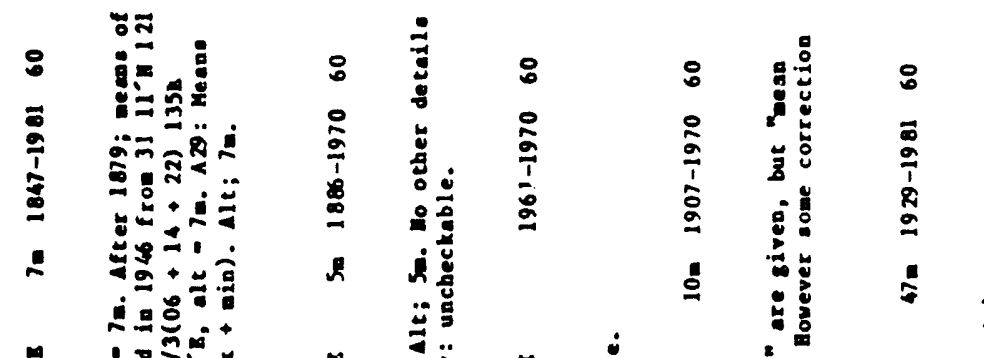

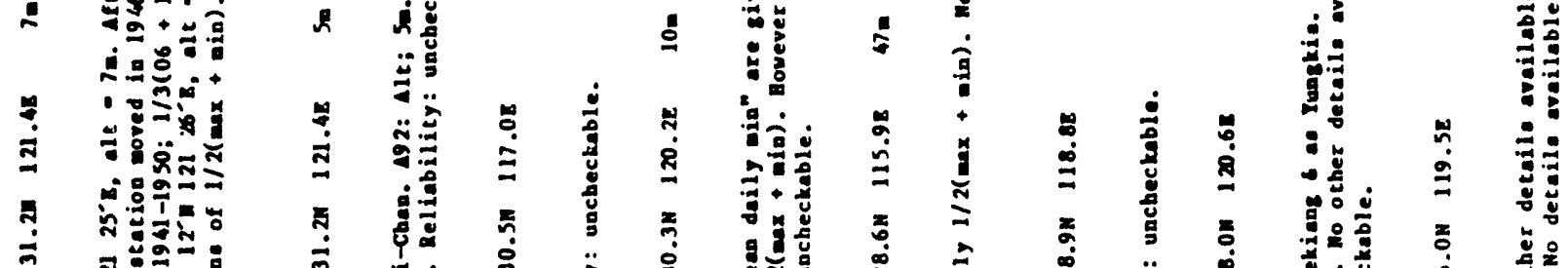

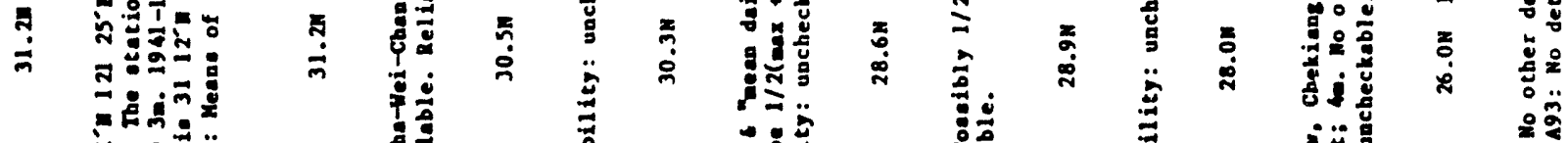

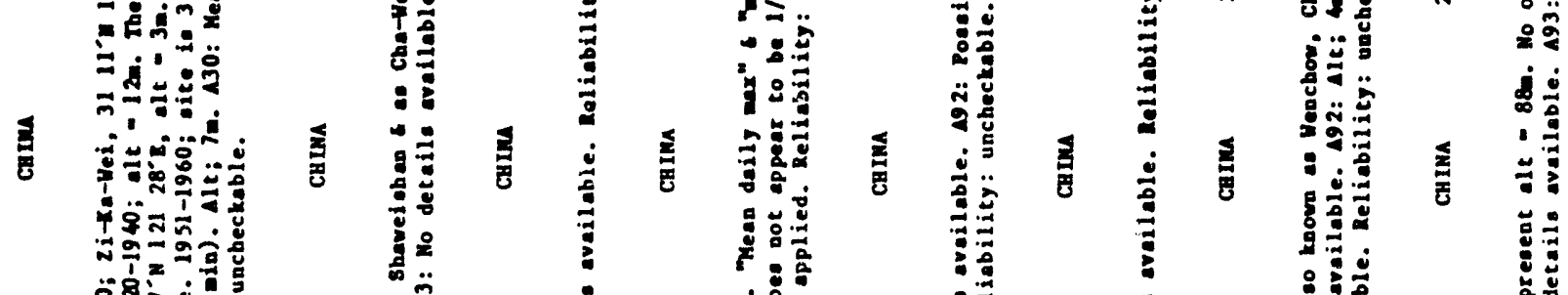

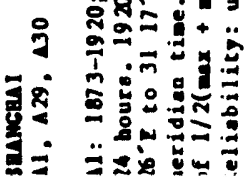

in

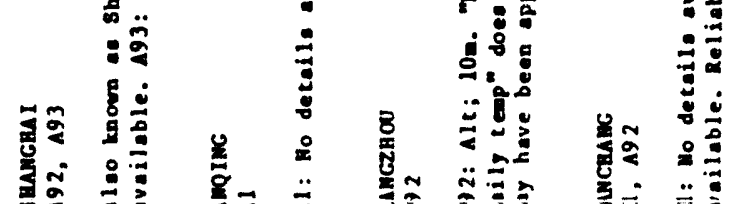

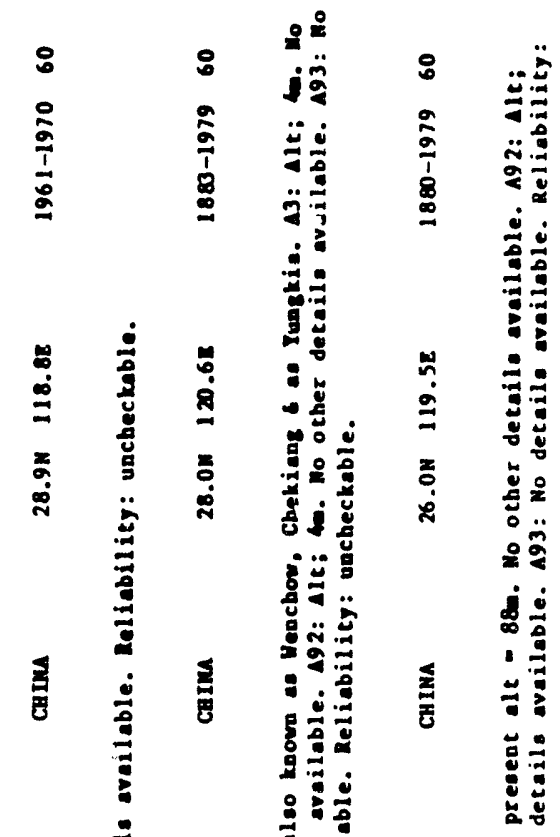

จ

$\frac{1}{1}$ 

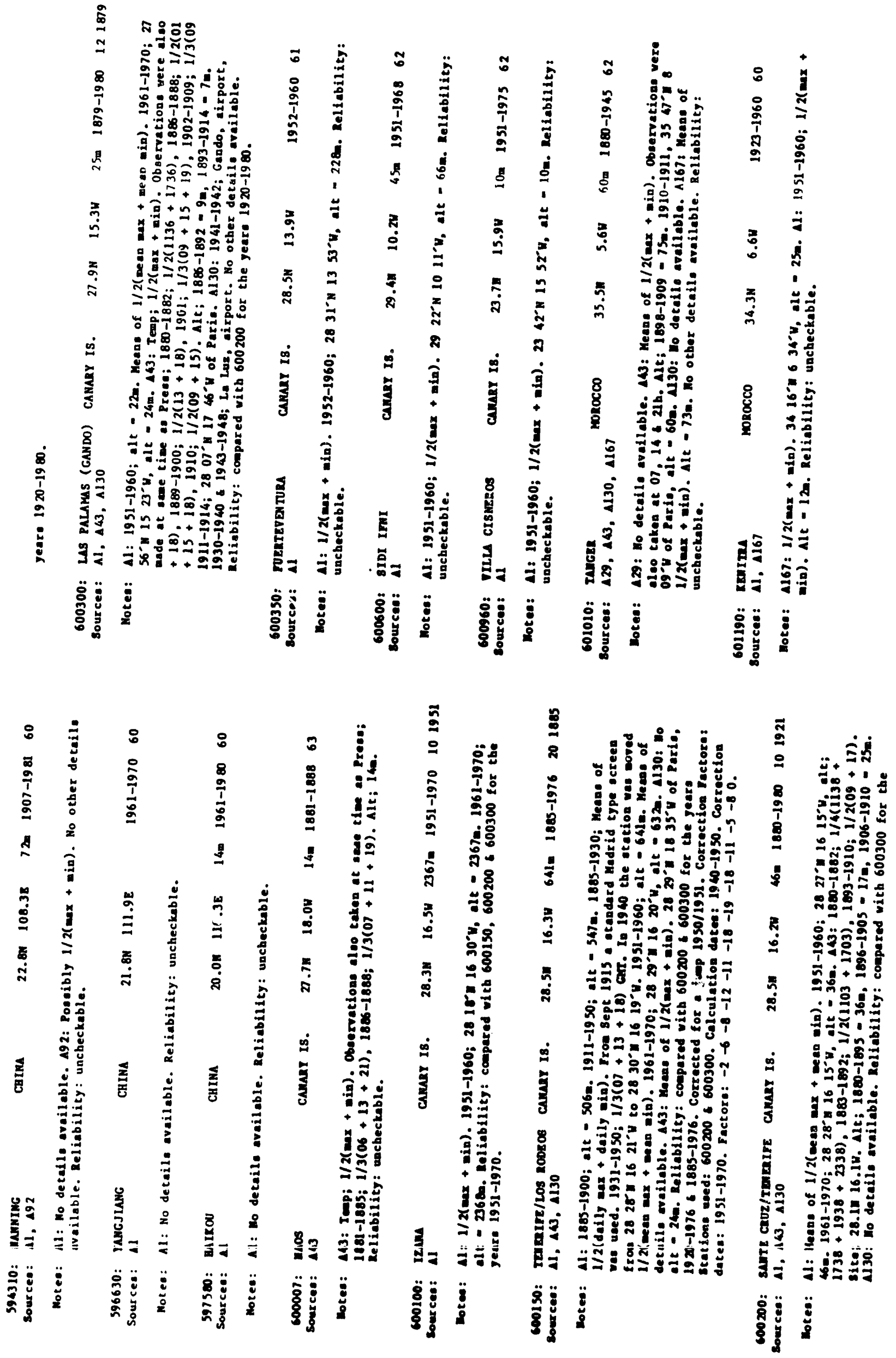


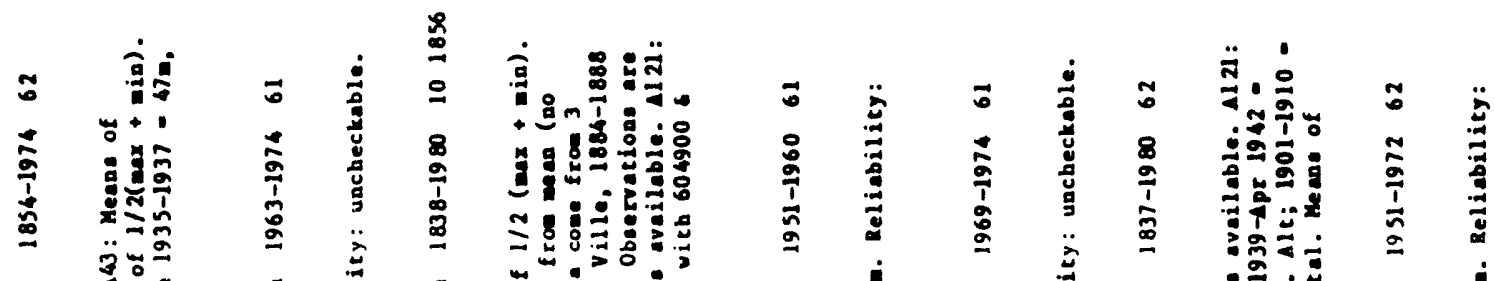

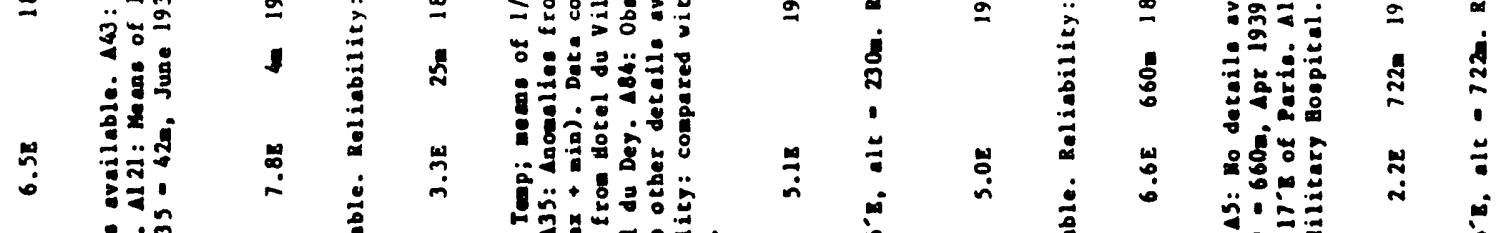

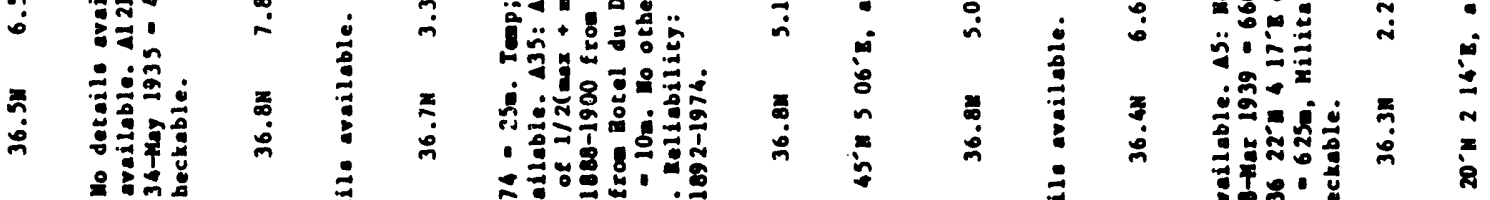

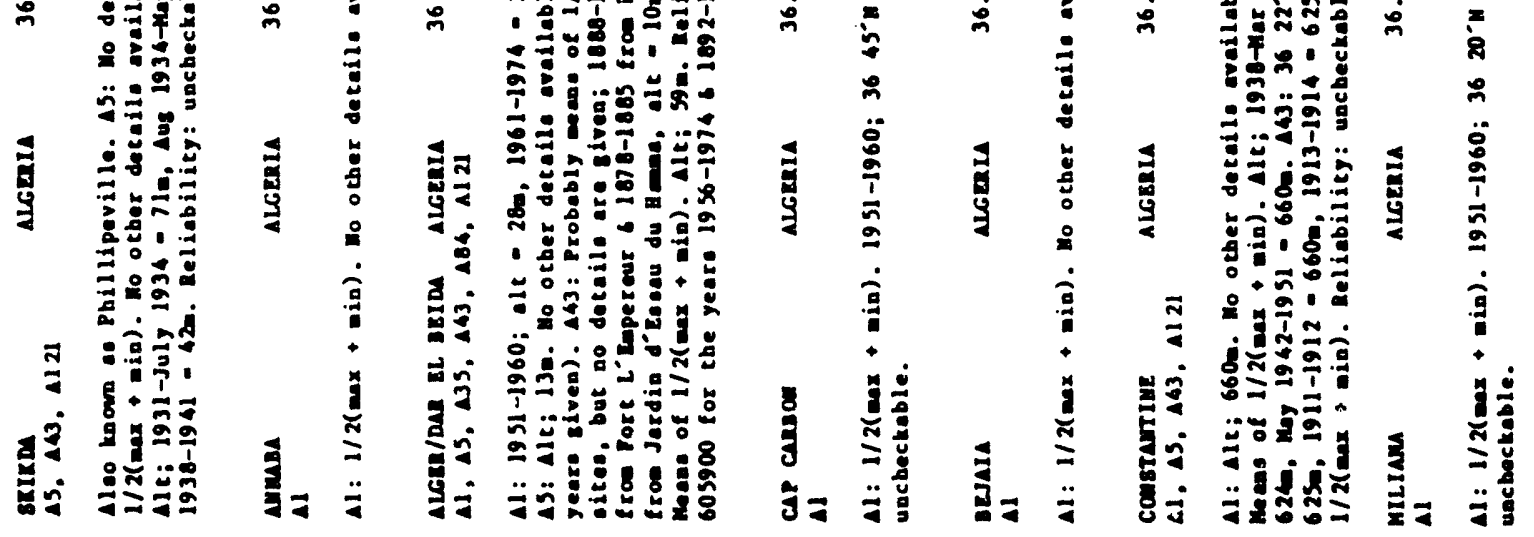

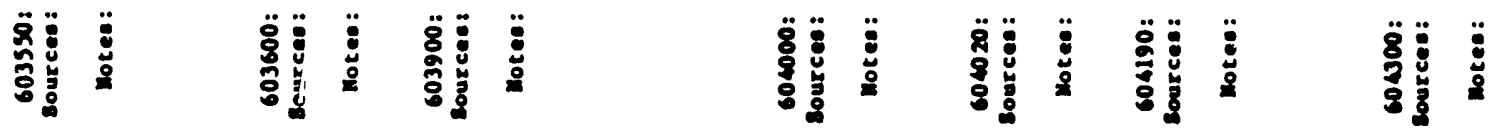

$\frac{9}{i}$

$\stackrel{\overrightarrow{0}}{\stackrel{1}{1}}$

$a$

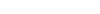

ว

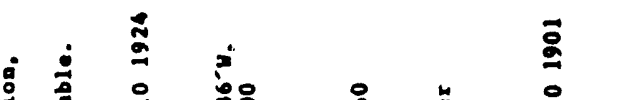

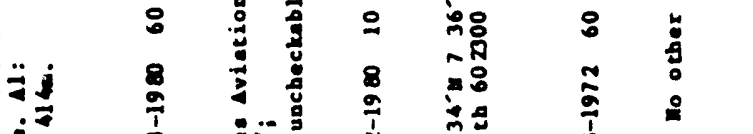

$\because \frac{1}{10}$ a

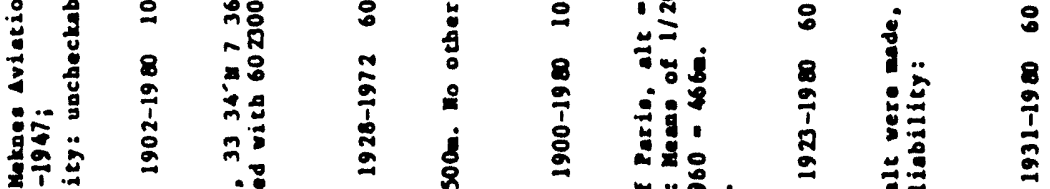

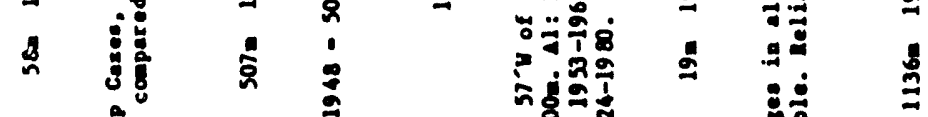

c d

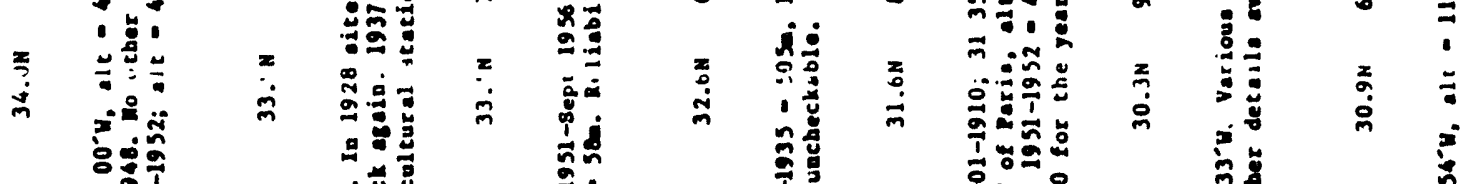

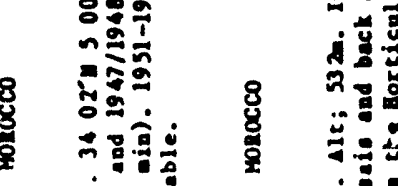

两

a

政

:

o

空:

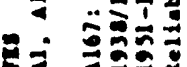

:

(2)

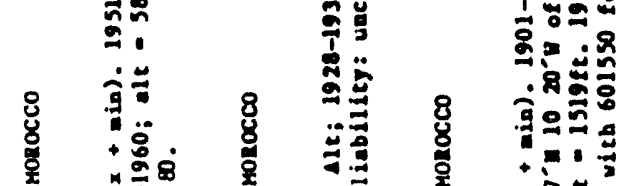

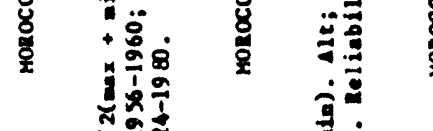

湜:

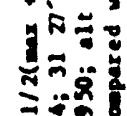

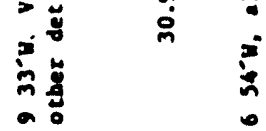

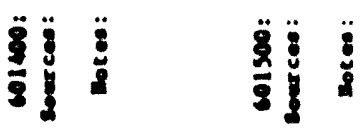

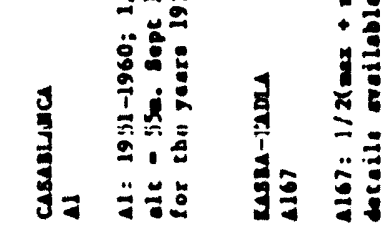

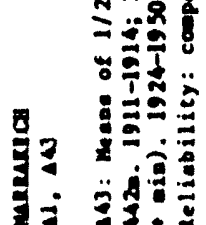

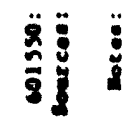

茴

की

in

官

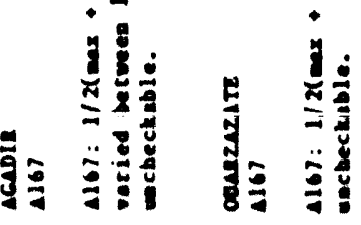




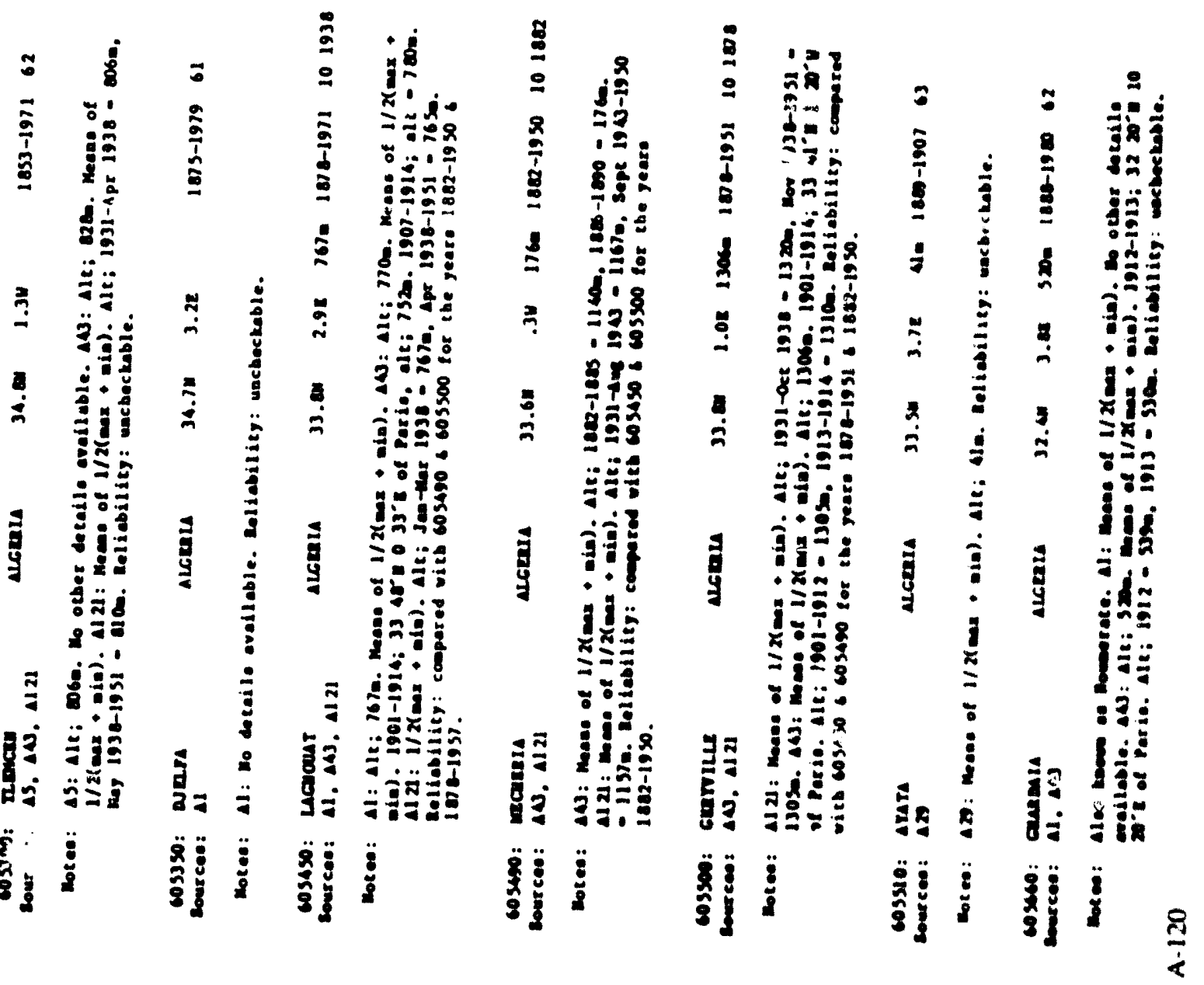

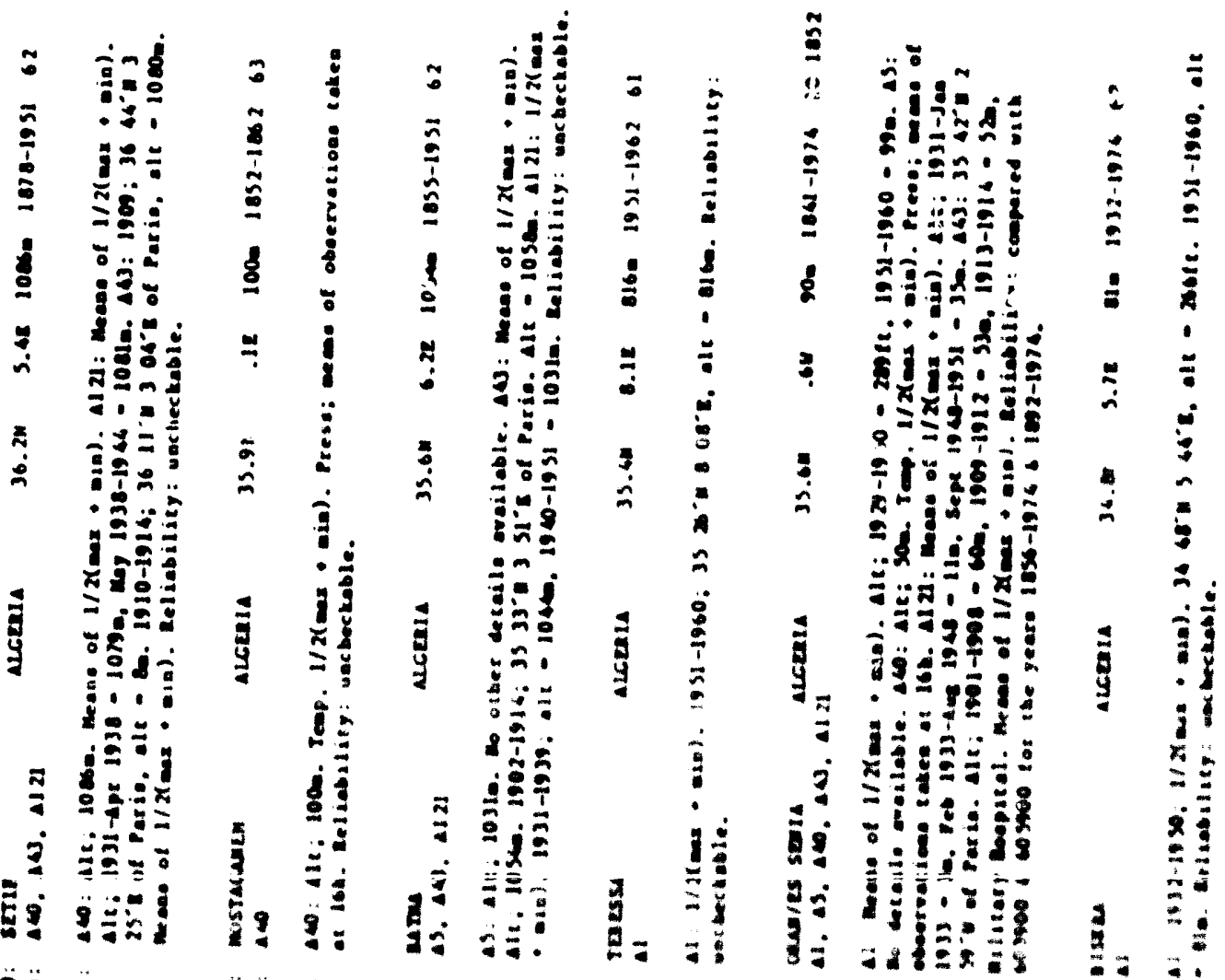

多 


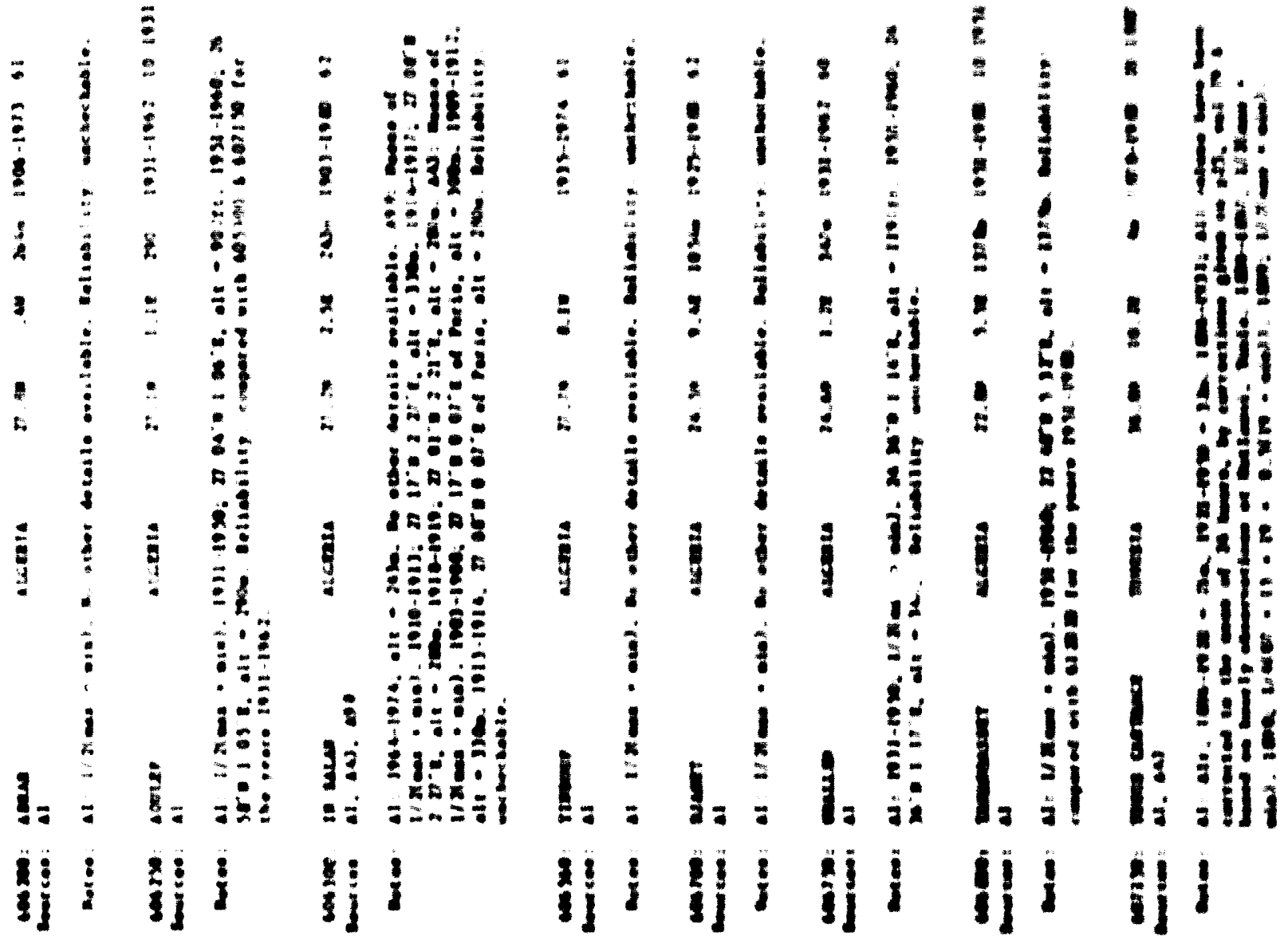

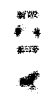

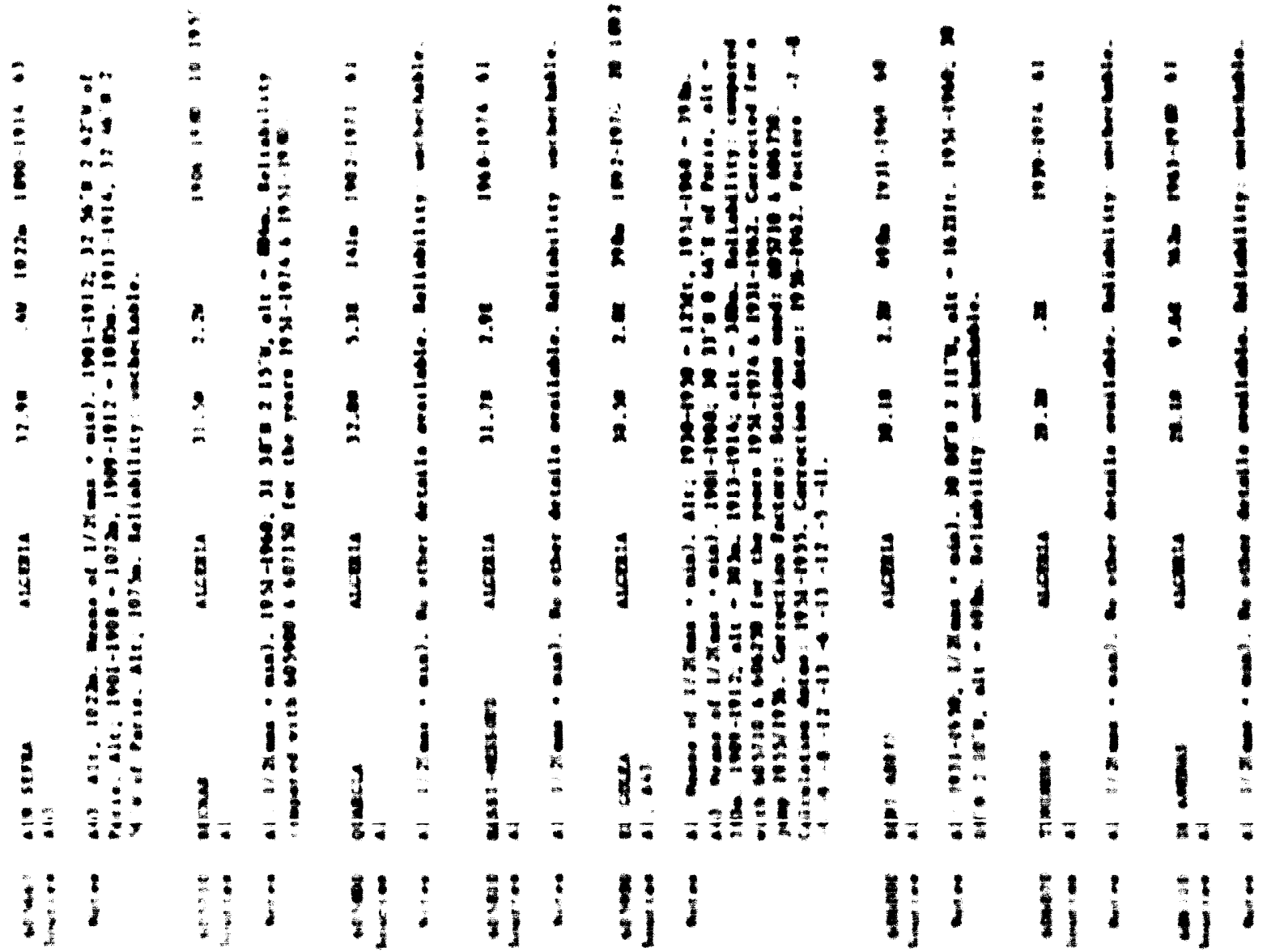


I 11

l.

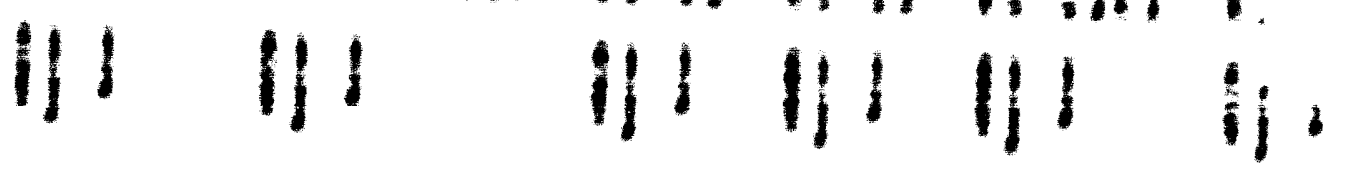

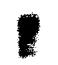

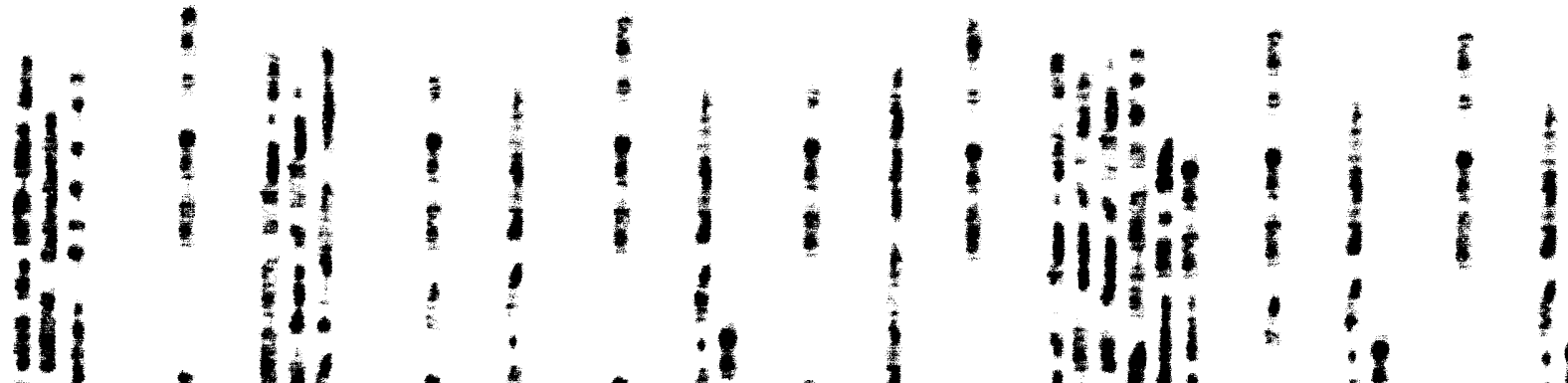

H:

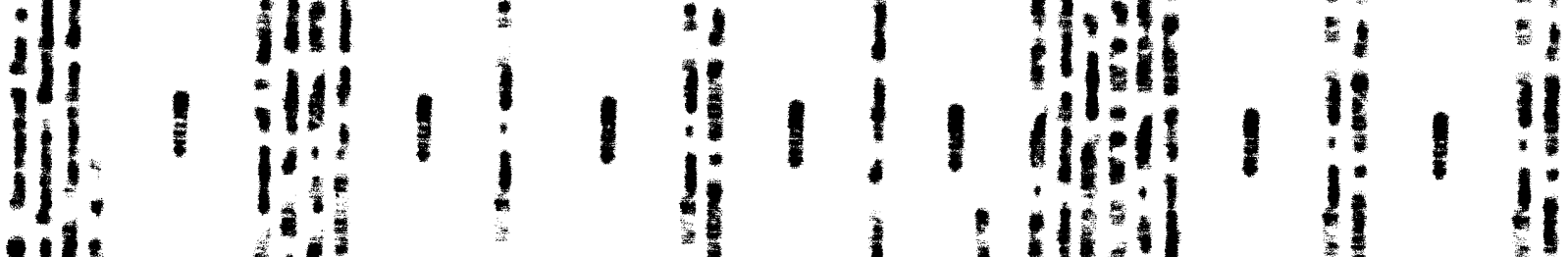

ili fill

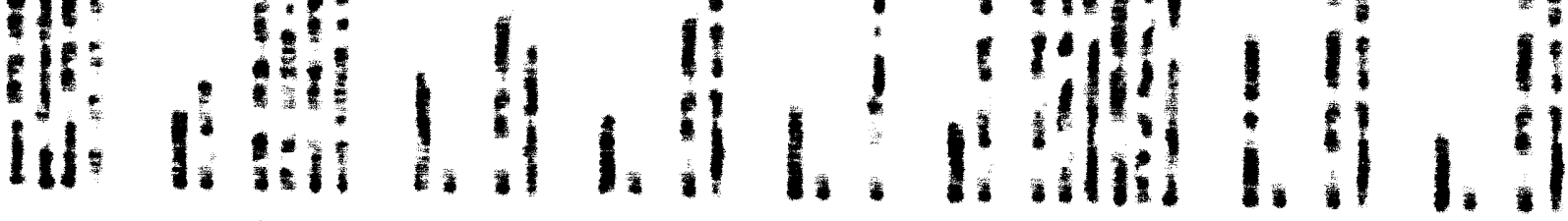

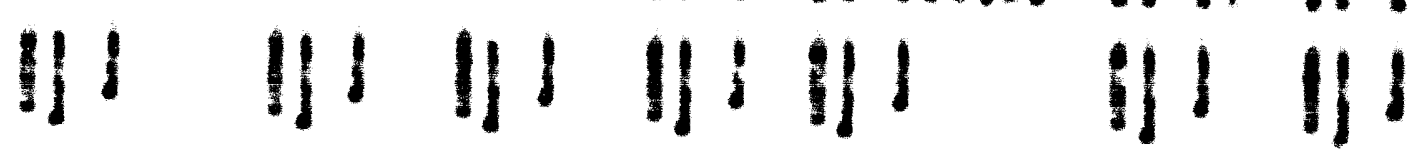

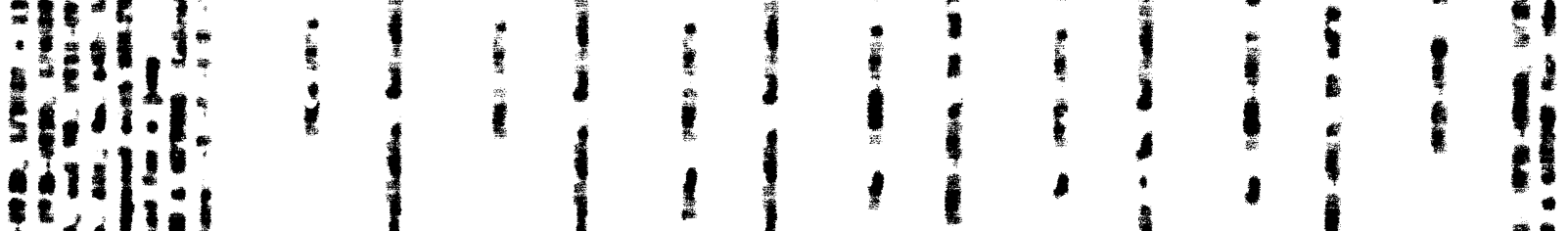

(1)

- 1812

- 151

mii

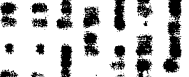

$=1.1$

t.

and

and

tet!it:

$+11$

? 

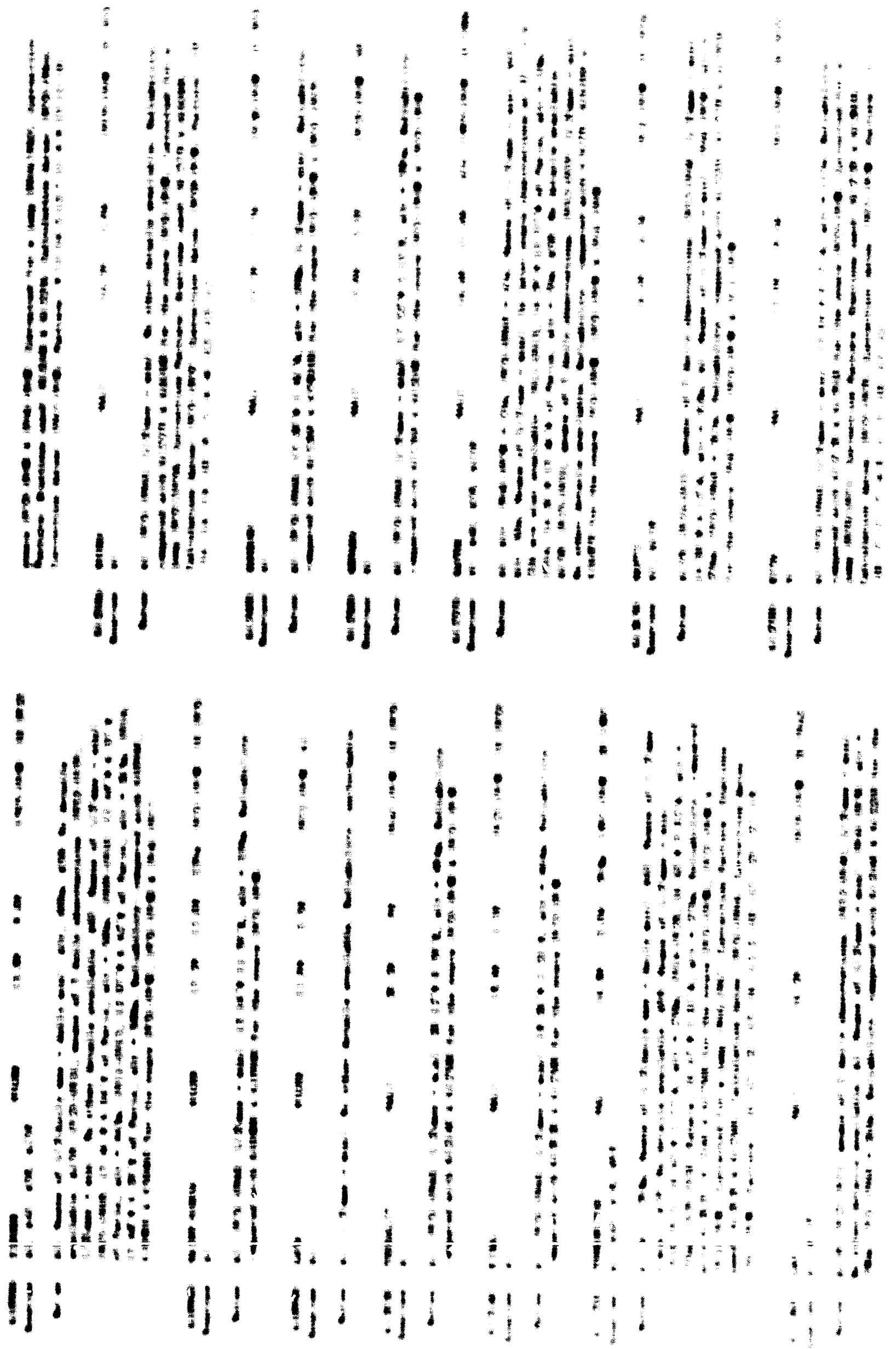


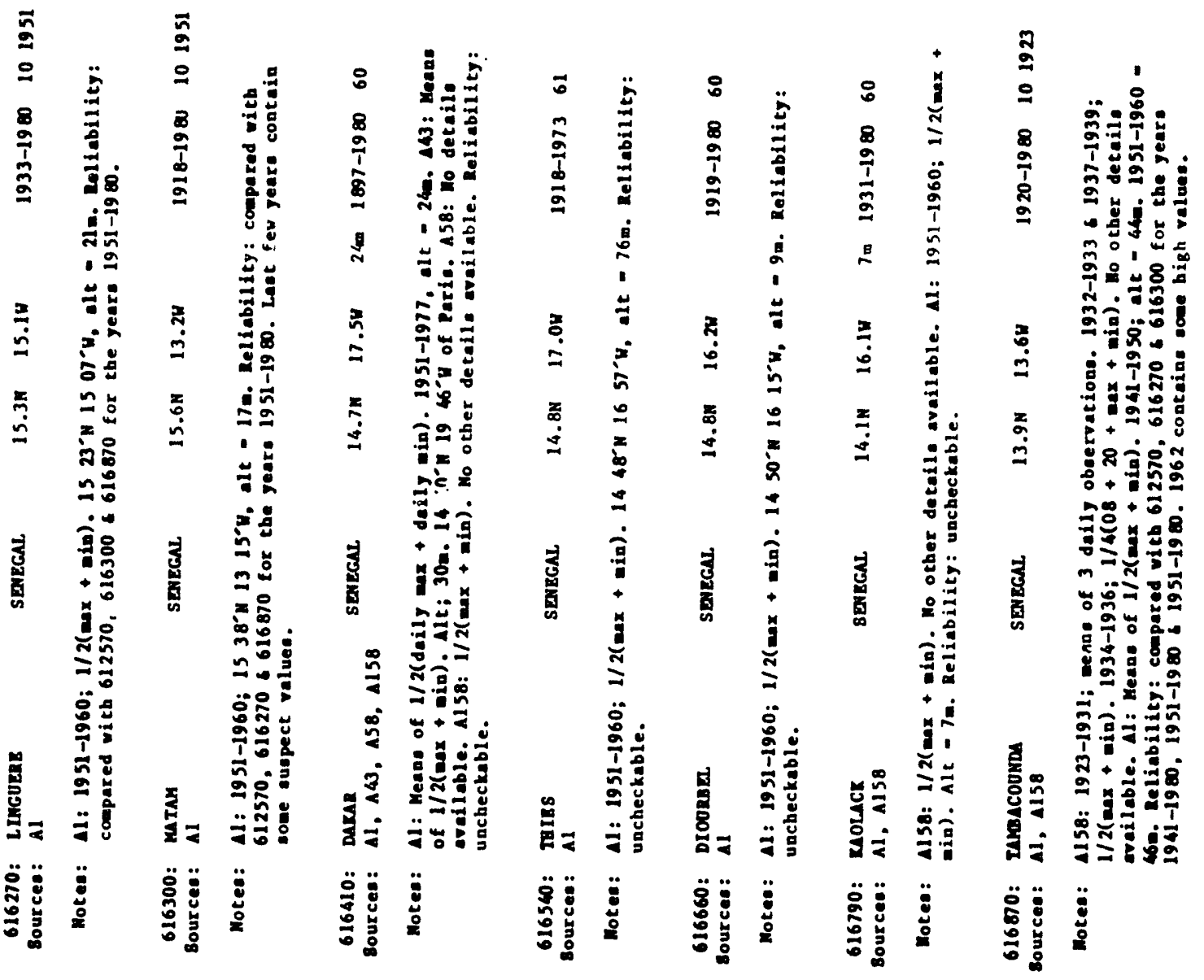

$\frac{2}{4}$

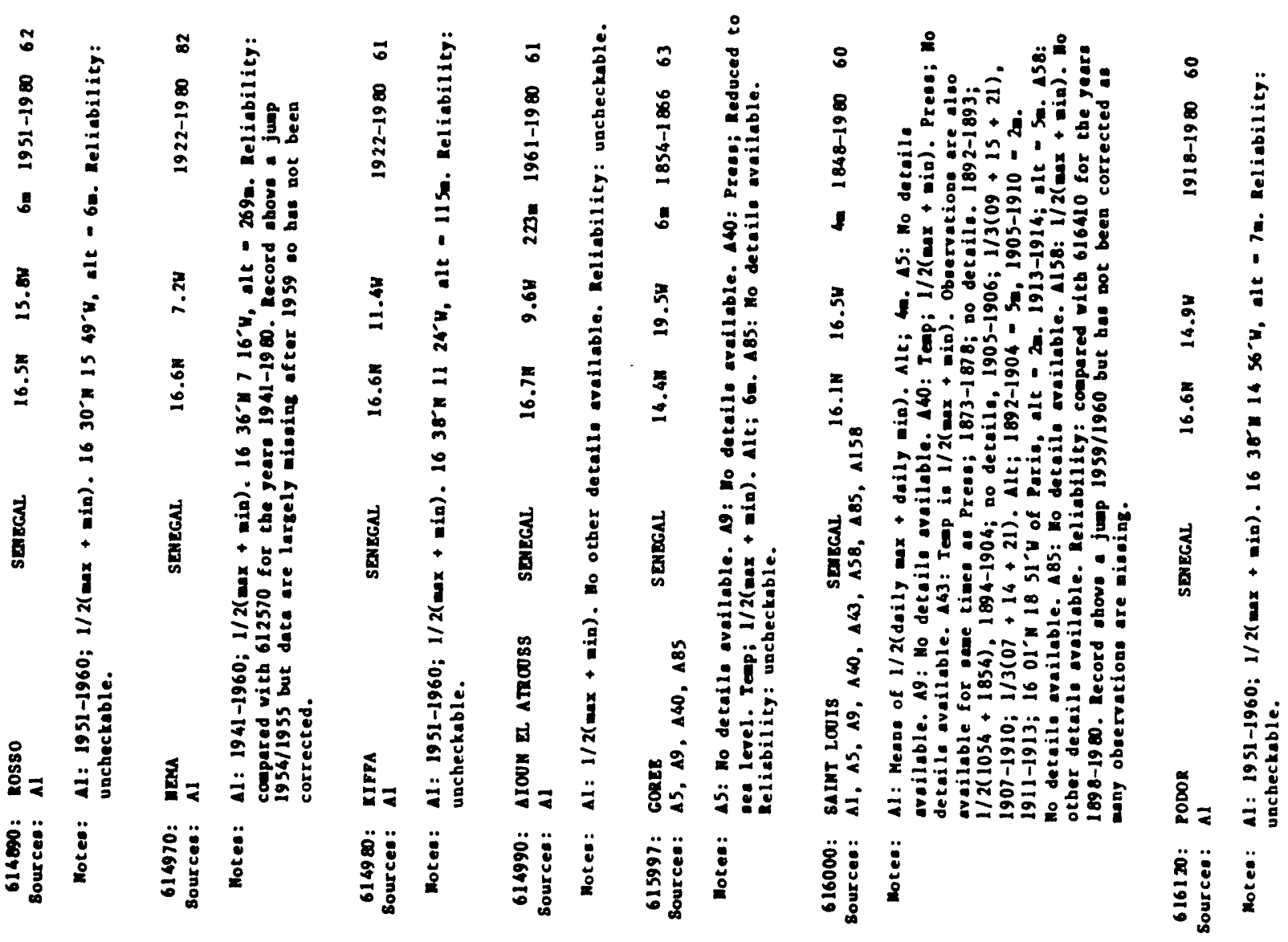




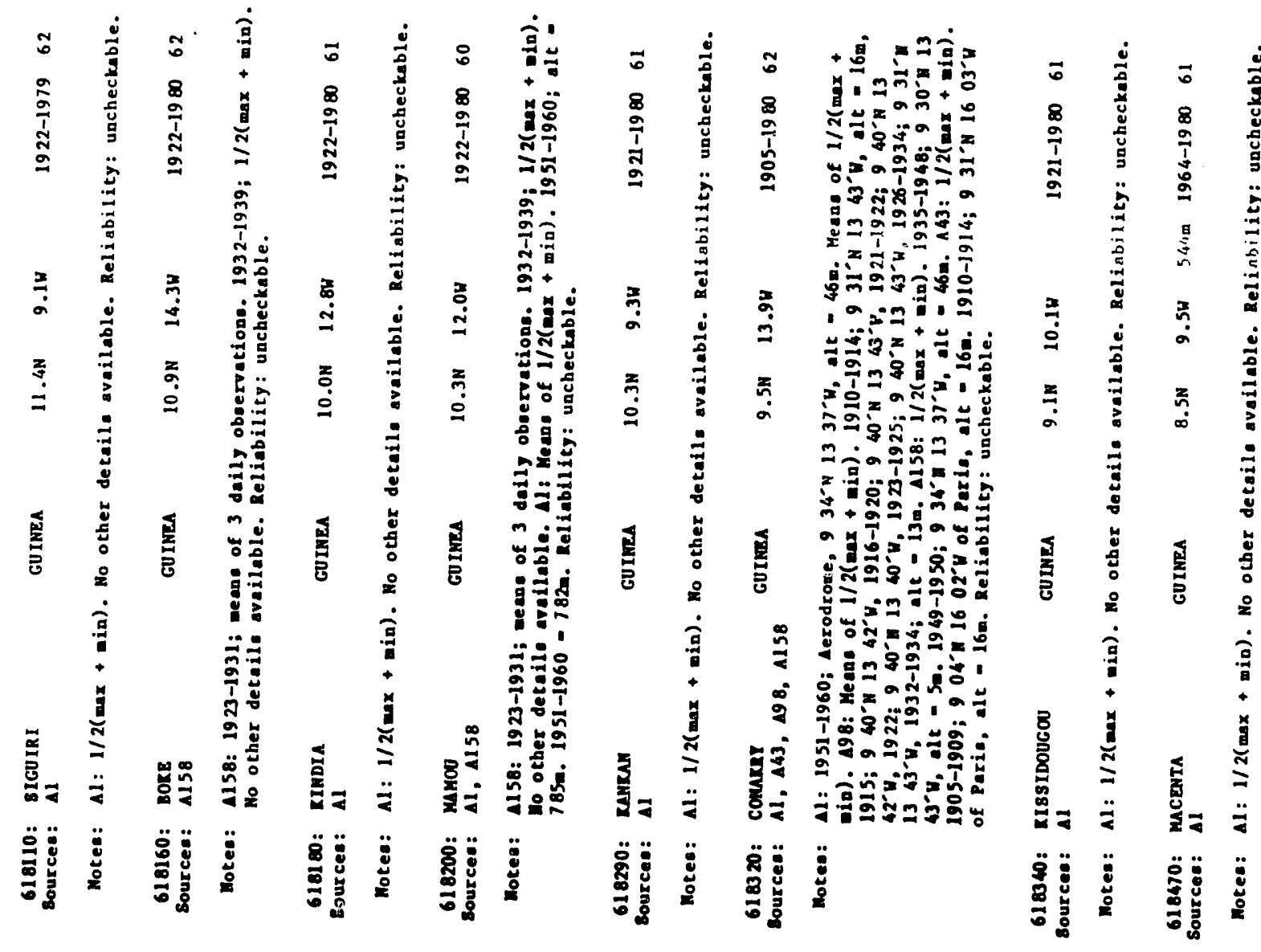

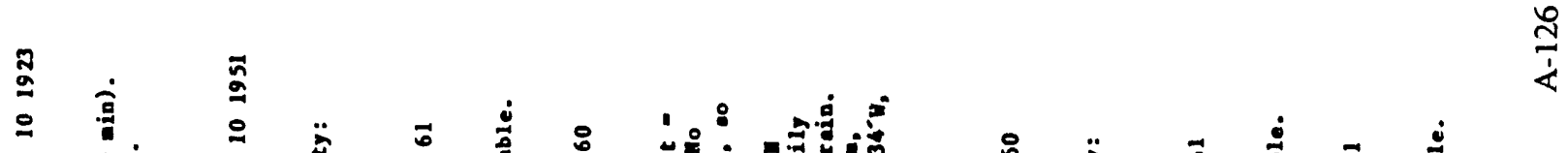

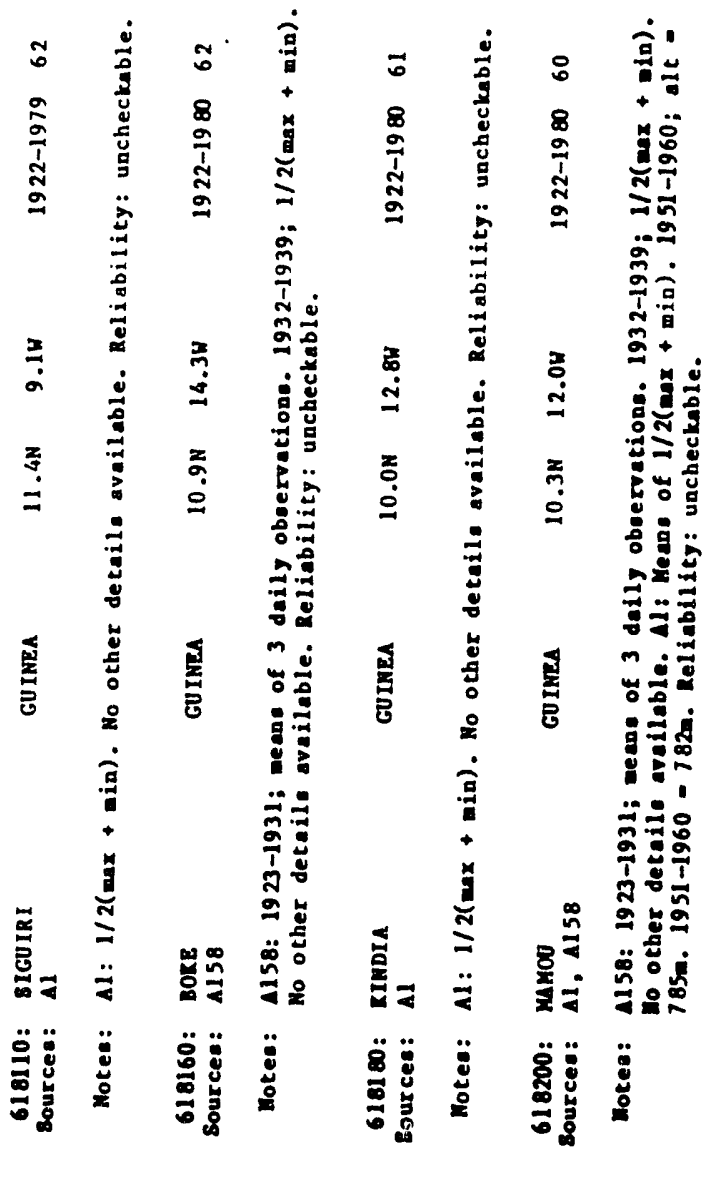

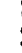

.

ก

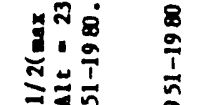

चี

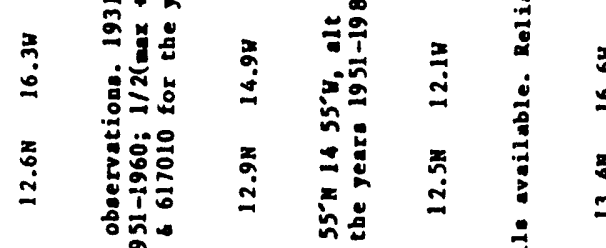

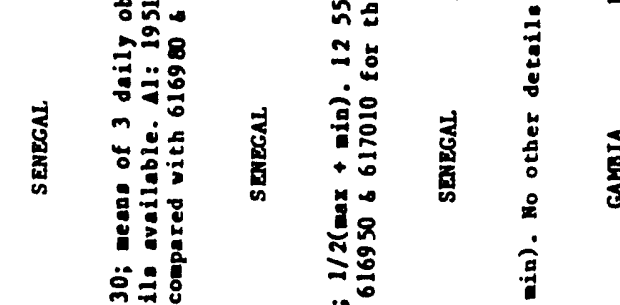

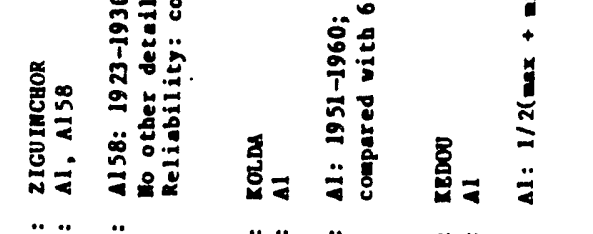

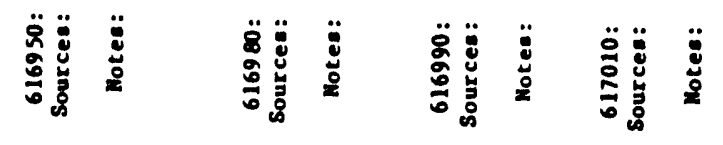

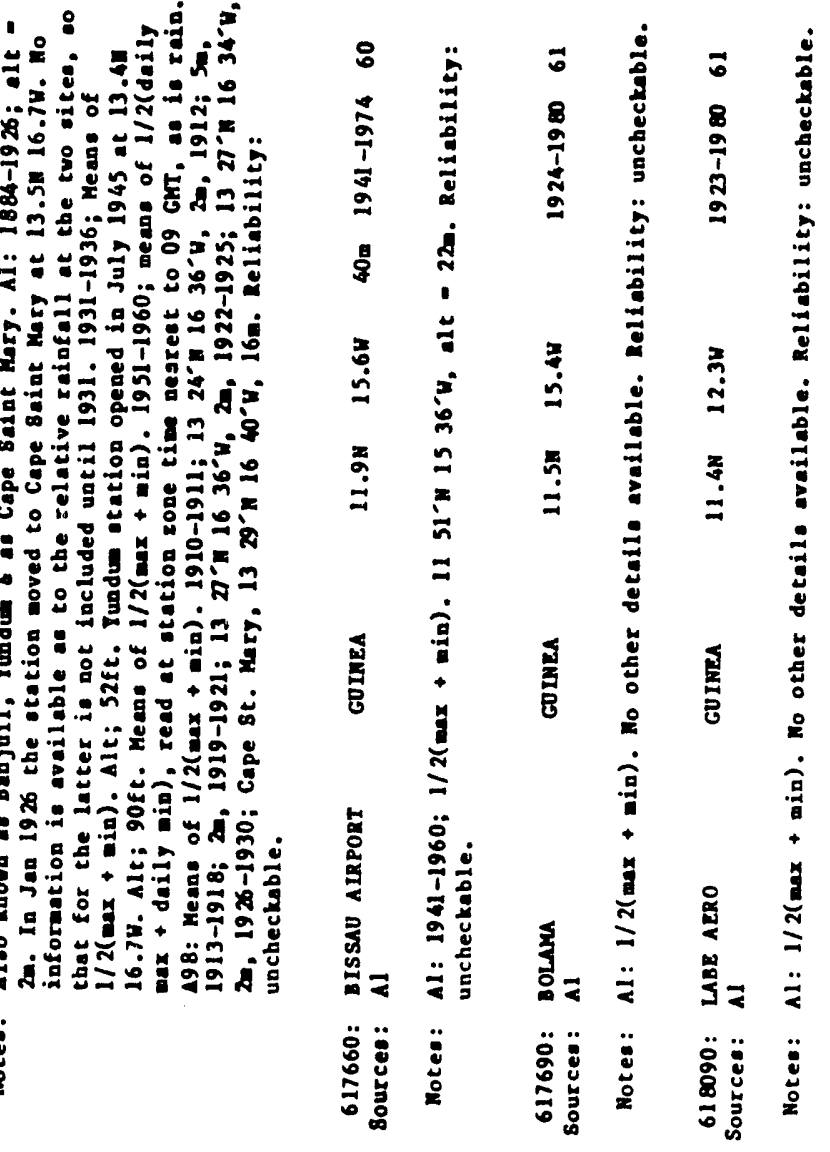




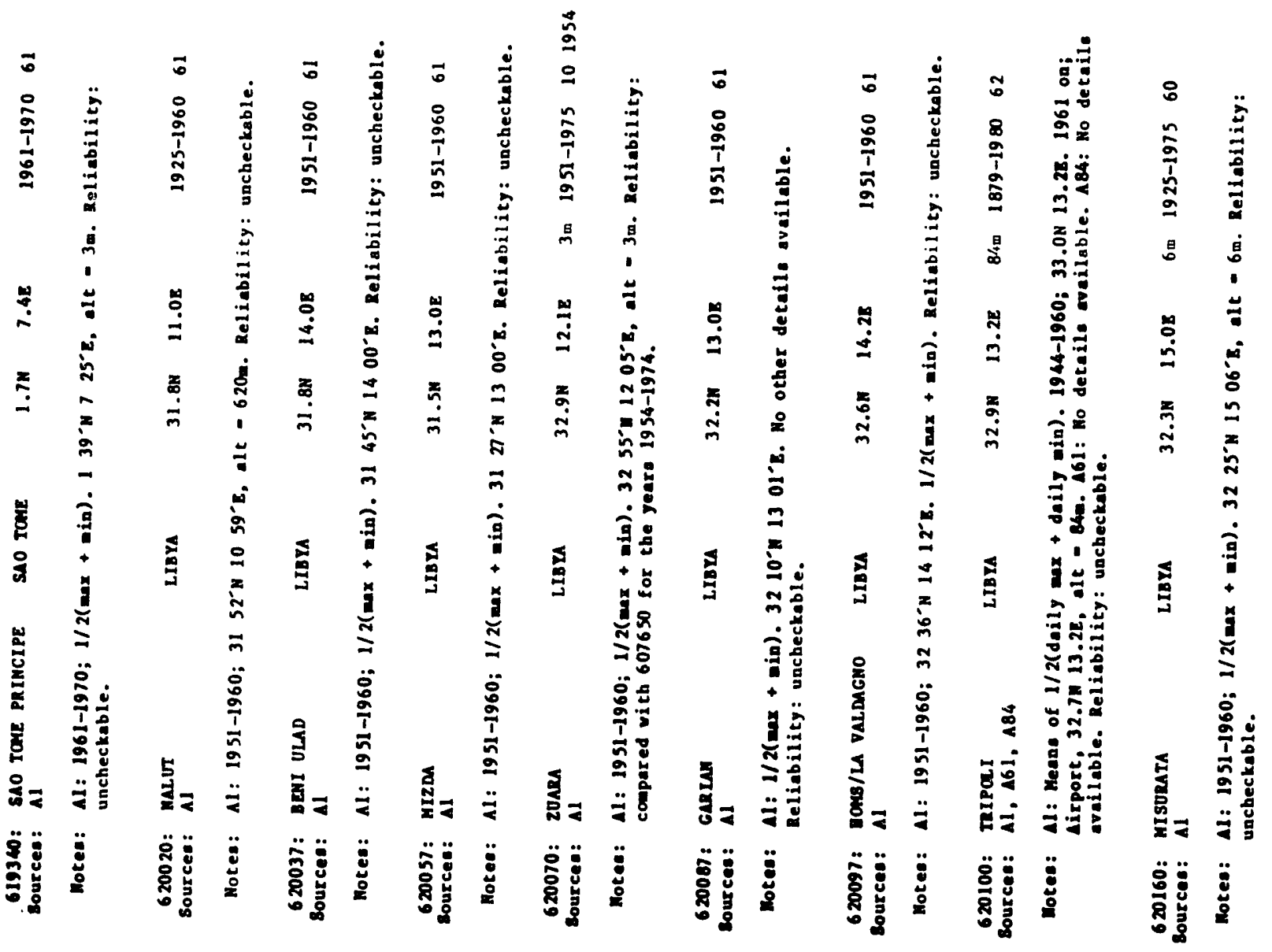

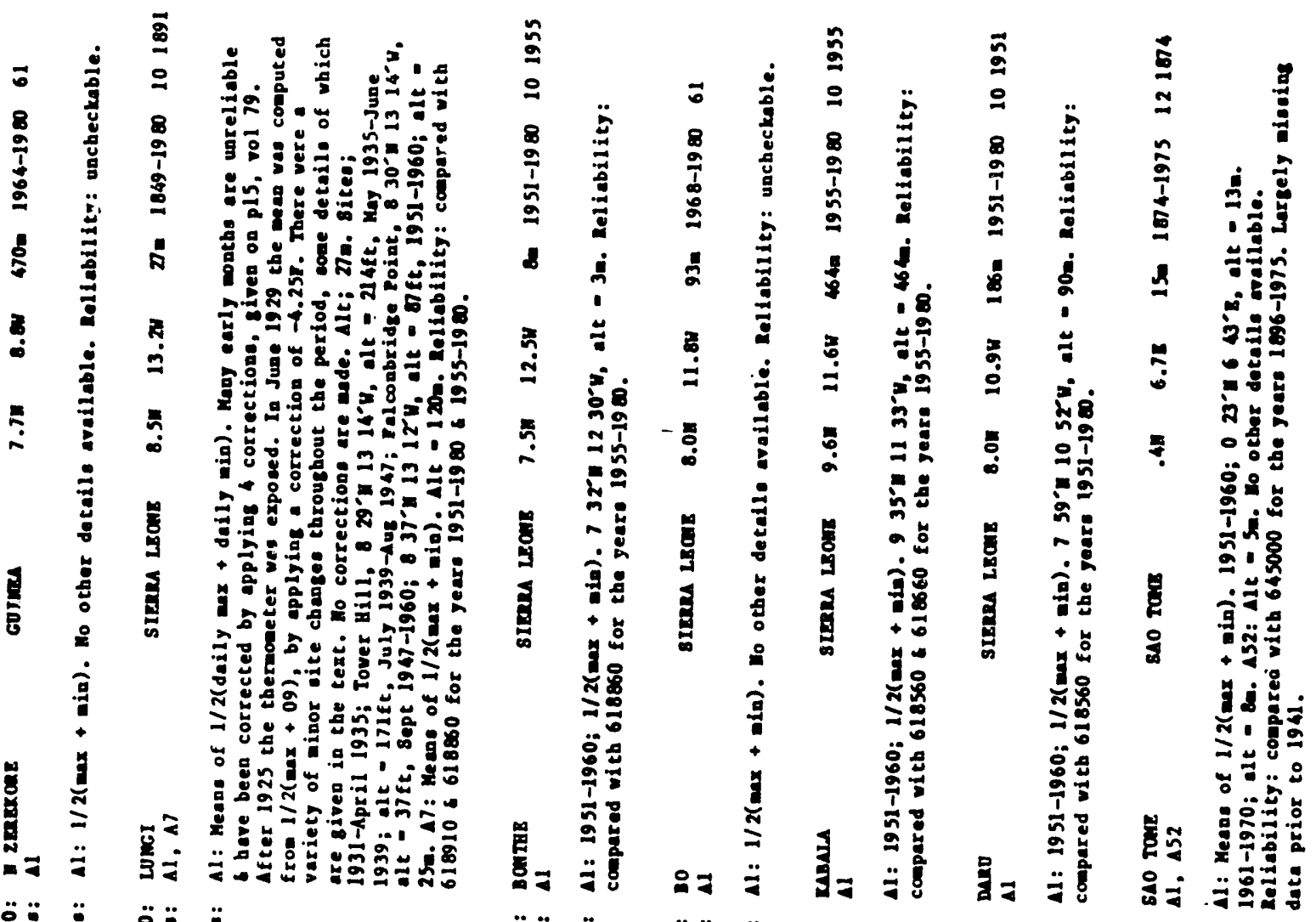

गิ जी 
管

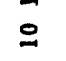

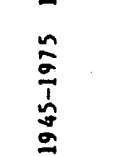

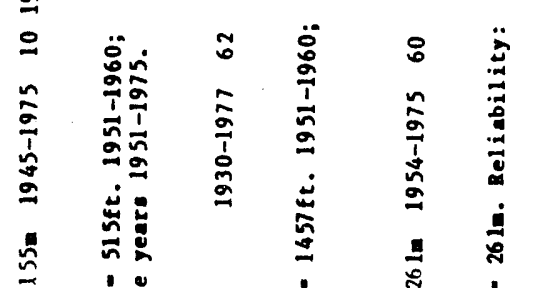

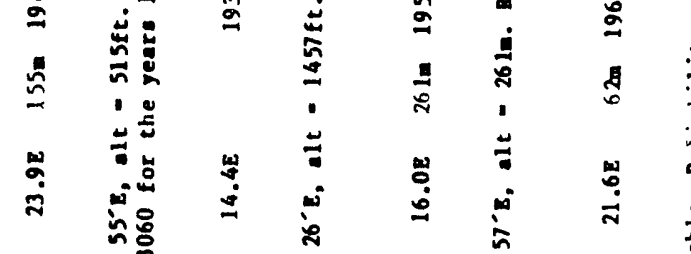

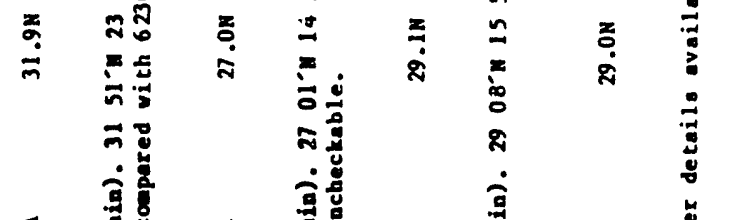

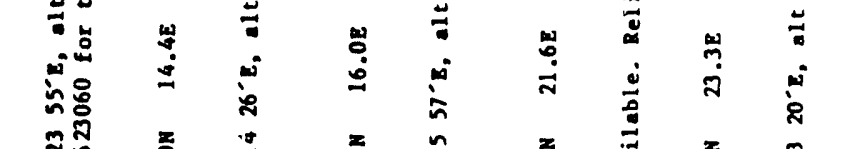

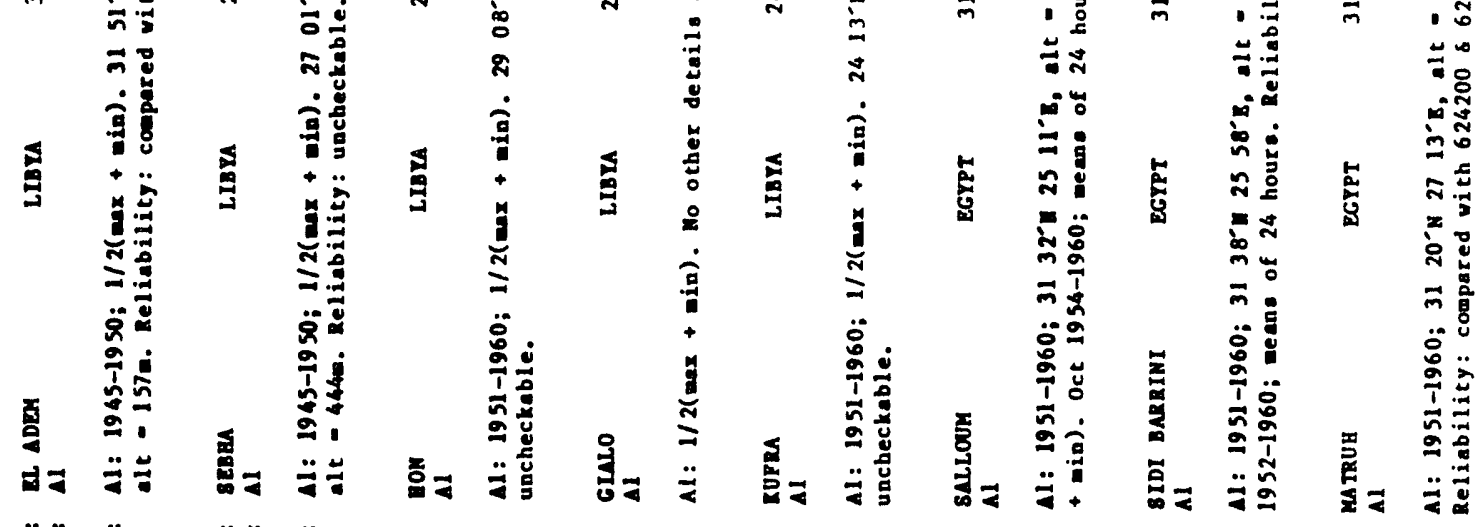
ป1

$\frac{\infty}{\frac{1}{4}}$

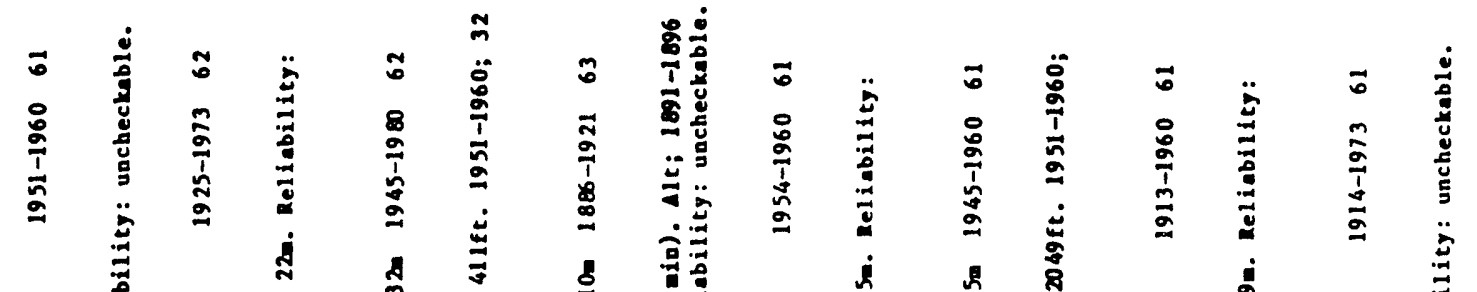

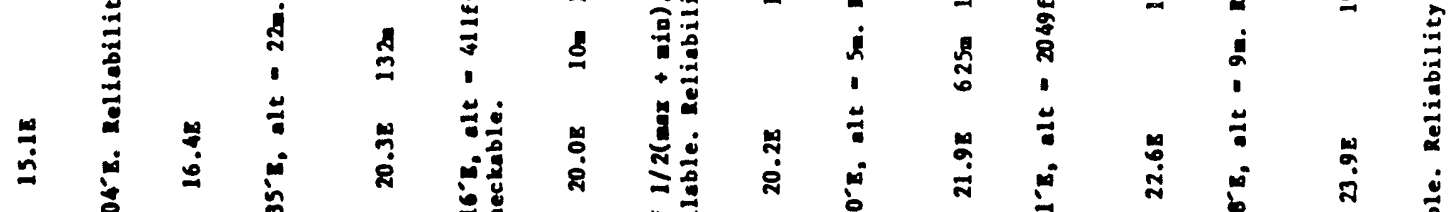

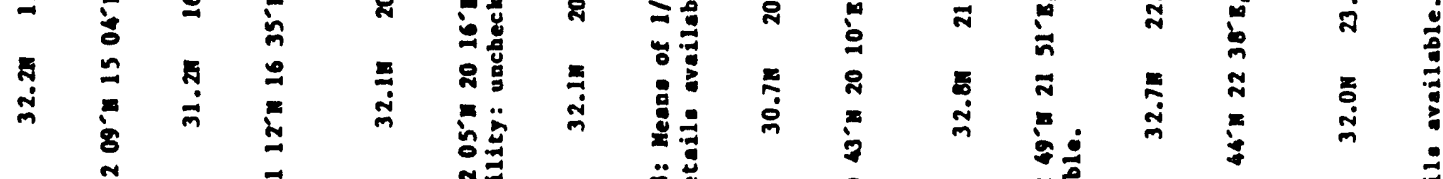

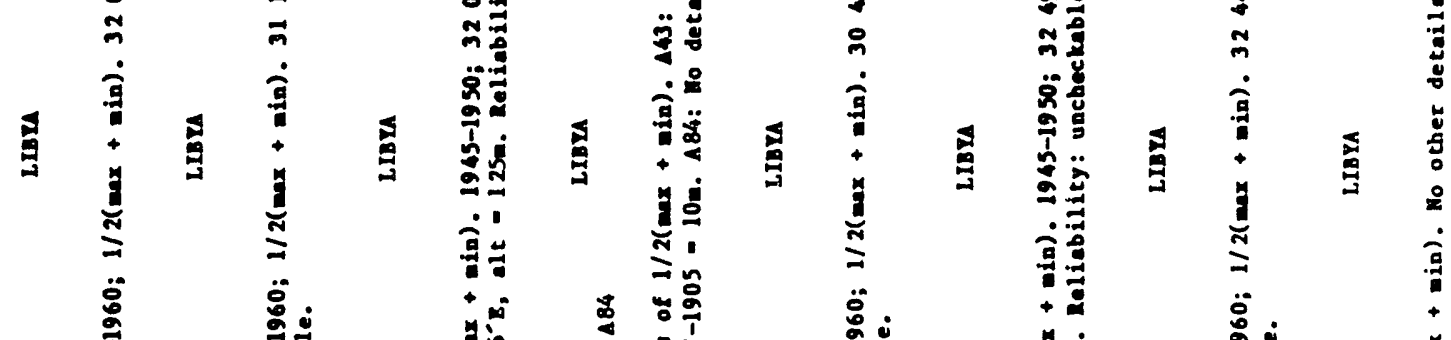

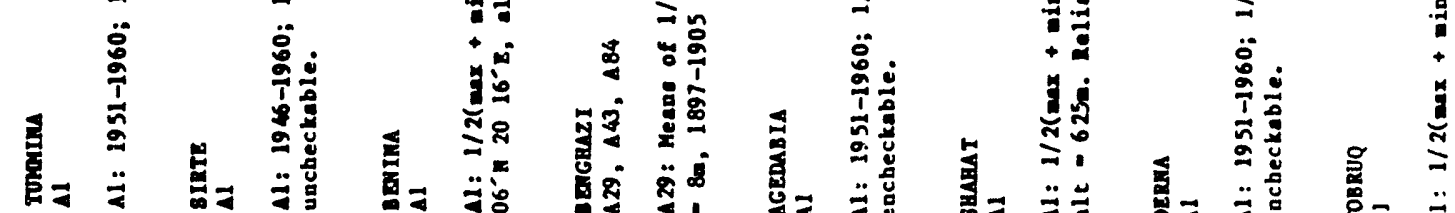

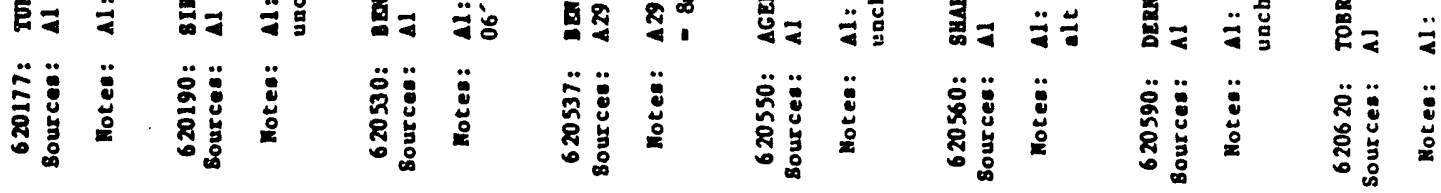


$\Phi$

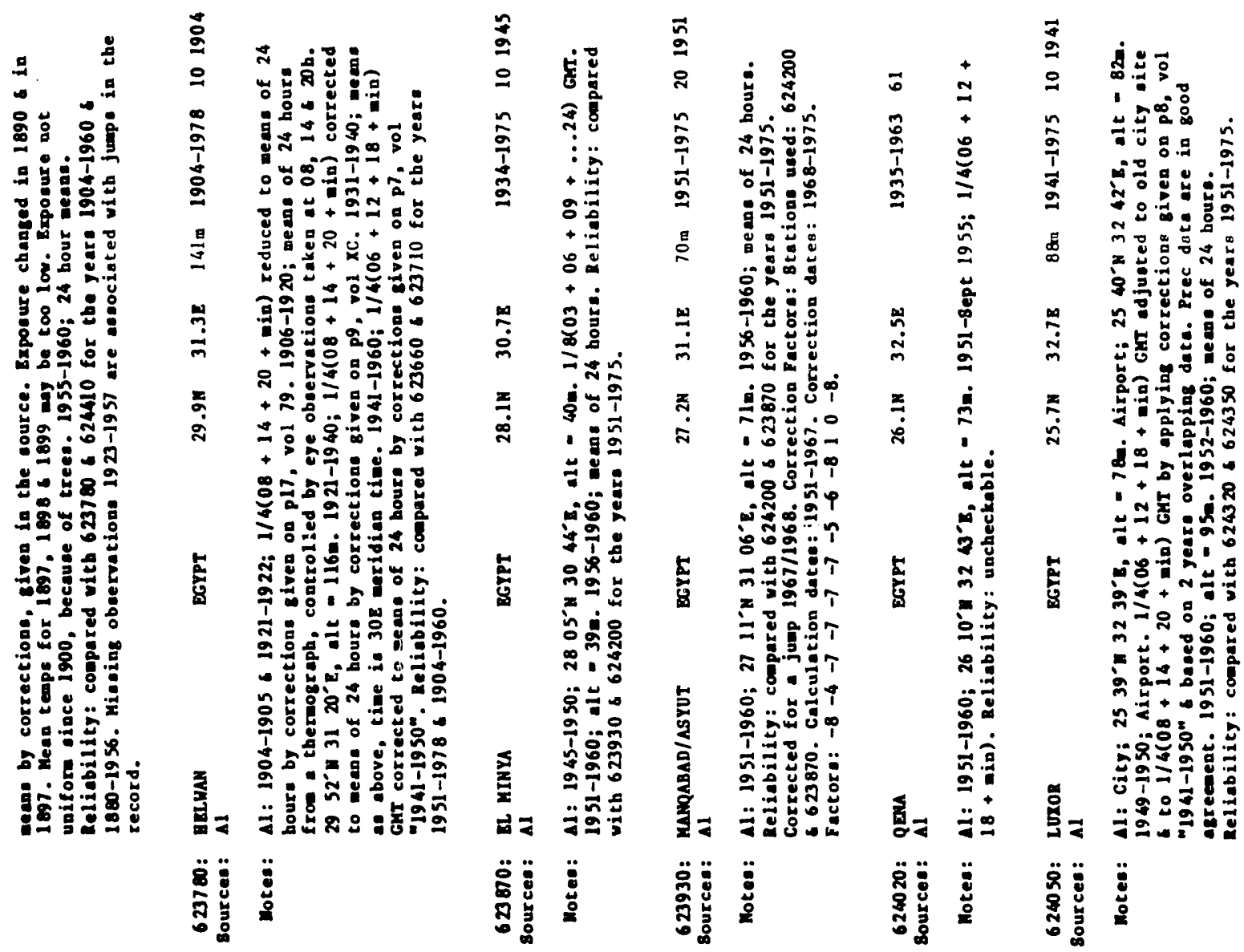

$\frac{2}{4}$

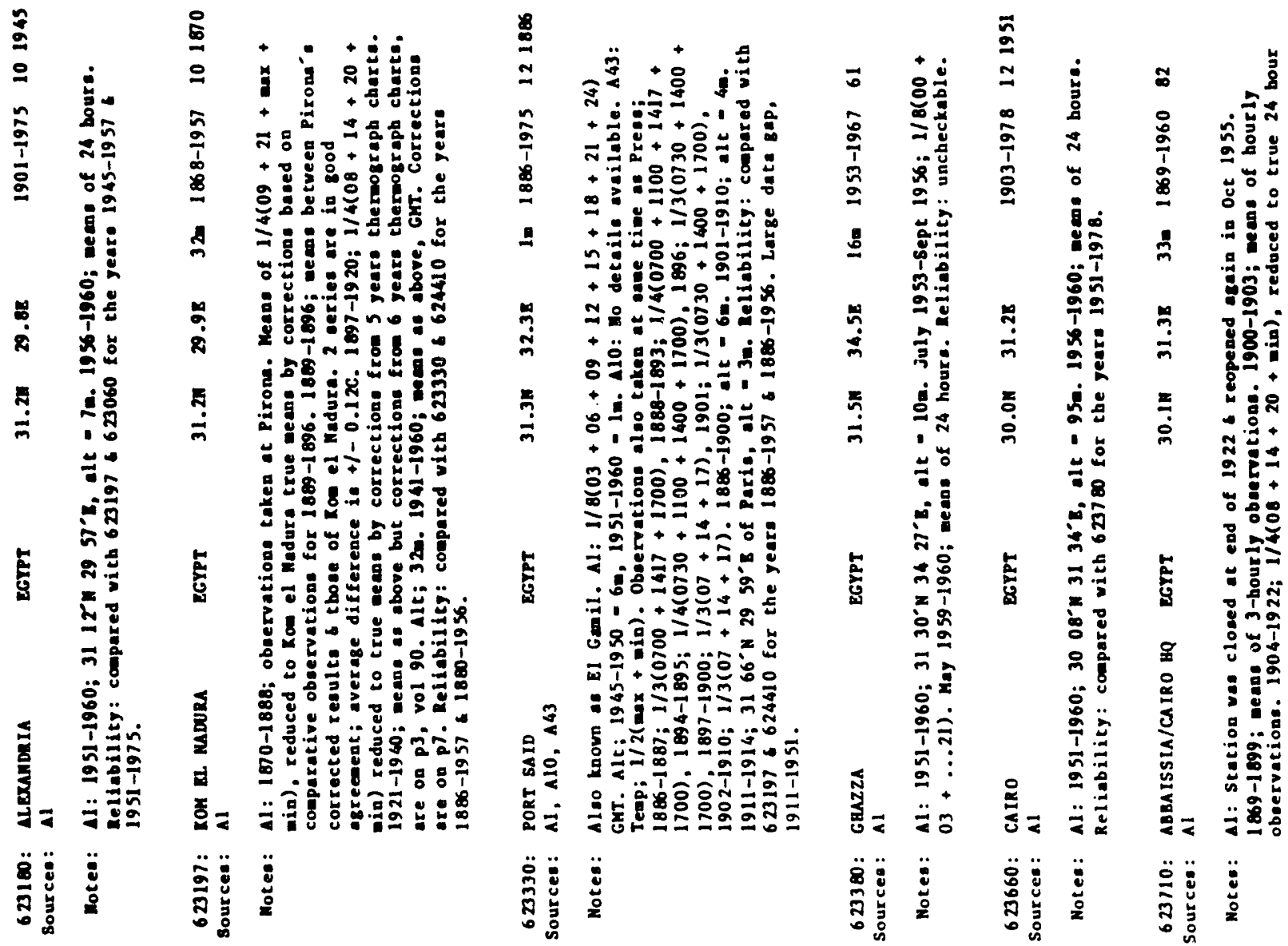



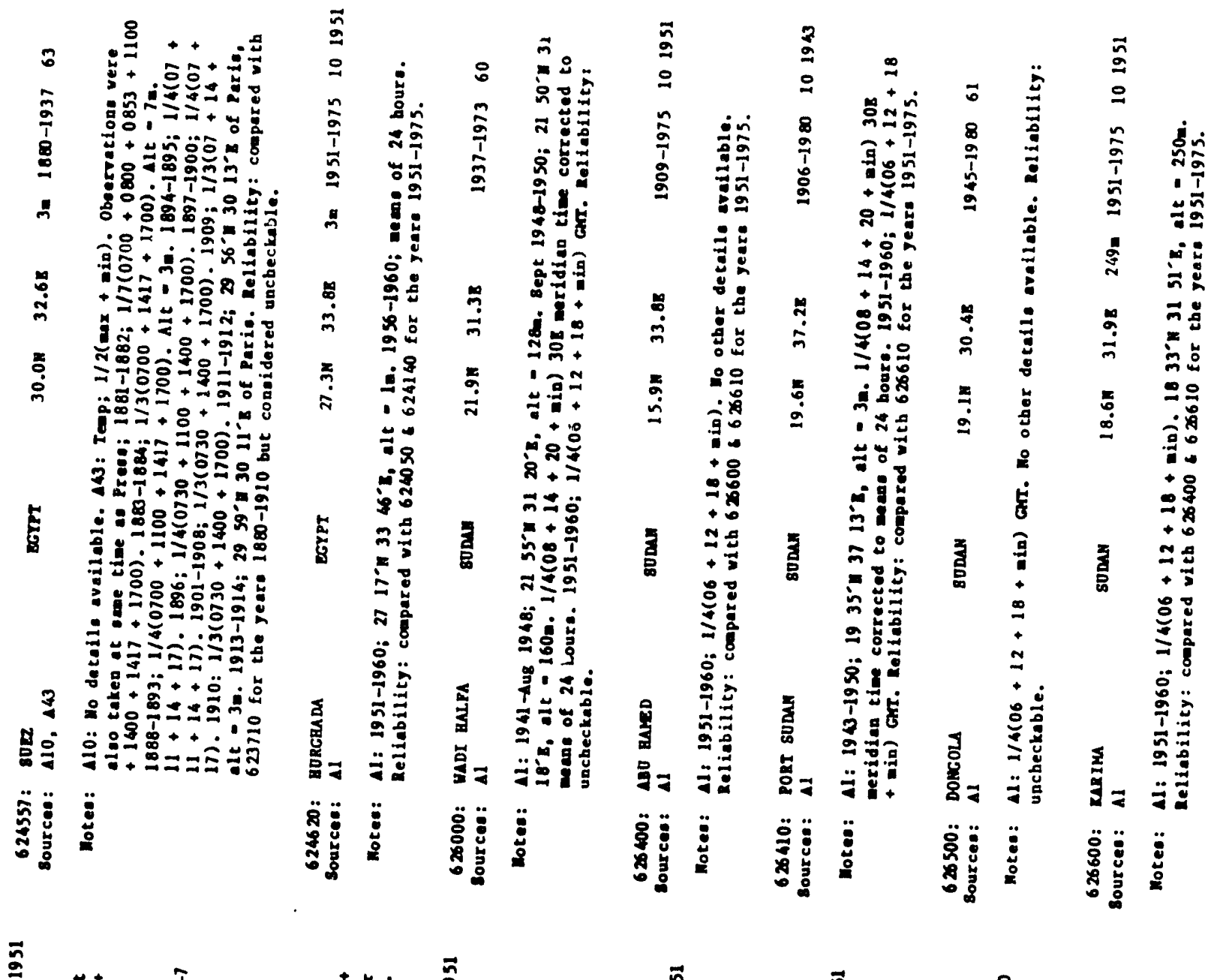

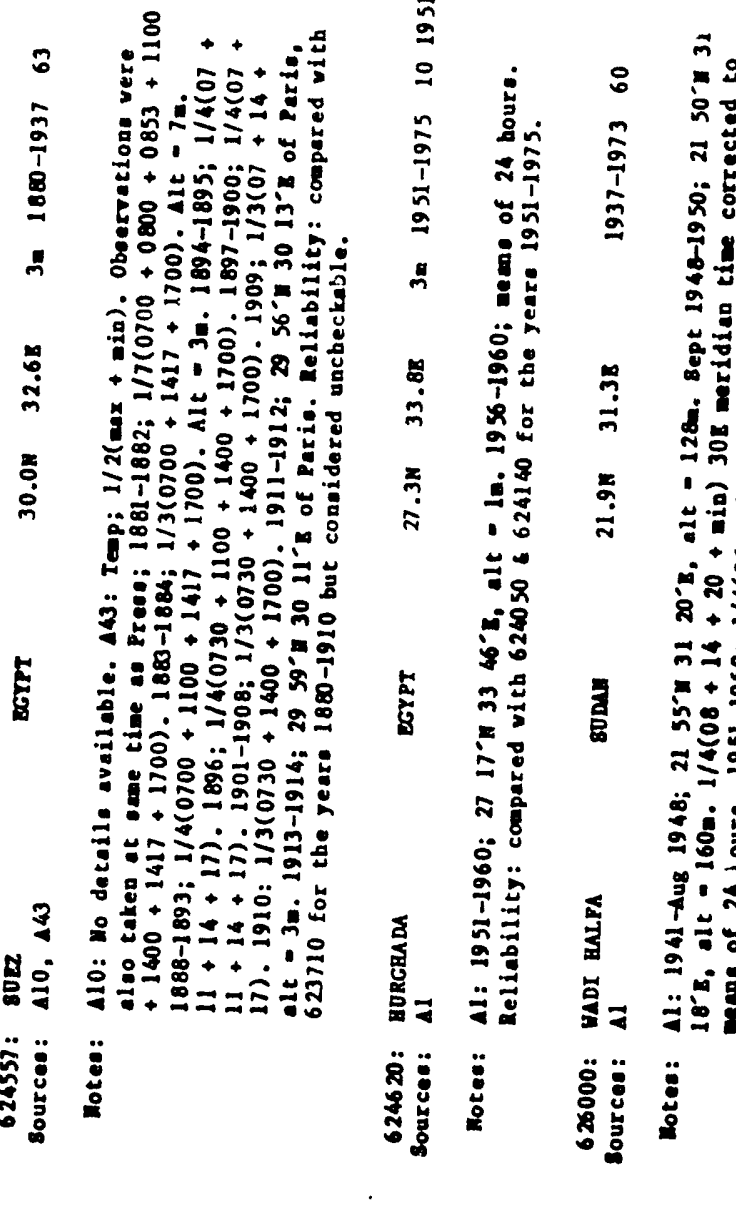

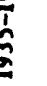

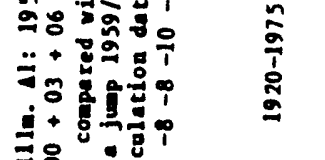

茫菏

艺范

ํํㅇํำ

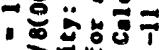

范

:

-

เ ㄷํㅇำ

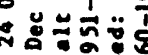

每

ล

ㄱํㅇ

용

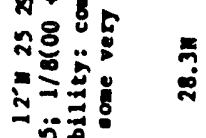

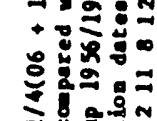

บำำ

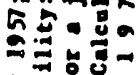

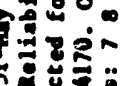

ลू.

ت

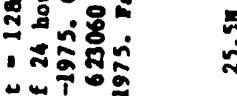

落

ลี

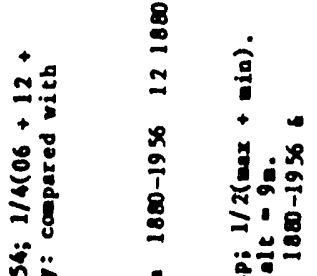

ำ

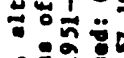

政

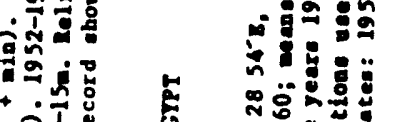

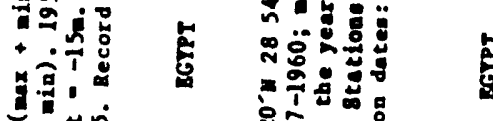

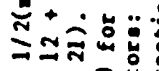

แ+十 +

$\underset{2}{*}+\frac{\pi}{1}$

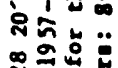

ลิ

प.

ำ 은

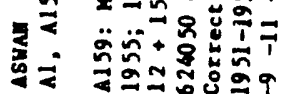

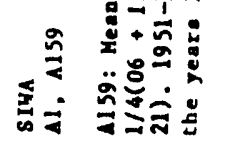

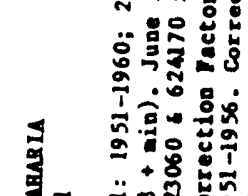

葛

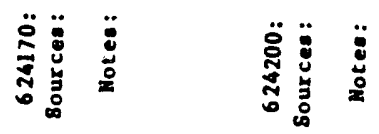

हो

影

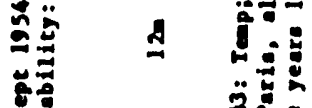

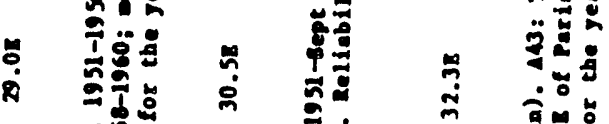

บ

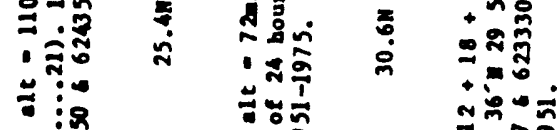

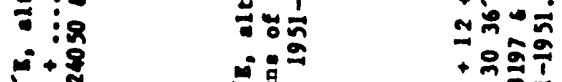

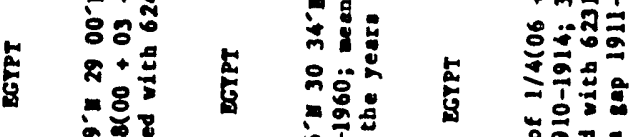

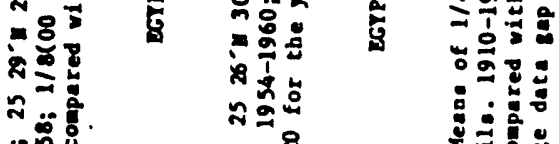

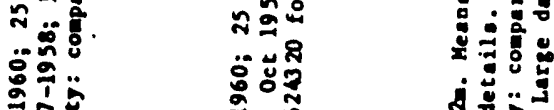

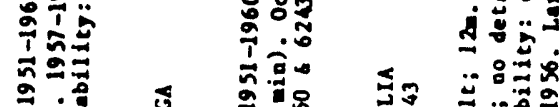

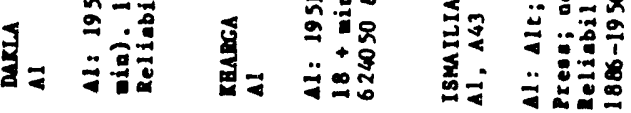




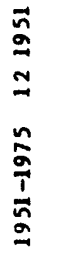

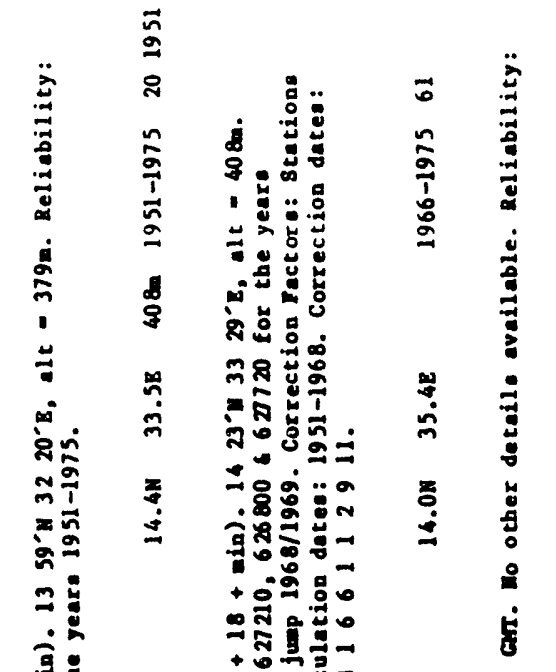

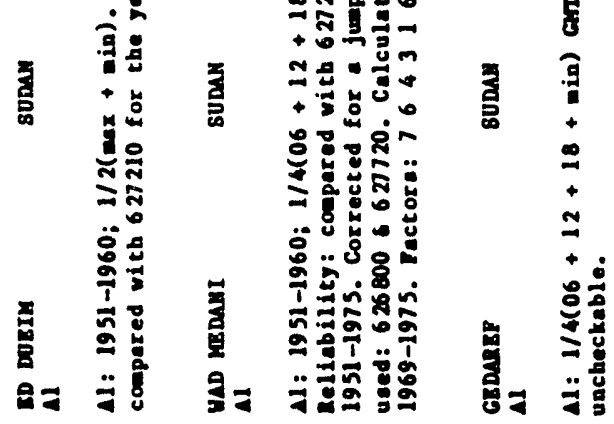

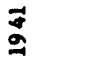

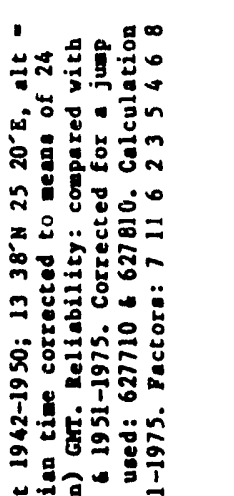

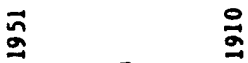

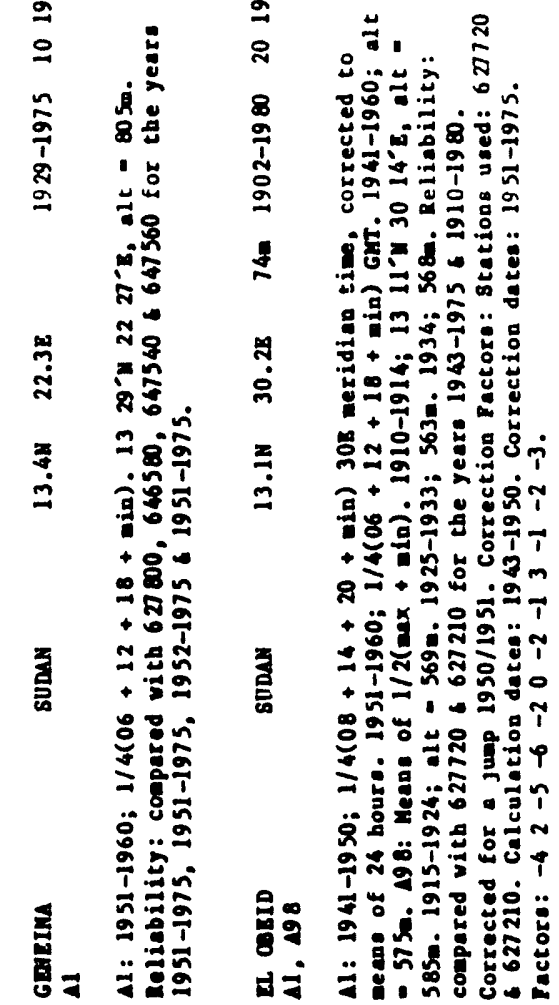

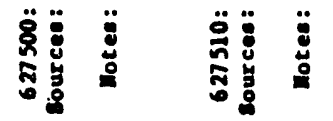

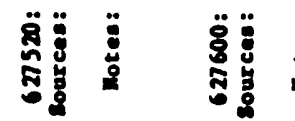

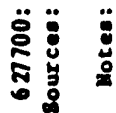

草范

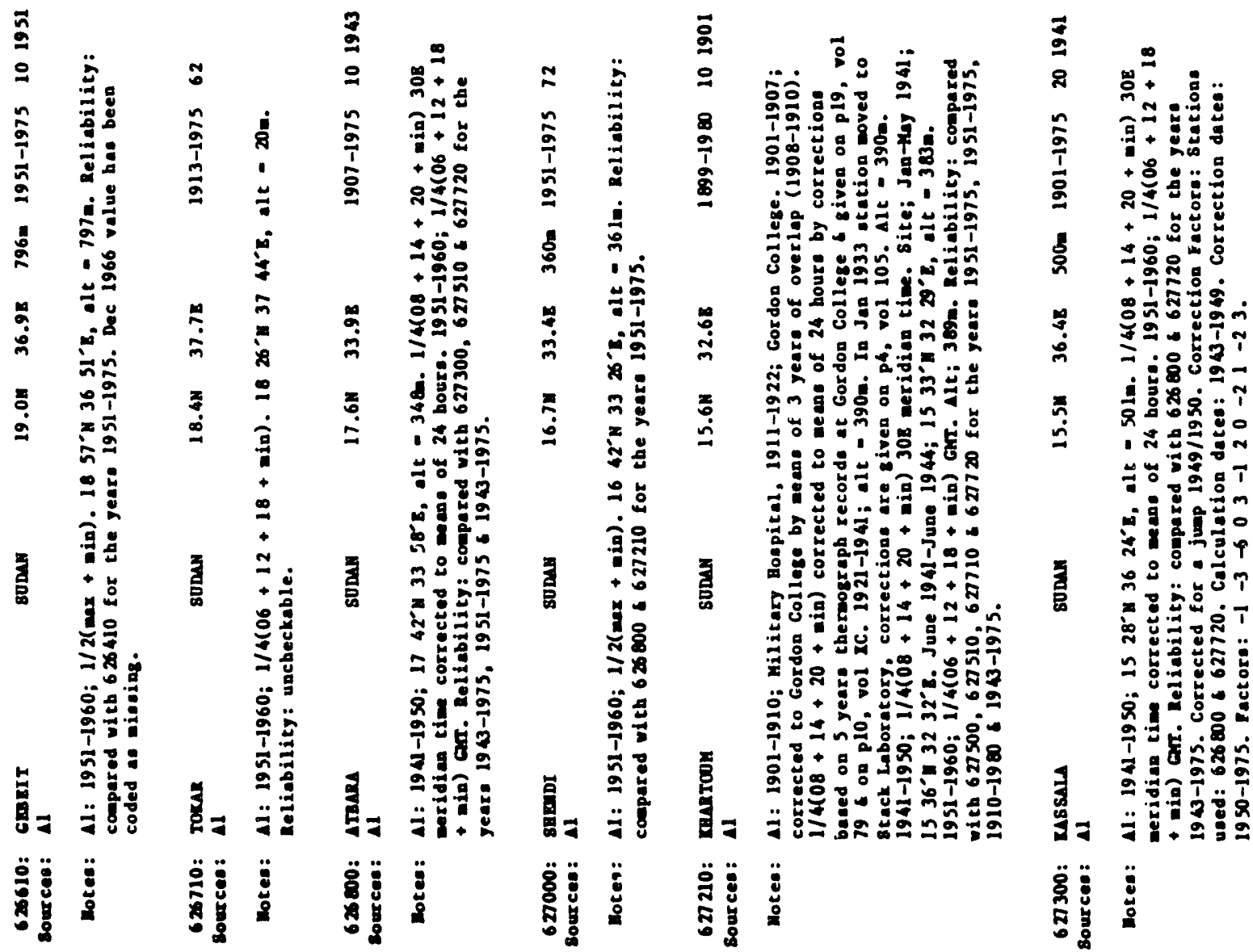




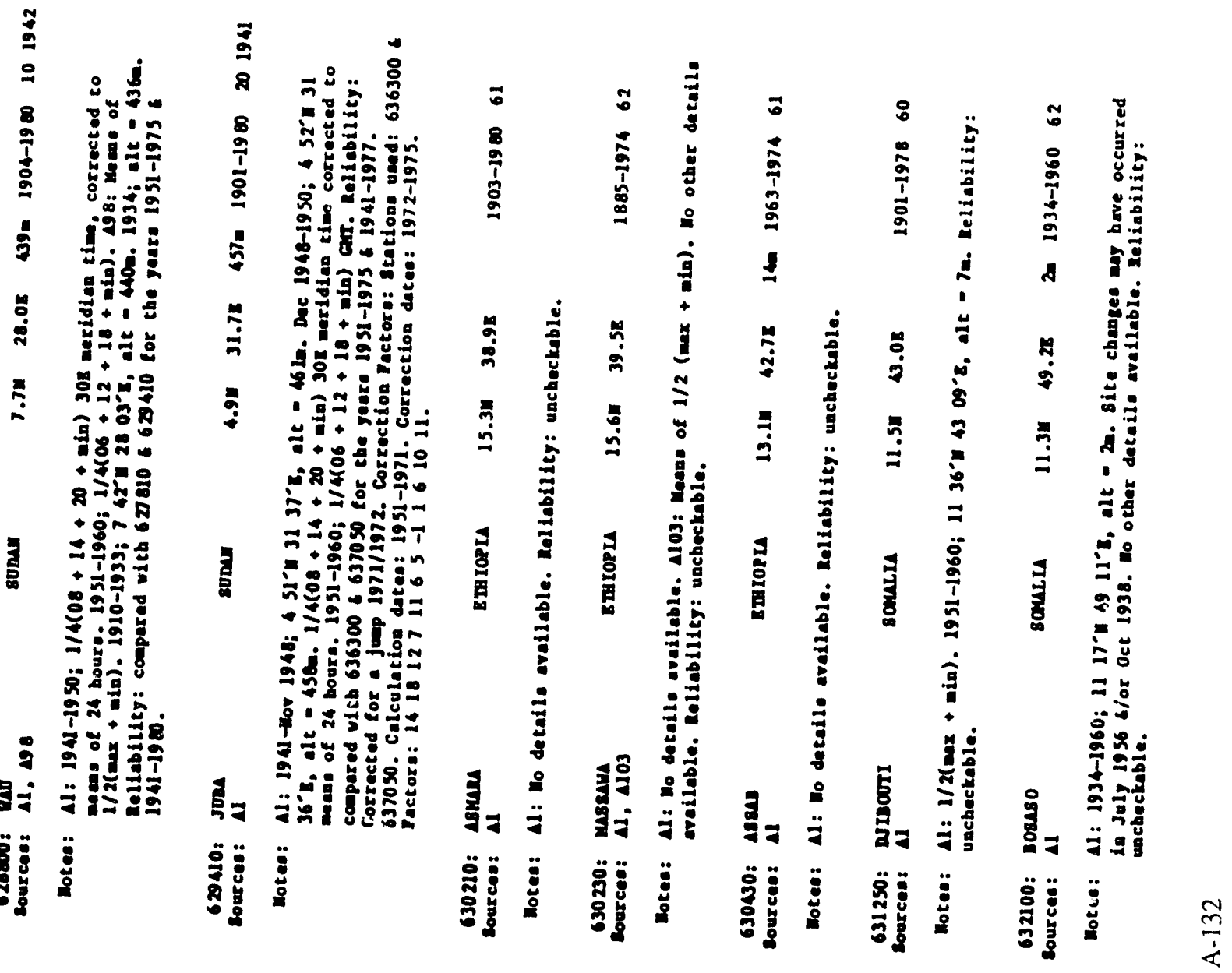

r

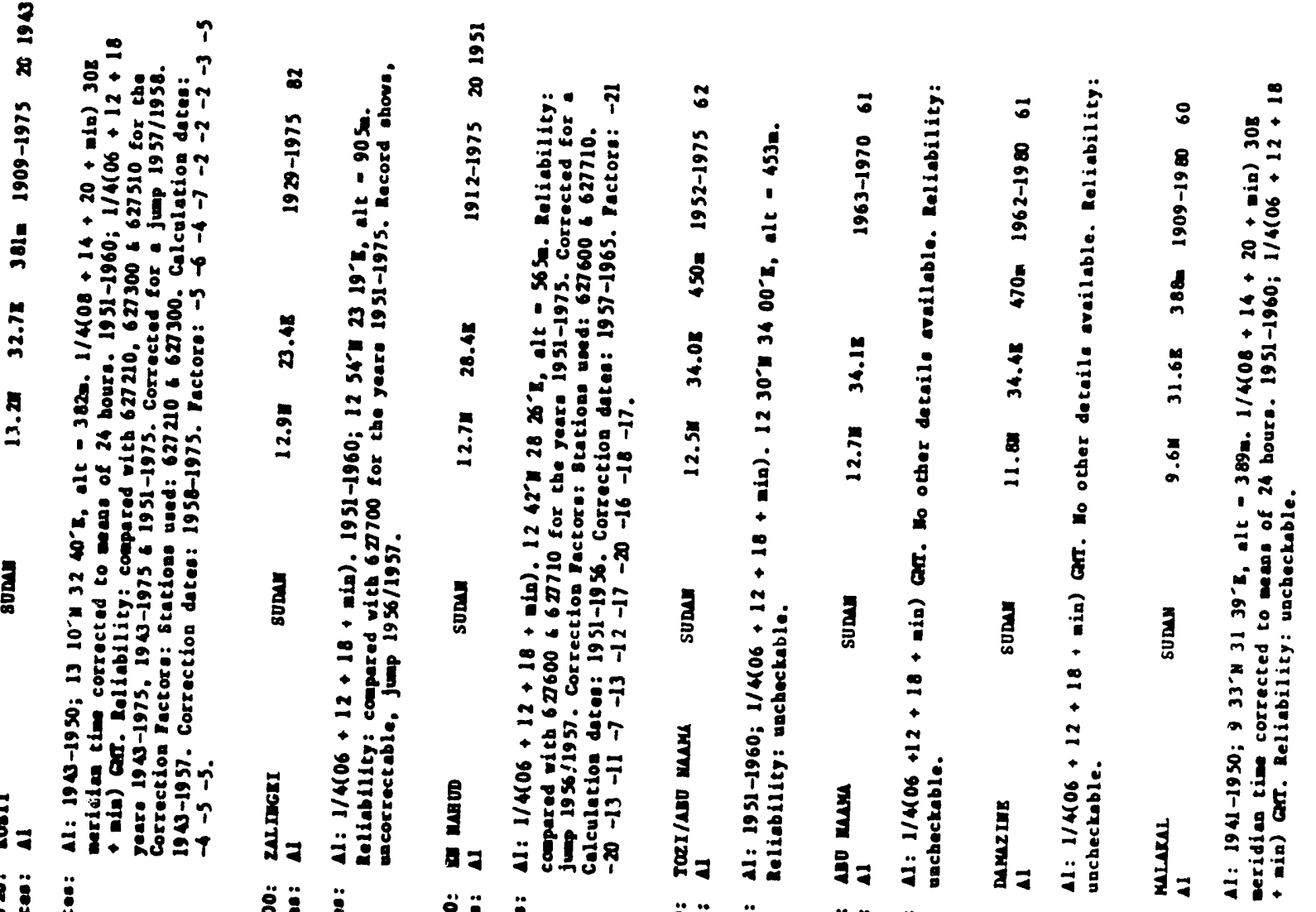

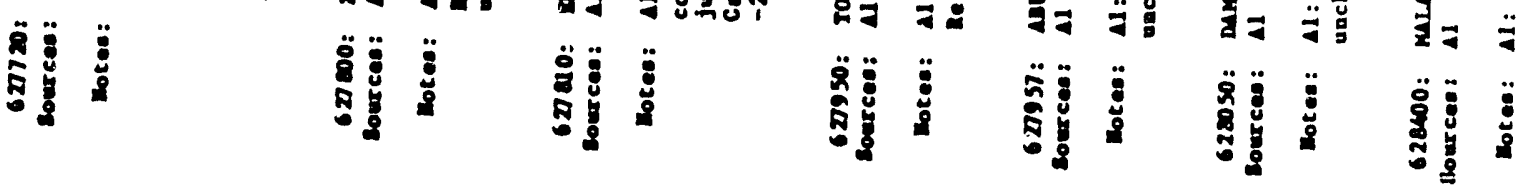




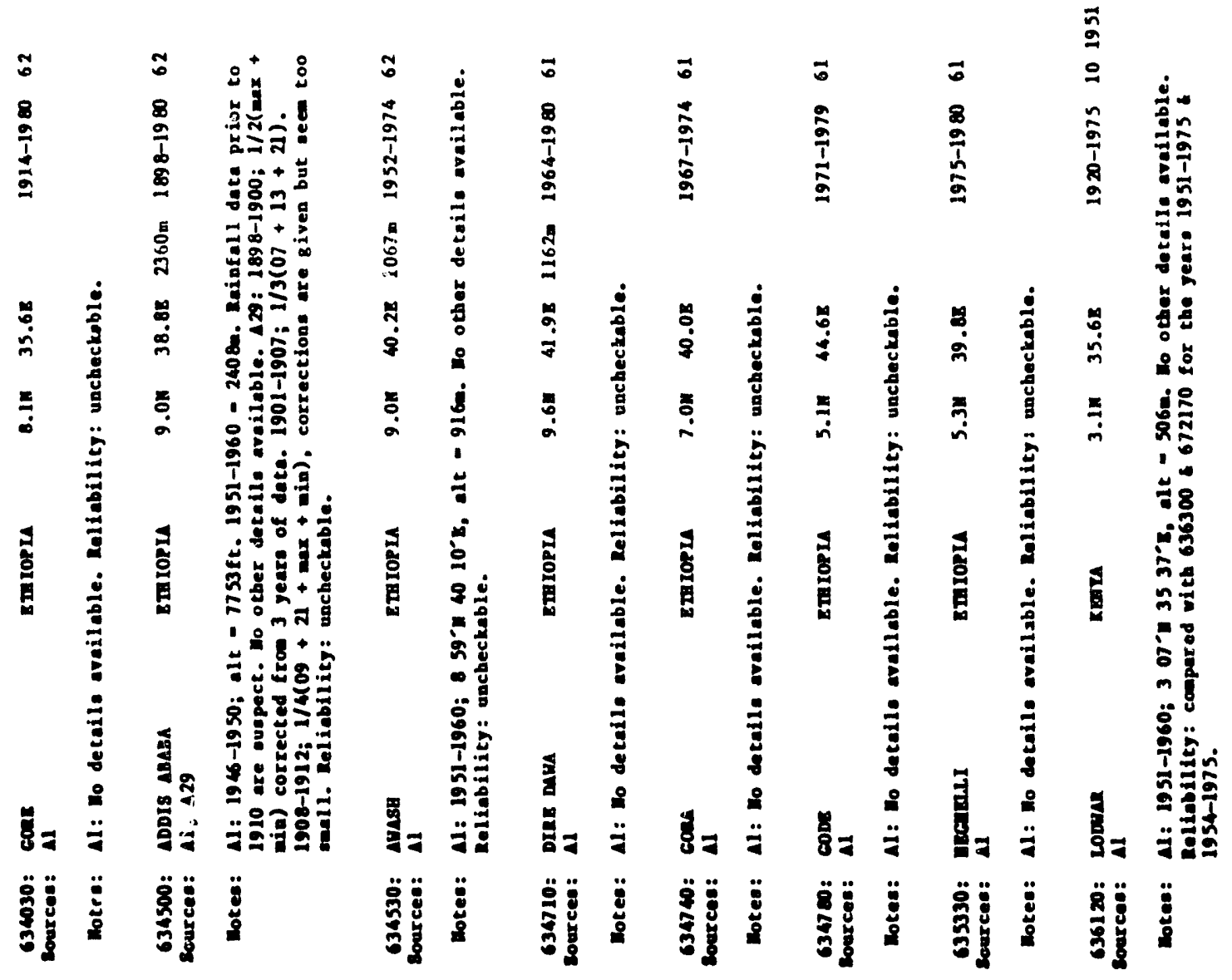

$\frac{m}{\dot{m}}$

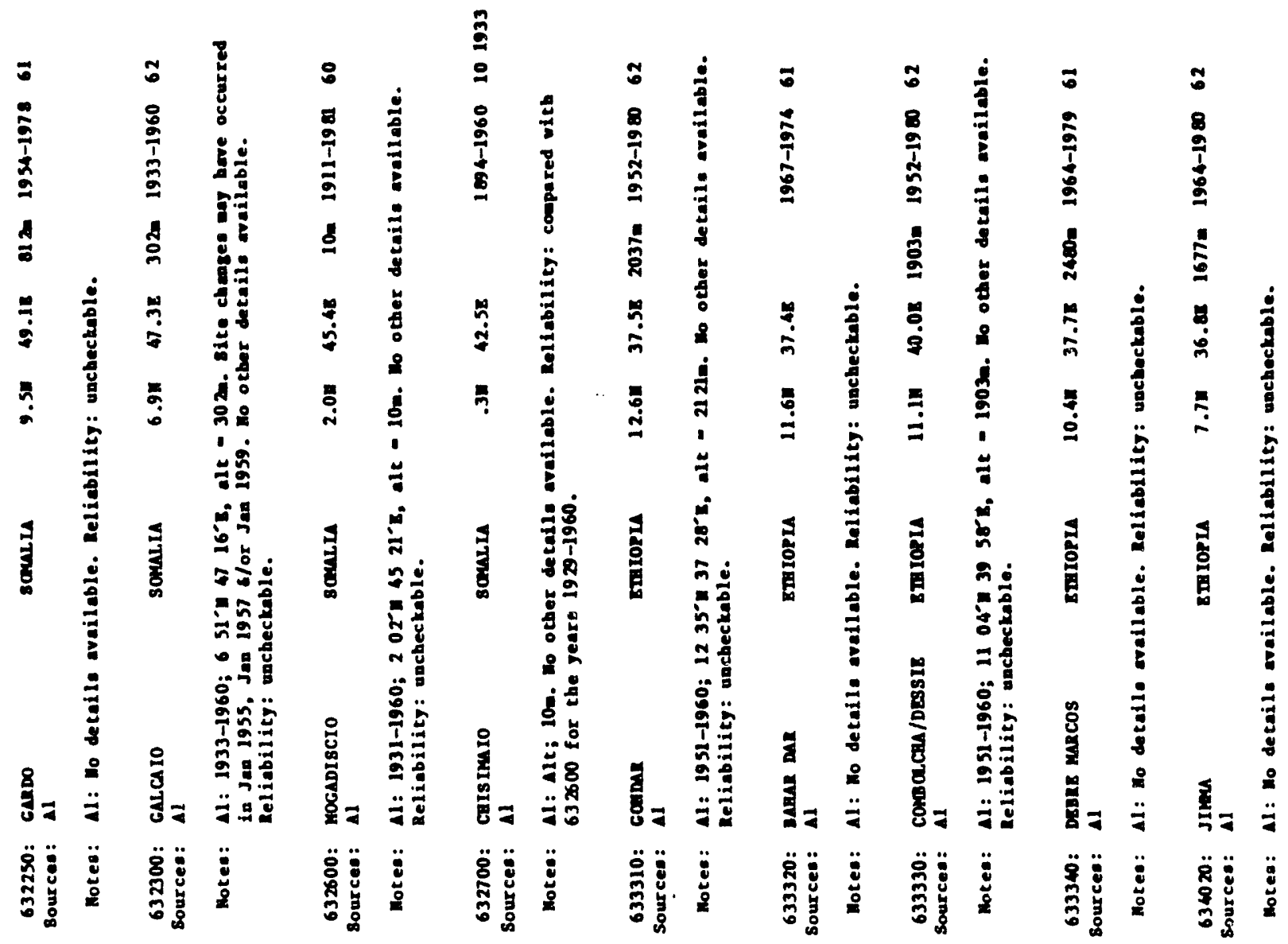



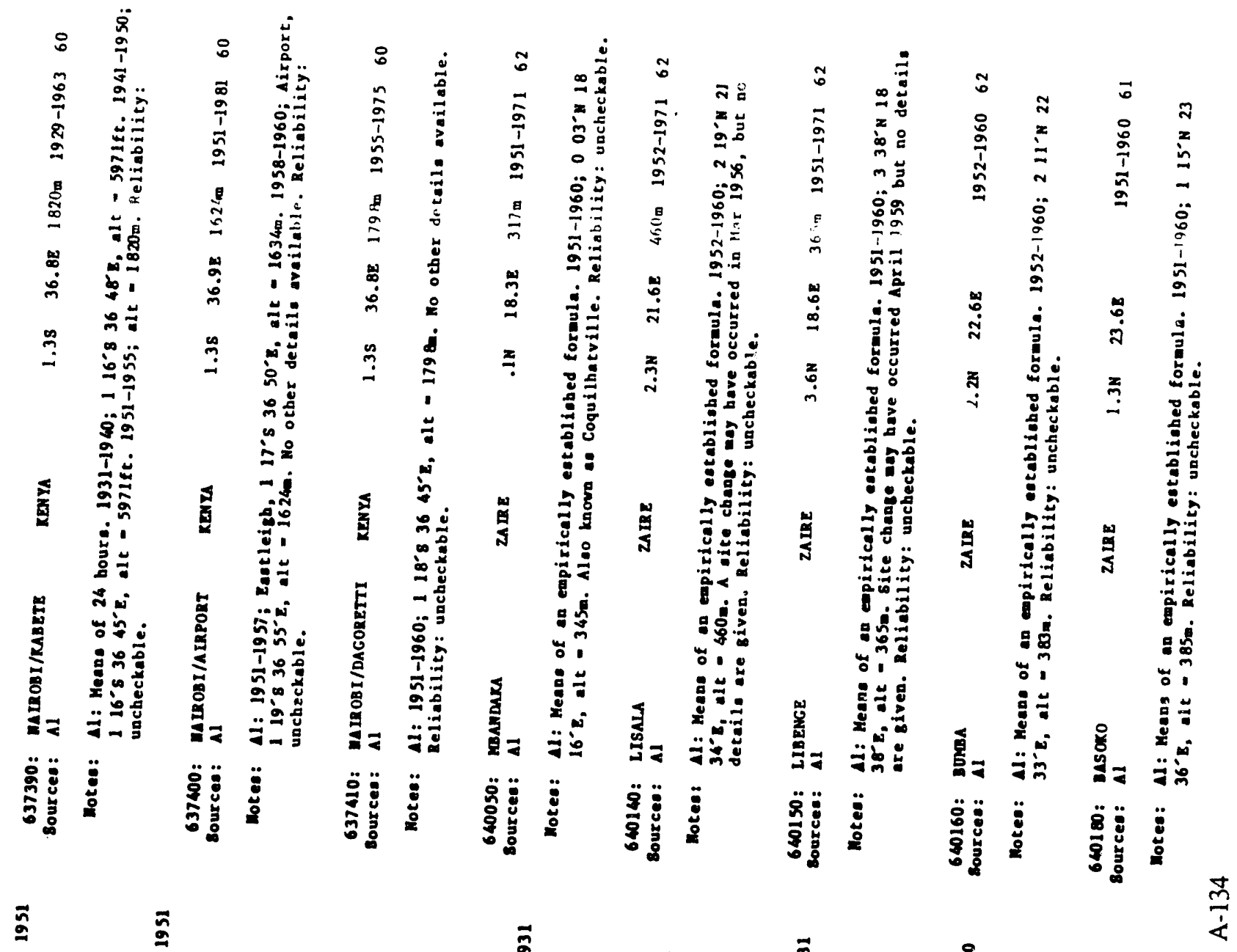

西

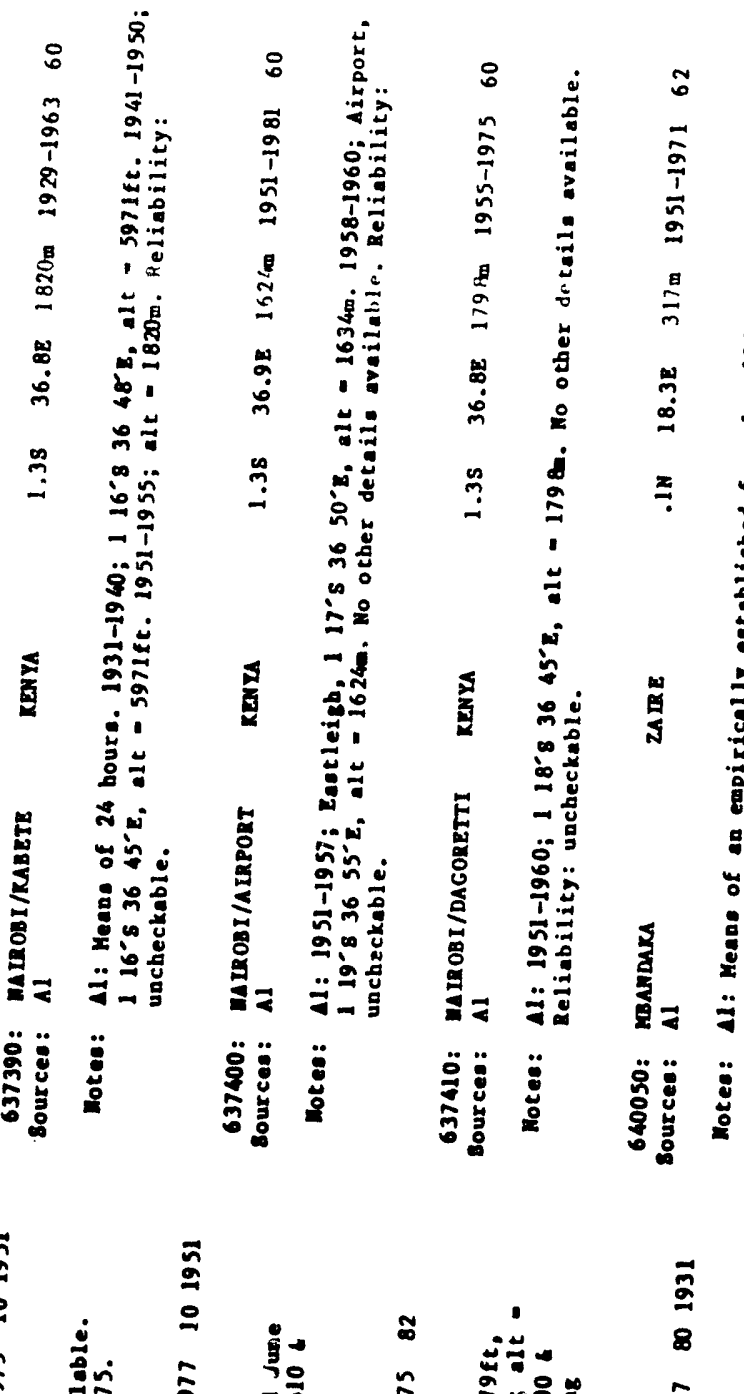

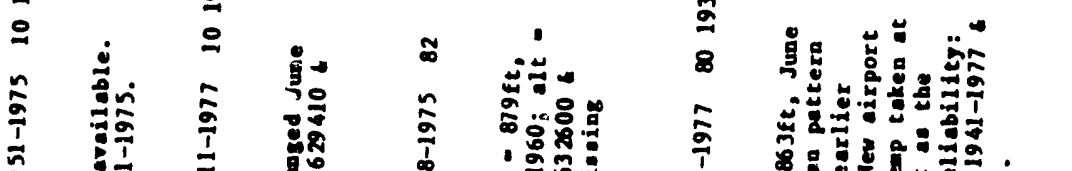

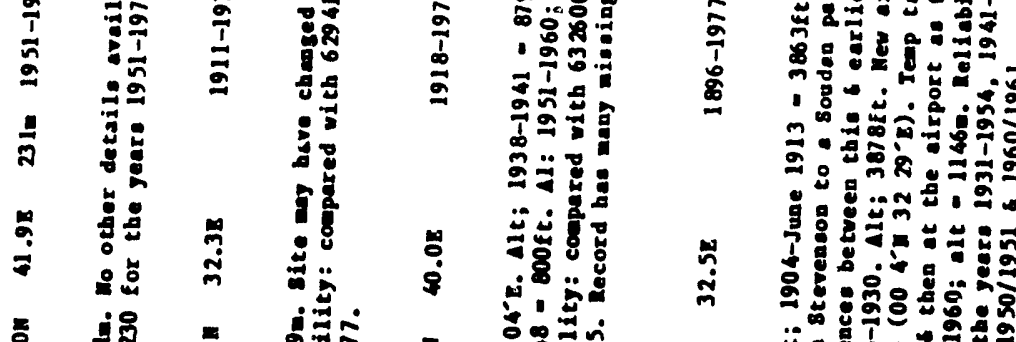

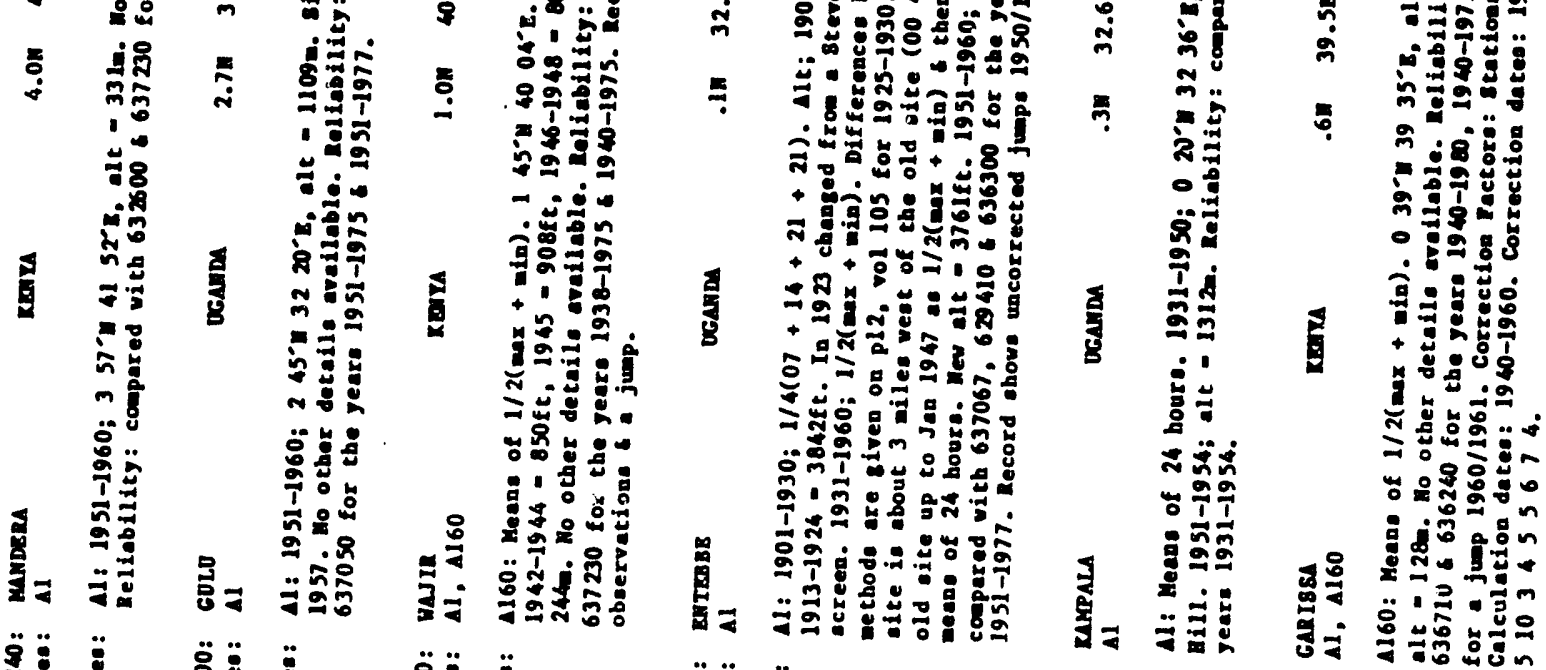

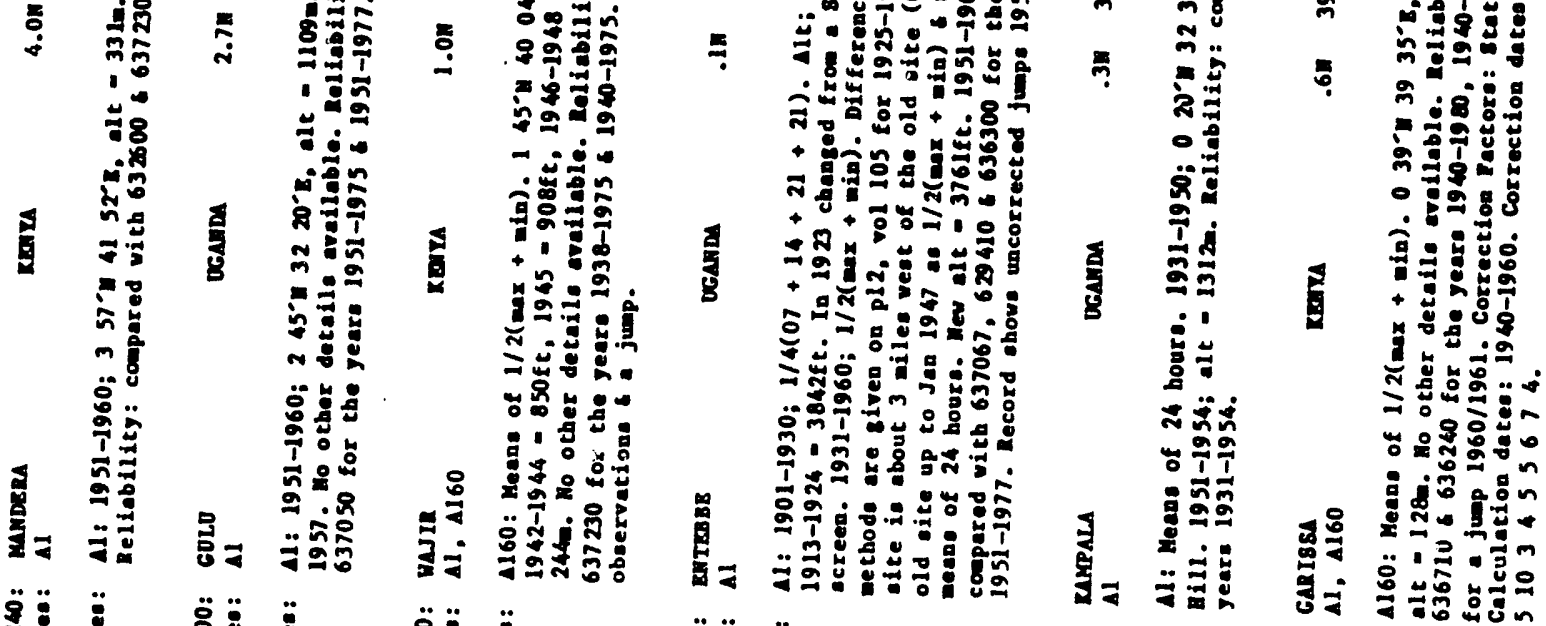
ป็ 敬 

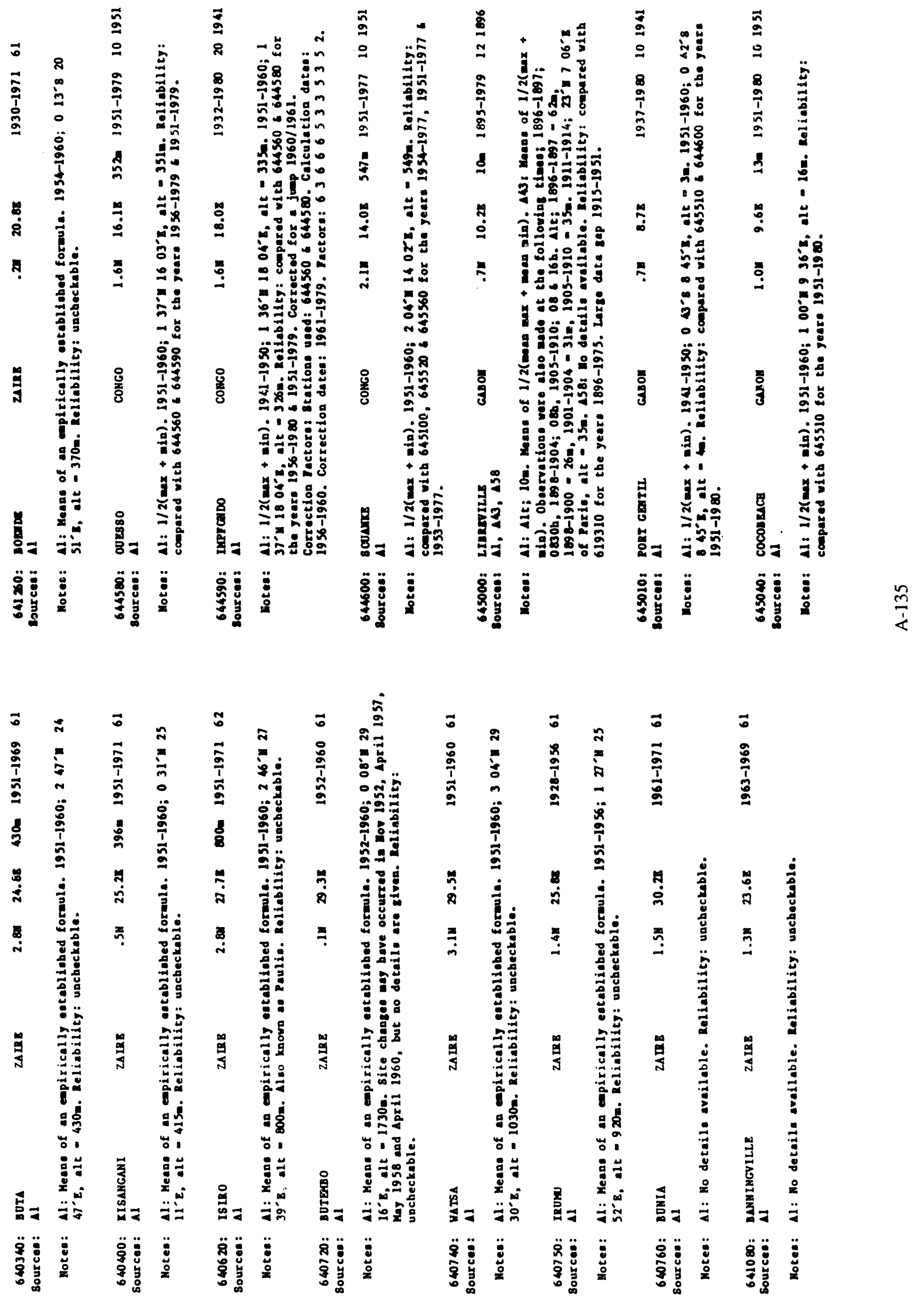

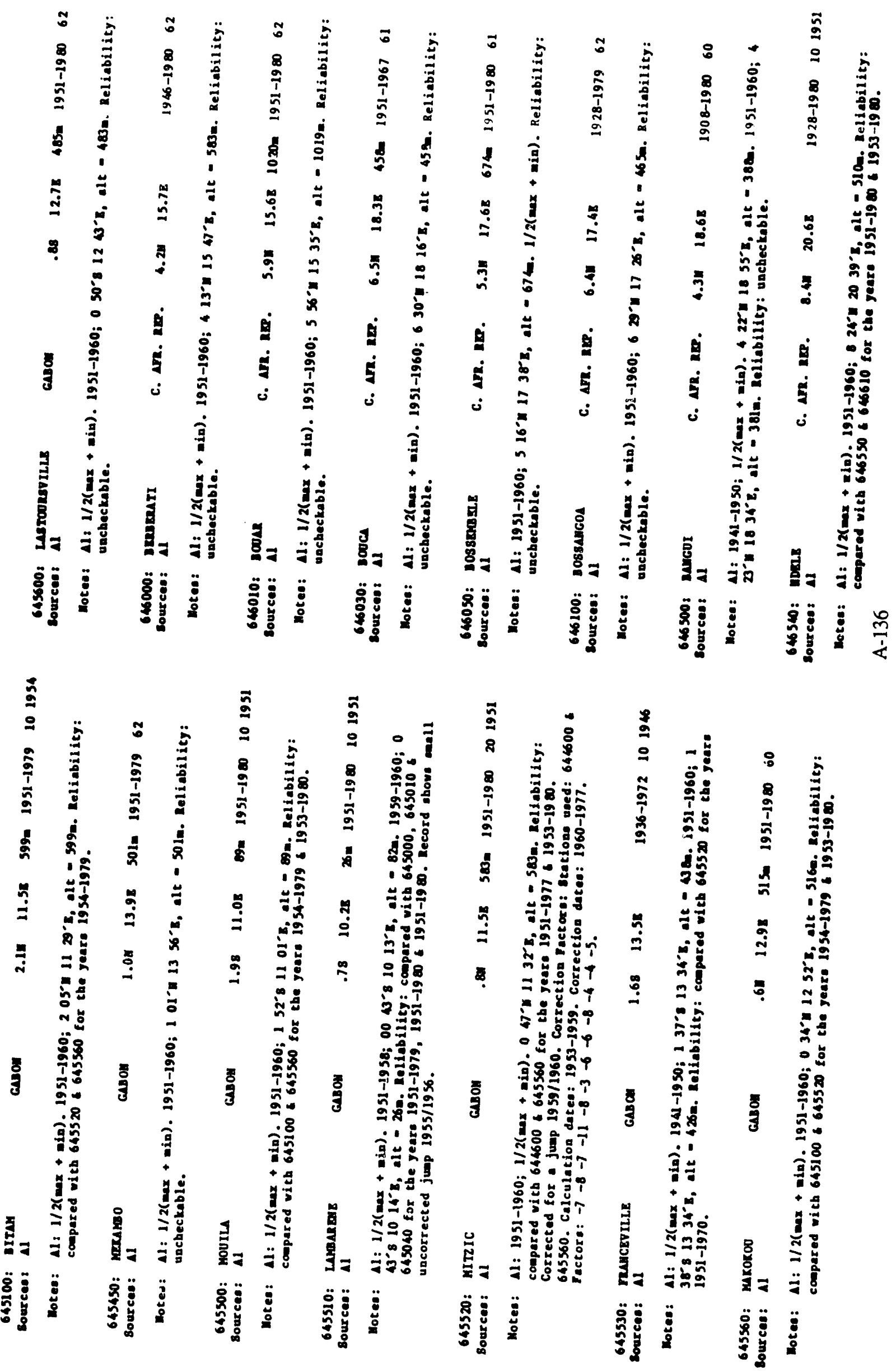


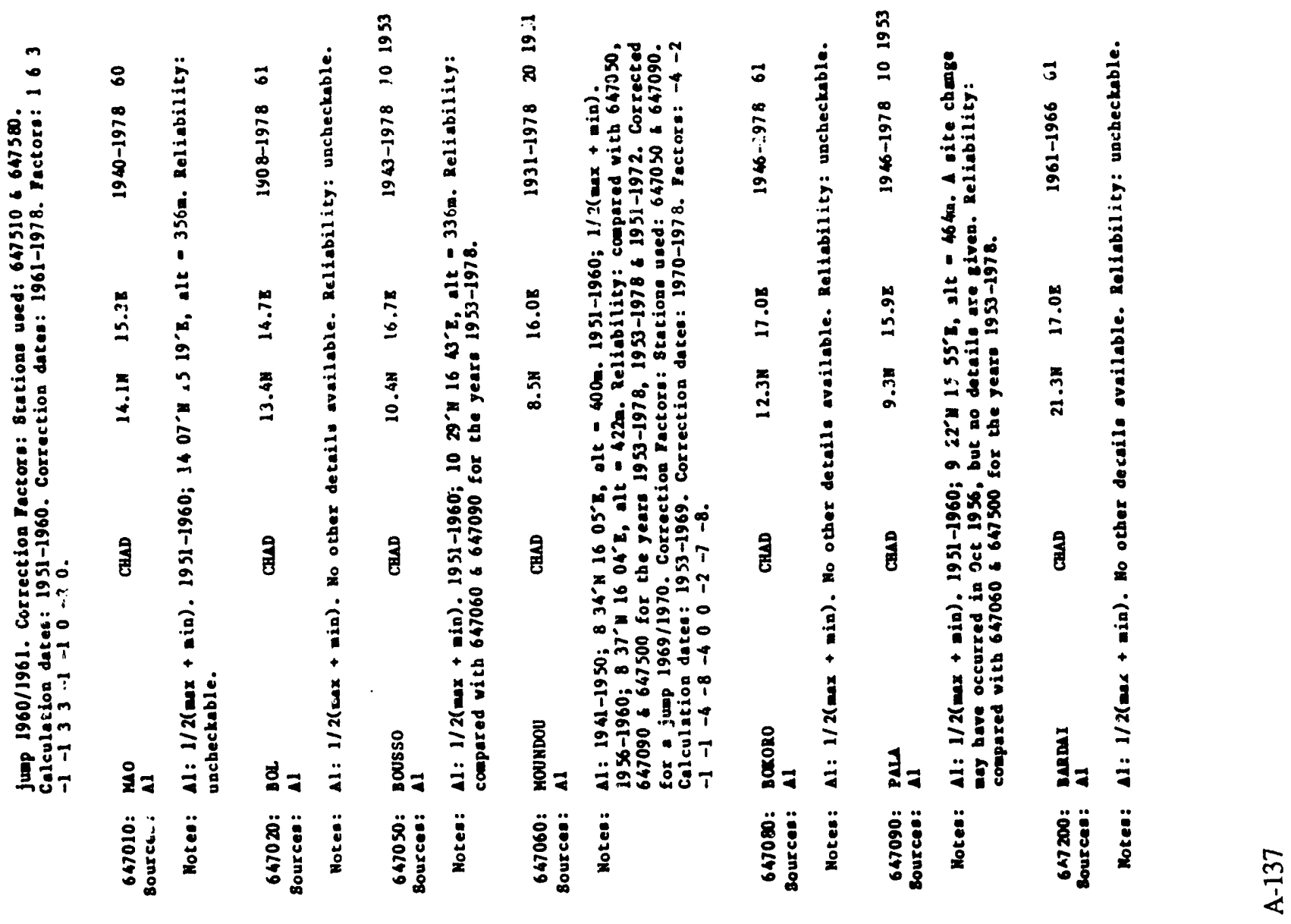

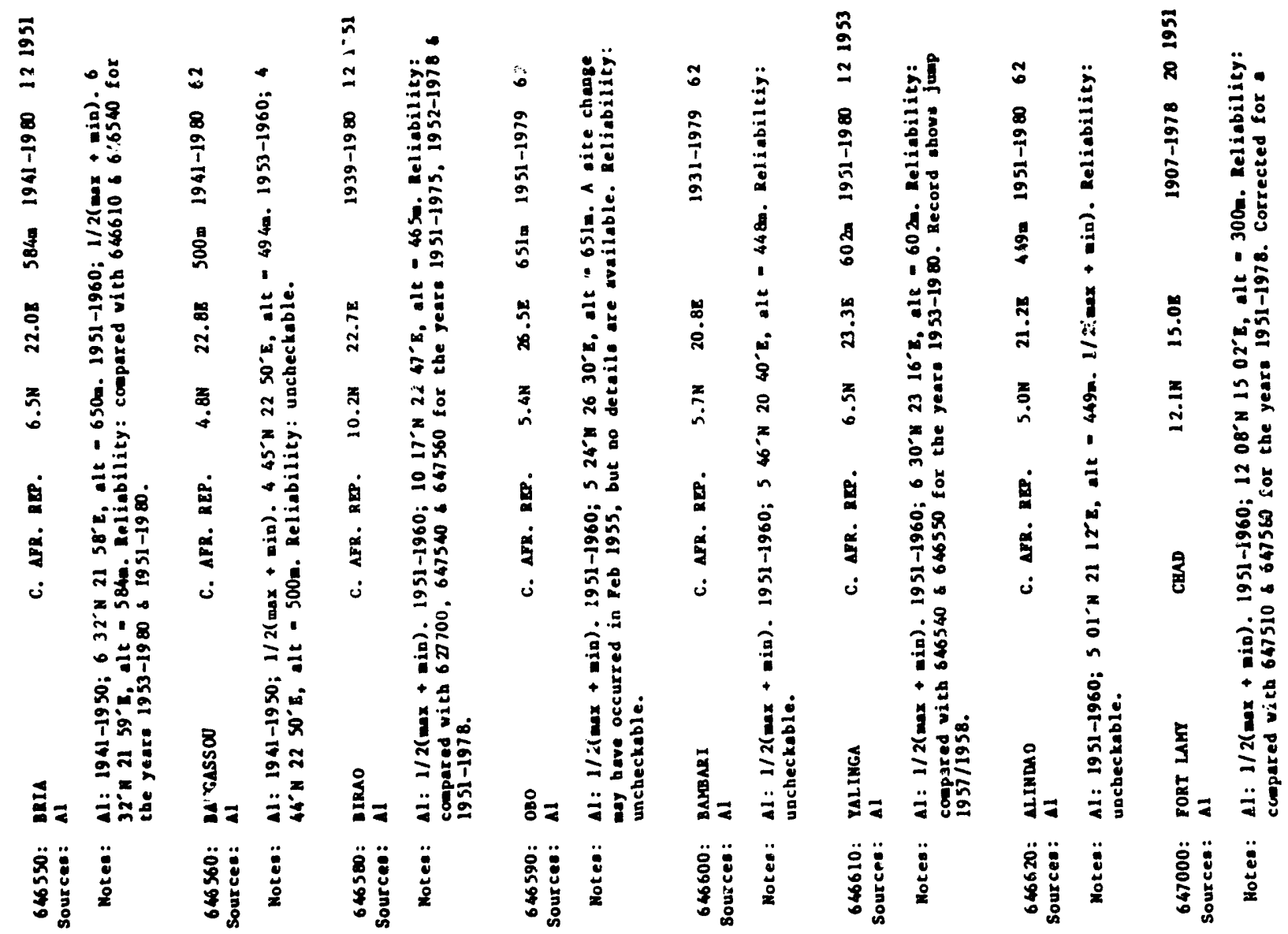




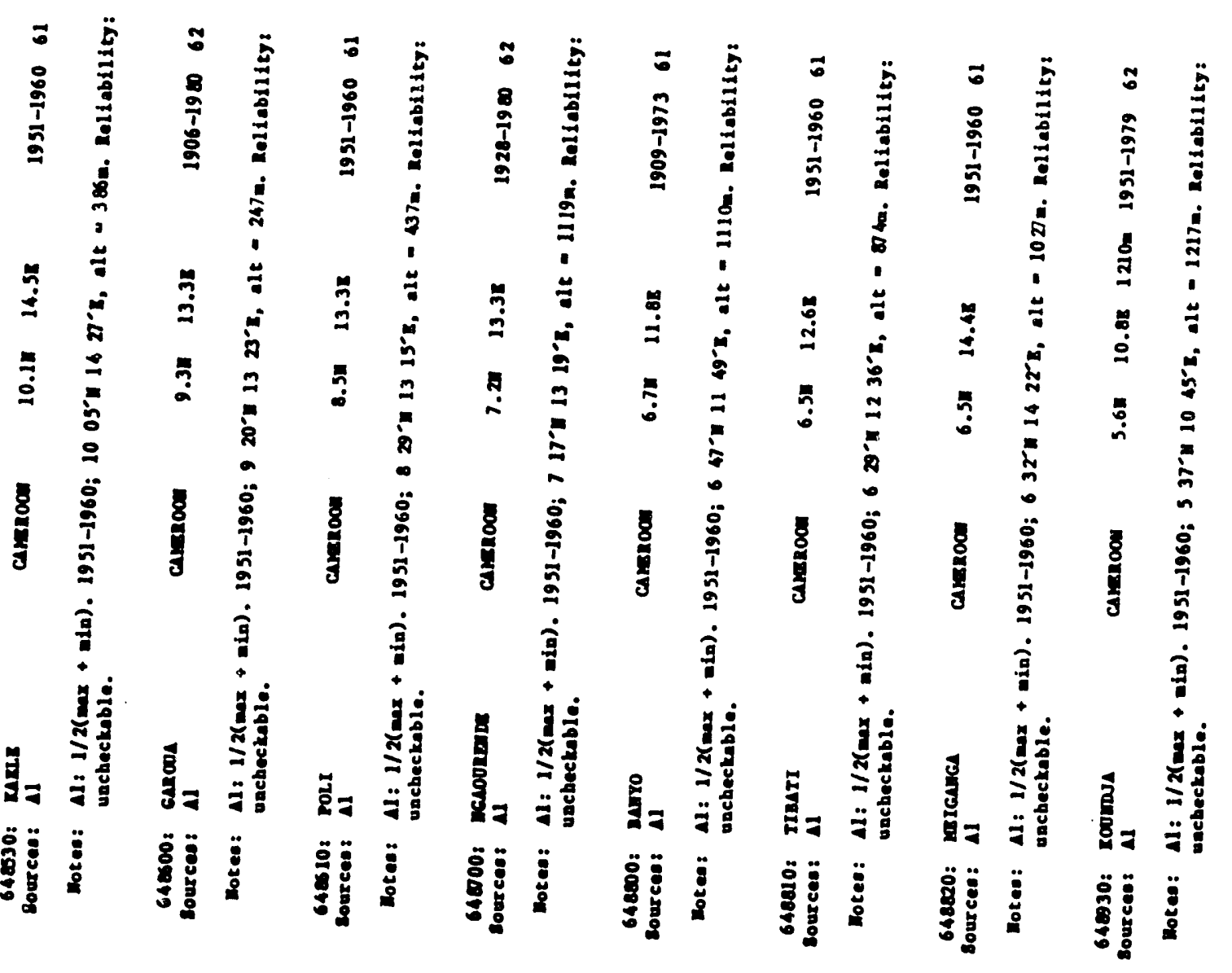

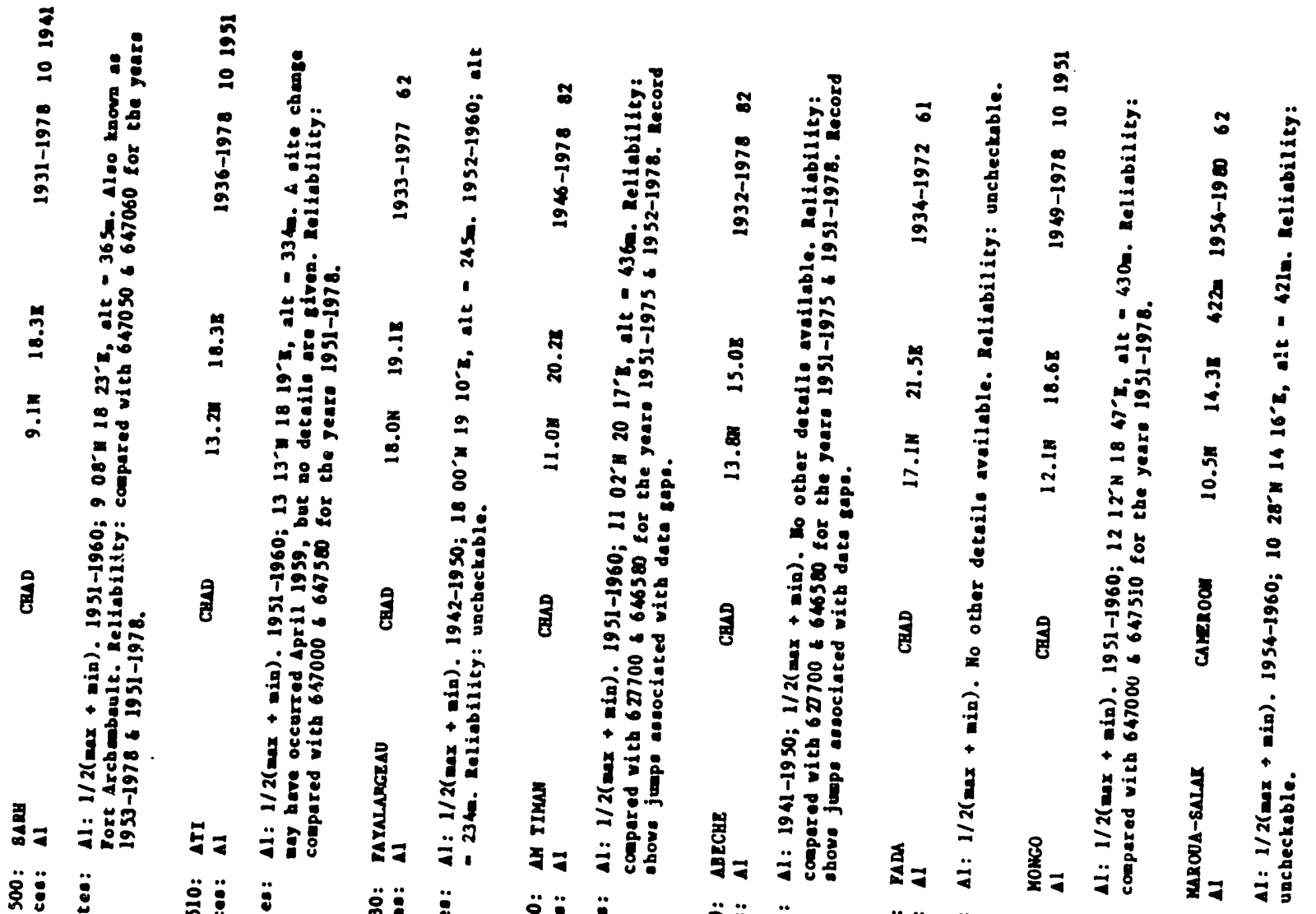

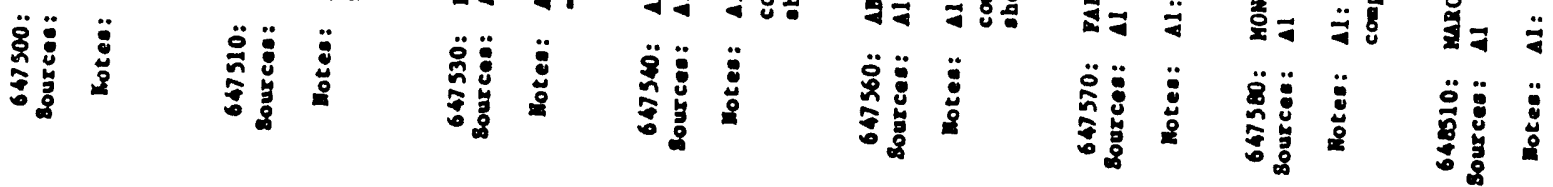



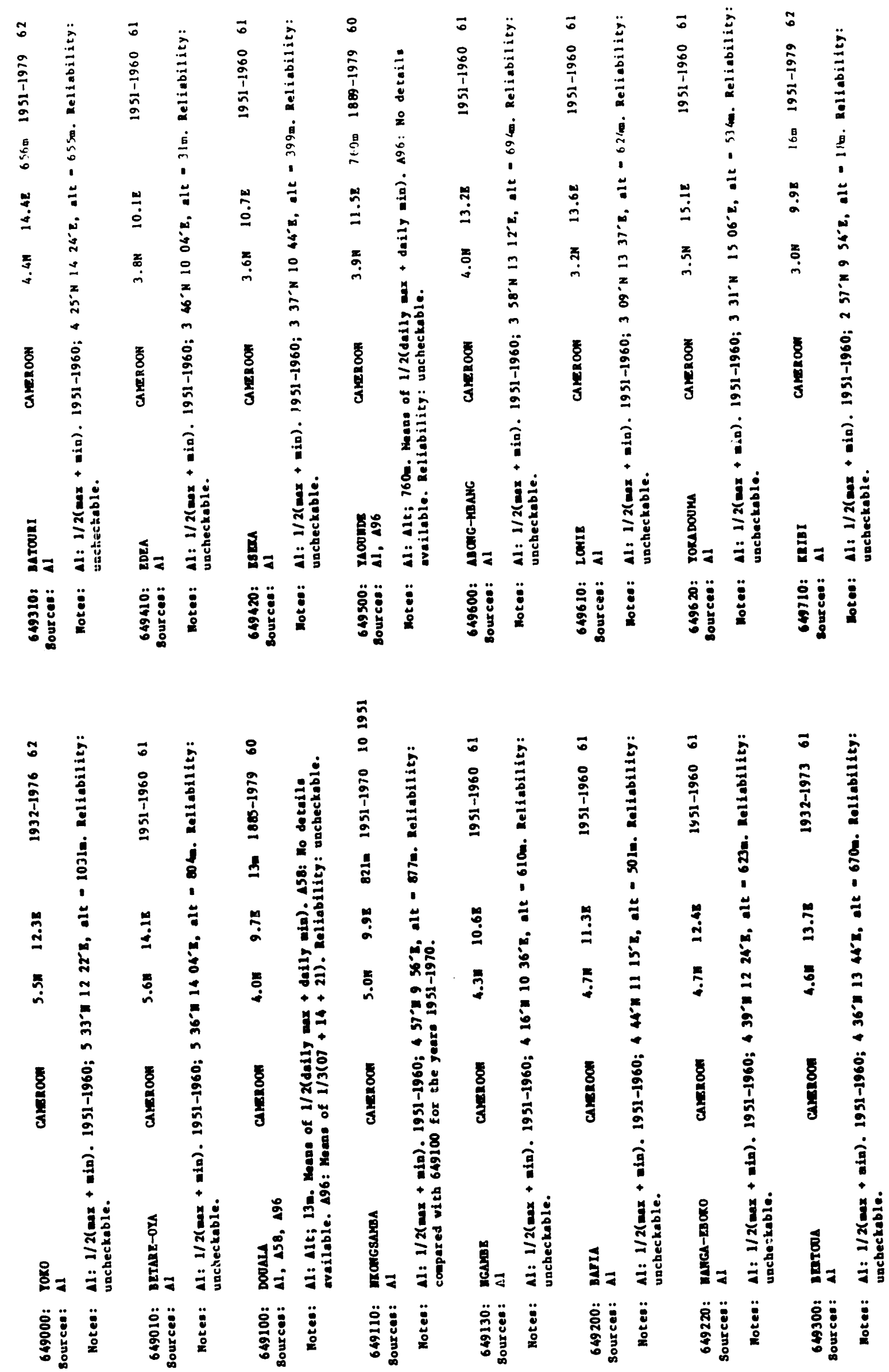


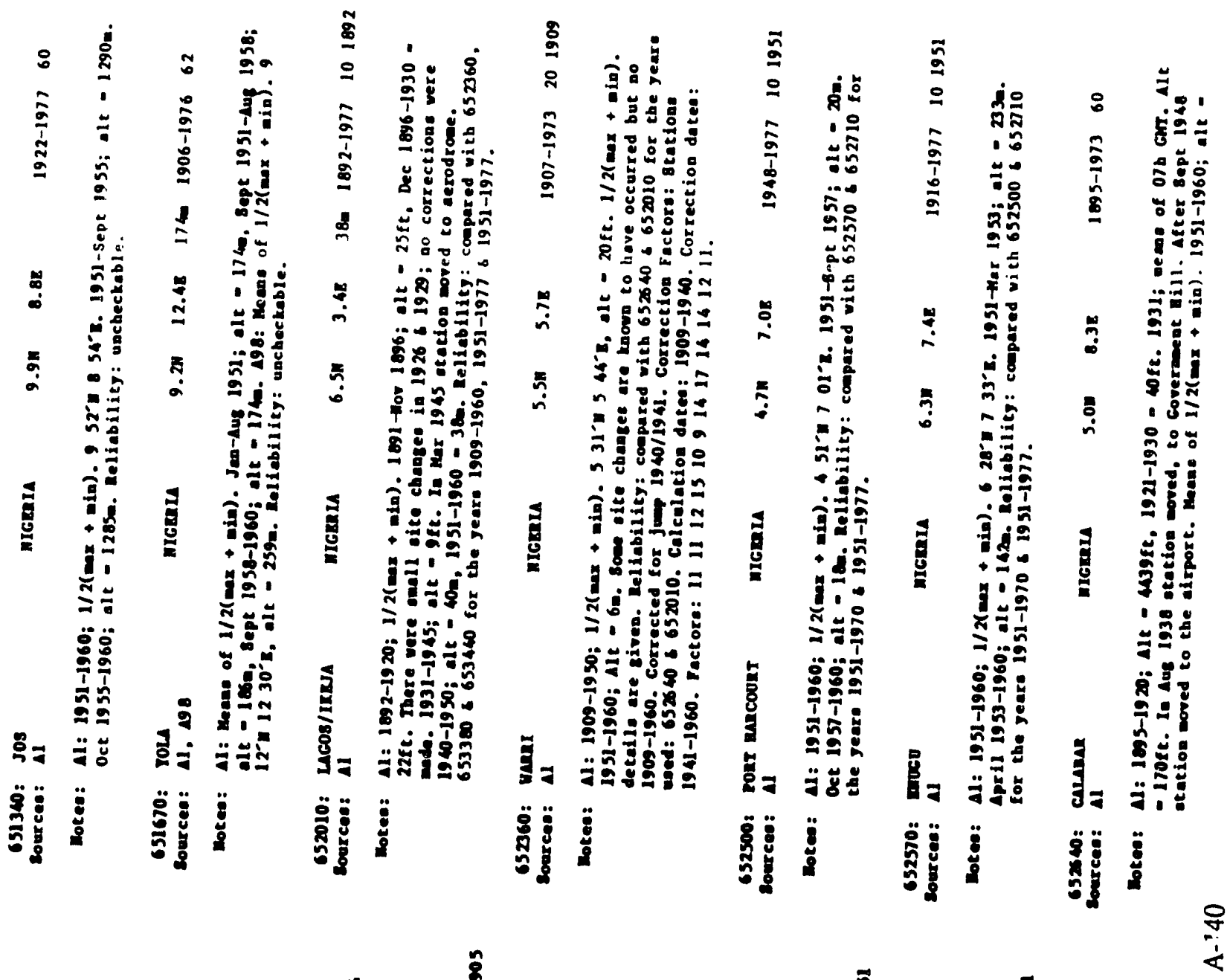

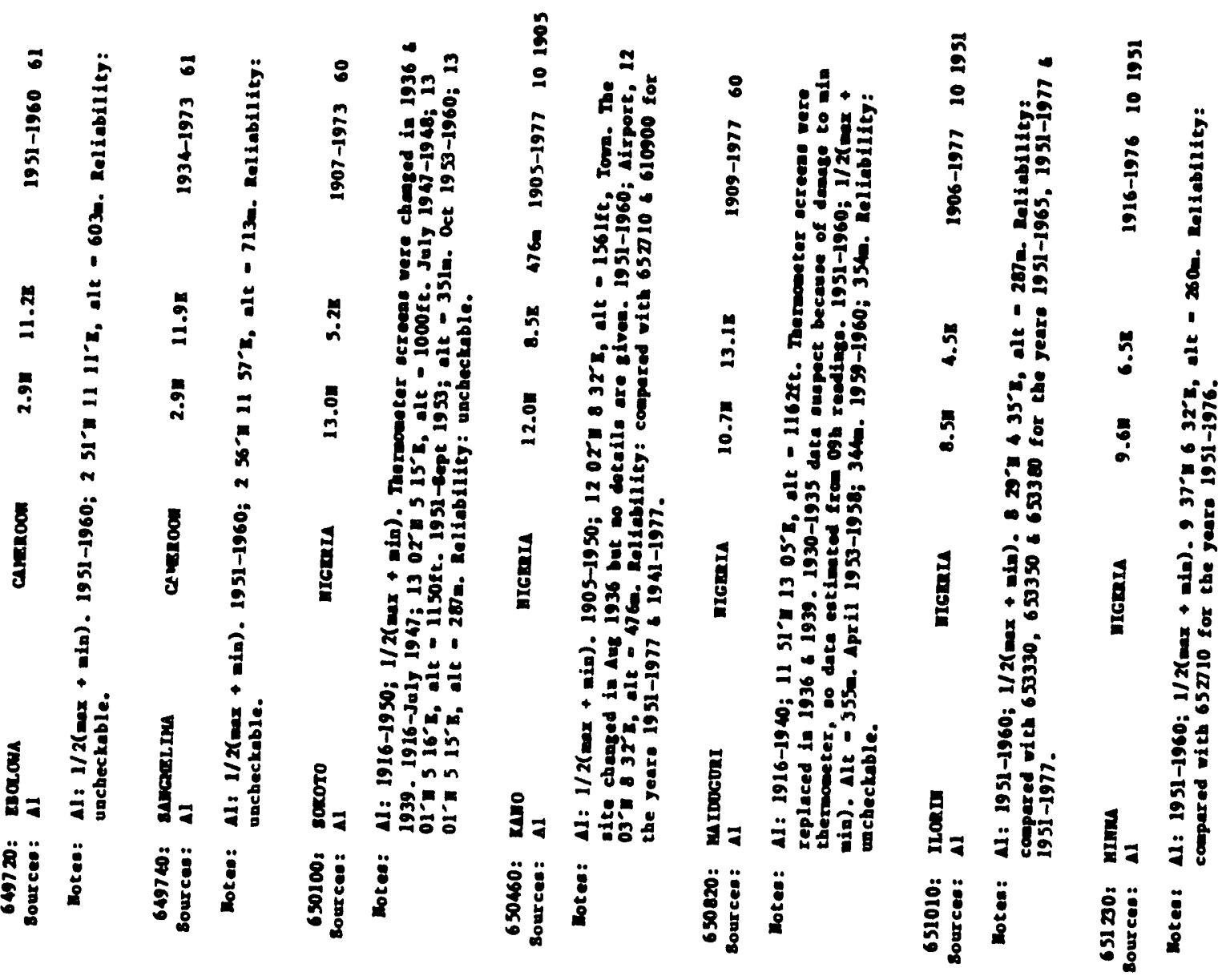



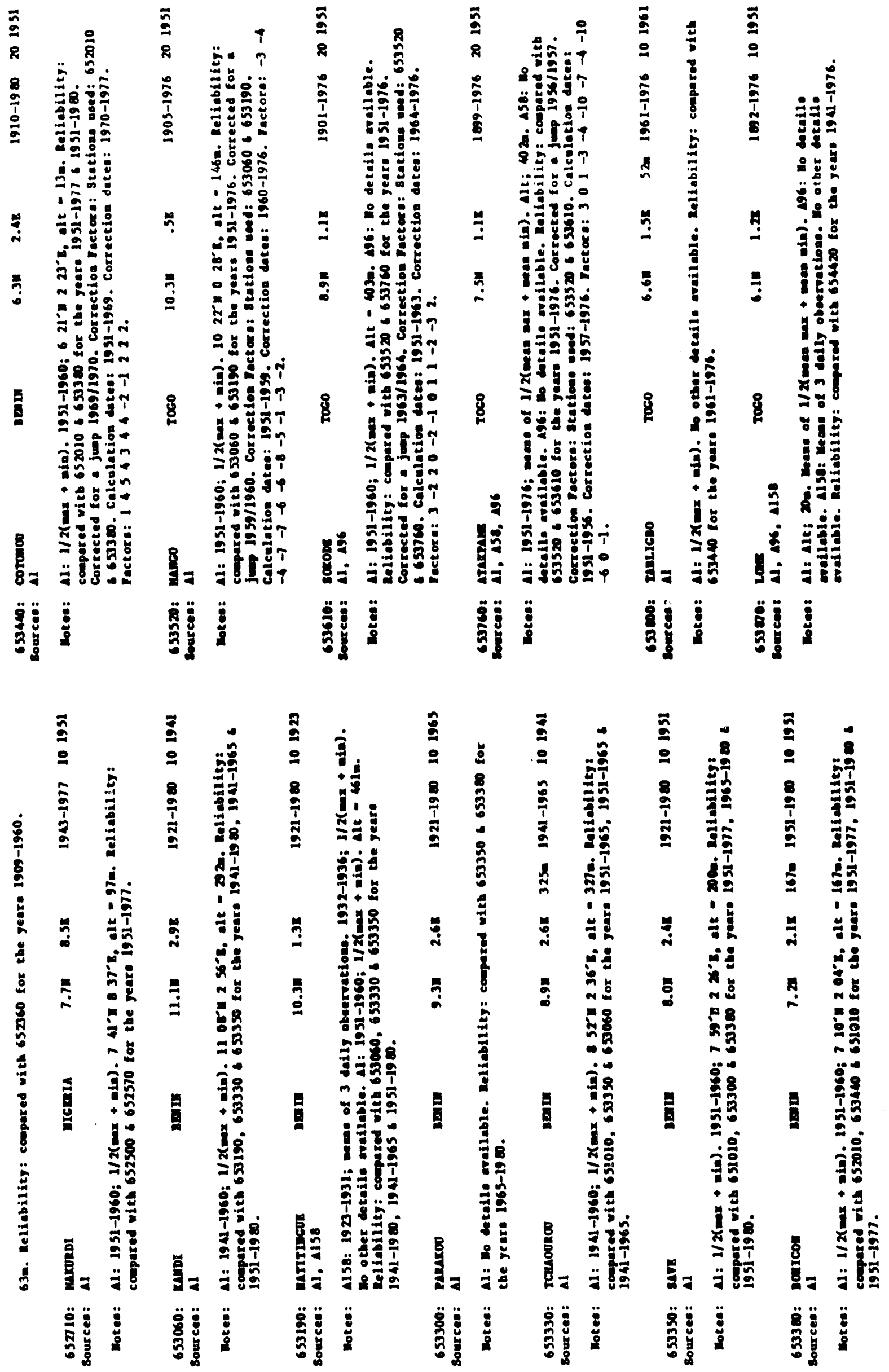

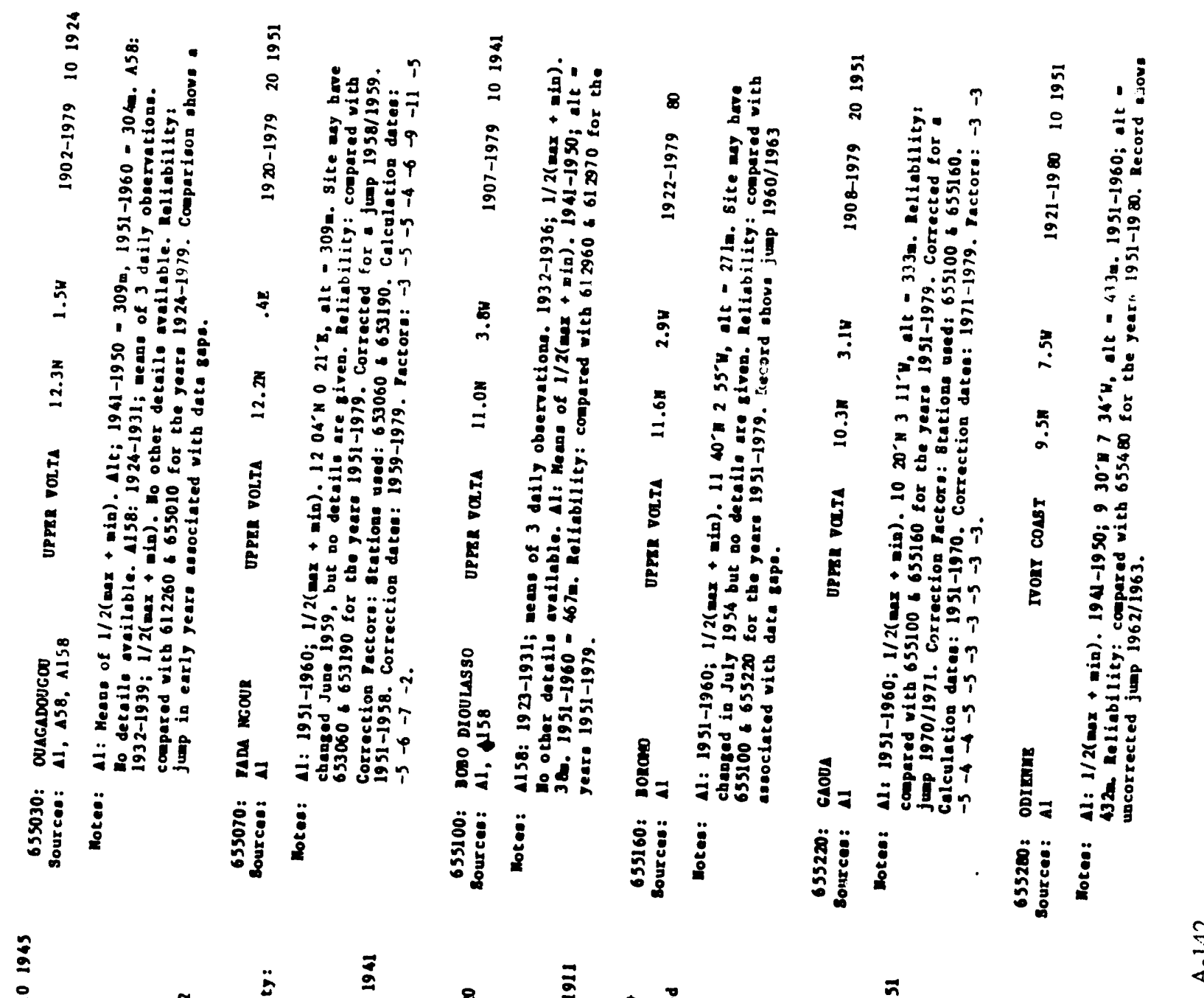

$\frac{1}{4}$

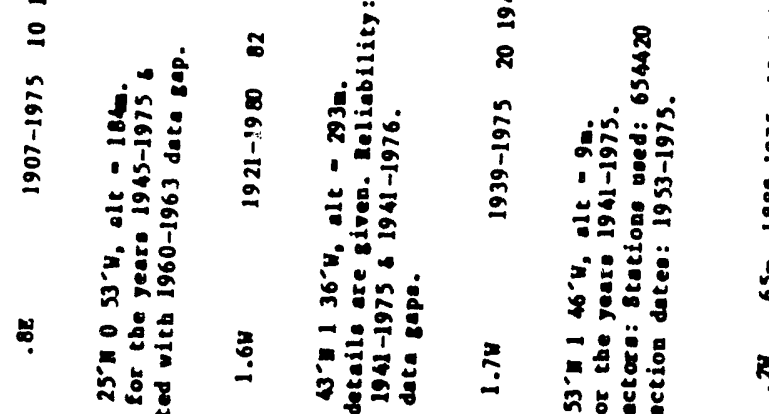




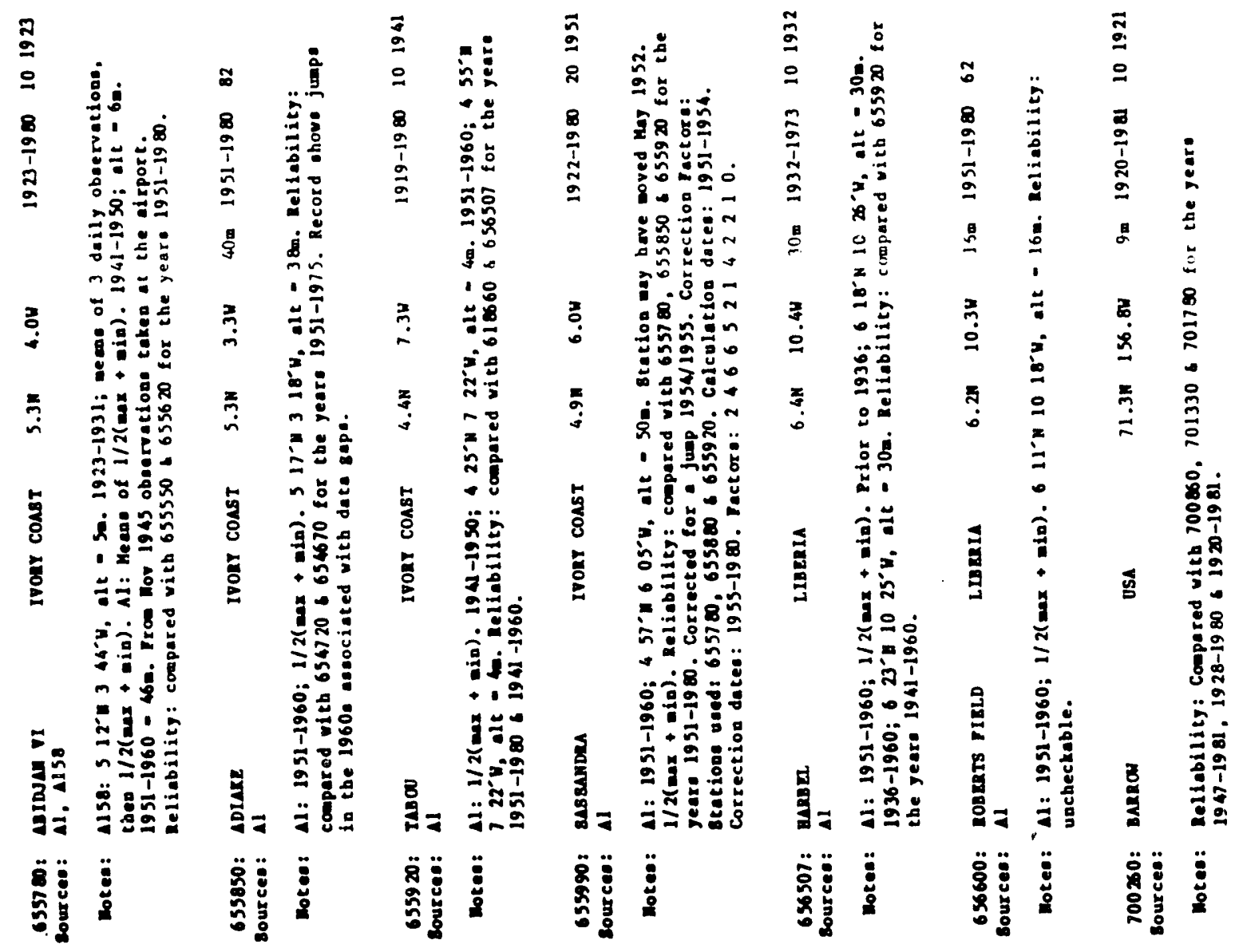

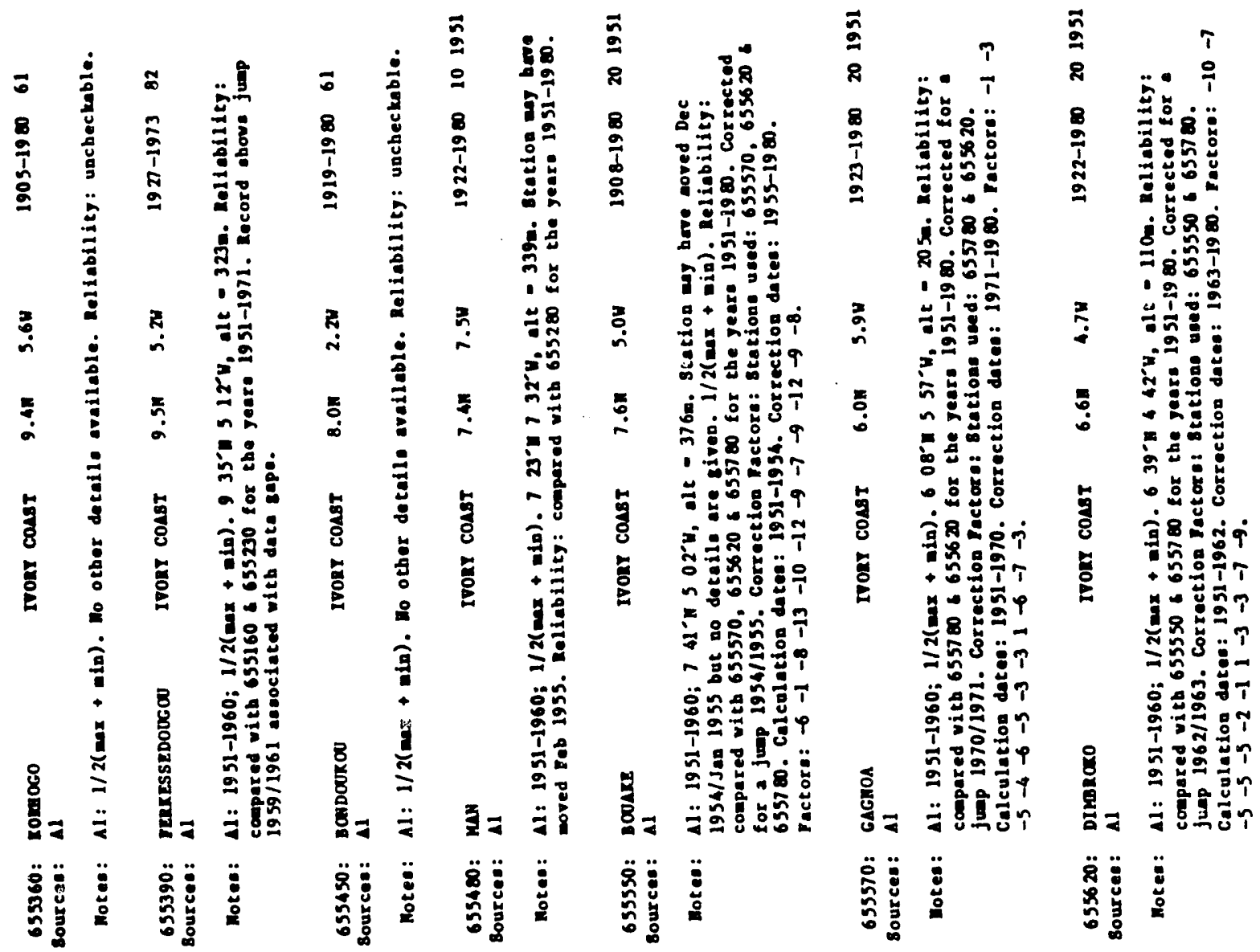




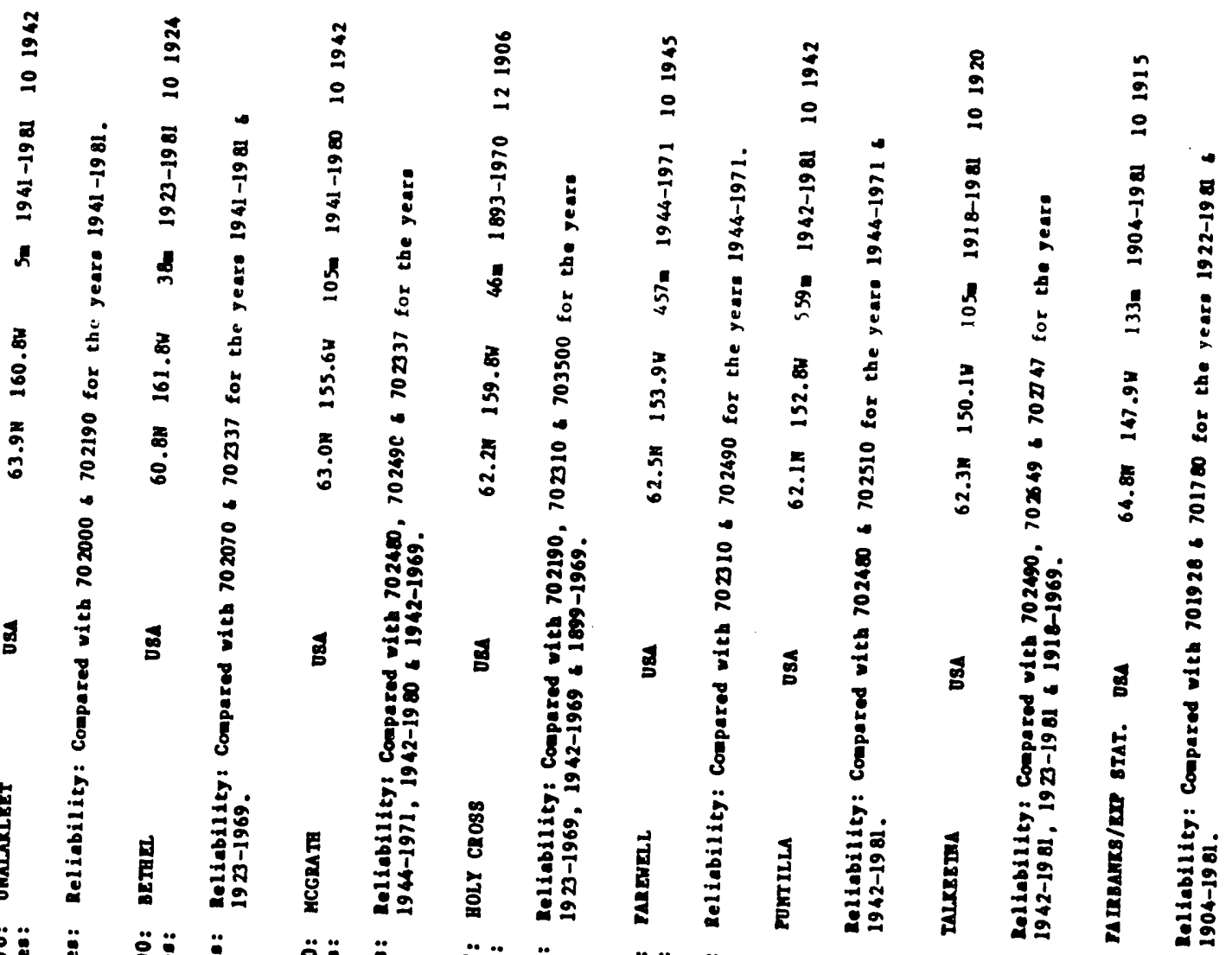

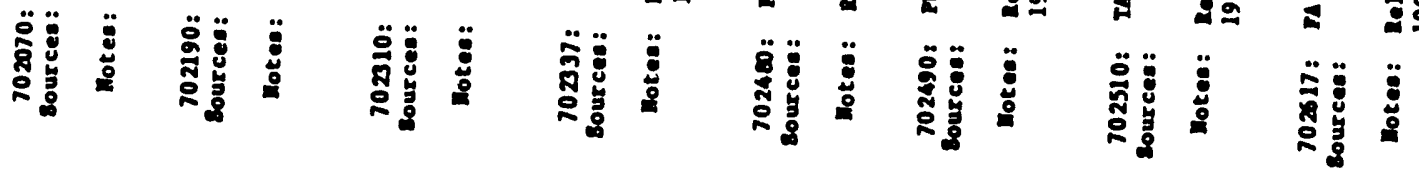

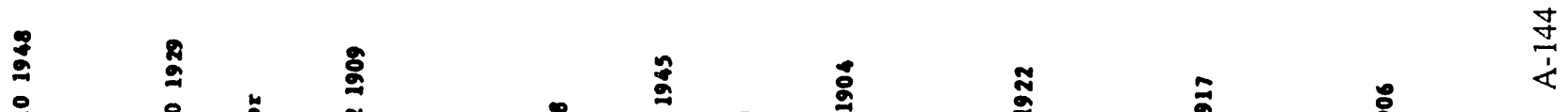

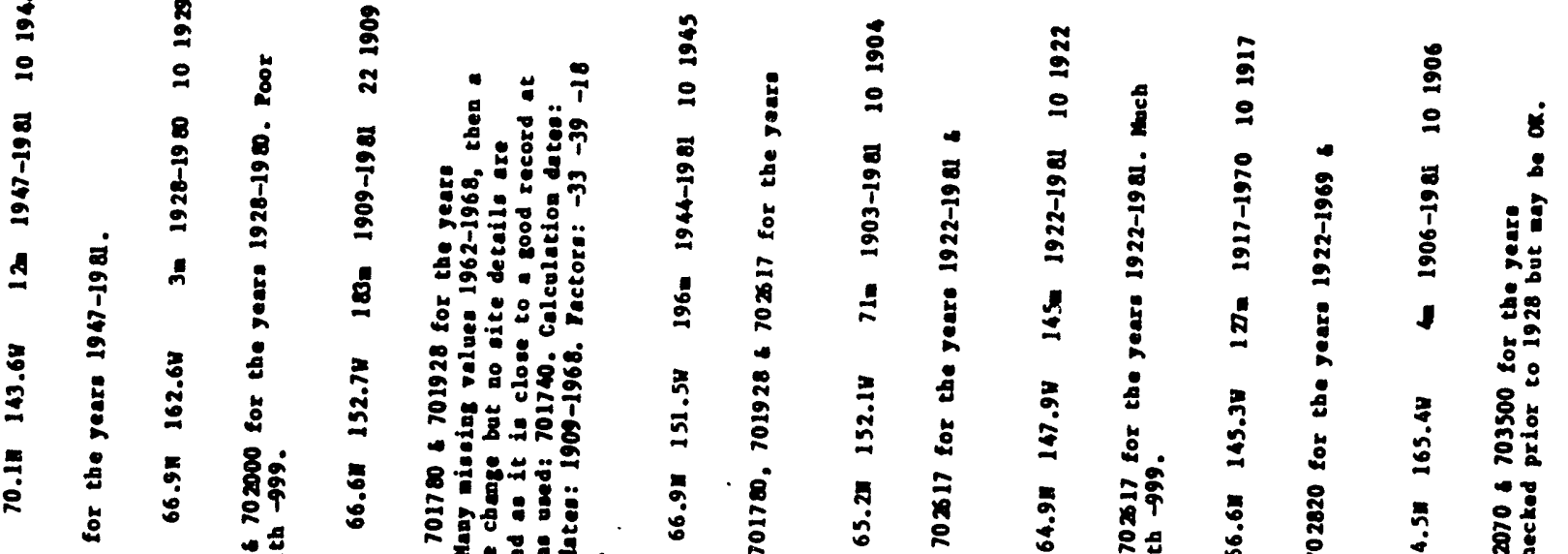

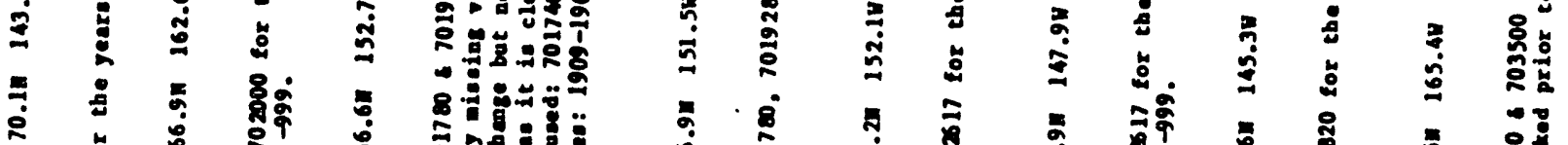



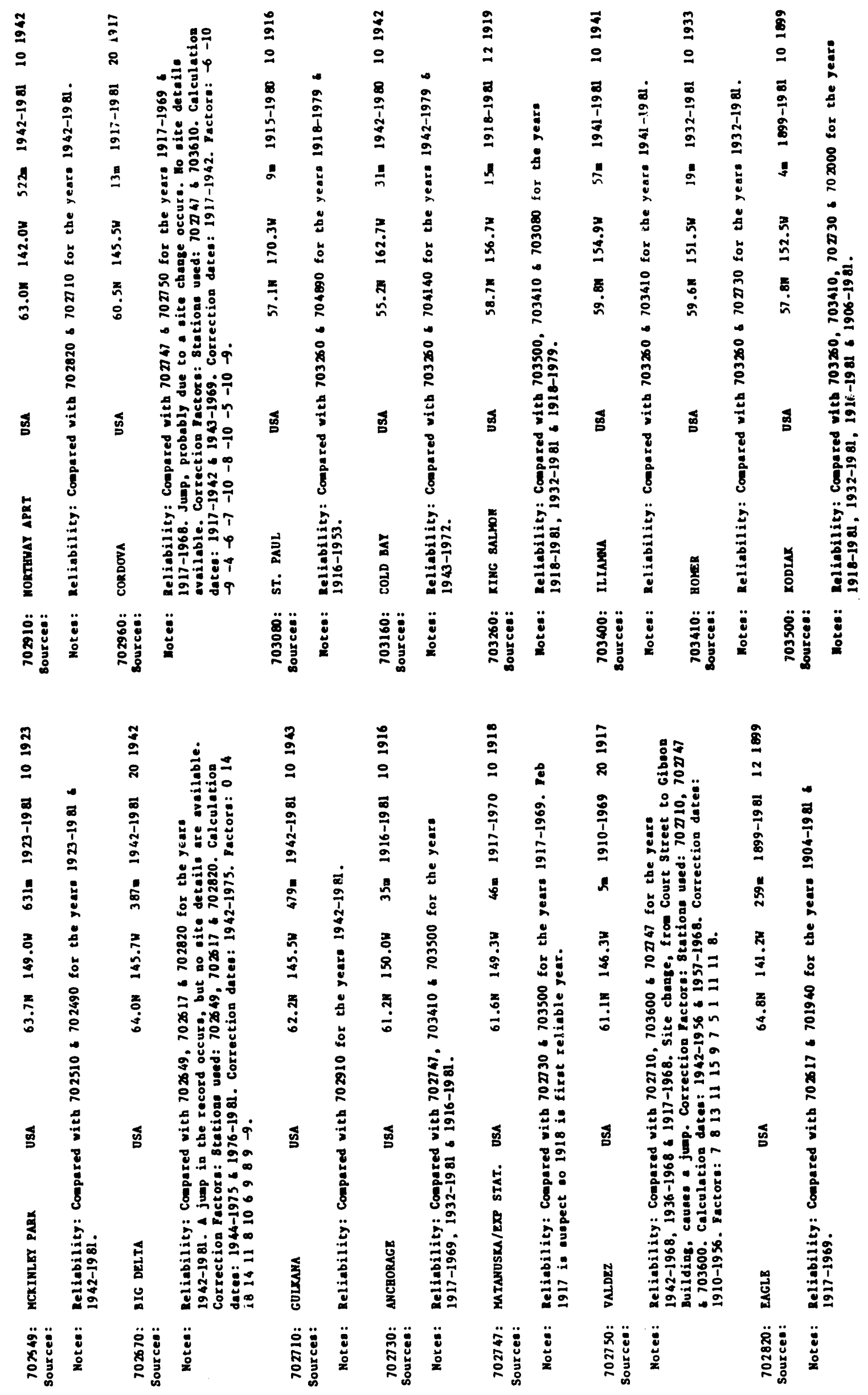
요

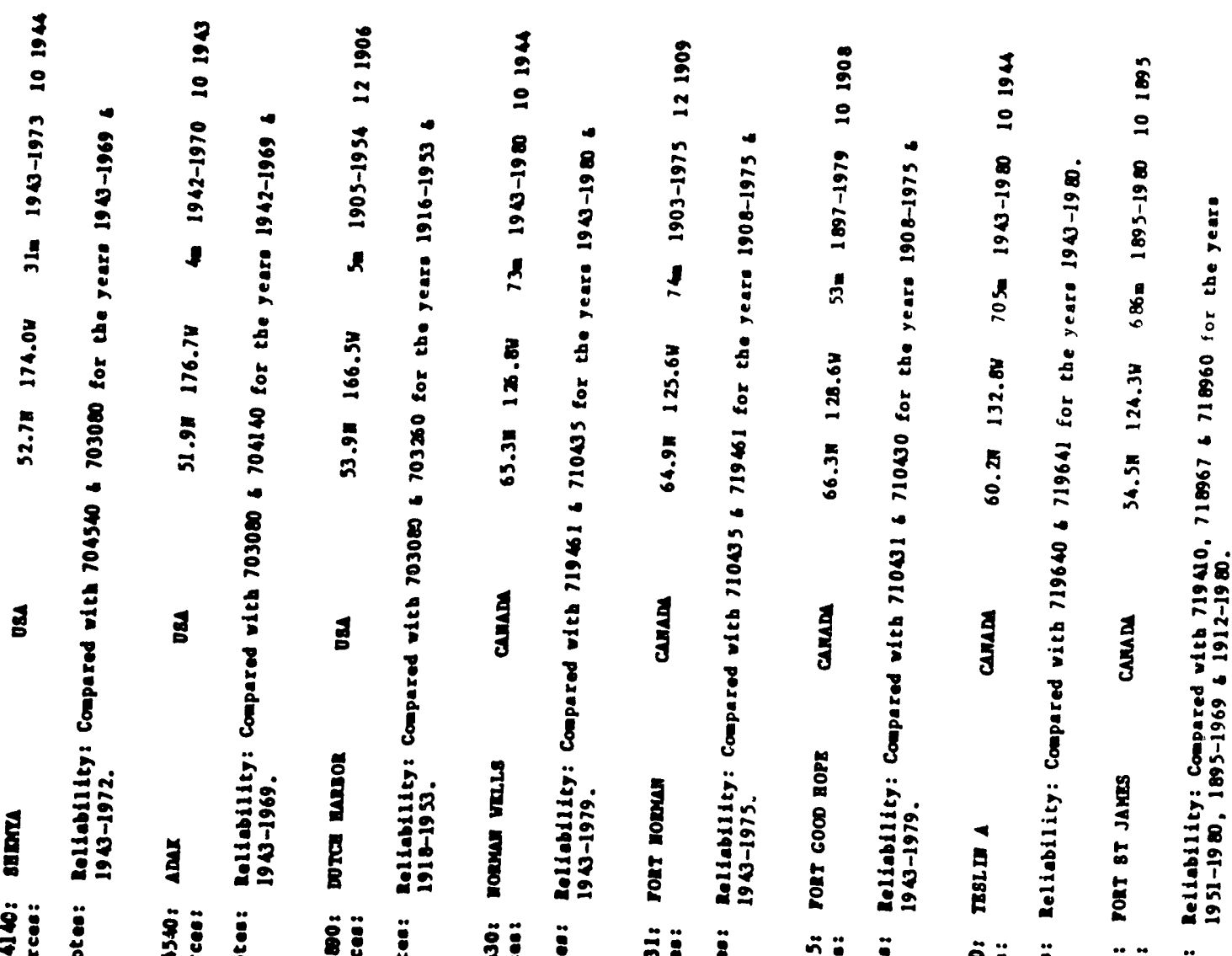

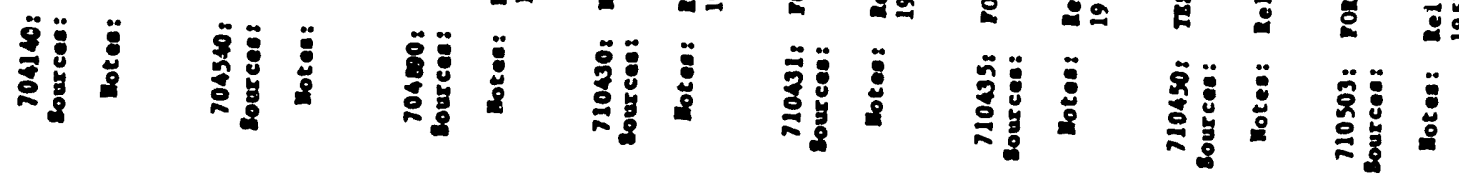

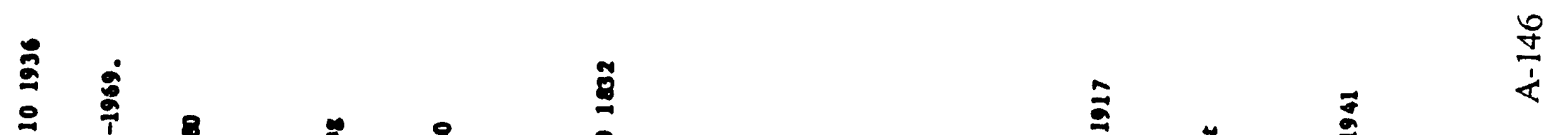

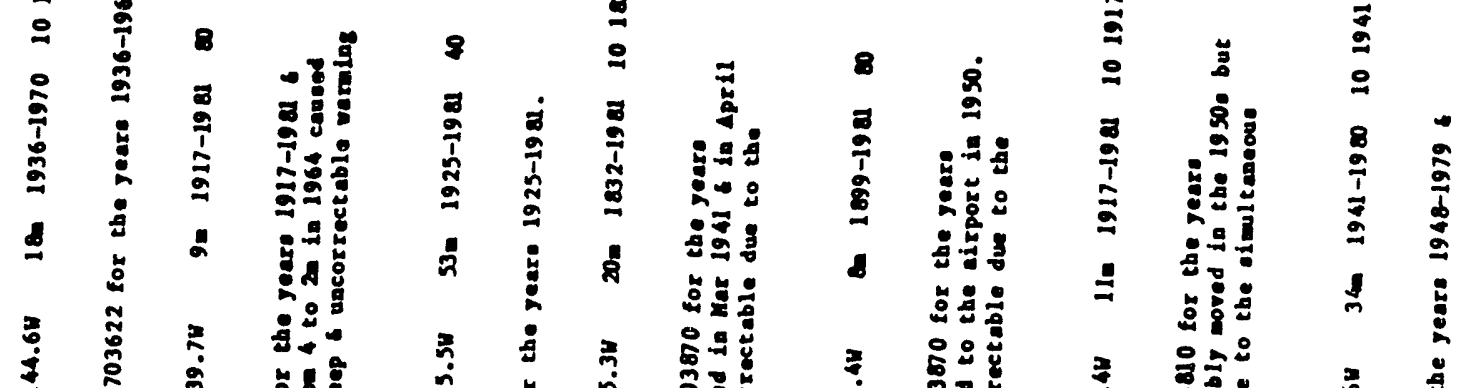

(1)

H

(1)

IIII 


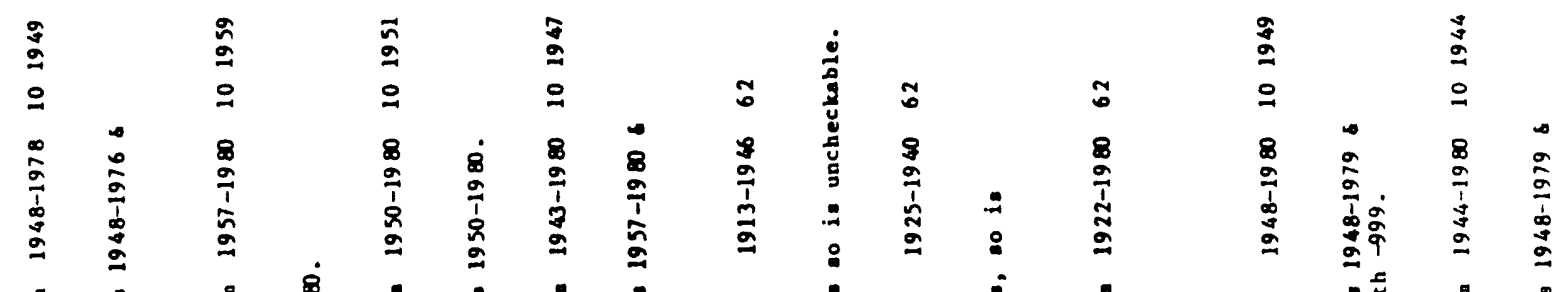

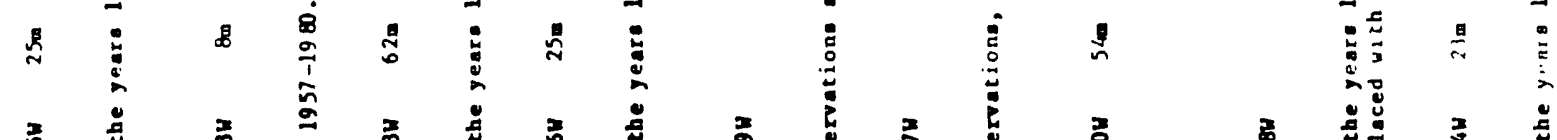

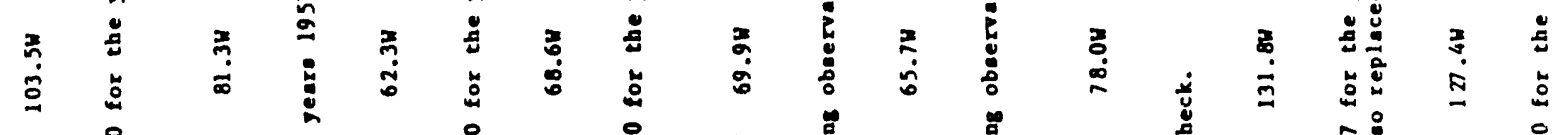

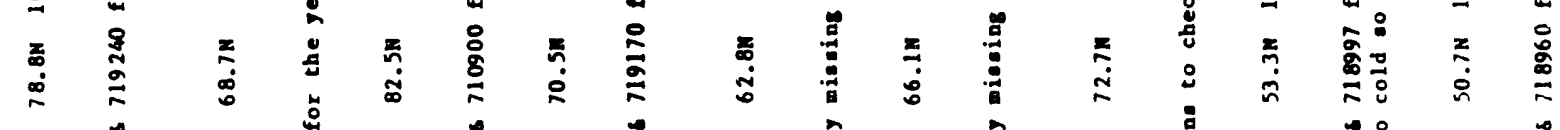

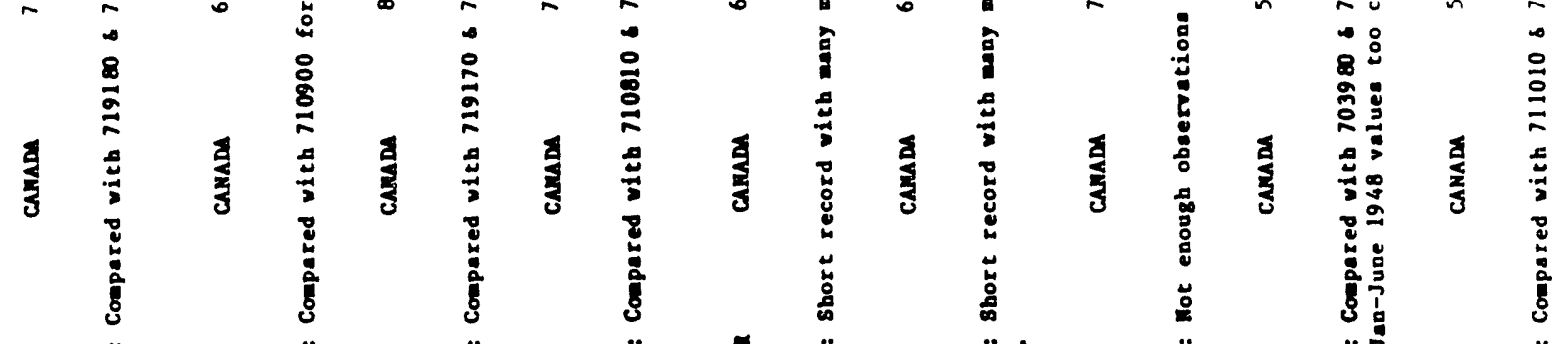

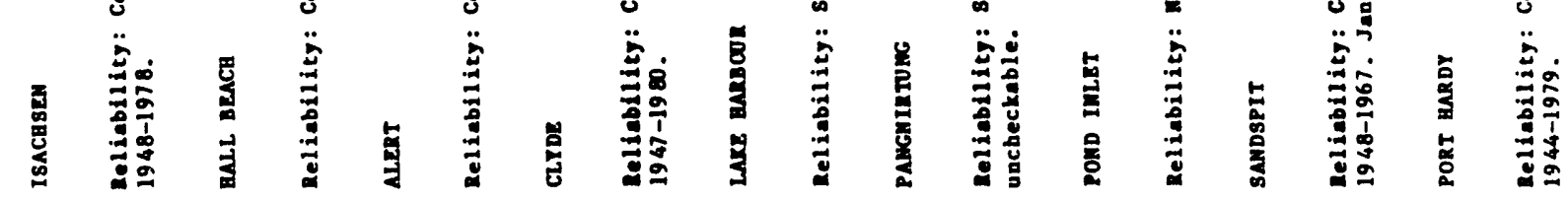

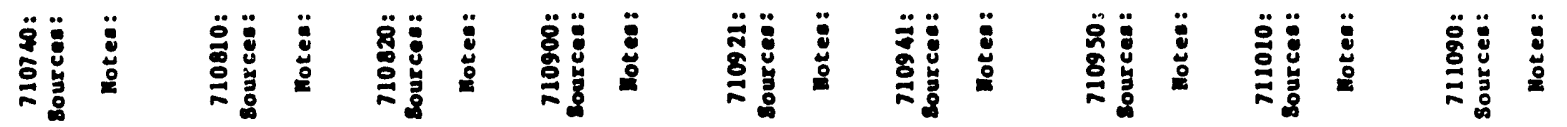

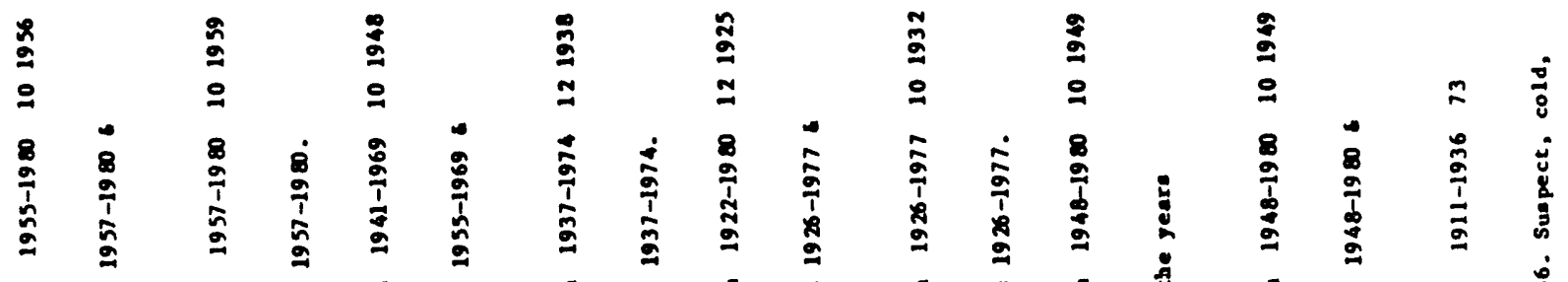

-

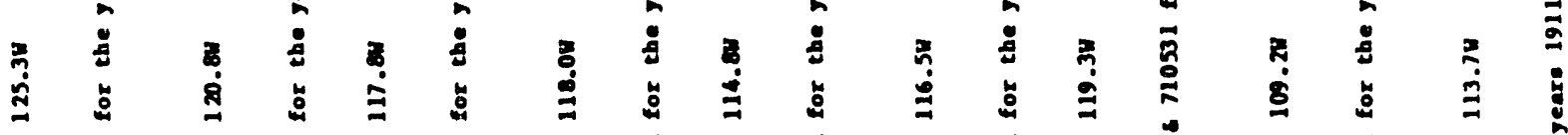

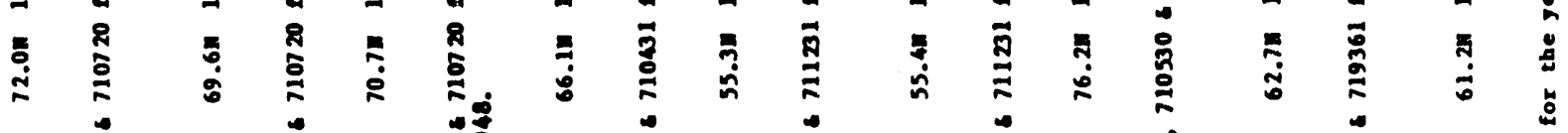

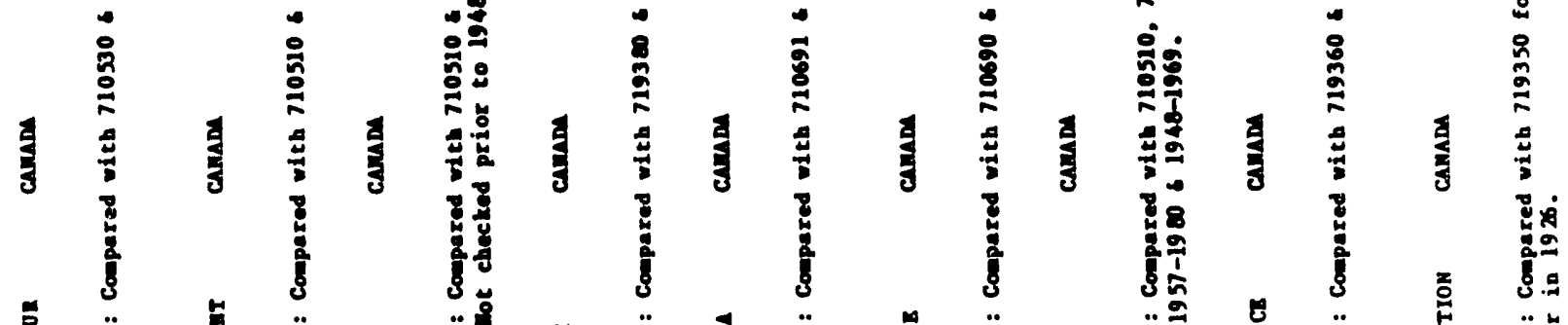

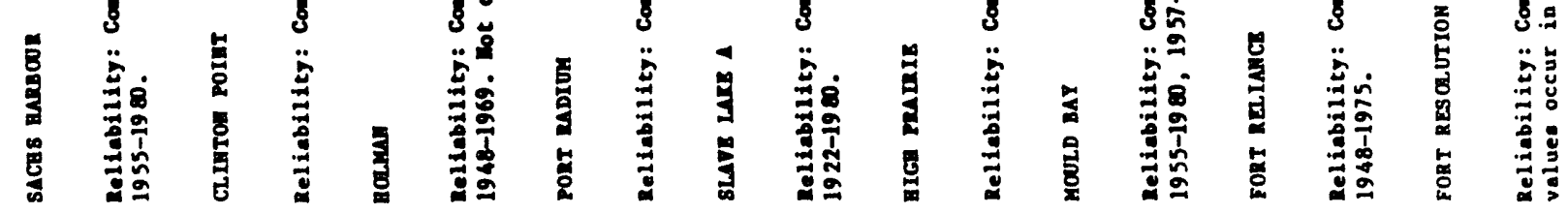

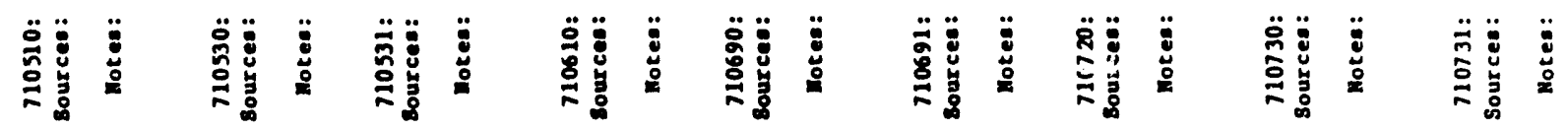




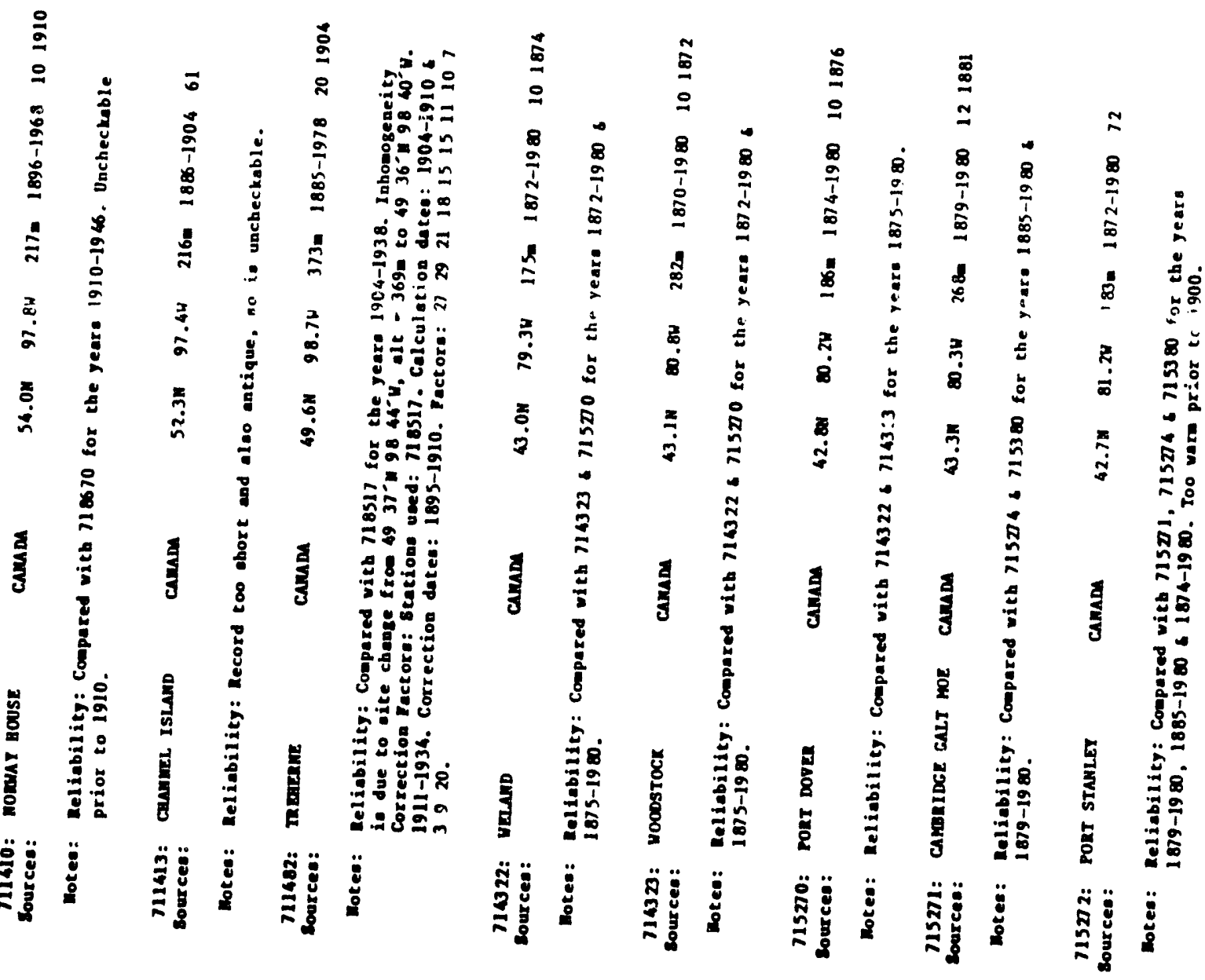

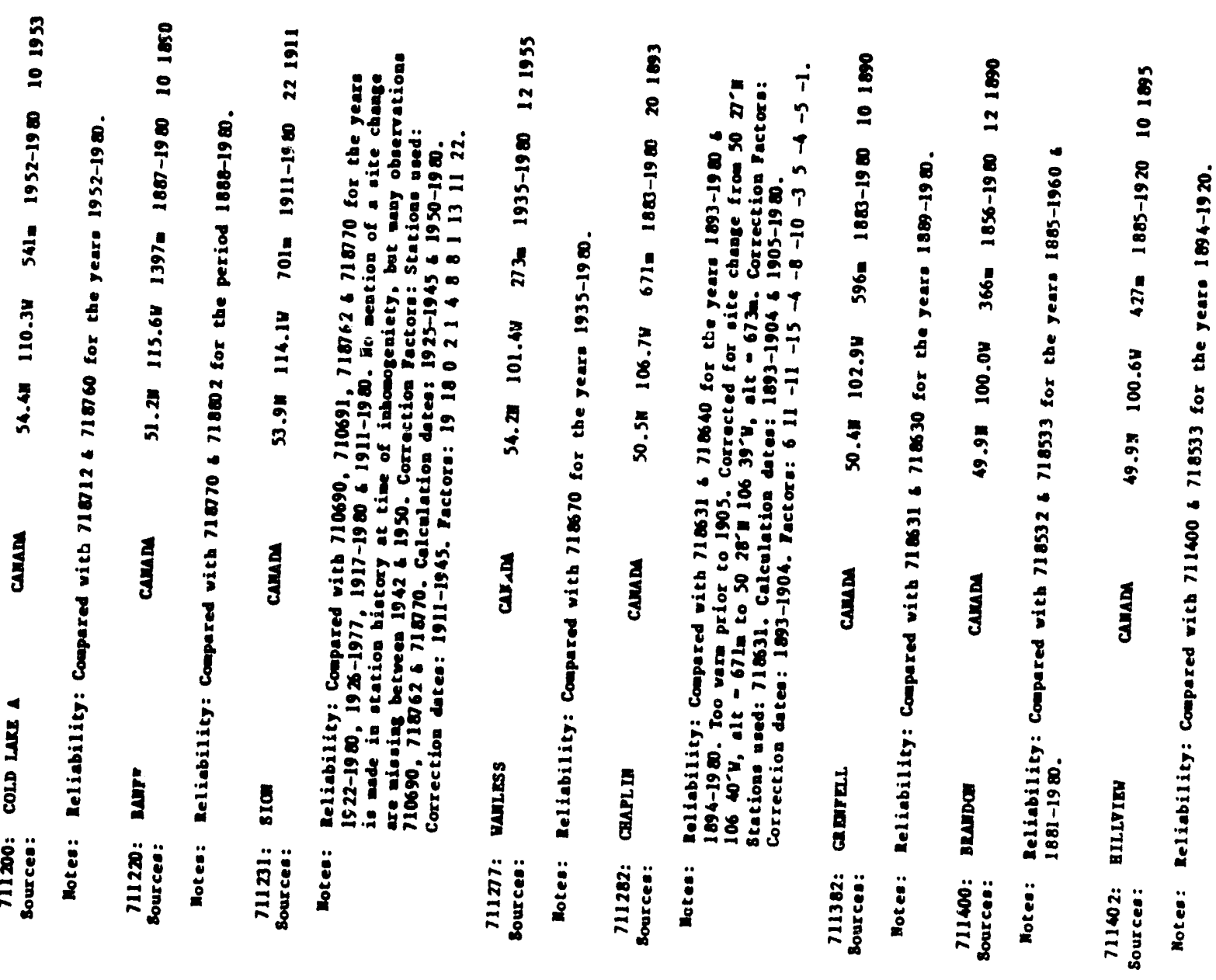




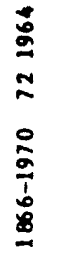

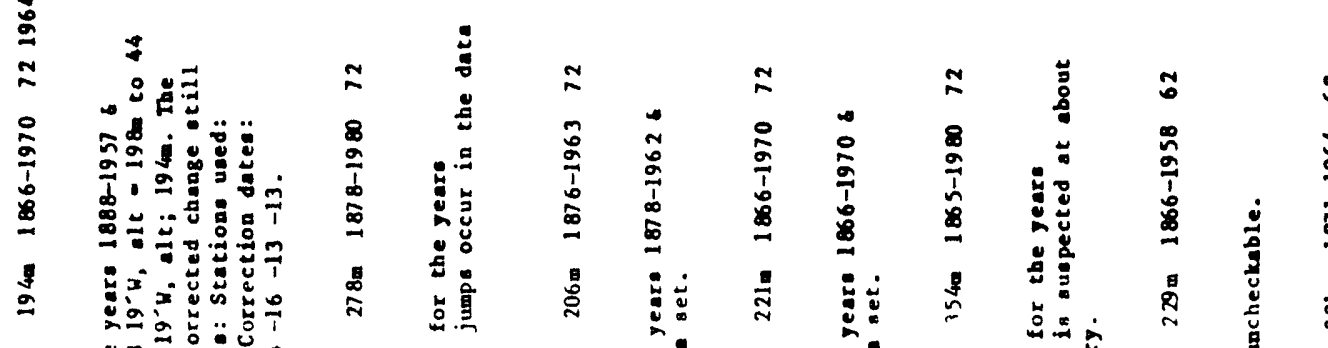

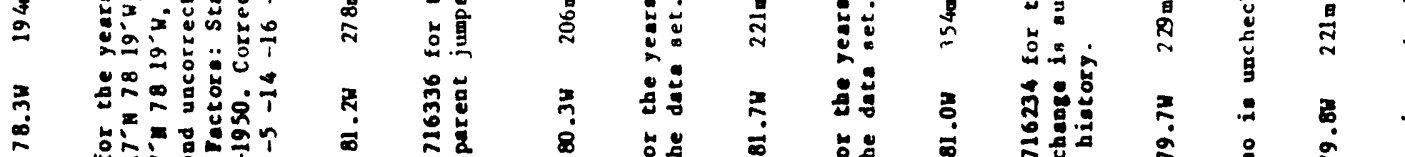

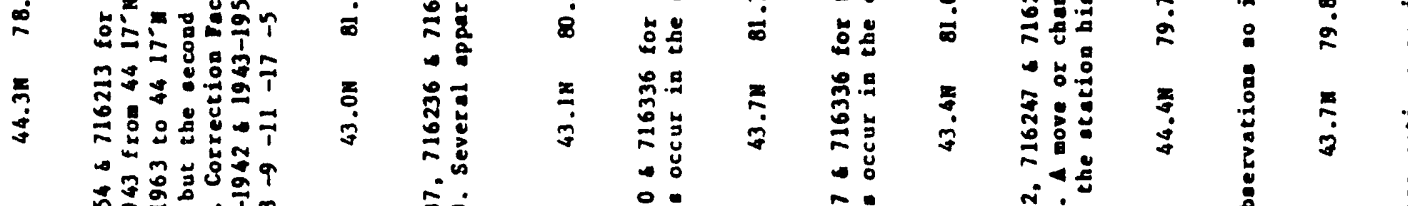

\%

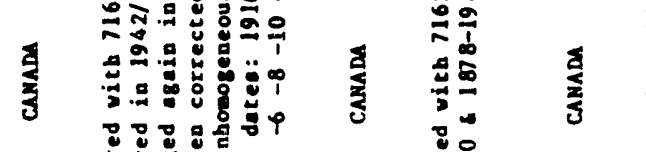

ํ.․

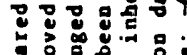

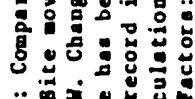

旅

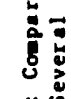

Imint

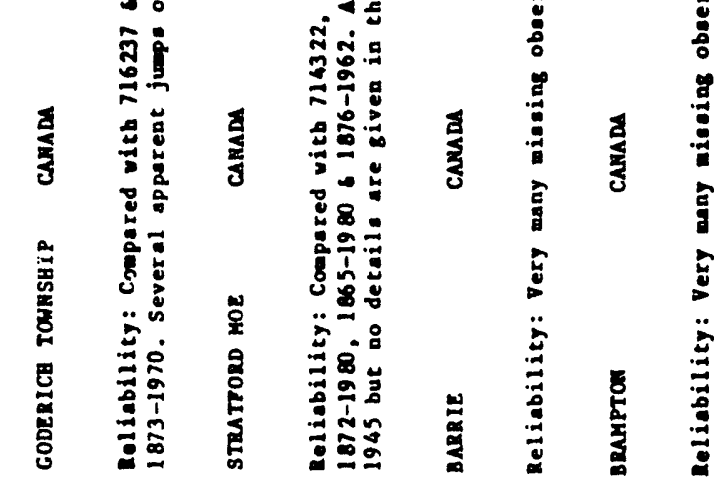

苔

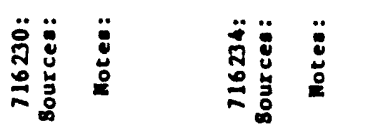

葛营

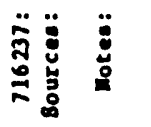

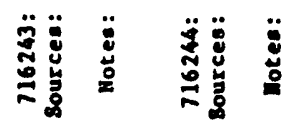

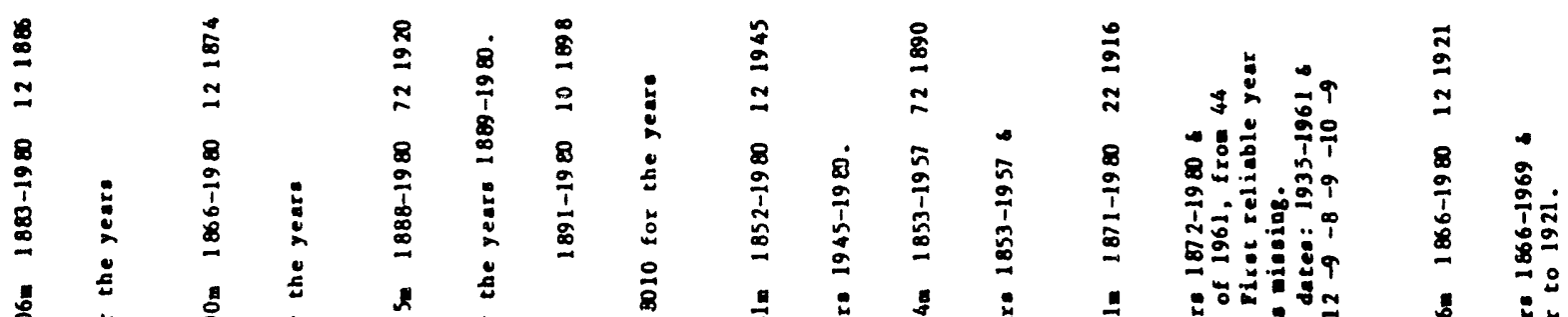

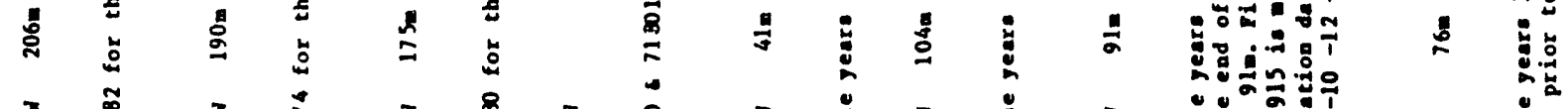

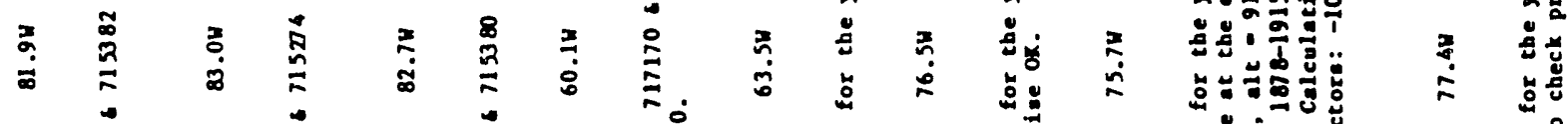

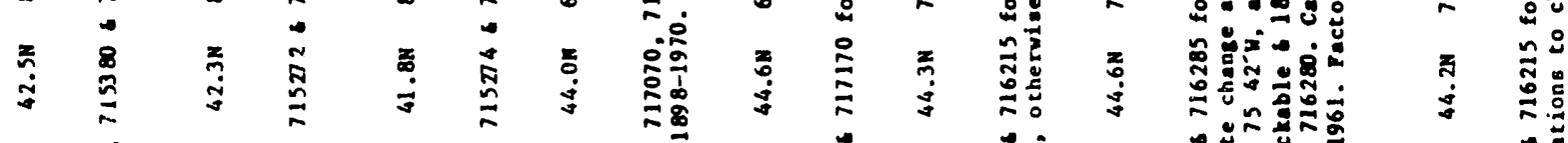

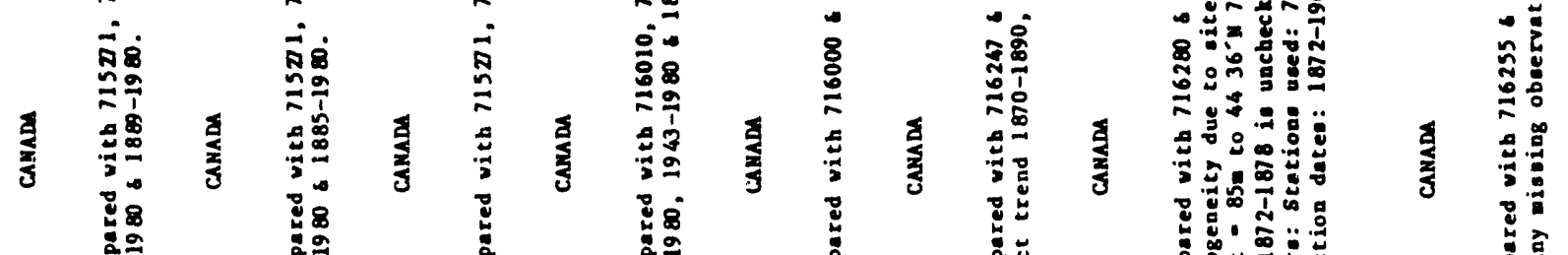

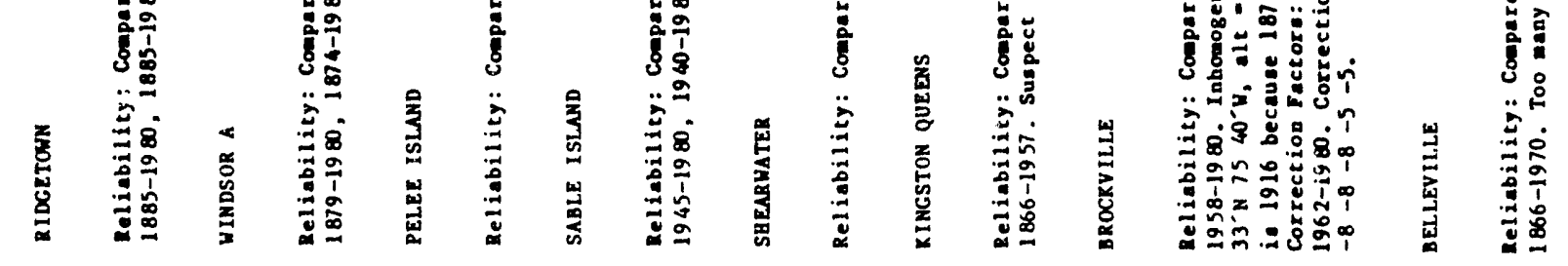

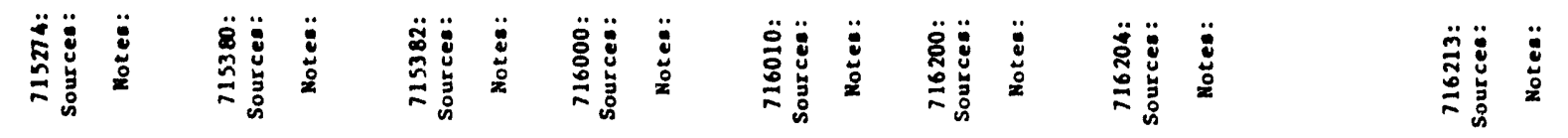




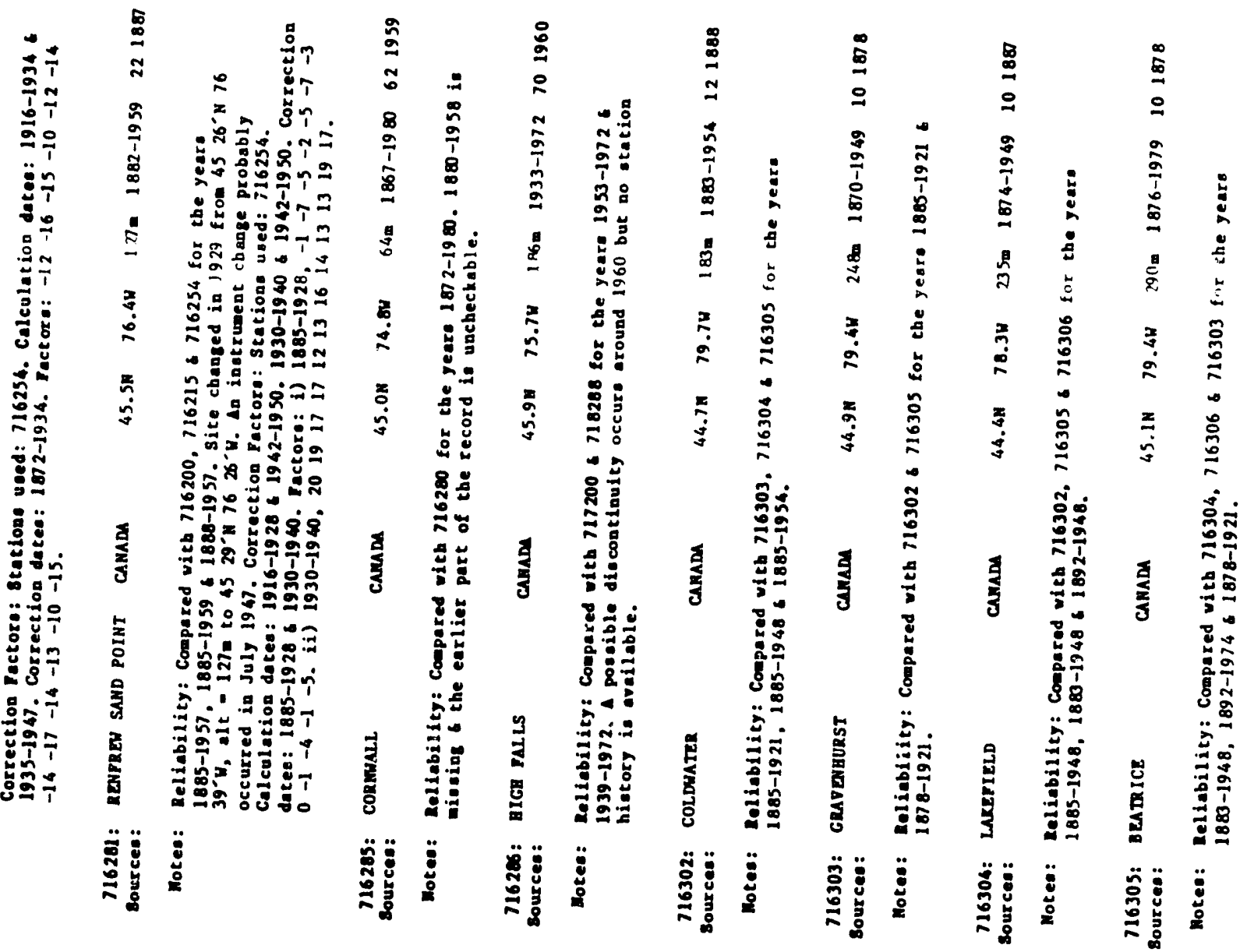

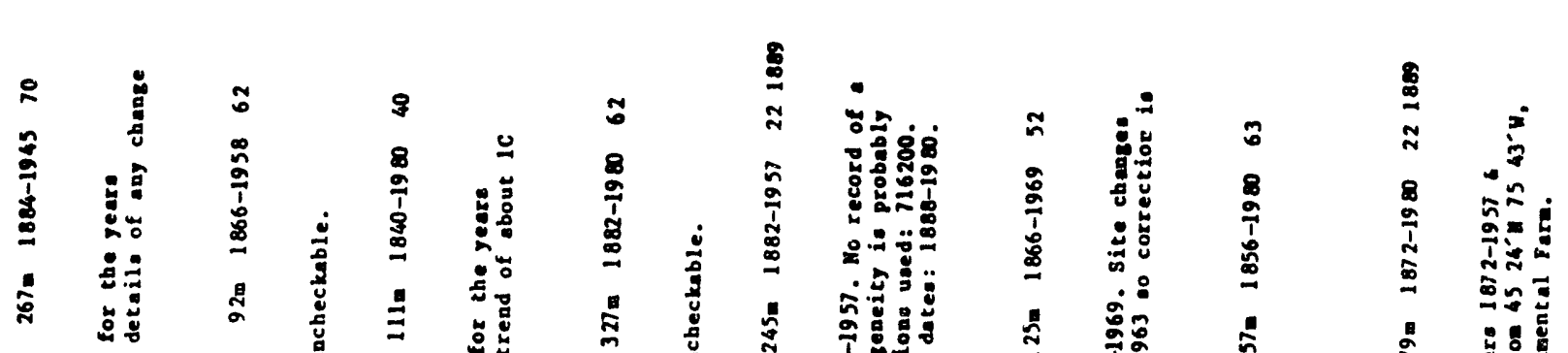

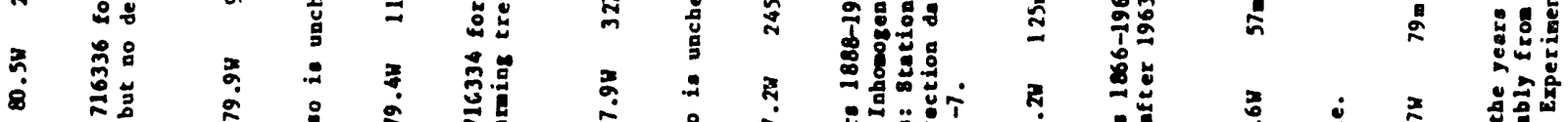

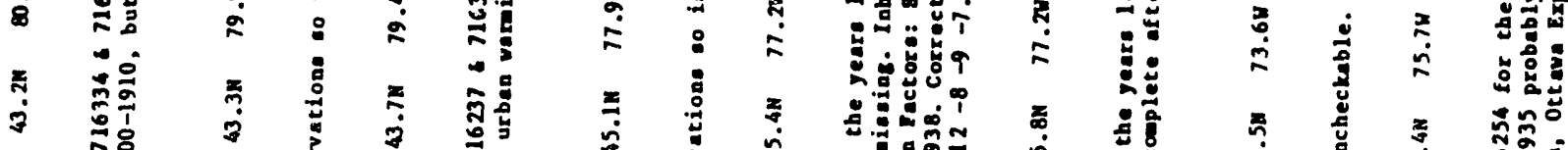

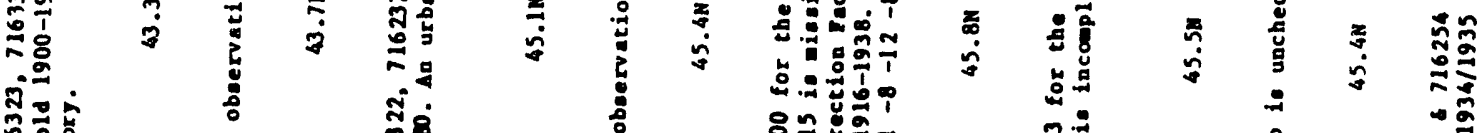

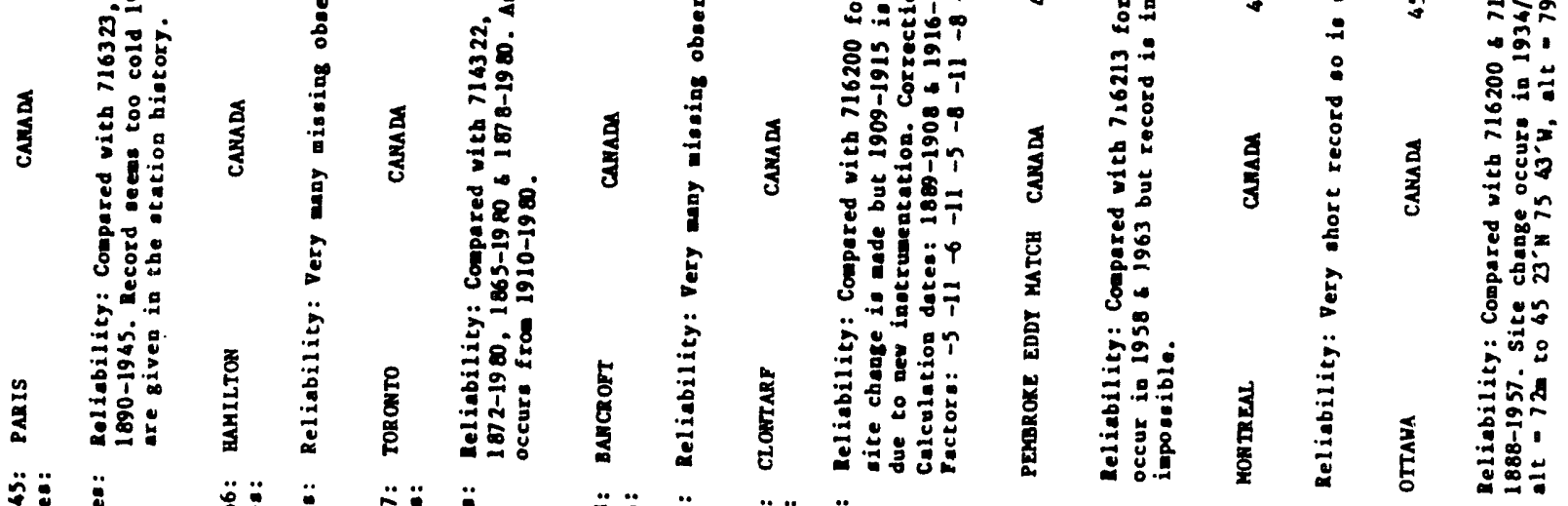

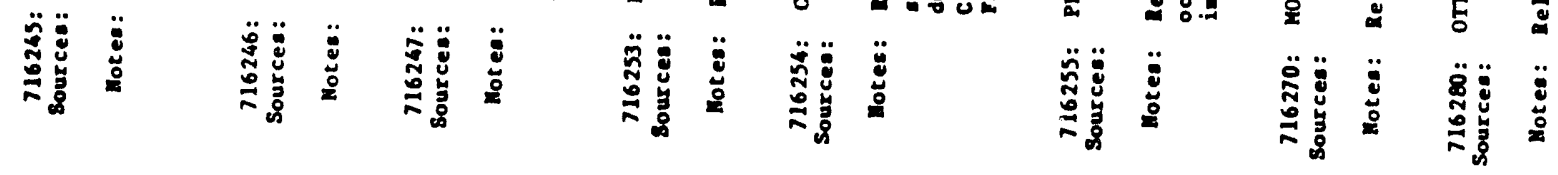


q

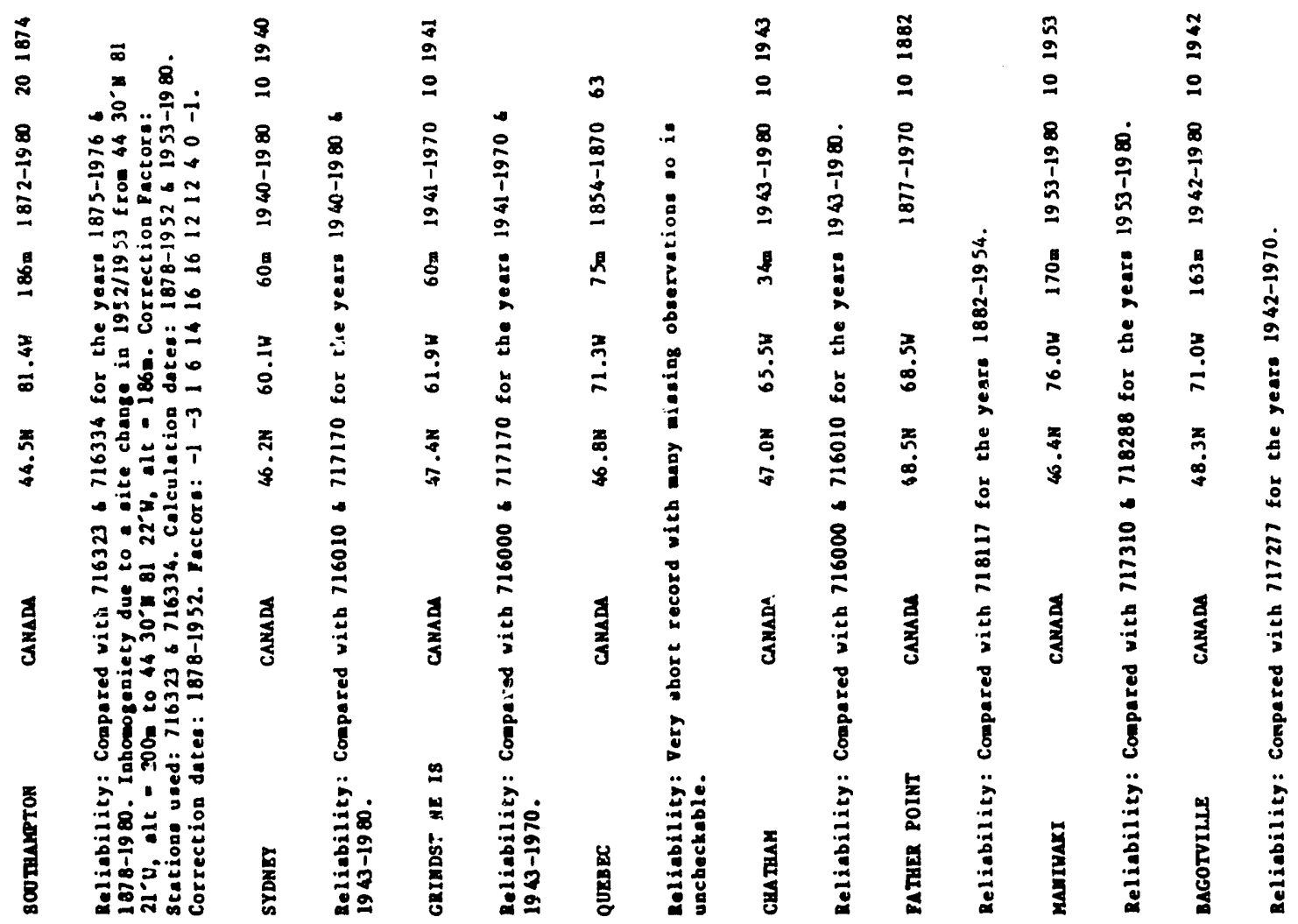

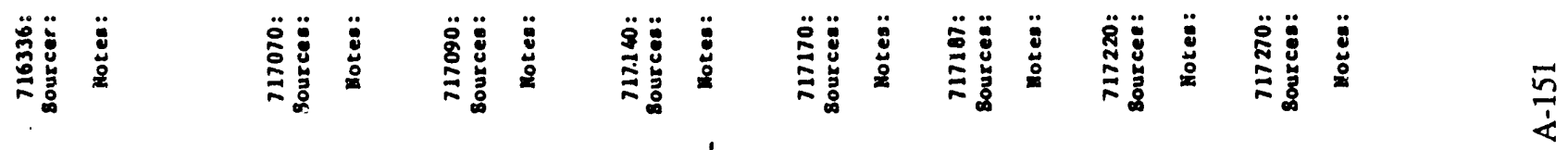

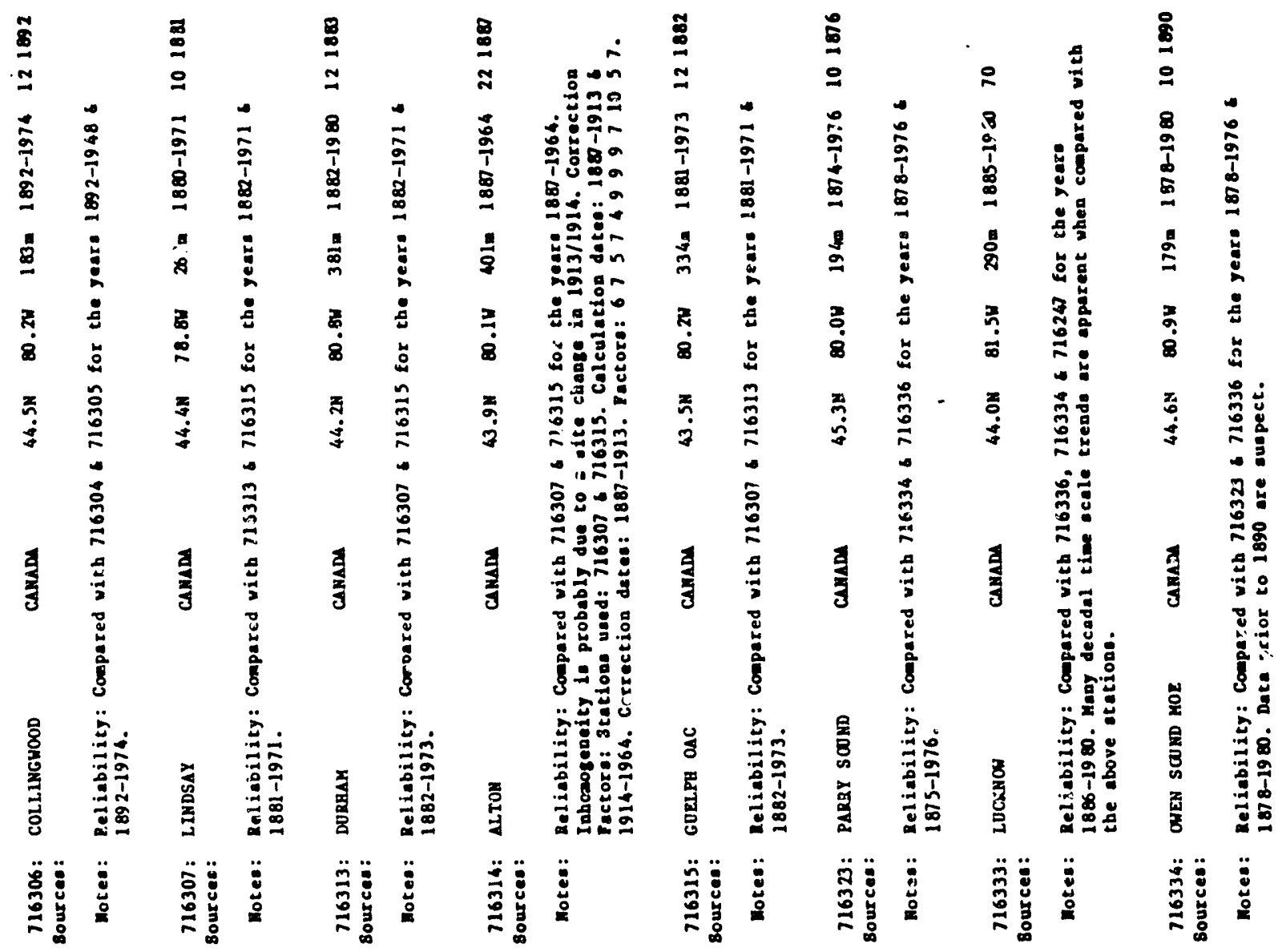




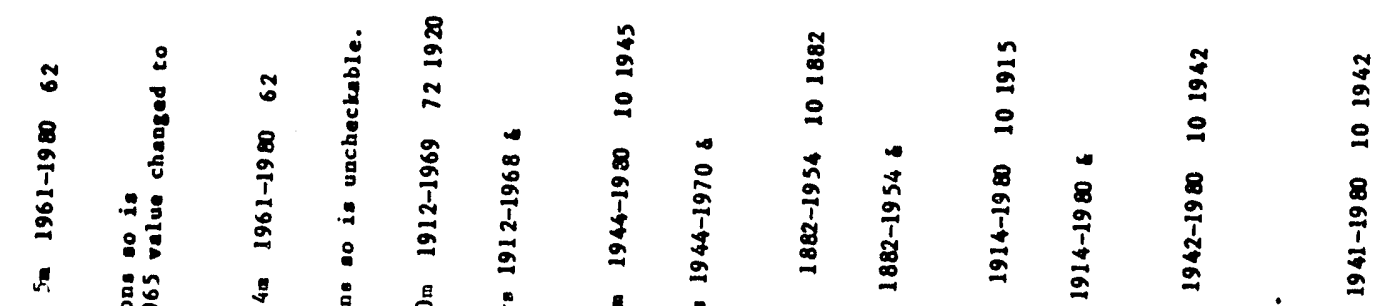

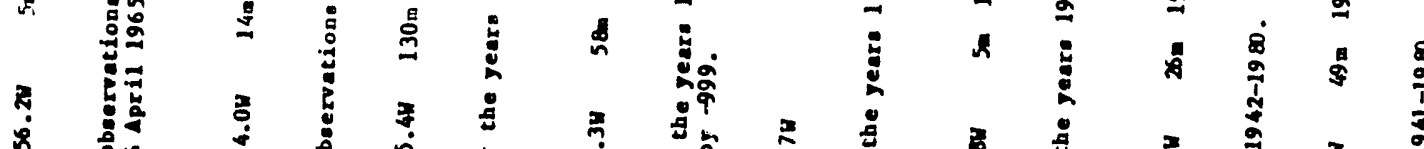

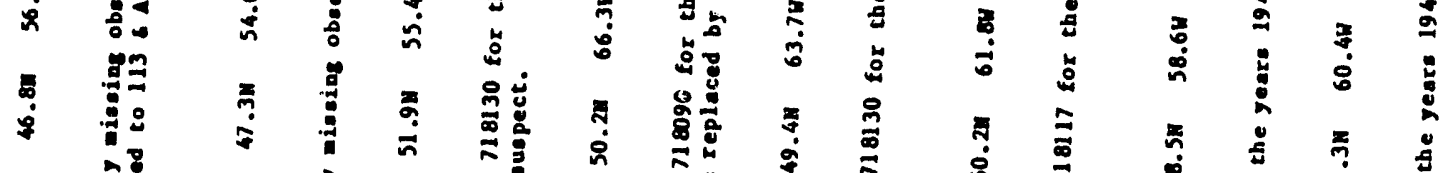

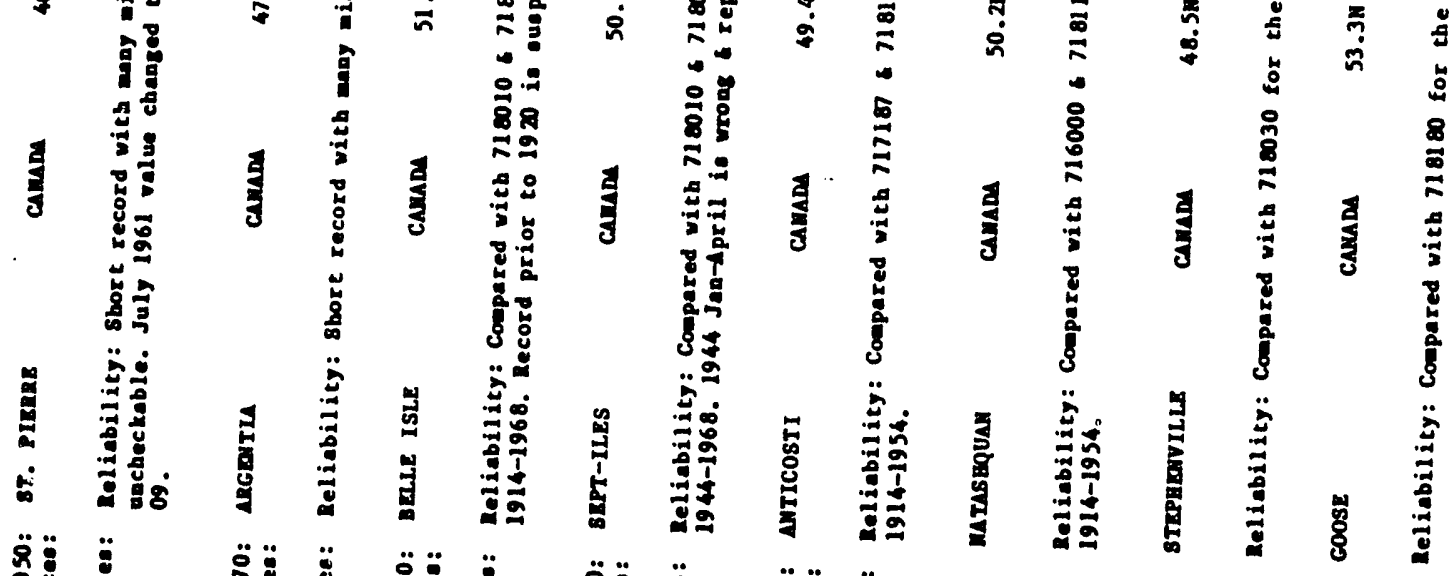

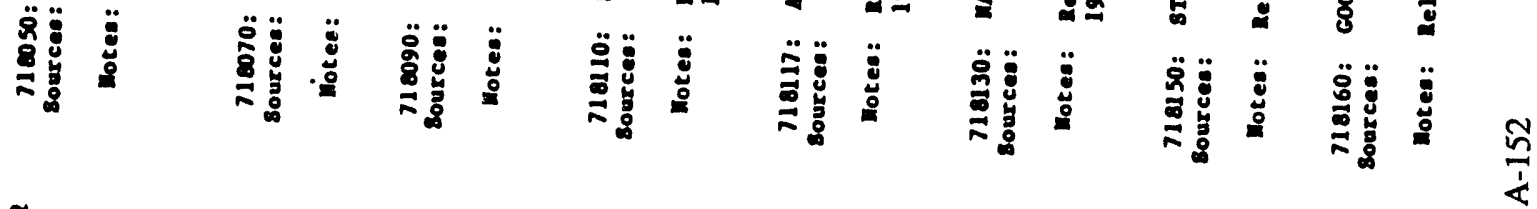

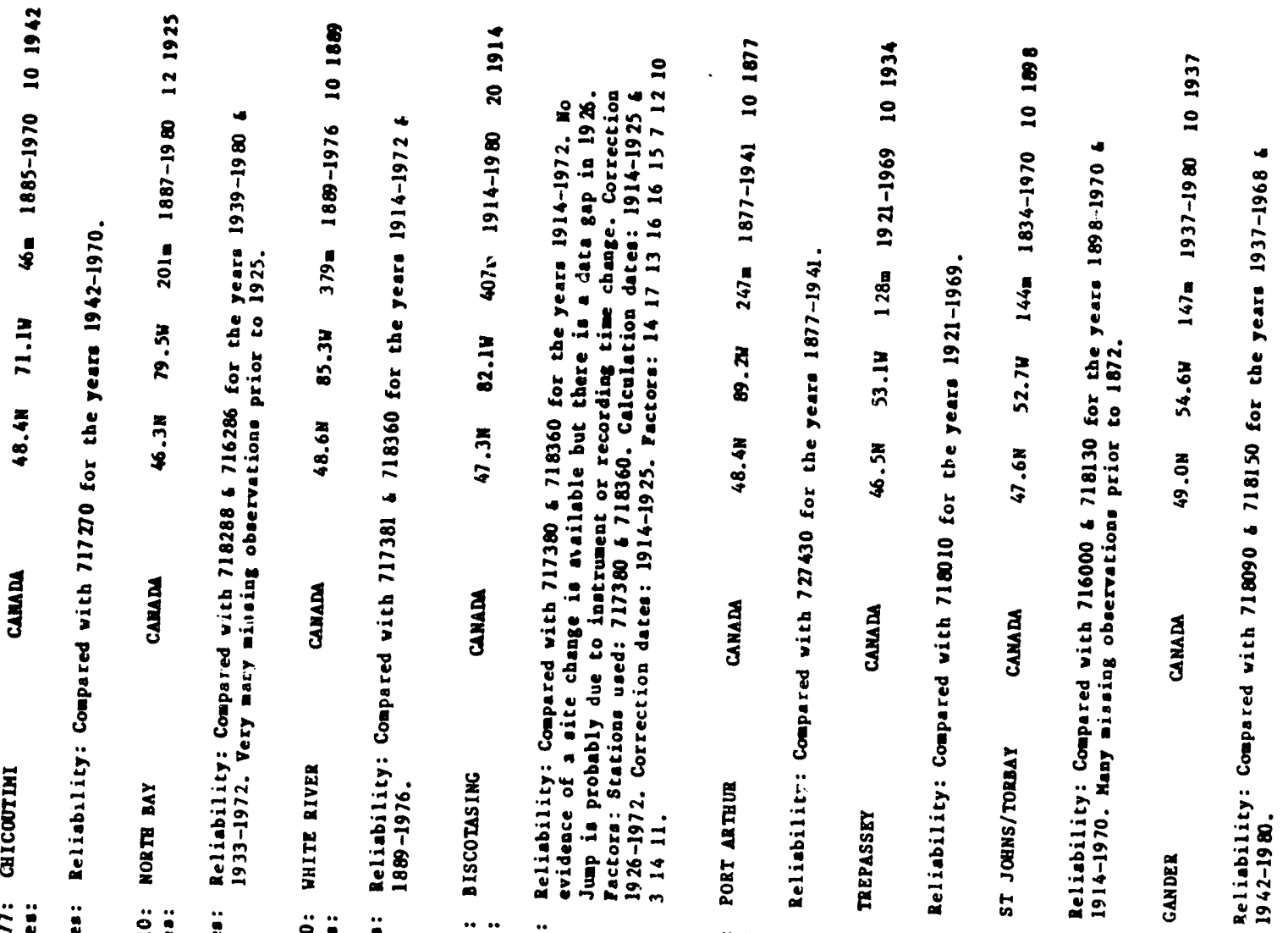

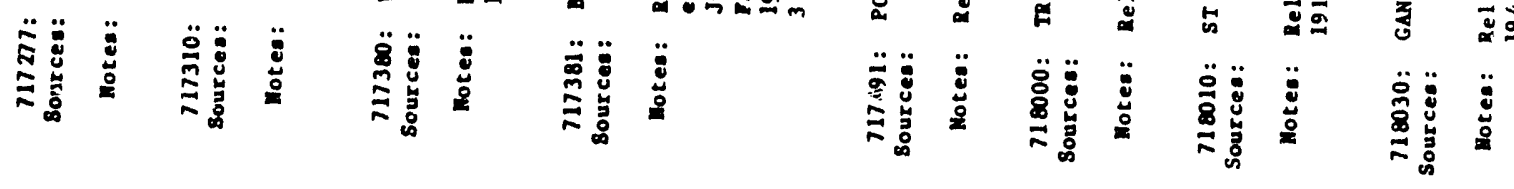




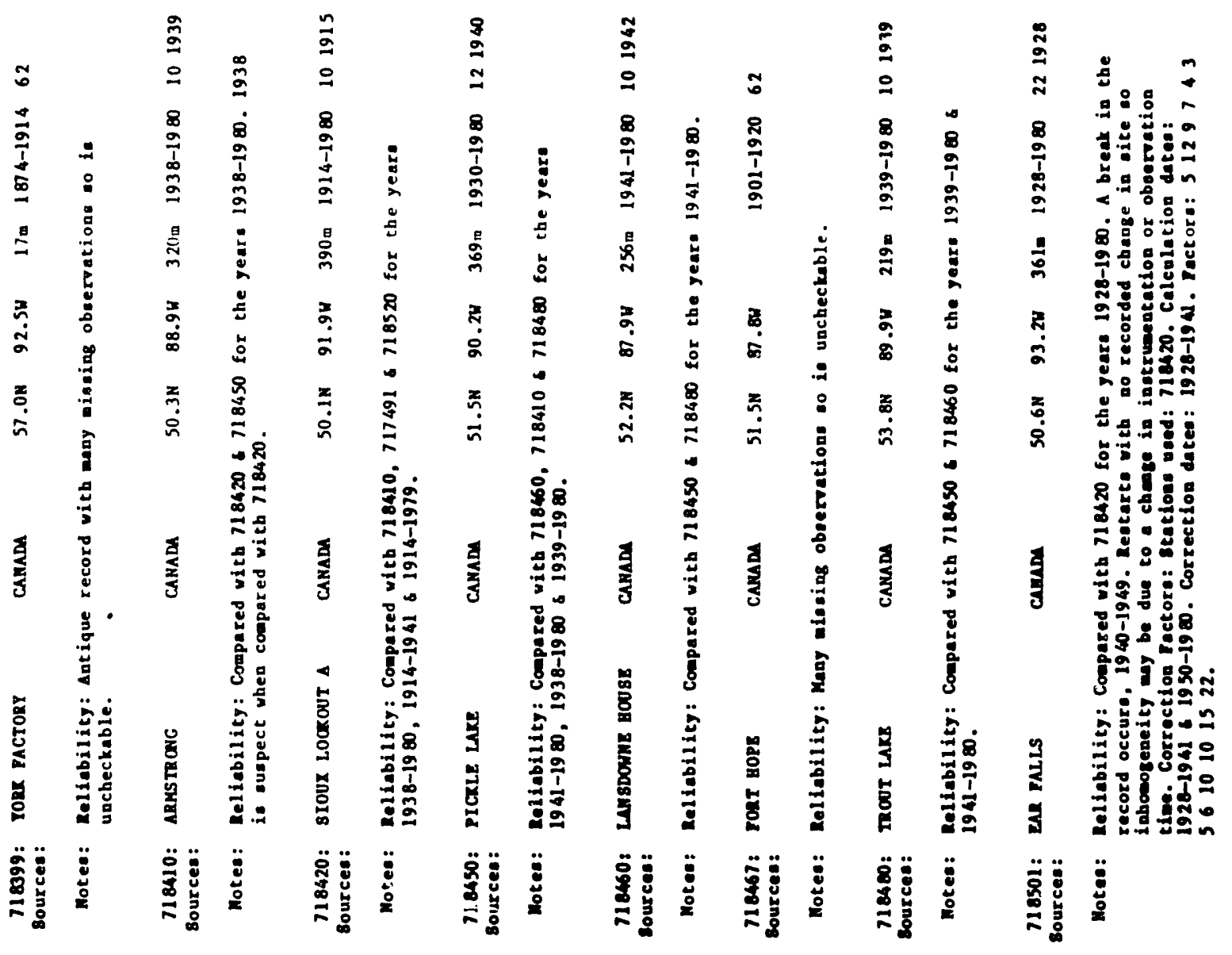

$\frac{n}{2}$

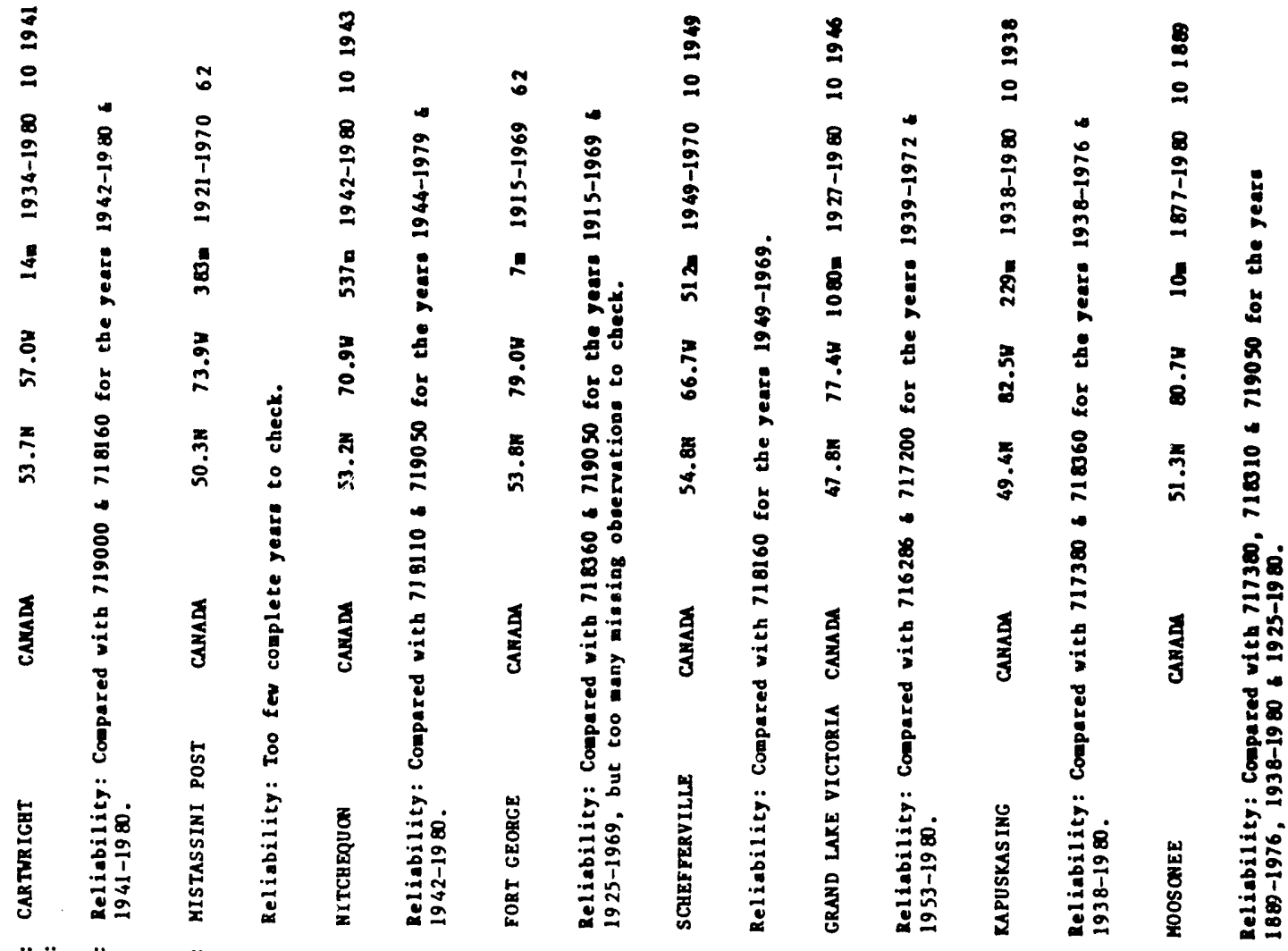

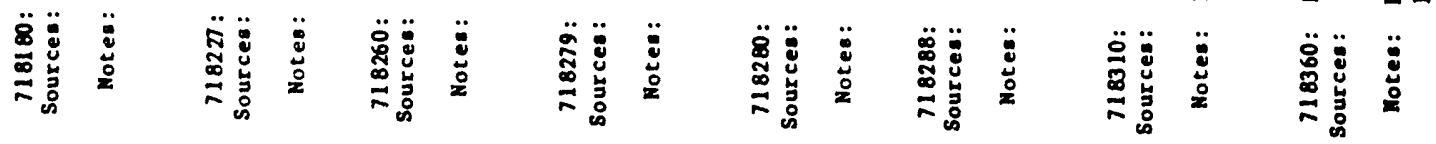




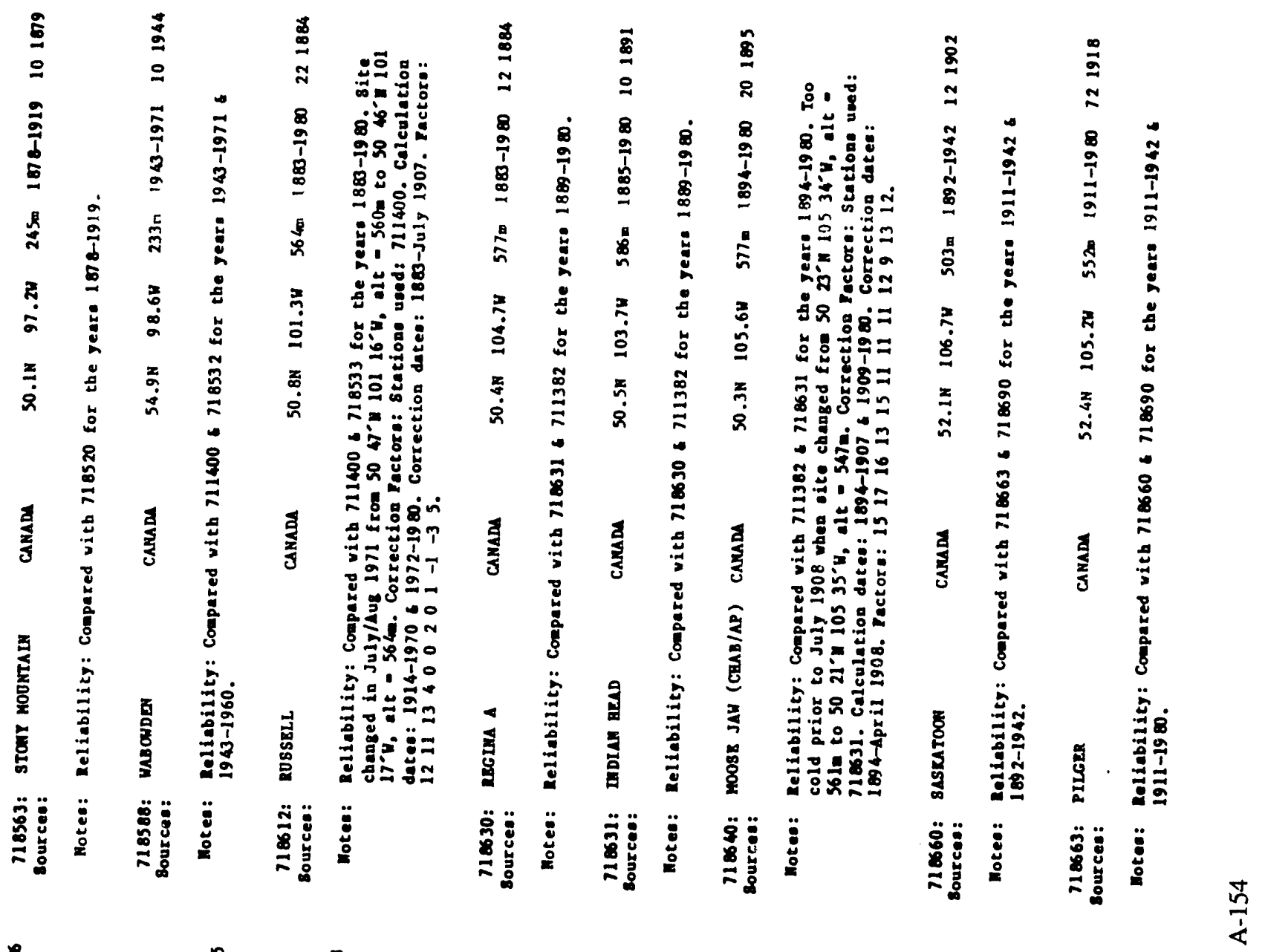

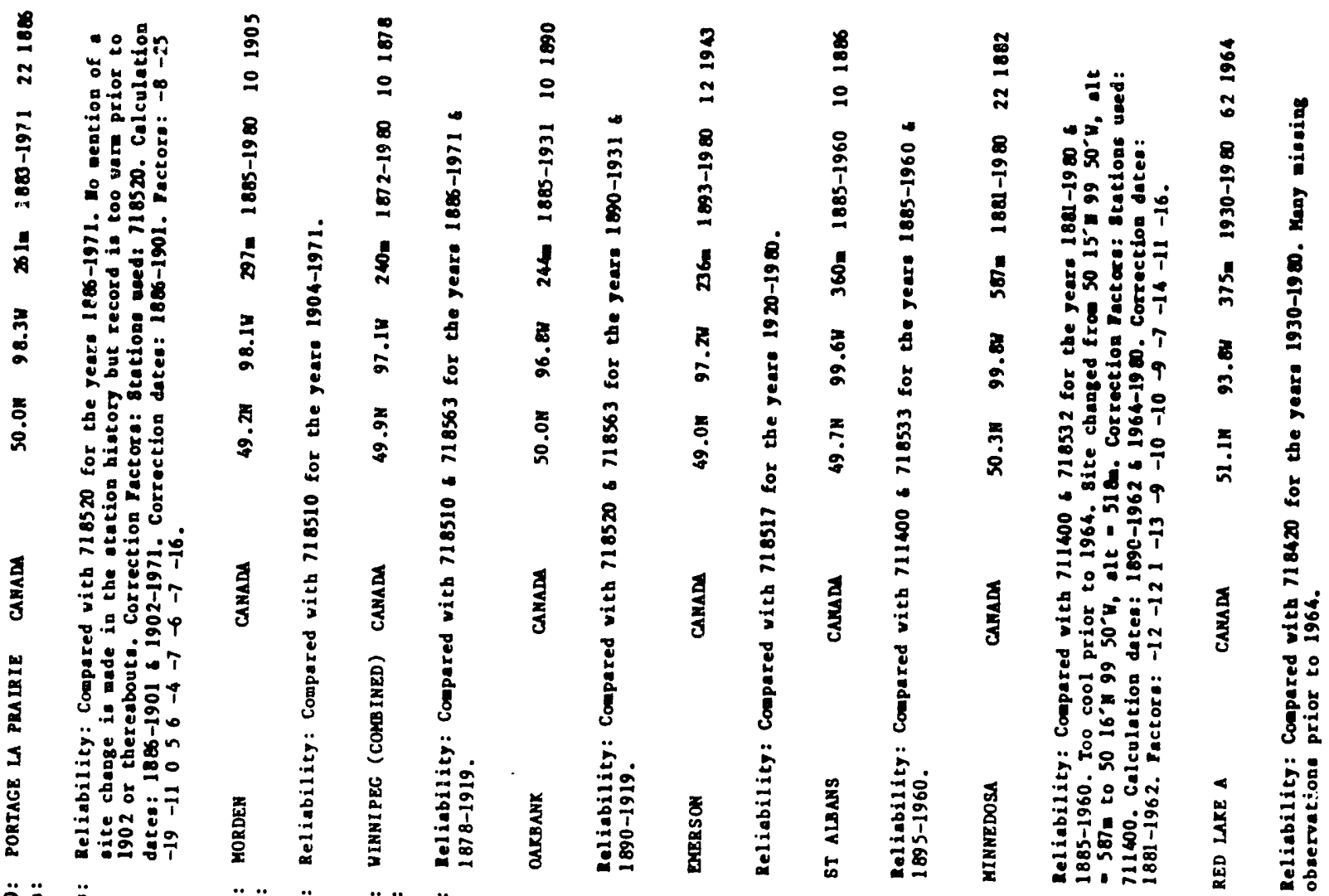

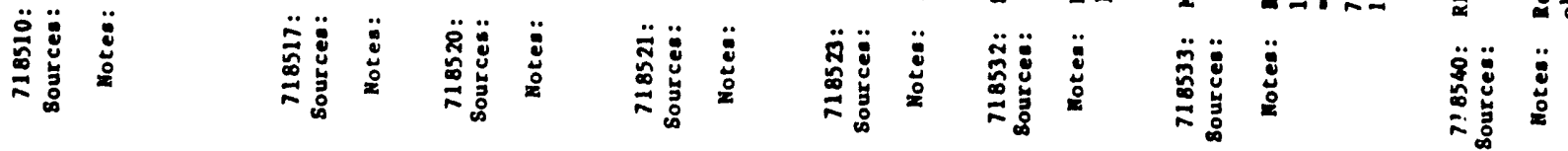



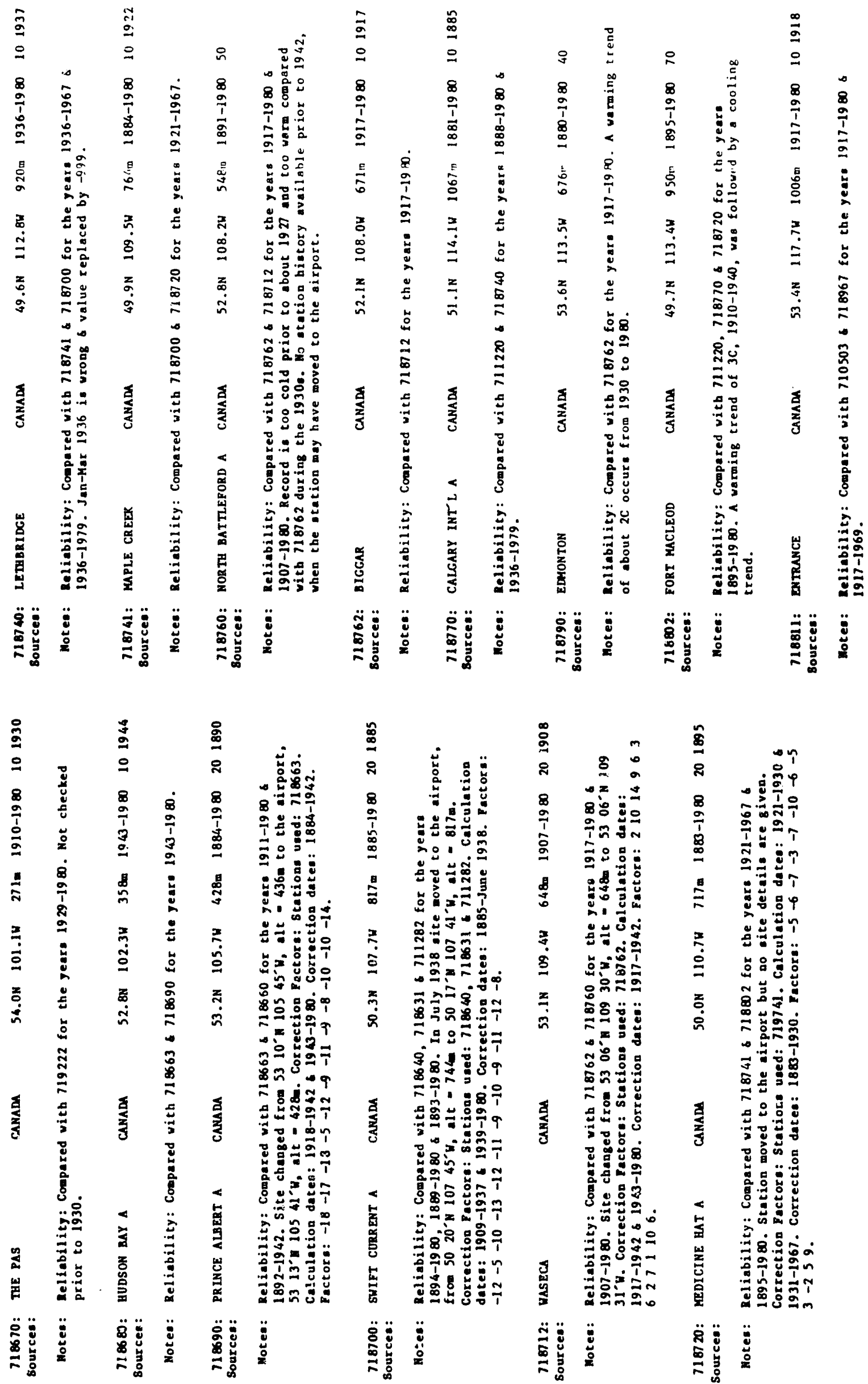


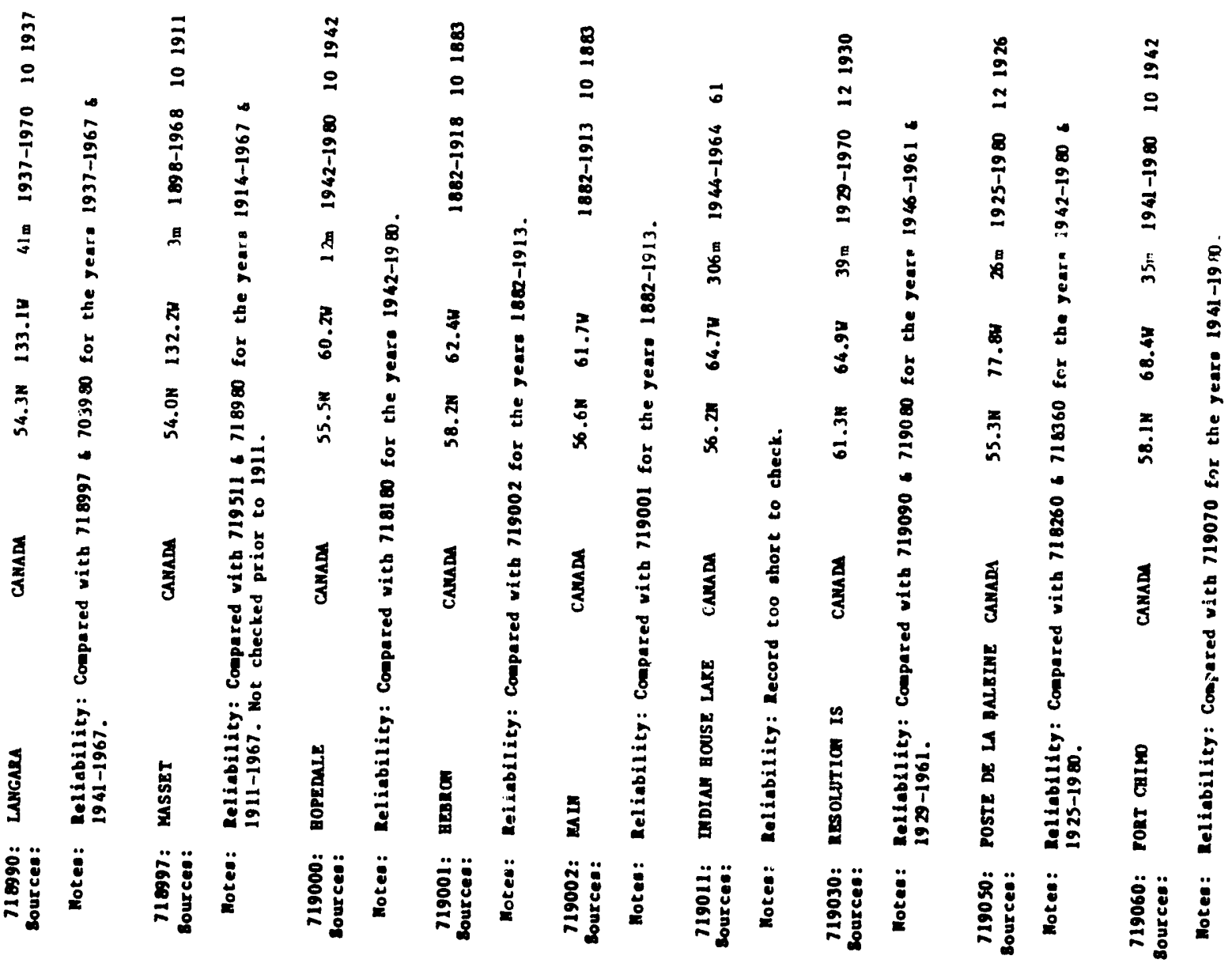

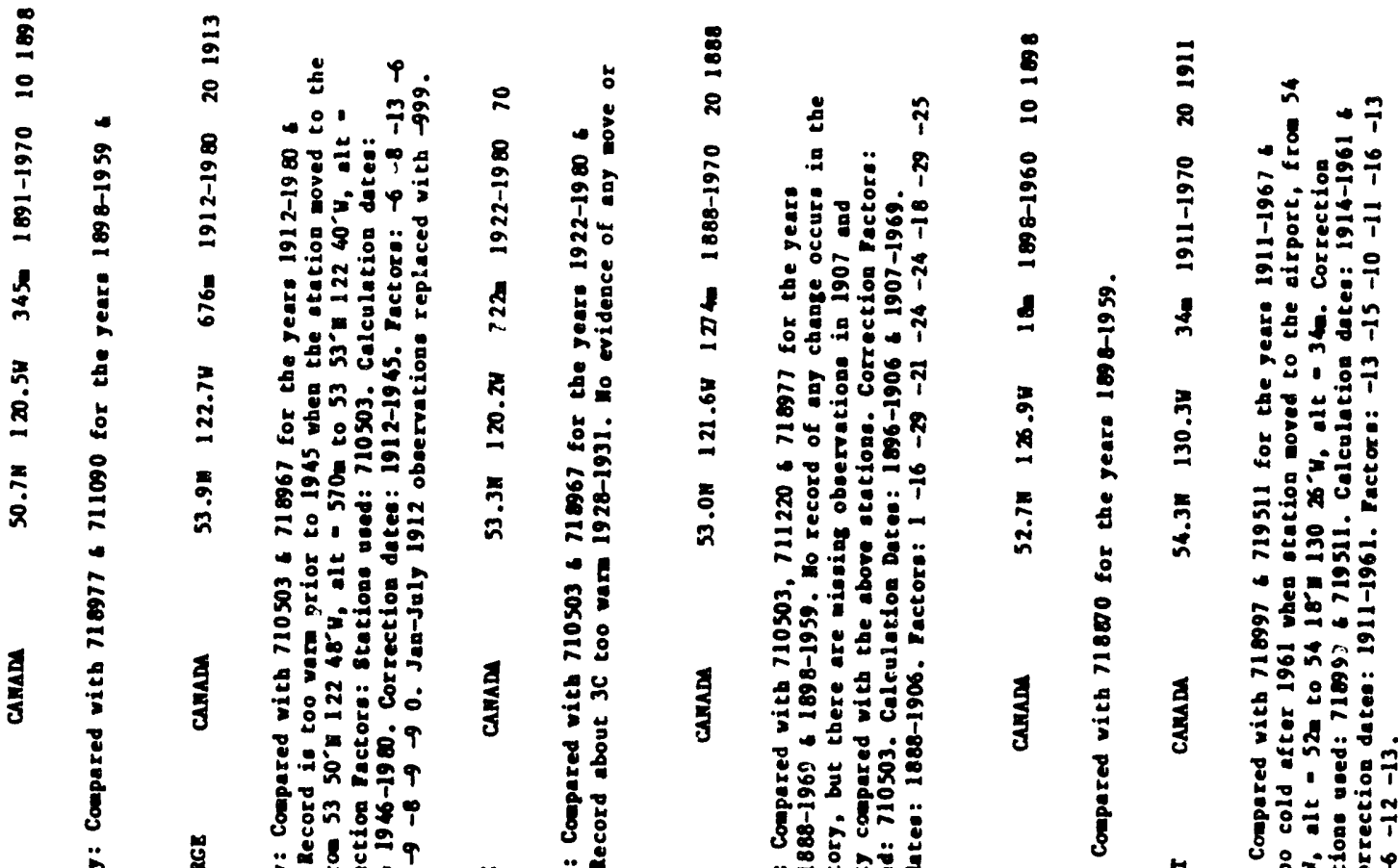

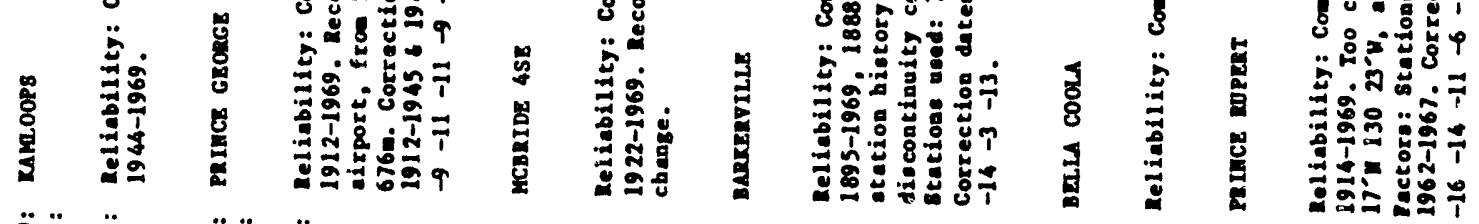

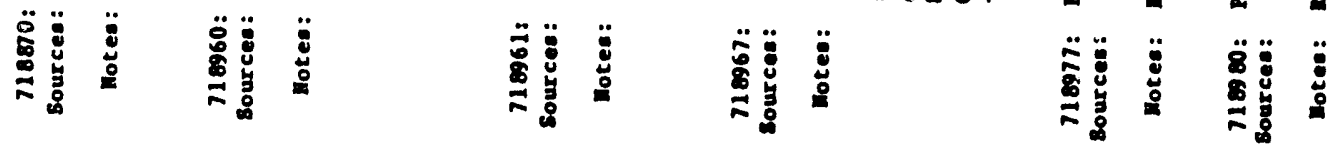




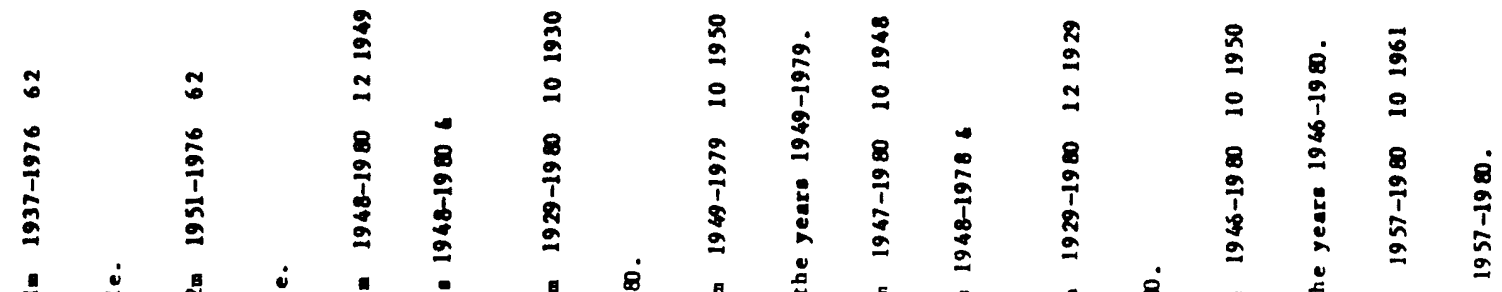

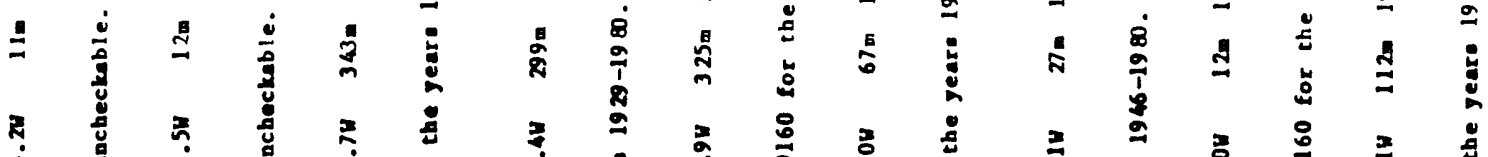

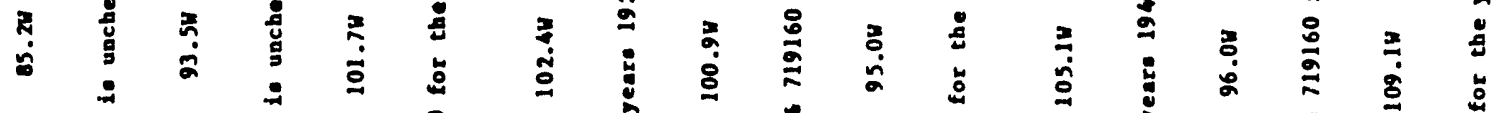

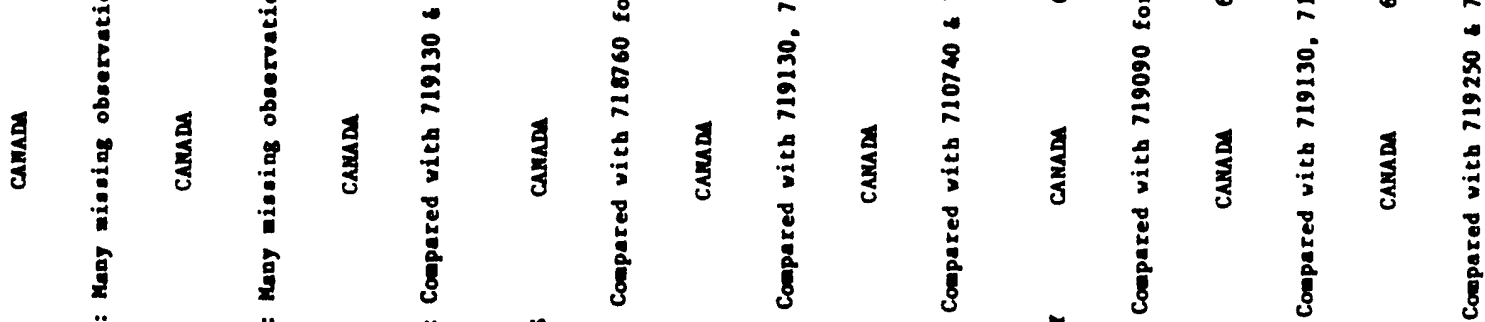

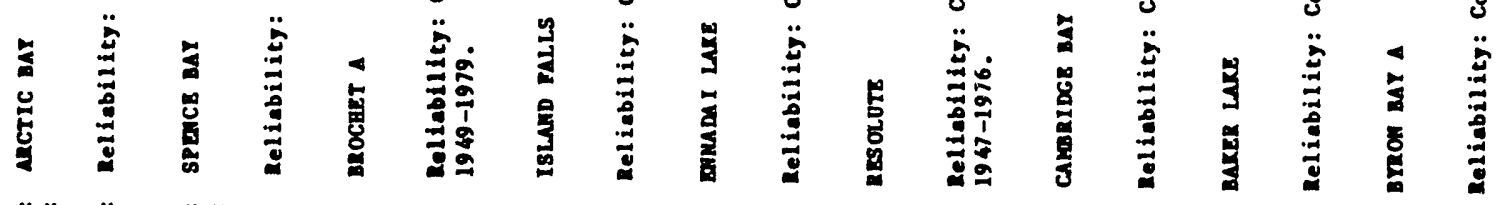

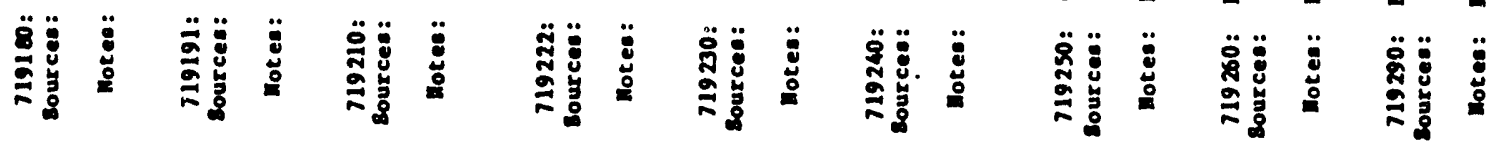

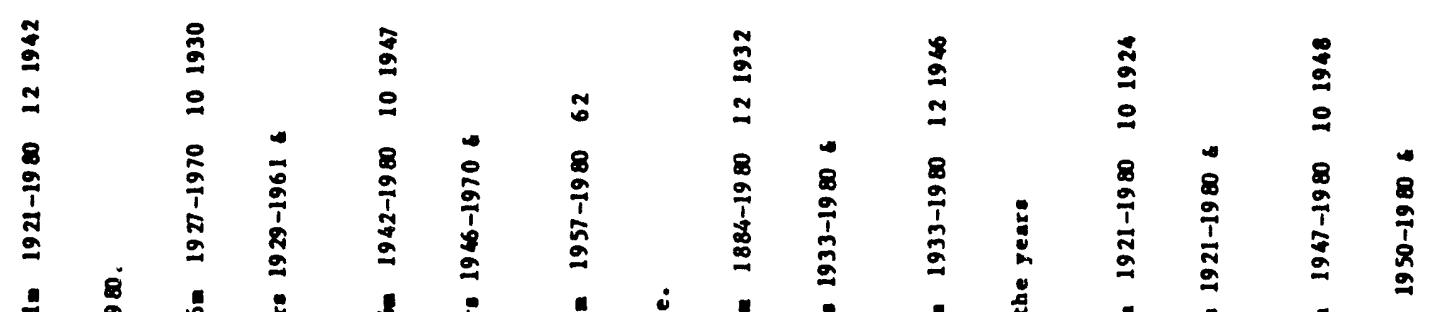

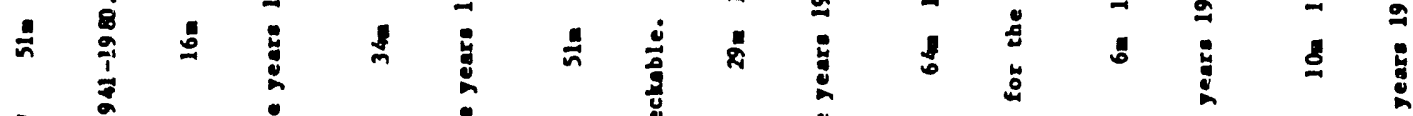

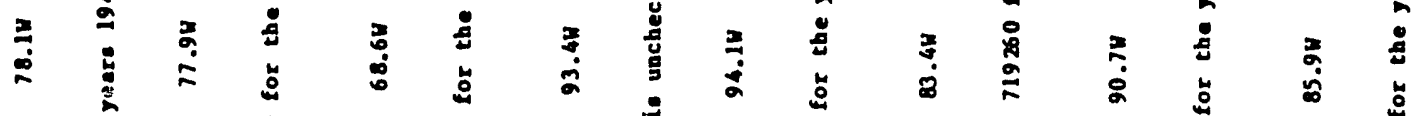

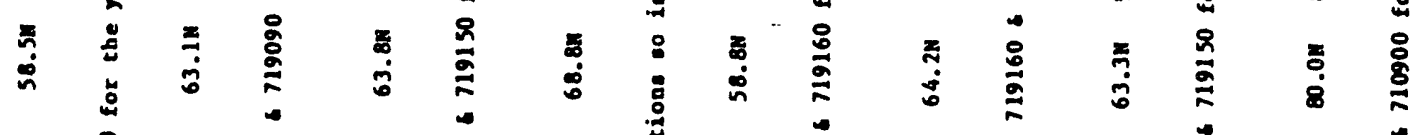

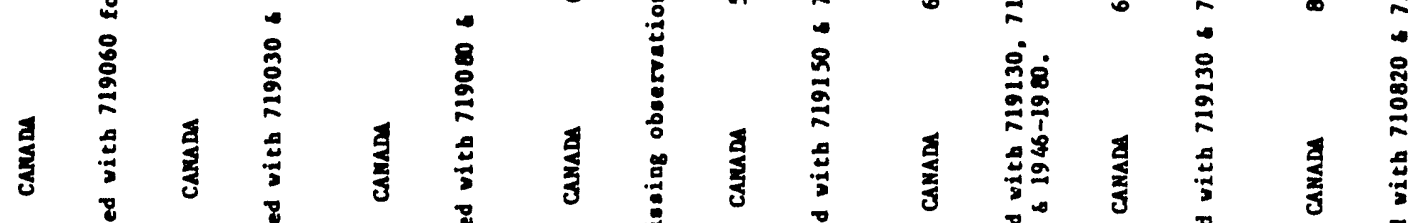

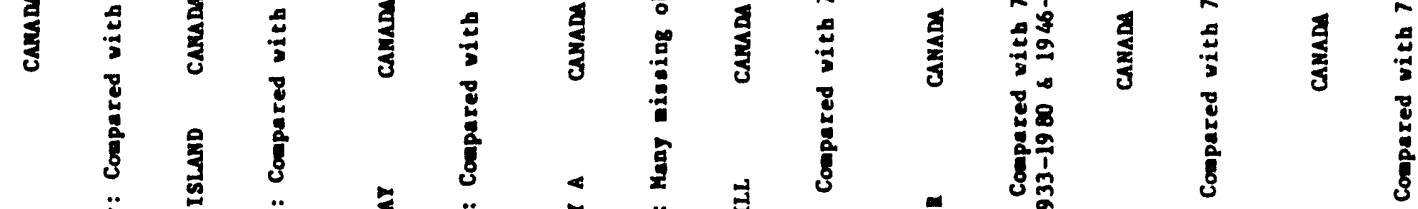

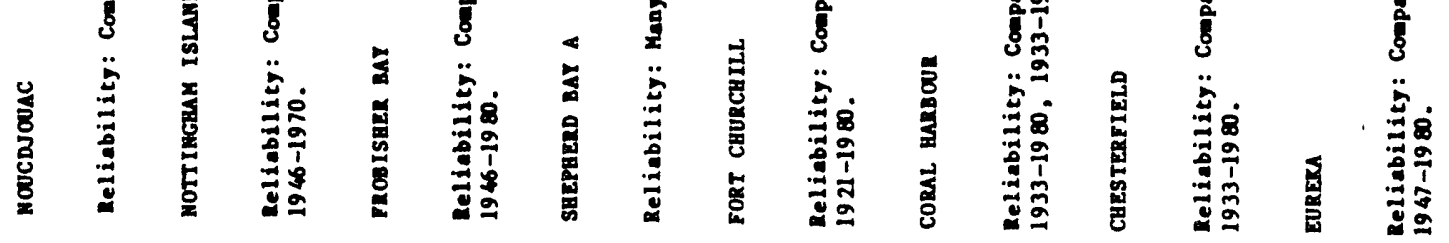

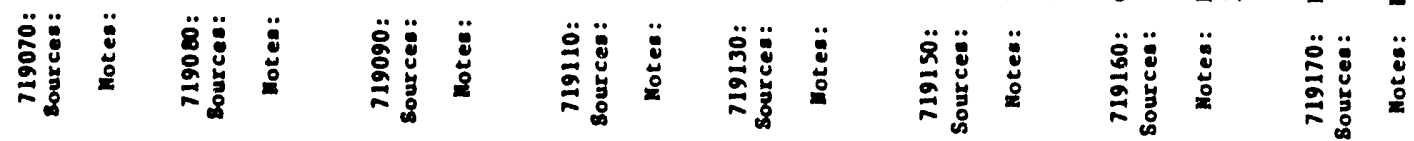




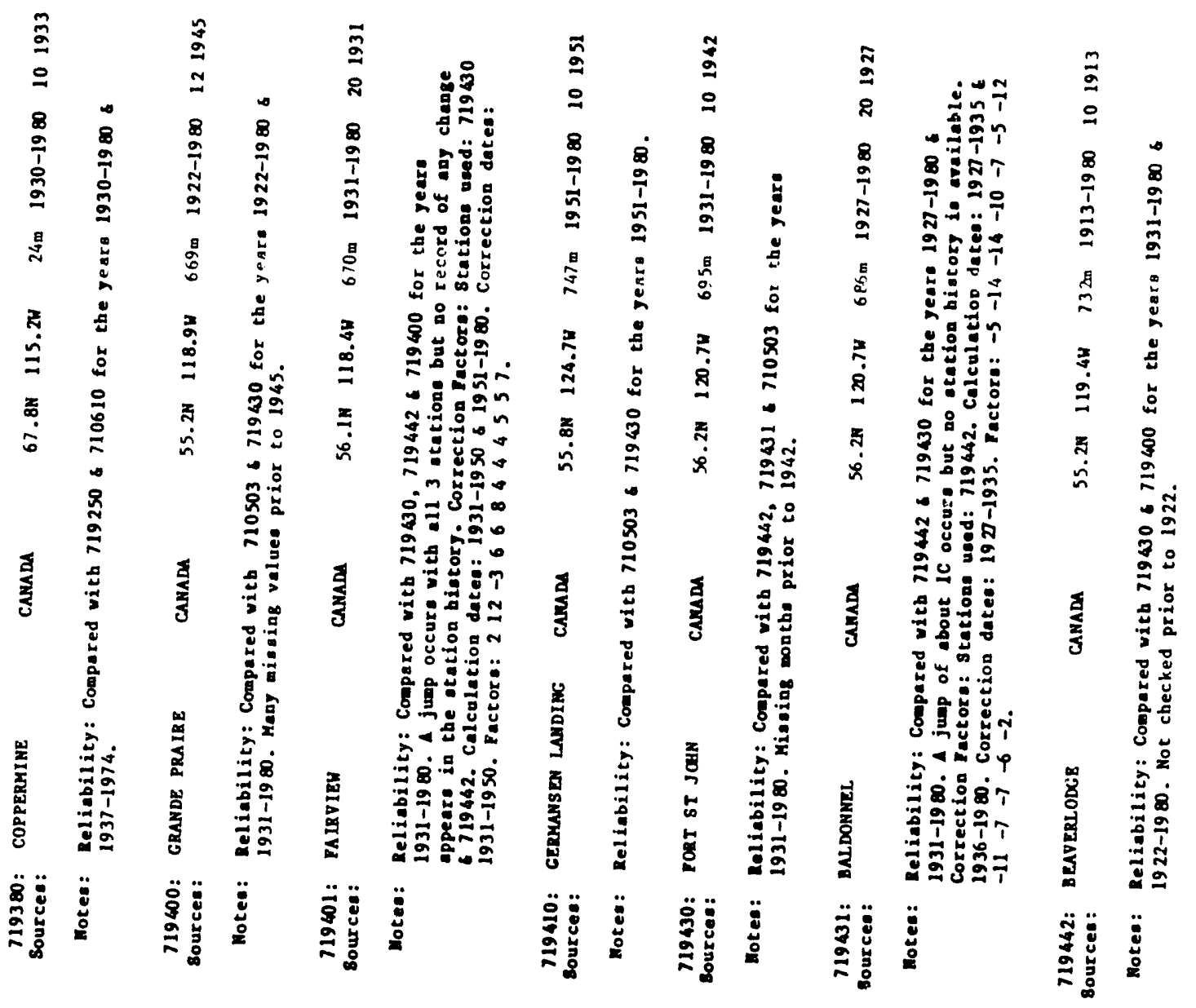

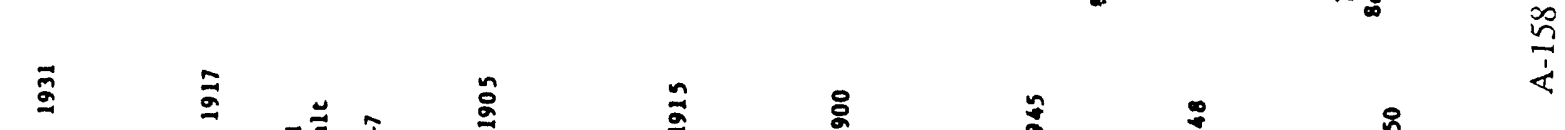

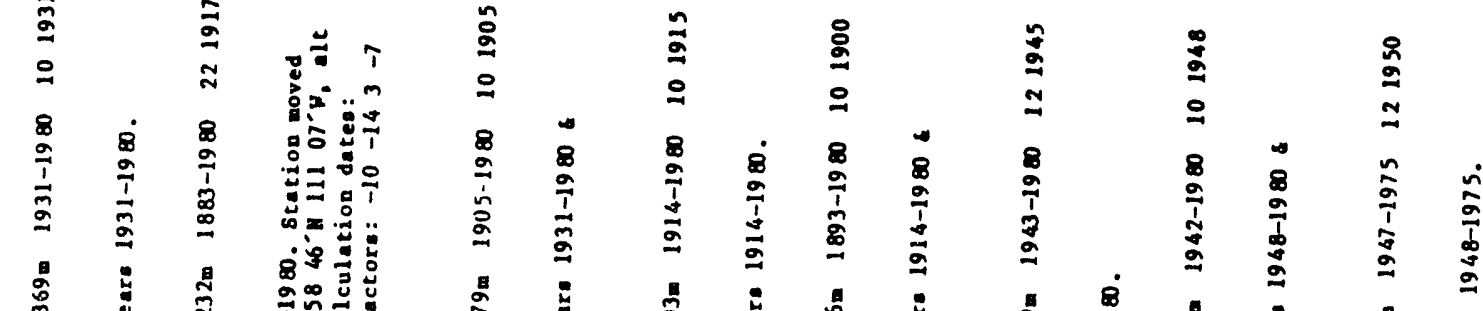

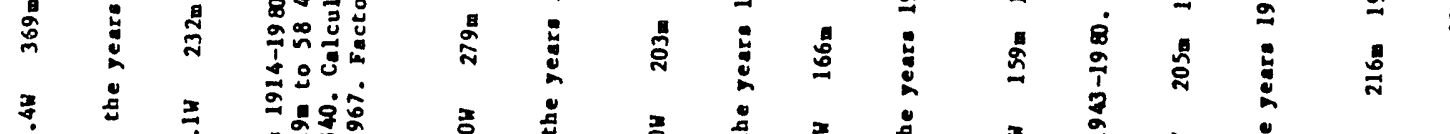

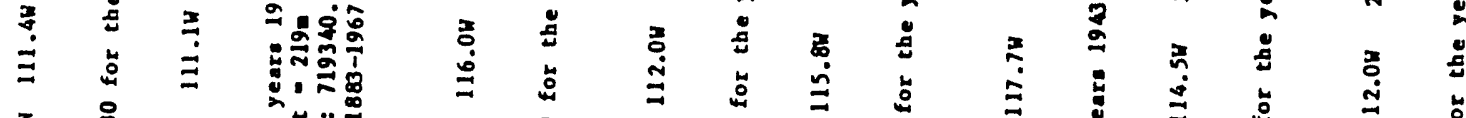

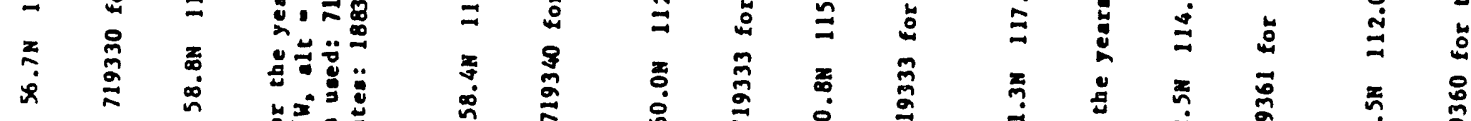

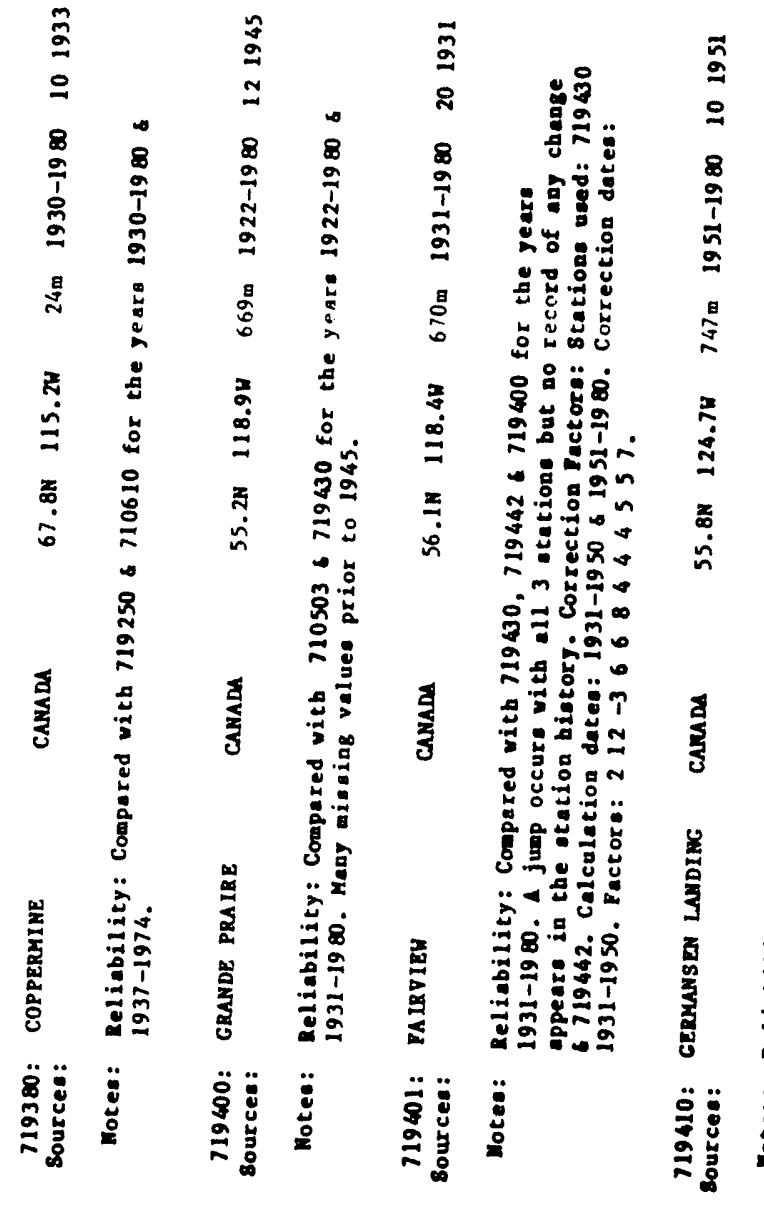

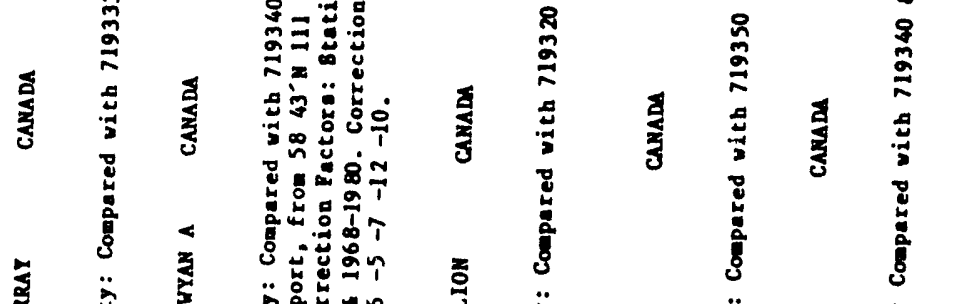

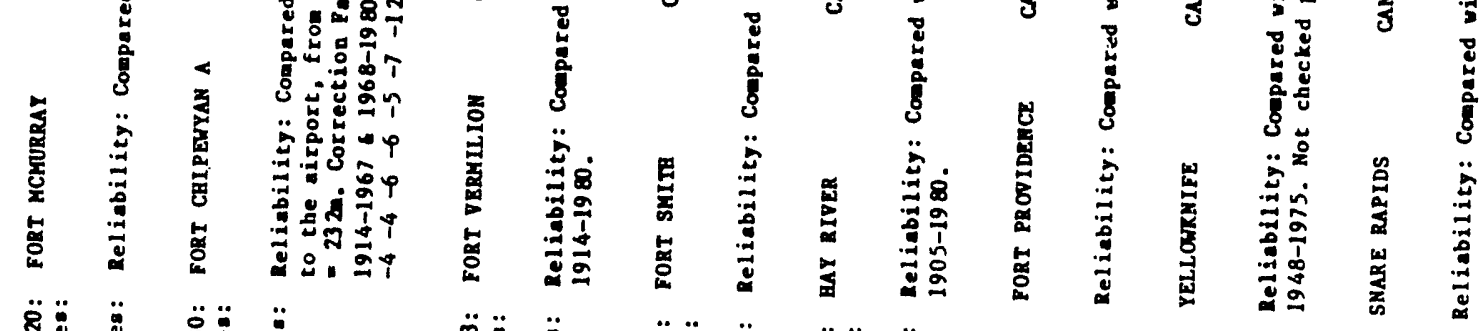

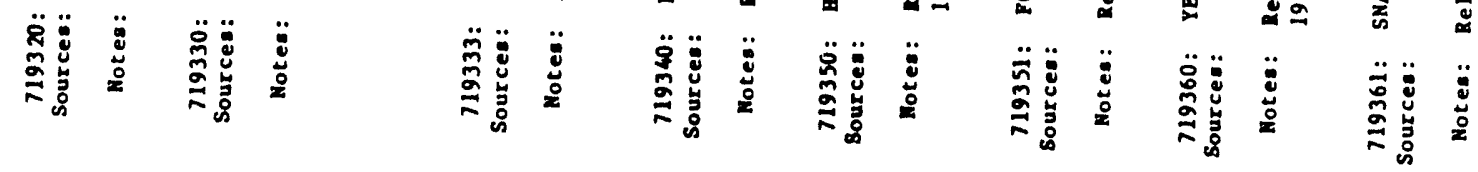




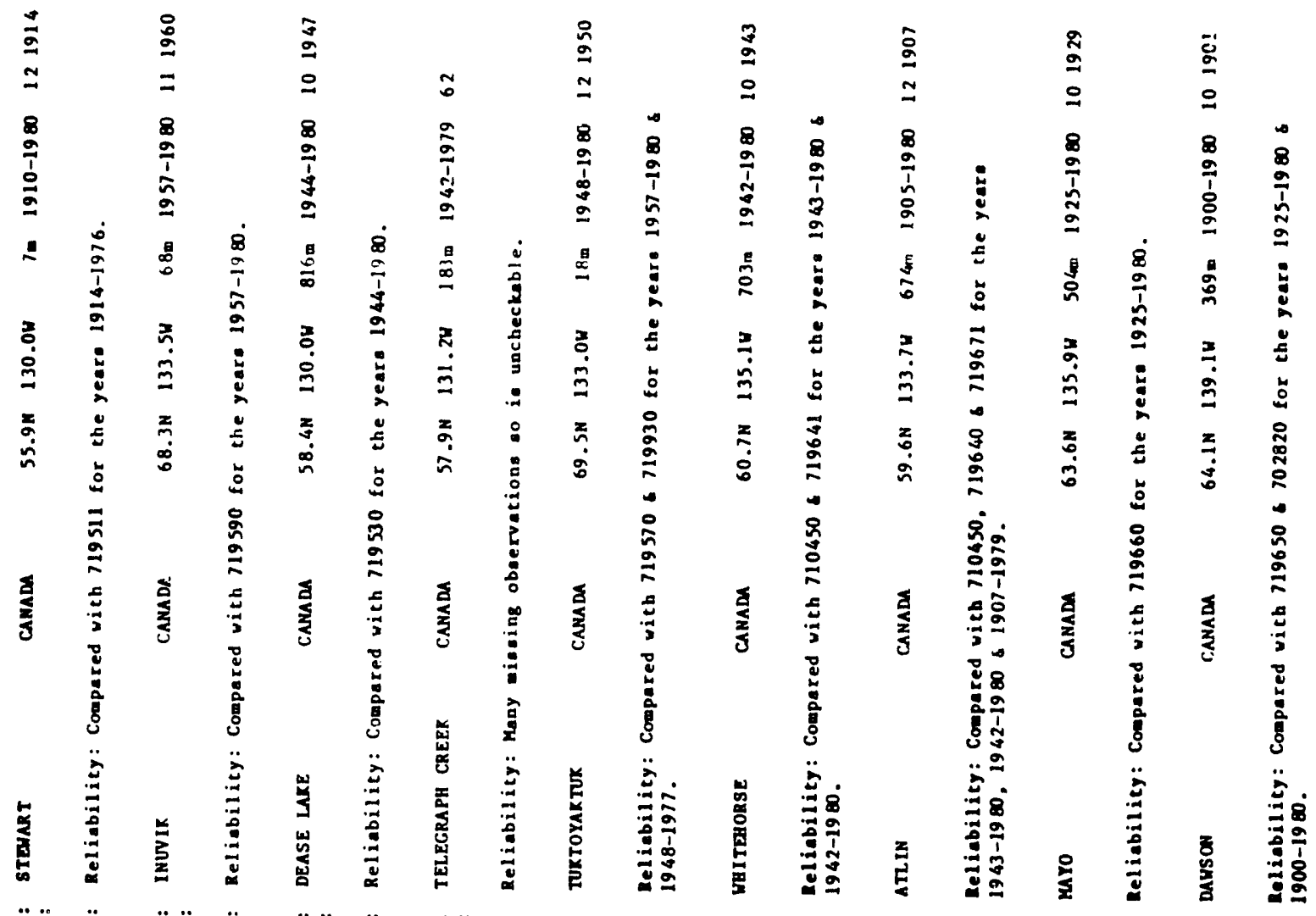

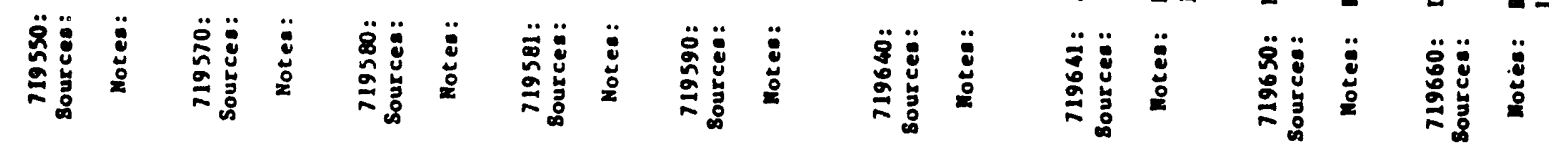

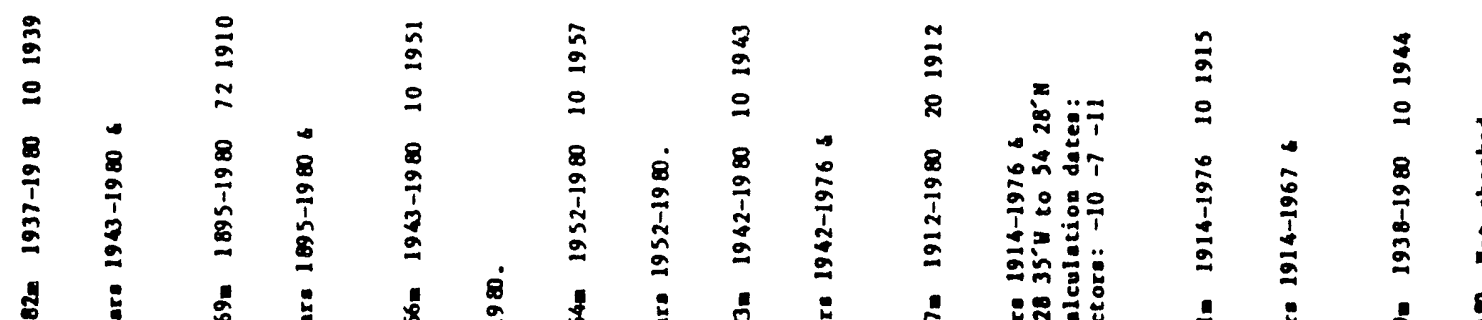

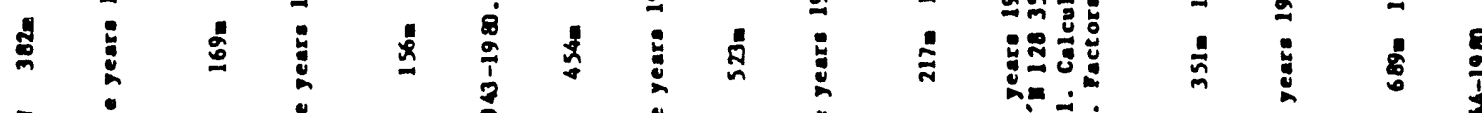

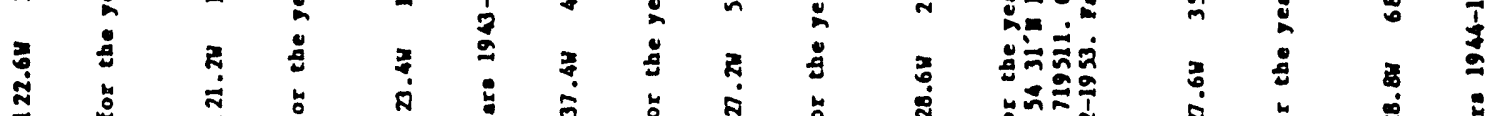

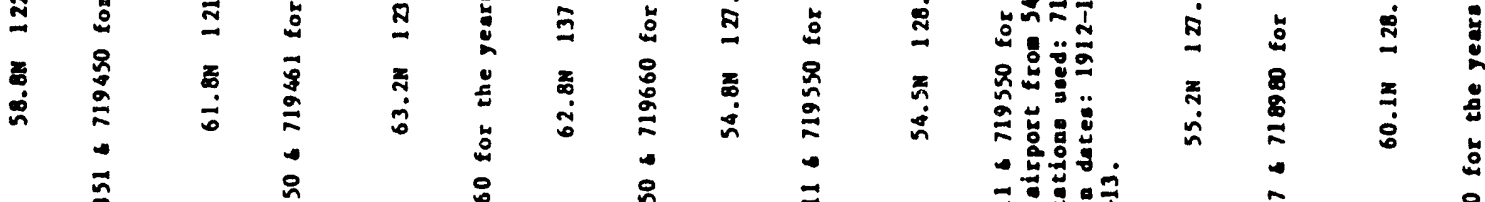

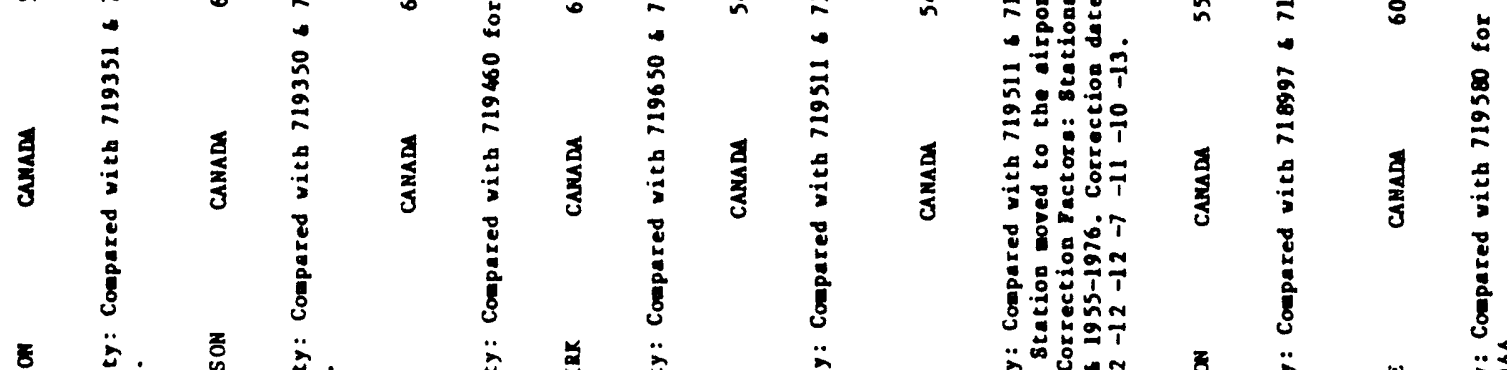

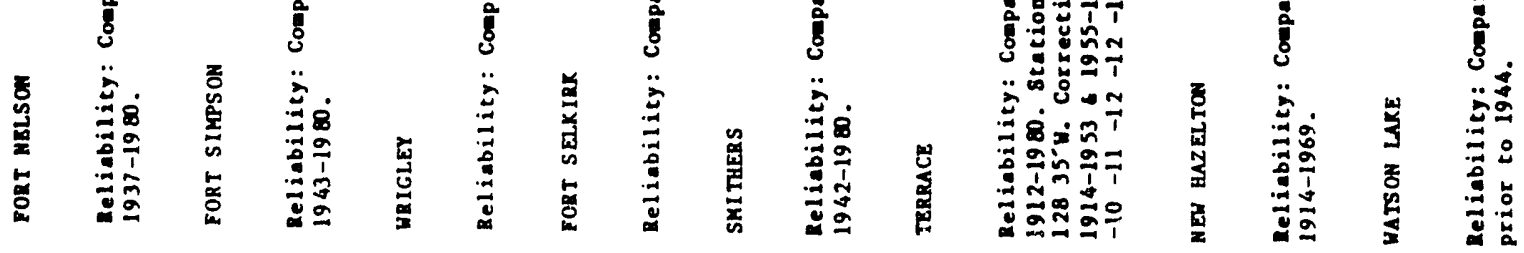

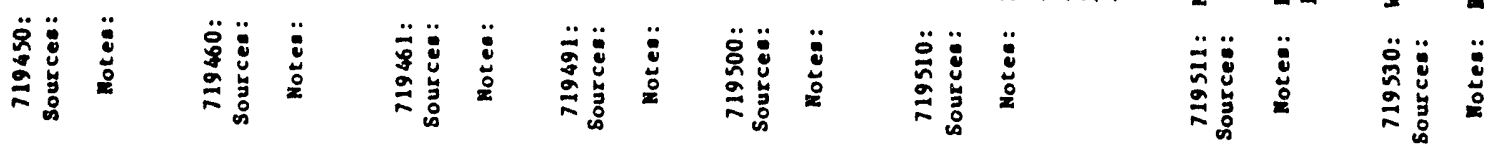



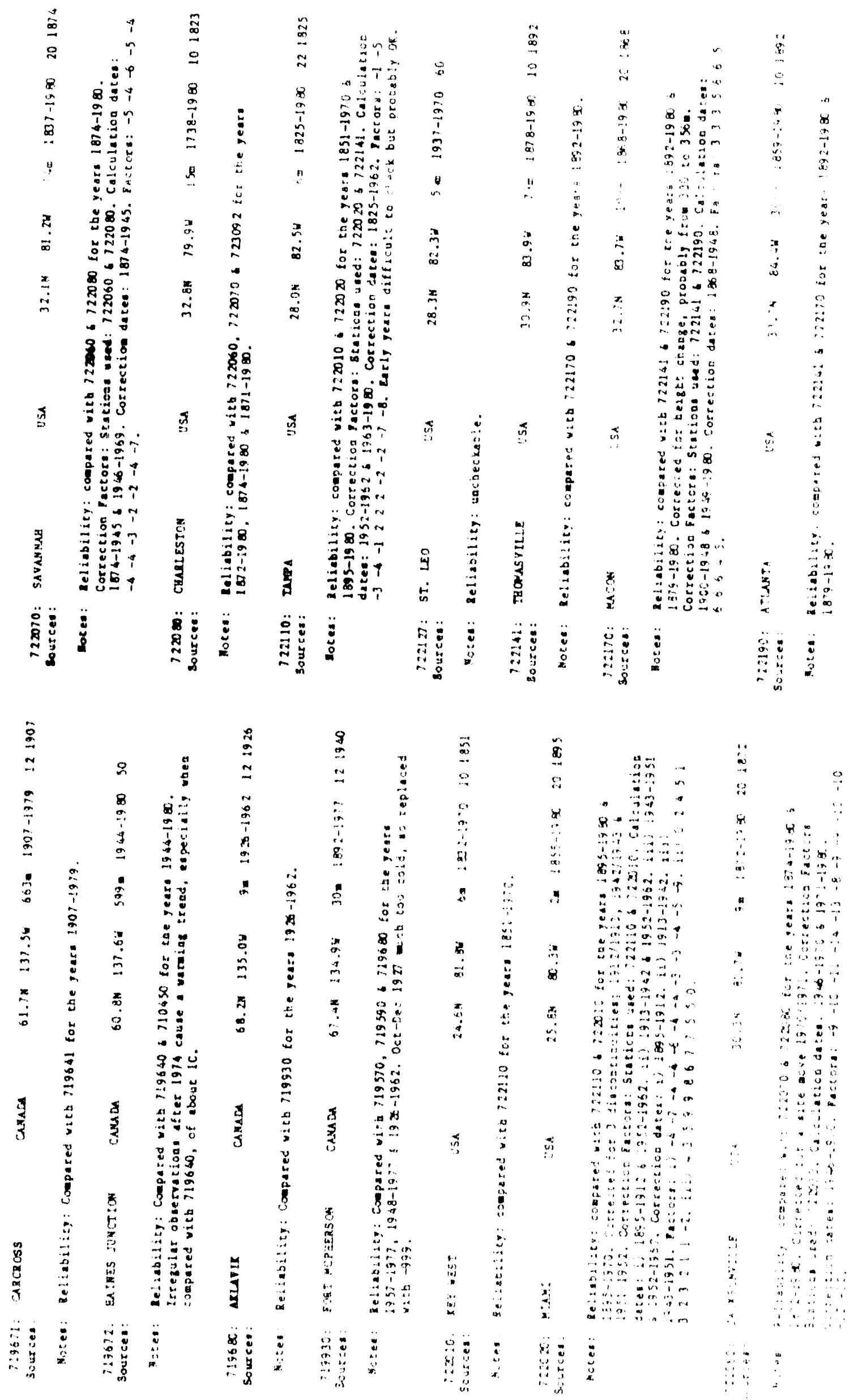

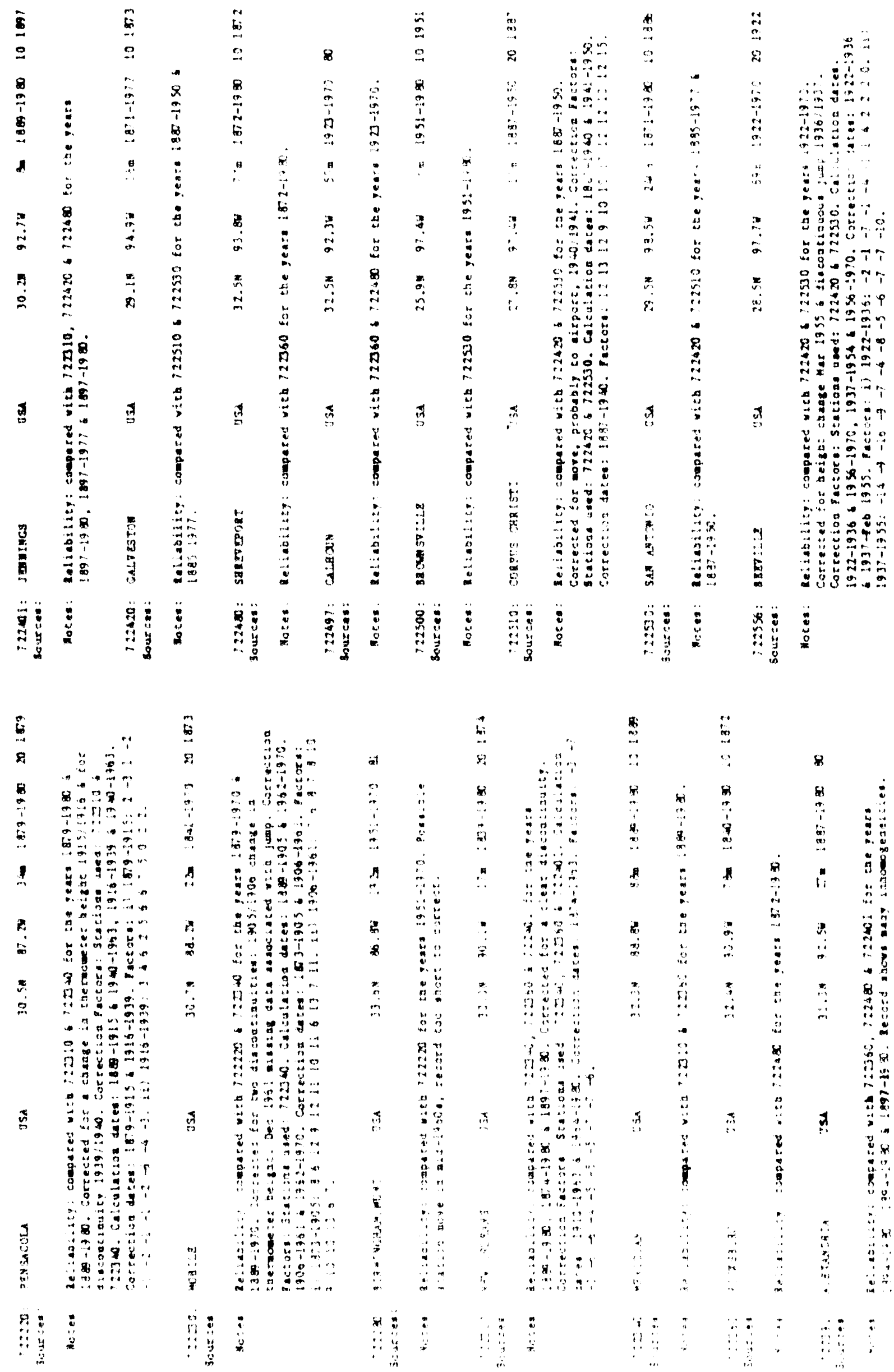


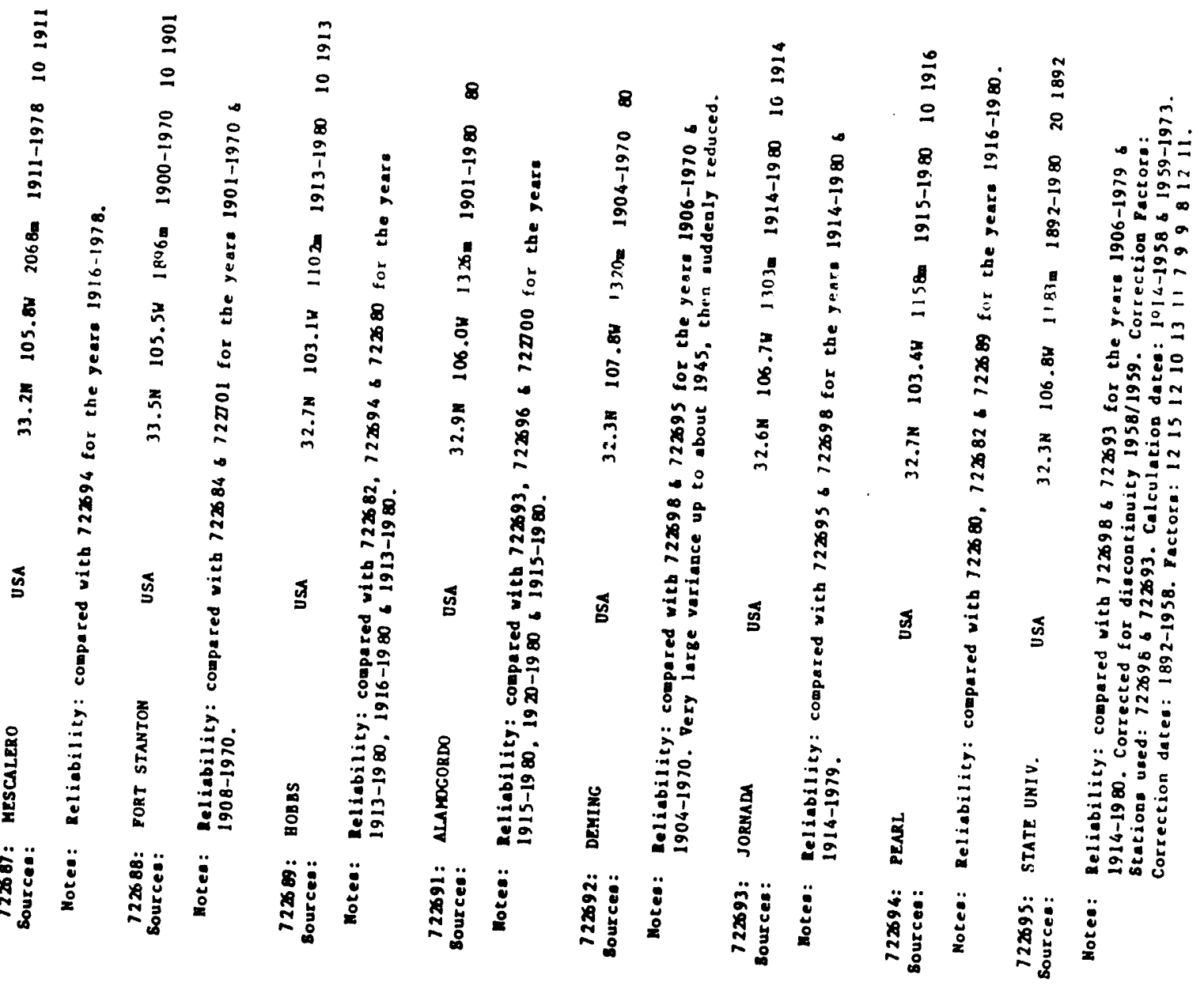

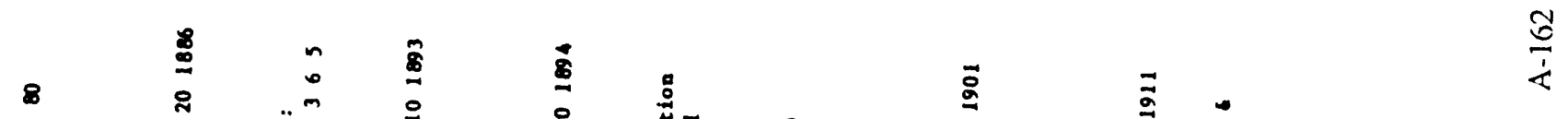

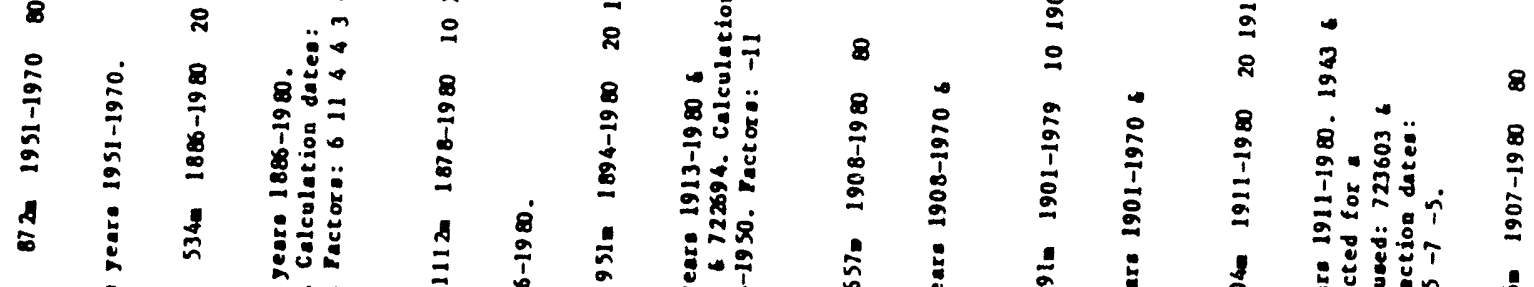

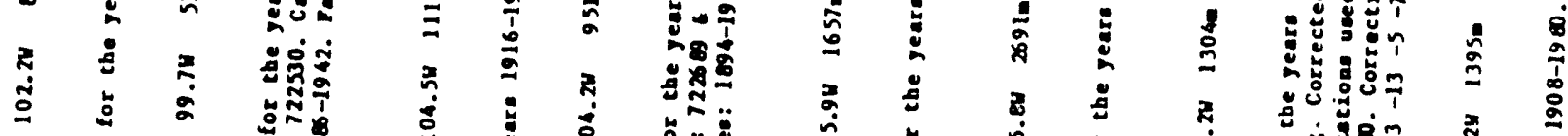

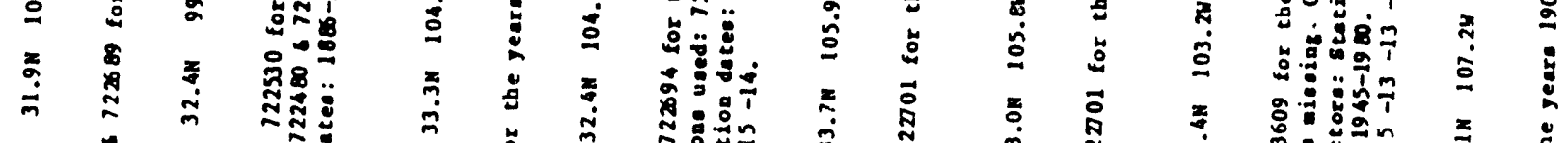

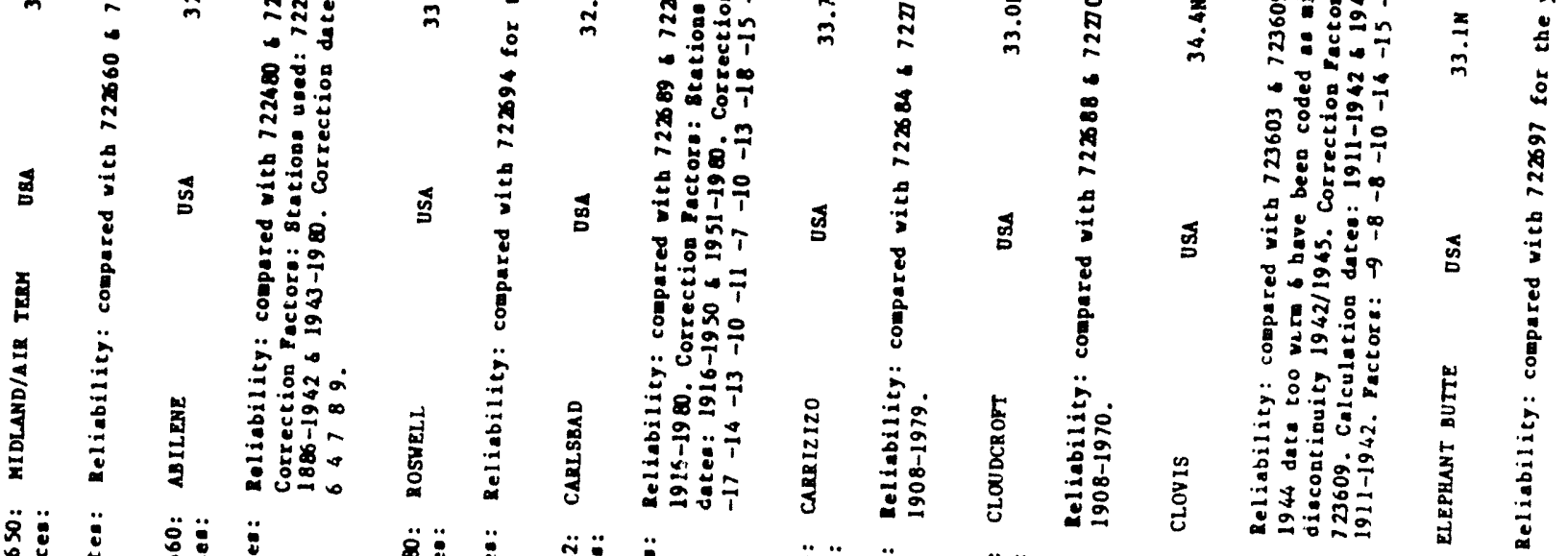
II 


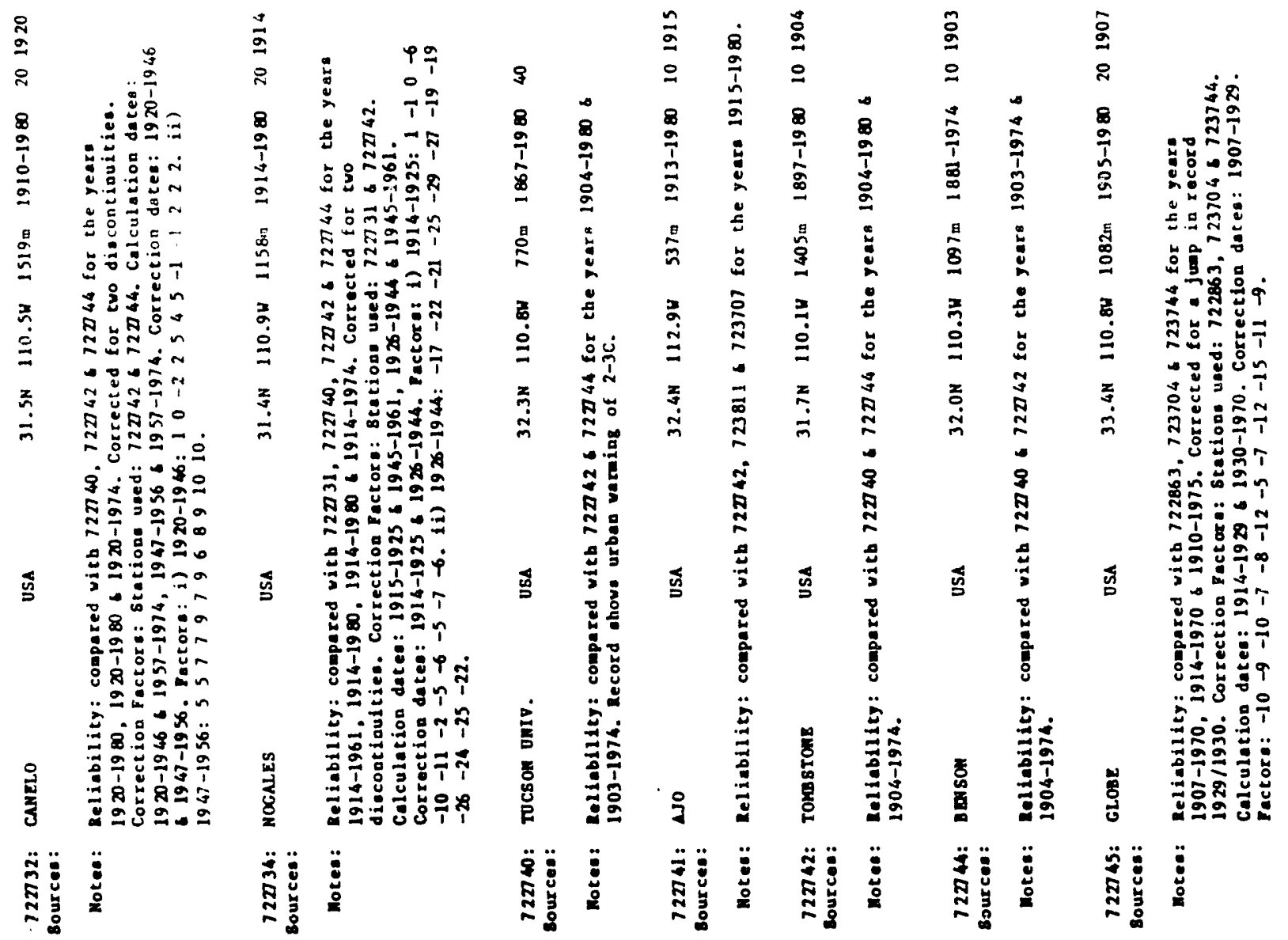

$\frac{a}{\frac{1}{4}}$

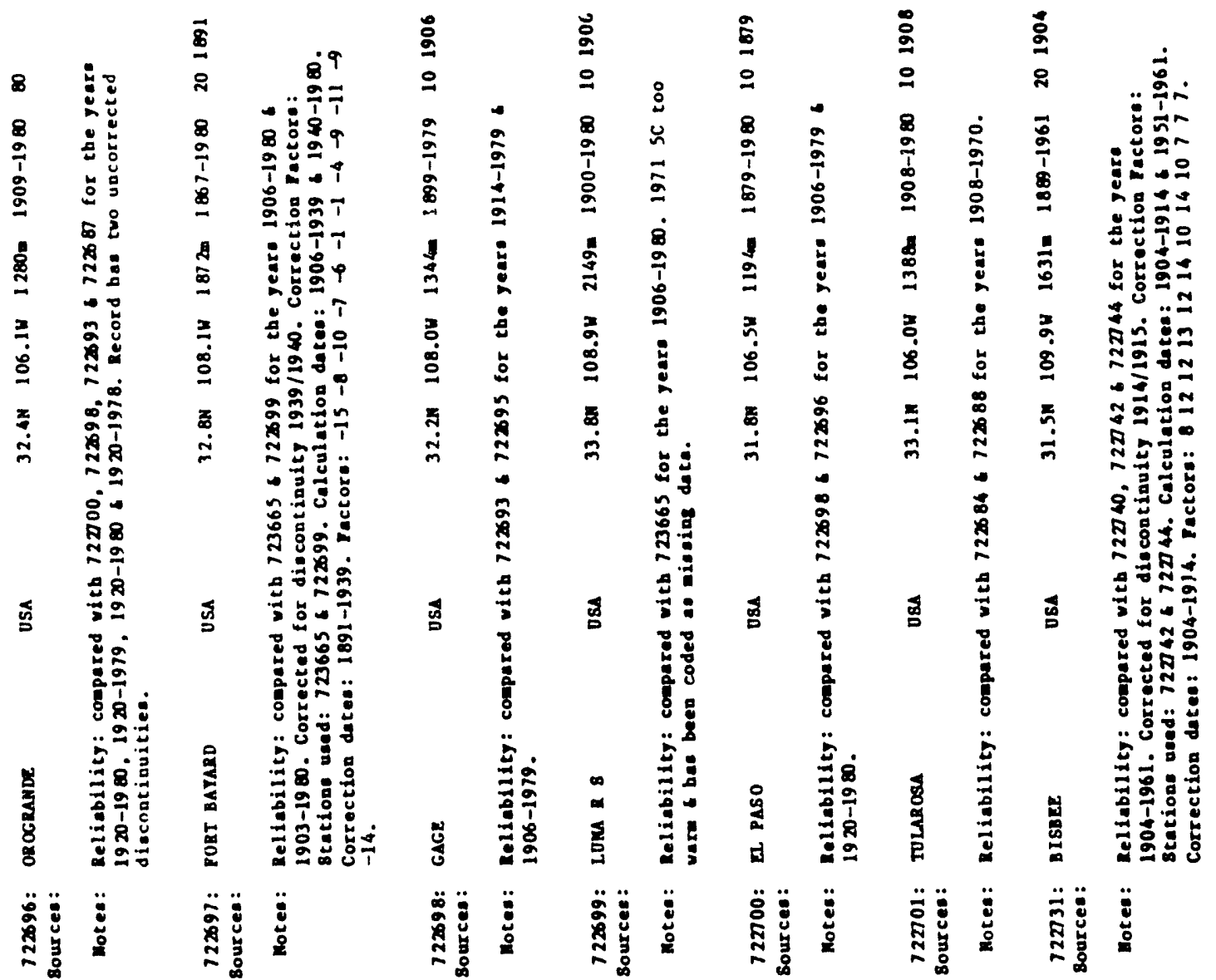




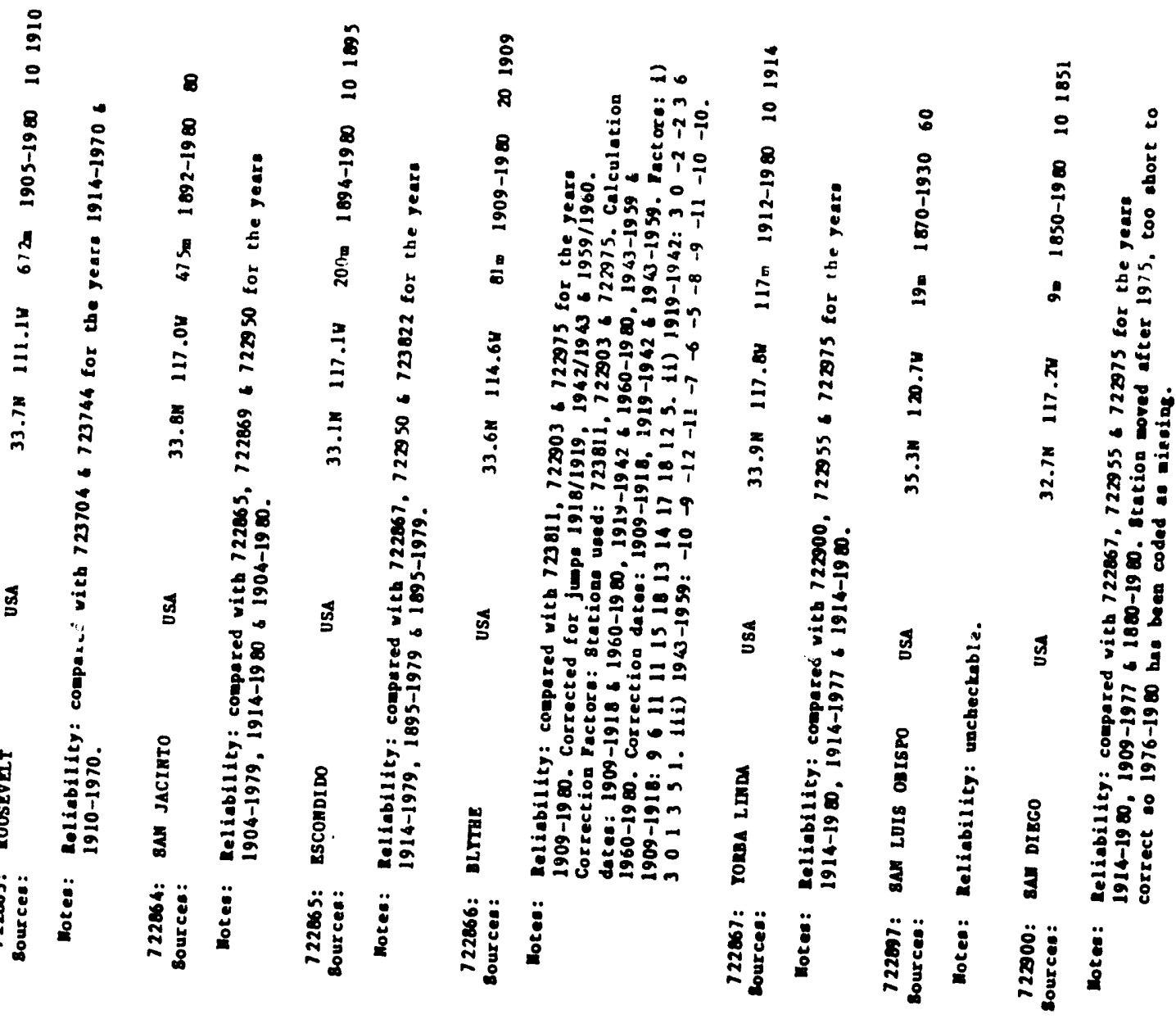

और

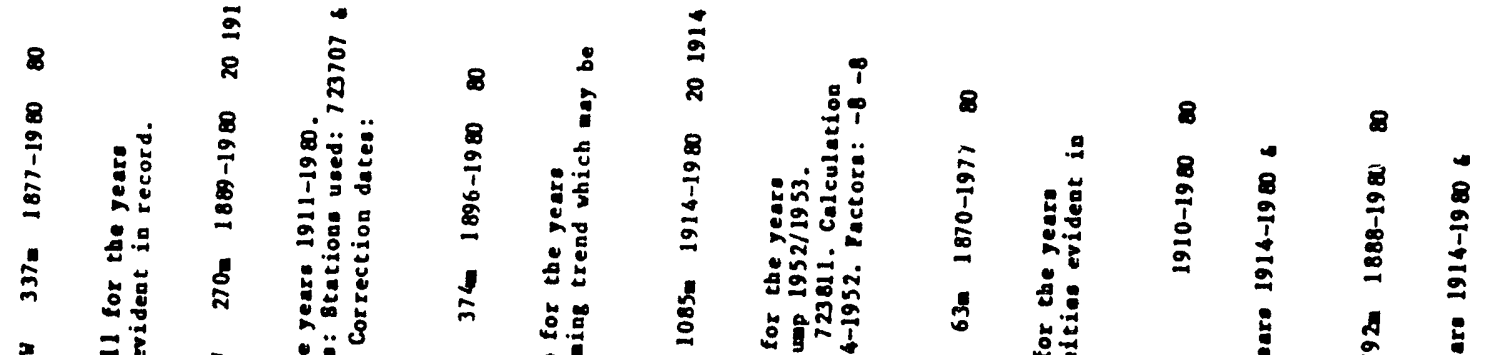

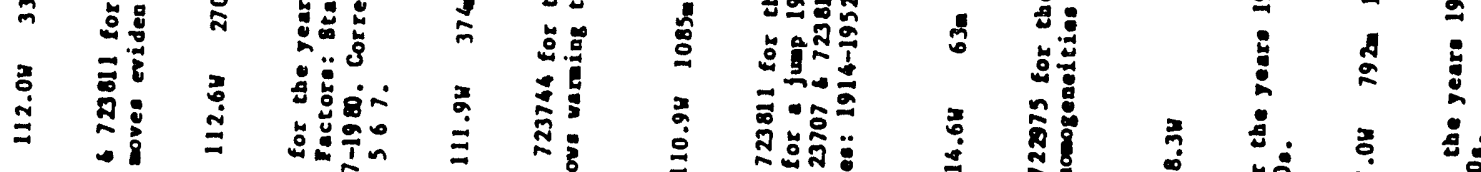

(1)

$=1$

$-$

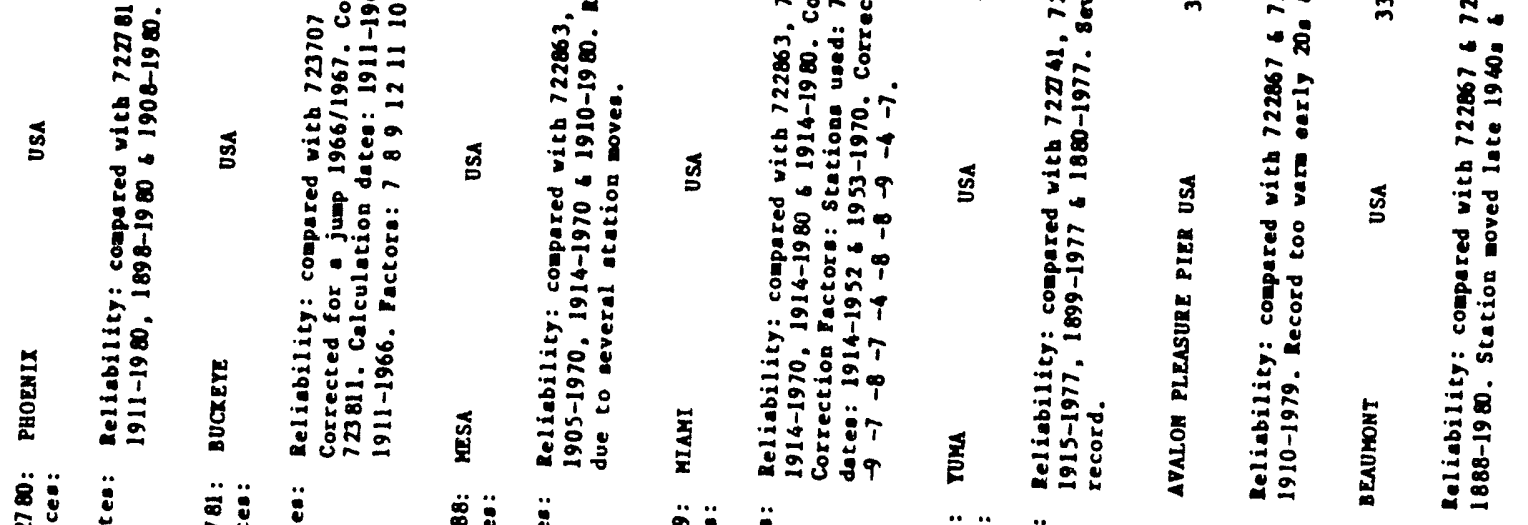

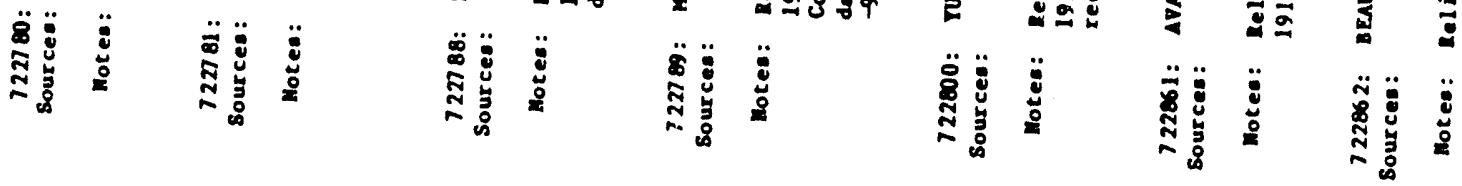




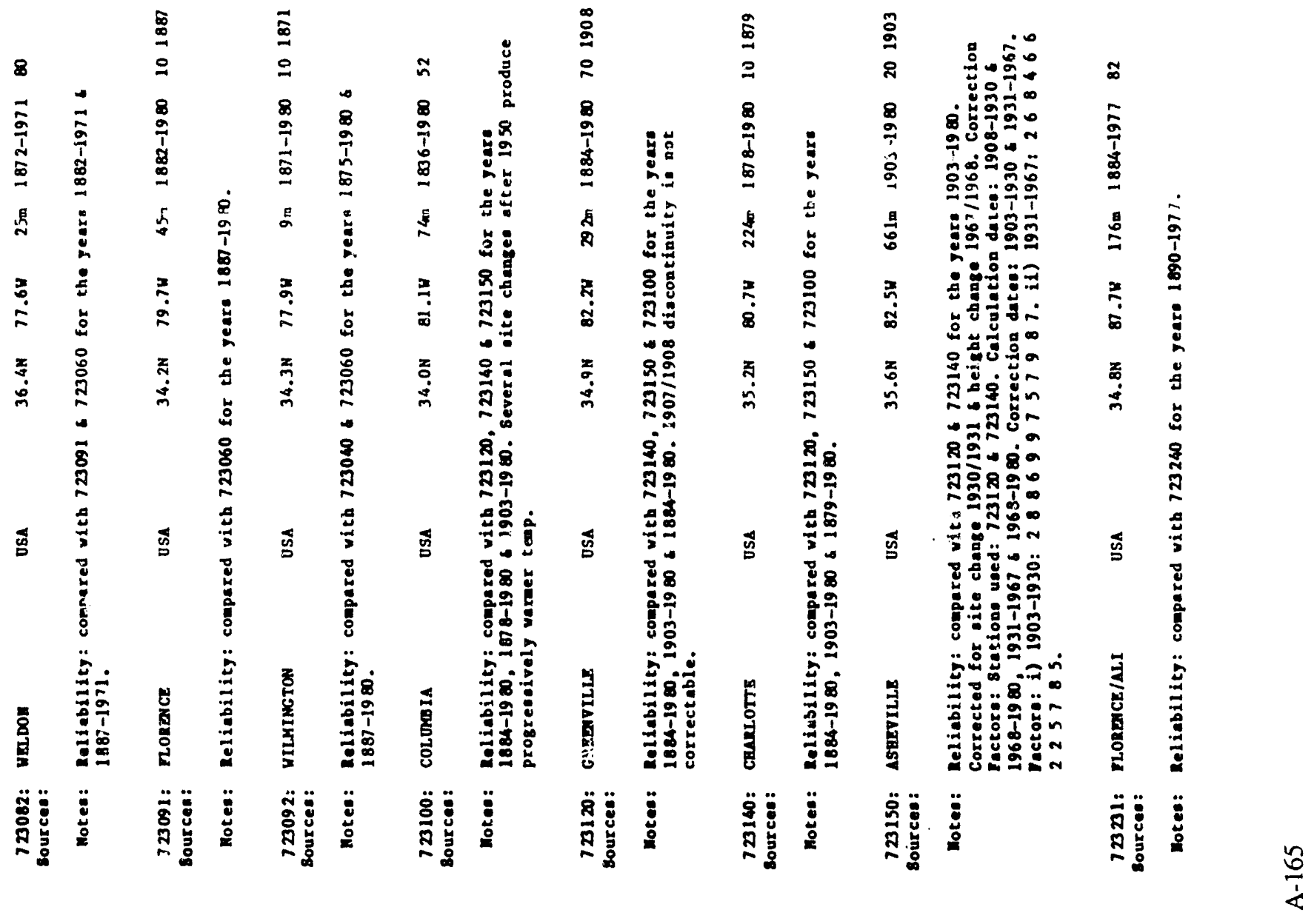

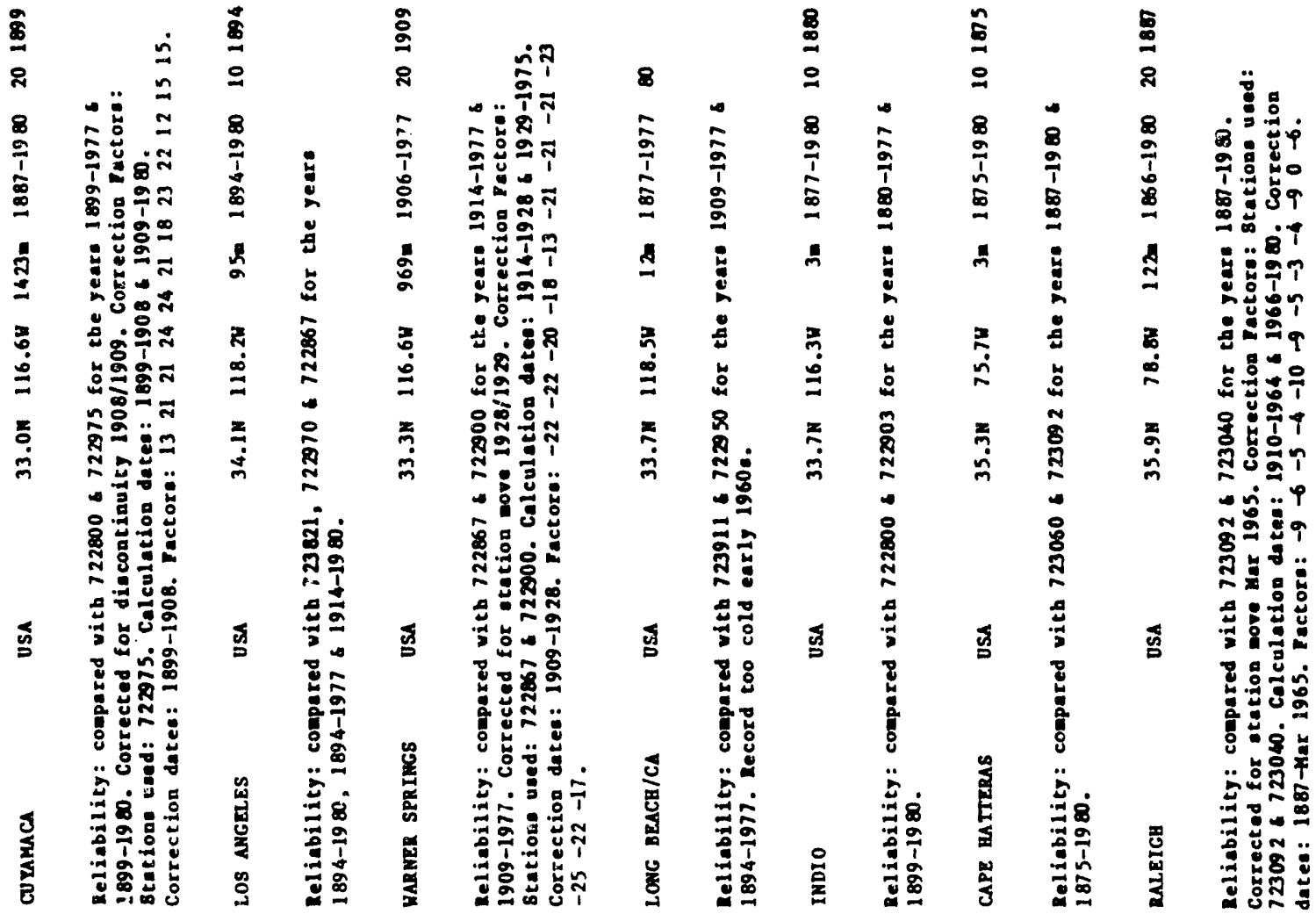

能 
$\begin{array}{lllllllll} & & & & \\ 0\end{array}$

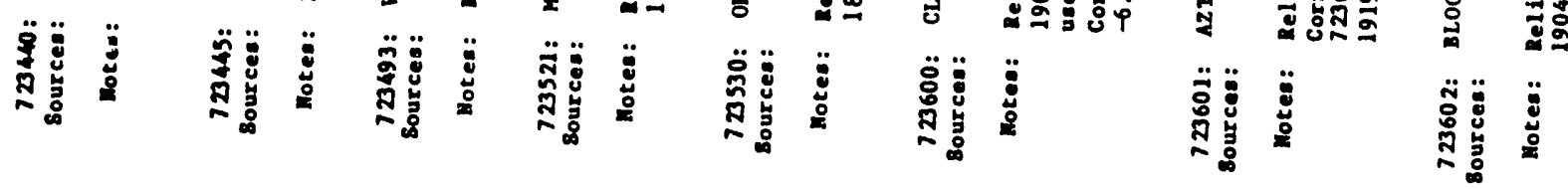

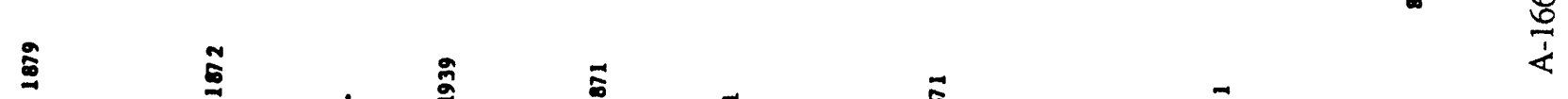

(1)

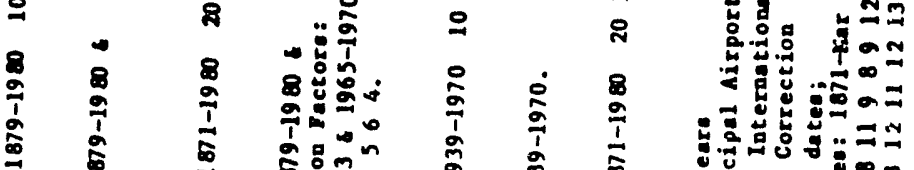

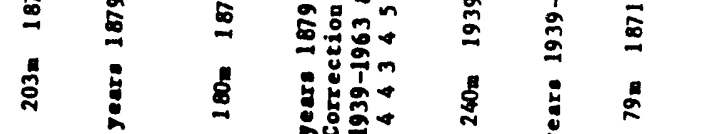

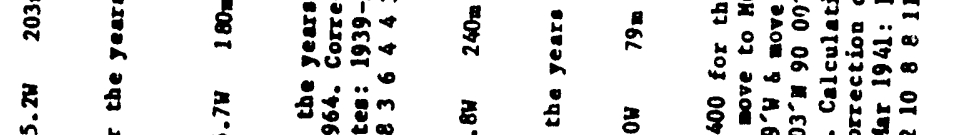

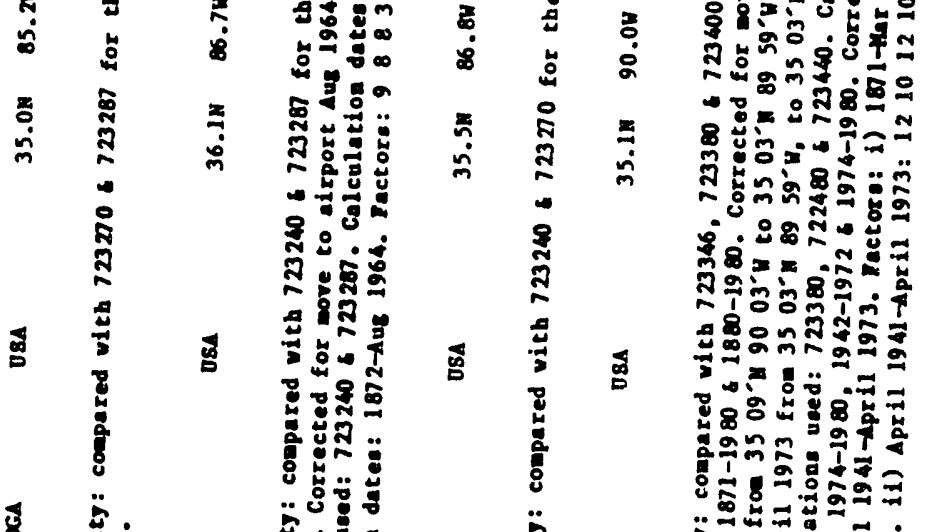

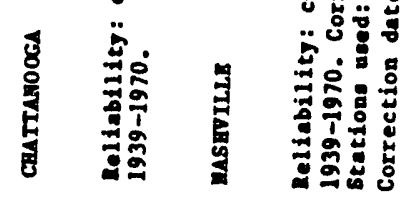

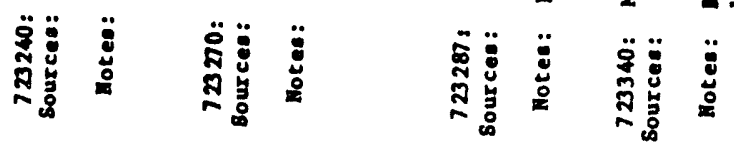

II IIUm

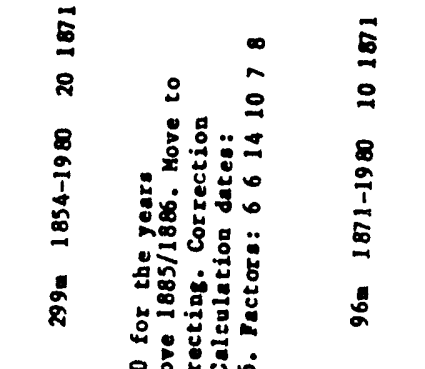

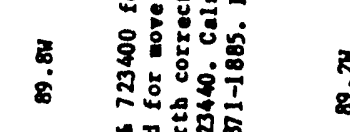

\&

ช.

品

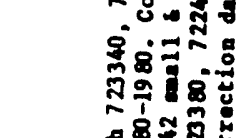

高

๕.

ี⿻ำ

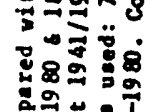

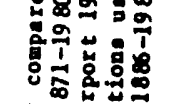

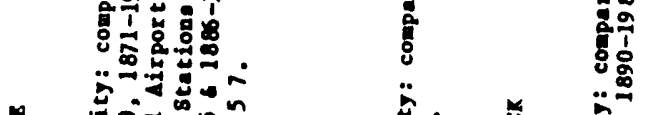

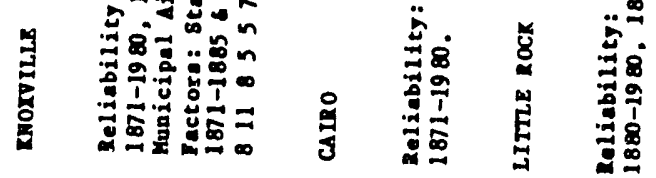

涉

解 


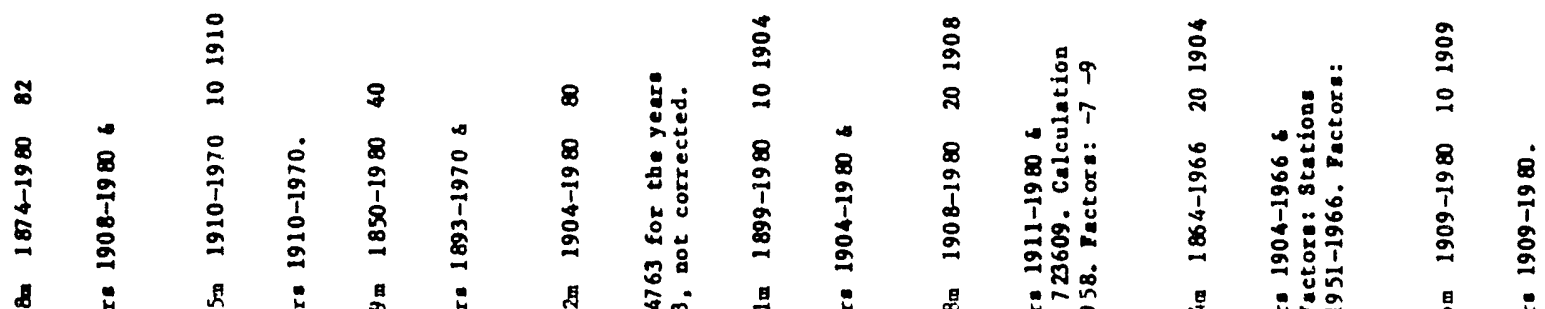
范

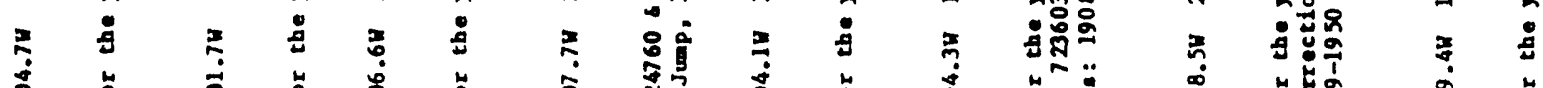

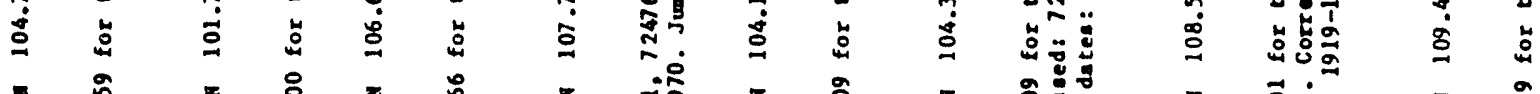
总

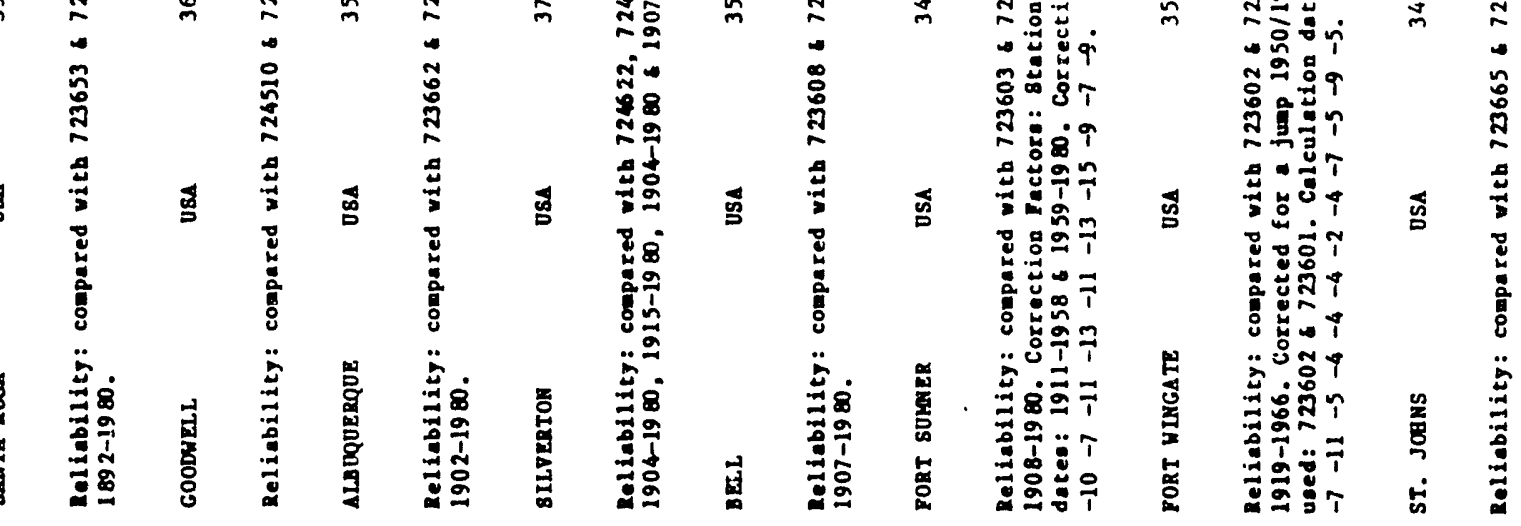

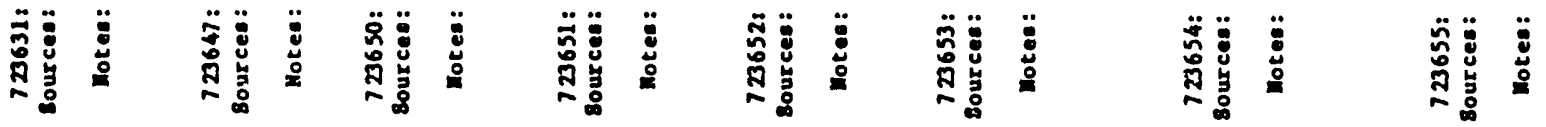

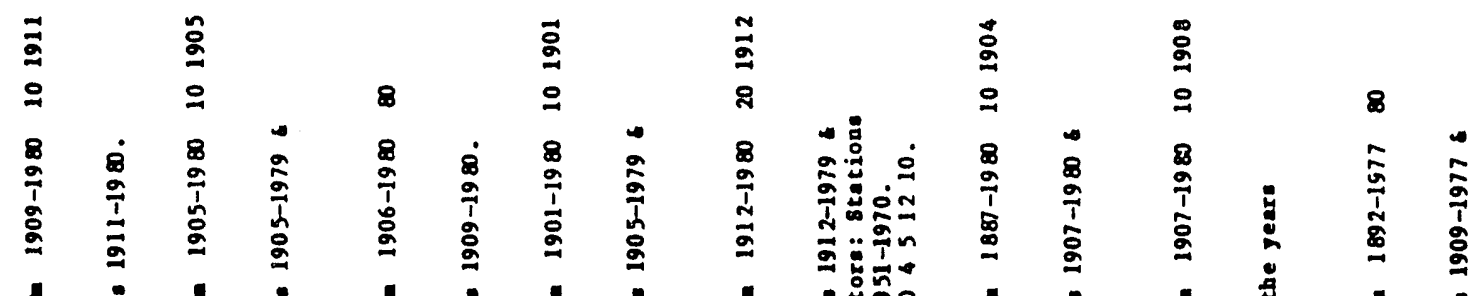
ม

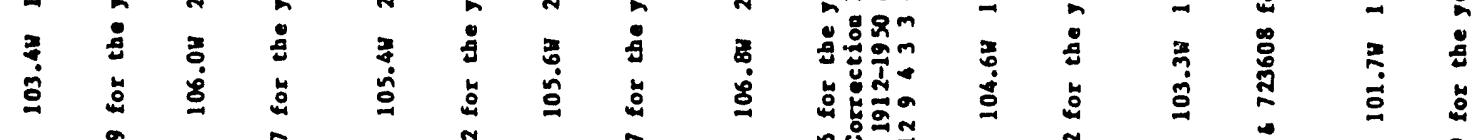

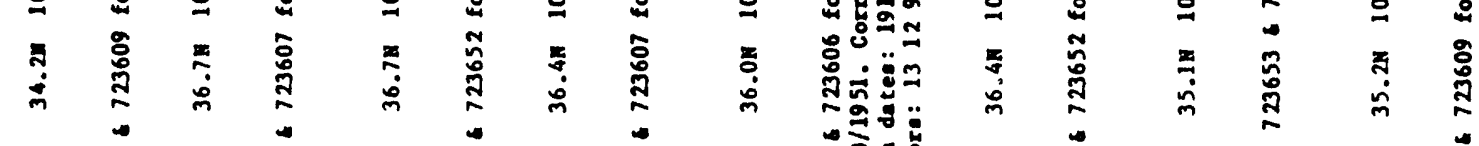

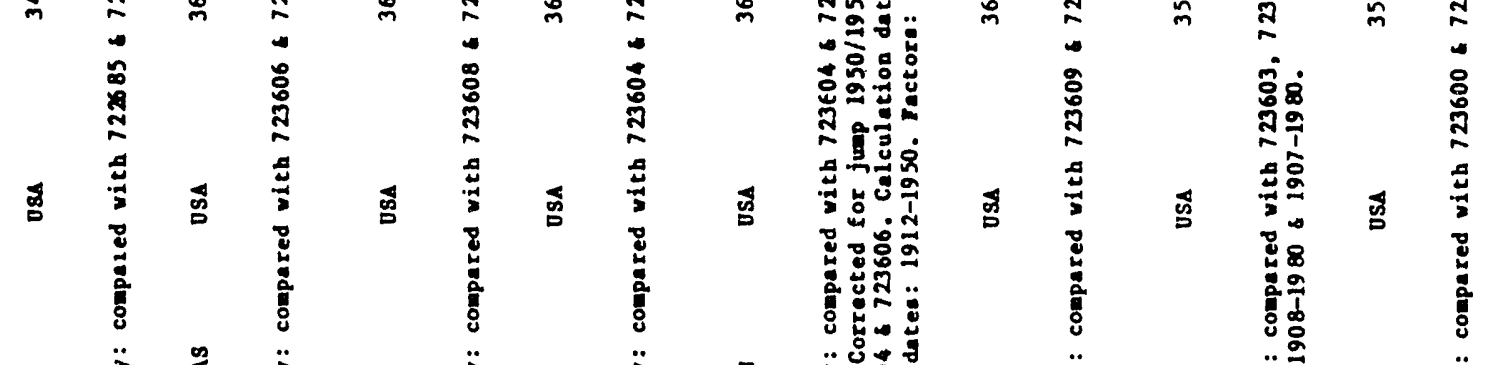

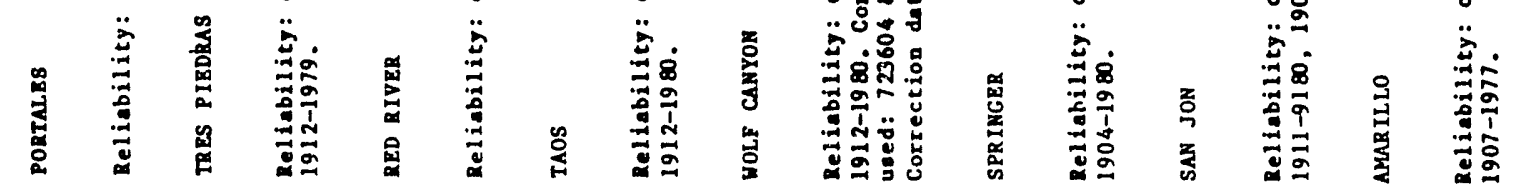

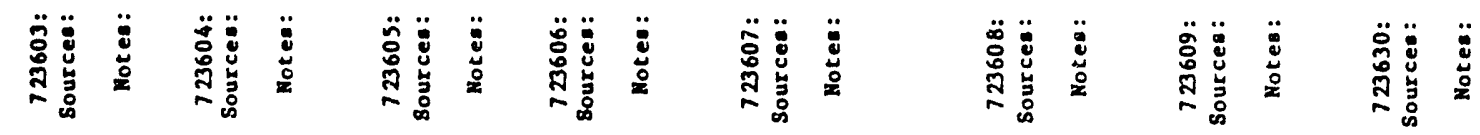




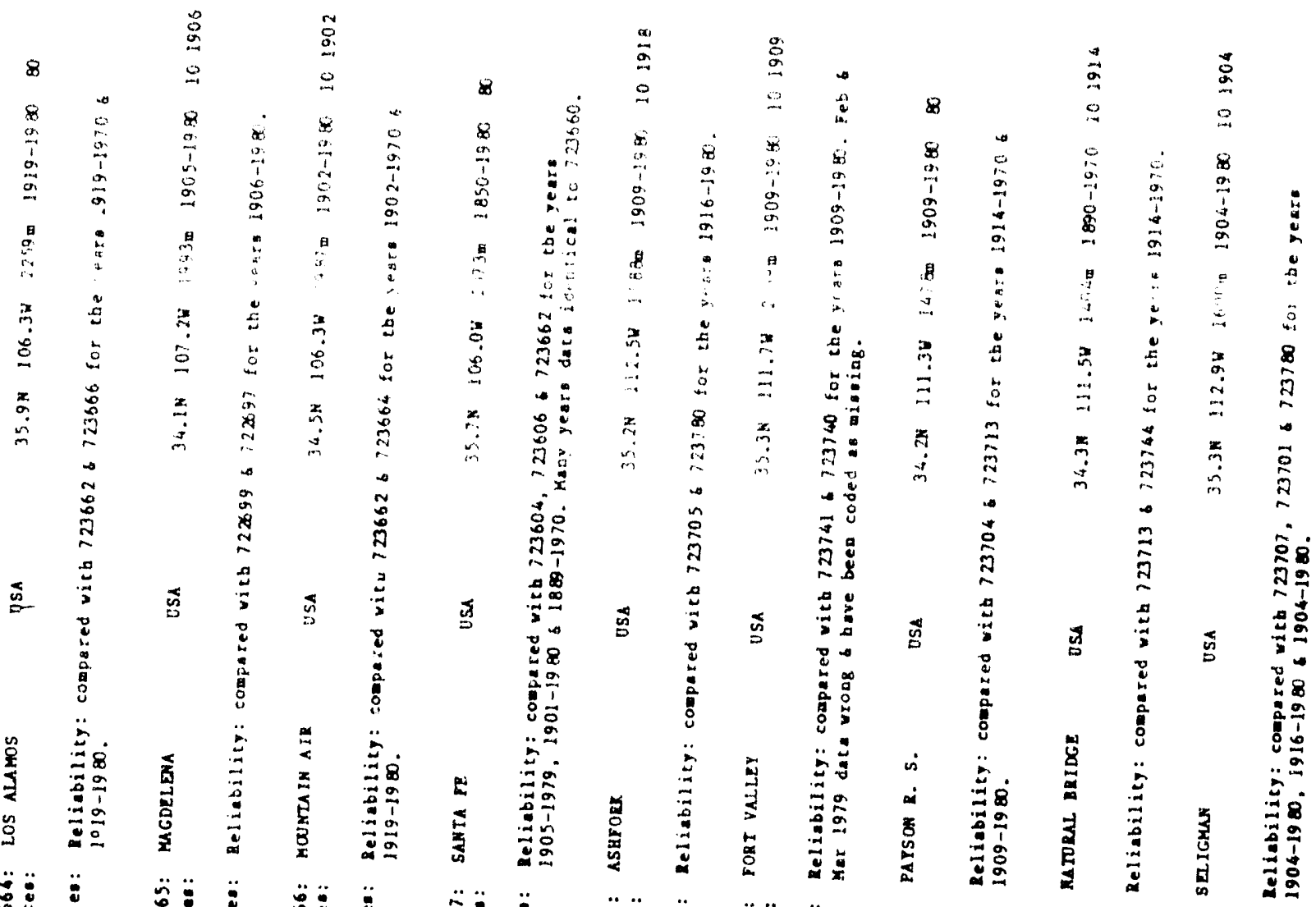

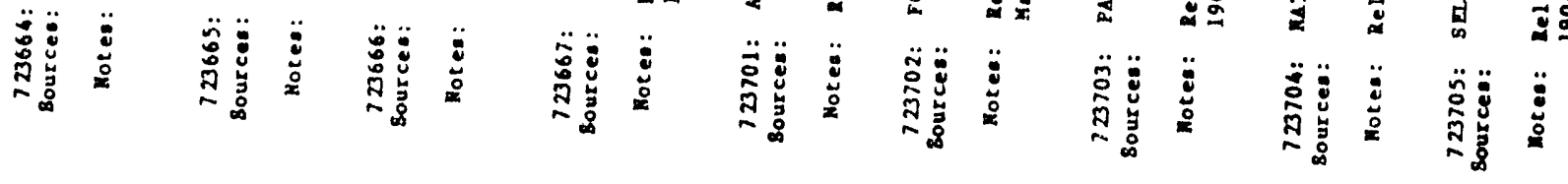

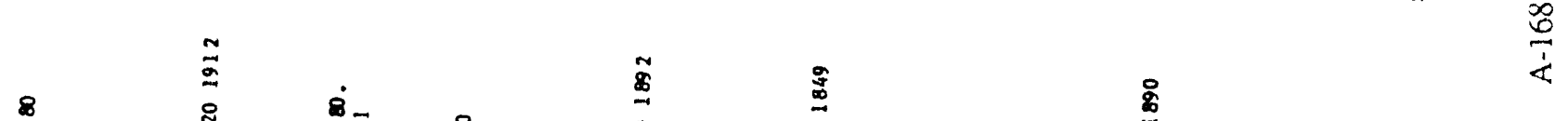

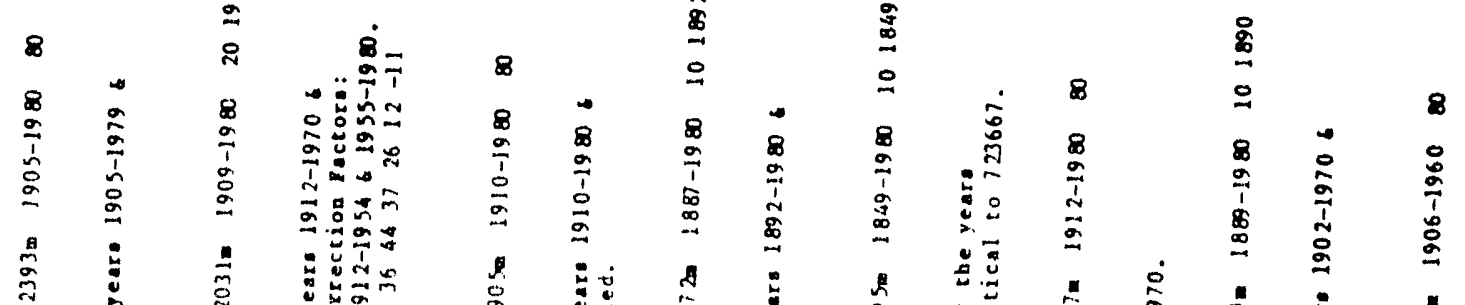

(1)

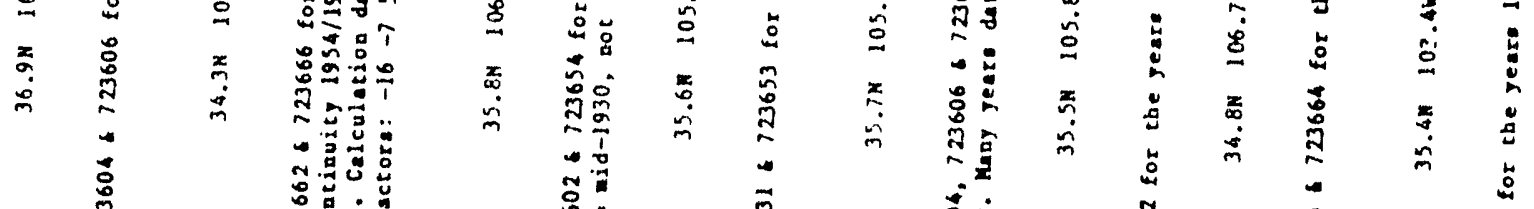

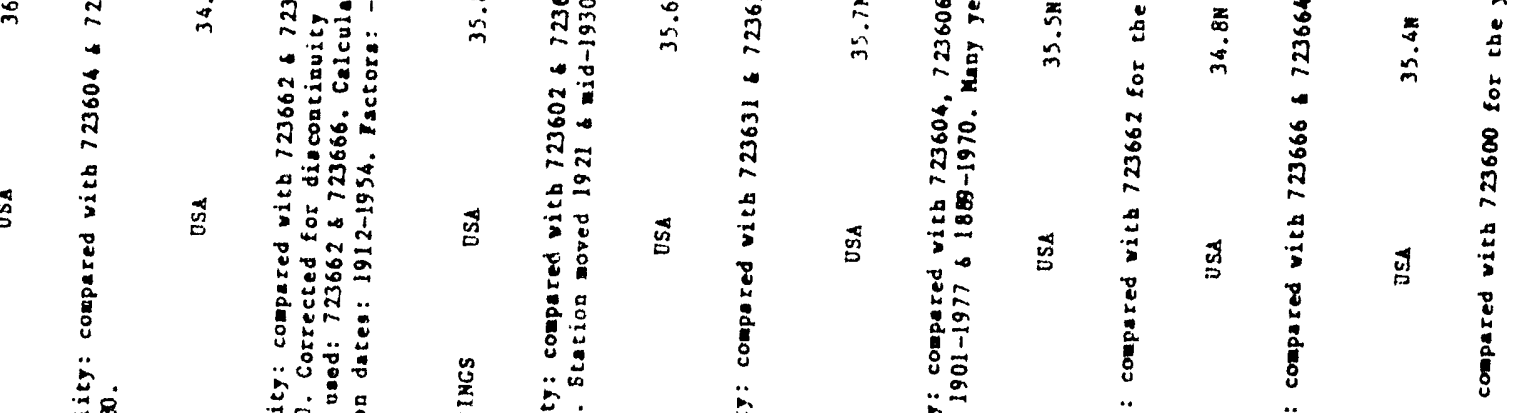

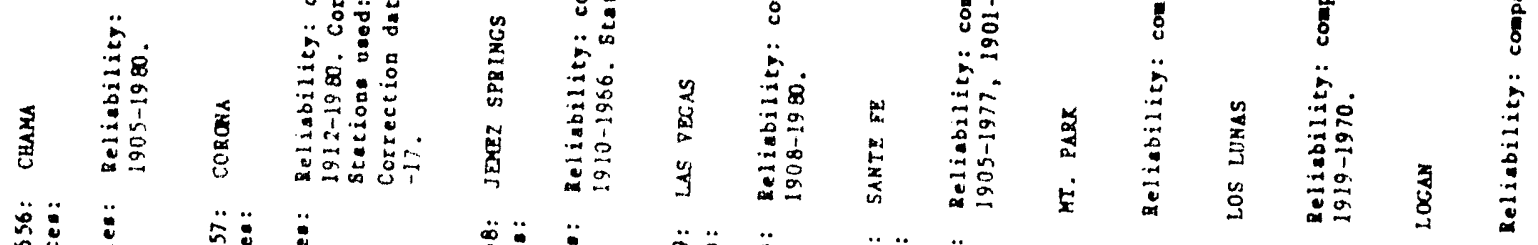

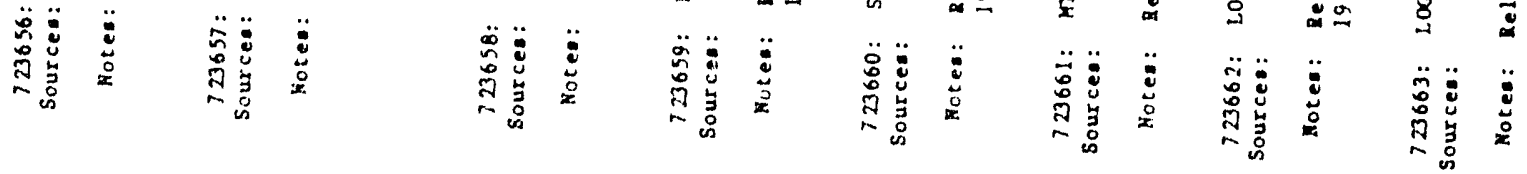



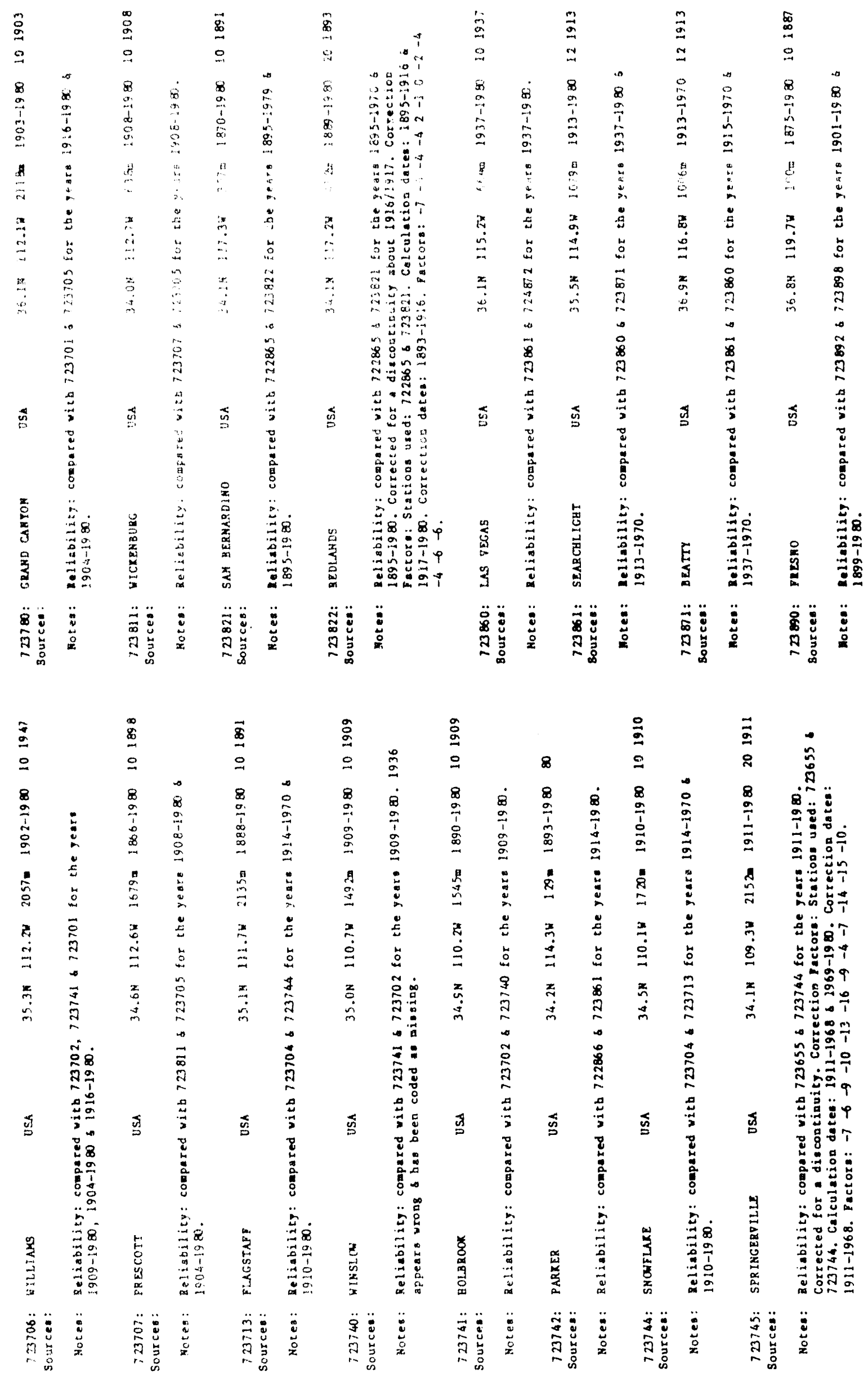
$\Xi$

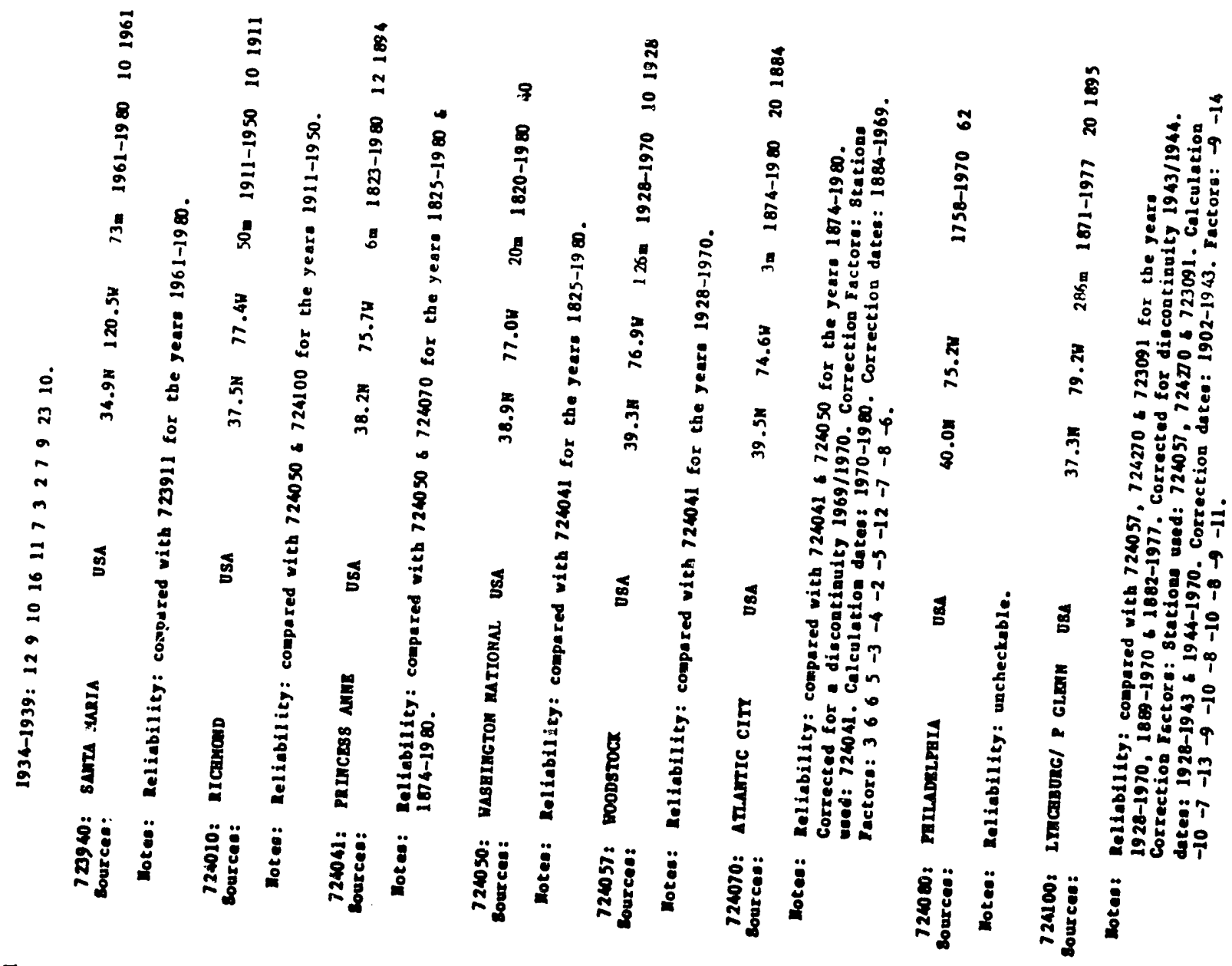

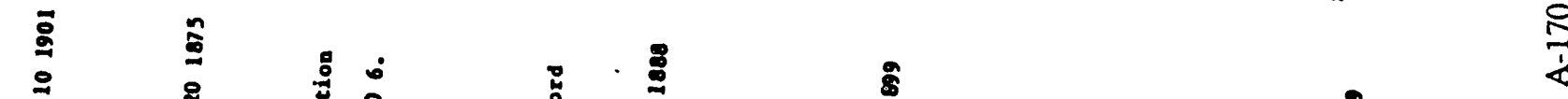
$\frac{\wp}{\dot{z}}$

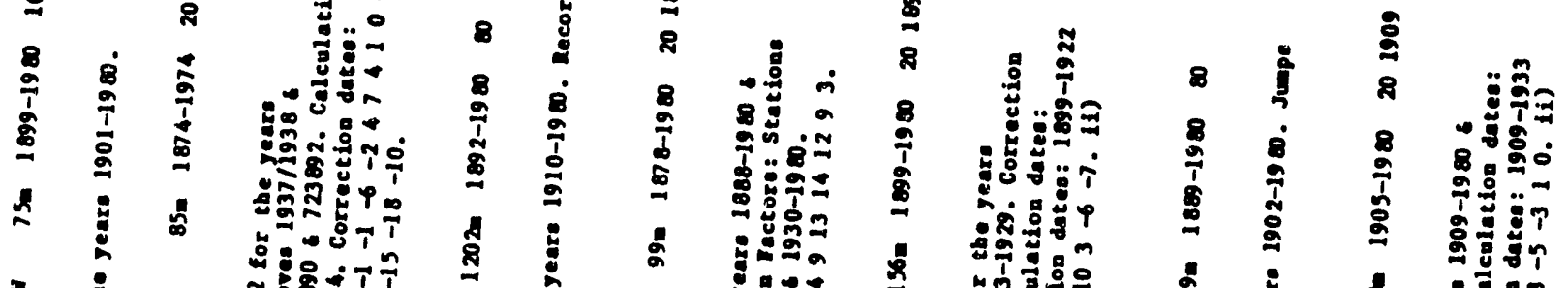

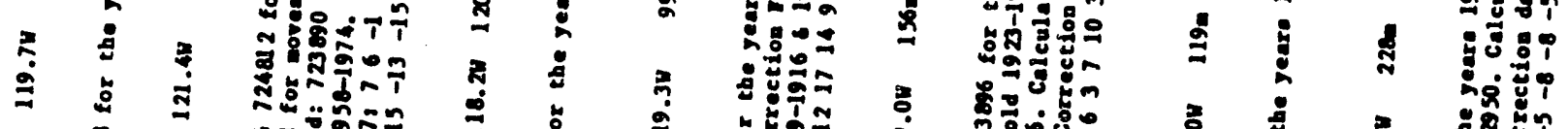

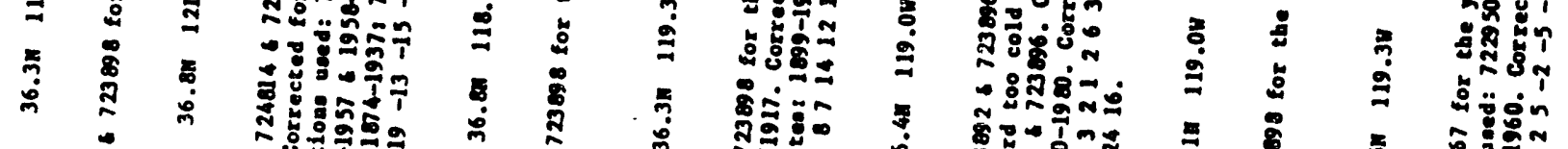

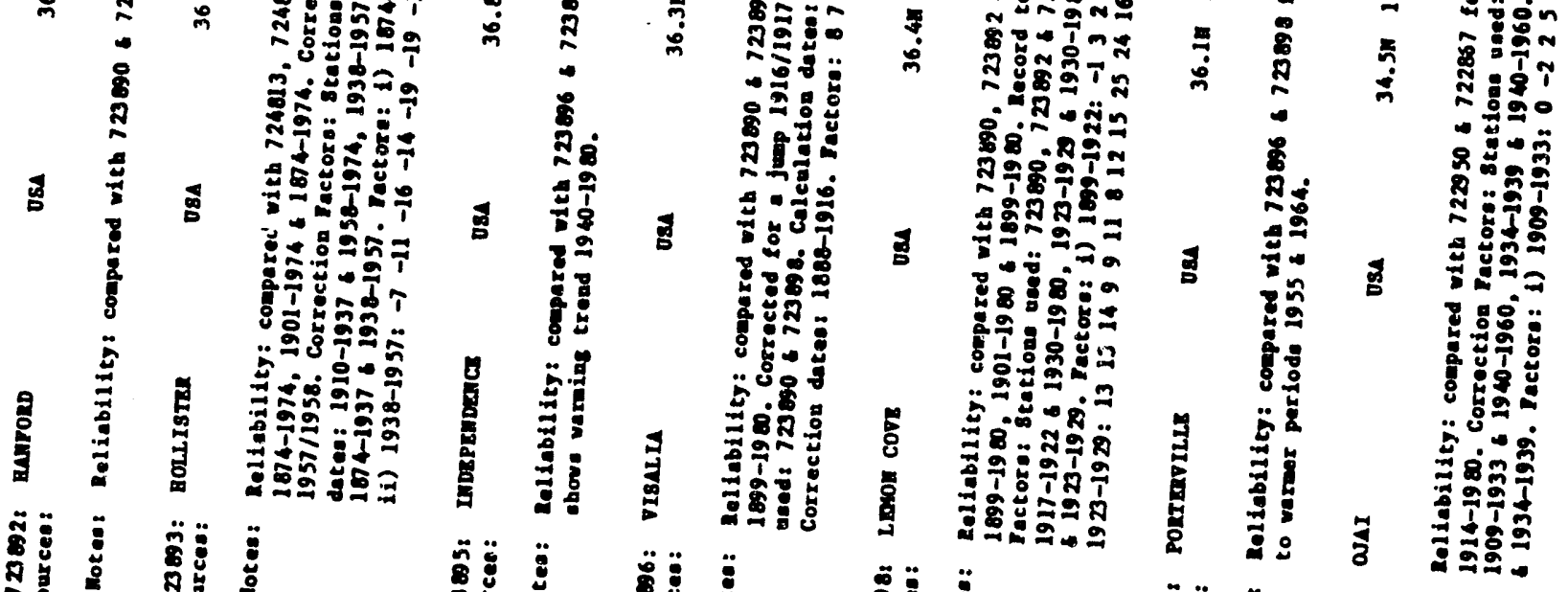

औI 


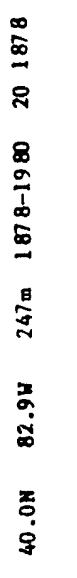

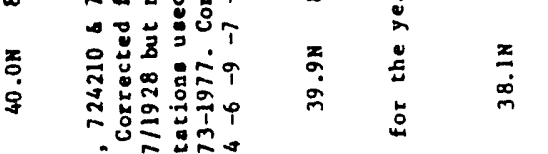

웡종

สิ๊人

要

政

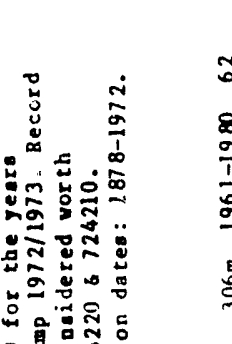

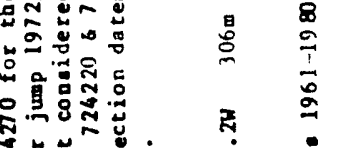

象范范

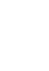

్ㅗㅀ

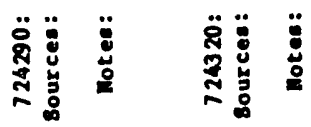

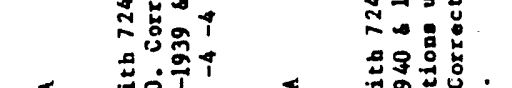

s. s.

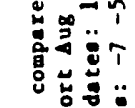

先
ఏ

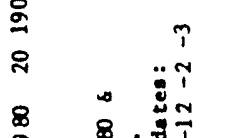

क号品

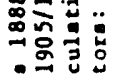

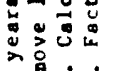

造通这

造㝴

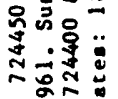

응ㅁㅇㅁㅇ

象象:

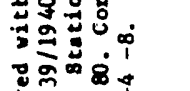

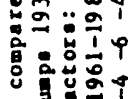

刍牙

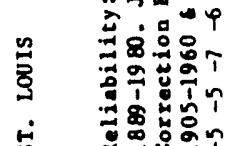

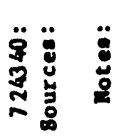

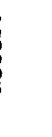

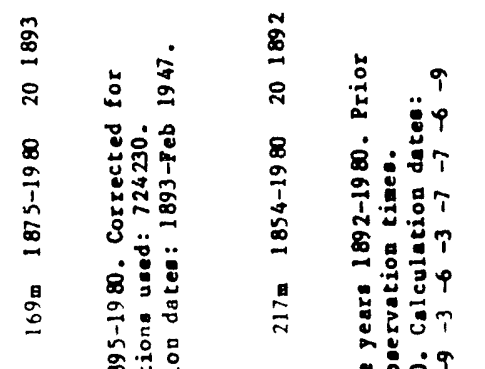

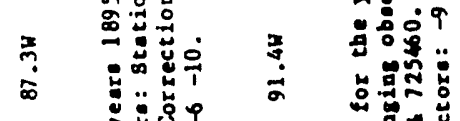

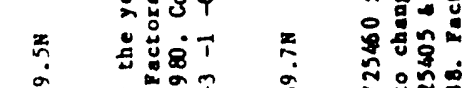

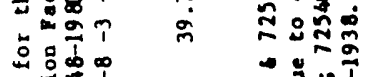

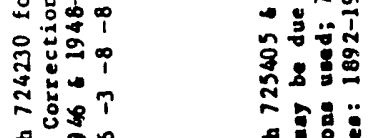

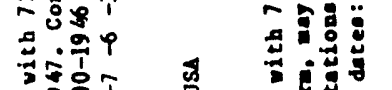

영 क्ष

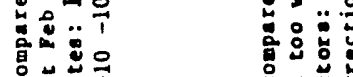

녕웡

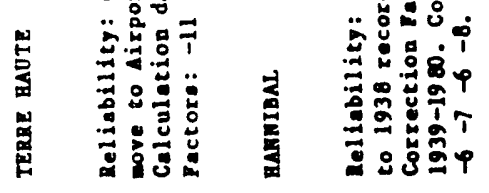

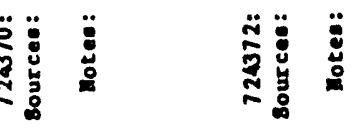

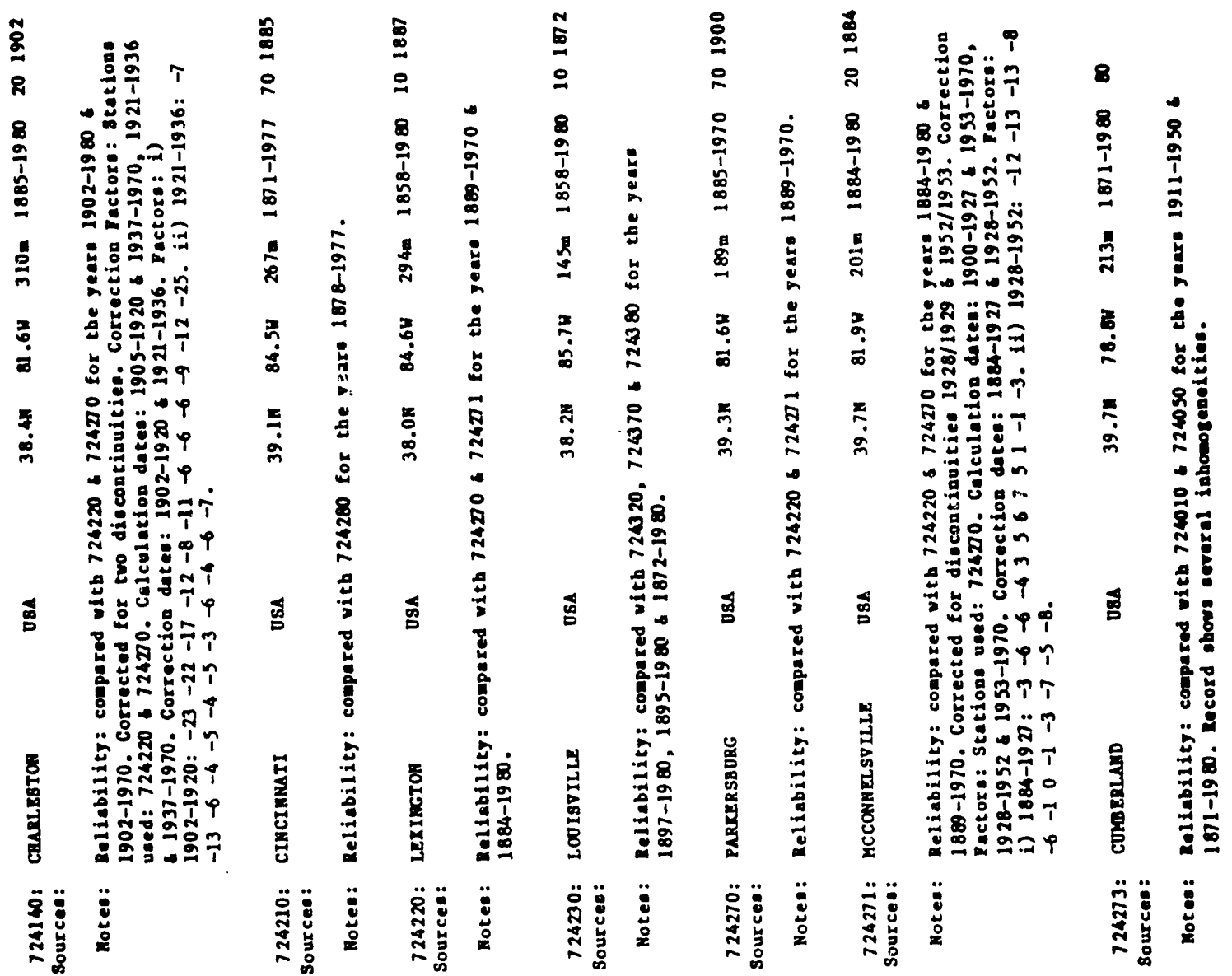

$\frac{1}{4}$ 


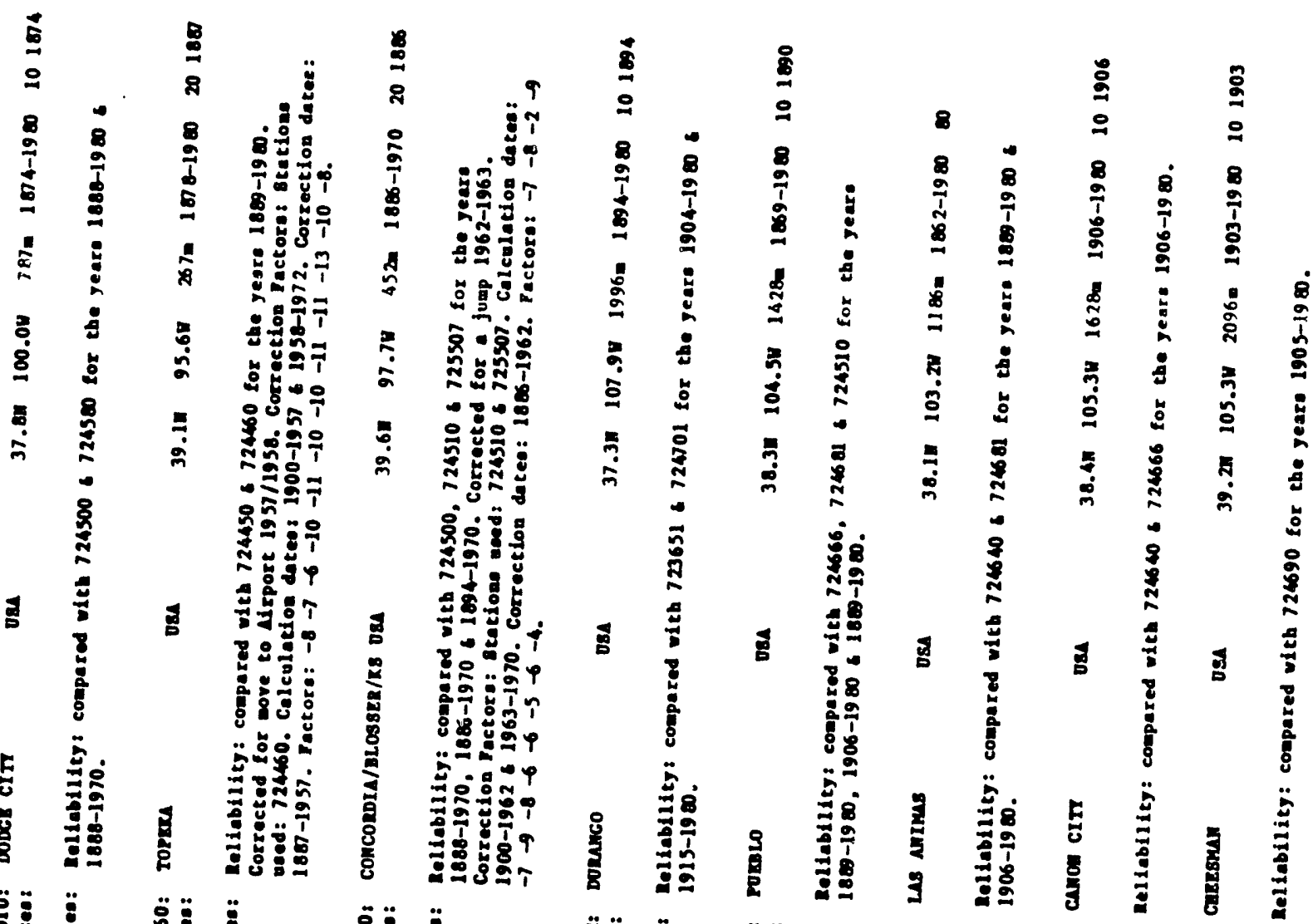

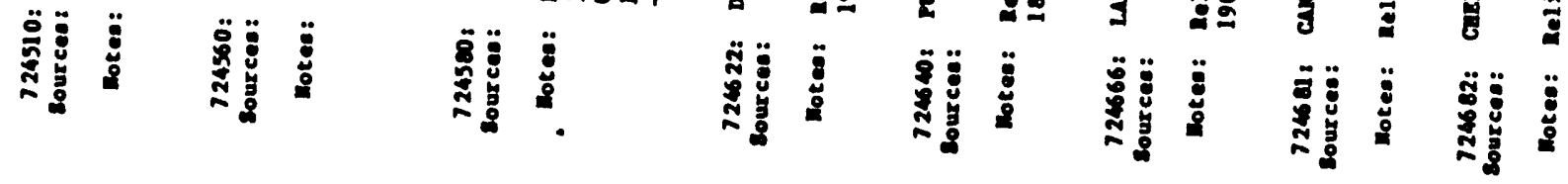

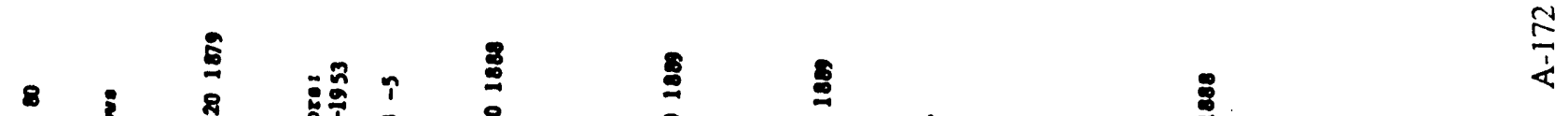

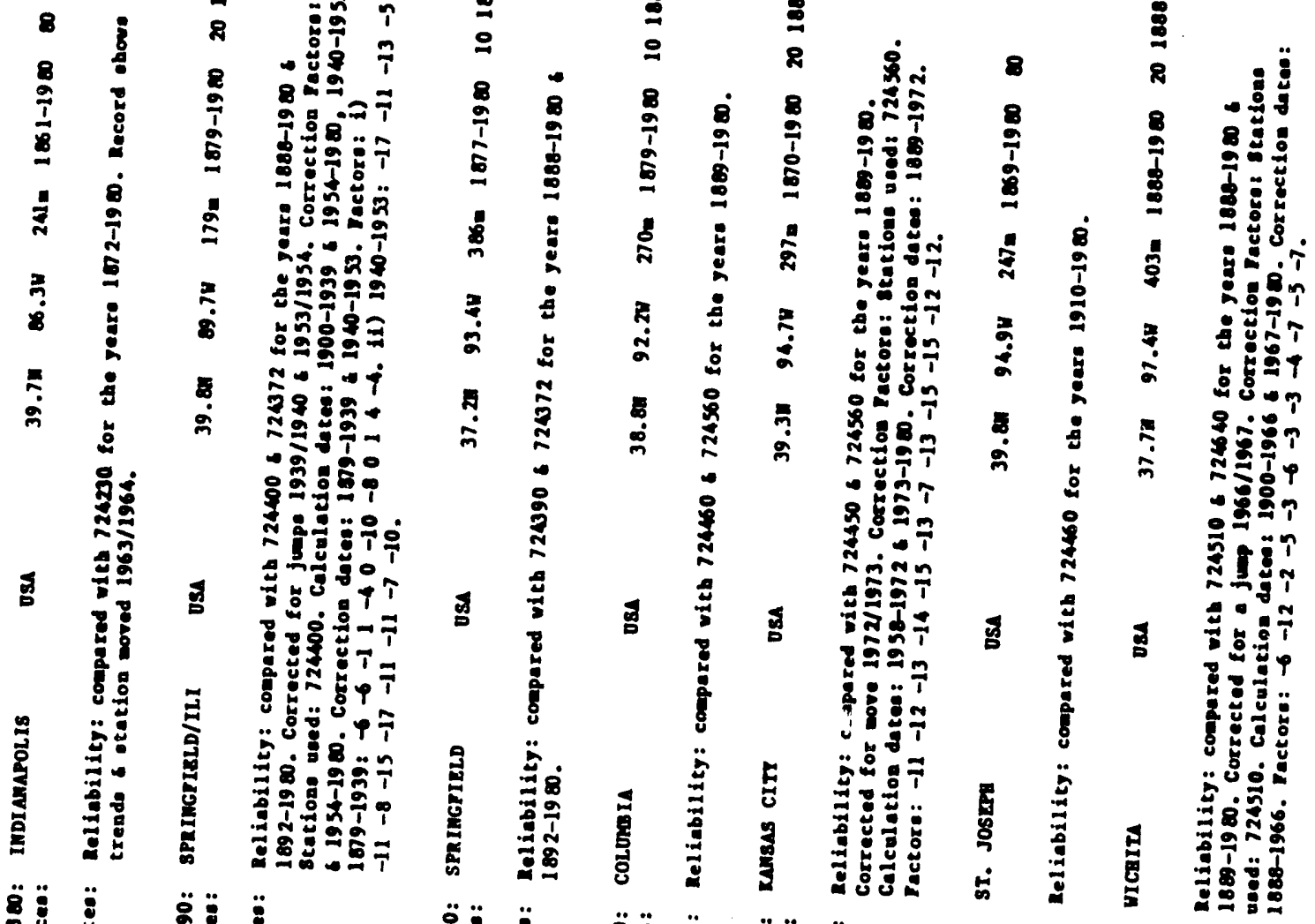

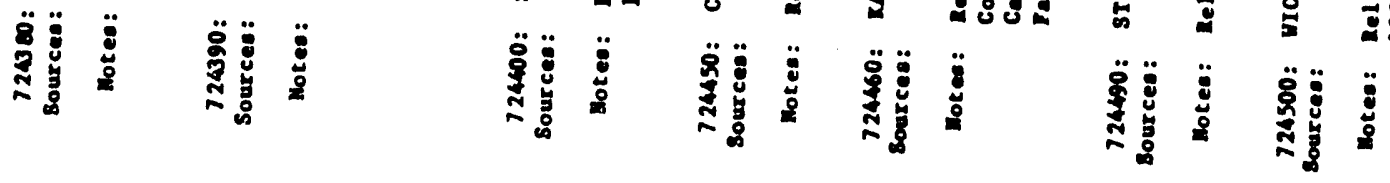


(1)

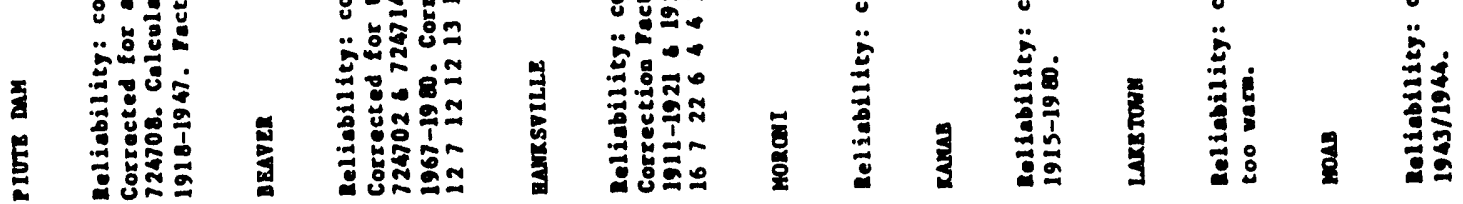

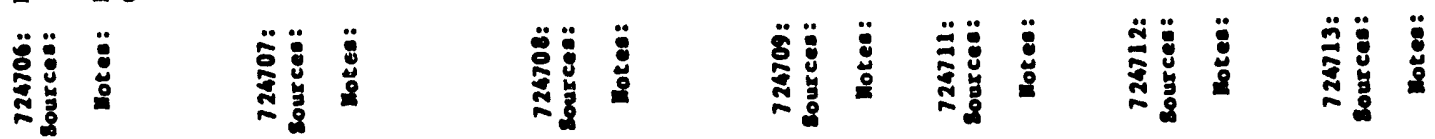

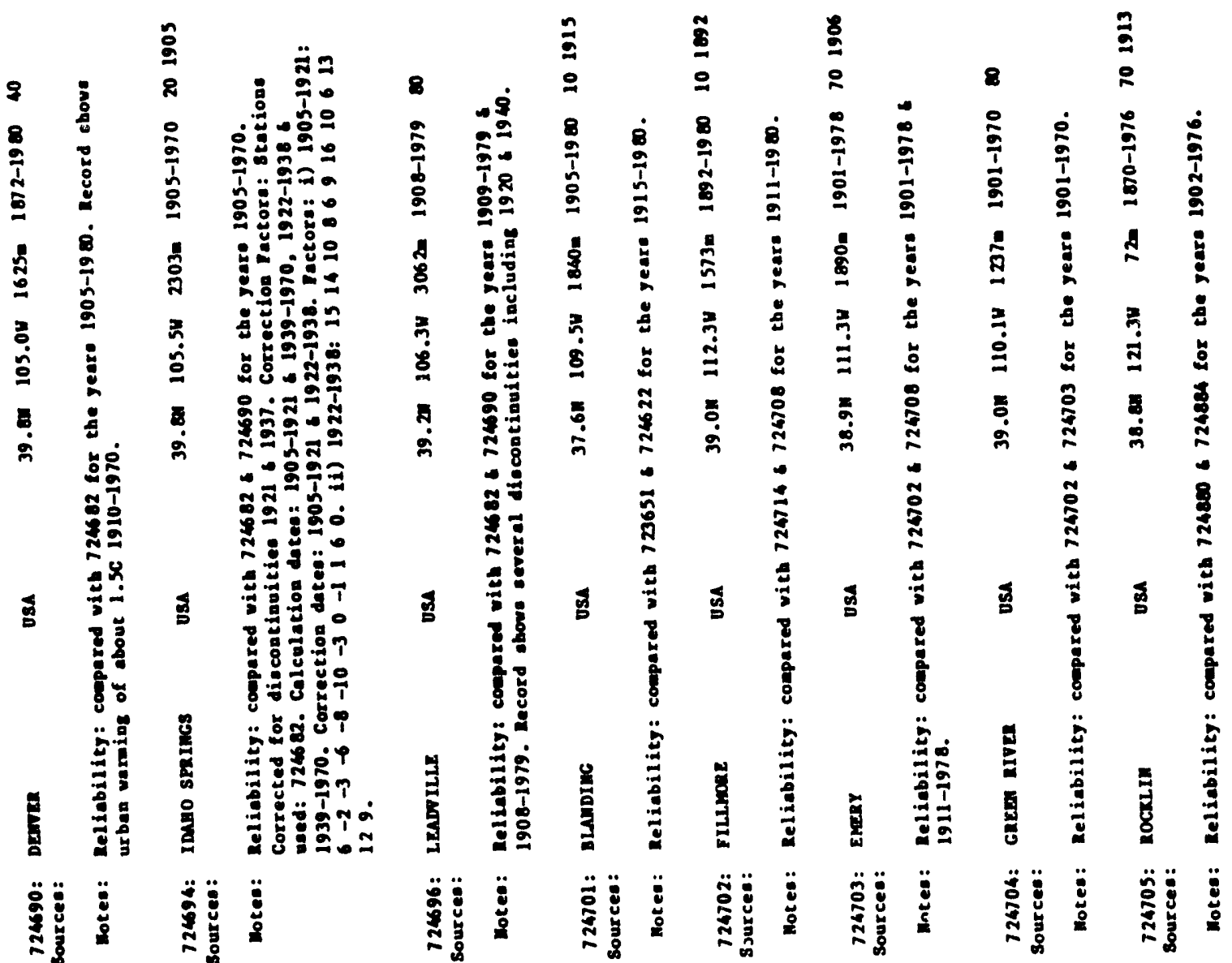




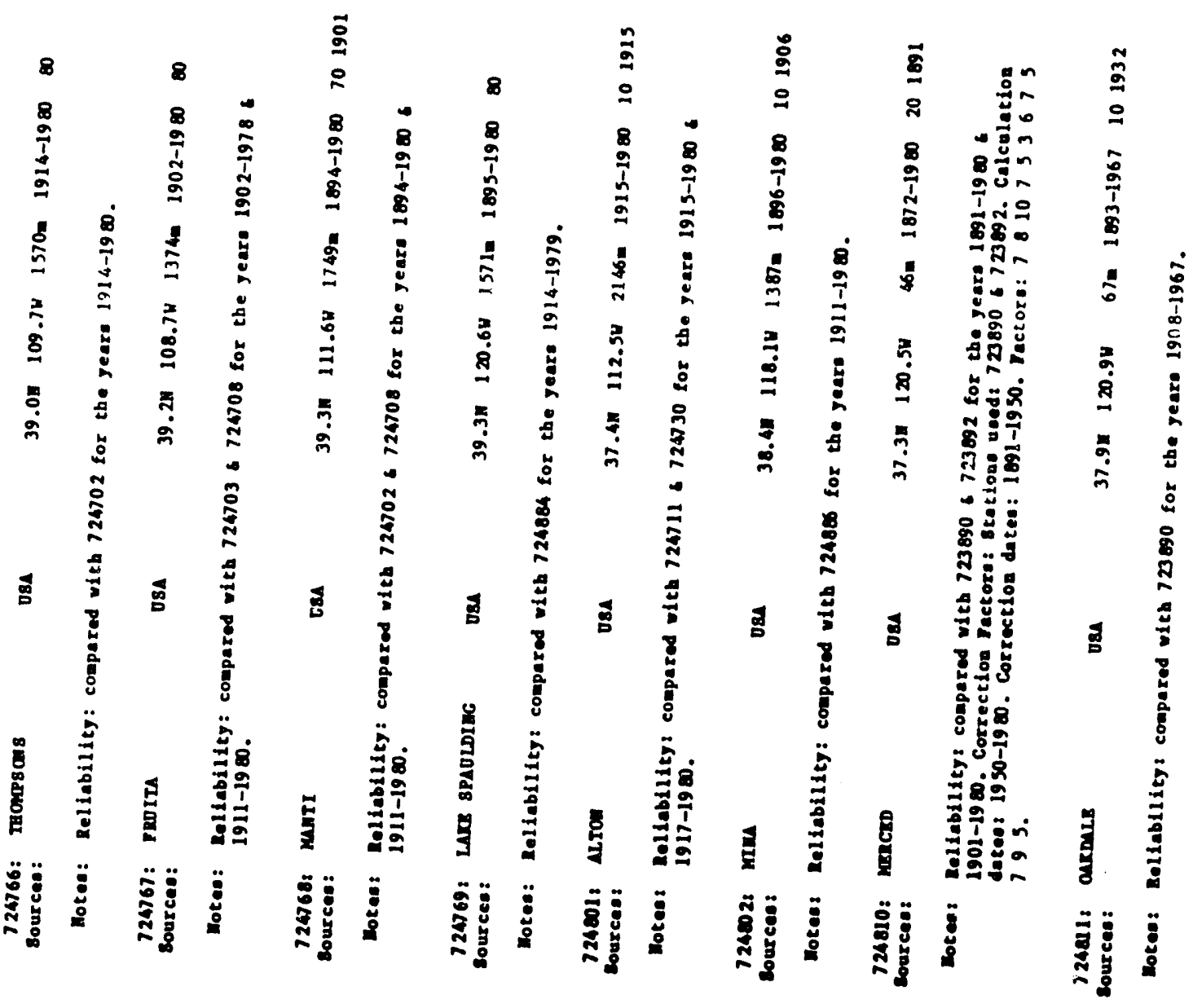

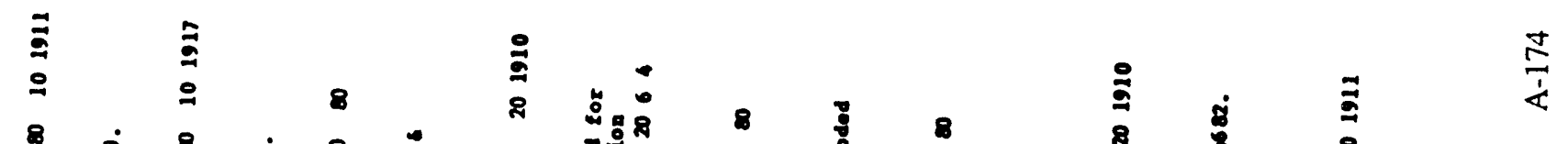

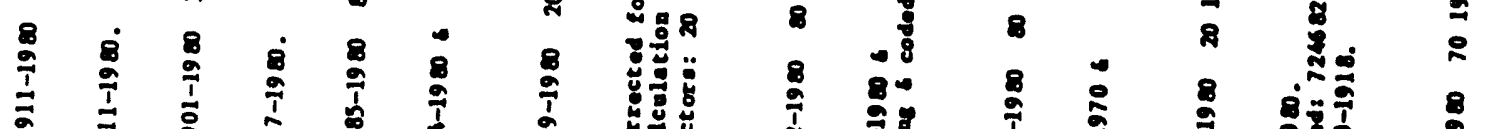

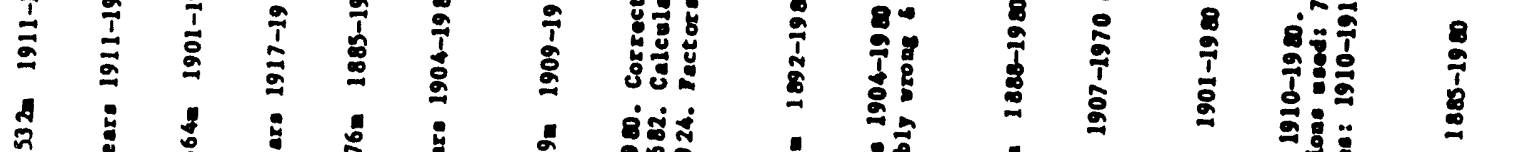

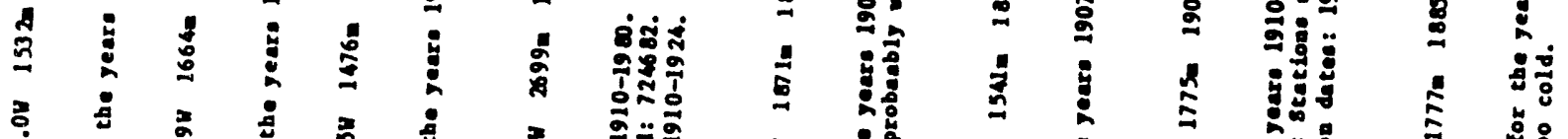

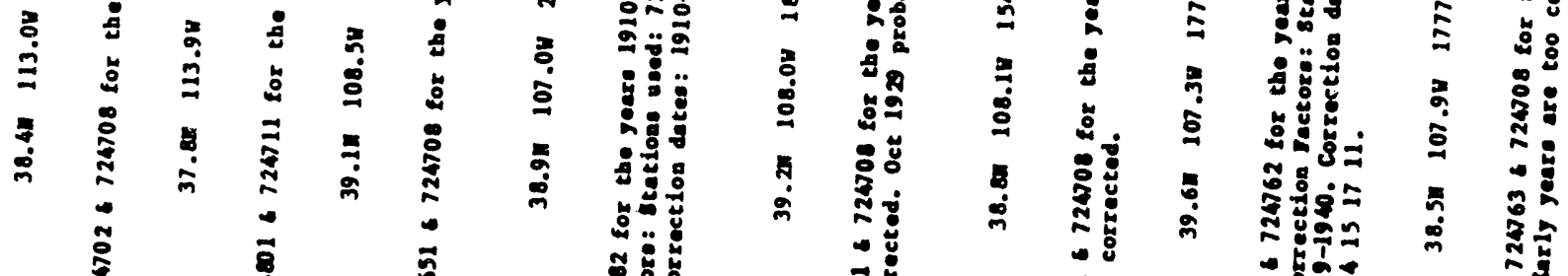

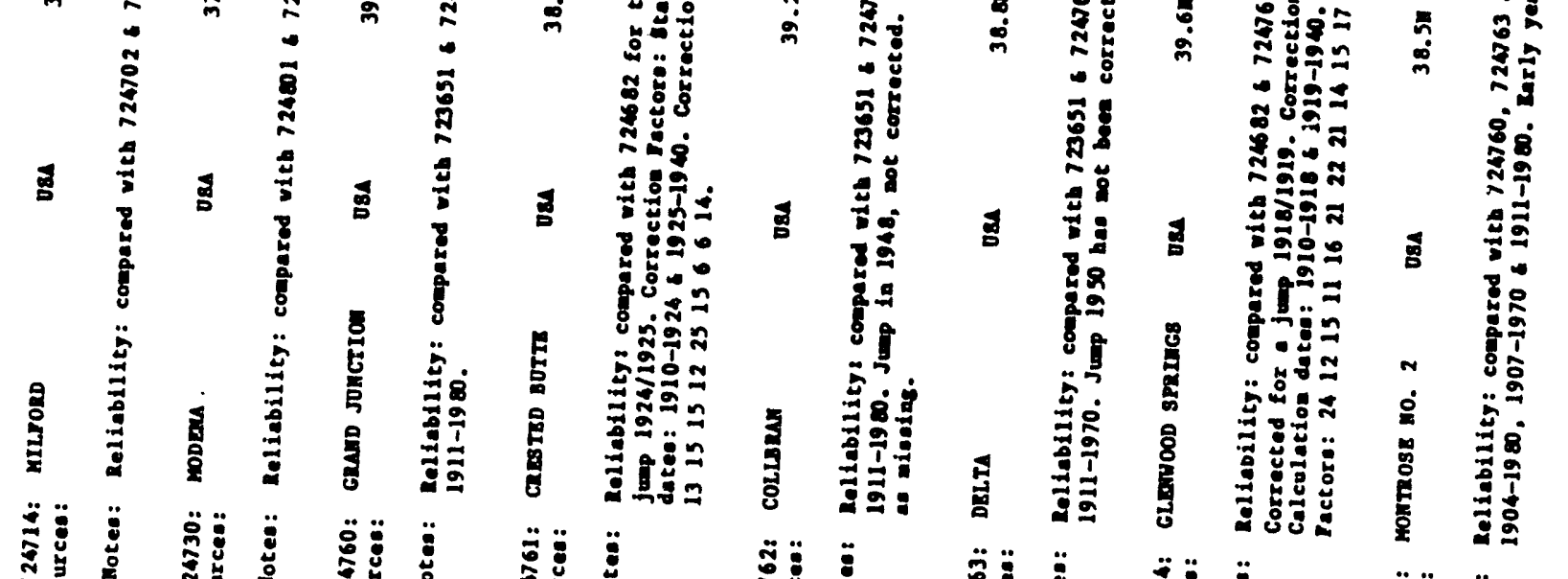

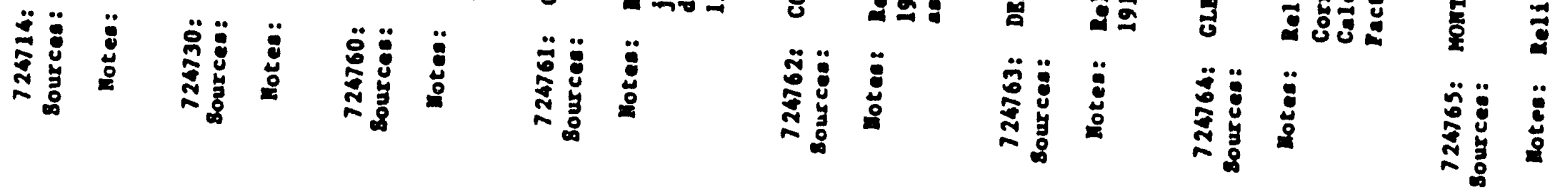




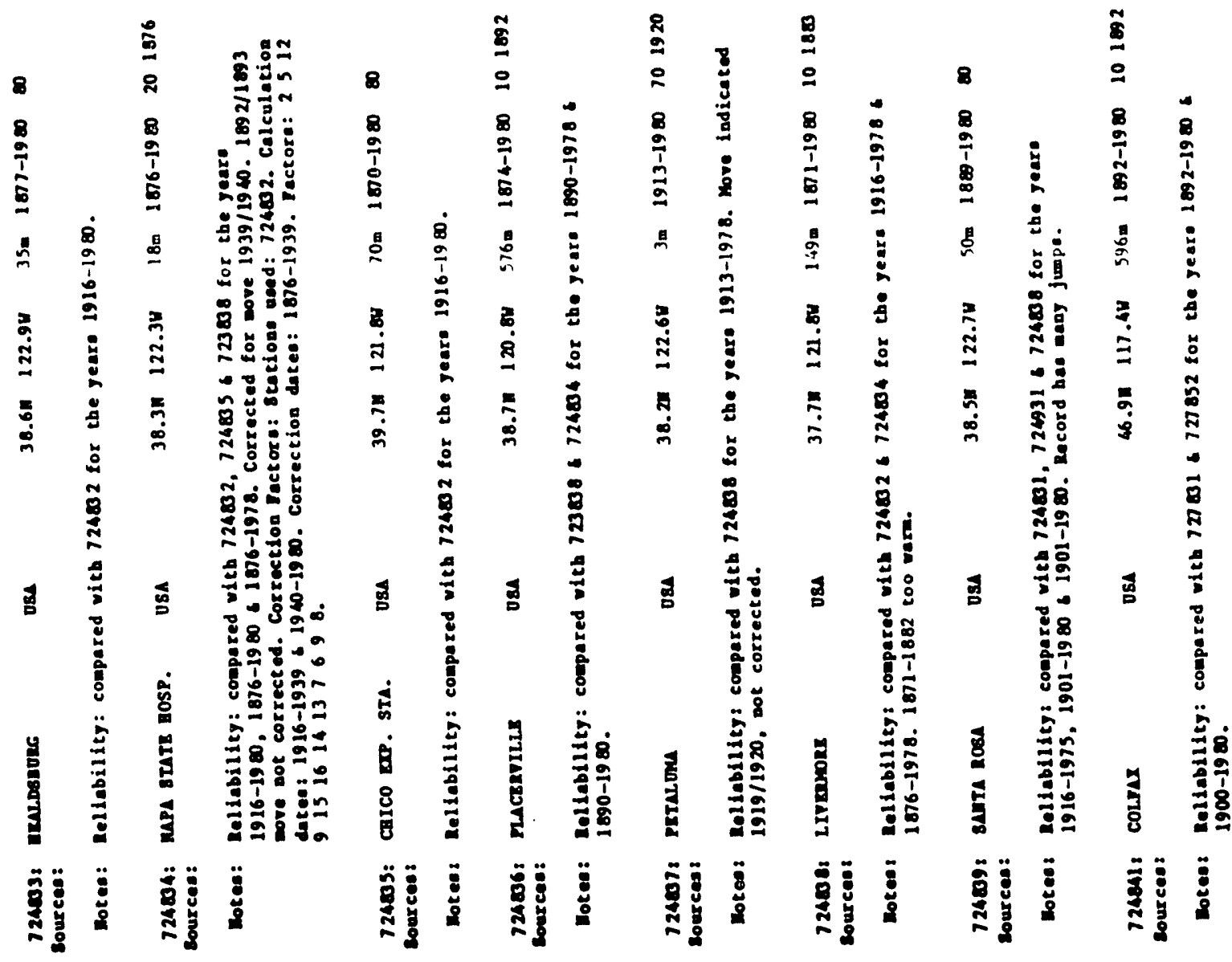




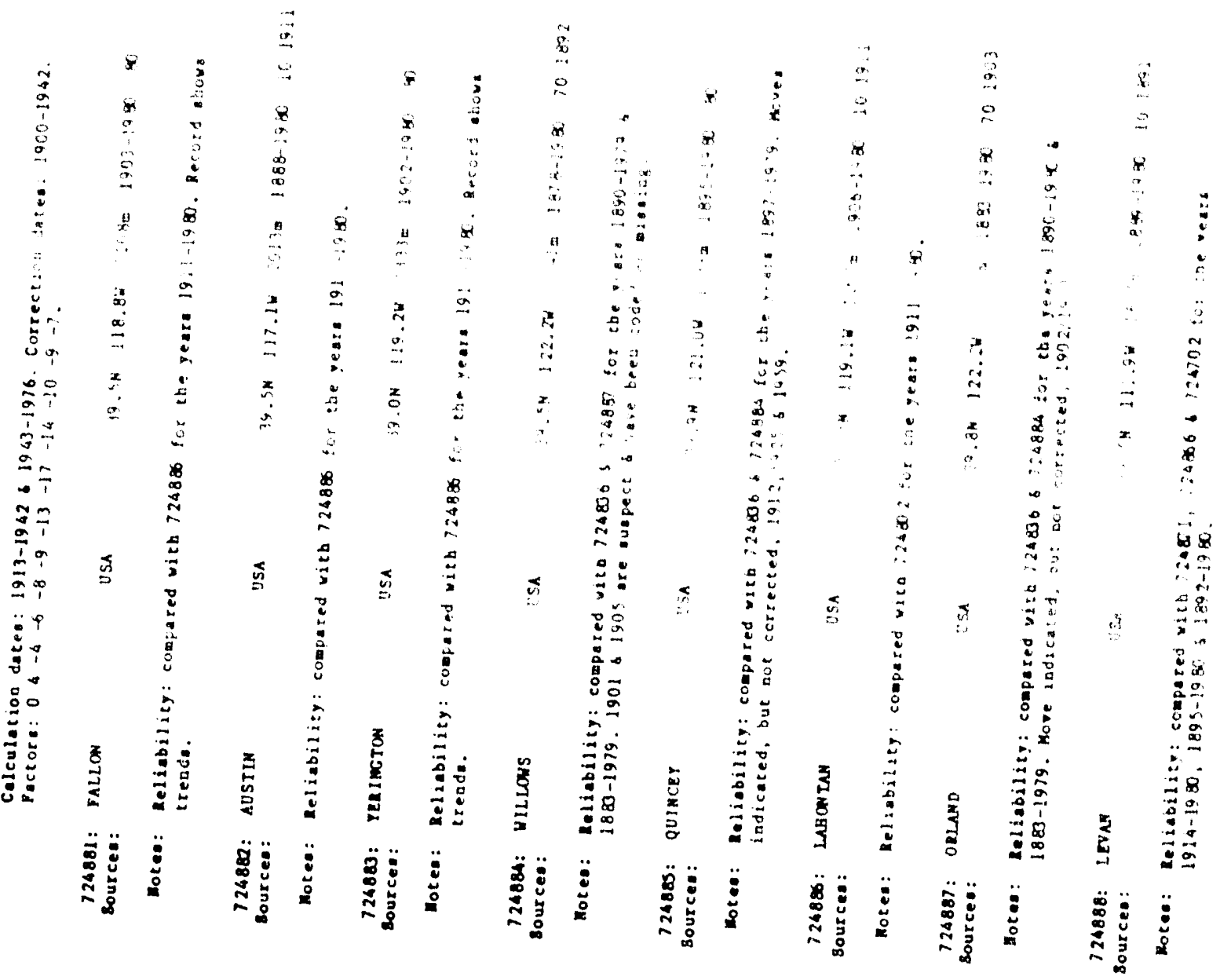

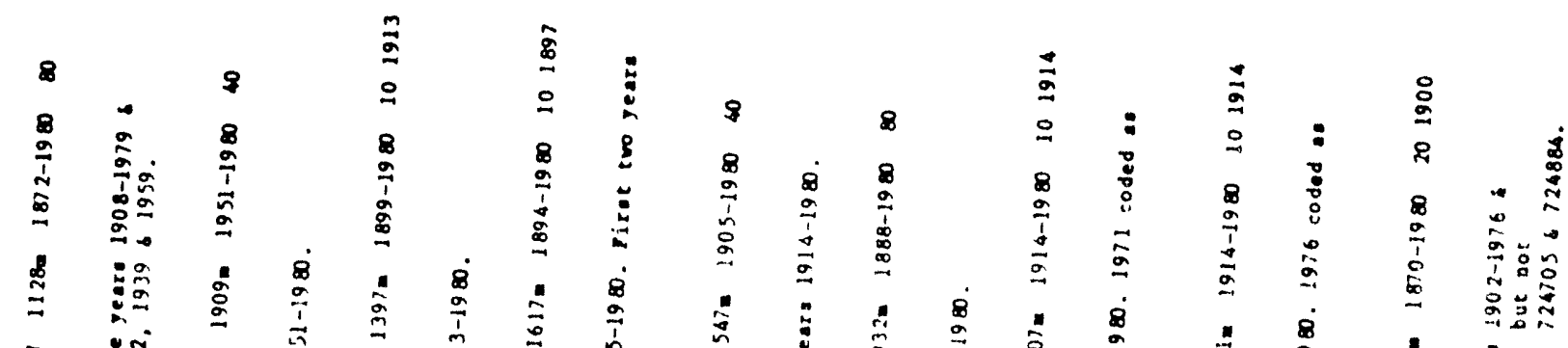

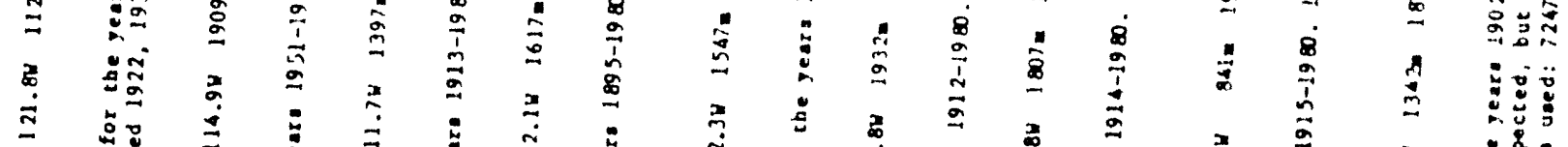

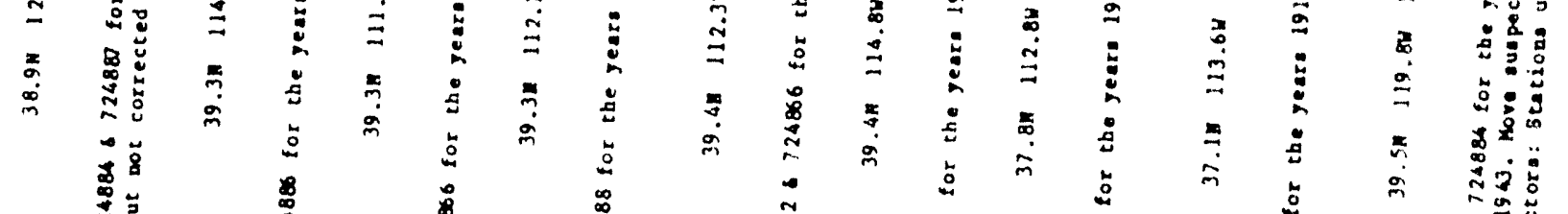

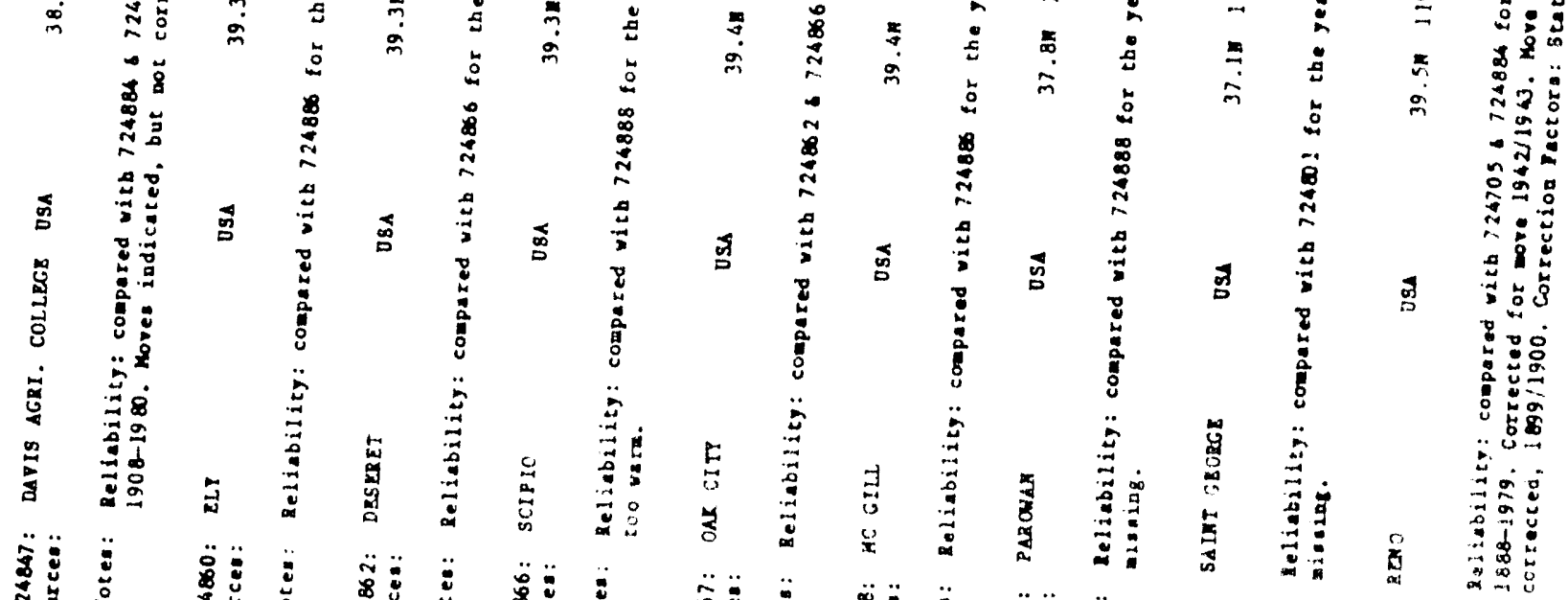

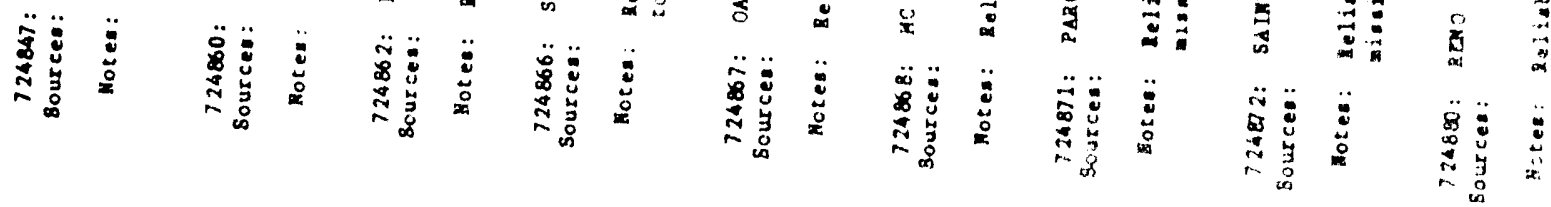



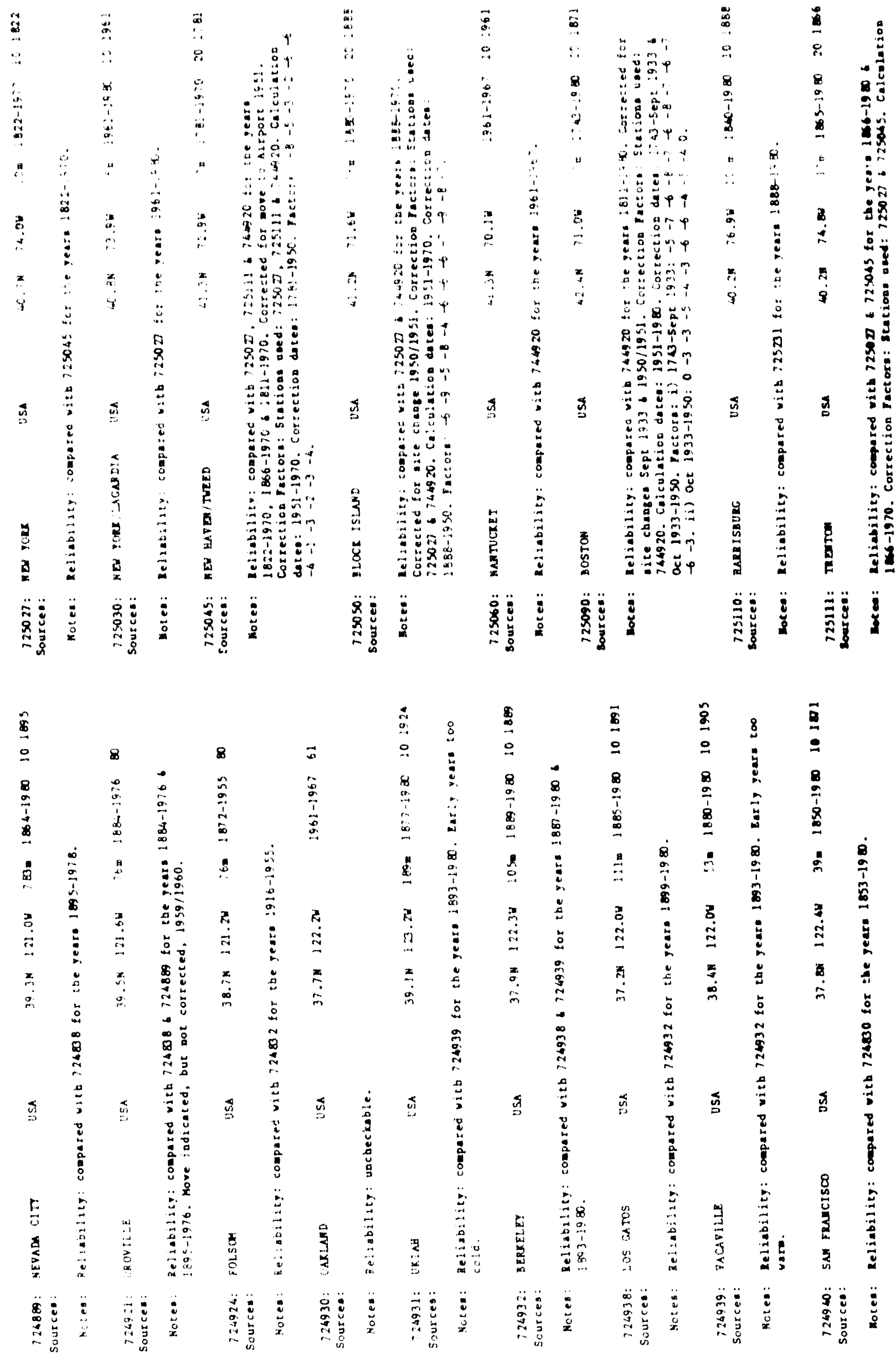
$\Sigma$

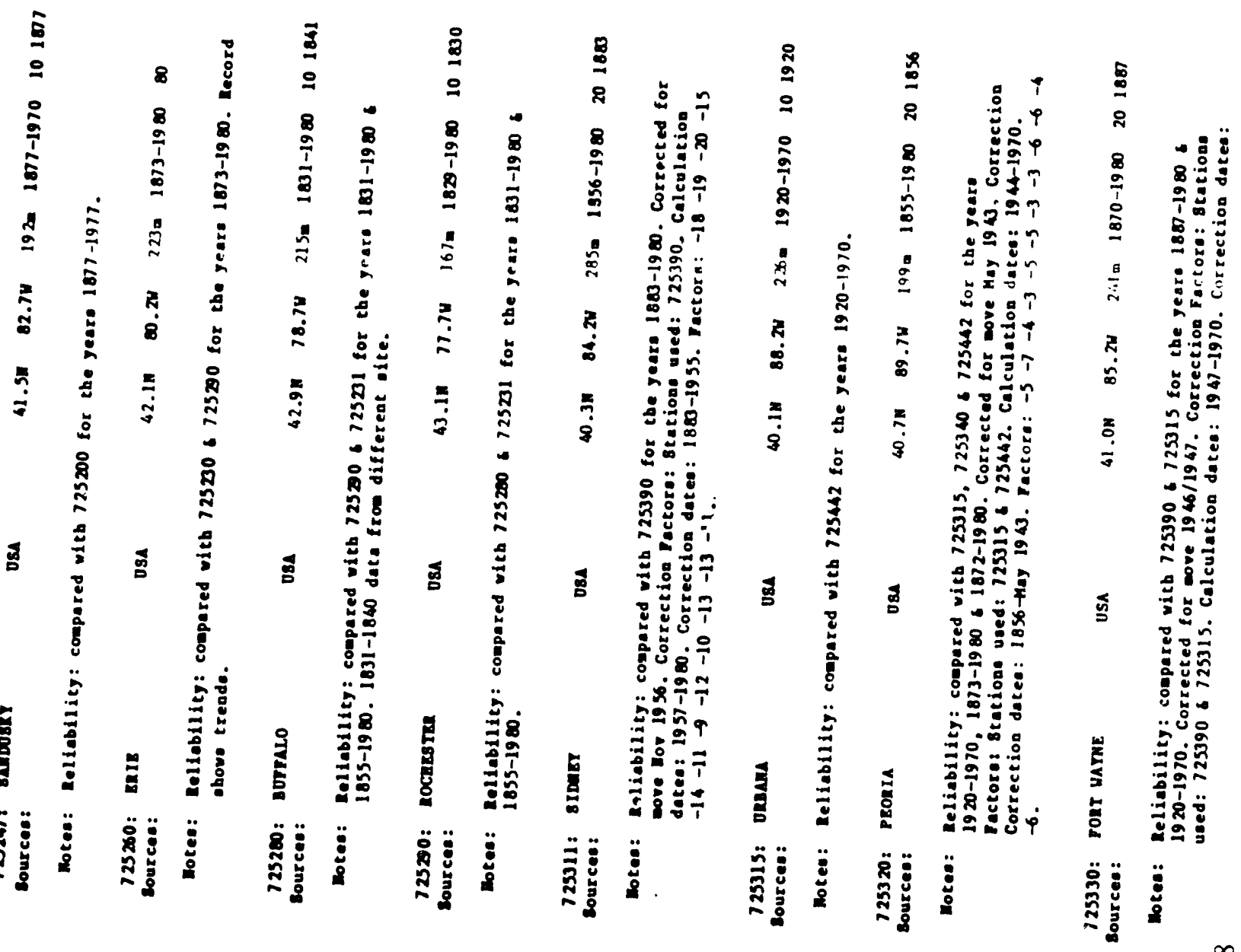

7.

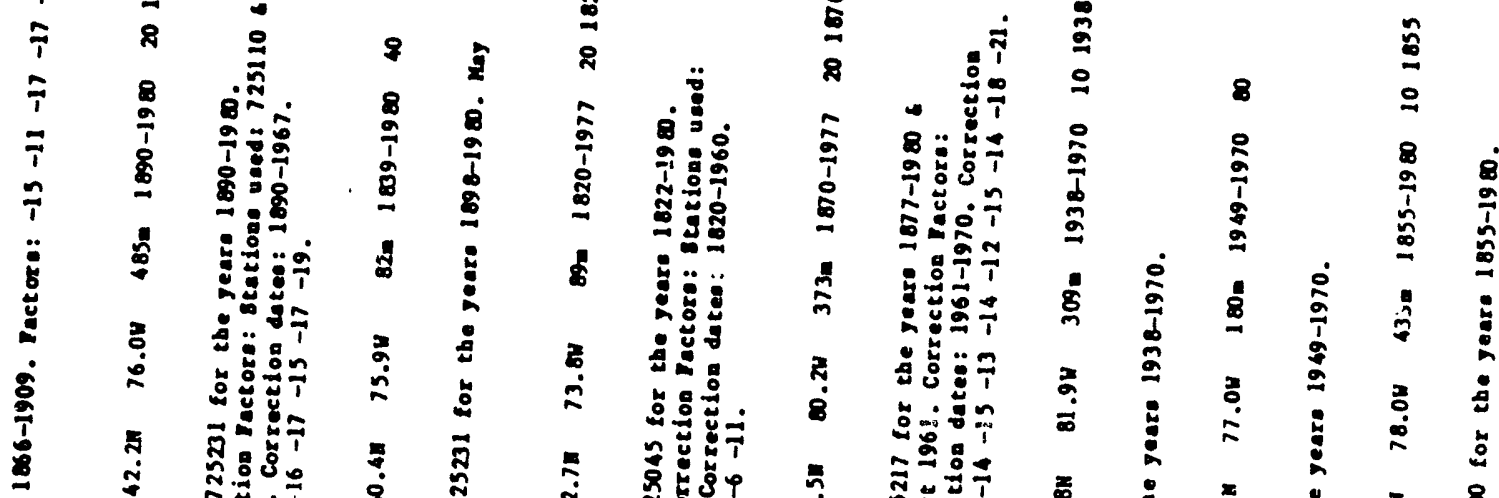

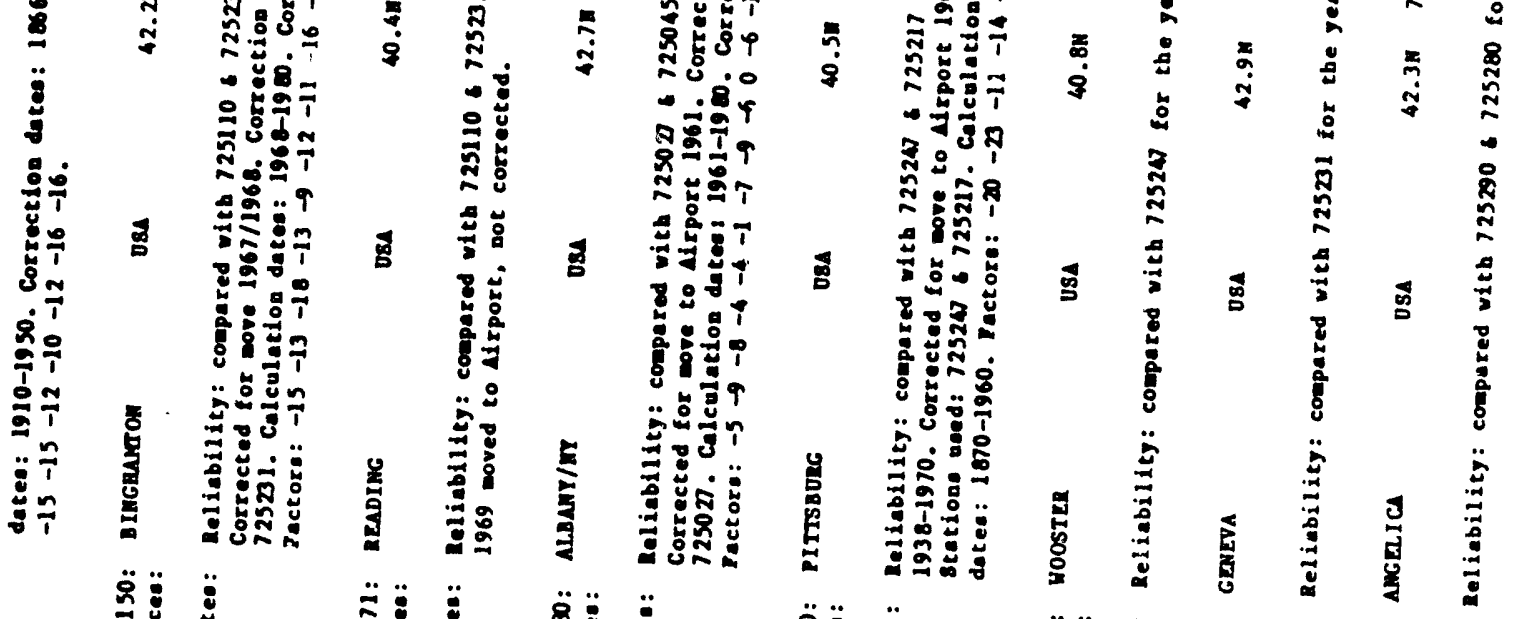

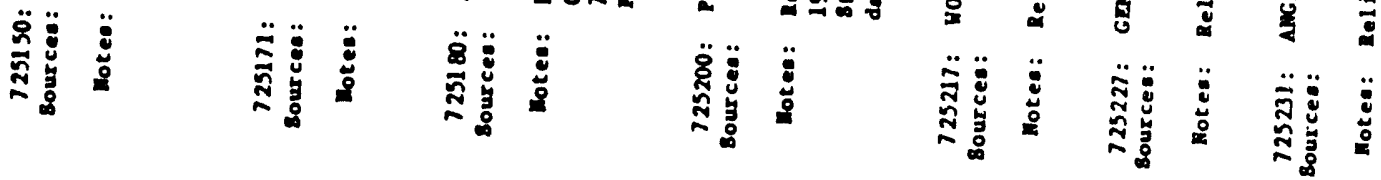




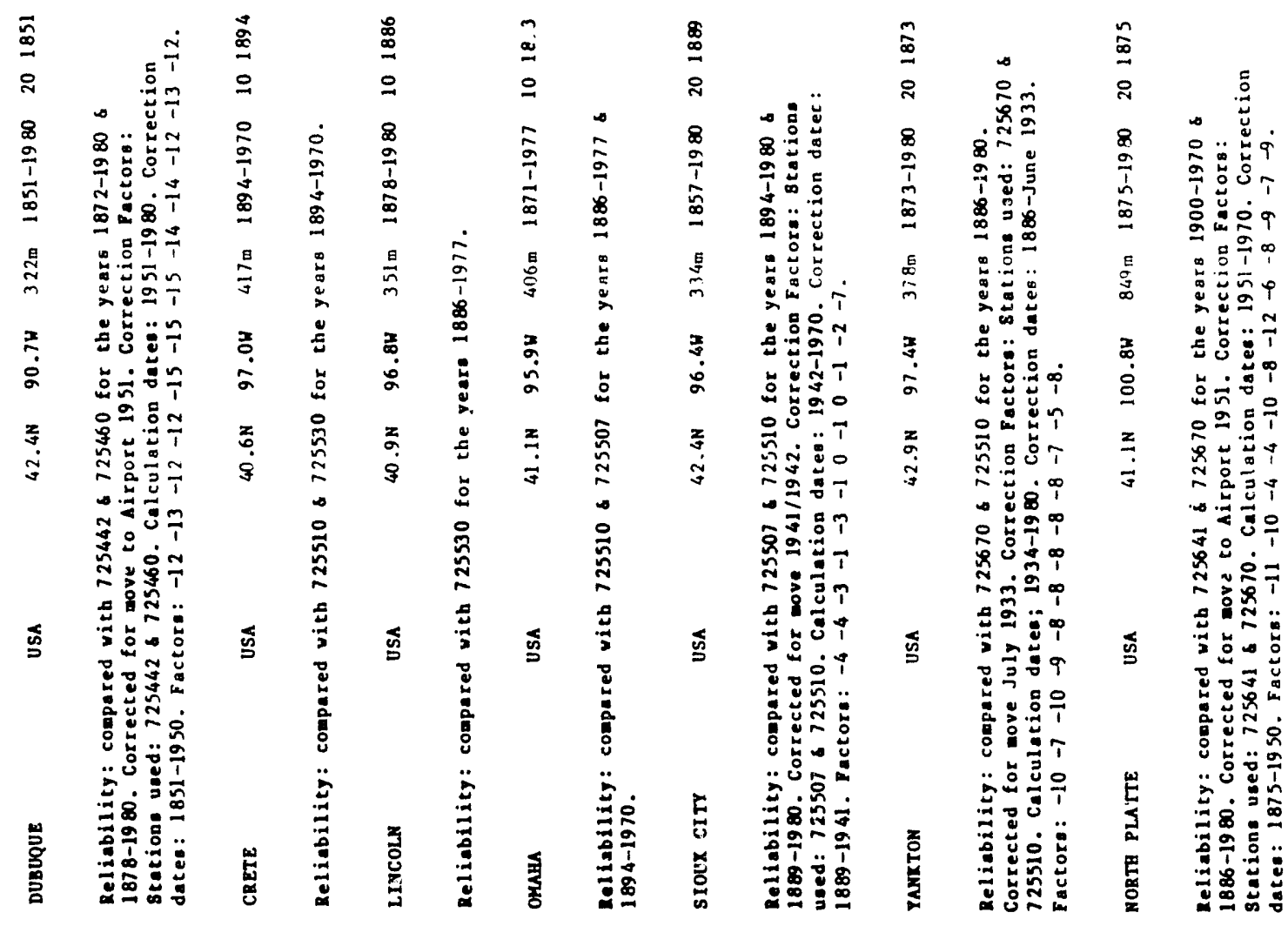

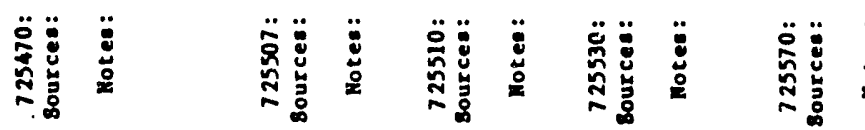

敬

$\frac{9}{3}$

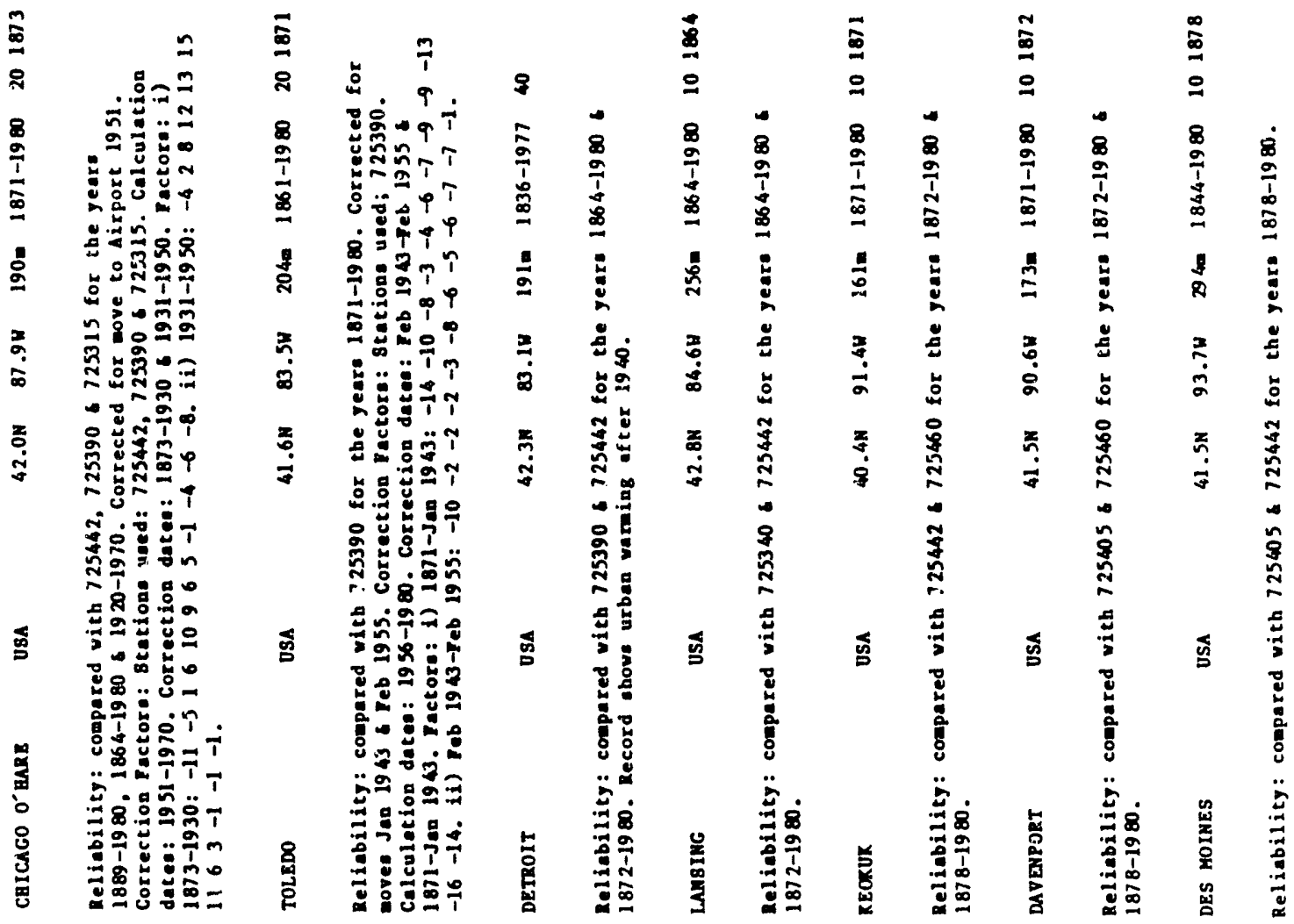

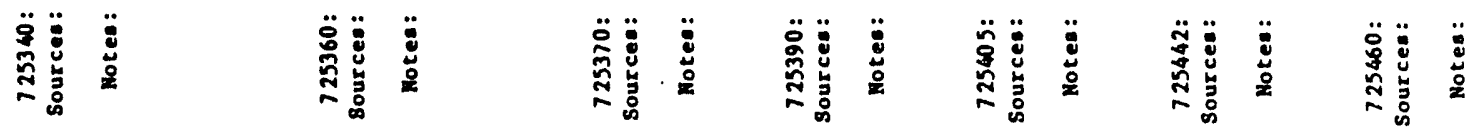




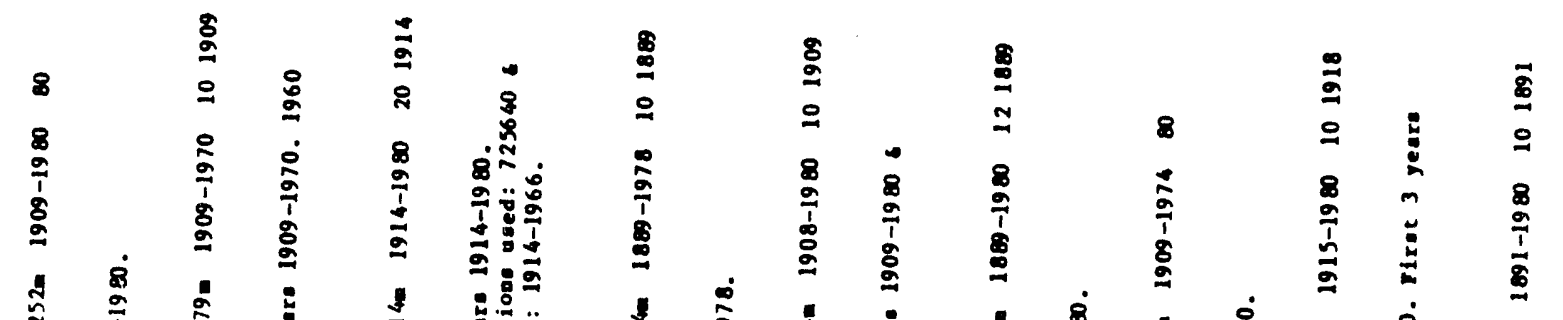

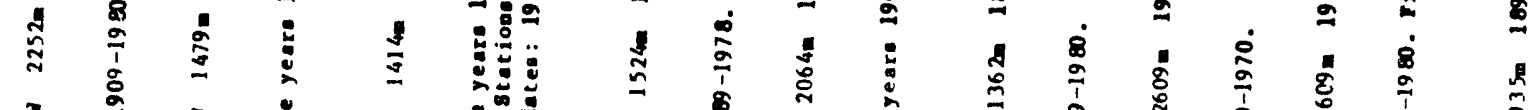

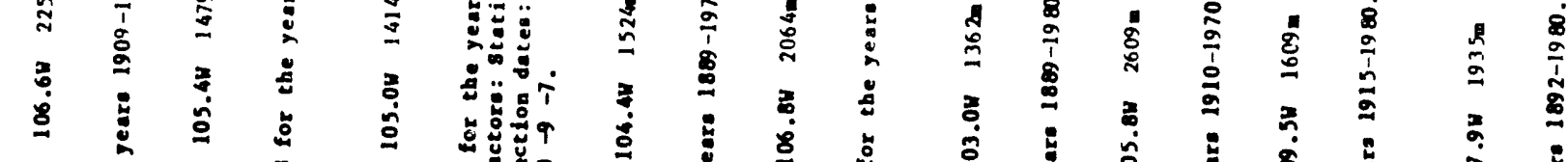

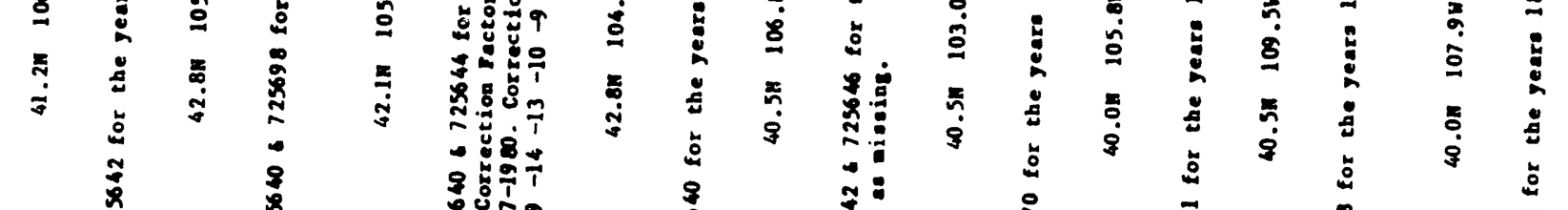

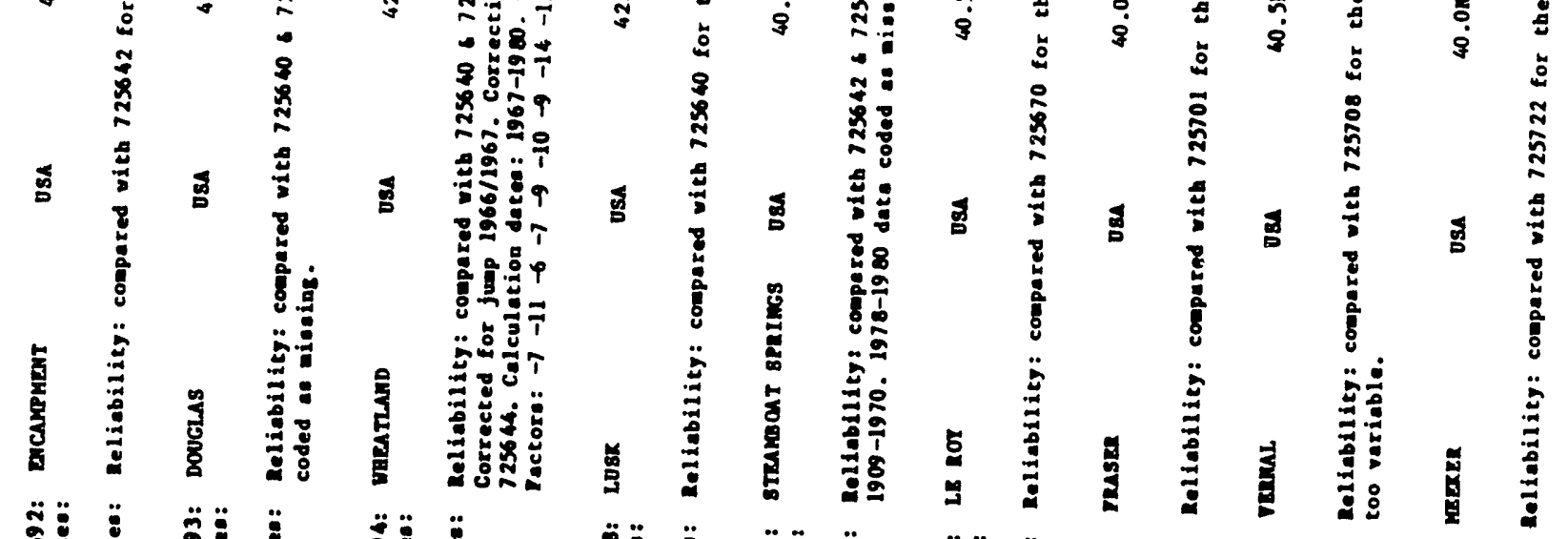

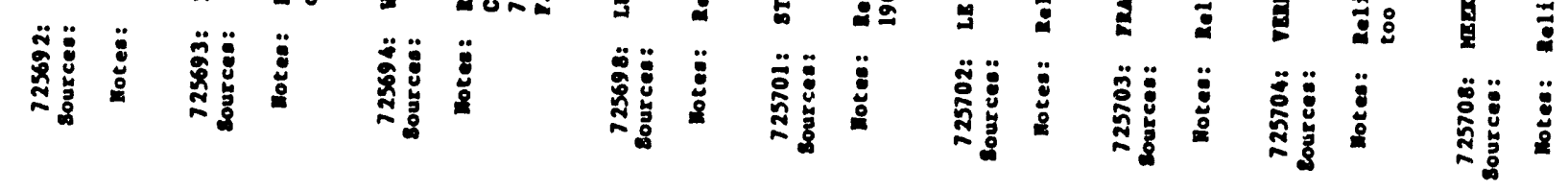

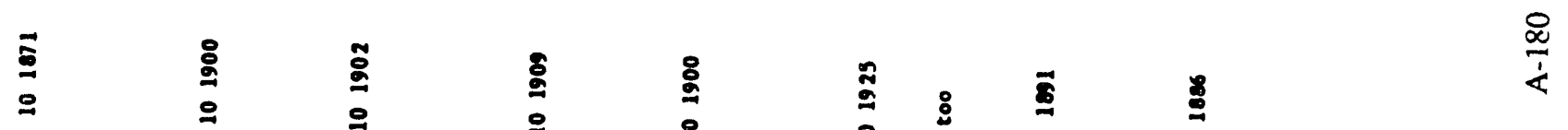

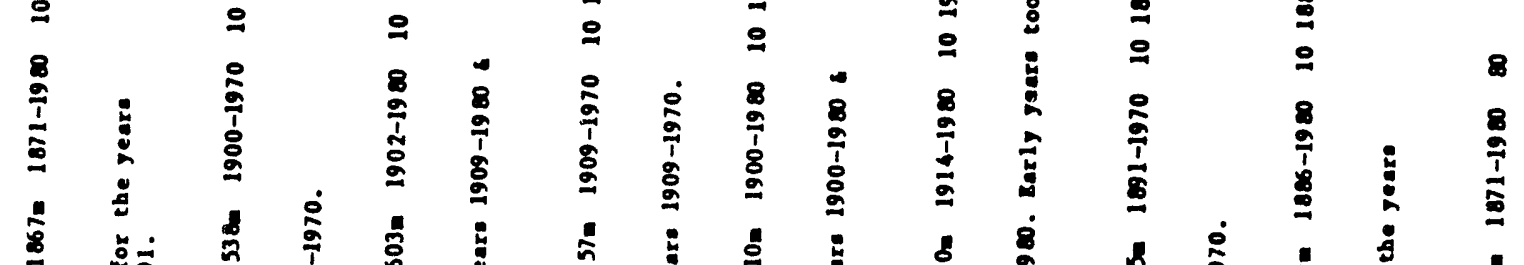

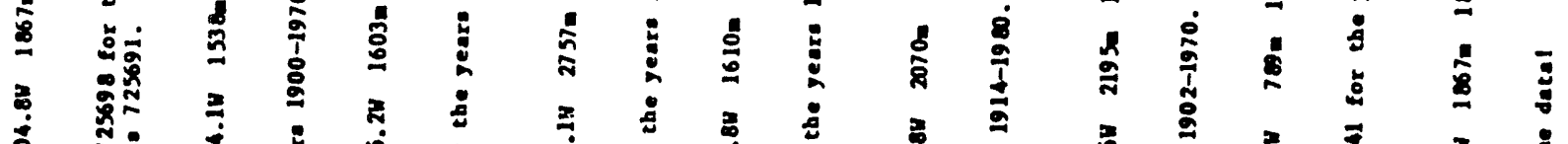

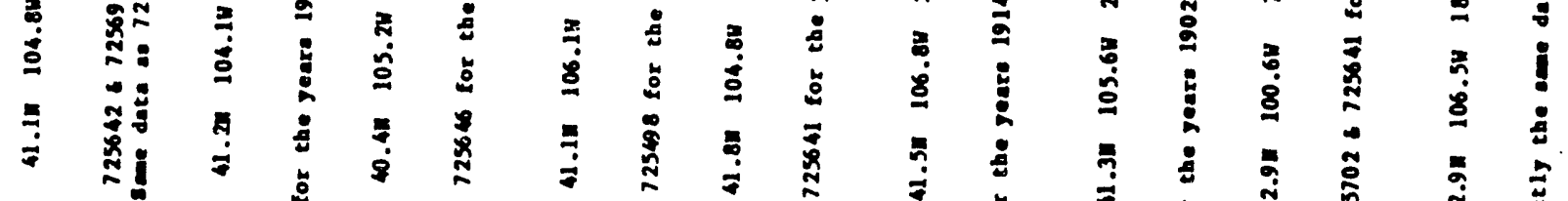

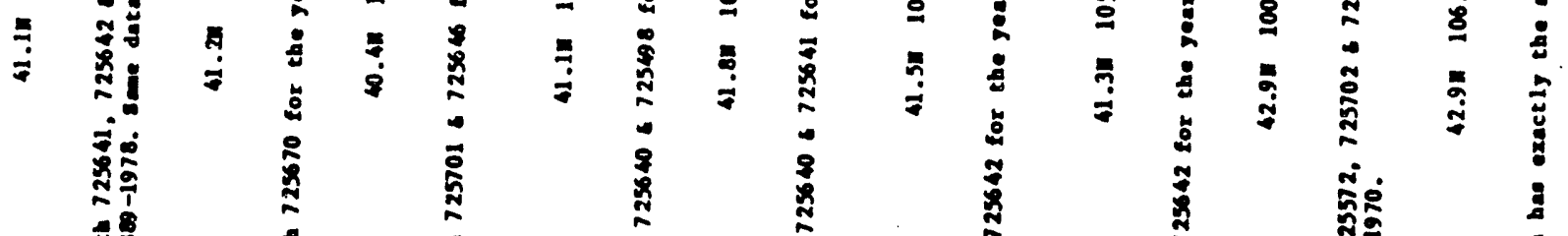

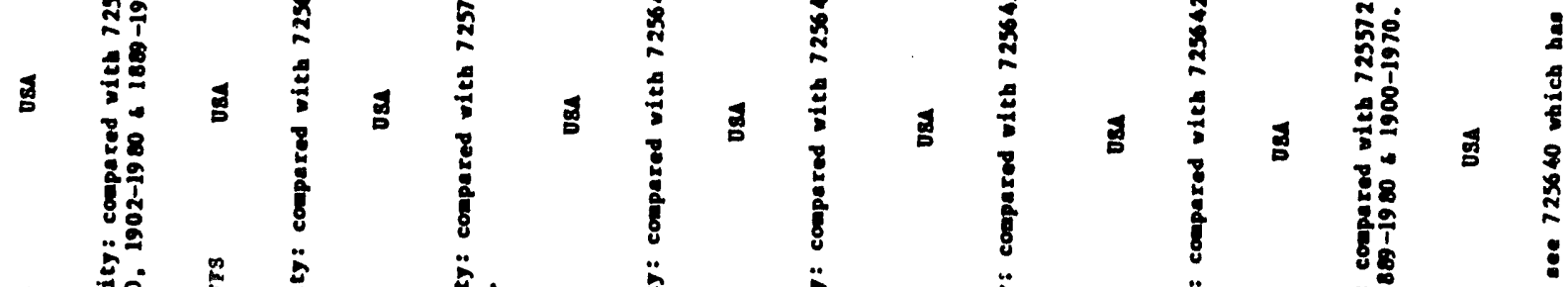

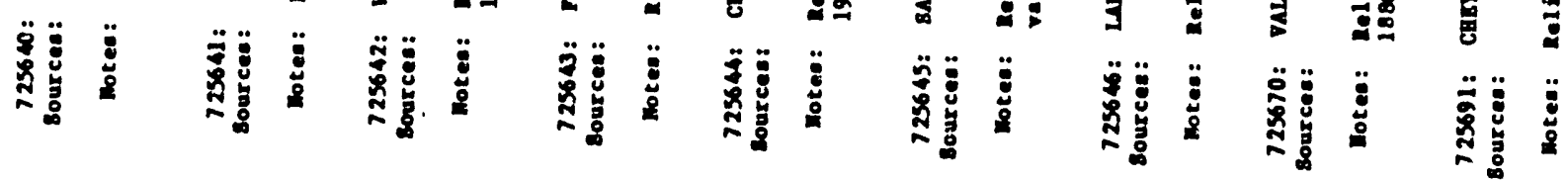




\section{ㄴ}

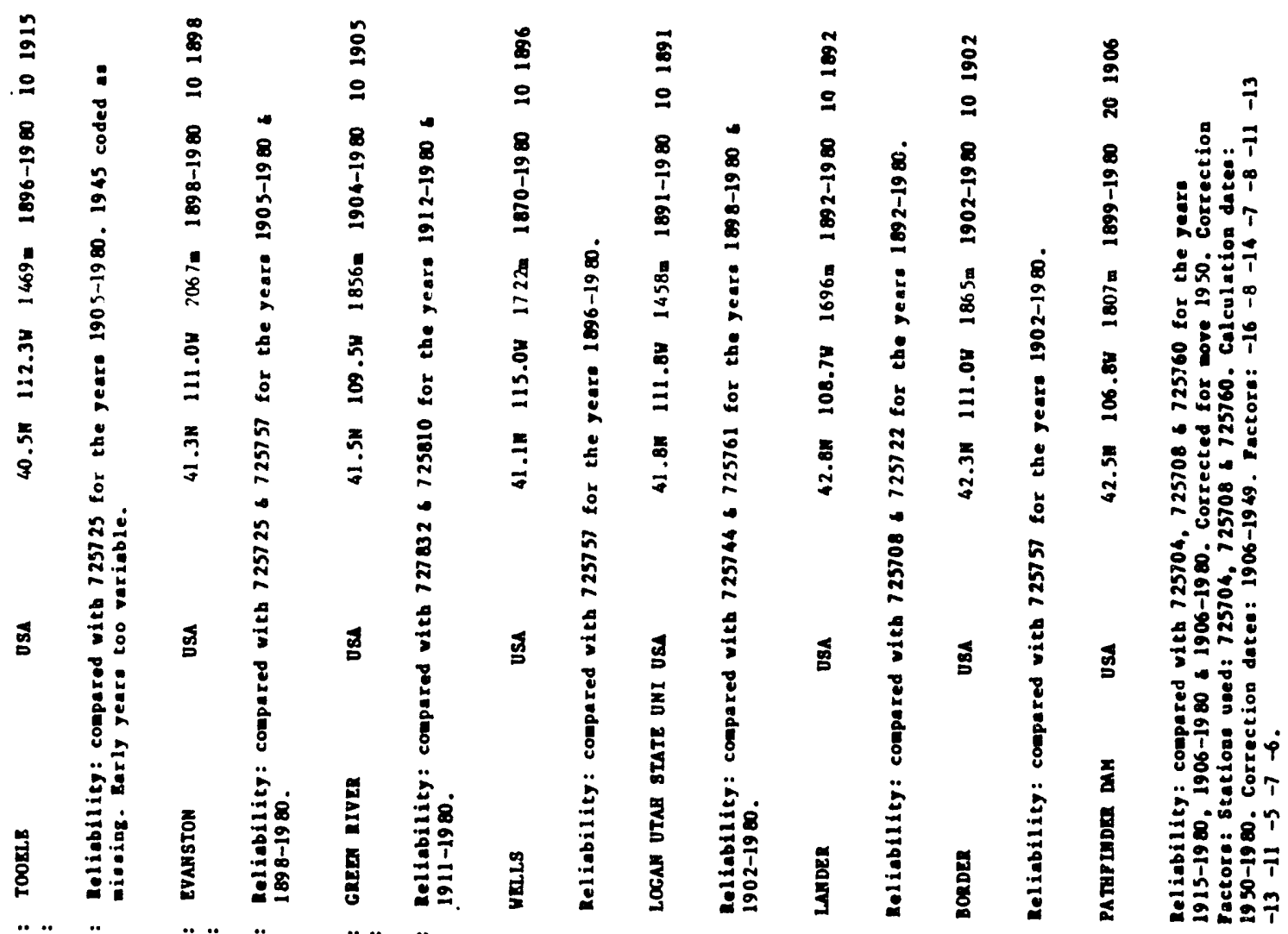

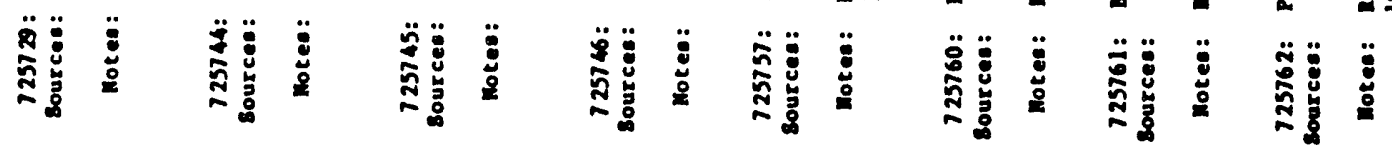

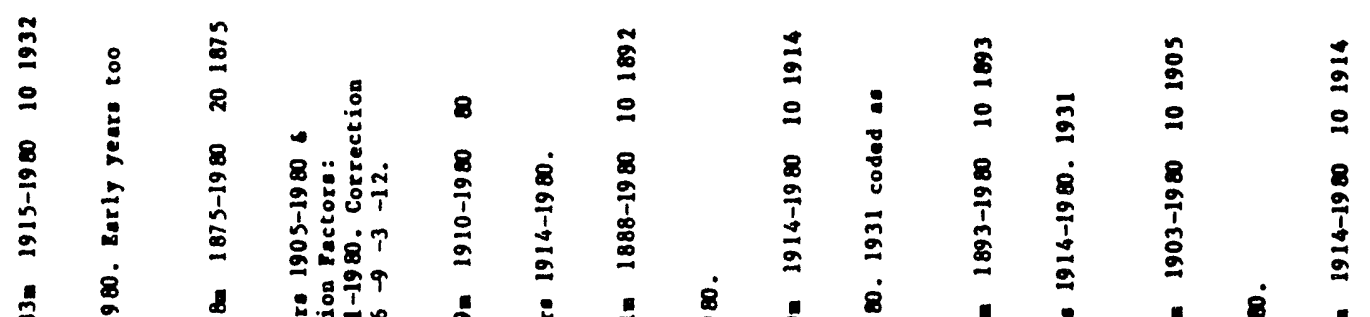

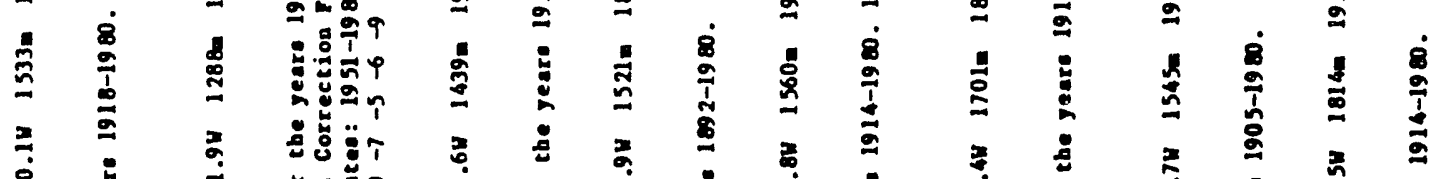

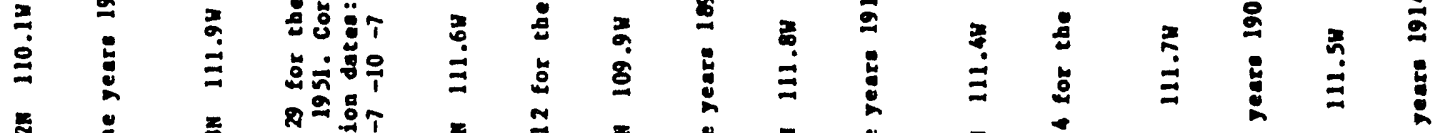

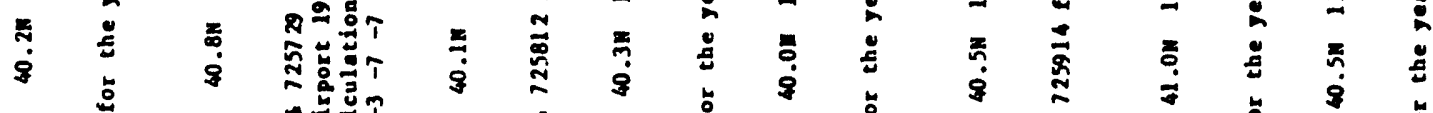

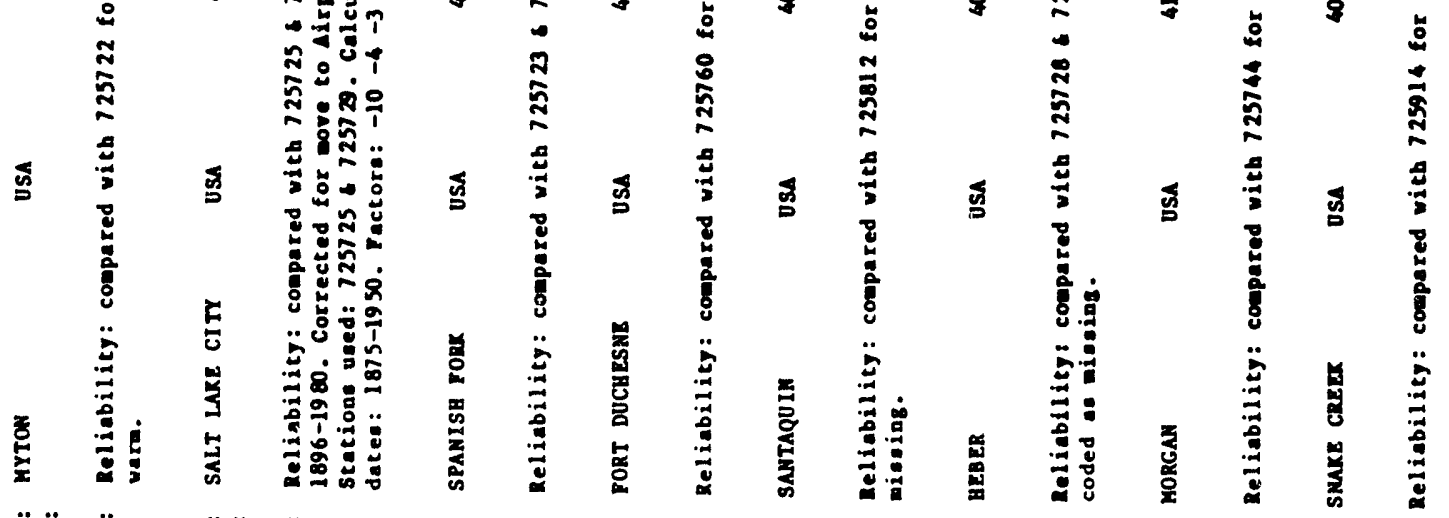

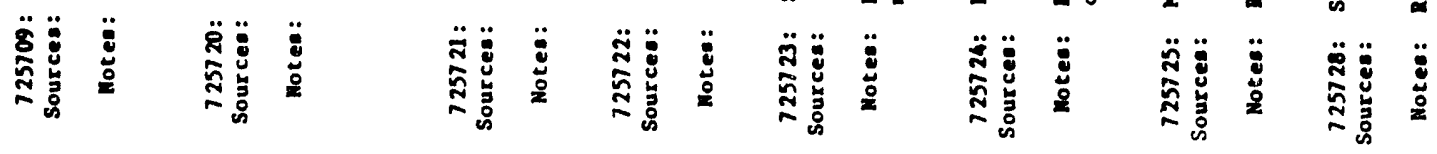




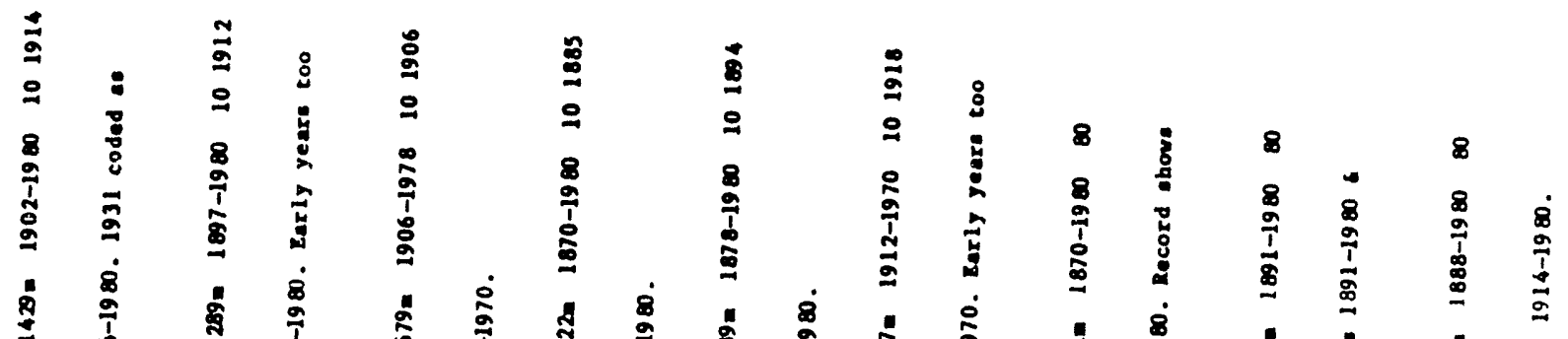

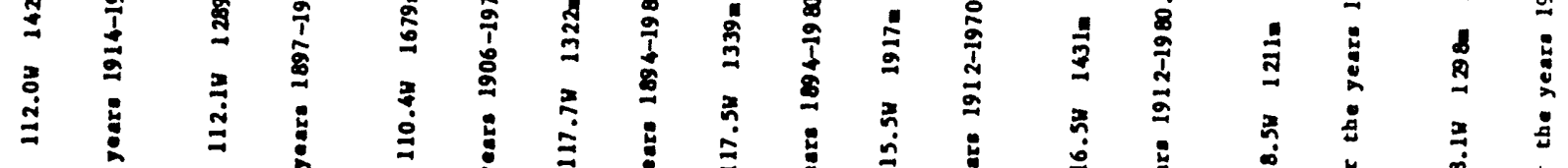

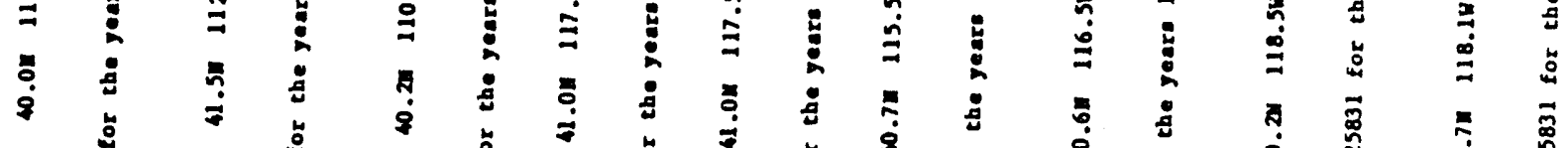

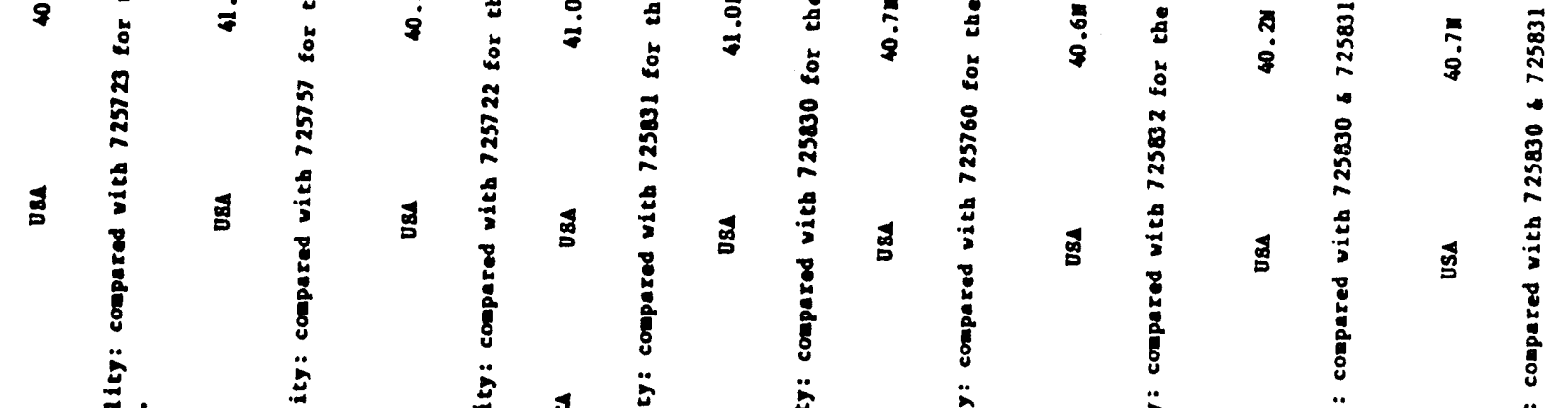

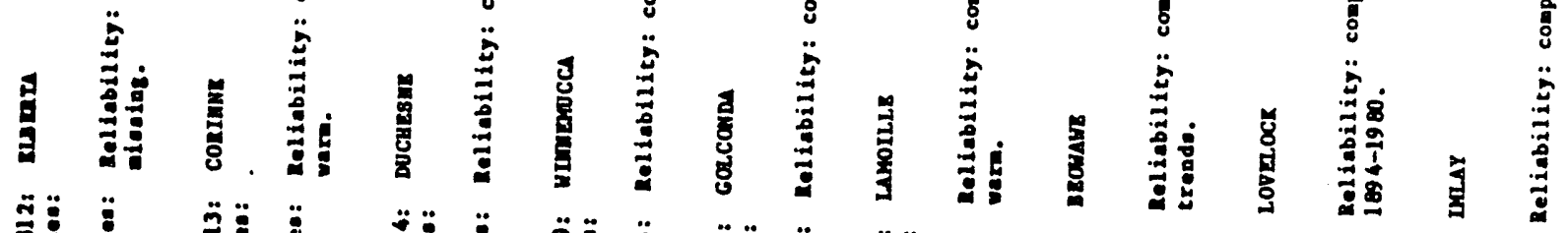

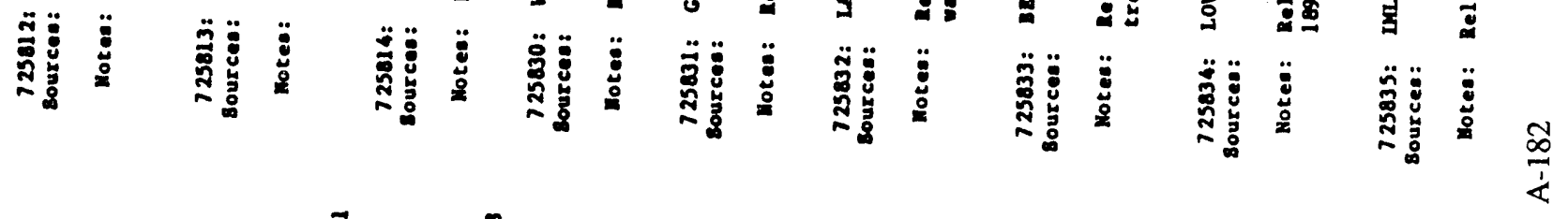

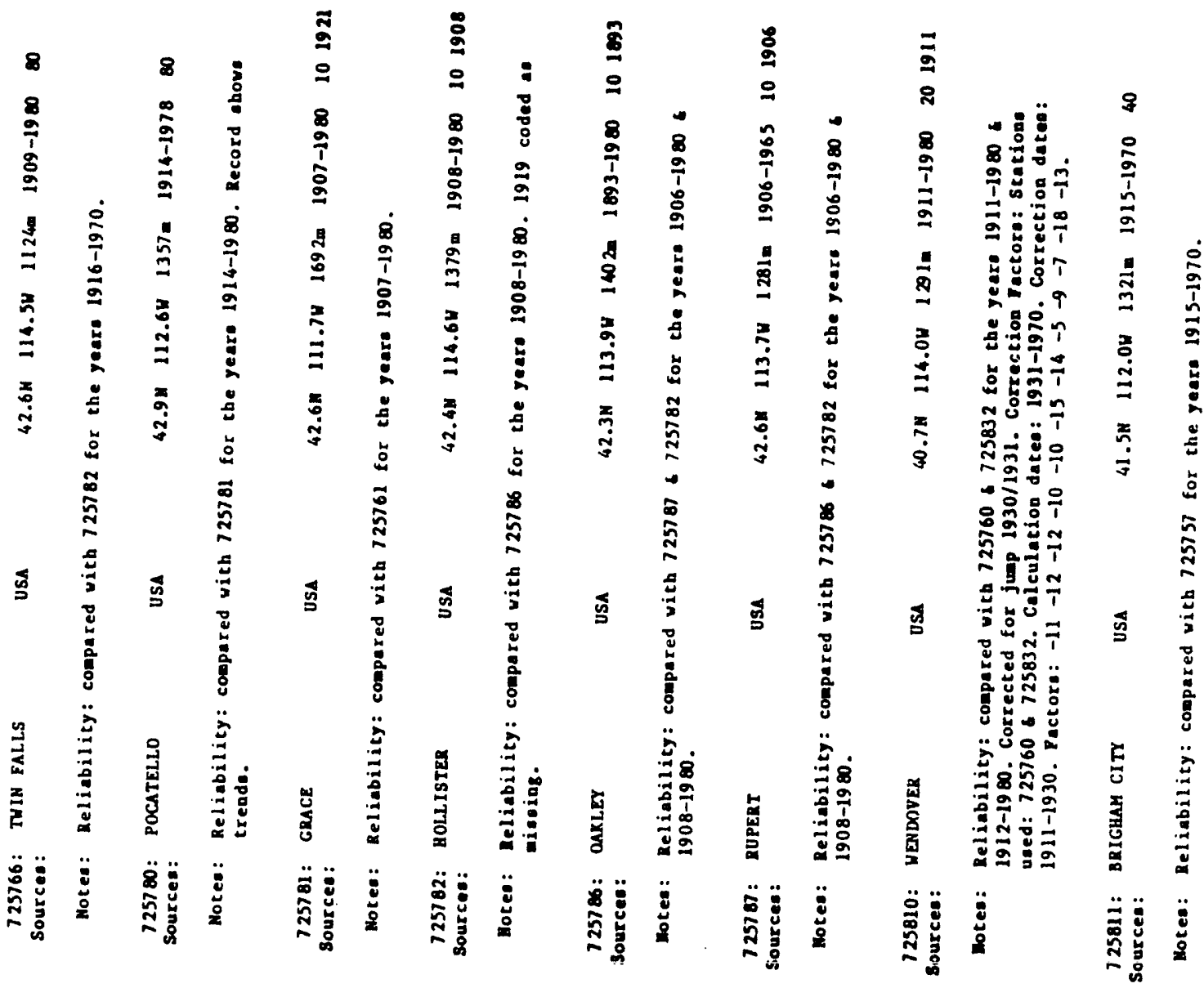


$E$

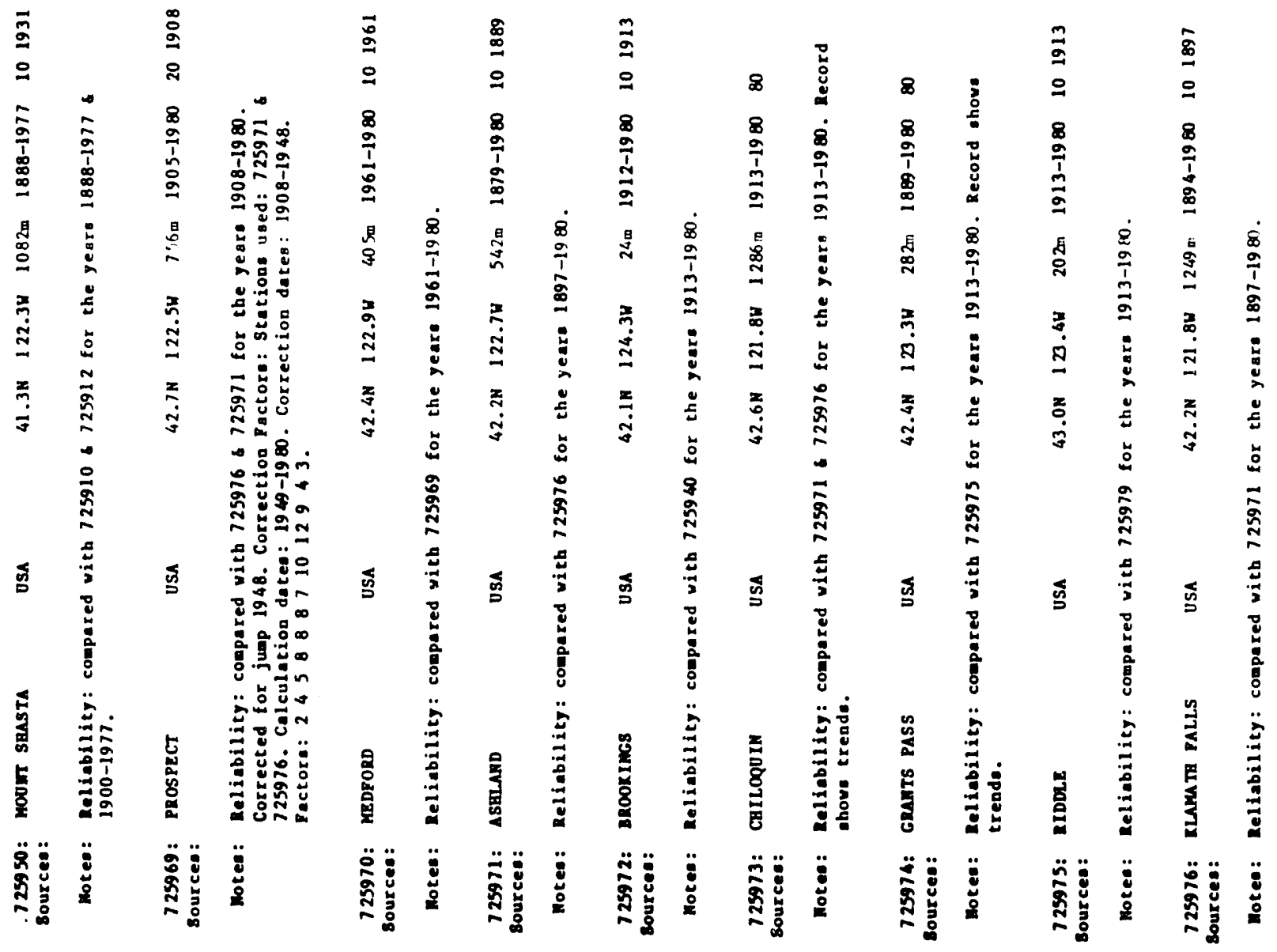

$\frac{\infty}{\dot{1}}$

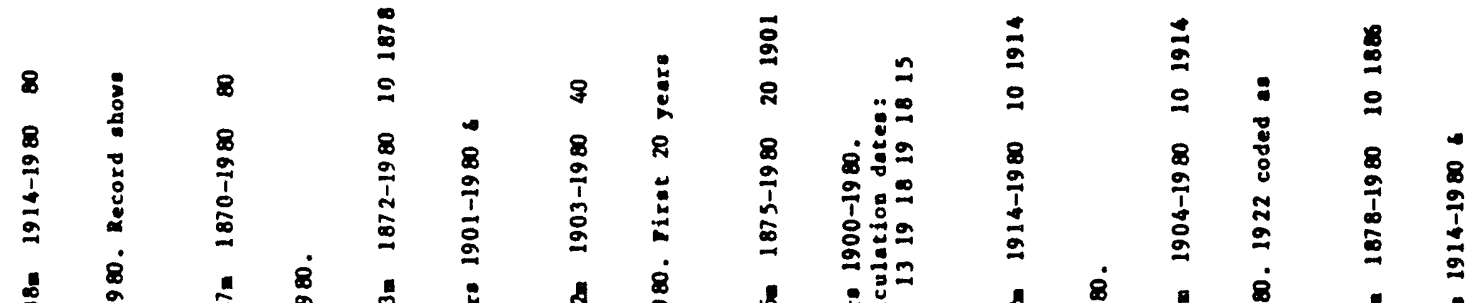

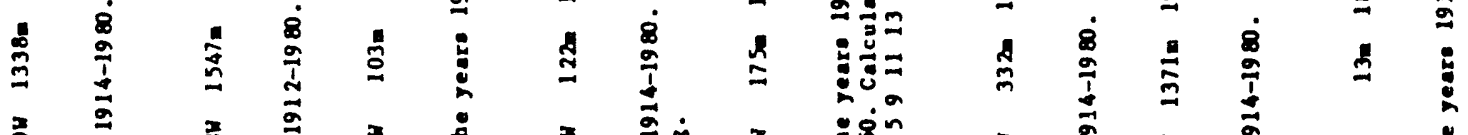

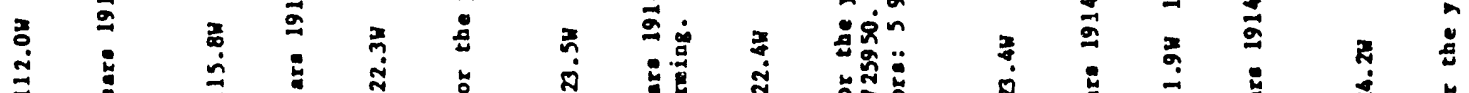

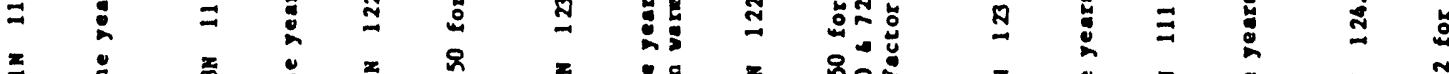

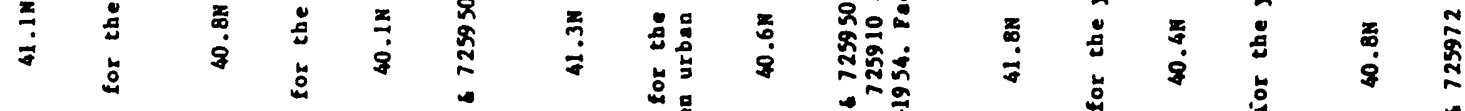

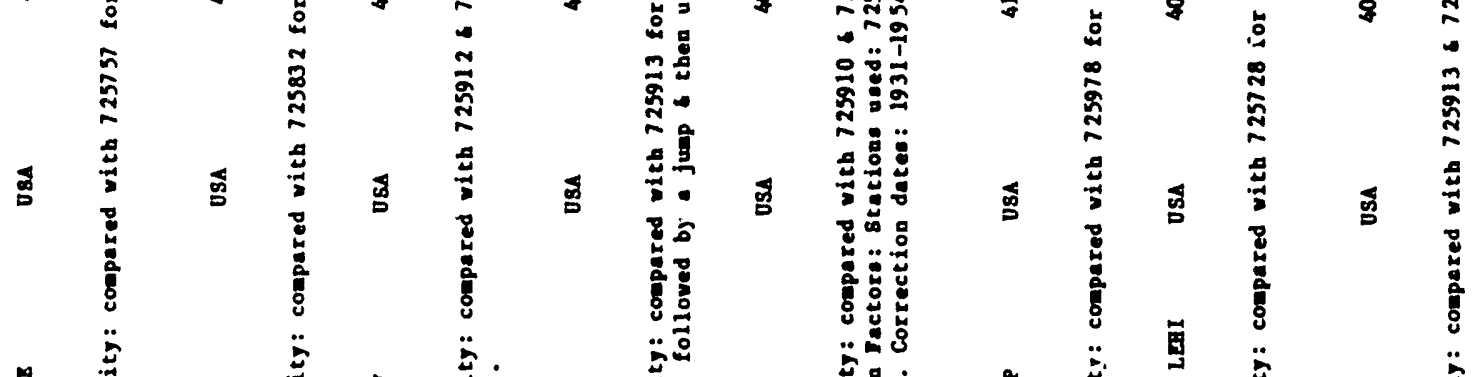

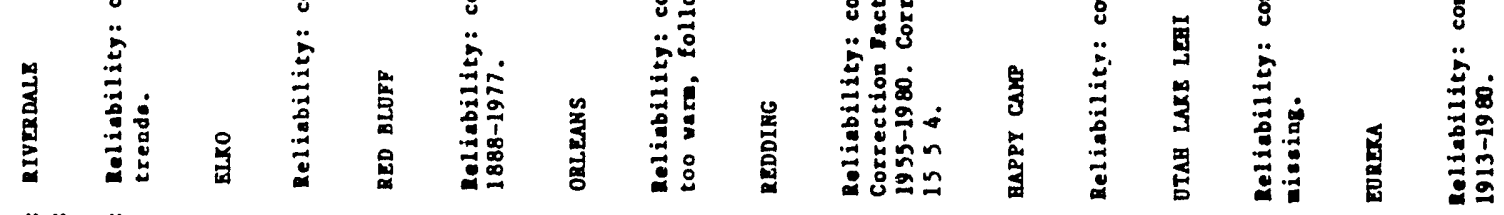

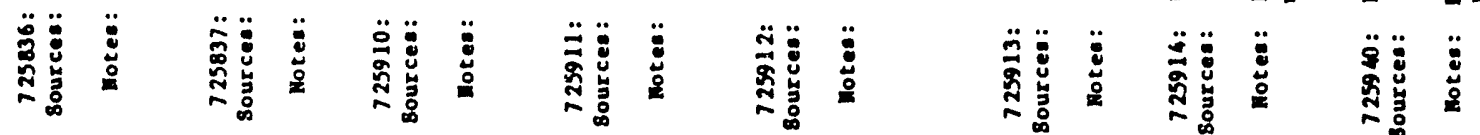




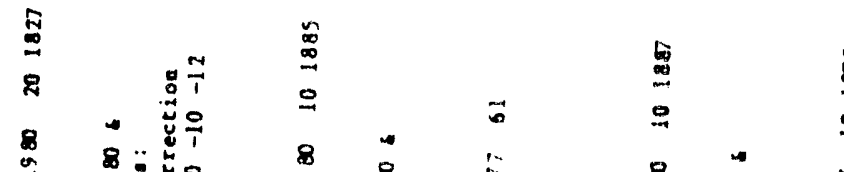

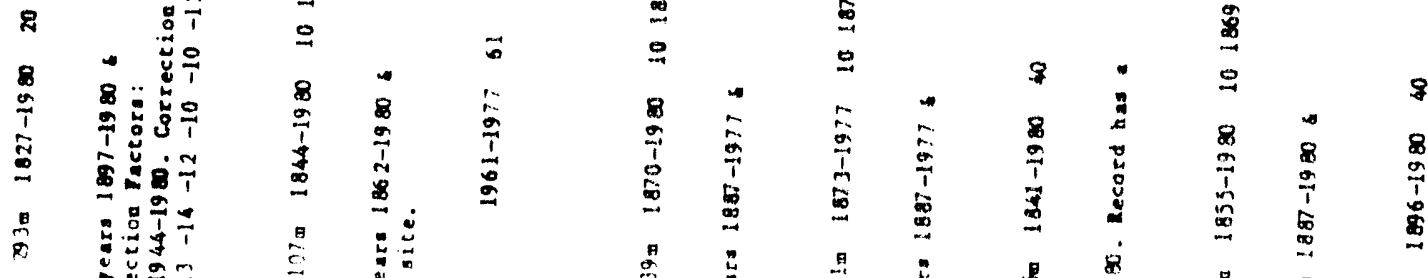

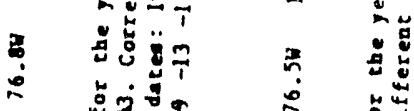

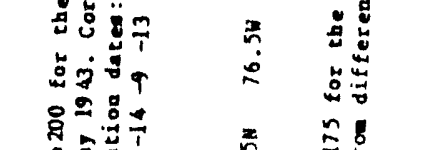

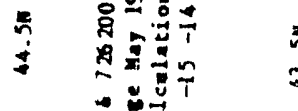

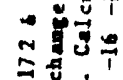

通

(1)

然

要

3

I!

II

!n

$\frac{1}{2}$

?

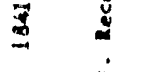

1 
(3)

(1)

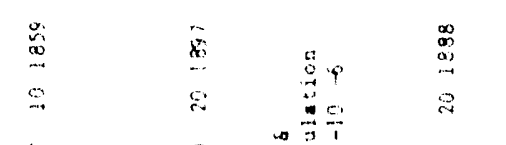

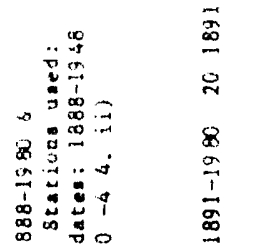

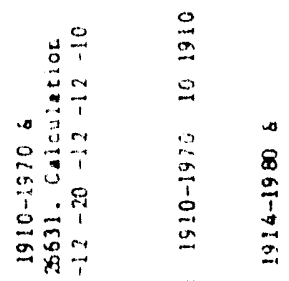

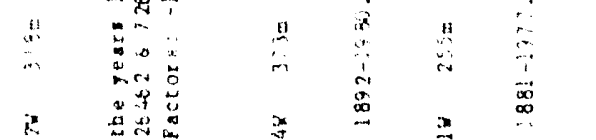

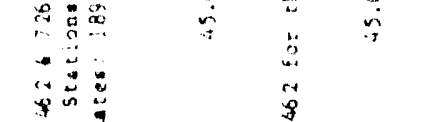

$\vdots$
$\vdots$
$\vdots$
$\vdots$
0

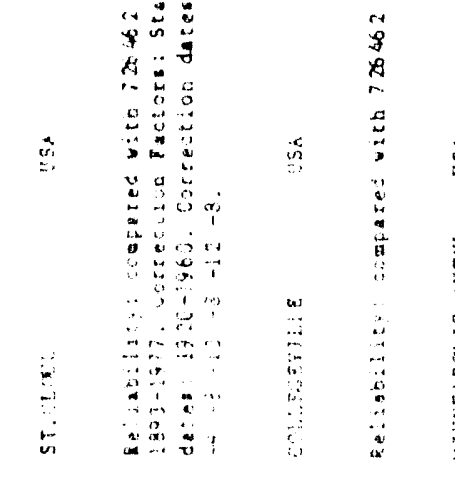

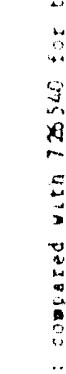

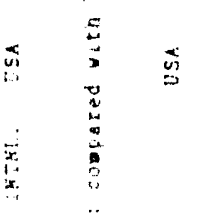

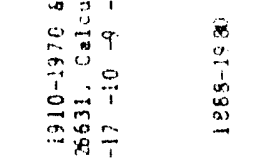

要

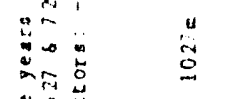

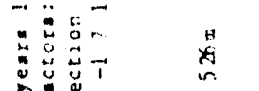

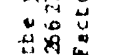

$\frac{3}{i}$

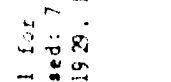

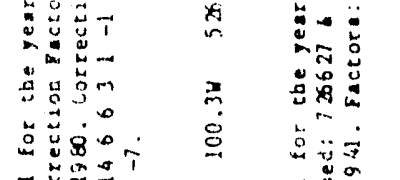

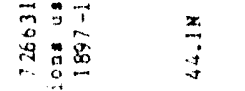

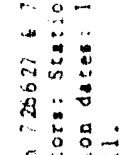

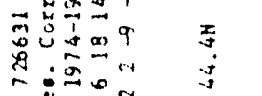

0
0
0

A

起范

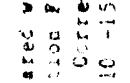

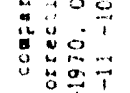

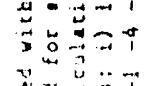

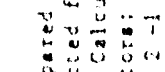

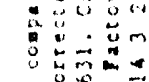

点二

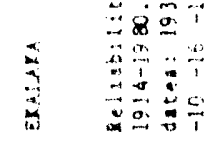

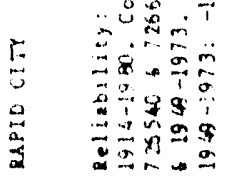

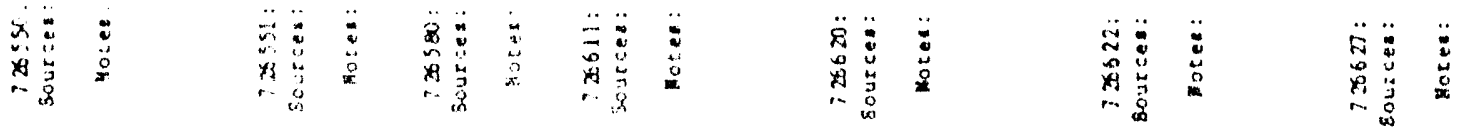

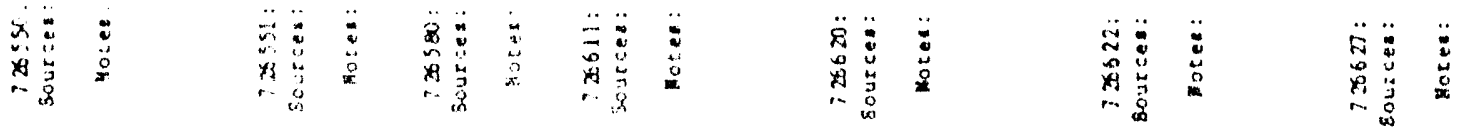

运家家

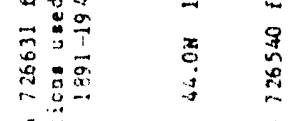

$-3$

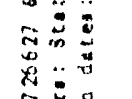

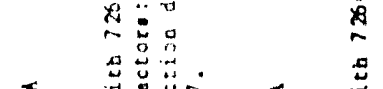

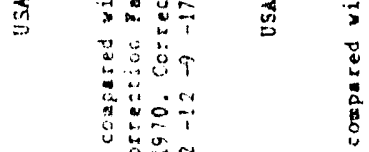

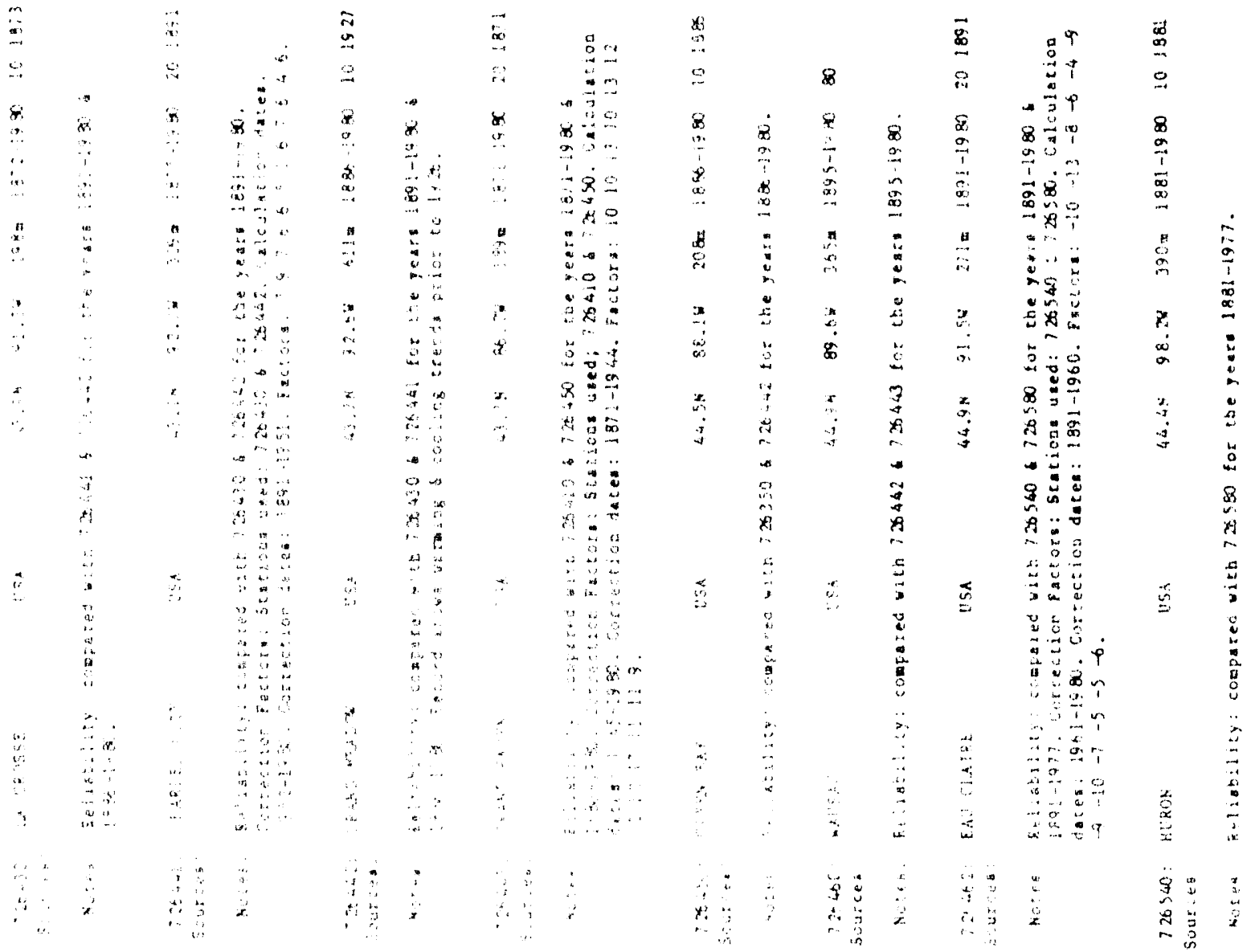




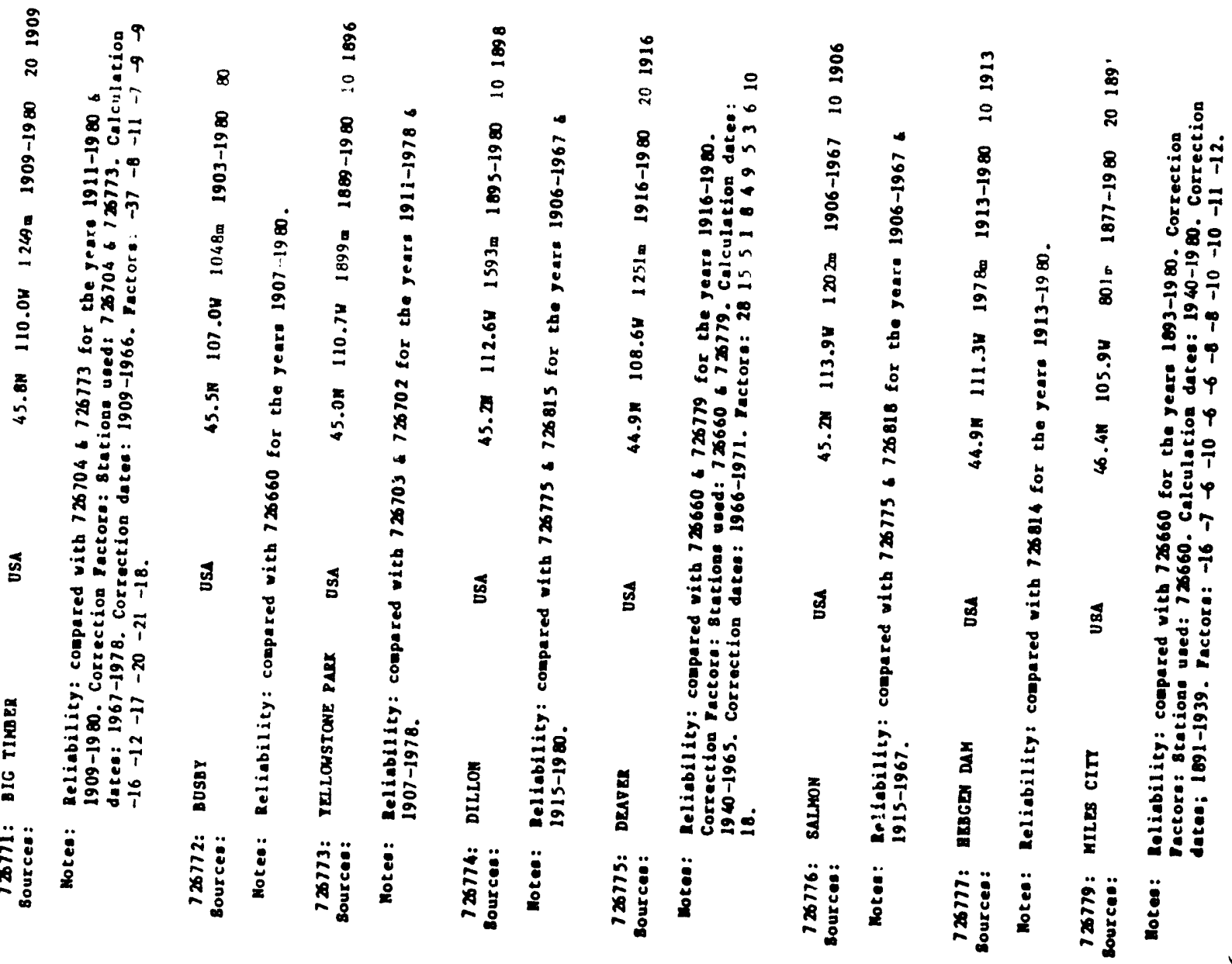

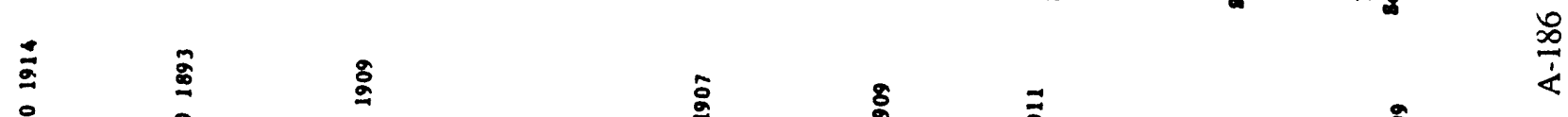

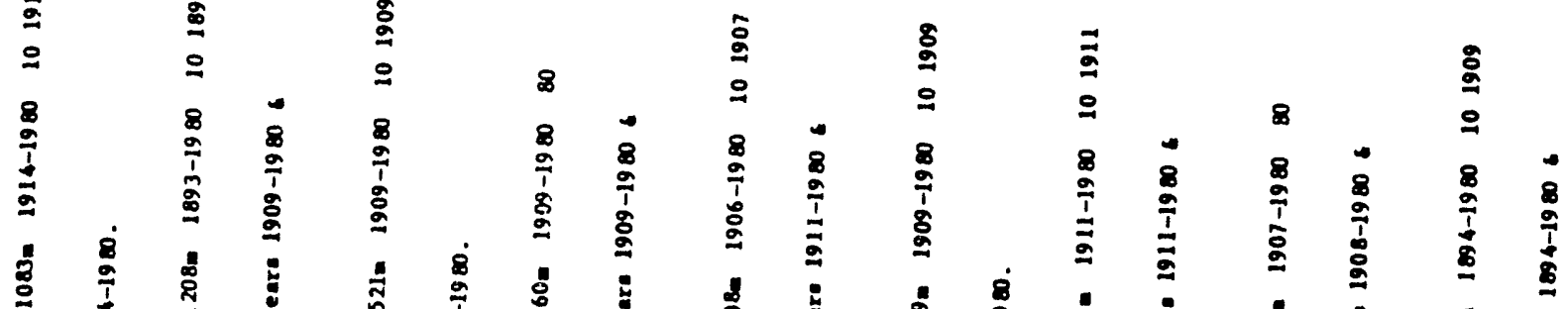

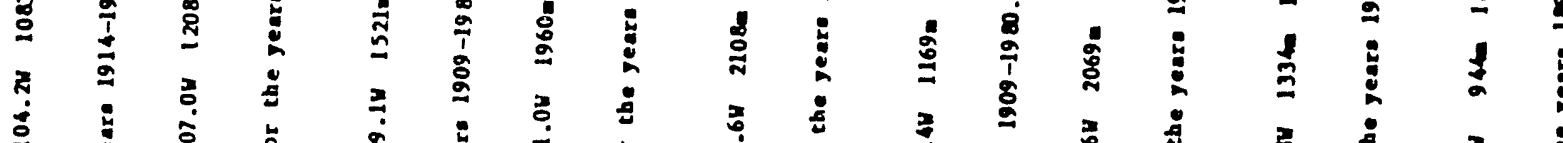

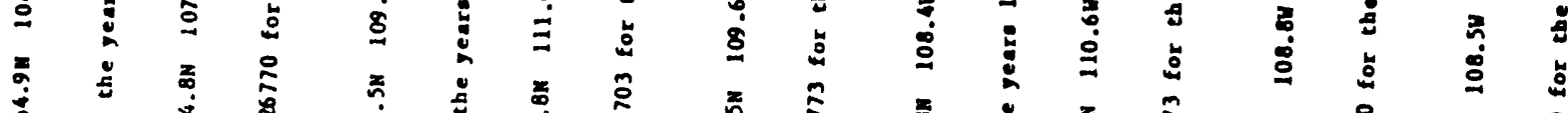

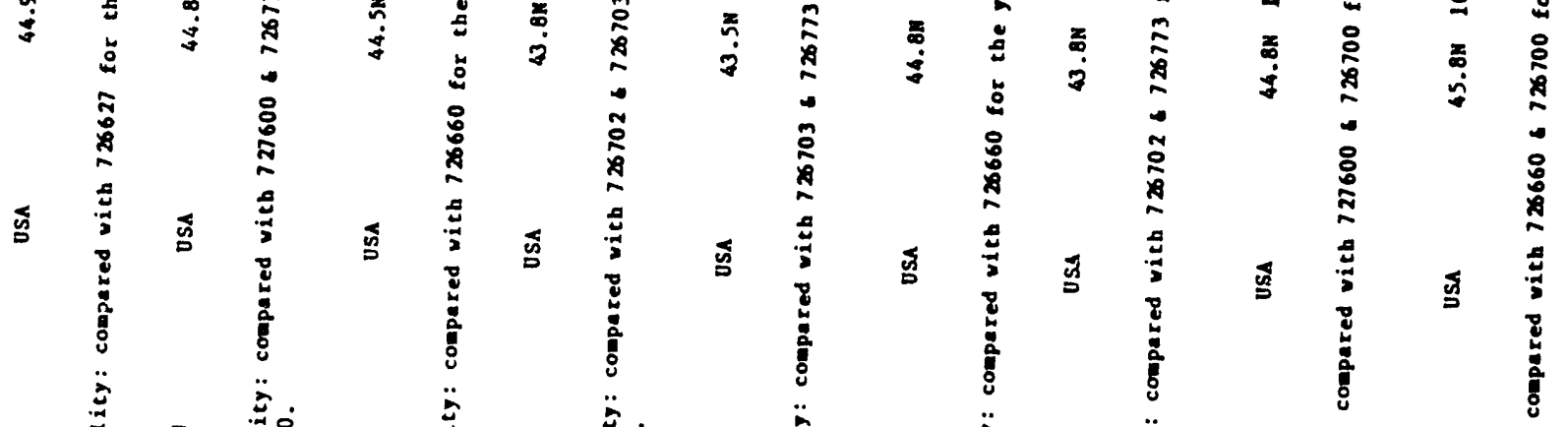

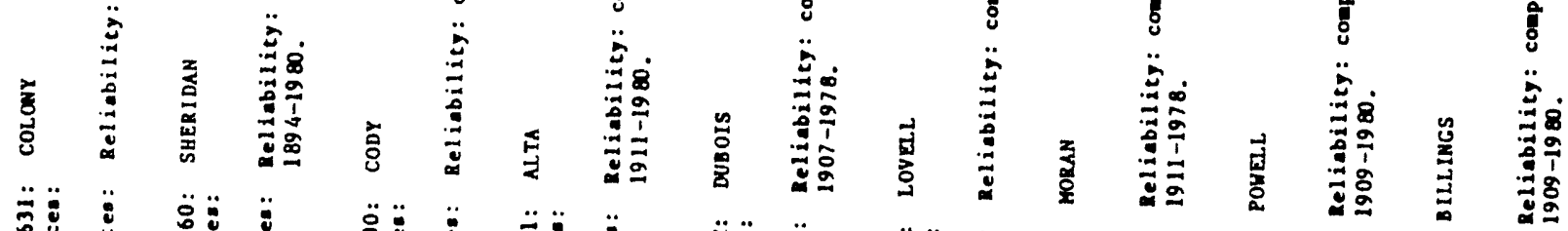

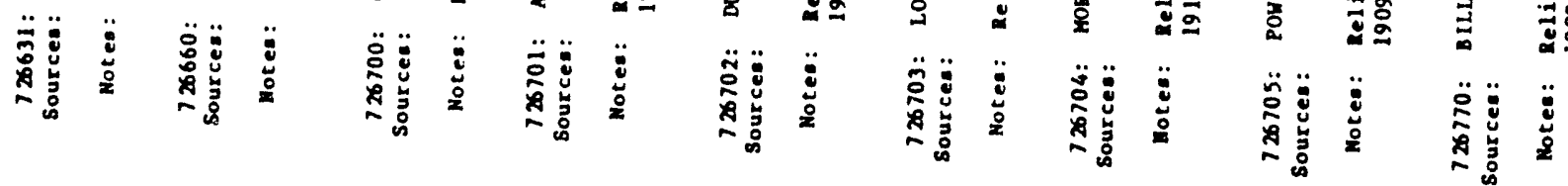




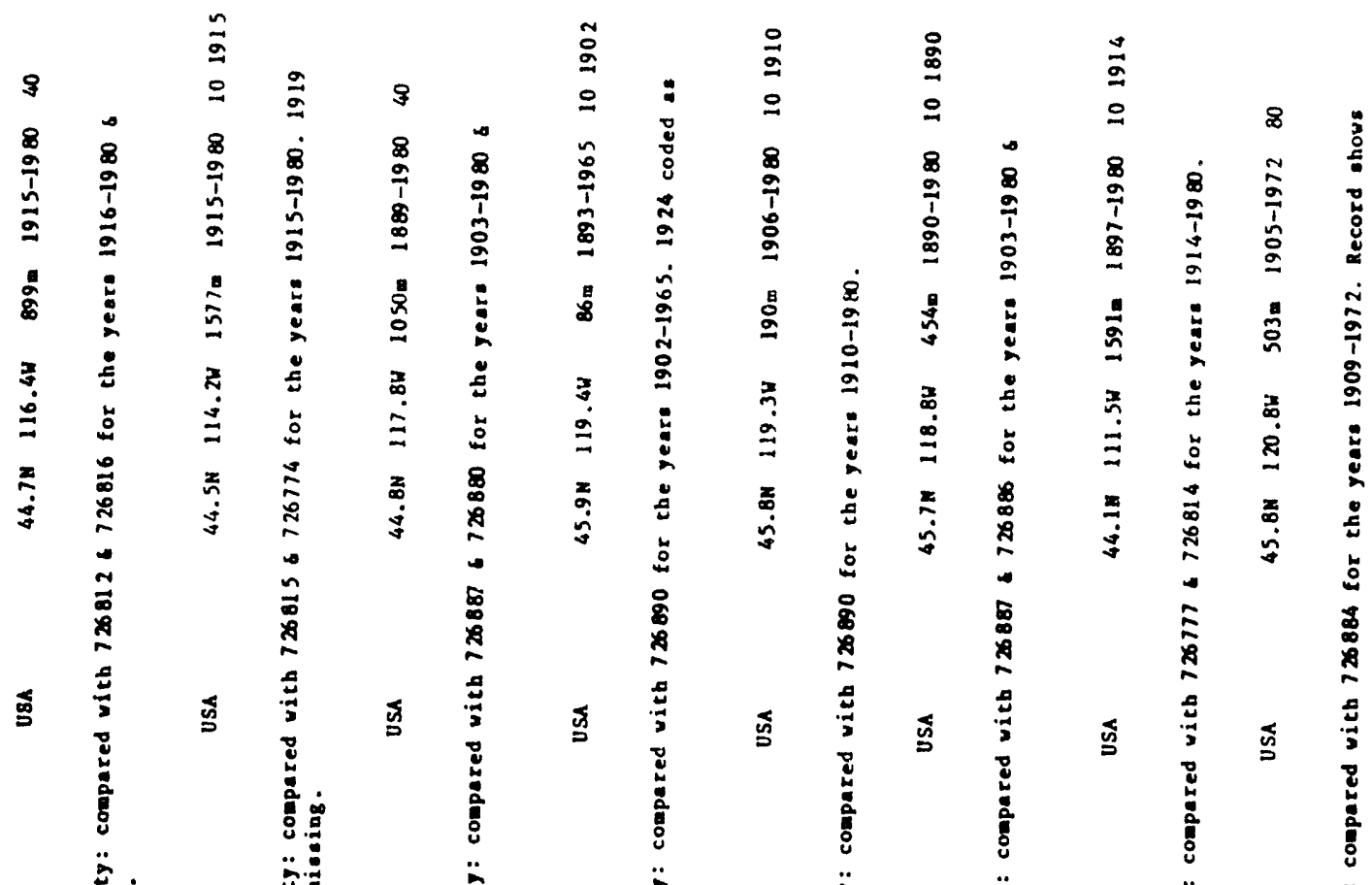

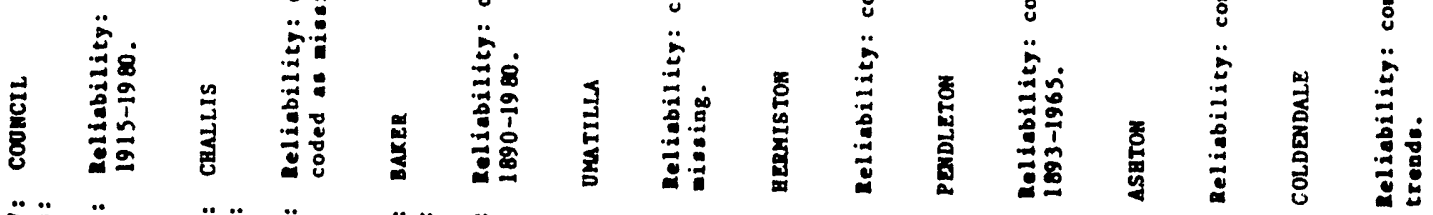

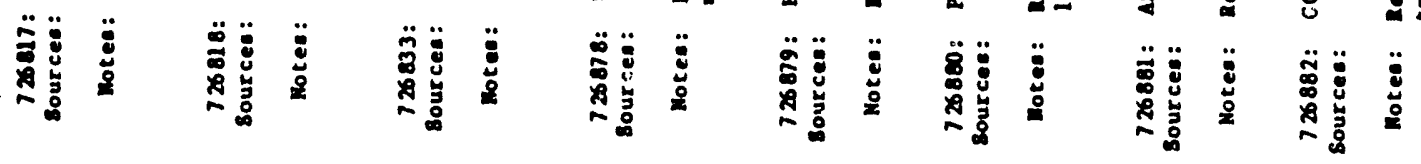

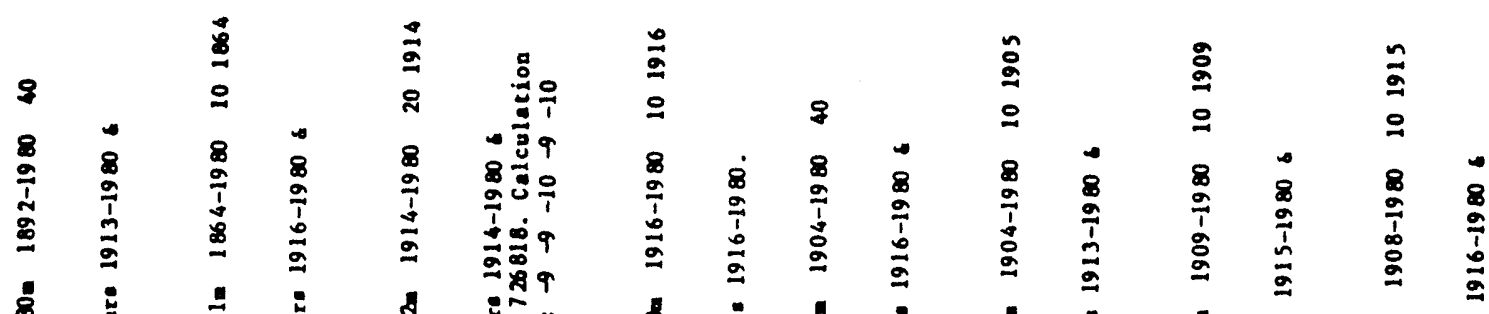

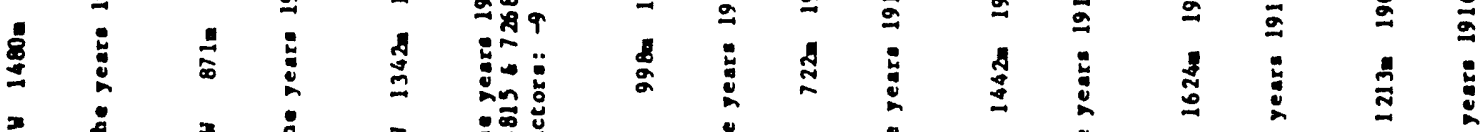

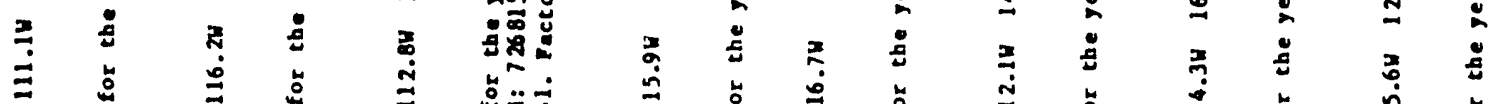

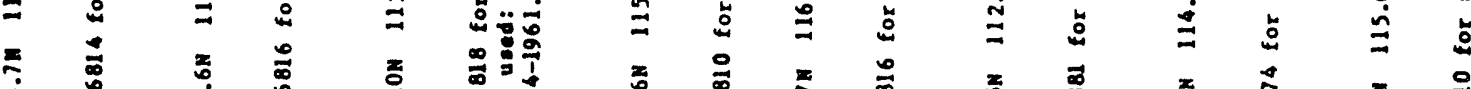

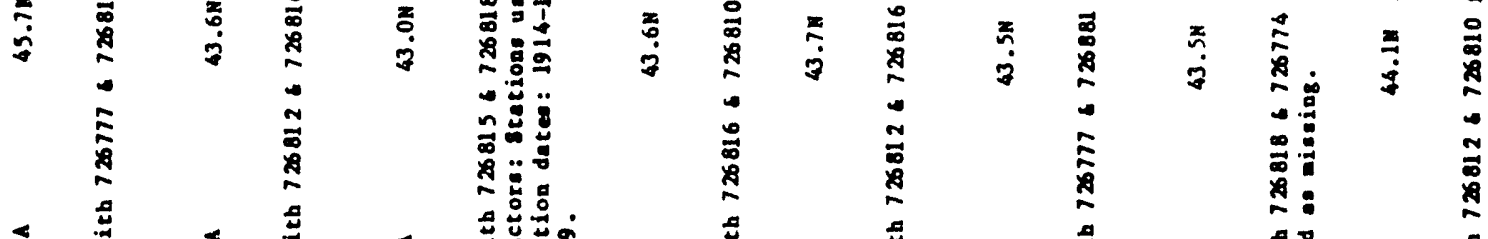

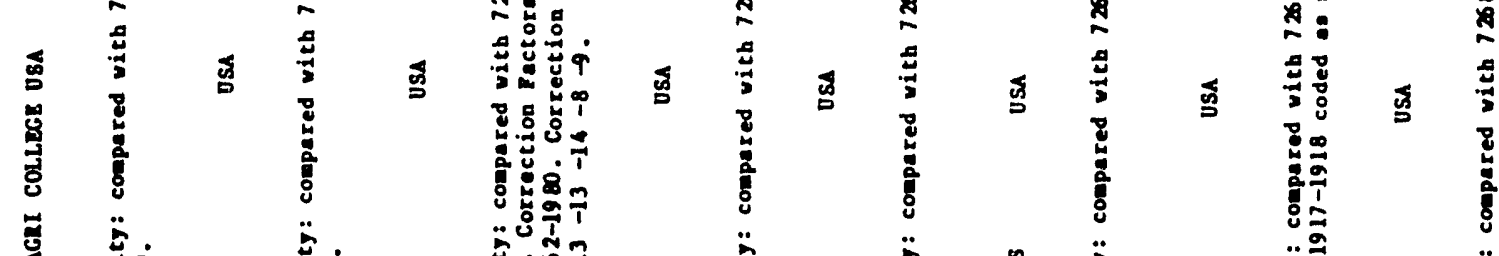

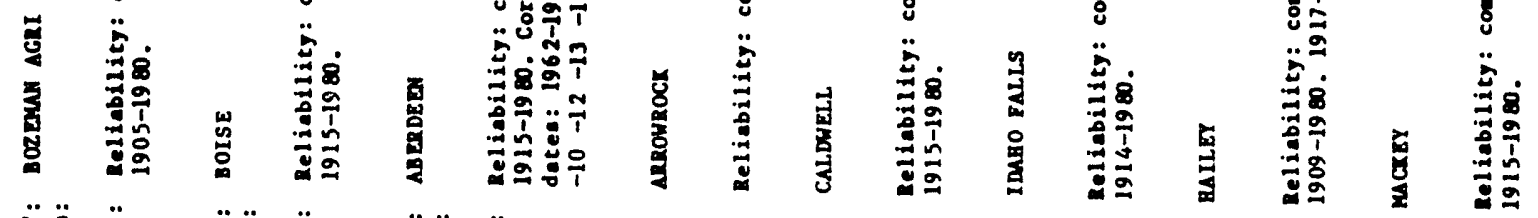

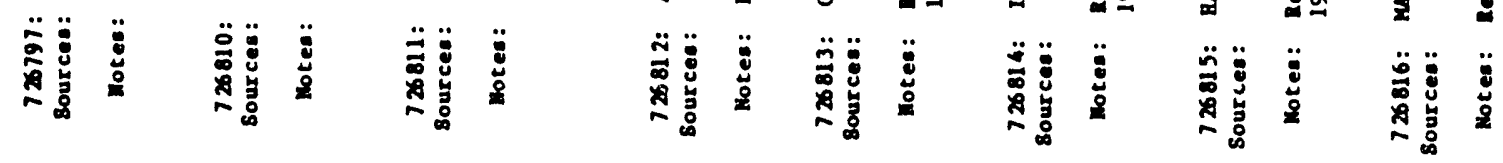




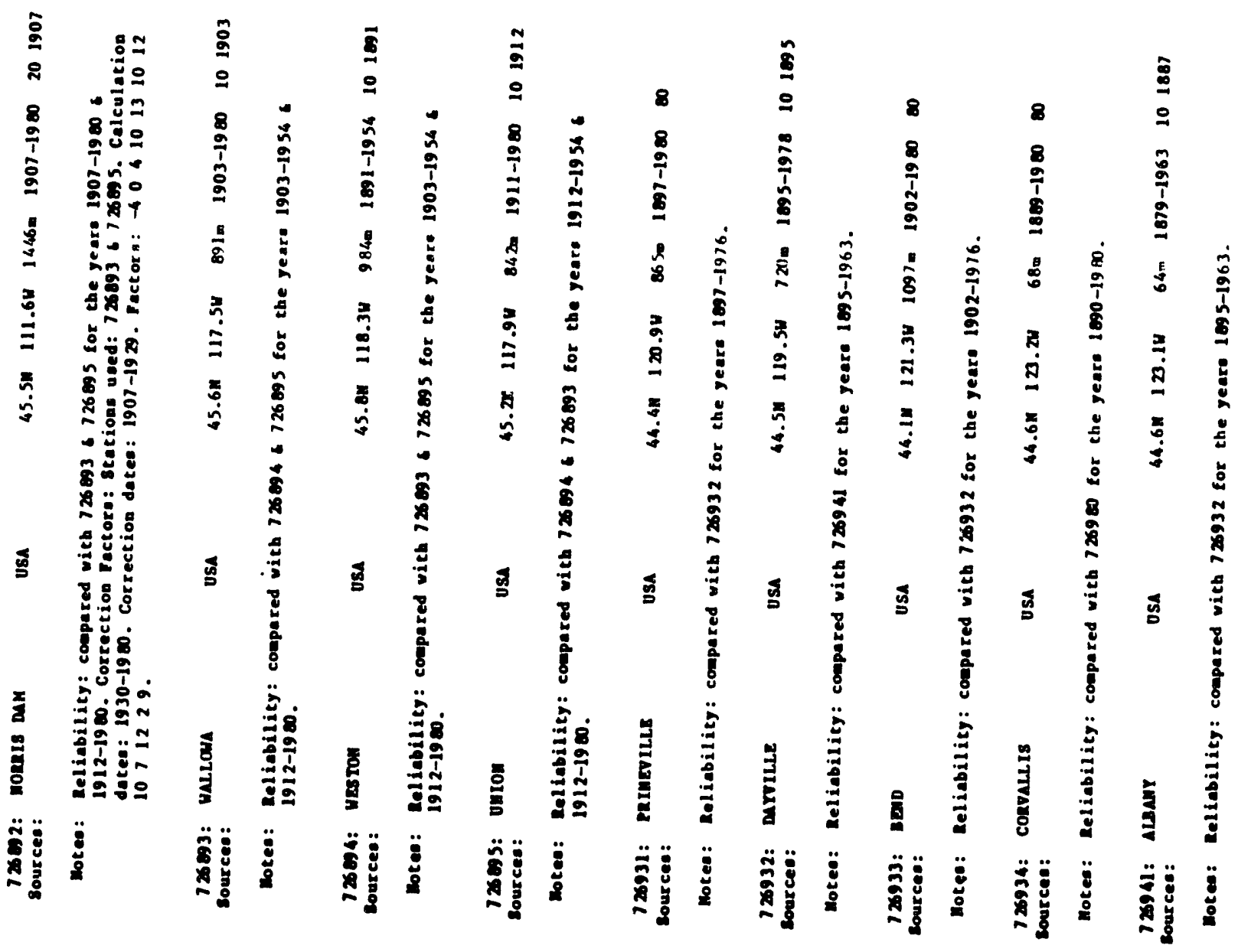

ะ

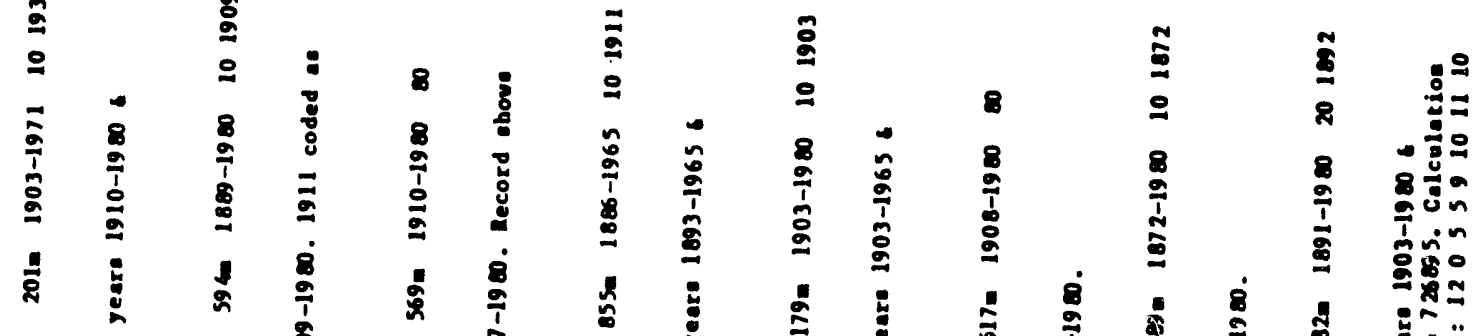

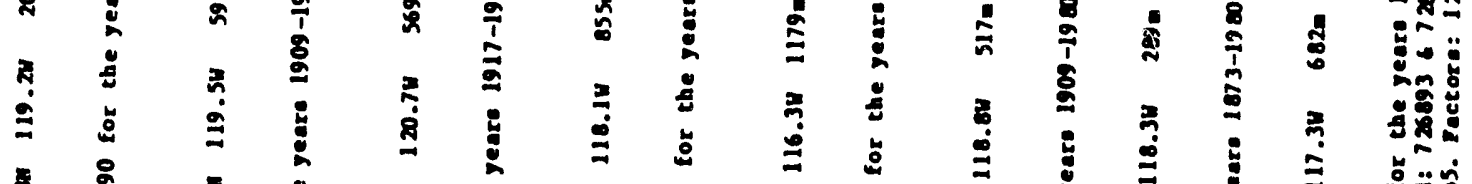

\$

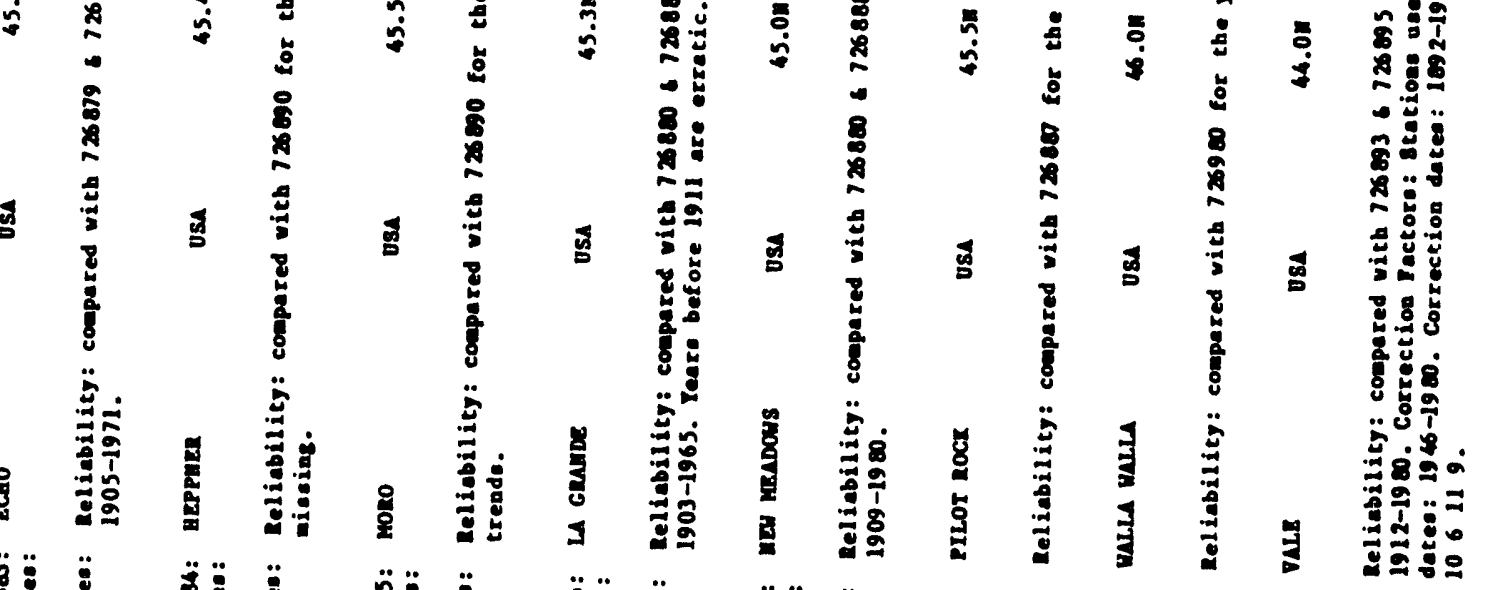

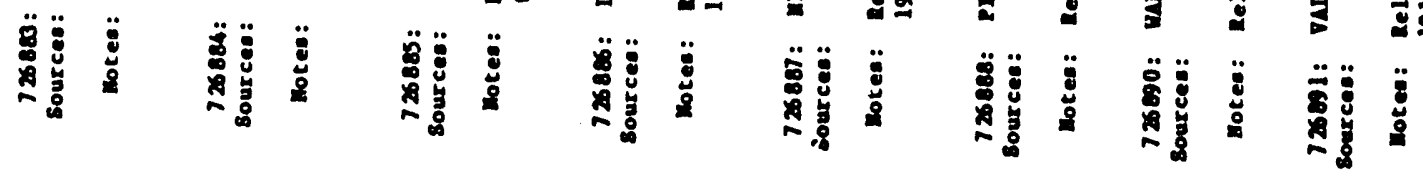




\section{$\underline{D}$}

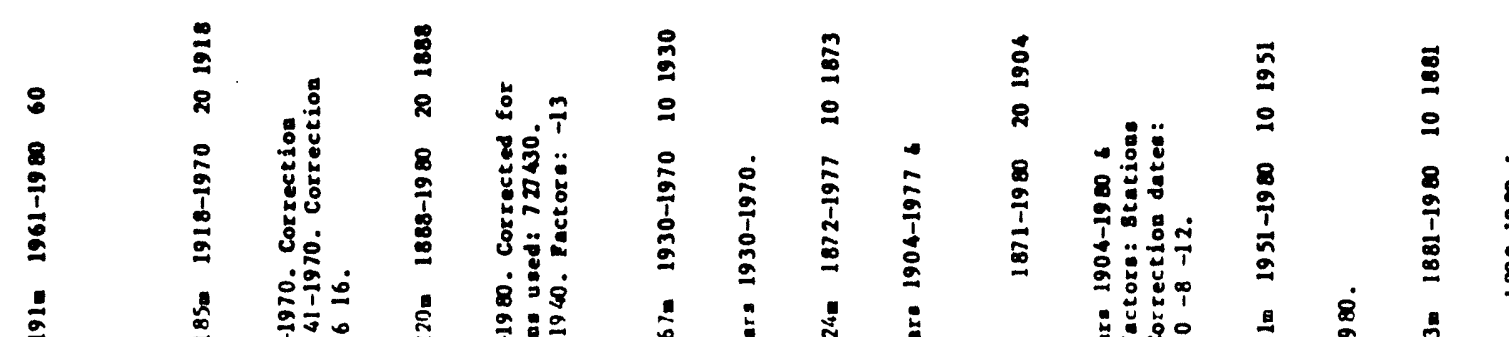

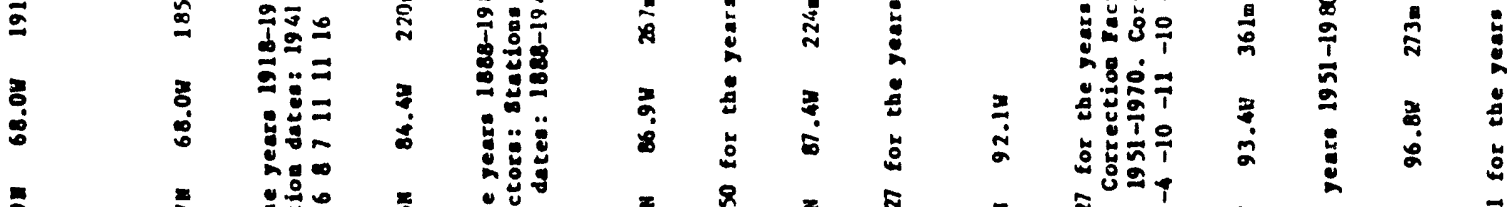

\$

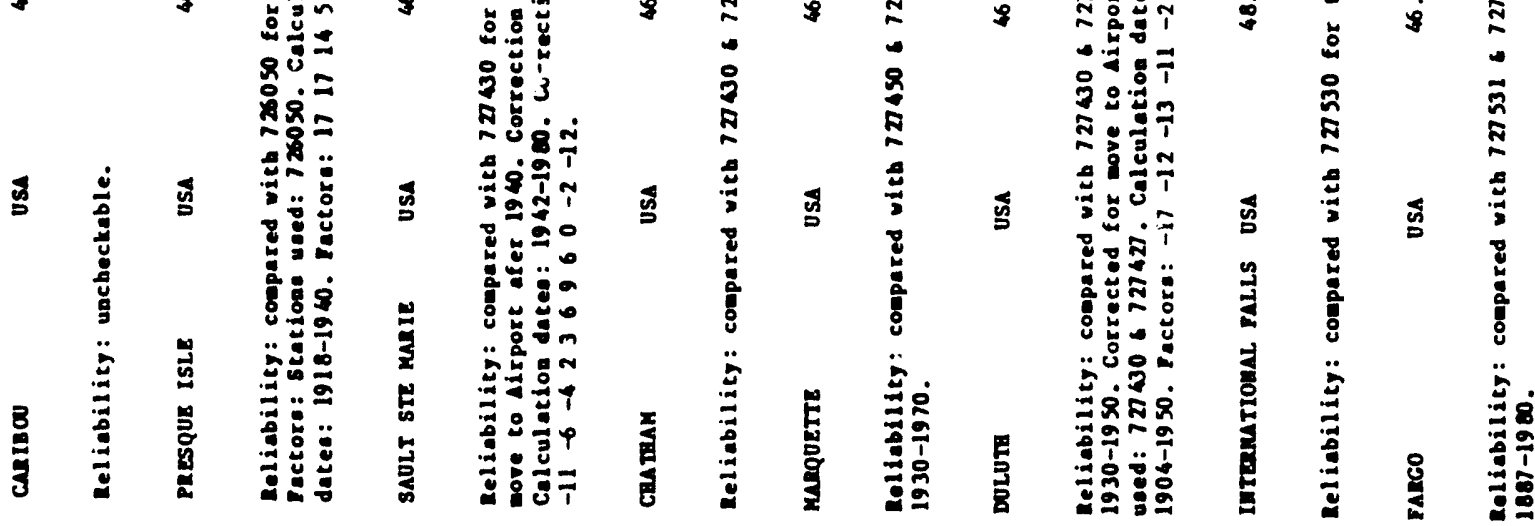

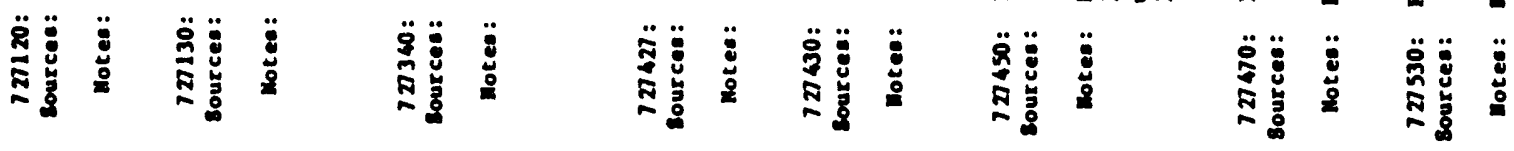

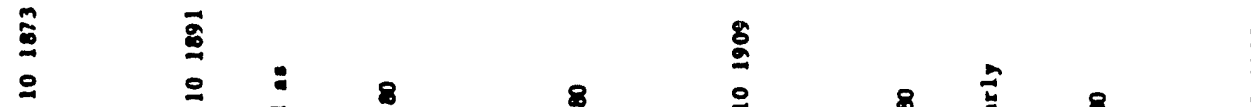

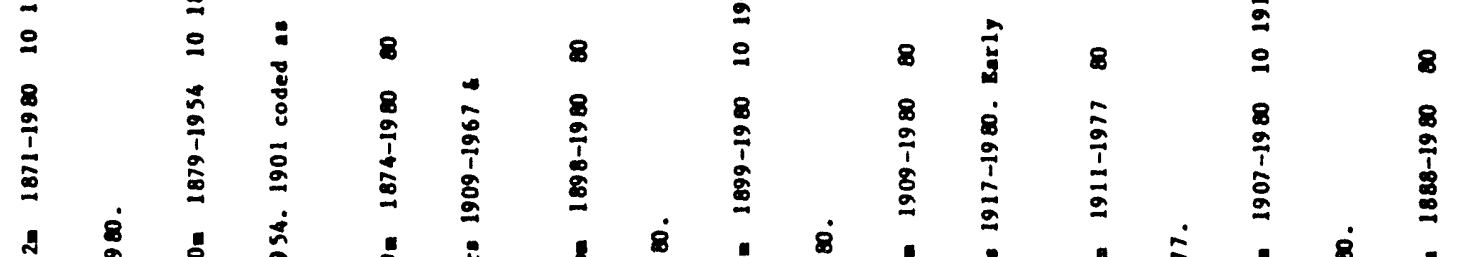

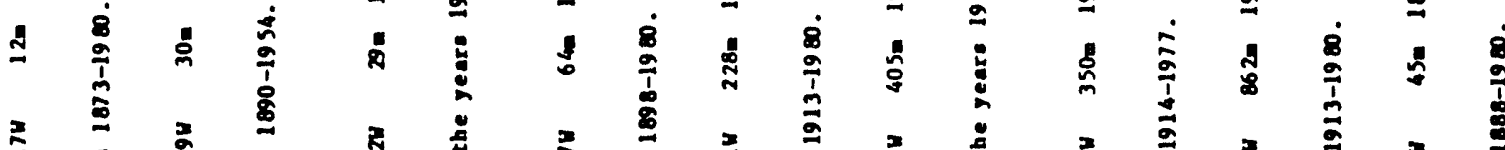

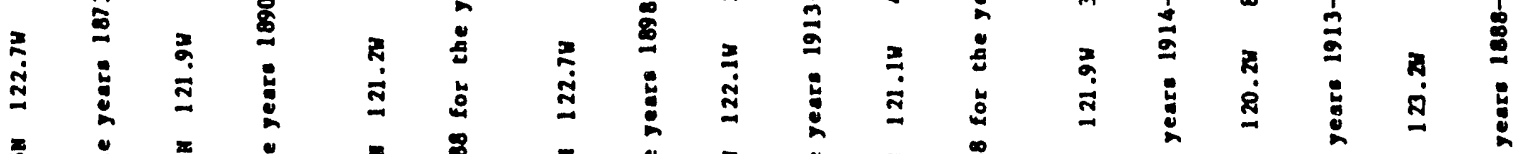

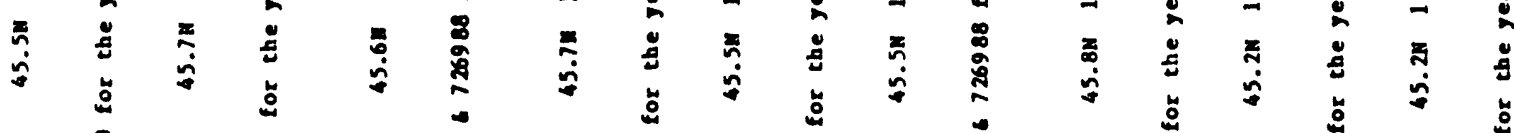

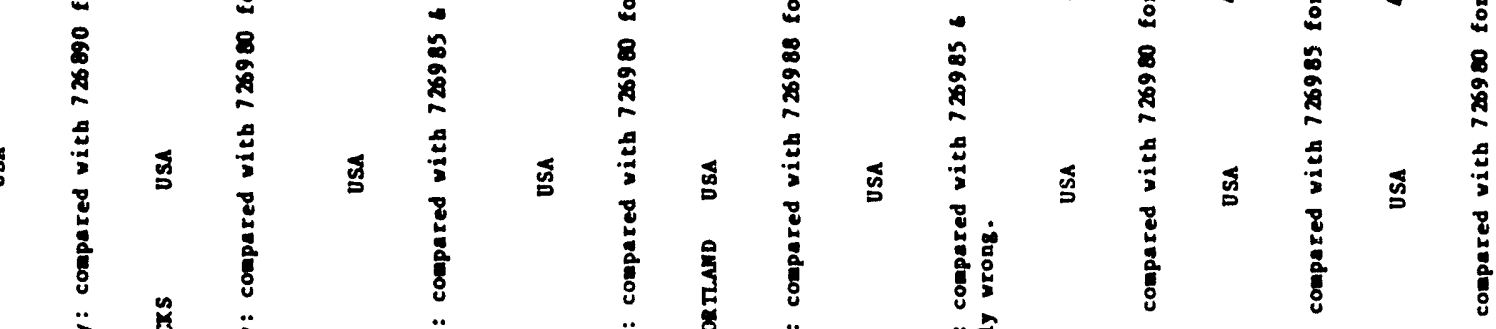

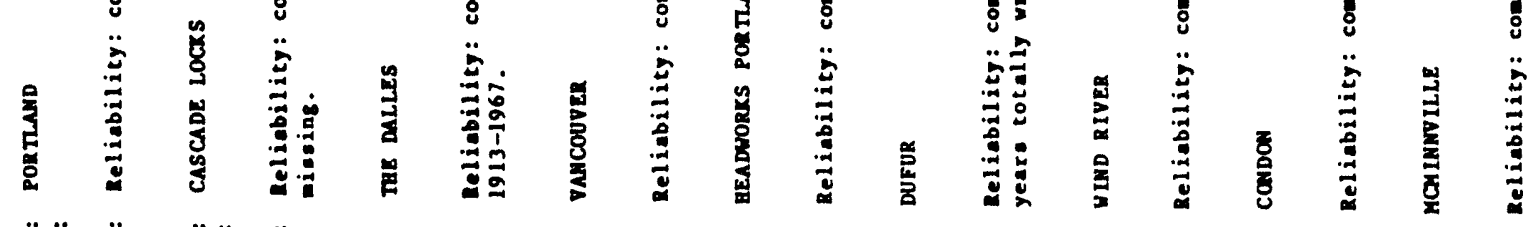

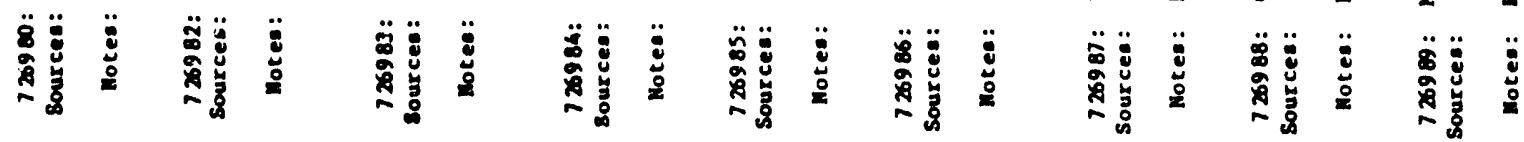


ळ

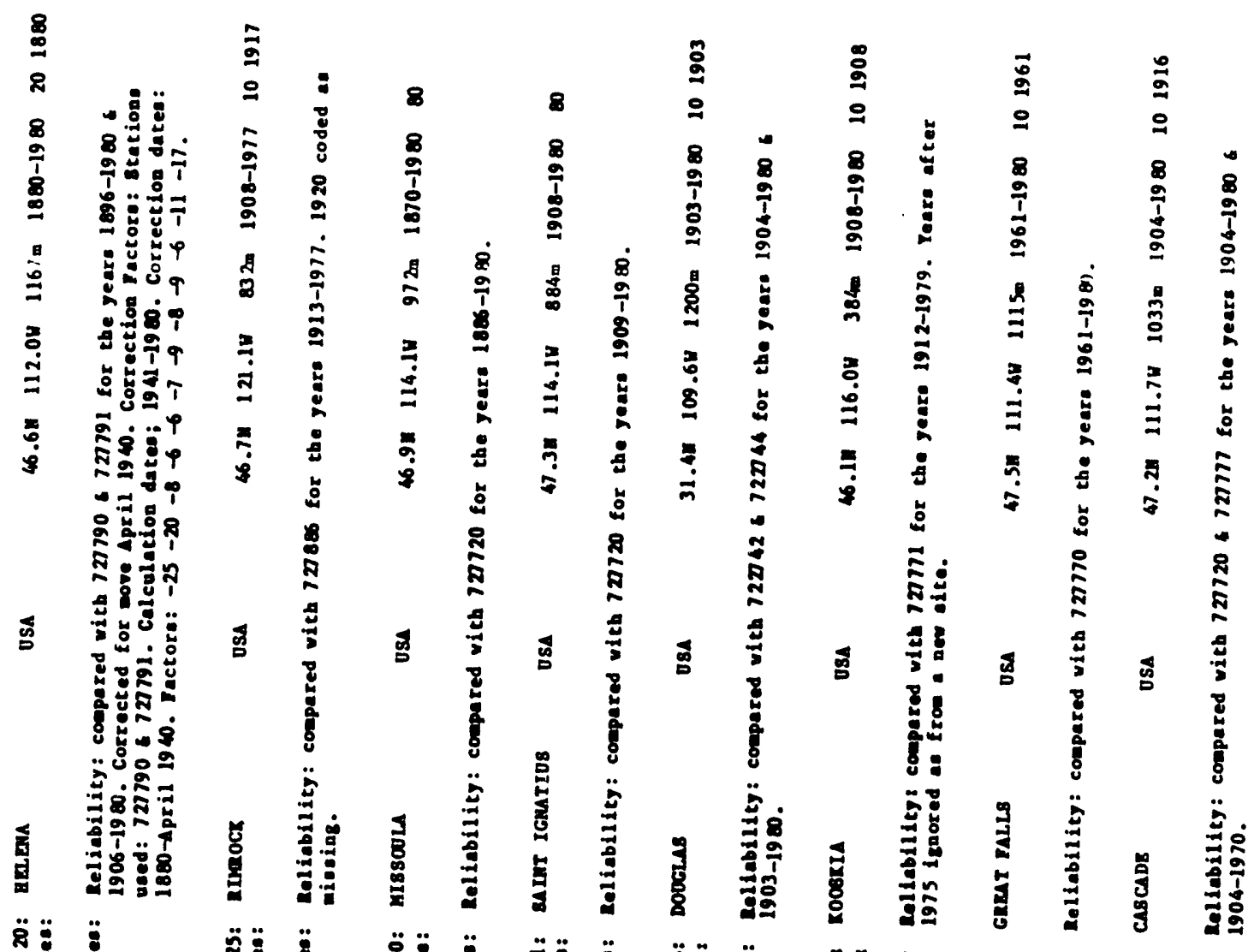

暨

1

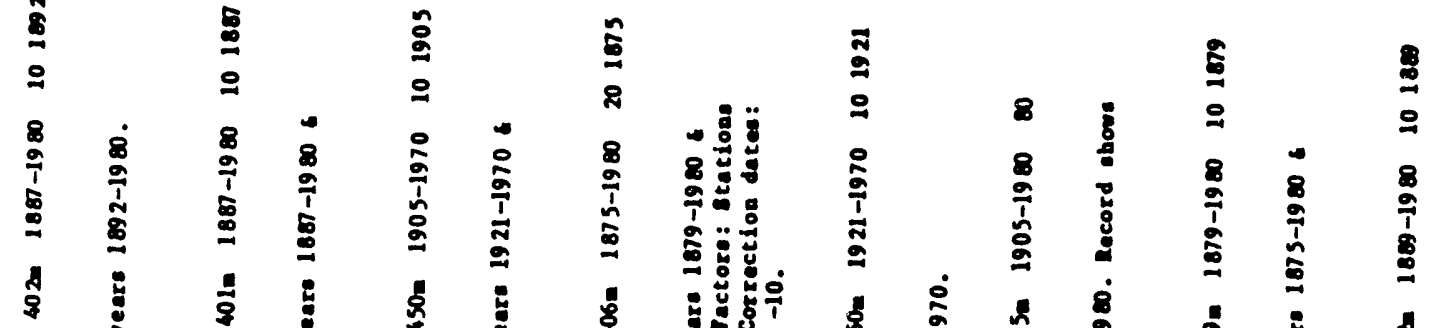

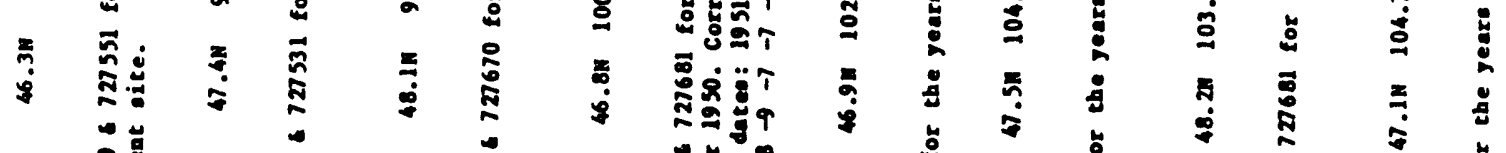

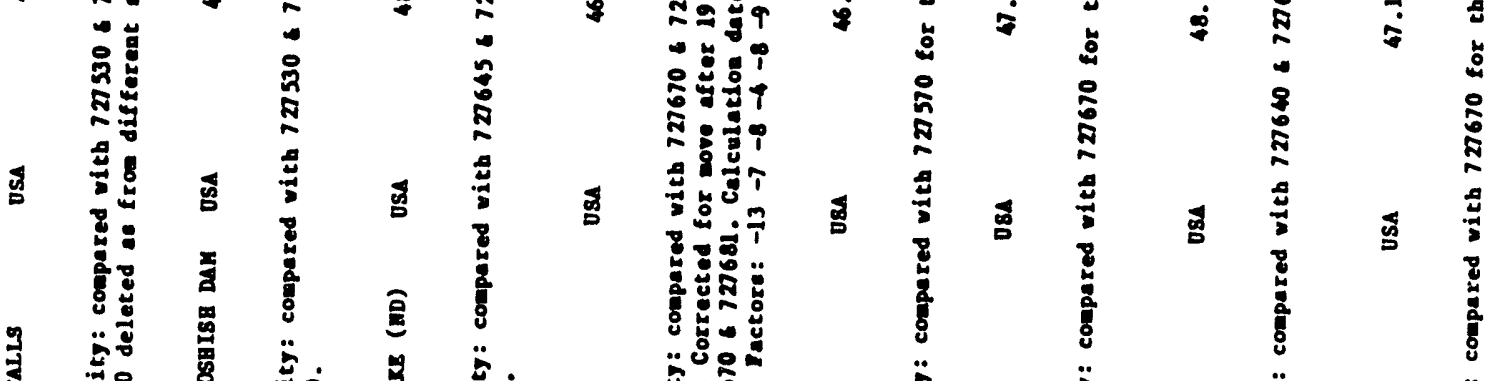

Ind

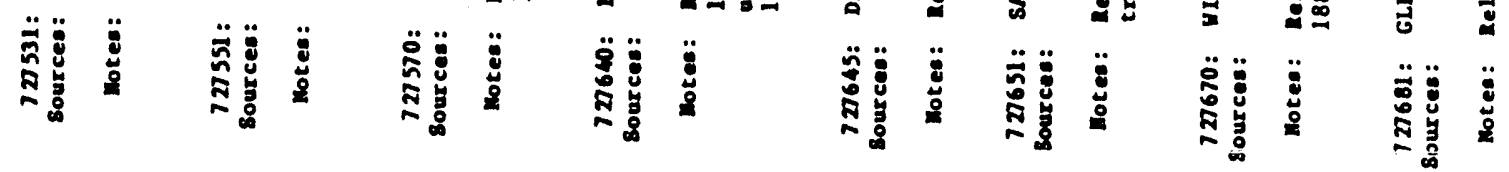




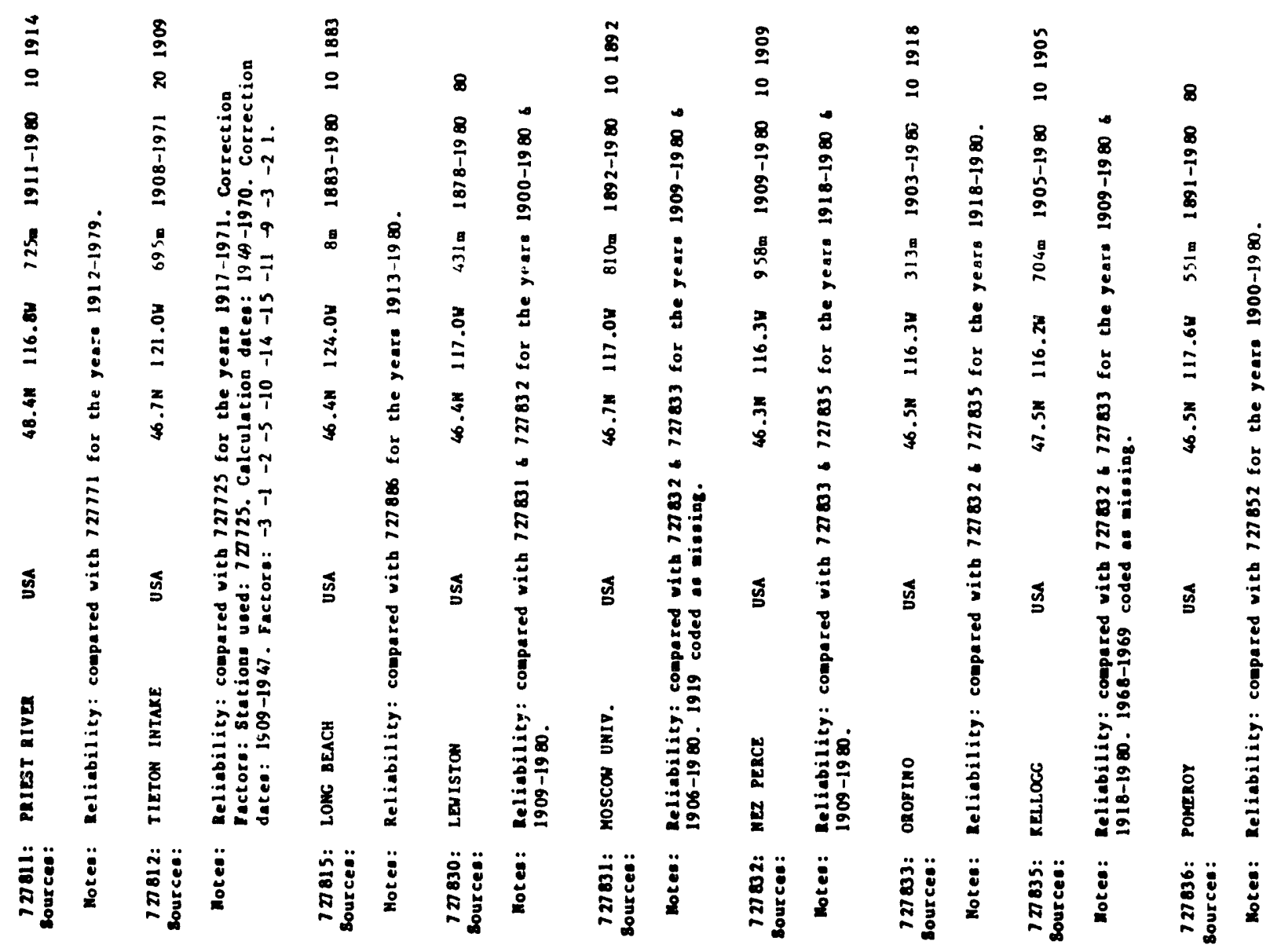

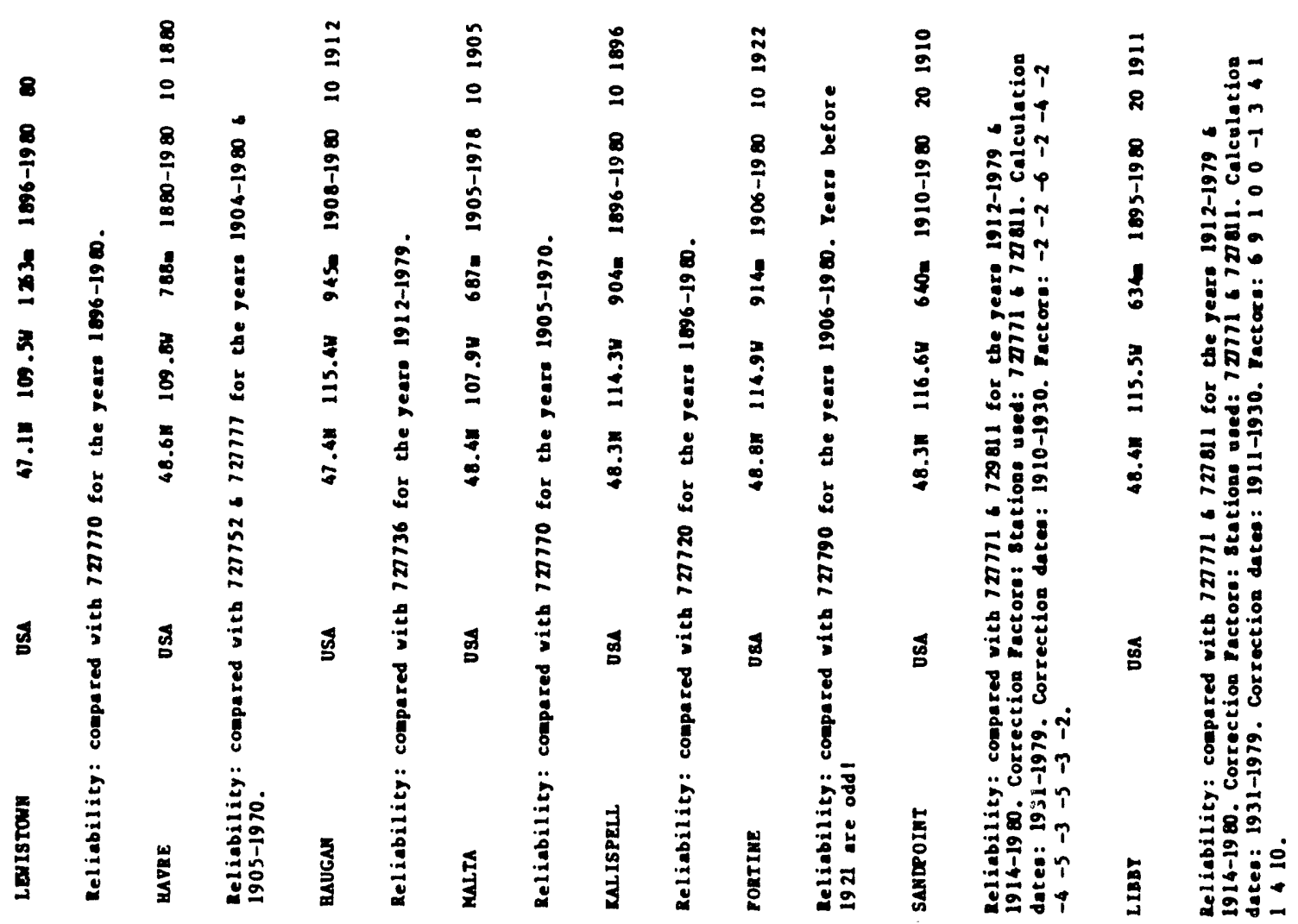

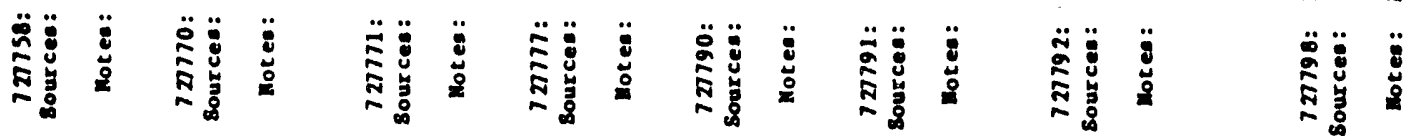




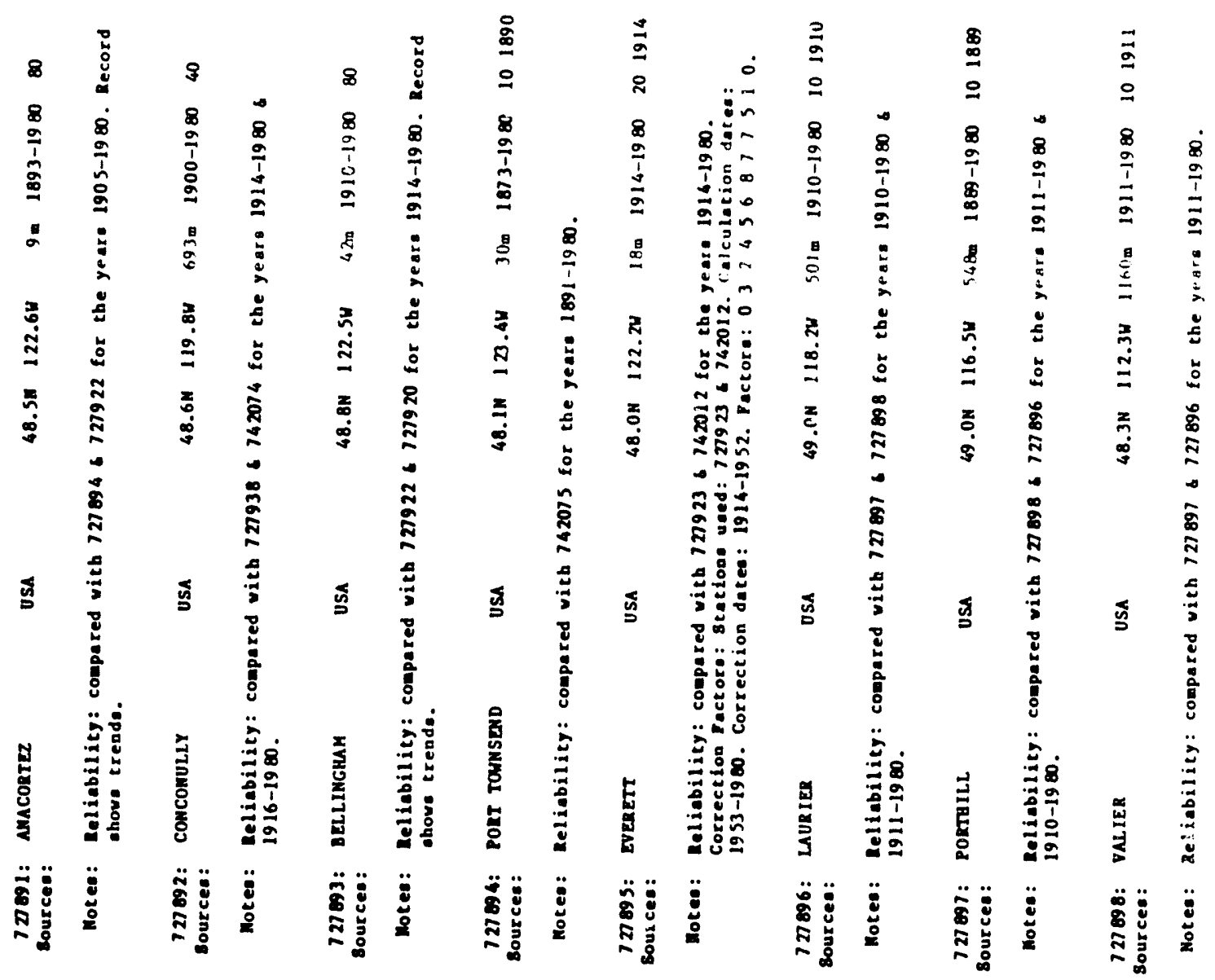

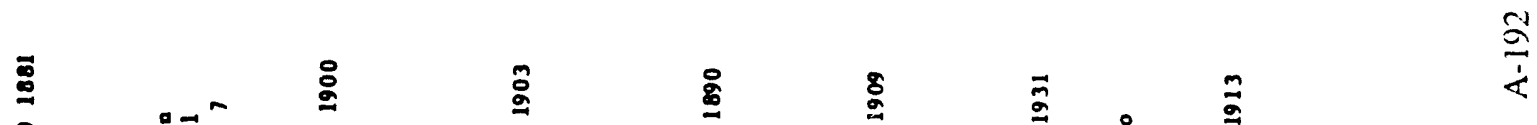
$8 x^{2}$

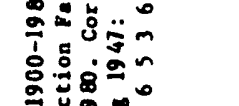

天

3 .

(1)

(1)

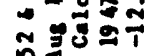

ํำ

4

$8 \div$

คิก

g.

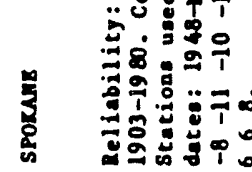

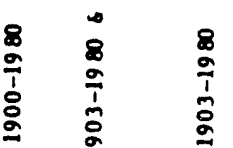
告 เ

(3)

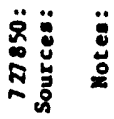

काष

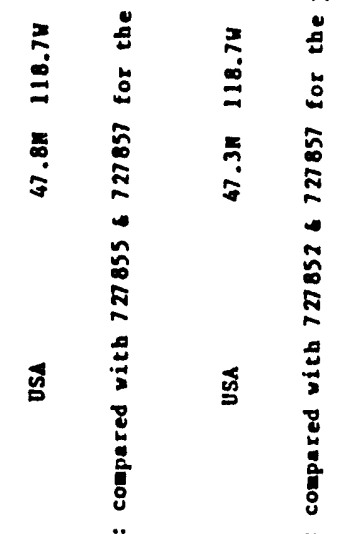

$\stackrel{2}{2}$

$\underline{\underline{D}}$ 
$\Phi$

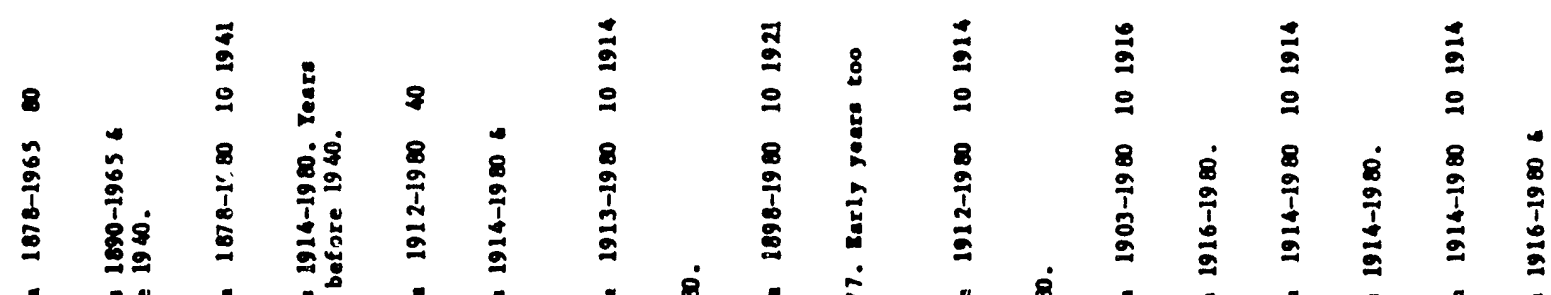
1 ป

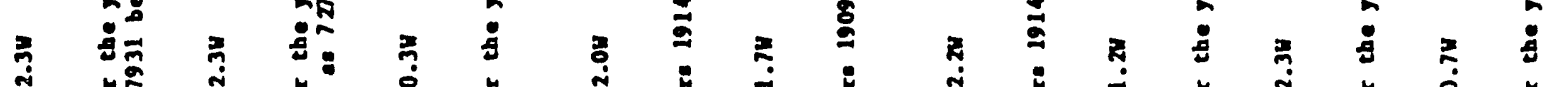

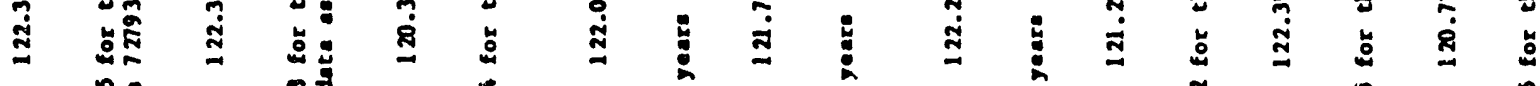

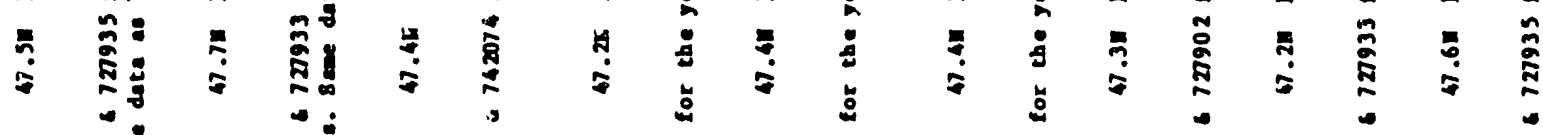

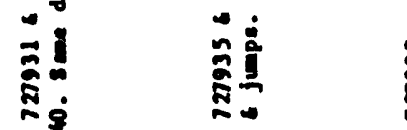

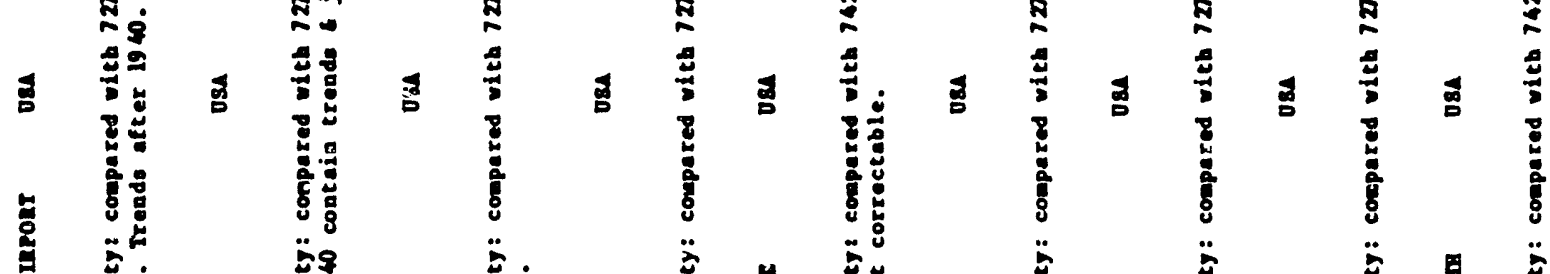

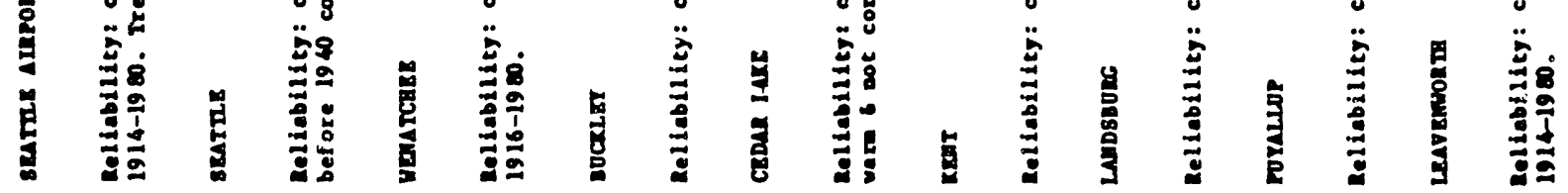

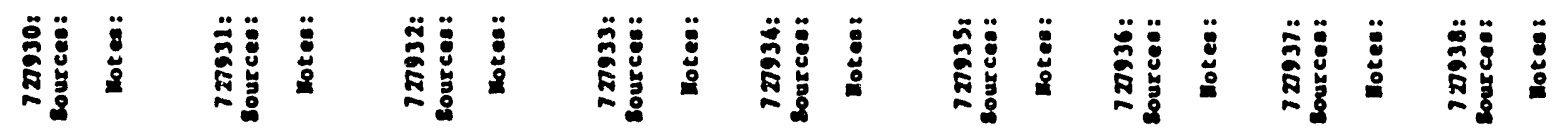

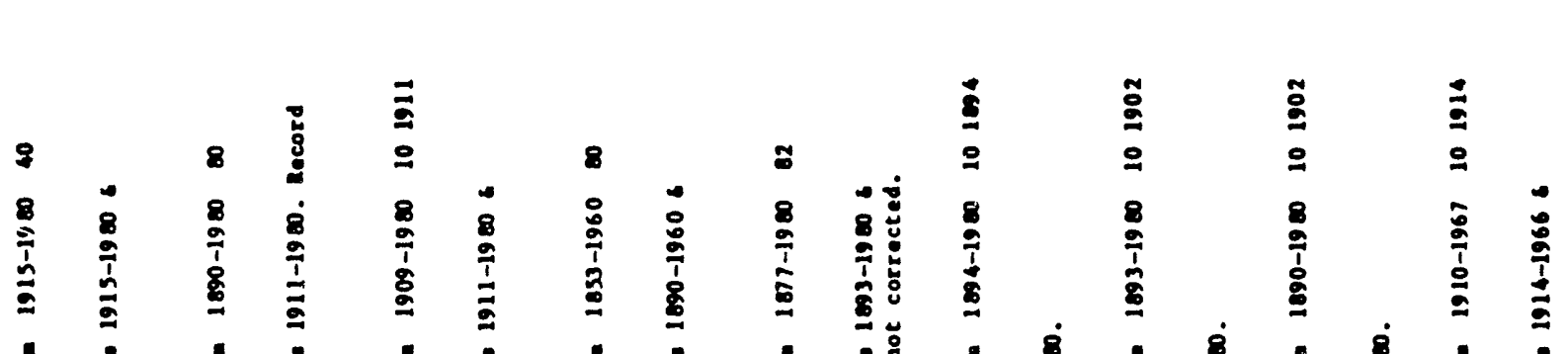

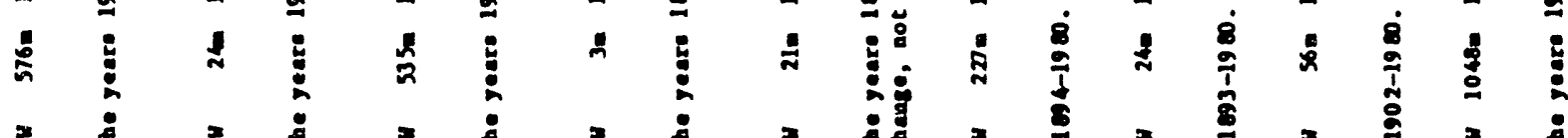
ว

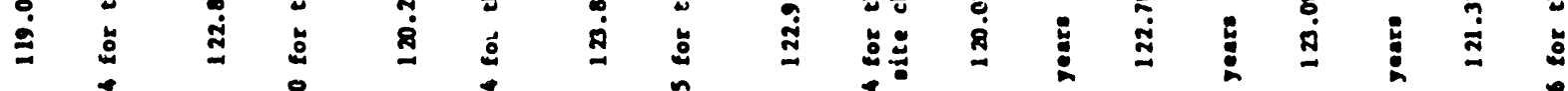
ว

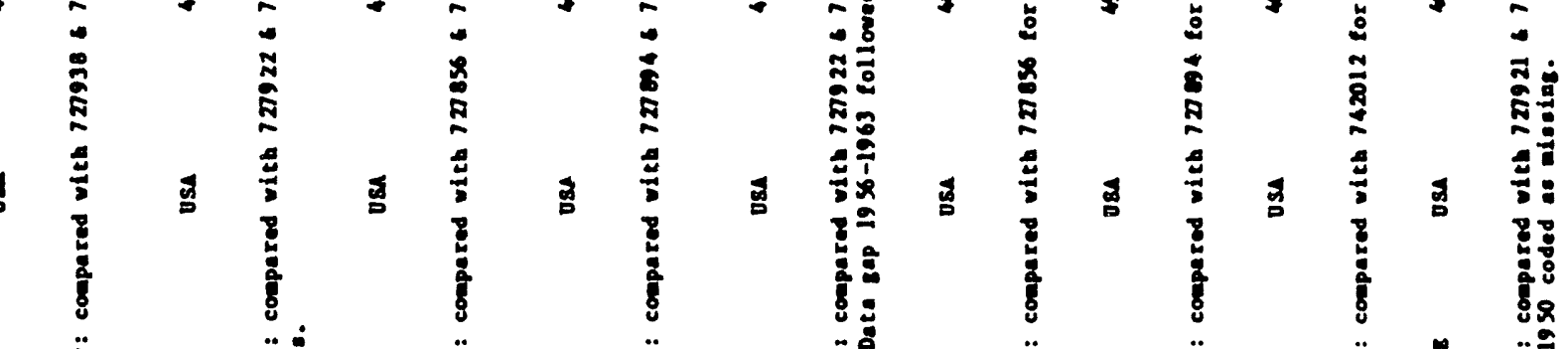

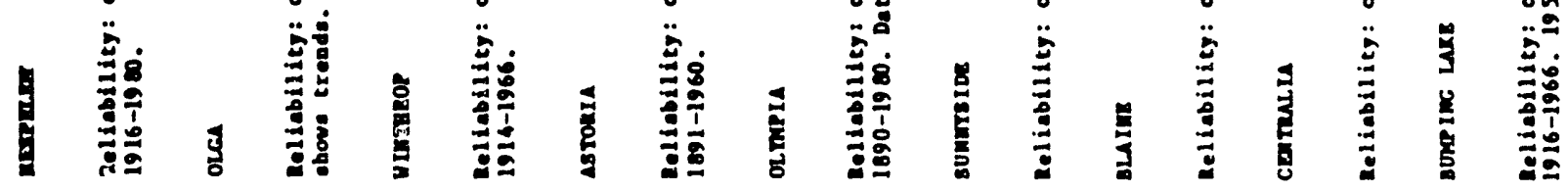

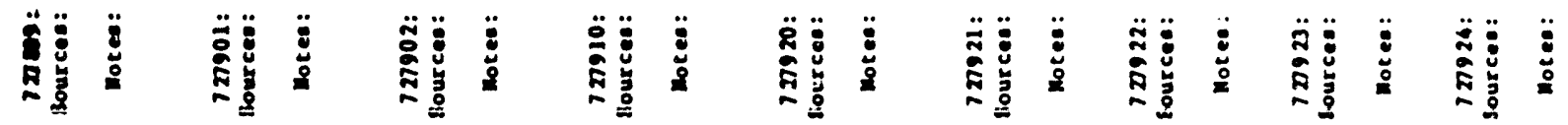



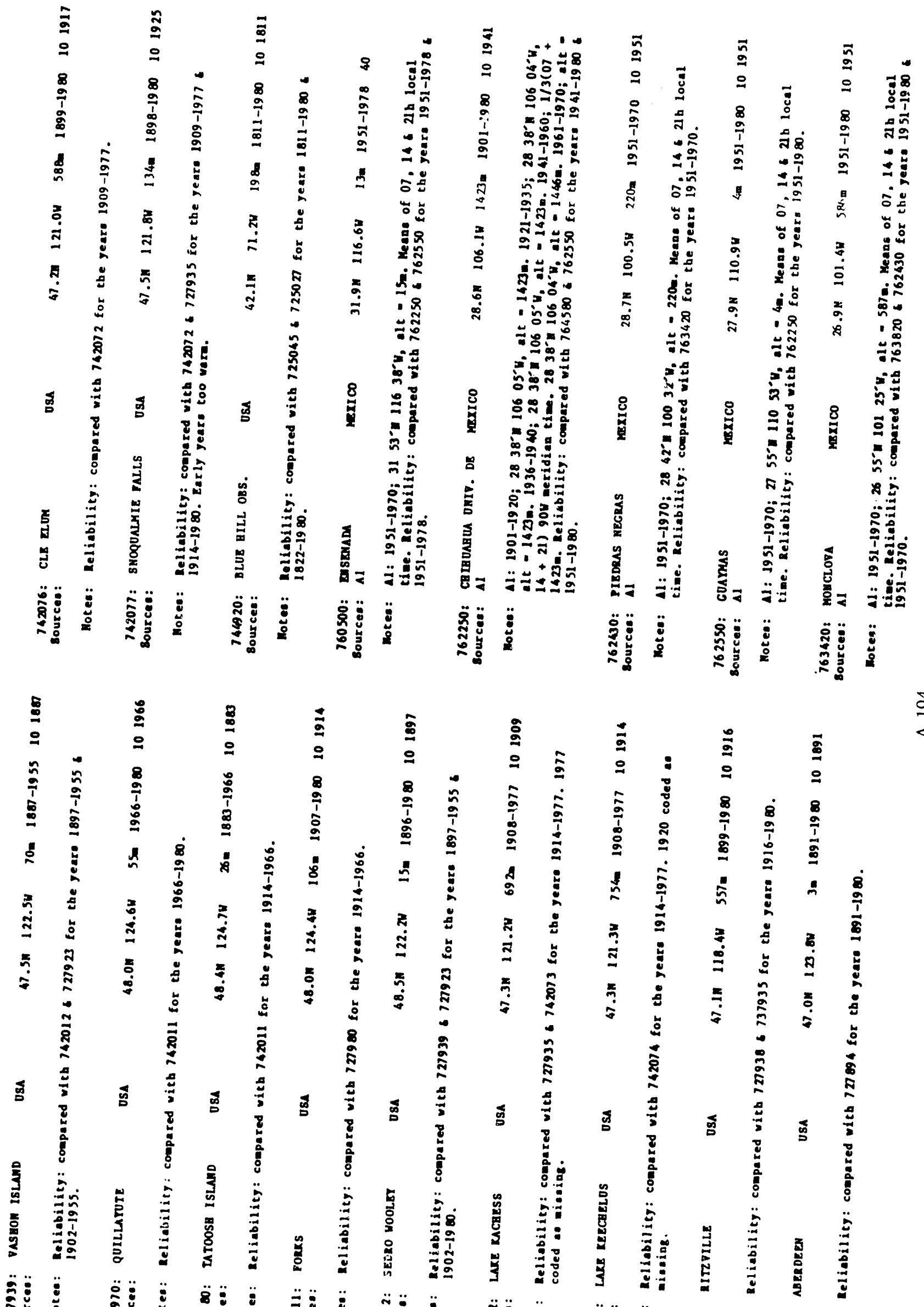

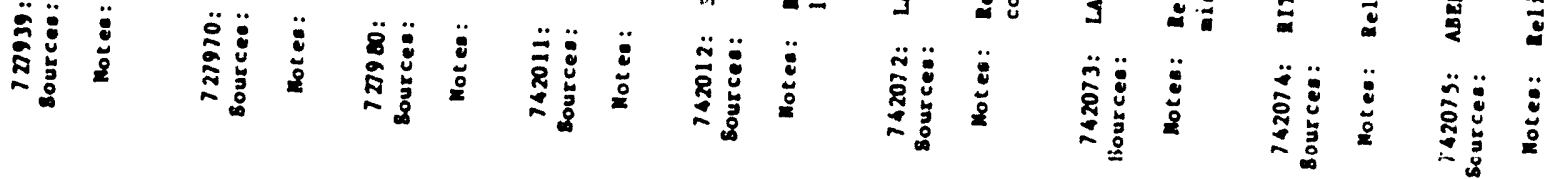




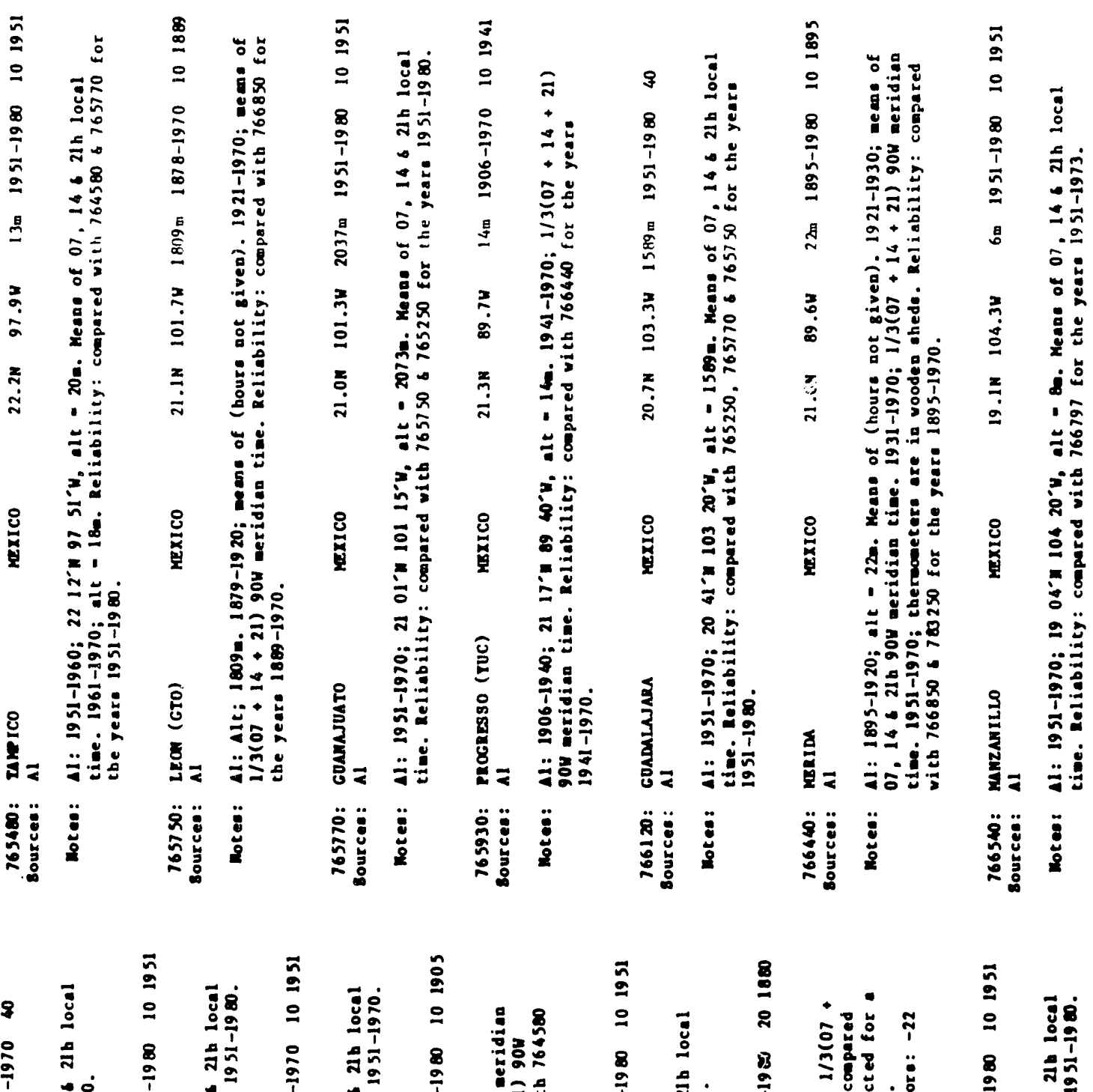

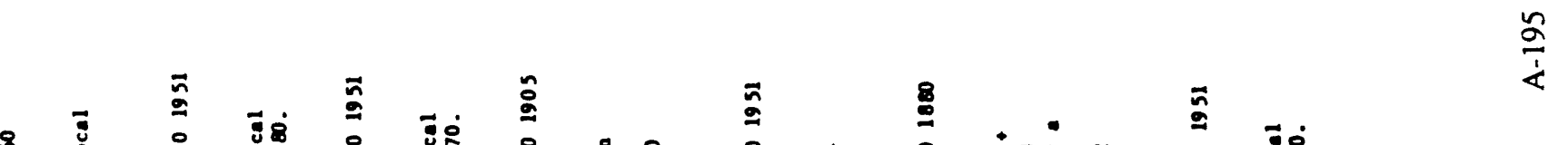

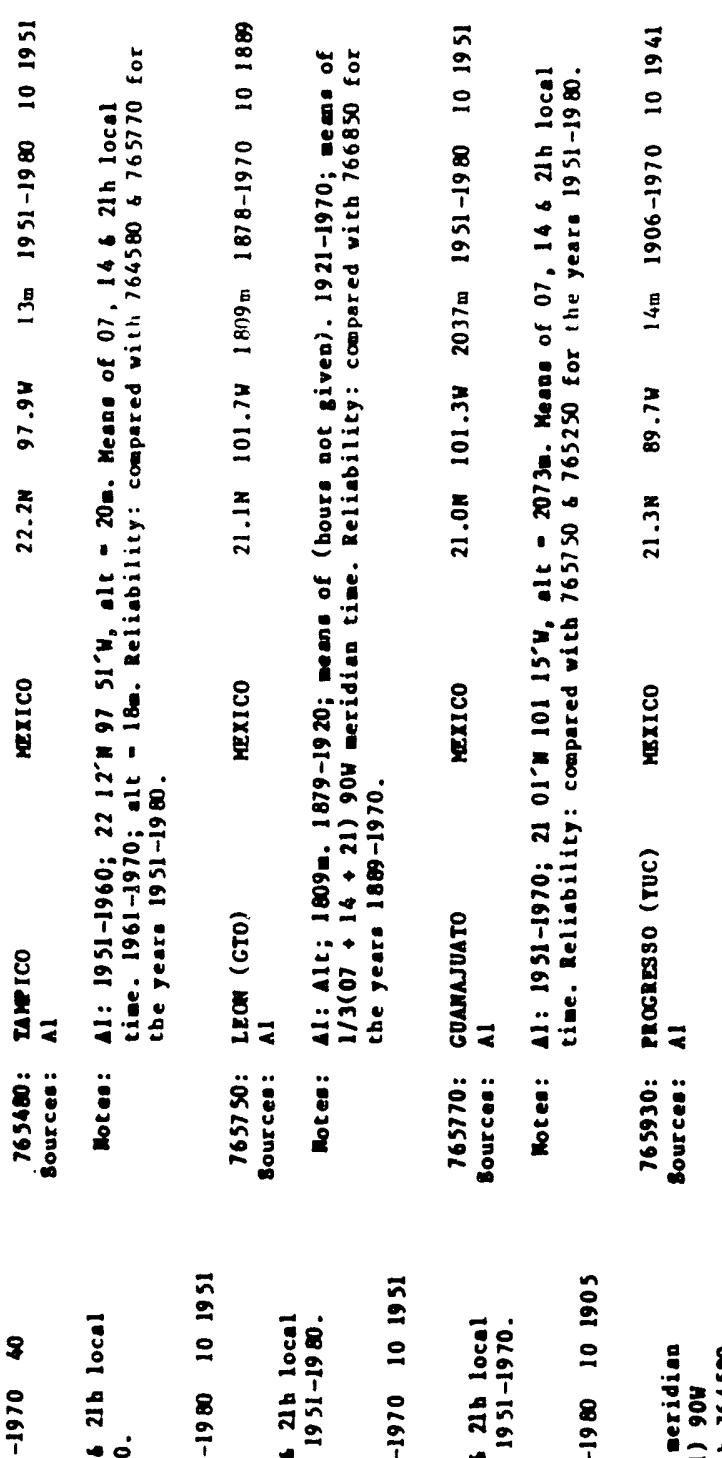

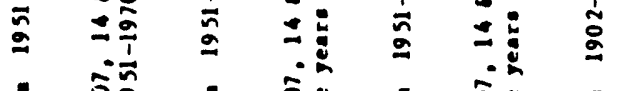

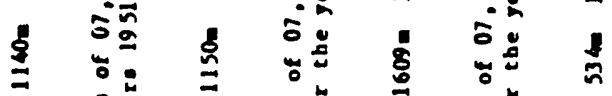

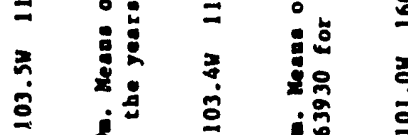

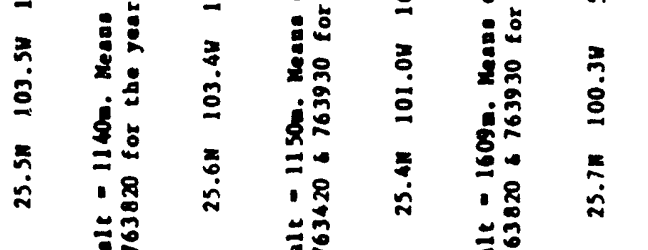

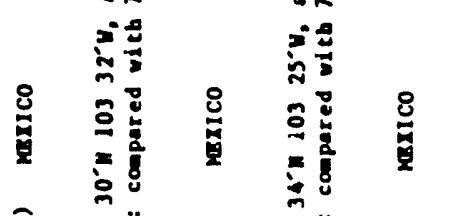

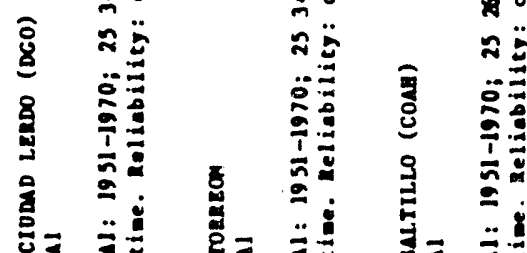

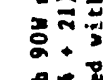

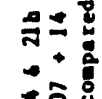

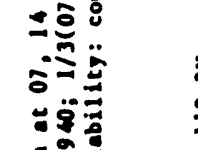

高

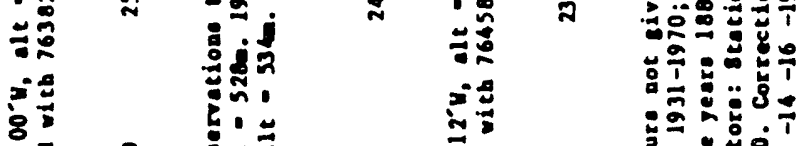

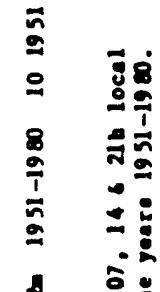

i.

A

อั

总

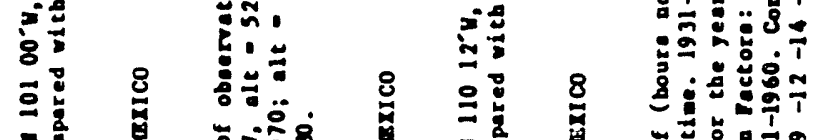

:

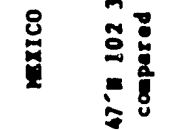

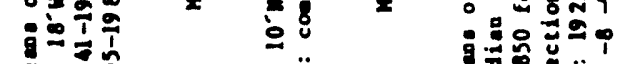

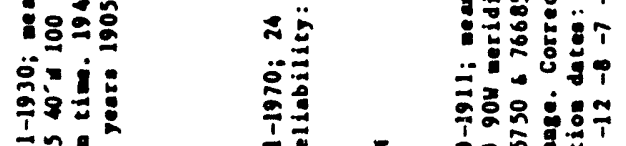

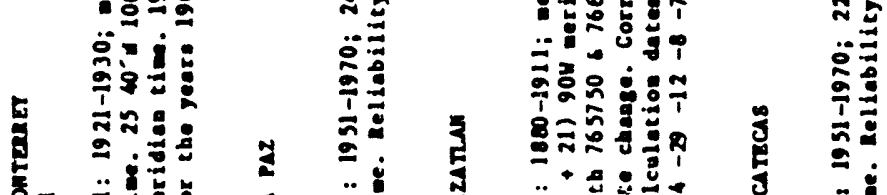

व

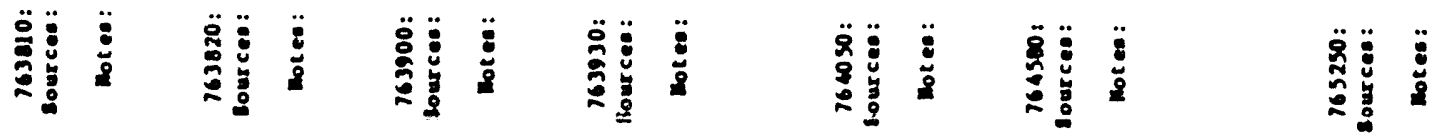



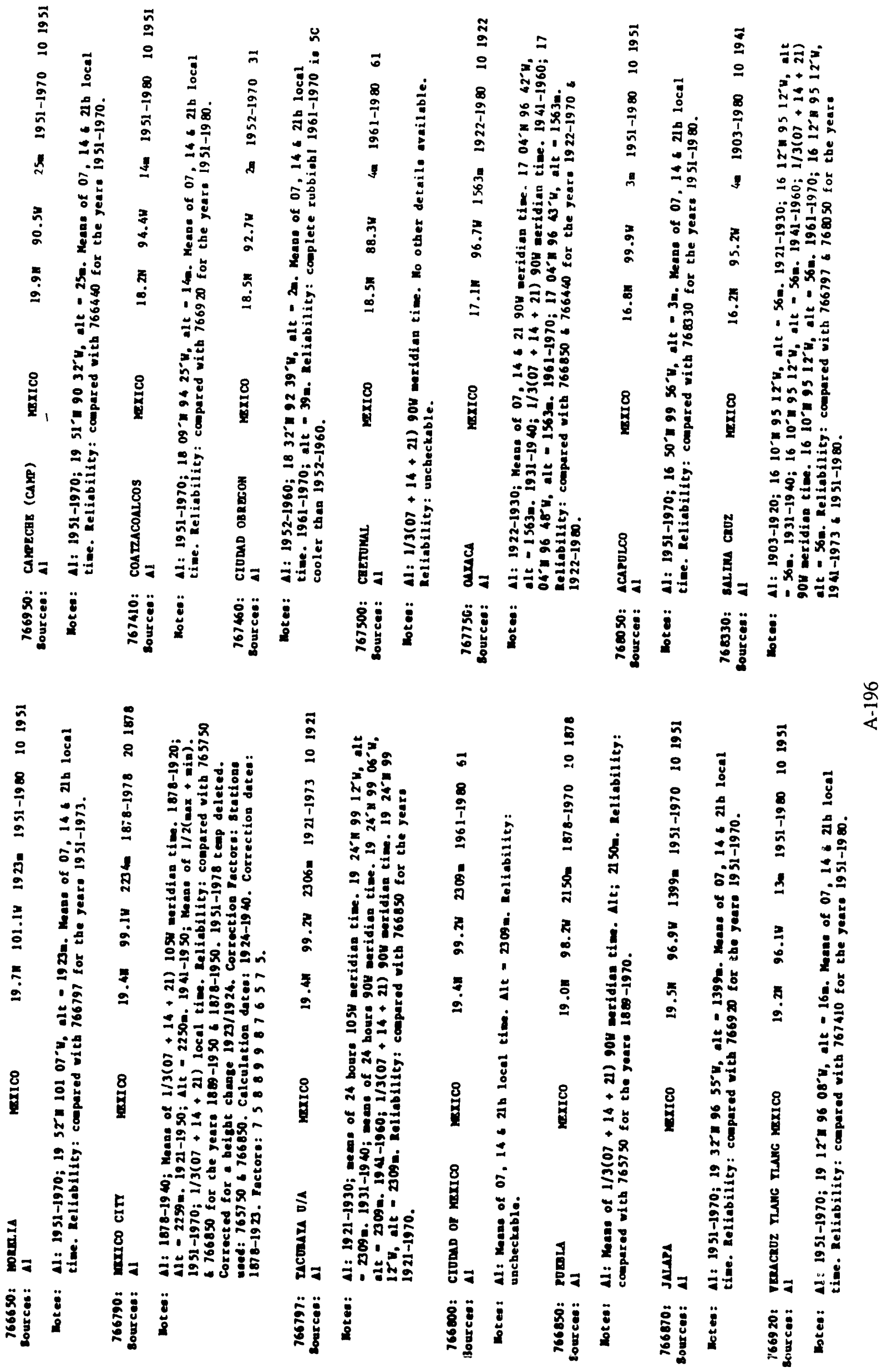


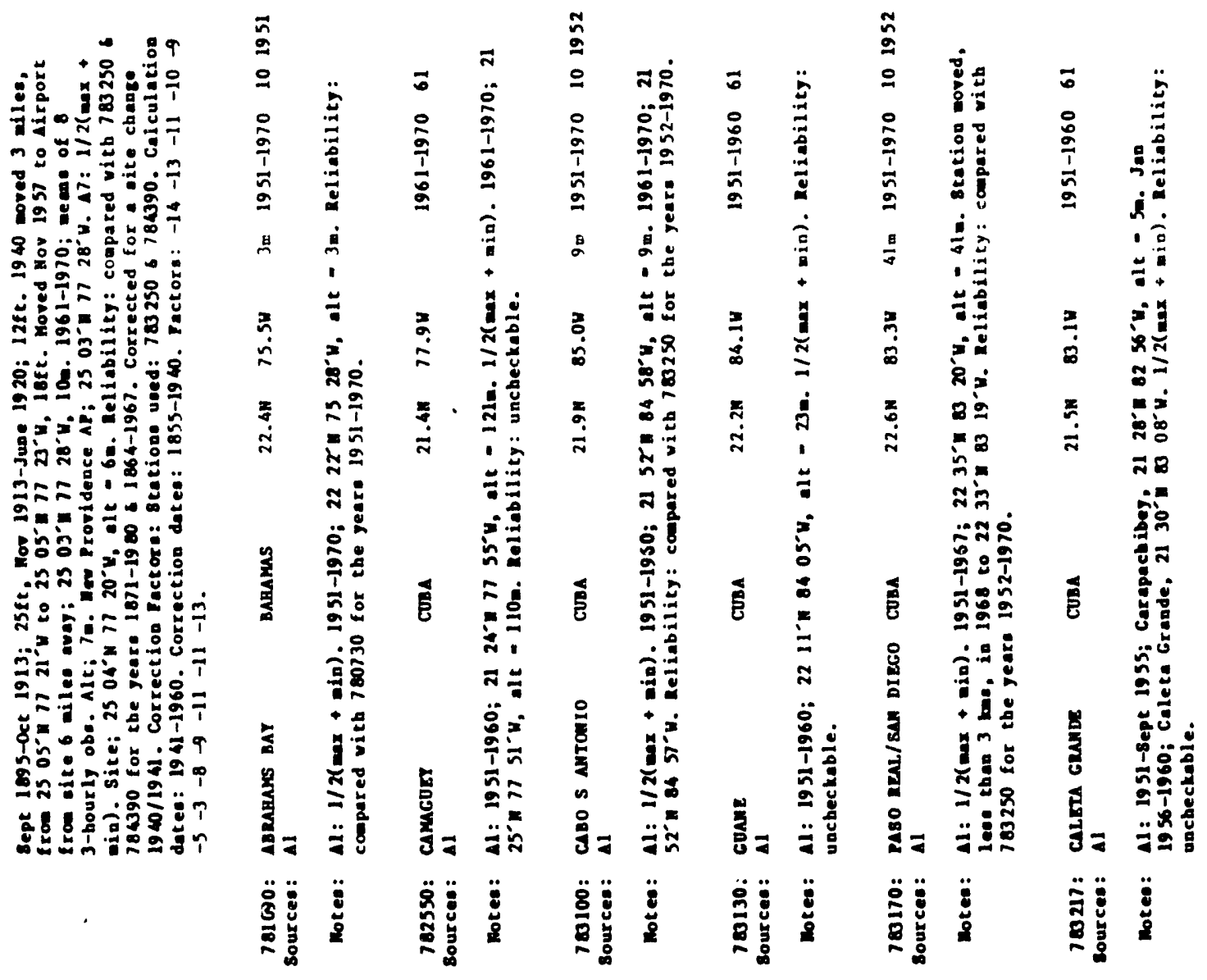

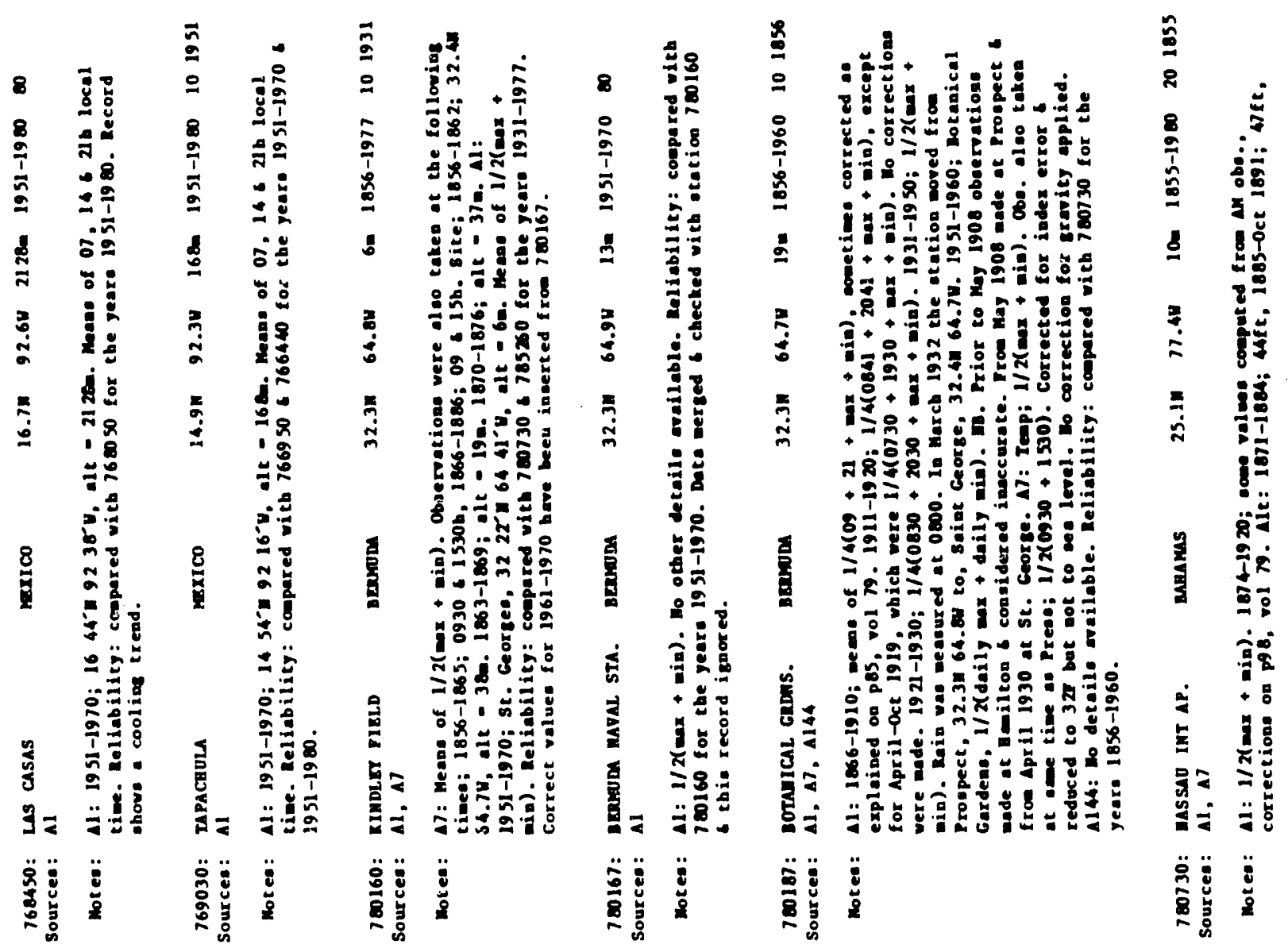




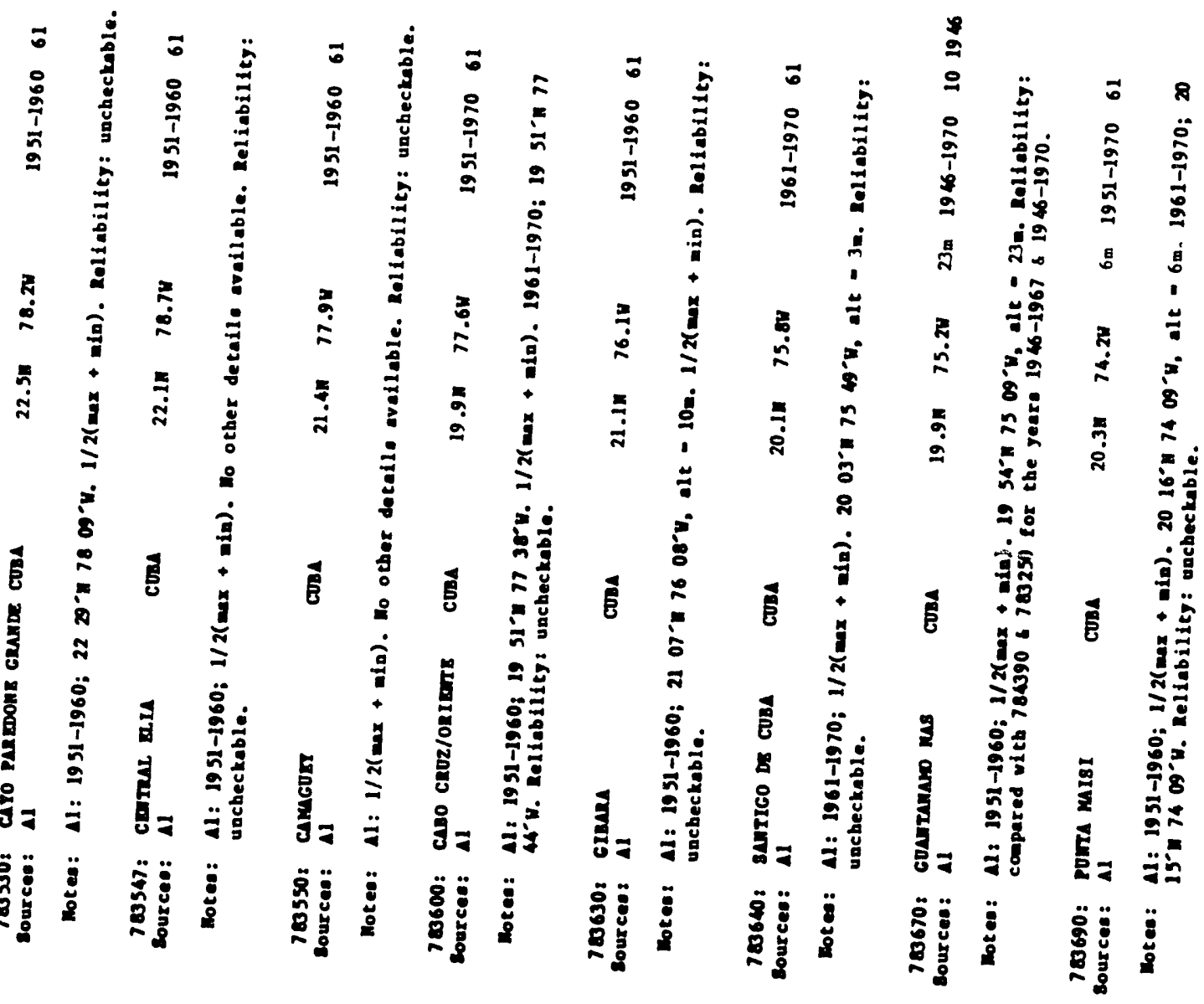

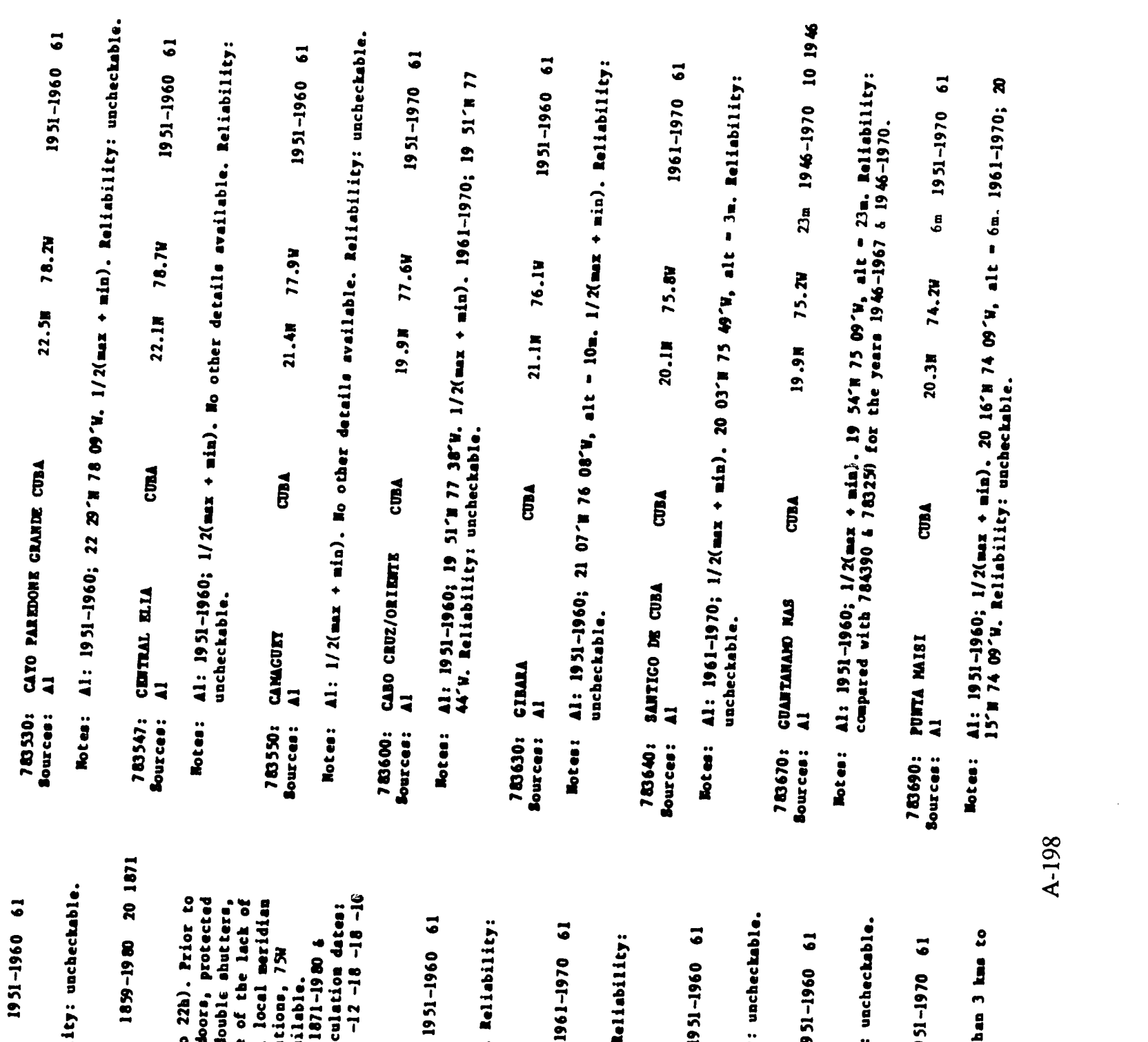

西

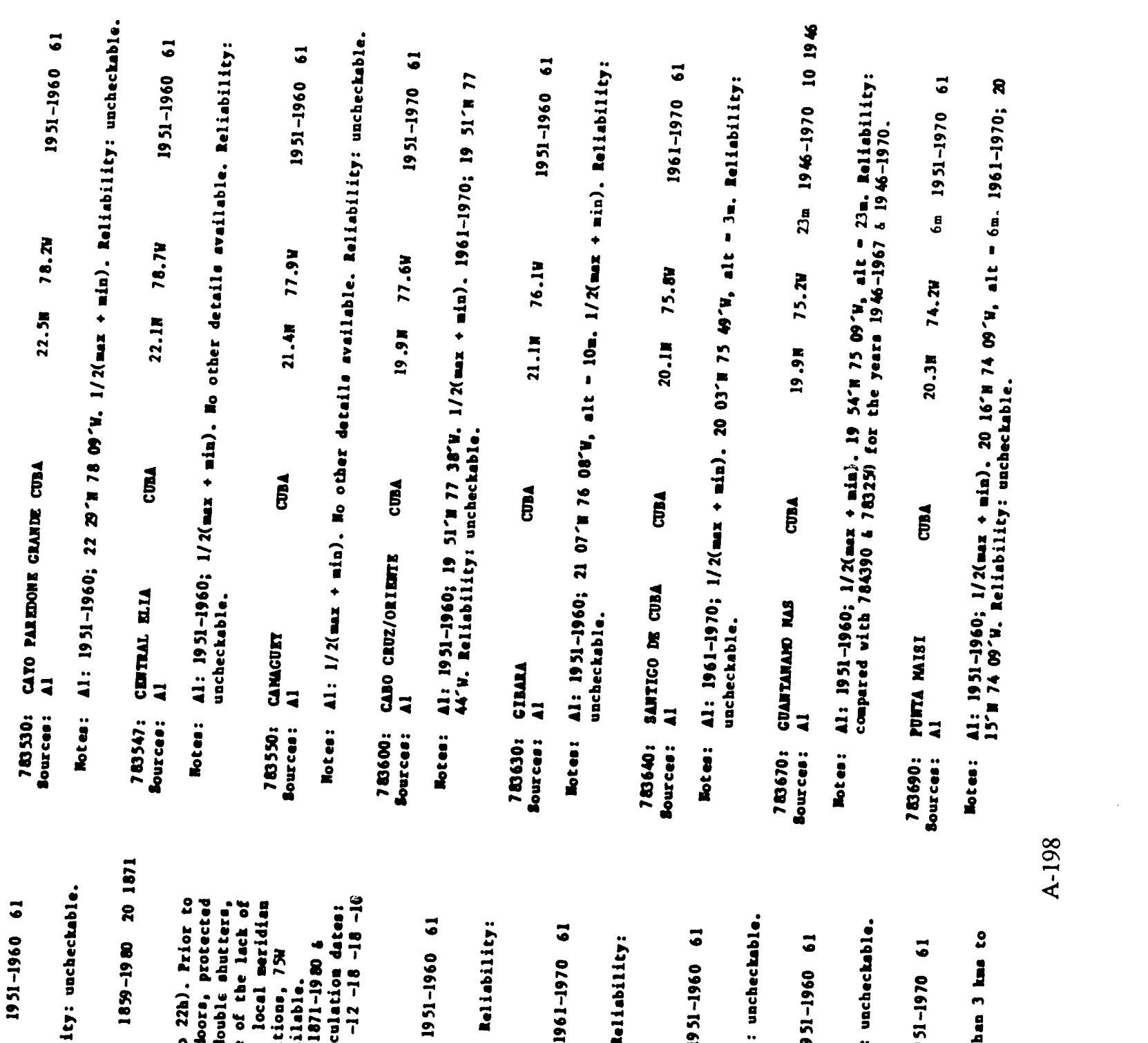

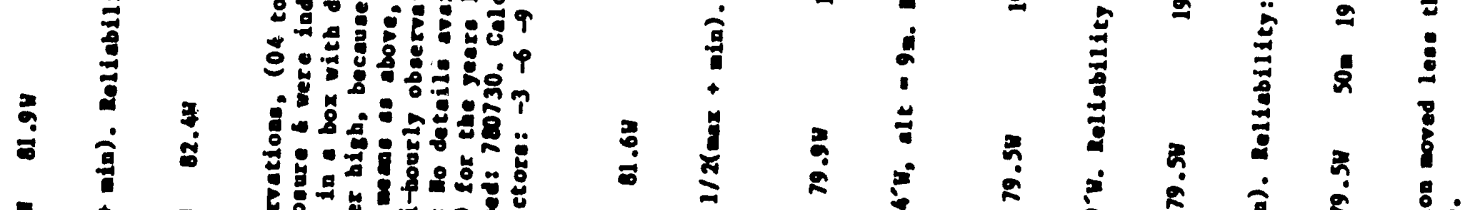

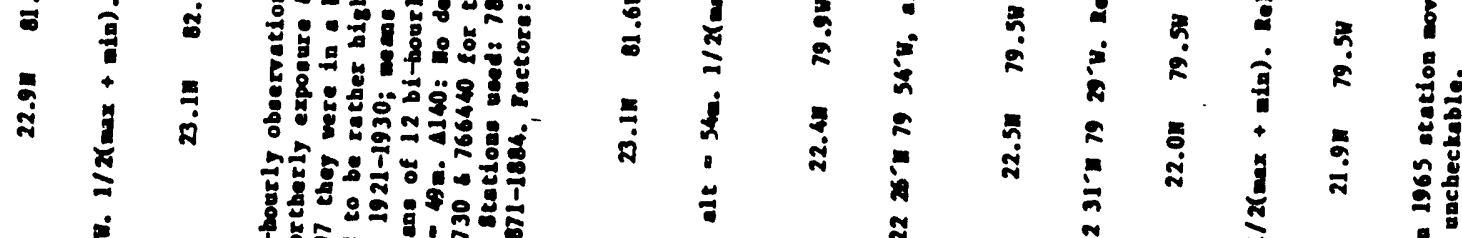

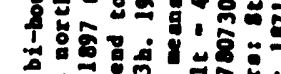

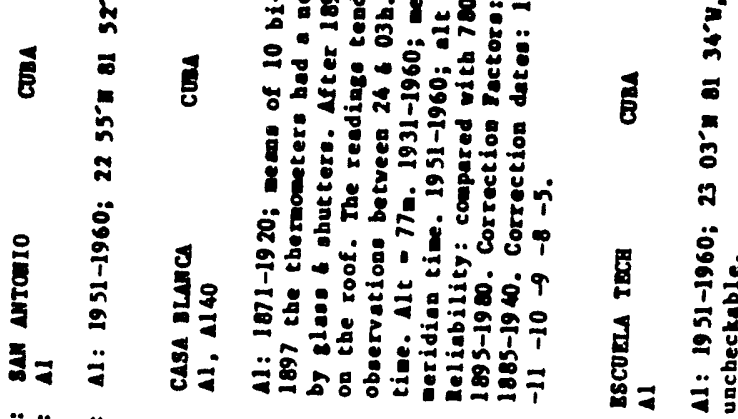

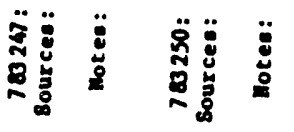

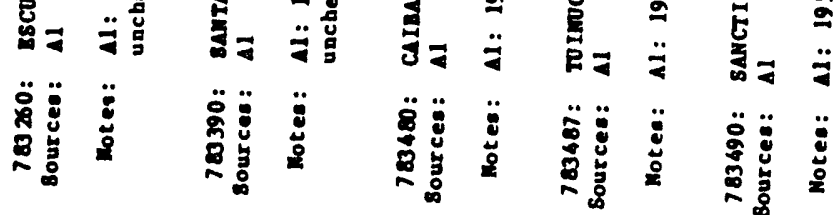



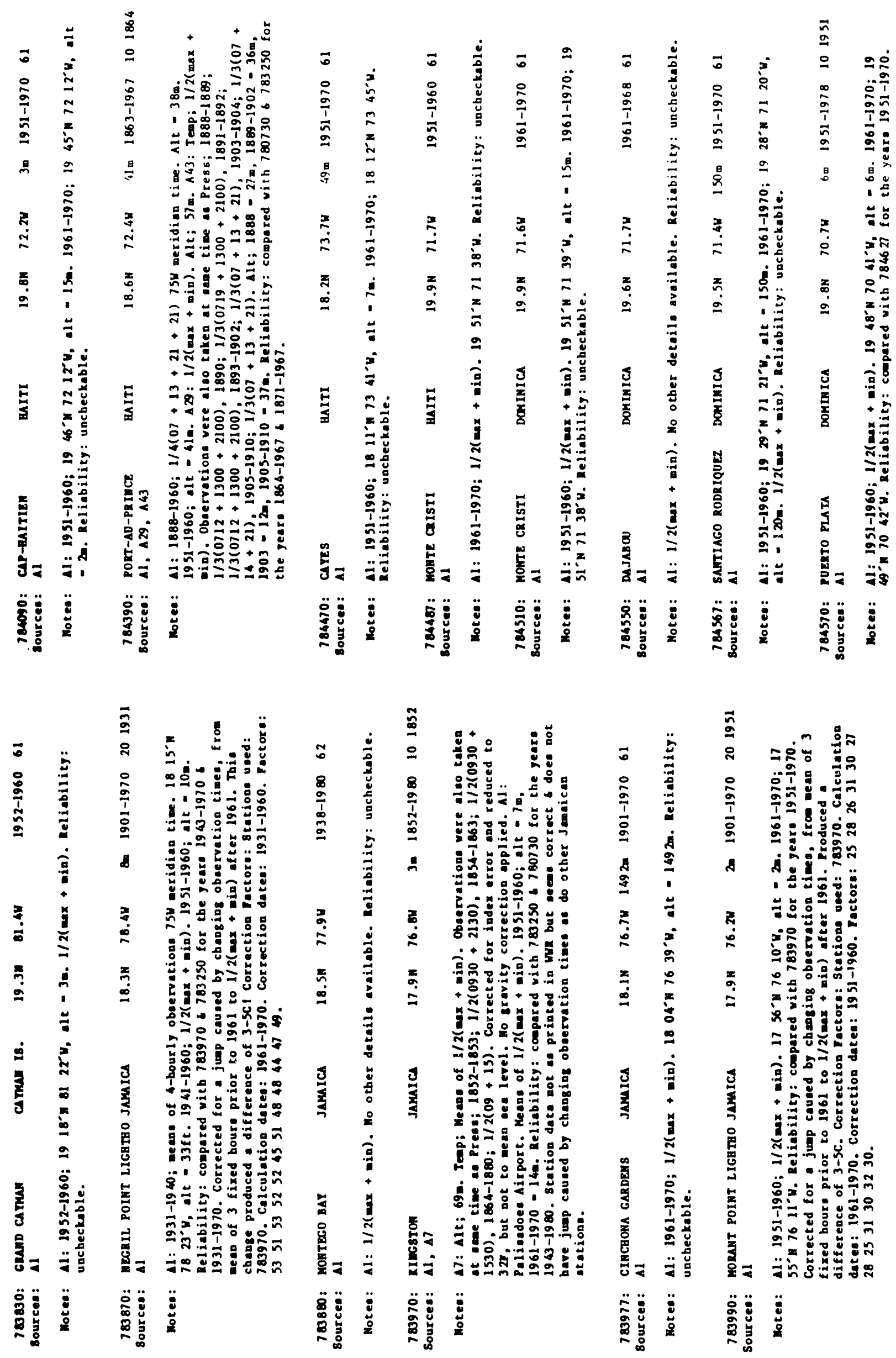


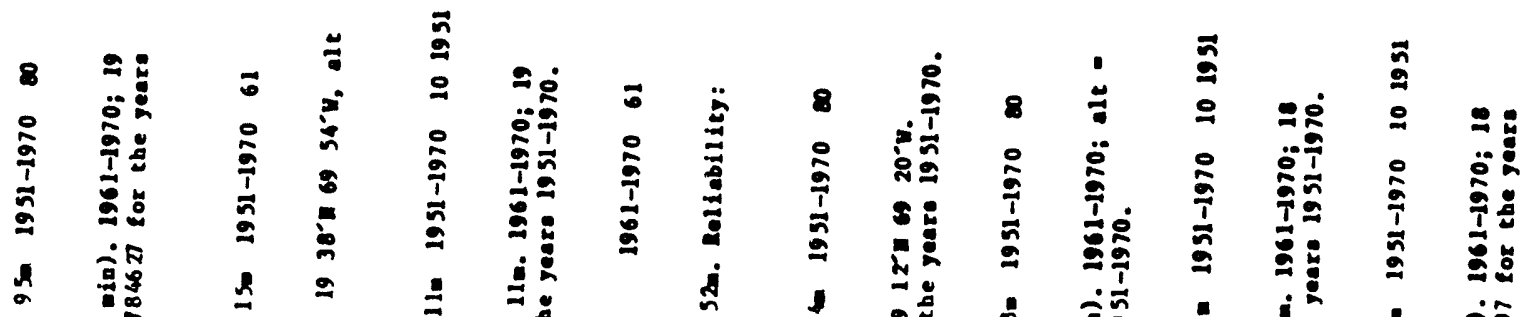

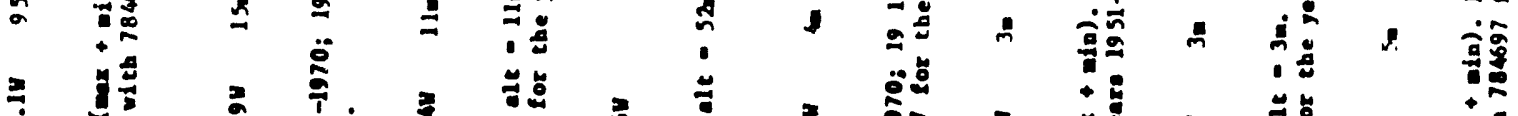

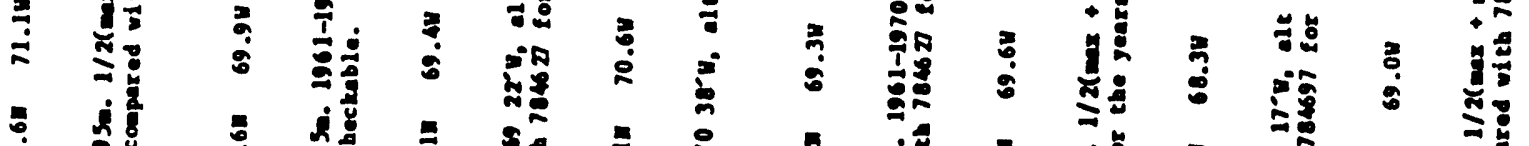

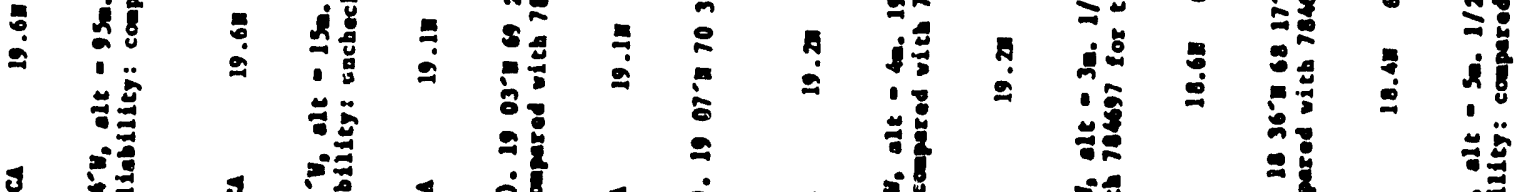

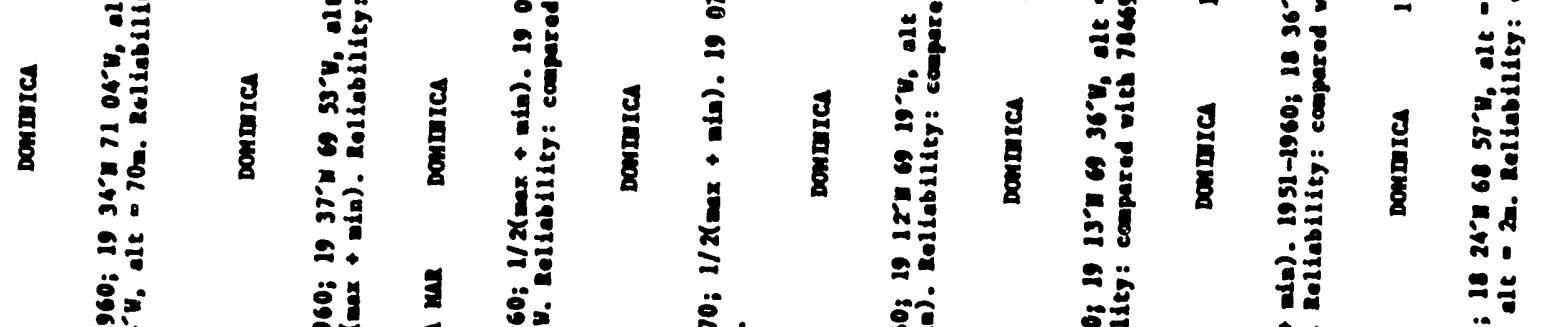

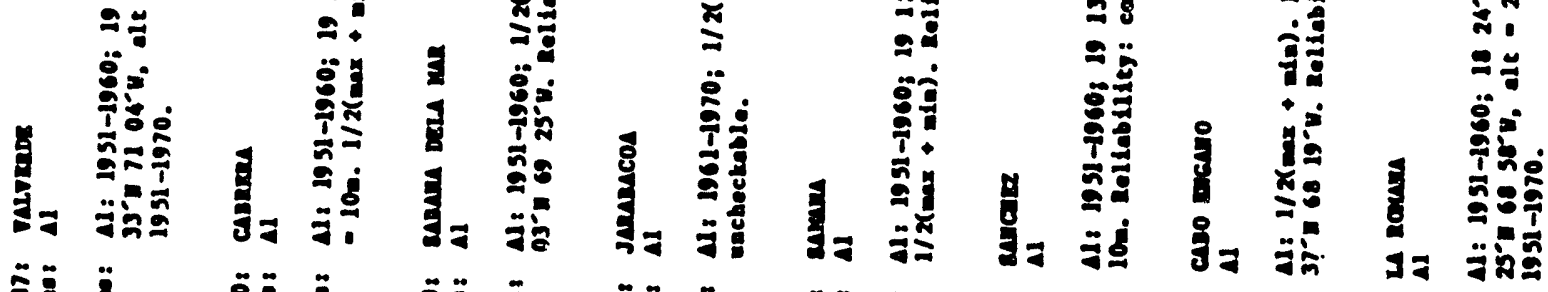

II II II II II

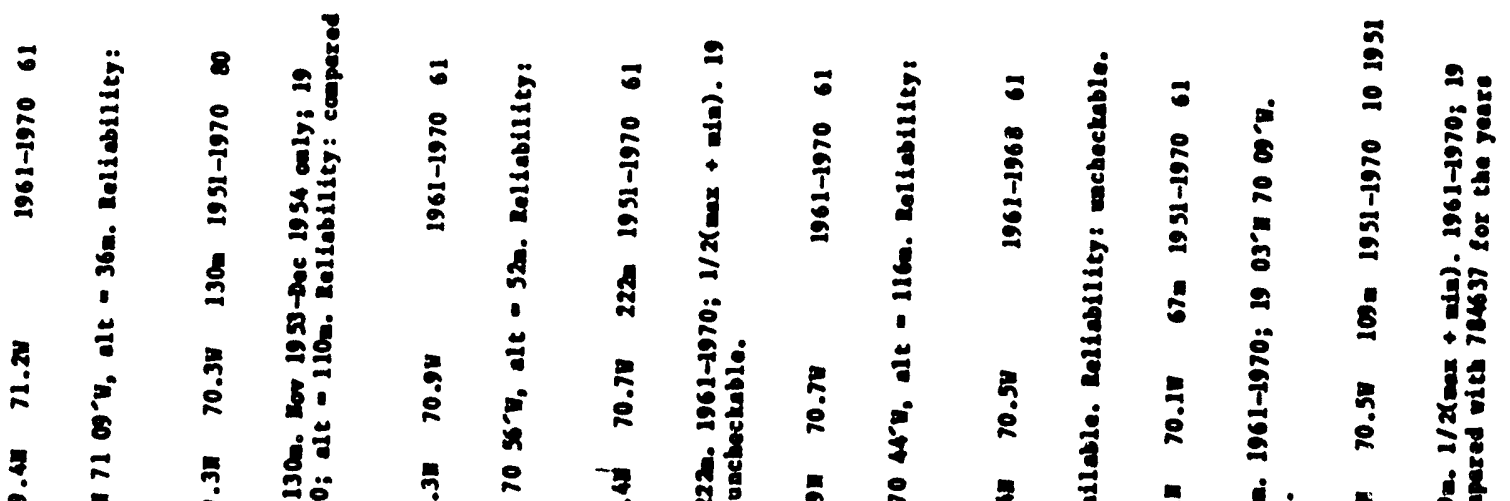

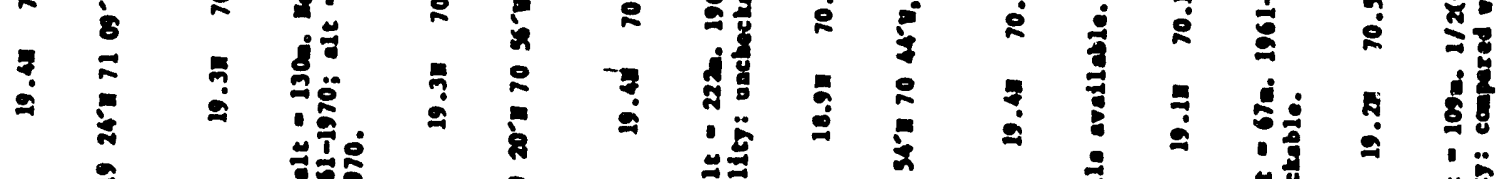

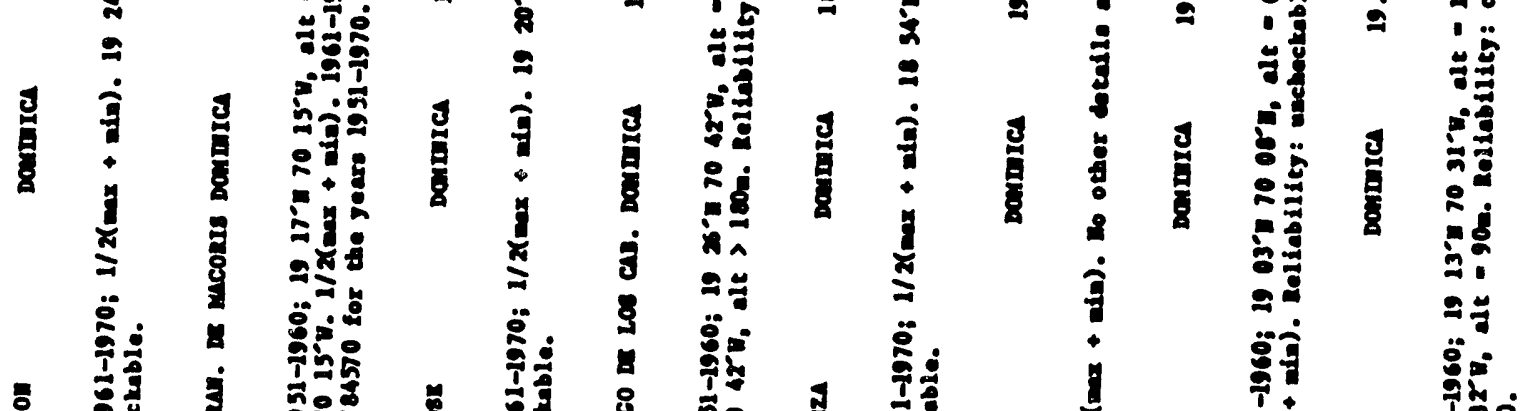

II II 


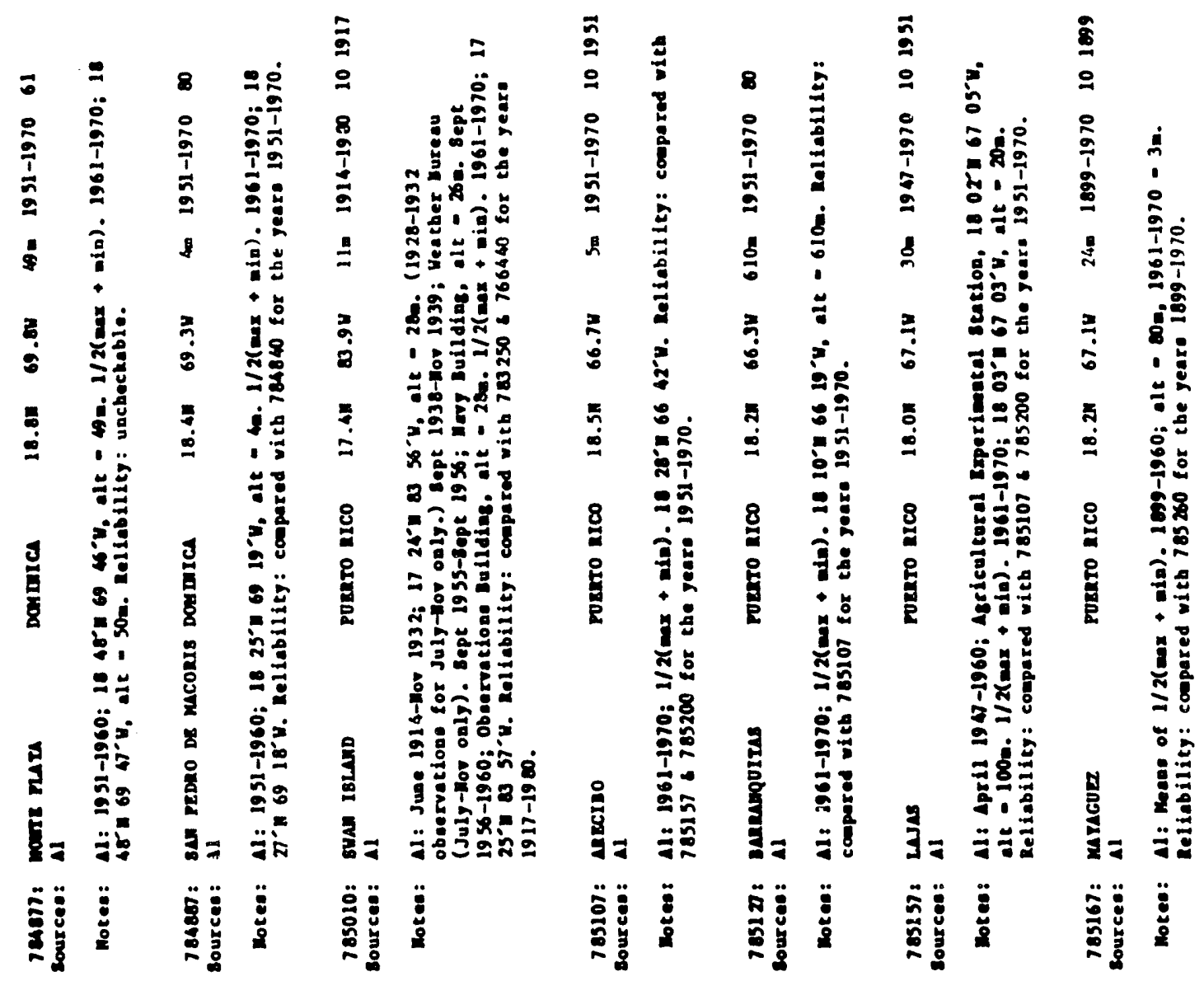

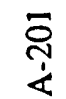

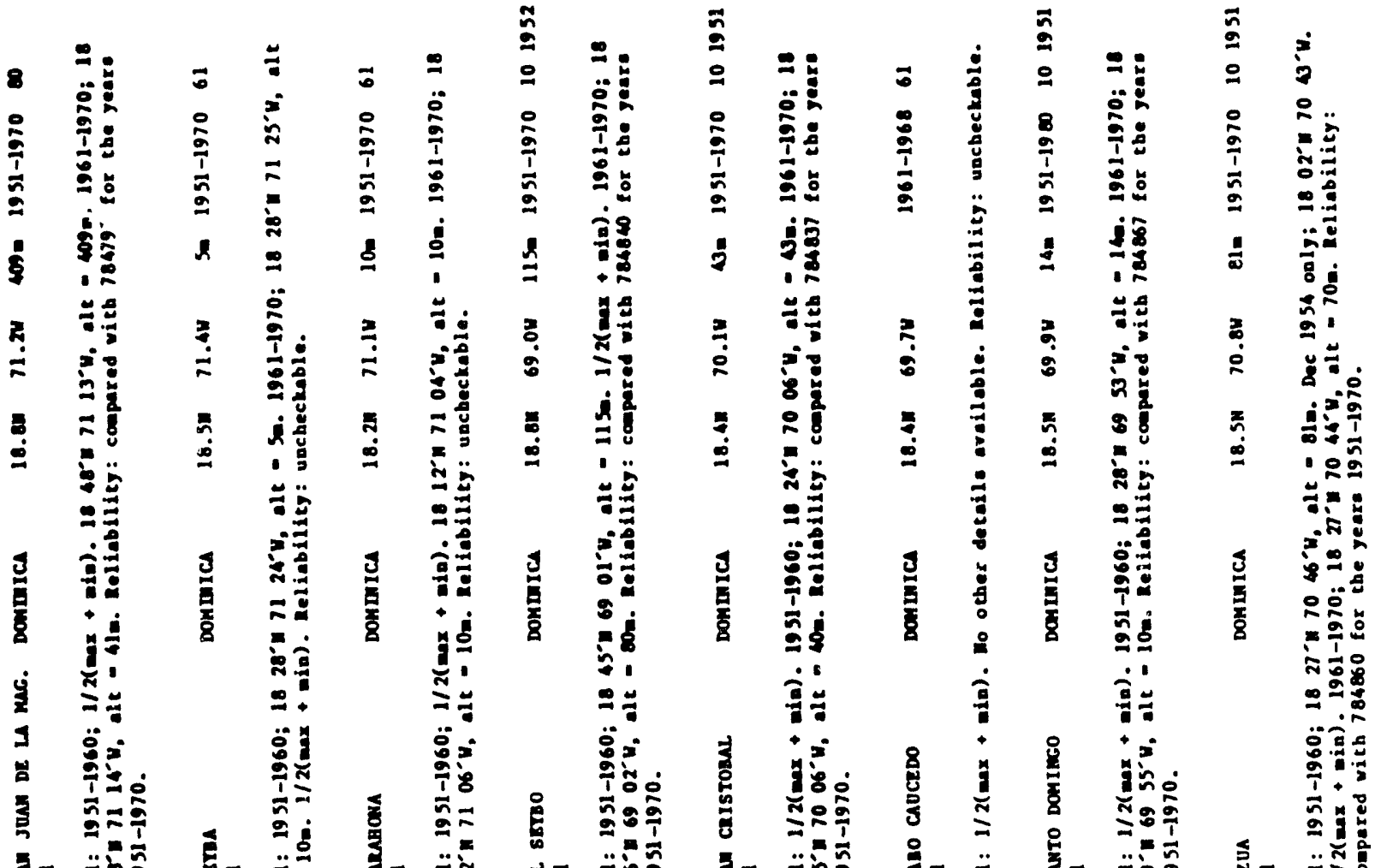

引z

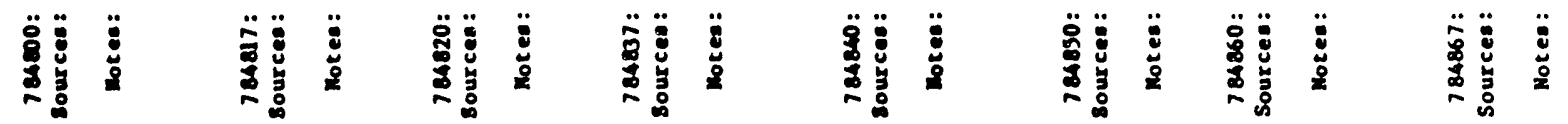




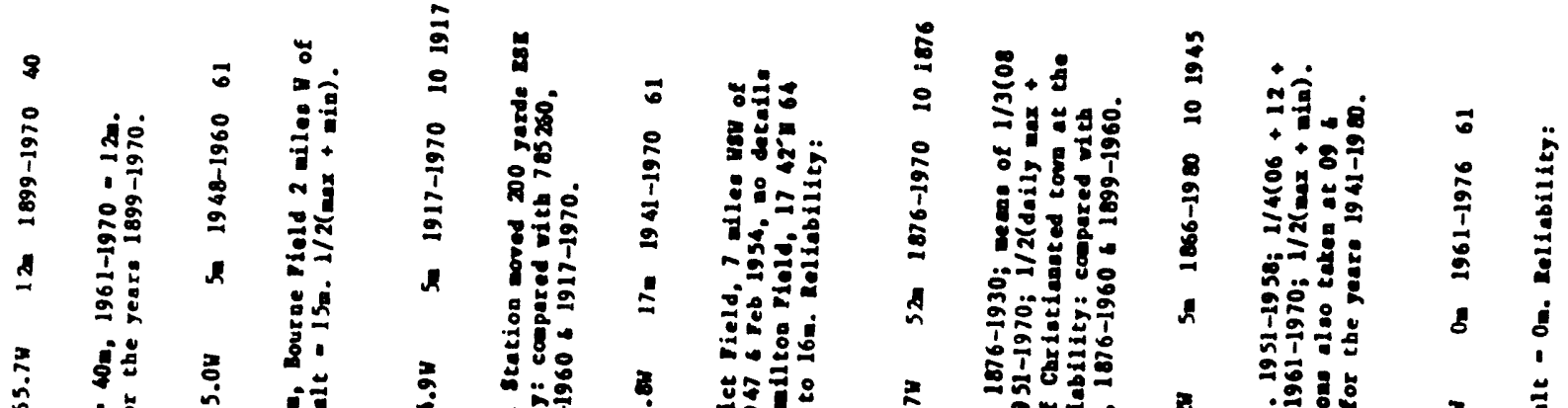

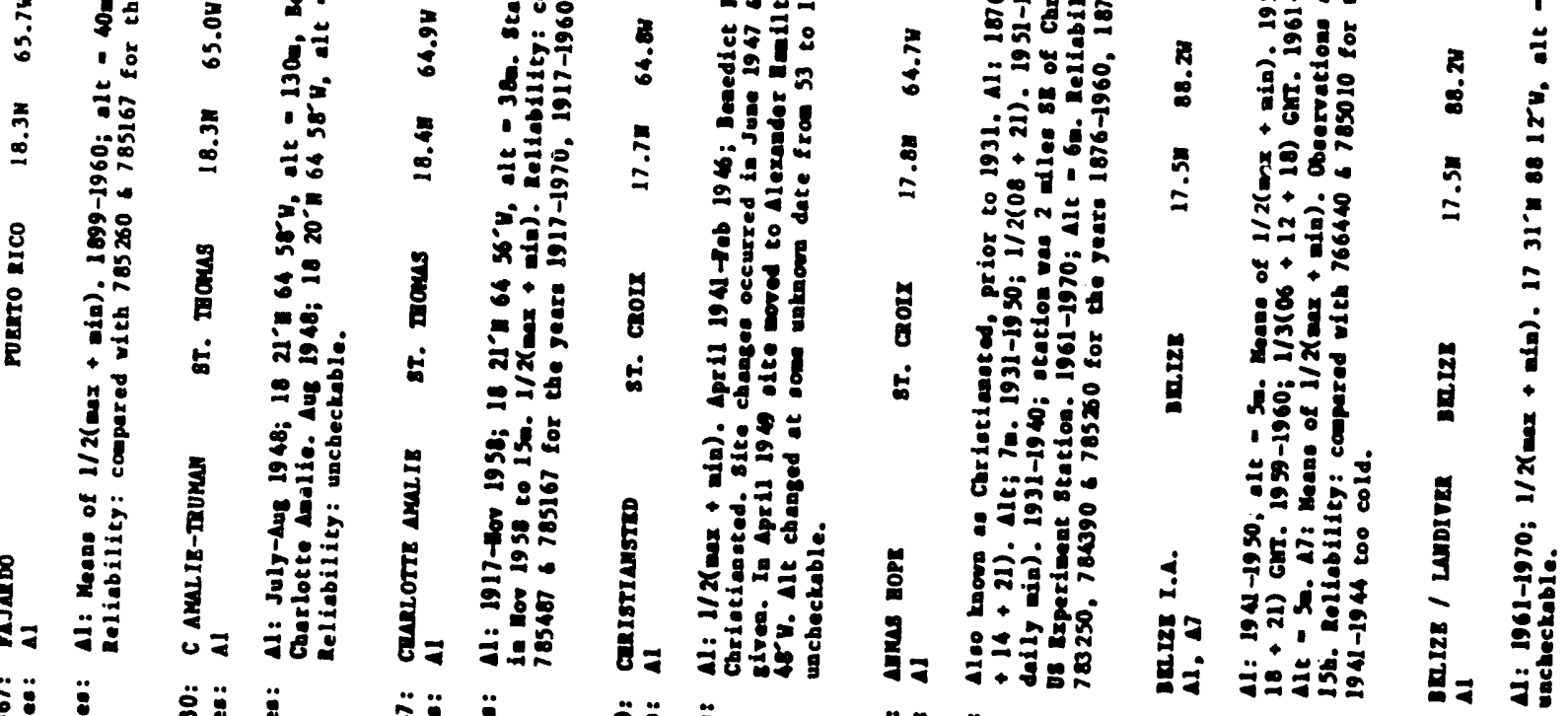

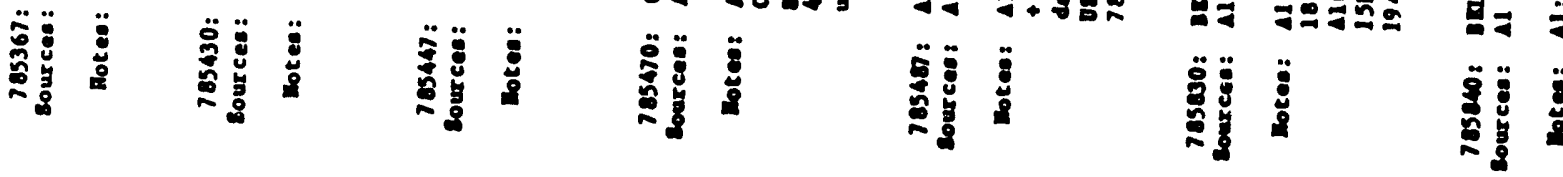

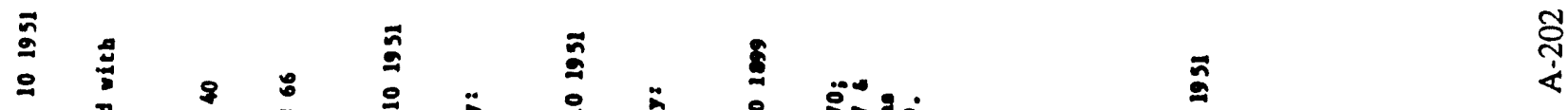

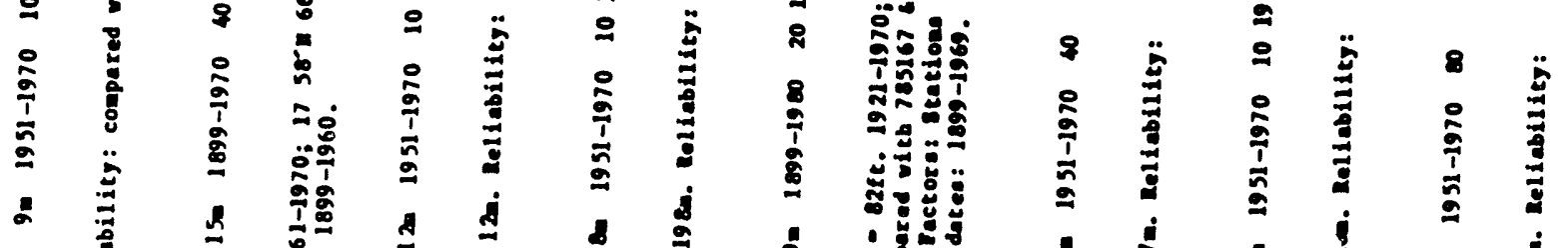

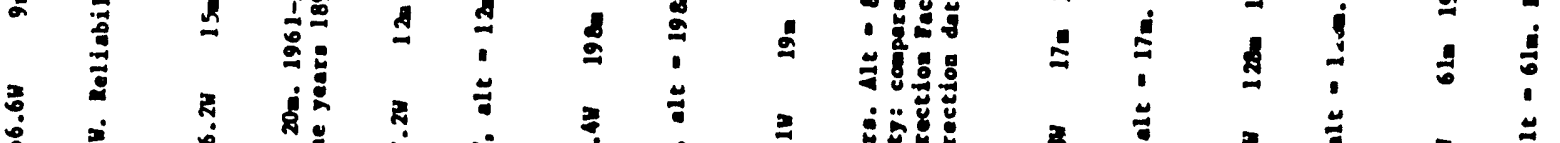

-

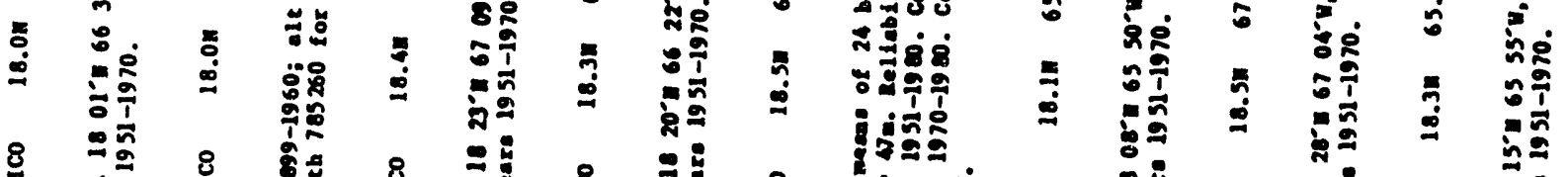

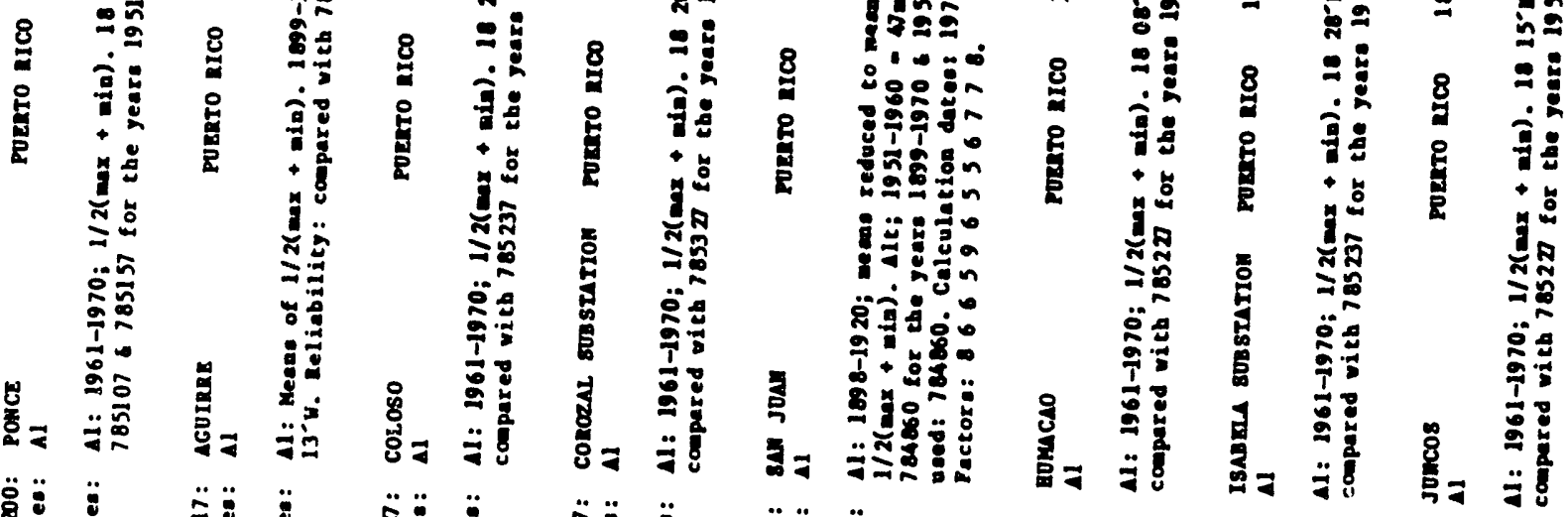

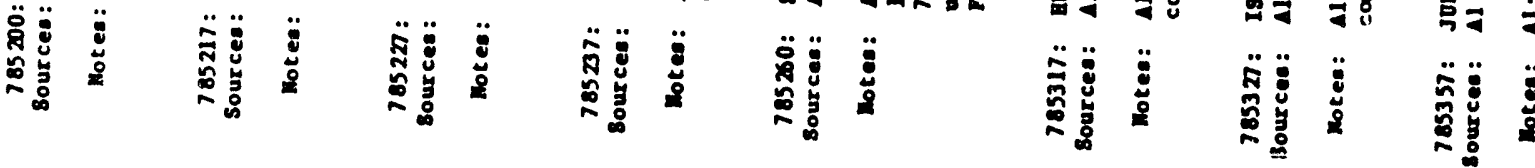


II

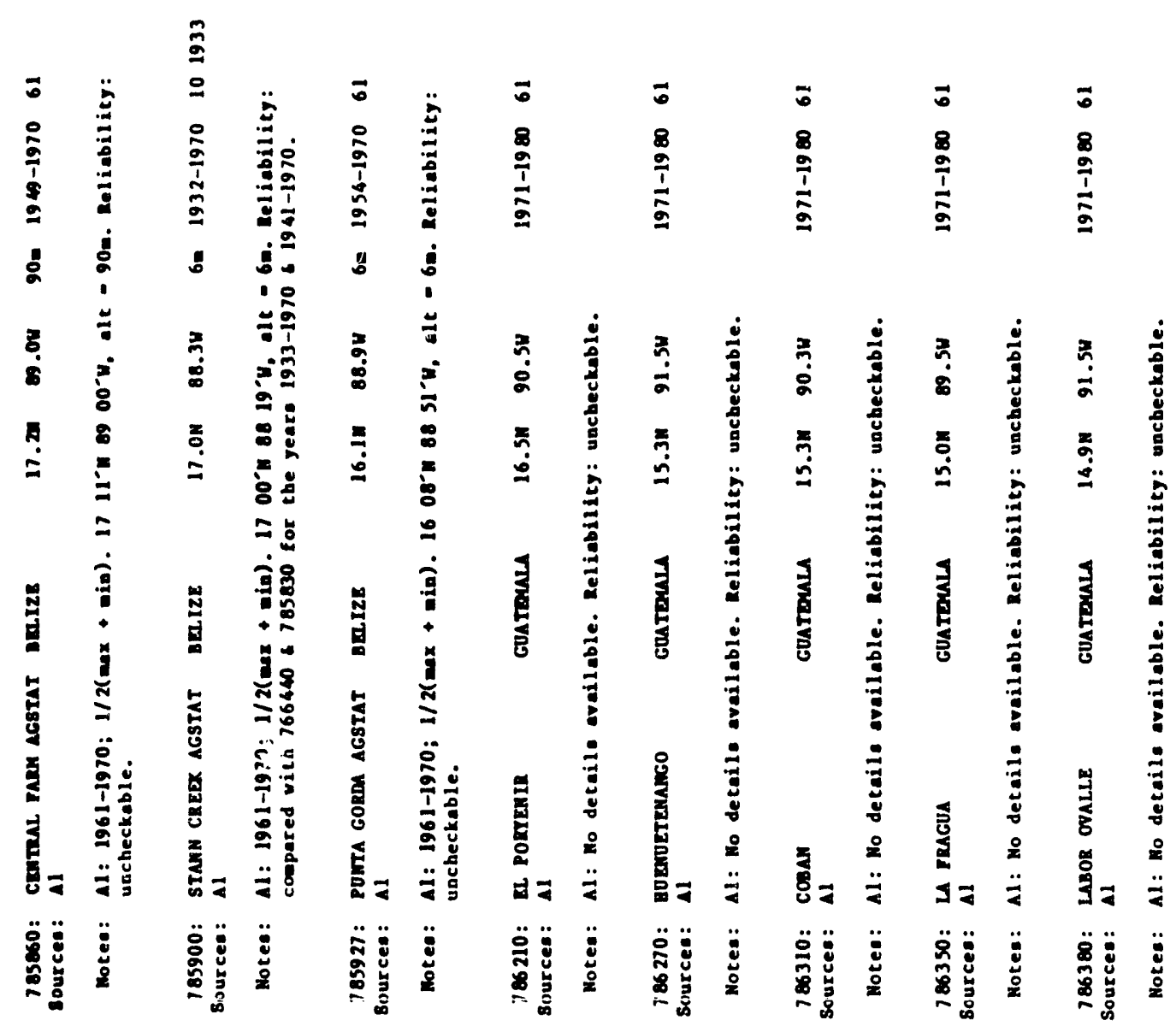




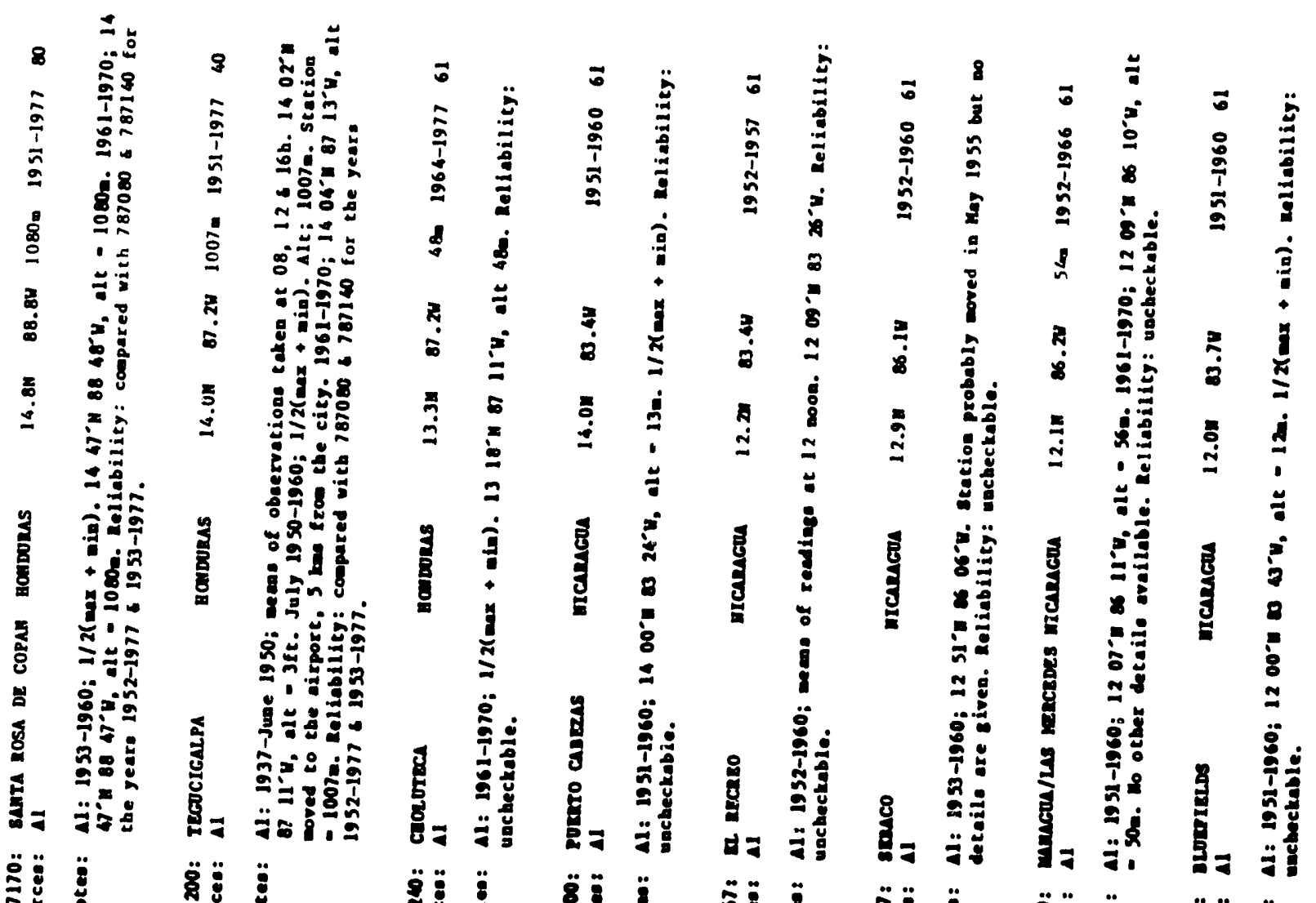

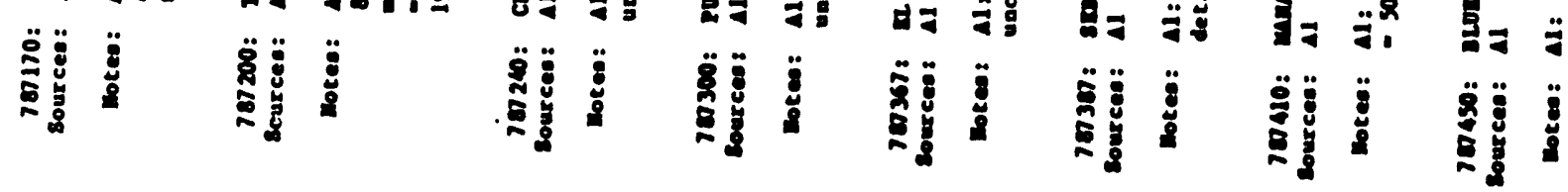

$\div$

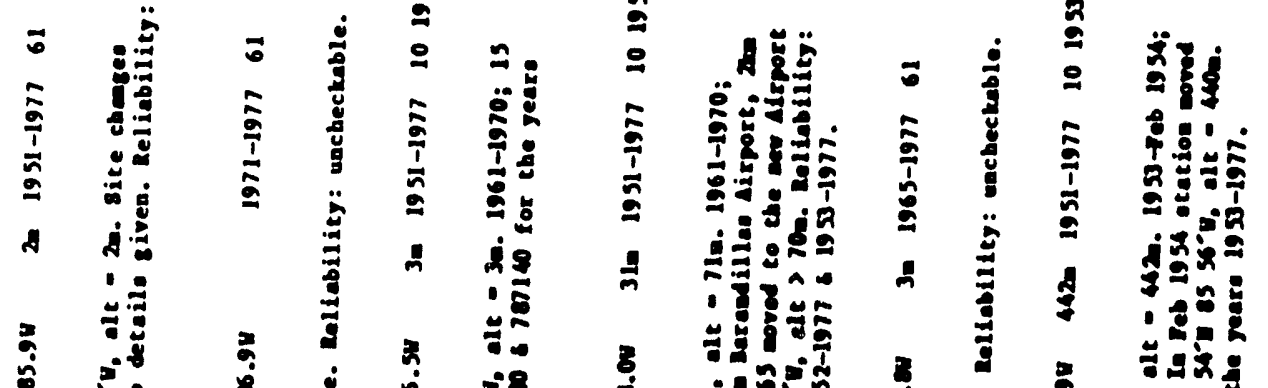

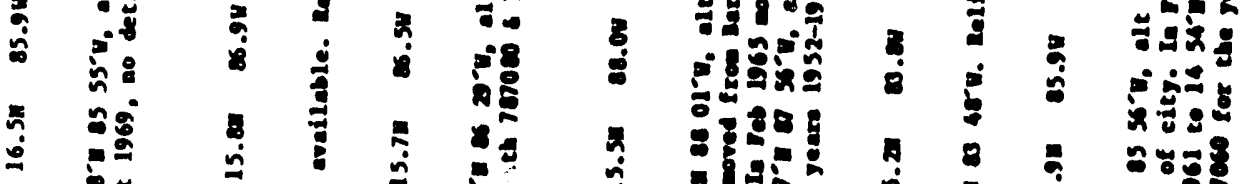

$\because$

I 1

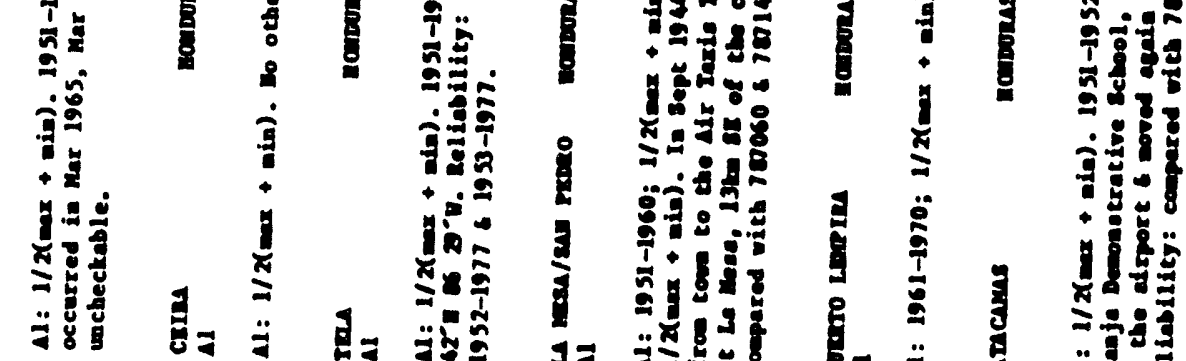

II 


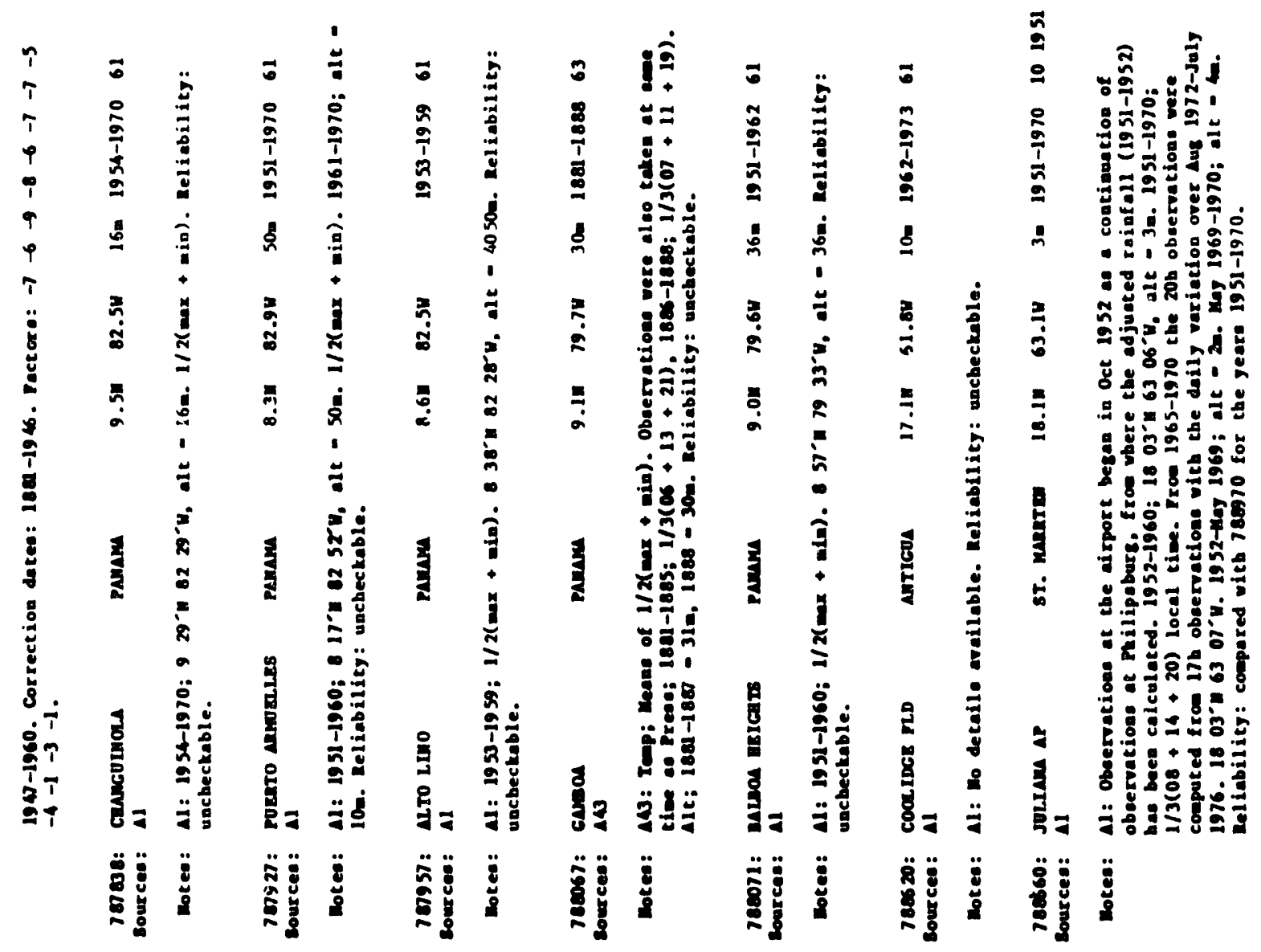

$\frac{n}{4}$

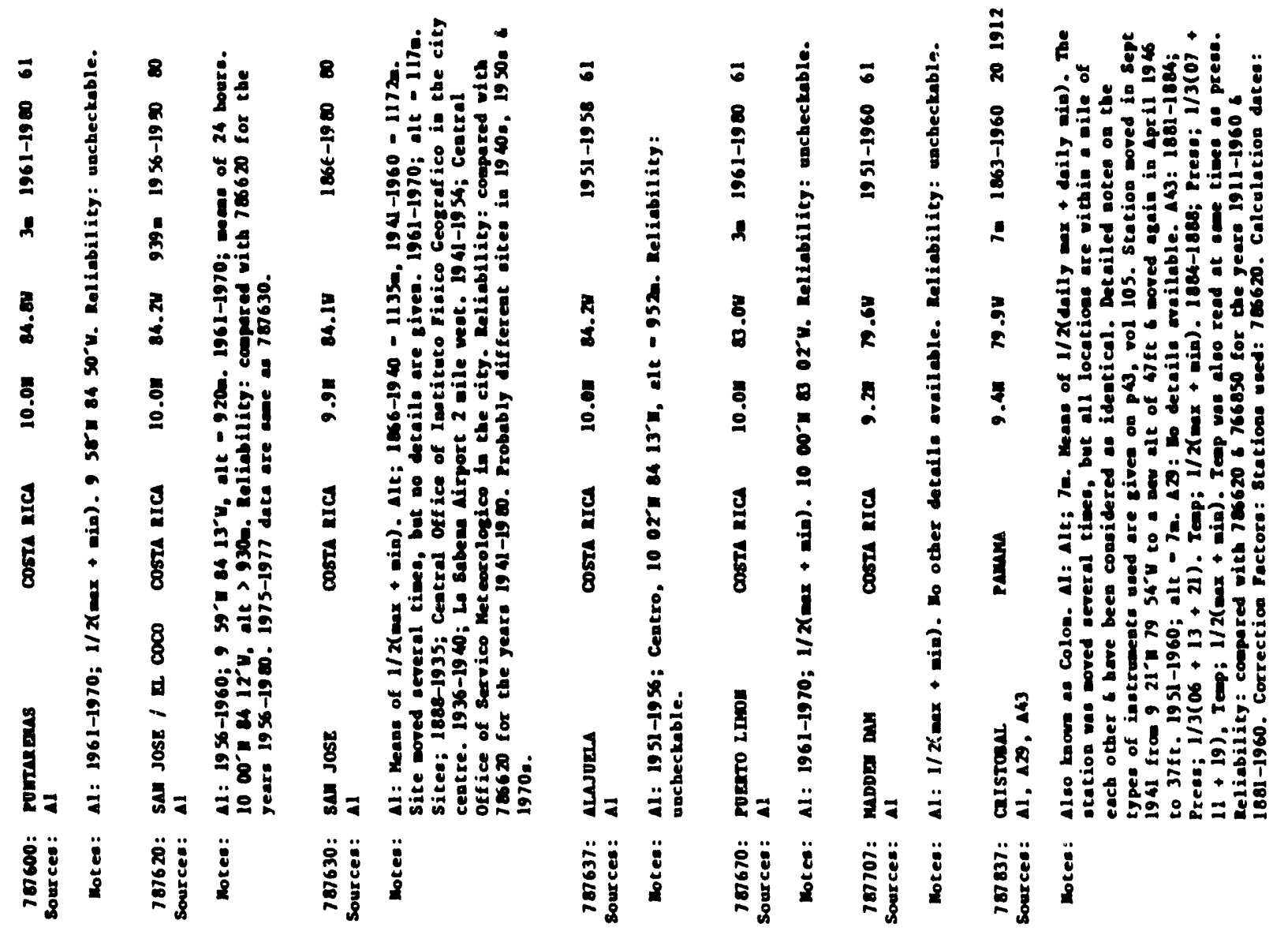



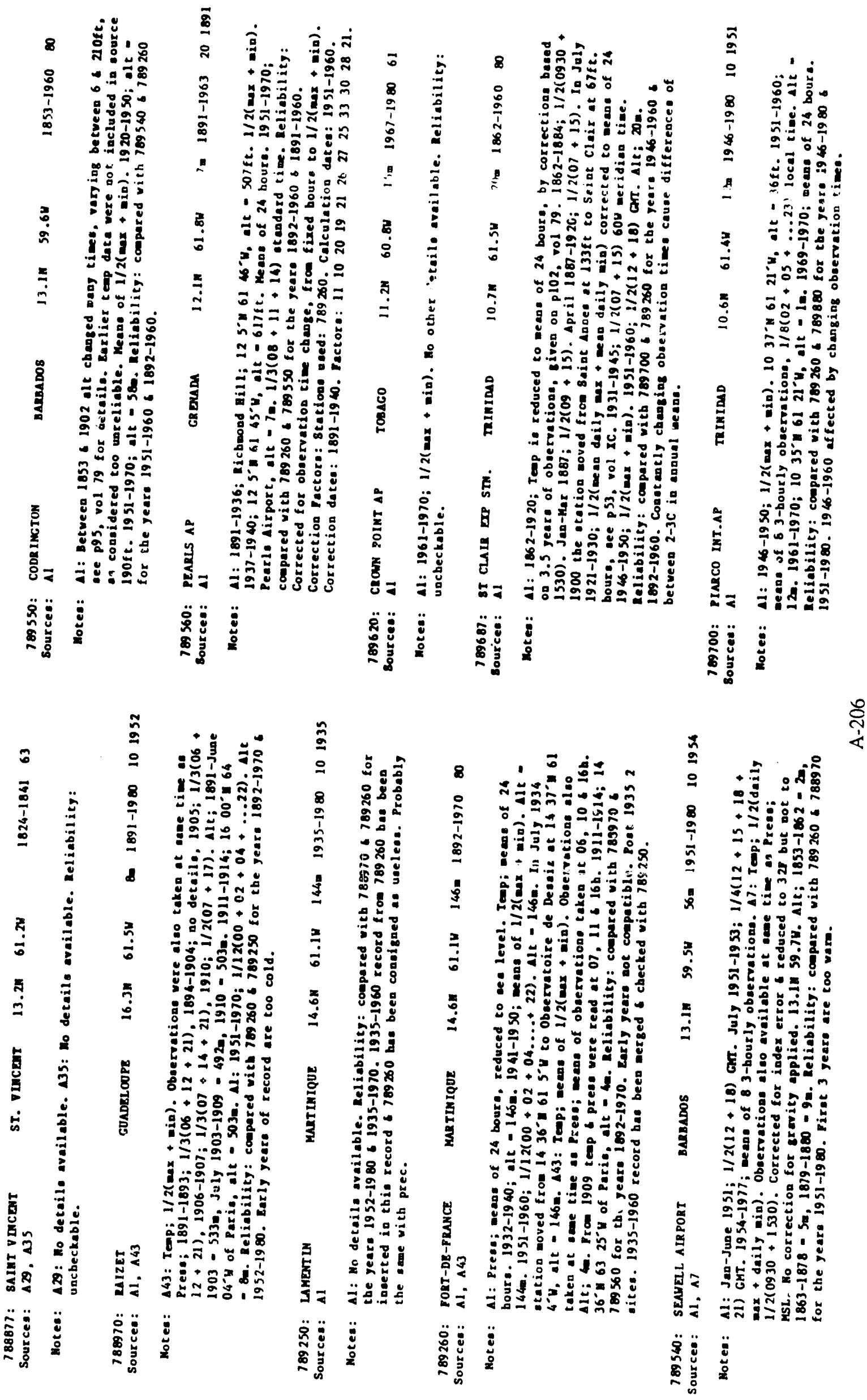
$\bar{\alpha}$

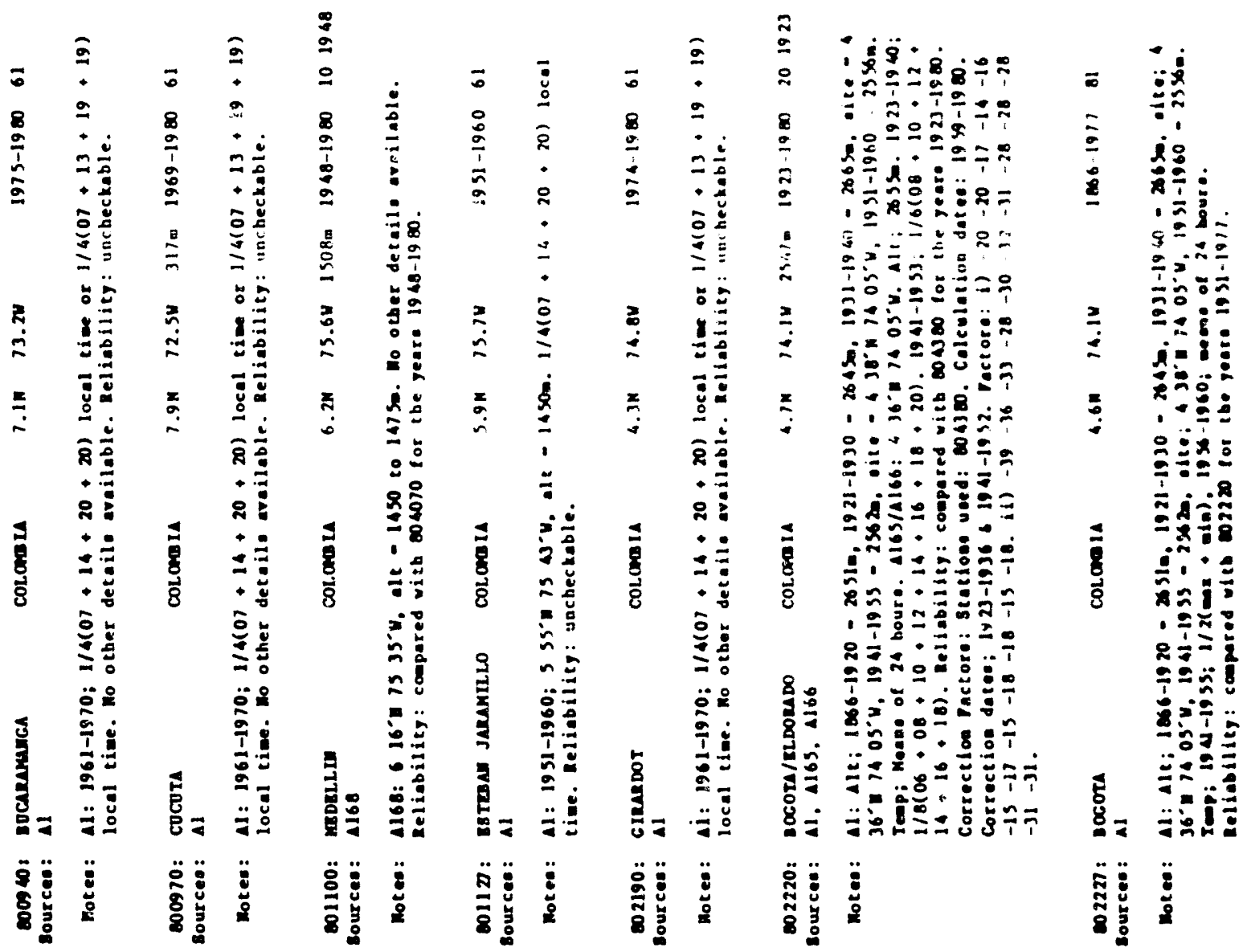

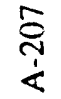

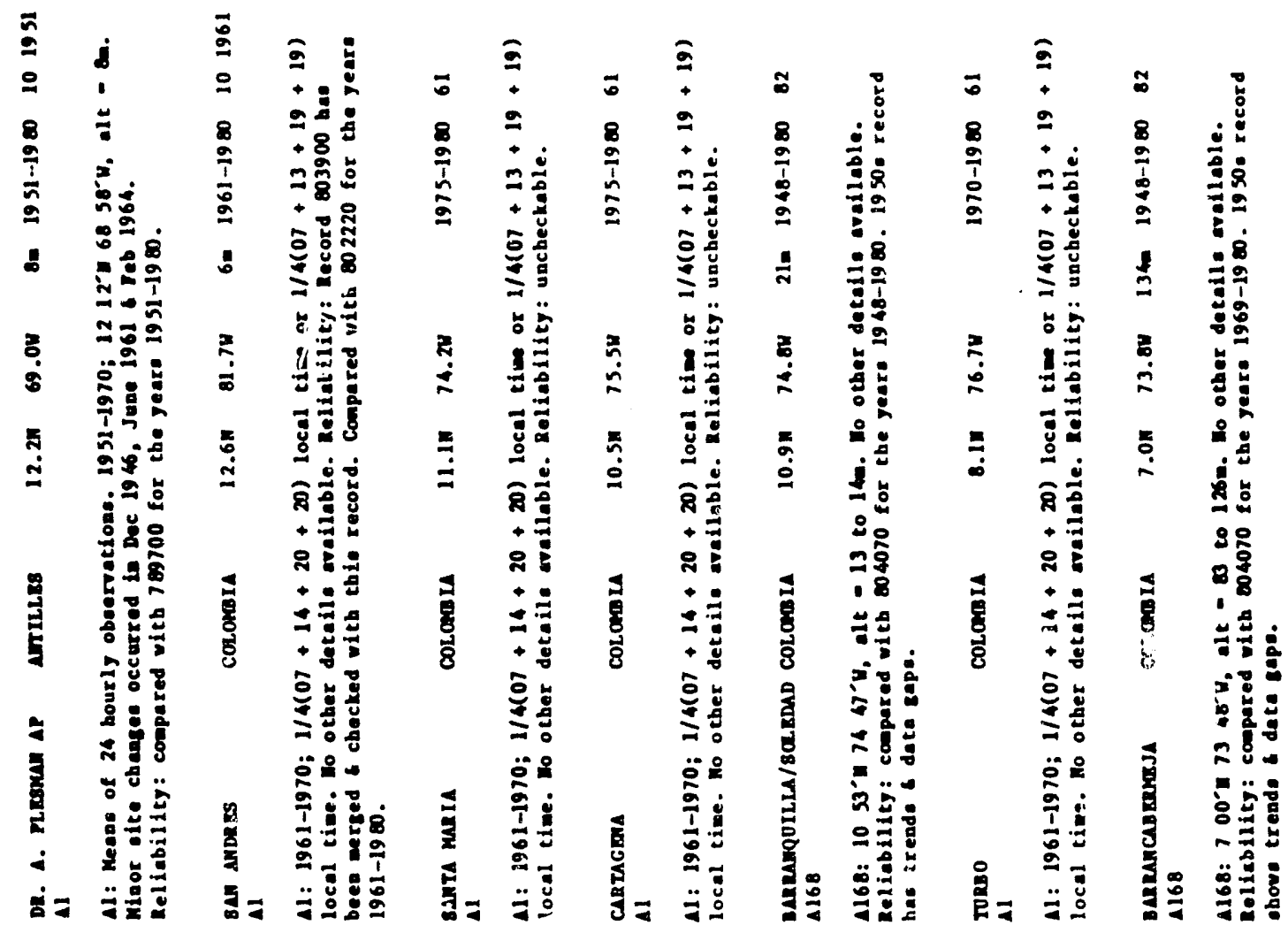

แI 


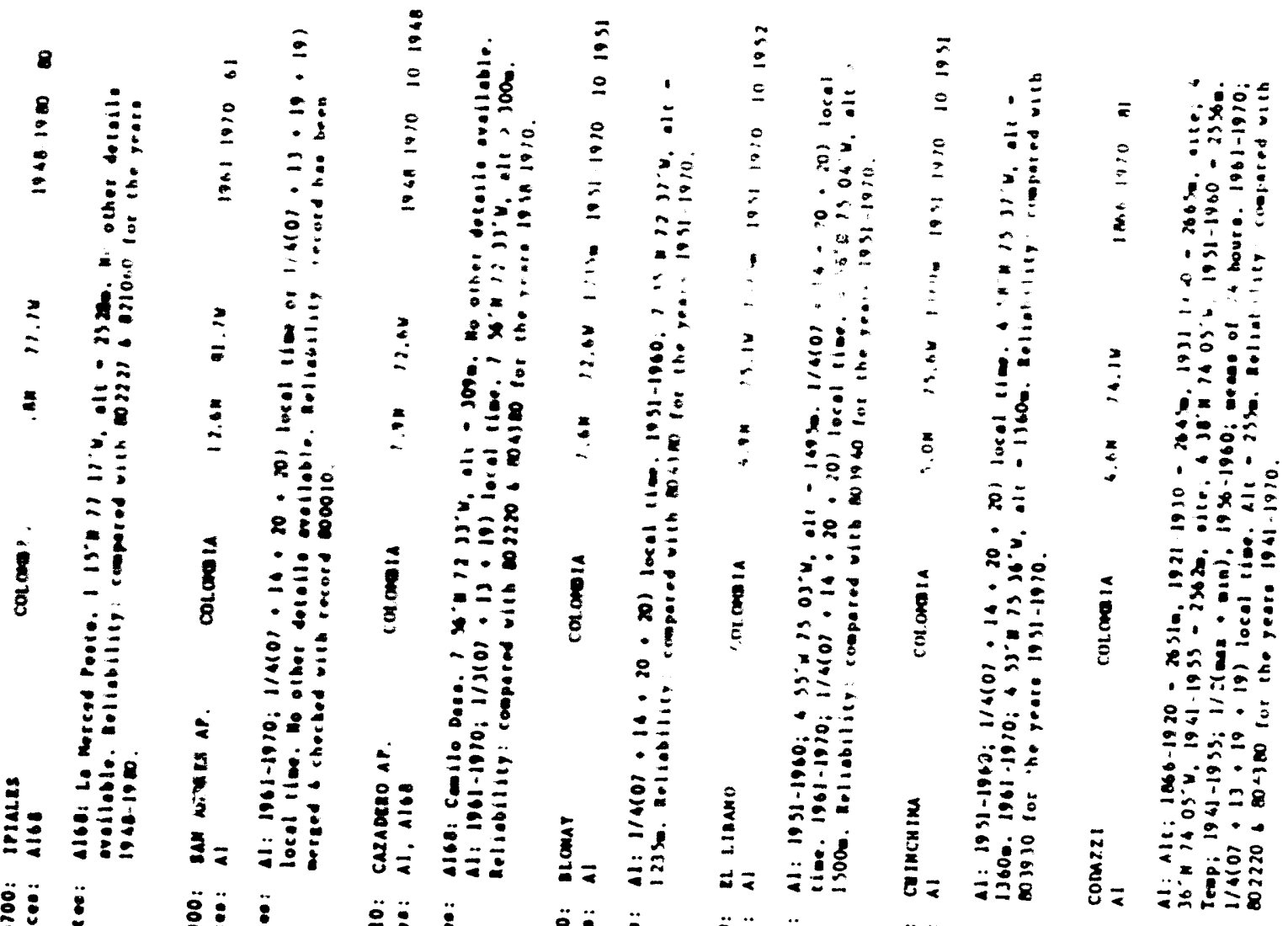

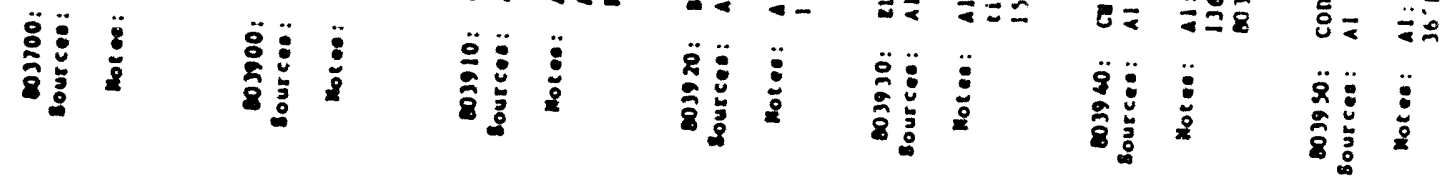

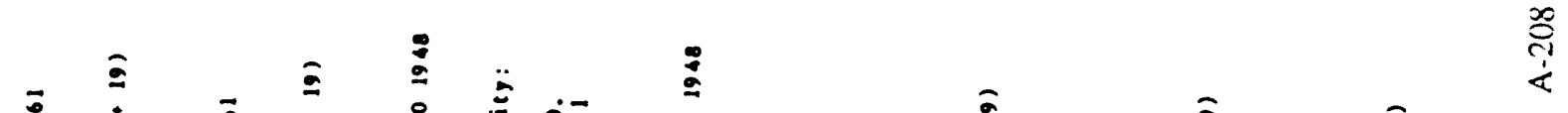

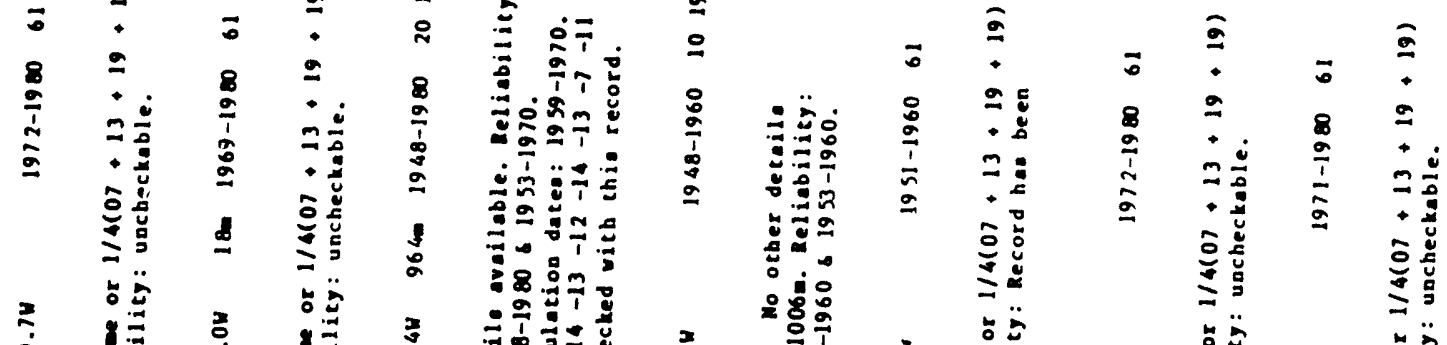

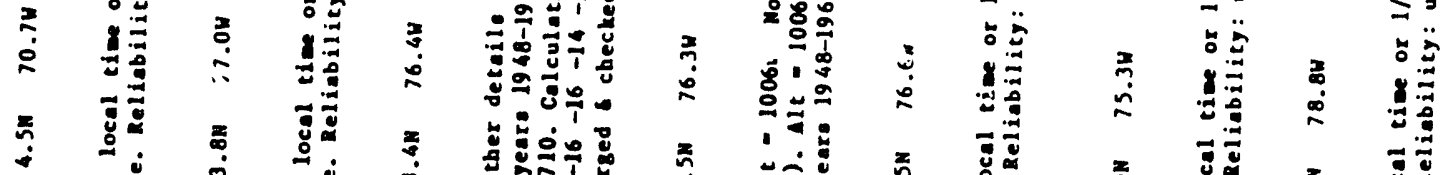

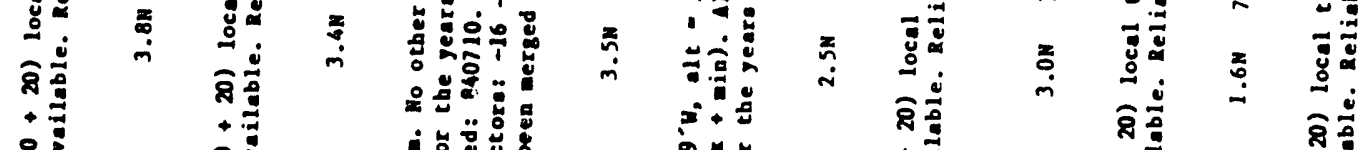

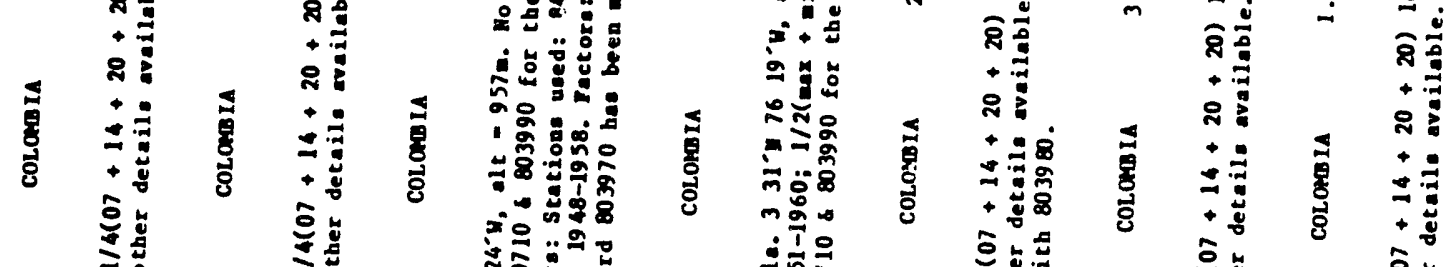

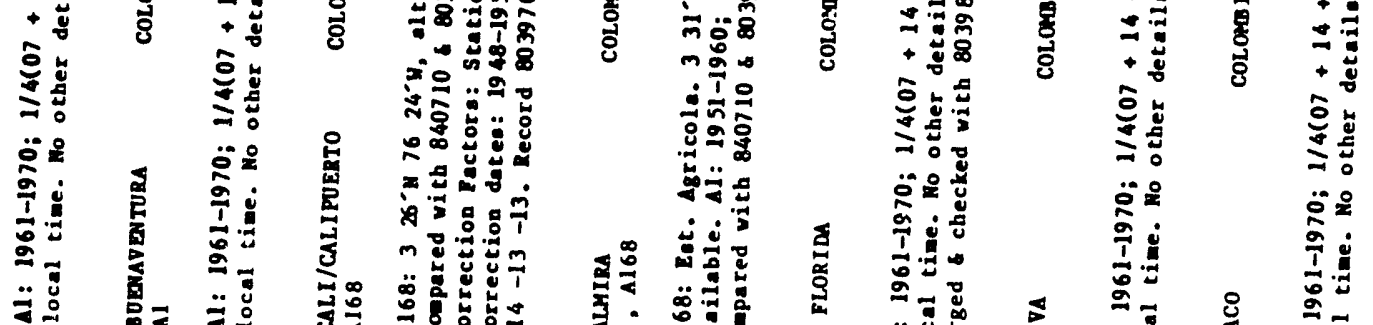

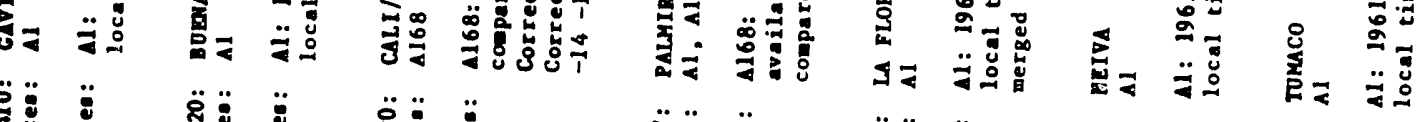

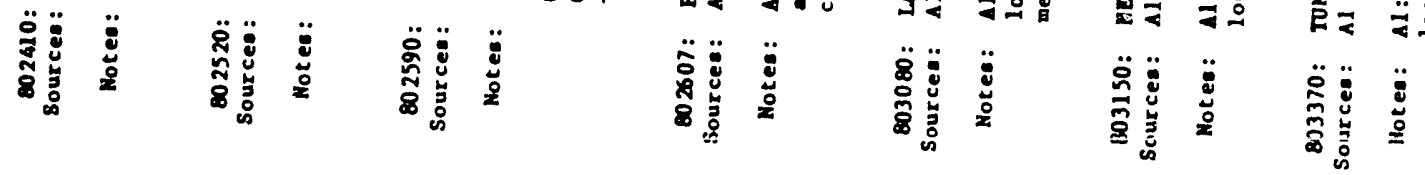



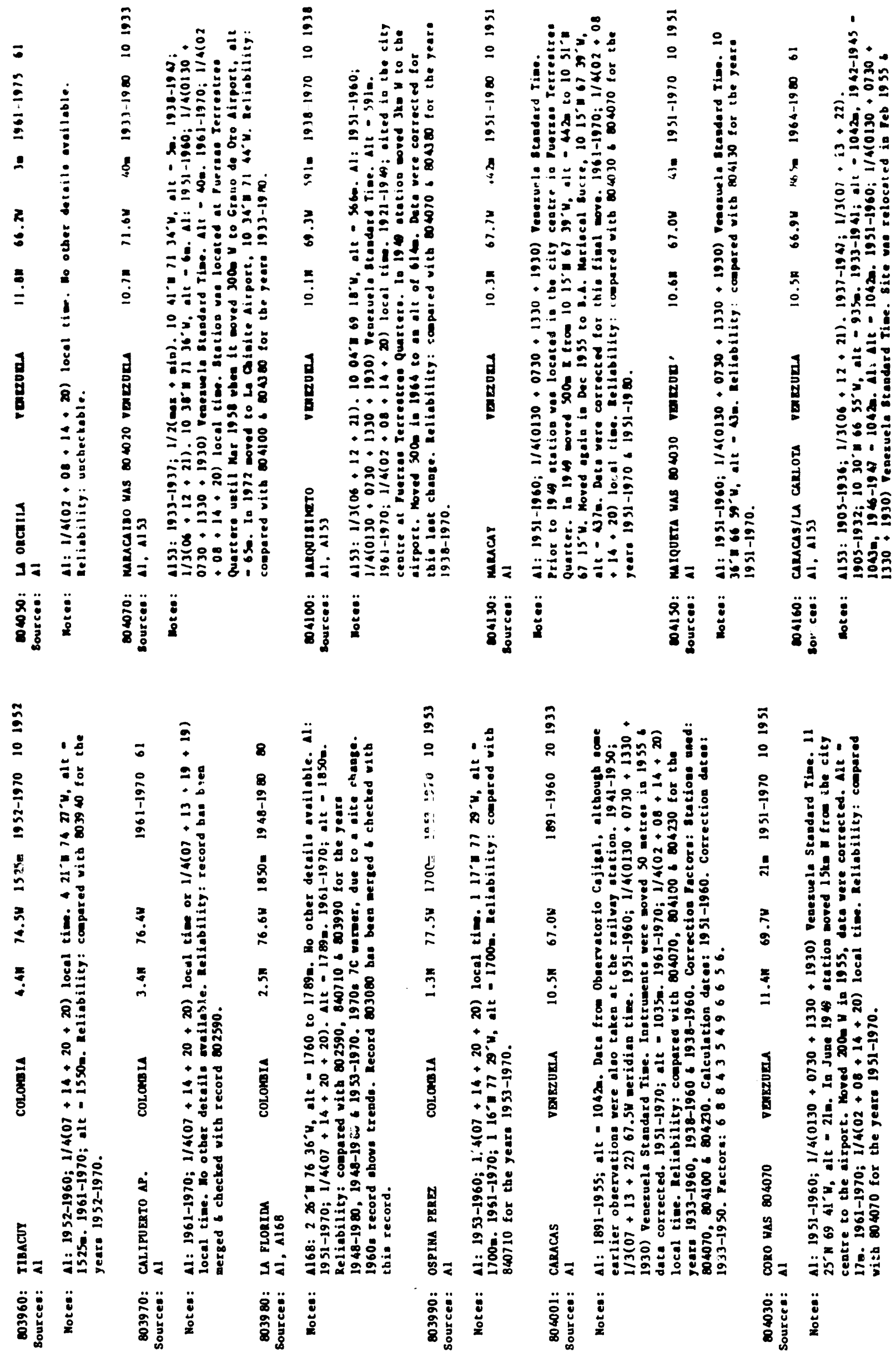


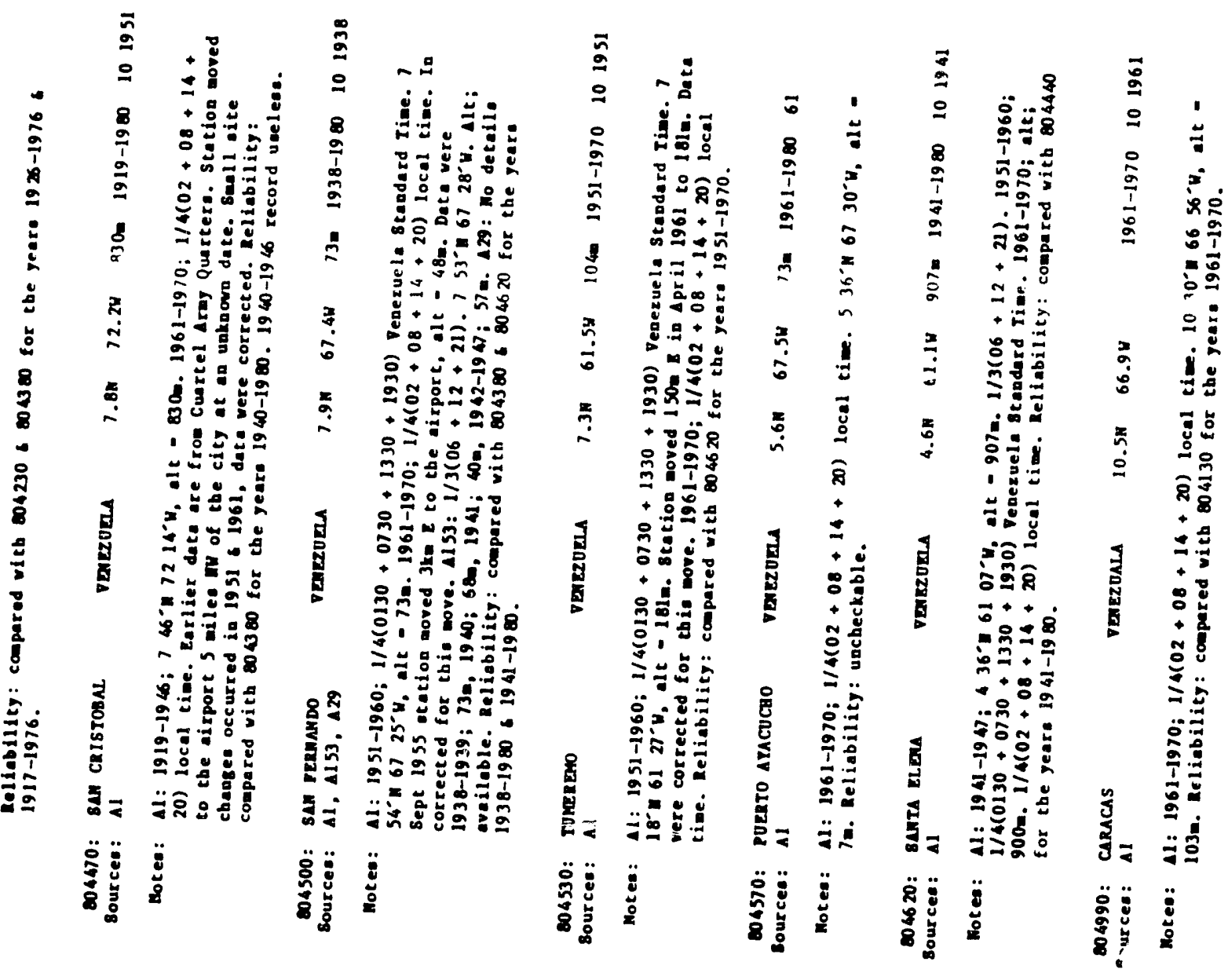

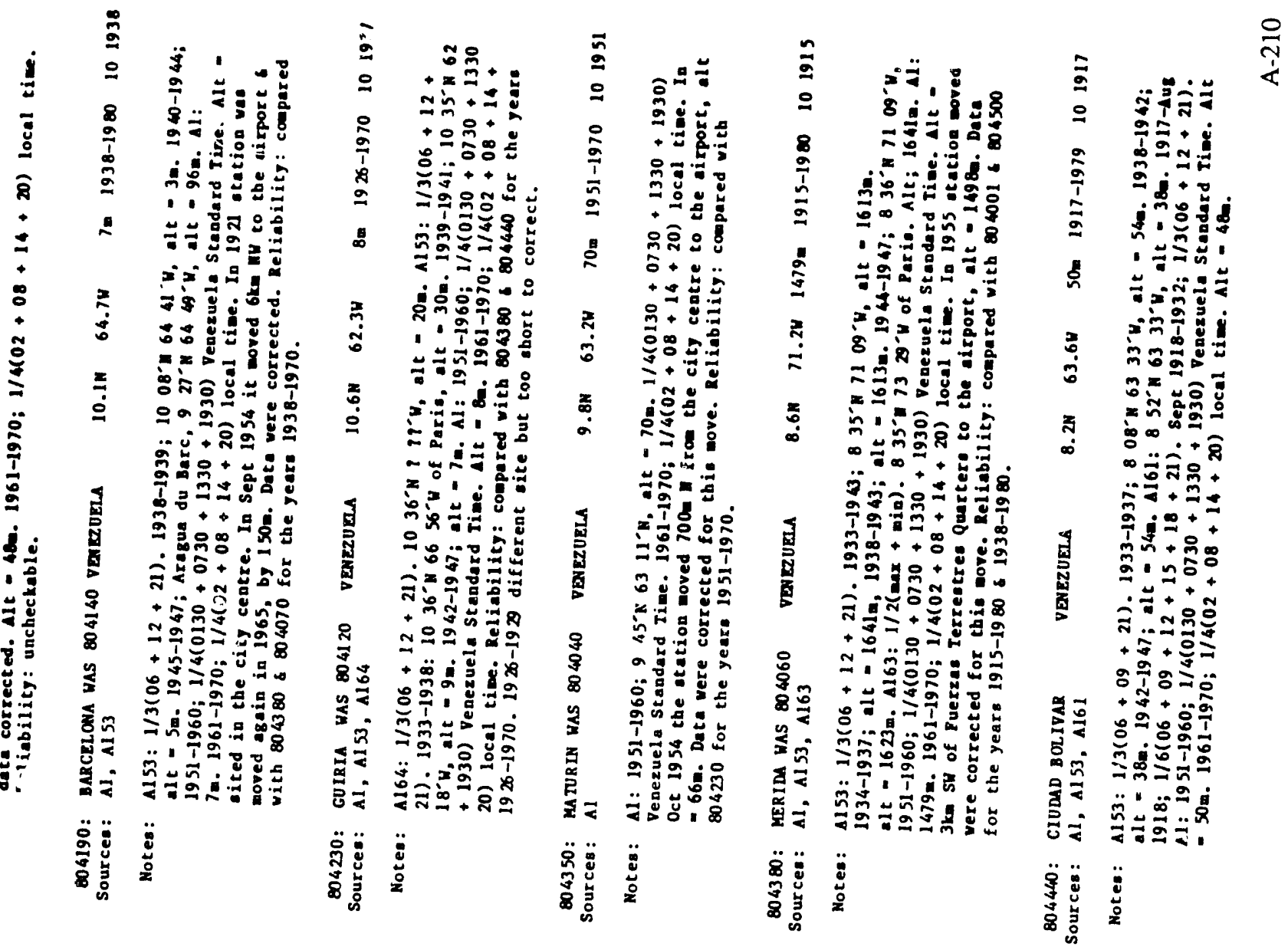




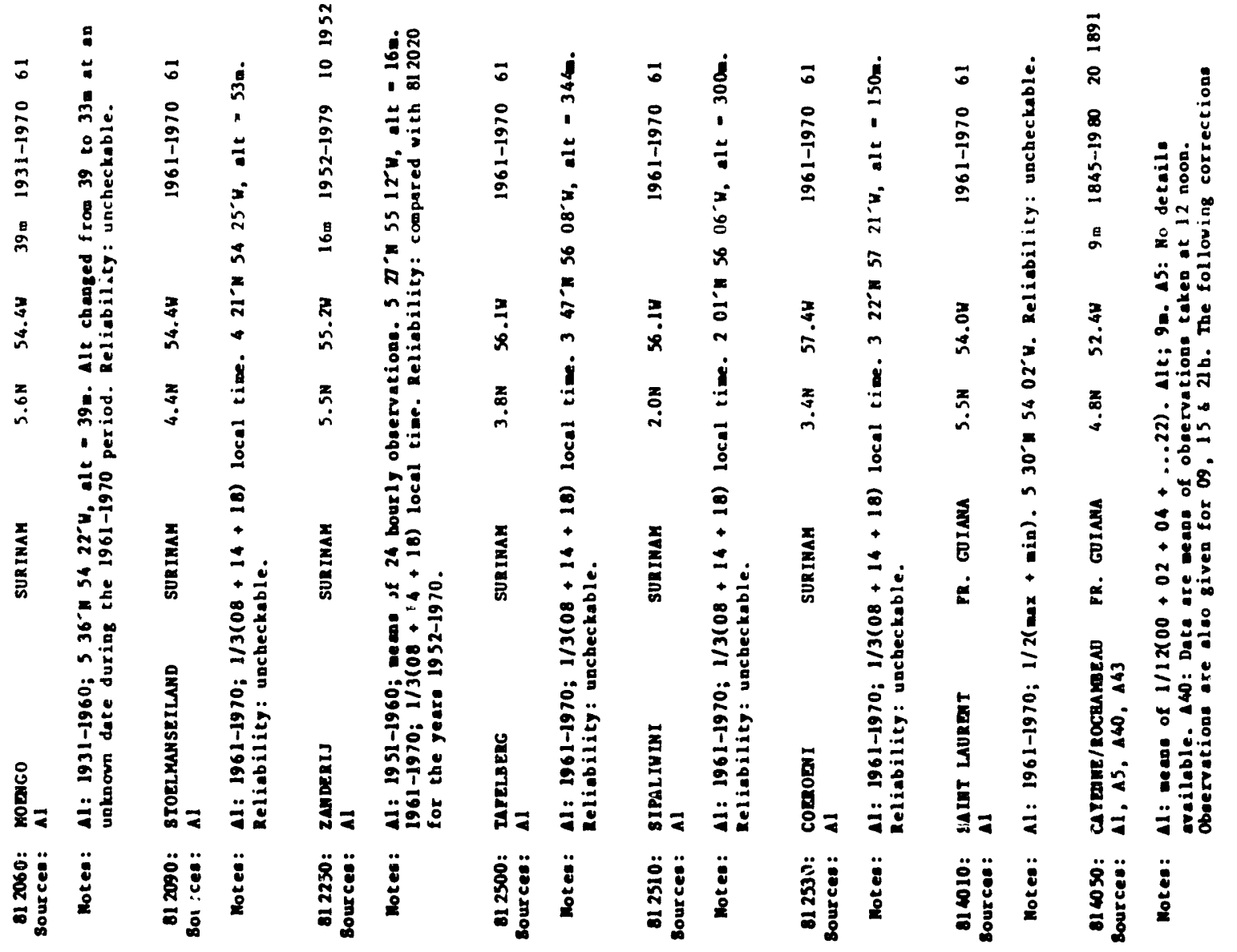

若

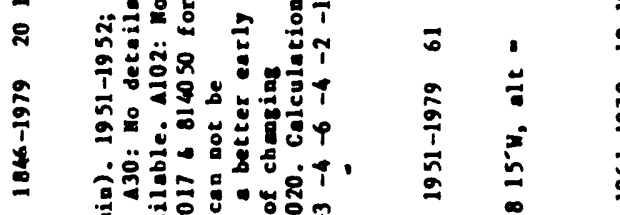

$\rightarrow$

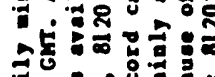

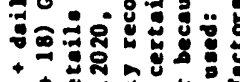

$7+\div$

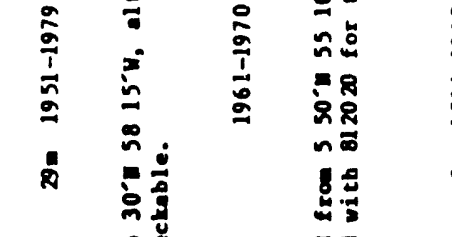

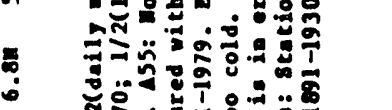

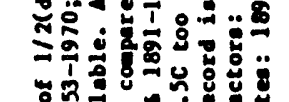

-

ใ

म่

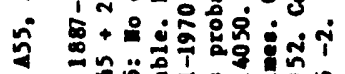

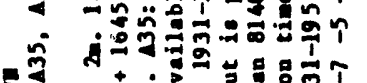

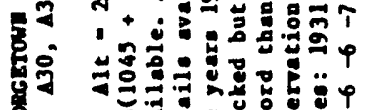

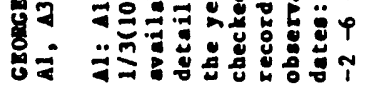

ㄱำ

Z

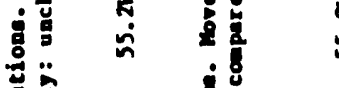

कू

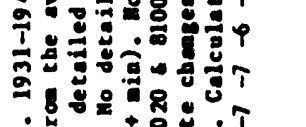

范

要

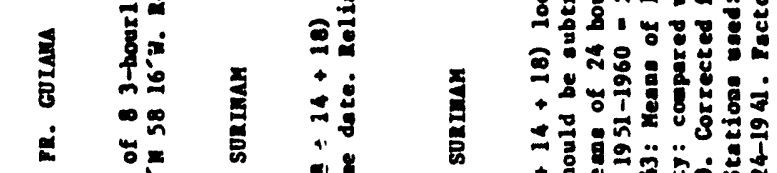

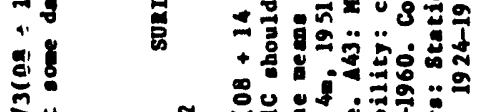

:

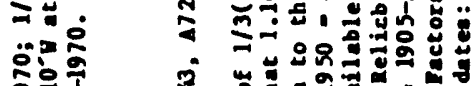

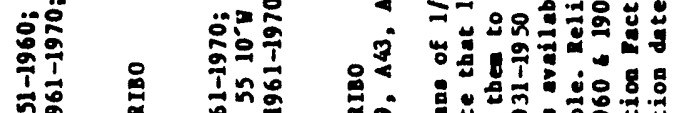

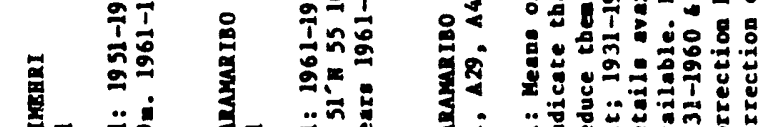

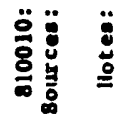

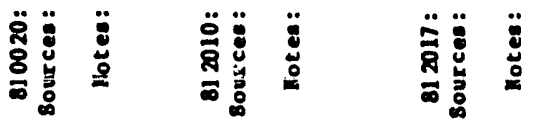

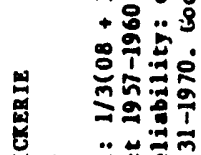

i.

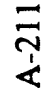




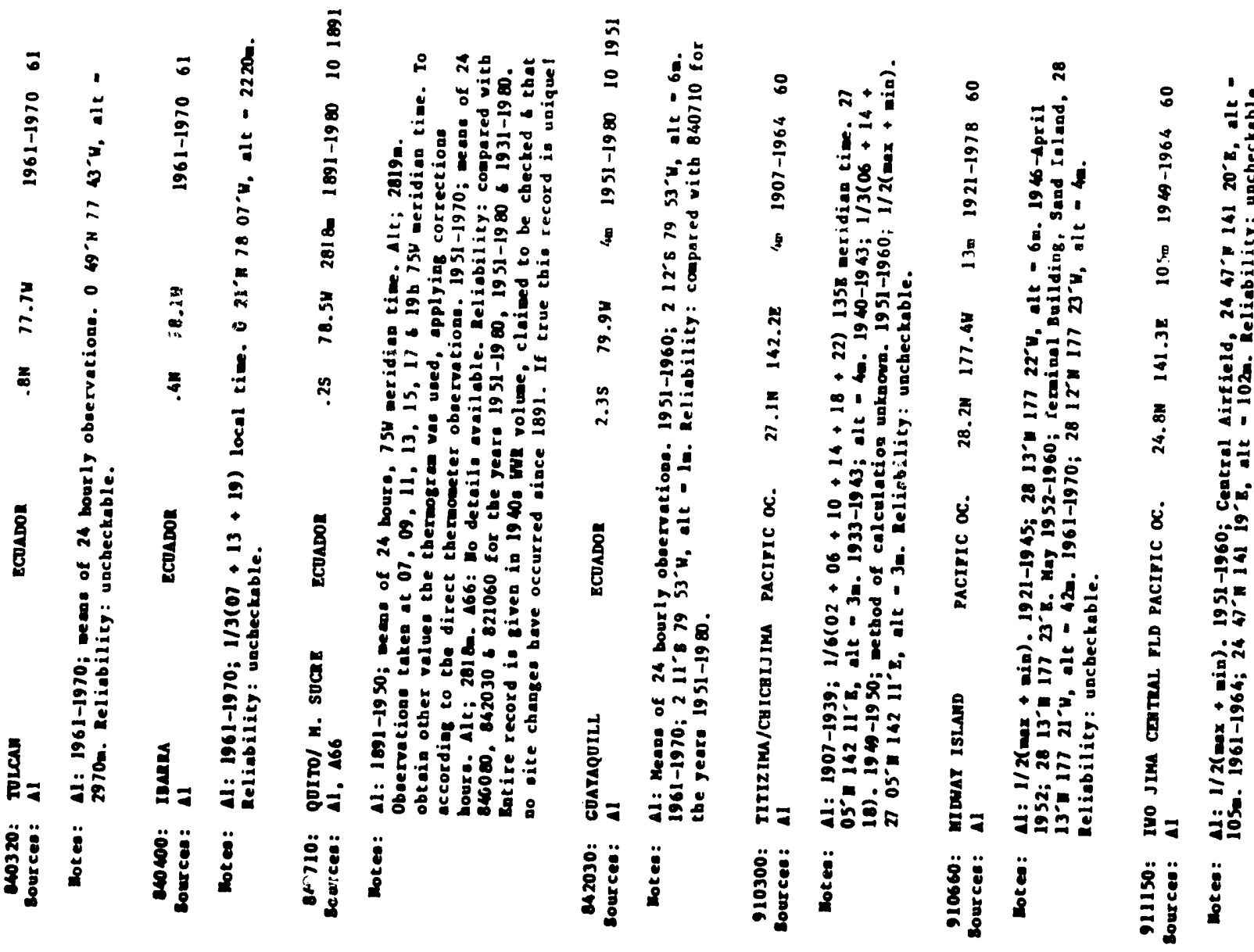

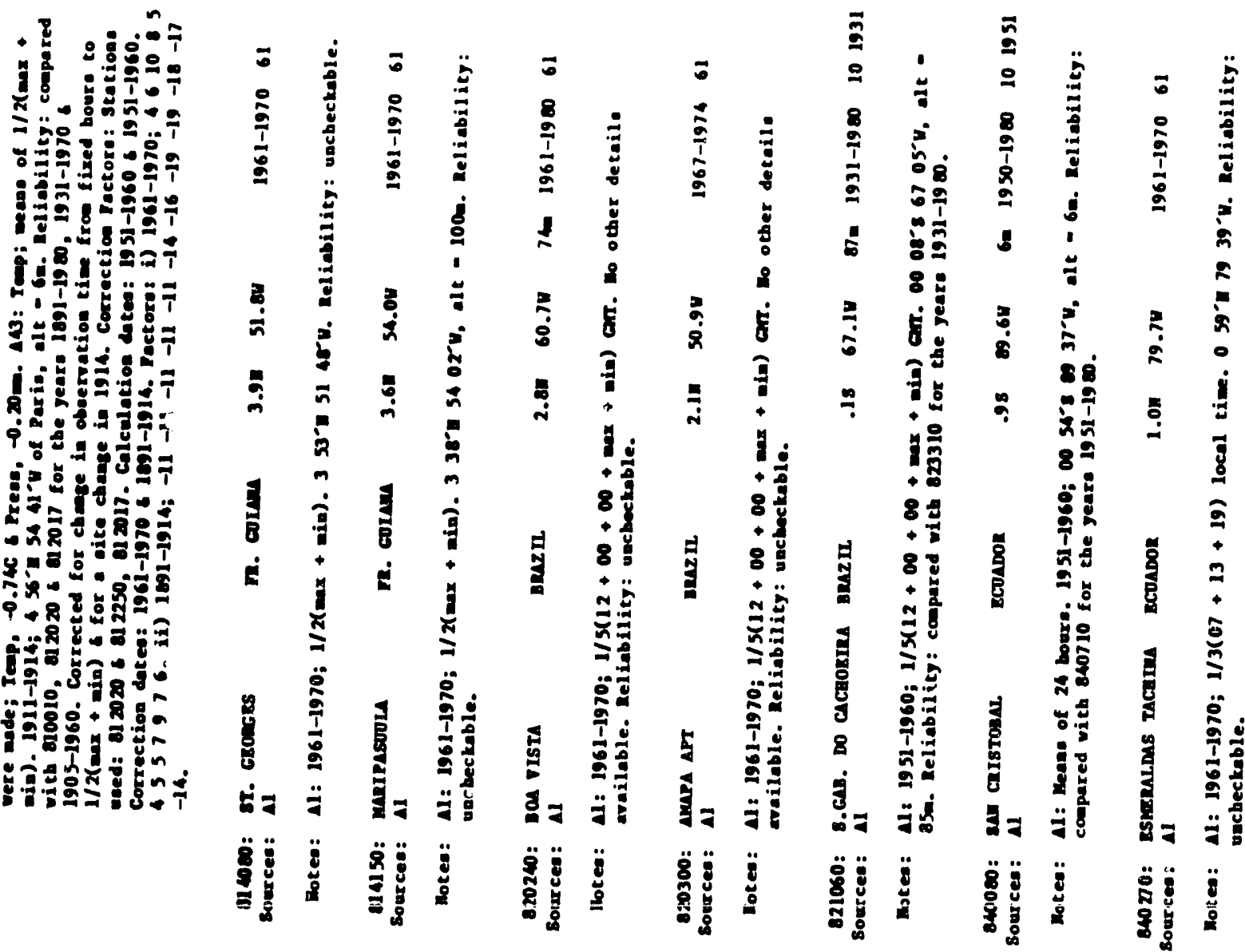


ผิ

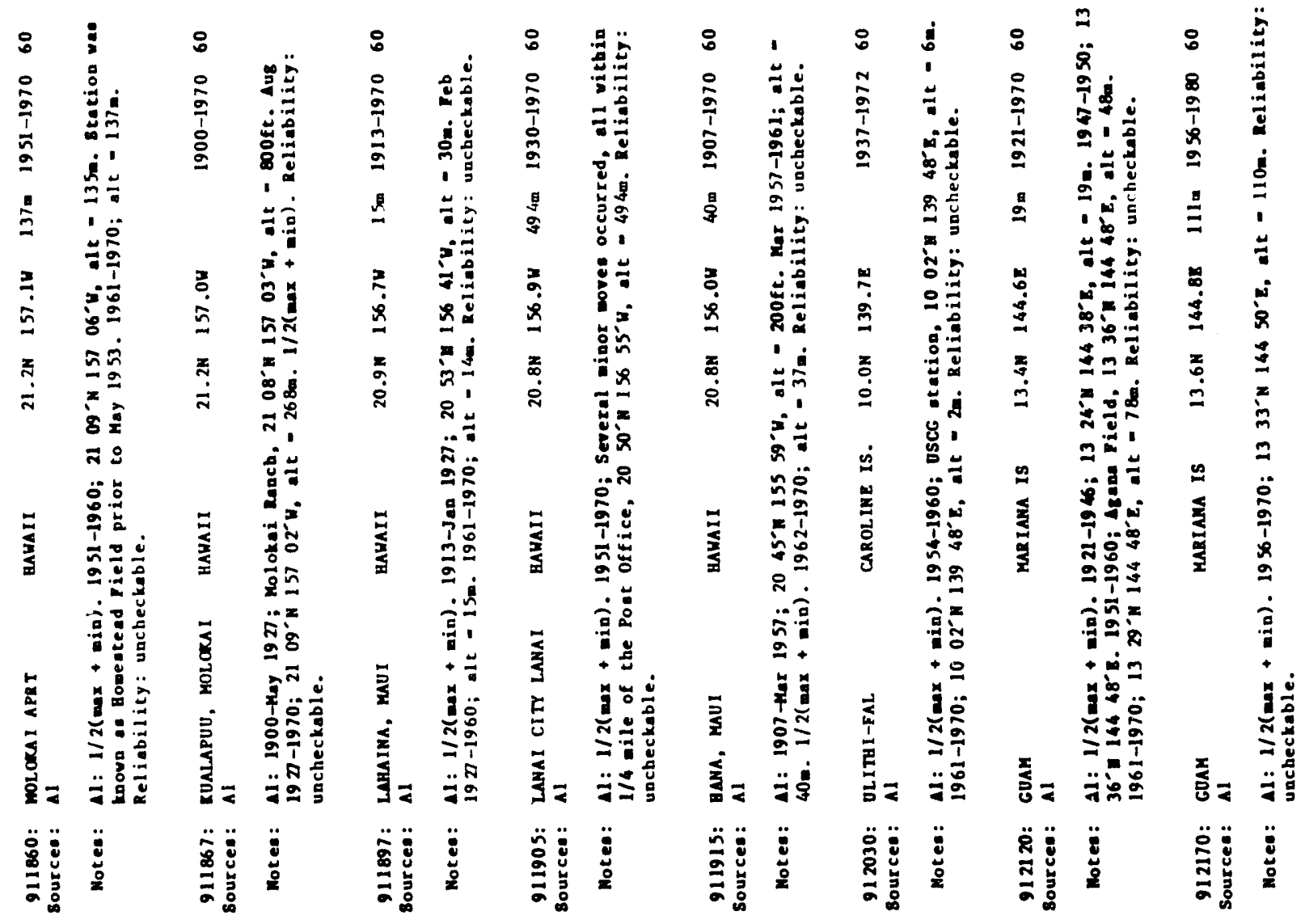

$\frac{n}{2}$

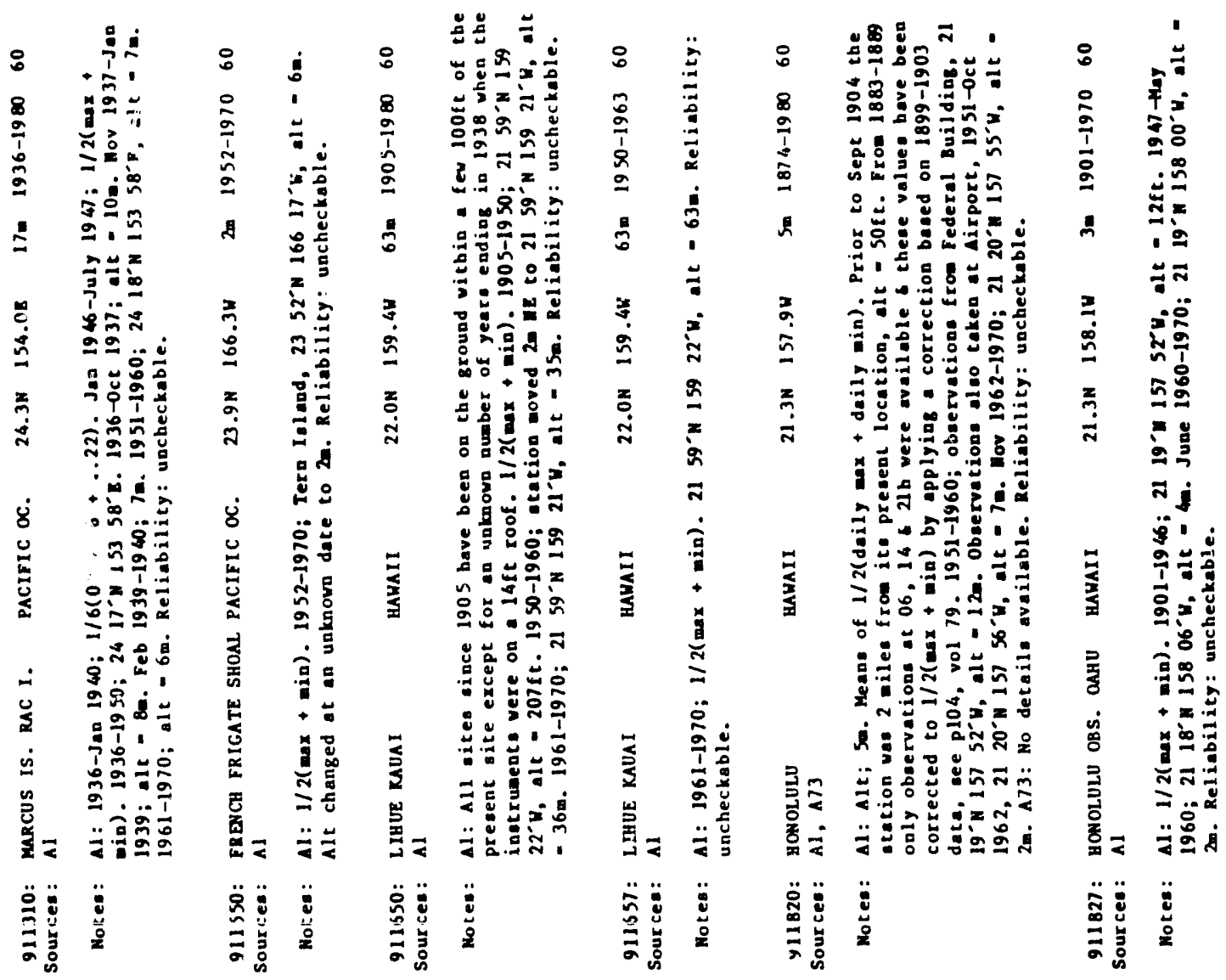



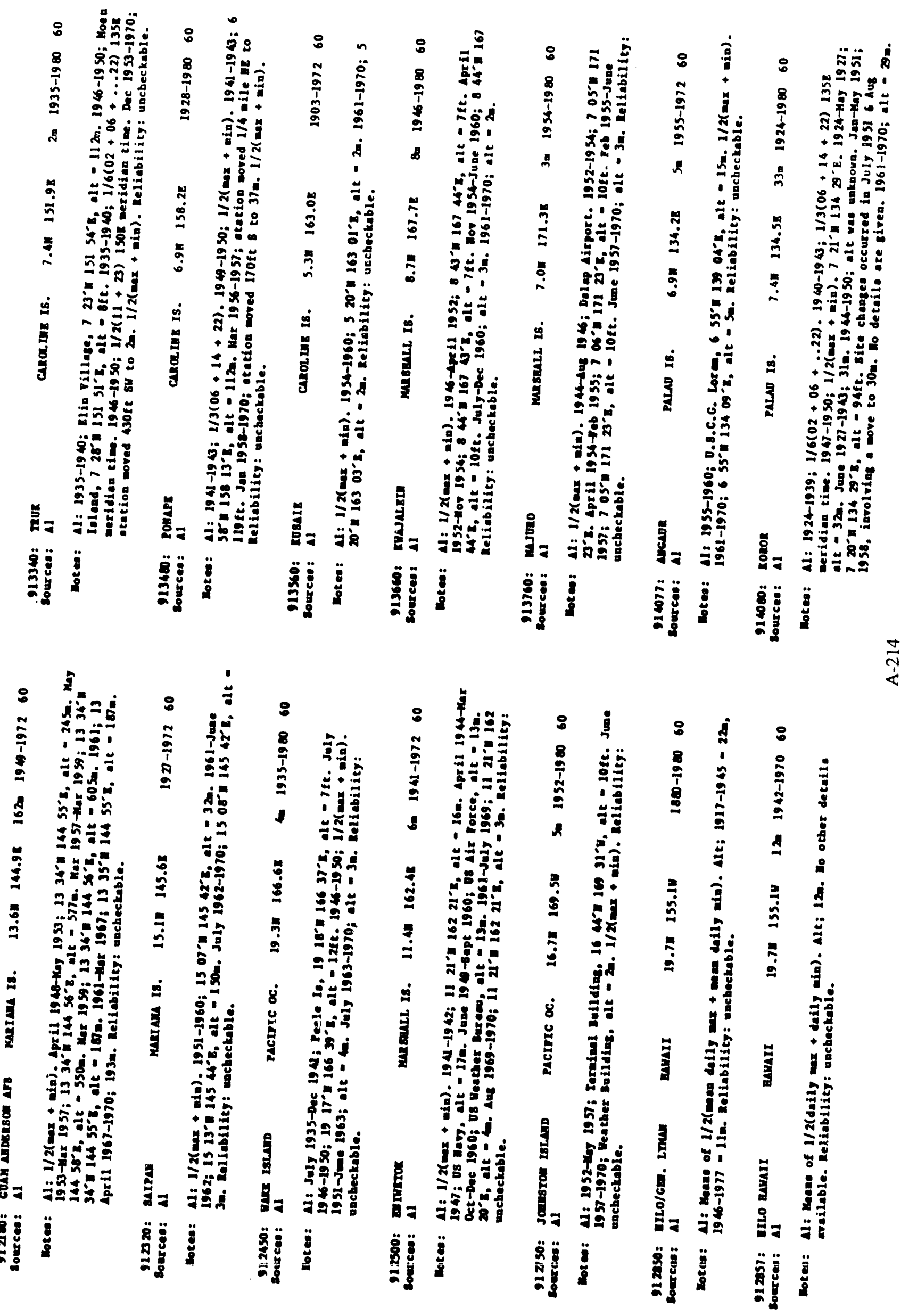


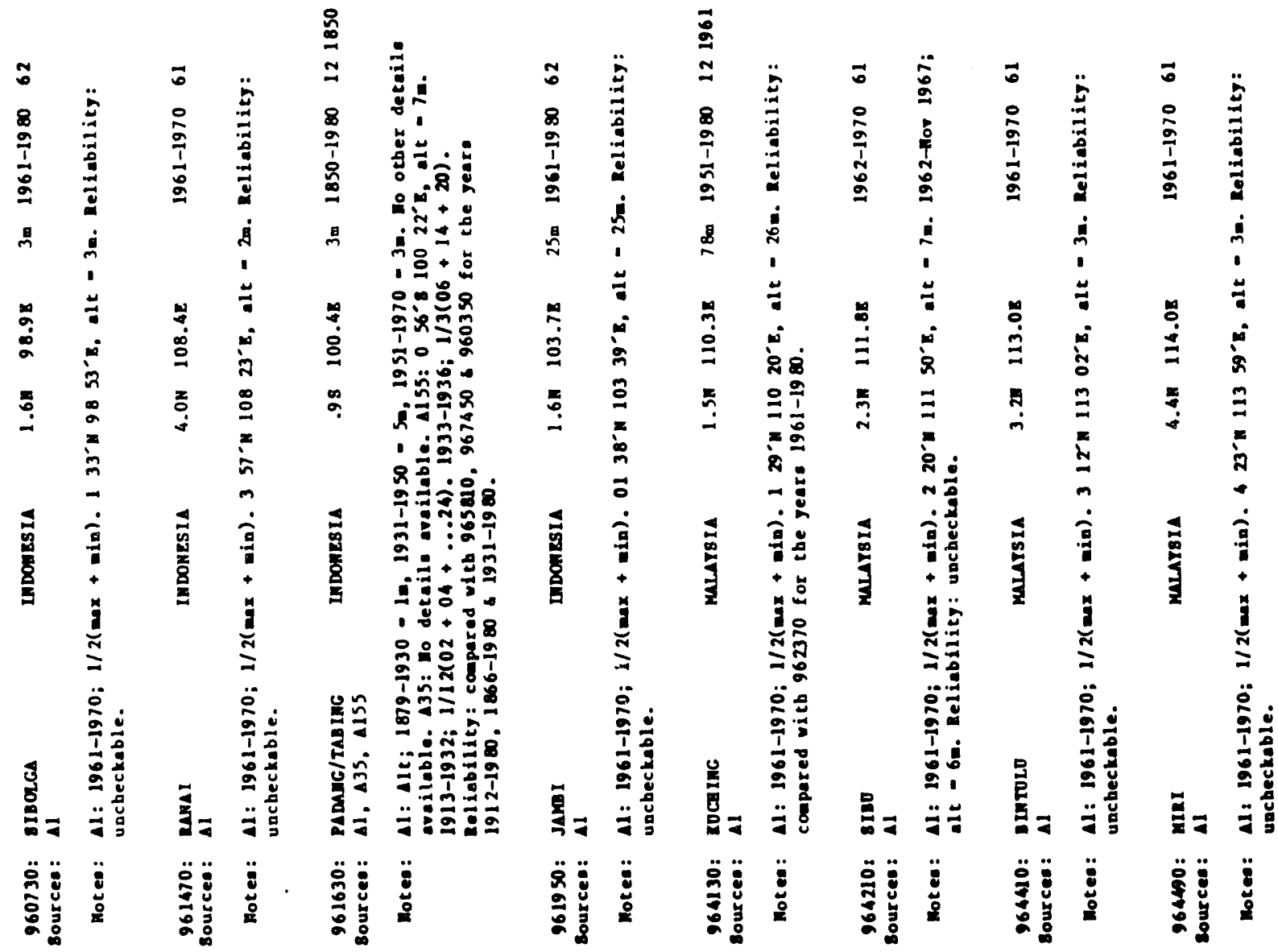

$\frac{n}{2}$

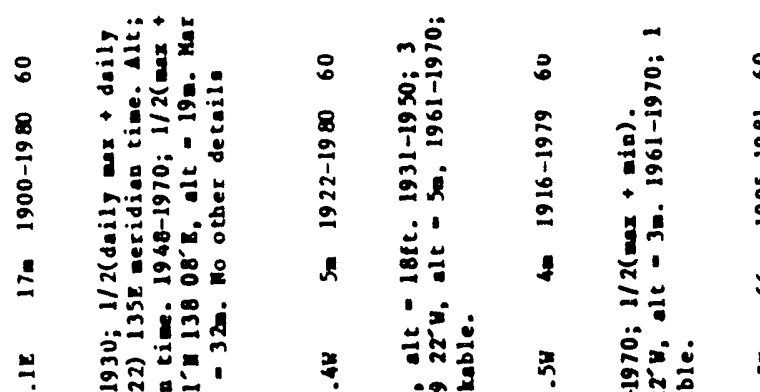

品

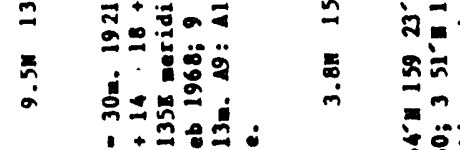

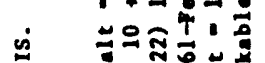

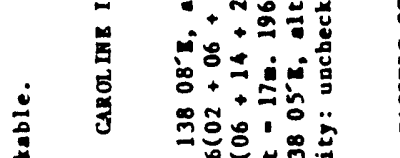

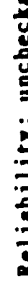

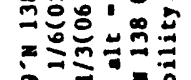

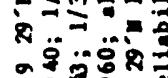

8

ลีّ

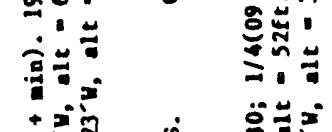

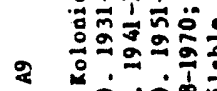

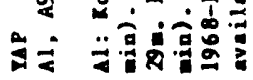

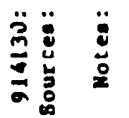

象管
:

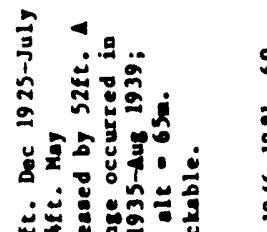

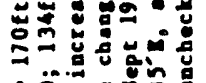

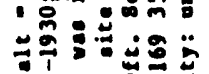

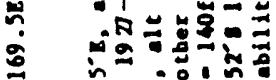

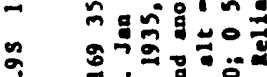

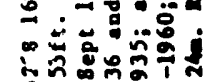

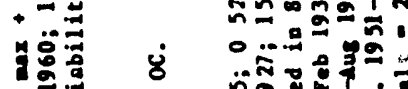

न

+

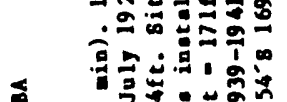

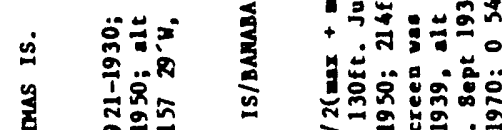

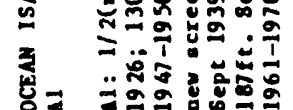

$\begin{array}{lll} & \vdots & \vdots \\ 0 & \vdots & \vdots \\ 0 & \vdots & 9 \\ \vdots & \vdots & \vdots\end{array}$

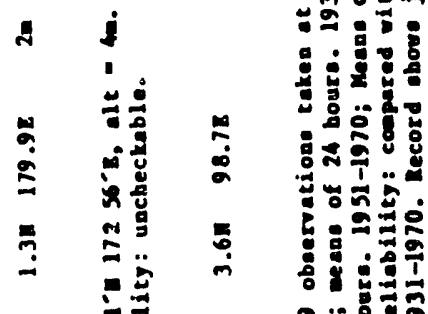

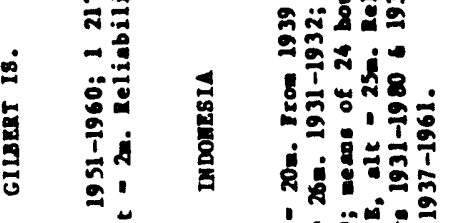

$\begin{array}{ll} & \\ & \end{array}$

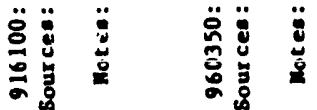


\&ิ

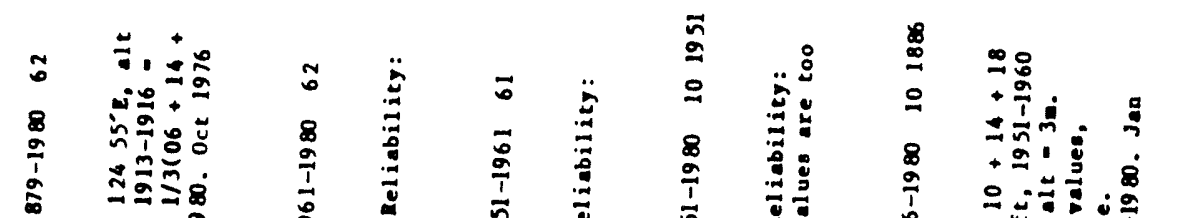

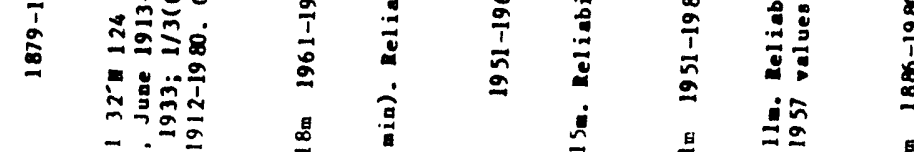

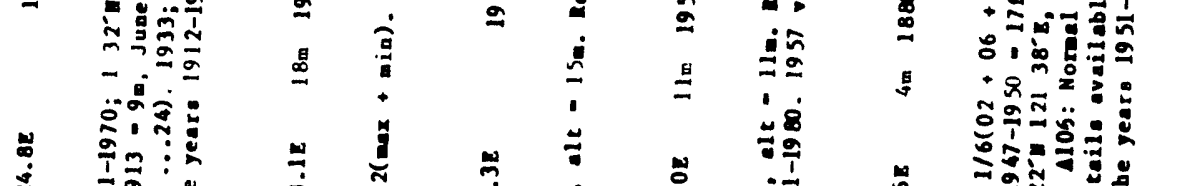

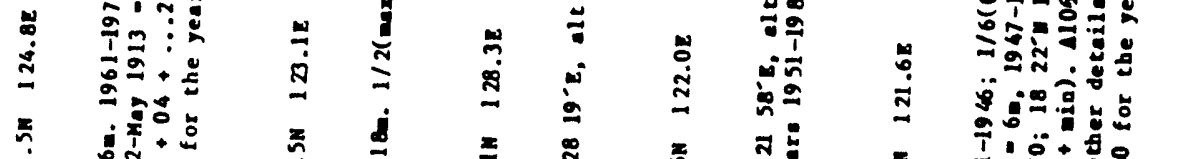

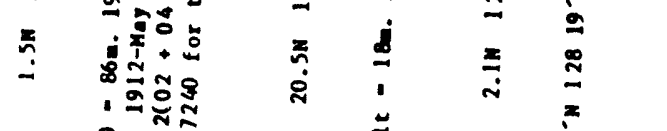

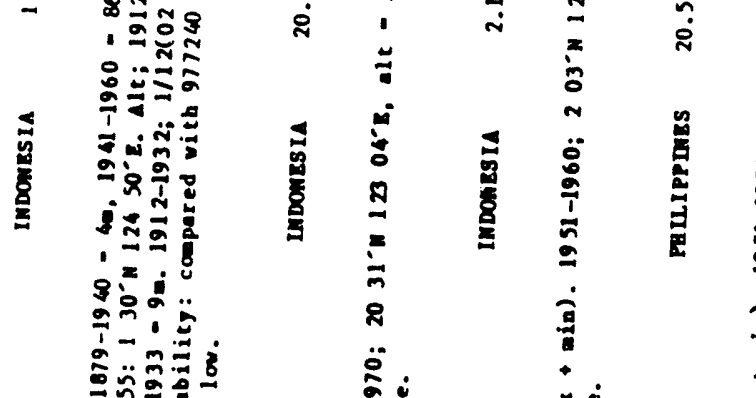

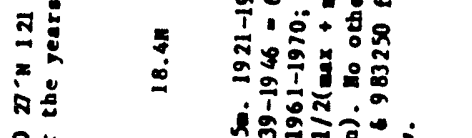

ฉ

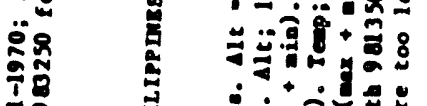

ลิำ

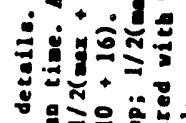

ช.

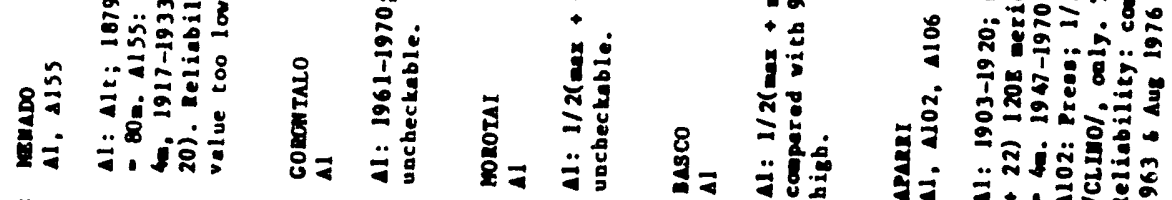
: औौ

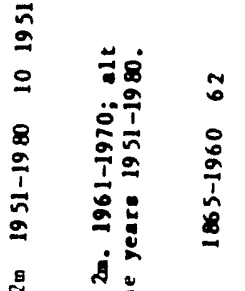

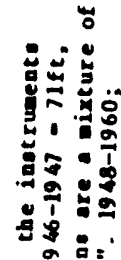

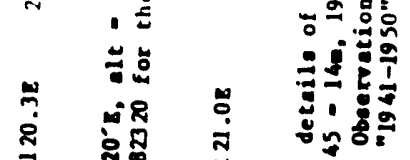

₹ हิ

$\therefore$ 욤

o

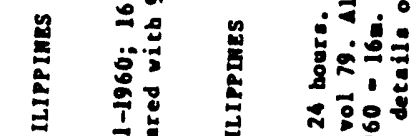

है

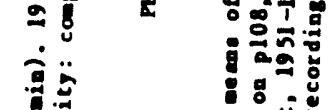

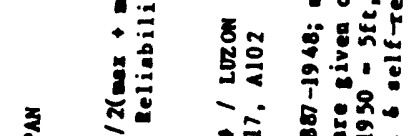

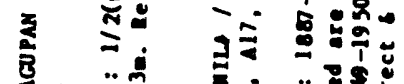

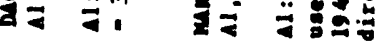

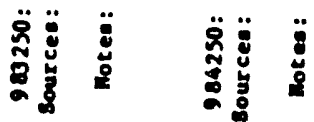

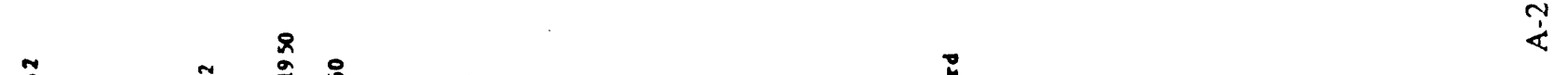

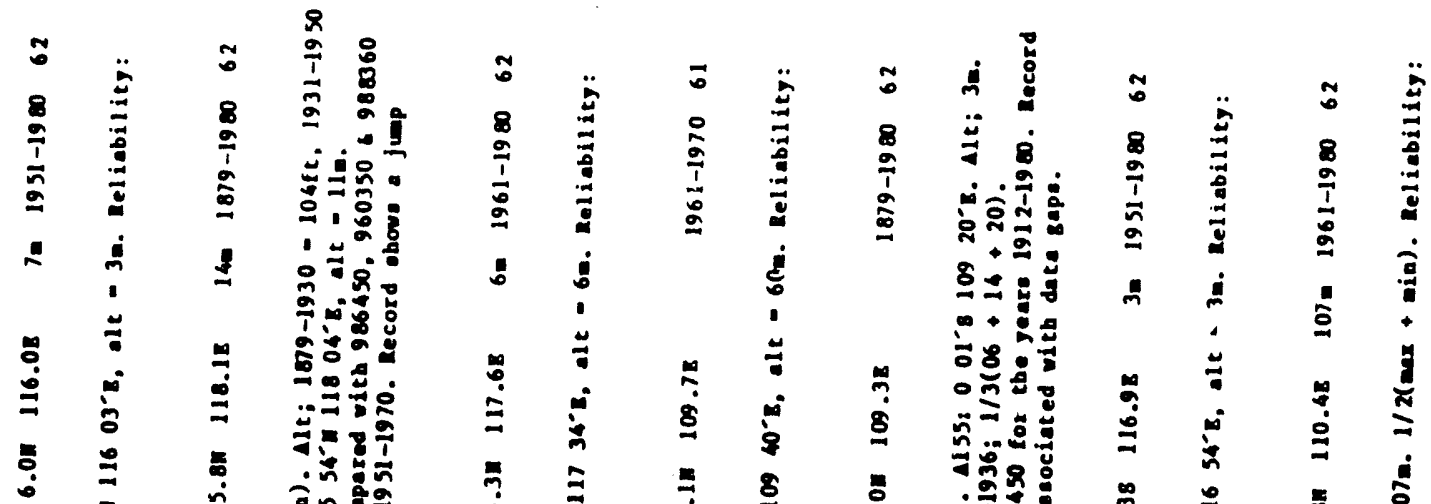

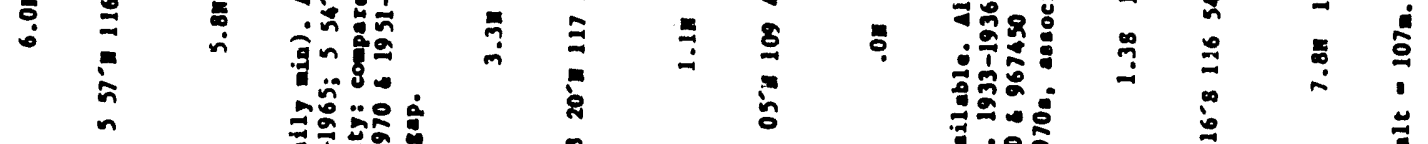

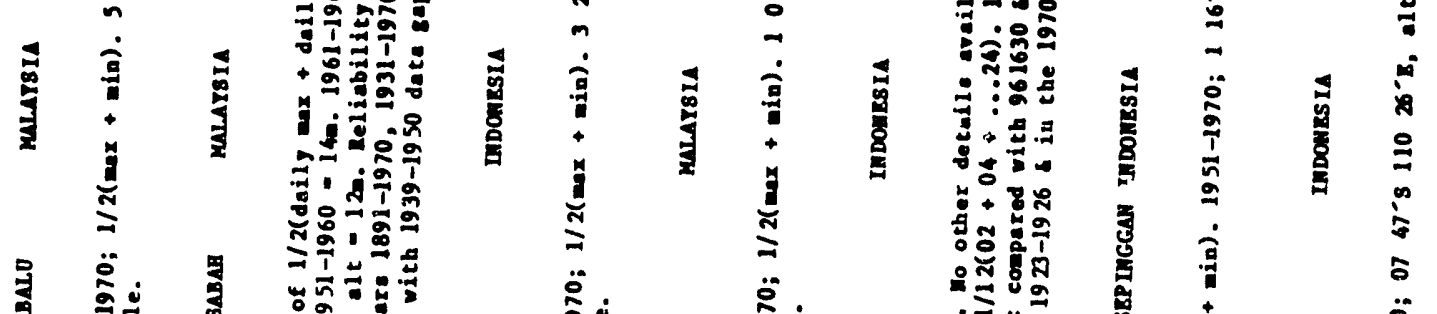

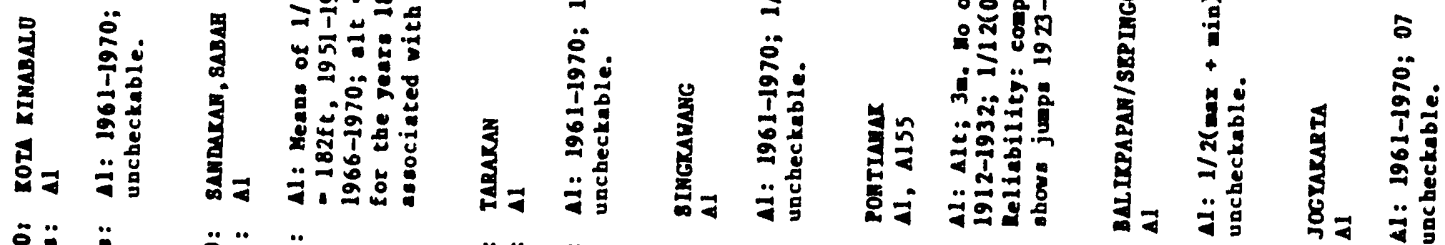

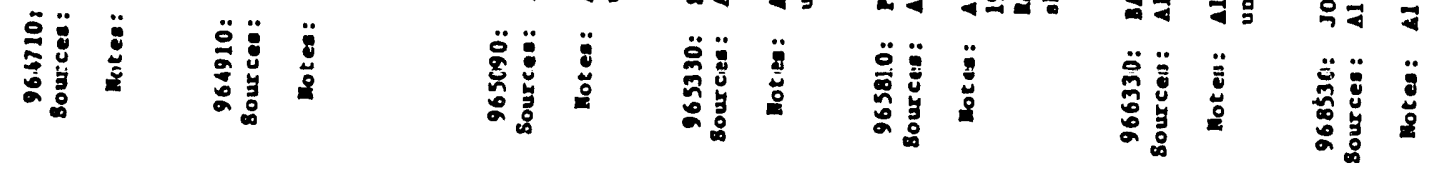



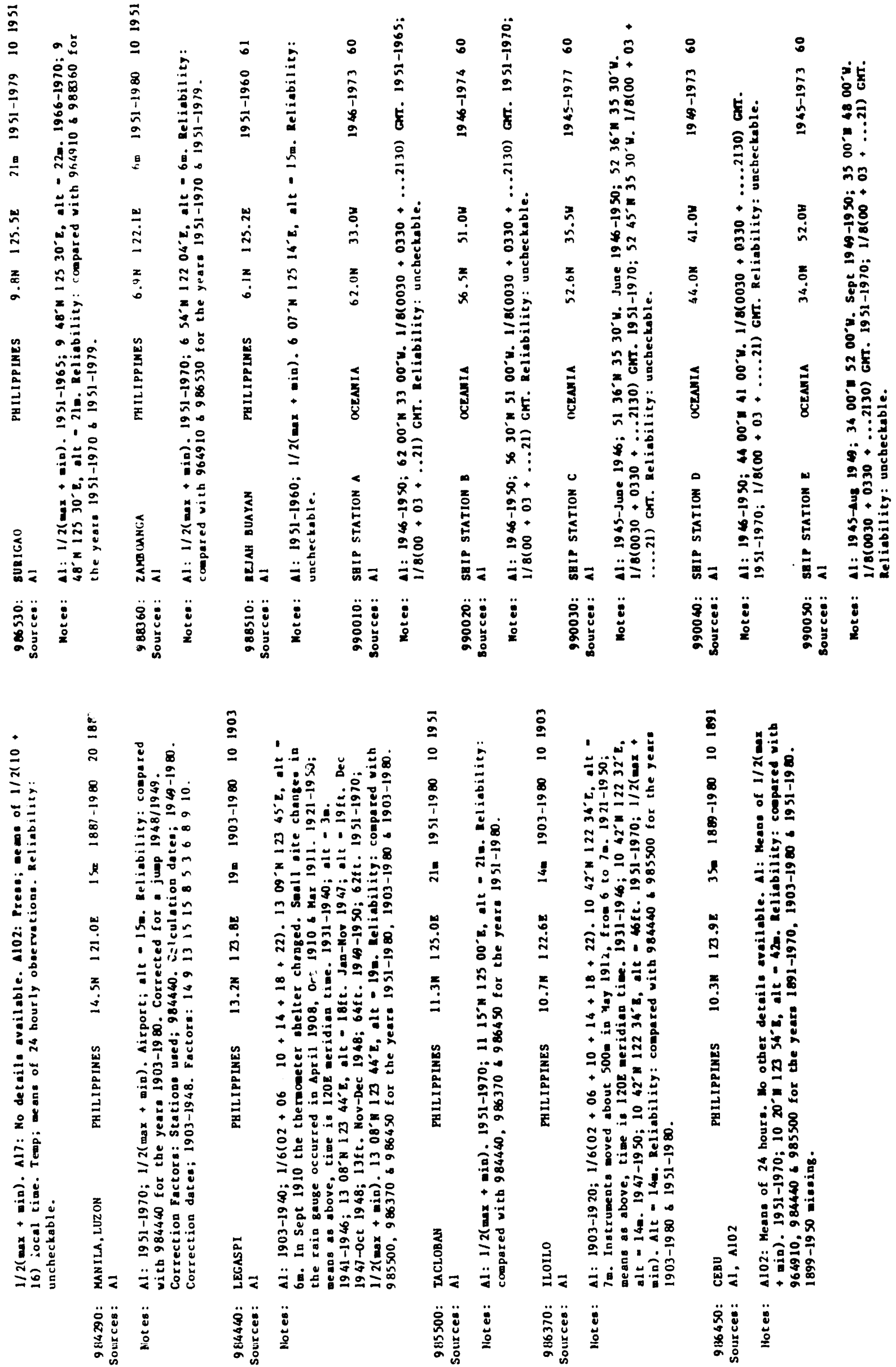


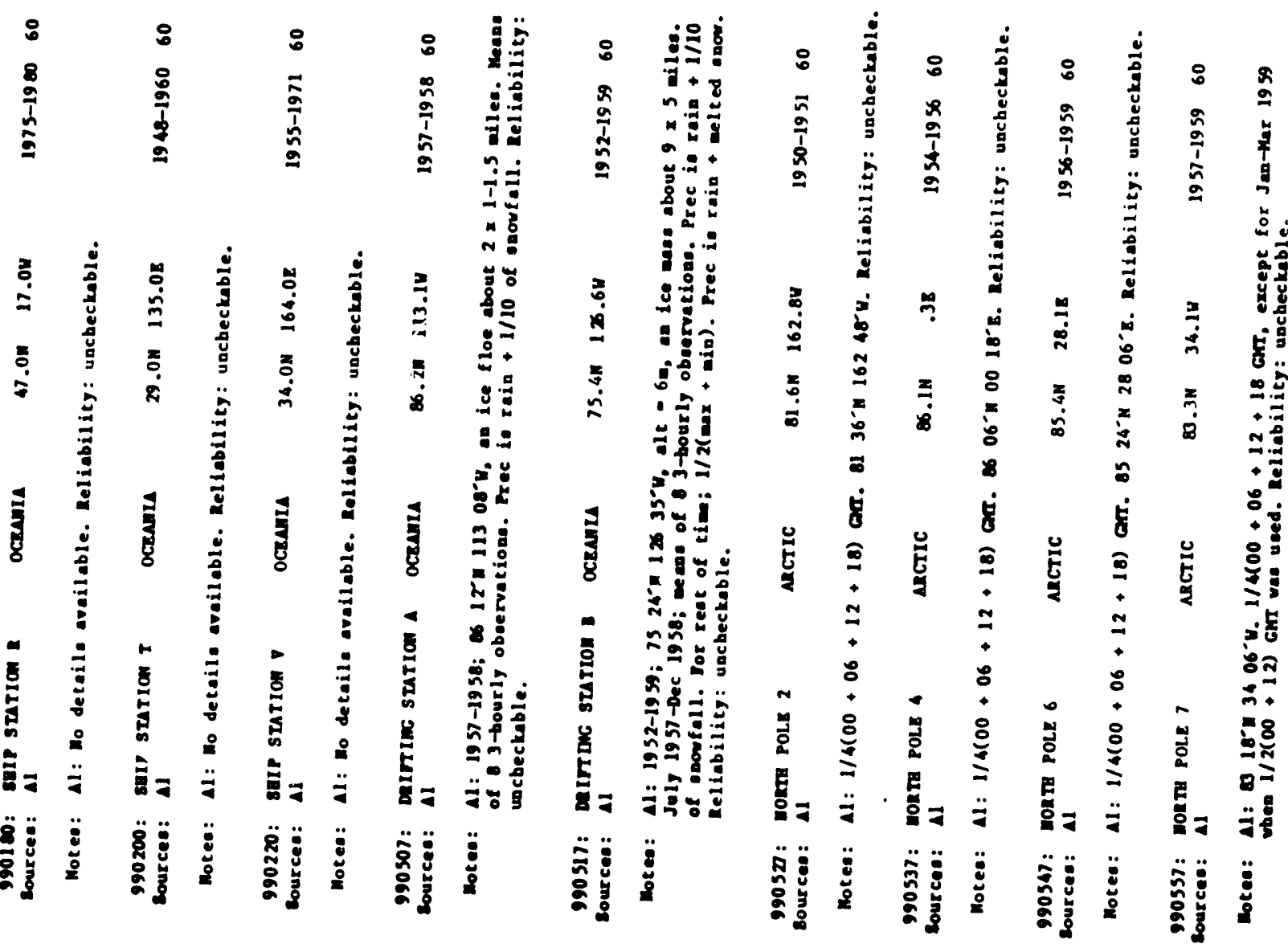

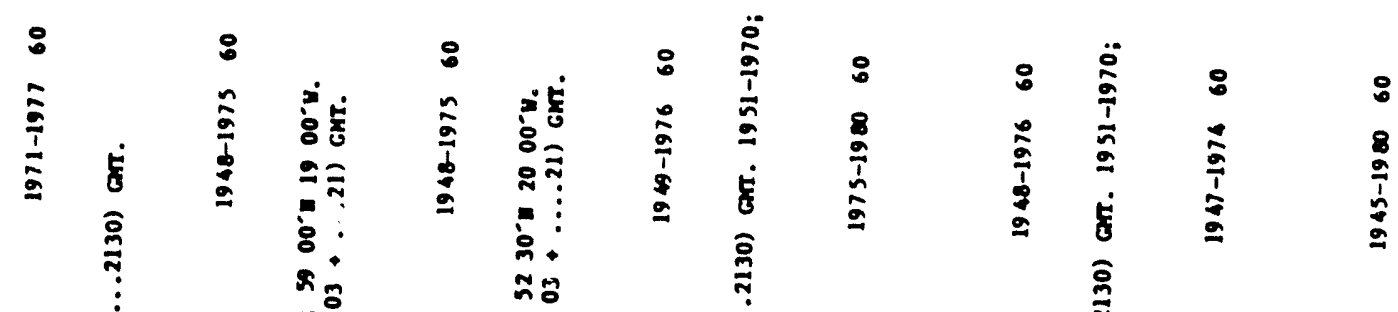

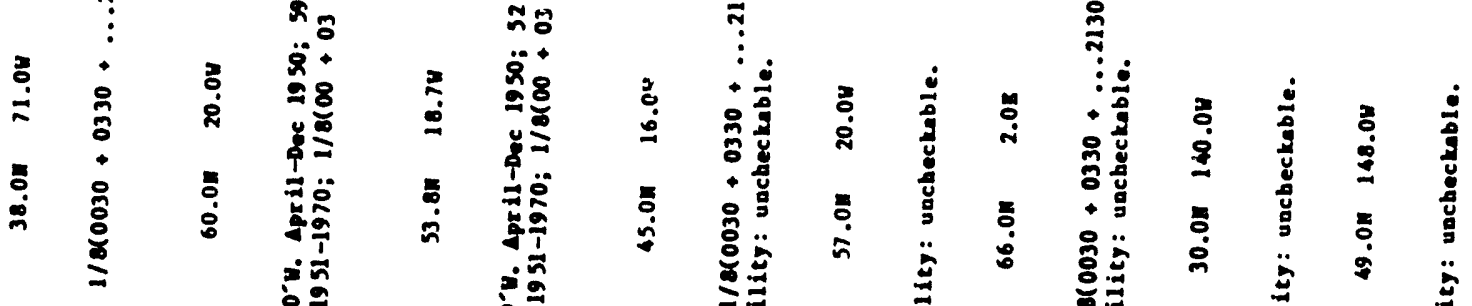

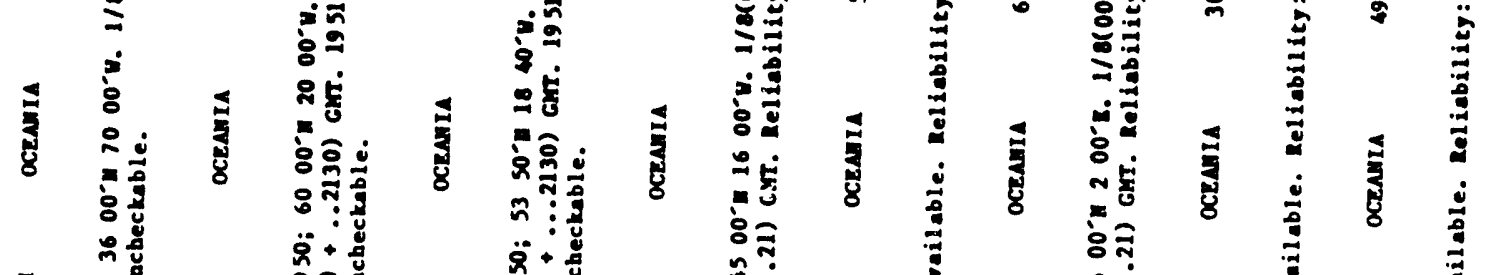

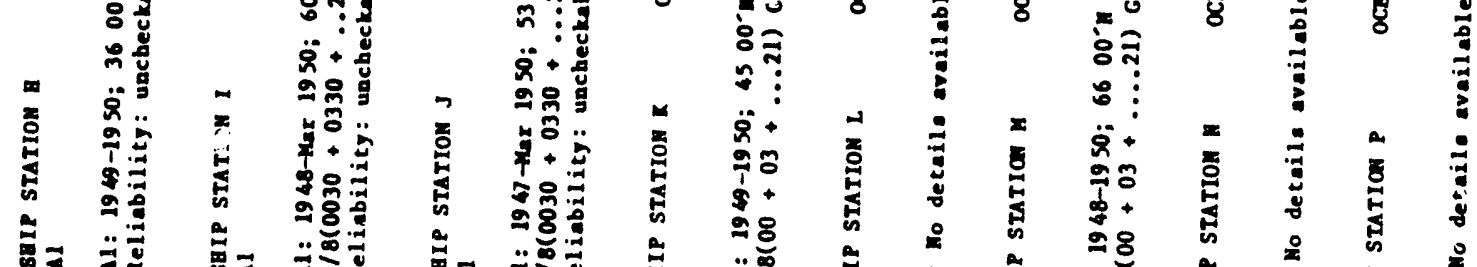
\%̈ ق

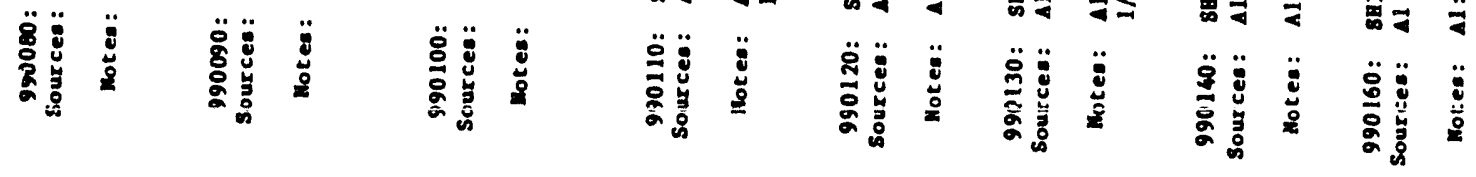




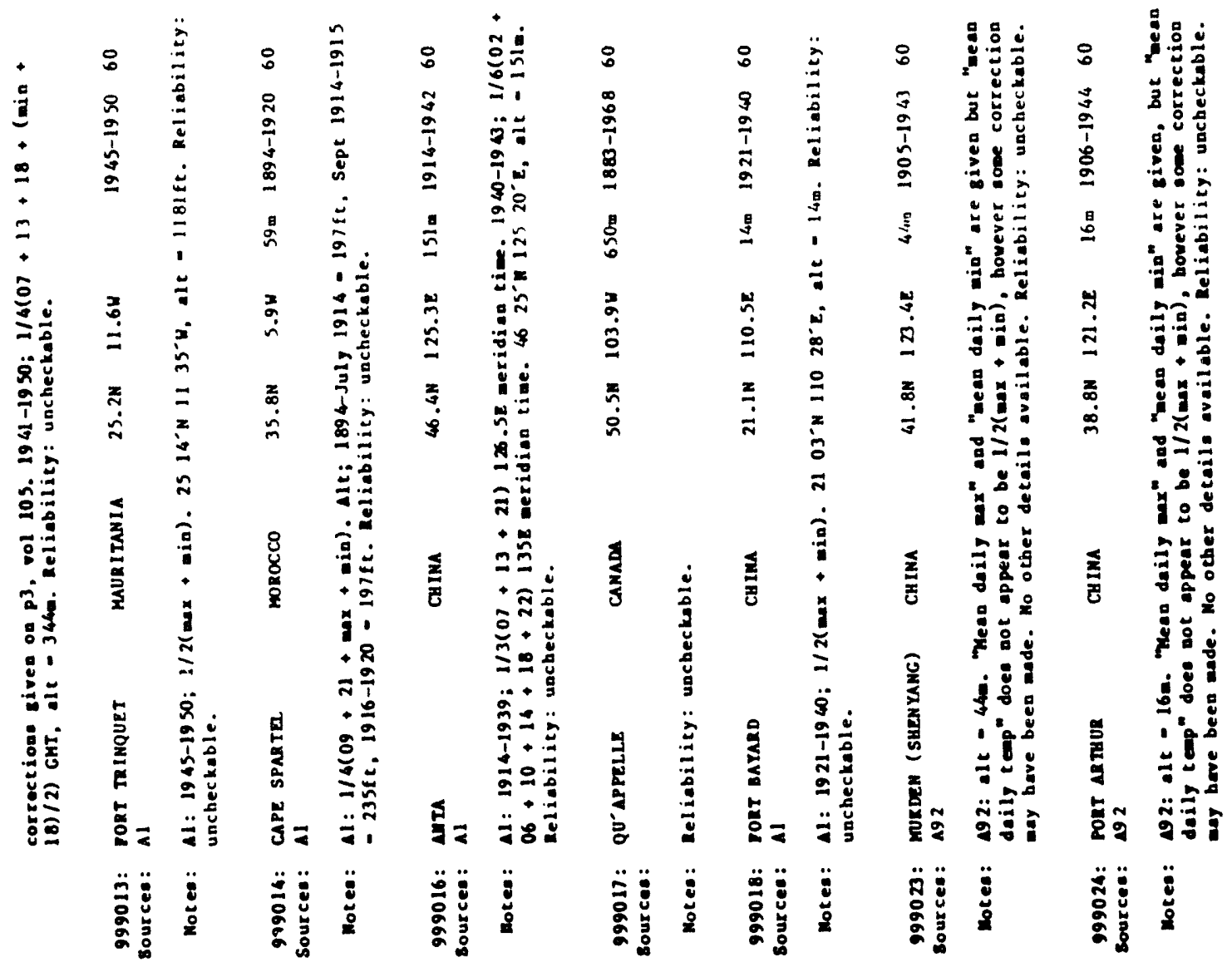

$\frac{2}{\grave{\alpha}}$

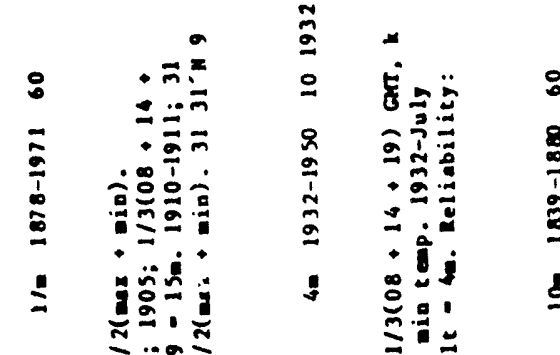

ว.

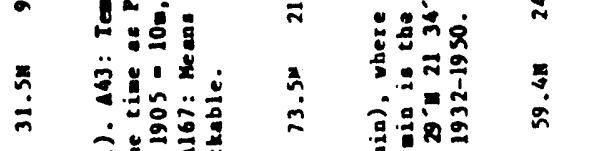

जิ

(1)

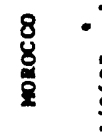

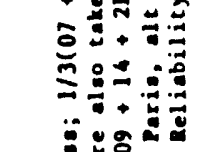

อ

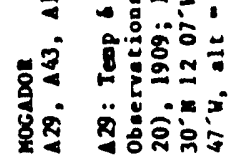

若
:

워르.

옹ํำ

承家:

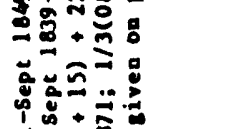

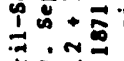

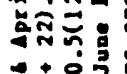

㐭

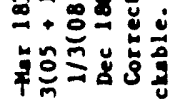

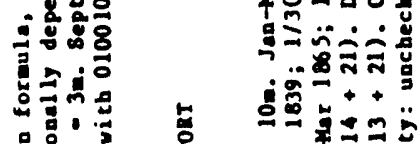

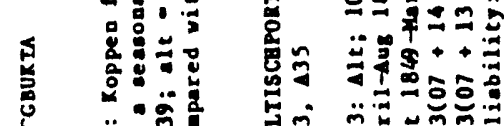

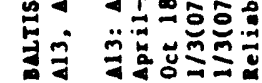

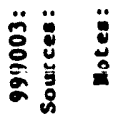

(1)

:

:

$2 \quad=\vdots$

$\div \quad \frac{8}{0}$

要

迹范

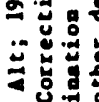

范

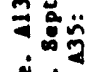

药

茫

ว

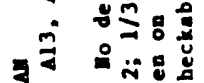

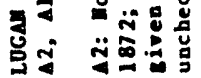

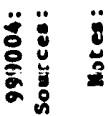

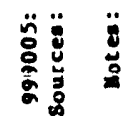

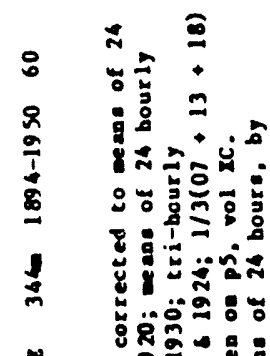

ल

วิ음

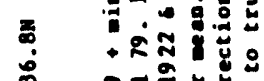

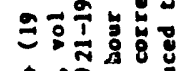

ดั

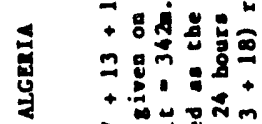

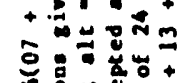

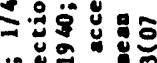

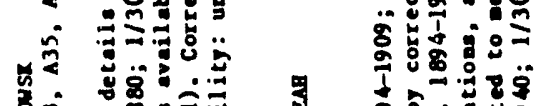

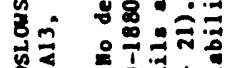

过

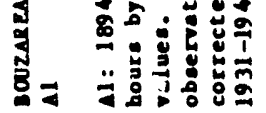

站 


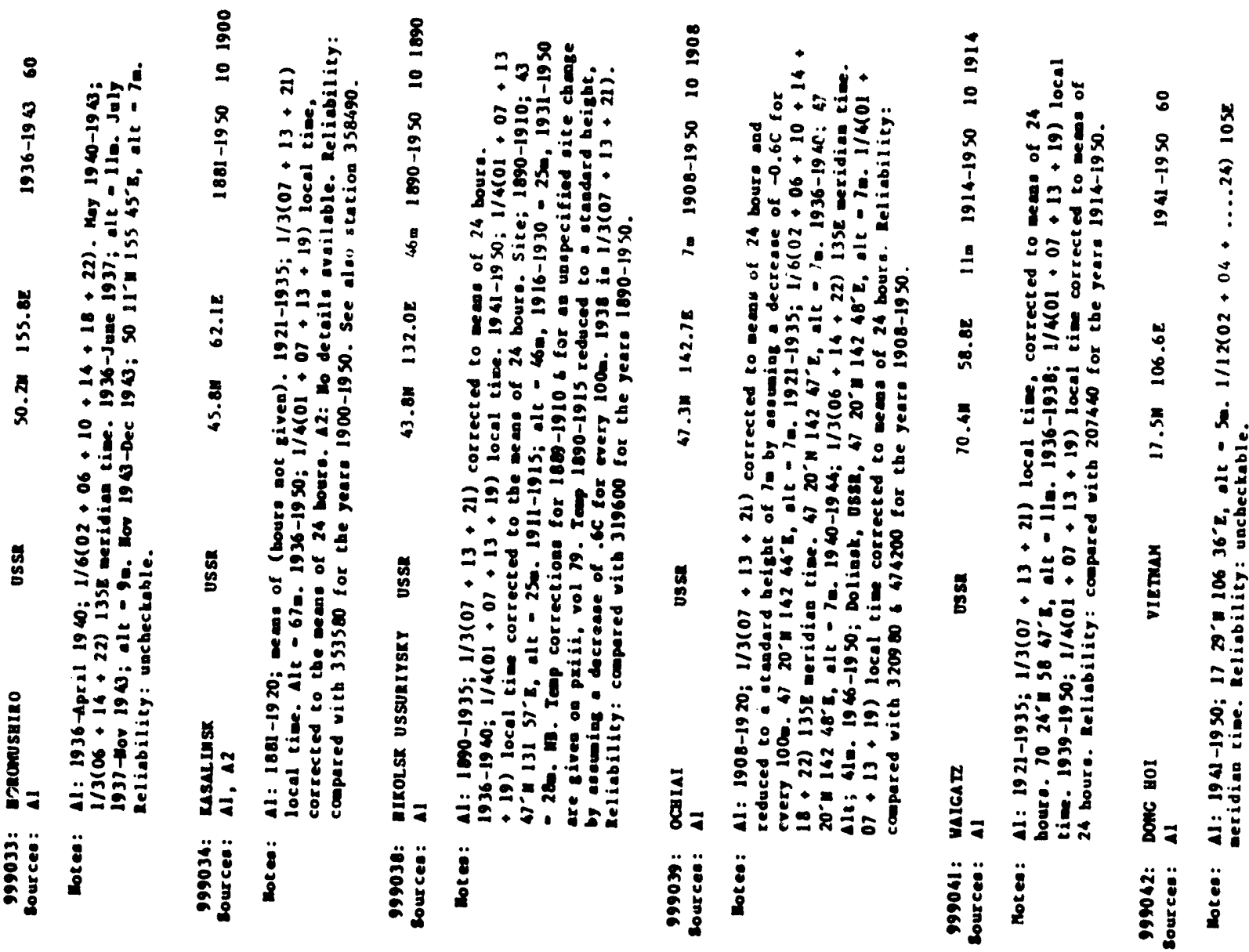

ใ

(1)

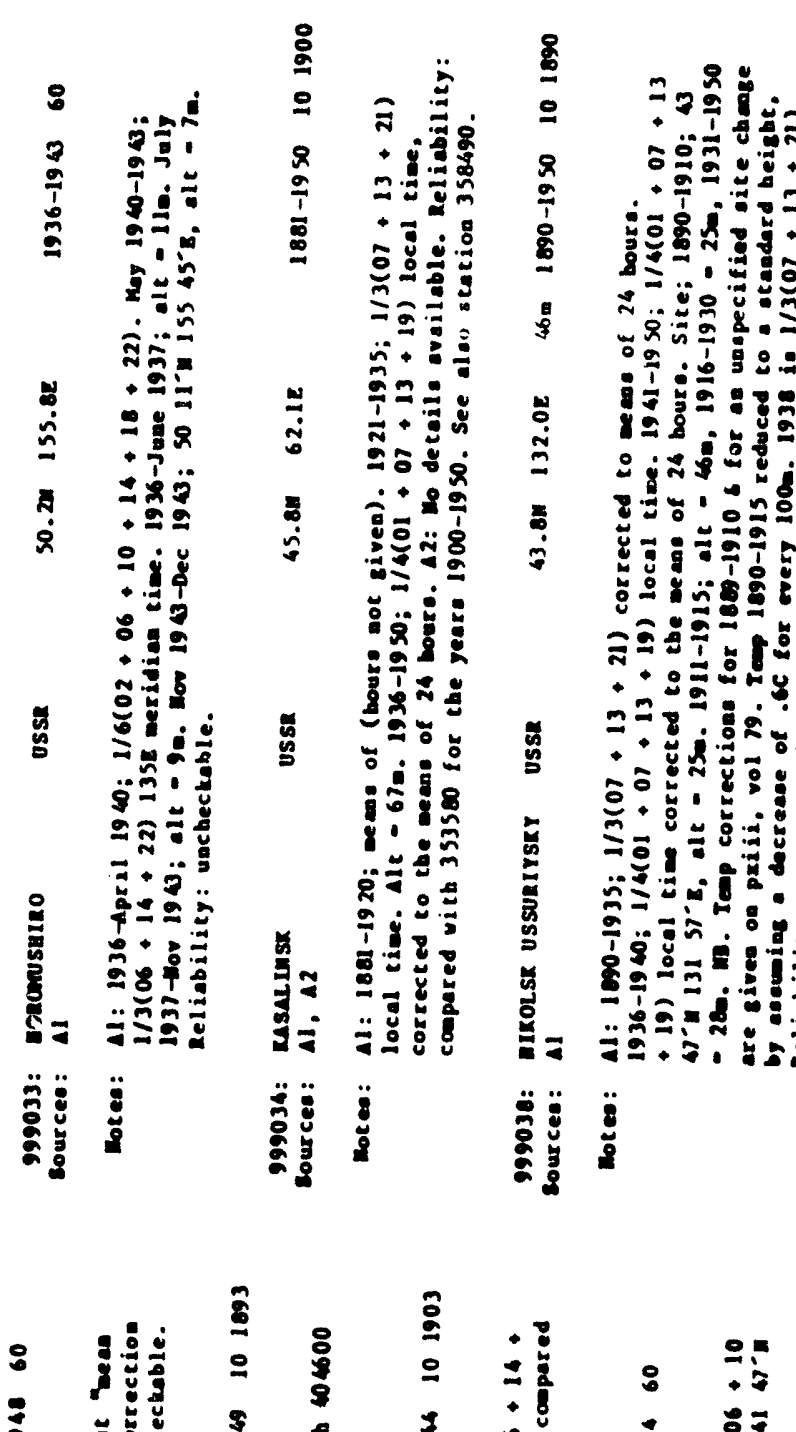

คे

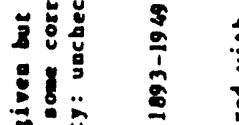

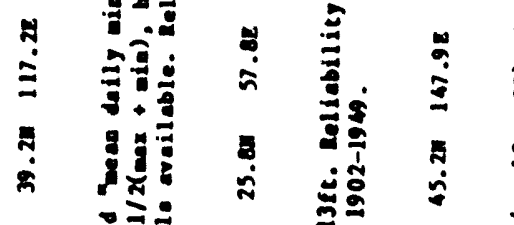

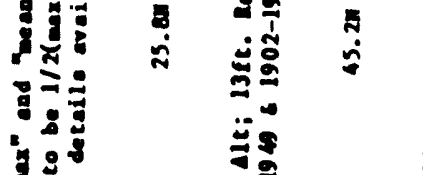

1

in

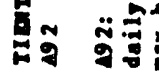

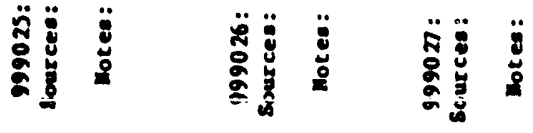

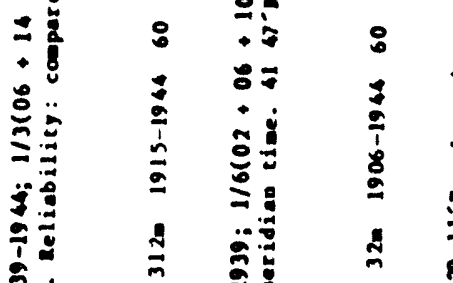

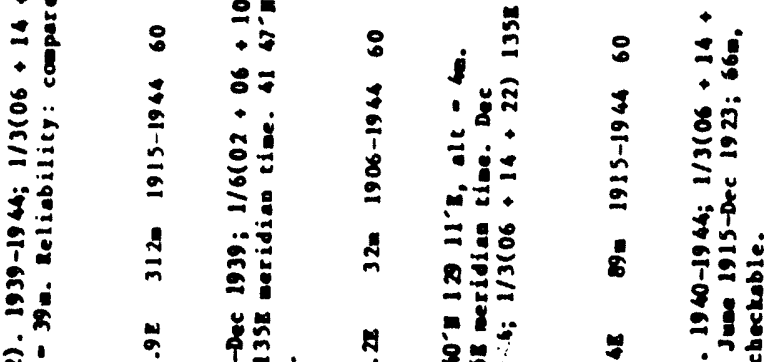

ลับ

洨高

$= \pm$

ปั

बิ8

造

$\therefore \quad 9$

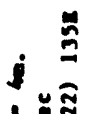

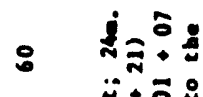

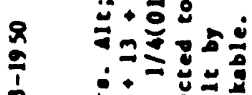

$\frac{1}{5}$

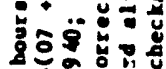

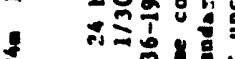

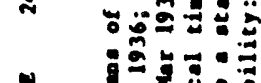

ค

र

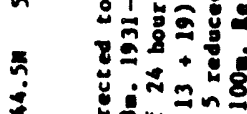

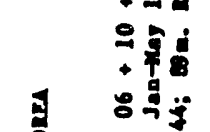

$\because=\frac{7}{5}$

ํํำ

ลิ

8 告

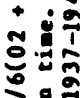

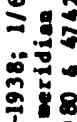

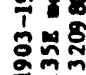

总

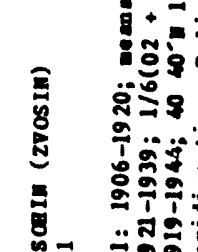

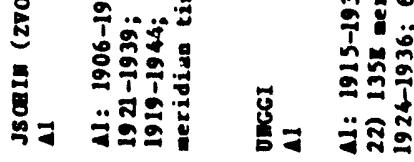

苟

䓂苛 


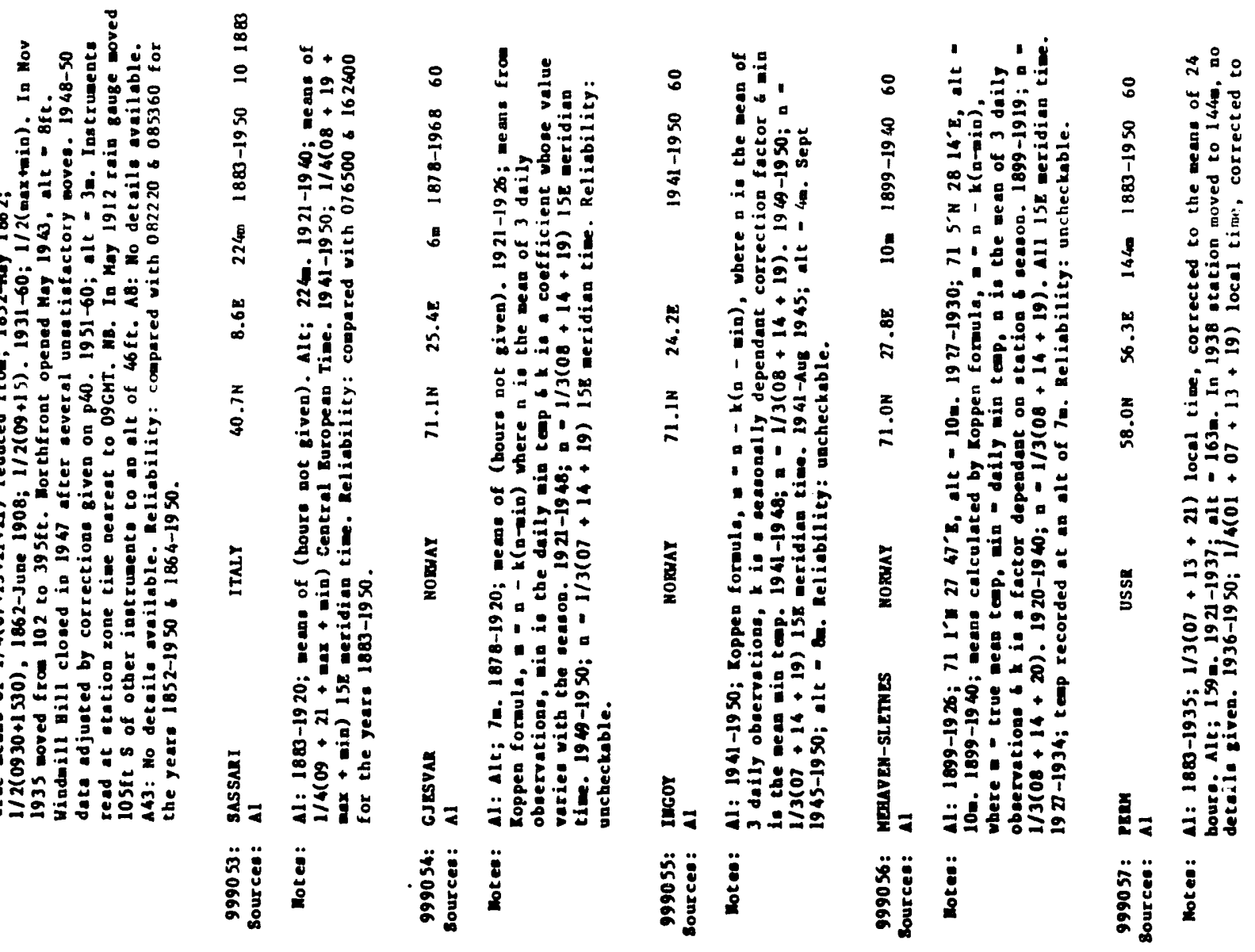

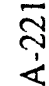

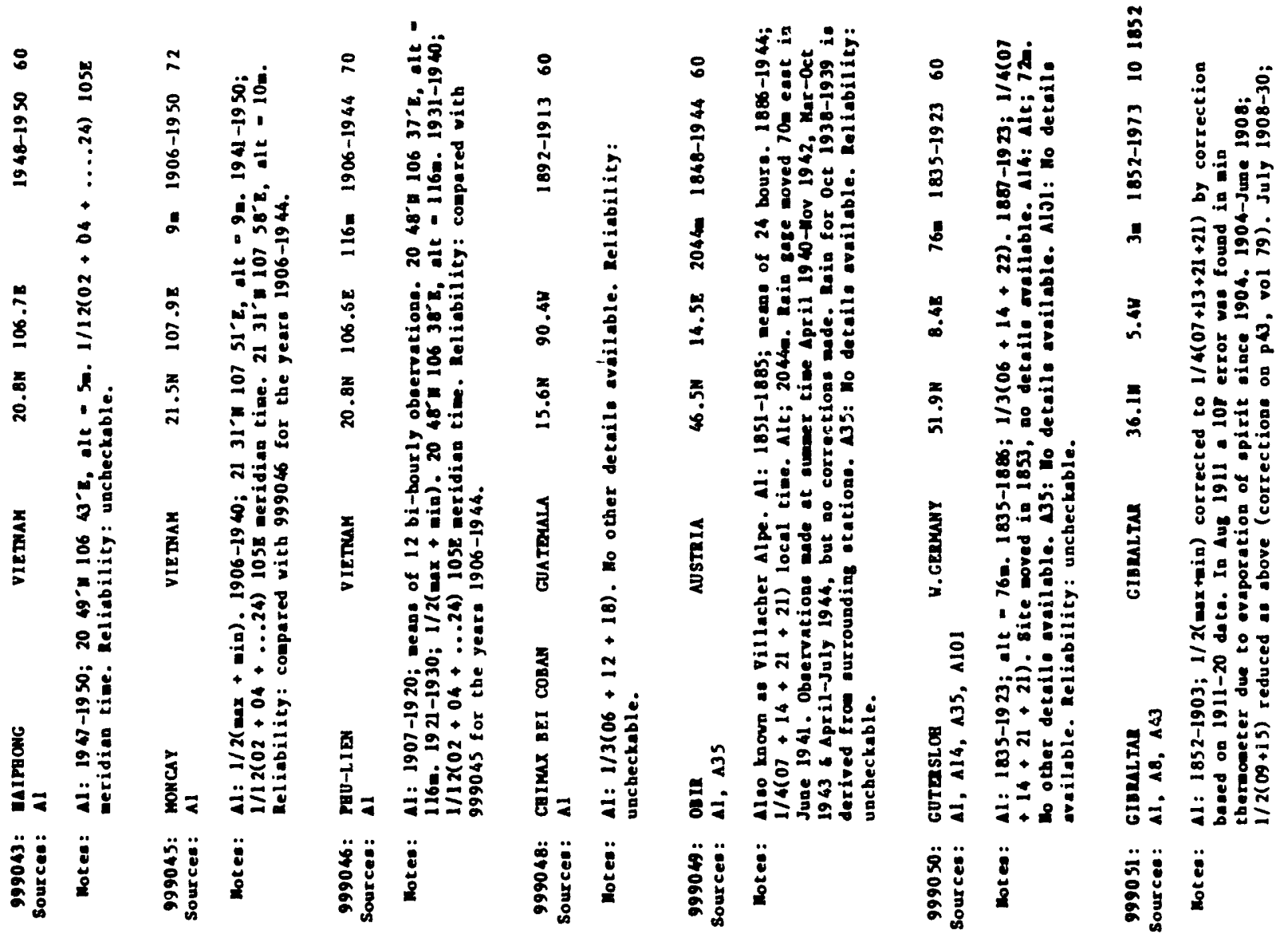




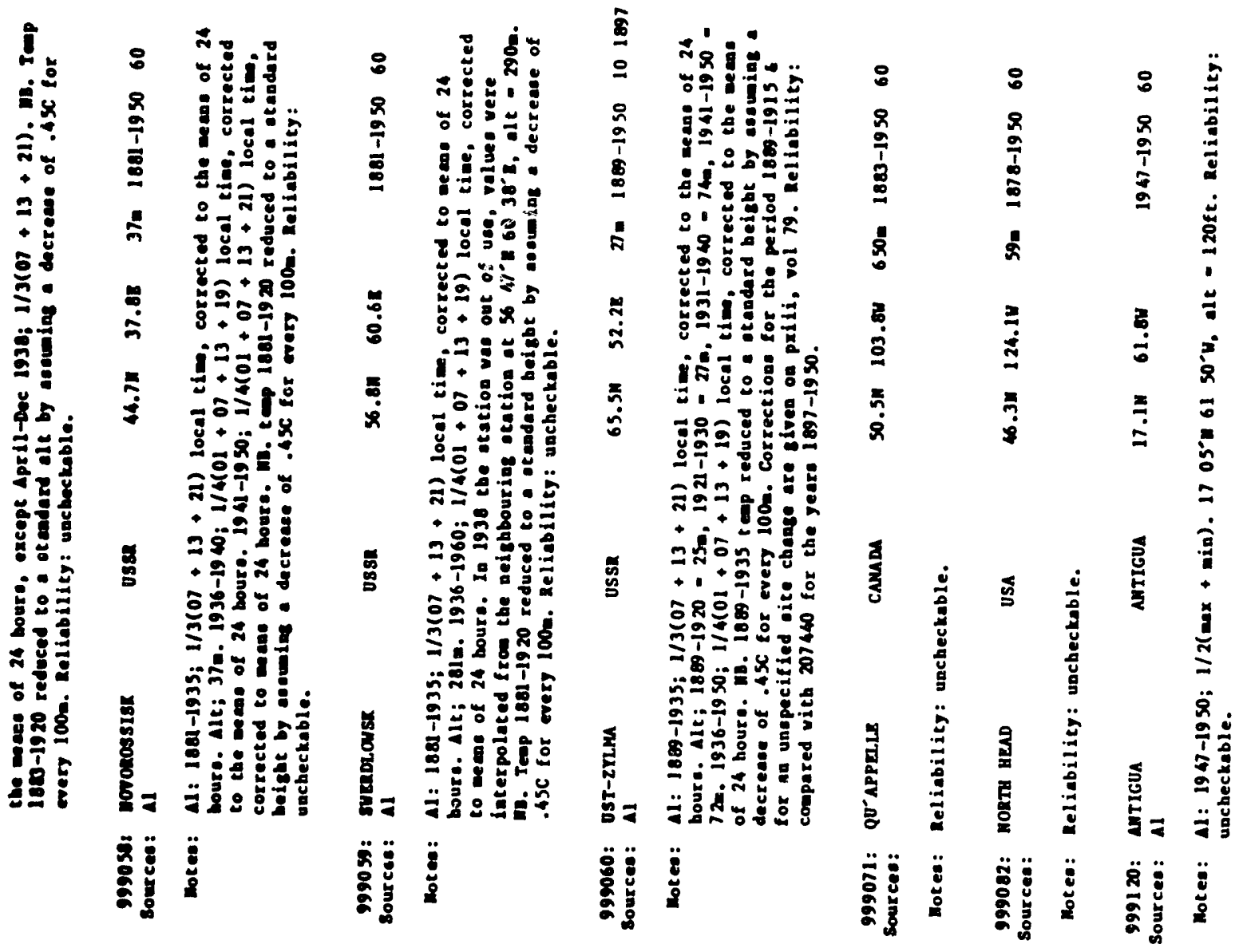




\section{APPENDIX B}

Stations used in the gridding algorithm

Column headings:

ID - WhO Number (generally with additional 0)

IAT = Latitude (in tenths of degrees; minus sign indicates Southern Bemisphere)

LONG - Longitude (in tenths of degrees; minus sign indicates east of Greewich)

ALT = Altitude (metres)

Station Name

Country

Onit Indicator $(1$ - tenths of degrees celcius)

First year of temperature data

Last year of data

Station used in the gridding process (GP)

First reliable year of data $(0$ - first year of data)

Quality control code (see Appendix A for details) 
ID LAT LONG ALT STATION MAYE

9 JAN MAYEN

\begin{tabular}{|c|c|c|c|c|c|}
\hline $\begin{array}{l}10250 \\
10280 \\
10650 \\
10980 \\
11520 \\
12410 \\
12580 \\
13160 \\
14150 \\
14920 \\
20570 \\
20760 \\
20800 \\
21270 \\
21960 \\
22260 \\
23610 \\
24180 \\
24640 \\
25500 \\
25900 \\
28360 \\
28970 \\
29110 \\
29350 \\
29720 \\
29740 \\
30050 \\
30260 \\
30680 \\
30910 \\
31000 \\
31400 \\
31540 \\
31600 \\
31607 \\
31620 \\
33020 \\
33230 \\
33340 \\
33400 \\
33770 \\
34970 \\
35340 \\
37898\end{array}$ & $\begin{array}{l}695 \\
745 \\
695 \\
704 \\
673 \\
637 \\
634 \\
604 \\
589 \\
599 \\
656 \\
599 \\
685 \\
651 \\
658 \\
632 \\
626 \\
594 \\
594 \\
578 \\
577 \\
672 \\
643 \\
631 \\
624 \\
605 \\
602 \\
601 \\
582 \\
576 \\
572 \\
565 \\
559 \\
551 \\
560 \\
559 \\
553 \\
533 \\
534 \\
534 \\
534 \\
532 \\
526 \\
525\end{array}$ & $\begin{array}{r}84 \\
-142 \\
-190 \\
-190 \\
-255 \\
-311 \\
-144 \\
-96 \\
-105 \\
-53 \\
-56 \\
-107 \\
-221 \\
-176 \\
-225 \\
-172 \\
-242 \\
-147 \\
-180 \\
-135 \\
-181 \\
-142 \\
-183 \\
-266 \\
-277 \\
-218 \\
-257 \\
-223 \\
-250 \\
12 \\
63 \\
31 \\
21 \\
69 \\
43 \\
31 \\
34 \\
32 \\
32 \\
45 \\
29 \\
23 \\
15 \\
-17 \\
17 \\
26\end{array}$ & $\begin{array}{r}11 \\
14 \\
133 \\
15 \\
13 \\
7 \\
115 \\
44 \\
8 \\
96 \\
16 \\
15 \\
327 \\
327 \\
7 \\
-999 \\
8 \\
55 \\
52 \\
232 \\
28 \\
181 \\
136 \\
8 \\
145 \\
54 \\
56 \\
82 \\
3 \\
32 \\
59 \\
9 \\
-999 \\
-999 \\
35 \\
134 \\
239 \\
10 \\
-999 \\
77 \\
-999 \\
68\end{array}$ & 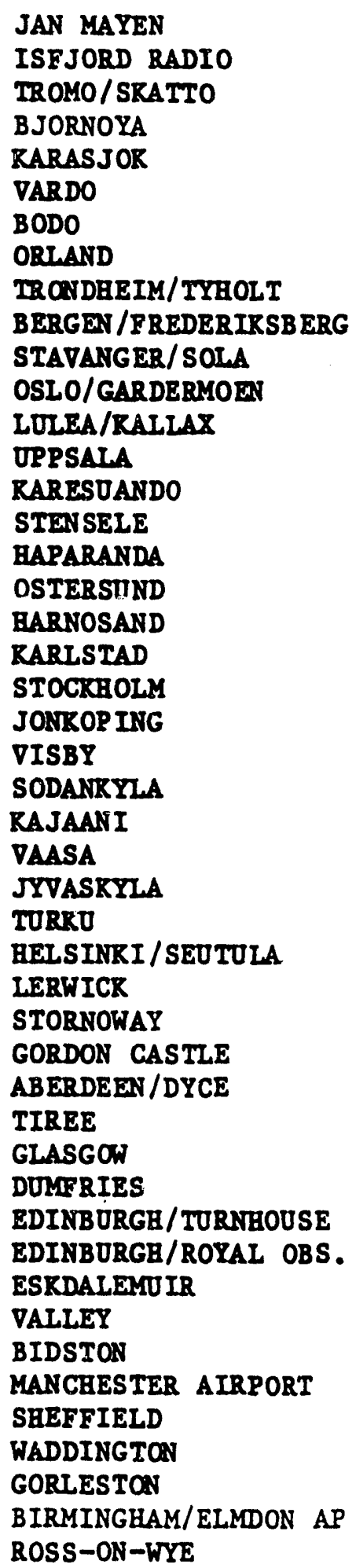 & $\begin{array}{l}\text { NORWAY } \\
\text { NORWAY } \\
\text { NORWAY } \\
\text { NORWAY } \\
\text { NORWAY } \\
\text { NORWAY } \\
\text { NORWAY } \\
\text { NORWAY } \\
\text { NORWAY } \\
\text { NORWAY } \\
\text { NORWAY } \\
\text { NORWAY } \\
\text { SWEDEN } \\
\text { SWEDEN } \\
\text { SWEDEN } \\
\text { SWEDEN } \\
\text { SWEDEN } \\
\text { SWEDEN } \\
\text { SWEDEN } \\
\text { SWEDEN } \\
\text { SWEDEN } \\
\text { SWEDEN } \\
\text { SWEDEN } \\
\text { FINLAND } \\
\text { FINLAND } \\
\text { FINLAND } \\
\text { FINLAND } \\
\text { FINLAND } \\
\text { FINLAND } \\
\text { UR } \\
\text { UR } \\
\text { UR } \\
\text { UR } \\
\text { UR } \\
\text { UR } \\
\text { UR } \\
\text { UR } \\
\text { UR } \\
\text { UR } \\
\text { UR } \\
\text { UR } \\
\text { UR } \\
\text { UR } \\
\text { UR } \\
\text { UR } \\
\text { UR } \\
\text { UR } \\
\text { UTI }\end{array}$ \\
\hline
\end{tabular}

STATOS 


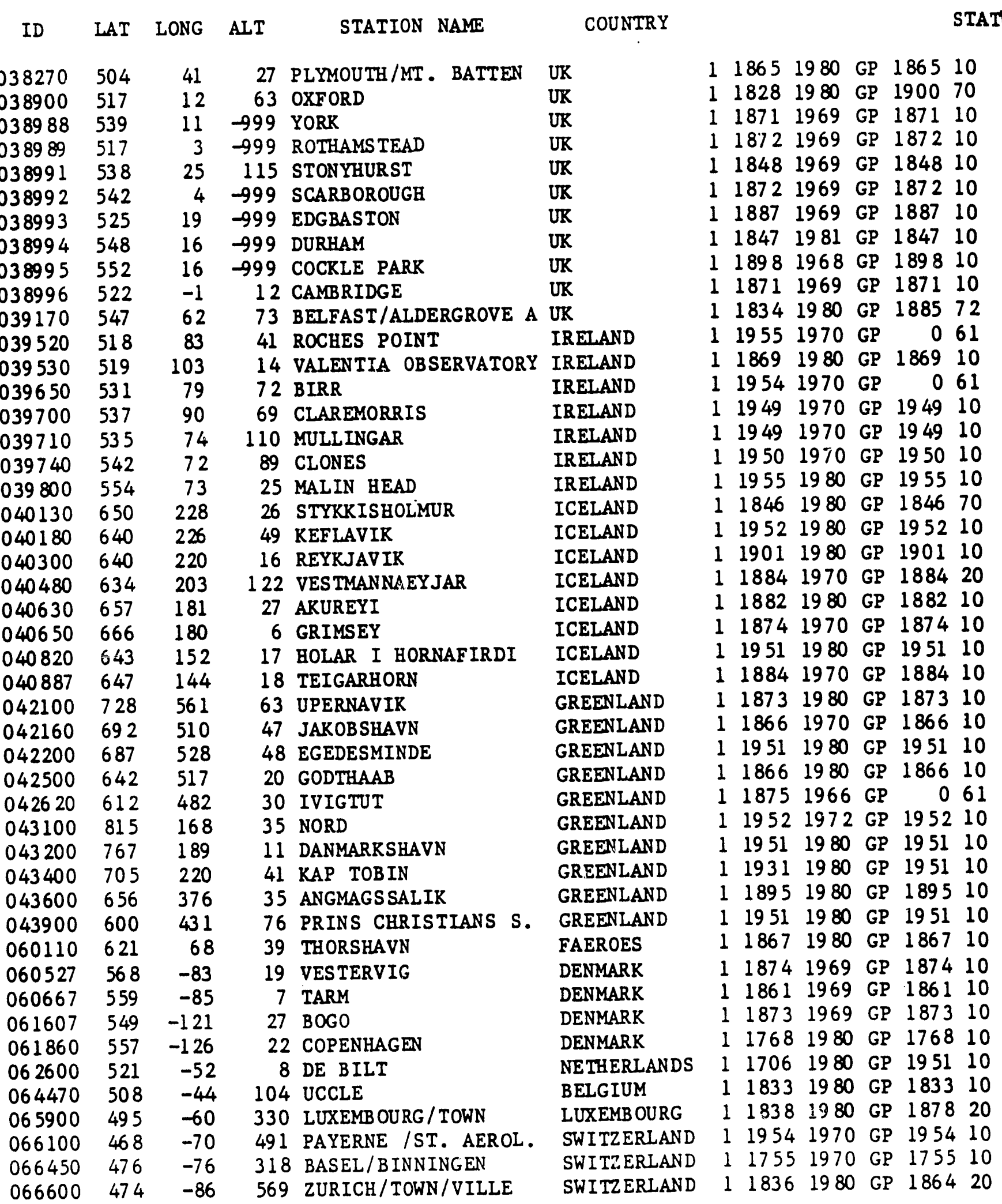




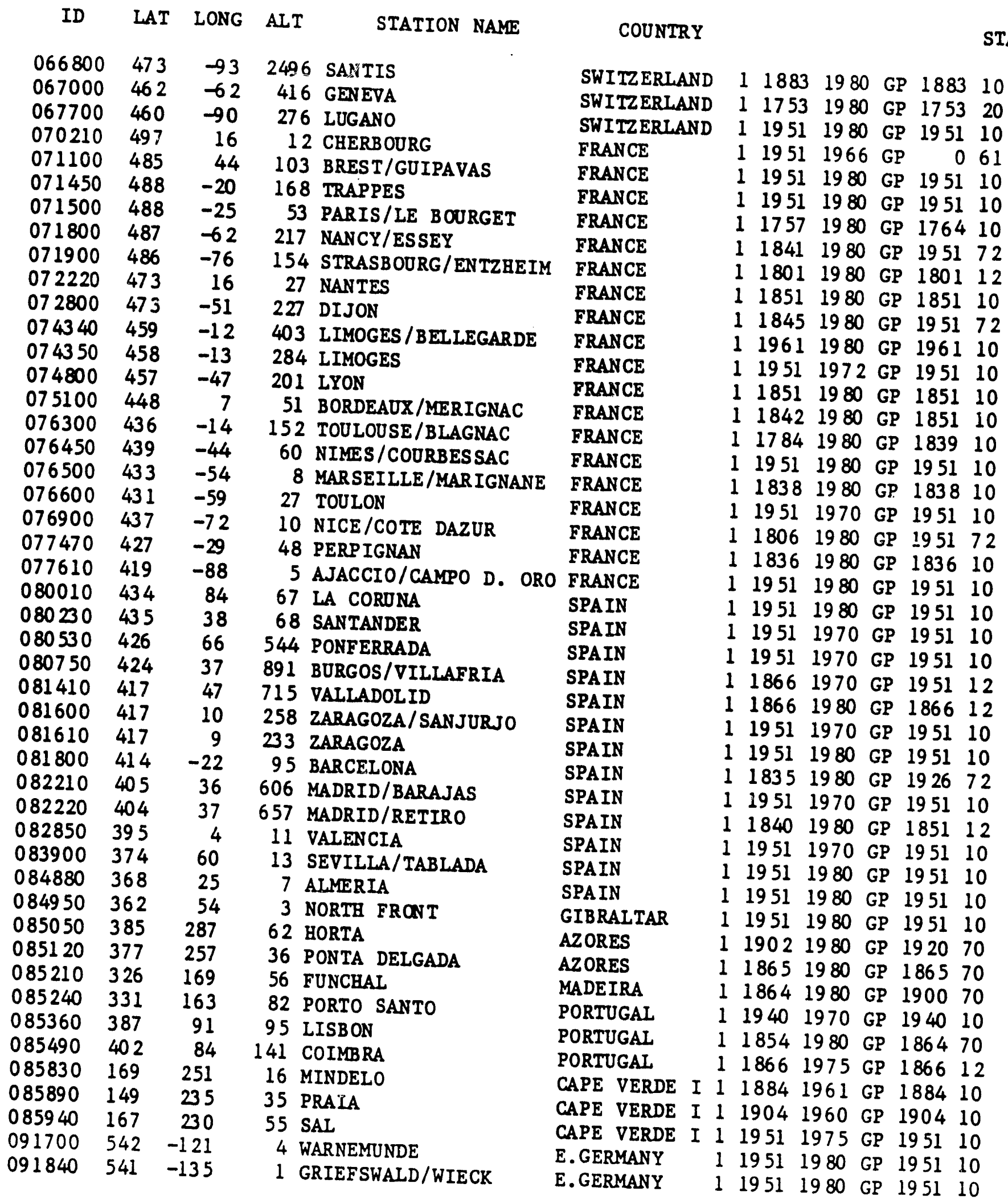


ID LAT LONG ALT STATION NAME COUNTRY

STATUS

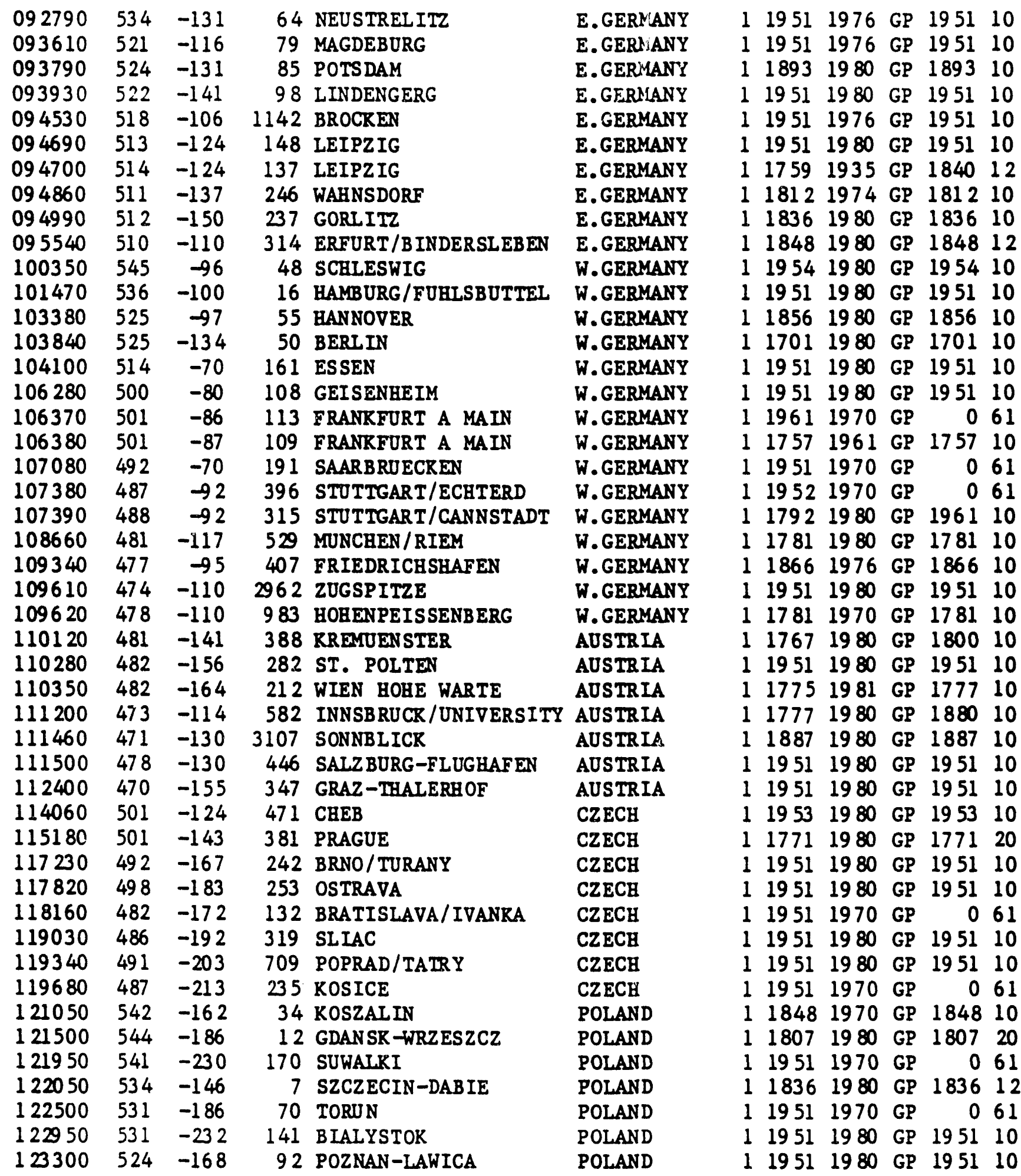




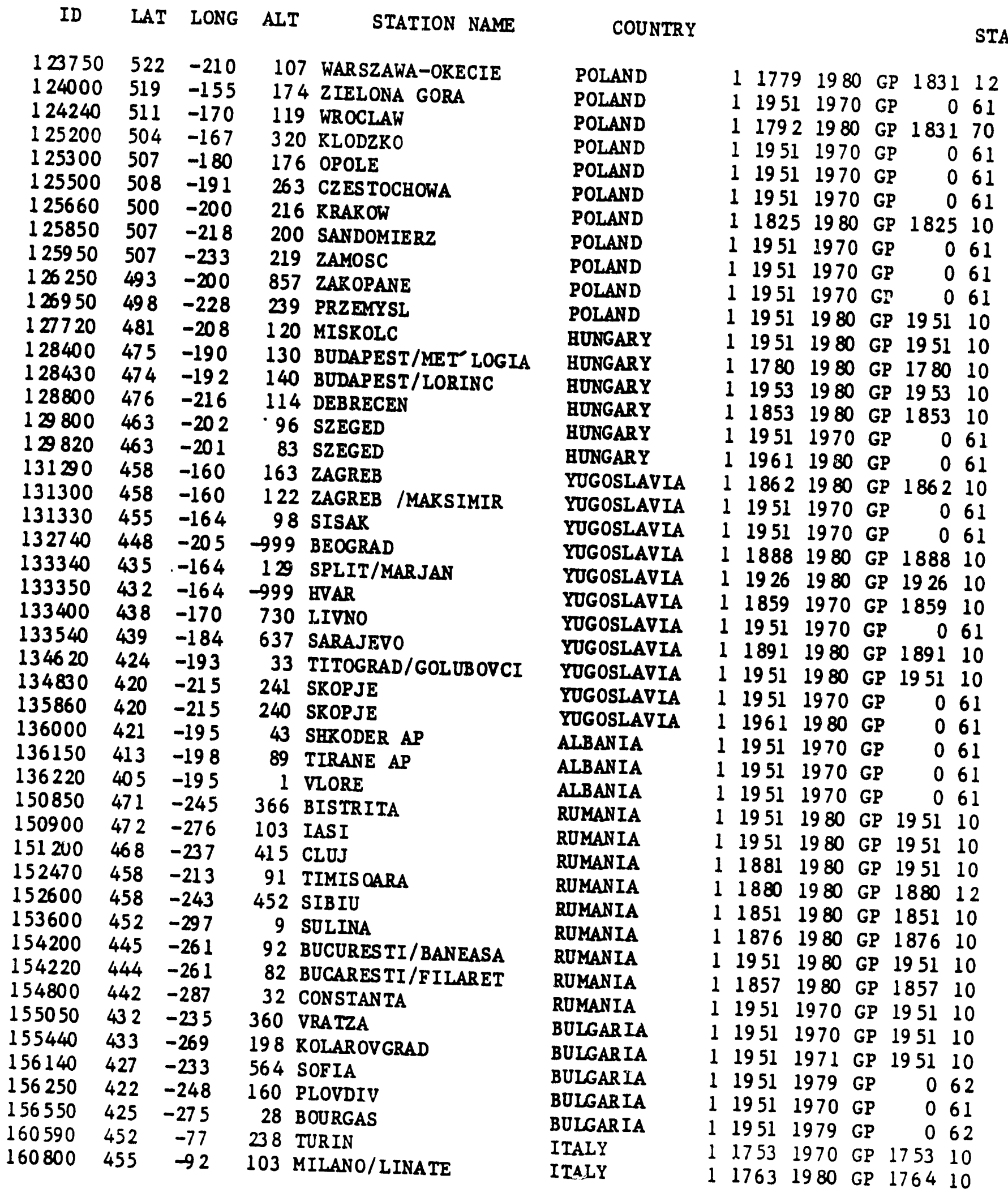



IAT LONG ALT STATION NAME

COUNTRY

STATUS

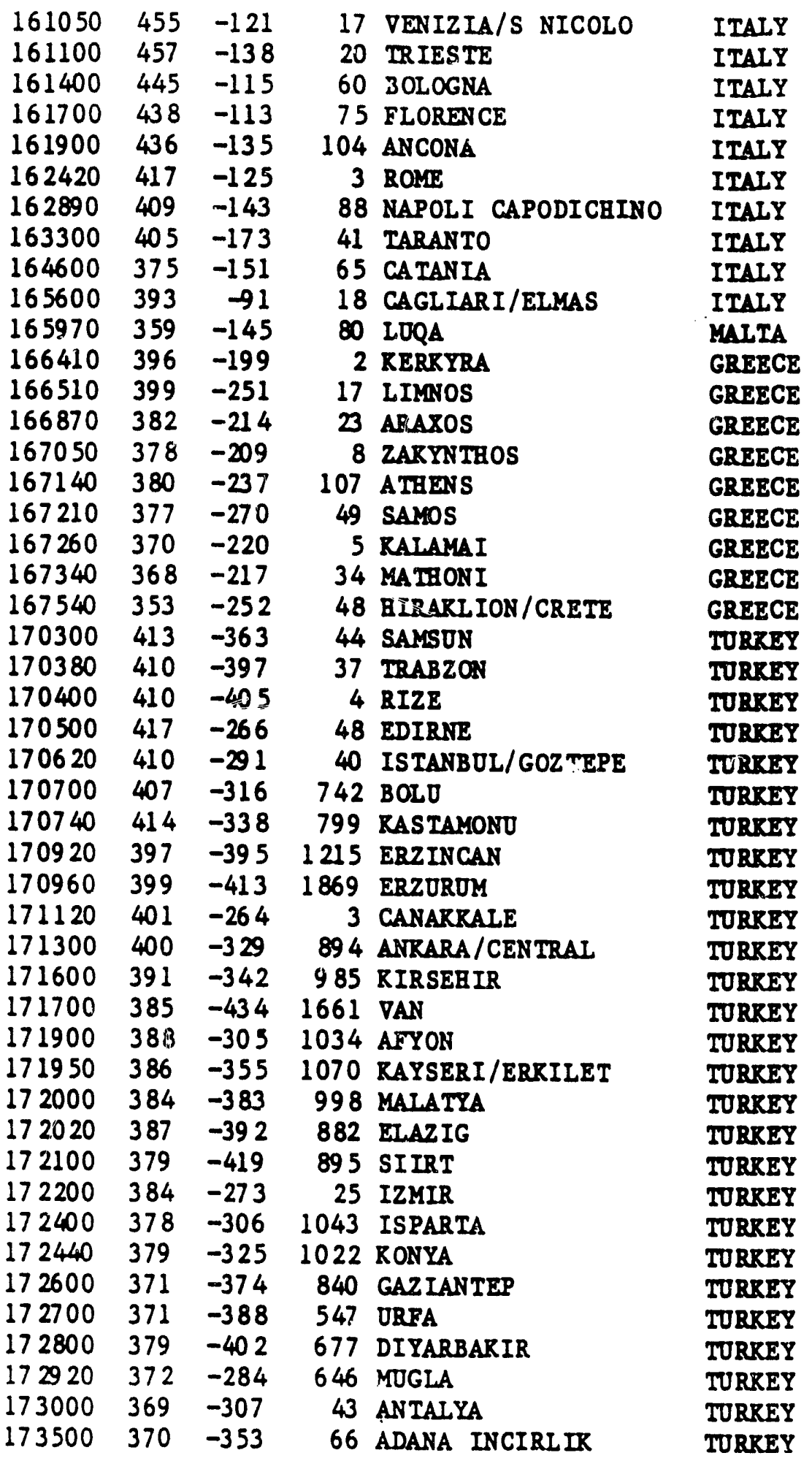

$\begin{array}{llllll}1 & 1951 \quad 1980 & \text { GP } & 1951 \quad 10\end{array}$

$\begin{array}{lllllll}1 & 1841 & 1980 & \text { GP } & 1841 \quad 10\end{array}$

118081970 GP 180812

118321970 GP 183212

119511978 GP 195110

$\begin{array}{llllll}1 & 1811 & 1980 & \text { GP } & 1811 & 10\end{array}$

$\begin{array}{lllllll}1 & 18661980 & \text { GP } & 1866 \quad 22\end{array}$

119511967 GP 061

118921980 GP 189220

$\begin{array}{llllll}1 & 1951 & 1980 & \text { GP } & 1951 & 10\end{array}$

$\begin{array}{lllllll}1 & 18531980 & \text { GP } & 1853 \quad 20\end{array}$

118521980 GP 195172

119511970 GP 061

119511970 GP 061

119511980 GP 062

\& 18581980 GP 185810

119511970 GP $\quad 061$

$11951 \quad 1980$ GP $\quad 062$

$119511970 \mathrm{GP} \quad 061$

$\begin{array}{llllll}1 & 1951 & 1980 \text { GP } 195110\end{array}$

118191980 GP 192910

$119511970 \mathrm{GP} \quad 061$

$\begin{array}{llllll}1 & 1929 & 1980 & \text { GP } & 1929 & 10\end{array}$

$\begin{array}{llllll}1 & 1929 & 1980 & \text { GP } & 1929 & 10\end{array}$

$\begin{array}{llllll}1 & 1839 & 1980 & \text { GP } & 1839 & 12\end{array}$

$119511970 \mathrm{GP} \quad 061$

$11951 \quad 1980$ GP 195110

119511980 GP 195110

119291980 GP $1929 \quad 10$

$11951 \quad 1980$ GP 195110

$11926 \quad 1980$ GP $1926 \quad 10$

$11951 \quad 1970$ GP 061

119511980 GP 195110

119511980 GP 195110

119511980 GP 195110

119511980 GP 195110

$119511970 \mathrm{GP} \quad 061$

$11951 \quad 1970 \mathrm{GP} \quad 061$

118431980 GP 192910

$11951 \quad 1980$ GP 195110

$\begin{array}{llllll}1 & 1951 & 1980 & \text { GP } & 1951 & 10\end{array}$

119511970 GP 061

119001980 GP 195110

$\begin{array}{llllll}1 & 1929 & 1980 & \text { GP } & 1929 & 10\end{array}$

$\begin{array}{llllll}1 & 1951 & 1980 & \text { GP } & 1951 & 10\end{array}$

119301980 GP 193010

$\begin{array}{llllll}1 & 1929 & 1980 & \text { GP } & 1929 & 10\end{array}$ 


\begin{tabular}{|c|c|c|c|c|}
\hline ID & LAT & LONG & ALT & STATION NAME \\
\hline 176060 & 352 & -333 & 220 & NICOSIA \\
\hline 200690 & 795 & -770 & 18 & OSTROV VIZE \\
\hline 202920 & 777 & -1043 & 13 & MYS CELJUSRIN \\
\hline 203530 & 770 & -686 & -999 & MYS ZELANIJA \\
\hline 206740 & 735 & -804 & 20 & OSTROV DIRSON \\
\hline 207440 & 724 & -527 & 46 & MALYE RARMAROLY \\
\hline 208910 & 720 & -1025 & 24 & HATANGA/KHATANGA \\
\hline 214320 & 760 & -1379 & 10 & OSTROV KOTELNYJ \\
\hline 218240 & 803 & -526 & -999 & BUKHTA TIBRAYHA \\
\hline 219460 & 706 & -1479 & 48 & CORURDAH \\
\hline 219650 & 706 & -1624 & 6 & CETYREHSTOLB OVOI \\
\hline 221130 & 690 & -331 & 46 & MURMANSK \\
\hline 221650 & 687 & -433 & -999 & RANIN NOS \\
\hline 224220 & 659 & -348 & 10 & GRIDINO \\
\hline 225220 & 650 & -348 & 10 & REM PORT \\
\hline 225500 & 646 & -406 & 13 & ARKHANGERSK \\
\hline 226020 & 638 & -308 & 181 & REBOLY \\
\hline 228020 & 617 & -307 & 18 & SORTOVALA \\
\hline 228200 & 618 & -343 & 40 & PEIROZAVODSK \\
\hline 228540 & 617 & -402 & 224 & NJANDOMA \\
\hline 230740 & 694 & -862 & -999 & DUDINRA \\
\hline 231460 & 685 & -736 & 7 & MYS RAMENNYJ \\
\hline 232050 & 677 & -530 & 7 & NAR JAN-MAR \\
\hline 233300 & 665 & -665 & 35 & SALEHARD \\
\hline 234720 & 659 & -876 & 37 & TURUBANSR \\
\hline 236310 & 639 & -651 & 20 & BEREZOV \\
\hline 238040 & 617 & -509 & 96 & SYKIYVKAR \\
\hline 8490 & 613 & -735 & 43 & SURGUT \\
\hline 38840 & 616 & -900 & 60 & PODRAMENNAJA \\
\hline 239330 & 610 & -691 & 40 & BANTY - MANSIJSR \\
\hline 241250 & 685 & -1124 & 127 & OL ENAER \\
\hline 242660 & 676 & -1334 & 137 & VERH OJANSK \\
\hline 245070 & 642 & -1001 & 140 & TORA \\
\hline 246410 & 638 & -1216 & 107 & VILJOJSR \\
\hline 246880 & 633 & -1432 & 726 & OJMJAKON \\
\hline 248170 & 613 & -1080 & 282 & ERB OGACEN \\
\hline 249440 & 604 & -1204 & 226 & OLEROYINSR \\
\hline 249590 & 620 & -1297 & 103 & JAROTSK \\
\hline 249660 & 604 & -1345 & 175 & UST MAJA \\
\hline 251730 & 689 & 1795 & 7 & MYS SMIDTA \\
\hline 252480 & 673 & -1682 & 426 & ILIRNEJ \\
\hline 253990 & 662 & 1698 & 7 & MYS UZLEN \\
\hline 254000 & 657 & -1509 & 43 & ZYRJANRA \\
\hline 630 & 648 & -1776 & 62 & ANADYR \\
\hline 030 & 629 & -1524 & 207 & SEJMCAN \\
\hline 540 & 604 & -1660 & 2 & KORF \\
\hline & 594 & -248 & 44 & TALLIN \\
\hline
\end{tabular}

\begin{tabular}{|c|c|c|c|c|c|}
\hline COUN & & & & & STATUS \\
\hline CYPRUS & 11887 & 1974 & - GP & 1887 & $7 \quad 10$ \\
\hline OSSR & 11951 & 1980 & GP & 1951 & 110 \\
\hline USSR & 11951 & 1980 & GP & 1951 & 10 \\
\hline USSR & 11931 & 1960 & GP & 1931 & 10 \\
\hline USSR & 11917 & 1980 & GP & 1917 & 10 \\
\hline USSR & 11897 & 1963 & GP & 1897 & 10 \\
\hline USSR & 11951 & 1980 & GP & 1951 & 10 \\
\hline USSR & 11951 & 1980 & GP & 1951 & 10 \\
\hline USSR & 11920 & 1960 & $G P$ & 1929 & 10 \\
\hline USSR & 11951 & 1980 & GP & 1951 & 10 \\
\hline USSR & 11951 & 1980 & GP & 1951 & 10 \\
\hline USSR & 11951 & 1980 & GP & 1951 & 10 \\
\hline USSR & 11951 & 1980 & GP & 1951 & 10 \\
\hline USSR & 11951 & 1970 & GP & 1951 & 10 \\
\hline USSR & 11862 & 1970 & GP & 0 & 60 \\
\hline USSR & 11813 & 1980 & GP & $\therefore 813$ & 10 \\
\hline USSR & 11951 & 1980 & GP & 1951 & 10 \\
\hline USSR & 11951 & 1970 & GP & 1951 & 10 \\
\hline USSR & 11816 & 1979 & GP & 1951 & 12 \\
\hline USSR & 11951 & 1970 & GP & 1951 & 10 \\
\hline USSR & 11906 & 1960 & GP & 1906 & 10 \\
\hline USSR & 11951 & 1980 & GP & 1951 & 10 \\
\hline USSR & 11961 & 1980 & GP & 1961 & 10 \\
\hline USSR & 11883 & 1980 & GP & 1883 & 10 \\
\hline USSR & 11881 & 1980 & GP & 1881 & 10 \\
\hline USSR & 11881 & 1960 & GP & 1881 & 10 \\
\hline USSR & 11817 & 1980 & GP & 18.7 & 10 \\
\hline USSR & 11885 & 1980 & GP & 1885 & 10 \\
\hline USSR & 11951 & 1980 & GP & 0 & 60 \\
\hline USSR & 11951 & 1980 & GP & 1951 & 10 \\
\hline USSR & 11951 & 1980 & GP & 1951 & 10 \\
\hline USSR & 11885 & 1980 & GP & 1885 & 10 \\
\hline OSSR & 11951 & 1980 & GP & 1951 & 10 \\
\hline USSR & 11951 & 1980 & GP & 1951 & 10 \\
\hline USSR & 11951 & 1980 & GP & 1951 & 10 \\
\hline USSR & 11951 & 1980 & GP & 1951 & 10 \\
\hline USSR & 11882 & 1960 & GP & 1882 & 10 \\
\hline OSSR & 11829 & 1980 & GP & 1882 & 10 \\
\hline USSR & 11893 & 1960 & GP & 1893 & 10 \\
\hline USSR & 11951 & 1980 & GP & 1951 & 10 \\
\hline USSR & 11951 & 1980 & GP & 1951 & 10 \\
\hline USSR & 11951 & 1980 & GP & 1951 & 10 \\
\hline USSR & 11951 & 1980 & GP & 1951 & 10 \\
\hline USSR & 11898 & 1980 & GP & 1898 & 10 \\
\hline USSR & 11951 & 1980 & GP & 1951 & 10 \\
\hline USSR & 11951 & 1980 & GP & 1951 & 10 \\
\hline USSR & 11806 & 1980 & GP & 1806 & 12 \\
\hline
\end{tabular}




\begin{tabular}{|c|c|c|c|c|c|}
\hline 262580 & $\begin{array}{l}600 \\
578\end{array}$ & $\begin{array}{l}-303 \\
-284\end{array}$ & $\begin{array}{r}4 \\
42\end{array}$ & $\begin{array}{l}\text { LEN INGRAD/TOWN/VILLE } \\
\text { PSKOV }\end{array}$ & $\begin{array}{l}\text { USSR } \\
\text { USSR }\end{array}$ \\
\hline 62890 & 580 & -332 & 219 & VALDAJ & USSR \\
\hline 62980 & 579 & -341 & 178 & BOLOGOE & USSR \\
\hline 264060 & 566 & -210 & 8 & LIEPAJA & OSSR \\
\hline 64220 & 570 & -241 & 3 & RIGA & OSSR \\
\hline 770 & 56 & -306 & 98 & VELIRIE LURI & USSR \\
\hline 20 & 549 & -239 & 75 & RAUNAS & SSR \\
\hline 20 & 54 & -205 & 27 & RALININGRAD & USSR \\
\hline 300 & 546 & -253 & 189 & VIL'NJUS & SSR \\
\hline 810 & 548 & -321 & 241 & SMOLEN SR & SSR \\
\hline 268500 & 539 & -275 & 234 & MINSR & SSR \\
\hline 268 & 533 & -342 & 162 & BRJAN SR & USSR \\
\hline 0 & 59 & -399 & 118 & VOLOGDA & USSR \\
\hline 271960 & 587 & -496 & 164 & RIROV & USSR \\
\hline 213200 & 562 & -438 & 82 & GORRIJ & USSR \\
\hline 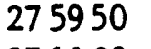 & 55 & -491 & 64 & RAZAN & USSR \\
\hline 120 & 558 & -376 & 156 & MOSKVA & USSR \\
\hline 650 & 550 & -445 & 206 & LUROJANOV & USSR \\
\hline 9470 & 52 & -415 & 139 & TAMB OV & USSR \\
\hline 0 & 580 & -563 & 161 & PERM & OSSR \\
\hline 28 & 582 & -682 & 44 & TOBOLSR & USSR \\
\hline 284400 & 568 & -606 & 237 & SVERDLOVSK & USSR \\
\hline 286980 & 55 & -734 & 94 & OMSK & OSSR \\
\hline 289520 & 53 & -635 & 171 & ROSTANAJ & USSR \\
\hline 2310 & 58 & -829 & 76 & ROLPASEV & USSR \\
\hline 2630 & 585 & -922 & 78 & ENISEJSR & JSSR \\
\hline 0 & 565 & -850 & 121 & TOMSR & ISSR \\
\hline 40 & 560 & -929 & 194 & RRASNOJARSR & USSR \\
\hline 30 & 533 & -838 & 196 & BARNAUL & USSR \\
\hline 8660 & 537 & -917 & 251 & MINUS INSR & USSR \\
\hline 302300 & 578 & -1081 & 261 & RIRENSK & USSR \\
\hline 303090 & 561 & -1018 & 326 & BRATSR & USSR \\
\hline 305540 & 546 & -1131 & 1310 & TROICKIJ PRIISR & USSR \\
\hline 30 & 523 & -1043 & 485 & IRROTSR & USSR \\
\hline 30 & 520 & -1 & 685 & CITA & OSSR \\
\hline 30 & 513 & -1 & 620 & NERCINSRIJ ZAVOD & USSR \\
\hline 310040 & 586 & -1254 & 682 & ALDAN & USSR \\
\hline 310880 & 594 & -1433 & 6 & OHOTSR & USSR \\
\hline 312530 & 547 & -1289 & 357 & BOMNAR & USSR \\
\hline 3136 & 531 & -1407 & 47 & NIROLAEVSR NA AMURE & USSR \\
\hline 315100 & 503 & -1275 & 137 & BLAGOVESCENSR & USSR \\
\hline 31735 & 485 & -1352 & 72 & BABAROVSR & USSR \\
\hline & 431 & -1319 & 138 & VLADIVOSTOR & USSR \\
\hline 320 & 509 & -1422 & -999 & ALERSANDROVSR & USSR \\
\hline 320980 & 492 & -1431 & 4 & PORONAISR & USSE \\
\hline
\end{tabular}

$\begin{array}{llllll}1 & 1743 & 1980 & \text { GP } & 1743 \quad 20\end{array}$

$\begin{array}{llllll}1 & 1951 & 1979 & \text { GP } & 1951 & 10\end{array}$

$11951 \quad 1970$ GP $1951 \quad 10$

$11951 \quad 1970$ GP $1951 \quad 10$

$11951 \quad 1970$ GP $1951 \quad 10$

117951970 GP 179512

$\begin{array}{llllll}1 & 1951 \quad 1980 & \text { GP } & 1951 \quad 10\end{array}$

$\begin{array}{llllll}1 & 1951 & 1980 & \text { GP } & 1951 & 10\end{array}$

$11848 \quad 1970$ GP $1848 \quad 10$

$\begin{array}{llllllll}1 & 1777 \quad 1970 & \text { GP } & 1777 \quad 10\end{array}$

$\begin{array}{llllll}1 & 1951 & 1979 & \text { GP } & 1951 \quad 10\end{array}$

$\begin{array}{lllllll}1 & 1951 & 1980 & \text { GP } & 1951 & 10\end{array}$

$11951 \quad 1970$ GP $1951 \quad 10$

$\begin{array}{lllllll}1 & 1951 & 1980 & \text { GP } & 1951 & 10\end{array}$

$11845 \quad 1980$ GP $1845 \quad 12$

$\begin{array}{llllll}1 & 1951 \quad 1970 & \text { GP } & 1951 \quad 10\end{array}$

118121980 GP 181212

$\begin{array}{lllllll}1 & 1779 & 1980 & \text { GP } & 1779 & 10\end{array}$

$11951 \quad 1970$ GP 195110

$11951 \quad 1970$ GP $1951 \quad 10$

$\begin{array}{lllllll}1 & 1883 & 1980 & \text { GP } & 1883 & 10\end{array}$

118321980 GP 183210

$\begin{array}{lllllll}1 & 1831 & 1980 & \text { GP } & 1831 & 10\end{array}$

$\begin{array}{lllllll}1 & 1887 & 1980 & \text { GP } & 1887 & 10\end{array}$

$\begin{array}{lllllll}1 & 1951 & 1980 & \text { GP } & 1951 & 10\end{array}$

$\begin{array}{lllllll}1 & 1951 \quad 1980 & \text { GP } & 1951 & 10\end{array}$

$\begin{array}{lllllll}1 & 1871 & 1980 & \text { GP } & 1871 & 10\end{array}$

$\begin{array}{lllllll}1 & 1837 \quad 1960 & \text { GP } & 1837 \quad 12\end{array}$

$\begin{array}{llllll}1 & 1951 & 1980 & \text { GP } & 1951 & 10\end{array}$

$\begin{array}{lllllll}1 & 1838 & 1980 & \text { GP } & 1838 & 10\end{array}$

$\begin{array}{lllllll}1 & 1886 & 1980 & \text { GP } & 1886 & 10\end{array}$

$\begin{array}{lllllll}1 & 1892 & 1980 & \text { GP } & 1892 & 20\end{array}$

$\begin{array}{llllll}1 & 1951 & 1980 & \text { GP } & 1951 & 10\end{array}$

$\begin{array}{llllll}1 & 1951 & 1980 & \text { GP } & 1951 & 10\end{array}$

$\begin{array}{llllll}1 & 1820 & 1980 & \text { GP } & 1820 & 10\end{array}$

$\begin{array}{lllllll}1 & 1890 & 1980 & \text { GP } & 1890 & 10\end{array}$

$\begin{array}{llllll}1 & 1839 & 1978 & \text { GP } & 1839 & 12\end{array}$

$\begin{array}{lllllll}1 & 1951 & 1980 & \text { GP } & 1951 & 10\end{array}$

$\begin{array}{llllll}1 & 1890 & 1980 & \text { GP } & 1890 & 10\end{array}$

$\begin{array}{llllll}1 & 1951 & 1980 & \text { GP } & 1951 & 10\end{array}$

$\begin{array}{llllll}1 & 1854 & 1980 & \text { GP } & 1854 & 10\end{array}$

$\begin{array}{lllllll}1 & 1881 & 1980 & \text { GP } & 1881 & 10\end{array}$

$\begin{array}{llllll}1 & 1909 & 1980 & \text { GP } & 1909 \quad 10\end{array}$

$\begin{array}{lllllll}1 & 1872 & 1980 & \text { GP } & 1872 & 10\end{array}$

119011960 GP $1901 \quad 10$

119081964 GP 190810

$\begin{array}{llllll}1 & 1951 \quad 1980 & \text { GP } & 1951 \quad 10\end{array}$ 


\begin{tabular}{|c|c|c|c|c|c|}
\hline ID & LAT & LONG & ALT & STATION NAME & \\
\hline 321950 & 469 & -1519 & 26 & SIMUS IR & DSSR \\
\hline 325400 & 530 & -1586 & 7 & PETROPAVLOVSR & USSR \\
\hline 326180 & 552 & -1660 & 6 & OSTROV BERINGA & USSR \\
\hline 330080 & 521 & -237 & 144 & BRES T & USSR \\
\hline 333010 & 506 & -261 & 234 & ROVNO & USSR \\
\hline 333450 & 505 & -305 & 179 & RIEV & USSR \\
\hline 333930 & 498 & -240 & 325 & LVOV & USSR \\
\hline 336310 & 486 & -223 & 118 & UZGOROD & USSR \\
\hline 336580 & 483 & -260 & 240 & CERNOVCY & USSR \\
\hline 336990 & 481 & -309 & 103 & JUZNO BUGSKAJA & USSR \\
\hline 337110 & 485 & -323 & 148 & RIROVOGRAD & OSSR \\
\hline 338150 & 470 & -289 & 90 & RISINEV & USSR \\
\hline 338370 & 465 & -307 & 64 & ODESSA & USSR \\
\hline 339340 & 457 & -344 & -999 & DZANROJ & USSR \\
\hline 339460 & 450 & -340 & 205 & SIMFEROPOL & USSR \\
\hline 341220 & 517 & -392 & 164 & VORONEZ & USSR \\
\hline 341390 & 511 & -407 & 194 & RAMENNAYA STEPPE & USSR \\
\hline 341630 & 516 & -455 & 190 & ORTIABRSRII GORODOR & USSR \\
\hline 341720 & 516 & -460 & 156 & SARATOV & USSR \\
\hline 343000 & 499 & -363 & 152 & HAR ROV & USSR \\
\hline 345600 & 487 & -444 & 145 & VOLGOGRAD & USSR \\
\hline 346010 & 478 & -353 & 86 & ZAPOROZE & USSR \\
\hline 347310 & 473 & -398 & 77 & ROSTOV-NA-DONO & USSR \\
\hline 347590 & 466 & -437 & 108 & REMONTINO & USSR \\
\hline 348660 & 462 & -454 & -7 & JASKOL & USSR \\
\hline 348800 & 464 & -480 & 18 & ASTRABAN & OSSR \\
\hline 349290 & 450 & -392 & 33 & KRASNODAR & OSSR \\
\hline 351210 & 518 & -551 & 109 & ORENB OURG ( TCERALOV) & USSR \\
\hline 351880 & 511 & -714 & 348 & CELINOGRAD & USSR \\
\hline 353580 & 496 & -635 & 123 & TURGAJ & OSSR \\
\hline 353940 & 498 & -731 & 555 & KARAGANDA & USSR \\
\hline 357000 & 470 & -519 & 23 & GUREV & USSR \\
\hline 357960 & 469 & -750 & 423 & BALHAS / BALRABASH & USSR \\
\hline 358490 & 458 & -621 & 67 & KAZALINSK & USSR \\
\hline 361770 & 504 & -803 & 206 & SEMIPALATINSK & JSSR \\
\hline 368700 & 433 & -769 & -999 & ALMA-ATA & USSR \\
\hline 369740 & 414 & -760 & 2049 & NATYN & USSR \\
\hline 370180 & 441 & -391 & 95 & TUAPSE & USSR \\
\hline 370310 & 450 & -411 & 208 & ARMAVIR & USSR \\
\hline 370500 & 441 & -430 & 532 & PJATIGORSR & USSR \\
\hline 370540 & 442 & -431 & 314 & MINERALNYE VODY & USSR \\
\hline 370990 & 436 & -397 & 56 & SOCHI & USSR \\
\hline 375490 & 417 & -448 & 490 & TBILISI & USSR \\
\hline 379850 & 387 & -488 & 11 & LENKORAN & USSR \\
\hline 380010 & 446 & -503 & 3820 & FORT SEVCENRO & USSR \\
\hline 382620 & 430 & -598 & 66 & CIMBAJ / CHIMBAY & USSR \\
\hline 70 & 413 & -693 & 428 & TASKENT & USSR \\
\hline
\end{tabular}

$\begin{array}{llllll}1 & 1951 & 1980 & \text { GP } & 1951 \quad 10\end{array}$

$\begin{array}{llllll}1 & 1891 & 1980 & \text { GP } & 189120\end{array}$

119511980 GP 195110

119511978 GP 195110

118121980 GP 181220

$\begin{array}{lllllll}1 & 1824 & 1980 \text { GP } 182410\end{array}$

$\begin{array}{llllll}1 & 1951 & 1978 \text { GP } 1951 \quad 10\end{array}$

$\begin{array}{lllllll}1 & 1880 & 1978 \text { GP } & 1880 & 10\end{array}$

$\begin{array}{llllll}1 & 1951 & 1970 & \text { GP } & 1951 & 10\end{array}$

$11951 \quad 1978$ GP $1951 \quad 10$

$\begin{array}{lllllll}1 & 18251970 \text { GP } 1825 \quad 22\end{array}$

118211980 GP 182110

$11951 \quad 1970$ GP $1951 \quad 10$

$\begin{array}{llllll}1 & 1821 & 1980 \text { GP } & 1821 & 12\end{array}$

$\begin{array}{llllll}1 & 1951 & 1980 & \text { GP } & 1951 & 10\end{array}$

$\begin{array}{llllll}1 & 1951 & 1970 & \text { GP } & 1951 & 10\end{array}$

$11881 \quad 1970$ GP 188110

$\begin{array}{llllll}1 & 1951 & 1980 & \text { GP } & 1951 & 20\end{array}$

119011980 GP $1901 \quad 10$

119011970 GP 190110

$\begin{array}{llllll}1 & 1951 & 1970 \text { GP } & 1951 & 10\end{array}$

119011980 GP 190110

$11951 \quad 1970$ GP $1951 \quad 10$

$11951 \quad 1970$ GP 195110

$\begin{array}{lllllll}1 & 1837 & 1980 & \text { GP } & 1837 & 10\end{array}$

$\begin{array}{llllll}1 & 1951 & 1970 \text { GP } 1951 \quad 10\end{array}$

$\begin{array}{llllll}1 & 1832 & 1980 & \text { GP } & 1832 & 10\end{array}$

$\begin{array}{llllllll}1 & 1891 & 1978 \text { GP } 189110\end{array}$

119001980 GP 190110

$\begin{array}{llllll}1 & 1951 & 1980 & \text { GP } & 1951 & 10\end{array}$

$\begin{array}{llllll}1 & 1951 & 1980 & \text { GP } & 1951 & 10\end{array}$

$\begin{array}{llllll}1 & 1951 & 1980 & \text { GP } & 1951 & 10\end{array}$

$\begin{array}{llllll}1 & 1921 & 1978 & \text { GP } & 1921 & 10\end{array}$

$\begin{array}{llllll}1 & 1951 & 1980 & \text { GP } & 1951 & 10\end{array}$

$\begin{array}{llllll}1 & 1881 & 1980 & \text { GP } & 1881 & 20\end{array}$

$\begin{array}{lllllll}1 & 1886 & 1960 & \text { GP } & 1886 & 10\end{array}$

$\begin{array}{lllllll}1 & 1951 & 1970 & \text { GP } & 1951 & 10\end{array}$

$\begin{array}{llllll}1 & 1951 & 1970 & \text { GP } & 1951 & 10\end{array}$

$\begin{array}{llllll}1 & 1951 & 1980 & \text { GP } & 1951 & 10\end{array}$

$11951 \quad 1970$ GP 195110

$\begin{array}{llllll}1 & 1951 & 1970 & \text { GP } & 1951 & 10\end{array}$

118441980 GP 184410

$\begin{array}{llllll}1 & 1951 & 1970 & \text { GP } & 1951 & 10\end{array}$

$\begin{array}{lllllll}1 & 1848 & 1980 & \text { GP } & 1848 & 10\end{array}$

$\begin{array}{llllll}1 & 1951 & 1980 & \text { GP } & 1951 & 10\end{array}$

$\begin{array}{lllllll}1 & 1881 & 1980 & \text { GP } & 1881 & 10\end{array}$ 


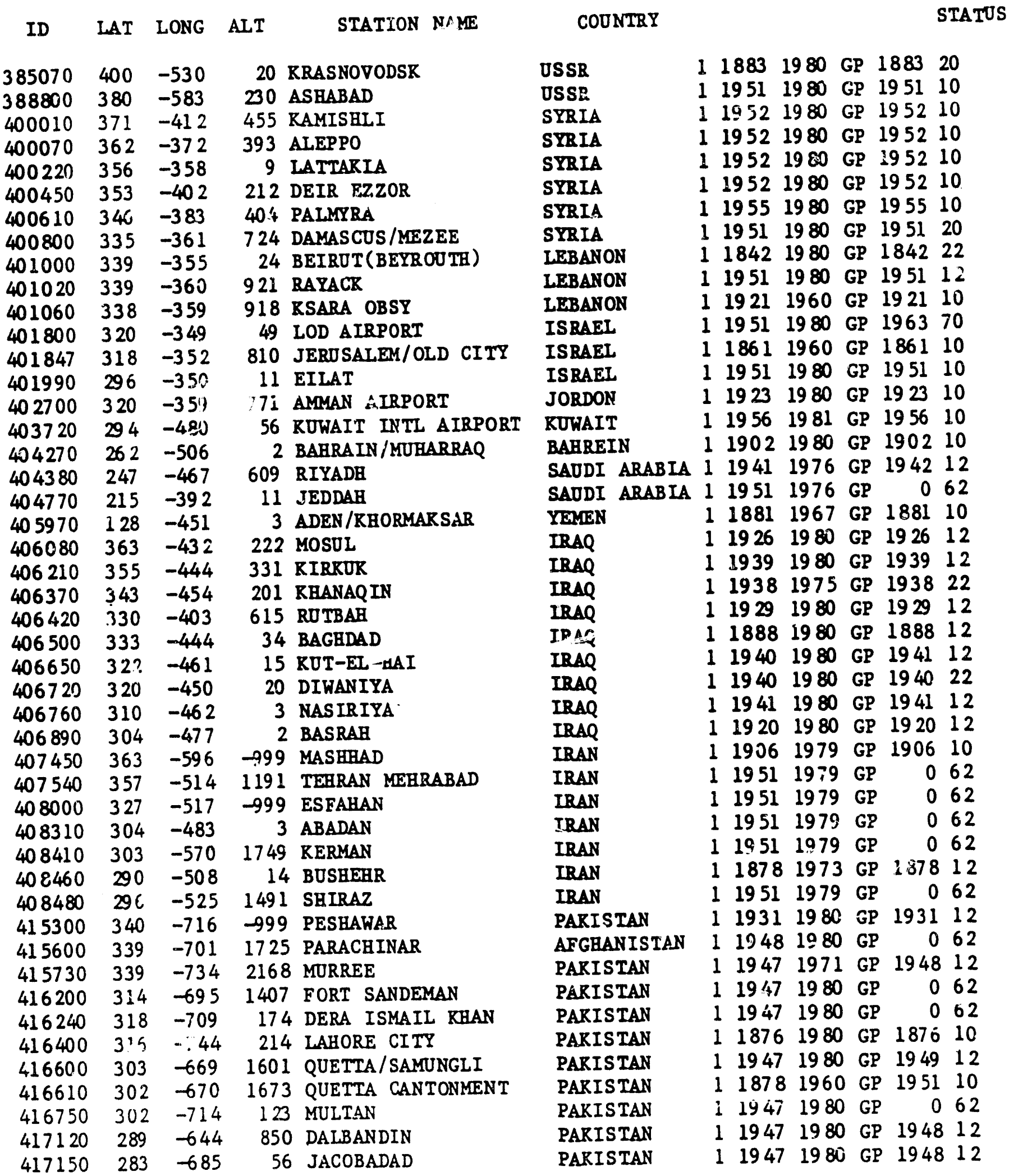




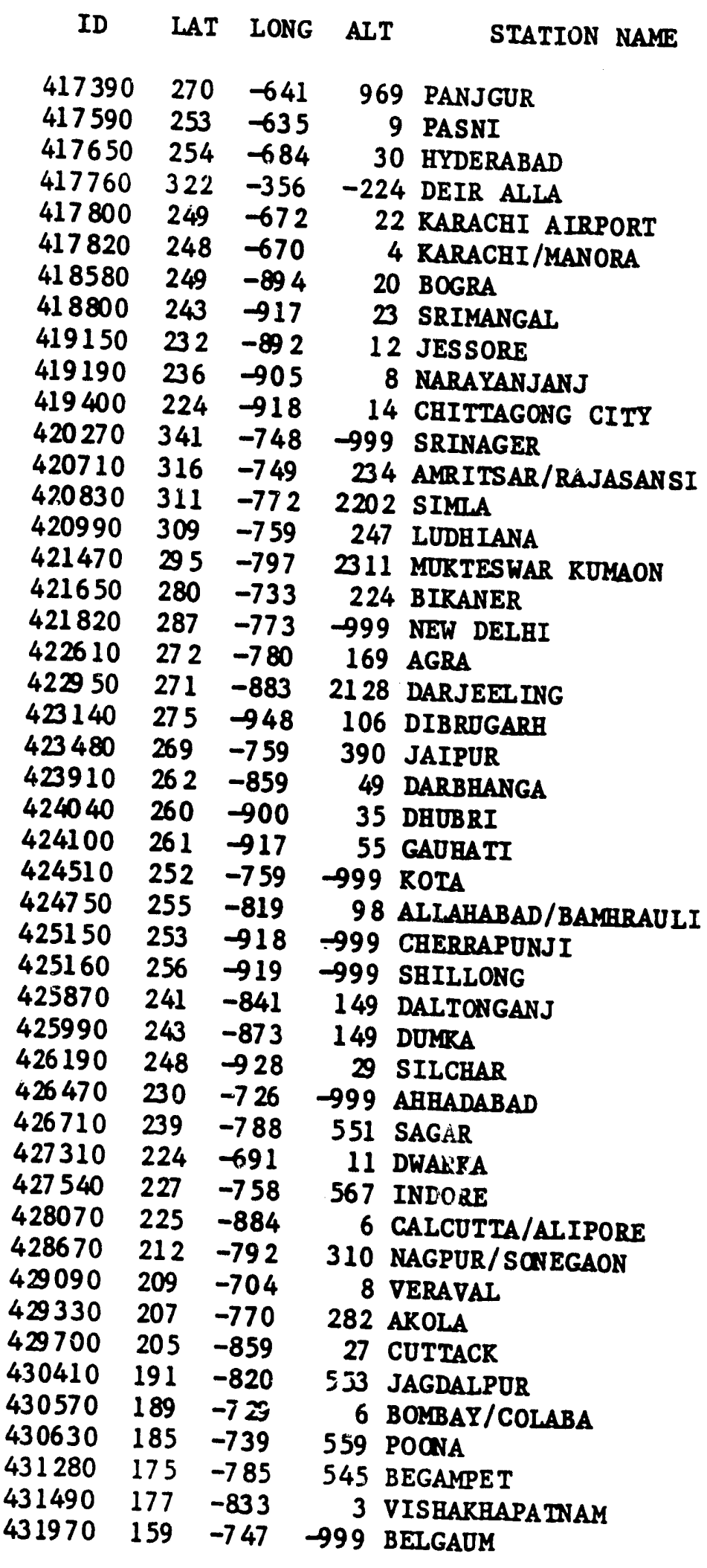

$\quad$ COUNTRY
PARISTAN
PARISTAN
PARISTAN
JORDON
PARISTAN
PARISTAN
BANGLADESB
BANGLADESH
BANGLADESH
BANGLADESH
BANGLADESH
INDIA
INDIA
INDIA
INDIA
INDIA
INDIA
INDIA
INDIA
INDIA
INDIA
INDIA
INDIA
INDIA
INDIA
INDIA
INDIA
INDIA
INDIA
INDIA
INDIA
INDIA
INDIA
INDIA
INDIA
INDIA
INDIA
INDIA
INDIA
INDIA
INDIA
INDIA
INDIA
INDIA
INDIA
INDIA
INDIA

STATUS

$11947 \quad 1980 \mathrm{GP} \quad 062$

119471970 GP $\quad 062$

$\begin{array}{lllllll}1 & 1878 & 1980 & \text { GP } & 1878 & 12\end{array}$

$119521970 \mathrm{GP} \quad 061$

119471980 GP 194812

$\begin{array}{lllll}1 & 1876 & 1971 \text { GP } 1878 \quad 10\end{array}$

119471971 GP 062

$119471970 \mathrm{GP} \quad 062$

119471971 GP $\quad 062$

$119471970 \mathrm{GP} \quad 062$

$119471980 \mathrm{GP} \quad 062$

$\begin{array}{lllllll}1 & 18931980 & \text { GP } & 1893 \quad 10\end{array}$

$\begin{array}{lllllll}1 & 1948 & 1980 & \text { GP } & 1949 & 10\end{array}$

118761960 GP 189110

118751980 GP 187610

$\begin{array}{llllll}1 & 18971980 & \text { GP } & 189810\end{array}$

$\begin{array}{llllll}1 & 1878 & 1980 & \text { GP } & 1878 & 20\end{array}$

$\begin{array}{lllllll}1 & 1931 & 1980 & \text { GP } & 1931 & 10\end{array}$

$\begin{array}{llllllll}1 & 1876 & 1980 & \text { GP } & 1876 \quad 20\end{array}$

$\begin{array}{lllllll}1 & 18481978 \text { GP } & 1848 \quad 22\end{array}$

119011980 GP 190210

$\begin{array}{llllll}1 & 1881 \quad 1960 \text { GP } 1881 \quad 10\end{array}$

$\begin{array}{llllll}1 & 1876 \quad 1980 & \text { GP } & 1876 \quad 10\end{array}$

$\begin{array}{llllll}1 & 1881 & 1980 & \text { GP } & 1882 & 10\end{array}$

119021980 GP 190310

$\begin{array}{llllll}1 & 18981979 & \text { GP } & 1898 & 10\end{array}$

$\begin{array}{llllll}1 & 1876 & 1980 & \text { GP } & 1876 & 10\end{array}$

119031980 GP 190312

119031960 GP 190310

118931980 GP 189310

118931980 GP 189310

118701974 GP 187022

$\begin{array}{llllll}1 & 1941 & 1980 & \text { GP } & 1941 & 20\end{array}$

$\begin{array}{llllll}1 & 1875 & 1980 & \text { GP } & 1875 & 10\end{array}$

119011978 GP 190110

118781980 GP 189670

118161980 GP $1876 \quad 10$

$\begin{array}{lllllll}1 & 1875 & 1980 & \text { GP } & 1875 & 20\end{array}$

$\begin{array}{lllllll}1 & 1890 & 1980 & \text { GP } & 1893 & 10\end{array}$

$\begin{array}{llllll}1 & 1875 & 1980 & \text { GP } & 1875 & 10\end{array}$

$\begin{array}{llllll}1 & 18781973 \text { GP } 1879 \quad 10\end{array}$

$\begin{array}{llllll}1 & 19091980 & \text { GP } & 190910\end{array}$

$\begin{array}{lllllll}1 & 18421980 & \text { GP } & 1893 \quad 10\end{array}$

$\begin{array}{llllll}1 & 1876 & 1980 & \text { GP } & 1876 & 20\end{array}$

$\begin{array}{llllll}1 & 1893 & 1980 & \text { GP } & 1893 & 20\end{array}$

$\begin{array}{llllll}1 & 1889 & 1980 & \text { GP } & 1889 & 10\end{array}$

119411975 GP 062 
ID LAT LONG ALT STATION NAME COUNIRY

STATUS

\begin{tabular}{|c|c|c|c|c|c|c|c|c|c|c|c|}
\hline 432790 & 131 & -803 & 16 & MADRAS / MINAMBAKRAM & INDIA & 1 & 1796 & 1980 & GP & 1875 & 10 \\
\hline 432830 & 129 & -749 & -999 & MANGALORE & INDIA & 1 & 1941 & 1980 & GP & 1941 & 10 \\
\hline 432950 & 130 & -776 & 921 & BANGALORE & INDIA & 1 & 1875 & 1980 & GP & 1875 & 10 \\
\hline 433110 & 111 & -728 & 4 & AMIN I & INDIA & 1 & 1892 & 1960 & GP & 1892 & 20 \\
\hline 33330 & 117 & -928 & 79 & PORT BLAIR & INDIA & 1 & 1868 & 1980 & GP & 1876 & 10 \\
\hline 3390 & 102 & -775 & 2343 & RODA IRANAL & INDIA & 1 & 1900 & 1960 & GP & 1908 & 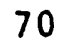 \\
\hline 10 & 100 & -763 & 3 & FORT COCHIN & INDIA & 1 & 375 & 1973 & GP & 1891 & (6 \\
\hline 30 & 93 & -793 & 11 & PAMBAN & INDIA & 2 & 1891 & 1980 & GP & 1892 & 10 \\
\hline & 83 & -728 & -999 & MINICOY & IDIA & 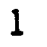 & 1931 & 1980 & GP & 1931 & \\
\hline 10 & 85 & -770 & 64 & TRIVANDRUM & INDIA & 1 & 1837 & 1980 & GP & 1837 & 20 \\
\hline 30 & 90 & -799 & 3 & MAHNAR & SRI LANRA & 1 & 1951 & 1980 & GP & 1966 & . \\
\hline 80 & 86 & -812 & 7 & TRINCOMALEE & SRI LANRA & 1 & 1865 & 1980 & GP & 1920 & \\
\hline 4660 & 69 & -799 & 6 & COLOMBO & SRI LANRA & 1 & 1853 & 1980 & GP & 1853 & 20 \\
\hline 4970 & 61 & -811 & 20 & HAMBANTOTA & SRI LANRA & 1 & 1921 & 1980 & GP & 1921 & \\
\hline 5440 & 342 & -777 & 3514 & LEH RASEMIR & INDIA & 1 & 1882 & 1968 & GP & 1882 & \\
\hline 050 & 223 & -1142 & 33 & HONG RONG/ROYAL OBS. & HONG RONG & 1 & 1853 & 1980 & GP & 1853 & 20 \\
\hline 110 & 222 & -1136 & 59 & MACAO & MACAO & 1 & 1931 & 1980 & GP & 1931 & 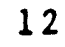 \\
\hline 20 & 250 & -1215 & 9 & TAIPEI & TAIWAN & 1 & 1897 & 1972 & GP & 1897 & \\
\hline 90 & 242 & -1207 & 85 & TAICBUNG & TAIWAN & 1 & 1897 & 1960 & GP & 1897 & \\
\hline 50 & 378 & -1289 & 27 & RANGNUNG & ROREA & 1 & 1951 & 1980 & GP & 1952 & \\
\hline & 376 & -1268 & 18 & SEOUL CITY/AP & ROREA & 1 & 1954 & 1980 & GP & 1954 & \\
\hline 20 & 375 & -1266 & 70 & INCAON & ROREA & 1 & 1905 & 1980 & GP & 5 & \\
\hline 0 & 359 & -1286 & 61 & TAEGD ARTCC (RRST) & ROREA & 1 & 1907 & 1960 & GP & 1916 & \\
\hline 0 & 348 & -1264 & 56 & MOKPO & ROREA & 1 & 1905 & 1980 & GP & 1905 & \\
\hline 0 & 454 & -1417 & 3 & WARKANAI & JAPAN & 1 & 1951 & 1980 & GP & 1 & \\
\hline 0 & 440 & -1443 & 39 & ABASBIRI & JAPAN & 1 & 1890 & 1980 & GP & 1890 & \\
\hline 20 & 431 & -1414 & 18 & SAPPORO & JAPAN & & 1889 & 1980 & GP & 89 & \\
\hline 0 & 4.33 & -1456 & 20 & NEMURO & JAPAN & 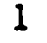 & 1880 & 1980 & GP & 80 & \\
\hline 476 & 422 & -1428 & 34 & URARAWA & JAPAN & & 1951 & 1980 & GP & 51 & \\
\hline 475 & 397 & -1401 & 10 & ARITA & JAPAN & 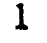 & 1886 & 0 & GP & & \\
\hline 475 & 396 & -1420 & 47 & MIYARO & JAPAN & 1 & 1883 & 0 & GP & 86 & \\
\hline 475 & 383 & -1409 & 40 & SENDAI & JAPAN & & 1 & 1980 & GP & 51 & \\
\hline 0 & 379 & -1391 & 7 & NIIGATA & JAPAN & 1 & & 0 & GP & 6 & \\
\hline 0 & 366 & -1367 & 28 & RANAZAWA & JAPAN & & 1 & 1980 & GP & 1 & \\
\hline 476 & 362 & -1380 & 611 & MATSUMOTO & JAPAN & & 8 & 1980 & GP & & \\
\hline 476 & 364 & -1391 & 113 & MAEBASEI & JAPAN & & & 1980 & GP & & \\
\hline 47 & 352 & -1370 & 56 & NAGOYA & JAPAN & & 1 & 1980 & GP & & \\
\hline 476 & 357 & -1408 & 28 & CHOSHI & JA & & 37 & 1980 & GP & & \\
\hline $47 \epsilon$ & 346 & -1382 & 47 & OMAEZARI & AN & & 1951 & 1980 & GP & & \\
\hline 47 & 358 & -1398 & 36 & TORYO & PAN & 1 & 1876 & 1980 & GP & & \\
\hline & 331 & -1398 & 81 & BACBIJOJ IMA & AN & 1 & & 1980 & GP & 1 & \\
\hline 477 & 354 & -1334 & 8 & YONAGO & JAPAN & 1 & 1940 & 1980 & GP & 1 & \\
\hline & 344 & 24 & 30 & BIROSHIMA & AN & + & 1879 & 1980 & GP & 1 & \\
\hline & 347 & & 50 & OSAKA & JAPAN & & & 1980 & GP & 1 & \\
\hline & 335 & & 75 & SHIONOMISAKI & JAPAN & 2 & & 1980 & GP & 1913 & \\
\hline & 34 & & 22 & IZUHARA & & & & 1980 & GP & 1887 & \\
\hline 470 & 336 & 04 & 14 & FUROORA & JAPAN & $\perp$ & 1890 & 1980 & GP & 1890 & \\
\hline
\end{tabular}




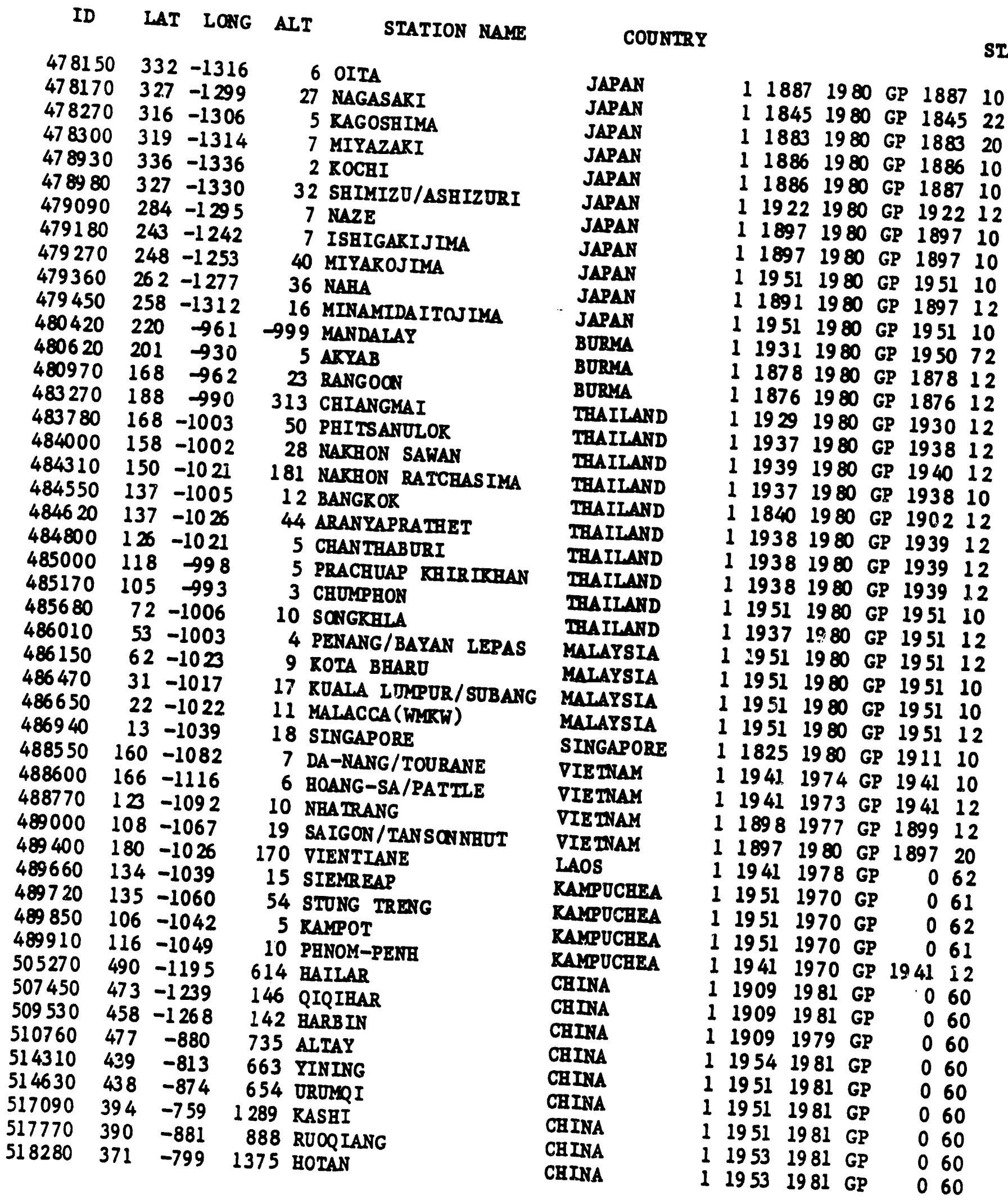




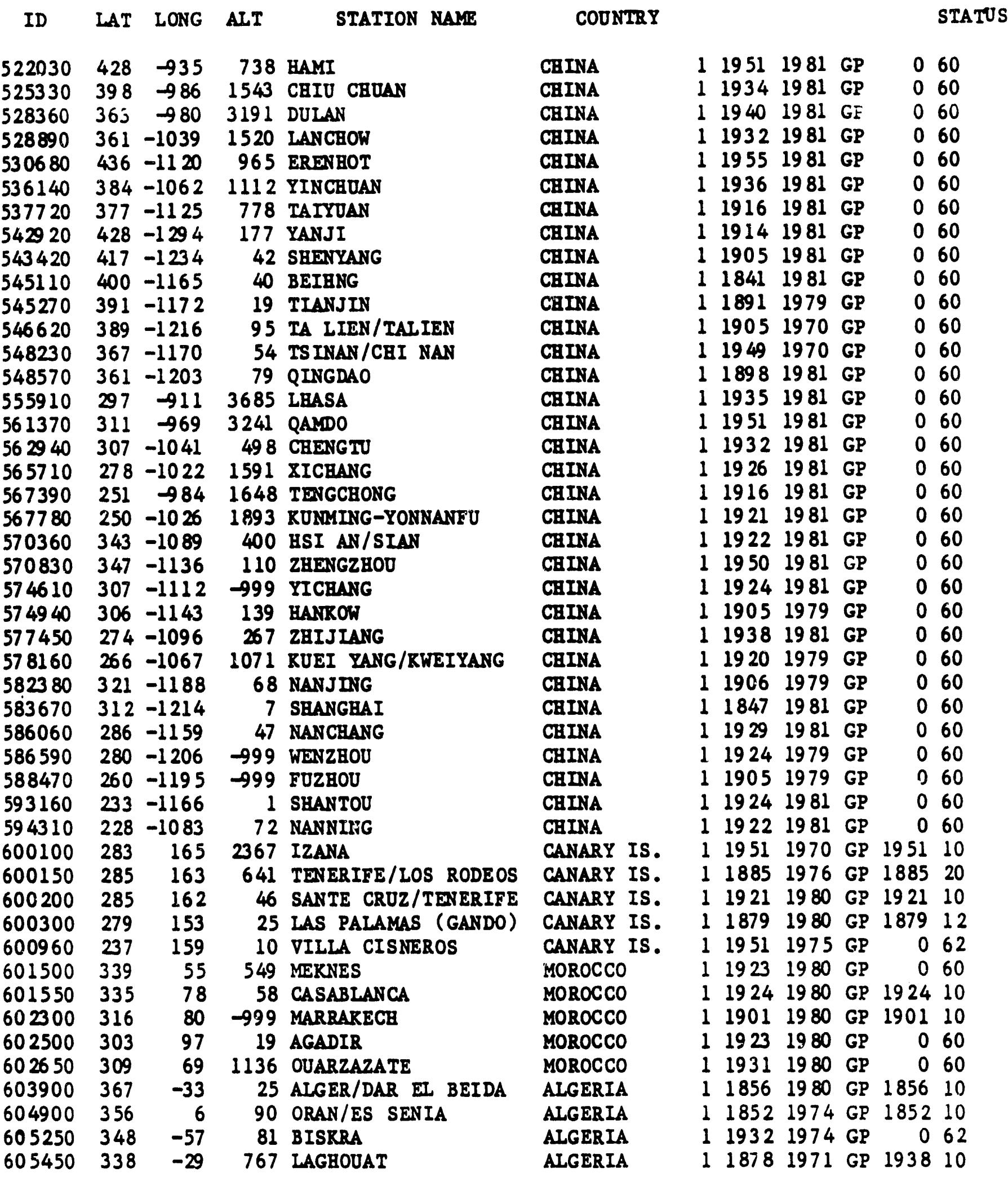




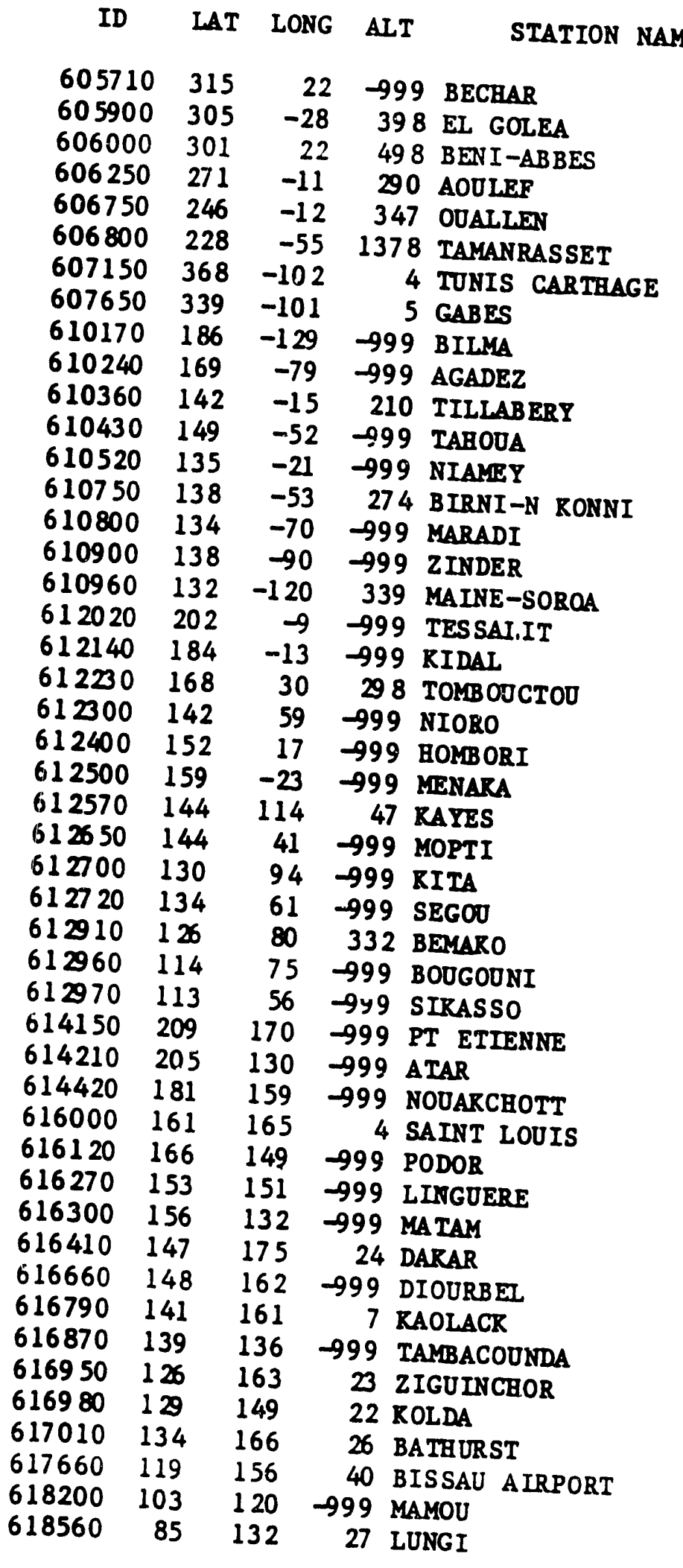

\section{COUNTRY}

STATOS

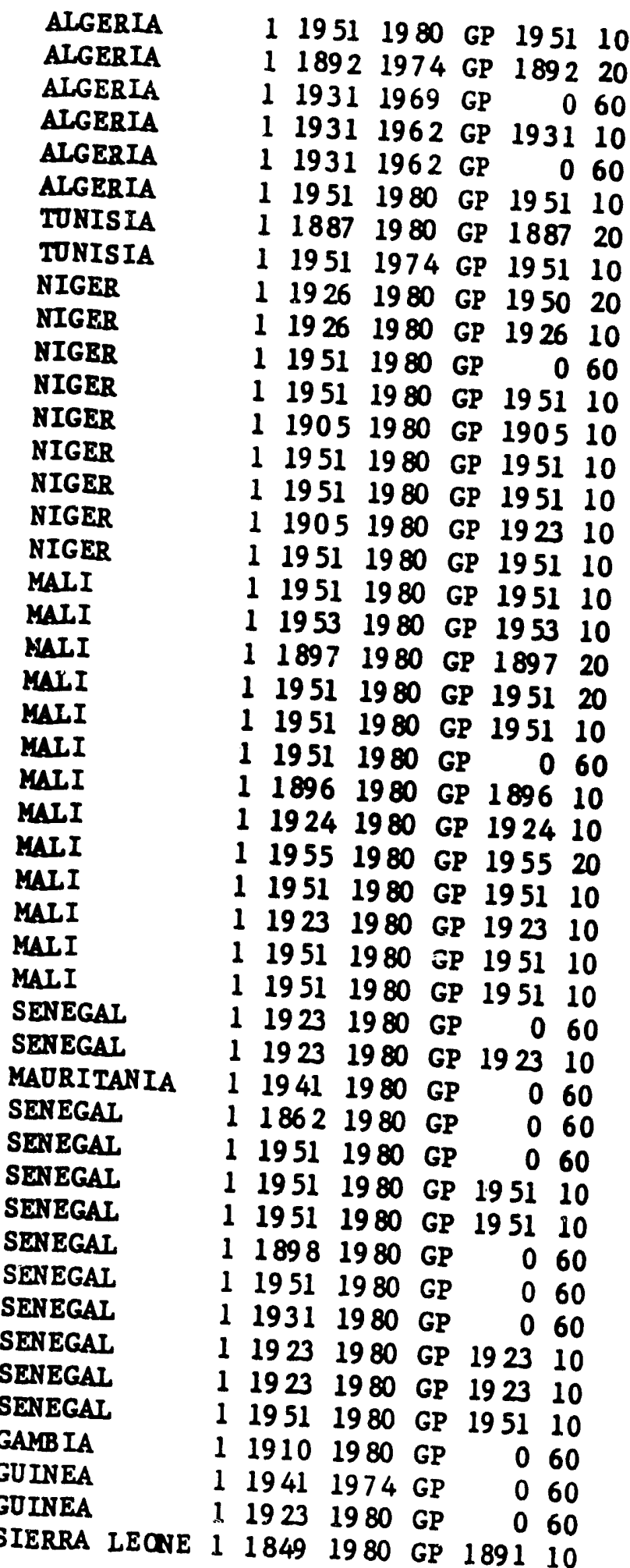


ID LAT LONG ALT STATION NAME

\begin{tabular}{|c|c|c|c|c|}
\hline 618660 & 75 & 125 & 8 & BON THE \\
\hline 618910 & 80 & 109 & 186 & DARU \\
\hline 619310 & 4 & -67 & 15 & SAO TOME \\
\hline 620100 & 329 & -132 & 84 & TRIPOLI \\
\hline 620530 & 321 & -203 & 132 & BEN INA \\
\hline 620630 & 319 & -239 & 155 & EL ADEM \\
\hline 622710 & 242 & -233 & -999 & KUFRA \\
\hline 623000 & 315 & -252 & 6 & SALLOUM \\
\hline 623060 & 313 & -272 & -999 & MATRUH \\
\hline $\begin{array}{l}623180 \\
623197\end{array}$ & 312 & -298 & -999 & ALEXANDRIA \\
\hline $\begin{array}{l}623197 \\
623330\end{array}$ & 312 & -299 & 32 & KOM EI NADURA \\
\hline $\begin{array}{l}623330 \\
623660\end{array}$ & 313 & -323 & 1 & PORT SAID \\
\hline $\begin{array}{l}623660 \\
623780\end{array}$ & 300 & -312 & -999 & CAIRO \\
\hline $\begin{array}{l}623780 \\
623870\end{array}$ & 299 & -313 & 141 & BELWAN \\
\hline 623870 & 281 & -307 & -999 & EL MINYA \\
\hline 623930 & 272 & -311 & 70 & MANQABAD/ASYUT \\
\hline 624050 & 257 & -327 & 88 & LUXOR \\
\hline 624140 & 240 & -328 & -999 & ASWAN \\
\hline 624320 & 255 & -290 & -999 & DARLA \\
\hline 624350 & 254 & -305 & -999 & RHARGA \\
\hline 624620 & 273 & -338 & 3 & BURGBADA \\
\hline 626000 & 219 & -313 & -999 & WADI BALFA \\
\hline $\begin{array}{l}626400 \\
626410\end{array}$ & 159 & -338 & -999 & ABD BAMED \\
\hline 626410 & 196 & -372 & -999 & PORT SUDAN \\
\hline 626600 & 186 & -319 & 249 & RARIMA \\
\hline 626610 & 190 & -369 & 796 & GEBEIT \\
\hline 626800 & 176 & -339 & -999 & ATBARA \\
\hline 627210 & 156 & -326 & -999 & RHARTOOM \\
\hline 627300 & 155 & -364 & 500 & KASSAIA \\
\hline 627500 & 140 & -323 & 378 & ED DUEIM \\
\hline 627510 & 144 & -335 & 408 & WAD MEDANI \\
\hline 627600 & 136 & -254 & 730 & EL FASEER \\
\hline 627700 & 134 & -223 & -999 & GENEINA \\
\hline 627710 & 131 & -302 & 74 & EL OBEID \\
\hline 627720 & 132 & -327 & 381 & ROSTI \\
\hline 627810 & 127 & -284 & -999 & EN NABUD \\
\hline 628400 & 96 & -316 & 388 & 3 MALARAL \\
\hline 628800 & 77 & -280 & 439 & WAD \\
\hline 629410 & 49 & -317 & 457 & JUBA \\
\hline 631250 & 115 & -430 & -999 & DJ IB OUTI \\
\hline 632250 & 95 & -491 & 812 & GARDO \\
\hline 632600 & 20 & -454 & 10 & MOGADISCIO \\
\hline 636120 & 31 & -356 & -999 & LODWAR \\
\hline 636240 & 40 & -419 & 231 & MANDERA \\
\hline 636300 & 27 & -323 & -999 & GULU \\
\hline 637230 & 6 & -395 & -999 & GAR ISSA \\
\hline 637390 & -13 & -368 & 1820 & NAIROBI/RA \\
\hline
\end{tabular}

COUNTRY

STATUS

SIERRA LEONE 119511980 GP 195510 SIERRA LEONE $111951 \quad 1980$ GP $1951 \quad 10$

$\begin{array}{lllllllll}\text { SAO TOME } & 1 & 1874 & 1975 & \mathrm{GP} & 1874 & 12\end{array}$ LIBYA $\quad 118921980 \mathrm{GP} \quad 062$ LIBYA $\quad 119451980 \mathrm{GP} \quad 062$ LIBYA $\quad 119451975$ GP 194510 LIBYA $\quad 119511980 \mathrm{GP} \quad 062$ $\begin{array}{lllllll}\text { EGYPT } & 1 & 19511975 \mathrm{GP} & 0 & 62\end{array}$ $\begin{array}{lllllll}\text { EGYPT } & 1 & 1951 & 1978 & \text { GP } & 1951 & 10\end{array}$ $\begin{array}{lllllll}\text { EGYPT } & 1 & 19451975 \text { GP } & 194510\end{array}$ $\begin{array}{lllllll}\text { EGYPT } & 1 & 1870 & 1957 & \text { GP } & 1870 & 10\end{array}$ $\begin{array}{llllllll}\text { EGYPT } & 1 & 1886 & 1975 & \text { GP } & 1886 & 12\end{array}$ EGYPT EGYPT EGYPT

\section{EGYPT}

EGYPT

EGYPT

EGYPT

EGYPT

EGYPT

SUDAN

SUDAN

SUDAN

SUDAN

SUDAN

SUDAN

SUDAN

SUDAN

SUDAN

SUDAN

SUDAN

SUDAN

SUDAN

SUDAN

SUDAN

SUDAN

SUDAN

SUDAN

SOMALIA

SOMALIA

SOMALIA

RENYA

RENYA

UGANDA

KENYA

RENYA $\begin{array}{llllll}1 & 1951 & 1978 & \text { GP } & 1951 & 12\end{array}$

119041978 GP 190410

119451975 GP 194510

$11951 \quad 1975$ GP 195120

119411975 GP 194110

119351978 GP 195120

$\begin{array}{lllllll}1 & 1951 & 1978 & \text { GP } & 1951 \quad 10\end{array}$

119511975 GP 195110

119511975 GP 195110

119411964 GP 060

119511975 GP 195110

119431980 GP 194310

$11951 \quad 1975$ GP 195110

119511975 GP 195110

119431975 GP $1943 \quad 10$

119011980 GP $1901 \quad 10$

$\begin{array}{llllll}1 & 1941 & 1975 & \text { GP } & 1941 \quad 20\end{array}$

$\begin{array}{lllllll}1 & 1951 & 1975 & \text { GP } & 1951 \quad 12\end{array}$

$\begin{array}{llllll}1 & 1951 & 1975 \text { GP } 195120\end{array}$

$\begin{array}{lllllll}1 & 1941 & 1980 & \text { GP } & 1941 \quad 20\end{array}$

$\begin{array}{lllllll}1 & 1951 & 1975 & \text { GP } & 1951 & 10\end{array}$

$\begin{array}{llllllll}1 & 1910 & 1980 & \text { GP } & 1910 & 20\end{array}$

119431975 GP $1943 \quad 20$

$11951 \quad 1975$ GP $1951 \quad 20$

$11941 \quad 1980 \mathrm{GP} \quad 060$

$\begin{array}{llllll}1 & 1910 & 1980 & \text { GP } & 1942 & 10\end{array}$

$\begin{array}{lllllll}1 & 1941 & 1980 & \mathrm{GP} & 1941 \quad 20\end{array}$

$11951 \quad 1978 \mathrm{GP} \quad 060$

$119541978 \mathrm{GP} \quad 061$

$11911 \quad 1981$ GP $\quad 060$

$\begin{array}{llllll}1 & 1951 \quad 1975 \text { GP } & 1951 \quad 10\end{array}$

$\begin{array}{llllllll}1 & 1951 & 1975 & \text { GP } & 1951 \quad 10\end{array}$

$\begin{array}{lllllll}1 & 1951 & 1977 \text { GP } 1951 \quad 10\end{array}$

119401980 GP 194020

$119291955 \mathrm{GP} \quad 060$ 


\begin{tabular}{|c|c|c|c|c|c|c|c|c|c|c|}
\hline ID & LAT & LONG & ALT & STATION NAME & COUNTRY & & & & & STATUS \\
\hline 637400 & -13 & -369 & 1624 & NAIROBI/AIRPORT & RENYA & 11951 & 1981 & GP & 0 & 60 \\
\hline 637410 & -13 & -368 & 1798 & NAIROBI/DAGORETTI & RENYA & 11955 & 1975 & GP & 0 & 60 \\
\hline 644580 & 16 & -161 & 352 & OUESSO & CONGO & 11951 & 1979 & GP & 1951 & 10 \\
\hline 644590 & 16 & -180 & -999 & IMPFONDO & CONGO & 11941 & 1980 & GP & 1941 & 20 \\
\hline 644600 & 21 & -140 & 547 & SOUANRE & CONGO & 11951 & 1977 & GP & 1951 & 10 \\
\hline 645000 & 7 & -102 & 10 & LIBREVILLE & GABON & 11896 & 1979 & GP & 1896 & 12 \\
\hline 645010 & 7 & -87 & -999 & PORT GENTIL & GABON & 11941 & 1980 & GP & 1941 & 10 \\
\hline 645040 & 10 & -96 & 13 & COCOBEACH & GABON & 11951 & 1980 & GP & 1951 & 10 \\
\hline 645100 & 21 & -115 & 599 & BITAY & GABON & 11954 & 1979 & GP & 1954 & 10 \\
\hline 645500 & -19 & -110 & 89 & MOUIIAA & GABON & 11951 & 1980 & GP & 1951 & 10 \\
\hline 645510 & -7 & -102 & 26 & LAMBARENE & GABON & 11951 & 1980 & GP & 1951 & 20 \\
\hline 645520 & 8 & -115 & 583 & MITZIC & GABON & 11951 & 1980 & GP & 1951 & 20 \\
\hline 5530 & -16 & -135 & -999 & FRANCEVILLE & GABON & 11946 & 1970 & GP & 1946 & 10 \\
\hline $\begin{array}{l}645560 \\
645600\end{array}$ & $\begin{array}{r}6 \\
-8\end{array}$ & $\begin{array}{l}-129 \\
-127\end{array}$ & $\begin{array}{l}515 \\
485\end{array}$ & $\begin{array}{l}\text { MAROROO } \\
\text { LASTOURSVIILE }\end{array}$ & $\begin{array}{l}\text { GABON } \\
\text { GABON }\end{array}$ & $\begin{array}{ll}1 & 1953 \\
1 & 1954\end{array}$ & $\begin{array}{l}1980 \\
1979\end{array}$ & $\begin{array}{l}\text { GP } \\
\text { GP }\end{array}$ & $\begin{array}{l}0 \\
0\end{array}$ & $\begin{array}{l}60 \\
62\end{array}$ \\
\hline 646000 & 42 & -157 & -999 & BERBERATI & C. AFR. REP. & 11951 & 1980 & GP & 0 & 62 \\
\hline 646010 & 59 & -156 & 1020 & BOUAR & C. AFR. REP. & 11951 & 1980 & GP & 0 & 62 \\
\hline 646030 & 65 & -183 & 458 & BOOCA & C. AFR. REP. & 11951 & 1967 & GP & 0 & 61 \\
\hline 646500 & 43 & -186 & -999 & BANGUI & C. AFR. REP. & 11941 & 1980 & GP & 0 & 60 \\
\hline 646540 & 84 & -206 & -999 & NDELE & C. AFR. REPP. & 11951 & 1980 & GP & 1951 & 10 \\
\hline 646550 & 65 & -220 & 584 & BRIA & C. AFR. REP. & 11951 & 1980 & GP & 1951 & 12 \\
\hline 646560 & 48 & -228 & 500 & BANGASSOO & C. AFR. REP. & 11946 & 1980 & GP & 0 & 62 \\
\hline 80 & 102 & -227 & -999 & BIRAO & C. AFR. REP. & 11951 & 1980 & GP & 1951 & 12 \\
\hline 90 & 54 & -265 & 651 & OBO & C. AFR. REP. & 11954 & 1979 & GP & 0 & 62 \\
\hline 46600 & 57 & -208 & -999 & BAMBARI & C. AFR. REP. & 11953 & 1979 & GP & 0 & 62 \\
\hline 46610 & 65 & -233 & 602 & YALINGA & C. AFR. REP. & 11953 & 1980 & GP & 1953 & 12 \\
\hline 647000 & 121 & -150 & -999 & FORT LAMP & CHAD & 11951 & 1978 & GP & 1951 & 20 \\
\hline 47050 & 104 & -167 & -999 & BOOSSO & CHAD & 11953 & 1978 & GP & 1953 & 10 \\
\hline 47060 & 85 & -160 & -999 & MOUNDOD & CHAD & 11951 & 1978 & GP & 1951 & 20 \\
\hline 47090 & 93 & -159 & -999 & PALA & CBAD & 11953 & 1978 & GP & 1953 & 10 \\
\hline 7500 & 91 & -183 & -999 & SARH & CBAD & 11941 & 1978 & GP & 1941 & 10 \\
\hline 647510 & 132 & -183 & -999 & ATI & CHAD & 11951 & 1978 & GP & 1951 & 10 \\
\hline 647530 & 180 & -191 & -999 & FAYALARGEAU & CHAD & 11946 & 1977 & GP & 0 & 62 \\
\hline 647580 & 121 & -186 & -999 & MONGO & CBAD & 11951 & 1978 & GP & 1951 & 10 \\
\hline 648700 & 72 & -133 & -999 & NGAOURENDE & CAMEROON & 11951 & 1980 & GP & 0 & 62 \\
\hline 48930 & 56 & -108 & 1210 & ROONDJA & CAMEROON & 11951 & 1979 & GP & 0 & 62 \\
\hline 9100 & 40 & -97 & 13 & DOUALA & CAMEROON & 11885 & 1979 & GP & 0 & 60 \\
\hline 00 & 39 & -115 & 760 & YAOUNDE & CAMEROON & 11889 & 1979 & GP & 0 & 60 \\
\hline 00 & 130 & -52 & -999 & SOROTO & NIGERIA & 11916 & 1960 & GP & 0 & 60 \\
\hline 60 & 120 & -85 & 476 & RANO & NIGERIA & 11905 & 1977 & GP & 1905 & 10 \\
\hline 820 & 107 & -131 & -999 & MAIDUGURI & NIGERIA & 11916 & 1977 & GP & 0 & 60 \\
\hline 1010 & 85 & -45 & -999 & ILORIN & NIGERIA & 11951 & 1977 & GP & 1951 & 10 \\
\hline & 96 & -65 & -999 & MINNA & NIGERIA & 11951 & 1976 & GP & 1951 & 10 \\
\hline & 99 & -88 & -999 & JOS & NIGERIA & 11951 & 1977 & GP & 0 & 60 \\
\hline & 92 & -124 & 174 & YOLA & NIGERIA & 11910 & 1976 & GP & 0 & 62 \\
\hline & 0. & -34 & 38 & LAGOS/IREJA & NIGERIA & 11892 & 1977 & GP & 1892 & 10 \\
\hline & 55 & -57 & -999 & WARRI & NIGERIA & 11909 & 1960 & GP & 1909 & 20 \\
\hline
\end{tabular}




\begin{tabular}{|c|c|c|c|c|c|c|c|c|c|c|c|}
\hline ID & LAT & LONG & ALT & STATION NAME & COUNTRY & & & & & & \\
\hline 52500 & 47 & -70 & -999 & PORT HARCOURT & NIGERIA & 1 & 1951 & 1977 & GP & 1951 & \\
\hline 52570 & 63 & -74 & -999 & ENOGO & NIGERIA & 1 & 1951 & 1977 & GP & 1951 & \\
\hline 52640 & 50 & -83 & -999 & CALABAR & NIGERIA & 1 & 1909 & 1960 & GP & 0 & \\
\hline 710 & 77 & -85 & -999 & MAKURDI & NIGERIA & 1 & 1951 & 1977 & GP & 1951 & \\
\hline 60 & 111 & -29 & -999 & RANDI & BENIN & 1 & 1941 & 1980 & $\mathbf{G P}$ & 1941 & \\
\hline 90 & 103 & -13 & -999 & NATITINGUE & BENIN & 1 & 1923 & 1980 & GP & 1923 & \\
\hline & 80 & -24 & -999 & SAVE & BENIN & 1 & 1951 & 1980 & GP & 1951 & \\
\hline & 72 & -21 & 167 & BOBICON & BEN IN & 1 & 1951 & 1980 & GP & 1951 & \\
\hline 40 & 63 & -24 & - l & COTONOU & BENIN & 1 & 1951 & 1980 & GP & 1951 & \\
\hline 53520 & 103 & -5 & -999 & MANGO & TOGO & 1 & 1951 & 1976 & GP & 1951 & \\
\hline 610 & 89 & -11 & -999 & SORODE & TOGO & 1 & 1951 & 1976 & GP & 1951 & \\
\hline 60 & 75 & -11 & -999 & ATAKPAME & TOGO & 1 & 1951 & 1976 & GP & 1951 & \\
\hline 370 & 61 & -12 & -999 & LOME & TOGO & 1 & 1926 & 1976 & GP & 1951 & \\
\hline 180 & 94 & -8 & -999 & TAMALE & GHANA & 1 & 5 & 1975 & GP & 1945 & \\
\hline 10 & 48 & 17 & -999 & TARORADI & GBANA & 1 & 1 & 1975 & GP & 1941 & \\
\hline 20 & 56 & 2 & & ACCRA (WAS 654490) & GHANA & 1 & 1 & 15 & GP & 1911 & \\
\hline 0 & 123 & 15 & -999 & OUAGADOUGOO & OPPER & 1 & 4 & 9 & GP & 24 & \\
\hline 0 & 122 & -4 & -999 & FADA NGOUR & UPPER VOLTA & 1 & 1 & 9 & GP & $i 1$ & \\
\hline 0 & 110 & 38 & -999 & BOBO DIOULASSO & UPPER VOLTA & 1 & 3 & 9 & GP & 41 & \\
\hline 20 & 103 & 31 & -999 & GAODA & UPPER VOLTA & 1 & 1951 & 1979 & GP & 1951 & \\
\hline 30 & 95 & 75 & -999 & ODIENNE & IVORY COAST & 1 & 1941 & 1980 & GP & 1951 & \\
\hline 0 & 74 & 75 & -999 & MAN & IVORY COAST & 1 & 1951 & 1980 & GP & 51 & \\
\hline 0 & 76 & 50 & -9 & BODARE & IVORY COAST & 1 & 15 & 1980 & GP & 51 & \\
\hline & 60 & 59 & -99 & GAGNOA & IVORY COAST & 1 & 1951 & 1980 & GP & 51 & \\
\hline & 66 & 47 & -9 & DIMBRORO & IVORY COAST & 1 & 15 & 1980 & GP & 51 & \\
\hline & 53 & 40 & -9 & ABIDJAN VI & IVORY COAST & 1 & 1 & 1980 & GP & 23 & \\
\hline & 44 & 73 & -999 & TABOD & IVORY COAST & 1 & 1941 & 1980 & GP & 1941 & \\
\hline & 49 & 60 & -999 & SASSANDRA & IVORY COAST & 1 & 1951 & 1980 & GP & 1951 & \\
\hline & 64 & 104 & 30 & HARBEL & LIBER IA & 1 & 1932 & 1960 & GP & 1932 & \\
\hline & 62 & 103 & 16 & ROBERTS FIELD & LIBERIA & 1 & & 1980 & GP & & \\
\hline & 713 & 1568 & 9 & BARROW & DSA & 1 & 1920 & 1981 & GP & 1921 & \\
\hline 0 & 701 & 1436 & 12 & BARTER ISLAND & USA & 1 & 1947 & 1981 & GP & 1948 & \\
\hline 10 & 669 & 1626 & 3 & ROTZEBUE & USA & 1 & 1928 & 1980 & GP & 29 & \\
\hline 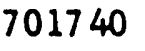 & 669 & 1515 & 196 & BETTLES & USA & 1 & 19 & 1981 & GP & 45 & \\
\hline$n$ & 652 & 1521 & 71 & TANANA & USA & 1 & 1903 & 1981 & GP & 4 & \\
\hline 8 & 649 & 147 & 145 & UNIVERSITY EXP STA & USA & 1 & 1922 & 19 & GP & 22 & \\
\hline 0 & 645 & 1654 & 4 & NOME & USA & 1 & 1906 & 1981 & GP & 1 & \\
\hline 0 & 639 & 1608 & 5 & ONALARLEET & USA & 1 & 1941 & 1981 & GP & 1942 & \\
\hline 10 & 608 & 16 & 38 & BETHEL & OSA & 1 & 1923 & 1981 & GP & 24 & \\
\hline 0 & 630 & 1 & 105 & MCGRA TH & USA & 1 & 1942 & 1980 & GP & 1942 & \\
\hline 702 & 622 & & 46 & BOLY CROSS & USA & 1 & 1893 & 1969 & GP & 1906 & \\
\hline 702480 & 625 & & 457 & FAREWELL & USA & 1 & 1944 & 1971 & GP & 1945 & \\
\hline 702490 & 621 & 15 & 559 & PONTILLA & USA & 1 & 1942 & 1981 & GP & 1942 & \\
\hline 702510 & 623 & 1501 & 105 & TALREETNA & USA & 1 & 1918 & 1981 & GP & 1920 & \\
\hline 702617 & 648 & & 133 & FAIRBANRS/EXP STAT. & USA & 1 & 1904 & 1981 & GP & 1915 & \\
\hline 702649 & 637 & 14 & 631 & MCKINLEY PARK & USA & 1 & 1923 & 1981 & GP & 1923 & \\
\hline 02670 & 640 & 1457 & 387 & BIG DELTA & USA & 1 & 1942 & 1981 & GP & 1942 & \\
\hline
\end{tabular}




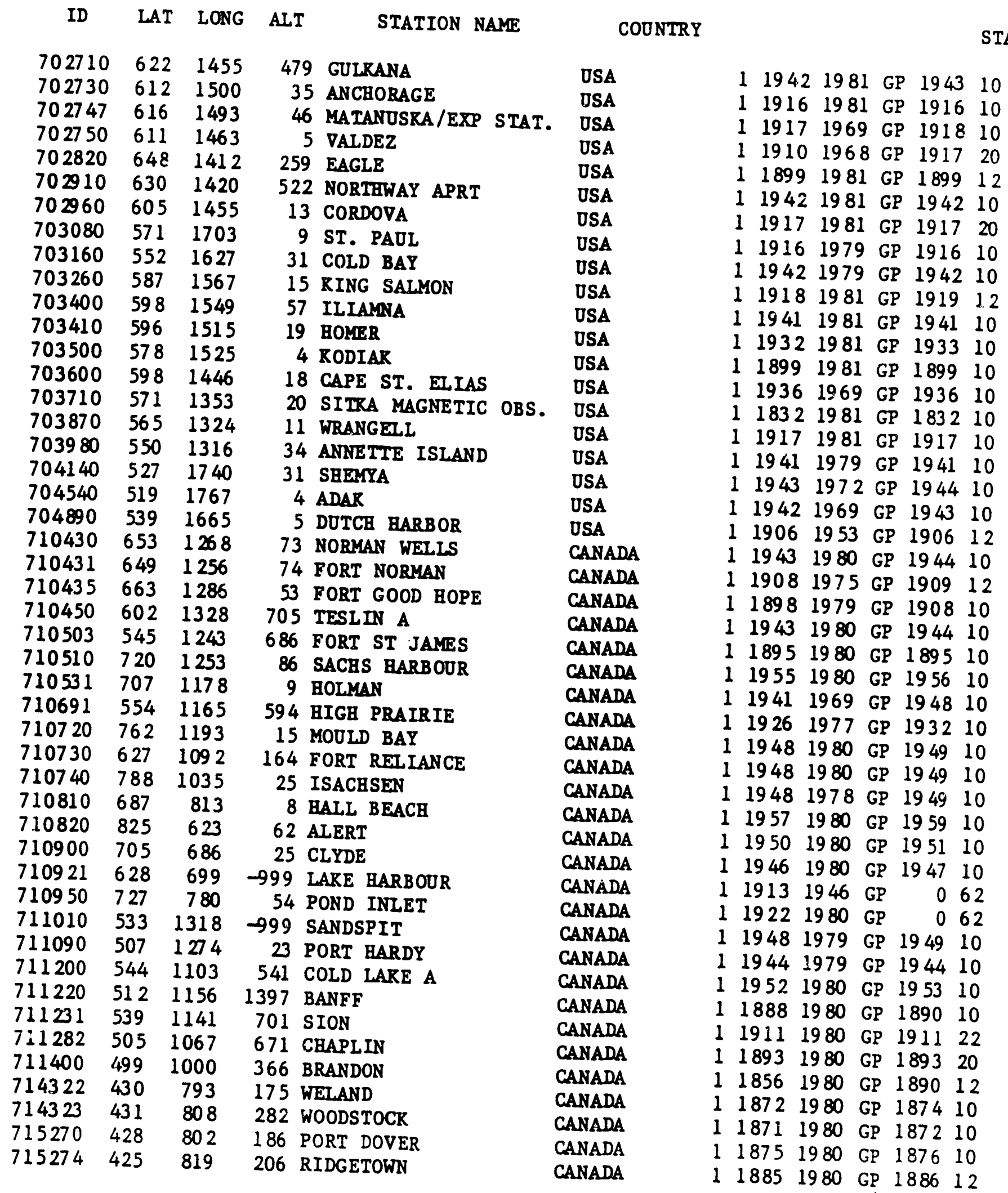




\begin{tabular}{|c|c|c|c|c|c|}
\hline ID & LAT & LONG & ALT & STATION NAME & \\
\hline 5380 & 42 & 830 & 190 & WINDSOR A & \\
\hline & 41 & & 175 & PELEE ISLAND & \\
\hline & 440 & 601 & -999 & SABLE ISLAND & ANADA \\
\hline & 446 & 635 & 41 & SAEARWATER & WAD \\
\hline & 446 & 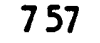 & 1 & BROCRV ILLE & LNADA \\
\hline & 442 & 774 & 76 & BELLEVILLE & ANADA \\
\hline & 443 & 783 & 194 & PETERB OROOGH & ANADA \\
\hline & 454 & 75 & 79 & OTTAWA & ANADA \\
\hline & 459 & 757 & 186 & HIGH FALIS & ANADA \\
\hline & 451 & 794 & 290 & BEATRICE & ANADA \\
\hline & 444 & 788 & 267 & LINDSAY & ANADA \\
\hline & 442 & 808 & 381 & DORHAM & CANADA \\
\hline & 435 & 802 & 334 & GUELPB OAC & ANADA \\
\hline & 453 & 800 & 194 & PARRY SOOND & ANADA \\
\hline & 445 & 814 & 186 & SOOTHAMPTON & ANADA \\
\hline & 462 & 601 & 60 & SYDNEY & ANADA \\
\hline & 474 & 61 & 60 & GRINDSTONE IS & ANADA \\
\hline 10 & 470 & 055 & 34 & CBATHAM & ANADA \\
\hline 37 & 485 & 68 & -999 & FATHER POINT & ANADA \\
\hline 20 & 464 & 76 & 170 & MANIWARI & ANADA \\
\hline 70 & 483 & 71 & 163 & BAGOTVILLE & ANADA \\
\hline 77 & 484 & 71 & 46 & CHICODTIMI & ANADA \\
\hline 10 & 46 & 795 & 201 & NORETE BAY & ANADA \\
\hline & 48 & 85 & 379 & WHITE RIVER & CANADA \\
\hline & 46 & 53 & 128 & TREPASSEY & CANADA \\
\hline & 47 & 52 & 144 & ST JOANS/TORBAY & CANADA \\
\hline & 49 & 54 & 147 & GANDER & LANADA \\
\hline & 51 & & 130 & BELLE ISLE & CANADA \\
\hline & 50 & & 58 & SEPT-ILES & CANADA \\
\hline & 50 & & 5 & MATASBQDAN & ANADA \\
\hline & 48 & & 26 & STEPBENVILLE & ANADA \\
\hline & 53 & & 49 & GOOSE & ANADA \\
\hline & 53 & 57 & 14 & CARTWRIGHT & ANADA \\
\hline & 50 & & 383 & MISTASSINI POST & ANADA \\
\hline & 53 & & 537 & NITCBEQDON & ANADA \\
\hline & 54 & 6 & 512 & SCHEFFERVILLE & ANADA \\
\hline & 47 & 77 & 1080 & GRAND LARE VICTORIA & ANADA \\
\hline & 49 & 825 & 220 & RAPUSRAS ING & ANADA \\
\hline & 51 & 80 & 10 & MOOSONEE & ANADA \\
\hline & 50 & 88 & 320 & ARMSTRONG & ANADA \\
\hline & 50 & & 390 & SIOUX LOORODT A & ANADA \\
\hline & 52 & ( & 256 & LANSDOWNE BOOSE & ANADA \\
\hline & 53 & 8 & 219 & TROOT LAKE & ANADA \\
\hline & 50 & & 361 & EAR FALLS & ANADA \\
\hline & 50 & & 261 & PORTAGE LA PRAIRIE & CANADA \\
\hline & 49 & $98-1-x-1-1)$ & 297 & MORDEN & ANADA \\
\hline & 49 & 97 & 240 & WINNIPEG（COMB INED） & CANADA \\
\hline
\end{tabular}

118661980 GP 187412

$\begin{array}{llllllll}1 & 1889 & 1980 & \text { GP } & 1920 & 72\end{array}$

$\begin{array}{lllllll}1 & 1898 & 1980 & \text { GP } & 1898 & 10\end{array}$

$\begin{array}{llllll}1 & 1852 & 1980 & \text { GP } & 1945 & 12\end{array}$

$\begin{array}{lllllll}1 & 1872 & 1980 & \text { GP } & 1916 \quad 22\end{array}$

$\begin{array}{lllllll}1 & 1866 & 1980 & \text { GP } & 1921 & 12\end{array}$

$11866 \quad 1970 \quad$ GP 196472

$\begin{array}{llllll}1 & 1872 & 1980 & \text { GP } & 1889 & 22\end{array}$

119331972 GP 196070

$\begin{array}{lllllll}1 & 1878 & 1979 & \text { GP } & 1878 & 10\end{array}$

$1 \quad 18801971$ GP $1881 \quad 10$

$\begin{array}{llllll}1 & 1882 & 1980 & \text { GP } & 1883 & 12\end{array}$

$\begin{array}{llllll}1 & 1881 & 1973 & \text { GP } & 1882 & 12\end{array}$

$1 \quad 18751976$ GP $1876 \quad 10$

118731980 GP 187420

119401980 GP 194010

$11941 \quad 1970$ GP $1941 \quad 10$

119431980 GP 194310

118771970 GP 188210

$\begin{array}{llllll}1 & 1953 \quad 1980 & \text { GP } & 1953 \quad 10\end{array}$

119421980 GP 194210

$119311970 \mathrm{GP} 194210$

$\begin{array}{llllll}1 & 1887 & 1980 & \text { GP } & 1925 & 12\end{array}$

118891976 GP 188910

119211969 GP 193410

118341970 GP 189810

$\begin{array}{lllllll}1 & 1937 & 1980 & \text { GP } & 1937 \quad 10\end{array}$

119121968 GP 192072

119441979 GP 194510

$\begin{array}{lllllll}1 & 1914 & 1980 & \text { GP } & 1915 & 10\end{array}$

$\begin{array}{lllllll}1 & 1942 & 1980 & \text { GP } & 1942 & 10\end{array}$

$11941 \quad 1980$ GP 194210

$\begin{array}{lllllll}1 & 19341980 \text { GP } 1941 \quad 10\end{array}$

$\begin{array}{llllll}1 & 1921 & 1969 & \text { GP } & 0 & 62\end{array}$

119421980 GP 194310

$\begin{array}{lllllll}1 & 1949 & 1969 & \text { GP } & 1949 & 10\end{array}$

$\begin{array}{llllll}1 & 1939 & 1980 & \text { GP } & 1946 & 10\end{array}$

119381980 GP 193810

$\begin{array}{lllllll}1 & 1877 & 1980 & \text { GP } & 1889 & 10\end{array}$

$\begin{array}{lllllll}1 & 1938 & 1980 & \text { GP } & 1939 & 10\end{array}$

$1 \quad 19141980$ GP 191510

119411980 GP 194210

$\begin{array}{llllll}1 & 1939 & 1980 & \text { GP } & 1939 & 10\end{array}$

$\begin{array}{lllllll}1 & 1928 & 1980 & \text { GP } & 1928 & 22\end{array}$

$\begin{array}{lllllll}1 & 1886 & 1971 & \text { GP } & 1886 & 22\end{array}$

119041980 GP 190510

$\begin{array}{llllll}1 & 18721979 & \text { GP } 187810\end{array}$ 


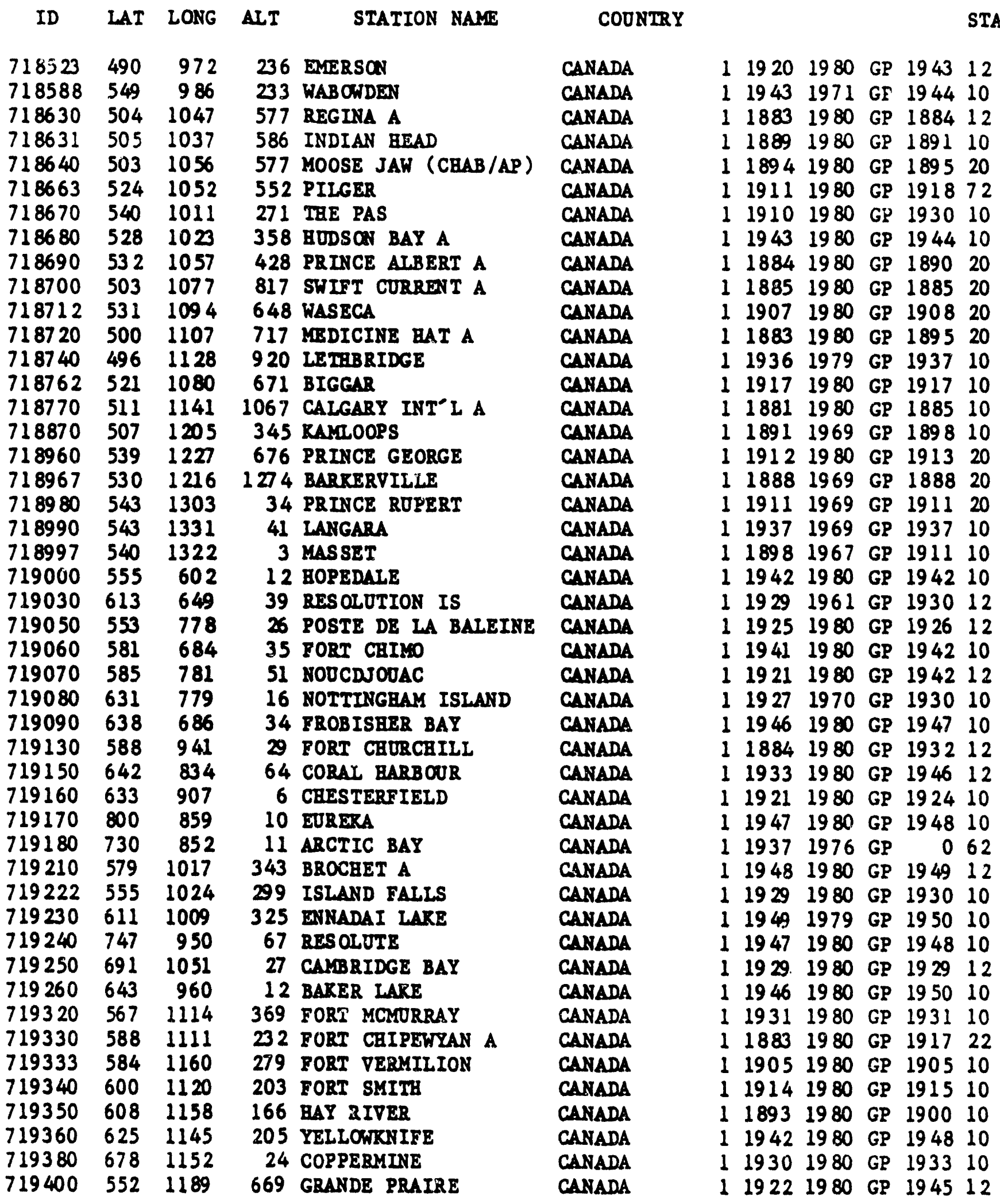




\begin{tabular}{|c|c|c|c|c|c|c|c|c|c|c|}
\hline ID & LAT & LONG & ALT & STATION NAME & COUNIRY & & & & & SI \\
\hline 719401 & 561 & 1184 & 670 & FAIRVIEW & CANADA & 11931 & 1980 & GP & 1931 & \\
\hline 719410 & 558 & 1247 & 747 & GERMANSEN LANDING & CANADA & 11951 & 1980 & GP & 1951 & 10 \\
\hline 719430 & 562 & 1207 & 695 & FORT ST JOHN & CANADA & 11931 & 1980 & GP & 1942 & 10 \\
\hline 719431 & 562 & 1207 & 686 & BALDONNEL & CANADA & 11927 & 1980 & GP & 1927 & 20 \\
\hline 719442 & 552 & 1194 & 732 & BEAVERLODGE & CANADA & 11913 & 1980 & GP & 1913 & 10 \\
\hline 719450 & 588 & 1226 & 382 & FORT NELSON & CANADA & 11937 & 1980 & GP & 1939 & 10 \\
\hline 719460 & 618 & $1 \angle 2$ & 169 & FORT SIMPSON & CANADA & 11895 & 1980 & GP & 1910 & 1.2 \\
\hline 719461 & 632 & 1234 & 156 & WRIGLEY & CANADA & 11943 & 1980 & GP & 1951 & 10 \\
\hline 719491 & 628 & 1374 & 454 & FORT SELRIRR & CANADA & 11952 & 1980 & GP & 1957 & 10 \\
\hline 719500 & 548 & 1272 & 523 & SMITHERS & CANADA & 942 & 1980 & GP & 1943 & 10 \\
\hline 719510 & 545 & 1286 & 217 & TERRACE & CANADA & 12 & 1980 & GP & 1912 & \\
\hline 719511 & 552 & 1276 & 351 & NEW BAZELTON & CANADA & 14 & 1976 & GP & 1915 & \\
\hline 719530 & 601 & 1288 & 689 & WATSON LARE & CAMADA & 38 & 1980 & GP & 1944 & \\
\hline 719570 & 683 & 1335 & 68 & INOVIR & CANADA & 57 & 1980 & GP & 1960 & \\
\hline 719580 & 584 & 1300 & 816 & DEASE LARE & CANADA & 44 & 1980 & GP & 1947 & \\
\hline 719590 & 695 & 1330 & 18 & TUKTOYAKTUR & CANADA & 48 & 1980 & GP & 1950 & \\
\hline 719640 & 607 & 1351 & 703 & WHI TERORSE & CANADA & 11942 & 1980 & GP & 1943 & \\
\hline 719650 & 636 & 1359 & 504 & MAYO & CANADA & 11925 & 1980 & GP & 1929 & \\
\hline 719 & 641 & 1391 & 369 & DAWS ON & CANADA & 11900 & 1980 & GP & 1901 & \\
\hline 719680 & 682 & 1350 & 0 & ARIAVIK & CANADA & 11926 & 1962 & GP & 1926 & \\
\hline 719930 & 674 & 1349 & 30 & FORT MCPHERSON & CANADA & 11892 & 1977 & GP & 1940 & \\
\hline 722010 & 246 & 818 & 6 & REY WEST & USA & 11851 & 1970 & GP & 1851 & \\
\hline 72 & 258 & 803 & 2 & MIAMI & DSA & 11895 & 1980 & GP & 1895 & \\
\hline $72:$ & 303 & 817 & 9 & JACKS ONVILLE & OSA & 11872 & 1980 & GP & 1872 & \\
\hline 722 & 321 & 812 & 14 & SAVANNAH & USA & $1187 \cdot 4$ & 1980 & GP & 1874 & \\
\hline 722 & 328 & 799 & 15 & CEARLESTON & USA & 11823 & 1980 & GP & 1823 & \\
\hline 722 & 280 & 825 & 6 & TAMPA & USA & 11825 & 1980 & GP & 1825 & \\
\hline 722 & 283 & 823 & 54 & ST. LEO & DSA & 11937 & 1970 & GP & 0 & \\
\hline 72 & 309 & 839 & 79 & THOMASVILLE & USA & 11892 & 1980 & GP & 1892 & \\
\hline 72 & 327 & 837 & 108 & MACON & USA & 11868 & 1980 & GP & 1868 & \\
\hline 72 & 337 & 844 & 308 & ATZANTA & USA & 11879 & 1980 & GP & 1892 & \\
\hline 72 & 305 & 872 & 34 & PENSACOLA & USA & 11879 & 1980 & GP & 1879 & \\
\hline 72 & 307 & 882 & 22 & MOBILE & USA & 11873 & 1970 & GP & 1873 & \\
\hline 10 & 300 & 901 & 17 & NEW ORLEANS & USA & 11874 & 1980 & GP & 1874 & \\
\hline 722340 & 323 & 888 & 88 & MERIDIAN & USA & 11889 & 1980 & GP & 1889 & \\
\hline 722360 & 324 & 909 & 78 & VICRSBURG & USA & 11871 & 1980 & GP & 1872 & \\
\hline 722401 & 302 & 927 & 8 & JENNINGS & USA & 11897 & 1980 & GP & 1897 & \\
\hline 722420 & 291 & 949 & 16 & GALVESTON & USA & 11873 & 1977 & GP & 1873 & \\
\hline 722480 & 325 & 938 & 77 & SHREVEPORT & USA & 11872 & 1980 & GP & 1872 & \\
\hline 722500 & 259 & 974 & 6 & BROWNSVILLE & USA & 11951 & 1980 & GP & 1951 & \\
\hline 722530 & 295 & 985 & 240 & SAN ANTONIO & USA & 11885 & 1980 & GP & 1886 & \\
\hline 722556 & 285 & 977 & 69 & BEEVILLE & USA & 11922 & 1970 & GP & 1922 & \\
\hline 722660 & 324 & 997 & 534 & ABILENE & USA & 11886 & 1980 & GP & 1886 & \\
\hline 722680 & 333 & 1045 & 1112 & ROSWELL & USA & 11893 & 1980 & GP & 1893 & \\
\hline 722682 & 324 & 1042 & 951 & CARLSBAD & USA & 118 & 1980 & GP & 1894 & \\
\hline 722684 & 330 & 1058 & 2691 & CLOUDCROFT & US & 11901 & 1970 & GP & 1901 & \\
\hline 722685 & 344 & 1032 & 1304 & CLOVIS & USA & 11911 & 1980 & GP & 1911 & \\
\hline
\end{tabular}




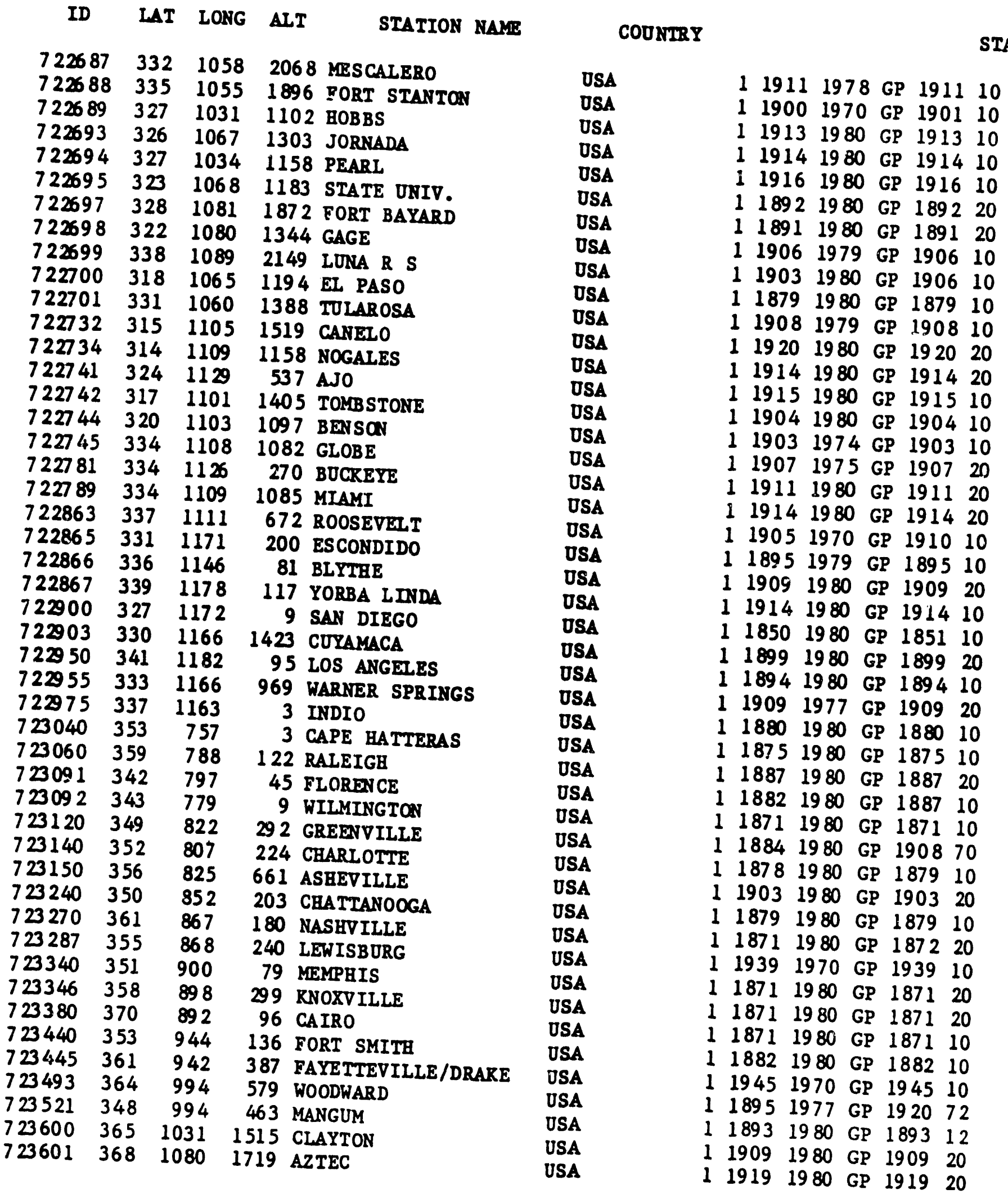




\begin{tabular}{|c|c|c|c|c|c|c|c|c|c|c|}
\hline ID & LAT & I,ONG & ALT & STATION NAME & & & & & & $\mathrm{S}$ \\
\hline 602 & 367 & 1080 & 1757 & BLOOMF IELD & USA & 11904 & 1980 & GP & 1904 & 10 \\
\hline 23603 & 342 & 1034 & 1222 & PORTALES & USA & 11911 & 1980 & GP & 1911 & 10 \\
\hline 23604 & 367 & 1060 & 2475 & TRES PIEDRAS & USA & 11905 & 1979 & GP & 1905 & 10 \\
\hline 23606 & 364 & 1056 & 2117 & TAOS & USA & 11901 & 1980 & GP & 1901 & 10 \\
\hline 23607 & 360 & 1068 & 2484 & WOLF CANYON & USA & 11912 & 1980 & GP & 1912 & 20 \\
\hline 23608 & 364 & 1046 & 1785 & SPRINGER & USA & 11891 & 1980 & GP & 1904 & 10 \\
\hline 23609 & 351 & 1033 & 1289 & SAN JON & USA & 11907 & 1980 & GP & 1908 & 10 \\
\hline 3647 & 366 & 1017 & 1003 & GOODWELL & USA & 11910 & 1970 & GP & 1910 & 10 \\
\hline 3652 & 355 & 1041 & 1371 & BELI & USA & 11904 & 1980 & GP & 1904 & 10 \\
\hline 3653 & 345 & 1043 & 1228 & FORT SUMAER & USA & 11908 & 1980 & GP & 1908 & 20 \\
\hline 654 & 355 & 1085 & 2134 & FORT WINGATE & USA & 11897 & 1966 & $\mathrm{GP}$ & 1904 & 20 \\
\hline 3655 & 345 & 1094 & 1746 & ST. JOHNS & USA & 11909 & 1980 & GP & 1909 & 10 \\
\hline 3657 & 343 & 1056 & 2031 & CORONA & USA & 11912 & 1980 & GP & 1912 & 20 \\
\hline 3659 & 356 & 1052 & 1972 & LAS VEGAS & USA & 11892 & 1980 & GP & 1892 & 10 \\
\hline 3660 & 357 & 1059 & 2195 & SANTE FE & USA & 11849 & 1977 & GP & 1849 & io \\
\hline 23662 & 348 & 1067 & 1489 & LOS LUNAS & USA & 11889 & 1970 & GP & 1890 & 10 \\
\hline 23665 & 341 & 1072 & 1993 & MAGDELENA & USA & 11906 & 1980 & GP & 1906 & 10 \\
\hline 23666 & 345 & 1063 & 1987 & MOUNTAIN AIR & USA & 11902 & 1980 & GP & 1902 & 10 \\
\hline 23701 & 352 & 1125 & 1588 & ASHFORK & USA & 1 íy 16 & 1980 & GP & 1918 & 10 \\
\hline 23702 & 353 & 1117 & 2239 & FORT VALLEY & USA & 11909 & 1980 & GP & 1909 & 10 \\
\hline 23704 & 343 & 1115 & 1404 & NATURAL BRIDGE & USA & 11914 & 1970 & GP & 1914 & 10 \\
\hline 23705 & 353 & 1129 & 1500 & SEL IGMAN & USA & 11904 & 1980 & GP & 1904 & 10 \\
\hline 23706 & 353 & 1122 & 2057 & WILLIAMS & USA & 11902 & 1980 & GP & 1947 & 10 \\
\hline 37 & 346 & 1126 & 2679 & PRESCOTT & USA & 11898 & 1980 & GP & 1898 & 10 \\
\hline 37 & 351 & 1117 & 2135 & FIAGSTAFF & USA & 11891 & 1980 & GP & 1891 & 10 \\
\hline 37 & 350 & 1107 & $: 4 \overline{2} 2$ & WINSLOW & USA & 11909 & 1980 & GP & 1909 & 10 \\
\hline 7.7 & 349 & 1102 & 1545 & HOLBROOK & USA & 11904 & 1980 & GP & 1909 & 10 \\
\hline 2374 & 345 & 1101 & 1720 & SNOWF LARE & USA & 11910 & 1980 & GP & 1910 & 10 \\
\hline 23745 & 341 & 1093 & 2152 & SPRINGERVILLE & USA & 11911 & 1980 & GP & 1911 & 20 \\
\hline 23780 & 361 & 1121 & 2118 & GRAND CANYON & USA & 11903 & 1980 & GP & 1903 & 10 \\
\hline 23811 & 340 & 1127 & 638 & WICKENBURG & USA & 11908 & 1980 & GP & 1908 & 10 \\
\hline 1 & 341 & 1173 & 257 & SAN BERNARDINO & USA & 11891 & 1980 & GP & 1891 & 10 \\
\hline 2 & 341 & 1172 & 412 & REDILANDS & USA & 11893 & 1980 & GP & 1893 & 20 \\
\hline 23860 & 351 & 1152 & 664 & LAS VEGAS & USA & 11937 & 1980 & GP & 1937 & 10 \\
\hline 1 & 355 & 1149 & 1079 & SESRCHLIGHT & USA & 11913 & 1980 & GP & 1913 & 12 \\
\hline 1 & 369 & 1168 & 1006 & BEATTY & USA & 11913 & 1970 & GP & 1913 & 12 \\
\hline 0 & 368 & 1197 & 100 & FRESNO & USA & 11887 & 1980 & GP & 1887 & 10 \\
\hline 2 & 363 & 1197 & 75 & BANFORD & USA & 11901 & 1980 & GP & 1901 & 10 \\
\hline 3 & 368 & 1214 & 85 & HOLLISTER & USA & 11874 & 1974 & GP & 1875 & 20 \\
\hline & 363 & 1193 & 99 & VISALIA & USA & 11888 & 1980 & GP & 1888 & 20 \\
\hline 238 & 364 & 1190 & 156 & LEMON COVE & USA & I 1899 & 1980 & GP & 1899 & 20 \\
\hline 3911 & 345 & 1193 & 228 & OJAI & USA & 11909 & 1980 & GP & 1909 & 20 \\
\hline 4041 & 382 & 757 & 6 & PRINCESS ANNE & USA & 11823 & 1980 & GP & 1894 & 12 \\
\hline .4057 & 393 & 769 & 126 & WOODSTOCR & USA & 11928 & 1970 & GP & 1928 & 10 \\
\hline & 395 & 746 & 3 & AILANTIC CITY & USA & 11874 & 1980 & GP & 1884 & 20 \\
\hline & 400 & 752 & -999 & PHILADELPHIA & USA & 11758 & 1970 & GP & 0 & 62 \\
\hline & 373 & 792 & 286 & LYNCHBURG/ & USA & 1871 & 1977 & GP & 1895 & \\
\hline
\end{tabular}




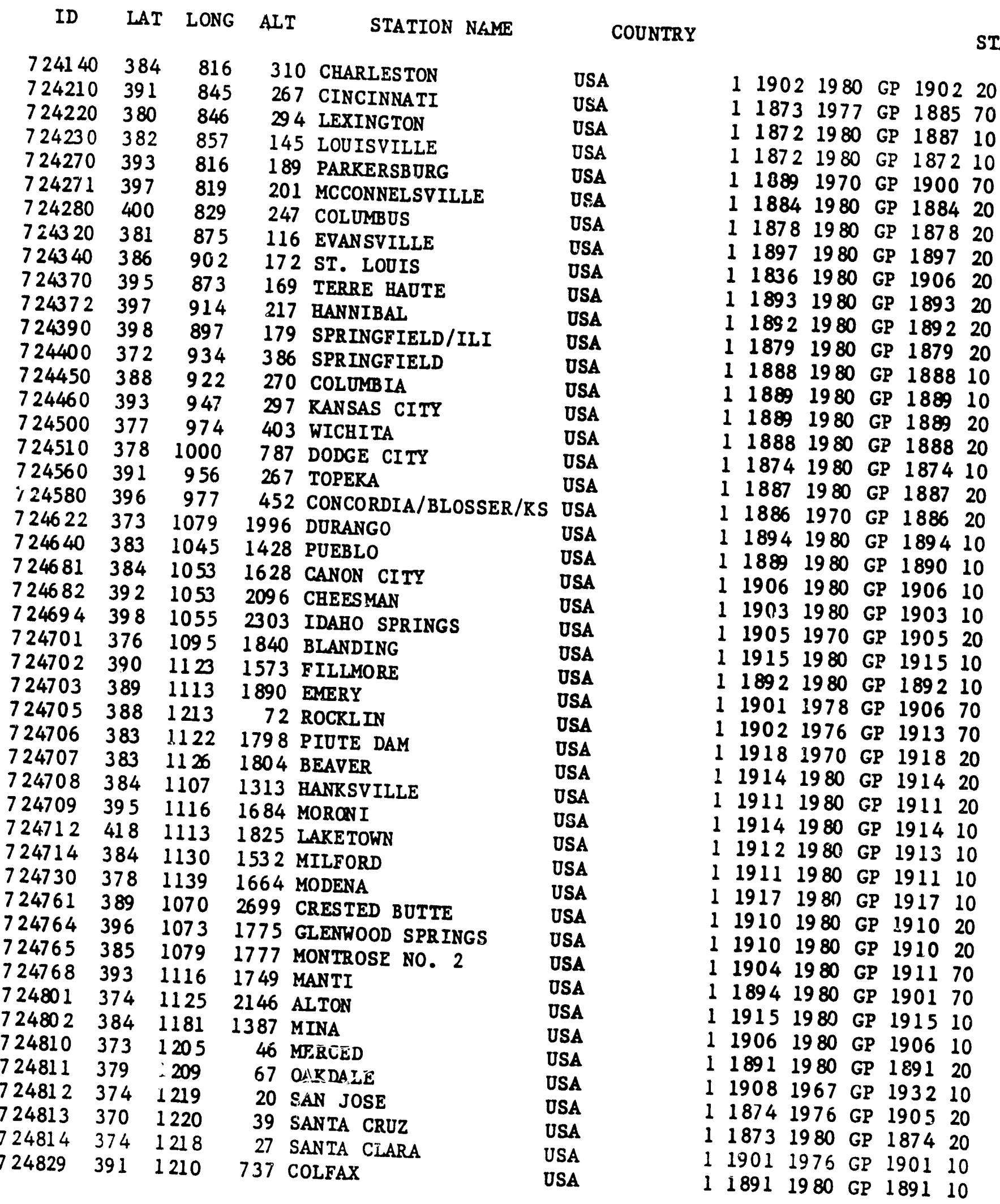


ID LAT LONG ALT STATION NAMR

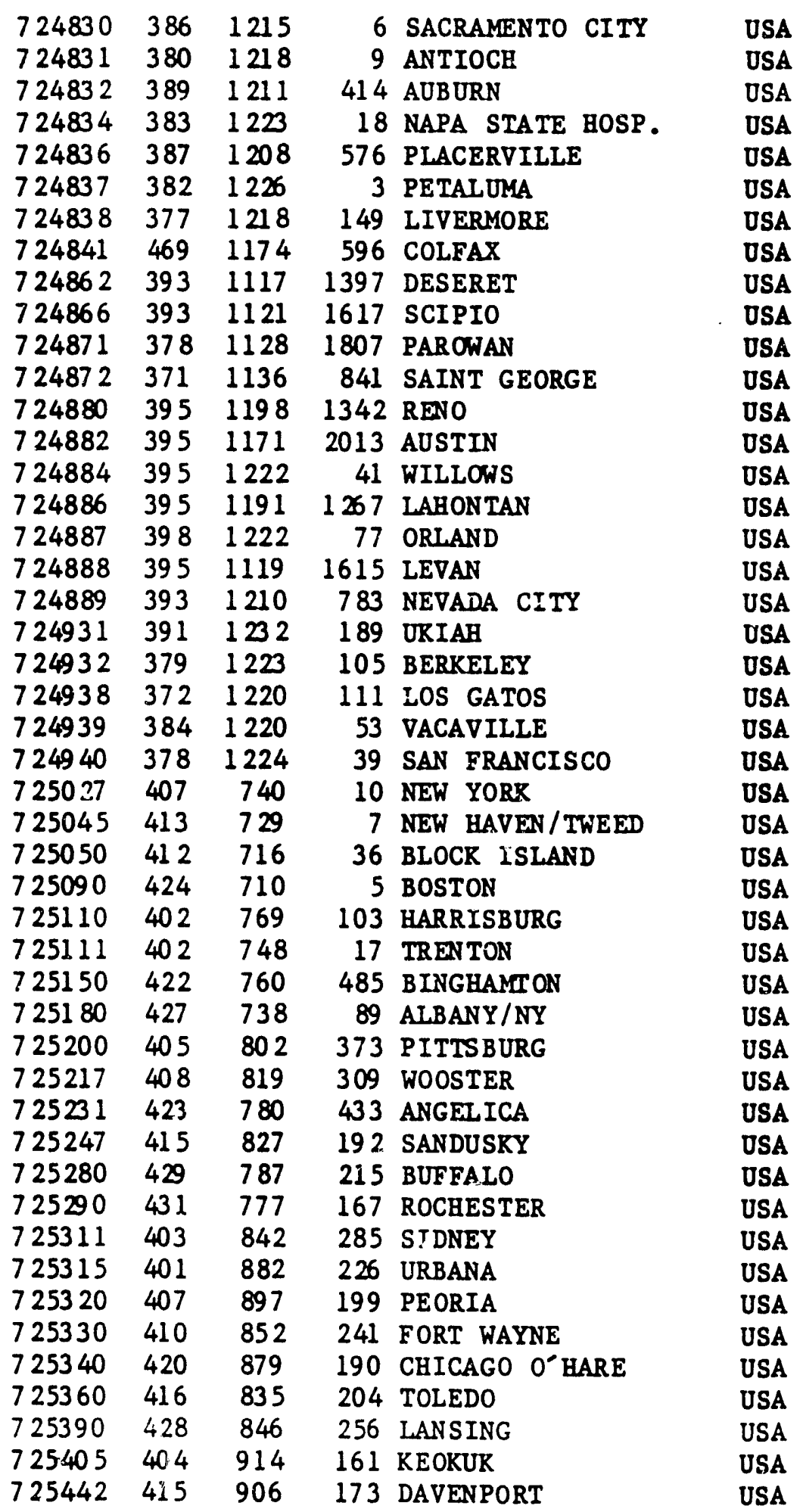

COONTRY

STATUS

$\begin{array}{llllll}1 & 1853 & 1980 & \text { GP } & 1853 \quad 20\end{array}$

119161975 GP 192470

$\begin{array}{lllllll}1 & 1916 \quad 1980 & \text { GP } & 1916 \quad 10\end{array}$

$\begin{array}{llllll}1 & 1876 \quad 1980 & \text { GP } & 1876 \quad 20\end{array}$

$\begin{array}{lllllll}1 & 1890 & 1980 & \text { GP } & 1892 & 10\end{array}$

$\begin{array}{lllllll}1 & 1913 \quad 1980 & \text { GP } & 1920 & 70\end{array}$

$\begin{array}{lllllll}1 & 1871 & 1978 & \text { GP } & 1883 & 10\end{array}$

$\begin{array}{lllllll}1 & 1892 & 1980 & \text { GP } & 1892 & 10\end{array}$

$\begin{array}{lllllll}1 & 1913 & 1980 & \text { GP } & 1913 & 10\end{array}$

$\begin{array}{lllllll}1 & 18951980 & \text { GP } & 1897 \quad 10\end{array}$

119141980 GP 191410

119141980 GP $1914 \quad 10$

$\begin{array}{lllllll}1 & 1888 & 1980 & \text { GP } & 1900 & 20\end{array}$

$\begin{array}{llllllll}1 & 1888 & 1980 & \text { GP } & 1911 & 10\end{array}$

$\begin{array}{lllllll}1 & 1878 & 1979 & \text { GP } & 1892 & 70\end{array}$

$\begin{array}{lllllll}1 & 1911 & 1980 & \text { GP } & 1911 & 10\end{array}$

$\begin{array}{lllllll}1 & 1883 & 1980 & \text { GP } & 1903 & 70\end{array}$

$\begin{array}{lllllll}1 & 1891 & 1980 & \text { GP } & 1891 & 10\end{array}$

$\begin{array}{lllllll}1 & 1895 & 1980 & \text { GP } & 1895 & 10\end{array}$

$\begin{array}{lllllll}1 & 18921980 & \text { GP } & 1924 & 10\end{array}$

$\begin{array}{lllllll}1 & 1889 & 1980 & \text { GP } & 1889 & 10\end{array}$

$\begin{array}{lllllll}1 & 1887 & 1980 & \text { GP } & 1891 & 10\end{array}$

$\begin{array}{llllll}1 & 1893 \quad 1980 & \text { GP } & 190510\end{array}$

$\begin{array}{llllll}1 & 1851 & 1982 & \text { GP } & 1871 & 10\end{array}$

$\begin{array}{llllll}1 & 1822 & 1977 & \text { GP } & 1822 & 10\end{array}$

$\begin{array}{llllll}1 & 1781 & 1970 & \text { GP } & 1781 & 20\end{array}$

$\begin{array}{lllllll}1 & 1880 & 1970 & \text { GP } & 1888 & 20\end{array}$

$\begin{array}{lllllll}1 & 1743 & 1980 & \text { GP } & 1871 & 20\end{array}$

$\begin{array}{lllllll}1 & 1888 & 1980 & \text { GP } & 1888 & 10\end{array}$

$\begin{array}{lllllll}1 & 1866 & 1980 & \text { GP } & 1866 & 20\end{array}$

$\begin{array}{llllll}1 & 1890 & 1980 & \text { GP } & 1890 & 20\end{array}$

$\begin{array}{llllll}1 & 1820 & 1977 & \text { GP } & 182020\end{array}$

$\begin{array}{lllllll}1 & 1870 & 1977 & \text { GP } & 1870 \quad 20\end{array}$

$\begin{array}{lllllll}1 & 19381970 & \text { GP } & 193810\end{array}$

$\begin{array}{lllllll}1 & 1855 & 1980 & \text { GP } & 1855 & 10\end{array}$

$\begin{array}{lllllll}1 & 1877 & 1970 & \text { GP } & 1877 & 10\end{array}$

$\begin{array}{llllll}1 & 1831 & 1980 & \text { GP } & 1841 & 10\end{array}$

$\begin{array}{lllllll}1 & 1830 & 1980 & \text { GP } & 1830 & 10\end{array}$

$\begin{array}{lllllll}1 & 1883 & 1980 & \text { GP } & 1883 & 20\end{array}$

$\begin{array}{lllllll}1 & 1920 & 1970 & \text { GP } & 1920 & 10\end{array}$

$\begin{array}{lllllll}1 & 1856 & 1980 & \text { GP } & 1856 \quad 20\end{array}$

$\begin{array}{lllllll}1 & 1887 & 1980 & \text { GP } & 1887 & 20\end{array}$

$\begin{array}{lllllll}1 & 1873 & 1980 & \text { GP } & 1873 & 20\end{array}$

$\begin{array}{lllllll}1 & 1871 & 1980 & \text { GP } & 1871 & 20\end{array}$

$\begin{array}{llllllll}1 & 1864 & 1980 & \text { GP } & 1864 & 10\end{array}$

$\begin{array}{lllllll}1 & 1871 & 1980 & \text { GP } & 1871 & 10\end{array}$

118721980 GP 187210 


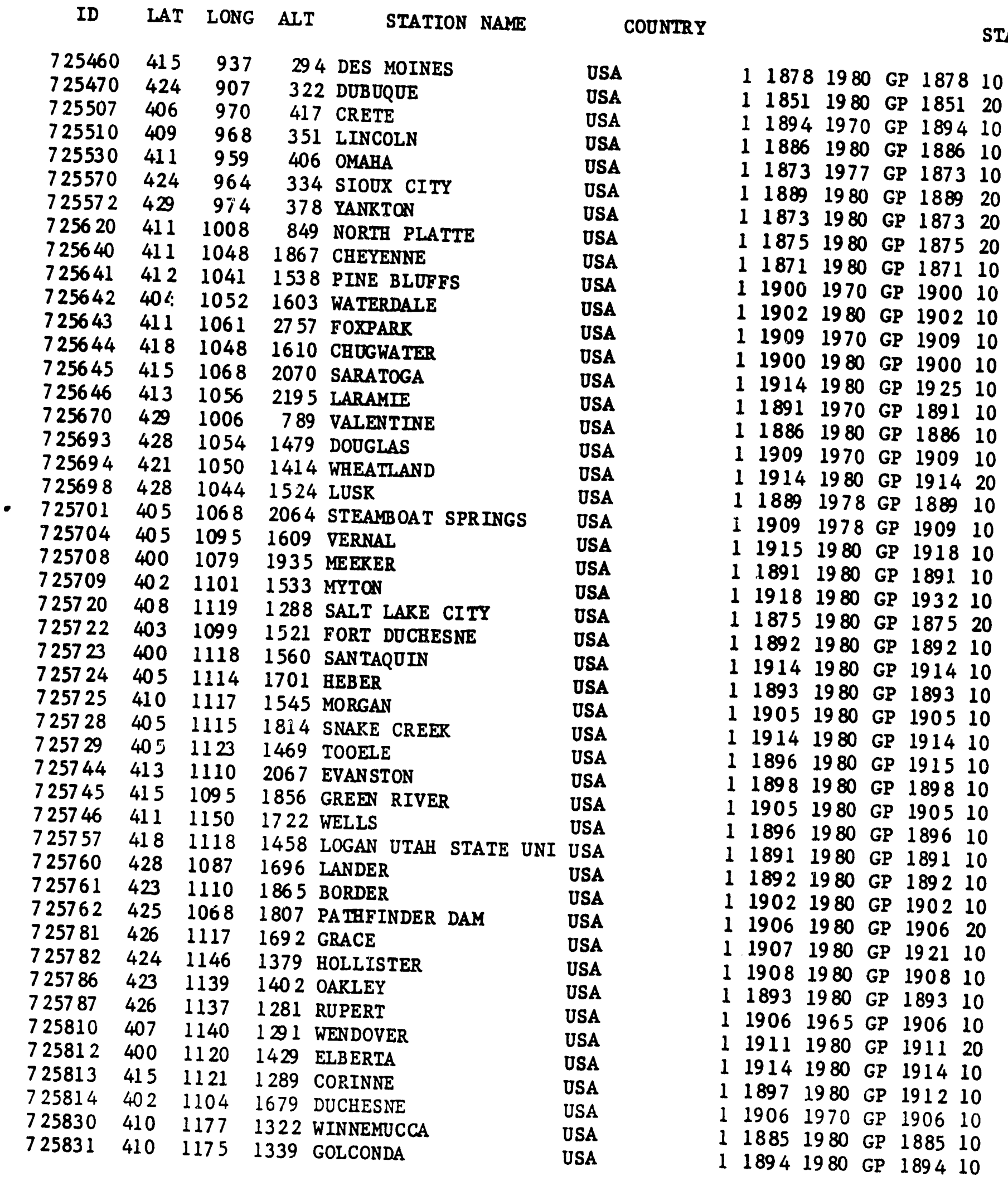




\begin{tabular}{|c|c|c|c|c|c|c|c|c|c|c|}
\hline ID & LAT & LONG & $A \perp T$ & STATION NAME & & & & & & \\
\hline 725832 & 407 & 1155 & 1917 & LAMOILLE & USA & 11912 & 1970 & GP & 1918 & \\
\hline 725910 & 401 & 1223 & 103 & RED BLUFF & USA & 11872 & 1980 & GP & 1878 & \\
\hline 725912 & 406 & 1224 & 175 & REDDING & USA & 11901 & 1980 & GP & 1901 & \\
\hline 725913 & 418 & 1234 & 332 & HAPPY CAMP & USA & 11914 & 1980 & GP & 1914 & \\
\hline 25914 & 404 & 1119 & 1371 & OTAB LARE LEHI & USA & 11914 & 1980 & GP & 1914 & \\
\hline 125940 & 408 & 1242 & 13 & EUREKA & USA & 11886 & 1980 & GP & 1886 & \\
\hline 25950 & 413 & 1223 & 1082 & MOUNT SHASTA & USA & 11888 & 2977 & GP & 1931 & \\
\hline 25969 & 427 & 1225 & 756 & PROSPECT & USA & 11908 & 1980 & GP & 8 & \\
\hline 25971 & 422 & 1227 & 542 & ASHLAND & USA & 11889 & 1980 & GP & 89 & \\
\hline 25972 & 421 & 1243 & 24 & BROORINGS & USA & 11913 & 1980 & GP & 13 & \\
\hline 25975 & 430 & 1234 & 202 & RIDDLE & USA & 11913 & 1980 & GP & 13 & \\
\hline 25976 & 422 & 1218 & 1249 & RIAMATH FALLS & USA & 11897 & 1980 & GP & 1897 & \\
\hline 25978 & 417 & 1226 & 802 & YRERA & USA & 11914 & 1980 & GP & 1914 & \\
\hline 25979 & 432 & 1234 & 142 & ROSEBURG & OSA & 11877 & 1980 & GP & 77 & \\
\hline 50 & 432 & 715 & 104 & CONCORD & USA & 11871 & 1980 & GP & 1871 & \\
\hline 26 & 445 & $\begin{array}{l}732 \\
751\end{array}$ & 101 & BURLINGTON & USA & 11884 & 1980 & GP & 1884 & \\
\hline $\begin{array}{l}26 \\
26\end{array}$ & $\begin{array}{l}446 \\
443\end{array}$ & $\begin{array}{l}751 \\
740\end{array}$ & 134 & $\begin{array}{l}\text { CANTON } \\
\text { IARF PI DACTD }\end{array}$ & US & 11862 & 1980 & GP & 1862 & \\
\hline 5 & $\begin{array}{l}440 \\
445\end{array}$ & $\begin{array}{l}740 \\
768\end{array}$ & $\begin{array}{l}591 \\
293\end{array}$ & IARE PLACID & US & 11897 & 1980 & GP & 1931 & \\
\hline $\begin{array}{l}726175 \\
726200\end{array}$ & 435 & 765 & $\begin{array}{l}293 \\
107\end{array}$ & $\begin{array}{l}\text { ITHACA } \\
\text { OSWEGO }\end{array}$ & US & 11827 & 1980 & GP & 1827 & \\
\hline & 429 & 855 & 239 & $\begin{array}{l}\text { OSWEGO } \\
\text { GRAND RAPIDS }\end{array}$ & $\begin{array}{l}\text { USA } \\
\text { USA }\end{array}$ & 854 & 1980 & GP & 85 & \\
\hline 726390 & 451 & 834 & 211 & ALPENA/PHELPS & USA & $\begin{array}{ll}1 & 1008 \\
1 & 1873\end{array}$ & $\begin{array}{l}1980 \\
1977\end{array}$ & GP & $\begin{array}{l}1881 \\
1873\end{array}$ & \\
\hline 726410 & 431 & 893 & 262 & MADISQN & USA & 1. 1869 & 1980 & GP & 1869 & \\
\hline 726430 & 439 & 913 & 198 & LA CROSSE & USA & 11873 & 1980 & GP & 1873 & \\
\hline 726441 & 431 & 927 & 309 & CHARLES CITY & USA & 11891 & 1980 & GP & 1891 & \\
\hline 726442 & 437 & 926 & 411 & GRAND KEADOW & DSA & 11886 & 1980 & GP & 1927 & \\
\hline 726443 & 431 & 862 & 189 & GRAND BAVEN & DSA & 11871 & 1980 & GP & 1871 & \\
\hline 726450 & 445 & 881 & 208 & GREEN BAT & USA & 11886 & 1980 & GP & 1886 & \\
\hline 726462 & 449 & 915 & 271 & EAU CLAIRE & USA & 11891 & 1980 & GP & 1891 & \\
\hline 726 & 444 & 982 & 390 & HURON & USA & 11881 & 1980 & GP & 1881 & \\
\hline 726550 & 456 & 942 & 318 & ST.CLOUD & USA & 11893 & 1980 & GP & 1893 & \\
\hline 726 & 450 & 931 & 255 & MINNEAPOLIS INTNL. & USA & 11859 & 1977 & GP & 1859 & \\
\hline 726611 & 459 & 1045 & 1044 & ERALARA & USA & 11 & 1980 & GP & 1897 & \\
\hline 726620 & 441 & 1031 & 1027 & RAPID CITY & OSA & 11888 & 1980 & GP & 1888 & \\
\hline 726622 & 444 & 1003 & 526 & PIERRE & USA & 11891 & 1980 & GP & 1891 & \\
\hline 2 & 440 & 1019 & 736 & COTTONWOOD & USA & 11910 & 1970 & GP & 1910 & \\
\hline 726631 & 449 & 1042 & 1083 & COLONY & OSA & 11914 & 1980 & GP & 14 & \\
\hline 26660 & 448 & 1070 & 1208 & SHERIDAN & USA & 11893 & 1980 & GP & 3 & \\
\hline 1 & 445 & 1091 & 1521 & CODY & USA & 11909 & 1980 & GP & 1909 & \\
\hline 726702 & 435 & 1096 & 2108 & DUB OIS & USA & 11907 & 1980 & GP & 1907 & \\
\hline 726703 & 4.48 & 1084 & 1169 & LOVELL & USA & 11909 & 1980 & GP & 1909 & \\
\hline 726704 & 433 & 1106 & 2069 & MORAN & USA & 11911 & 1980 & GP & 1911 & \\
\hline 726770 & 458 & 1085 & 944 & BILLINGS & USA & 11894 & 1980 & GP & 1909 & \\
\hline 726771 & 458 & 1100 & 1249 & BIG TIMBER & USA & 11909 & 1980 & GP & 1909 & \\
\hline 726773 & 450 & 1107 & 1899 & YELLOWSTONE PARK & USA & 11896 & 1978 & GP & 1896 & \\
\hline 726774 & 452 & 1126 & 1593 & DILLON & USA & 1 & 1980 & GP & 1898 & \\
\hline 2 & 449 & 1086 & 1251 & DEAVER & USA & 16 & 1980 & GP & 1916 & \\
\hline
\end{tabular}




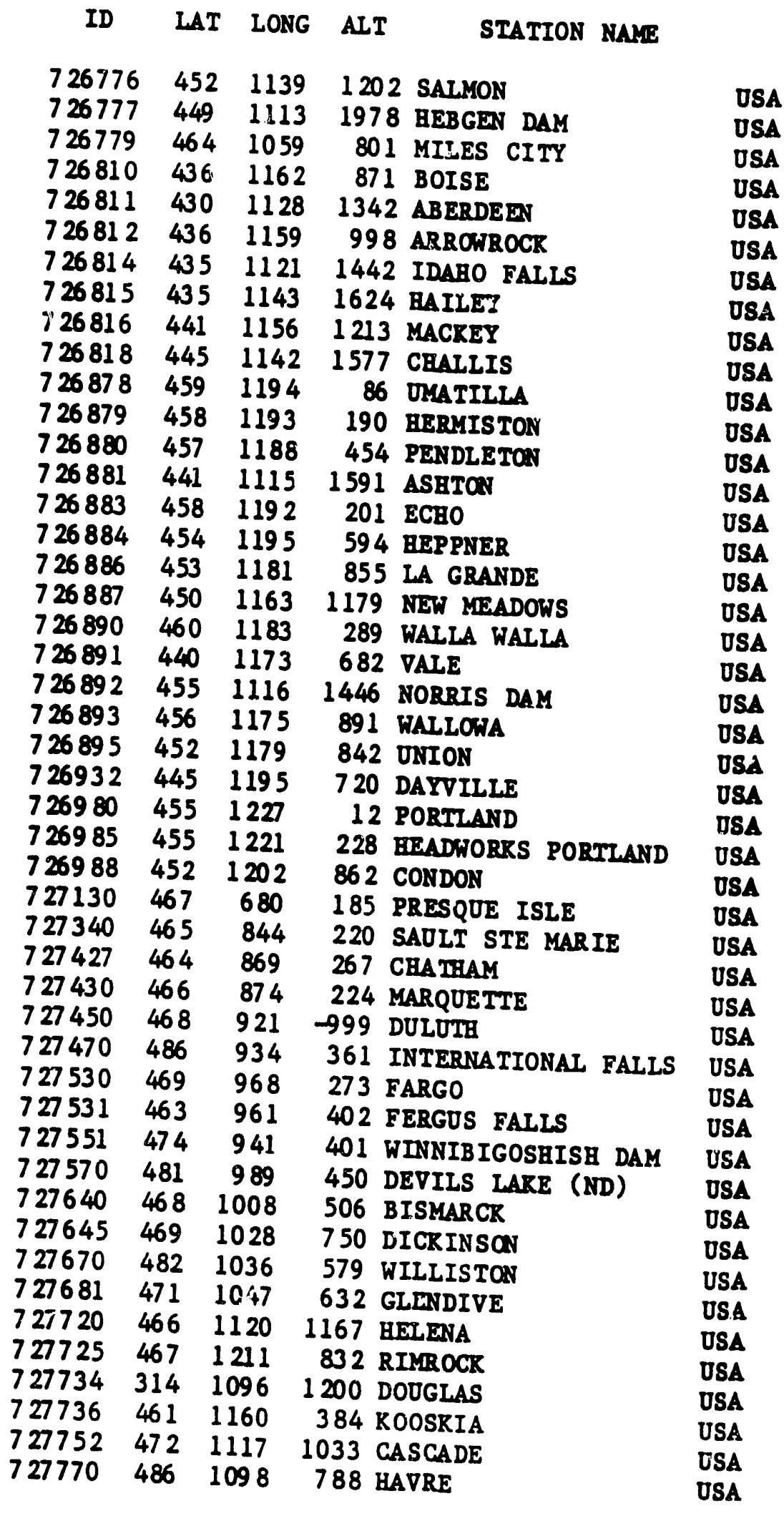

$\begin{array}{lllllll}\text { USA } & 1 & 19061967 & \text { GP } 1906 \quad 10\end{array}$

$\begin{array}{lllllll} & 1 & 1913 & 1980 & \text { GP } & 1913 & 10\end{array}$

USA $\quad 118911980$ GP 189120

OSA $\quad 118641980$ GP 186410

OSA 119141980 GP 191420

$\begin{array}{lllllll}1 & 19161980 \text { GP } 1916 \quad 10\end{array}$

119051980 GP 190510

OSA 119091980 GP $1909 \quad 10$

USA $\quad 119151980$ GP 191510

USA $\quad 119151980$ GP 191510

JSA $\quad 119021965$ GP 190210

USA 1191080 GP 191010

OSA 11890 GP 189010

USA 119051971 GP 193110

USA $\quad 119091980$ GP 190910

USA $\quad 118931965$ GP 191110

ISA 119031980 GP 190310

118721980 GP 187210

$\begin{array}{lllll}1 & 18921980 \text { GP } 189220\end{array}$

119071980 GP $1907 \quad 20$

119031980 GP 190310

119121980 GP 191210

118951976 GP 189510

$\begin{array}{lllllll}1 & 18731980 \text { GP } & 187310\end{array}$

$\begin{array}{lllll}1 & 19091980 & \text { GP } 190910 & 10\end{array}$

119131980 GP 191310

119181970 GP 191820

$\begin{array}{lllllll}1 & 1888 & 1980 & \text { GP } & 1888 & 20\end{array}$

119301970 GP 193010

118731977 GP 187310

119041980 GP 190420

$11951 \quad 1980$ GP 195110

$\begin{array}{llllll}1 & 1881 & 1980 & \text { GP } & 1881 & 10\end{array}$

$\begin{array}{llllll}1 & 1892 & 1975 \text { GP } & 1892 & 10\end{array}$

$\begin{array}{llllll}1 & 1887 & 1980 & \text { GP } & 1887 & 10\end{array}$

119051970 GP 190510

118751980 GP 187520

$11921 \quad 1970$ GP 192110

$\begin{array}{lllllll}1 & 1879 & 1980 & \text { GP } & 1879 & 10\end{array}$

$\begin{array}{llllll}1 & 1889 & 1980 & \text { GP } & 1889 & 10\end{array}$

$\begin{array}{llllll}1 & 1880 & 1980 & \text { GP } & 1880 & 20\end{array}$

$\begin{array}{llllllll}1 & 1917 & 1977 & \text { GP } & 1917 & 10\end{array}$

119031972 GP 190310

119081974 GP 190810

119041980 GP 191610

$\begin{array}{llllll}1 & 1880 & 1980 & \mathrm{GP} & 1880 & 10\end{array}$ 

ID

\section{1}

727777

727790

727791

727792

727798

727811

727812

727815

727831

727832

727833

727835

727850

727852

727855

727856

727857

727858

727886

727894

727895

727896

727897

727898

727902

727921

727922

727923

727924

727931

727933

727934

727935

727936

727937

727938

727980

742011

742012

742072

742073

742074

742075

742076

742077

744920
LAT LONG ALT STATION NAME

\section{$474 \quad 1154$}

$484 \quad 1079$

$483 \quad 1143$

$\begin{array}{ll}488 & 1149\end{array}$

$\begin{array}{lll}483 & 1166\end{array}$

$484 \quad 1155$

$484 \quad 1168$

$467 \quad 1210$

$464 \quad 1240$

$\begin{array}{ll}467 & 1170\end{array}$

4631163

$465 \quad 1163$

$475 \quad 1162$

$477 \quad 1174$

$\begin{array}{lll}478 & 1187\end{array}$

$473 \quad 1187$

$477 \quad 1201$

$477 \quad 1181$

4751159

$463 \quad 1198$

$481 \quad 1234$

$480 \quad 1222$

$490 \quad 1182$

$490 \quad 1165$

$483 \quad 1123$

$485 \quad 1202$

4631200

$\begin{array}{ll}490 & 1227\end{array}$

$467 \quad 1230$

$469 \quad 1213$

$477 \quad 1223$

4721220

$\begin{array}{ll}474 & 1217\end{array}$

$474 \quad 1222$

$473 \quad 1212$

$472 \quad 1223$

4761207

$484 \quad 1247$

$480 \quad 1244$

$485 \quad 1222$

$473 \quad 1212$

$473 \quad 1213$

$471 \quad 1184$

$470 \quad 1238$

4721210

$\begin{array}{lll}475 & 1218\end{array}$

$421 \quad 712$
945 BAUGAN

687 MALTA

904 RALISPELL

914 FORTINE

640 SANDPOINT

634 LIBBY

725 PRIEST RIVER

695 TIE TON INTARE

8 LONG BEACB

810 MOSCOW UNIV.

958 NEZ PERCE

313 OROFINO

704 RELLOGG

721 SPORANE

658 WILBUR

469 ODESSA

798 WATERVILLE

749 DAVENPORT

894 WALLACE WOODLAND

275 PROSSER 4

30 PORT TOWNSEND

18 EVERETT

501 LAORIER

548 PORTEILL

1160 VALIER

535 WINTEROP

227 SUNNYSIDE

24 BLAINE

56 CENTRALIA

1048 BUNPING IARE

6 SEATILE

208 BOCKLEY

475 CEDAR LARE

12 RENT

692 LANDSBURG

15 PUYALLUP

354 LEAVENWORTH

26 TATOOSH ISLAND

106 FORRS

15 SEDRO WOOLEY

692 LARE RACHESS

754 LARE REECHEL OS

557 RITZVILLE

3 ABERDEEN

588 CLE ELUM

134 SNOQUALMIE FALLS

198 BLUE BILL OBS.
COONTRY

STATUS

OSA

USA

USA

USA

OSA

USA

USA

USA

OSA

USA

USA

USA

OSA

USA

USA

USA

USA

USA

USA

USA

OSA

USA

USA

OSA

OSA

OSA

USA

USA

USA

USA

USA

USA

OSA

USA

USA

USA

USA

USA

USA

USA

USA

USA

USA

USA

USA

USA

USA
119121979 GP 191210

119051970 GP 190510

118961980 GP 189610

119061980 GP 192210

119101980 GP 191020

119111980 GP 191120

119141980 GP 191410

119091971 GP 190920

$\begin{array}{lllllll}1 & 1883 & 1980 & \text { GP } & 1883 & 10\end{array}$

118921980 GP 189210

119091980 GP 190910

119061980 GP 191810

119051980 GP 190510

$11881 \quad 1980$ GP 188120

119001980 GP 190010

119031980 GP 190310

$\begin{array}{lllllll}1 & 1890 & 1980 & \text { GP } & 1890 & 10\end{array}$

119091980 GP $1909 \quad 10$

119171980 GP 193110

119131980 GP 191310

118901980 GP 189010

119141980 GP 191420

119101980 GP 191010

118891980 GP 188910

119111980 GP 191110

119111980 GP 191110

118941980 GP 189410

$\begin{array}{lllllll}1 & 18931980 \text { GP } 190210\end{array}$

119021980 GP 190210

119141966 GP 191410

$118901980 \mathrm{GP} 1941 \quad 10$

119141980 GP 191410

119141980 GP 192110

119141980 GP $1914 \quad 10$

119161980 GP 191610

119141980 GP 191410

119141980 GP 191410

$\begin{array}{lllllll}1 & 1883 & 1966 & \text { GP } & 1883 & 10\end{array}$

$\begin{array}{llllllll}1 & 1914 & 1980 & \mathrm{GP} & 1914 & 10\end{array}$

$\begin{array}{llllll}1 & 18971980 & \text { GP } & 1897 \quad 10\end{array}$

119091976 GP 190910

119141977 GP 191410

119161980 GP 191610

$\begin{array}{lllllll}1 & 1891 & 1980 & \text { GP } & 1891 & 10\end{array}$

$\begin{array}{lllllll}1 & 1899 & 1980 & \text { GP } & 1917 & 10\end{array}$

$\begin{array}{lllllll}1 & 1899 & 1980 & \text { GP } & 1925 & 10\end{array}$

$\begin{array}{lllllll}1 & 1811 & 1980 \text { GP } 181110\end{array}$ 


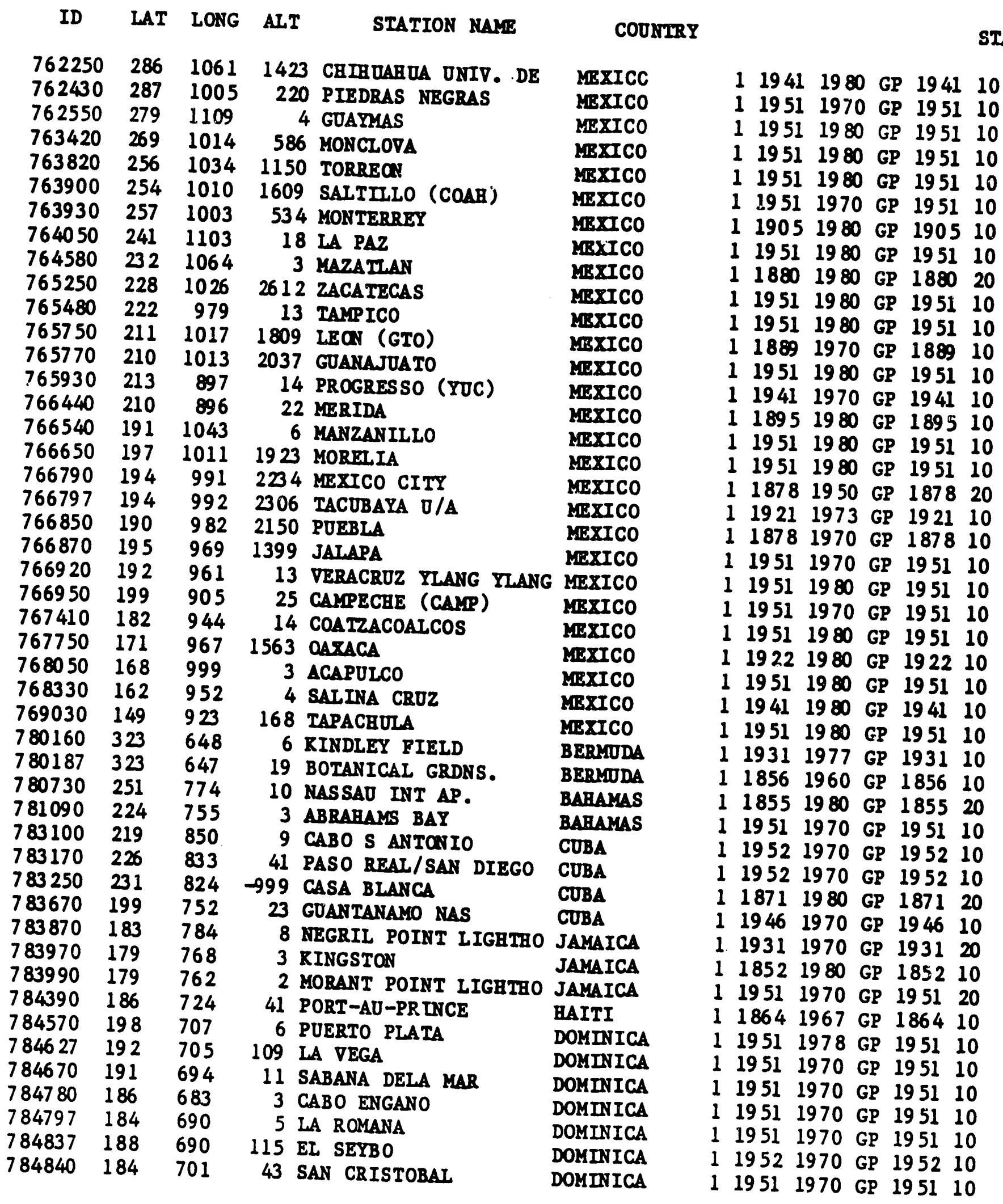


ID LAT LONG ALT STATION NAME

COUNTRY

STATUS

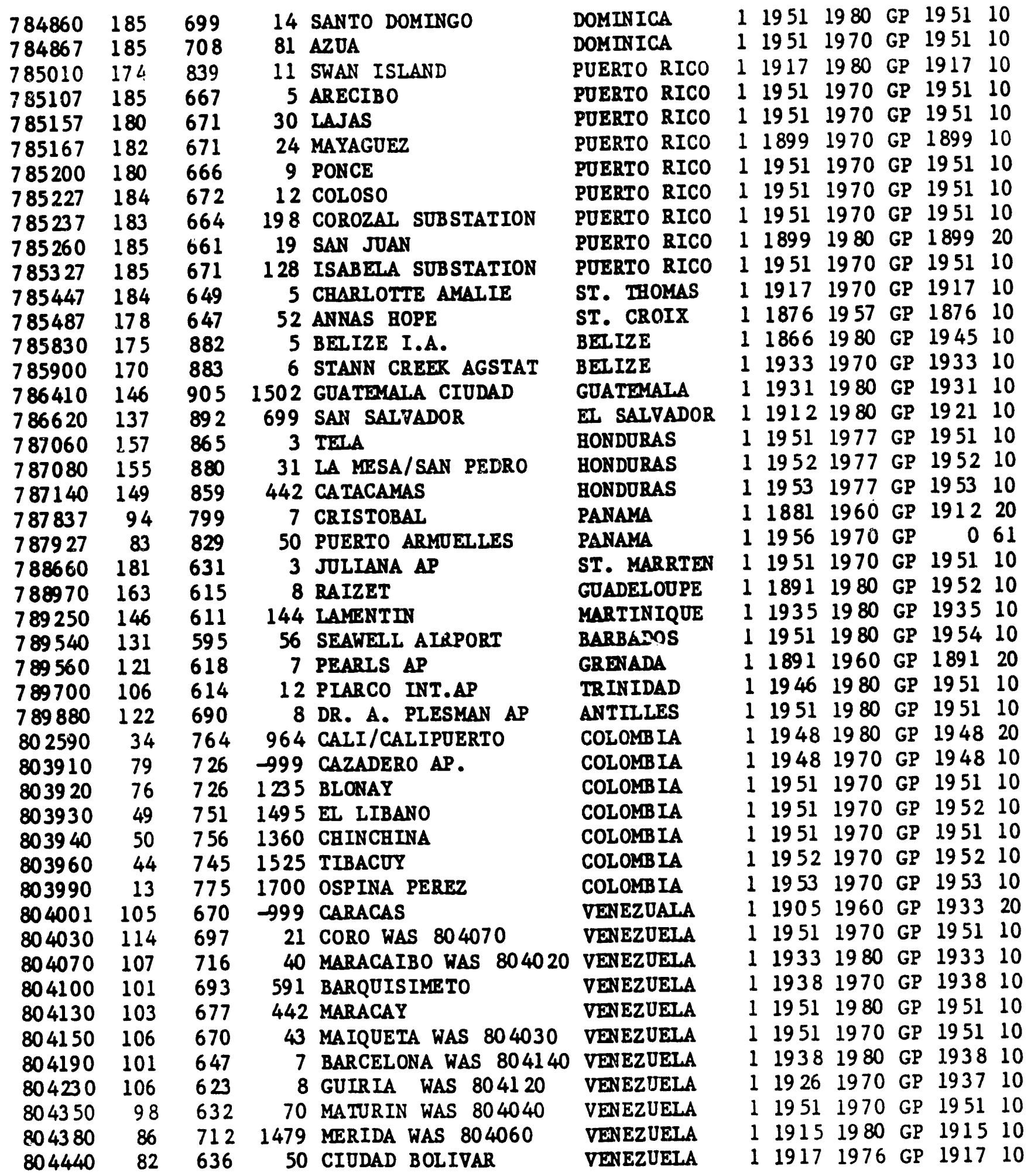




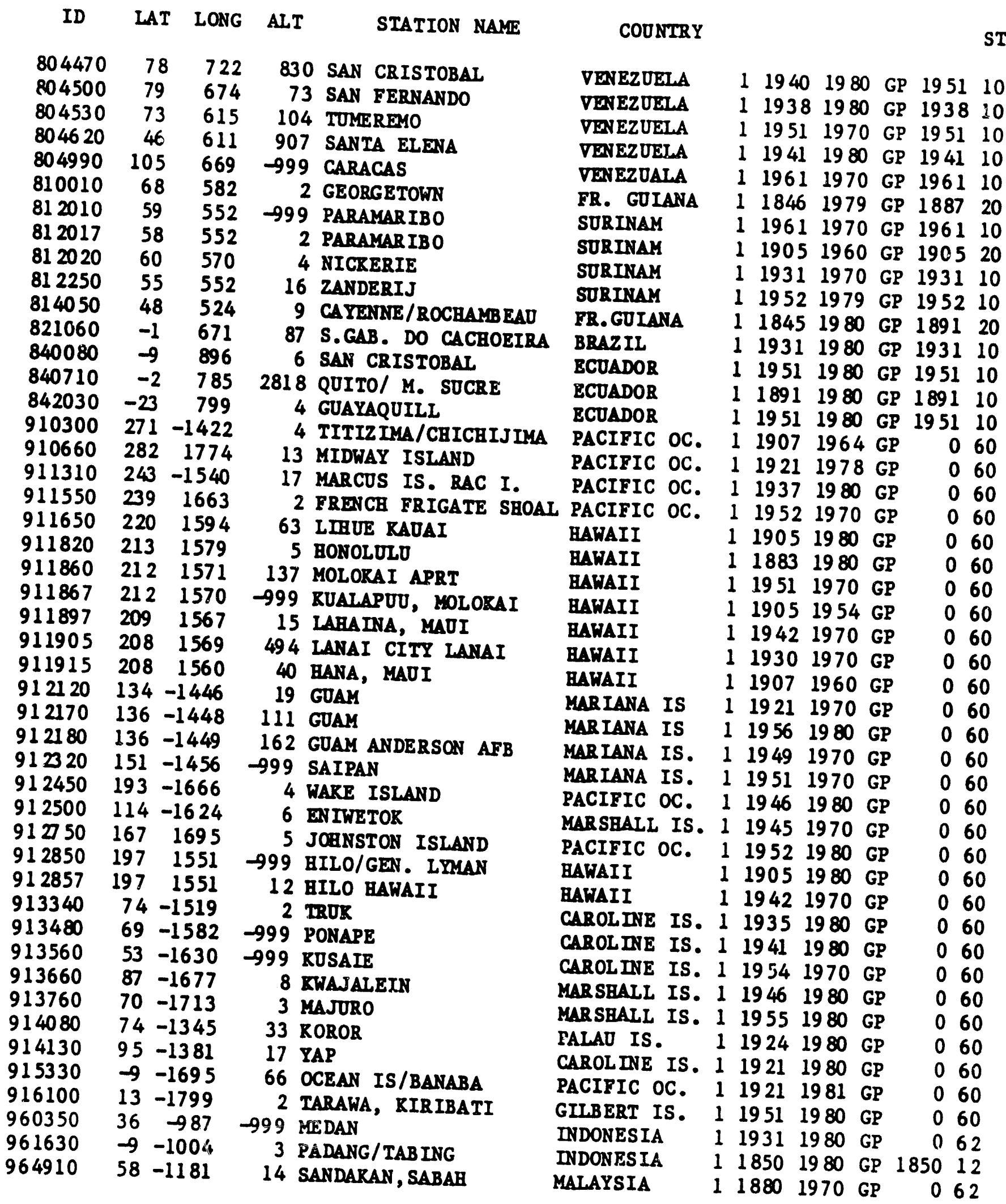




\begin{tabular}{|c|c|c|c|c|c|c|c|c|c|c|}
\hline ID & LAT & LONG & $A \perp T$ & STATION NAME & COUNTRY & & & & & \\
\hline $\begin{array}{l}965810 \\
966330 \\
970140 \\
981350 \\
982320 \\
983250 \\
984290 \\
984440 \\
985500 \\
986370 \\
986450 \\
986530 \\
988360 \\
990010 \\
990020 \\
990030 \\
990040 \\
990050 \\
990090 \\
990100 \\
990110 \\
990130 \\
990140 \\
999002 \\
999026 \\
999027 \\
999034 \\
999038 \\
999039 \\
999041 \\
999051 \\
999053 \\
999060\end{array}$ & $\begin{array}{r}0 \\
-13 \\
15 \\
205 \\
184 \\
161 \\
145 \\
132 \\
113 \\
107 \\
103 \\
98 \\
69 \\
620 \\
565 \\
526 \\
440 \\
340 \\
600 \\
538 \\
450 \\
660 \\
300 \\
735 \\
258 \\
452 \\
458 \\
438 \\
473 \\
704 \\
361 \\
407 \\
655\end{array}$ & $\begin{array}{r}-1093 \\
-1169 \\
-1248 \\
-1220 \\
-1216 \\
-1203 \\
-1210 \\
-1238 \\
-1250 \\
-1226 \\
-1239 \\
-1255 \\
-1221 \\
330 \\
510 \\
355 \\
410 \\
520 \\
200 \\
187 \\
160 \\
-20 \\
1400 \\
216 \\
-578 \\
-1479 \\
-621 \\
-1320 \\
-1427 \\
-588 \\
54 \\
-86 \\
-522\end{array}$ & $\begin{array}{r}-999 \\
3 \\
-999 \\
11 \\
4 \\
2 \\
15 \\
19 \\
21 \\
14 \\
35 \\
21 \\
6 \\
-999 \\
-999 \\
-999 \\
-999 \\
-999 \\
-999 \\
-999 \\
-999 \\
-999 \\
-999 \\
4 \\
4 \\
39 \\
-999 \\
46 \\
7 \\
11 \\
3 \\
224 \\
27\end{array}$ & 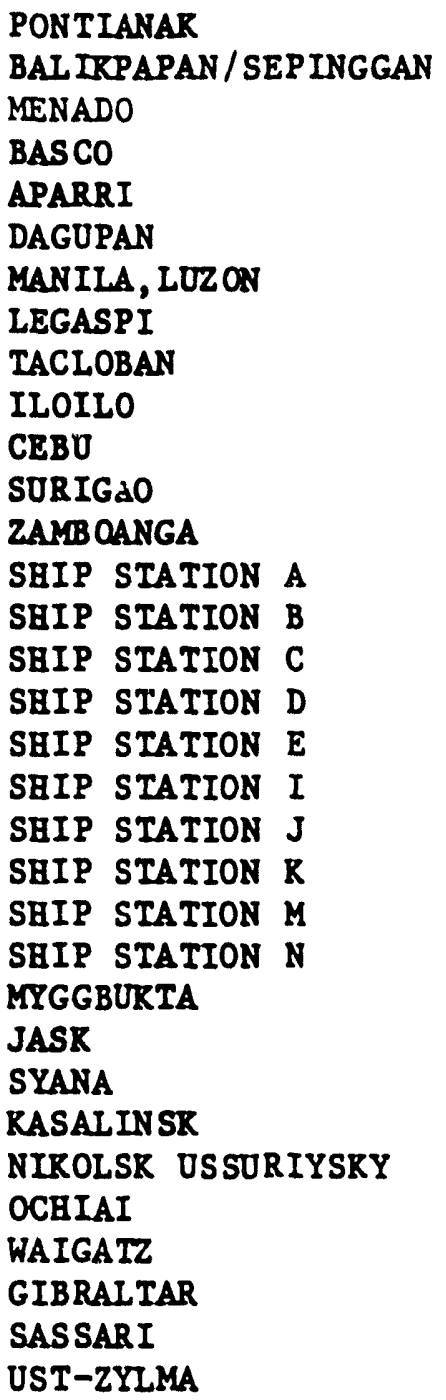 & $\begin{array}{l}\text { INDONES IA } \\
\text { INDONESIA } \\
\text { INDONES IA } \\
\text { PBILIPPINES } \\
\text { PBILIPPINES } \\
\text { PBILIPPINES } \\
\text { PBILIPPINES } \\
\text { PHILIPPINES } \\
\text { PBILIPPINES } \\
\text { PBILIPPINES } \\
\text { PBILIPPINES } \\
\text { PHILIPPINES } \\
\text { PHILIPPINES } \\
\text { OCEANIA } \\
\text { OCEANIA } \\
\text { OCEANIA } \\
\text { OCEANIA } \\
\text { OCEANIA } \\
\text { OCEANIA } \\
\text { OCEANIA } \\
\text { OCEANIA } \\
\text { OCEANIA } \\
\text { OCEANIA } \\
\text { GREENLAND } \\
\text { IRAN } \\
\text { JAPAN } \\
\text { USSR } \\
\text { USSR } \\
\text { USSR } \\
\text { OSSR } \\
\text { GIBRALTAR } \\
\text { ITAI.Y } \\
\text { USSR }\end{array}$ & $\begin{array}{ll}1 & 1912 \\
1 & 1951 \\
1 & 1912 \\
1 & 1951 \\
1 & 1886 \\
1 & 1951 \\
1 & 1887 \\
1 & 1903 \\
1 & 1951 \\
1 & 1903 \\
1 & 1891 \\
1 & 1951 \\
1 & 1951 \\
1 & 1946 \\
1 & 1946 \\
1 & 1945 \\
1 & 1949 \\
1 & 1945 \\
1 & 1948 \\
1 & 1948 \\
1 & 1949 \\
1 & 1948 \\
1 & 1947 \\
1 & 1932 \\
1 & 1893 \\
1 & 1903 \\
1 & 1881 \\
1 & 1890 \\
1 & 1908 \\
1 & 1914 \\
1 & 1852 \\
1 & 1883 \\
1 & 1889\end{array}$ & $\begin{array}{l}1980 \\
1980 \\
1980 \\
1980 \\
1980 \\
1980 \\
1980 \\
1980 \\
1980 \\
1980 \\
1980 \\
1979 \\
1980 \\
1973 \\
1974 \\
1977 \\
1973 \\
1973 \\
1975 \\
1975 \\
1976 \\
1976 \\
1974 \\
1950 \\
1949 \\
1944 \\
1950 \\
1950 \\
1950 \\
1950 \\
1950 \\
1950 \\
1950\end{array}$ & $\begin{array}{l}\text { GP } \\
\text { GP } \\
\text { GP } \\
\text { GP } \\
\text { GP } \\
\text { GP } \\
\text { GP } \\
\text { GP } \\
\text { GP } \\
\text { GP } \\
\text { GP } \\
\text { GP } \\
\text { GP } \\
\text { GP } \\
\text { GP } \\
\text { GP } \\
\text { GP } \\
\text { GP } \\
\text { GP } \\
\text { GP } \\
\text { GP } \\
\text { GP } \\
\text { GP } \\
\text { GP } \\
\text { GP } \\
\text { GP } \\
\text { GP } \\
\text { GP } \\
\text { GP } \\
\text { GP } \\
\text { GP } \\
\text { GP } \\
\text { GP }\end{array}$ & $\begin{array}{r}0 \\
0 \\
0 \\
1951 \\
1886 \\
1951 \\
1887 \\
1903 \\
1951 \\
1903 \\
1891 \\
1951 \\
1951 \\
0 \\
0 \\
0 \\
0 \\
0 \\
0 \\
0 \\
0 \\
0 \\
0 \\
1932 \\
1893 \\
1903 \\
1900 \\
1890 \\
1908 \\
1914 \\
1852 \\
1883 \\
1897\end{array}$ & $\begin{array}{l}62 \\
62 \\
62 \\
10 \\
10 \\
10 \\
20 \\
10 \\
10 \\
10 \\
10 \\
10 \\
10 \\
60 \\
60 \\
60 \\
60 \\
60 \\
60 \\
60 \\
60 \\
60 \\
60 \\
10 \\
10 \\
10 \\
10 \\
10 \\
10 \\
10 \\
10 \\
10 \\
10\end{array}$ \\
\hline
\end{tabular}




\title{
GLOBAL-SCALE TEMPERATURE CHANGES TO AOGUST 1987 AND
}

A COMPARISON OF SATELLITE AND CONVENTIONAL DATA

\author{
P.D. Jones, T.M.L. Wigley, G. Ohring *, A. Thomase $11^{*}$. \\ Climatic Research Unit \\ University of East Anglia \\ Norwich NR4 7TJ, UR.
}

\author{
and \\ *NOAA/NESDIS \\ Satellite Research Laboratory \\ Washington, D.C. 20233
}

Introduction: Until recently, most estimates of long-term trends in global mean temperature were derived from land-based station data for the Northern Hemisphere (Wigley et al., 1985; Jones et al., 1986a). Improvements have (Jones et al., 1986b) and by including data for the Southern Hemisphere data for the ocean areas (Folland inclusion of sea surface temperature (SST) Despite these improvements there et al., 1984; Jones et al., 1986c). land and marine areas of no coverage are over the Southern Ocean, $45-65^{\circ}$ greatest regions of sparse or Pacific Ocean away from the South fmerican $45-65^{\circ} \mathrm{S}$, and over the southeastern

For the land regions of both hemispheres there are still areas of scanty or no coverage. These gaps are due to the lack of adequate monthly GTS land-based GTS stations. whilst examples of the many Arctic regions. Here we occur over the Sahara desart, Antarctica and masses based on satellite estimates of

Satellite data: The satel NOAA/NESDIS Satellite Research data used here have been produced at the brightness temperature, of surface temperature. The THIR/TOMS cloud data set. The data degrees Kelvin for target The data are monthly means expressed in absolute to October 1984 (Thomasel1 and Ohring, 1987). for the 67 months, April 1979

Gridpoint comparisons: Comparison of the satellite data with conventional the hemispheric can be performed either at the individual grid point level or necessary to interpolate the satellite grid-point comparison is possible it is latitude by $10^{\circ}$ longitude points. The data to the conventional grid of $5^{\circ}$ expressed as anomalies from the five or six values for the appropriate monthly mean, calculated using The conventional data for that month within the 67 month period of record. period used in our earlier therefore arise because the two reference periods. This, howeverween the mean annual cycles over differences are small relative however, is a secondary effect because such the data. 
Figure 1 shows correlation coefficients between the corventional and interpolated satellite data for the Northern (a) and Southarn (b)

Hemispheres. Agreement is excellent over high latitude regions and in middle latitude areas away from coasts, but noticeably poorer over tropical regions.

The algorith used to compute surface temperature needs an initial estimate of the surface temperature (from USAF analyses) for the time of the satellite pass, in order to distinguish between cloudy and "cloud free" (less than $50 \%$ cloud cover) areas. Surface brightness temperatures are those which correspond to cloud free pixels. In order to determine the presence of low level clouds it is essential to have an accurate estimate of the surface temperature, and the method is clearly sensitive to the accuracy of the USAF data. Problems may arise in a number of ways. For example, the $50 \%$ cut-off in defining "cloud free" introduces some uncertainty in the temperature estimates. In some regions the identification of "cloud fiee" pixels may be unreliable due to uncertainties in the USAF temperature field which arise from data coverage problems. In addition, there may be other regions in which cloud is prevalent, giving only a limited number of cloud free pixels at certain times of the year. The results shown in Figure 1 highlight the major problem regions.

Hemispheric Comparisons: A direct comparison can be achieved by using only those grid points in the satellite data set which also have data available from conventional analyses. Figure 2 shows the two estimates for the Northern Aemisphere and Figure 3 shows similar estimates for the Southern Hemisphere. Correlation coefficients between the two time series for the 67 month period are 0.71 and 0.45 for the Northern and Southern Hemispheres respectively. The poorer result for the Southern Hemisphere is compatible with the earlier results in Figure 1.

In Figures 4 and 5, comparisons between estimates of Arctic and Antarctic area-average temperatures from satellite and conventional means are made. The satellite results here are based on all grid point data poleward of $62.5^{\circ}$, whereas the conventional data estimates are based on more limited coverage spanning the same regions. In both cases data over land and marine areas are combined, as distinct from the other analyses which used only land data. Correlation coefficients for the two areas are 0.80 (Arctic) and 0.61 (Antarctic) over the April 1979 to October 1984 period. The satellite time series for Antarctica shows considerably less variability from month to month than that based on conventional means. For the Arctic, the satellite and conventional time series show much closer variability. For Antarctica the satellite time series shows much less variablity than the satellite-based Arctic time series. It is not clear whether the Antarctic results reflect an overestimate of variability in the time series based on conventional data or an underestimate in the satellite-based time series. The conventionally derived Antarctic series (updated from Raper et al., 1984) is estimated from only 16 stations, roughly equally spaced over the continent. Although this average may be slightly over-estimating variability because it is based on only a small number of stations, the coverage problem does not appear to be sufficient to explain the difference between the two time series. Spatial correlations over Antarctica are quite high and the error induced by lack of coverage, as estimated by Raper et al. (1984), is relatively small. 
Update of conventional series: In Figures 2 to 5 , time series based on conventional data are shown from April 1979 to August 1987. For the Northern Hemisphere, the warmth experienced during 1981 and 1983 has returned during 1986 and 1987. Over the Southern Hemisphere, almost all months since 1979 have been warmer than the 1951-70 reference period. The 8 month period from January to August 1987 is the warmest recorded since 1858. April 1987 was the warmest such month recorded over this $5-60^{\circ} \mathrm{S}$ region. Over Antarctica, August 198 ? was the coldest such month recorded since comparable records began in 1957. Over the Arctic region, conditions have remained generally cooler than the 195/-70 reference period throughout 1986 and 1987.

\section{References}

Folland, C.R. et al., 1984: Nature 310, 670-673.

Jones, P.D., 1985: C1 imate Monitor 14, 43-49.

Jones, P.D. et al., 1986a: Journal of Climate and Applied Meteorolony 25, 161-179.

Jones, P. D. et al., 1986b: Journal of Climate and Applied Meteorology 25, $1213-1230$.

Jones, P.D. et a1., 1986c: Nacure 322, 430-434.

Raper, S.C.B. et al., 1984: Monthly Weather Review 112, 1341-1353.

Thomase11, A. and Ohring, G., 1987: Paper presented at IUGG meeting in Vancouver.

Wigley, T.M.L. et al., 1985: In Detecting the Climatic Effects of Increasing Carbon Dioxide (M. C. MacCracken and F.M. Luther, eds.), DOE/ER-0235, 55-90.

\section{Acknowledgement}

The work at the Climatic Researcb Unit was supported by the U.S. Department of Energy under grant No. DE-FG02-86-ER60397. 


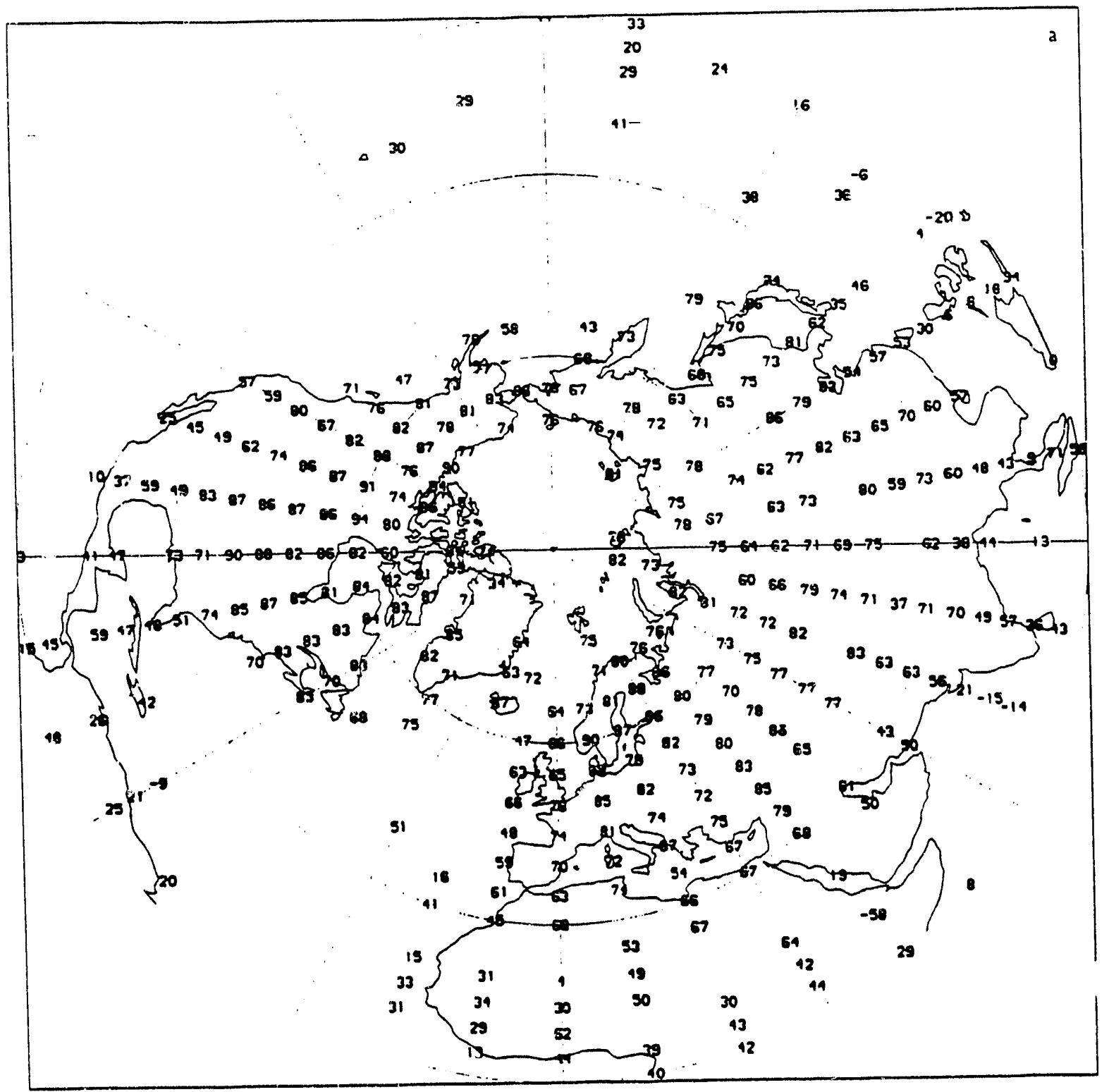

Figure 1: Correlation coefficients $(\times 100)$ of coincident land and satellite grid points. R-valuez based on up to 67 months of data, April 1979 to October 1984. a) Northern Hemisphere, b) Southern Hemisphere. 


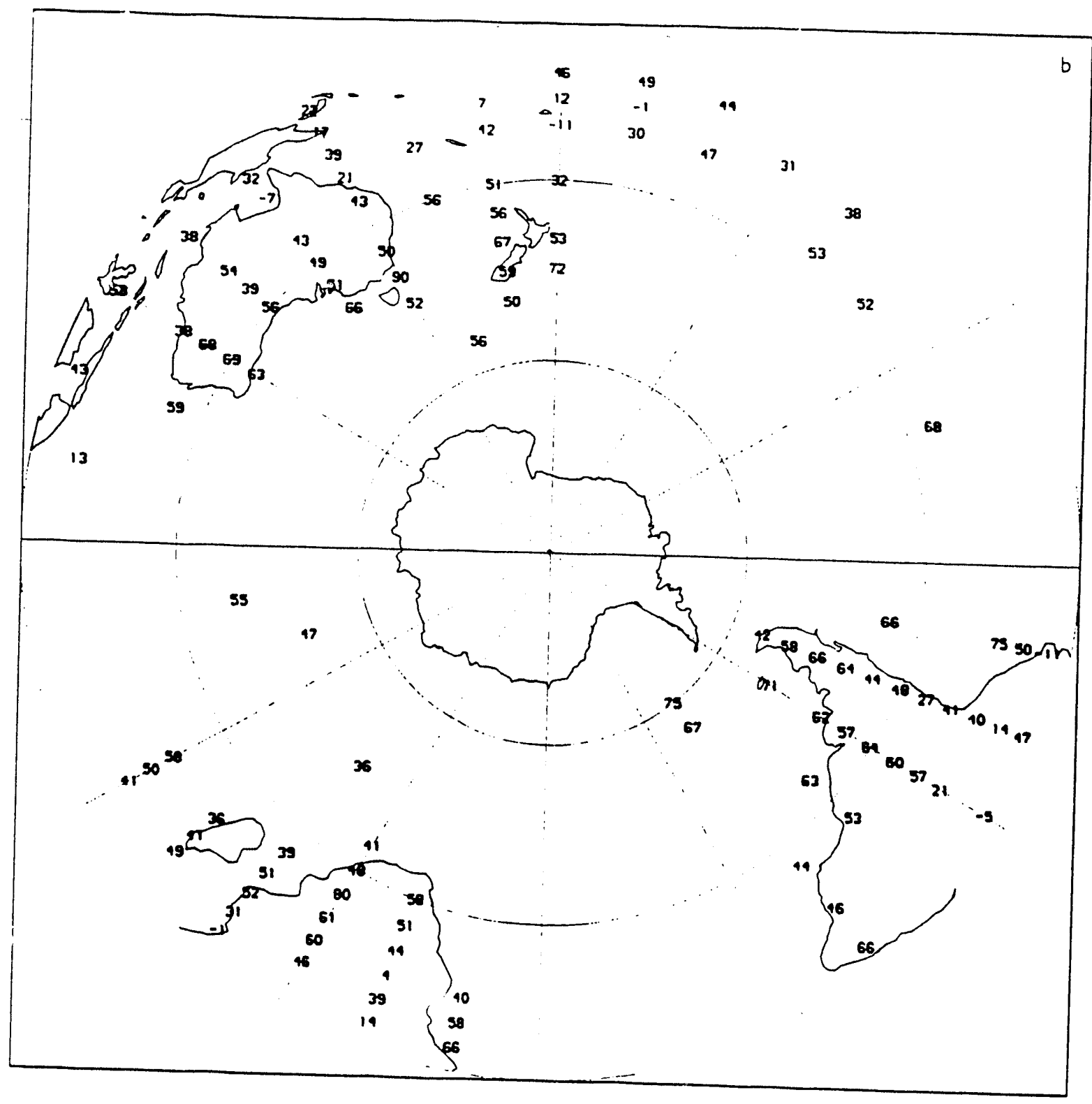



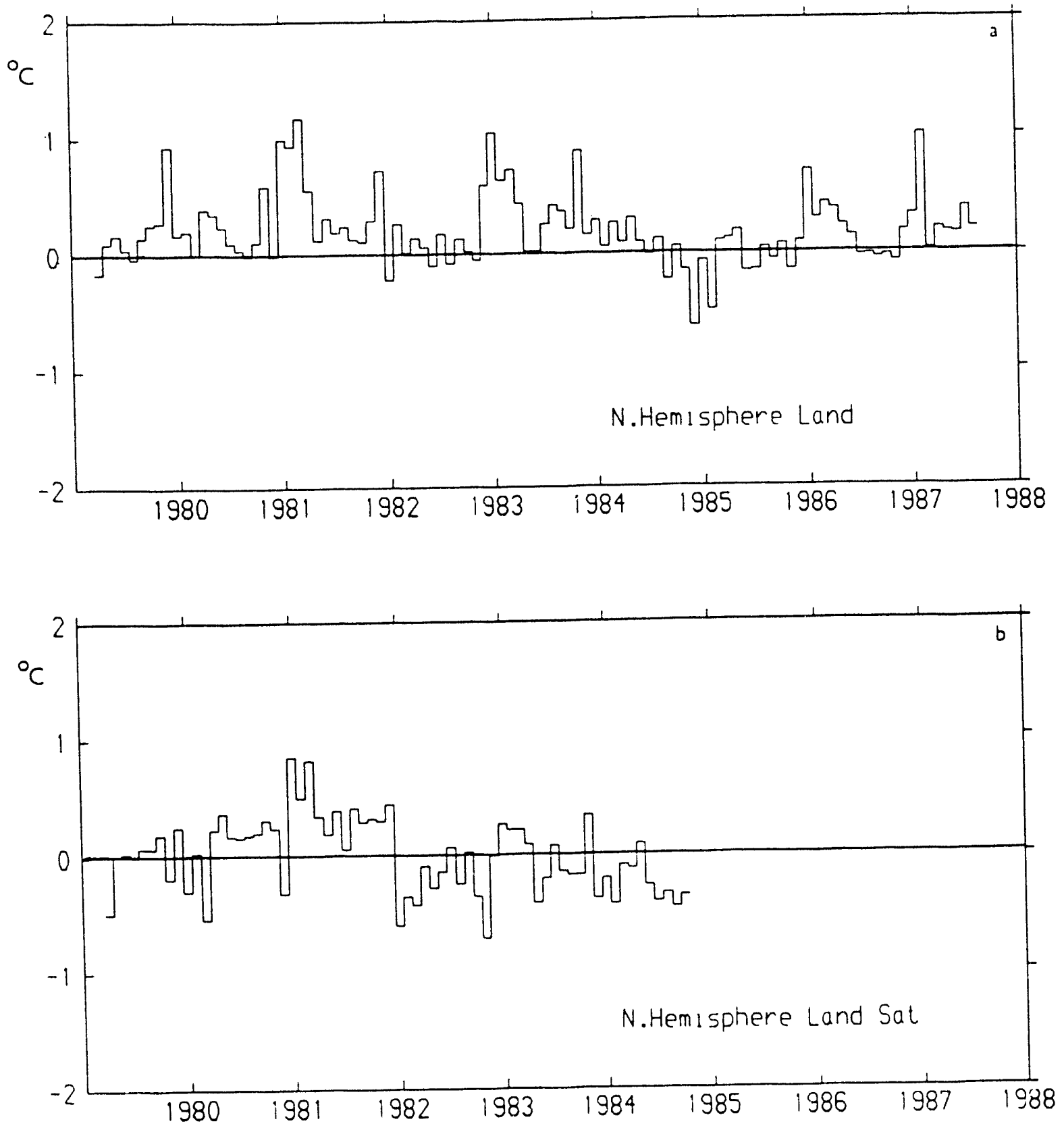

Figure 2: Monthly surface air temperature anomalies for the Northern Hemisphere. a) conventional (Jones et al., 1986a), anomalies from the 1951-i0 reference period. b: satellite, anomalles irmm the April 1979-octoter 1984 reference period. 

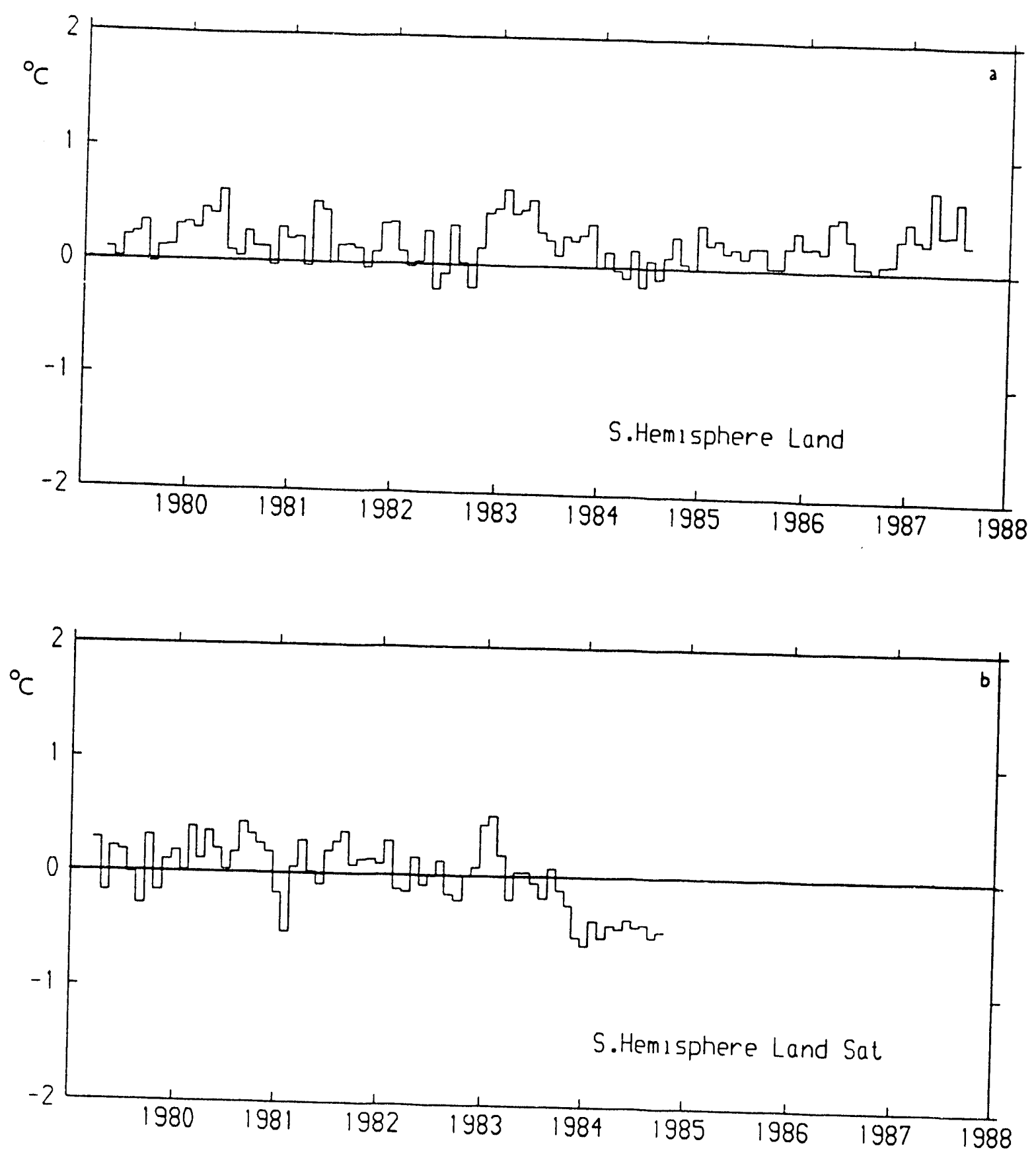

Figure 3: Monthly surface air temperature anomalies for the Southern Hemisphere $\left(5-60^{\circ} \mathrm{s}\right.$ inclusive). a) conventional (Jones et al., $1986 \mathrm{~b})$, anomalies from the 1951-70 reference period. b) satelite, anomalies from the April 1979-0ctober 1984 reference period. 

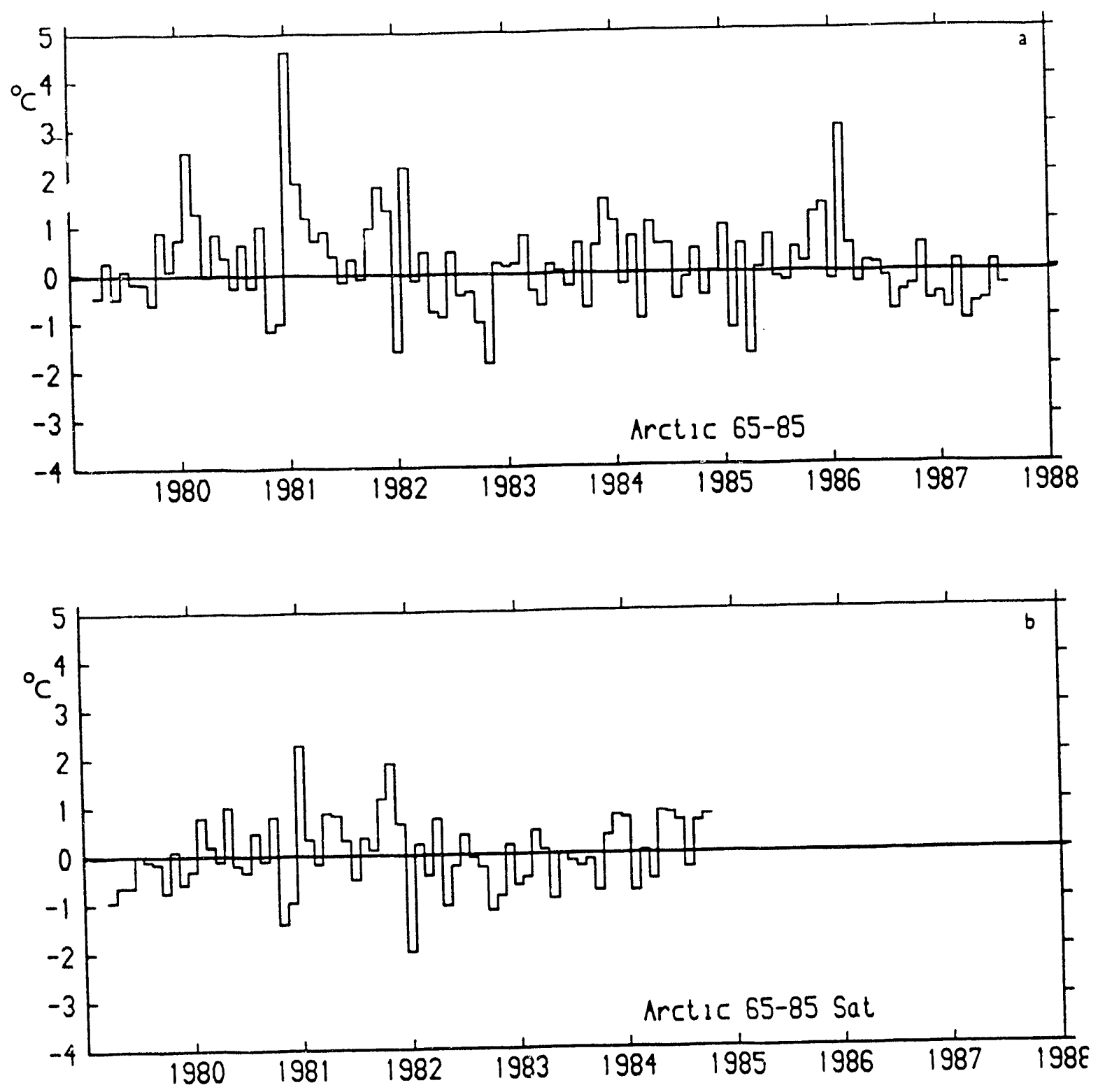

\footnotetext{
Higure 4: Monthly surface air temperature anomalses for the Arclic region $\left(65-85^{\circ} \mathrm{N}\right.$ inclusive). a) conventional (Jones, 1985), anomalies from the 1951-70 reference period. b) satellite, anomalies from the April 1979-October 1984 reference period.
} 

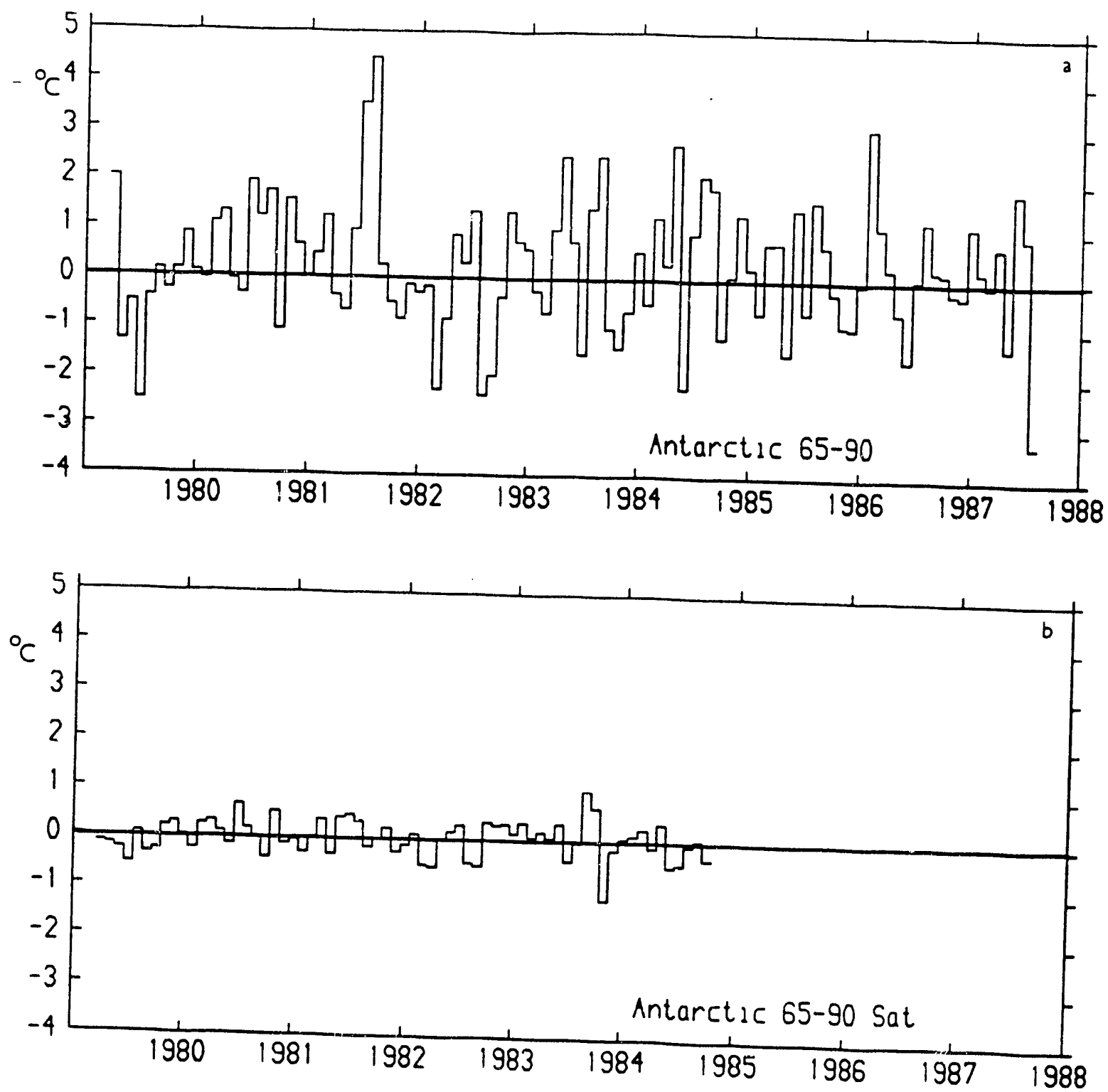

Figure 5: Monthly surface air temperature anomalies for the Antarctic region $\left(65-90^{\circ} \mathrm{S}\right.$ inclusive). a) conventional (Raper et al., 1984), anomalies from the 1957-75 reference period. b) satellite, anomalies from the April 1979-October 1984 reference period. 


\section{TRO27}

\section{A Grid Point Surface Air Temperature Data Set for the Southern Hemisphere}
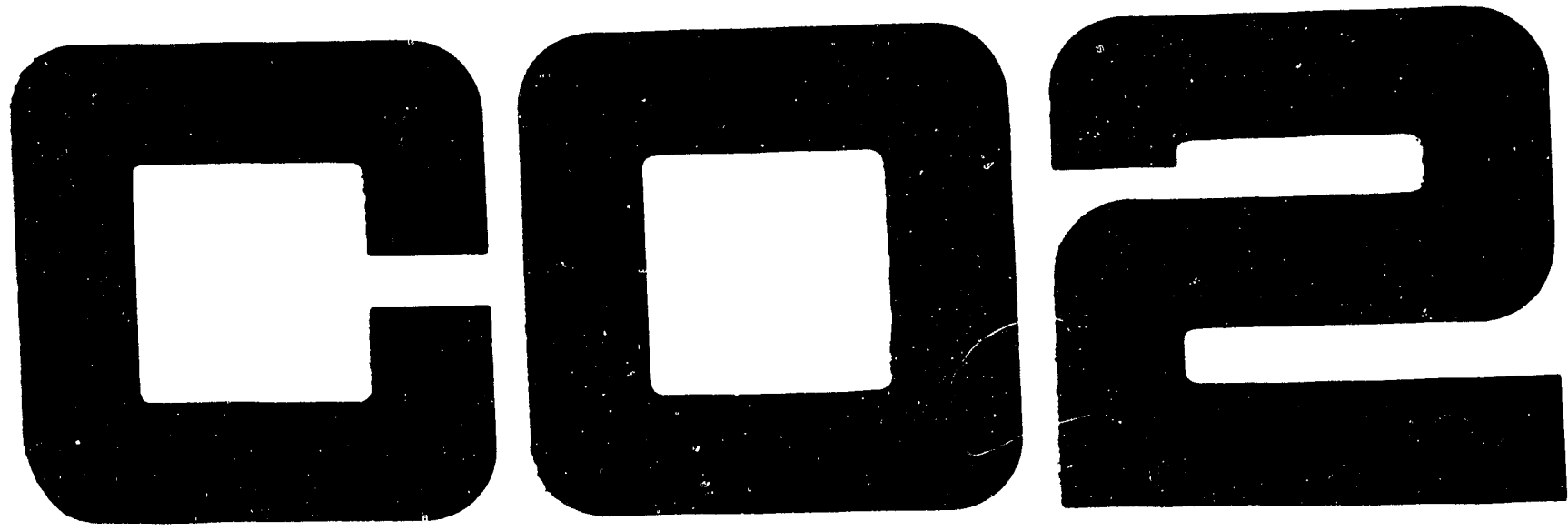


\section{A Grid Point Surface Air Temperature Data Set for the Southern Hemisphere}

Prepared by:

P.D. Jones, S.C.B. Raper, C.M. Goodess

B.S.G. Cherry and T.M.L. Wigley

Climate Research Unit

University of East Anglia

Norwich NR4 7TJ, UK

Under Contract No. DE-AC02-79EV10098 
ABSTRACT

A compilation of 610 station records of monthly surface air temperature has been assembled for the Southern Hemisphere, north of $62.5^{\circ} \mathrm{S}$. In order to use these data to construct the first grid point temperature data set for the Southern Hemisphere, the homogeneity of each of the station records has been assessed. Each station has been clsssed into one of three groups; immediately usable, corrected, or uncorrectable. The results are presented in tabular form.

Of the 610 station records, 293 were used to produce a gridded data set on a $5^{\circ}$ latitude by $10^{\circ}$ longitude grid between $5^{\circ} \mathrm{S}$ and $60^{\circ} \mathrm{S}$ inclusive. Grid point anomalies for 1851-1984, with respect to the reference period 1951-70, were interpolated from stacion data using simple algorithm. In order to produce a best possible data set, Antarctic data were included after they became available in 1957. 
TABLE OF CONTENTS

$\begin{array}{ll}\text { Abstract } & \text { Page } \\ \text { Table of Contents } & \text { i } \\ \text { List of Figures } & \text { ii } \\ \text { Acknowledgements } & \text { iii } \\ \text { Introduction } & \text { v } \\ \text { Station Homogeneity Assessment } & 1 \\ \text { Gridding the Station Data } & 4 \\ \text { Conclusions } & 12 \\ \text { References } & 14 \\ \text { Appendix A: } \quad \text { Station History Information and Homogeneity } & 17 \\ \text { Appendix B: } \quad \text { Stations used in the Gridding Algorithm } & 19\end{array}$


LIST OF FIGURES

Figure 1: Station temperature difference time series: Curitiba $\left(25.4^{\circ} \mathrm{S}, 49.3^{\circ} \mathrm{W}\right)$ minus Rio de Janiero $\left(22.9^{\circ} \mathrm{S}, 43.2^{\circ} \mathrm{W}\right)$, 1901-1980. The analysis identifies Rio de Janiero as the errant station as a similar jump at 1941 al so occurs when the station is compared with Iguape $\left(24.7^{\circ} \mathrm{S}, 47.5^{\circ} \mathrm{W}\right)$. The station history information reveals that the observation time and station height were altered around 1940. The straight 1 ines are the mean station differences for the two periods, 1901-1939 and 1941-1980. Correction details are given in Appendix $A$.

Figure 2: Station temperature difference time series: Ushuaia $\left(54.9^{\circ} \mathrm{S}, 68.4^{\circ} \mathrm{W}\right)$ minus Punta Arenas $\left(53.3^{\circ} \mathrm{S}, 70.9^{\circ} \mathrm{W}\right)$, 1931-1980. The analysis identifies Punta Arenas as the errant station as a similar jump at 1963 al so occurs when the station is compared with Rio Gallegos $\left(51.6^{\circ} \mathrm{S}\right.$, $69.4 \%$ W). A change of station site is indicated because of a data gap around 1963. The straight lines are the mean station differences for the two periods, 1931-1963 and 1964-1980. Correction details are given in Appendix A.

Figure 3: Station temperature difference time series: Johannesburg $\left(26.2^{\circ} \mathrm{S}, 28.1^{\circ} \mathrm{W}\right)$ minus Durban $\left(23.9^{\circ},, 31.0^{\circ} \mathrm{W}\right), 1905-$ 1960. The analysis identifies Durba.: as the errant station as a similar jump at 194,1 al so occurs when the station is compared with Aliwai North $\left(30.7^{\circ} \mathrm{S}, 26.7^{\circ} \mathrm{W}\right)$. The station history information reveals that the station was moved to the airport in 1941. The straight lines are the mean station differences for the two periods, 19051940 and 1941-1960. Correction details are given in Appendix A.

Figure 4: Station temperature difference time series: Lauthala Bay $\left(18.1^{\circ} \mathrm{S}, 178.4^{\circ} \mathrm{E}\right)$ minus $\mathrm{Nandi}\left(17.9^{\circ} \mathrm{S}, 177.5^{\circ} \mathrm{E}\right), 1943-$ 1980. The analysis identifies $\mathrm{Nandi}$ as the errant station as a similar jump occurs when the station is compared with Ono-i-lau $\left(20.8^{\circ} \mathrm{S}, 178.8^{\circ} \mathrm{E}\right)$. The station history suggests a change of observation times after 1971. The straicht 1 ines are the mean station differences for the two periods, 1951-1970 and 1971-1980. Correction details are given in Appendix A. 
Figure 5: Locations of the 293 stations used in the gridding technique. The Antarctic stations were used by Raper et al. (1984) are not included

Figure 6: The Southern Hemisphere Temperature (SHT) series 18581984 (anomalies relative to 1951-70). 
ACKNOWLEDGEMENTS

The work described in this Technical Report was funded by the U.S.

Department of Energy under Contract No. DE-ACO2-79EV10098 and Grant No. DEFG02-86-ER60397. 
IN TRODUCTION

Although rany studies have been undertaken with temperature time series purporting to represent the whole globe, most are only representative of conditions over the Northern Hemisphere land masses. A truly representative average for the whole globe can only be achieved by incorporation of data from both the land and marine areas of both hemispheres.

Early studies by Willett (1950) and Mitchel1 (1961) using land-based data from both hemispheres indicated that a reasonable proxy for global conditions could be formed from averages for the Northern Hemisphere 1 and mass only. Indeed, this was a convenient supposition to make, because data for the Northern Hemisphere 1 and masses are the most plentiful and readily available. In support of this supposition it has been argued that external forcing factors should affect the hemispheres similarly, in both degree and timing. However, the representativeness of the Northern Hemisphere land data in a global context can be questioned because the number of Southern Hemisphere stations used by Willett and Mitchell was small, only one fifth of those used for the Northern Hemisphere with almost all being located between the equator and $40^{\circ} \mathrm{S}$.

Rezent work by Folland et a1. (1984) using marine data has shown that important differences are apparent between the land and marine records for the Northern Hemisphere (Jones et al., 1986a) and between the marine reco: 3 for the two hemispheres. The differences are most apparent in the degree of warming and cooling during the present century (see Wigley et al., 1985 , 1986). 
A detailed study of the hemispheric temperature trends for the Southern Hemisphere will enable more detailed comparisons of the Northern and Southern Hemisphere land and marine data sets to be made. The land areas of the Southern Hemisphere have often been ignored in previous studies; the only recent analysis to consider this region comprehensively being that of Hansen et a $1 .(1981)$.

Data Sources

The basic source of station air temperature data for the Southern Hemisphəre land masses is the set of volumes of World Weather Records (WWR) (Smithsonian Institution, 1927, 1934, 1947 and U.S. Weather Bureau, 19591982; available in digitized form from the National Center for Atmospheric Research (NCAR), Jenne, 1975). A considerable amount of additional temperature data for Argentina and Chile for the years 1931-60 has recently been added to this set. In WWR, these countries only have data available from 1951 (see Pittock, 1980, for further details).

Searches for data in archives as part of the present project yielded additional data for Indonesia and Australia and for some Pacific islands, particularly Tahiti. Additional daza for New Zealand was found in Salinger (1981). For Peru, the Peruvian Meteorological Service supplied information for about ten stations covering the 1940s and 1950s. Additional data for Australia was provided by their Bureau of Meteorology. All of these sources are gratefully acknowledged.

Altogether 610 stations (between $2.5^{\circ} \mathrm{S}$ and $62.5^{\circ} \mathrm{S}$ ) were used in this analysis. The names, locations, elevations and record lengths of all 610 stations are 1 isted in Appendix A. 
For the Antarctic region we used the data given in Raper et al. (1984) and updated in various issues of Climate Monitor. 
It has long been known that the basic source of temperature data, World Weather Records, contains many records that are not homogeneous. Furthermore, we assumed that a significant fraction of the new station data could be non-homogeneous, although Salinger (1981) has inspected and corrected most of the New Zealand data. Station data may contain the effects of changes that result from numerous non-climatic factors (see Jones et al., 1985, 1986a, and Bradley and Jones, 1985, for a list of these factors and examples of their effects). The composite Southern Hemisphere data set was therefore analysed for homogeneity in a manner similar to that for the Northern Hemisphere (Jones et al., 1985).

For each of the 610 stations in this data set, data homogeneity was assessed, where possible, by comparing each station record with neighbouring station data. The technique is outlined in Jones et al. (1986a). When identified, inhomogeneities were corrected by comparison with neighbouring station data in a manner described by Jones et al. (1985).

Four examples of the homogeneity assessment are shown in Figures 1 to 4 , each being discussed in the appropriate figure caption. The examples are:

Fig. 1, Curitiba (WMO No. 838420) minus Rio de Janeiro ( 837430 ) (Brazil)

Fig. 2, Ushuaia ( 879380 ) minus Punta Arenas ( 859340 ) (Argentina-Chile)

Fig. 3, Johannesburg (683697) minus Durban (685880) (South Africa)

Fig. 4, Lauthala Bay (916900) minus Nandi (916800) (Fiji).

Further examples are given in Jones et al. (1986b).

Details of this assessment are 1 isted in Appendix A, which includes reference to some of the neighbouring stations used for comparisons, 


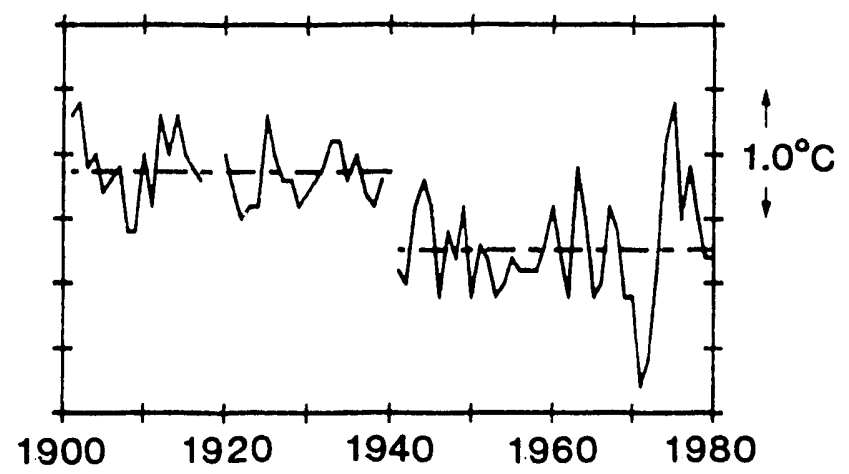

Figure 1:

Station temperature difference time series: Curitiba $\left(25.4^{\circ} \mathrm{S}, 49.3^{\circ} \mathrm{W}\right)$ minus Rio de Janiero $\left(22.9^{\circ} \mathrm{S}, 43.2^{\circ} \mathrm{W}\right)$, 1901-1980. The analysis identifies Rio de Janiero as the errant station as a similar jump at 1941 also occurs when the station is compared with Iguape $\left(24.7^{\circ} \mathrm{S}, 47.5^{\circ} \mathrm{W}\right)$. The station history information reveals that the observation time and station height were altered around 1940. The straight 1 ines are the mean station differences for the two periods, 1901-1939 and 1941-1980. Correction details are given in Appendix A.

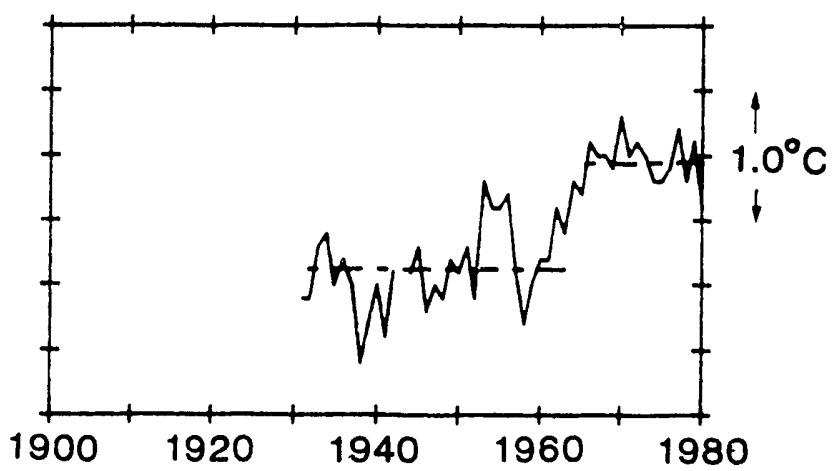

Figure 2: Station temperature difference time series: Ushuaia $\left(54.9^{\circ} \mathrm{S}\right.$, $\left.68.4^{\circ} \mathrm{W}\right)$ minus Punta Arenas $\left(53.3^{\circ} \mathrm{S}, 70.9^{\circ} \mathrm{W}\right), 1931-1980$. The analysis identifies Punta Arenas as the errant station as a similar jump at 1963 also occurs when the station is compared with Rio Gallegos $\left(51.6^{\circ} \mathrm{S}, 69.4^{\circ} \mathrm{W}\right)$. A change of station site is indicated because of a data gap around 1963 . The straight lines are the mean station differences for the two periods, 1931-1963 and 1964-1980. Correction details are given in Appendix A. 


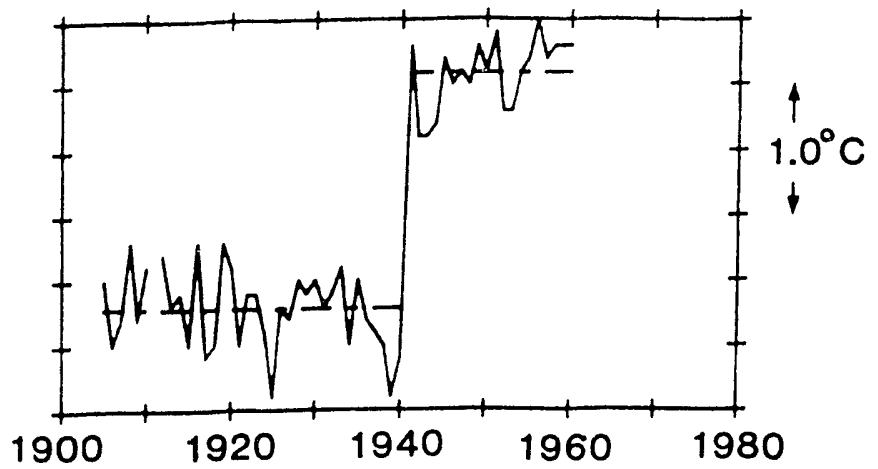

Figure 3:

Station temperature difference time series: Johannesbur 8 $\left(26.2^{\circ} \mathrm{S}, 28.1^{\circ} \mathrm{W}\right)$ minus Durban $\left(29.9^{\circ} \mathrm{S}, 31.0^{\circ} \mathrm{W}\right), 1905-1960$. The analysis identifies Durban as the errant station as a similar jump at 1941 also occurs when the station is compared with Aliwal North $\left(30.7^{\circ} \mathrm{S}, 26.7^{\circ} \mathrm{W}\right)$. The station history information reveals that the station was moved to the airport in 1941. The straight lines are the mean station differences for the two periods, $1905-1940$ and $1941-$ 1960. Correction details are given in Appendix A.

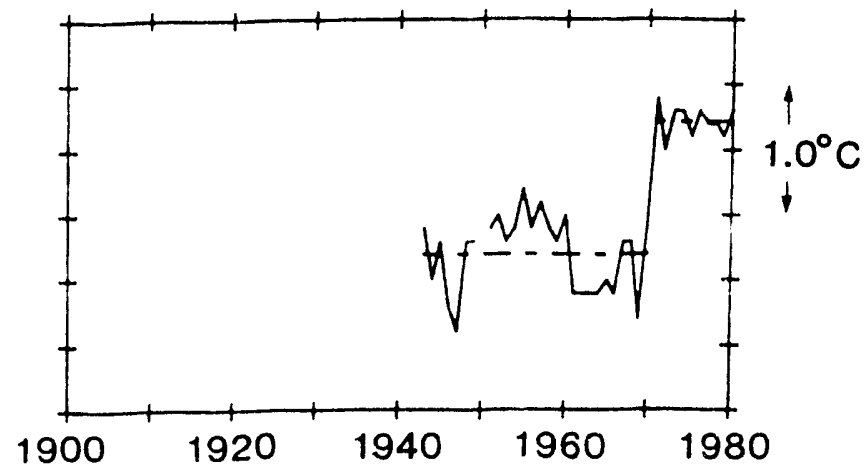

Figure 4: Station temperature difference time series: Lauthala Bay $\left(18.1^{\circ} \mathrm{S}, 178.4^{\circ} \mathrm{E}\right)$ minus $\mathrm{Nandi}\left(17.9^{\circ} \mathrm{S}, 177.5^{\circ} \mathrm{E}\right), 1943-1980$. The analysis identifies Nandi as the errant station as a similar jump occurs when the station is compared with Ono-i1 au $\left(20.8^{\circ} \mathrm{S}, 178.8^{\circ} \mathrm{E}\right)$. The station history suggests a change of observation times after 1971. The straight 1 ines are the mean station differences for the two periods, 19511970 and 1971-1980. Correction details are given in Appendix A. 
corrections applied, (if any) and station history information. The format of this Appendix is exactly the same as given in Bradley et a 1. (1985) and Jones et a 1. (1985).

\section{Results of the Station Homogeneity Assessment}

Each station has been assigned a quality control code, identifying records which are correct, homogenized, uncheckable, incorrect, or affected by non-climatic warming trends. The quality control codes are given in Appendix A. In some instances 'correct' stations are only correct after a specified year - the first reliable year. In these cases earlier data are suspect and could not be reliably checked. These early data have not been used to derive grid point anomalies.

The numbers of stations in each homogenization category are 1 isted in Table 1 for the three main continental regions of the Southern Hemisphere: southern Africa, South America and Australasia. Island stations are associated with the appropriate WMO region (i.e. Africa includes stations south of $2.5^{\circ} \mathrm{S}$ with WMO identifiers commencing with a 6 , South America includes stations between $2.5^{\circ} \mathrm{S}$ and $62.5^{\circ} \mathrm{S}$ with wMO indentifiers commencing with a 8 , and Australasia includes stations south of $2.5^{\circ} \mathrm{S}$ with WMO identifiers commencing with a 9 ).

The number of stations which cannot be checked is roughly $46 \%$ of the total. Most of these records are too short for the homogenization analysis, generally having less than 20 years of data. Over half of these stations are located in South America, especially in Brazil. The lack of Brazilian data has been highlighted in Jones et al. (1986b). The proportion of incorrect 
Table 1: Numbers of stations in each homogenization category for different regions of the Southern Hemisphere $\left(2.5-62.5^{\circ} \mathrm{S}\right)$

\begin{tabular}{|c|c|c|c|c|c|c|}
\hline & A & B & C & D & $E$ & F \\
\hline Africa & 59 & 26 & 52 & 2 & 0 & 139 \\
\hline S. America & 87 & 24 & 147 & 13 & 1 & 272 \\
\hline $\begin{array}{l}\text { Australia, Indonesia, } \\
\text { New Zealand }\end{array}$ & 91 & 15 & 81 & 10 & 2 & 199 \\
\hline All 3 regions & 237 & 65 & 280 & 25 & 3 & 610 \\
\hline$\%$ of 610 & 38.9 & 10.7 & 45.9 & 4.1 & 0.5 & \\
\hline
\end{tabular}

A: Stations correct after a specified year. (The specified year is not always the first year of record. In such cases, the early parts of the record were not used in any subsequent analyses.)

B : Stations homogenized.

C: Stations not examined (record too short or no adjacent stations for comparison).

D: Stations incorrect (e.g. numerous jumps and/or trends including nonclimatic cooling trends).

E: Stations with non-climatic warming trends.

F: Station totals. 
$-9-$

stations which could not be corrected is considerably smaller than for the Northern Hemisphere (Jones et al., 1985), although this was not a problem in the Northern Hemisphere because of the greater total number of stations.

In order to average the station data to produce regional and hemispheric mean values it is necessary to reduce all the monthly station data to anomalies. This eliminates the effect of different station elevations and other factors. The period with best data coverage, 1951-70, has been used as the basic reference period. The numbers of correct and homogenized dats with sufficient reference period data (at least 15 of the 20 years between 1951 and 1970) for the three regions are listed in Table 2. A few stations with a long period of record, but without adequate reference period data have been included. For these stations, reference period means were estimated by comparison with neighbouring stations. The accuracy of this estimation is $\pm 0.2^{\circ} \mathrm{C}$.

Altogether 293 stations were used in subsequent analyses. The names, locations and years of operation of these stations are listed in Appendix $B$. The locations of the 293 stations are shown in Figure 5. Further discussion of the station homogeneity assessment is given in Jones et al. (1986b). 
$-10-$

Table 2: Stations with sufficient data in the reference period, 1951-70.

$\begin{array}{lcccr} & \text { A } & \text { B } & \text { C } & \text { Sum } \\ \text { Africa } & 52 & 26 & 8 & 86 \\ \text { S. America } & 70 & 23 & 14 & 107 \\ \begin{array}{l}\text { Australia, Indonesia, } \\ \text { New Zealand }\end{array} & 83 & 15 & 2 & 100 \\ \text { All 3 regions } & & & & 293 \\ \text { \% of 293 } & 205 & 64 & 24 & \end{array}$

A : Stations correct after a specified year.

B: Stations homogenized.

C: Stations not checked.

Sum: Station totals by region and overall. 
In order to overcome the irregular spatial distribution of the station data, we have interpolated the data onto a regular $5^{\circ}$ latitude by $10^{\circ}$ longitude grid. This is exactly the same grid spacing as used for the Northern Hemisphere by Jones et a1. (1986a) and Vinnikov et al. (1981). As was noted earlier, it is necessary to reduce all the station data to anomalies because of different station elevations and, to a lesser extent, different observation times. The reference period used was 1951-70.

Each station was associated with its nearest grid point in terms of great circle distance. Grid-point departures (from the 1951-70 reference period) were calculated by averaging all the stations near a point using inverse distance weighting.

$$
T_{g}=\sum_{s=1}^{n} \alpha_{s} T_{s} / \sum_{s=1}^{n} \alpha_{s}
$$

where $\mathrm{T}_{8}$ is the interpolated grid point temperature anomaly

$I_{s}(s=1, n)$ is the station temperature anomaly

$\alpha_{s}(s=1, n)$ is the inverse of the great circle distance between the the station and the grid point (constrained to $1 / \alpha_{s}<0.02$ nautical miles since some stations are located very close to grid points.)

The number of stations nearest to a particular grid point varied from grid point to grid point and from one period to another. In many cases only one station was used, and the station value simply becomes the grid-point value. In others, up to ten stations were averaged. Areas of denser station 


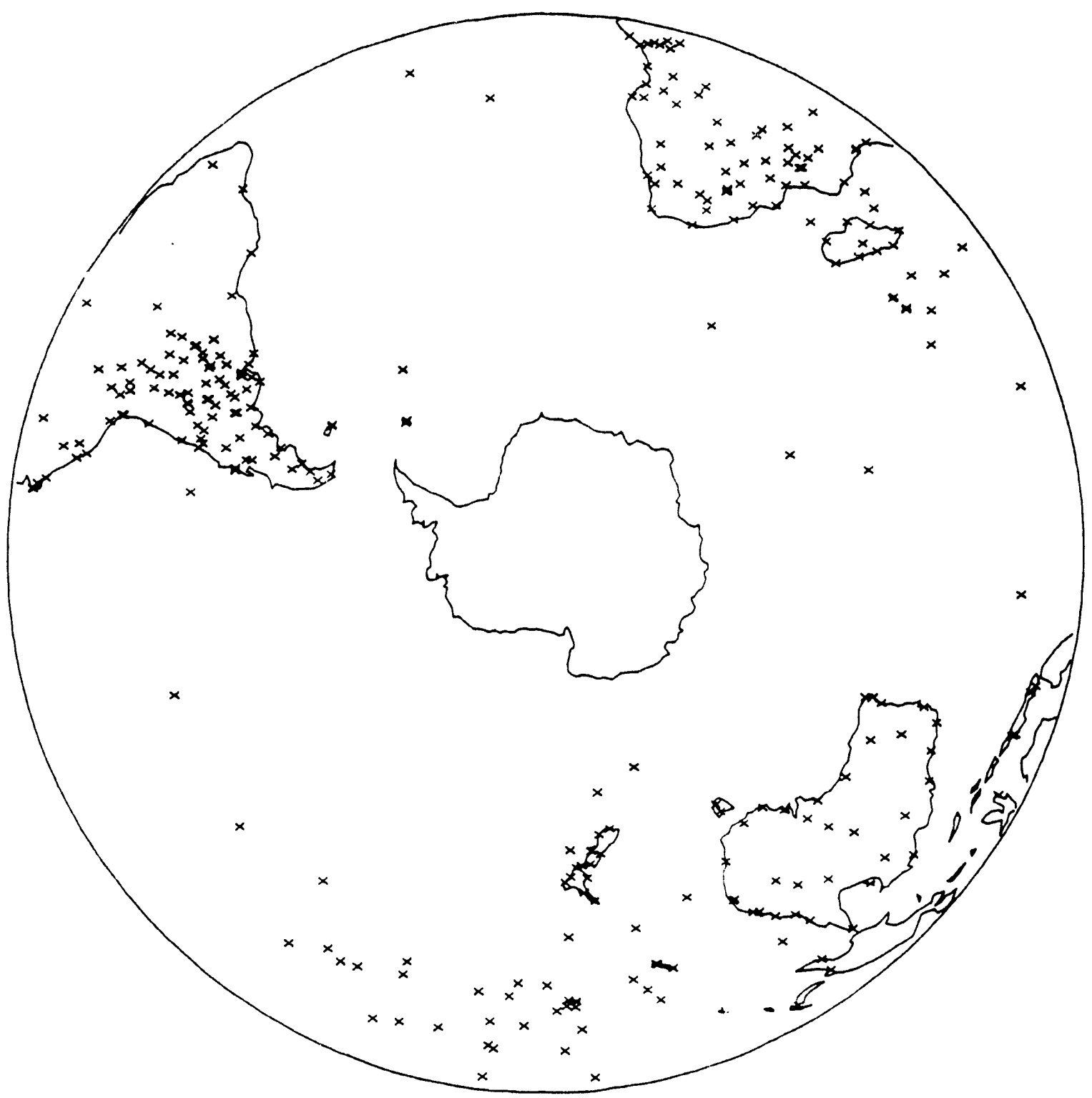

Figure 5:

Locations of the 293 stations used in the gridding technique. The Antarctic stations were used by Raper et al. (1984) are not included 
coverage include New Zeal and and northern Argentina.

Monthly mean grid point anomalies, relative to 1951-70, were calculated back to 1851 for al 1 possible grid points between $5^{\circ} \mathrm{S}$ and $60^{\circ} \mathrm{S}$ inclusive. Grid points anomalies have been calculated and are stored to an accuracy of $0.01^{\circ} \mathrm{C}$, a though this does not reflect the accuracy of the original data. The results are not particularly sensitive to the method of gridding, as demonstrated in Jones et al. (1986a). Other uncertainties, however, mean that individual monthly grid point anomalies are probably only accurate to $\pm 0.2^{\circ} \mathrm{C}$. Our gridded data file includes two measures which can be used to assess the reliability of the grid point interpolations: the number of stations used $(n)$ and the value of $1 / n \sum_{s=1}^{n} a_{s}$. These two quantities are given for each month and for each grid point.

The data set is available on a computer magnetic tape. 
CONCULSIONS

Using this particular grid it is relatively easy to calculate an average time series $(\mathrm{SH} 60)$ for the land areas of the Southern Hemisphere between $2.5^{\circ} \mathrm{S}$ and $62.5^{\circ} \mathrm{S}$ :

$$
\text { SH60 }=\sum_{g=1}^{M} T_{g} \cos \left(\phi_{g}\right) / \sum_{g=1}^{M} \cos \left(\phi_{g}\right)
$$

where $M$ is the number of grid points with temperature anomalies $\left(T_{g}\right)$ in a particular month and $g$ is the latitude of the grid point. The number of grid points incorporated into SH60 increases with time reaching maximum coverage between 1951-1970, during which period approximately $27 \%$ of the entire Southern Hemisphere can be gridded (i.e. $30 \%$ of the $2.5-62.5^{\circ} \mathrm{S}$ region).

The effect of less complete coverage prior to 1951 has been assessed by Jones et al. (1986b). This assessment was carried out by comparing hemispheric estimates based on a sequence of frozen grids (viz. grid points available for each decade between the 1850 s and the 1930s) with estimates based on the best possible grid. Comparisons were made over the period 194180. The results indicate that $\mathrm{SH} 60$ is a reasonably homogeneous and representative time series back to about 1890 . Although the series is undoubted ly less reliable prior to this time, decadal mean values are useful indicators of mean temperature back to the 1860 s.

In order to produce the best possible land average for the entire Southern Hemisphere it is necessary to include Antarctic data. Sufficient data for this continent are only available since the International 


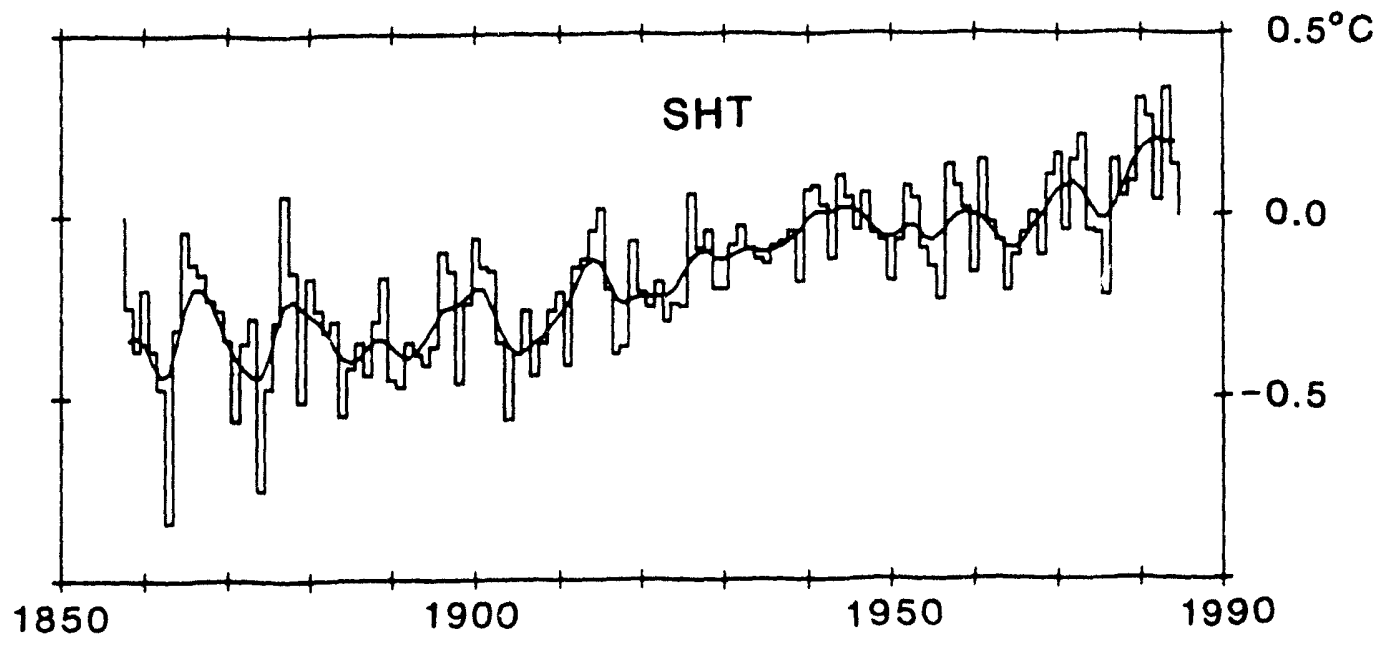

Figure 6: The Southern Hemisphere Temperature (SHT) series 1858-1984 (anomalies relative to 1951-70). 
Geophysical Year in 1957. The best possible Southern Hemisphere area average, SHT, was calculated using

$$
\text { SHT }=(a(\text { SH60) }+b(A N T)) /(a+b)
$$

where ANT is the Antarctic series produced by Raper et a 1. (1984), ard a and $b$ are the areas of coverage of each series, expressed as proportions of the total Southern Hemisphere area. Although a and b vary slightly with time between 1957 and 1984, a is approximately four times b. Prior to 1956, the best possible Southern Hemisphere land average is simply the SH60 series (i.e. ShT and SH6O are identical).

The SHT series shows little overall trend during the nineteenth century (Figure 6). After 1900, the series shows a warming trend to the mid $1940 \mathrm{~s}$. Between about 194 : and 1970 no trend can be seen. Since 1970 a strong warming trend has set in. The three warmest years of the entire record are 1980,1981 and 1983. The overal 1 warming trend since 1900 is about $0.5^{\circ}$, of which roughly $0.3^{\circ} \mathrm{C}$ occurred between 1900 and 1945 and $0.2^{\circ} \mathrm{C}$ since 1970 .

The history of the land-based Southern Hemisphere temperature series is, therefore, not dissimilar to that for the Northern Hemisphere. However, the early twentieth century warming up to 1940 is smaller in magnitude and the cooling evident in the Northern. Hemisphere between 1940 and 1965 appears only as a hiatus in the longer-term warming trend. Further discussion of this data set and comparisons with the marine data for the Southern Hemisphere are given in Jones et a $1 .(1986 b)$. 


\section{REFERENCES}

Bradley, R.S., and P.D. Jones, 1985: Data bases for detecting $\mathrm{CO}_{2}$-induced ci imatic change. ( $\mathrm{In}$ ) U.S. Dept. of Energy State of the Art Report the Detection of Climatic Change. U.S. Dept. of Energy Carbon Dioxide Research Division, Washington, D.C., (to be published).

Eradley, R.S., P.M. Kelly, P.D. Jones, H.F. Diaz and C. Goodess, 1985: A climatic data bank for the Northern Hemisphere, 1851-1980. DoE

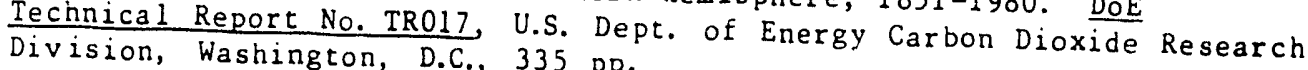

Fol land, C.K., D.E. Parker and F.E. Kates, 1984: Worldwide marine cemperature fluctuations, 1856-1981. Nature, 310, 670-673. Hansen, J.E., D. Johnson, A. Lacis, S. Lebedeff, P. Lee, D. Rind and G.
Russeli, 1981 : Climatic impact of increasing atmospheric carbon diox Science, $213,957-966$.

Jenne, R., 1975: Data sets for meteorological researci. NCAR-TN/JA-111. National Center for Atmospheric Research, Boulder, Co., $194 \mathrm{pp}$.

Jones, P.D., S.C.B. Raper, B.S. Santer, B.S.C. Cherry, C. Goodess, R.S. Bradley, H.F. Diaz, P.M. Kelly and T.M.L. Wigley, 1985: A grid poin DoE Technical Report No data set for the Northern Hemisphere, 1851-1984. Research Division, W. 22. U.S. Dept. of Energy Carbon Dioxide Research Division, Washington, D.C., 251 pp.

Jones, P.D., S.C.B. Raper, R.S. Bradley, H.F. Diaz, P.M. Kelly and T.M.L. Wigley, 1986a: Northern Hemisphere surface air temperature variations, 1851-1984. J. Clim. App 1. Met. 25, 161-179.

Jones, P.D., S.C.B. Raper and T.M.L. Wigley, 1986b: Southern Hemisphere (in prese air temperature variations 1851-1984. J. Clim. Appl. Met. 25

Mitche11, J.M. Jr., 1961: Recent secular changes of global temperature.
Ann. NY Acad. Sci., 95, 235-250.

Raper, S.C.B., T.M.L. Wigley, P.R. Mayes, P.D. Jones and M.J. Salinger, 1984: Variations in surface air temperatures, Part 3: The Antarctic, 1957-82. Monthly Weather Review, 112, 1341-1353.

Pittock, A.B., 1980: Patterns of climatic variation in Argentina and Chile - II. Temperature, 1931-60. Monthly Weather Review, 108, 1362-1369.

Salinger, M.J., 1981: New Zealand climate: the instrumental record. Ph.D. Thesis, Victoria University, Wellington, New Zealand. 
Smithsonian Institution, 1927, 1935, 1947: World Weather Records, Smithsonian Inst., Miscellaneous Collections, Vol. 79,90 and 104. Smithsonian Inst., Washington, D.C.

U.S. Weather Bureau, 1959-82: World Weather Records, 1941-50 (1361 pp.), $1951-50$ (Vol. 1-6), 1961-70 (Vols. 1-6), U.S. Department of Commerce, Washington, D.C.

Vinnikov, K.Ya., G.V. Gruza, V.F. Zakharov, A.A. Kirillov, N.P. Kovyneva and E.Ya. Ran'kova, 1980: Current climatic changes in the Northern Hemisphere. Meteorologiya i Gidrologiya 1980, no. 6, 5-17.

Wigley, T.M.L., J.K. Angel 1 and P.D. Jones, 1985: Analysis of the temperature record. ( $I n$ ) U.S. Department of Energy State of the Art Report on the Detection of Climatic Change. U.S. Dept. of Energy Carbon Dioxide Research Division, Washington, D.C., (to be published).

Wigley, T.M.L., P.D. Jones and P.M. Kelly, 1986: Empirical climate studies: warm world scenarios and the detection of $\mathrm{CO}_{2}$-induced climatic change. (In) The Greenhouse Effect: Climatic Change and Ecosystems, B. Bolin, J. Jyger, B.R. DU8s and R.A. Warrick, Eds., SCOPE Report No. 29, Wiley, New York (to be published).

Willett, H.C., 1950: Temperature trends of the past century. (In) Centenary Proceedings Royal Meteorological Society, 195-206. 
Station History Information and Homogeneity Assessment Details Column Headings

Line 1:

WMO Number (generally with additional 0 )

Station Name

Country

Latitude

Long i tude

Height

First year of data (In some cases this may be the first year with precipitation data. Temperature data starts later.)

Last year of data

Quality code

First reliable year of data

Line 2:

Source: Codes used by Bradley et al. (1985)

Subsequent 1 ines:

Notes and homogeneity details.

Additional Information

Missing Codes:

Latitude - 999

Longitude - 1999

Height - 999

Quality Code:

First Digit

1 - Reliable back to first reliable year

2 - Corrected back to first reliable year

4 - Affected by urban warming

5,8 - Non-homogeneous and uncorrectable

6 - Not compared with neighbouring stations 7 - Reliable back to first reliable year, uncorrectable for earlier

Second Digit

0 - Record $90 \%$ complete

1 - Short record of less than 20 years

2 - Record less than $90 \%$ complete, generally containing many years of missing data

3 - Antique record with data almost entirely from the nineteenth century or earlier 

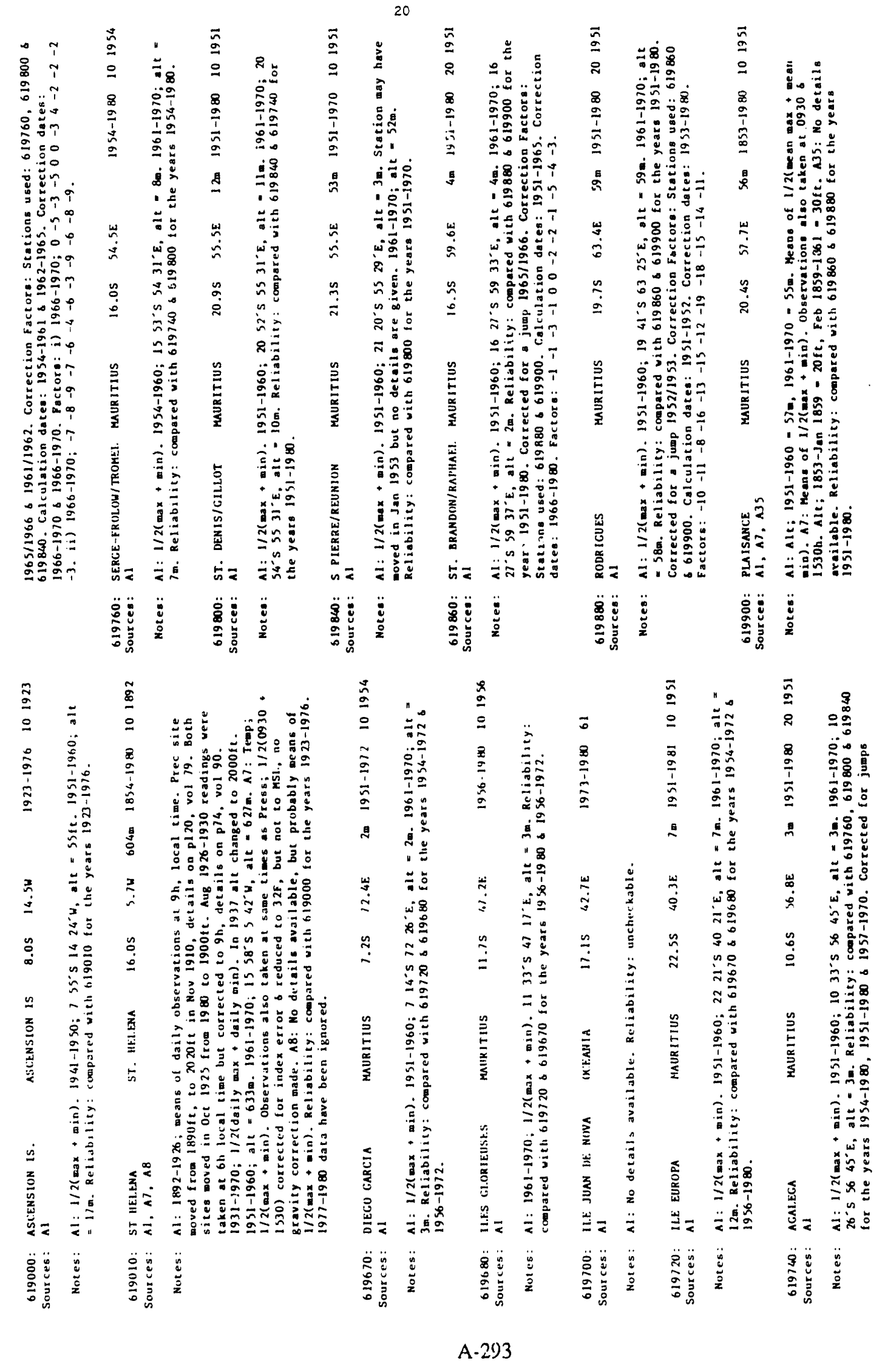

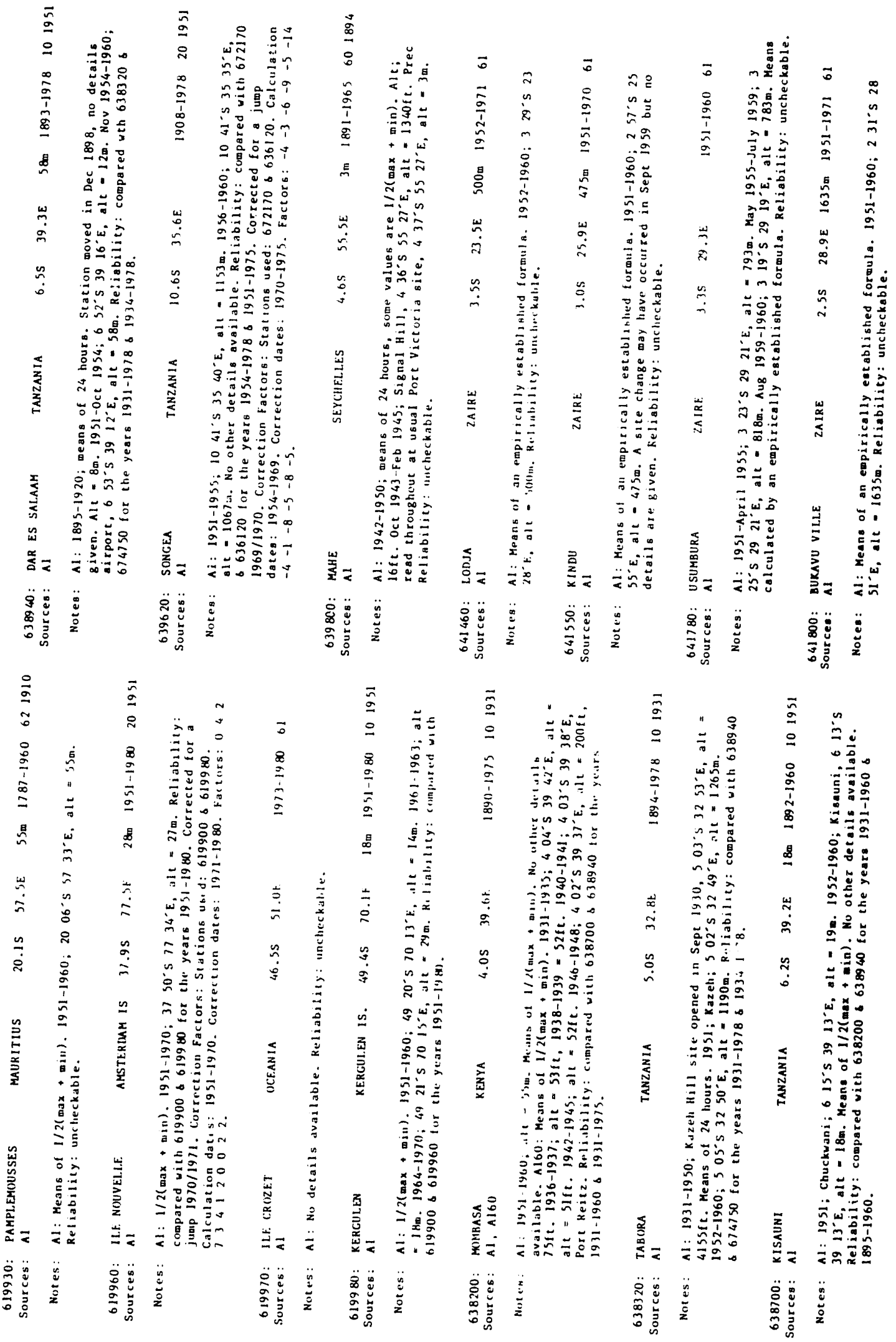


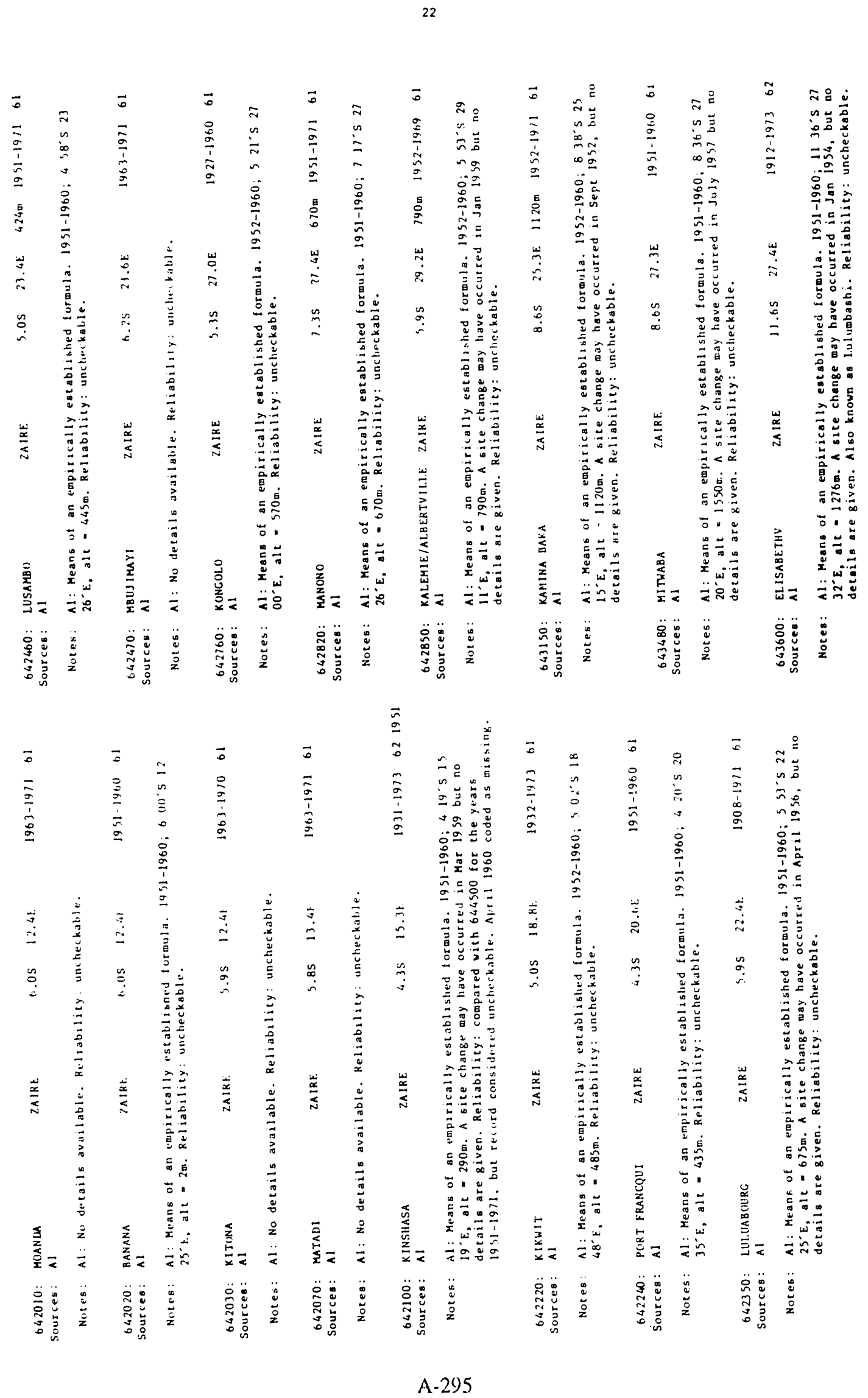


23
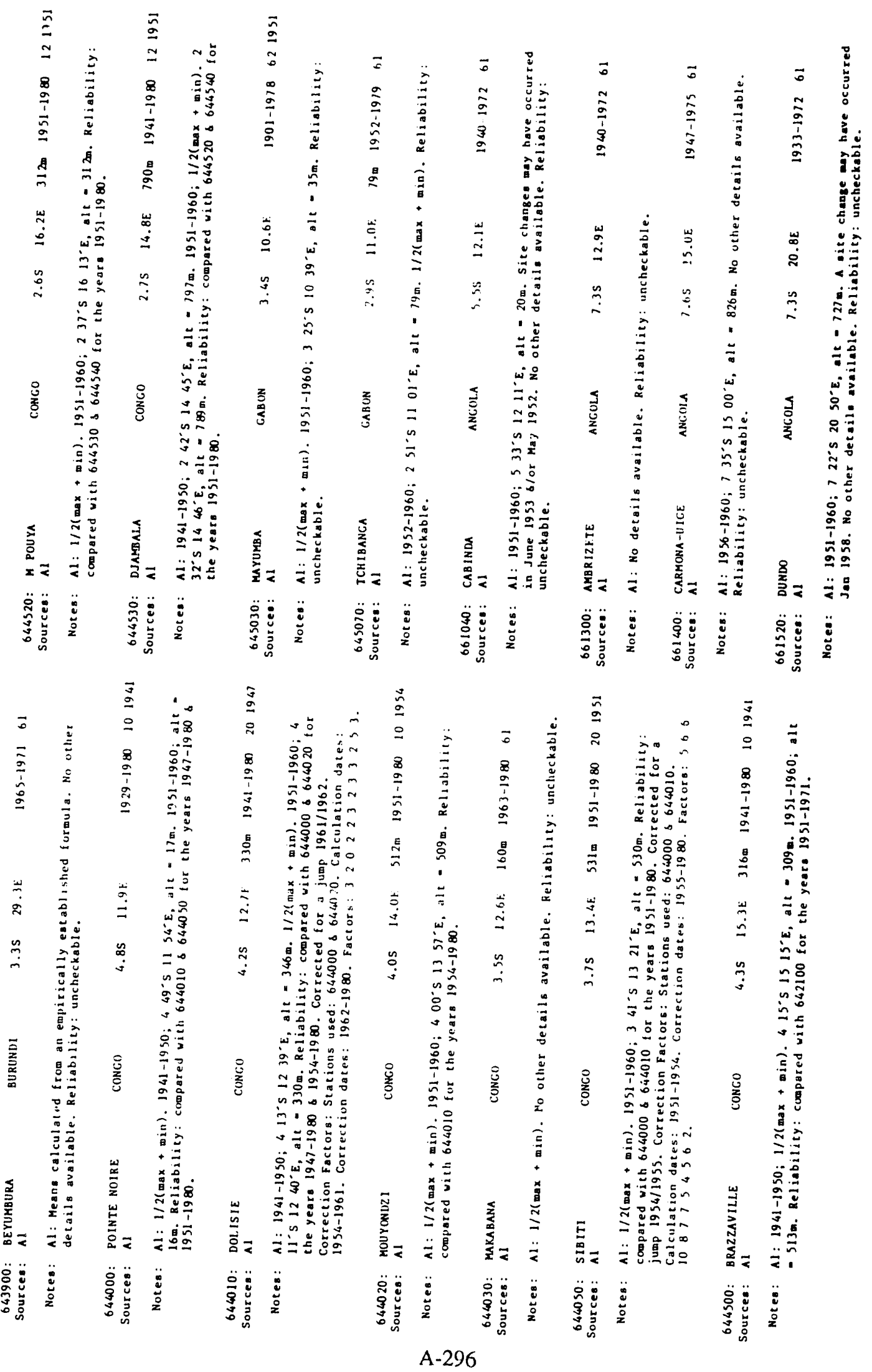

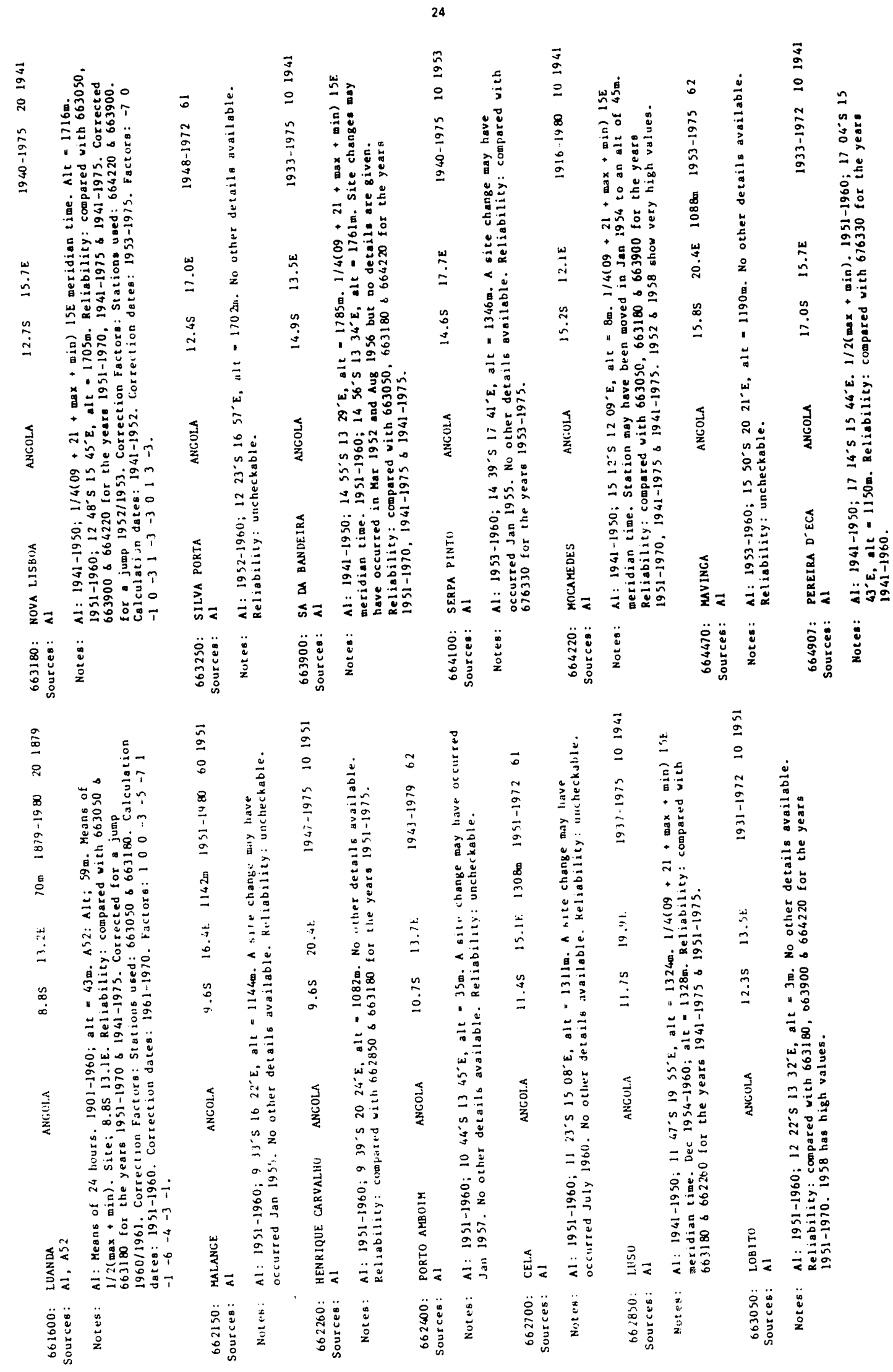
25
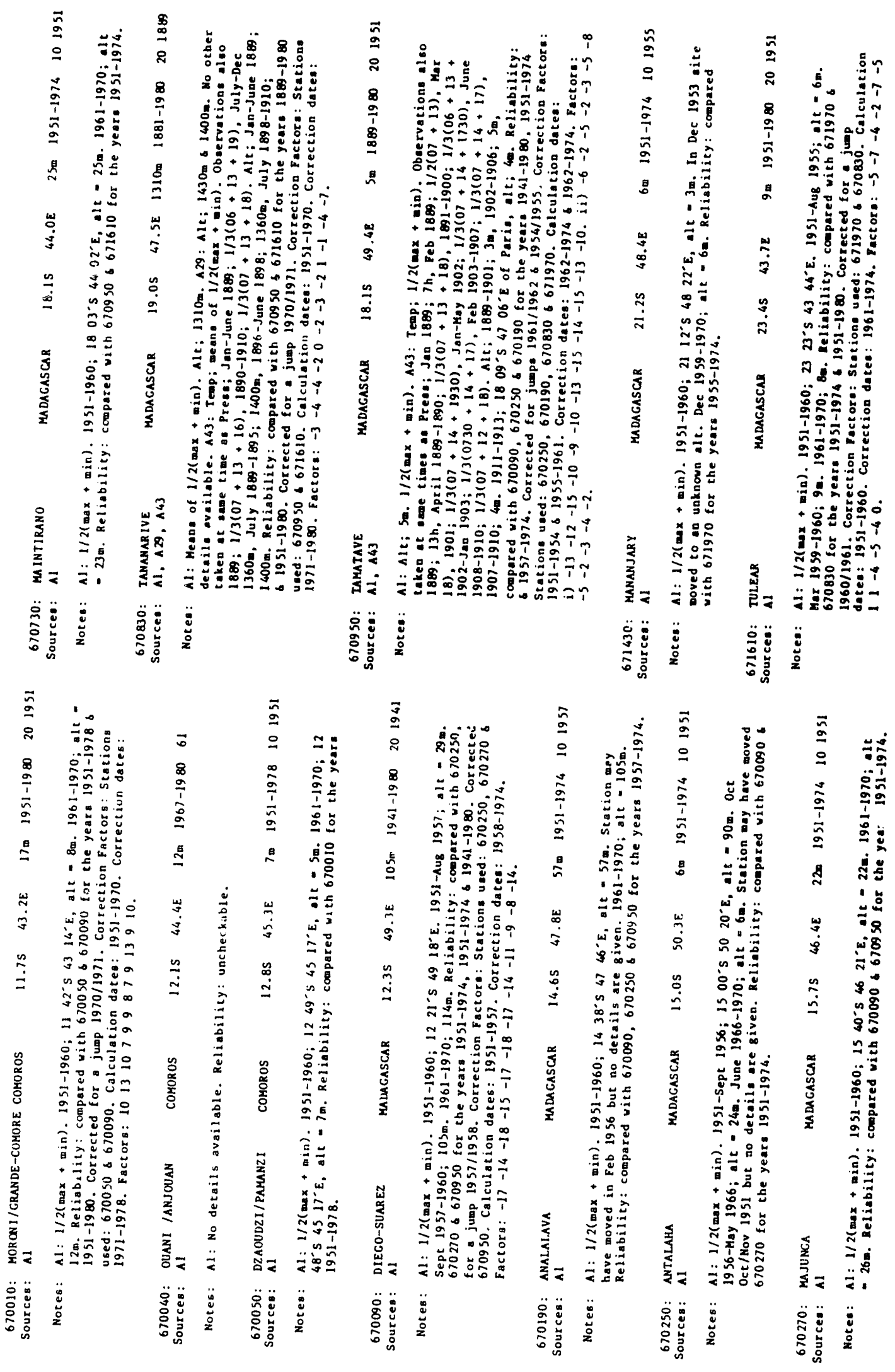

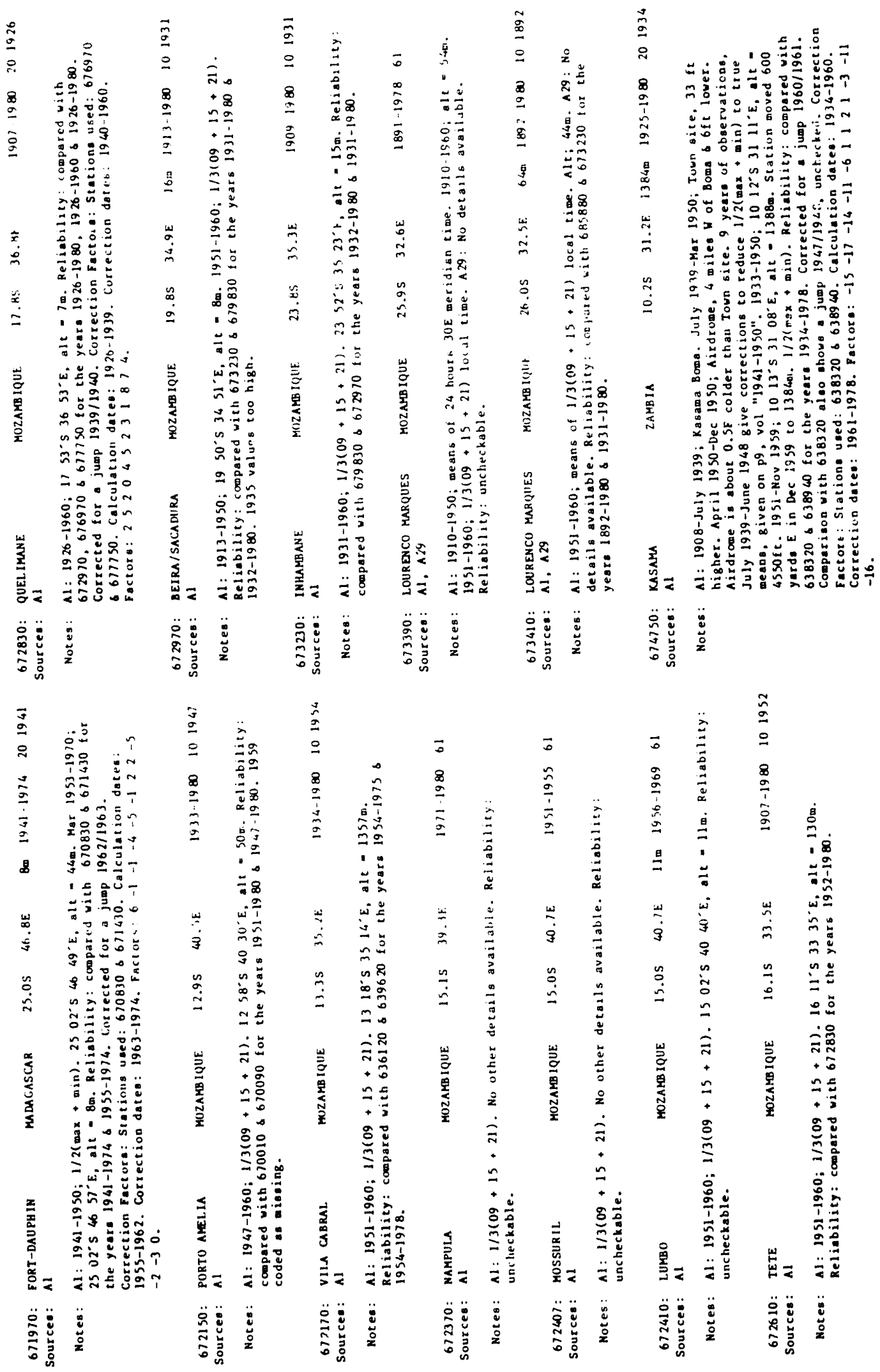


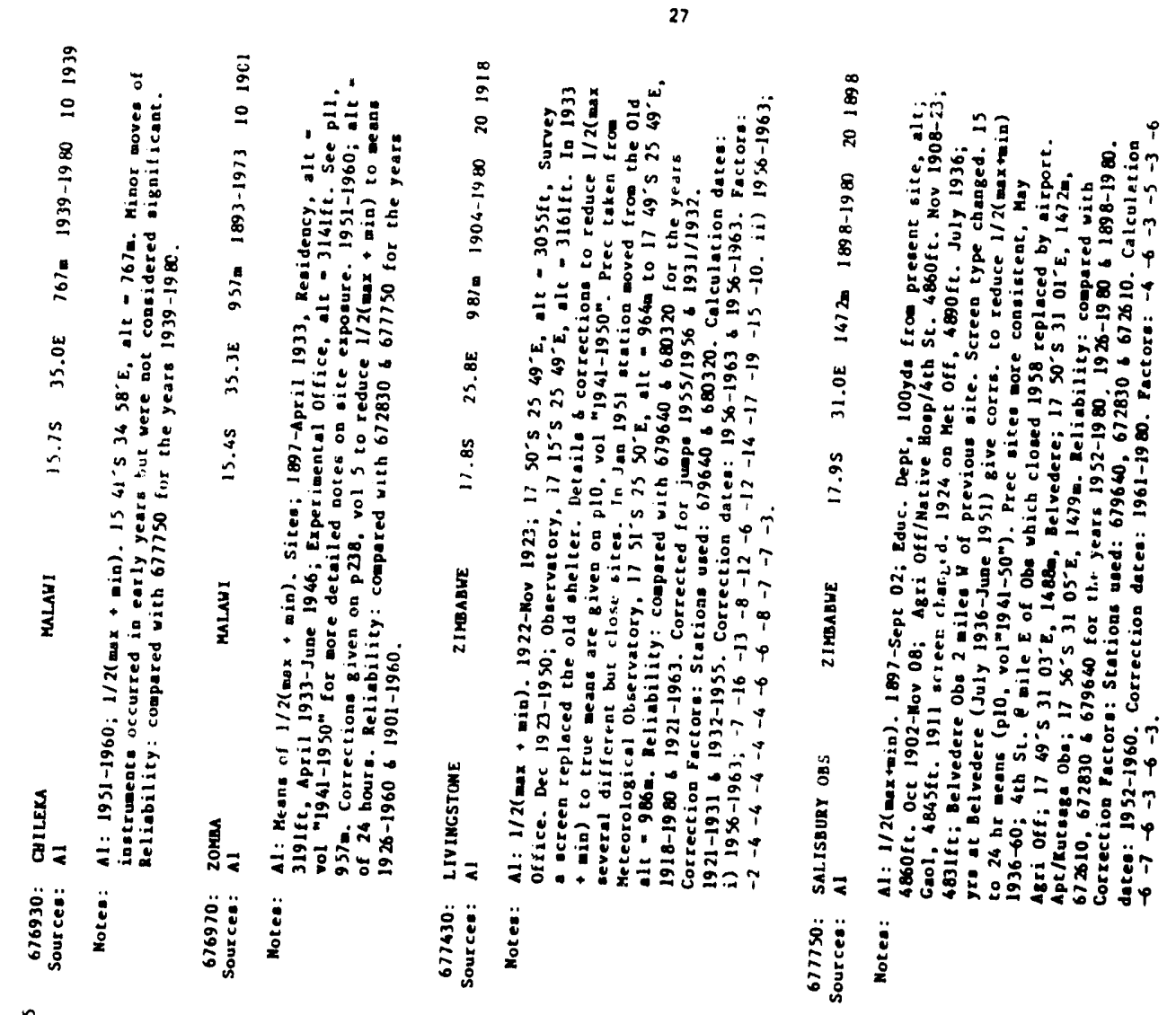

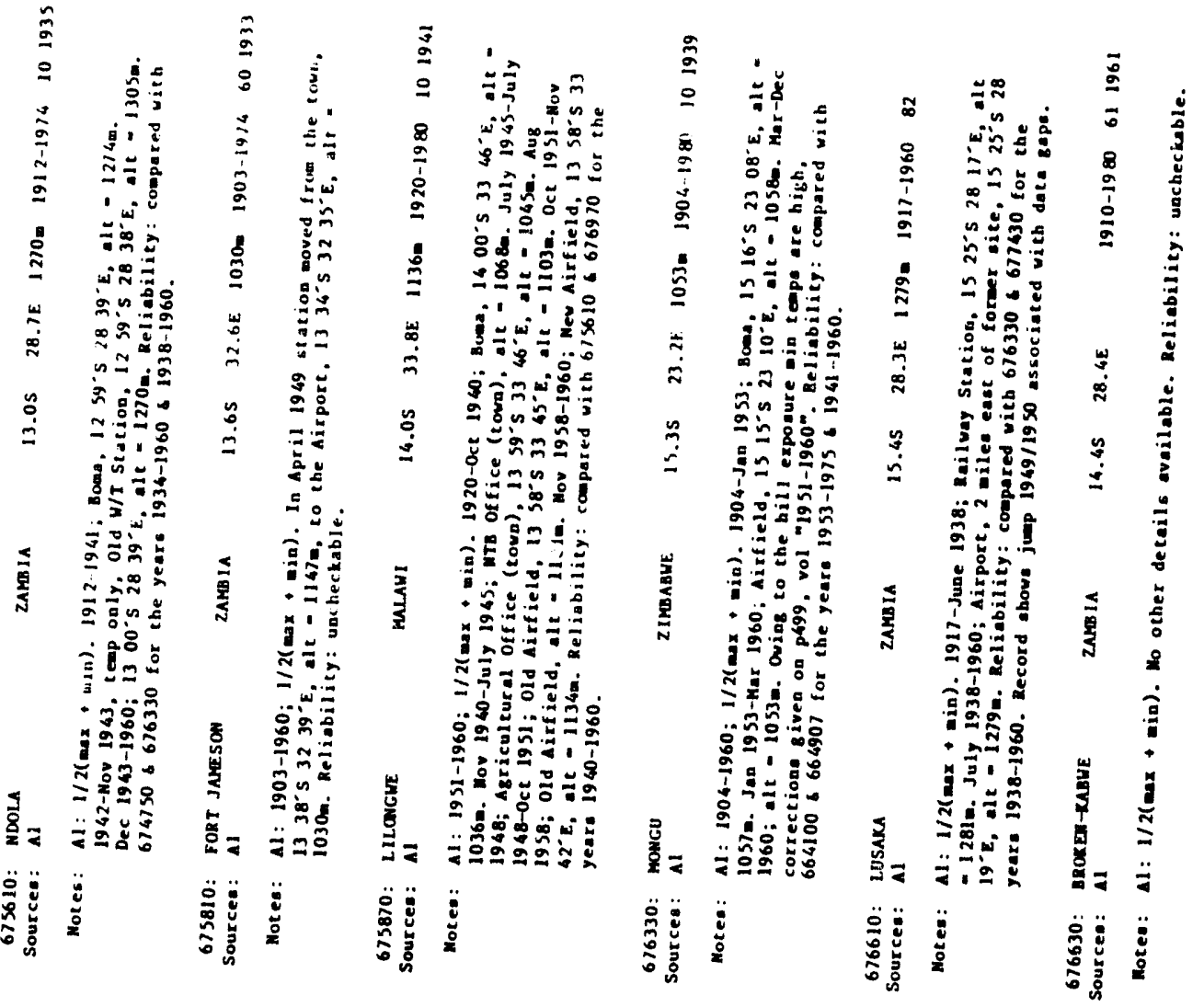



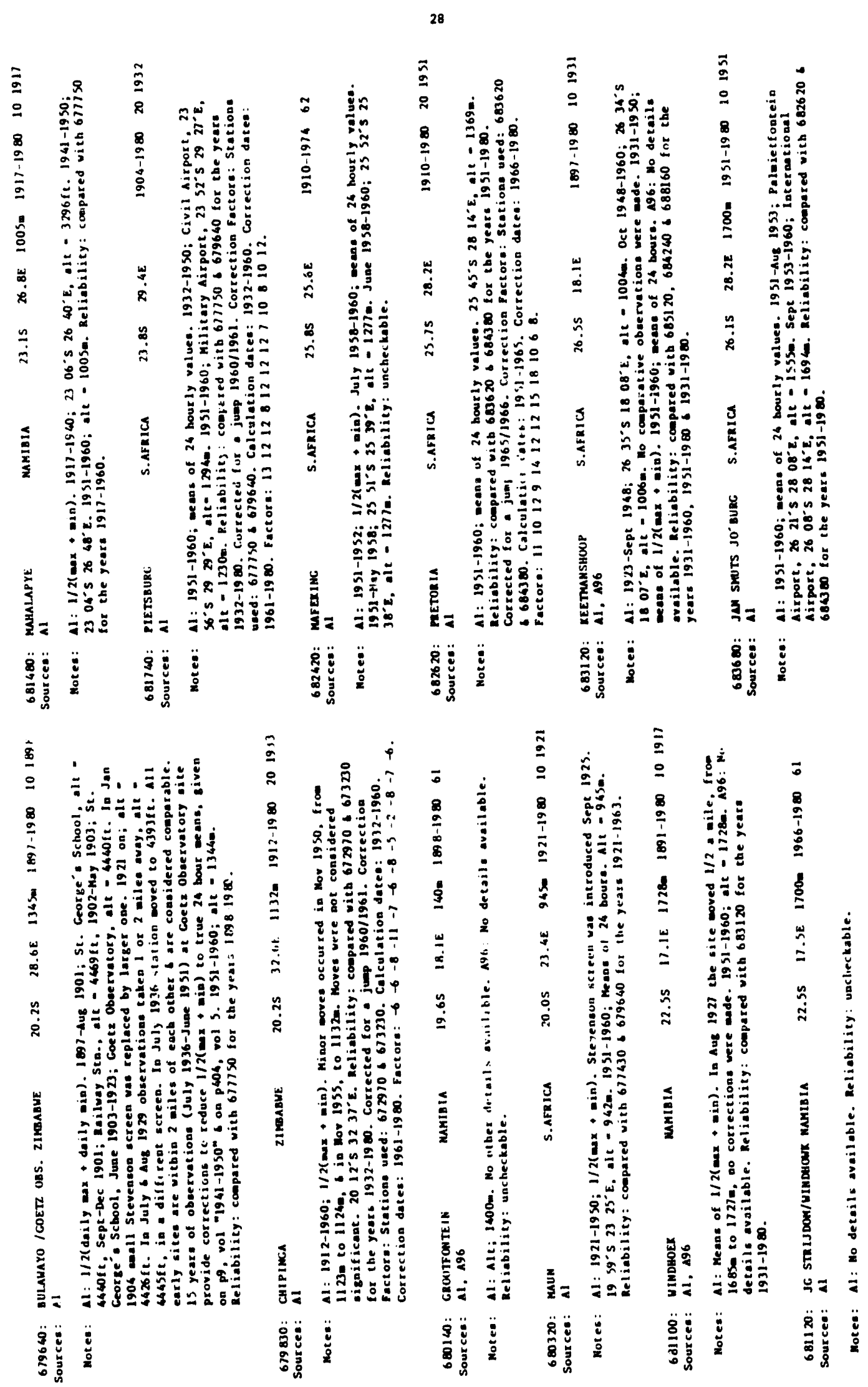

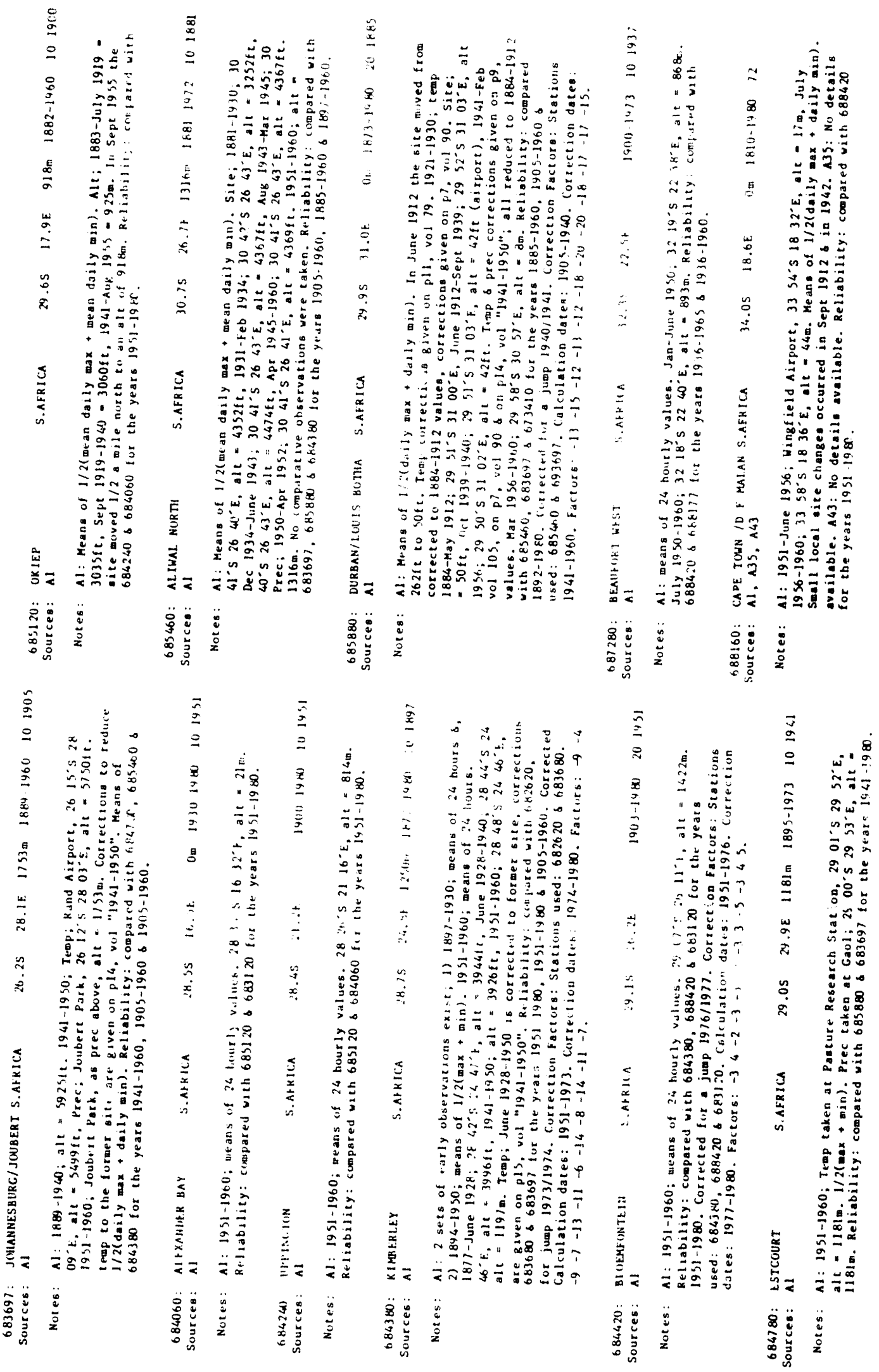

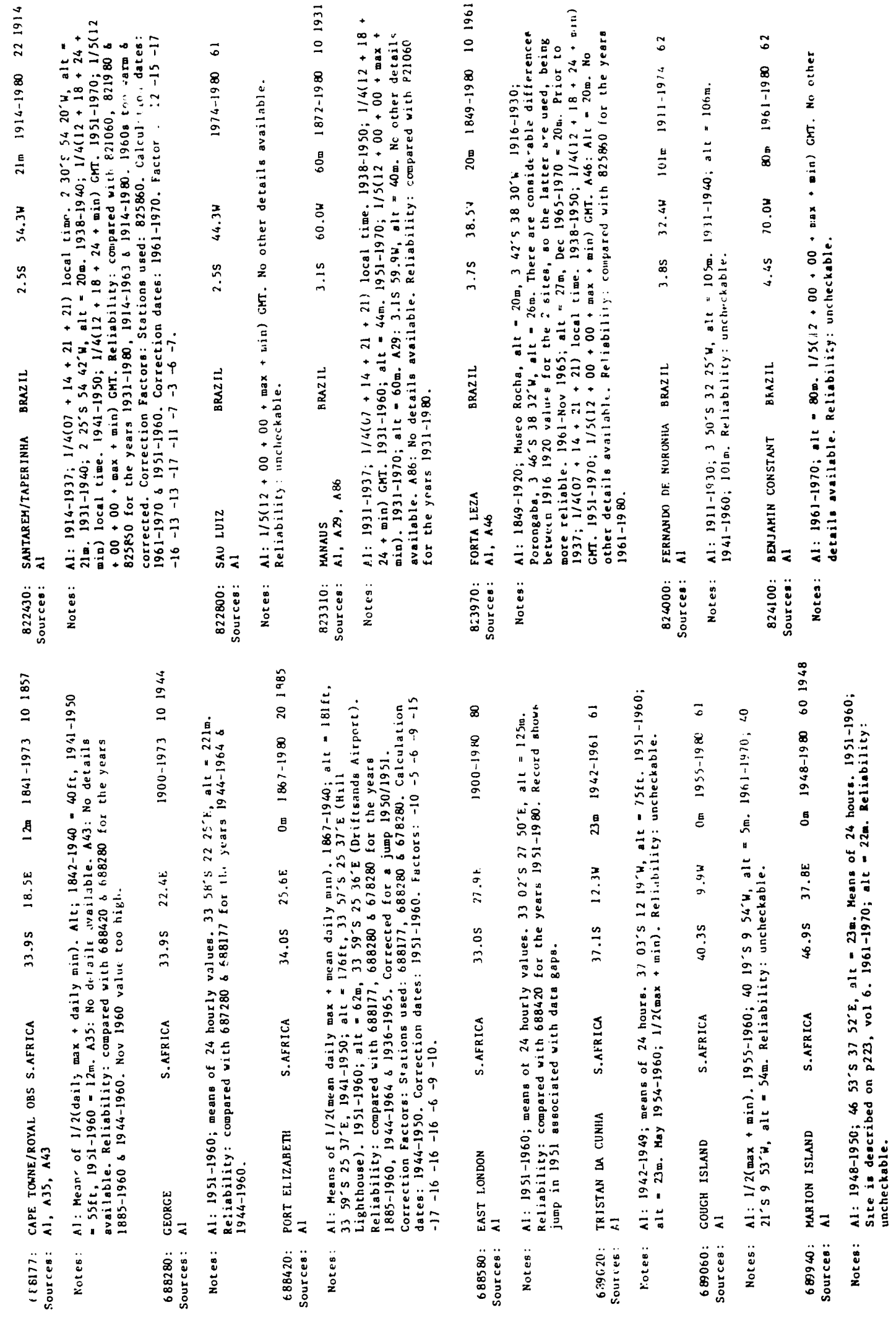

A-303 

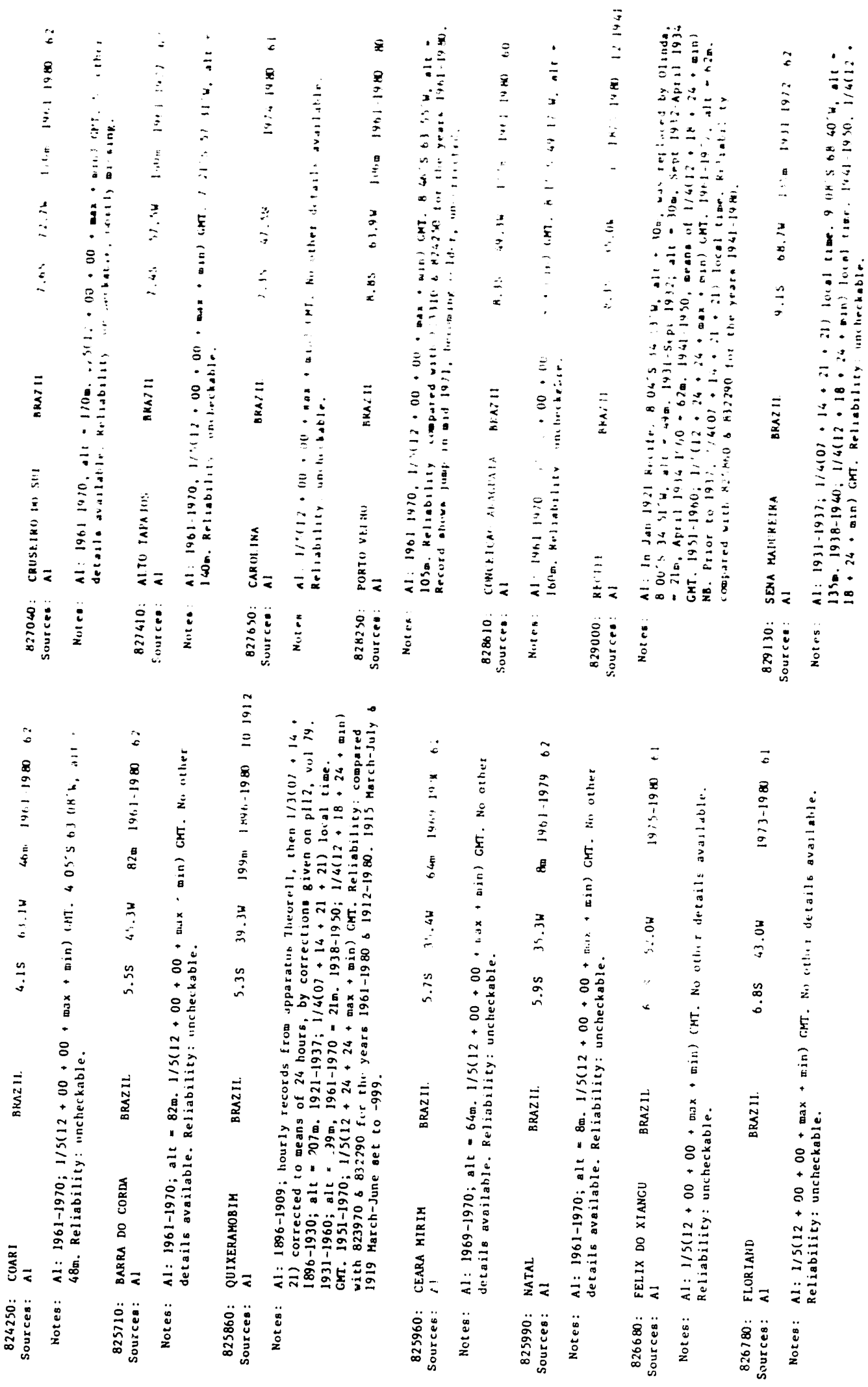

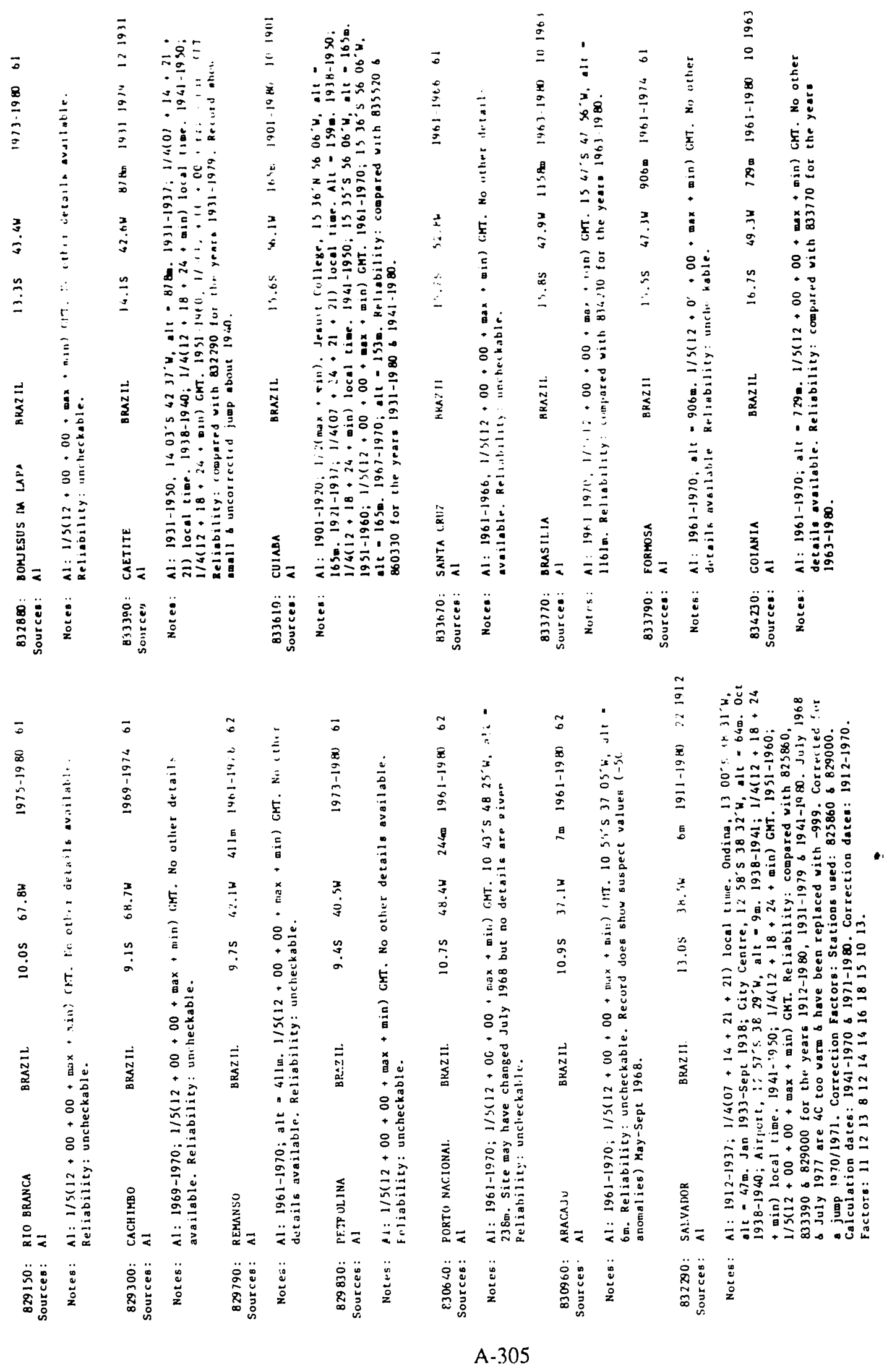

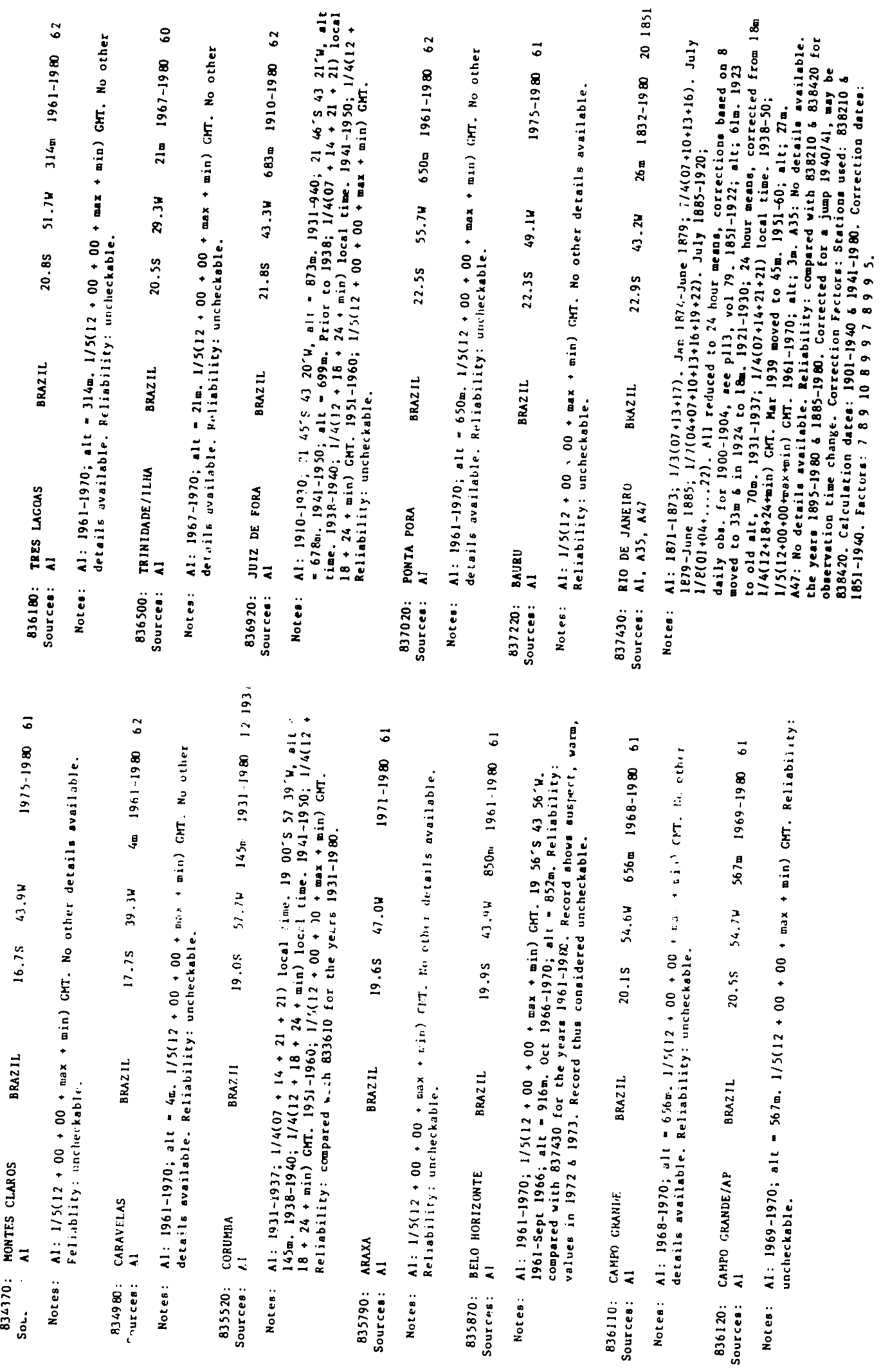
年)

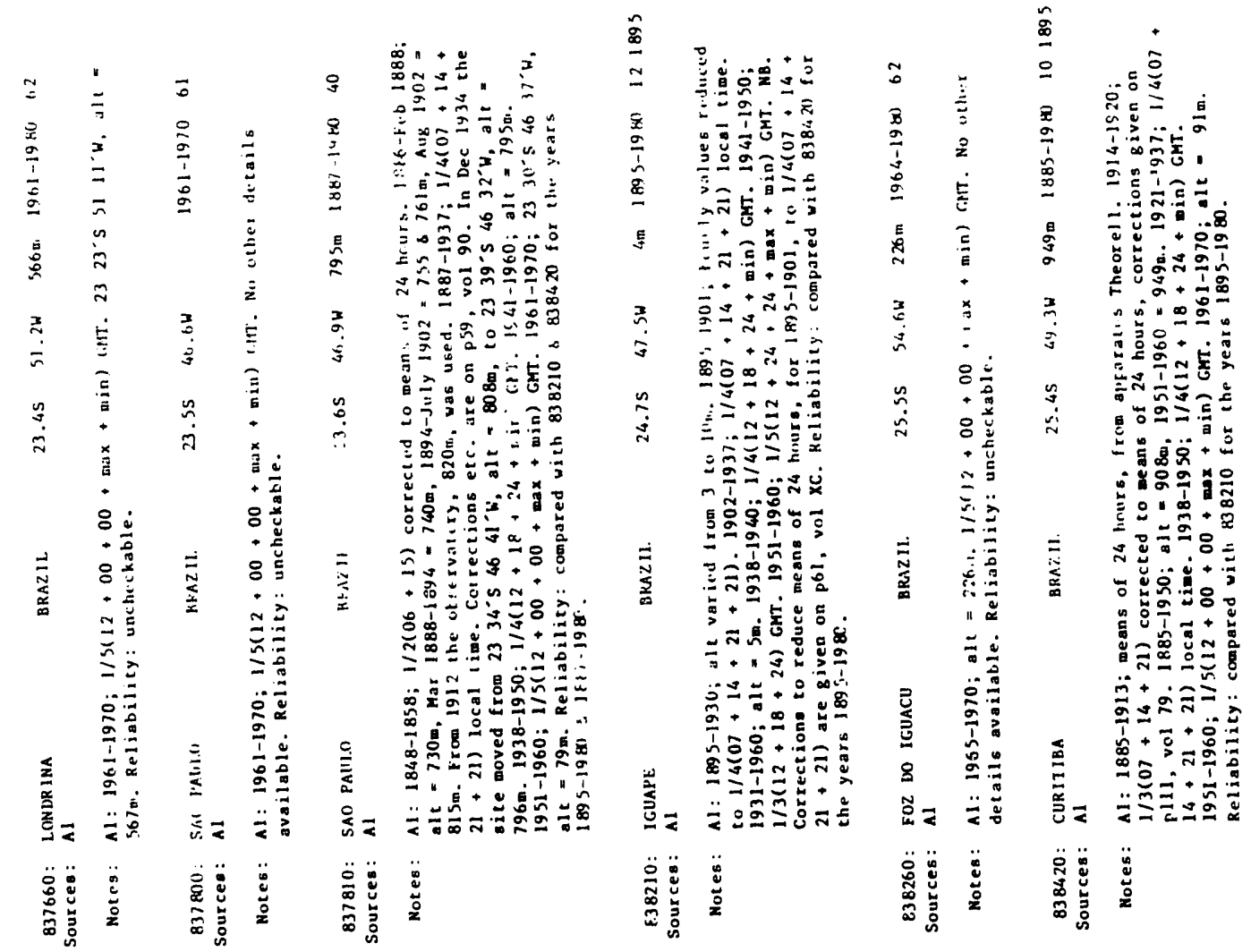

A. 307 

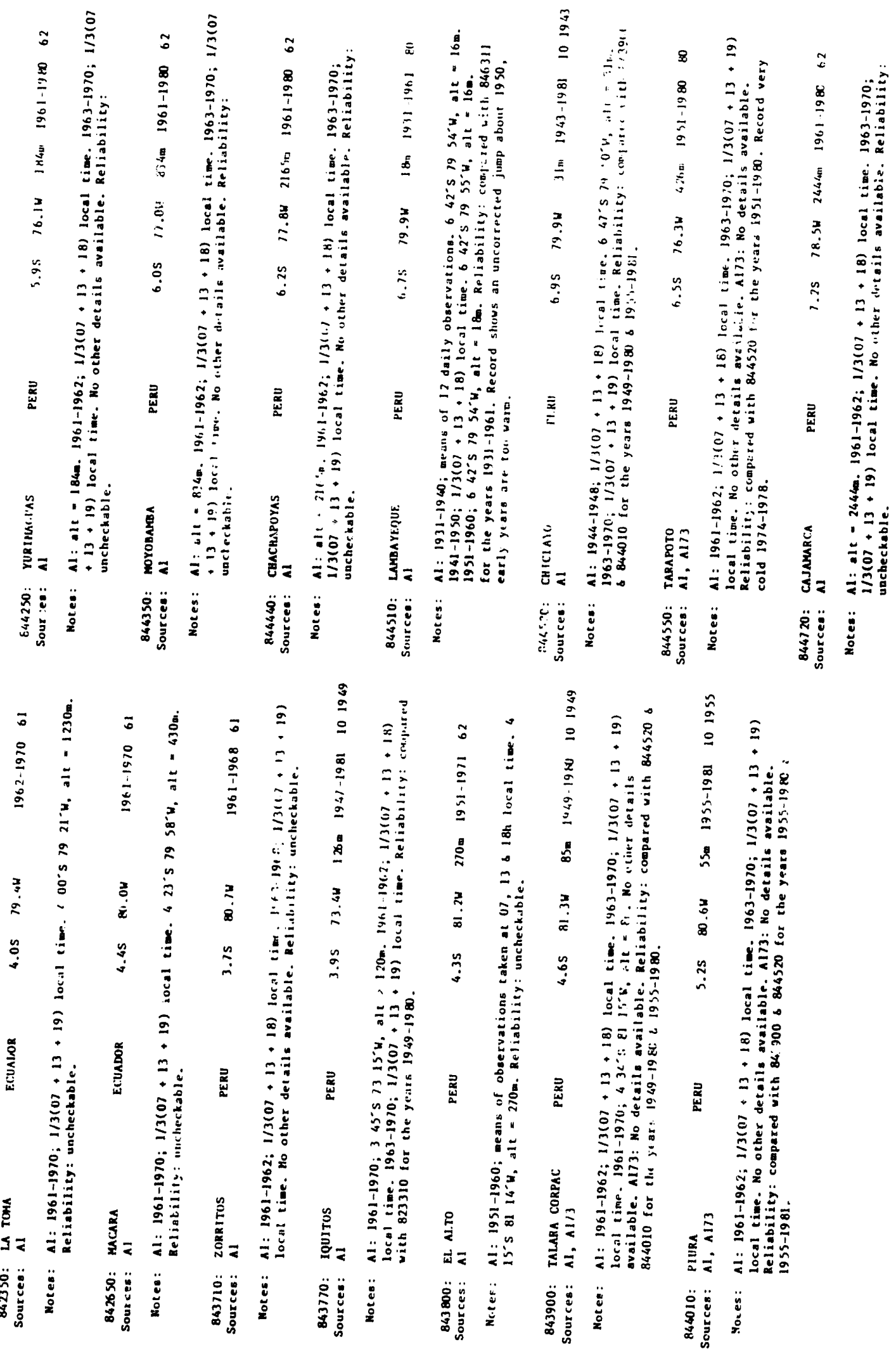


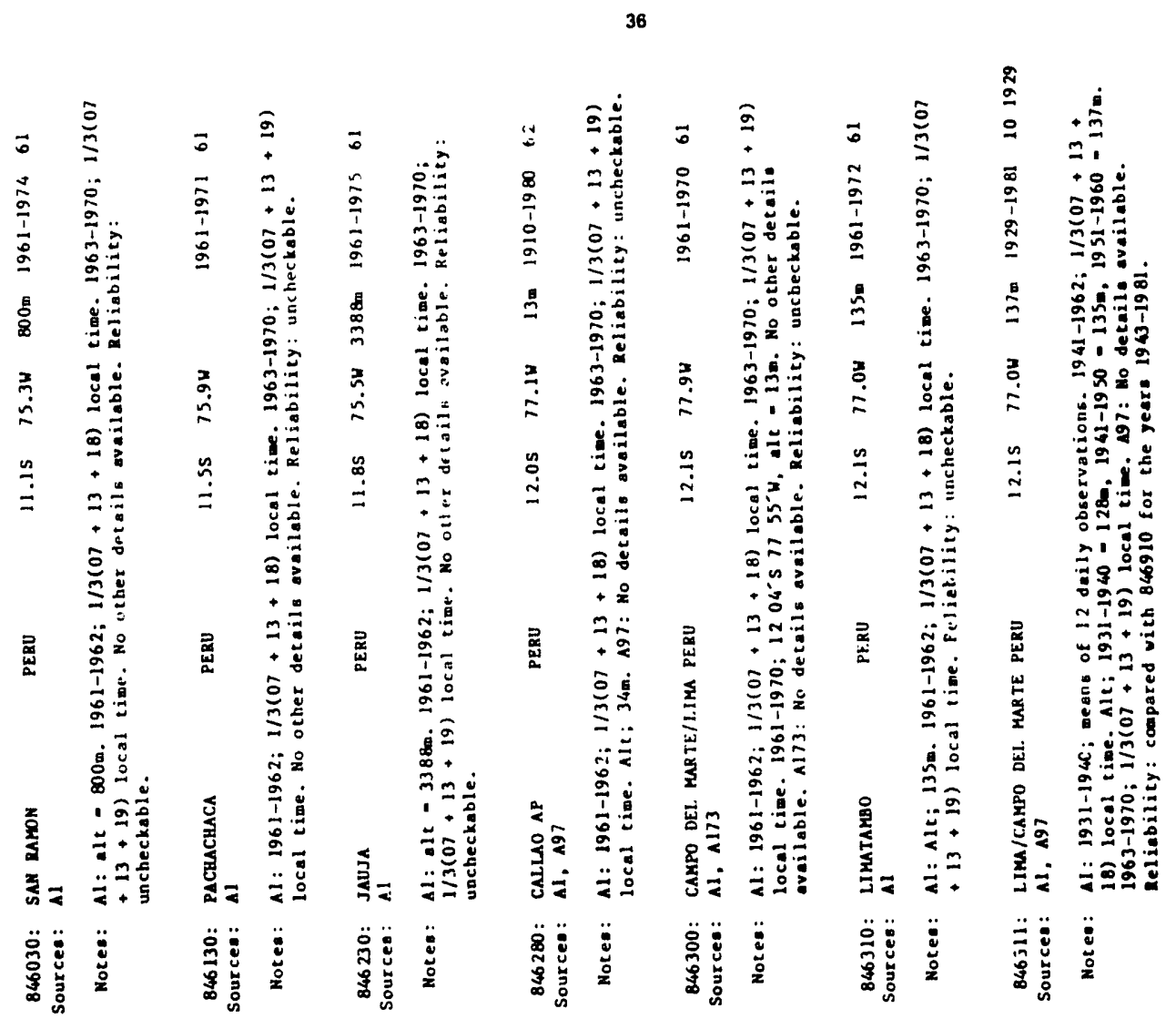

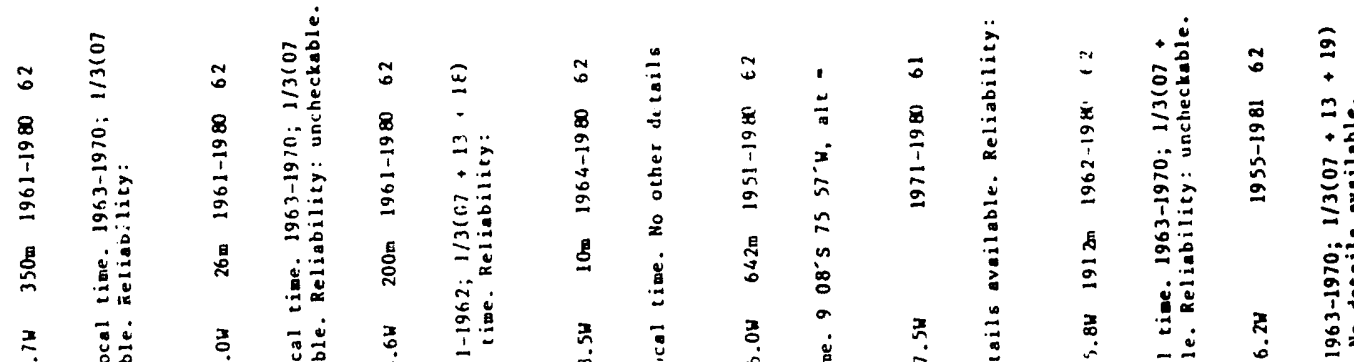

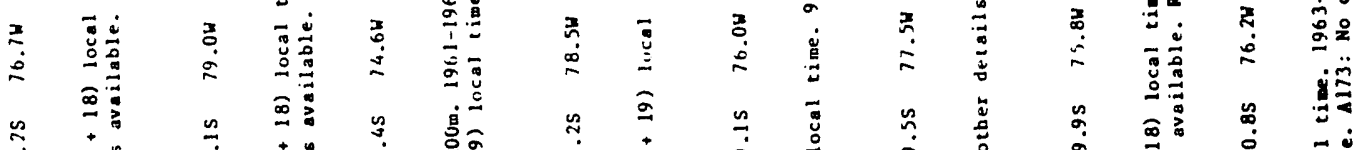

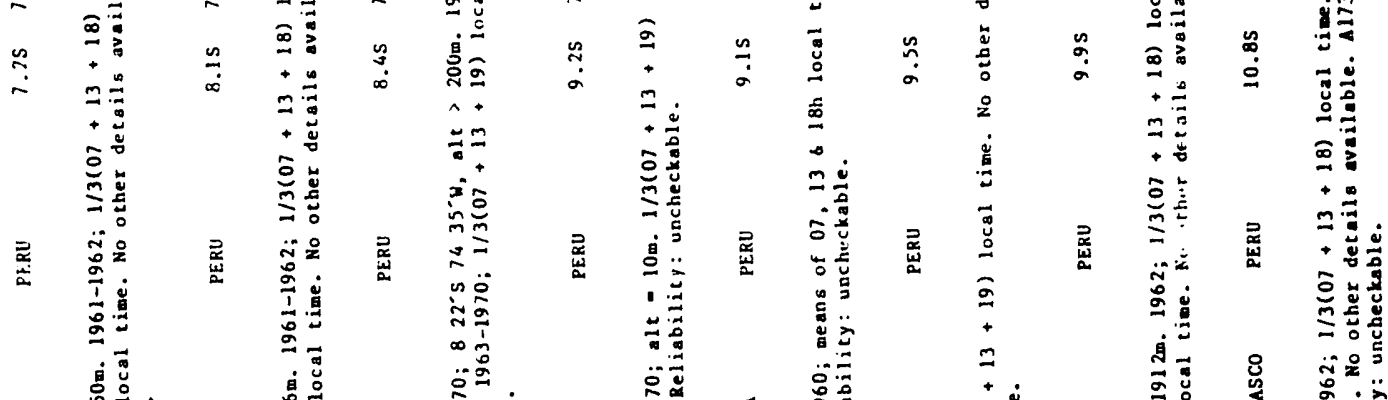

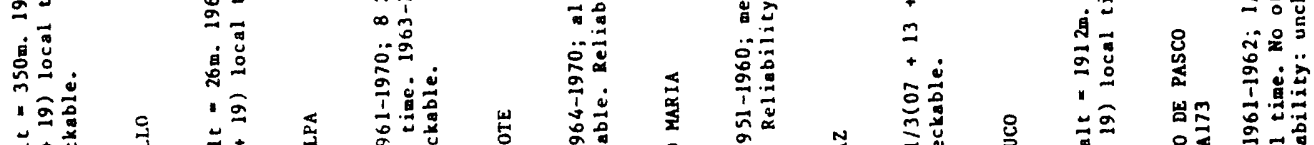

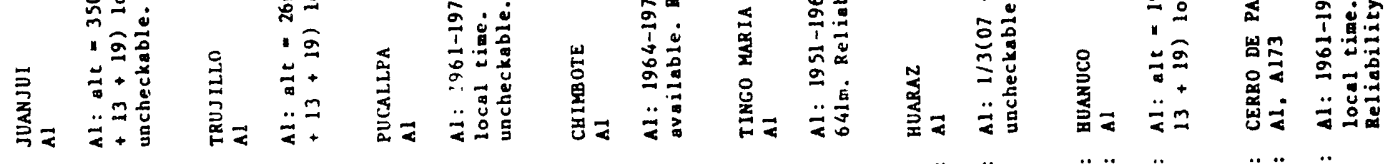

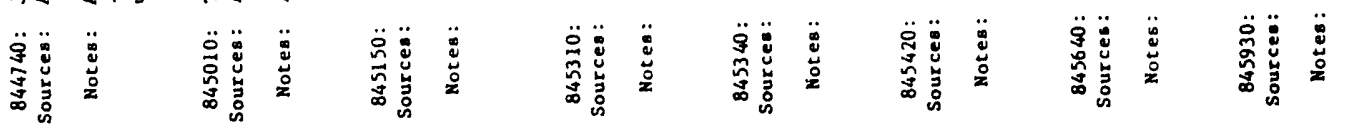



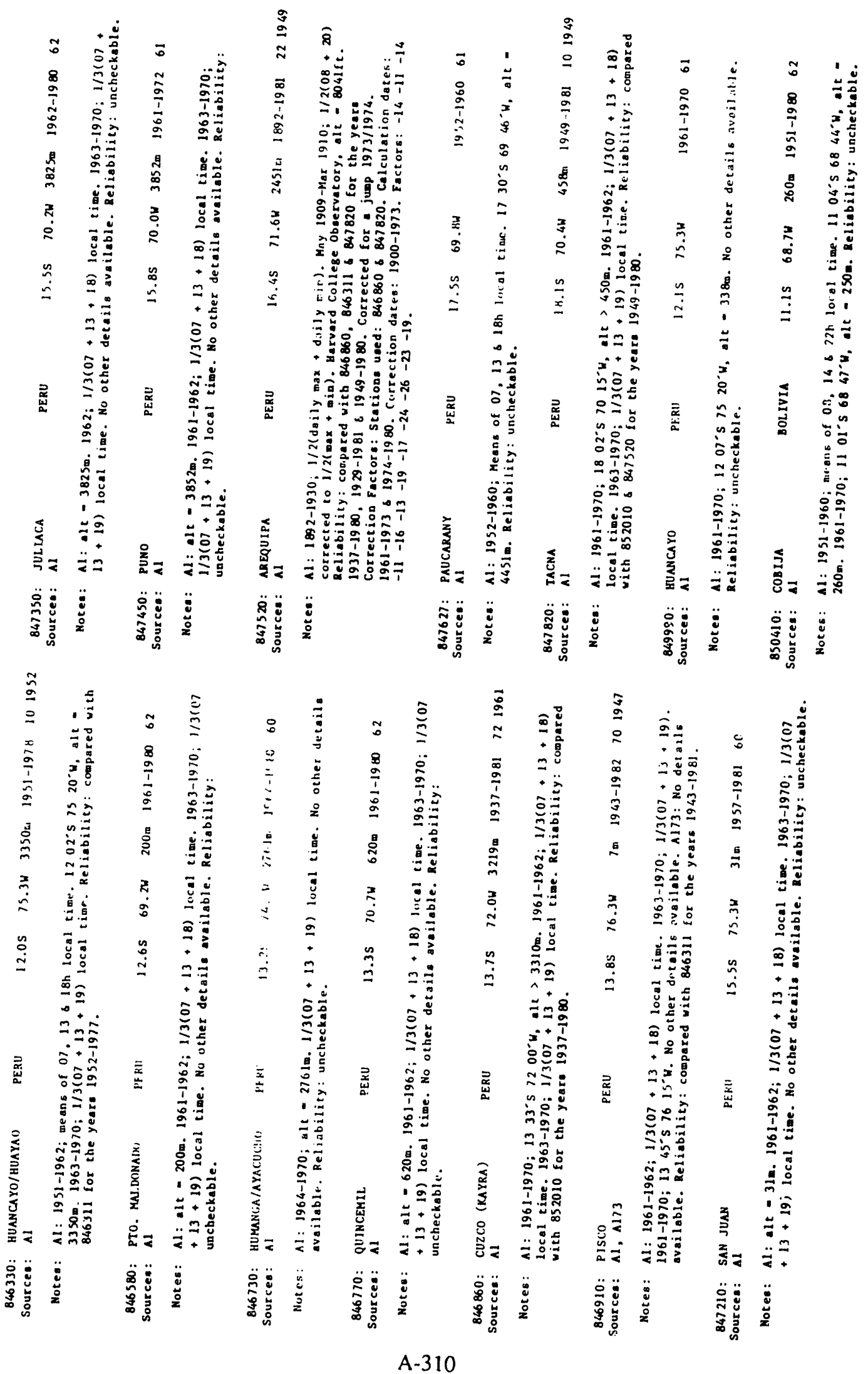
(2)

8 迹通家

寈

ำ

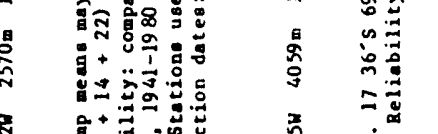

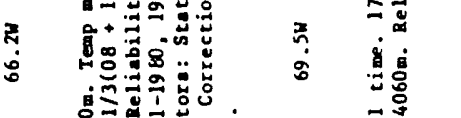

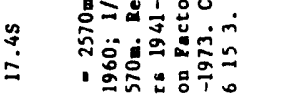

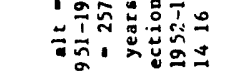

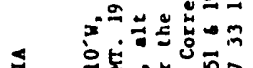

I

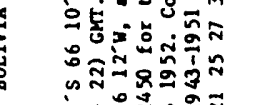

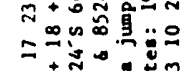

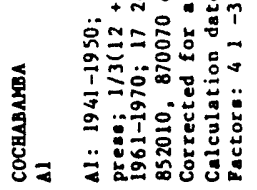

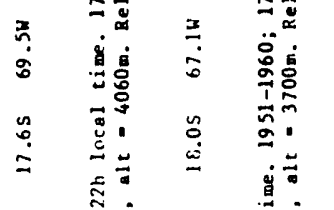

in

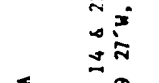

息家.

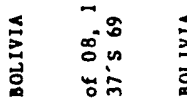

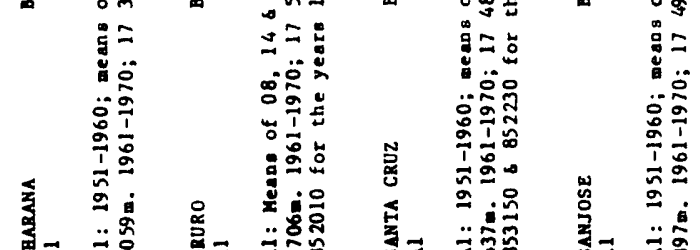

a

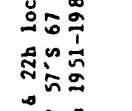

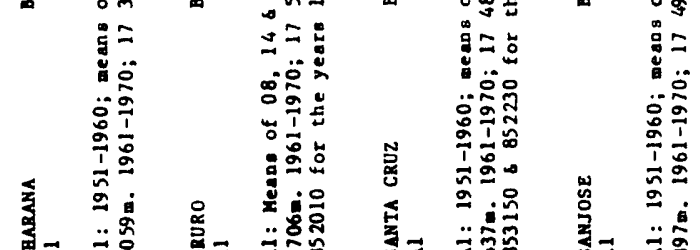

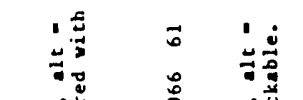

势

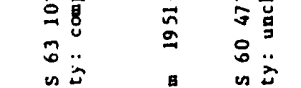

苛

7



家。

范

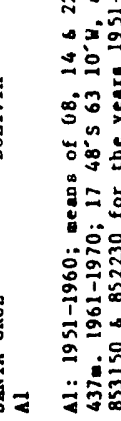

II

II

跑

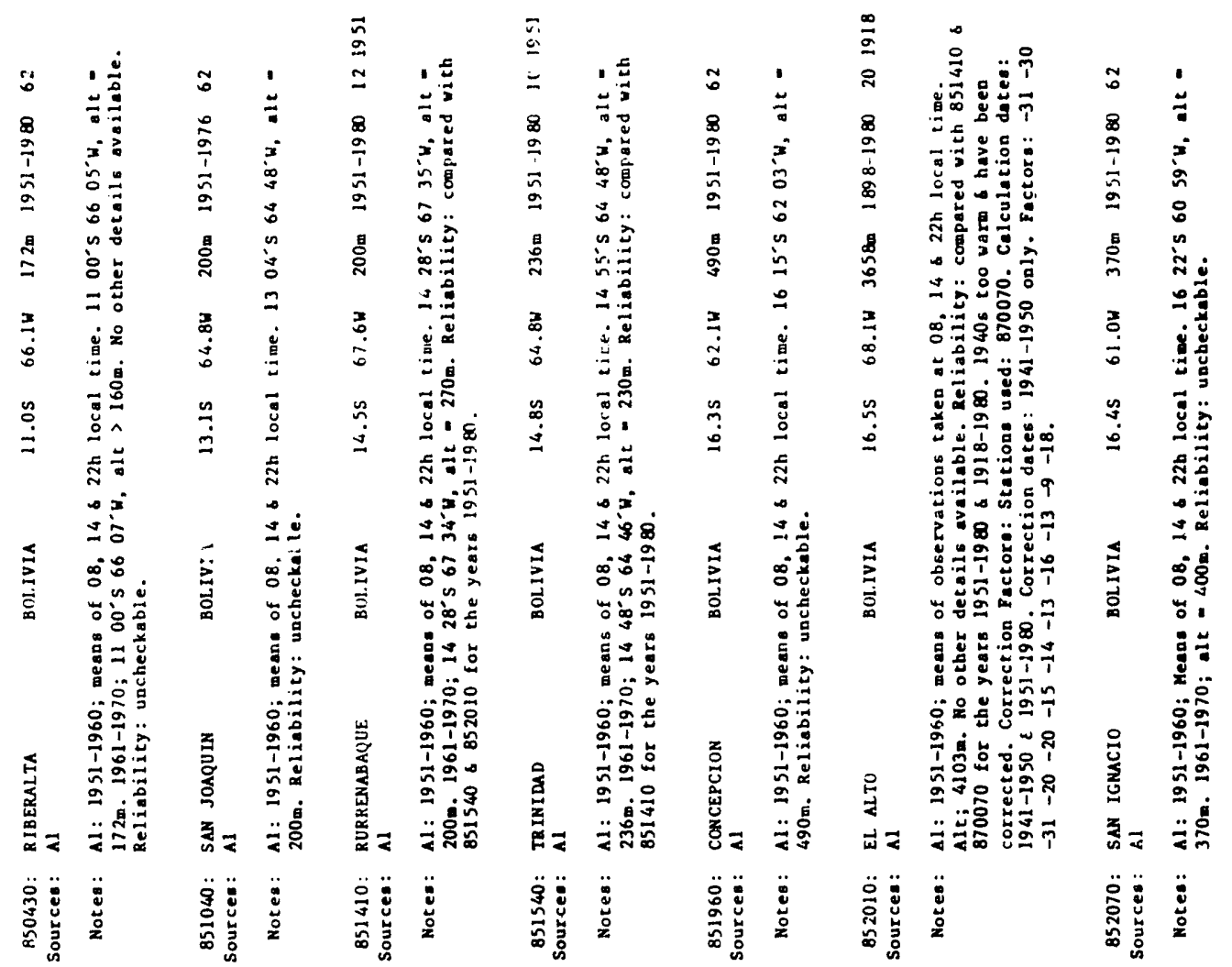



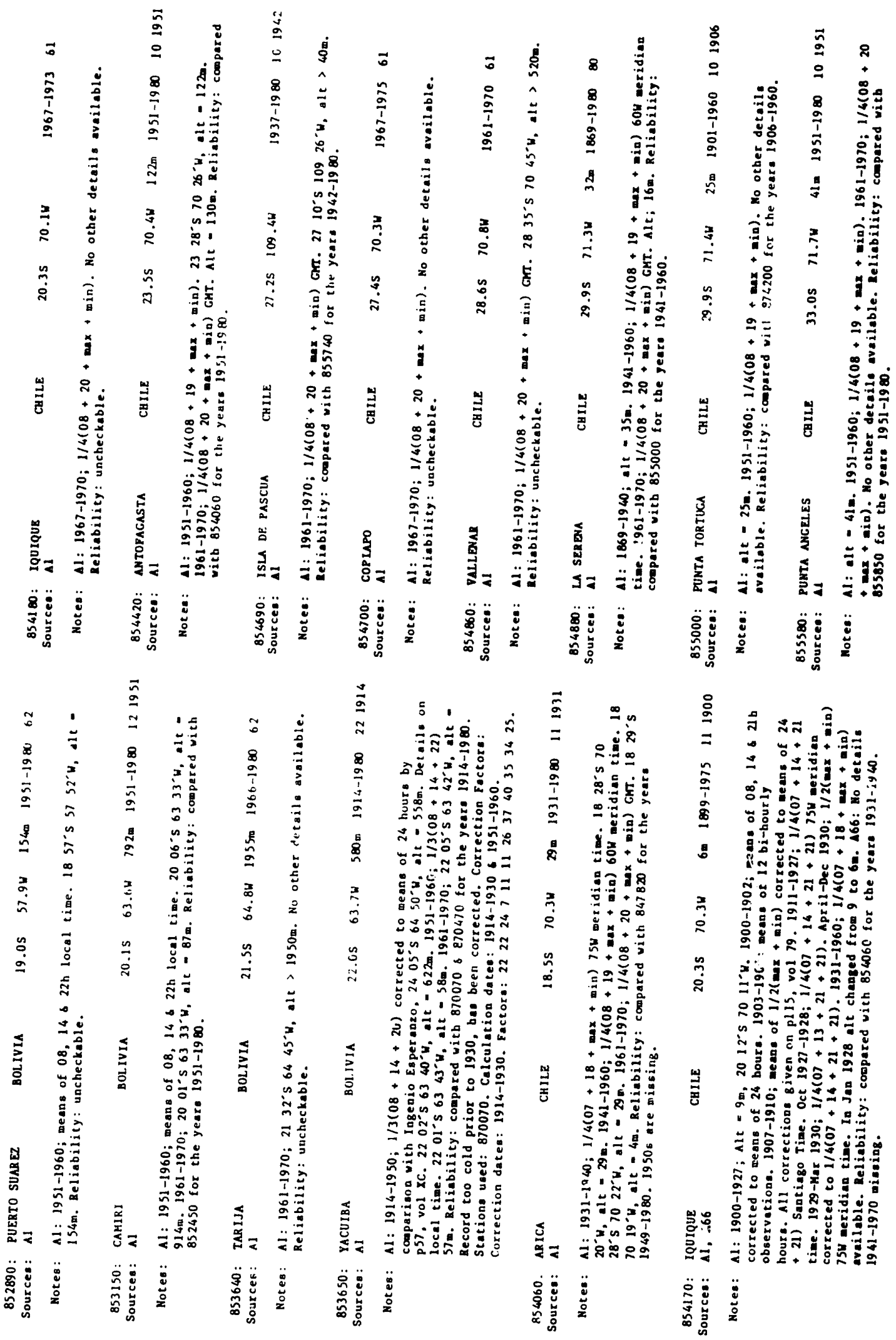

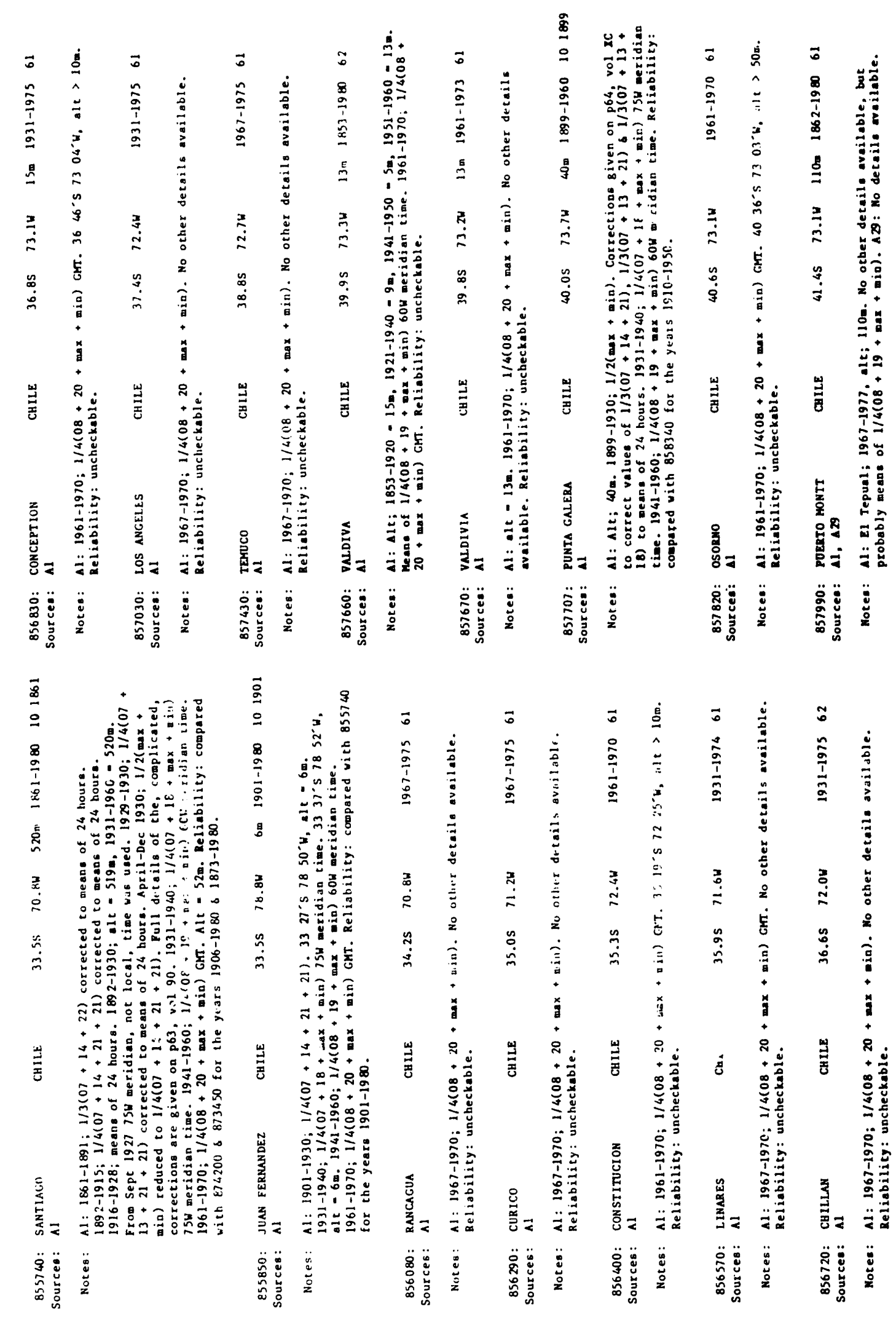


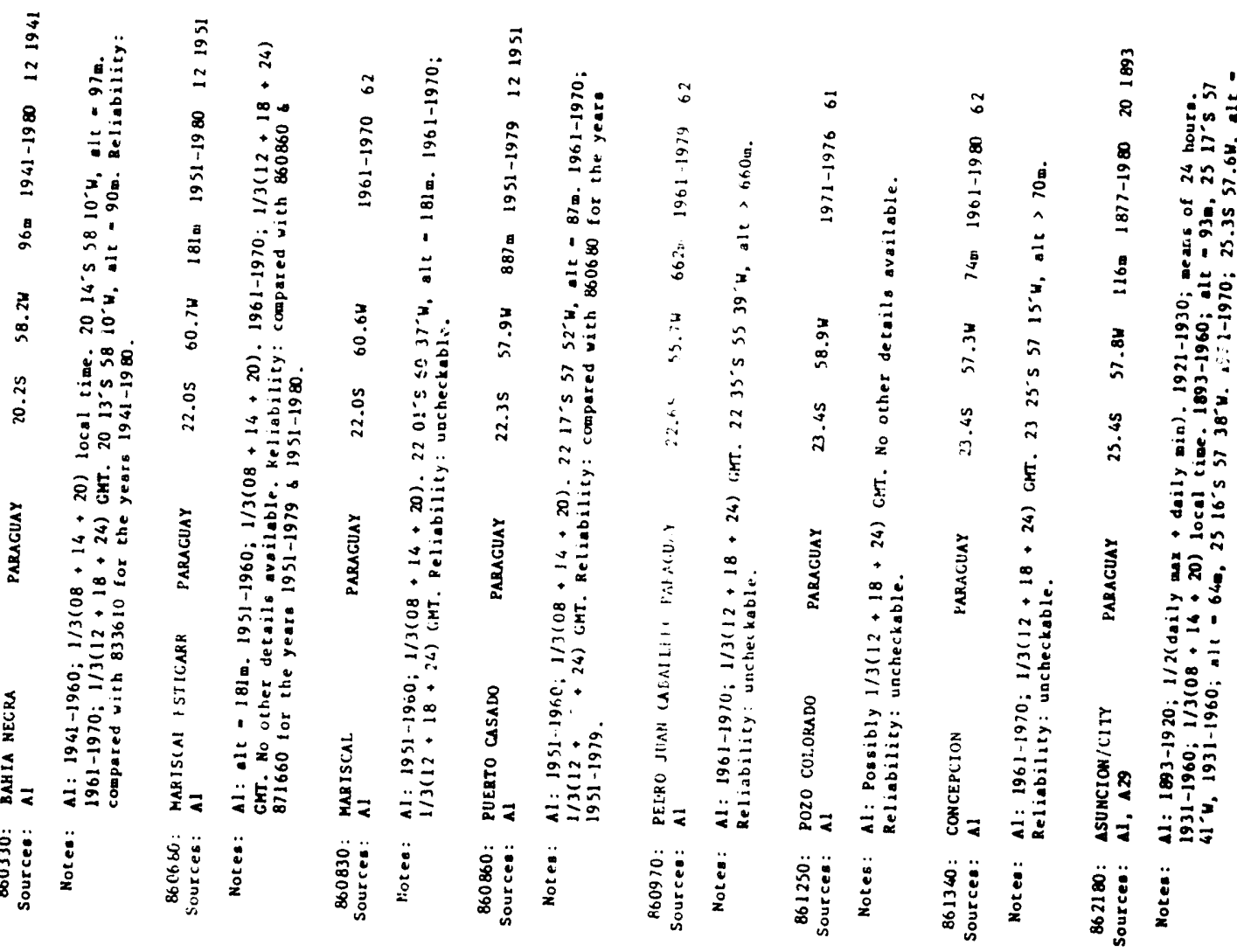

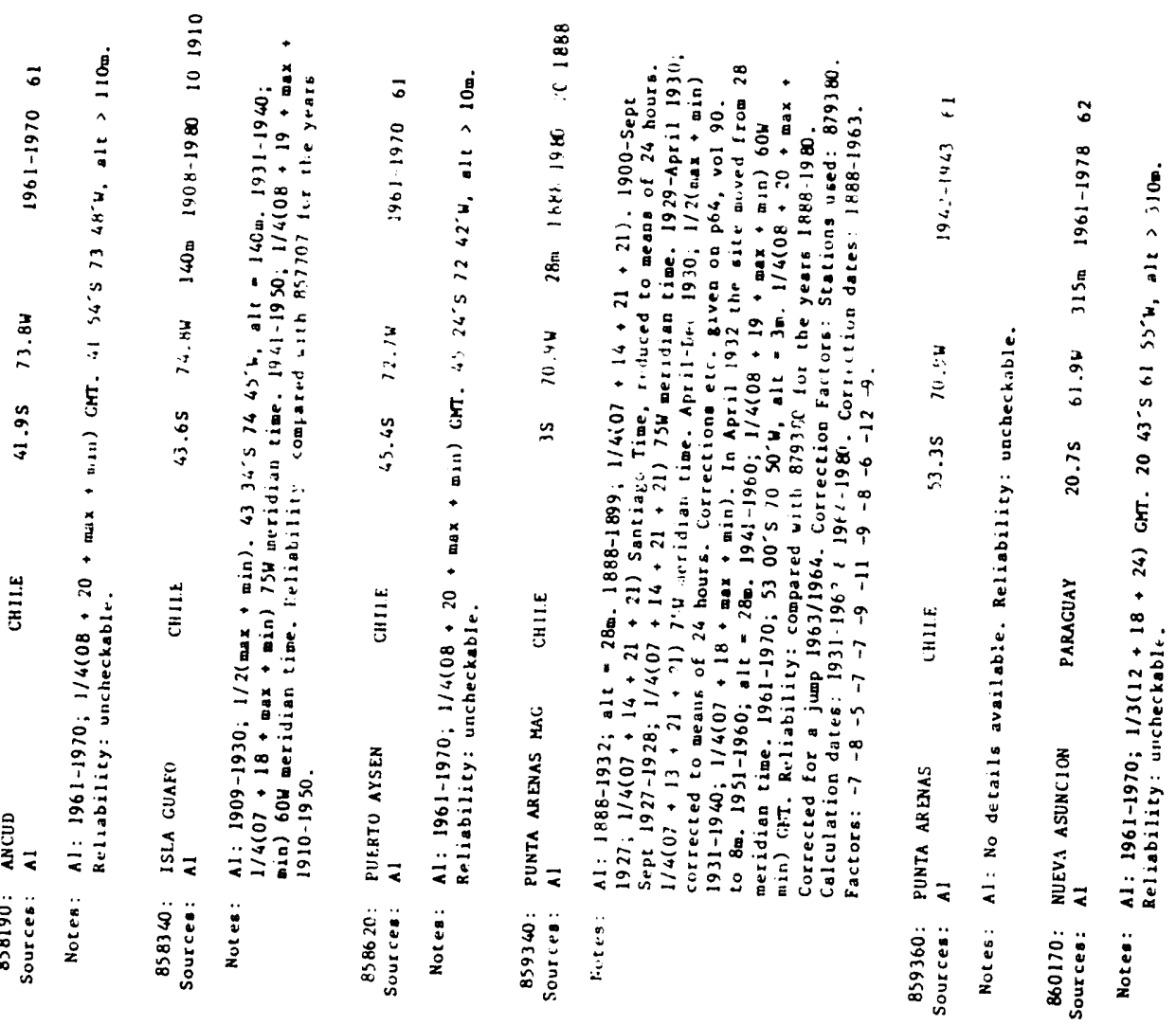




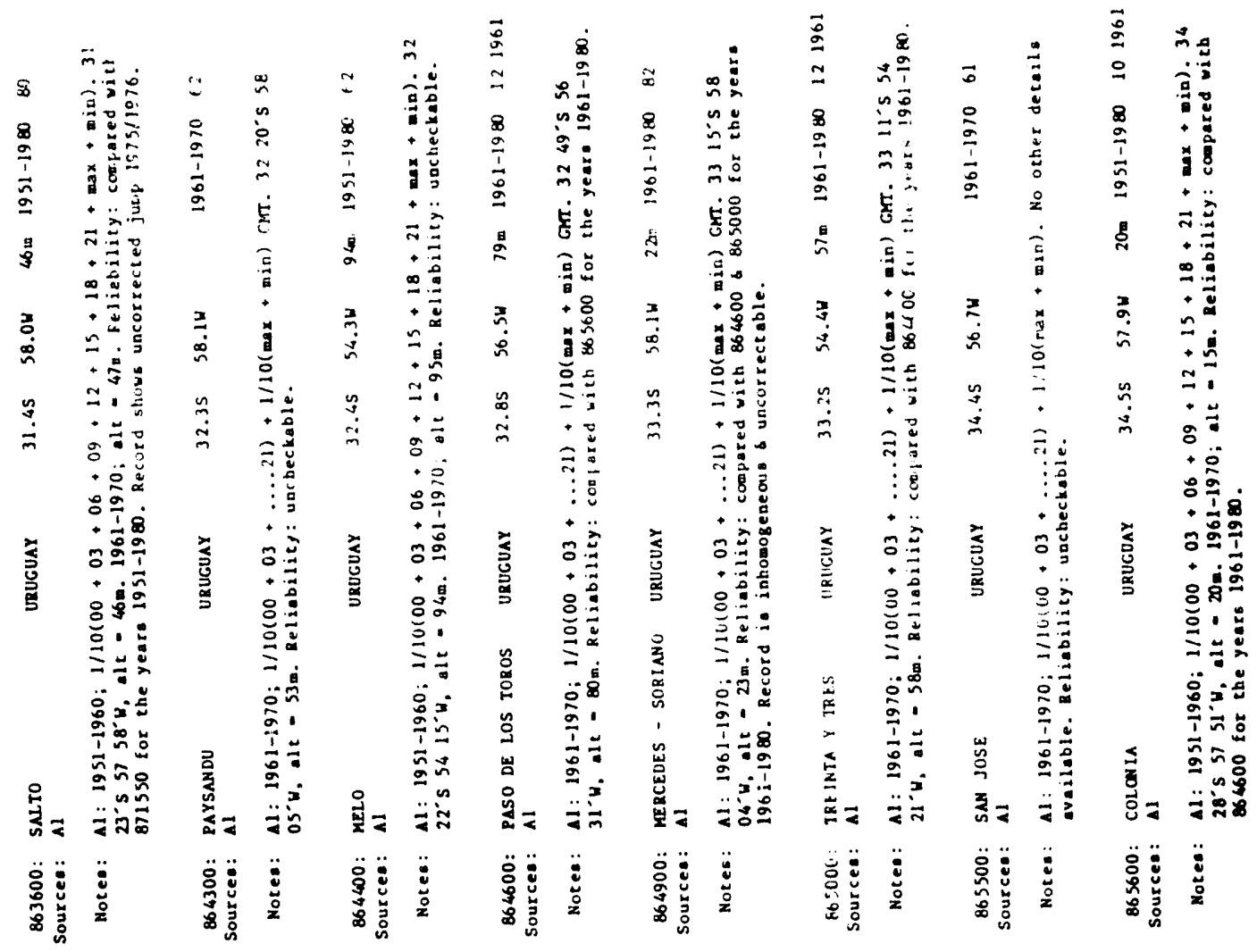

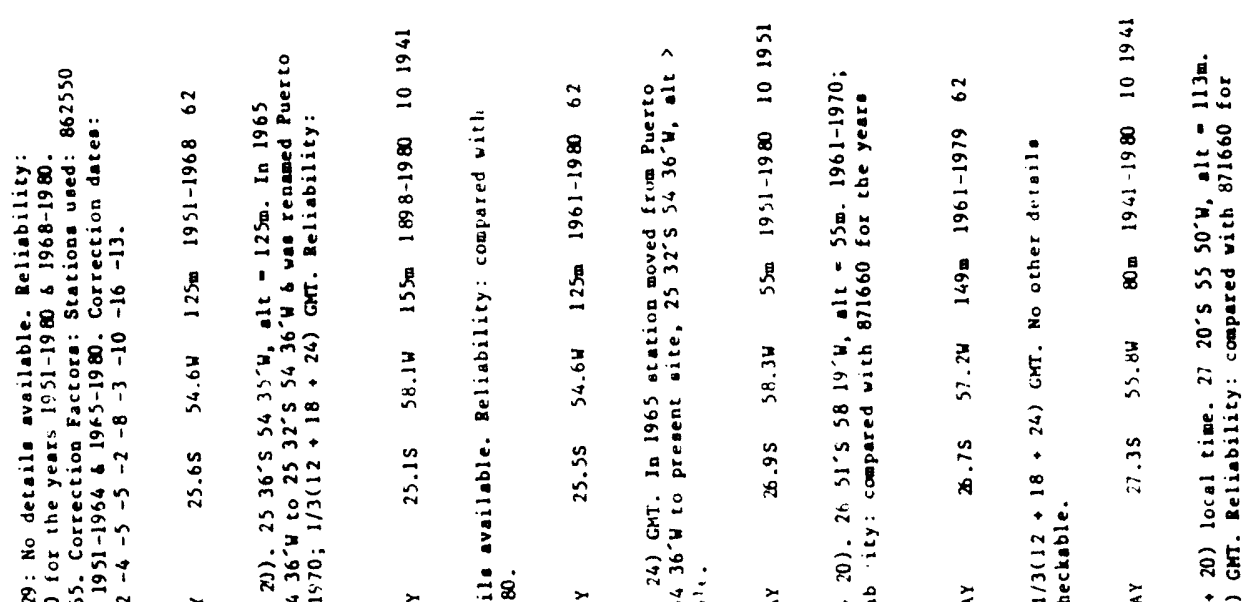

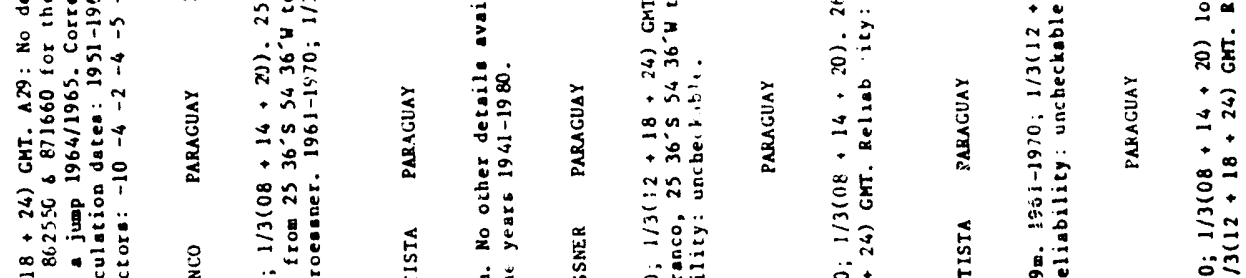
$+\frac{\infty}{5}$

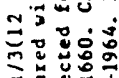
IIIs

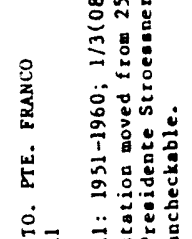

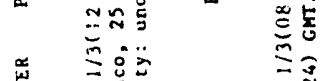

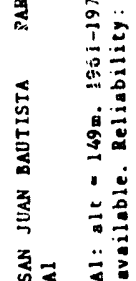

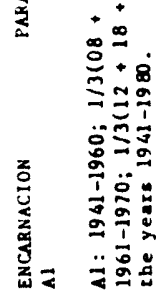

II

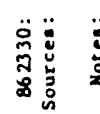

!)

A-315 

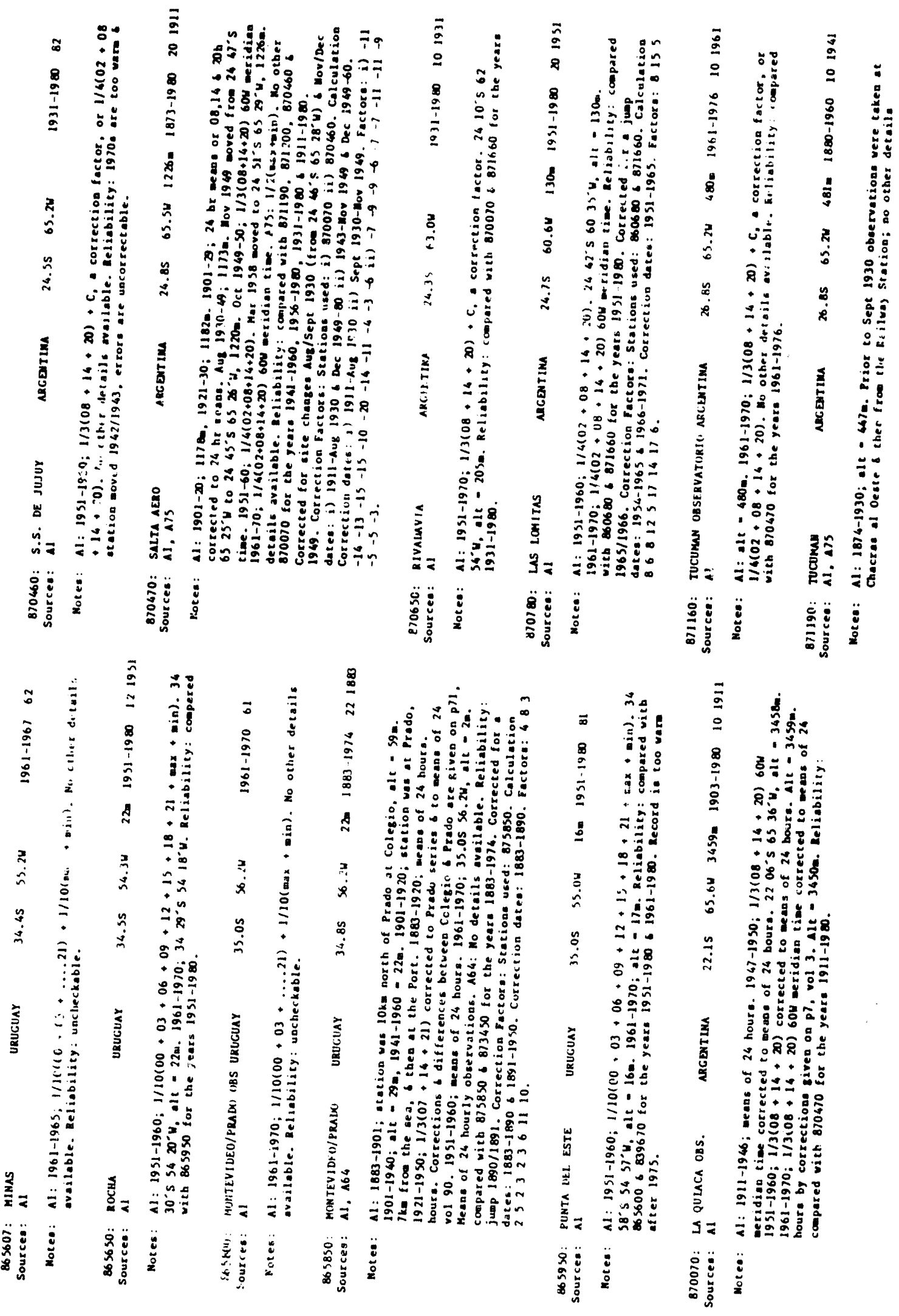


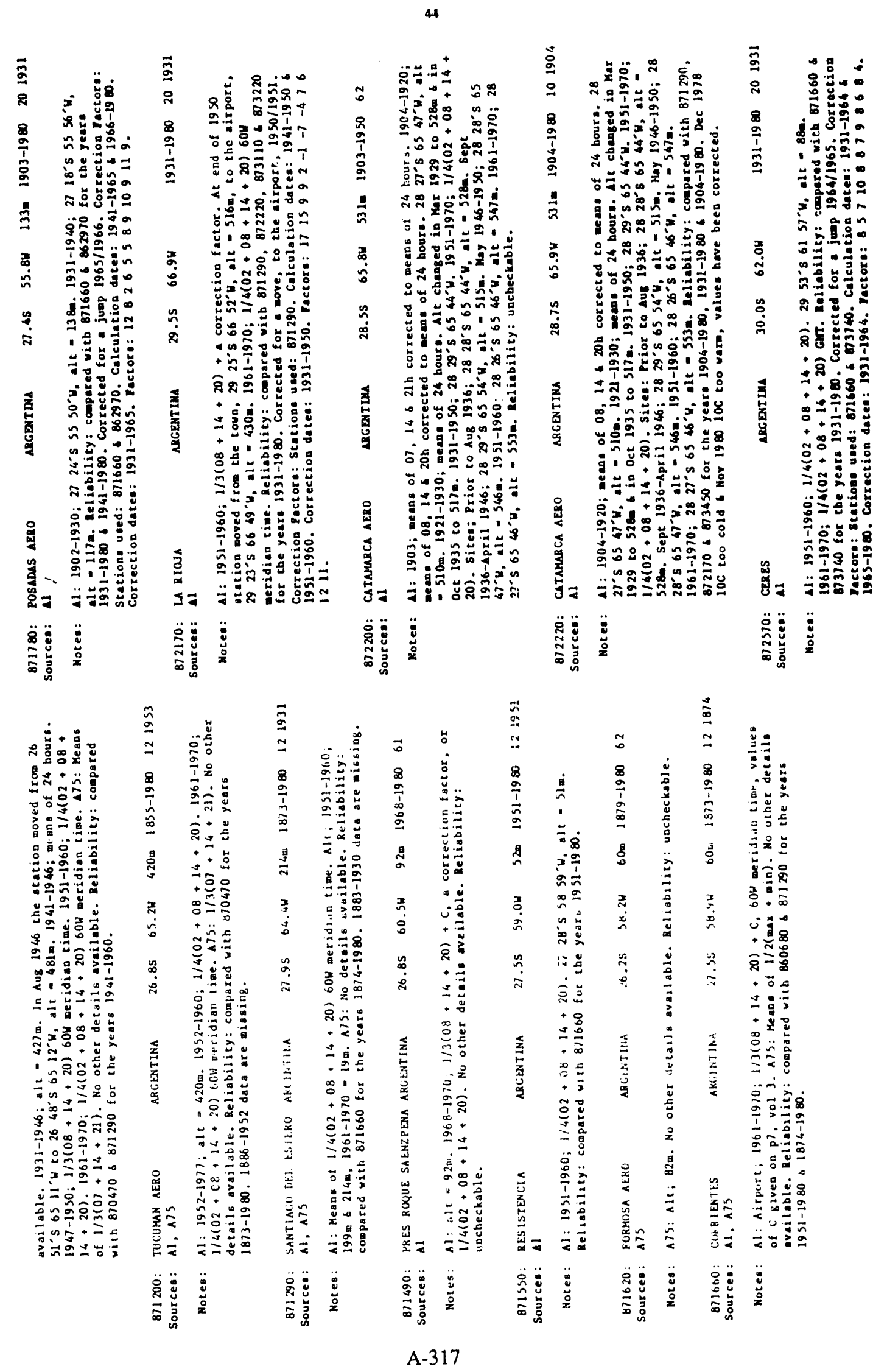




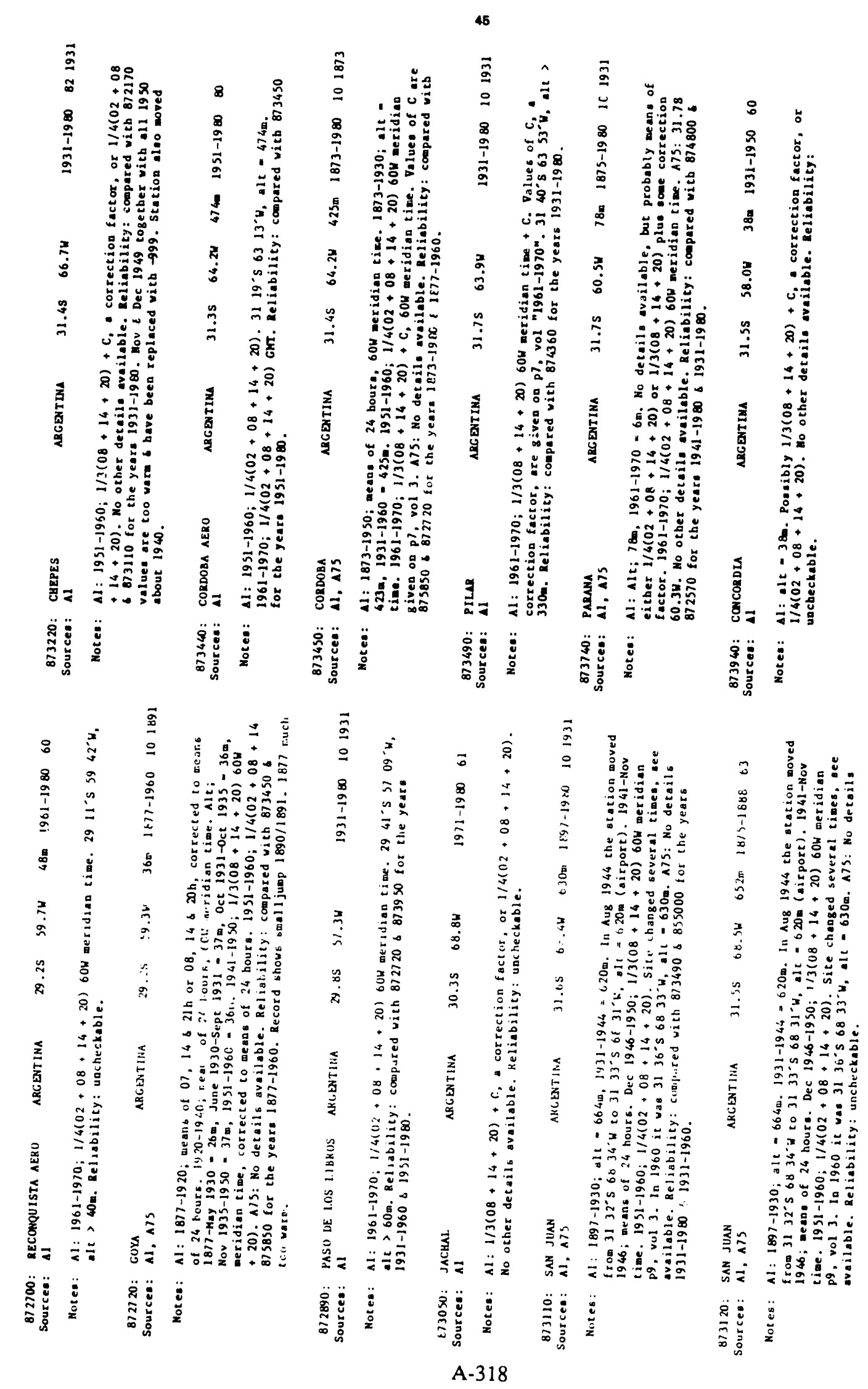


46

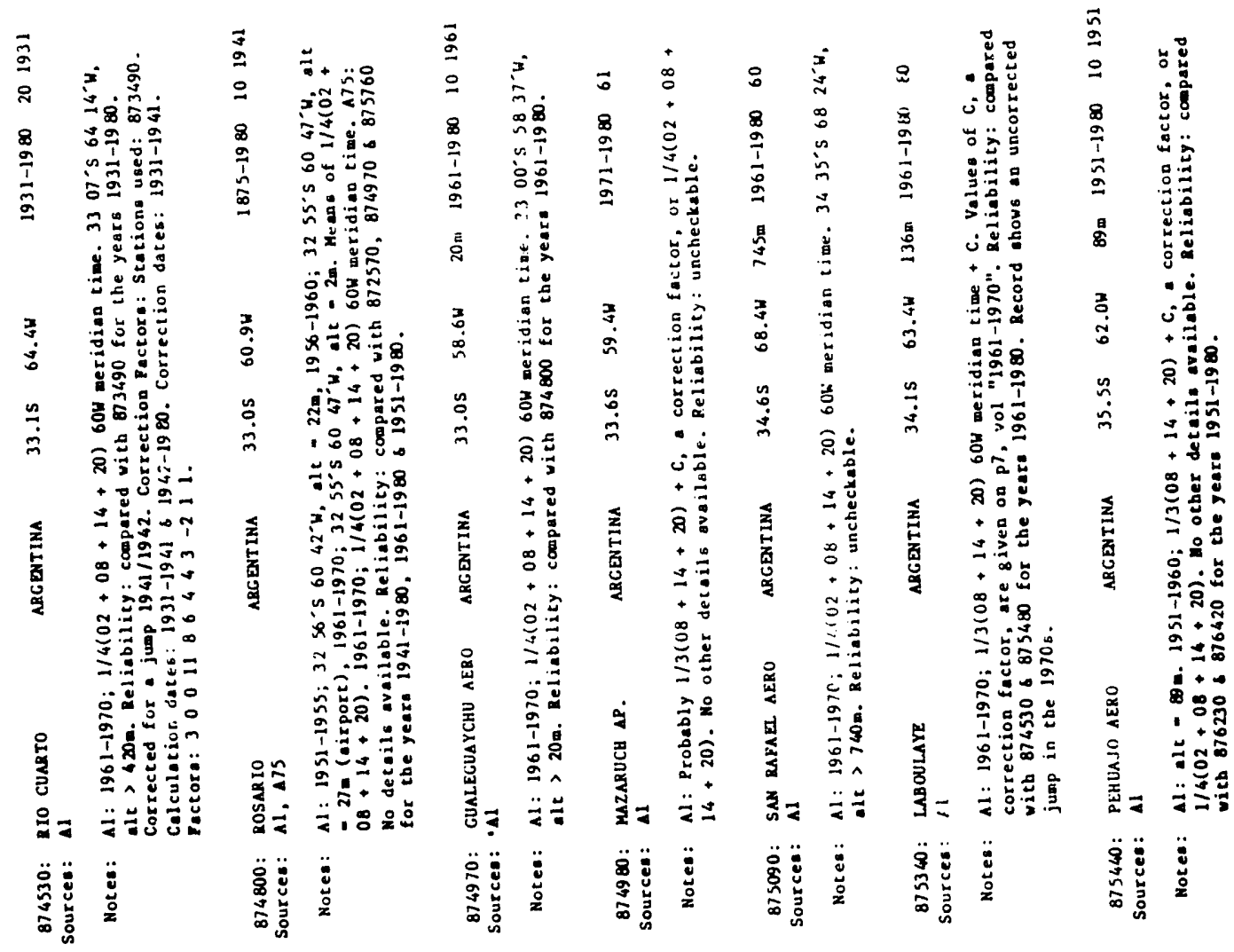

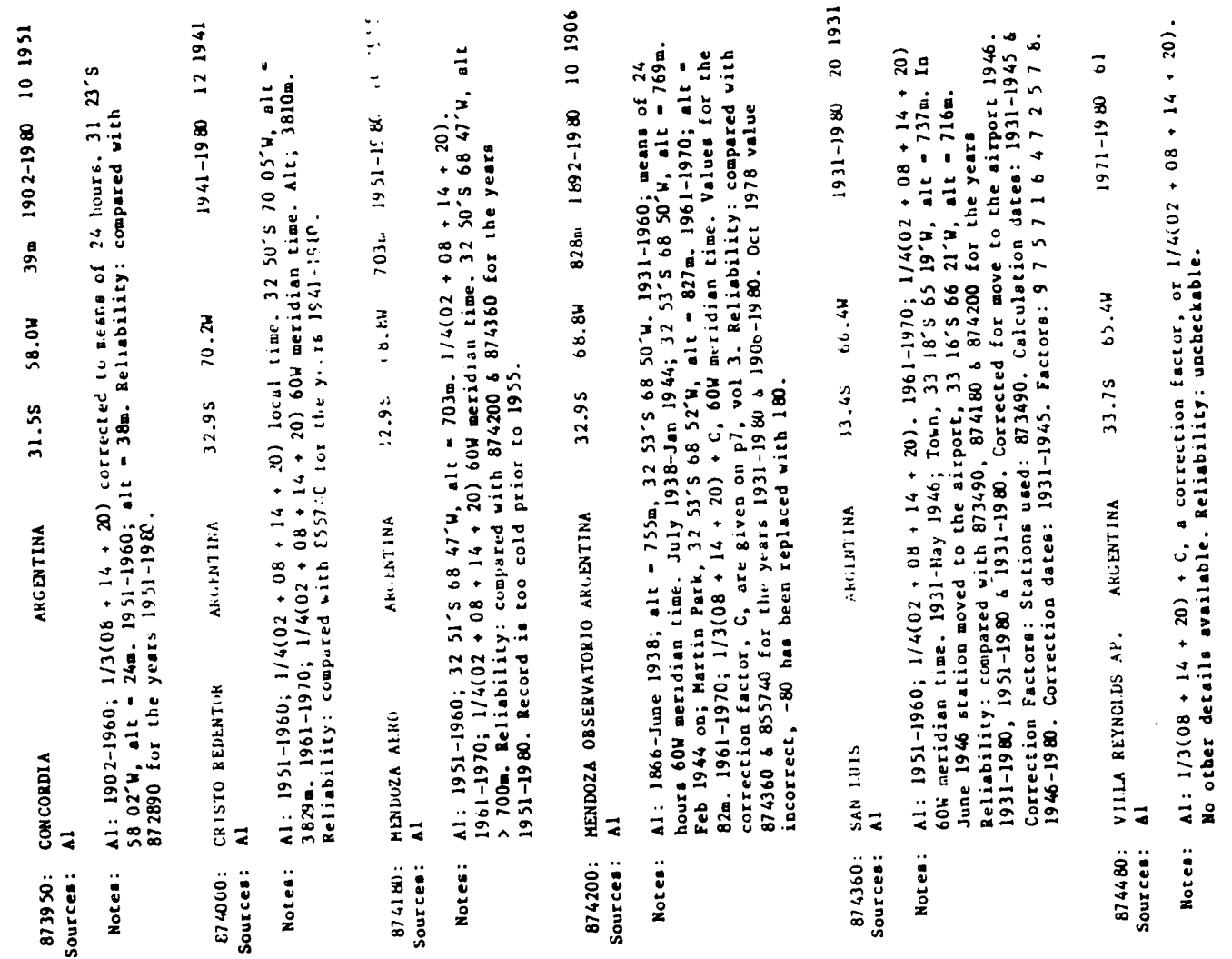




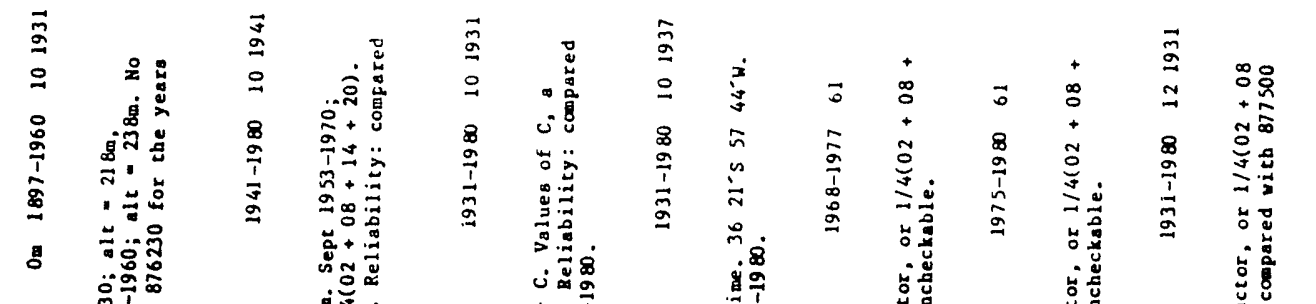

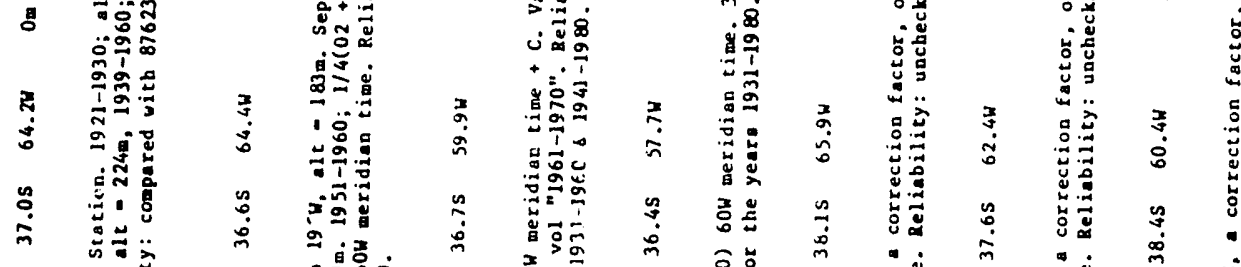

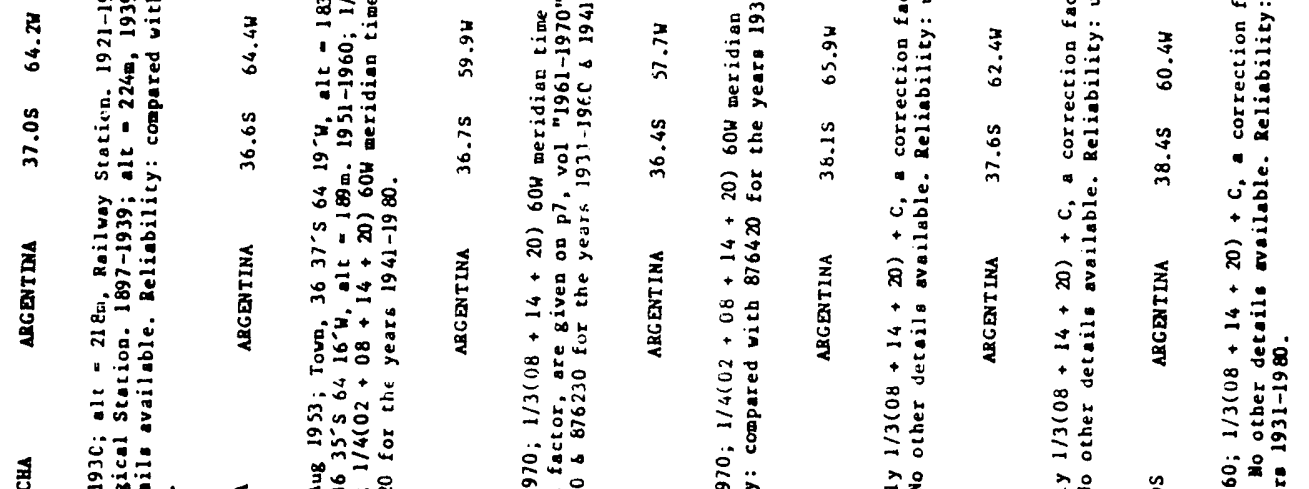

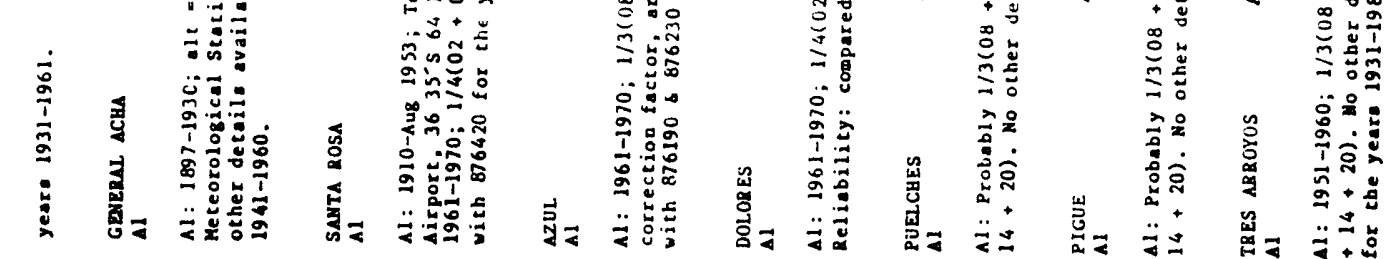

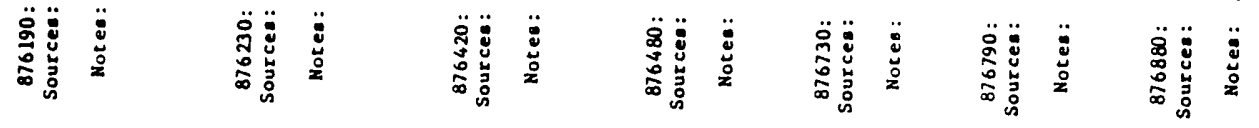

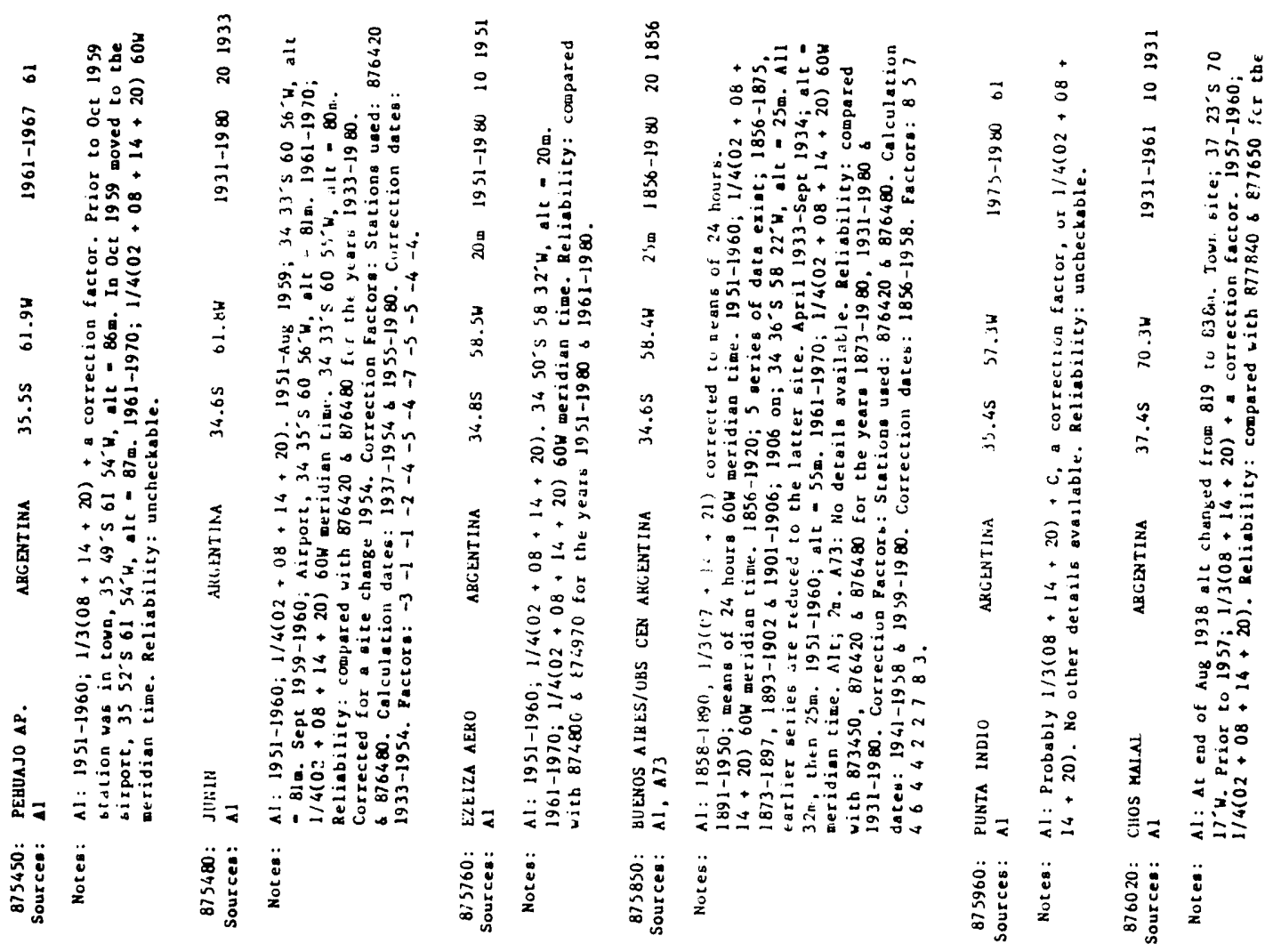

$$
\begin{aligned}
& \text { A- } 320
\end{aligned}
$$



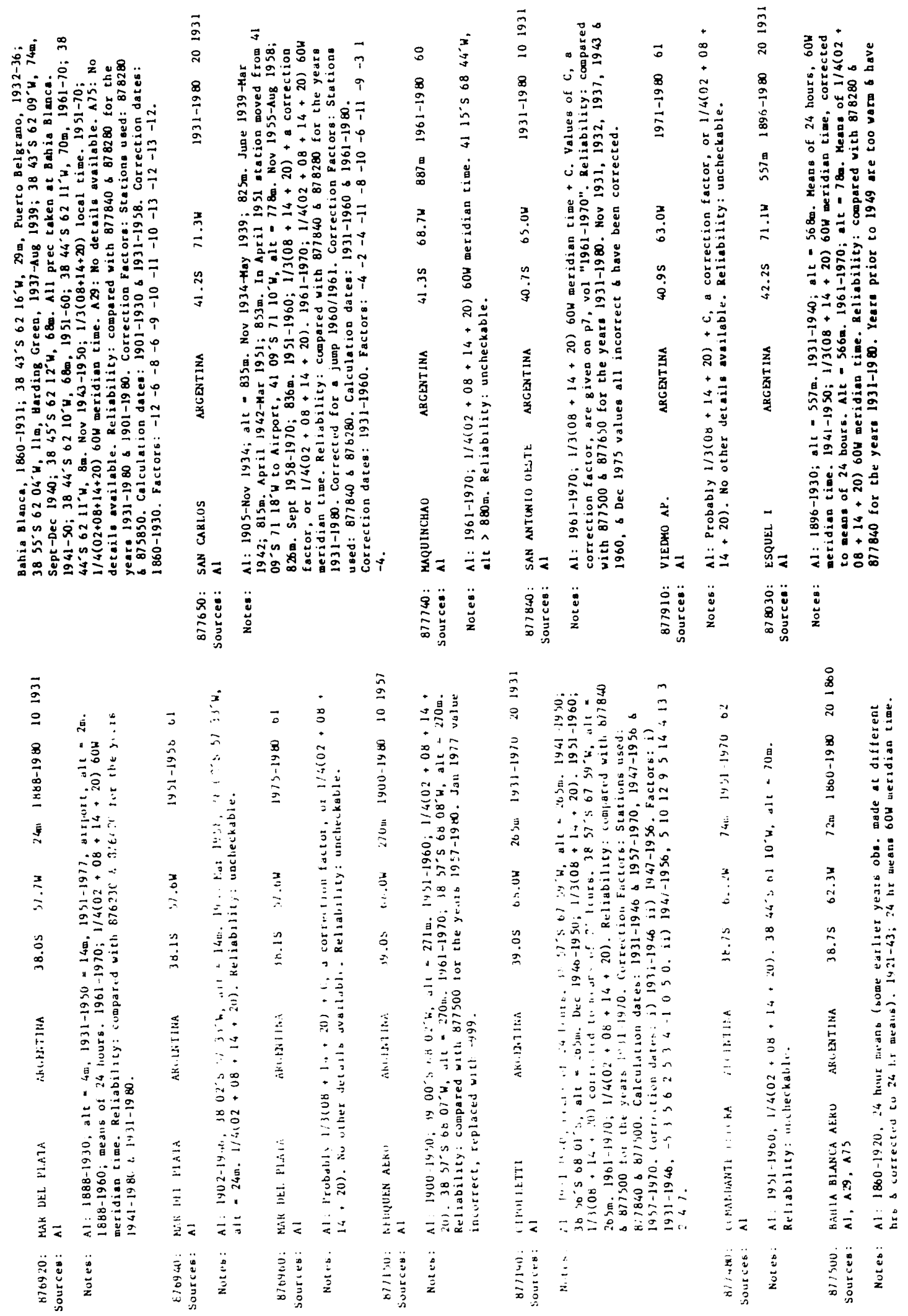


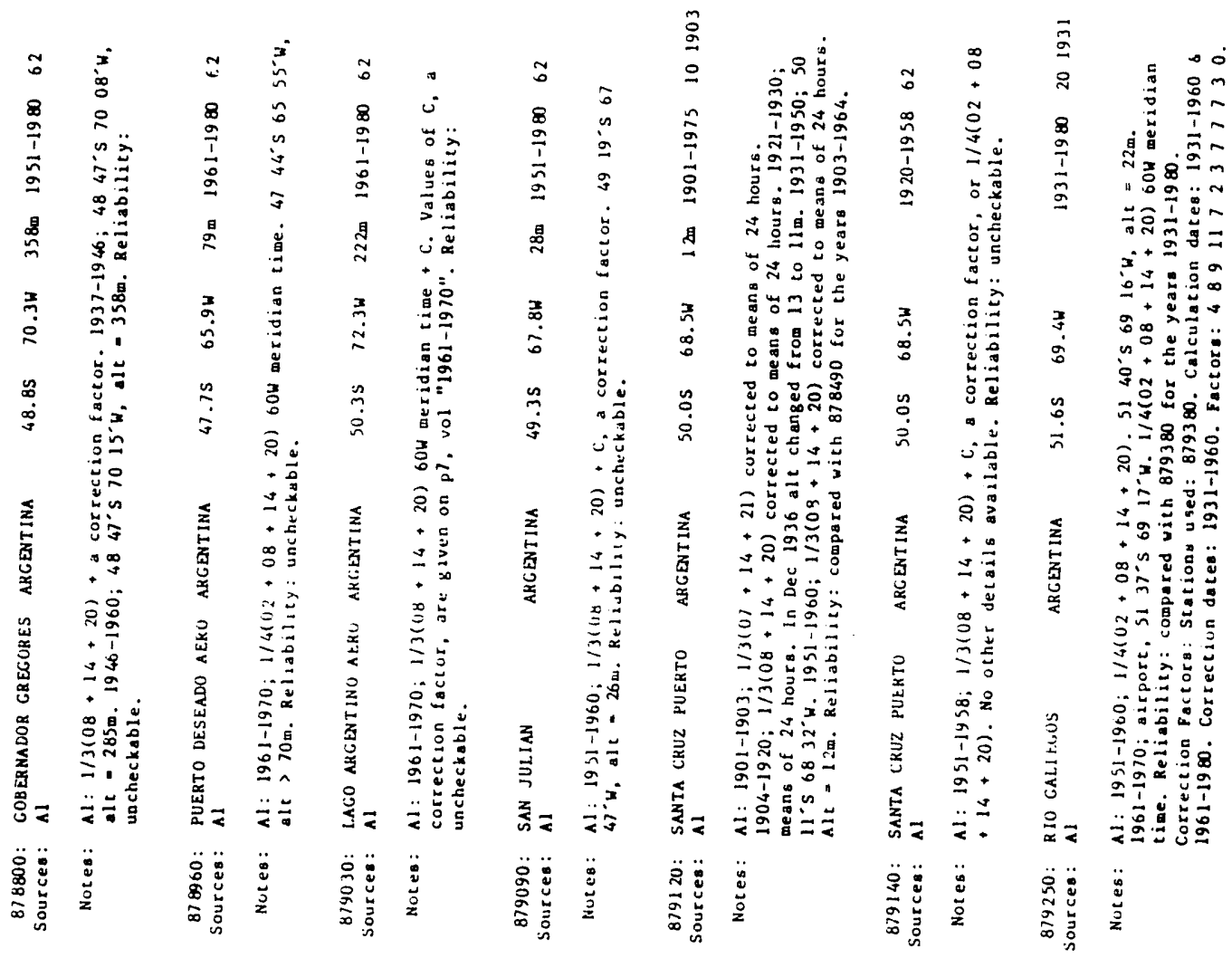

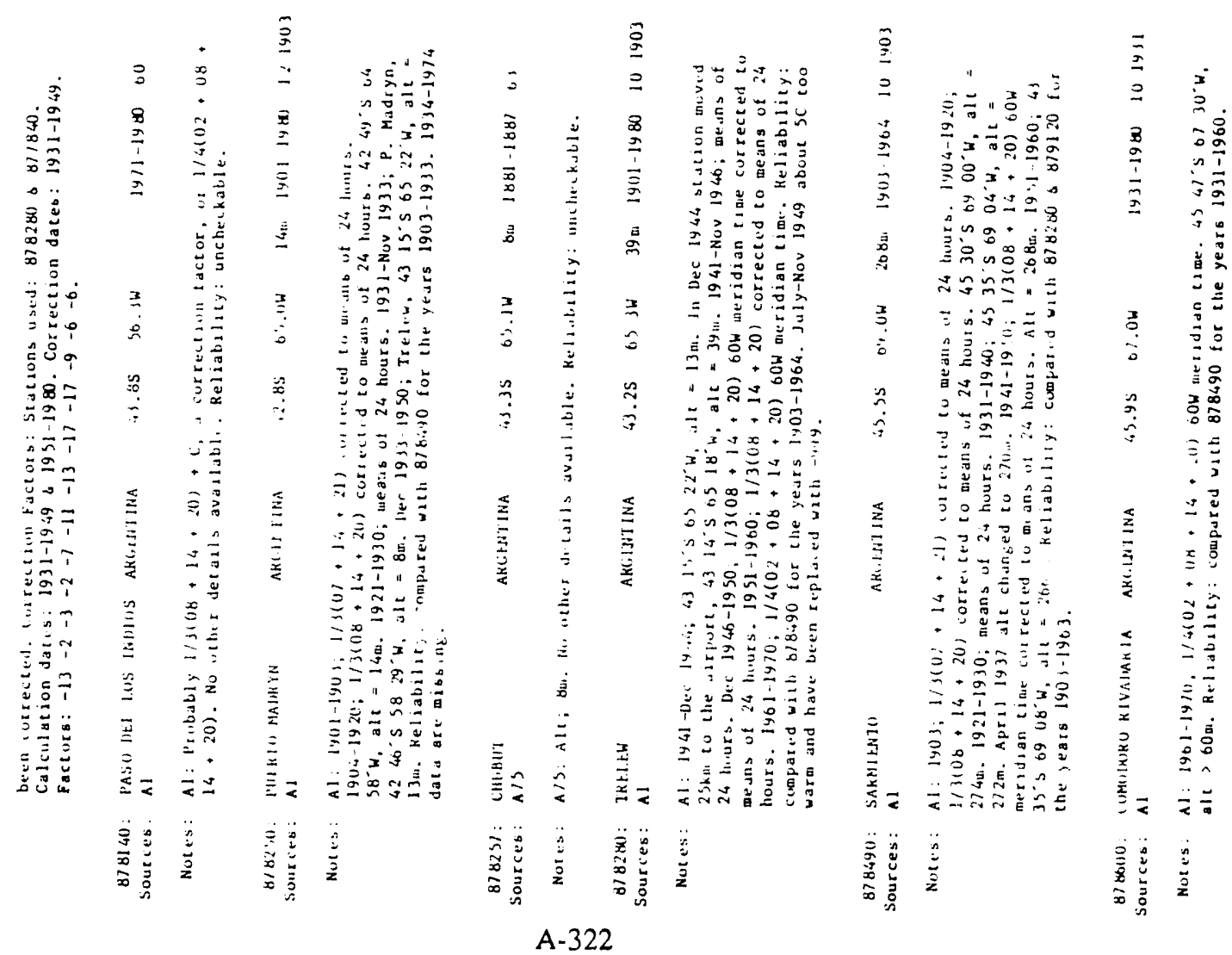




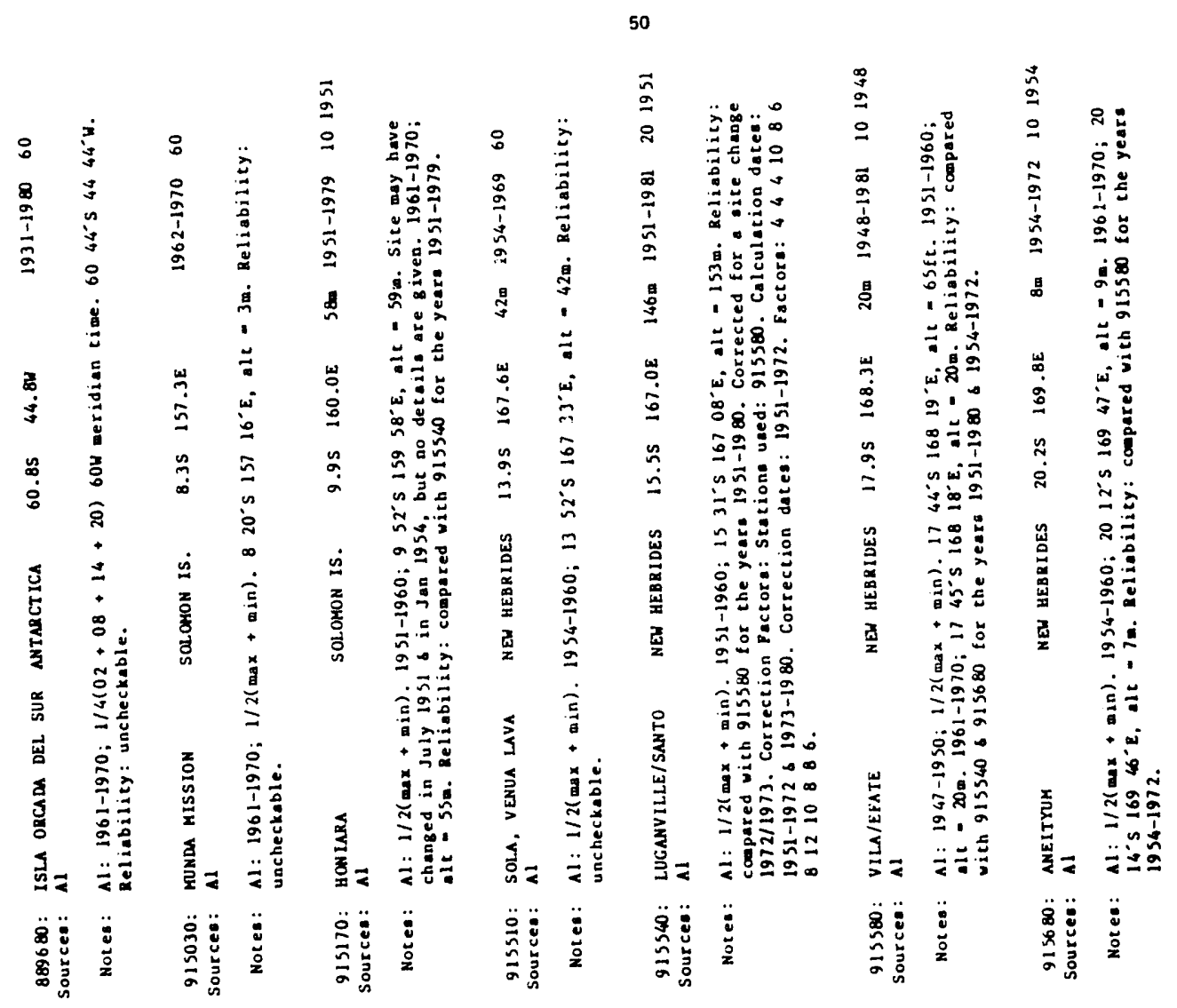

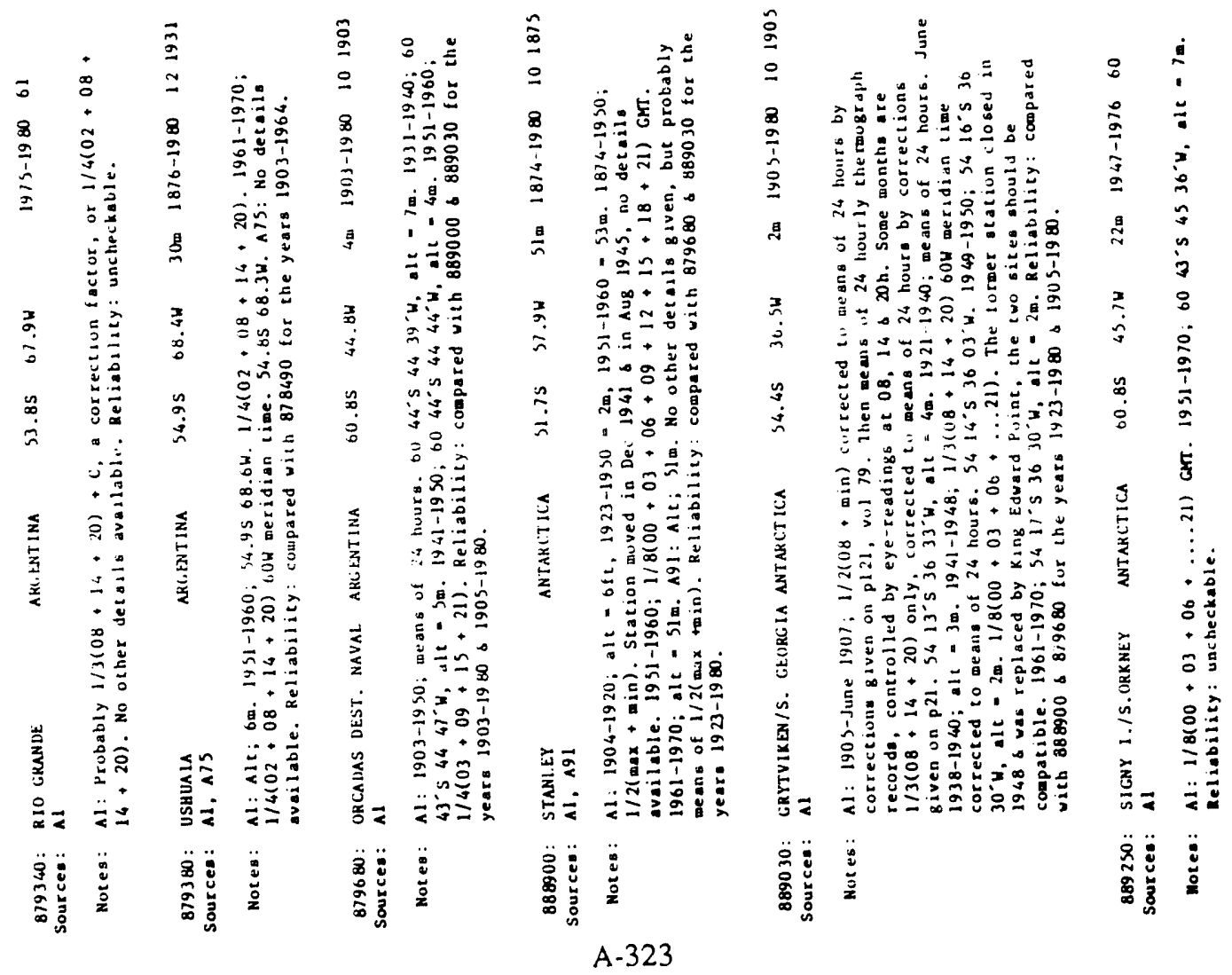



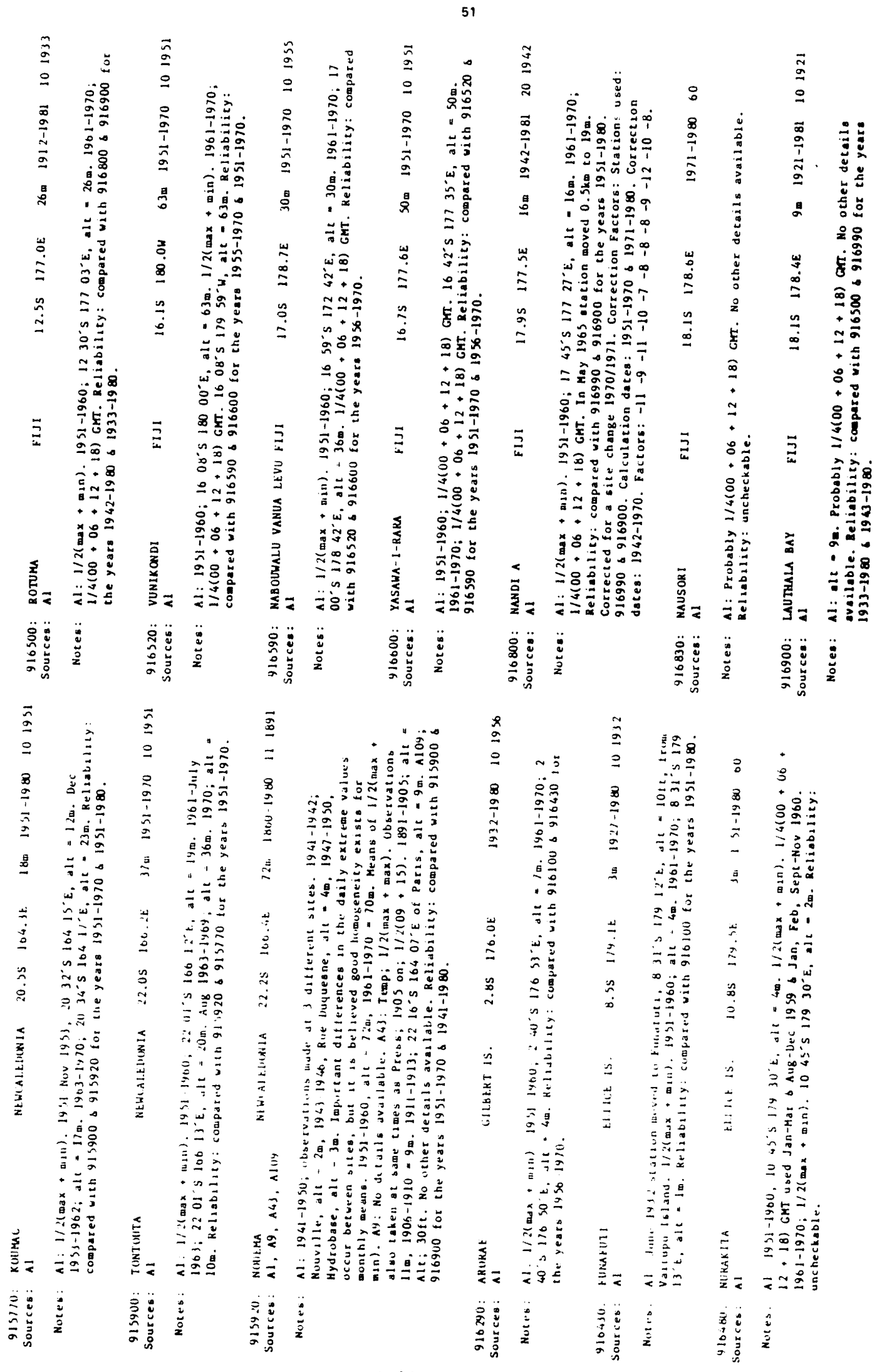
52
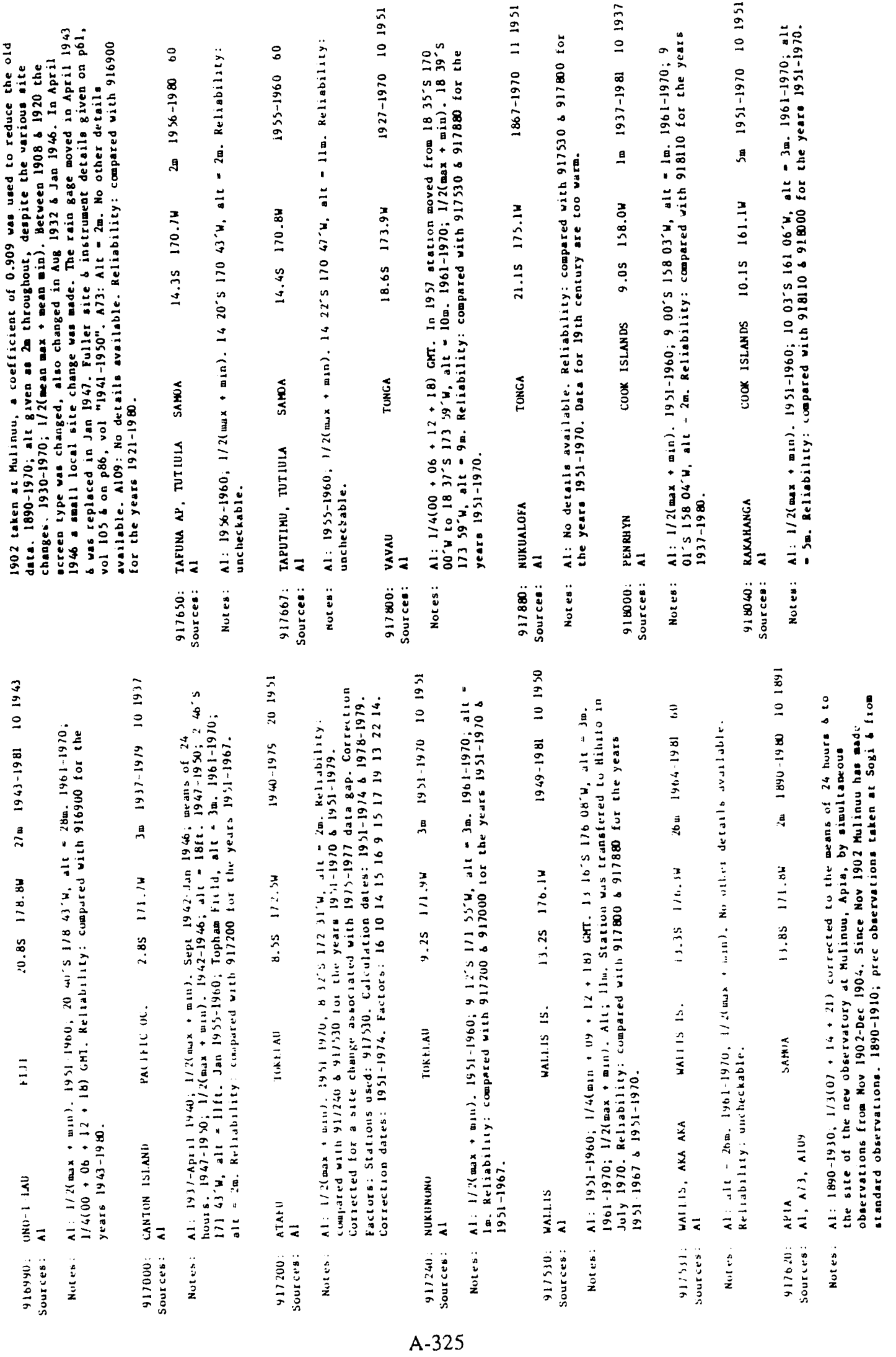
53
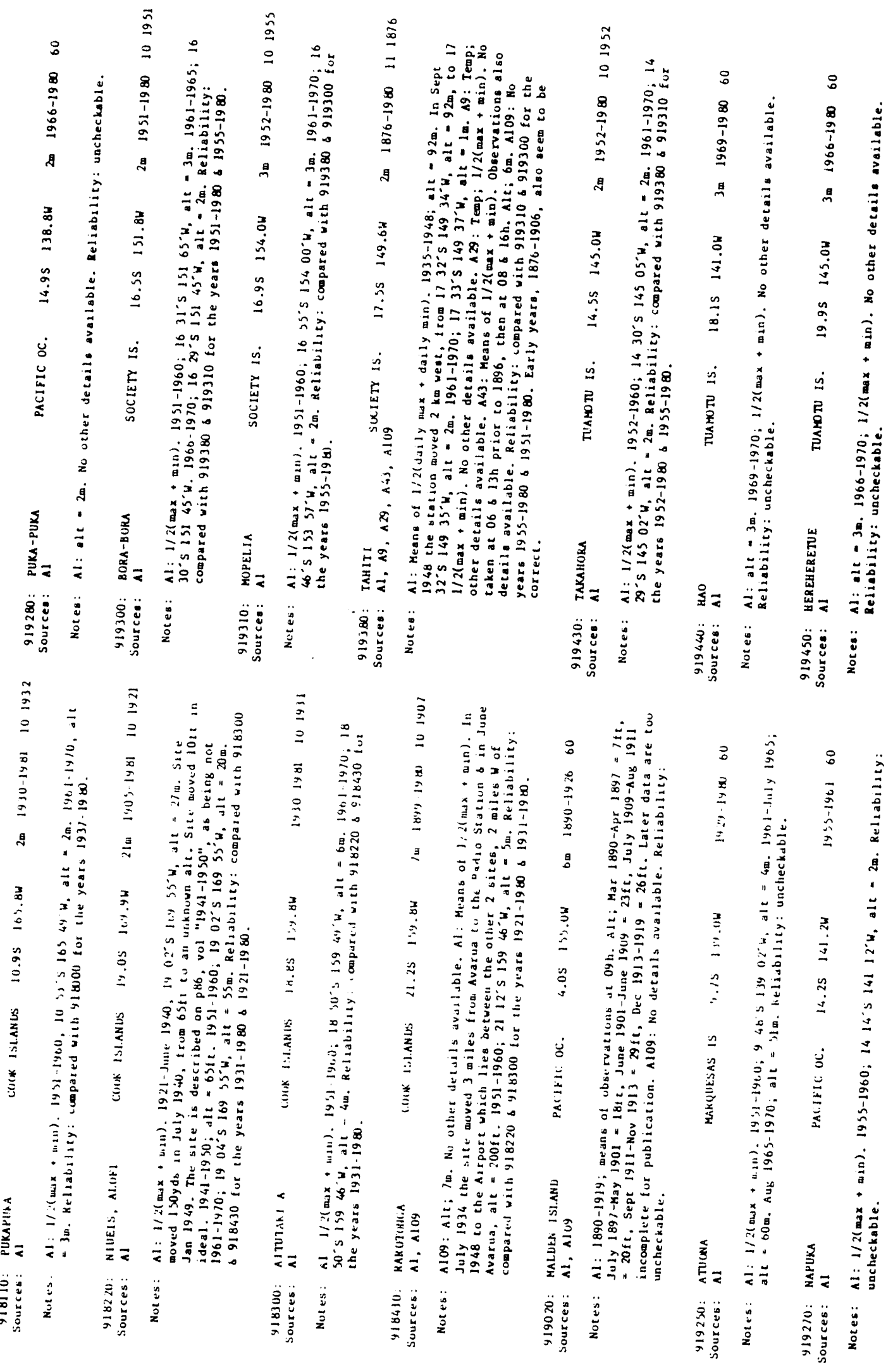

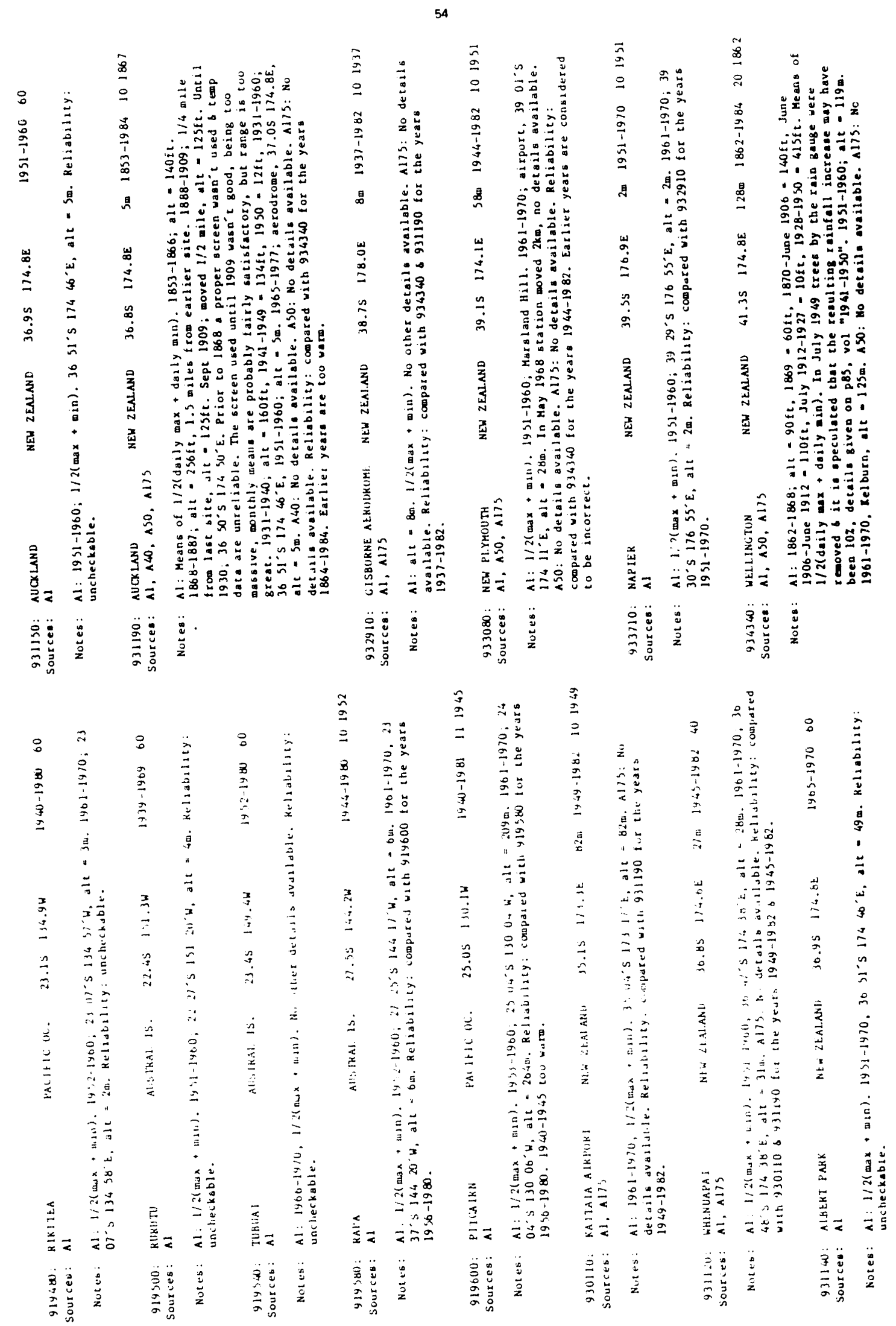

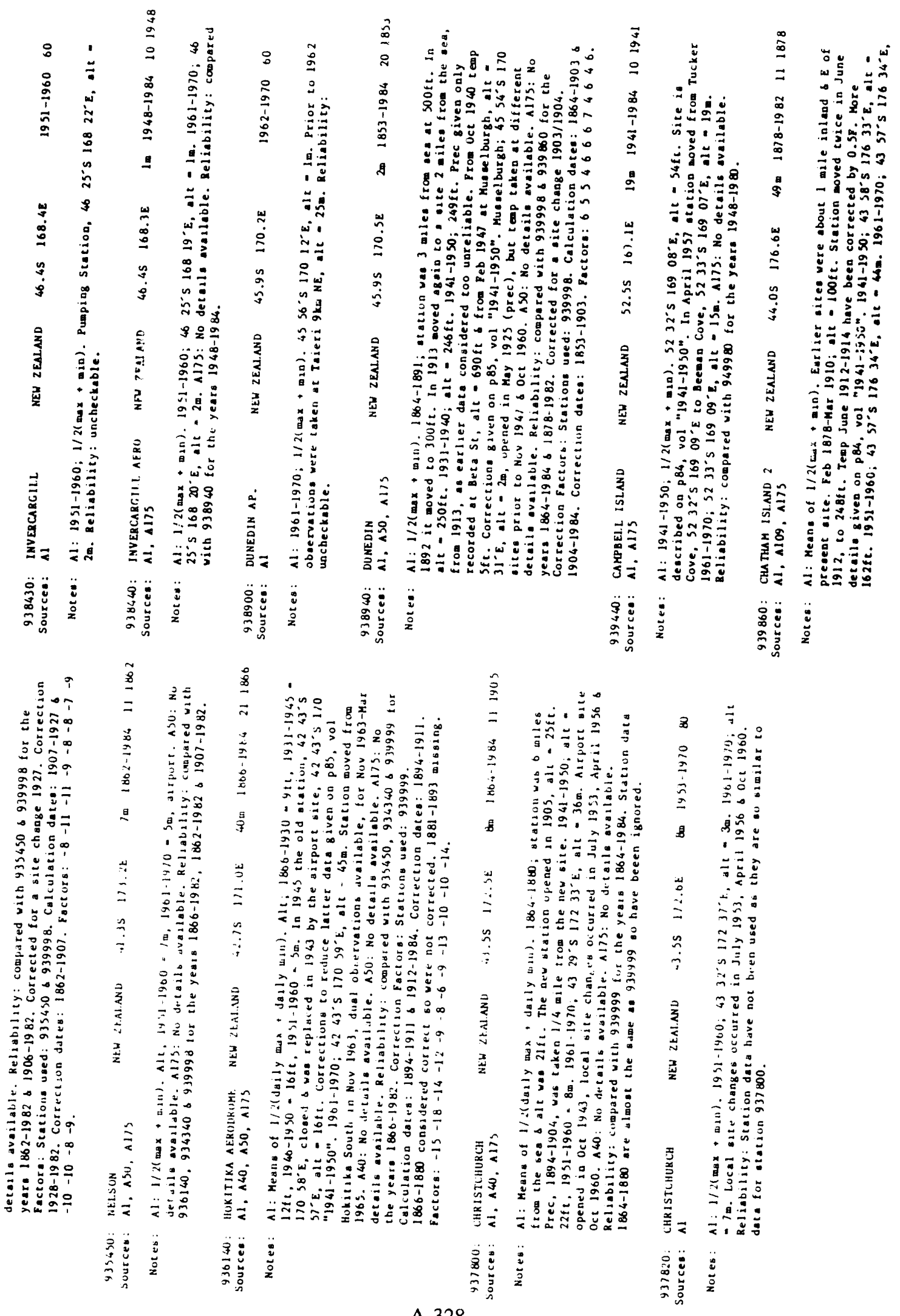
56
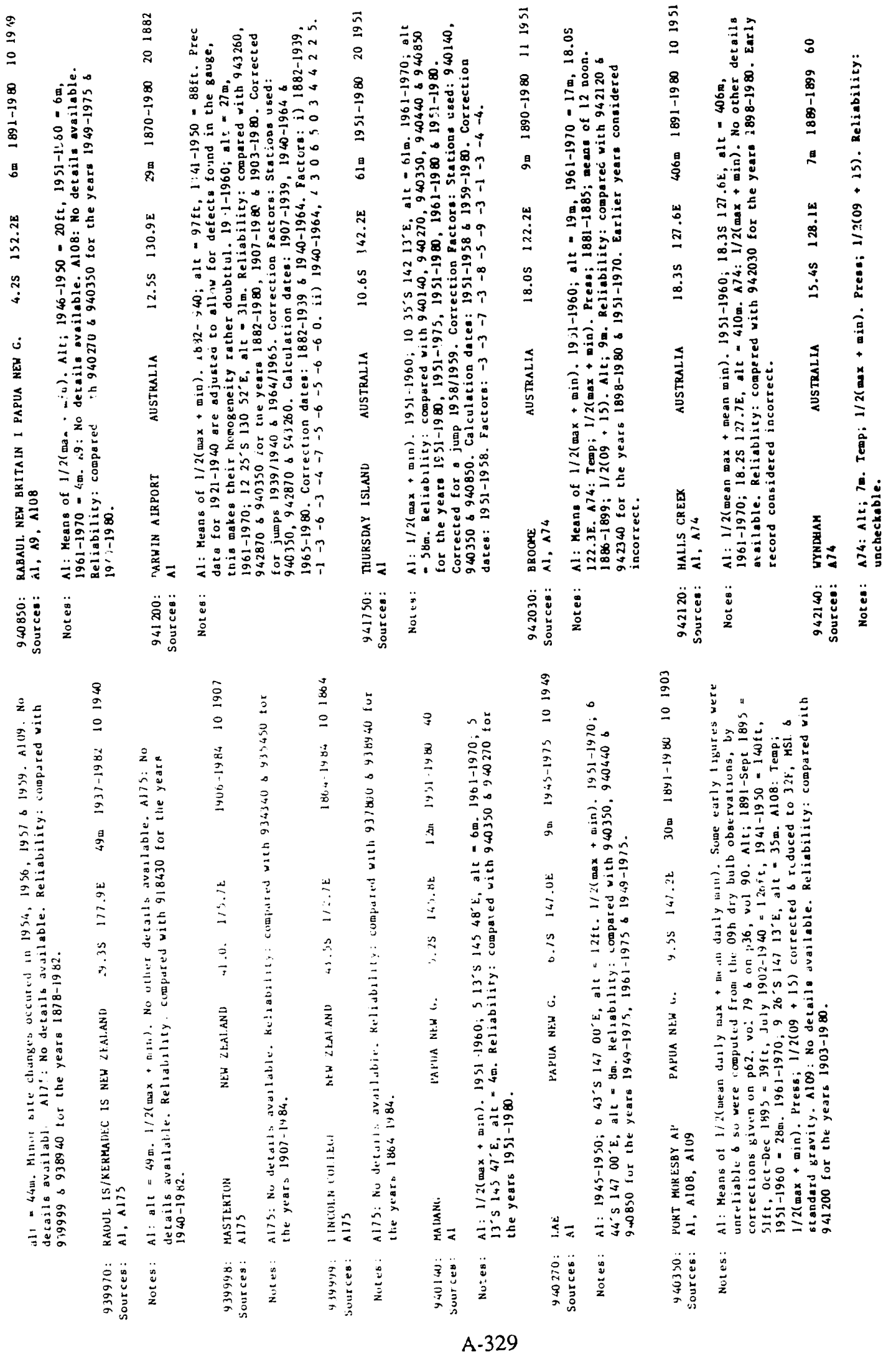


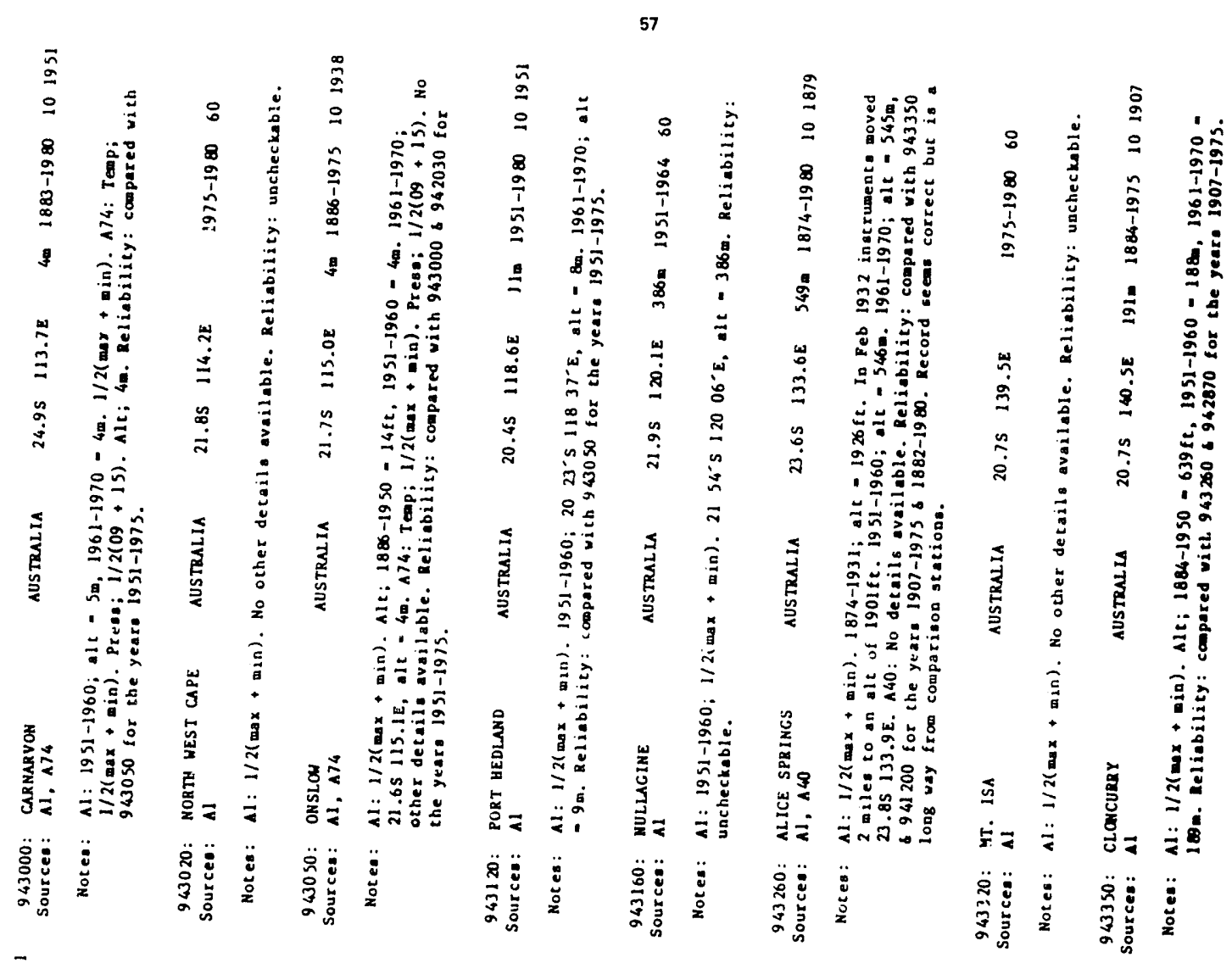

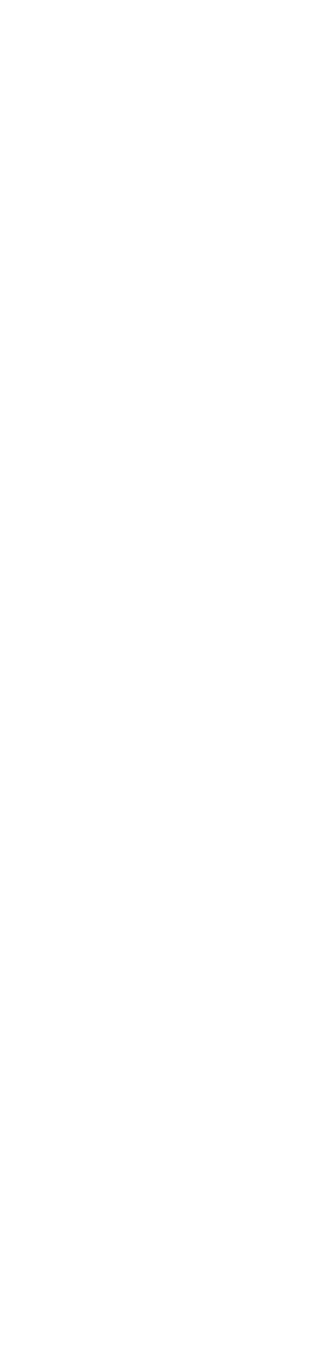

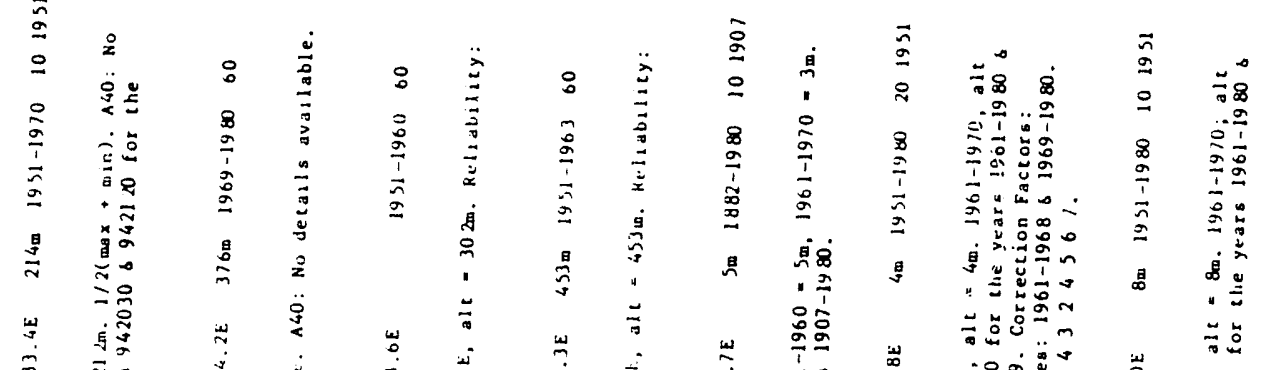

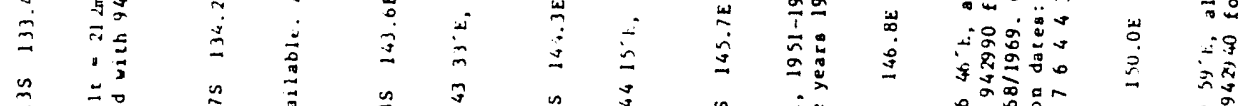

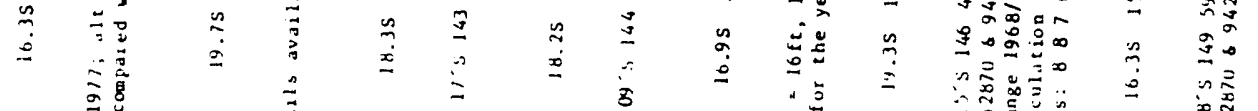

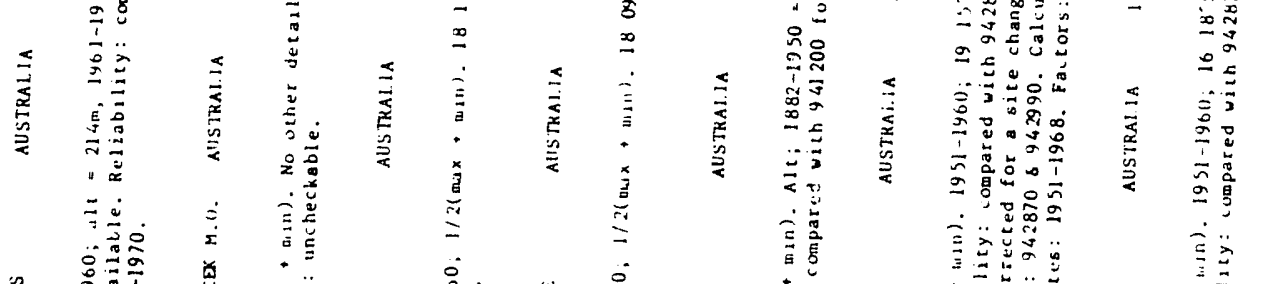

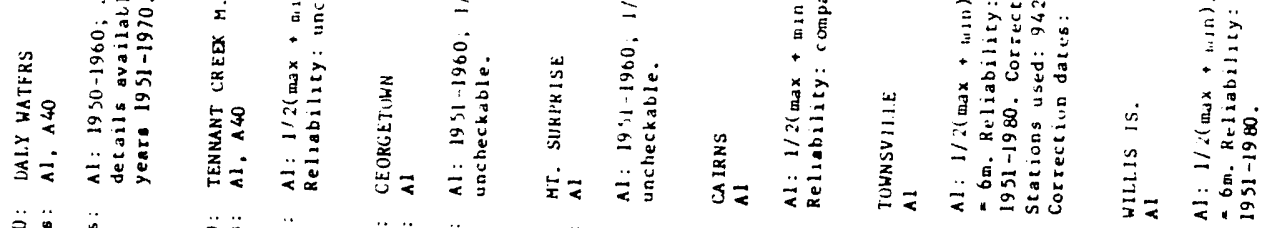

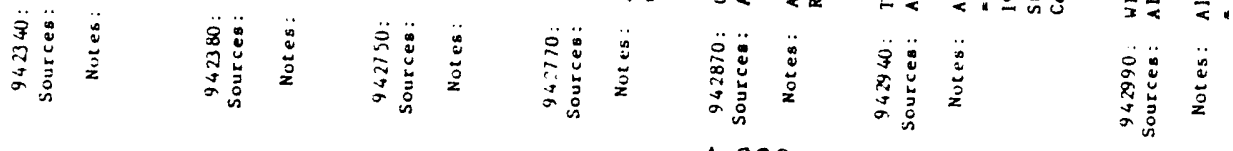




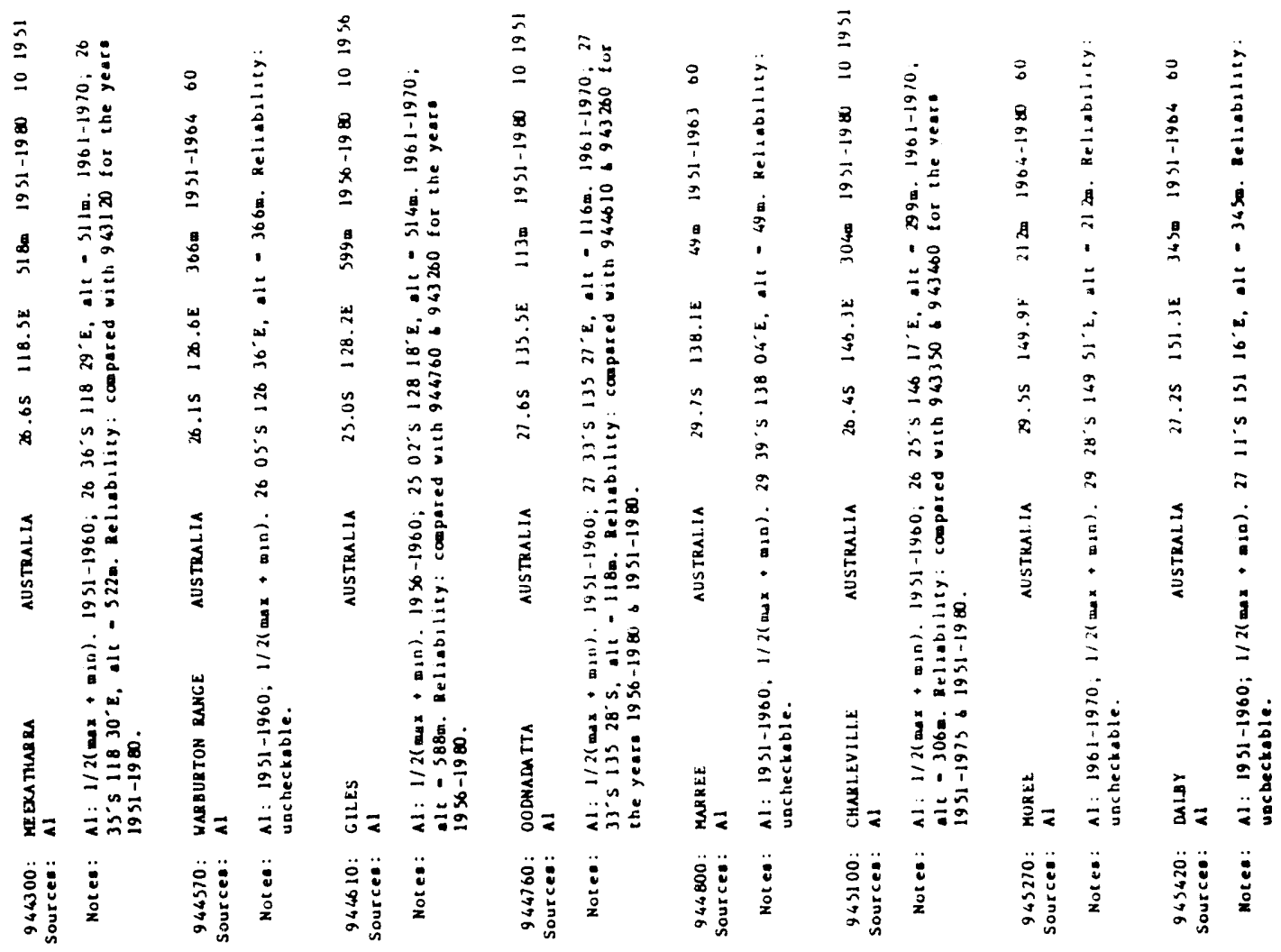

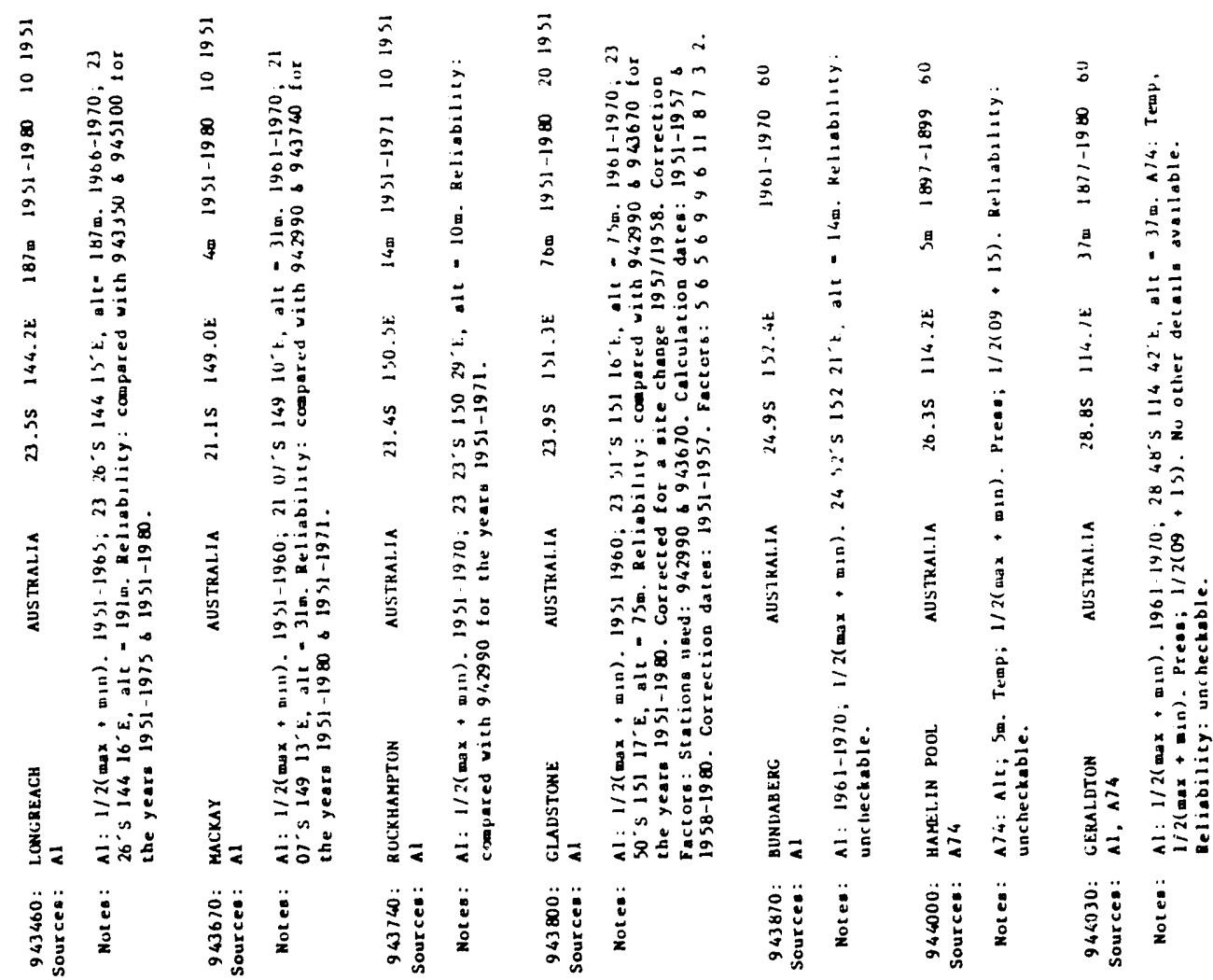




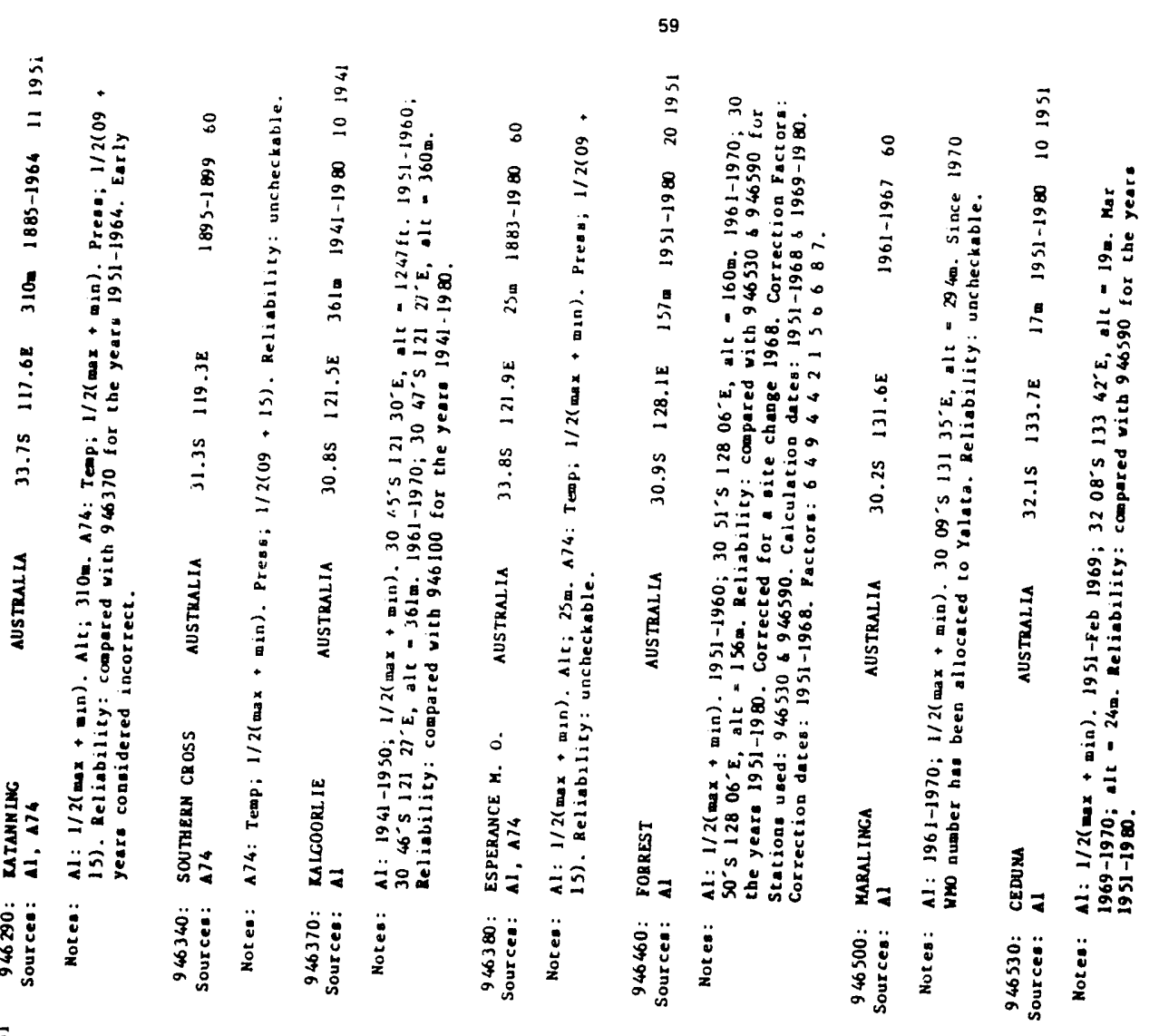

ะ

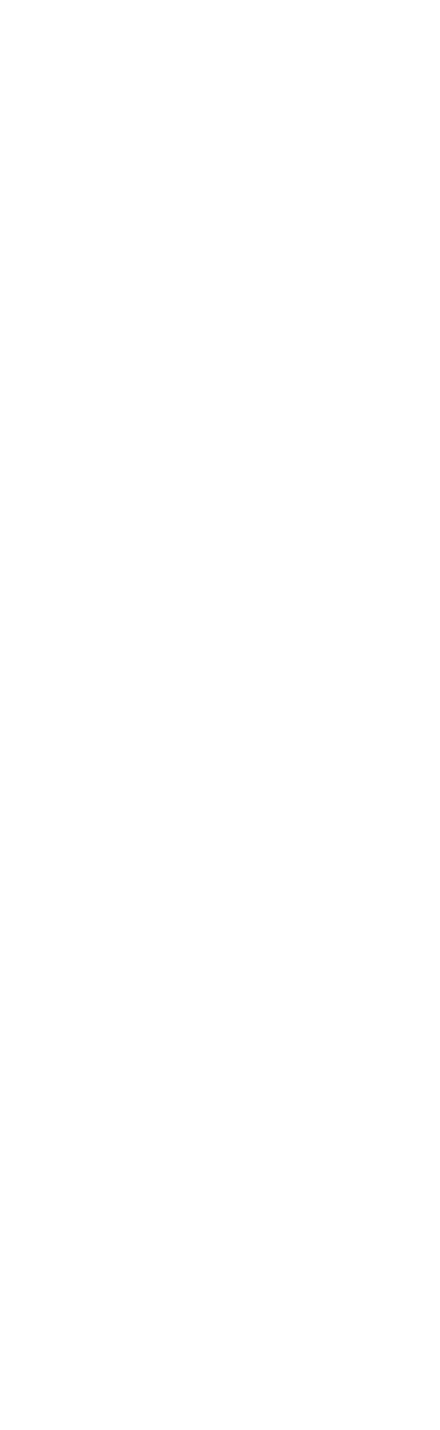

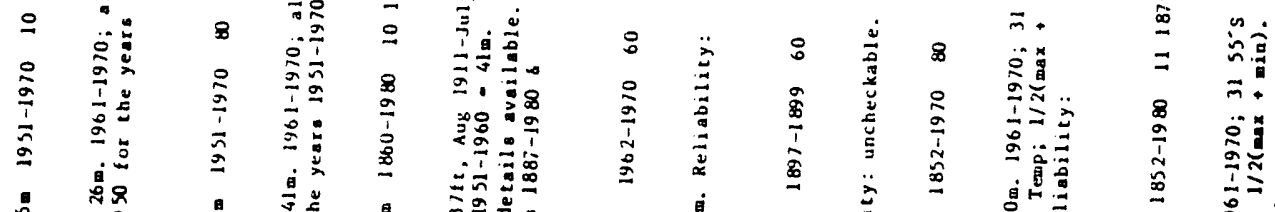

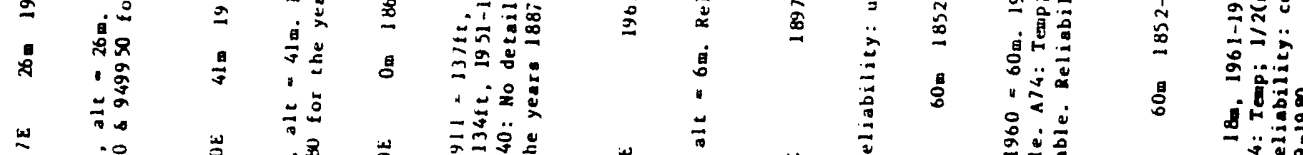

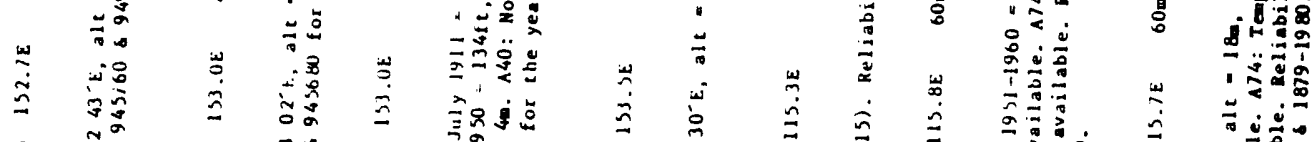

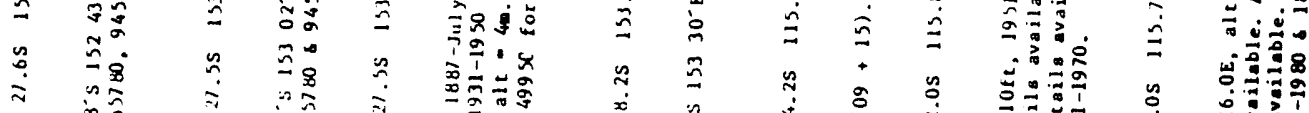

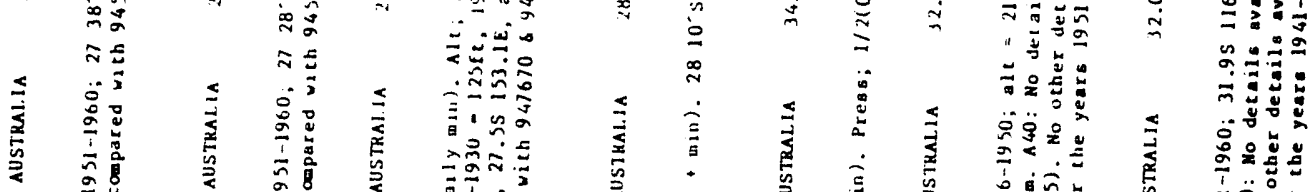

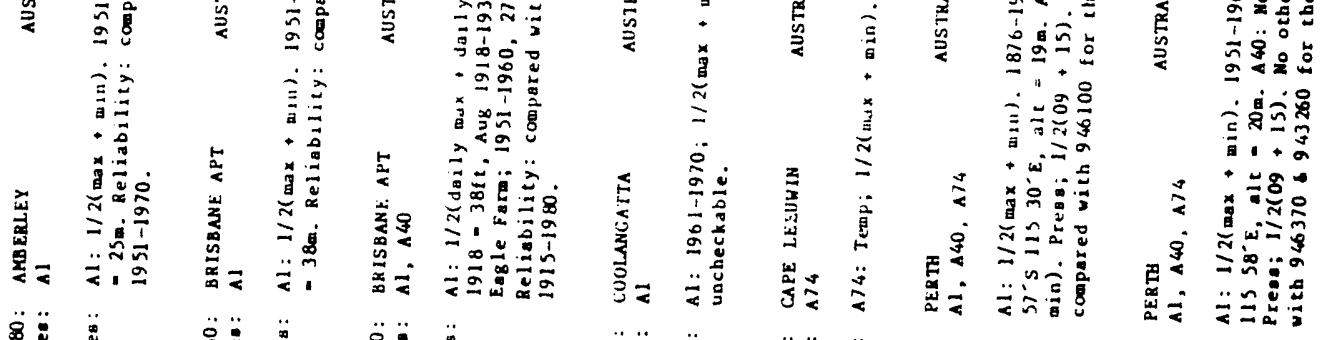

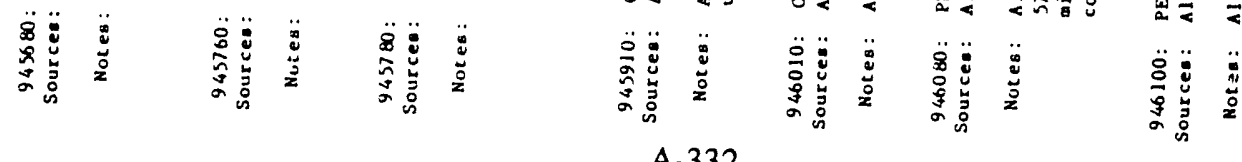



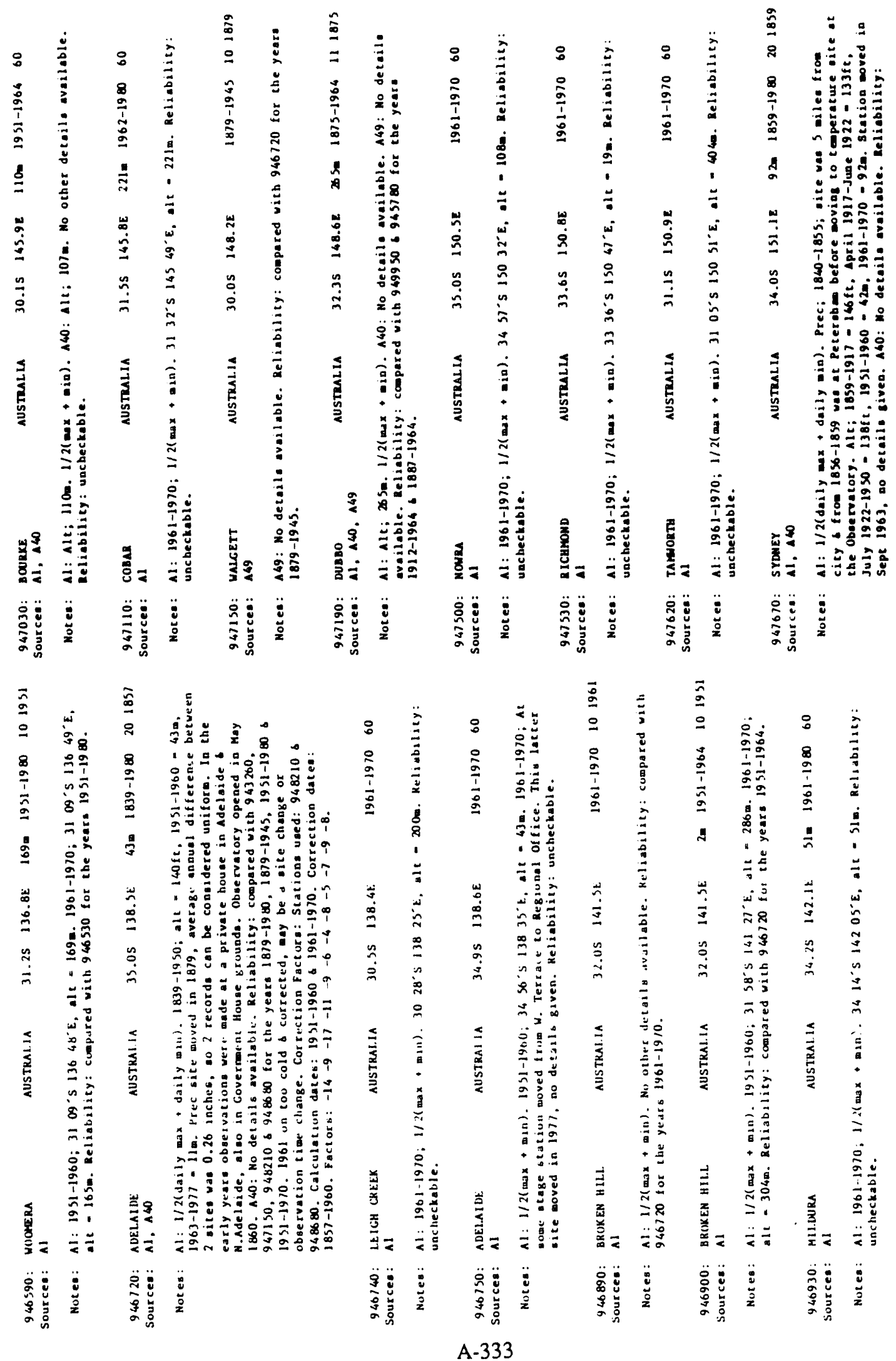


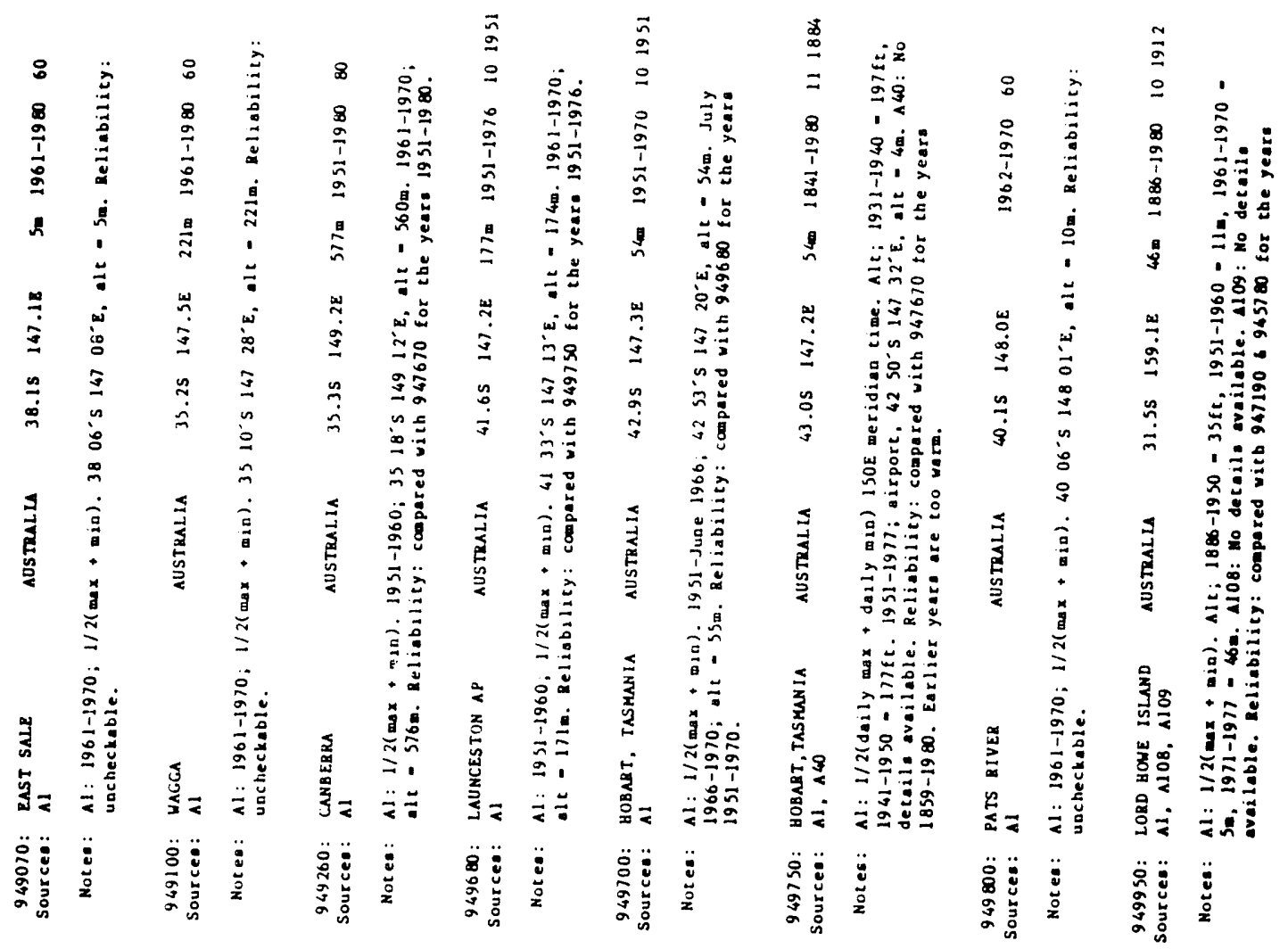

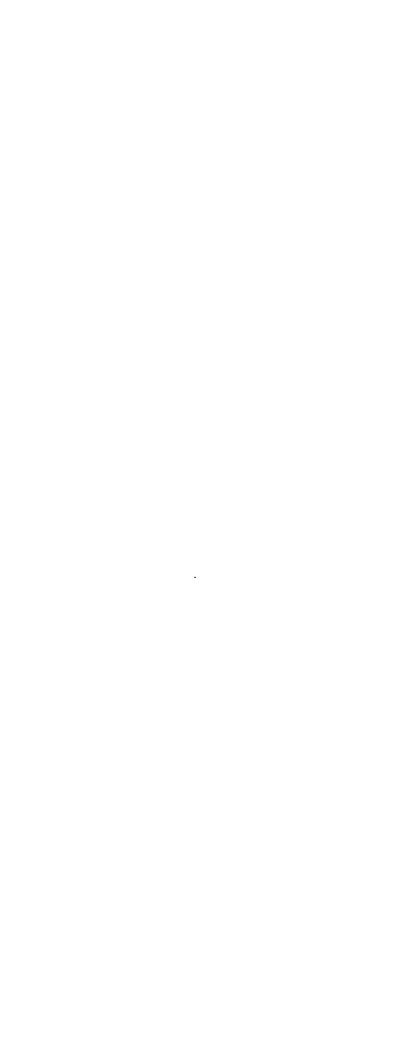

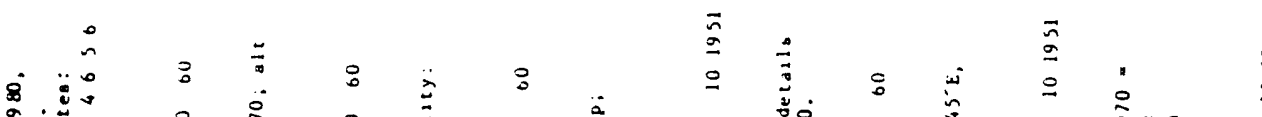

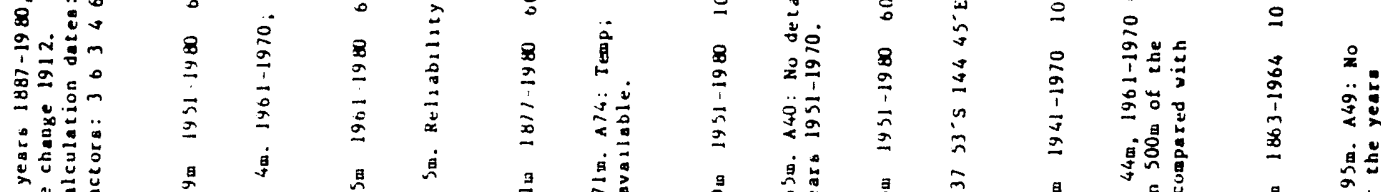

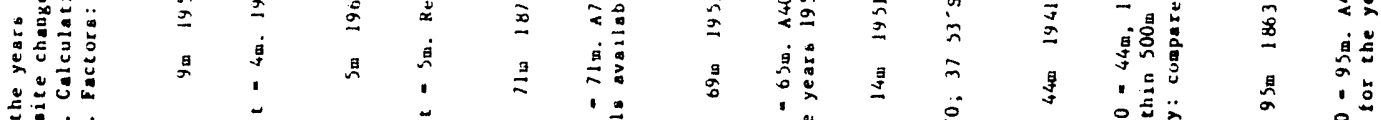

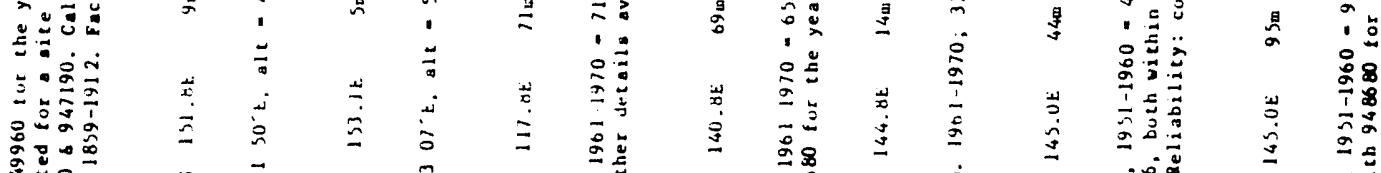

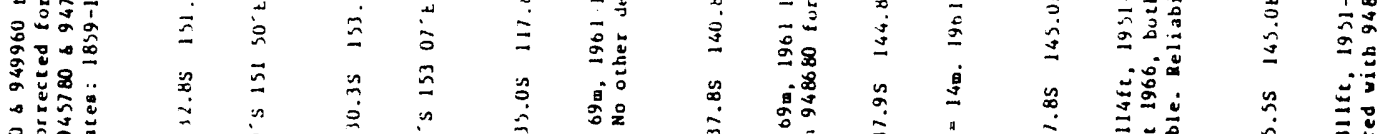

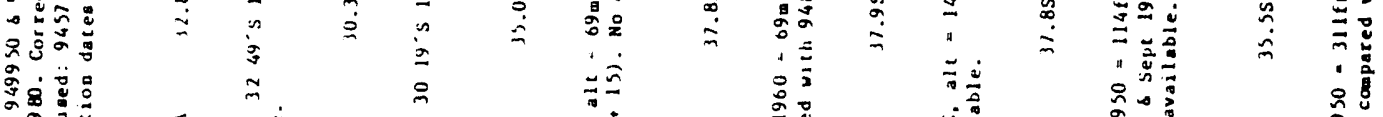

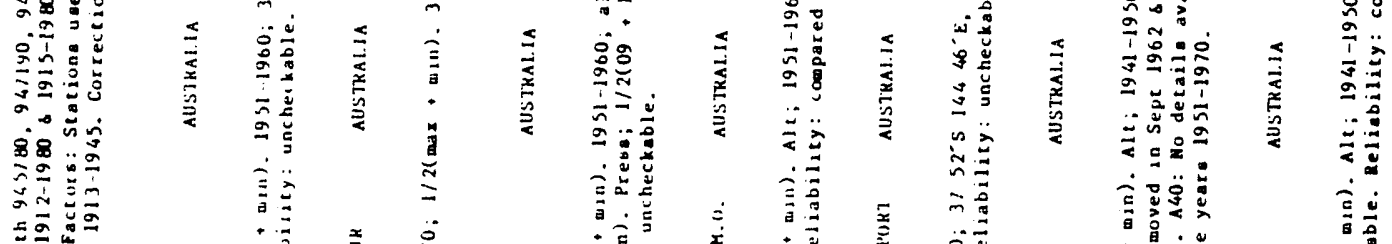

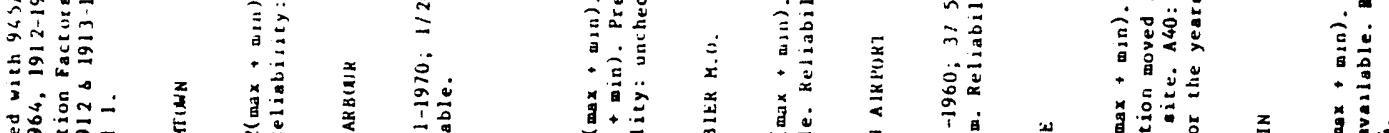

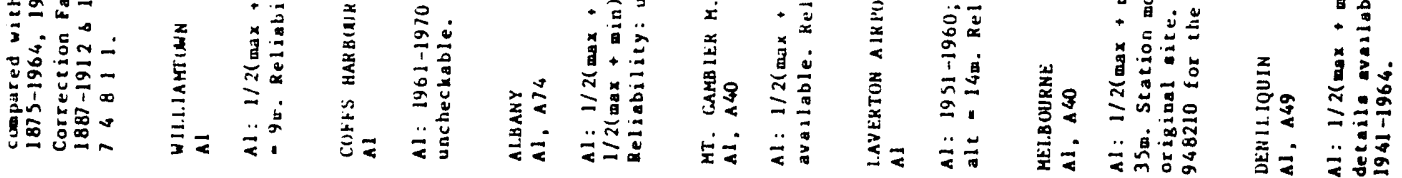

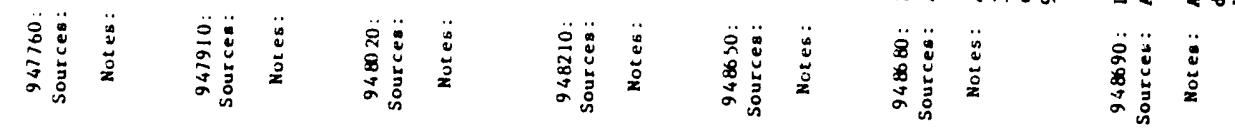

A. 334 

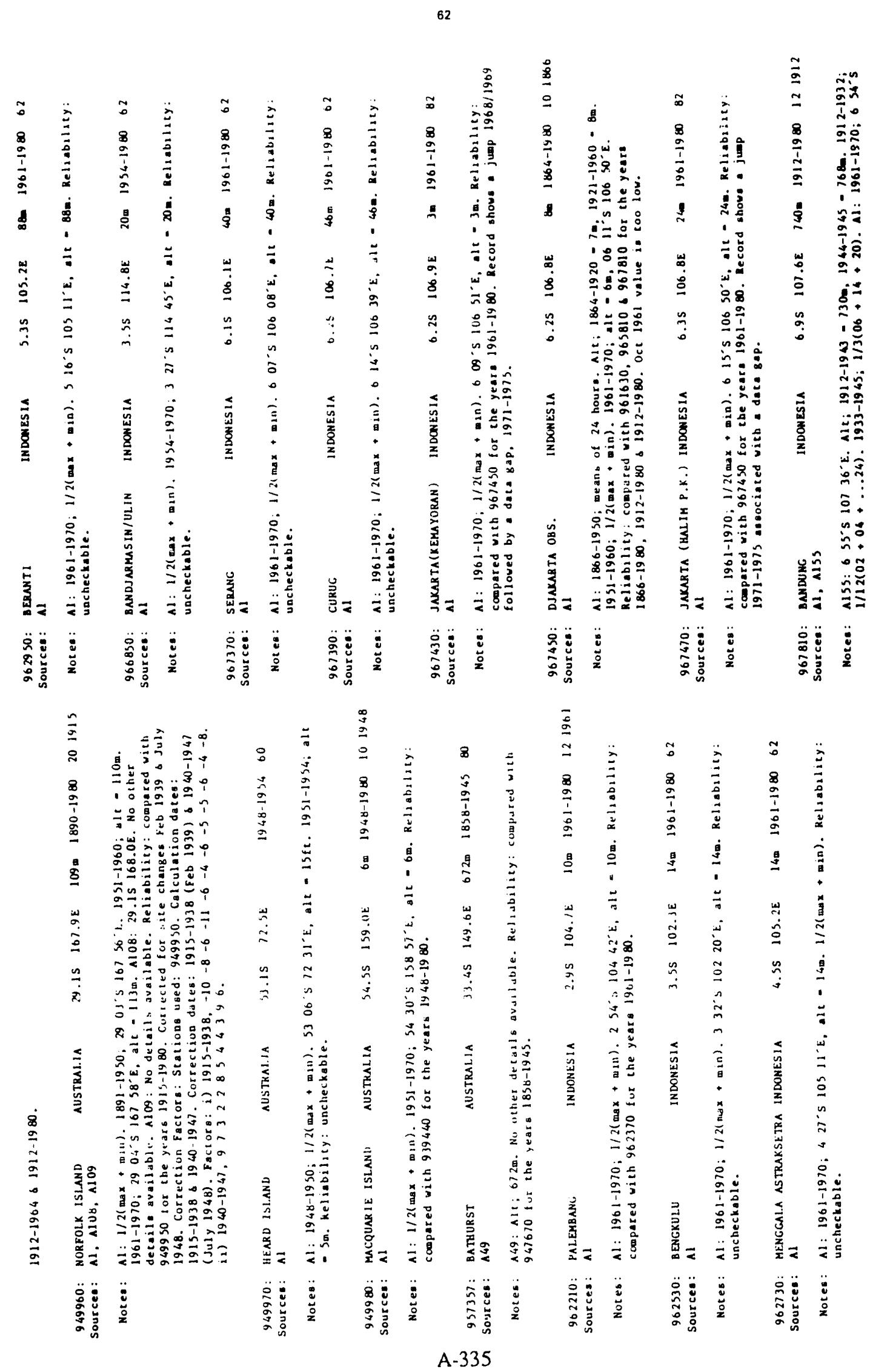
63

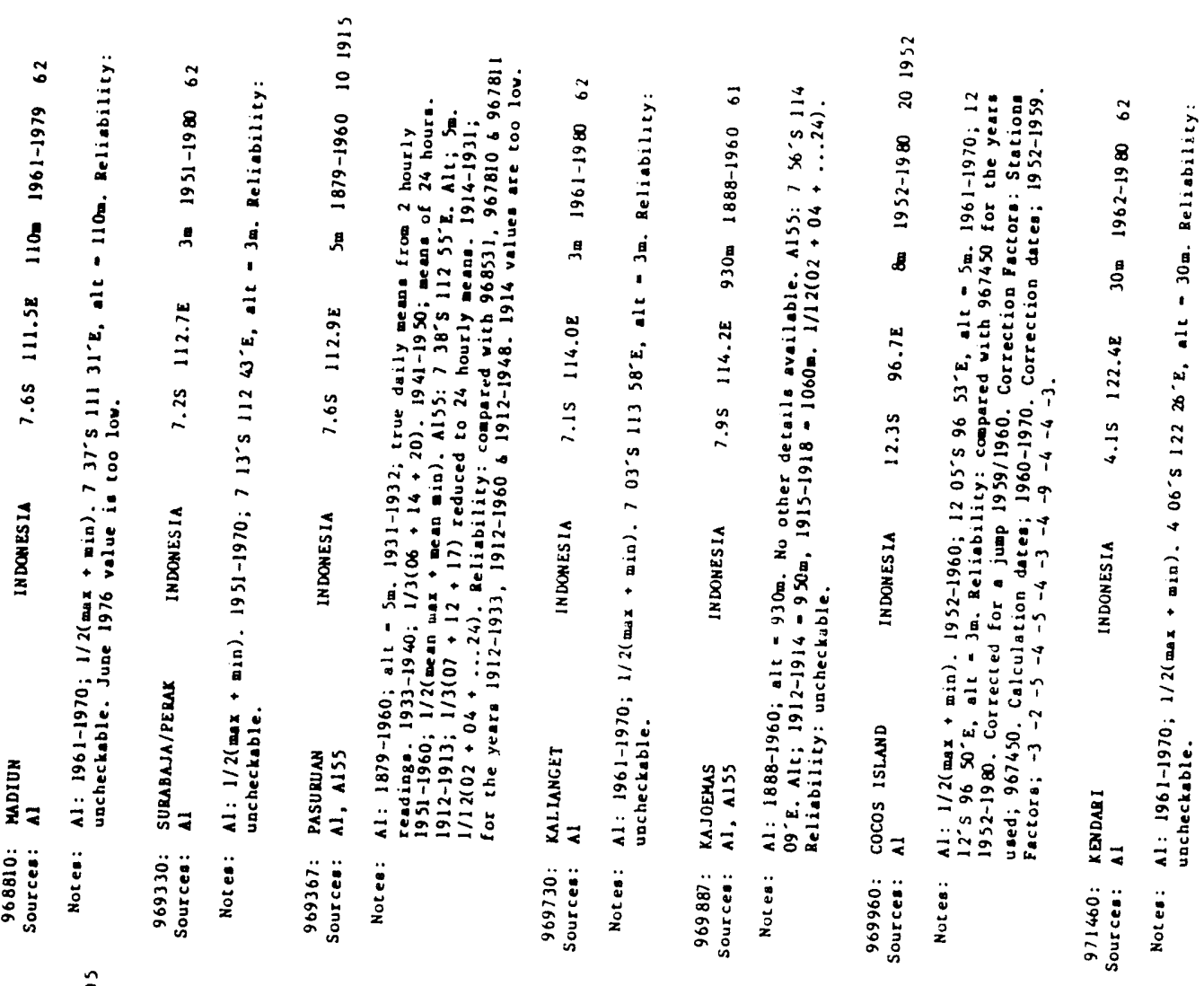

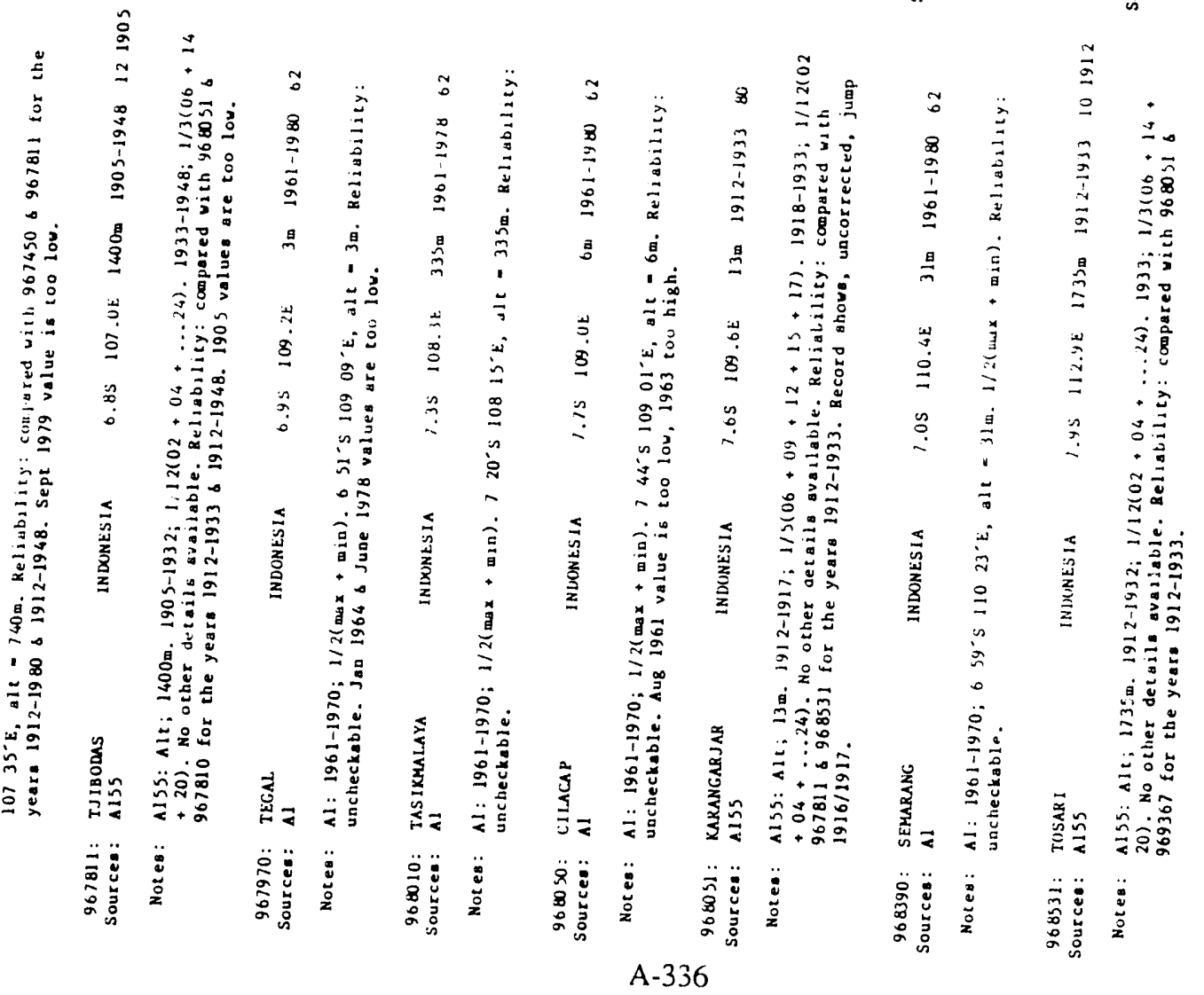



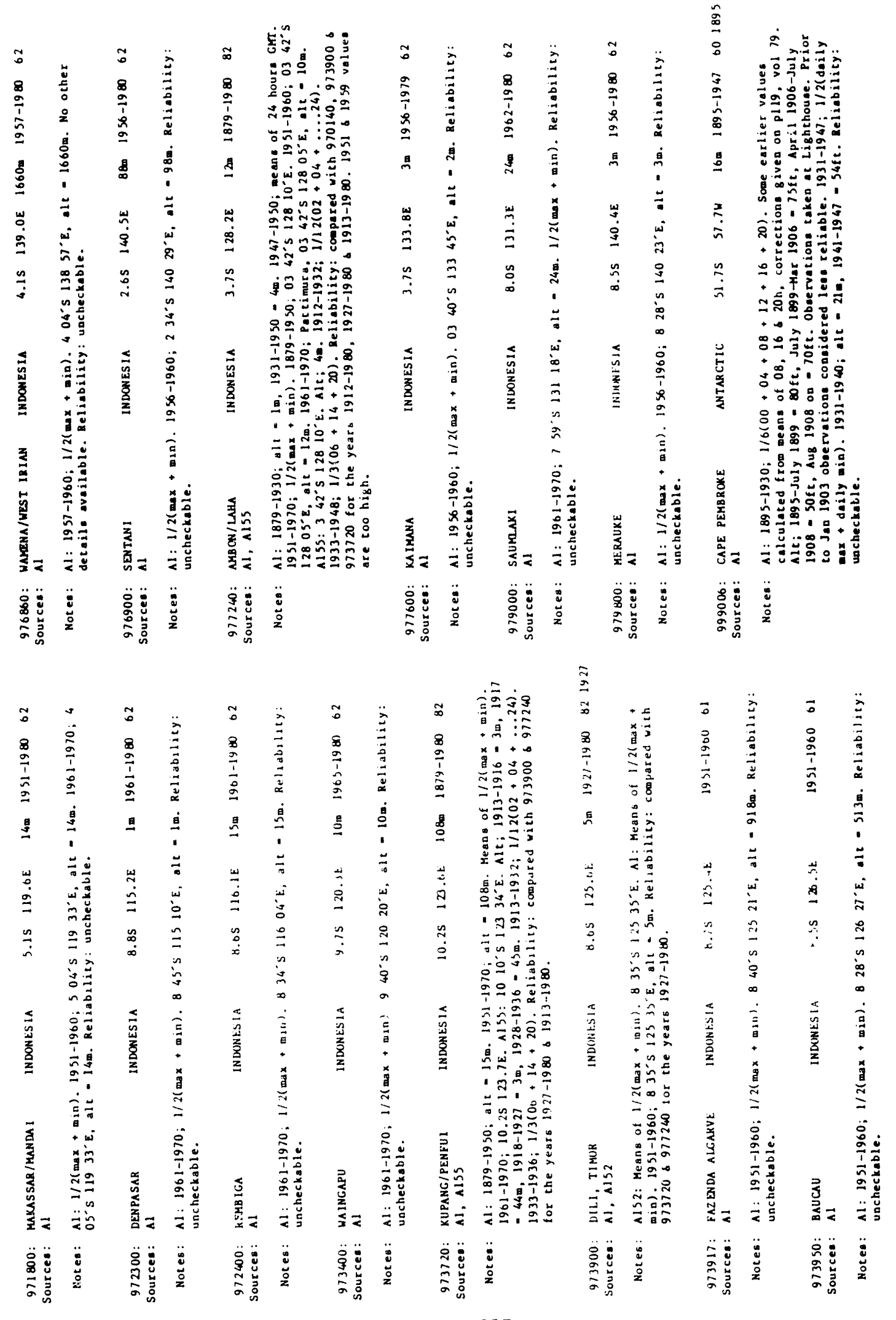


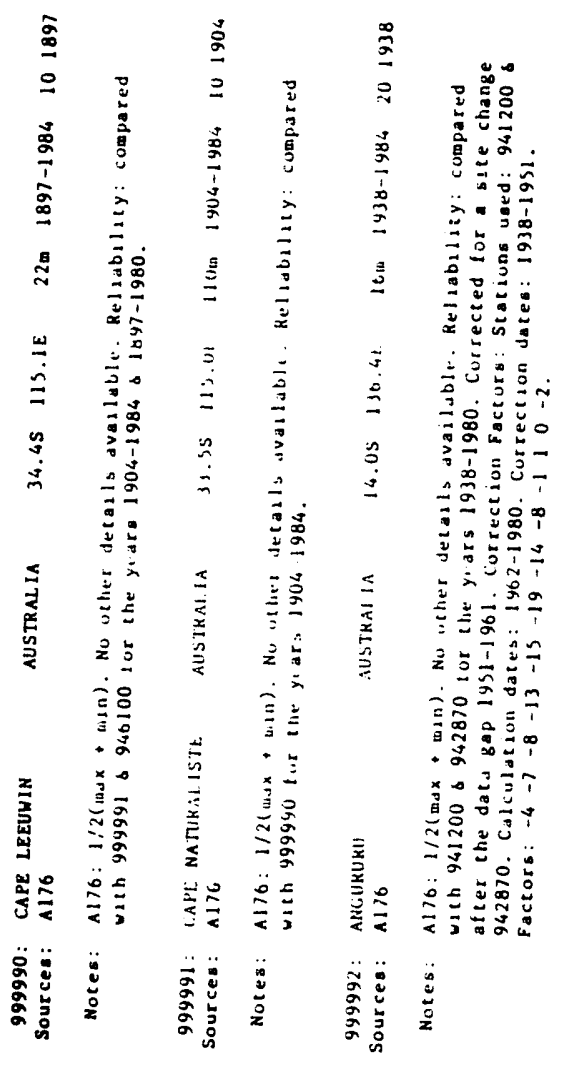


APPENDIX B

\section{Stations used in the gridding algorithm}

\section{Column headings:}

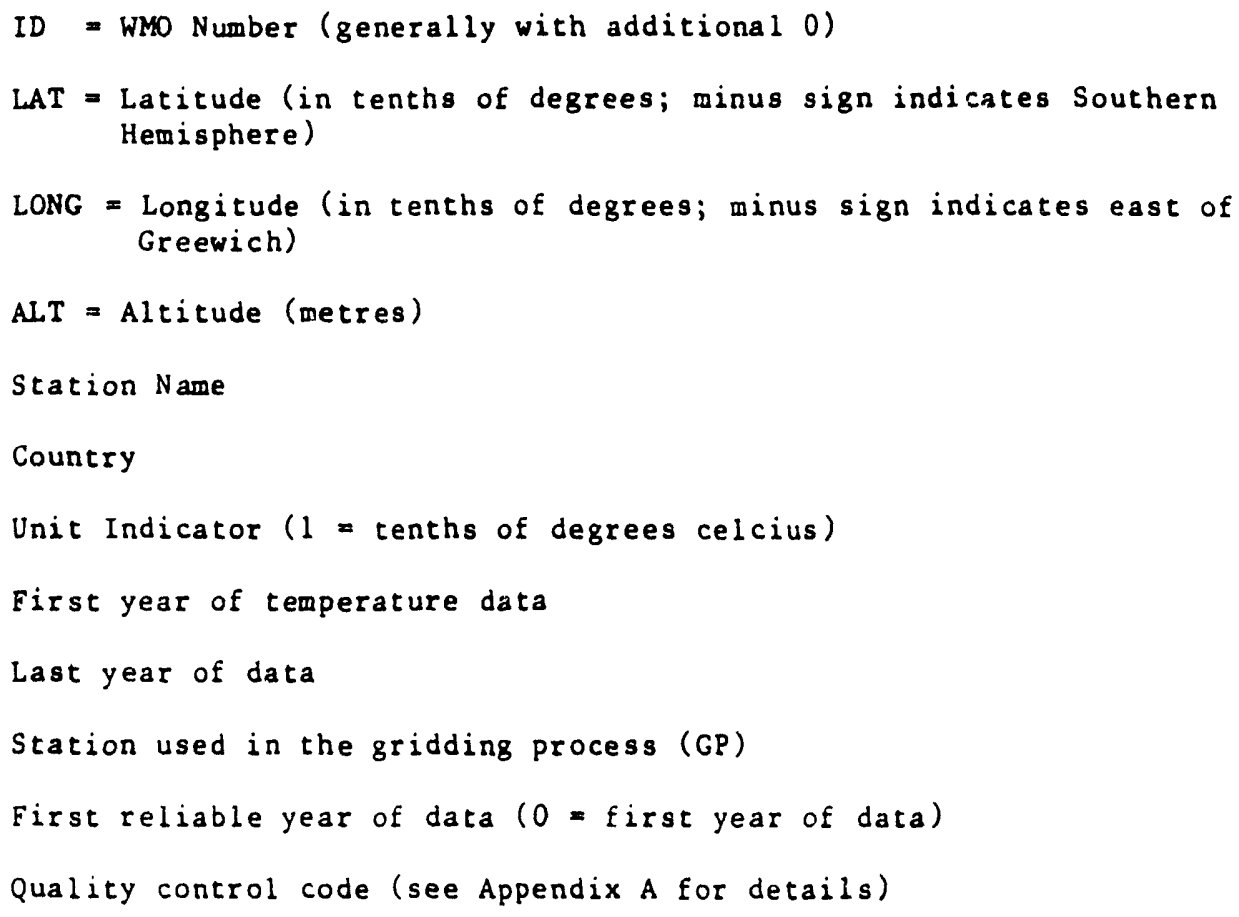




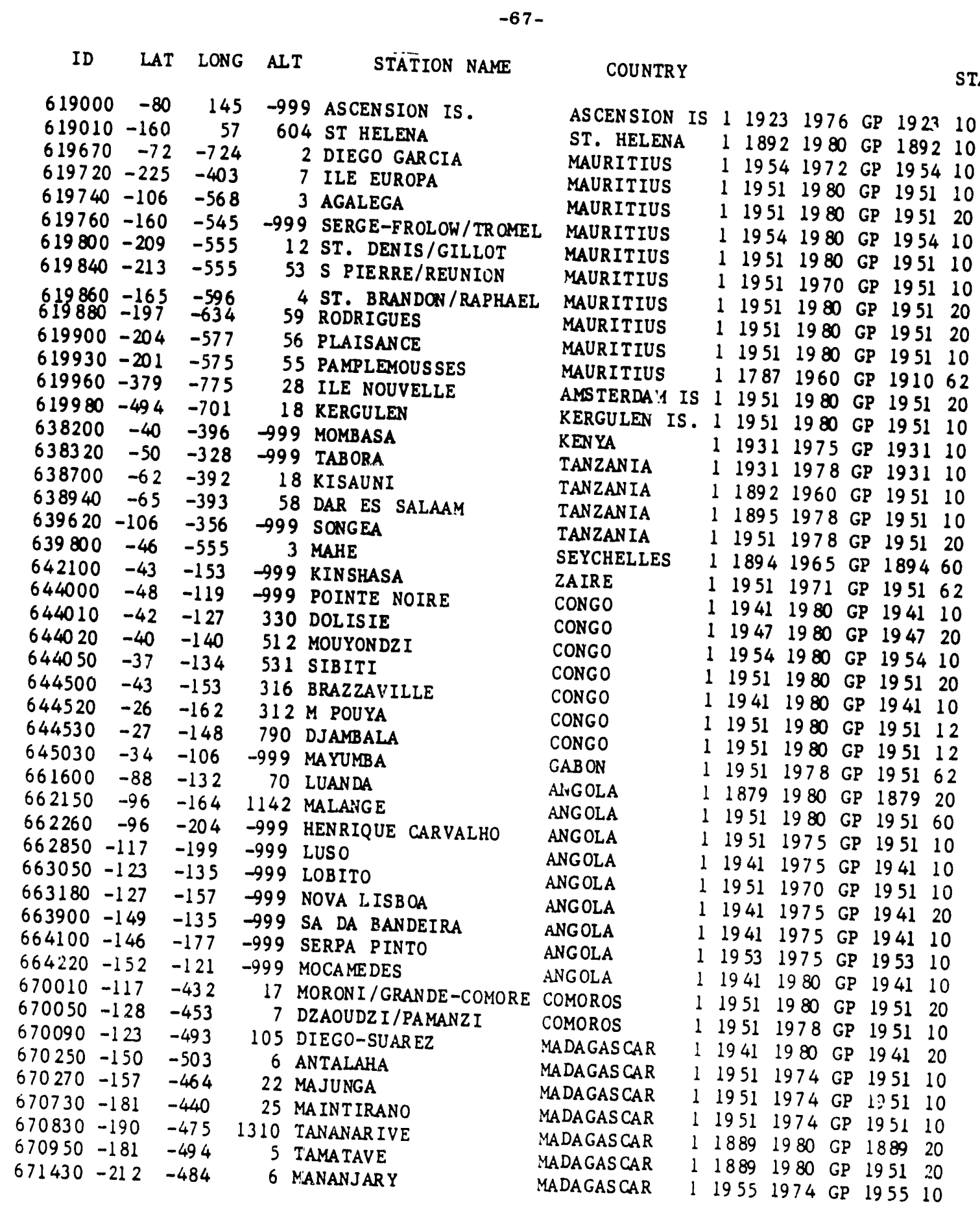




\begin{tabular}{|c|c|c|c|c|c|c|c|c|c|c|}
\hline ID & LAT & LONG & ALT & STATION NAME & COUNTRY & & & & & \\
\hline 71610 & -234 & -437 & 9 & TULEAR & MADAGASCAR & 11951 & 1980 & GP & 1951 & \\
\hline & -250 & -468 & 8 & FORT-DAUPHIN & MADAGASCAK & 11941 & 1974 & GP & 1941 & \\
\hline & -125 & $\pi$ & -999 & PORTO AMEL IA & MOZAMB IQUE & 11947 & 1980 & GP & 1947 & \\
\hline 72170 & -133 & -352 & -999 & VILA CABRAL & MOZAMB IQUE & 11954 & 1980 & GP & 1954 & \\
\hline $\begin{array}{l}72610 \\
72830\end{array}$ & $\begin{array}{l}-161 \\
-178\end{array}$ & $\begin{array}{l}-335 \\
-368\end{array}$ & $\begin{array}{l}-999 \\
-999\end{array}$ & $\begin{array}{l}\text { TETE } \\
\text { QUEL IMANE }\end{array}$ & $\begin{array}{l}\text { MOZAMB IQUE } \\
\text { MOZAMB IQUE }\end{array}$ & $\begin{array}{ll}1 & 1952 \\
1 & 1926\end{array}$ & $\begin{array}{l}1980 \\
1980\end{array}$ & $\begin{array}{l}\text { GP } \\
\text { GP }\end{array}$ & $\begin{array}{l}1952 \\
1926\end{array}$ & 20 \\
\hline 72970 & -198 & -349 & 16 & BEIRA / SACADURA & MOZAMB IQUE & 11913 & 1980 & GP & 1931 & 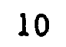 \\
\hline $\begin{array}{l}30 \\
10\end{array}$ & $\begin{array}{l}-238 \\
-260\end{array}$ & $\begin{array}{l}-353 \\
-325\end{array}$ & $\begin{array}{r}-999 \\
64\end{array}$ & $\begin{array}{l}\text { INHAMBANE } \\
\text { LOURENCO MARQUES }\end{array}$ & $\begin{array}{l}\text { MOZAMB IQUE } \\
\text { MOZAMB IQUE }\end{array}$ & $\begin{array}{ll}1 & 1931 \\
1 & 1892\end{array}$ & $\begin{array}{l}1980 \\
1980\end{array}$ & $\begin{array}{l}\text { GP } \\
\text { GP }\end{array}$ & $\begin{array}{l}1931 \\
1892\end{array}$ & \\
\hline 74750 & -102 & -312 & 1384 & KASAMA & ZAMB IA & 11934 & 1980 & GP & 1934 & \\
\hline & -130 & -287 & 1270 & NDOLA & ZAMB IA & 11933 & 1960 & GP & 1935 & \\
\hline & -136 & -326 & 1030 & FORT JAMES ON & $z$ & 119 & 1960 & GP & & \\
\hline 0 & -140 & -338 & 1136 & LILONGWE & MALA & 11940 & 1980 & GP & 1 & \\
\hline & -153 & -232 & 1053 & MONGU & WE & 119 & 30 & GP & 1939 & \\
\hline & -1 & -2 & -999 & BROK $\triangle N-K A B W E$ & & & 0 & GP & 1 & \\
\hline 30 & -157 & -350 & 767 & CHILEKA & VI & 1 & 0 & GP & 9 & \\
\hline $\begin{array}{l}0 \\
0\end{array}$ & $\begin{array}{l}-154 \\
-178\end{array}$ & -35 & 957 & ZOMBA & MA & 11 & 1960 & GP & 1 & \\
\hline $\begin{array}{l}677430 \\
677750\end{array}$ & -179 & -310 & 1472 & SALISBURY OBS & IE & $\begin{array}{l}11918 \\
11898\end{array}$ & $\begin{array}{l}1980 \\
1980\end{array}$ & $\begin{array}{l}\text { GP } \\
\text { GP }\end{array}$ & $\begin{array}{l}18 \\
38\end{array}$ & \\
\hline 40 & -202 & -286 & 1345 & BULAWAYO / GOETZ OBS. & $\mathrm{ZI}$ & 11897 & 1980 & GP & 1898 & \\
\hline 0 & -20 & -326 & 1132 & CHIPINGA & & 11 & 30 & GP & & \\
\hline 80320 & -200 & -234 & 945 & MAUN & S.AFRICA & 11921 & 1963 & GP & 1921 & \\
\hline 31100 & -225 & -171 & 1728 & WINDHOEK & NAM & 11 & 1980 & GP & 1917 & \\
\hline 81480 & -231 & -268 & 1005 & MAHALAPYE & $\mathrm{NAl}$ & 11917 & 1960 & $\mathrm{GP}$ & 19 & \\
\hline 681740 & -238 & -294 & -999 & PIE TS BURG & S.AF & 11 & 1980 & $\mathrm{GP}$ & 19 & 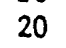 \\
\hline 682620 & -257 & -282 & -999 & PRETORIA & s. & 1 & 1980 & GP & & \\
\hline 683120 & -265 & -181 & -999 & KEE TMAN SHOOP & S. & 11 & 1980 & $G P$ & & \\
\hline 683680 & -261 & -282 & 1700 & JAN SMUTS JO'BURG & S. & 11951 & 1980 & GP & 1 & 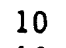 \\
\hline 7 & -262 & -281 & 1753 & JOHAN NESBURG / JOUB ERT & $\mathrm{S}$. & 11 & 60 & GP & & \\
\hline & -285 & -16 & 0 & ALEXANDER BAY & & 11 & 80 & GP & & \\
\hline 40 & -284 & -212 & -999 & UPPINGTON & S. & 11951 & 0 & $\mathrm{GP}$ & 1 & \\
\hline & -287 & -2 & 50 & KIMBE & & 11 & 0 & GP & & \\
\hline & -291 & -26 & -999 & TEIN & & 11 & 0 & $\mathrm{GP}$ & & \\
\hline 0 & -296 & -17 & 918 & OKIEP & S. & 11 & 60 & $G P$ & 0 & 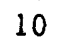 \\
\hline & -307 & -26 & 1316 & AL IWAL NORTH & S. & 1 & 1960 & $\mathrm{GP}$ & 81 & u \\
\hline 30 & -299 & -3 & 0 & DURBAN/LOUIS BOTHA & & 1 & 30 & GP & 85 & \\
\hline 688177 & -339 & -185 & 12 & CAPE TOWNE/ROYAL OBS & S.AF & 11 & 1960 & GP & 1857 & 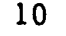 \\
\hline 20 & -340 & -256 & 0 & PORT ELIZABETH & S.AFRICA & 11 & 1980 & GP & 1885 & 20 \\
\hline & & -378 & 0 & MARION ISLAND & & 11948 & 1980 & GP & 1948 & 60 \\
\hline 823310 & -31 & 600 & 60 & MANAUS & BRAZIL & 11931 & 1980 & GP & 1931 & 10 \\
\hline 825860 & -53 & 393 & 199 & QUIXERAMOBIM & RRA2 & 11896 & 1980 & GP & 1912 & 10 \\
\hline 832290 & -130 & 385 & 5 & SALVADOR & & 11912 & 1980 & $\mathrm{GP}$ & 1912 & 2 \\
\hline 833610 & -156 & 561 & 165 & CUIABA & $B R$ & 11901 & 80 & GP & 1901 & 0 \\
\hline & -229 & 43 & 26 & RIO DE JANEIRO & $B R$ & 11832 & 1980 & GP & 1851 & 20 \\
\hline & -254 & 493 & 949 & CURITIBA & BRAZ I & 11885 & 1980 & $\mathrm{GP}$ & 1895 & 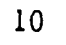 \\
\hline 843770 & -39 & 734 & 126 & IQUITOS & PERU & 11949 & 1981 & $G P$ & 1949 & 10 \\
\hline 843800 & -43 & 812 & 270 & EL ALTO & PERU & 11951 & 1971 & $\mathrm{GP}$ & 0 & \\
\hline
\end{tabular}




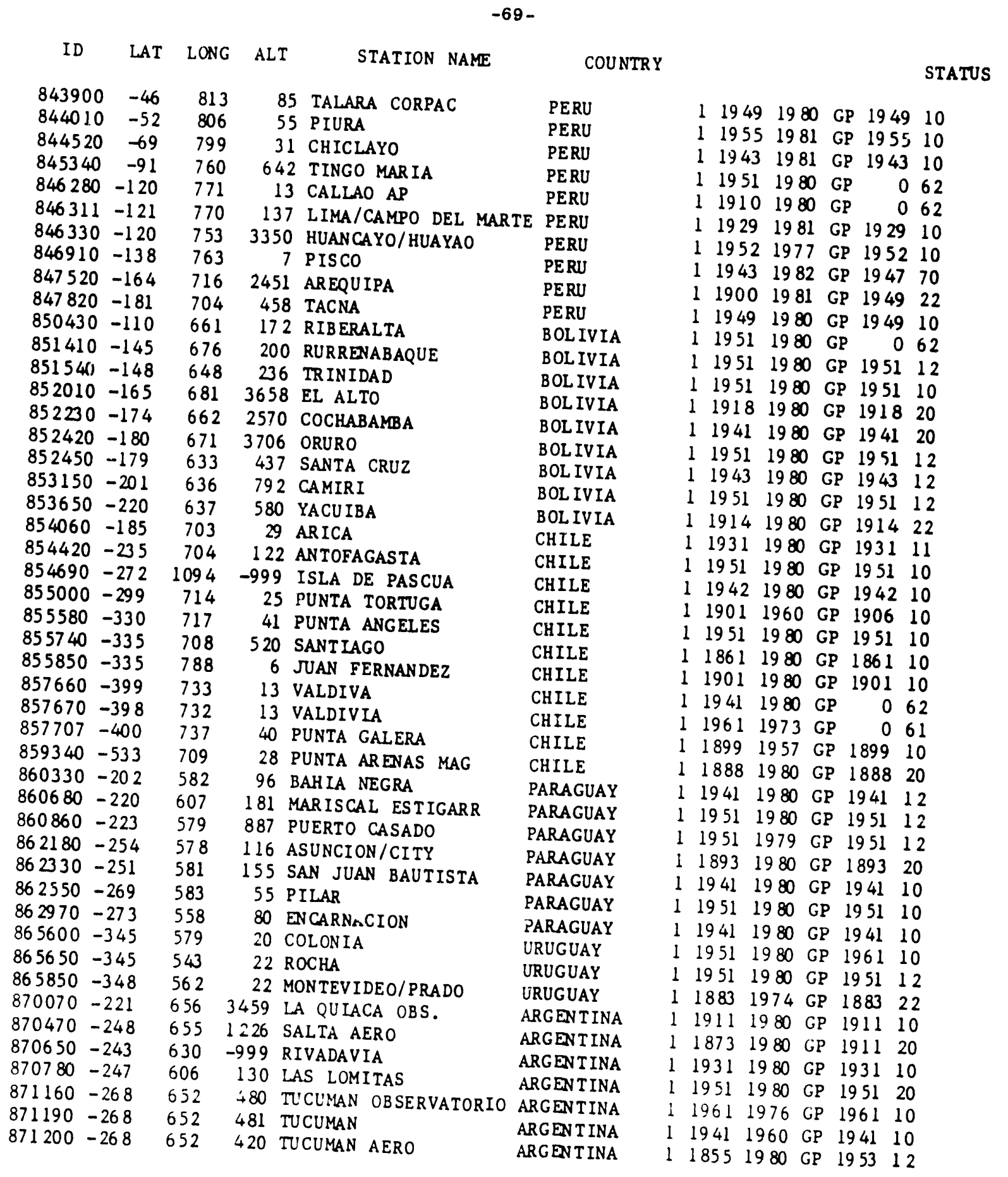


ID LAT LONG ALT STATION NAME COUNTRY

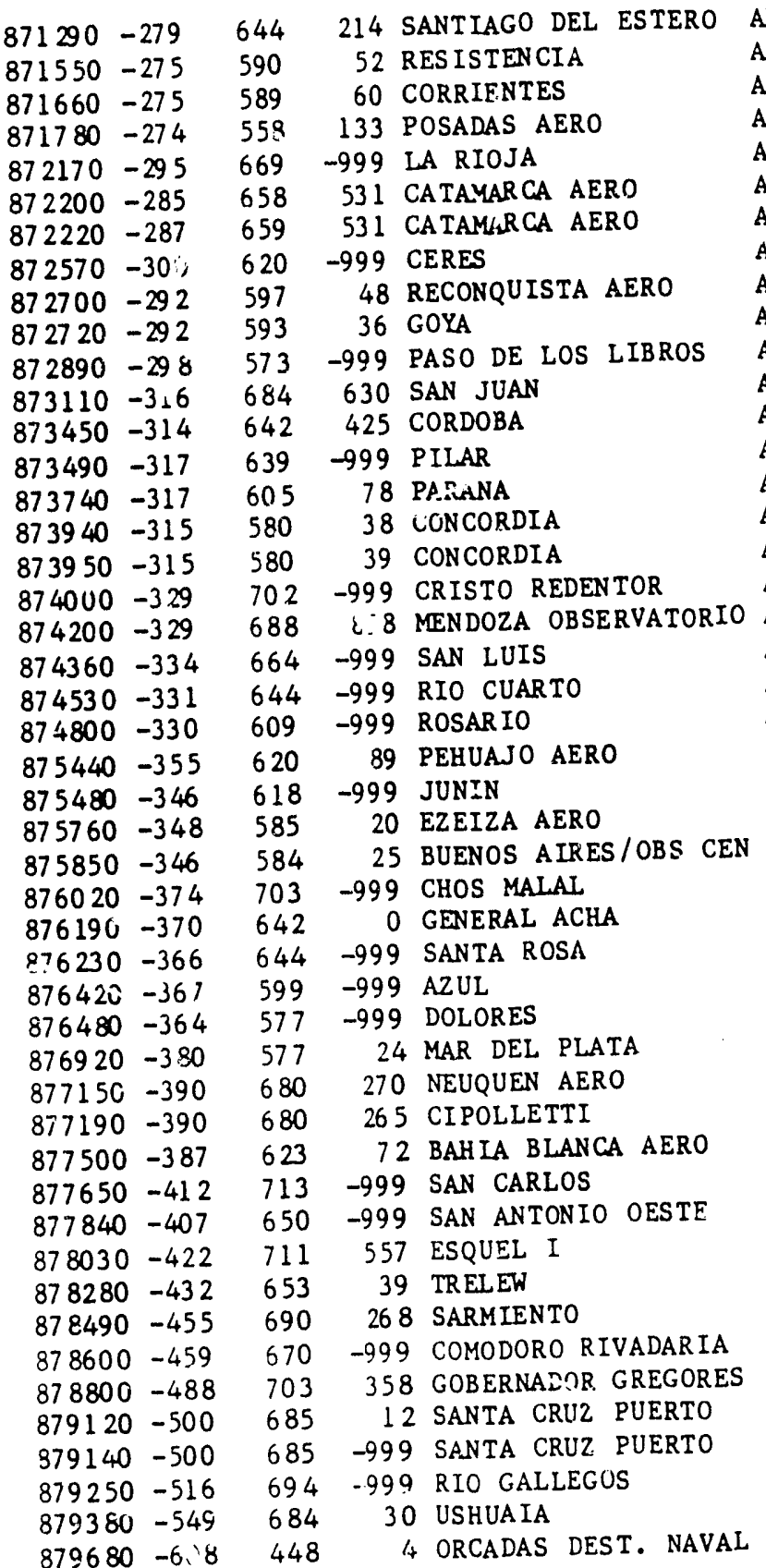

ARGENTINA ARGENT INA ARGENTINA ARGENTINA ARGENTINA ARGENTINA ARGENTINA ARGENT INA ARGENT INA ARGENT:INA ARGEN'T INA ARG ENT INA ARGENTINA ARG ENT INA ARG ENT INA ARG ENT INA ARG ENT INA ARGENTINA ARGENTINA ARG EN TINA ARG EN T INA ARGENTINA ARGENTINA ARGENTINA ARG ENTINA ARG ENTINA ARG ENT INA ARG ENT INA ARG ENT INA ARG ENT INA ARG ENT INA ARG ENT INA ARG ENTINA ARG ENT INA ARG ENT INA ARG ENT INA ARG ENT INA ARG ENT INA ARGEN I INA ARG ENT INA ARG ENT INA ARG ENT INA ARG ENT INA ARG ENT INA ARG EN'T INA ARGEN T INA ARG ENT INA $\begin{array}{llllll}1 & 1874 & 1980 & \text { GP } & 1931 & 12\end{array}$

$11951 \quad 1980$ GP $1951 \quad 12$

$1 \quad 18731980$ GP 187412

119311980 GP 193120

119311980 GP 193120

$119311950 \mathrm{GP} \quad 062$

119041980 GP $1904 \quad 10$

119311980 GP 193120

$\begin{array}{llllll}1 & 1361 & 1980 & \mathrm{GP} & 060\end{array}$

$\begin{array}{llllll}1 & 1877 & 1960 & \text { GP } & 1891 & 10\end{array}$

119311980 GP 193110

119311980 GP 193110

118731980 GP $1873 \quad 10$

119311980 GP 193110

118761980 GP 193110

$119311950 \mathrm{GP} \quad 060$

$\begin{array}{llllll}1 & 1951 & 1980 & \text { GP } & 1951 \quad 10\end{array}$

$1 \quad 1941 \quad 1980$ GP $1941 \quad 12$

$11906 \quad 1980$ GP $1906 \quad 10$

119311980 GP 193120

119311980 GP 193120

$1 \quad 1941 \quad 1980$ GP $1941 \quad 10$

$11951 \quad 1980$ GP $1951 \quad 10$

119331980 GP 193320

$11951 \quad 1980$ GP 195110

118561980 GP 185620

119311961 GP 193110

119311960 GP 193110

$11341 \quad 1980$ GP 194110

$1 \quad 19311980$ GP 193110

119311980 GP $1937 \quad 10$

$\begin{array}{lllllll}1 & 1931 & 1980 & \text { GP } & 1931 & 10\end{array}$

119571980 GP $1957 \quad 10$

119311970 GP 193120

$11860 \quad 1980$ GP 186020

119311980 GP 193120

119311980 GP 193110

$\begin{array}{lllllll}1 & 1931 & 1980 & \text { GP } & 1931 & 20\end{array}$

119011980 GP 190310

119031964 GP 190310

$\begin{array}{lllllllll}1 & 1931 & 1980 & \text { GP } & 1931 & 10\end{array}$

$1 \quad 1951 \quad 1980$ GP 062

$1190 \mathrm{~J} .1975$ GP 19J3 10

$119201958 \mathrm{GP} \quad 062$

119311980 GP 193120

$11876 \quad 1980$ GP 193112

119031980 GP 190310 


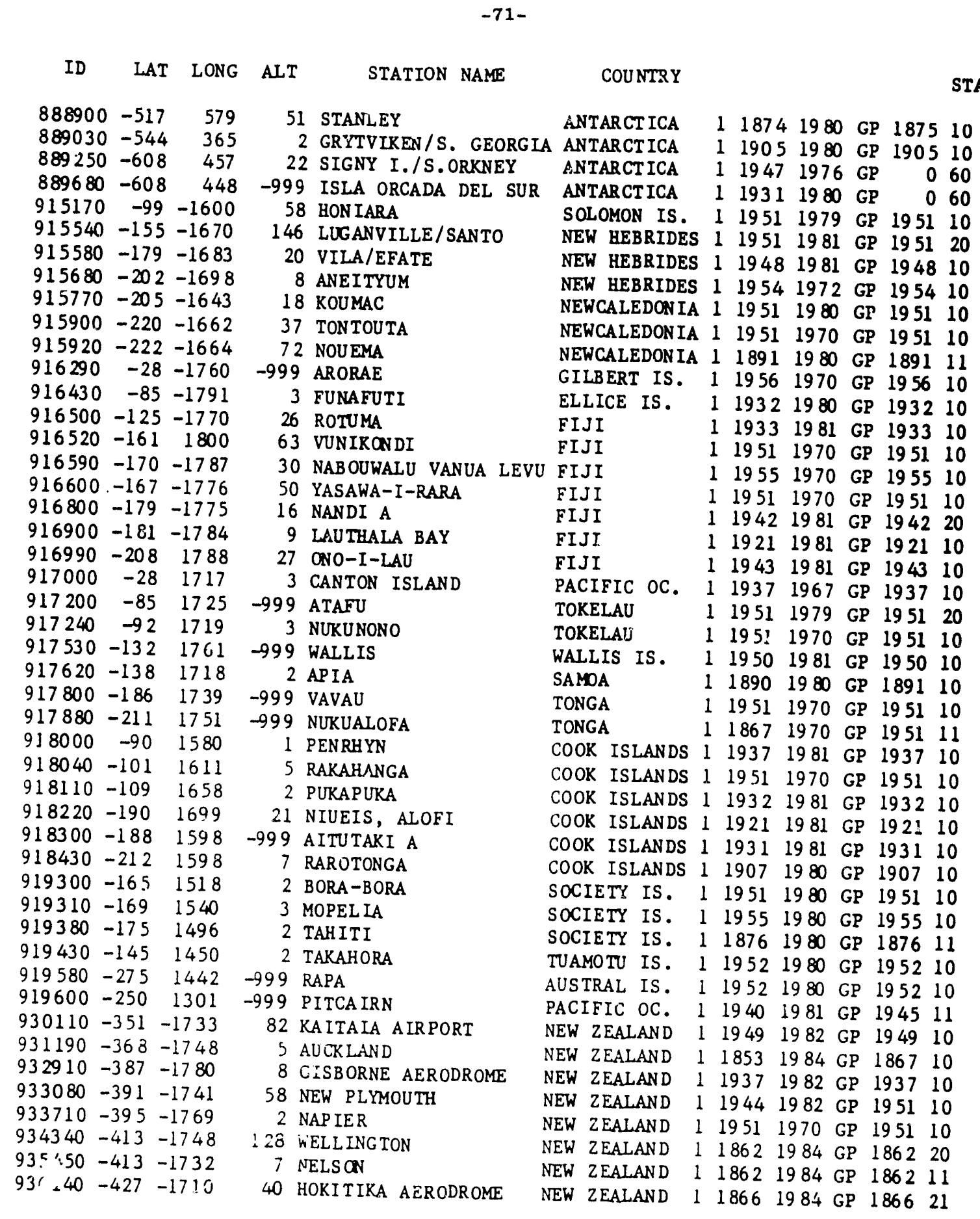

A-344 


\begin{tabular}{|c|c|c|}
\hline $\begin{array}{l}37800 \\
38440\end{array}$ & $\begin{array}{l}-435 \\
-464\end{array}$ & -168 \\
\hline $\begin{array}{l}3894 C \\
39440 \\
39860\end{array}$ & $\begin{array}{l}-459 \\
-525 \\
-440\end{array}$ & $\begin{array}{l}-1705 \\
-1691 \\
-1766\end{array}$ \\
\hline $\begin{array}{l}939970 \\
939998 \\
939999\end{array}$ & $\begin{array}{l}-293 \\
-410 \\
-435\end{array}$ & $\begin{array}{l}-1779 \\
-1757 \\
-1727\end{array}$ \\
\hline 940270 & -67 & -1470 \\
\hline & $\begin{array}{l}-95 \\
-42\end{array}$ & $\begin{array}{l}-1472 \\
-1522\end{array}$ \\
\hline $\begin{array}{l}50 \\
50 \\
30\end{array}$ & $\begin{array}{l}-125 \\
-106 \\
-180\end{array}$ & $\begin{array}{l}-1309 \\
-1422 \\
-1222\end{array}$ \\
\hline 20 & -183 & -1276 \\
\hline & $\begin{array}{l}-163 \\
-169\end{array}$ & $\begin{array}{l}-1334 \\
-1457\end{array}$ \\
\hline 40 & -193 & -1468 \\
\hline & $\begin{array}{l}-163 \\
-249\end{array}$ & \\
\hline $\begin{array}{l}943050 \\
943120 \\
943260\end{array}$ & $\begin{array}{l}-217 \\
-204 \\
-236\end{array}$ & $\begin{array}{l}-1150 \\
-1186 \\
-1336\end{array}$ \\
\hline & $\begin{array}{l}-207 \\
-235 \\
-211\end{array}$ & $\begin{array}{l}-1405 \\
-1442 \\
-1490\end{array}$ \\
\hline & $\begin{array}{l}-211 \\
-234\end{array}$ & - \\
\hline & -239 & \\
\hline 00 & -266 & \\
\hline 944760 & -276 & -1 \\
\hline+5100 & -264 & $\begin{array}{l}-146 \\
-152\end{array}$ \\
\hline 945680 & -276 & -1527 \\
\hline 945780 & -275 & -1530 \\
\hline 0 & -320 & -1157 \\
\hline 370 & -308 & -1215 \\
\hline 946460 & -309 & -1281 \\
\hline 946530 & -321 & $\begin{array}{l}-13 \\
-13\end{array}$ \\
\hline 946590 & -312 & -1368 \\
\hline 946720 & -350 & -1385 \\
\hline & -340 & -151 \\
\hline 210 & -378 & -1408 \\
\hline 948680 & -378 & -1450 \\
\hline 49680 & -416 & -147 \\
\hline 949700 & -429 & -1473 \\
\hline 9497 & -430 & -1472 \\
\hline & & \\
\hline & & \\
\hline
\end{tabular}

8 CHRISTCHURCH

1 INVERCARGILL AERO

2 DUNEDIN

19 CAMPBELI, ISLAND

49 CHATHAM ISLAND 2

49 RAOUL IS/KERMADEC IS

-999 MASTERTON

$\rightarrow 99$ LINCOLN COLLEGE

9 LAE

30 PORT MORESBY AP

6 RABAUL NEW BRITAIN I

29 DARWIN AIRPORT

61 THURSDAY ISLAND

9 BROOME

406 HALLS CREEK

214 DALY WATERS

5 CAIRNS

4 TOWN SVILLE

8 WILLIS IS.

4 CARNARVON

4 ON SLOW

11 PORT HEDLAND

549 ALICE SPRINGS

191 CLONCURRY

187 LONGREACH

4 MACKAY

14 ROCKHAMPT ON

76 GLADSTONE

518 MEEKA THARRA

113 OODNADA TTA

304 CHARLEVILLE

26 AMB ERLEY

0 BRISBANE APT

60 PERTH

361 KALGOORLIE

157 FORREST

17 CEDUNA

169 WOOMERA

43 ADELAIDE

92 SYDNEY

59 ITT. GAMBIER M.O.

+4 MELBOURNE

177 LAUNCESTON AP

54 HOBART, TASMANIA

54 HOBART, TASMAN IA

46 LORD HOWE ISLAND

109 NORFOLK ISLAND
NEW ZEALAND 118641984 GP 190511 NEW ZEALAND 1119481984 GP $1948 \quad 10$ NEW ZEALAND 118531984 GP $1853 \quad 20$ NEW ZEALAND $11941 \quad 1984$ GP $1941 \quad 10$ NEW ZEALAND 118781982 GP $1878 \quad 11$ NEW ZEALAND $11940 \quad 1982$ GP $1940 \quad 10$ NEW ZEALAND $11906 \quad 1984$ GP $1907 \quad 10$ NEW ZEALAND $11864 \quad 1984$ GP $1864 \quad 10$ PAPUA NEW G. 119491975 GP 194910 PAPUA NEW G. 119031980 GP 190310 PAPUA NEW G. 119491980 GP $1949 \quad 10$ $\begin{array}{lllllll}\text { AUSTRALIA } & 1 & 1882 & 1980 & \text { GP } & 1882 & 20\end{array}$ $\begin{array}{llllllll}\text { AUSTRALIA } & 1 & 1951 & 1980 & \text { GP } & 1951 & 20\end{array}$ $\begin{array}{llllllll}\text { AUSTRALIA } & 1 & 1894 & 1980 & \text { GP } & 1951 & 11\end{array}$ AUSTRALIA $\quad 118981980$ GP $1951 \quad 10$ $\begin{array}{lllllll}\text { AUSTRALIA } & 1 & 1951 & 1970 & \text { GP } & 1951 & 10\end{array}$ $\begin{array}{lllllll}\text { AUSTRALIA } & 1 & 1907 & 1980 & \text { GP } & 1907 & 10\end{array}$ $\begin{array}{llllllll}\text { AUSTRALIA } & 1 & 1951 & 1930 & \text { GP } & 1951 & 20\end{array}$ AUSTRALIA $\quad 11951 \quad 1980$ GP $1951 \quad 10$ AUSTRALIA $\quad 11951 \quad 1980$ GP $1951 \quad 10$ AUSTRALIA $\quad 119381975$ GP 193810 AUSTRALIA $\quad 119511980$ GP $1951 \quad 10$ $\begin{array}{llllllll}\text { AUSTRALIA } & 1 & 1879 & 1980 & \mathrm{GP} & 1879 & 10\end{array}$ $\begin{array}{llllllll}\text { AUSTRALIA } & 1 & 1907 & 1975 & \text { GP } & 1907 & 10\end{array}$ AUSTRALIA $\quad 119511980$ GP $1951 \quad 10$ $\begin{array}{lllllllll}\text { AUSTRALIA } & 1 & 1951 & 1980 & \text { GP } & 1951 & 10\end{array}$ $\begin{array}{lllllll}\text { AUSTRALIA } & 1 & 1951 & 1971 & \text { GP } & 1951 & 10\end{array}$ $\begin{array}{lllllll}\text { AUSTRALIA } & 1 & 1951 & 1980 & \text { GP } & 1951 & 20\end{array}$ AUSTRALIA $\quad 11951$ i980 GP $1951 \quad 10$ AUSTRALIA $\quad 119511 \% 80$ GP 195110 AUSTRALIA AUSTRALIA AUSTRALIA AUSTRALIA AUSTRALIA AUSTRALIA AUSTRALIA AUSTRAL LA AUSTRAL IA AUSTRALIA AUSTRALIA AUSTRAL IA AUSTRALIA AUSTRALIA AUSTRALIA AUSTRALIA AUSTRALIA
$1 \quad 1951 \quad 1980$ GP $1951 \quad 10$

$11951 \quad 1970$ GP $1951 \quad 10$ $\begin{array}{llllll}1 & 1887 & 1980 & \text { GP } & 1887 & 10\end{array}$ 118521980 GP 187611 $11941 \quad 1980$ GP $1941 \quad 10$ $11951 \quad 1980$ GP 195120 $1 \quad 1951 \quad 1980$ GP $1951 \quad 10$ $1 \quad 1951 \quad 1980$ GP $1951 \quad 10$ $\begin{array}{llllll}1 & 1857 & 1980 & \text { GP } & 1857 & 20\end{array}$ $\begin{array}{llllll}1 & 1859 & 1980 & \text { GP } & 1859 & 20\end{array}$ $1 \quad 1951 \quad 1980$ GP $1951 \quad 10$ 119411970 GP $1951 \quad 10$ 119511976 GP 195110 $\begin{array}{llllll}1 & 1951 & 1970 & \text { GP } & 1951 & 10\end{array}$ $11841 \quad 1980$ GP 188411 119121980 GP 191210 119151980 GP 191520 


\begin{tabular}{crrrl} 
ID & LAT & LONG & ALT & \multicolumn{1}{c}{ STATION NAME } \\
949980 & -545 & -1590 & 6 & MACQUAR IE ISLAND \\
967450 & -62 & -1068 & 8 & DJAKARTA OBS. \\
967810 & -69 & -1076 & 740 & BANDUNG \\
969330 & -72 & -1127 & 3 & SURABAJA/PERAK \\
969367 & -76 & -1129 & 5 & PASURUAN \\
969960 & -123 & -967 & 8 COCOS ISLAND \\
971800 & -51 & -1196 & 14 MAKAS SAR/MANDA I \\
999006 & -517 & 577 & 16 CAPE PEMBROKE \\
999990 & -344 & -1151 & 22 & CAPE LEEUWIN \\
999991 & -335 & -1150 & 110 & CAPE NATURALISTE \\
999992 & -140 & -1.64 & 16 & ANGURURU
\end{tabular}

COUNTRY
AUSTRALIA
INDONES IA
INDONES IA
INDONES IA
INDONES IA
INDONES IA
INDONES IA
ANTARCT IC
AUSTRAL. IA
AUSTRAL IA
AUSTRAL IA

STATUS

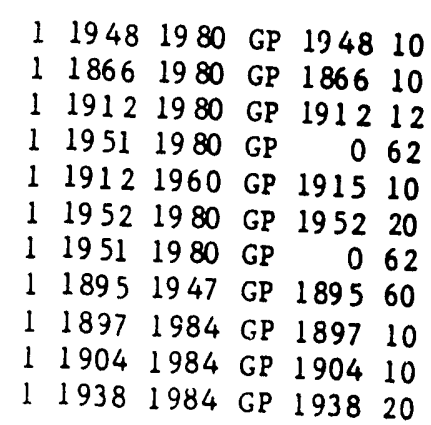




\section{INTERNAL DISTRIBUTION}

1. T. A. Boden

2. M. P. Farrell

3. P. Kanciruk

4. D. E. Reichle

5. R. J. Sepanski

6. R. I. Van Hook

7-206. CDIAC

207. Central Research Library

208-211. ESD Library

212. Information Analysis Library

213-214. Laboratory Records Department

215. Laboratory Records, RC

216. ORNL Patent Office

217. ORNL Y-12 Technical Library

\section{EXTERNAL DISTR.BBUTION}

218. R. S. Bradley, Department of Geology and Geography, University of Massachusetts, Amherst, Massachusetts 01003-0026

219. B. S. G. Cherry, Climatic Research Unit, University of East Anglia, Norwich, Norfolk, United Kingdom NR4 7TJ

220. Roger C. Dahlman, Carbon Dioxide Research Program, Environmental Sciences Division, Office of Health and Environmental Research, ER-74, U.S. Department of Energy, Washington, DC 20585

221. H. F. Diaz, National Oceanic and Atmospheric Administration, Environmental Research Laboratories, R/E/AR6, 325 Broadway, Boulder, Colorado 80303

222. Jerry F. Franklin, Bloedel Professor of Ecosystem Analysis, College of Forest Resources, University of Washington, Anderson Hall (AR-10), Seattle, WA 98195

223. David J. Galas, Otfice of Health and Environmental Research, ER-70, U.S. Department of Energy, Washington, DC 20585

224. C. M. Goodess, Climatic Research Unit, University of East Anglia, Norwich, Norfolk, United Kingdom NR4 7TJ 
225. Thomas J. Gross, Carbon Dioxide Research Program, Environmental Sciences Division, Office of Health and Environmental Research, ER-74, U.S. Department of Energy, Washington, DC 20585

226. George M. Hornberger, Department of Environmental Sciences, Clark Hall, University of Virginia, Charlottesville, VA 22903

227-231. P. D. Jones, Climatic Research Unit, University of East Anglia, Norwich, Norfolk, United Kingdom NR4 7TJ

232. G. Y. Jordy, Directur, Office of Program Analysis, Office of Energy Research, ER30, G-226, U.S. Department of Energy, Washington, DC 20585

233. P. M. Kelly, Climatic Research Unit, University of East Anglia, Norwich, Norfolk, United Kingdom NR4 7TJ

234. H. M. McCammon, Acting Deputy Director, Environmental Sciences Division, Office of Health and Environmental Research, Office of Energy Research, ER-74, U.S. Department of Energy, Washington, DC 20585

235. R. H. Olsen, Vice President for Research, University of Michigan, Medical Science Building II, \#5605, 1301 East Catherine Street, Ann Arbor, MI 48109-0620

236. Ari Patrinos, Acting Director, Environmental Sciences Division, Office of Health and Environmental Research, ER-74, U.S. Department of Energy, Washington, DC 20585

237. S. C. B. Raper, Climatic Research Unit, University of East Anglia, Norwich, Norfolk, United Kingdom NR4 7TJ

238. Michacl R. Riches, Carbon Dioxide Research Program, Environmental Sciences Division, Office of Health and Environmental Research, ER-74, U.S. Department of Energy, Washington, DC 20585

239. B. Santer, Climatic Research Unit, University of East Anglia, Norwich, Norfolk, United Kingdom NR4 7TJ

240. T. M. L. Wigley, Climatic Research Unit, University of East Anglia, Norwich, Norfolk, United Kingdom NR4 7TJ

241. F. J. Wobber, Environmental Sciences Division, Office of Health and Environmental Research, Office of Energy Research, ER-74, U.S. Department of Energy, Washington, DC 20585

242. Office of Assistant Manager for Energy Research and Development, Oak Ridge Operations, P. O. Box 2001, U.S. Department of Energy, Oak Ridge, TN 37831-8600

243-252. Office of Scientific and Technical Information, P. O. Box 62, Oak Ridge, TN 37831 

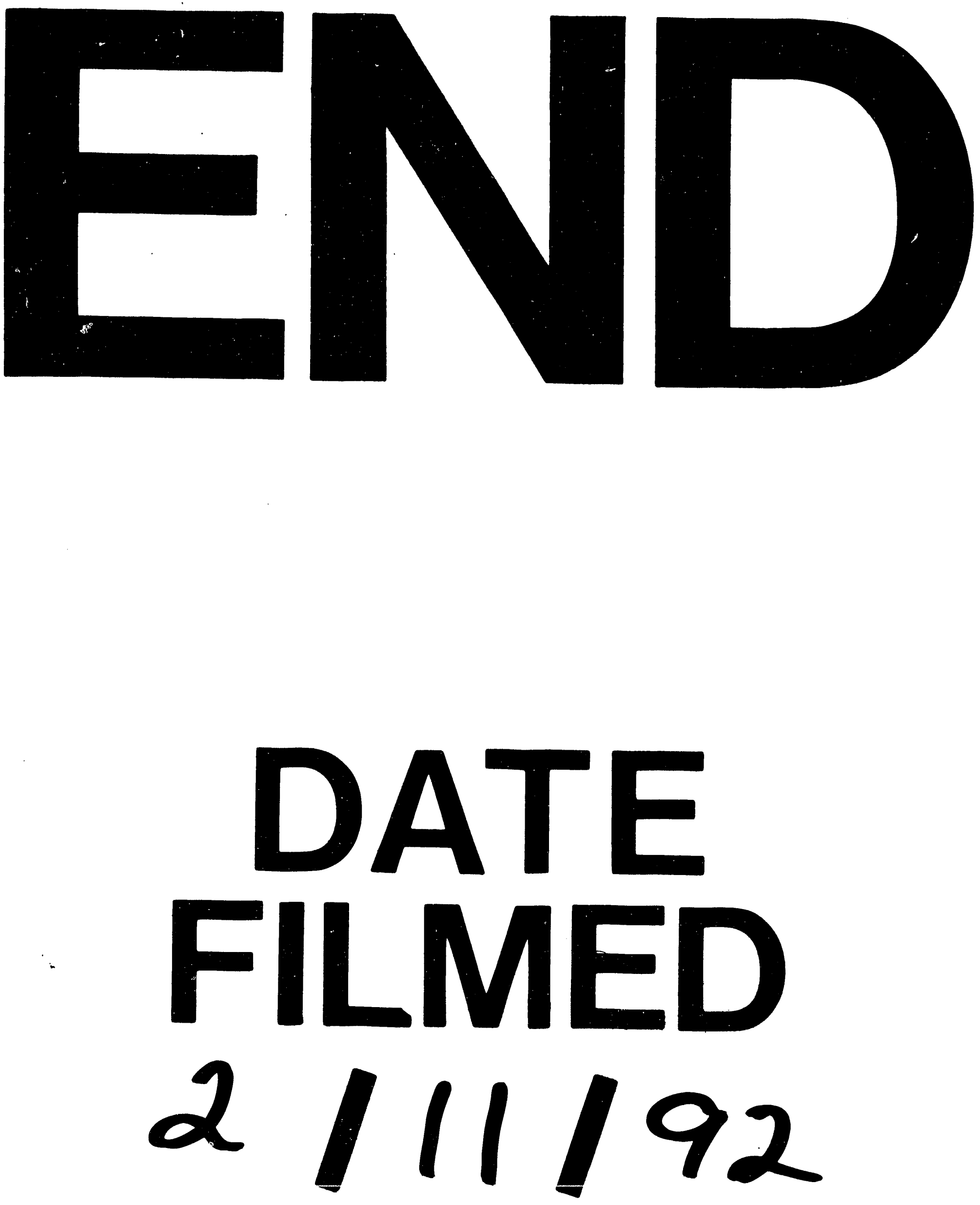
